Anthony J. Jakeman · Olivier Barreteau Randall J. Hunt · Jean-Daniel Rinaudo Andrew Ross Editors

integrated

Groundwater

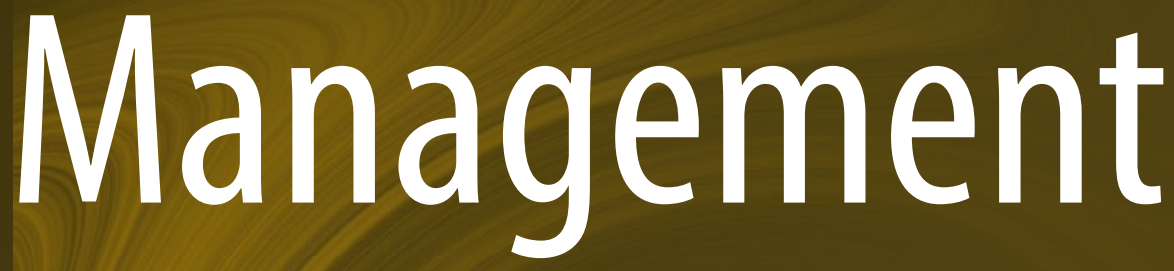

Concepts, Approaches and Challenges

Springer Open 
Integrated Groundwater Management 
Anthony J. Jakeman • Olivier Barreteau • Randall J. Hunt - Jean-Daniel Rinaudo • Andrew Ross

Editors

\section{Integrated Groundwater Management}

Concepts, Approaches and Challenges 


\author{
Editors \\ Anthony J. Jakeman \\ National Centre for Groundwater \\ Research and Training \\ Fenner School of Environment \\ and Society \\ Australian National University \\ Canberra, ACT, Australia \\ Randall J. Hunt \\ Wisconsin Water Science Center \\ US Geological Survey \\ Middleton \\ Wisconsin, USA \\ Andrew Ross \\ National Centre for Groundwater \\ Research and Training \\ Fenner School of Environment \\ and Society \\ Australian National University \\ Canberra, ACT, Australia
}

\author{
Olivier Barreteau \\ IRSTEA \\ UMR G-EAU \\ Montpellier, France
}

\author{
Jean-Daniel Rinaudo \\ Water Department \\ BRGM, French Geological Survey \\ Montpellier, France
}

ISBN 978-3-319-23575-2

ISBN 978-3-319-23576-9 (eBook)

DOI 10.1007/978-3-319-23576-9

\section{Library of Congress Control Number: 2015957968}

(C) The Editor(s) (if applicable) and The Author(s) 2016. This book is published with open access at SpringerLink.com

Open Access This book is distributed under the terms of the Creative Commons AttributionNoncommercial 2.5 License (http://creativecommons.org/licenses/by-nc/2.5/) which permits any noncommercial use, distribution, and reproduction in any medium, provided the original author(s) and source are credited.

The images or other third party material in this book are included in the work's Creative Commons license, unless indicated otherwise in the credit line; if such material is not included in the work's Creative Commons license and the respective action is not permitted by statutory regulation, users will need to obtain permission from the license holder to duplicate, adapt or reproduce the material.

This work is subject to copyright. All commercial rights are reserved by the Publisher, whether the whole or part of the material is concerned, specifically the rights of translation, reprinting, reuse of illustrations, recitation, broadcasting, reproduction on microfilms or in any other physical way, and transmission or information storage and retrieval, electronic adaptation, computer software, or by similar or dissimilar methodology now known or hereafter developed.

The use of general descriptive names, registered names, trademarks, service marks, etc. in this publication does not imply, even in the absence of a specific statement, that such names are exempt from the relevant protective laws and regulations and therefore free for general use.

The publisher, the authors and the editors are safe to assume that the advice and information in this book are believed to be true and accurate at the date of publication. Neither the publisher nor the authors or the editors give a warranty, express or implied, with respect to the material contained herein or for any errors or omissions that may have been made.

Disclaimer: No responsibility is assumed by the editors, authors, or the U.S. Government and other institutions with which they are affiliated, for any errors, mistakes, or misrepresentations that may occur from the use of this book, and no compensation will be given for any damages or losses whatever their cause. Any use of trade, firm, or product names is for descriptive purposes only and does not imply endorsement by the U.S. Government.

Printed on acid-free paper

This Springer imprint is published by Springer Nature

The registered company is Springer International Publishing AG Switzerland 
The updated original version of this book was revised. An erratum to the book can be found at DOI 10.1007/978-3-319-23576-9_29. 


\section{Foreword}

I am delighted to introduce Integrated Groundwater Management, a text I consider an essential contribution to the water management field exploring relevant governance, biophysical, socioeconomic and decision support standpoints as they relate to the issue of groundwater.

Groundwater is a vital resource for humans, the environment and planet earth as a whole. It provides over $97 \%$ of accessible freshwater on the planet. Half of the world's drinking water and nearly half of irrigation water for agriculture come from groundwater.

Groundwater is the sole source of water in many regions; in most other regions, it becomes a crucial buffer resource when other sources are not sufficient. As our increasing reliance on it demonstrates, groundwater depletion, pollution, and impacts on dependent ecosystems are pressing issues for humanity worldwide.

Contemporary groundwater management has moved well beyond a concern with how much water is stored underground or can be extracted from aquifers. Today we recognise that integrated, effective and efficient groundwater management relies on pulling together work in a variety of disciplines such as climate science, ecology, socioeconomics, public policy and law, as well as hydrogeology. However, whilst we realise the importance of multiple perspectives and a diversity of contexts and data, the challenge of integrating and organising all of this information into a decision making framework remains.

It is also abundantly clear that sharing and access to water is a fundamentally political issue and that solutions depend on full engagement of stakeholders as well as mobilisation of knowledge and technologies.

Consider some of the issues covered in the book: groundwater dependent ecosystems, managed aquifer recharge, the impacts of climate change on groundwater availability, water supply and security, conjunctive use of surface and groundwater, safeguarding environmental and cultural flows, and other cross-sectoral issues particularly with respect to energy. These are just a few of the pressing, contemporary, international issues that will demand not only rigorous interdisciplinary groundwater science but must be managed in ways that appreciate and consider the variety of contexts in which the problem exists. The book argues how we can progress and solve such scientific, management and policy problems using a thoughtful and thorough process that involves: problem framing and ensuing 
conceptual modelling with interest groups; understanding the social, policy and institutional settings, constraints and opportunities; and focusing the science components on the identified questions, attributes and scales of interest. Often the components are best integrated into more computational models so that the effects of policy drivers can be gauged along with non-controllable forces like climate and trade conditions on outcomes. Outcomes of a triple bottom line nature will also need to be identified as trade-offs and their uncertainty managed so that one can more confidently decide among alternative courses of action. An overriding theme should always be appropriate engagement in all stages of the process so that knowledge is shared, trust is engendered and adoption of good outcomes is more likely.

This book was initially conceived by the National Centre for Groundwater Research and Training in Australia to address a substantial gap in the literature on the interdisciplinary aspects of addressing groundwater-related issues. From this initial conceptualisation, it grew to encompass work occurring worldwide, and now brings together some 74 world leading authors with broad ranging expertise in all facets of integrated groundwater management, in a wide variety of hydrologic and human settings.

The combined experience, insights, and learnings laid out in the pages of this book hold the key to progressing groundwater management as we know it, in a complex and interrelated world. The case for and value of problem-focused interdisciplinary research put forward by the authors, absolutely necessary for integrated groundwater management, are compelling. Each chapter reveals new approaches to a world interconnected by groundwater. These ideas, knowledge and experience illustrate how future effective decision making will hinge on integrating the larger environmental, social and political context into groundwater management. It reveals the components of a powerful applied interdisciplinary toolkit, how it works in theory and in practice and, to my mind, why it is absolutely necessary.

This book succeeds in moving well beyond the clichés of interdisciplinarity that one often hears. It shows us, in vivid and illustrative ways, precisely how interdisciplinarity can enhance and transform decision making and resource management in practice. Just as important, it indicates the fallacy of management "solutions" when such interdisciplinary thinking is necessary but missing. It pushes us to understand how research is conducted at, and across, disciplinary interfaces. It points to the vital and transformational payoffs for these additional efforts.

Integrated groundwater management can be academically challenging and interesting. But most importantly, it is essential to ensuring sound and defensible groundwater management that is based upon rigorous and problem-centred interdisciplinary science. Simply put, current and foreseeable groundwater management problems cannot hope to be truly addressed without considering the wide variety of approaches promoted here.

The book explores one of the most important grand challenges in our discipline and presents a vision for groundwater science and management in the twenty-first century. Integrated groundwater management underpinned by rigourous interdisciplinary science will be vital for wise stewardship of groundwater into the future. 
I believe that this book is a pioneering contribution. We, as a community of researchers, technicians, managers and policy makers, are the fortunate benefactors of the editors' and authors' collective efforts. I wholeheartedly commend this book to you as a quintessential and inspirational must-read. If we rise to, and learn from, the challenges and opportunities set out in this book, the often bleak predictions for water resources in the future can include more hopeful and effective alternatives, with immeasurable benefits for current and future generations.

National Centre for Groundwater Research Craig T. Simmons, FTSE and Training, Bedford Park, SA, Australia Flinders University, Bedford Park, SA, Australia Australian Academy of Technological Sciences and Engineering, Melbourne, VIC, Australia 


\section{Contents}

\section{Part I Integration Overview and Problem Settings}

1 Integrated Groundwater Management: An Overview of Concepts and Challenges ...................... 3 Anthony J. Jakeman, Olivier Barreteau, Randall J. Hunt, Jean-Daniel Rinaudo, Andrew Ross, Muhammad Arshad, and Serena Hamilton

2 The International Scale of the Groundwater Issue . . . . . . . . . Michael N. Fienen and Muhammad Arshad

3 Disentangling the Complexity of Groundwater Dependent Social-ecological Systems . . . . . . . . . . . . . . .

Olivier Barreteau, Yvan Caballero, Serena Hamilton, Anthony J. Jakeman, and Jean-Daniel Rinaudo

4 Groundwater Management Under Global Change: Sustaining Biodiversity, Energy and Food Supplies . . . . . . . . . . . 75 Jamie Pittock, Karen Hussey, and Andrew Stone

5 Linking Climate Change and Groundwater . . . . . . . . . . . 97 Timothy Richard Green

\section{Part II Governance}

6 Groundwater Governance in Australia, the European Union

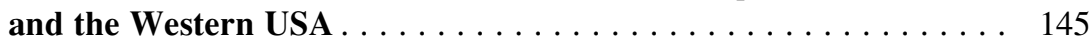
Andrew Ross

7 Groundwater Law . . . . . . . . . . . . . . . . . . 173 Rebecca Nelson and Philippe Quevauviller

8 Groundwater Regulation and Integrated Water Planning . . . . . 197 Philippe Quevauviller, Okke Batelaan, and Randall J. Hunt

9 Conjunctive Management Through Collective Action .......... . 229 Cameron Holley, Darren Sinclair, Elena Lopez-Gunn, and Edella Schlager 
10 The Social-Environmental Justice of Groundwater Governance . . . 253 Marian J. Neal (Patrick), Francesca Greco, Daniel Connell, and Julian Conrad

11 Social Justice and Groundwater Allocation in Agriculture:

A French Case Study . . . . . . . . . . . . . . . . . . . . . . . . . . . 273

Jean-Daniel Rinaudo, Clémence Moreau, and Patrice Garin

Part III Biophysical Aspects

12 Ecohydrology and Its Relation to Integrated Groundwater Management

Randall J. Hunt, Masaki Hayashi, and Okke Batelaan

13 Groundwater Dependent Ecosystems: Classification, Identification Techniques and Threats . . . . . . . . . . . . . 313 Derek Eamus, Baihua Fu, Abraham E. Springer, and Lawrence E. Stevens

14 Interactions of Water Quality and Integrated Groundwater Management: Examples from the United States and Europe . . . . . 347 Kelly L. Warner, Fabienne Barataud, Randall J. Hunt, Marc Benoit, Juliette Anglade, and Mark A. Borchardt

15 Soil and Aquifer Salinization: Toward an Integrated Approach for Salinity Management of Groundwater

Richard Greene, Wendy Timms, Pichu Rengasamy,

Muhammad Arshad, and Richard Cresswell

16 Managed Aquifer Recharge: An Overview of Issues and Options .

Joël Casanova, Nicolas Devau, and Marie Pettenati

17 Managed Aquifer Recharge in Integrated Water Resource Management . . . . . . . . . . . . . . . . . . . . . 435

Peter Dillon and Muhammad Arshad

\section{Part IV Socioeconomics}

18 Towards Integrated Groundwater Management in China . . . . . . . 455 Jie Liu and Chunmiao Zheng

19 Social Science Contributions to Groundwater Governance . . . . . . . 477 Allan Curtis, Michael Mitchell, and Emily Mendham

20 Lessons to Be Learned from Groundwater Trading in Australia and the United States . . . . . . . . . . . . . . . . . . . . 493 Sarah Ann Wheeler, Karina Schoengold, and Henning Bjornlund 
21 Integrated Assessment of Economic Benefits of Groundwater Improvement with Contingent Valuation . . . . . . . . . . . . . . . . 519 Cécile Hérivaux and Jean-Daniel Rinaudo

22 Controlling Groundwater Exploitation Through Economic Instruments: Current Practices, Challenges and Innovative Approaches . Marielle Montginoul, Jean-Daniel Rinaudo, Nicholas Brozović, and Guillermo Donoso

23 Liberation or Anarchy? The Janus Nature of Groundwater Use on North Africa's New Irrigation Frontiers . . . . . . . . . . . . 583 Marcel Kuper, Nicolas Faysse, Ali Hammani, Tarik Hartani, Serge Marlet, Meriem Farah Hamamouche, and Fatah Ameur

\section{Part V Modeling and Decision Support}

24 Incorporating Human Aspects into Groundwater Research and Policy Making: A Soft and Critical Systems Thinking Approach . . . . . . . . . . . . . . . . . . . . . . . . . . . 619 Sondoss Elsawah and Joseph H.A. Guillaume

25 Decision Support Systems and Processes for Groundwater . . . . . . 639 Suzanne A. Pierce, John M. Sharp Jr, and David J. Eaton

26 Integrated Groundwater Data Management . . . . . . . . . . . . . . 667 Peter Fitch, Boyan Brodaric, Matt Stenson, and Nate Booth

27 Hydroeconomic Models as Decision Support Tools for Conjunctive Management of Surface and Groundwater . Manuel Pulido-Velazquez, Guilherme F. Marques, Julien J. Harou, and Jay R. Lund

28 Methods for Exploring Uncertainty in Groundwater Management Predictions

Joseph H.A. Guillaume, Randall J. Hunt, Alessandro Comunian, Rachel S. Blakers, and Baihua Fu

Erratum to: Integrated Groundwater Management . . . . . . . . . . E1

IGM Author Biographies . . . . . . . . . . . . . . . . . . . . 739

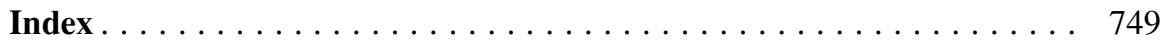




\section{Part I}

Integration Overview and Problem Settings 


\title{
Integrated Groundwater Management: An Overview of Concepts and Challenges
}

\author{
Anthony J. Jakeman, Olivier Barreteau, Randall J. Hunt, Jean-Daniel \\ Rinaudo, Andrew Ross, Muhammad Arshad, and Serena Hamilton
}

\begin{abstract}
Managing water is a grand challenge problem and has become one of humanity's foremost priorities. Surface water resources are typically societally managed and relatively well understood; groundwater resources, however, are often hidden and more difficult to conceptualize. Replenishment rates of groundwater cannot match past and current rates of depletion in many parts of the world. In addition, declining quality of the remaining groundwater commonly cannot support all agricultural, industrial and urban demands and ecosystem functioning, especially in the developed world. In the developing world, it can fail to even meet essential human needs. The issue is: how do we manage this crucial resource in
\end{abstract}

\footnotetext{
A.J. Jakeman $(\bowtie) \cdot$ A. Ross

National Centre for Groundwater Research and Training, Fenner School of Environment and Society, Australian National University, Canberra, ACT, Australia e-mail: tony.jakeman@anu.edu.au

O. Barreteau

IRSTEA - UMR G-EAU, 361 rue Jean-François Breton, BP5095, F-34196 Montpellier, France

R.J. Hunt

United States Geological Survey, 8505 Research Lane, Middleton, WI 53562, USA

e-mail: rjhunt@usgs.gov

J.-D. Rinaudo

Water, Environment and Ecotechnologies Department, BRGM (French Geological Survey), Montpellier, France

M. Arshad

iCAM, Fenner School of Environment and Society, and National Centre for Groundwater Research and Training, Australian National University, Canberra, ACT, Australia

S. Hamilton

Centre for Ecosystem Management, School of Science, Edith Cowan University, Joondalup, WA, Australia

e-mail: s.hamilton@ecu.edu.au
} 
an acceptable way, one that considers the sustainability of the resource for future generations and the socioeconomic and environmental impacts? In many cases this means restoring aquifers of concern to some sustainable equilibrium over a negotiated period of time, and seeking opportunities for better managing groundwater conjunctively with surface water and other resource uses. However, there are many, often-interrelated, dimensions to managing groundwater effectively. Effective groundwater management is underpinned by sound science (biophysical and social) that actively engages the wider community and relevant stakeholders in the decision making process. Generally, an integrated approach will mean "thinking beyond the aquifer", a view which considers the wider context of surface water links, catchment management and cross-sectoral issues with economics, energy, climate, agriculture and the environment. The aim of the book is to document for the first time the dimensions and requirements of sound integrated groundwater management (IGM). The primary focus is on groundwater management within its system, but integrates linkages beyond the aquifer. The book provides an encompassing synthesis for researchers, practitioners and water resource managers on the concepts and tools required for defensible IGM, including how IGM can be applied to achieve more sustainable socioeconomic and environmental outcomes, and key challenges of IGM. The book is divided into five parts: integration overview and problem settings; governance; socioeconomics; biophysical aspects; and modelling and decision support. However, IGM is integrated by definition, thus these divisions should be considered a convenience for presenting the topics rather than hard and fast demarcations of the topic area.

\subsection{Introduction}

Managing groundwater has all the features of "wicked or messy" problems (Rittel and Webber 1973), which have multiple stakeholders and decision makers with competing goals, and where the systems of interest are complex, changing and multifaceted having interactive social, economic, and ecological components - that are subject to a range of uncertainties caused by limited data, information and knowledge.

It is also a grand challenge problem in its severity, pervasiveness and importance. Stores of groundwater represent over $90 \%$ of readily available freshwater on earth (UNEP 2008). However, historically, groundwater has been out of sight and thus underappreciated. Moreover, the time for groundwater system degradation to reach thresholds of concern, even if recognized, is typically longer than many timeframes used in societal decision making. As a result, despite its importance groundwater remains a minor player in water resources management. This relative inattention is changing. Groundwater usage surpasses surface water usage in many parts of the world, which is expected to increase further with advances in drilling and pumping. As well there is a growing awareness of the crucial connectedness of freshwater systems (Villhoth and Giordano 2007), and competition for all types of water has intensified across the globe, driven by the growing world population, and 
increased agriculture, industrial and economic development. Finally, the hidden nature of, and difficulty in characterizing, groundwater systems mean that once a groundwater system is degraded it is not quick, cheap, or easy to remedy. In this way a precautionary principle applies: an ounce of prevention truly may be worth a pound of cure.

The dependence of human and ecological communities on groundwater and their respective challenges varies substantially across the globe, but in no location is groundwater not utilized. The dependence of communities on groundwater can be seasonal or episodic; for example the resource may become critical to survival during severe drought when surface water resources run dry. There are countries, such as Belgium, Denmark, Saudi Arabia and Austria, where over $90 \%$ of total water consumption is sourced from aquifers (Zektser and Everett 2004). However, on average, groundwater comprises approximately $20 \%$ of the world's water use. In many humid regions, such as Japan and northern Europe, groundwater is mostly used for industrial and domestic purposes (Villhoth and Giordano 2007). In most countries outside the humid inter-tropical zone, groundwater is predominantly used for agricultural purposes, especially irrigation (Zektser and Everett 2004). Many large aquifers vital to agriculture, notably in India, Pakistan, Saudi Arabia, USA, China, Iran and Mexico, are under threat from overexploitation (Gleeson et al. 2012; Wada et al. 2012).

Where groundwater abstraction exceeds recharge over long periods and over extensive areas, the subsequent decline in watertable level affects natural groundwater discharge, which in turn may have harmful impacts on groundwater dependent streams, wetlands and ecosystems (Wada et al. 2010). Furthermore, lowered groundwater levels can reduce well yields and increase pumping costs, as well as lead to land subsidence on large scales (Konikow and Kendy 2005). The last can be particularly important. When sufficiently dewatered, accompanying aquifer compaction cannot be reversed, and no options are available to regain the lost aquifer storage. The groundwater in this case is truly "mined" and non-renewable. Partly due to its hidden nature, groundwater usage in many regions has been less monitored than surface water resources. Groundwater managers are typically "flying blind," especially in less advanced countries. Impacts of groundwater overexploitation and pollution can remain undetected for decades or even centuries, presenting further challenges for managing today's resource.

In addition to the poor scientific understanding of groundwater systems, other drivers of poor groundwater management practice have included suboptimal governance, short time horizons of management, and the resource being undervalued and underpriced. More practically, even seemingly small technology shortcomings such as the difficulty and lack of metering hinder implementation of integrated groundwater management. Declines in groundwater quality have also adversely affected use, reuse, and management efforts. As a result, the major threats to groundwater are multi-faceted. The wide range of interests that contribute to groundwater problems illustrates that groundwater issues are not a sector, state, or national issue, but a human issue. Given the complex nature of groundwater systems and their increasing importance as a source of water, there is broad 
consensus that an effective integrated approach to groundwater management is essential.

\subsection{Integrated Groundwater Management}

Integrated Groundwater Management (IGM) is viewed here as a structured process that promotes the coordinated management of groundwater and related resources (including conjunctive management with surface water), taking into account non-groundwater policy interactions, in order to achieve balanced economic, social welfare and ecosystem outcomes over space and time.

A valuable meta-discipline for such a process is that of integrated assessment (IA) (Risbey et al. 1996; Rotmans and van Asselt 1996; Rotmans 1998). IA is defined by The Integrated Assessment Society (www.tias-web.info) as "the scientific meta-discipline that integrates knowledge about a problem domain and makes it available for societal learning and decision making processes." Also "Public policy issues involving long-range and long-term environmental management are where the roots of integrated assessment can be found. However, today, IA is used to frame, study and solve issues at other scales. IA has been developed for acid rain, climate change, land degradation, water and air quality management, forest and fisheries management and public health. The field of Integrated Assessment engages stakeholders and scientists, often drawing these from many disciplines." In terms of water resource management, Jakeman and Letcher (2003) summarise key features and principles of IA (Table 1.1) and highlight the role of computer modelling in the process. The latter will be expanded upon in Part IV of this book. It is noteworthy that IA can bridge multiple topics; for example: although water and energy assessments are distinct threads in the IA literature, the meta-discipline offers a way forward to capture multiple issues and their interactions/interrelations.

Table 1.1 Common features of integrated assessment (Adapted from Jakeman and Letcher 2003) A problem-focussed activity, needs driven; and likely project-based

An interactive, transparent framework; enhancing communication

A process enriched by stakeholder involvement and dedicated to adoption

Linking of research to policy

Connection of complexities between natural and human environment

Recognition of spatial dependencies, feedbacks, and impediments

An iterative, adaptive approach

A focus on key elements

Recognition of essential missing knowledge for inclusion

Team-shared objectives, norms and values; disciplinary equilibration

Science components not always new but intellectually challenging

Identification, characterisation and reduction of important uncertainties in predictions 
To produce outputs that are useful for an intended purpose such as decision making, it is essential that IGM and IA address all important dimensions of integration. Below we discuss ten key dimensions of IGM based on a framework applied to Integrated Modelling proposed by Hamilton et al. (2015). These dimensions correspond to the integration of multiple, often disparate, topics: issues of concern; management options and governance arrangements; stakeholders; natural subsystems; human subsystems; spatial scales; temporal scales; disciplines; methods, models, tools and data; and sources and types of uncertainty. This book covers a wide range of challenges relating to groundwater management and the integration across and within the ten dimensions, as well as potential solutions to addressing such challenges.

\subsubsection{Issues of Concern}

IGM recognises that many issues are interrelated and thus cannot be solved in isolation. For instance, the modernisation of traditional gravity irrigation systems reduces groundwater recharge important for other uses; economic incentives (subsidies) provided by agricultural or energy policies can thus drive groundwater use. Similarly, policy interventions initially designed to solve a groundwater management problem may interfere (positively or negatively) with other policies or groundwater activity. For example, the enforcement of pumping restrictions to ensure that the sustainable use is not exceeded may lead to drastic changes in agricultural production and competiveness of a local agroindustry.

Clearly, addressing groundwater issues in isolation can inadvertently create or exacerbate other problems. Therefore, a joint assessment and treatment of issues across the policy sectors in Fig. 1.1 is important to avoid adversely offsetting actions. A holistic treatment of groundwater related issues is also needed to ensure that all stakeholder views are included and conflicts considered. The essence of IGM consists of clearly articulating and making trade-offs to limit adverse impacts and balance the needs and values associated with competing objectives. This process can involve selecting appropriate environmental, social and/or economic indicators as evaluation criteria, and using integrated assessment and modelling to assess the system performance under different scenarios (Hamilton et al. 2015).

\subsubsection{Governance}

The governance dimension of integration is ubiquitous yet is often a primary stumbling block to effective IGM. Groundwater governance comprises the promotion of responsible collective action to ensure control, protection and socially sustainable utilisation of groundwater resources and aquifer systems. This is facilitated by the legal and regulatory framework, shared knowledge and awareness of sustainability challenges, effective institutions, and policies, plans, finances and incentive structures aligned with society's goals (GEF et al. 2015). Governance can 


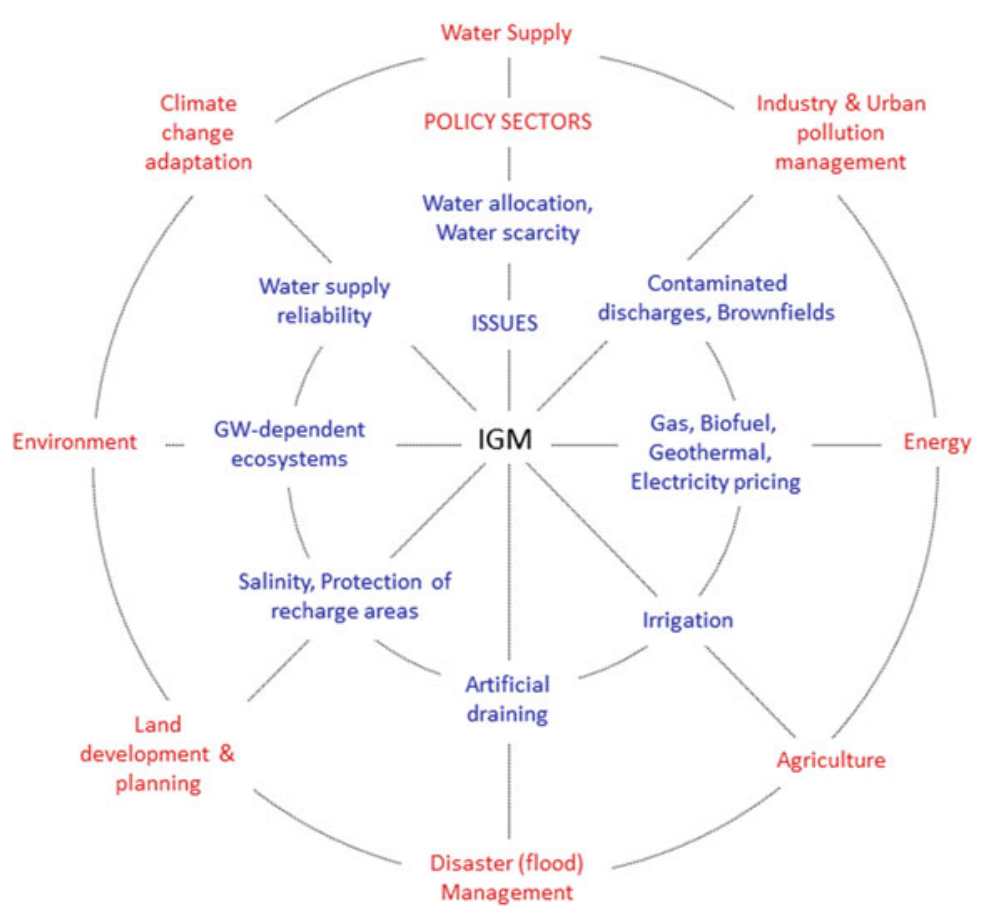

Fig. 1.1 Examples of diverse issues related to groundwater and their relevant policy sectors

be examined from various perspectives including institutional architecture, who is involved, and who is accountable for what to whom.

Such discussions include a mix of policy approaches, including the five types of instruments (Kaufmann-Hayoz et al. 2001):

- Command and control instruments such as regulatory standards, licences, and management zones; these tools aim to improve the behaviour of a target group through State intervention.

- Economic instruments such as taxes, subsidies or water markets, which influence micro-economic choices towards a desirable state, by influencing the costs and benefits of possible actions.

- Collaborative agreements which aim at strengthening cooperative behaviours between groundwater users, by enhancing non-economic motivations (altruism, reciprocity, trust, concerns for future generations)

- Communication and diffusion instruments, to distribute information aimed at influencing the knowledge, attitudes and/or motivations of individuals and their decision making (e.g. related to individual water consumption)

- Infrastructure instruments/investments, which describe the public sector investments intended to improve groundwater management such as those used to initiate managed aquifer recharge. 
Ideally, decision makers should develop strategies and institutions that effectively combine these instruments to deliver acceptable environmental and socioeconomic outcomes, and are also robust under potential changes to the natural and human settings (e.g., climate change, population increase). One of the main issues is ensuring the consistency of the interventions. Implementing one instrument may facilitate or inhibit the effectiveness of other instruments; it is important to consider possible synergies. IGM should provide a process for identifying intervention options and instruments and assessing their effectiveness under different scenarios. Groundwater governance is a complex process, where its effectiveness is influenced by challenges related to determining and implementing policies for groundwater allocation, and coordination of responsibilities across geographical, sectoral and jurisdictional boundaries.

\subsubsection{Stakeholders}

It is increasingly recognised that successful treatment of any wicked problem engages stakeholders appropriately. This particularly applies to groundwater management due to the invisible nature of the resource and the expense and related lack of high-quality information. Stakeholders are individuals or groups involved or interested in the problem - for example local/regional/national government, groundwater users, community groups, the water industry and those with relevant expertise (e.g. hydrologists, hydrogeologists, environmental modellers, agronomists, social scientists, ecologists, etc.). Though often avoided by groundwater scientists, the stakeholder engagement process is critical for effective IGM because it ensures that a broad range of interests, knowledge and perspectives are considered, shared and understood. Stakeholder engagement is also a valuable process in mutually educating, reducing conflict and building trust among researchers, decision makers and other stakeholders. Stakeholder engagement helps to develop a better understanding of demands on the resource and assimilates and publicizes scientific information used by managers. It also promotes mutual learning between users, managers, and policy makers in different domains (agriculture, water supply, energy, etc.). Perhaps most importantly, it can be considered as a necessary condition to gain acceptance of proposed management strategies needed for effective implementation by as many as hundreds or thousands of individual groundwater users. That is, those that are not included in the discussions about the groundwater resource are often those least likely to accept solutions proposed.

\subsubsection{Human Setting}

IGM operates within the human setting, including the social, political, cultural and economic characteristics of the stakeholders. One key role of groundwater managers is to make trade-offs between demand for water use and demand for groundwater sustainability. The demand for use is determined by prevailing market conditions 
and economic policies and to a lesser extent by societal values, including market conditions, policies and values concerning connected resources. The demand for groundwater sustainability and protection is determined by social drivers, including concerns for ecosystems and future generations. These drivers can in turn be influenced by the existing political context. Social drivers also shape the evolution of the institutional set-up, already described in the governance section above.

To effectively management groundwater systems it is necessary to understand how the human setting directly and indirectly relates to the groundwater system. This includes human responses to management interventions and other drivers like climate, and the socioeconomic impact of reduced access to groundwater or reduced groundwater quality. The human setting also underlies behavioural and socioeconomic factors that influence the adoption of better practices or new technologies identified by IGM.

\subsubsection{Natural Setting}

Most importantly, the natural setting forms the extent, limits, and service area of the natural resource from which all IGM must stem. This dimension relates to the integration and communication of the relevant scientific underpinnings and biophysical components of the system. The natural setting includes any substantive connection between aquifers and other natural features such as rivers, lakes, wetlands and springs. It also includes intra-aquifer connectivity within heterogeneous aquifers and inter-aquifer connectivity in multi-aquifer groundwater systems. The natural setting may encompass non-freshwater resources; the hydraulic connection between groundwater and the sea can be important as in estuary health and saltwater intrusion into pumping centres. IGM can also include joint consideration of groundwater and surface water systems with climate, vegetation, fauna and soils. It is increasingly being recognised that these compartments cannot operate or be managed in isolation, as demonstrated by the recent greater demand for conjunctive management of surface and groundwater resources.

\subsubsection{Spatial Scales}

The biophysical and socioeconomic processes related to groundwater systems occur at different spatial scales, ranging from global and regional scales (e.g. climate processes) down to the local scale (e.g. practices of individual farmers, endangered species restricted to a single spring, drinking water well protection zone). A single groundwater system can range from less than $10 \mathrm{~km}^{2}$ to over $100,000 \mathrm{~km}^{2}$ in size, and processes can operate at vastly different scales depending on the system. Biophysical processes can also operate at very different scales and boundaries than socioeconomic processes because groundwater flow is driven by gravity, not political boundaries. One of the key challenges of integrated 
assessment and modelling is accommodating the multiple spatial scales of system processes and interests. The stakeholders may also focus on scales that differ from the actual system processes, for example policy makers might have to develop strategies for groundwater management at a state or national level. Process upscaling/downscaling is commonly required to resolve potential mismatch of scales in integrated assessment frameworks. In many cases, mixed spatial scales are needed depending on what part of the system is represented.

\subsubsection{Time Scales}

Temporal aspects also operate at different scales - as might be expected when groundwater system processes typically occur over much longer time than human timeframes. The mismatch of temporal scales in IGM presents a considerable challenge in characterizing, understanding, and communicating aspects of groundwater systems, as well as how to manage them. Cause and effect may not be readily apparent due to substantial time lags between an action and its result; for example in some systems the effects of overexploitation of groundwater or poor land management may not be apparent in streamflow quantity or quality for several years or even decades. Similarly, even if extraction is reduced to sustainable limits, it may take decades before the effects are noticeable at land surface. Accurately attributing the effect of disturbance or management is further complicated by other confounding disturbances in the intervening period (e.g. extreme climate) and legacy effects from past practices (e.g., aquifers with low hydraulic diffusivity). The appropriate choice of time horizon (extent) and time step (resolution) is ultimately driven by the purpose of the IGM activity, and typically is selected to ensure important processes and responses can be captured.

\subsubsection{Disciplines}

To provide a holistic understanding of the system, IGM typically requires integration of knowledge and competencies from a broad range of paradigms (e.g. positivistic, interpretive) and disciplines (e.g., geology, hydrogeology, hydrology, hydrochemistry, engineering, ecology, law, economics, computer science, sociology, political science and psychology). Integrating disciplines involves challenges associated with incorporating divergent views and interests, theories, assumptions, types and formats of information, languages, research methodologies and tools (e.g. Hunt and Wilcox 2003; Hancock et al. 2009). IGM calls for a new breed of research, one focused on teams who are much more interdisciplinary and systems focused in their approach. Moreover, the interdisciplinary focus requires investments of time to communicate and understand points of view outside of one's field of expertise. 


\subsubsection{Methods, Models, Other Tools and Data}

This dimension relates to the technical integration of different methods, models, tools and data from various disciplines and/or representing different processes or perspectives. There is a wide range of modelling and analytical tools that can be integrated to develop a comprehensive framework to facilitate IGM - both for the groundwater system itself as well as the socioeconomic drivers that act on the groundwater system. Integrated modelling is the common platform used for performing integrated assessment as it can support a systematic and transparent approach to integration (see Sect. 1.3 below). Combining diverse tools and data is a challenge in interfacing, interoperability, and appropriate distribution of limited available resources and effort. Such challenges have been the focus of work involving model and data standardisations and information exchange, work that is ongoing.

\subsubsection{Uncertainty}

No environmental system (natural and/or socioeconomic) can be perfectly characterized, especially when many of its key characteristics are inferred and imperfectly sampled. Handling the lack of detailed understanding of groundwater systems is one of the key challenges to their effective management. Uncertainty is embedded in all aspects of IGM, from our ability to represent the biophysical systems to the social systems in which they are embedded. Though the system cannot be perfectly characterized, the presence of uncertainty is well accepted and thus cannot be ignored. Effective IGM recognizes the source, nature and level of uncertainties associated with problem definition, social/political context, communication, and models and tools used in the assessment process. Due to the inherent and often large uncertainties associated with managing groundwater systems, there is a need to communicate decision making in the context of uncertainty and, when possible, develop robust management strategies that perform well under a range of plausible conditions.

\subsection{Integrated Assessment, Modelling, and Other IGM Tools}

Many tools can be used to support the development of policies in IGM. The development of conceptual models amongst stakeholders is a common starting point to frame the relevant issues, define outcomes, and manage complexity. A vital first step is to draw system boundaries wide enough to encompass the interacting influences, while keeping the conceptualisation only as complex as necessary to conduct useful analysis (Bazilian et al. 2011). Integrated models are generally considered the primary tool to articulate and test such conceptualisations because they can represent potential scenarios of policy interventions, uncontrollable drivers and uncertainties, and outputs that capture trade-offs or impacts of 
alternative actions. When properly constructed, they can also allow exploration of system feedbacks and linkages within a single framework. Because IGM encompasses a wide variety of drivers, feedbacks and spatio-temporal scales, integrated models that couple component models representing different system components (often from different paradigms) are often required (Kelly et al. 2013). For example, in exploring the socioeconomic and ecological impacts of reduced water allocations and adaptation options by farmers, Jakeman et al. (2014) developed an integrated model that couples surface-groundwater models with social Bayesian networks, crop metamodels, economic optimisation of production values, policy rule models, and ecological expert opinion. On the other hand, integrated models typically include one modelling methodology (e.g. Bayesian networks, system dynamics, agent-based models, expert systems) rather than a combination to represent the whole system. Including multiple methods is a topic of ongoing work.

The nature of integrated assessment, including the need to integrate perspectives from different disciplines and stakeholder groups, requires a process and modelling framework that is adaptive and facilitates participatory procedures. Often there is a flow of information from stakeholders on their knowledge of the system and preferences about the policy environment. This information, along with scientific knowledge, supports the conceptualisation, construction, and use of a model (Fig. 1.2). Model conceptualisation includes elements such as issue definition, specification of system boundaries and identification of measures, criteria, indicators and processes. The model, in turn, provides insight on the possible impacts and trade-offs under selected scenarios, which then flows back to inform stakeholder and policy preferences and system understanding. Scientists gain understanding from the modelling process as well through their interactions with stakeholders.

There are several important considerations handled when constructing integrated models. The purpose of the model drives the selection of system

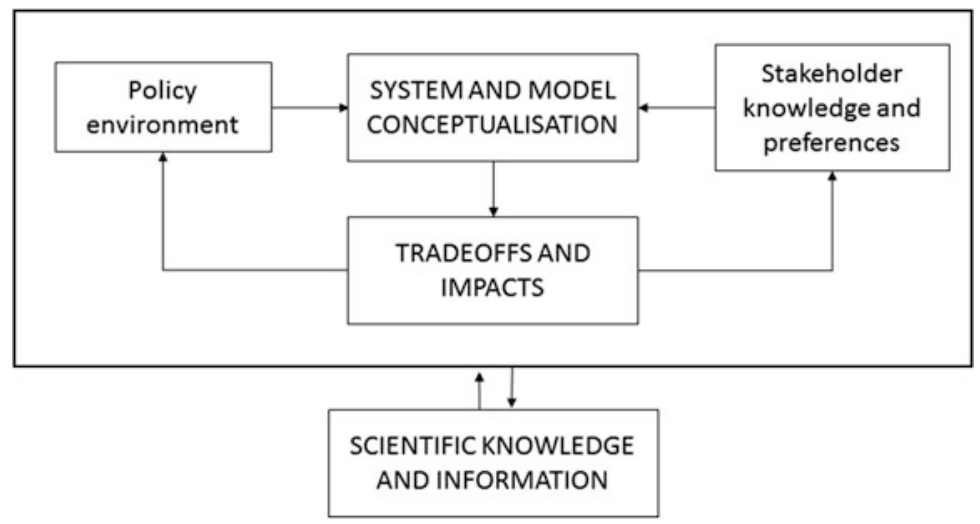

Fig. 1.2 Integrated modelling framework 
processes, which in turn dictates the model structure that is applied and evaluated (Jakeman et al. 2006). Appropriate modelling takes into account the spatiotemporal detail required in the modelling, the nature of the data (qualitative and/or quantitative), the level of ability to represent uncertainty and feedbacks (Kelly et al. 2013). The choice of approach may also be dictated by human and computational resources. For example, Bayesian networks may be suitable when data is sparse or system understanding is limited but quickly interrogated; and processbased models may be suitable if system processes are understood and important for the IGM activity. The system dynamics approach may be appropriate when dynamic processes or system feedbacks are of interest, whereas agent-based models are appropriate when interactions between individuals are of interest (Kelly et al. 2013). Scenario analysis is useful when future conditions are difficult to estimate and underpin overarching uncertainty (e.g. climate change - See Anderson et al. 2015, Chap. 10). In summary, integrated assessment and modelling is often best supported by a suite of tools, with individual tools applied to leverage different information that is then compiled to provide an encompassing assessment of the system. The challenge is then ensuring effective communication between tools.

The outputs of integrated models are not a crystal ball defining one future. Rather, they are typically a heuristic tool that provides insights to support decision or policy making, a tool that articulates the trade-offs inherent to IGM. When properly used, these tools facilitate IGM through: (1) improving and articulating understanding (regarding potential impacts as well as system feedbacks and interactions); (2) educating scientists, decision- and policy-makers and other stakeholders; (3) limiting options explored to those that are feasible; and (4) building interaction and rapport between stakeholder groups, which can influence the range of policy changes considered.

\subsection{Book Overview and Key Messages}

The book is divided into five parts. An overview of each part and associated key messages are provided below.

\subsubsection{Part I: Integration Overview and Problem Settings}

This first part of the book provides a broad examination of integrated groundwater management and associated issues and challenges. As we have seen in Chap. 1, Integrated Groundwater Management is a grand societal challenge, perhaps the most urgent as many societies and ecosystems depend on the sustainability of their groundwater systems. Effective IGM considers the dimensions discussed in Sect. 1.2, and the effectively tailors the wealth of model platforms and tools available to support IGM to a specific problem context. Scientists and decision makers need to engage extensively with stakeholders and think and plan for the longer term inherent to all groundwater systems. Chapter 2 examines the 
international scale of groundwater issues, both in severity and extent. It points to the need for understanding the interconnections among aquifers, surface water, ecosystems, and human needs, especially given the complexities of socialecological systems dependent on the resource. Chapter 3 discusses the interactions within components of groundwater-dependent and social-ecological systems, and proposes a conceptual framework to describe their complexity.

Chapters 4 and 5 examine the challenge of groundwater management under global change. Chapter 4 focuses on the water-energy-food nexus whereas Chap. 5 considers potential climate change impacts on groundwater, in addition to potential feedbacks of groundwater on the global climate system. Energy demand management measures have positive synergies in reducing consumption of water, but the impacts of new energy technologies on groundwater are mixed. The direct impacts of climate change on groundwater will vary with different combinations of soils/aquifer materials, vegetation, and climatic zone. Long-term monitoring of natural systems (groundwater, surface water, vegetation and land use patterns) provides a critical baseline to identify and evaluate effects of future change. Climate change mitigation and adaptation policies are expected to change, and in some cases (carbon sequestration in the landscape, some renewable energy technologies) exacerbate, the challenges associated with groundwater use and management.

\subsubsection{Part II: Governance}

Here six chapters deal with issues related to the governance of groundwater, focused on three case study regions: Australia, the European Union and the USA. It begins in Chap. 6 with a comparative study of groundwater governance in the three regions, classifying groundwater governance issues into the five blocks used in the Earth Systems Governance Framework. Strengths and weaknesses are elucidated as well as the governance difficulties and dilemmas faced in these three regions. A review of the fundamental legal principles relating to groundwater in the three regions, including the challenges of these legal frameworks in a crossboundary context is discussed in Chap. 7. Australia, the western United States, and Europe display key differences in how they conceive of fundamental aspects of groundwater regulation, such as ownership and principles for permitting groundwater withdrawals. Yet they face very similar challenges in relation to integrating regulation of groundwater and surface water, groundwater and dependent environments, and groundwater across boundaries. Commonly, they deal with similar challenges in different ways, where a range of potential legal tools are used across the globe. In Chap. 8, groundwater challenges are examined through integrated management and planning approaches, with specific examples of policy frameworks for water management adopted in parts of the three study regions. From these examples, integrated groundwater management appears a "living" or iterated mechanism that is updated, refined and (if necessary) changed as new information and experience are gained. Chapter 9 explores the opportunities and challenges of 
delivering conjunctive management of water resources through collective action by governments and water users. Australia, Spain and the United States have made some progress in pursing conjunctive management through collective action, but their experiences have highlighted a number of practical and policy limitations. Conjunctive management through collective action is more likely where social and environmental crisis arise and where there is institutional recognition of hydrological connections (between groundwater and surface water), and where management tools are devolved to local water users.

Groundwater governance challenges, and associated potential social and environmental injustices, are addressed in Chap. 10, including how equity in water use is considered and how it has been translated into practice. The rationale for sharing or allocating groundwater is guided by the principle of equitable and reasonable utilization. Environmental justice is a useful lens in the arsenal of researchers, policy makers and natural resource managers that can be used to highlight the importance of a systems approach when dealing with common pool resources such as groundwater. In the last Chap. (11) of Part II, social justice and different groundwater allocation rules are contrasted in a French case study. It analyses the acceptability of rules for apportioning groundwater resources among agricultural users in over-used / over-allocated groundwater basins. The study highlights that acceptance of new water allocation rules is not only determined by how stakeholders perceive these rules in terms of distributive justice. Farmers' judgment is also influenced by their perception of the legitimacy (moral, pragmatic and cognitive) of the policy in which the question of allocation rule is embedded. Another determining factor is the perceived implementation difficulties that are expected to result from allocation rules.

\subsubsection{Part III: Biophysical Aspects}

The biophysical aspects of IGM are examined in Part III. It begins with a background to ecohydrology in Chap. 12, which considers how ecology and hydrology interactions are critical for determination of groundwater availability and sustainability, and once articulated, can be incorporated into effective groundwater management. In many cases, success of integrated groundwater management is measured by how well the interaction between ecology and hydrology aspects is articulated and addressed. Groundwater dependent ecosystems (GDEs), their structure and function, are reviewed in Chap. 13, and are discussed in terms of the potential threats resulting from over-extraction of groundwater. Defining the response function of ecosystems to groundwater extraction is a key research challenge for the future, with major implications to policy, legislation and sustainable management of GDEs and groundwater resources. Chapter 14 uses examples to illustrate how natural and anthropogenic water quality issues can drive IGM and its implementation - factors that can in some cases eclipse water quantity issues that may also exist. Water quality concerns can come from naturally occurring or human induced contaminants; moreover, such concerns are often based on 
public perception, which can limit the use and availability of groundwater. In this way, "acceptable" water quality is not a static definition, but changes with time with increasing analytical precision and increased knowledge on effects on human and environmental health. Chapter 15 examines the processes and issues around salinization and drainage in irrigation schemes. As the salinization of shallow aquifers is closely related to root-zone salinization, the two are considered together. A case study of root-zone salinization was taken from a developing country (Pakistan), whilst that of shallow aquifer salinization was taken from a developed country (Australia). Both case studies underscore how mitigation strategies to overcome groundwater salinization need to be integrated with policy.

In Chaps. 16 and 17 the promise and challenges of managed aquifer recharge (MAR) are explored, including opportunities to save excess water underground and reduce evaporation losses. MAR can augment groundwater with available surface water and can act alongside conjunctive use of surface waters and groundwater to sustain water supplies and achieve groundwater and surface water management objectives such as protection of ecosystems. Chapter 16 argues that specific local characteristics of each MAR site, precludes a single universal solution for all settings, suggesting existing legal frameworks must take this into account. Moreover, MAR function and the impacts on water availability, water quality, sustainability as well as on the local and downstream environment, need to be communicated to promote cost-effective implementation. Chapter 17 further describes the potential role of MAR in IGM for conserving surface water resources, improving groundwater quality and increasing groundwater availability. MAR may be used to replenish depleted aquifers, in association with demand management strategies to bring aquifers closer to hydrologic equilibrium needed for sustainable use. In suitable hydrogeologic locations, MAR options have been shown to be economic when compared to other sources such as seawater desalination.

\subsubsection{Part IV: Socioeconomics}

Part IV focuses on the social science and economic considerations of IGM. Chapter 18 examines groundwater management in modern-day China, which is facing unprecedented challenges that reflect many social, cultural and political drivers. The chapter examines how changes to the legislation system, institutional reforms and better management instruments can help China progress towards more integrated groundwater management. Chapter 19 explores the social dimensions of groundwater governance and how social sciences, including stakeholder engagement, social impact assessment and collaborative approaches, contribute to the IGM process. Difficult or 'wicked' natural resource management issues are often best addressed by engaging stakeholders in processes that involve dialogue, learning, and action to build and engage social and human capital. Human and social capital underpins much of the capacity of any community to respond to the challenges of sustainability. When conducting integrated research, it is critical for 
social researchers to be engaged from the outset in problem definition and setting research priorities.

In Chap. 20 the use of groundwater trading as a management strategy is investigated, where attempts in Australia and the USA to establish groundwater markets are used to frame important underlying issues. Before groundwater markets can successfully develop, institutions and regulations have to exist at some level. For fully efficient and effective policy, there is a need to invest in high quality economic and scientific research, where social concerns are not the sole important drivers for efficient and effective groundwater markets. In Chap. 21, assessment of the benefits of groundwater improvement and protection is addressed from an economic viewpoint of contingent valuation. Such economic analysis integrates benefits for present and future generations, and includes the "bequest" or "heritage" value, defined as the value of satisfaction from improving groundwater resources for future generations. Potential and limits to this approach are discussed using literature review and two case studies from France and Belgium. Chapter 22 evaluates strategies for groundwater management through economic instruments, current practices, challenges and innovative approaches. The last Chap. (23) of Part IV examines the expanding groundwater economy in North Africa, where aquifers have commonly been overexploited as a result of the short-term interests of private entities and the absence of effective governance.

\subsubsection{Part V: Modelling and Decision Support}

Lastly, Part V focuses on concepts of modelling, data management, and decision support for facilitating and informing IGM. Chapter 24 discusses the use of systems thinking, particularly soft- and critical-systems approaches, for incorporating human aspects (i.e. cognitive, social, cultural, and political) into groundwater management and research. It stresses the value of a multi-method approach to accommodate different perspectives using four international case studies, and suggests that practitioners and researchers need to be aware and explicit about their theoretical and methodological stance, but also creative about how they adapt and localise their approaches. Chapter 25 examines the use of decision support processes and models for articulating and improving groundwater management policies and trade-offs. Decision support systems (DSS) provide a means for water managers to evaluate complex data sets that include hydrogeologic, economic, legal and environmental elements. Although distributed groundwater modelling approaches are improving, examples of integrated groundwater DSS or participatory processes are not widespread. Nevertheless DSS are well suited for integrated groundwater problems because they can provide a set of applications, methodologies, and tools to communicate and cope with inherent complexity and uncertainty.

Chapter 26 discusses challenges that ripple to data management needed for IGM as new technologies in monitoring and computing, including data networks, are developed. Integrated studies typically have large data requirements, which not only 
need to be well stored, but also well described, easily discoverable and accessible, and in consistent form for use in integrated groundwater studies. Data networks are increasingly being used to provide access to large national data holdings in a consistent open standards based manner, which facilitates their use in integrated groundwater studies. Chapter 27 reviews the use of hydro-economic models as decision support tools for conjunctive management of surface and groundwater. It considers technical challenges involved in incorporating aquifer dynamics, stream-aquifer interactions, nonlinearities and multiple objectives into integrated frameworks. Hydroeconomic models can provide a useful insight into a more efficient operation of conjunctive use and the economic implications of different conjunctive use strategies. The final Chap. (28) relates IGM to uncertainty uncertainty that resides in managing groundwater systems and in groundwater system models. A range of methods for exploring uncertainties and how they can be applied are discussed. Because no one approach is appropriate for all applications, techniques are often decided by the judgement of the modeller. As the scientific method cannot prove correctness, making predictions of uncertain outcomes needs to focus on eliminating the impossible and incorrect potential outcomes, and focus on elucidating alternative models and conclusions. One does not need to be able to use all possible alternatives, but it is important to be aware of alternatives that have not been used but could affect associated conclusions.

And perhaps one final message is warranted. Difficult problems and crises involving groundwater will only increase. Opportunities for IGM will then operate on two levels, the first being steadfast application of standard approaches to problems well recognized. Less predictable, come windows of opportunities for reform and more effective IGM. The challenge for all parties - decision-makers, water managers, scientists and other stakeholders - is to be prepared to seize opportunities to implement more sustainable and effective groundwater management. The aim of this book was to prepare the reader for such windows of opportunity by laying out the major disciplinary and interdisciplinary components, challenges, and opportunities, for integrated and sustainable management of groundwater.

Open Access This chapter is distributed under the terms of the Creative Commons AttributionNoncommercial 2.5 License (http://creativecommons.org/licenses/by-nc/2.5/) which permits any noncommercial use, distribution, and reproduction in any medium, provided the original author(s) and source are credited.

The images or other third party material in this chapter are included in the work's Creative Commons license, unless indicated otherwise in the credit line; if such material is not included in the work's Creative Commons license and the respective action is not permitted by statutory regulation, users will need to obtain permission from the license holder to duplicate, adapt or reproduce the material. 


\section{References}

Anderson MP, Woessner WW, Hunt RJ (2015) Applied groundwater modeling: simulation of flow and advective transport. Elsevier Academic Press, Amsterdam, 564 p. ISBN 9780120581030

Bazilian M, Rogner H, Howell M, Hermann S, Arent D, Gielen D, Steduto P, Mueller A, Komor P, Tol RSJ, Yumkella KY (2011) Considering the energy, water and food nexus: towards an integrated modelling approach. Energy Policy 39:7896-7906

GEF, World Bank, UNESCO-IHP, FAO and IAH (2015) Global groundwater governance a call to action: a shared vision for 2030. http://www.fao.org/fileadmin/user_upload/groundwater governance/docs/general/GWG_VISION.pdf. Accessed 11 June 2015

Gleeson T, Wada Y, Bierkens MFP, van Beek LPH (2012) Water balance of global aquifers revealed by groundwater footprint. Nature 488:197-200

Hamilton S, El Sawah S, Guillaume JHA, Jakeman AJ (2015) Integrated assessment and modelling: a review and synthesis of salient dimensions. Environ Model Software 64:215-229

Hancock PJ, Hunt RJ, Boulton AJ (2009) Preface: hydrogeoecology, the interdisciplinary study of groundwater dependent ecosystems. Hydrogeol J 17(1):1-4. doi:10.1007/s10040-008-0409-8

Hunt RJ, Wilcox DA (2003) Ecohydrology - why hydrologists should care. Ground Water 41(3): 289. doi:10.1111/j.1745-6584.2003.tb02592.x

Jakeman AJ, and 17 others (2014) Modelling for the complex issue of groundwater management. In: Obaidat MS et al. (eds) Simulation and modelling methodologies, technologies and applications, vol 256, Advances in intelligent systems and computing. Springer, London, pp 25-41. doi:10.1007/978-3-319-03581-9. ISSN 2194-5357, ISBN 978-3-319-03580-2

Jakeman AJ, Letcher RA (2003) Integrated assessment and modelling: features, principles and examples for catchment management. Environ Model Software 18:491-501

Jakeman AJ, Letcher RA, Norton JP (2006) Ten iterative steps in development and evaluation of environmental models. Environ Model Softw 21:602-614

Kaufmann-Hayoz R, Battig C, Bruppacher S, Defila R, Di Giulio A, Flury-Kleubler P, Friederich U, Garbely M, Gutscher H, Jaggi C, Jegen M, Mosier H-J, Müller A, North N, Ulli-Beer S, Wichtermann J (2001) A typology of tools for building sustainable strategies. In: KaufmannHayoz R, Gutscher H (eds) Changing things - moving people. Birkhauser, Basel, p 33e108. Kelleher C, Wagener T, 2011

Kelly RA, Jakeman AJ and 11 others (2013) Selecting among five common modelling approaches for integrated environmental assessment and management. Environ Model Softw 47:159-181

Konikow LF, Kendy E (2005) Groundwater depletion: a global problem. Hydrogeol J 13:317-320

Risbey J, Kandlikar M, Patwardhan A (1996) Assessing integrated assessments. Clim Change 34: 369-395

Rittel HWJ, Webber MM (1973) Dilemmas in a general theory of planning. Policy Sci 4:155-169

Rotmans J (1998) Methods for IA: the challenges and opportunities ahead. Environ Model Assess 3:155-179

Rotmans J, van Asselt M (1996) Integrated assessment: a growing child on its way to maturity. Clim Change 34:327-336

UNEP (2008) Vital water graphics - an overview of the state of the world's fresh and marine waters, 2nd edn. UNEP, Nairobi. ISBN 92-807-2236-0

Villhoth KG, Giordano M (2007) Groundwater use in a global perspective - can it be managed? In: Giordano M, Villholth KG (eds) The agricultural groundwater revolution: opportunities and threats to development, vol 3, Comprehensive assessment in agriculture. CAB International, Wallingford, pp 393-402

Wada Y, van Beek LPH, van Kempen CM, Reckman JWTM, Vasak S, Bierkens MFP (2010) Global depletion of groundwater resources. Geophys Res Lett 37, L20402. doi:10.1029/ 2010GL044571

Wada Y, van Beek LPH, Bierkens MFP (2012) Nonsustainable groundwater sustaining irrigation: a global assessment. Water Resour Res 48:W00L06. doi:10.1029/2011WR010562

Zektser IS, Everett LG (eds) (2004) Groundwater resources of the world and their use, IHP-VI series on groundwater No 6. UNESCO, Paris 


\title{
The International Scale of the Groundwater Issue
}

\author{
Michael N. Fienen and Muhammad Arshad
}

\begin{abstract}
Throughout history, and throughout the world, groundwater has been a major source of water for sustaining human life. Use of this resource has increased dramatically over the last century. In many areas of the world, the balance between human and ecosystem needs is difficult to maintain. Understanding the international scale of the groundwater issue requires metrics and analysis at a commensurate scale. Advances in remote sensing supplement older traditional direct measurement methods for understanding the magnitude of depletion, and all measurements motivate the need for common data standards to collect and share information. In addition to metrics of groundwater availability, four key international groundwater issues are depletion of water, degradation of water quality, the water-energy nexus, and transboundary water conflicts. This chapter is devoted to introducing these issues, which are also discussed in more detail in later chapters.
\end{abstract}

\section{$2.1 \quad$ Introduction}

Throughout history, groundwater has been a major source of water for sustaining human life. Because it is buffered from short-term variability in weather patterns, groundwater has often been considered a stable and reliable resource. With the advent of efficient pumps and rural electrification, global groundwater extraction increased from $312 \mathrm{~km}^{3} /$ year in the $1960 \mathrm{~s}$ to $743 \mathrm{~km}^{3} /$ year in 2000 (Wada et al. 2010); approximately $70 \%$ of this extraction is used for agriculture. About half of domestic human water consumption in urban areas is from groundwater

M.N. Fienen $(\bowtie) \bullet$ M. Arshad

US Geological Survey, Wisconsin Water Science Center, Middleton, 53562, Wisconsin, USA

e-mail: mnfienen@usgs.gov 
(Giordano 2009). With increased water use comes a related possibility of local, regional, and international conflict over groundwater resources.

Groundwater, surface water, humans, and ecosystems are all interconnected in ways that necessitate an integrated approach to management. To manage in this way requires an understanding not only of the component aspects of the problem but also of the components' interconnections. See Chap. 1 for a comprehensive list and description of the dimensions of an integrated approach. Determining the scope of these issues, a first dimension, is challenging on a global scale, primarily because groundwater systems themselves are not all connected, and each system has its own characteristics; thus, any measurements of a specific system reflect specific local conditions, making extrapolation from data-rich to data-poor regions problematic. In contrast to measurements of streams which can integrate information over an entire watershed, point measurements of groundwater conditions commonly reflect a smaller land area, requiring more measurements to evaluate a comparable region. Remote sensing techniques such as the Gravity Recovery and Climate Experiment (GRACE) satellite provide information over larger areas, but they also require sitespecific calibration information and are more accurate for determining changes than for assessing conditions at a certain time. A realistic picture of global conditions, then, must be based on aggregation of data from a variety of widely distributed organizations, many of them local in focus. These data must also be used with modeling techniques to obtain estimates of groundwater conditions.

Once information from observations and models is assembled, metrics that allow comparison among regions can be developed to guide management. These metrics are typically based on water balance computations, which in turn are based on estimates of human extraction and returns, removal from storage, water required for ecosystem services, and natural replenishment. The management challenge then becomes making the difficult choices regarding the level of sustainability required, because the relationship of humans to groundwater resources differs from place to place.

Four key international groundwater issues are depletion of water, degradation of water quality (see also the devoted coverage in Chap. 15), the water-energy nexus (Chap. 4), and transboundary water conflicts (Chap. 6). In the context of these issues, technical challenges abound in attempting to understand and quantify current impacts and resources, even more so in attempting to plot a way forward. Yet, some advances in understanding are being made, and common threads of challenges related to scale, governance, and the need for integrated data also provide opportunities to impact multiple issues with each advance.

Depletion is a major groundwater issue, but the definition of depletion is not completely obvious and has changed over time. Dating back to 1915, concepts of safe yield in relation to groundwater were proposed. Originally, a balance was sought between groundwater extraction and replenishment by recharge such that extraction could continue in equilibrium. This early definition did not incorporate transient conditions, nor did it consider ecosystem impacts (as covered in Sect. 2.3, Chaps. 12 and 13). The concept of depletion has since evolved into one that acknowledges sustainability and integrated water management, but a true accounting of depletion also must embrace socioeconomic considerations (as covered in 
Sect. 2.4, and Chaps. 20 and 21). Depletion is still typically measured by decreases in groundwater levels and decreases in baseflow or levels in connected surface water bodies and degradation in water quality.

Degradation of water quality falls into two broad categories (Chap. 14): that due to natural conditions and that due to anthropogenic causes. Both forms of degradation can result from human extraction of groundwater. Extraction or changes to recharge can alter groundwater flow directions or expose aquifer material to air, allowing for previously clean water to encounter natural contaminants such as radium, salt, arsenic, and fluoride and resulting in poor water quality and associated health impacts. On the other hand, chemical and biological contaminants emanating from industry and agriculture also cause water quality degradation.

As expounded in Chap. 4, the water-energy nexus is an integrative issue with feedbacks among water extraction, water quality, and energy production/consumption. Declining water levels due to extensive extraction lead to increased lift required by pumps, thereby increasing the amount of energy required for irrigation and domestic use. Exploration for new energy sources-for example, shale gasalso has the potential to create groundwater contamination from various activities associated with its production, such as during hydraulic fracturing and deep disposal of drilling fluids.

Transboundary aquifers (Chap. 6) have often been cited as potential hotspots of global conflict. Many aquifers are bounded by the borders of a single country so, whereas internal conflicts arise and can be substantial, they are less likely to be violent than conflicts between nations. Exceptions include the Nubian Aquifer in North Africa and aquifers in the Israel/Palestine region. Conflicts less intense than war nonetheless occur within nations at scales ranging from individual ranches to larger regions. Dire predictions of wars over groundwater resources have been made for many years, and although some violence has occurred, extraordinary cooperation has sometimes been motivated by mutual need for groundwater resources. Uncertainties related to groundwater resources - in contrast with surface water systems - may increase the likelihood of future conflicts.

In this chapter, we explore each of these integrated issues more deeply. We also discuss technologies and techniques for better understanding them. The goal is to highlight the need for integrated management and to set a conceptual framework for the discussion and potential solutions described in more detail throughout the book.

\subsection{The Concept of Groundwater Depletion}

When evaluating the international scale of the groundwater issue, it is important to establish what makes groundwater an issue in the first place. Understanding concepts of sustainability, safe yield, and depletion are central to this. These concepts guide definitions of where groundwater stresses are important.

A parallel evolution in thinking has occurred in the last 100 years regarding (1) the connections between surface water and groundwater and (2) the importance 
of water provided to ecosystems. Despite previous misconceptions of "safe yield" (for example, using calculations of recharge as a basis for allotting an amount of water that can be "safely" extracted from a groundwater basin), it has become more widely accepted that discharge to streams, springs, etc., is often the limiting water balance element. With regard to ecosystem services, the concept of "safe yield" has evolved to "sustainability," augmenting consideration of undesirable economic impacts of depletion with the maintenance of discharge flows at levels that support ecosystem dependence on surface water and groundwater from aquifers.

As early as 1915, the term "safe yield" (Lee 1915) of a groundwater basin was used to define "the net annual supply which may be developed by pumping and Artesian flow without persistent lowering of the ground-water plane." Subsequent work (Todd 1959) made a more general definition as "the amount of water which can be withdrawn from it annually without producing an undesired result." Two important aspects of this definition warrant further scrutiny.

First, the specific source of water needs to be understood to evaluate whether withdrawals are balanced with sources. In Lee's original definition, the entire water balance was considered, and it was acknowledged that often the source of water to pumping wells is the interception of discharge to surface water bodies rather than the collection of recharge. The early workers (Lee 1915) stated that "It is obvious that water permanently extracted from an underground reservoir, by wells or other means, reduces by an equal quantity the volume of water passing from the basin by way of natural channels." Work by Theis (1940) and others also highlighted the importance of intercepted discharge to surface water or evapotranspiration as more significant than collection of recharge. However, over time, the importance of intercepted discharge was neglected and focus on balancing recharge with pumping became a popular definition of safe yield-including codification in legislation in some parts of the United States (Sophocleous 1997). This oversimplified concept has been called the "water budget myth" (Bredehoeft et al. 1982; Bredehoeft 1997; Sophocleous 1997).

Conservation of mass is a tenet of science, formally dating back to 1748 (Hockey et al. 2007), so the establishment of water budgets is a natural approach to assessing groundwater availability. Simply by accounting for inputs (through recharge and regional flow) and outputs (natural discharge to surface water, evapotranspiration, and anthropogenic extraction) and the change in storage, the amount of available groundwater can be established. Prior to pumping, the groundwater system is typically in dynamic equilibrium, with storage being constant and the sum of all inputs equal to the sum of all outputs. If a new stress acts on the system, either recharge must increase, discharge must decrease, or water must be removed from storage. It is uncommon for pumping to be accompanied by an increase in recharge from precipitation, so the change must result from some combination of a decrease in discharge or removal of water from storage. As water is removed from storage, the groundwater surface - the water table in unconfined aquifers or the potentiometric surface in confined aquifers-drops, which can increase the cost and difficulty of removing water through pumping. Through a dropping water surface, directly intercepted discharge, or a combination of those two effects, streams and 
springs can be reduced in flow or completely dried up. Removal of water from storage is referred to as "mining" or "overdraft," and some water is always mined before a new equilibrium is achieved after the addition of a stress such as human extraction through wells (Theis 1940). In the extreme, if all water is removed from storage, a groundwater basin could be, for practical purposes, depleted. A challenge for integrated groundwater management is to understand the sources of water where extraction is planned and to appropriately account for the deficiencies caused by extraction.

Second, in the 100 years since Lee's work, the concept of what is an undesired result has evolved significantly. Meinzer (1923), in the decade following Lee's work, in fact did not indicate specific undesired results, but rather defined safe yield as "...the rate at which water can be withdrawn from an aquifer for human use without depleting the supply to such an extent that withdrawal at this rate is no longer economically feasible." At that time, as noted by Reilly and coworkers (Reilly et al. 2008), indoor plumbing was not widespread in the United States and the population was dispersed. It was natural, then, that the feasibility of future human consumption would guide concepts of preserving future use. Another widespread attitude of those times was that water flowing to springs or lost to evapotranspiration was "wasted" (Lee 1915). More recently, ecosystem health has been recognized as an important consideration for current and future use, and the dialogue has shifted from a concept of "safe yield" to one of "sustainability" (Alley and Leake 2004). Sustainable development was coined as part of the development that "... meets the needs of the present without compromising the ability of future generations to meet their own needs" (World Commission on Environment and Development 1987). This broad definition is meant to encompass not only the economic needs of future generations but also the health of the ecosystems they depend upon. When viewed in this framework, groundwater use must be balanced not only with the ability of an aquifer to continue supplying water to wells for human consumption but also with the capacity to maintain discharge to surface water, phreatophytic vegetation, and other habitats that make up the ecosystems surrounding and connected to the groundwater system.

It is clear that managing groundwater in a way that does not deplete the source of water or displace water from all dependent ecosystems-including humans-is a technical challenge. Some impact is inherent in the disruption of natural equilibrium through human activity - the challenge is to establish an agreed-upon acceptable level of disruption. Pierce et al. (2012) propose a continuum approach that balances socioeconomic, ecosystem, and sustainability constraints. Recently, Werner et al. (2013b) evaluated and ranked occurrences of mega storage depletion worldwide in terms of physical processes and the importance of the resource. Such nuances in definition and approach can pose challenges in coming to agreement among stakeholders (Llamas 2004), but the result of concurring on a definition and approach is much better management of the resource, tailored to the specific environmental and socioeconomic needs of a specific area. Giordano (2009) highlights this complexity noting that groundwater mining in Libya and Saudi Arabia, although unsustainable by most strict definitions, may provide 
socioeconomic benefit with little or no ecological impact that outweighs the downside of acknowledged depletion that is taking place.

By taking into account water quality, aquifer salinization (Chap. 16), risk of sea water intrusion, and subsidence issues, Konikow and Kendy (2005) described depletion as a physical process that renders reduction in the total or usable volume of the resource. Thus, depletion leads to consequences realized or perceived to be negative for the current and future use of the resource. Consequences of depletions such as salinization can be substantial, because it commonly is very time and resource expensive to bring a degraded aquifer back to its natural state. Further, some impacts—such as subsidence—can be irreversible (Zektser et al. 2005).

Today's nuanced understanding of differences in source from recharge, discharge, and storage is generally well documented and supported in the scientific literature. Yet, the water budget myth persists where science meets policy because it is much simpler to use a single metric_-"recharge"- to regulate how much water may be extracted from an aquifer without undesired consequences without regard to the importance of timescale (Harou and Lund 2008). Many of the metrics available to document depletion must pass over these nuances to apply at a large scale and still rely on balancing recharge with human extraction-including metrics referred to in this chapter. Although the concept of sustainability has made its way into the dialogue through acknowledgement that ecological flows should be maintained, the recommended solution still often seems to be regulating pumping rates at less than or equal to recharge rates (ASCE 2004; Beck 2000).

\subsection{Groundwater Depletion Globally}

Groundwater demands for consumptive and environmental uses are expected to grow, while supplies will remain constrained by unsustainable use of the aquifers. In the last five decades, economic gains from groundwater use have been substantial, but they have been realized at high social and environmental costs (Custodio 2002; Birol et al. 2010). Groundwater levels in many places have already dropped and are further dropping in response to excessive extraction. Adverse effects of overdraft have been observed in many places in the forms of reduced flows in streams and wetlands, stream-aquifer disconnection, water quality degradation through intrusion of saline or poor-quality surface or groundwater, reduced availability of groundwater for consumptive uses, land and aquifer subsidence, and increased costs of pumping. Recent studies have also quantified the contribution of groundwater depletion to sea level rise, accounting for as much as $13 \%$ in recent years (Konikow 2011; Wada et al. 2012)

\subsubsection{Global Estimates of Groundwater Extraction}

Giordano (2009) reported global groundwater extraction in excess of $650 \mathrm{~km}^{3}$ per year (Fig. 2.1), with India, the United States, China, Pakistan, Iran, Mexico, 


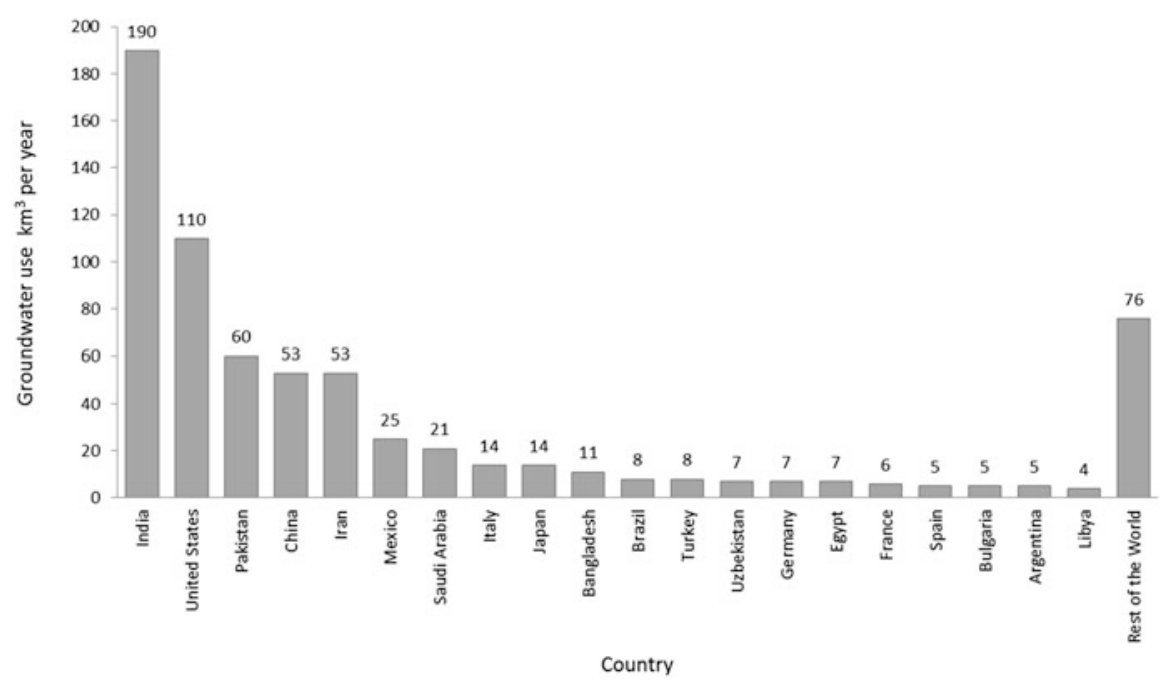

Fig. 2.1 Groundwater use by country, in cubic kilometers per year (Adapted from Giordano (2009))

and Saudi Arabia collectively accounting for $75 \%$ of the global annual water extraction.

The GRACE analysis reports an approximate doubling of global groundwater extraction between 1960 and 2000. From 1960 to 2000, global groundwater annual extraction increased from $312 \mathrm{~km}^{3}$ in 1960 to $734 \mathrm{~km}^{3}$ in 2000. Major hot spots of depletion were observed in arid and semiarid parts of the world, mainly resulting from high population density, heavy reliance on groundwater, little and highly variable rainfall that generates quick runoff, and low rates of natural recharge. For subhumid and arid parts of the world Wada et al. (2010), prepared a global map of groundwater depletion by calculating the difference between global groundwater recharge and groundwater extraction for the year 2000. Hot spots of groundwater depletion were reported in the northwest of India, northeast of China, northeast of Pakistan, and in the High Plains and California Central Valley aquifers in the United States. Other countries where depletion was significant included parts of Iran, central Yemen, and southern Spain. The total global groundwater depletion in those areas was reported as $283( \pm 40) \mathrm{km}^{3}$ per year (Wada et al. 2010). Using an index based approach, Werner et al. (2013b) reported mega storage depletion cases around the world from more than 50 published sources. The largest depletion indices were reported for China, Spain, and the United States.

\subsubsection{Global Depletion Examples}

Depletion is typically measured by decreases in groundwater levels and decreases in baseflow in surface water bodies that are connected to aquifers. Regions where 
depletion has been significant as quantified through the best available scientific information include south and central parts of Asia, north China, the Middle East and North Africa, North America, parts of Australia, and many localized areas in southern Europe. In the United States, about $700-800 \mathrm{~km}^{3}$ of groundwater has been depleted from aquifers in the last 100 years (Konikow and Kendy 2005). In the Fuyang River Basin in the North China Plain, the water surface has dropped from 8 to 50 m during 1967-2000 (Shah et al. 2000). In India, consumptive uses are depleting the groundwater reserves of Rajasthan, Punjab, and Haryana at a rate of or $17.7 \pm 4.5 \mathrm{~km}^{3} /$ year. Similarly, a volume of $143.6 \mathrm{~km}^{3}$ of groundwater was depleted during the period 2003 and 2009 in the in the north-central Middle East, including portions of the Tigris and Euphrates River Basins and western Iran (Voss et al. 2013).

Next we provide an overview of the major depletion examples; the cases discussed are representative and not an exhaustive inventory of the global depletion cases. More details of the global depletion cases can found in Konikow (2011), Morris et al. (2003), Wada et al. (2010) and Werner et al. (2013b).

\subsubsection{High Plains Aquifer, United States}

In the United States, $60 \%$ of irrigation relies on groundwater. The High Plains (HP) aquifer is one of the largest freshwater groundwater systems in the world, covering eight states and encompassing over $450,000 \mathrm{~km}^{2}$ in area. The HP aquifer is the most intensively used aquifer in the United States, responsible for nearly one-third of the total groundwater extraction, and it provides drinking water to nearly 2.3 million people residing within in the boundaries and vicinity of the aquifer system (Dennehy et al. 2002). Groundwater is considered as the major economic driver for the HP region, known as the "breadbasket of the United States" and annually contributing US $\$ 35$ billion of the US $\$ 300$ billion in national total agricultural production in 2007 (Scanlon et al. 2012a).

On the basis of groundwater monitoring data from 1950 to 2007 from 3600 wells, Scanlon et al. (2012a) estimated that $330 \mathrm{~km}^{3}$ of groundwater was depleted from the HP aquifers. This storage decline in the HP aquifer accounts for nearly $36 \%$ of the total groundwater depleted in the United States during 1900-2008 (Scanlon et al. 2012b). If the depletion were assumed to be uniform throughout the HP aquifer, the corresponding drop in water surface over the entire HP region would be $4 \mathrm{~m}$.

The effects of depletion in terms of water surface decline are highly variable spatially. For example, recent groundwater monitoring from GRACE, (Scanlon et al. 2012d) indicates almost negligible depletion and water surface decline in the northern HP (Nebraska, $0.3 \mathrm{~m}$ ), concurrent with much greater decline in the water surface in the central HP (Kansas, $7 \mathrm{~m}$ ) and the southern HP (Texas, $11 \mathrm{~m}$ ). In localized pockets of the southern HP and large areas of Kansas and Texas, a decline of more than $30 \mathrm{~m}$ was observed over $17,000 \mathrm{~km}^{2}$, where the ratio of the rates of extraction to natural recharge was found to be 10 and greater. Large variation in the depletion is primarily due to a decrease in natural recharge from north to south but partially due to the amount of water pumped from the aquifer. A common view of 
the HP aquifer is that it contains old water that has been mined and depleted continuously since 1950s. Groundwater age dating indicates that some of the fossil water in the central and south HP aquifer was recharged as long ago as 13,000 years. Policy implemented to control groundwater use in the HP is described in Chap. 21.

\subsubsection{Northwestern India}

India has become the largest consumer of groundwater at the global scale with an estimated total annual consumption of $230 \mathrm{~km}^{3}$ per year, or about one-fourth of the total global groundwater extraction annually. The annual replenishable groundwater resources of India are estimated as $433 \mathrm{~km}^{3}$, with net availability of $399 \mathrm{~km}^{3}$ (Chatterjee and Purohit 2009). India's apparent groundwater surplus can be misleading because of large variation across regions in terms of groundwater availability and extraction, as well as natural recharge. This imbalance of pumping and natural recharge has placed several aquifers in a state of overexploitation and many under semicritical and critical categories (Rodell et al. 2009).

In comparison to the only 20 million ha of land irrigated with surface storage, the irrigated area fed by groundwater now exceeds 45 million ha. Production returns from groundwater irrigation are almost twice those of surface water irrigation because of high reliability and cheaper access. About $70 \%$ of India's agricultural production is generated through use of groundwater (Fishman et al. 2011). The economic value of groundwater irrigation in India in 2002 was estimated at US $\$ 8$ billion per year (World Bank 2010). Groundwater is a primary source of drinking water supplies for rural villages and a growing number of urban areas. A major portion ( $85 \%$ ) of rural drinking water supply comes from groundwater.

The exploitation of groundwater in many states of India has expanded over the last five decades through installation of millions of irrigation wells (Shah 2009). And the scale of resource exploitation has accelerated in the last two decades. The number of tubewells was less than a million in 1980, jumped to 8 million in the mid-1990s, and exceeded 15 million by 2010 (Shah et al. 2012). In addition to cheaper pumps and low well installation costs, electric power subsidies to farms have played a pivotal role in the phenomenal growth of tubewells and overexploitation of groundwater in 16 major states of India. The flat power tariff reduced the marginal cost of pumping groundwater to near zero (Shah et al. 2012).

Because of the heavy reliance on groundwater for consumptive uses in India, the resource is now approaching its critical limit in some states. The national groundwater assessment in 2004 indicated one-third of India's aquifers fall in the overexploited, semicritical, or critical categories (Rodell et al. 2009). An increasing number of aquifers in northwestern India have reached unsustainable levels of exploitation. In the northern state of Punjab, groundwater in $75 \%$ of the aquifers is overdrawn; in the western Rajasthan state, the corresponding fraction is $60 \%$ (Rodell et al. 2009; World Bank 2010). The potential social and economic consequences of groundwater depletion are serious because aquifer depletion is concentrated in densely populated and economically productive areas. The implications can be serious for achieving food security and sustaining economic growth and environmental quality. 


\subsubsection{Northeastern China}

In China, significant shifts toward groundwater dependency have occurred over the last 50 years (see Chap. 19 for a comprehensive overview of Integrated Groundwater Management in China). The installation and use of tubewells across China has increased dramatically, from 150,000 in 1965 in all of China to 4.7 million by the end of 2003 (Wang et al. 2007). In many parts of the country, groundwater levels have been falling at astonishing rates, often more than one to tens of meters per year. Overdraft occurs in more than 164 locations across 24 of China's 31 provinces, affecting more than $180,000 \mathrm{~km}^{2}$ (Werner et al. 2013b).

Aquifers of the North China Plain (NCP) play a central role in China's food production. The region supplies nearly half of China's wheat and one-third of other cereal grains. The NCP covers $320,000 \mathrm{~km}^{2}$ and is home to more than 200 million people. In the NCP, groundwater overexploitation for agricultural, industrial, and urban uses began in the early 1970s and became a serious problem after the 1980 s with more intensive groundwater extraction. The negative impacts of overexploitation became evident during the 1990s in many parts of the NCP with rapid declines in water levels in both unconfined and confined aquifers. Cones of depression in the potentiometric surface have developed and expanded, with decreases in storage causing subsidence and water quality degradation associated with water surface declines. Groundwater depletion has led to seawater intrusion into the freshwater aquifer system; for example, in the coastal plain of Laizhou city, lateral sea water intrusion into the fresh aquifer system has increased from $50 \mathrm{~m}$ per year in 1976 to more than $404.5 \mathrm{~m}$ per year in 1988 (Changming et al. 2001). Groundwater depletion has salinized $44 \%$ of the total area between the coastal plain and the city. The Chinese government has implemented a series of water-saving initiatives such as water efficiency in irrigation techniques, water pricing and groundwater licensing, and similar measures. However, the lack of information on volumetric groundwater extraction and limited groundwater monitoring networks make groundwater management challenging.

\subsubsection{Middle East and North Africa (MENA)}

From the standpoint of declining water availability, the Middle East and North Africa (MENA) region is considered by many to be the most water-scarce region of the world. The MENA countries possess annual renewable water resources of $1274 \mathrm{~m}^{3}$ per capita - the lowest in the world-making the region the most water stressed globally by this metric. MENA is home to about $6 \%$ of the world's population, consisting of 22 countries with 381 million people. And the population is projected to reach nearly 700 million by 2050 (Droogers et al. 2012). Population densities in MENA are largest where irrigation systems are present, including the Nile Delta in Egypt, the central part of Iraq, and Iran (Abu Zeid 2006).

Countries and small territories in the MENA region such as Bahrain, the Gaza Strip, Kuwait, Libya, Oman, Qatar, Saudi Arabia, the United Arab Emirates (UAE), and Yemen have few renewable water resources and heavily rely on groundwater and desalination for most of their supply. The region has some 2800 desalination 
plants that produce about $10 \mathrm{~km}^{3}$ of freshwater annually, representing about $38 \%$ of global desalination capacity.

Other countries in MENA such as Egypt, Iraq, Iran, Jordan, Lebanon, the West Bank, Sudan, and Syria get much of their water from river systems but at the same time depend on groundwater for supplemental use. Aquifers in MENA contain both renewable and fossil water. Many countries in the region are depleting groundwater at a rate that exceeds recharge. For example, the ratio of annual groundwater extraction to the estimated recharge exceeds 3.5 in Egypt, is about 8 in Libya, and is 9.54 in Saudi Arabia (Michel et al. 2012). GRACE data (Voss et al. 2013) show that a volume of $143.6 \mathrm{~km}^{3}$ of groundwater was depleted during the period 2003-2009 in the north-central Middle East, including portions of the Tigris and Euphrates River Basins and western Iran.

In Chap. 24 of this book, the scale of the groundwater-dependent economy in Algeria, Morocco, and Tunisia is discussed. These three countries in North Africa have a high reliance on groundwater for irrigated agriculture, with more than 1.75 million ha of farmland and probably more than 500,000 farm holdings. Algeria's $88 \%$, Tunisia's $64 \%$, and Morocco's $42 \%$ of irrigated land rely on groundwater resources. The official figures reported in Chap. 24 indicate that more than half the aquifers in Algeria and Morocco and about one-quarter of the aquifers in Tunisia are overexploited.

\subsubsection{Australia}

Groundwater resources are of great socioeconomic and environmental significance for Australia. The Great Artesian Basin (GAB) is the largest groundwater aquifer system in Australia and underlies $22 \%$ of the Australian continent. The GAB includes considerable areas of the states of Queensland, New South Wales, the Northern Territory, and South Australia. Limited available information on the potential of the GAB resource indicates that nearly $60,000 \mathrm{~km}^{3}$ of water is contained in the GAB. Groundwater in Australia is pumped mainly from unconfined aquifers, and there is increasing concern regarding the potential impact of groundwater depletion on the sustainability of the resource.

Because of limited and highly variable surface water availability, groundwater use for irrigation has substantially increased in Australia. From the National Land and Water Resources Audit (2001), Khan (2008) reported a $90 \%$ increase in groundwater use across Australia between 1985 and 2000. At present, the volumes of water pumped from aquifers are much greater than natural recharge (Nevill 2009). In many parts of Australia, overdraft from the aquifers is resulting in falling groundwater levels in the shallow unconfined systems and decreasing groundwater pressures in the deep confined and semiconfined systems (MDBA 2012). Many aquifers in the Murray Darling Basin in particular are showing negative socioeconomic and environmental effects as a result of overdraft from aquifers. In many coastal aquifers, saline seawater has intruded to the fresh groundwater aquifers; thus, degradation of groundwater quality is further undermining use of the already scarce resource. A detailed account of saltwater intrusion in Australia and elsewhere is provided in Chap. 16. 


\subsubsection{Techniques for Assessing Groundwater Depletion}

Data assimilation of water level fluctuation is the most direct and simplest method to estimate the volume of water depleted from an aquifer. The technique integrates head changes over the aquifer area and multiplies the obtained area by a representative aquifer storage factor to yield an estimate of storage depletion. Major challenges confronted by this simple technique are to establish large-scale monitoring networks and to collect water level data over large areas at regular time intervals. Maintaining a large-scale groundwater data base and keeping the data updated are costly and complex tasks. Community data integration-such as the Incorporated Research Institutions for Seismology (IRIS 2013)-combines centralized data serving with common data standards. Although Aquastat (FAO 2013) is an example of serving water information internationally, it does not include seamless data integration as does IRIS and has limited data on the spatial distribution of groundwater storage and water levels. Particularly in developing countries, advances in data integration will enable managers and researchers to work with more complete information to assess and manage groundwater resources. See Chap. 27 which is devoted to advances in integrated data management.

Even with the great advances in other techniques discussed in the following paragraphs, personal communication with various governmental agencies and ministries remains the most robust and definitive method of assessing groundwater levels and, thus, depletion. Efforts at personal communication can run up against cultural and language barriers-including the desire of some governments to treat water data as strategic and secret (Voss et al. 2013) — and can be very tedious and time consuming. Without organizing community efforts and common data standards, compiling data on the regional scale often requires many late-night phone calls and individual persistence (Fan Y (2013), Personal Communication). Such long-term individual effort can lead to a snapshot in time on conditions at the continental scale (Gleeson et al. 2011) and the global scale (Fan et al. 2013); but without a time series, depletion values cannot be easily obtained. This challenge is less acute for aquifers that fall under a single government's management authority but is exacerbated in transboundary aquifers.

In the United States and Canada, efforts have been made to adopt the Groundwater Markup Language (GWML, (Boisvert and Brodaric 2011)) to unify data among agencies and organizations within both countries. The First Groundwater Interoperability Experiment (Open Geospatial Consortium Inc. 2011) worked toward harmonizing groundwater data across the border between the two nations. In the Second Groundwater Interoperability Experiment (Open Geospatial Consortium Inc. 2013), Australia and Europe are joining the effort. This progress represents steps down a path toward consolidating data and enabling evaluation of conditions on a global scale, but large gaps of information still remain for many areas (Fan et al. 2013).

Even though direct regional groundwater depletion estimates can be integrated to provide global depletion estimates, groundwater data collection and data interpretation are subject to a high level of inconsistencies across countries and regions. 
When groundwater data are of questionable quality, information generated through such data tends to be less reliable. This is why the magnitude of depletion is imperfectly assessed and poorly documented at the global scale (Giordano 2009). The water balance approach uses a number of scientific methods to estimate and account for various types of recharge and discharge processes to estimate groundwater storage differences and depletion over specific periods. Numerical simulation models based on water balance calculations have been helpful to estimate net groundwater removed from an aquifer. But the accuracy of the model to predict depletion depends on the quality of hydrogeological data provided as input to the model. Recent advances in the development of three-dimensional hydrogeological models have made it possible to provide better representation of the aquifers, underlying geological formations, and the processes that link the groundwater system both to surface water in general and ecological processes specifically. Examples include HydroGeoSphere (Therrien et al. 2012), GSFLOW (Markstrom et al. 2008), and MIKE SHE (DHI Software 2012). Three-dimensional modeling enables more detailed estimates of depletion and impact on surface water, but it remains limited by the data. At the continental and global scales, models of recharge processes and groundwater flow are typically data-driven, with relatively simple treatment of the physics integrated over coarse grids (Cao et al. 2013; Fan et al. 2013; Scanlon et al. 2006; Wood et al. 2011).

In practice, direct measurement of groundwater depletion at the global scale is imperfect. The imperfections arise because of insufficient groundwater monitoring data networks and inconsistent data collection and reporting standards. Another challenge arises when the depletion process is viewed from multiple dimensions, leading to different definitions of the depletion process and its estimation. Recently, satellite-based GRACE has been able to more confidently measure the changes in groundwater storage over large regions. GRACE measurements are made by measurement of the Earth's gravity, detected from the distance between two coordinated satellites that are generally separated by about $220 \mathrm{~km}$ (Tapley et al. 2004). Small changes in gravity on short timescales are generally a function of changes in water storage (underground, on the surface, and in the atmosphere), so quantification of gravity changes can be converted to estimates of water storage changes (Ramillien et al. 2008). Parsing of water content among groundwater, snow, the atmosphere, and surface water requires some processing that differs for various locations and scales (Scanlon et al. 2012c; Longuevergne et al. 2010). Although not a replacement for direct measurement of groundwater storage, GRACE observations have the potential to extend estimates of storage over time, although only back as far as the 2002 launch of the GRACE satellites. Rates of storage depletion in important groundwater-stressed regions have been made using GRACE, including the High Plains of the United States (Scanlon et al. 2012a), India (Rodell et al. 2009), and the Tigris, Euphrates, western Iran region in MENA (Voss et al. 2013). 


\subsection{Contamination of Groundwater}

Water in nature, on the surface or underground, is never free from impurities and typically contains many dissolved and suspended constituents (salts, other inorganic and organic chemicals, sediments, and microorganisms). Contamination of a water body or an aquifer occurs when the concentration of one or more substances increase to a level such that the resulting water quality undermines the use of resource and, in some instances, becomes a hazard to the environment and a risk to human, animal, or plant life (Morris et al. 2003). The principal causes of groundwater contamination due to human activity can be classed as agricultural, industrial, and urban (Foster et al. 2002). Human activity can add salts, chemicals, and microorganisms (pathogens) that affect quality of groundwater.

This section provides an overview of major issues and concerns related to contamination of groundwater. See Chaps. 15 and 16 for a more detailed discussed of water quality.

Here, the significance of the widespread groundwater contamination problem is highlighted with relevant examples. Three groundwater contamination examples and their effects are summarily discussed: (i) land and aquifer salinization, (ii) contamination due to chemicals, and (iii) contamination due to microorganisms.

\subsubsection{Land and Aquifer Salinization}

Salinization of land and water is a widespread phenomenon that is an issue in more than 100 countries, including China, India, and the United States. Current global estimates indicate that over 1 billion ha are affected by various degrees of soil salinization (Shahid 2013). Globally 45 million ha (18\%) of the total 230 million ha of irrigated land are negatively affected by irrigation-related salinity (Ghassemi et al. 1995), which can result from a high water table, poor drainage conditions, and use of saline-brackish water for irrigation with insufficient drainage.

The Indus Basin of Pakistan is an example of a region severely affected by land and aquifer salinization problems that resulted from continuous irrigation without sufficient drainage. It is estimated that out of the total 16.3 million ha of irrigated land in Pakistan, about 6.2 million ha (38\%) have become waterlogged, with water table levels of $<1.5 \mathrm{~m}$ below the surface; additionally, 2.3 million ha (14\%) have become saline, with soil ECe (soil saturated extract) $>4 \mathrm{dS} / \mathrm{m}$ (Kahlown and Azam 2002).

Detail beyond the following overview of land and aquifer salinization process is given in Chap. 16.

\subsubsection{Land Salinization}

Salinization is a characteristic of soil and water which relates to their water-soluble salt content. Such salts predominantly include sodium chloride, but sulfates, carbonates, and magnesium may also be present. A saline soil is one which contains 
sufficient soluble salts to adversely affect plant growth and crop production. Waterlogging and salinity have been persistent problems in many irrigation regions of the world. Irrigation water normally contains salts in the range of $300-500 \mathrm{mg} / \mathrm{l}$ (IWMI 2007). A simple calculation shows that, in the absence of effective leaching, an annual irrigation of $1000 \mathrm{~mm}$ with good quality irrigation water and with salt content as low as $300 \mathrm{mg} / \mathrm{l}$ adds $300 \mathrm{~kg}$ of salts per hectare of irrigated land in a single year. Rainwater, which is considered a source of pure water, can also become a source of salt addition to aquifers and land. Raindrops, during their brief residence in the atmosphere, dissolve carbon dioxide to form a weak carbonic acid. During infiltration, the weak carbonic acid reacts with minerals and rocks in the soil to dissolve them more readily to become a source of salt in aquifers (Hillel 2000). Changes in properties of soil and water lead to the development of an environment which deteriorates soil and water quality.

Waterlogging, another major problem in irrigated land, is the saturation of soil particles with water that results from the rising of the water table due to overirrigation, seepage, or inadequate drainage. Salinization, however, is a process that increases the concentration of salts in water or soil beyond a threshold limit; that is, mean electircal conductivity in the root zone $\left(\mathrm{EC}_{\mathrm{e}}\right)$ in excess of 4 deci-siemens per meter $(\mathrm{dS} / \mathrm{m})$ at $25^{\circ} \mathrm{C}$ (Hillel 2000). The processes of waterlogging and salinization, although different in their characteristics, usually occur together and adversely affect water quality and crop yield.

\subsubsection{Aquifer Salinization}

Mixing of saline water with freshwater is a frequent cause of aquifer salinization in many coastal regions (Werner et al. 2013a). Coastal aquifers are more vulnerable to groundwater extraction because of high population densities and predicted sea-level rise (Ferguson and Gleeson 2012). Coastal areas are the most densely populated areas in the world, with 8 of the 10 largest cities of the world located at coastlines. Nearly half of the world's population resides in coastal areas (Post 2005), and coastal aquifers provide a water source for more than one billion people.

In most cases, coastal aquifers are hydraulically connected to seawater. Under natural conditions, the hydraulic gradient (in part, a function of the density variation of the seawater and freshwater systems) maintains net water flow from the freshwater aquifer toward the sea. However, the gradient is usually small, and any excessive groundwater pumping can alter the hydraulic balance and allow seawater to enter and replace the freshwater pumped out from the aquifer (Werner et al. 2013a). The quality of groundwater aquifers can also be adversely affected by pumping if interlink connections exist between brackish or saline water. Additionally, a low rate of natural groundwater recharge in combination with sea-level rise can introduce and accelerate movement of saltwater into freshwater aquifers, although Ferguson and Gleeson (2012) found that the impact of groundwater extraction on coastal aquifers was more significant than the impact of sea-level rise or changes in groundwater recharge. 
The overall impact of saline water intrusion highly depends on the amount of extraction and natural groundwater recharge. Incorrect positioning of well fields can accelerate the problem. Climate change is expected to exacerbate many water resource problems, but the impact of seawater intrusion may be much more serious and widespread because many areas with moderate population densities and water demand are expected to experience saltwater intrusion.

Seawater intrusion has affected groundwater quality in major coastal irrigation regions around the globe where pumping has destabilized the hydraulic equilibrium of the aquifers. Coastal regions such as Queensland in Australia, Florida in the United States, the southern Atlantic coastline of Spain, and Lebanon are among the most highly visible and notable cases where saltwater has intruded into coastal aquifers. Other problem areas in the United States include Cape May County in New Jersey and in Monterey and Orange Counties in California (Barlow and Reichard 2010). Similarly, in the western State of Sonora in Mexico, seawater has intruded approximately $20-25 \mathrm{~km}$ inland, forcing the closure of irrigation wells. Likewise in Cyprus, Egypt and Israel, exploitation of groundwater resources for irrigation has lowered aquifers' hydraulic heads to allow seawater intrusion.

In the Burdekin coastal region of Queensland, Australia, more than 1800 wells are currently used for irrigation. The large volumes of groundwater extracted have at times lowered the regional water surfaces and made it challenging to control seawater intrusion (Narayan et al. 2007). To confront long droughts, future use of groundwater is likely to increase in Australia. This growing use of groundwater will stress the aquifers already in deficit. Thus, saltwater intrusion will likely become more challenging because of the extensive coastlines where the majority of the population resides.

\subsubsection{Groundwater Contamination Due to Chemicals}

Fertilizers, pesticides, and salts contained in irrigation water can be major agricultural contaminants. Excessive irrigation drives water from the root zone of crops to the groundwater below (Chowdary et al. 2005), carrying with them applied fertilizers and pesticides and their component nitrogen compounds, phosphorus, potassium and other minerals and chemical compounds (Langwaldt and Puhakka 2000). Because of the widespread areal extent of these contaminants, they are often referred to as "nonpoint-source" contaminants.

Industrial wastes contain a wide variety of heavy metals and solvents. A recent study by Dwivedi and Vankar (2014) reported contamination of groundwater potentially from industrial sources (tanning, textile, and several others) in the Kanpur-Unnao district of India. Concentrations of cadmium, cobalt, chromium, copper, mercury, nickel, lead, tin, and zinc were found to exceed the maximum permissible limit. When chemical releases occur at specific facilities, they are referred to as "point-source" contaminants. 
The accidental spillage and leakage of industrial chemicals can also cause serious groundwater contamination (Foster and Chilton 2003a). Subsurface releases of MTBE (methyl tertiary-butyl ether) can be a source of groundwater contamination. MTBE is a gasoline fuel additive that can leak from gasoline underground storage tanks and contaminate aquifers and wells. In the United States alone, releases of gasoline fuels has been reported at more than 250,000 sites, putting over 9000 municipal water supply wells at risk of contamination with MTBE (Einarson and Mackay 2001). Synthetic microorganic compounds also known as emerging organic contaminants (EOCs) are another and new source of groundwater contamination reported across Europe and many other parts of the world (Lapworth et al. 2012). EOCs are used for a range of industrial purposes including food preservation, pharmaceuticals, and healthcare products (Lapworth et al. 2012). Public health and environmental impacts of EOCs in groundwater are currently under-researched areas.

Arsenic and nitrate are two major contaminants with serious public health impacts. High concentrations of arsenic in groundwater have been recognized as a major public health concern in several countries and often are the result of natural conditions rather than human activity. The contamination of groundwater by arsenic in Bangladesh has been called the largest poisoning of a human population in history (Smith et al. 2000). An estimated 36 million people in the Bengal Delta alone (Bangladesh and India) are at risk of drinking arsenic-contaminated water (Nordstrom 2002). Long term exposure of arsenic in drinking water and its impacts on human health are documented in $\mathrm{Ng}$ et al. (2003). Geochemical processes in the presence of oxygen dissolve arsenopyrite [FeAsS], leading to increased concentrations of dissolved arsenic in groundwater. Oxidation can be a major driver to mobilize arsenic already present in aquifer rocks and can be promoted as a result of recharge by oxygenated waters or through lowering of the groundwater surface by excessive pumping (Nordstrom 2002). Chemical reactions among nitrate, iron, and oxygen can also increase mobilization of arsenic in aquifers (Höhn et al. 2006). The incidence of high concentrations of arsenic in drinking water is significant in Asian countries. The problem was initially detected in Bangladesh, India, and China. Most recently, the problem has been reported in Myanmar, Cambodia, parts of Europe, the United States, and Australia. A global summary of arsenic contamination of groundwater is available in Ravenscroft et al. (2011) and Mukherjee et al. (2006).

Nitrate contamination of groundwater is a widespread and global problem both in developed and developing nations. Excessive application of commercial fertilizers or animal waste and inadequate waste disposal of municipal and animal waste are associated with this problem. High concentration of nitrate in municipal groundwater $(10-50 \mathrm{mg} / \mathrm{l})$ is considered a public health hazard. Nitrate contamination of groundwater due to agrochemicals has become a serious problem in China and India (Foster and Chilton 2003b). A detailed review of nitrate contamination of groundwater and its health impact is available in Spalding and Exner (1993) and Canter (1996). 


\subsubsection{Groundwater Contamination Due to Microorganisms}

Microbial contamination of groundwater can be caused by inadequate protection of aquifers against release of sewage effluent into groundwater. Contamination of groundwater can occur via many pathways, such as from urban landfills in proximity to natural groundwater recharge sites, rural on-site sanitation facilities, leaking septic tanks and sewers, and waste from farm animals. The concentration of many harmful microorganisms attenuates (naturally reduces) when water passes through the unsaturated zone; however, the degree of pathogen removal depends on the type of soil, level of contamination, and type of contaminant. Natural attenuation generally is most effective in the unsaturated zone, especially in the top soil layers where biological activity is greatest (Morris et al. 2003).

Several viral and bacterial pathogens present in human and animal waste contaminate groundwater and cause human health problems. In 2012, more than 500,000 diarrhea deaths were estimated to be caused by microbially contaminated drinking water (Prüss-Ustün et al. 2014). Baldursson and Karanis (2011) give a comprehensive review of worldwide waterborne disease outbreaks that occurred and were documented between 2004 and 2010. Similarly, a recent study based on a systematic review by Ngure et al. (2014) provides a global assessment of drinkingwater microbial contamination. All incidence of waterborne diseases cannot be attributed to groundwater, because microbial contamination of water can occur in surface water bodies and in distribution pipes. However, a significant fraction of waterborne disease outbreaks may be associated with groundwater, given that more than $50 \%$ of population worldwide meet their primary drinking needs from groundwater that may be contaminated at some stage (Macler and Merkle 2000).

\subsection{The Water-Energy Nexus}

Water and energy are inextricably linked in many important ways and this issue is covered in more detail in Chap. 4. Water is used in the generation of energy, and energy is required for the movement and treatment of water. This linkage results in multiple management challenges.

The movement of water requires a significant portion of all energy generated worldwide. In California (United States), $19 \%$ of all electrical energy produced is used for water-related conveyance and treatment (Navigant Consulting Inc. 2006) - nearly $2 \%$ of all electrical energy in California is used for groundwater extraction through pumping (GEI Consultants/Navigant Consulting Inc 2010). Such energy requirements account also for significant contributions to greenhouse gas emissions, estimated as $0.6 \%$ of China's emissions (Wang et al. 2012) and 4-6 \% of India's emissions (Shah et al. 2012). These energy requirements increase with the distance the water must be lifted (depth to water) and decrease with pump efficiency. Hence, declining water levels will increase energy requirements for groundwater pumping unless offset by increased pump efficiency. This increased 
energy demand for pumping is exacerbated in India by government subsidies for electrical power for the purpose of groundwater extraction (Badiani et al. 2012)

In addition to energy use for water movement and treatment, groundwater plays an important role in the generation of energy - particularly the production of alternative energy such as biofuels (Gerbens-Leenes and Hoekstra 2012; Dominguez-Faus et al. 2009). Significant water is used both in the growing of feedstock to create ethanol and in the distillation of the feedstock into fuel. In the United States, governmental mandates require that ethanol from corn (maize) will continue into the future (Dominguez-Faus et al. 2009), although a wide range of water footprint calculations suggest that efficiencies may be found that could reduce groundwater extraction needs for irrigation and distillation (Gerbens-Leenes and Hoekstra 2012; Dominguez-Faus et al. 2009). Other alternative energy technologies can have surprising energy implications. Concentrated solar power generation on a large scale in desert environments can require large amounts of water for cooling and washing (Woody 2009; McKinnon 2010). In the United States, the National Research Council (2012) has also studied production of biofuel from algae, raising questions about sustainability.

In recent years, unconventional drilling for shale gas and coal bed methaneparticularly in the United States, China, and Australia—has increased dramatically (Vidic et al. 2013; Moore 2012). Improvements in the accuracy of horizontal well drilling, coupled with hydraulic fracturing, have made it practical to extract methane from thin, deep and tight strata. These advantages, coupled with increasing energy demand, have resulted in massive expansion of exploitation of these unconventional gas reserves. Hydraulic fracturing uses a focused large amount of water for short periods of time, resulting in competition with other water users-particularly in arid regions like the Eagle Ford Formation in Texas (United States). Hydraulic fracturing also uses a variety of chemical additives in the process. Some water contaminated with these additives returns as flowback water and must be disposed of, leading to a potential groundwater contamination source (Vidic et al. 2013). One concern is that methane liberated by the hydraulic fracturing process and additive chemicals could migrate to shallow aquifers or the surface. A recent study (Myers 2012) attempted to address this issue and prompted discussion and criticism (Saiers and Barth 2012; Myers 2013; Cohen et al. 2013), highlighting the level of uncertainty about the degree and nature of potential contamination from this activity. Further research in the field and through modeling is necessary for understanding of the depth and breadth of potential groundwater impacts to catch up with the rapid increase in development of unconventional gas resources (Jackson et al. 2013).

\subsection{Transboundary Water Conflict}

Most of the literature discussing transboundary water conflict has focused on surface water. Groundwater conflict has received less attention. However, owing to both "uncertainty in defining ground water flow...[and]...uncertainty of the 
hydraulic connection between groundwater and surface water" (Jarvis et al. 2005) and combined with increasing water usage needs-particularly for agricultural irrigation (Llamas and Martinez-Santos 2005) - it seems that serious conflict over transboundary groundwater resources may be inevitable. This condition is exacerbated by a lack of regulation and management of groundwater, which is often blamed on the same uncertainties surrounding the quantity and dynamics of groundwater at the regional scale (Llamas and Martinez-Santos 2005; Jarvis et al. 2005; Puri 2003). Several conceptual models can apply to transboundary aquifers, including cases where the source of water to the aquifer is in one country but the main demand is in another (for example, Eckstein and Eckstein 2005). Transboundary aquifers meeting these definitions number as many as 408 (UN-IGRAC 2012). Using analysis similar to the groundwater footprint (Gleeson et al. 2012), Wada and Heinrich (2013) performed a quantitative assessment of water stress (considering recharge, extraction, and environmental flows) for the 408 identified transboundary aquifers and determined that $8 \%$ of them are stressed by human consumption. They point out, however, that many of these transboundary aquifers are found in geopolitically charged areas such as the Arabian Peninsula, the United States-Mexico border, and India and Pakistan.

In one example of this type, the Ceylanpinar aquifer spans the border between Turkey and Syria, with recharge in the Turkish headwaters and the majority of discharge in the Ras al-Ain Springs in Syria (Oeztan and Axelrod 2011). Data availability is asymmetric, with much more information available about conditions in the aquifer in Turkey than in Syria. Nonetheless, Oeztan and Axelrod (2011) modeled the aquifer to try to calculate sustainable extraction rates based on discharge from the springs. Mutually beneficial organic agriculture along the border that previously was unfarmable due to extensive placement of landmines is proposed but would first depend on cooperation with respect to hydrogeologic and water use information. Joint management to prevent overdepletion requires collaboration, which may be at odds with other priorities of neighboring countries, but this example shows it can have positive outcomes.

Beyond water quantity, water quality concerns can arise when contaminants enter an aquifer under a different governance than that of the users of the aquifer; for example, such as bordering northeastern Greece (Vryzas et al. 2012) and Russia (Zektser 2012). Similar challenges as facing depletion problems are encountered in managing water quality. The parallel challenges of establishing responsibility for contamination and finding the motivation to remediate it can present opportunities for constructive collaboration but also may heighten tension in some areas.

In modern times (1948-present), no full-scale declarations or acts of war have been attributed to the tension related to the use of transboundary water (De Stefano et al. 2010). This is contrary to predictions stemming from at least the 1980s onward that major wars-particularly in the Middle East—would be fought over water because of stress over increasing demand for water resources due to increasing population, climate change, and depletion of water sources (see Cooley (1984) and Starr (1991), for example). It is still possible for this to happen, and indeed tensions and local violence have been attributed to water conflict, but thus far full-scale war 
has not resulted with the exception of the war between Sumerian city-states Lagash and Umma in 2500 BCE (Wolf 1998). Although a somewhat controversial notion, it has been argued that interactions among states involving water more often, of necessity, lead to cooperation than conflict (De Stefano et al. 2010; Wolf 2007).

In summary, transboundary aquifers present many challenges in integrated management. The connection between surface water and groundwater are all the more important because the source of water and the water's users (human or ecological) may be in different countries. Data sharing and integration are more challenging across national borders but are extremely important to reduce the uncertainties surrounding integrated management. An additional challenge is that protection of water resources in one country may depend on the actions taken in another country. This binding together for a common purpose provides the opportunity for cooperation but may also devolve into conflict. For these reasons, active management and communication are key to managing water resources across boundaries.

\subsection{Conclusion}

The issues outlined in this chapter highlight both the challenges and promise of the groundwater issue internationally. The growing importance of groundwater supply combined with the challenges in its characterization and measurement make management difficult. Yet, advances in data analysis, remote sensing, and modeling at regional to continental scales provide some hope for more informed planning, which may ultimately lead to sustainable and responsible management.

Depletion of groundwater-a precious resource for agriculture, ecosystem services, and domestic supply - has the potential to cause significant interruption of societal and ecological functions. The uncertainties inherent in managing a resource that is generally unseen create challenges in management and can lead to conflict among interests vying for the resource-because proving who is responsible for stresses and impacts is a challenge.

Advances in remote sensing (such as the GRACE satellite), data management, and numerical modeling provide hope of reducing the uncertainty of evaluating the magnitude and locations of depletion and degradation of groundwater resources. None of the technical and managerial issues raised in this chapter can be properly considered on its own. The water budget myth implied a simple balance between recharge and availability, but over the past century we have learned that the interconnections among groundwater-dependent ecosystems, human needs, and the groundwater system are deep and elaborate. Only an integrated approach to water management-viewing the components of the system together with competing needs - can maintain sustainability for future generations and a robust environment. Integration is also critical to manage the connections between seemingly disparate sectors of society and economics. As mentioned previously, the connection between electrical prices and agricultural pumping is an important 
consideration in India. The desire to mitigate climate change (see Chap. 5 for this issue) through alternative energy production can have a ripple effect of consequences on water resources, particularly in the case of biofuels. Agricultural policy beyond water use restrictions has important implications on water quality as it relates to chemical use and to salinization of soil and water. Even the stability of relationships among nations can hinge on proper water management.

Open Access This chapter is distributed under the terms of the Creative Commons AttributionNoncommercial 2.5 License (http://creativecommons.org/licenses/by-nc/2.5/) which permits any noncommercial use, distribution, and reproduction in any medium, provided the original author(s) and source are credited.

The images or other third party material in this chapter are included in the work's Creative Commons license, unless indicated otherwise in the credit line; if such material is not included in the work's Creative Commons license and the respective action is not permitted by statutory regulation, users will need to obtain permission from the license holder to duplicate, adapt or reproduce the material.

\section{References}

Abu Zeid M (2006) The middle east water report. The 4th World Water Forum March 17-22, 2006, Mexico City, Mexico

Alley WM, Leake SA (2004) The journey from safe yield to sustainability. Ground Water 42(1): $12-16$

ASCE (2004) Regulated riparian model water code. ASCE Standard, vol ASCE/EWRI 40-03. ASCE

Badiani R, Jessoe KK, Plant S (2012) Development and the environment: the implications of agricultural electricity subsidies in India. J Environ Dev 21(2):244-262. doi:10.1177/ 1070496512442507

Baldursson S, Karanis P (2011) Waterborne transmission of protozoan parasites: review of worldwide outbreaks - an update 2004-2010. Water Res 45(20):6603-6614

Barlow PM, Reichard EG (2010) Saltwater intrusion in coastal regions of North America. Hydrogeol J 18(1):247-260

Beck RE (2000) The regulated riparian model water code: blueprint for twenty first century water management. William \& Mary Environ Law Policy Rev 25(1):113-167

Birol E, Koundouri P, Kountouris Y (2010) Assessing the economic viability of alternative water resources in water-scarce regions: combining economic valuation, cost-benefit analysis and discounting. Ecol Econ 69(4):839-847

Boisvert É, Brodaric B (2011) GroundWater markup language specification v. 1.0. http://ngwdbdnes.cits.nrcan.gc.ca/service/api_ngwds:def/en/gwml.html. Accessed 12 July 2013

Bredehoeft J (1997) Safe yield and the water budget myth. Ground Water 35(6):929

Bredehoeft JD, Papadopulos SS, Cooper HH Jr (1982) Groundwater-the water-budget myth. In: Scientific basis of water-resource management. National Academy Press, Washington, DC, pp 51-57

Canter LW (1996) Nitrates in groundwater. CRC press, Boca Raton, Florida, USA

Cao G, Zheng C, Scanlon BR, Liu J, Li W (2013) Use of flow modeling to assess sustainability of groundwater resources in the North China plain. Water Resour Res 49(1):159-175. doi:10. 1029/2012WR011899

Changming L, Jingjie Y, Kendy E (2001) Groundwater exploitation and its impact on the environment in the North China plain. Water Int 26(2):265-272 
Chatterjee R, Purohit RR (2009) Estimation of replenishable groundwater resources of India and their status of utilization. Curr Sci 96(12):1581-1591

Chowdary VM, Rao NH, Sarma PBS (2005) Decision support framework for assessment of nonpoint-source pollution of groundwater in large irrigation projects. Agric Water Manag 75(3): 194-225. doi:10.1016/j.agwat.2004.12.013

Cohen HA, Parratt T, Andrews CB (2013) Potential contaminant pathways from hydraulically fractured shale to aquifers. Ground Water 51(3):317-319. doi:10.1111/gwat.12015

Cooley JK (1984) The war over water. Foreign Policy 54:3-26. doi:10.2307/1148352

Custodio E (2002) Aquifer overexploitation: what does it mean? Hydrogeol J 10(2):254-277

De Stefano L, Edwards P, de Silva L, Wolf AT (2010) Tracking cooperation and conflict in international basins: historic and recent trends. Water Policy 12(6):871-884. doi:10.2166/wp. 2010.137

Dennehy KF, Litke DW, McMahon PB (2002) The high plains aquifer, USA: groundwater development and sustainability. Geol Soc Lond Spec Publ 193(1):99-119. doi:10.1144/gsl. sp.2002.193.01.09

DHI Software (2012) MIKE SHE. http://www.dhisoftware.com/Products/WaterResources/ MIKESHE.aspx. Accessed 12 July 2013

Dominguez-Faus R, Powers SE, Burken JG, Alvarez PJ (2009) The water footprint of biofuels: a drink or drive issue? Environ Sci Technol 43(9):3005-3010. doi:10.1021/es802162x

Droogers P, Immerzeel WW, Terink W, Hoogeveen J, Bierkens MFP, van Beek LPH, Debele B (2012) Water resources trends in Middle East and North Africa towards 2050. Hydrol Earth Syst Sci 16(9):3101-3114

Dwivedi AK, Vankar PS (2014) Source identification study of heavy metal contamination in the industrial hub of Unnao, India. Environ Monit Assess 186(6):3531-3539

Eckstein Y, Eckstein GE (2005) Transboundary aquifers: conceptual models for development of international law. Ground Water 43(5):679-690. doi:10.1111/j.1745-6584.2005.00098.x

Einarson MD, Mackay DM (2001) Peer reviewed: predicting impacts of groundwater contamination. Environ Sci Technol 35(3):66A-73A

Fan Y, Li H, Miguez-Macho G (2013) Global patterns of groundwater table depth. Science 339(6122):940-943. doi:10.1126/science.1229881

FAO (2013) Aquastat. FAO—UN. http://www.fao.org/nr/water/aquastat/main/index.stm. Accessed 15 July 2013

Ferguson G, Gleeson T (2012) Vulnerability of coastal aquifers to groundwater use and climate change. Nat Clim Chang 2(5):342-345. http://www.nature.com/nclimate/journal/v2/n5/abs/ nclimate1413.html\#supplementary-information

Fishman RM, Siegfried T, Raj P, Modi V, Lall U (2011) Over-extraction from shallow bedrock versus deep alluvial aquifers: reliability versus sustainability considerations for India's groundwater irrigation. Water Resour Res 47(12):W00L05. doi:10.1029/2011WR010617

Foster S, Chilton P (2003a) Groundwater: the processes and global significance of aquifer degradation. Philos Trans R Soc Lond B Biol Sci 358(1440):1957-1972

Foster SS, Chilton PJ (2003b) Groundwater: the processes and global significance of aquifer degradation. Philos Trans R Soc Lond B Biol Sci 358(1440):1957-1972. doi:10.1098/rstb. 2003.1380

Foster S, Hirata R, Gomes D, D’Elia M, Paris M (2002) Groundwater quality protection: a guide for water utilities, municipal authorities, and environment agencies. World Bank, Washington, DC

GEI Consultants/Navigant Consulting Inc. (2010) Embedded energy in water studies study 1: statewide and regional water-energy relationship. California Public Utilities Commission Energy Division. San Francisco, California, USA

Gerbens-Leenes W, Hoekstra AY (2012) The water footprint of sweeteners and bio-ethanol. Environ Int 40:202-211. doi:10.1016/j.envint.2011.06.006

Ghassemi F, Jakeman AJ, Nix HA (1995) Salinisation of land and water resources: human causes, extent, management and case studies. CAB International, Wallington, Oxon 526 p.

Giordano M (2009) Global groundwater? Issues and solutions. Annu Rev Environ Resour 34: 153-178. doi:10.1146/annurev.environ.030308.100251 
Gleeson T, Marklund L, Smith L, Manning AH (2011) Classifying the water table at regional to continental scales. Geophys Res Lett 38(5), L05401. doi:10.1029/2010GL046427

Gleeson T, Wada Y, Bierkens MF, van Beek LP (2012) Water balance of global aquifers revealed by groundwater footprint. Nature 488(7410):197-200. doi:10.1038/nature11295

Harou JJ, Lund JR (2008) Ending groundwater overdraft in hydrologic-economic systems. Hydrogeol J 16(6):1039-1055

Hillel D (2000) Salinity management for sustainable irrigation: integrating science, environment, and economics. World Bank Publications, Washington, DC, USA

Hockey TA, Trimble V, Bracher K (2007) The biographical encyclopedia of astronomers. Springer reference. Springer, New York

Höhn R, Isenbeck-Schröter M, Kent DB, Davis JA, Jakobsen R, Jann S, Niedan V, Scholz C, Stadler S, Tretner A (2006) Tracer test with As(V) under variable redox conditions controlling arsenic transport in the presence of elevated ferrous iron concentrations. J Contam Hydrol 88(1-2):36-54. doi:10.1016/j.jconhyd.2006.06.001

IRIS (2013) Incorporated Research Institutions for Seismology. http://www.iris.edu/hq/. Accessed 15 July 2013

IWMI (2007) International Water Management Institute (IWMI). Technical reports on Salinity Management in Pakistan: multiple issues, IWMI, Colombo

Jackson RE, Gorody AW, Mayer B, Roy JW, Ryan MC, Van Stempvoort DR (2013) Groundwater protection and unconventional gas extraction: the critical need for field-based hydrogeological research. Ground Water 51(4):488-510. doi:10.1111/gwat.12074

Jarvis T, Giordano M, Puri S, Matsumoto K, Wolf A (2005) International borders, ground water flow, and hydroschizophrenia. Ground Water 43(5):764-770. doi:10.1111/j.1745-6584.2005. 00069.x

Kahlown MA, Azam M (2002) Individual and combined effect of waterlogging and salinity on crop yields in the Indus basin. Irrig Drain 51(4):329-338

Khan S (2008) Managing climate risks in Australia: options for water policy and irrigation management. Aust J Exp Agric 48(3):265-273

Konikow LF (2011) Contribution of global groundwater depletion since 1900 to sea-level rise. Geophys Res Lett 38(17), L17401. doi:10.1029/2011g1048604

Konikow LF, Kendy E (2005) Groundwater depletion: a global problem. Hydrogeol J 13(1): $317-320$

Langwaldt JH, Puhakka JA (2000) On-site biological remediation of contaminated groundwater: a review. Environ Pollut 107(2):187-197. doi:10.1016/S0269-7491(99)00137-2

Lapworth D, Baran N, Stuart M, Ward R (2012) Emerging organic contaminants in groundwater: a review of sources, fate and occurrence. Environ Pollut 163:287-303

Lee CH (1915) The determination of safe yield of underground reservoirs of the closed-basin type. Trans Am Soc Civ Eng 78:148-151

Llamas R (2004) Use of groundwater. Series on water and ethics. UNESCO, Paris

Llamas MR, Martinez-Santos P (2005) Intensive groundwater use: silent revolution and potential source of social conflicts. J Water Resour Plann Manag-Asce 131(5):337-341. doi:10.1061/ (asce)0733-9496(2005)131:5(337)

Longuevergne L, Scanlon BR, Wilson CR (2010) GRACE hydrological estimates for small basins: evaluating processing approaches on the High Plains Aquifer, USA. Water Resour Res 46(11), W11517. doi:10.1029/2009wr008564

Macler BA, Merkle JC (2000) Current knowledge on groundwater microbial pathogens and their control. Hydrogeol J 8(1):29-40

Markstrom SL, Niswonger RG, Regan RS, Prudic DE, Barlow PM (2008) GSFLOW-coupled ground-water and surface-water FLOW model based on the integration of the PrecipitationRunoff Modeling System (PRMS) and the Modular Ground-Water Flow Model (MODFLOW2005). Techniques and Methods 6-D1. Reston. http://pubs.usgs.gov/tm/tm6d1/pdf/tm6d1.pdf

McKinnon S (2010) Amid state's push for solar power, water-supply worries arise. The Arizona Republic, 17 January 
MDBA (2012) Murray-Darling Basin Authority 2012, The proposed Groundwater Baseline and Sustainable Diversion Limits: methods report. MDBA publication no: 16/12. Murray-Darling Basin Authority, Canberra

Meinzer OE (1923) Outline of ground-water hydrology, Water-supply paper 494. Geological survey water-supply papers, vol 949. United States Geological Survey, Washington, DC

Michel D, Pandya A, Hasnain SI, Sticklor R, Panuganti S (2012) Water challenges and cooperative response in the middle east and north Africa. Brookings Institution, New York, Available at http://www.brookings.edu/about/projects/islamic-world

Moore TA (2012) Coalbed methane: a review. Int J Coal Geol 101:36-81. doi:10.1016/j.coal. 2012.05.011

Morris BL, Lawrence AR, Chilton P, Adams B, Calow RC, Klinck BA (2003) Groundwater and its susceptibility to degradation: a global assessment of the problem and options for management. UNEP early warning and assessment vol report series RS. 03-3, Nairobi

Mukherjee A, Sengupta MK, Hossain MA, Ahamed S, Das B, Nayak B, Lodh D, Rahman MM, Chakraborti D (2006) Arsenic contamination in groundwater: a global perspective with emphasis on the Asian scenario. J Health Popul Nutr 24(2):142-163

Myers T (2012) Potential contaminant pathways from hydraulically fractured shale to aquifers. Ground Water 50(6):872-882. doi:10.1111/j.1745-6584.2012.00933.x

Myers T (2013) Potential contaminant pathways from hydraulically fractured shale to aquifers author's reply. Ground Water 51(3):319-321. doi:10.1111/gwat.12016

Narayan KA, Schleeberger C, Bristow KL (2007) Modelling seawater intrusion in the Burdekin Delta Irrigation Area, North Queensland, Australia. Agric Water Manag 89(3):217-228. doi:10.1016/j.agwat.2007.01.008

National Land and Water Resources Audit (2001) Australian water resources assessment 2000. Surface water and groundwater availability and quality. A report of the National Land and Water Resources Audit, Goanna Print, Turner

National Research Council (2012) Sustainable development of Algal Biofuels in the United States. The National Academies Press, Washington, DC

Navigant Consulting Inc. (2006) Refining estimates of water-related energy use in California. California Energy Commission, PIER Industrial/Agricultural/Water End Use Energy Efficiency Program. CEC-500-2006-118

Nevill C (2009) Managing cumulative impacts: groundwater reform in the Murray-Darling Basin, Australia. Water Resour Manag 23(13):2605-2631. doi:10.1007/s11269-009-9399-0

Ng JC, Wang J, Shraim A (2003) A global health problem caused by arsenic from natural sources. Chemosphere 52(9):1353-1359

Ngure FM, Reid BM, Humphrey JH, Mbuya MN, Pelto G, Stoltzfus RJ (2014) Water, sanitation, and hygiene (WASH), environmental enteropathy, nutrition, and early child development: making the links. Ann N Y Acad Sci 1308(1):118-128

Nordstrom DK (2002) Worldwide occurrences of arsenic in ground water. Science (Washington) 296(5576):2143-2145

Oeztan M, Axelrod M (2011) Sustainable transboundary groundwater management under shifting political scenarios: the Ceylanpinar Aquifer and Turkey-Syria relations. Water Int 36(5): 671-685. doi:10.1080/02508060.2011.601546

Open Geospatial Consortium Inc. (2011) Groundwater interoperability experiment. http://external. opengis.org/twiki_public/HydrologyDWG/GroundwaterInteroperabilityExperiment. Accessed 12 July 2013

Open Geospatial Consortium Inc. (2013) Groundwater interoperability experiment 2. http://external. opengeospatial.org/twiki_public/HydrologyDWG/GroundwaterInteroperabilityExperiment2. Accessed 12 July 2013

Pierce SA, Sharp JM, Guillaume JHA, Mace RE, Eaton DJ (2012) Aquifer-yield continuum as a guide and typology for science-based groundwater management. Hydrogeol J 21(2):331-340. doi:10.1007/s10040-012-0910-y

Post V (2005) Fresh and saline groundwater interaction in coastal aquifers: is our technology ready for the problems ahead? Hydrogeol J 13(1):120-123 
Prüss-Ustün A, Bartram J, Clasen T, Colford JM, Cumming O, Curtis V, Bonjour S, Dangour AD, De France J, Fewtrell L, Freeman MC, Gordon B, Hunter PR, Johnston RB, Mathers C, Mäusezahl D, Medlicott K, Neira M, Stocks M, Wolf J, Cairncross S (2014) Burden of disease from inadequate water, sanitation and hygiene in low- and middle-income settings: a retrospective analysis of data from 145 countries. Trop Med Int Health 19(8):894-905. doi:10.1111/tmi.12329

Puri S (2003) Transboundary aquifer resources-international water law and hydrogeological uncertainty. Water Int 28(2):276-279

Ramillien G, Famiglietti JS, Wahr J (2008) Detection of continental hydrology and glaciology signals from GRACE: a review. Surv Geophys 29(4-5):361-374. doi:10.1007/s10712-0089048-9

Ravenscroft P, Brammer H, Richards K (2011) Arsenic pollution: a global synthesis, vol 94. John Wiley and Sons, Hoboken, NJ, USA

Reilly TE, Dennehy KF, Alley WM, Cunningham WL (2008) Ground-water availability in the United States, vol 1323, U.S. Geological Survey circular. USGS, Reston

Rodell M, Velicogna I, Famiglietti JS (2009) Satellite-based estimates of groundwater depletion in India. Nature 460(7258):999-1002. doi:10.1038/nature08238

Saiers JE, Barth E (2012) Potential contaminant pathways from hydraulically fractured shale aquifers. Ground Water 50(6):826-828. doi:10.1111/j.1745-6584.2012.00990.x

Scanlon BR, Keese KE, Flint AL, Flint LE, Gaye CB, Edmunds WM, Simmers I (2006) Global synthesis of groundwater recharge in semiarid and arid regions. Hydrol Process 20(15): 3335-3370. doi:10.1002/hyp.6335

Scanlon BR, Faunt CC, Longuevergne L, Reedy RC, Alley WM, McGuire VL, McMahon PB (2012a) Groundwater depletion and sustainability of irrigation in the US High Plains and Central Valley. Proc Natl Acad Sci U S A 109(24):9320-9325

Scanlon BR, Faunt CC, Longuevergne L, Reedy RC, Alley WM, McGuire VL, McMahon PB (2012b) Groundwater depletion and sustainability of irrigation in the US High Plains and Central Valley. Proc Natl Acad Sci U S A 109(24):9320-9325. doi:10.1073/pnas.1200311109

Scanlon BR, Longuevergne L, Long D (2012c) Ground referencing GRACE satellite estimates of groundwater storage changes in the California Central Valley, USA. Water Resour Res 48(4): n/a-n/a. doi:10.1029/2011wr011312

Scanlon BR, Longuevergne L, Long D (2012d) Ground referencing GRACE satellite estimates of groundwater storage changes in the California Central Valley, USA. Water Resour Res 48(4), W04520. doi:10.1029/2011WR011312

Shah T (2009) Climate change and groundwater: India's opportunities for mitigation and adaptation. Environ Res Lett 4(3):035005. doi:10.1088/1748-9326/4/3/035005

Shah T, Molden D, Sakthivadivel R, Seckler D (2000) The global groundwater situation: overview of opportunities and challenges. International Water Management Institute, Colombo

Shah T, Giordano M, Mukherji A (2012) Political economy of the energy-groundwater nexus in India: exploring issues and assessing policy options. Hydrogeol J 20(5):995-1006

Shahid S (2013) Developments in soil salinity assessment, modeling, mapping, and monitoring from regional to submicroscopic scales. In: Abdelfattah MA, Taha FK, Shahid SA (eds) Developments in soil salinity assessment and reclamation. Springer, Dordrecht, The Netherlands, pp 3-43. doi:10.1007/978-94-007-5684-7_1

Smith AH, Lingas EO, Rahman M (2000) Contamination of drinking-water by arsenic in Bangladesh: a public health emergency. Bull World Health Organ 78(9):1093-1103

Sophocleous M (1997) Managing water resources systems: why "safe yield" is not sustainable. Ground Water 35(4):561

Spalding RF, Exner ME (1993) Occurrence of nitrate in groundwater-a review. J Environ Qual 22(3):392-402

Starr JR (1991) Water wars. Foreign Policy 82:17-36. doi:10.2307/1148639

Tapley BD, Bettadpur S, Watkins M, Reigber C (2004) The gravity recovery and climate experiment: mission overview and early results. Geophys Res Lett 31(9), L09607. doi:10. 1029/2004GL019920

Theis CV (1940) The source of water derived from wells. Civ Eng 10(5):277-280 
Therrien R, McLaren RG, Sudicky EA, Park Y-J (2012) HydroGeoSphere: a three-dimensional numerical model describing fully-integrated subsurface and surface flow and solute transport. Groundwater Simulations Group. Waterloo, Ontario, Canada

Todd DK (1959) Ground water hydrology. Wiley, New York

UN-IGRAC (2012) Transboundary Aquifers of the World 2012. United Nations International Groundwater Resources Assessment Centre. http://www.un-igrac.org/sites/default/files/resources/ files/FINAL_MAP_CMYK_withLogos.jpg. Accessed 24 Jun 2014

Vidic RD, Brantley SL, Vandenbossche JM, Yoxtheimer D, Abad JD (2013) Impact of shale gas development on regional water quality. Science 340(6134):1235009. doi:10.1126/science. 1235009

Voss KA, Famiglietti JS, Lo M, Linage C, Rodell M, Swenson SC (2013) Groundwater depletion in the Middle East from GRACE with implications for transboundary water management in the Tigris-Euphrates-Western Iran region. Water Resour Res 49(2):904-914. doi:10.1002/wrcr. 20078

Vryzas Z, Papadakis EN, Vassiliou G, Papadopoulou-Mourkidou E (2012) Occurrence of pesticides in transboundary aquifers of North-eastern Greece. Sci Total Environ 441:41-48. doi:10.1016/j.scitotenv.2012.09.074

Wada Y, Heinrich L (2013) Assessment of transboundary aquifers of the world-vulnerability arising from human water use. Environ Res Lett 8(2). doi:10.1088/1748-9326/8/2/024003

Wada Y, van Beek LPH, van Kempen CM, Reckman JWTM, Vasak S, Bierkens MFP (2010) Global depletion of groundwater resources. Geophys Res Lett 37(20), L20402. doi:10.1029/ $2010 \mathrm{~g} 1044571$

Wada Y, van Beek LPH, Sperna Weiland FC, Chao BF, Wu Y-H, Bierkens MFP (2012) Past and future contribution of global groundwater depletion to sea-level rise. Geophys Res Lett 39(9), L09402. doi:10.1029/2012g1051230

Wang J, Huang J, Rozelle S, Huang Q, Blanke A (2007) Agriculture and groundwater development in northern China: trends, institutional responses, and policy options. Water Policy 9(S1): $61-74$

Wang J, Rothausen SGSA, Conway D, Zhang L, Xiong W, Holman IP, Li Y (2012) China's water-energy nexus: greenhouse-gas emissions from groundwater use for agriculture. Environ Res Lett 7(1):014035. doi:10.1088/1748-9326/7/1/014035

Werner AD, Bakker M, Post VEA, Vandenbohede A, Lu C, Ataie-Ashtiani B, Simmons CT, Barry DA (2013a) Seawater intrusion processes, investigation and management: recent advances and future challenges. Adv Water Resour 51(0):3-26. doi:10.1016/j.advwatres.2012.03.004

Werner AD, Zhang Q, Xue L, Smerdon BD, Li X, Zhu X, Yu L, Li L (2013b) An initial inventory and indexation of groundwater mega-depletion cases. Water Resour Manag 27(2):507-533

Wolf AT (1998) Conflict and cooperation along international waterways. Water Policy 1(2): 251-265

Wolf AT (2007) Shared waters: conflict and cooperation. Annu Rev Environ Resour 32(1): 241-269. doi:10.1146/annurev.energy.32.041006.101434

Wood EF, Roundy JK, Troy TJ, van Beek LPH, Bierkens MFP, Blyth E, de Roo A, Döll P, Ek M, Famiglietti J, Gochis D, van de Giesen N, Houser P, Jaffé PR, Kollet S, Lehner B, Lettenmaier DP, Peters-Lidard C, Sivapalan M, Sheffield J, Wade A, Whitehead P (2011) Hyperresolution global land surface modeling: meeting a grand challenge for monitoring Earth's terrestrial water. Water Resour Res 47(5), W05301. doi:10.1029/2010wr010090

Woody T (2009) Alternative energy projects stumble on a need for water. The New York Times September 29, 2009

World Bank (2010) Deep wells and prudence: towards pragmatic action for addressing groundwater overexploitation in India. Tech. rep, Washington, DC

World Commission on Environment and Development (1987) Our common future. Oxford University Press, Oxford/New York

Zektser IS (2012) Investigation of transboundary aquifers in Russia: modern state and main tasks. In: NATO advanced research workshop on sustainable use and protection of groundwater 
resources-transboundary water management proceedings, pp 79-85. doi:10.1007/978-94007-3949-9_7

Zektser S, Loaiciga H, Wolf J (2005) Environmental impacts of groundwater overdraft: selected case studies in the southwestern United States. Environ Geol 47(3):396-404 


\title{
Disentangling the Complexity of Groundwater Dependent Social-ecological Systems
}

\author{
Olivier Barreteau, Yvan Caballero, Serena Hamilton, \\ Anthony J. Jakeman, and Jean-Daniel Rinaudo
}

\begin{abstract}
Groundwater resources are part of larger social-ecological systems. In this chapter, we review the various dimensions of these complex systems in order to uncover the diversity of elements at stake in the evolution of an aquifer and the loci for possible actions to control its dynamics. Two case studies illustrate how the state of an aquifer is embedded in a web of biophysical and sociopolitical processes. We propose here a holistic view through an IGM-scape that describes the various possible pathways of evolution for a groundwater related social-ecological system. Then we describe the elements of this IGM-scape starting with physical entities and processes, including relations with surface water and quality issues. Interactions with society bring an additional layer of considerations, including decisions on groundwater abstraction, land use changes and even energy related choices. Finally we point out the policy levers for groundwater management and their possible consequences for an aquifer, taking into account the complexity of pathways opened by these levers.
\end{abstract}

O. Barreteau $(\square)$

IRSTEA, UMR G-EAU, Montpellier, France

e-mail: olivier.barreteau@irstea.fr

Y. Caballero • J.-D. Rinaudo

Water Department, BRGM, French Geological Survey, Montpellier, France

e-mail: y.caballero@brgm.fr; jd.rinaudo@brgm.fr

S. Hamilton

Centre for Ecosystem Management, School of Science, Edith Cowan University, Joondalup, WA, Australia

e-mail: s.hamilton@ecu.edu.au

A.J. Jakeman

National Centre for Groundwater Research and Training, Fenner School of Environment and

Society, Australian National University, Canberra, ACT, Australia

e-mail: tony.jakeman@anu.edu.au 


\subsection{Introduction}

As discussed in Chap. 1, aquifers are generally part of larger complex systems, increasingly referred to as social-ecological systems (Folke et al. 2005; Janssen et al. 2006; Olsson et al. 2006). Social-ecological systems are composed of interacting socio-economic, bio-physical and human-made components. All too often these groundwater-dependent social-ecological systems are studied from a single or narrow subset of perspectives. Groundwater quality and quantity, for example, are determined by physical flows (water, microbial population, chemical pollutants, etc.) which result from natural processes and human activities (Chap. 14). However, drivers of groundwater dynamics can only be fully understood by enlarging the scope of the analysis. Indeed, the evolution of pressures exerted on groundwater by socio-economic factors depends on non-water related policies such as urban development, agricultural or energy policy (Fig. 1.1). It is also influenced by global market, technological and societal changes. The intensity of the groundwater management challenge also depends on the existence and quality of alternative resources, such as surface water, other aquifers, imported resources, and non-conventional water sources. Furthermore, the evolution of human activities shapes land use patterns, and as a consequence the pressure on the resource. Human activities in turn are shaped by values, beliefs and norms (Chap. 19) and associated policies and governance (Part II, Chap. 6).

In this chapter, we propose a conceptual framework to describe the complexity of groundwater-dependent social-ecological systems, to understand their long term dynamics, and to present the main research and management challenges. It presents a new perspective on groundwater management through: (i) the explicit re-integration of aquifers within much larger social-ecological systems; (ii) the identification of factors important for the system; and (iii) management to promote sustainable use of groundwater resources.

We expect that with such a foundation, Integrated Groundwater Management (IGM), will be more efficient and effective in practice.

\subsection{Groundwater: An Interaction Space of Several Interdependent Dynamics}

Various processes connect important entities associated with an aquifer. These connections make up possible pathways with positive or negative outcomes on the aquifer. In this section Integrated Groundwater Management analysis and policies are evaluated, and entities and interactions are mapped. The framework presented focuses on the integration of components across and within the natural system, human system and governance setting dimensions, and the associated issues of concern (Chap. 1). 


\subsubsection{Crau Aquifer: A Water Circular Economy}

The introductory example presented here is the Crau alluvial aquifer, located in southern France, east of the Rhone Delta. This agricultural area is known for its production of labeled high quality hay, irrigated with a traditional system of earthen gravity canals, developed in the sixteenth century. Water losses occurring in the canals and at field level contribute significantly to the recharge of the underlying alluvial aquifer (Mailhol and Merot 2008). Irrigation water is imported from the Durance River, a snow-fed regulated river with several competing uses along its course. The artificial recharge associated with flood irrigation has allowed groundwater use to develop. The aquifer is considered to have better water quality than the surface water, and is now used by a number of small cities nearby for water supply, by individual households, and by industries. The high water table in the aquifer also prevents sea water intrusion on its south-eastern fringe, where several industries are located. High water tables have also produced a specific agricultural and natural landscape considered as a regional heritage, to which people are culturally attached (Mérot et al. 2008).

This social-ecological system has evolved over several centuries, and is now threatened by a number of factors: (i) the traditional irrigation system needs maintenance work or redevelopment; (ii) the water abstraction fees charged by the Water Agency are increasing, pushing farmers to reduce water losses at canal and field level; (iii) there is increasing competition for the use of the Durance river basin, where the irrigation water originates. Several adaptation pathways are apparent. One pathway relies on modernization of the irrigation system, such as with drip irrigation to decrease water use and pumping in the aquifer, which will in turn drastically decrease aquifer recharge, with projected degradation of the amenities listed above. Another pathway consists in changes in surface irrigation techniques that generate little change in aquifer recharge, but is more expensive (Mérot et al. 2008). Non-farming beneficiaries of the externalities generated by high water tables (e.g., neighboring cities using the aquifer for domestic water supply) could also become part of the governance of the area and contribute funding to maintain the system.

This example illustrates the complexity of processes that determine the dynamics of a groundwater-dependent social-ecological system, highlighting the need to look beyond the confines of the aquifer.

\subsubsection{The Gnangara Mound}

Another example is the Gnangara Groundwater Mound, which currently supplies about half of the water needs of the city of Perth (population 1.8 million), Western Australia. In this social-ecological system, groundwater is an important source for 
the metropolitan water supply, irrigation of parks and gardens, horticulture and industry, and also supports a number of wetlands and groundwater dependent woodlands. However, groundwater levels have declined significantly over the past few decades, as a result of climate change, abstraction and land use changes.

Reduced rainfall has been identified as the major cause of groundwater level decline in the Mound (Yeserterner 2008). There has been strong evidence of a climate shift in the area since the mid-1970s, which has resulted in a 10-15\% reduction in annual rainfall and fewer storms with high rainfall intensities. Historically, such intense rainfall events were a key source of runoff for streams and recharge for aquifers (McFarlane et al. 2010). The climate shift has led to streamflow reductions of more than $50 \%$ as a result of the reduced runoff in addition to the reduced contribution from groundwater due to the lowered watertable levels and loss of groundwater-surface water connectivity (Bates et al. 2008; Petrone et al. 2010). A significant increase in groundwater abstraction from the Gnangara Mound over the decades has coincided with the decline in surface water supplies, with some changes in water use indirectly driven through policy. For example the noticeable drop in reservoir levels in the late 1970s led to a ban on the use of drinking water for irrigating private gardens. These restrictions led to a surge in the number of private bores, from approximately 25,000 in 1975 to 65,000 in 1980 (McFarlane et al. 2010).

Land use factors affecting the Gnangara Mound include pine plantations, land clearance, bush fires, and urban development. Pine plantations have had the strongest influence on groundwater levels, particularly in areas of dense plantation due to increased evapotranspiration and reduced recharge (Yesertener 2008). Land use practices that reduce leaf areas, such as land clearance, plantation thinning and bushfires, can lead to groundwater level rises, however the raised levels generally occur only for a few years until the vegetation is re-established.

The lowered groundwater levels in the Mound have caused declines in total abundance of groundwater dependent plants, and shifts in species composition towards more drought-tolerant species (Froend and Sommer 2010). The declining groundwater levels have led to incidences of reduced groundwater quality, including salt water intrusion in some coastal and estuarine parts of the Gnangara Mound. The lowered groundwater levels have also contributed to the acidification of several wetlands in the area through the exposure of acid sulphate soils. Artificial maintenance of water levels has been shown to restore some of the impact of droughtinduced acidification on macroinvertebrate communities but change the seasonal hydrological regime of the wetlands (Sommer and Horwitz 2009).

The Gnangara Mound case study highlights the intertwined connections between climate, surface water and groundwater resources, and the human and ecological communities that depend on groundwater, with relationships occurring through both direct and indirect pathways. 


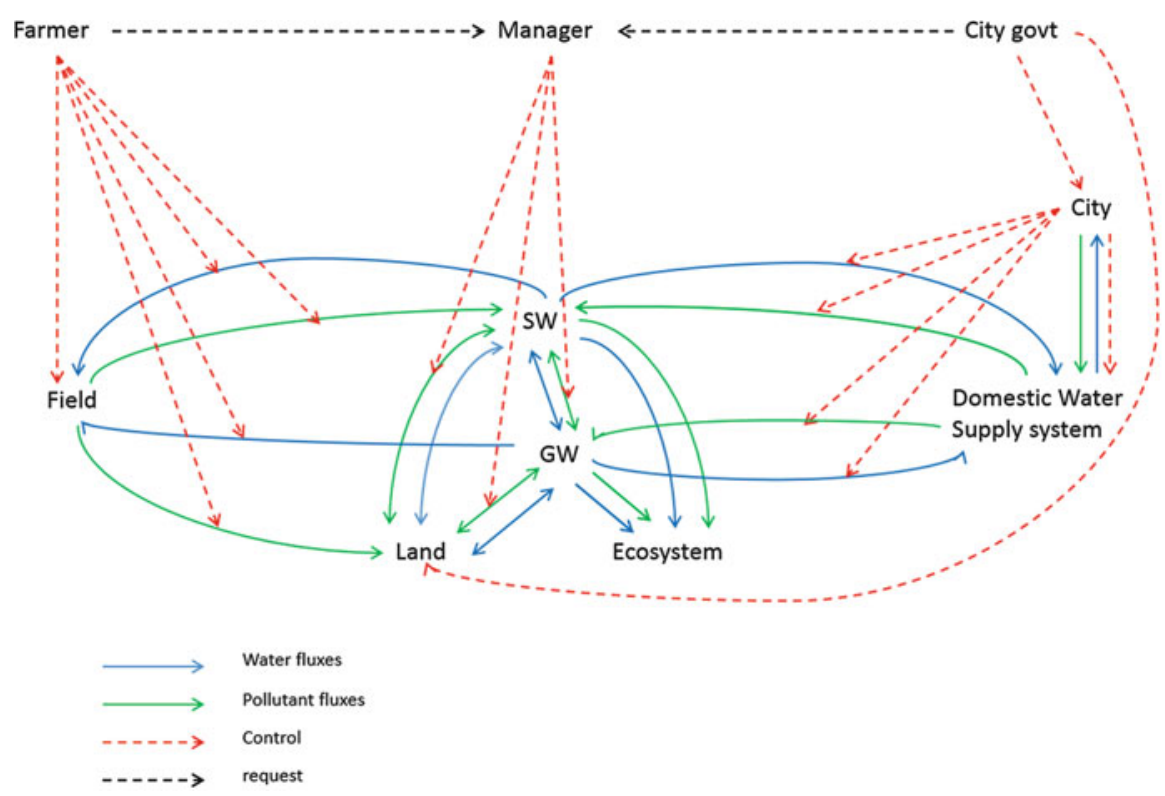

Fig. 3.1 Components at stake in groundwater management - The "IGM-scape"

\subsubsection{An Enlarged and Integrated Perspective on Groundwater Management}

The key external drivers, interactions and feedbacks, as well as a clear description of the metrics of desirable operation, are required so that performance and progress of any management can be evaluated. In this way, water becomes a means for optimization of a larger system rather than an end itself, and balances the needs for various water users, including the health of the ecosystems themselves. Main components and interactions to be taken into account for a social-ecological system features agricultural and domestic resource use (Fig. 3.1), and extends to include drivers like climate change (Chap. 5) and energy (Chap. 4). Altogether they constitute the "IGM-scape" - a holistic landscape of drivers important for effective IGM. A first circle lies around biophysical components: surface and ground water, but also related ecosystems and land. A second circle includes other material components through which water flows. A third circle represents main users, such as farming and urban development. The IGM-scape requires infrastructure; for example, conveyance mechanisms have to be available (Blomquist et al. 2001). Moreover, all these components are themselves dependent on external drivers: climate change, demographic development, markets, national or supranational policies, and knowledge development.

IGM benefits from such a starting framework because it identifies possible pathways that describe conduits for change to be expressed (i.e., external change 
or internal policy evolution). This enables identification of policy options, with subsequent conceptual and quantitative analysis of potential consequences.

IGM was defined in Chap. 1 as a structured process that promotes the coordinated management of groundwater and related resources in order to achieve shared economic, social welfare and ecosystem outcomes over space and time. To achieve this goal, IGM must: (i) identify most important pathways; (ii) consider policy options to control these pathways in line with holistic management objectives; and (iii) assess consequences and uncertainties. A key aspect of this stage is involving stakeholders and experts through use of hard and soft systems approaches (Chap. 24).

\subsection{Understanding Hydrogeological Complexity}

In this section we focus on hydrogeological processes that connect the "IGMscape". Since these flows are not easily seen, we include some methodological suggestions on possible techniques to assess these fluxes.

\subsubsection{Determinants of Groundwater Resource Quantity}

An initial priority for groundwater managers to ensure a more sustainable exploitation of their aquifer (see also Chap. 2) is to determine how much water can be abstracted without depleting its quantity and degrading its quality, and minimizing negative impacts for other components of the groundwater-dependent social-ecological system. It means assessing flows between surface and ground water and the interactions with their environment. These components are covered individually below.

\subsubsection{Aquifer Hydraulic Properties Characterization}

The hydraulic properties of an aquifer can be characterized using specific hydraulic tests (Domenico and Schwartz 1990), in conjunction with upscaling using groundwater flow modeling (e.g., Anderson et al. 2015). Longer tests (at least 3-days) are typically needed to describe aquifer geometry, hydrodynamic characteristics, and the type of boundary conditions (impervious, constant-head, constant-flow) that are locally important (e.g., Kruseman and de Ridder 1994). The aquifer properties and insights can then be up-scaled using modeling to account for other hydraulic interactions such as with a river (Kollet and Zlotnik 2003) or sea-water intrusion (Terzić et al. 2007).

\subsubsection{Aquifer Recharge Estimation}

Generally, recharge is a process where infiltration from the terrestrial land surface or from surface water crosses the water table (see De Vries and Simmers (2002) and Scanlon et al. (2002) for a conceptual description of recharge). Recharge can be diffuse over large areas when caused by precipitation or irrigation. It can also be 
concentrated at specific locations such as tectonic fractures or preferential infiltration landforms (sinkholes in karstic systems, e.g., Andreo et al. 2008) or surface water bodies such as rivers or lakes. Recharge generally follows downward fluxes, but it can also lead to lateral fluxes in the case of interactions with neighboring aquifers or with surface water bodies such as rivers or lakes (De Vries and Simmers 2002). In the latter case, the flow direction can change depending on the season or the location, as it is mainly controlled by the water head gradient, i.e. the difference in altitude between the water table in the aquifer and in the river or the lake (Sophocleous 2002).

There are several methods to characterize the recharge of an aquifer (see Scanlon et al. 2002; Healy 2010). For discussion purposes, we group recharge characterization into direct measurement (physical or chemical), empirical and analytical or modeling methods.

Local measurements can be obtained using lysimeters. In order to obtain accurate measures of the recharge rate the base of the lysimeter should not be deeper than the root zone. By using 28 lysimeters $(0.61 \mathrm{~m}$ diameter, $1 \mathrm{~m}$ long) in the Masser Recharge Site (central Pennsylvania, USA), Heppner et al. (2007) report that recharge averaged $32 \%$ of the annual rainfall (ranging from $21 \%$ to $52 \%$ ) between 1995 and 1999. Along with Seneviratne et al. (2012), they also discuss the main sources of uncertainty linked to the recharge estimation using lysimeter data.

Tracers (mainly chloride and environmental isotopes) can also be used to estimate local recharge. These methods are based on the analysis of the tracer concentration evolution between the input (in the rain water) and the output (springs, rivers or water table). For example, Marei et al. (2010) estimated the spatial distribution of recharge over the western side of the Jordan Rift Valley using chloride mass-balances. Tracer methods typically require several assumptions to account for anthropogenic perturbations, variability of climate, groundwater-rock chemical reactions, and difficulties inherent to output flux monitoring.

Empirical methods are based on linear correlations fitting between climate and recharge, and are typically calculated on an annual time scale. Although these correlations are generally specific to the climatic conditions of the locations calculated, they are relatively quick to perform. As an example, Kessler (1967) developed a way to optimize the calculation of recharge in carbonate aquifers, assuming that "the amount of precipitation falling in the first four months of the year (that is, preceding the development of the vegetation and prior to the large losses due to evaporation) is determinative". In order to consider the influence of the initial climatic context, a correction factor, derived from the amount of precipitation of the last four months of the previous year, is then applied. Finally, infiltration rates are proposed in order to estimate the recharge at the monthly time scale. This method has been applied to the Hungarian mountains, and later in a southern Spanish karstic aquifer where obtained results were realistic compared to other approaches (Andreo et al. 2008).

Modeling of aquifer recharge is typically most widely applied for large systems (see De Vries and Simmers (2002) and Scanlon et al. (2002) for extended reviews). There is a great variability in the approaches depending on the kind of data 
available to describe the aquifer dynamics. Simple hydrological balance methods such as those proposed by Thornthwaite (1948) or Dingman (2002) can be used to estimate infiltration out of the root zone and its availability for recharge. Therefore, the focus is on water that is not intercepted by the vegetation or consumed by evapotranspiration, nor lost as overland runoff. Typically, non-vegetated regions will have higher values than vegetated ones (Gee et al. 1994). The calculation of the distribution of infiltration (recharge) and other sinks is made using a combination of geomorphological, soil and lithology variables. There are methods that use spatially distributed information through GIS analysis (Mardhel et al. 2004) or though external computer codes designed to calculate recharge in space and time (e.g., Westenbroek et al. 2012). Typically models are applied at the daily time step, which can then be aggregated to longer time periods for groundwater analysis and modeling. Models simulating flow processes in the unsaturated zone can also be used to estimate recharge.

A variety of approaches for estimating recharge exist, ranging from soil-water storage-routing to numerical solutions to the Richards equation (see Scanlon et al. (2002) for an extended review); however their results can vary substantially. Fourteen different methods applied to the same arid setting in Nevada, USA led to recharge estimates ranging from 1 to $100 \mathrm{~mm} /$ year (Flint et al. 2002). A comparison of different methods to estimate recharge in another arid setting in the northern Sandveld area, Western Cape, South Africa also showed variability (Conrad et al. 2004), with estimates ranging from $0.2 \%$ to $8 \%$ of annual rainfall as recharge. Therefore, adequate description of how recharge was calculated for the IGM-scape is critical for acceptance by others.

\subsubsection{Aquifer Interactions with Surface Water}

Groundwater and surface water interaction is driven by hydraulic gradients (Gilfedder et al. 2012). The discharge of a river is often separated into two components, a fast and short response signal to rainfall corresponding to superficial and interflow sources and a slower response corresponding to aquifer drainage. Several techniques ranging from applying analytical methods for base flow separation to hydrographs (Gustard and Demuth 2009) to detailed hydrodynamic modeling or geochemical hydrograph separation (mainly using chloride concentration or stable isotopes of water) can be used to estimate the contribution of aquifer drainage to river discharge.

Commonly, aquifer water levels are highly sensitive to surface-water state, and can vary depending on the season (Allen et al. 2003). During high flows, river water typically recharges the aquifer and moves laterally away from the channel, causing groundwater levels to rise (Scibek et al. 2007); within a relatively short period after peak discharge, the groundwater flow direction is reversed. This is generally the case for river-aquifer interactions in natural conditions in humid climates. However, this relation can change in response to external stressors such as pumping. In some cases, water extracted from pumping wells can be almost exclusively derived from the surface water sources (e.g., Scibek et al. 2007). In some settings, extreme drought conditions and/or excessive pumping can lead to a complete river drying 
up. The potential for such adverse effects led regulators in several countries (e.g. France, Spain) to consider aquifer withdrawals close to rivers to be water withdrawals from the river itself. Even without complete drying, groundwater abstraction can affect ecological communities (Bradley et al. 2014; Chaps. 12 and 13).

In addition to well recognized surface water resources such as streams, rivers, and lakes, groundwater can also play a critical role for some wetlands (Chaps. 12 and 13). Groundwater contributes to the good ecological status of these water bodies through its effects on their physical and chemical characteristics. In terms of the IGM-scape, this importance has been recognized at the European level, where the EU Water Framework Directive (WFD) stipulates that groundwater abstraction must not unacceptably degrade ecological status of dependent wetlands. This relation to the groundwater system can be critically important even if the inflow from the aquifer represents a marginal part of the water supplying a wetland, and water levels in aquifers can represent the main environmental driver for wetland services (Gasca and Ross 2009).

Wetlands can also contribute significantly to the quality of the groundwater flowing through it, through soil characteristics that facilitate low oxidationreduction conditions, filtration properties, and interaction with hydrophytic vegetation. This can be important for the retention and the recycling of some pollutants for groundwater, such as nitrates and pesticides, which can be important to consider in IGM approaches.

In the case of coastal aquifers, groundwater level decline due to pumping is one of the main causes of seawater intrusion, defined here as the landward subsurface incursion of seawater. Other factors such as land-use changes, climate variations or sea-level fluctuations also control the timing and magnitude of intrusion. Werner et al. (2013) provides a comprehensive review on the diversity of the challenges associated with seawater intrusion issues. Many diverse processes can influence IGM efforts. Dynamic hydrological conditions must be assessed taking into account density-salinity relationships. Together with the slow dynamics of the processes involved, it raises significant challenges for groundwater managers charged with determining optimal groundwater use. Effective groundwater management of coastal aquifers requires characterization of the position and thickness of the mixing zone between freshwater and intruding seawater (the seawater wedge toe) and monitoring that combines head measurements, geophysical methods, and environmental tracers. Simple measures such as head measurements in an observation well can be confounded by groundwater density effects caused by salinity and fluctuations at the toe in an observation well (Shalev et al. 2009). Geophysical methods typically can detect the large electrical resistivity contrast between seawater and freshwater, allowing 1D vertical or lateral to 3D characterizations (e.g., Poulsen et al. 2010). Even simple ion analysis of coastal groundwater can document seawater intrusion occurrence. High total dissolved solids in groundwater can also be caused by rock dissolution, connate saline water and irrigation return flow (e.g., Bouchaou et al. (2008). 


\subsubsection{Determinants of Groundwater Quality}

Understanding infiltration processes, identifying flow direction, and information on aquifer lithology can provide first approximations of expected groundwater quality (see also Chaps. 14 and 15).

In addition to terrestrial recharge, surface water can supply appreciable recharge to an aquifer. The evolution of water quality in the surface-groundwater interaction context is typically influenced by several processes linked to geology (lithology of the aquifer, granulometry of the river banks), hydrogeology (aquifer permeability, confined/unconfined, clogging thickness and hydraulic conductivity of the river banks), hydrology (rain water chemistry, evaporation intensity, flow seasonality) and biology (temperature, micro-organisms, light, river bed vegetation, oxygenation and nitrate presence for the microbial activity). Interactions between surface water and aquifers can influence the water quality in both systems. The transition interface between surface water and aquifers (also called the hyporheic zone) can also play a significant role in the transformation and transport of pollution for example by filtering suspended particles and interacting with bacteria, viruses, and organic matter. Longer residence times of the water in the hyporheic zone commonly enhance biogeochemical reactions that are favorable to a natural attenuation of pollution (Gandy et al. 2007). For example, when filtrating through river banks, several processes affecting water quality between surface and groundwater are involved (see Hiscock and Grischek 2002). Regional monitoring networks for surface and groundwater show that poor chemical conditions of shallow groundwater lead to lower quality in receiving surface waters, and monitoring of the water quality of surface water during non-storm conditions can provide an integrated measure of groundwater quality. Alternatively, when surface water recharges an aquifer, monitoring of surface water quality can provide warnings of potential aquifer contamination.

Groundwater-surface water interaction, and the water quality ramifications, are often influenced by hydrologic stress applied to either system. Stresses such as pumping and dam construction, for example, can influence the flow direction between aquifers and rivers and change the residence time within the hyporheic zone. Large hydrologic stress can also appreciably affect aquifer hydraulic properties through development of unsaturated conditions beneath the river, due to abstraction rates higher than can be supported by capture from the surface water resource.

\subsection{Understanding the Complexity of Groundwater-Society Interactions}

Over centuries, changes to water infrastructures and land use have significantly altered hydrogeological processes, frequently affecting groundwater and dependent ecosystems. Effective IGM requires understanding of these two drivers, and 
appropriate integration of the relevant components within and across the natural and human systems.

\subsubsection{Infrastructures and Increased Human Interference in the Water Cycle}

\subsubsection{Groundwater Abstraction}

The development of groundwater abstraction infrastructures, for urban, industrial and agricultural uses, is perhaps the most obvious driver in the IGM-scape. Although traditional exploitation technologies (e.g., Persian wells, galleries in the Middle East) were relatively small stresses to the groundwater system, the development of modern pumping technologies has increased groundwater use by several orders of magnitude. New problems of groundwater depletion have resulted, including sea water intrusion, land subsidence, and reduced river, spring, and wetland flows (see Chap. 2 for an overview of these problems and their international scale). Increased exploitation has also resulted in greater seasonal and annual fluctuation of groundwater levels, frequently impacting dependent ecosystems and groundwater quality. As an example, groundwater is a source of clean water for more than 13 million people in Kolkata, India, but its quality is appreciably degrading due to intensive pumping that has induced recharge from areas of known contamination with heavy metals and arsenic (Sahu et al. 2013). Pumping in groundwater increases vertical gradients and related velocities from surface water sources (Gilfedder et al. 2012). Some studies report intensive withdrawal impacting not only on the capacity of other people to pump in the same resource but also on return flows from groundwater to surface water in low water period that can be reversed (Howe 2002; Webb and Leake 2006).

Understanding the effects of groundwater development is essential to IGM. Tradeoffs must be recognized; in agriculture, the construction of private borewells has improved the living conditions of millions of farmers, in developed as well as in developing countries (Llamas and Martinez-Santos 2005). Accessing groundwater increases autonomy, thus flexibility with regards to production, and ultimately income. Pumping from the groundwater system also improves water supply reliability, in particular during drought (Tsur 1990; Tsur and GrahamTomasi 1991). Municipal water utilities increasingly use groundwater to complement surface water supplies, again for increasing reliability of supply during drought or drier climate (e.g. the Gnangara Mound in Western Australia), or in the case of catastrophic events like floods, landslides, earthquakes or large scale nuclear contamination (Vrba and Verhagen 2011). Commonly industries develop groundwater self-supplies rather than purchase water from municipal utilities. Similarly, households may be tempted to drill bore wells for private use as in Perth (the Gnangara Mound case study above; Rinaudo et al. 2015); this phenomena has also been reported in other cities like Cape Town in south Africa (Saayman and Adams 2002), and southern France (Montginoul and Rinaudo 2011). 
Fig. 3.2 Motivations for substituting surface with groundwater

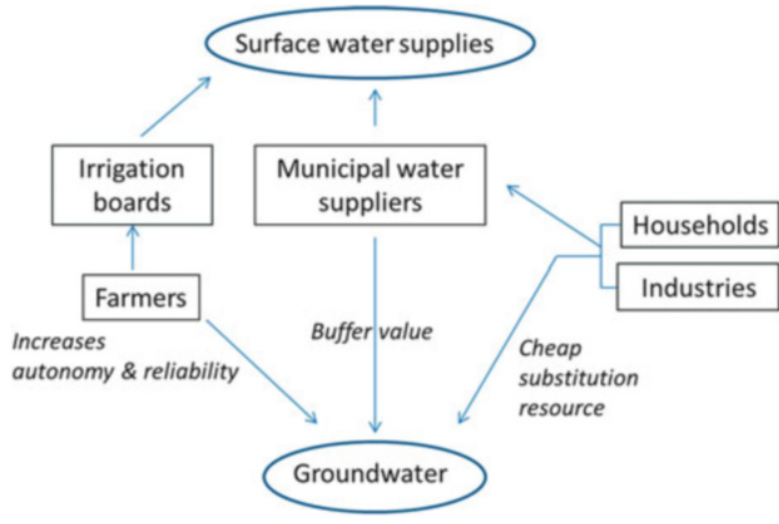

Overall, the development of groundwater use reflects the decision of various categories of economic agents to substitute their traditional collective surface water supply with independent groundwater supply (see Fig. 3.2). Understanding the motivations underlying individuals' decision to undertake this shift in water supply source is essential to design an effective groundwater protection policy. Groundwater management policy needs to use policy levers that interface with other policies, such as pricing policies of agricultural or urban water services.

\subsubsection{Irrigation and Drainage}

In many parts of the world, the development of irrigation and drainage (Chap. 15) has been a key factor affecting groundwater dynamics. The construction of large scale gravity irrigation structures, which divert water from surface sources over long distances, has appreciably increased groundwater recharge, through water losses that occur in canals and at farm level. In this way, the groundwater cycle is made more artificial, generating significant unintended effects - both good and bad for non-agricultural users (e.g., development of new surface ecosystems, waterlogging and enhanced salinization).

Scarcity of surface water resources led national and international agencies to promote more efficient surface irrigation schemes. Ancient gravity irrigation systems are progressively being turned into piped infrastructures, delivering pressurized water at farm level, where sprinkler and drip irrigation replace inefficient flood irrigation. While the technical and economic efficiency of irrigation has been rising, irrigation losses and artificial recharge of shallow aquifers is being reduced. Many unintended benefits generated for decades by gravity irrigation schemes are suddenly offset, as illustrated by the Crau case study presented earlier. This again illustrates the need for greater integration of various policy domains to ensure sustainable groundwater management.

\subsubsection{Artificial Groundwater Recharge}

Infrastructures have also been designed to increase aquifer recharge by using water diverted from rivers during high flow periods or with treated wastewater. Several 
Managed Artificial Recharge (MAR) techniques are now available to increase infiltration as well as to treat water through soil processes (see Chaps. 16 and 17). In this way, groundwater can be considered as a natural infrastructure for water storage. Consistent with an aquifer and surface water being a single resource, MAR slows down surface water flows and/or facilitates soil infiltration in dedicated places via infrastructures such as infiltration pounds or ditches, or injection wells. Despite potential design uncertainties, it has been now successfully implemented in various arid or semi-arid places of the world, such as the Llobregat basin near Barcelona (Pedretti et al. 2012) or in the southwestern United States (Blomquist et al. 2001). "In lieu recharge" is a similar management technique, which calls for the use of surface water first, hence keeping groundwater stored in aquifers for future use only when required. Diversion is performed first in the input flow before tapping into the groundwater storage, rather than tapping groundwater storage filled by a MAR process somewhere else. This approach needs accessible surface water, but it has been used even in water scarce areas such as the southwestern United States (Blomquist et al. 2001). One impediment to wider implementation of MAR lies in the legal definition of ownership of recharged water. Economic investment in MAR infrastructure is often contingent on the ability to recover the volume stored in the aquifer at a later point in time, as it happens in Kern County Groundwater Bank (Hanak and Stryjewski 2012).

Artificial recharge may also take place at smaller scales, such as in households to re-infiltrate rain water collected from their roofs. The promotion of such decentralized artificial recharge schemes is often a feature of urban development planning and policy. The concept of water sensitive urban design is gaining momentum (Hussey and Kay 2015) but issues regarding property rights can affect ownership of re-infiltrating roof water into the aquifer. Artificial recharge also can target improving poor quality, such as in Teheran, Iran, where $60 \%$ of domestic wastewater is re-injected into aquifers through some three million wells spread across the area (Bazargan-Lari et al. 2009). Once again, IGM for improving the groundwater resource is clearly affected by the integration of groundwater and urban development policies.

\subsubsection{The Impacts of Land Use Change on Groundwater}

The groundwater cycle can be significantly altered by land use changes (LUC). Land use influences local aquifer recharge and the quantity of pollutants produced at a point or diffuse source. IGM policy thus has to account for LUC, which calls for better understanding of LUC drivers and their impacts on the subsurface portion of the hydrological cycle. The four main LUCs impacting groundwater recharge and quality are shown in Fig. 3.3. Increased local demand for food or international market incentives (cash crops) generate significant conversion of natural landscapes (forest, rangeland, shrubland, wetlands) into agricultural land (1). The opposite evolution is also reported in poor agricultural areas, where cultivated land is progressively abandoned due to economic pressures and migration of the 
Fig. 3.3 Land use changes affecting groundwater recharge and quality

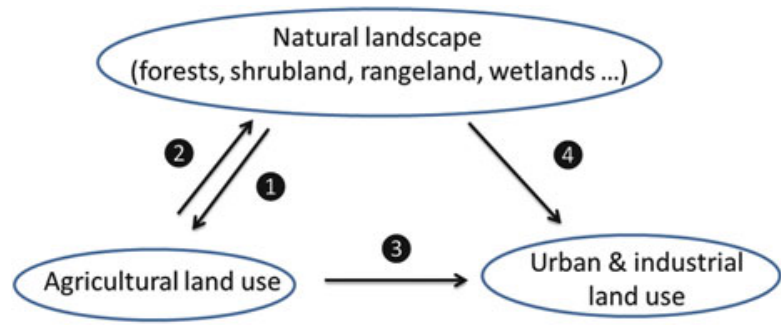

rural population towards cities (2). Concentration of population in urban area results in massive conversion of agricultural land and/or natural land into housing, transport, commercial or industrial land use - often involving a reduction in groundwater recharge over large areas (3 and (4).

\subsubsection{Agricultural Development and Groundwater}

The conversion of natural lands into agricultural land impacts the water cycle in four different ways. First, change in vegetation cover significantly alters evapotranspiration patterns. In the early growing season, agricultural crops have a lower evapotranspiration than natural vegetation. Infiltration is increased due to the high proportion of bare soil in early crop stages. Infiltration is also higher during fallow periods due to reduced plant interception and the presence of bare soil. Additionally, plowing and other farming practices such as terracing increase permeability of upper soils, thus facilitating infiltration beyond the capture of the root zone. Alternatively, compaction of soil by heavy farm machinery may reduce infiltration and enhance surface runoff (Steuer and Hunt 2001). Lastly, the conversion of natural land into agriculture is often accompanied by the development of irrigation based on imported water supply, which further increases recharge. A number of studies have demonstrated that the conversion of natural land into agricultural fields increases recharge, under various climates. In the western states of the USA, in semi-arid parts of Australia, and in the Indian subcontinent, the process has resulted in significant rise of the water table, waterlogging and soil salinization (see Chaps. 2 and 15). In Sri Lanka deforestation associated with agricultural development has caused an increase in groundwater recharge (Priyantha Ranjan et al. 2006). In addition, the water quality of infiltrating water changes, which can affect use of the groundwater resources (see Chap. 15).

\subsubsection{Urban and Industrial Land Use}

Urbanization also influences the subsurface flow regime and groundwater quality in three main ways. The increase in impervious surfaces results in: (i) reduced infiltration and recharge; (ii) reduced evapotranspiration; and (iii) possible increases in groundwater abstraction by industrial and commercial activities which do not necessarily require high quality water, and sometimes by households tapping shallow aquifers for irrigation (Rinaudo et al. 2015). Urban development policies and planning can influence the degree of impact of these factors, for example, by 
careful selection of locations for large impervious surfaces (industrial and commercial sites, transportation infrastructure), associated mitigation, and promoting low impact designs (Dams et al. 2008; Cho et al. 2009). Water sensitive urban design can result in increasing recharge and available groundwater resources, by redirecting runoff from roofs and roads into the soil and thereby the shallow aquifer (Wong 2006; Barron et al. 2013; Hussey and Kay 2015). In extreme cases, urbanization accompanied with infiltration of storm water can lead to a long term rise of water tables (Barron et al. 2013). In this way LUC can have similar impacts to managed artificial recharge infrastructure - yet LUC has two main advantages, of larger cost distribution and spatial distribution over a large area.

A second main impact of urbanization is on groundwater quality (Lawrence et al. 1998) as economic, industrial and commercial development introduces new potential contamination sources. Point source pollution, due to accidental spillages or long term leakages of chemical products, can generate large pollution plumes (petroleum, chlorinated hydrocarbons, and synthetic organic compounds) that are often mixed with other contamination sources. Contaminated soils form a more diffuse contamination source. Small size industries such as tanneries, printing, laundries, and metal processing, can be widely dispersed and generate liquid effluents such as spent disinfectants, solvents, lubricants that often reside in adjacent soil. Leakage from wastewater lagoons and sanitary sewer systems can also be appreciable. Storm water can carry significant loads from impervious surfaces as well as pathogenic bacteria and viruses. Pathogen water quality issues can result in areas where sanitary treatment is deficient (cesspit, latrines, and septic tanks) or even through aging infrastructure where treatment methods are well developed (e.g., Hunt et al. 2010).

\subsubsection{Energy: Groundwater Policy Interactions}

Groundwater can also be significantly affected by changes in energy policy (see Chap. 4 which covers the water-energy-global change nexus). In countries where electricity is widely available in rural areas, some authors suggest that an important lever to ensure sustainable groundwater management policies is electricity pricing policy (Scott and Shah 2004; Shah et al. 2008). Energy pricing can lead to unintended effects: Moroccan and Indian government subsidies of respectively domestic gas cylinders and electricity were intended for social welfare; however, farmers changed or adapted their pump engines to benefit from subsidies, resulting in an unintended increased of groundwater use for irrigated agriculture and overexploitation (Shah et al. 2008; Shah 2014).

Through the energy-water nexus, groundwater policy can also conflict with renewable energy development policies. In solar energy for instance, a range of technological innovations are being adopted by industry, and their development might impact groundwater in the future (Mills 2004). The principle of thermo-solar power plants consists of harnessing solar energy to generate electrical production with steam turbines, which require the use of large quantities of cooling water. 
Geothermal power plants use more water than conventional steam plants because of low heat-electricity conversion efficiency (Fthenakis and Kim 2010). Energy policy thus results in increased water demand, conflicting with a water conservation objective. The problem can be particularly acute in arid areas, which are characterized by high solar radiation and scarce water resources often stored in aquifers. In southern Spain, the development of thermo-solar power plants has already resulted in a transfer (and a concentration) of groundwater rights from agriculture to the energy sector, generating new groundwater management problems (Berbel, personal communication 2013).

Other issues may also occur with the development of low enthalpy geothermal energy, which uses large quantities of groundwater without recycling (open system). Where such open systems dominate, a competition for the groundwater resource could arise in the near future, between the low geothermal energy and drinking and agricultural water supply.

\subsection{Policies for the IGM-Scape}

The first order interactions between groundwater and society listed above (infrastructures, land use changes, or water energy nexus) have second order interactions when we include the impacts of one of them on another one. As such, their impacts on groundwater could be alleviated or magnified whenever they occur simultaneously, providing a strong impetus for an efficient governance setting for IGM and pathways across the IGM-scape of Fig. 3.1.

\subsubsection{Policy Levers to Promote Sustainable Groundwater Management}

Policy levers (as discussed in Parts II and IV) can be intentionally focused on the components (Sect. 5.1.1) or on fluxes (Sect. 5.1.2) of the IGM-scape as described on Fig. 3.1. The component versus flux distinction holds only at the level of intention of policy levers. Consequences of their activation disseminate all along pathways of the IGM-scape.

\subsubsection{Policies Tackling Components of the IGM-Scape}

Due to the connections across the IGM-scape, policies to promote sustainable groundwater management can either try to tackle head-on the isolated groundwater component of an aquifer system, or focus on a combination of components present in its IGM-scape. The hidden nature of the groundwater resource (Chap. 1) makes it difficult to effectively address directly; a focus on multiple components will likely be more effective.

Land use is a component that is highly suitable as a policy target. Therefore, controlling land use change is a key lever for ensuring sustainable management of 
groundwater as a matter of quantity as well as quality. In current practice, these levers can include:

- Innovative practices that favor recharge,

- Rules on urbanization that reduce impermeability of surfaces,

- Incentives to maintain agriculture instead of other urban land uses.

In the Perth region, for example, recognition of the impact of pine plantations on the groundwater levels led to a decision to progressively phase out the plantations on the Gnangara Mound by around 2030 (MacFarlane et al. 2010).

Fields and farming practices constitute a specific land use that can be more specifically controlled, first for improving groundwater quality and second for reducing the quantity of water withdrawn:

- Rules on agriculture practices can limit the use of potential pollutants, especially in domestic water supply catchment areas,

- Rules and economic incentives for crops with lower water demand can reduce abstraction.

These actions are targeted to farmers leading them to practices on their land suitable for larger aquifer system sustainability. Similar actions exist for urban uses, such as rules regarding digging private wells or economic incentives to implement low impact development techniques such as garden roofs. Inter-basin transfer of surface water is a similar lever, often with a direct impact on recharge due to leakage and infiltration occurring in canals, but also alleviation of needs in the area receiving water transfer.

\subsubsection{Policies Tackling Fluxes in the IGM-scape}

More direct policies can tackle fluxes in the IGM-scape, with emphasis on fluxes that end up in the aquifer. Artificial recharge is a policy lever that increases the flow capacity from surface to ground water. Still on the quantity side, one of the most common policies in water management deals with maximum abstraction flow controls. Typically the primary focus is on water scarcity and irrigation, where policy is designed to control abstraction with acceptable impacts on groundwater levels. With such a focus, levers can include simple actions such as equipping farmers with flow measuring devices.

On the quality aspects of fluxes in the IGM-scape, several means exist to mitigate poor water quality such as from pesticide pollution in a drained basin. In such settings, efforts focus on capturing pesticide before introduction into the groundwater system. These efforts might include focusing on enhancing ecosystem services provided by soil and vegetation. In practice several types of these levers exist, such as ditch networks and artificial wetlands (Stehle et al. 2011; Tournebize et al. 2012). The principle is either to treat the flux directly, or to divert it into parts of the ecosystem that can mitigate aspects of poor water quality. 


\subsubsection{Pathways Opened Up by These Policy Levers ... and Others}

The existence of externalities is a rule more than an exception, as far as water is concerned (Howe 2002). We generalize the concept of externality to any type of unintended side effect, beyond the targeted economic domain. However, water availability and quality are also affected by externalities generated by actions with no direct intervention on water flows as well. Decisions regarding land use change, for example, have feedback loops that augment and mitigate the source of externalities coming from groundwater management choices, while others are rooted elsewhere.

Whether driven by groundwater concerns or not, the groundwater-dependent social-ecological system changes are constrained along the pathways partly explained in the IGM-scape, due to such feedback and cascade effects, where each step includes uncertainty. Therefore, uncertainty issues are important to consider along with the feedback and cascade effects (see Chap. 28 for coverage of uncertainty).

\subsubsection{Policies with Indirect Effect on Groundwater}

Most components of an "IGM-scape" are typically responding to actions of other non-groundwater focused policies. Policies affecting land uses are one easily seen example because they modify water needs, water direct abstraction, infiltration rates and the capture of solutes. Urban development policies are also typically driven by concerns outside of the realm of water management policies. Even when urban development is supposed to be consistent with water management regulations, local policy makers find ways to get around the rules (Barone 2012).

Affected parties may mitigate sources of adverse externalities. Mitigation may not only be directed at water flows, or even affected parties downstream. Yet, many of these mitigation actions modify flows indirectly. For example, in France groundwater used by a private company to produce highly valued mineral water was being negatively impacted by nearby nonpoint source pollution associated with farming. As a consequence, the private company offered funds to farmers if they followed specific cropping patterns with less impact on the water quality (Deffontaines et al. 2000). Dealing with externalities is often in conjunction with payments for ecosystem services, such as flood protection of cropping areas through compensation to cover losses (Erdlenbruch et al. 2009).

Yet, changes to the system driven by externalities, like many groundwater changes, are often masked by long time lags between the change and the expression of their consequences. Moreover, in some cases changes resulting from externalities may occur with little consideration regarding water. For example, switching from one crop type to another at a farm level is typically an economic decision. Yet, competing societal use of water can drive IGM decision making. For example, surface water may be progressively reserved for uses other than irrigation as human populations increase (Gemma and Tsur 2007). 


\subsubsection{Uncertainties in Groundwater-Related Social-Ecological Systems Dynamics}

The previous discussion implicitly includes uncertainties (see Chap. 28), one of the salient dimensions of integrated assessment and modelling (Chap. 1). Beyond long term uncertainties, such as on climate change, IGM must handle uncertainties such as knowledge gaps, stochastic processes and external choices.

Henriksen et al. (2011) and Chap. 28 provide a good overview of sources of uncertainties associated with groundwater management. Implementation of managed aquifer recharge involves groundwater managers to make use of assumptions or imperfect representations of important processes, such as transfer of fluxes between surface water and groundwater. Socio-economic processes are also uncertain, since behavioral patterns of water users are never fully determined by their conditions of action as set by their social, economic and ecological environment. Managers have to monitor these uses and to constantly adapt and learn.

Several stochastic processes are also important. Rain and evaporation, as sources and sinks, constitute two easy to appreciate examples, but other forces like market prices also commonly possess a stochastic nature over various timescales. In general, stochastic processes can be associated with probabilities, which in turn can be used to assess the IGM-scape. Finally, external drivers to IGM like climate and international trade prices, present additional uncertainty as they involve choices beyond that of the domain of groundwater management. These influences have their own determinants and sources of uncertainties that may not be readily apparent to groundwater managers. In summary, the presence of such wide ranging sources of uncertainty underscores the need for adaptive understanding and flexibility for moving within the IGM-scape.

\subsubsection{The Governance Challenge Extended}

Throughout our discussion, several institutional factors can be seen as pushing the groundwater related social-ecological system along one pathway or another. Selection of policy levers as well as the complexity of the social-ecological system challenge governance frameworks. We consider that these challenges are of two types:

- a legitimacy challenge in order to involve the suitable people within the arena of IGM, i.e. those who are entitled to act on the components and fluxes all along the pathways of IGM-scape;

- a policy challenge that results in getting politically powerful groups to prioritize IGM issues.

\subsubsection{The Legitimacy Challenge}

Typically, government agencies remain the main regulator over land use, and often have the authority to limit possibilities of actions on water flows that would generate consequences unsuitable with the rights of others. However, the possibility 
of implementing effective controls depends on institutional authority and standing (see the chapters in the governance section). And, in practice, financial costs, land and water rights, transaction costs among the multiple stakeholders, can facilitate or impede actions implemented by policy makers (Blomquist et al. 2001). Availability of an appropriate knowledge base and suitable technologies is also a factor in implementing change.

Water rights are typically not straightforward, especially for hard to characterize aspects such as how ownership of land translates into ownership of terrestrial recharge and how competing uses of recharged water are prioritized (see Chap. 9). Institutions also commonly seek to establish benchmarks to assess use and its effects on recognized rights. Unfortunately, there is no widely accepted way to uniquely determine such benchmarks; rather, they typically result from sitespecific historical precedent, economic drivers, perceptions of suitability for local land use policy, etc.

Setting water and non-water priorities can become a primary governance challenge. In many cases, the drivers come from outside formal governance entities, such as when a company sets its price for surface water delivery: it frames the choice of the farmer in using one or the other source, as an economic choice. Doing so, the company produces a major driver on groundwater use, but may not be part of the arena where groundwater management is discussed (Lenouvel and Montginoul 2010). In some cases the drivers are appreciably different. For example, land and water resources can be separated by law; hence, forestry companies are entitled to develop their land, but the impact on groundwater recharge and level can create conflicts with a farming sector also entitled to develop their land (Gillet et al. 2014). At the extreme, stakeholders involved in arenas with major impacts may neither be interested nor have legitimacy to regulate or act on groundwater, such as the case of interaction among various policy sectors (e.g., energy and agriculture). Tradeoffs are required, however appropriate criteria and frameworks for evaluating the tradeoff may be difficult to construct and legitimize.

\subsubsection{Promoting Water at Policy Level}

Even if technical and legal challenges are met, there is a need for policy support by the regulated public so that groundwater is prioritized appropriately with respect to other policy issues. However, interest in the policy may not be automatic, and other entities that are already prioritized highly may not be keen to enter a competing realm involving IGM policies. In practice, hidden benefits of appropriate groundwater management commonly become subordinate to other more visible benefits from land development, even when the law puts water first. Yet, when evaluated, even though it is hidden, groundwater conservation often appears as a first priority among respondents (Razès et al. 2013). 


\subsection{Conclusions}

Aquifers are embedded in larger social-ecological systems whose components generate various multiple feedbacks impacting the state of the aquifer. All these components and their relations constitute an "IGM-scape", featuring potential pathways of evolution for groundwater as well as the social ecological systems in which it is embedded. An IGM-scape is based partly on physical components and fluxes. It increases the accuracy of the assessment of water flows and hence of water availability in the aquifer in pointing out the suitable levers to regulate it. In its most encompassing form, the IGM-scape extends this approach beyond physical processes, opening it up to institutional issues and interdisciplinary drivers. As a consequence, IGM must take into account non-water components in the system, including land, ecosystems, and economic drivers. Such holistic views of the IGM-scape facilitate the application of suitable levers for groundwater management.

Effective management of the IGM-scape requires, at a minimum, joint management of surface and groundwater at suitable scales. Management concerns and scale are temporal as well as spatial. If groundwater storage is a stated benefit of the IGM-scape, intervention to preserve surface water from being "lost" to groundwater reduces possible future uses and can affect larger areas when the aquifer at stake is transgressing boundaries, whether jurisdictional or attached to a river basin. Transfers across these boundaries need an IGM-scape approach to governance and explicit negotiation. Timing and lags between changes in land uses, water uses, and regulations may not be consistent. As such, effective management of the IGM-scape must recognize potentially irreversible consequences or important hysteresis effects, such as changes in soil structure, economies of scale with regard to costs of infrastructures, and important tipping points and thresholds that exist such as in the case of pollution of an aquifer. Although disconnection of water policies from other public policies has long been pointed out as a major issue for water governance, explicit recognition of the ties and pathways that characterize the IGM-scape is a first step towards effective integrated governance, so that inclusion of all important stakeholders in IGM arenas is possible.

Open Access This chapter is distributed under the terms of the Creative Commons AttributionNoncommercial 2.5 License (http://creativecommons.org/licenses/by-nc/2.5/) which permits any noncommercial use, distribution, and reproduction in any medium, provided the original author(s) and source are credited.

The images or other third party material in this chapter are included in the work's Creative Commons license, unless indicated otherwise in the credit line; if such material is not included in the work's Creative Commons license and the respective action is not permitted by statutory regulation, users will need to obtain permission from the license holder to duplicate, adapt or reproduce the material. 


\section{References}

Allen DM, Mackie DC, Wei M (2003) Groundwater and climate change: a sensitivity analysis for the Grand Forks aquifer, southern British Columbia. Can Hydrogeol J 12(3):270-290

Anderson MP, Woessner WW, Hunt RJ (2015) Applied groundwater modeling: simulation of flow and advective transports, 2nd edn. Elsevier, Amsterdam

Andreo B, Vías J, Durán JJ, Jiménez P, López-Geta JA, Carrasco F (2008) Methodology for groundwater recharge assessment in carbonate aquifers: application to pilot sites in southern Spain. Hydrogeol J 16:911-925

Barone S (2012) SCoT est-il plus SAGE ? Vertigo 12(2). http://vertigo.revues.org/12460

Barron OV, Barr AD, Donn MJ (2013) Effect of urbanisation on the water balance of a catchment with shallow groundwater. J Hydrol 485:162-176

Bates B, Hope P, Ryan B, Smith I, Charles S (2008) Key findings from the Indian ocean climate initiative and their impact on policy development in Australia. Clim Change 89:339-354

Bazargan-Lari MR, Kerachian R, Mansoori A (2009) A conflict-resolution model for the conjunctive use of surface and groundwater resources that considers water-quality issues: a case study. Environ Manage 43:70-482

Blomquist W, Heikkila T, Schlager E (2001) Institutions and conjunctive water management among three western states. Nat Resour J 41:653-684

Bouchaou L, Michelot JL, Vengosh A, Hsissou Y, Qurtobi M, Gaye CB, Bullen TD, Zuppi GM (2008) Application of multiple isotopic and geochemical tracers for investigation of recharge, salinisation, and residence time of water in the Souss-Massa aquifer, southwest Morocco. J Hydrol 352:267-287

Bradley DC, Streetly M, Farren E, Cadman D, Banham A (2014) Establishing hydroecological relationships to manage the impacts of groundwater abstraction. Water Environ J 28:114-123

Cho J, Barone VA, Mostaghimi S (2009) Simulation of land use impacts on groundwater levels and streamflow in a Virginia watershed. Agric Water Manag 96:1-11

Conrad J, Nel J, Wentzel J (2004) The challenges and implications of assessing groundwater recharge: a case study - northern Sandveld, Western Cape, South Africa. Water SA 30(5): $75-81$

Dams J, Woldeamlak ST, Batelaan O (2008) Predicting land-use change and its impact on the groundwater system of the Kleine Nete catchment Belgium. Hydrol Earth Syst Sci 12: $1369-1385$

De Vries JJ, Simmers I (2002) Groundwater recharge: an overview of processes and challenges. Hydrogeol J 10:5-17

Deffontaines J-P, Brossier J, Barbier M, Benoît M, Chia E, Fiorelli JL, Gafsi M, Gras F, Lemery H, Roux M (2000) Water quality, agricultural practices and changes in farming and agrarian systems. In: Collinson MP (ed) A history of farming systems research. CABI Publishing, New York, pp 382-390

Dingman L (2002) Physical hydrology, 2nd edn. Waveland Press, Long Grove. ISBN:978-157766-561-8

Domenico PA, Schwartz FW (1990) Physical and chemical hydrogeology. Wiley, New York, p 824

Erdlenbruch K, Thoyer S, Grelot F, Kast R, Enjolras G (2009) Risk-sharing policies in the context of the French food prevention action programmes. J Environ Manage 91:363-369

Flint AL, Flint LE, Kwicklis EM, Fabryka-Martin JT, Bodvarsson GS (2002) Estimating recharge at Yucca Mountain, Nevada, USA: comparison of methods. Hydrogeol J 10:180-204

Folke C, Hahn T, Olsson P, Norberg J (2005) Adaptive governance of social-ecological systems. Annu Rev Environ Resour 30:441-473

Froend R, Sommer B (2010) Phreatophytic vegetation response to climatic and abstractioninduced groundwater drawdown: examples of long-term spatial and temporal variability in community response. Ecol Eng 36:1191-1200 
Fthenakis V, Kim HC (2010) Life-cycle uses of water in U.S. electricity generation. Renew Sustain Energy Rev 14:2039-2048

Gandy CJ, Smith JWN, Jarvis AP (2007) Attenuation of mining-derived pollutants in the hyporheic zone: a review. Sci Total Environ 373(2-3):435-446. doi:10.1016/j.scitotenv. 2006.11.004

Gasca D, Ross D (2009) The use of wetland water balances to link hydrogeological processes to ecological effects. Hydrogeol J 17:115-133. doi:10.1007/s10040-008-0407-x

Gee GW, Wierenga PJ, Andraski BJ, Young MH, Fayer MJ, Rockhold ML (1994) Variations in water balance and recharge potential at three western desert sites. Soil Sci Soc Am J 58(1): $63-72$

Gemma M, Tsur Y (2007) The stabilization value of groundwater and conjunctive water management under uncertainty. Rev Agric Econ 29:540-548

Gilfedder M, Rassam DW, Stenson MP, Jolly ID, Walker GR, Littleboy M (2012) Incorporating land-use changes and surface groundwater interactions in a simple catchment water yield model. Environ Model Software 38:62-73

Gillet V, McKay J, Keremane G (2014) Moving from local to state water governance to resolve a local conflict between irrigated agriculture and commercial forestry in South Australia. J Hydrol 519(C):2456-2467

Gustard A, Demuth S (2009) Manual on low flow estimation and prediction, Operational hydrology report no 50, WMO No 1029. World Meteorological Organization, Geneva

Hanak E, Stryjewski E (2012) California's water market, by the numbers: update 2012. PPIC Press/Public Policy Institute of California, San Francisco

Healy RW (2010) Estimating groundwater recharge. Cambridge University Press, Cambridge, 245

Henriksen HJ, Zorilla-Miras P, de la Hera A, Brugnach M (2011) Use of Bayesian belief networks for dealing with ambiguity in integrated groundwater management. Integr Environ Assess Manag 8:430-444

Heppner CS, Nimmo JR, Folmar GJ, Gburek WJ, Risser DW (2007) Multiple methods investigation of recharge at a humid-region fractured rock site, Pennsylvania, USA. Hydrogeol J 15(5): 915-927

Hiscock KM, Grischek T (2002) Attenuation of groundwater pollution by bank filtration. J Hydrol 266:139-144

Howe CW (2002) Policy issues and institutional impediments in the management of groundwater. Environ Dev Econ 7:625-641

Hunt RJ, Borchardt MA, Richards KD, Spencer SK (2010) Assessment of sewer source contamination of drinking water wells using tracers and human enteric viruses. Environ Sci Technol 44(20):7956-7963. doi:10.1021/es100698m

Hussey K, Kay E (2015) The opportunities and challenges of implementing water sensitive urban design: lessons from stormwater management in Victoria, Australia. In: Grafton Q, Chan N, Daniell K, Nauge C, Rinaudo J.-D (eds) Understanding and managing urban water in transition. Springer, Dordrecht (in press)

Janssen M, Bodin O, Anderies JM, Elmqvist T, Ernstson H, McAllister RRJ, Olsson P, Ryan P (2006) Toward a network perspective of the study of resilience in social-ecological systems. Ecol Soc 11:15

Kessler H (1967) Water balance investigations in the karstic regions of Hungary. Hungarian Research Institute, Paris, pp 91-105

Kollet SJ, Zlotnik VA (2003) Stream depletion predictions using pumping test data from a heterogeneous stream-aquifer system (a case study from the Great Plains, USA). J Hydrol 281(1-2):96-114

Kruseman GP, de Ridder NA (1994) Analysis and evaluation of pumping test data. ILRI Publication 47, Wageningen

Lawrence AR, Morris BL, Foster SSD (1998) Hazards induced by groundwater recharge under rapid urbanization. Geol Soc Lond Eng Geol Spec Publ 15:319-328 
Lenouvel V, Montginoul M (2010) Groundwater management instruments in a conjunctive use system: assessing the impact on farmers' income using a Mixed Integer Linear Programming (MILP). Ger J Agric Econ 59:158-172

Llamas MR, Martinez-Santos P (2005) Intensive groundwater use: silent revolution and potential source of social conflicts. J Water Resour Plan Manag 131(5):337-341

Mailhol J-C, Merot A (2008) SPFC: a tool to improve water management and hay production in the Crau region. Irrig Sci 26:289-302

Mardhel V, Frantar P, Uhan J, Andjelov M (2004) Index of development and persistence of the river networks (IDPR) as a component of regional groundwater vulnerability assessment in Slovenia. In: Proceedings on the international conference on groundwater vulnerability assessment and mapping, Ustron, 15-18 June 2004

Marei A, Khayat S, Weise S, Ghannam S, Sbaih M, Geyer S (2010) Estimating groundwater recharge using the chloride mass-balance method in the West Bank, Palestine. Hydrol Sci J 55(5):780-791. http://dx.doi.org/10.1080/02626667.2010.491987

McFarlane D, Strawbridge M, Stone R, Paton A (2010) Managing groundwater levels in the face of uncertainty and change: a case study from Gnangara. Water Sci Technol 12(3):321-328

Mérot A, Bergez J-E, Capillon A, Wery J (2008) Analysing farming practices to develop a numerical, operational model of farmers' decision-making processes: an irrigated hay cropping system in France. Agr Syst 98:108-118

Mills D (2004) Advances in solar thermal electricity technology. Sol Energy 76:19-31

Montginoul M, Rinaudo J-D (2011) Controlling households' drilling fever in France: an economic modeling approach. Ecol Econ 71:140-150

Olsson P, Gunderson LH, Carpenter SR, Ryan P, Lebel L, Folke C, Holling CS (2006) Shooting the rapids: navigating transitions to adaptive governance of social-ecological systems. Ecol Soc 11:18

Pedretti D, Barahona-Palomo M, Bolster D, Fernàndez-Garcia D, Sanchez-Vila X, Tartakovsky DM (2012) Probabilistic analysis of maintenance and operation of artificial recharge ponds. Adv Water Resour 36:23-35

Petrone KC, Hughes JD, van Niel TG, Silberstein RP (2010) Streamflow decline in southwestern Australia, 1950-2008. Geophys Res Lett 37:L11401

Poulsen SE, Rasmussen KR, Christensen NB, Christensen S (2010) Evaluating the salinity distribution of a shallow coastal aquifer by vertical multielectrode profiling (Denmark). Hydrogeol J 18:161-171

Priyantha Ranjan S, Kazama S, Sawamoto M (2006) Effects of climate and land use changes on groundwater resources in coastal aquifers. J Environ Manage 80:25-35

Razès M, Barone S, Richard-Ferroudji A, Guerin-Schneider L (2013) Enquête sur les « élus de l'eau » des bassins Rhône-Méditerranée et Corse. Agence de l'eau Rhône Méditerranée et Corse

Rinaudo J-D, Montginoul M, Desprats JF (2015) The development of private bore-wells as independent water supplies: challenges for water utilities in France and Australia. In: Grafton Q, Chan N, Daniell K, Nauge C, Rinaudo J-D (eds) Understanding and managing urban water in transition. Springer, Dordrecht (in press)

Saayman IC, Adams S (2002) The use of garden boreholes in Cape Town, South Africa: lessons learnt from Perth, Western Australia. Phys Chem Earth A/B/C 27:961-967

Sahu P, Michael HA, Voss CI, Sikdar PK (2013) Impacts on groundwater recharge in areas of megacity pumping: analysis of potential contamination of Kolkata, India, water supply. Hydrol Sci J 58:1340-1360

Scanlon RB, Healy RW, Cook PG (2002) Choosing appropriate techniques for quantifying groundwater recharge. Hydrogeol J 10:18-39

Scibek J, Allen DM, Cannon AJ, Whitfield PH (2007) Groundwater-surface water interaction under scenarios of climate change using a high-resolution transient groundwater model. J Hydrol 333(2-4):165-181

Scott CA, Shah T (2004) Groundwater overdraft reduction through agricultural energy policy: insights from India and Mexico. Int J Water Resour Dev 20:149-164 
Seneviratne SI, Lehner I, Gurtz J, Teuling AJ, Lang H, Moser U, Grebner D, Menzel L, Schroff K, Vitvar T, Zappa M (2012) Swiss prealpine Rietholzbach research catchment and lysimeter: 32 year time series and 2003 drought event. Water Resour Res 48(6): W06526

Shah T (2014) Towards a managed aquifer recharge strategy for Gujarat India: an economist's dialogue with hydro-geologists. J Hydrol 518:94-107. doi:10.1016/j.jhydrol.2013.12.022

Shah T, Bhatt S, Shah RK, Talati J (2008) Groundwater governance through electricity supply management: Assessing an innovative intervention in Gujarat, western India. Agric Water Manag 95:1233-1242

Shalev E, Lazar A, Wollman S, Kington S, Yechieli Y, Gvirtzman H (2009) Biased monitoring of fresh water-salt water mixing zone in coastal aquifers. Ground Water 47:49-56

Sommer B, Horwitz P (2009) Macroinvertebrate cycles of decline and recovery in Swan Coastal Plain (Western Australia) wetlands affected by drought-induced acidification. Hydrobiologia 624:191-203

Sophocleous M (2002) Interactions between groundwater and surface water: the state of the science. Hydrogeol J 10:52-67

Stehle S, Elsaesser D, Gregoire C, Imfeld G, Niehaus E, Passeport E, Payraudeau S, Schafer RB, Tournebize J, Schulz R (2011) Pesticide risk mitigation by vegetated treatment systems: a meta-analysis. J Environ Qual 40:1068-1080

Steuer JJ, Hunt RJ (2001) Use of a watershed-modeling approach to assess hydrologic effects of urbanization, North fork pheasant branch basin near Middleton, Wisconsin. U.S. Geological Survey Water-Resources Investigations Report 01-4113, p 49. http://pubs.er.usgs.gov/publication/ wri014113

Terzić J, Šumanovac F, Buljana R (2007) An assessment of hydrogeological parameters on the karstic island of Dugi Otok, Croatia. J Hydrol 343(1-2):29-42

Thornthwaite CW (1948) An approach toward a rational classification of climate. Geogr Rev 38: $55-94$

Tournebize J, Gramaglia C, Birmant F, Bouarfa S, Chaumont C, Vincent B (2012) Co-design of constructed wetlands to mitigate pesticide pollution in a drained catch-basin: a solution to improve groundwater quality. Irrig Drain 61:75-86

Tsur Y (1990) The stabilization role of groundwater when surface water supplies are uncertain: the implications for groundwater development. Water Resour Res 26:811-818

Tsur Y, Graham-Tomasi T (1991) The buffer value of groundwater with stochastic surface water supplies. J Environ Econ Manag 21:201-224

Vrba J, Verhagen B (2011) Groundwater for emergency situations. IHP - VII series on groundwater. UNESCO - International Hydrological Programme, Paris

Webb RH, Leake SA (2006) Ground-water surface-water interactions and long-term change in riverine riparian vegetation in the southwestern United States. J Hydrol 320:302-323

Werner AD, Bakker M, Post VEA, Vandenbohede A, Lu C, Ataie-Ashtiani B, Simmons CT, Barry DA (2013) Seawater intrusion processes, investigation and management: recent advances and future challenges. Adv Water Resour 51:3-26

Westenbroek SM, Doherty JE, Walker JF, Kelson VA, Hunt RJ, Cera TB (2012) Approaches in highly parameterized inversion: TSPROC, a general time-series processor to assist in model calibration and result summarization. U.S. Geological Survey Techniques and Methods Report, Book 7, Section C, Chapter 7, 73 p. http://pubs.usgs.gov/tm/tm7c7/

Wong T (2006) Water sensitive urban design - the journey thus far Australian. J Water Res 10: 213-222

Yesertener C (2008) Assessment of the declining groundwater levels in the Gnangara groundwater mound. Report for the Department of Water, Western Australia. Hydrogeological Record Series HG14 


\title{
Groundwater Management Under Global Change: Sustaining Biodiversity, Energy and Food Supplies
}

\author{
Jamie Pittock, Karen Hussey, and Andrew Stone
}

\begin{abstract}
This chapter grapples with the challenge of simultaneously sustaining biodiversity, energy and food supplies in conjunction with efforts to mitigate and adapt to climate change. Managing groundwater supplies sustainably is critical to that challenge, and the chapter assesses the positive synergies and perverse impacts for sustaining groundwater resources from both climate change mitigation and adaptation policies. The chapter finds that the pressures on groundwater resources will likely increase in the future, with the location, scale and magnitude of groundwater use shifting in response to other pressures. For example, changing energy policies are resulting in rapid deployment of thirsty technologies. Similarly, climate change adaption will increasingly rely on the water storage capacity of aquifers, yet many adaptation measures may also increase groundwater use. For better groundwater management under global change pressures we recommend a focus on complementary measures to: integrate information, deploy appropriate new technologies, apply market-based incentives and improve cross-sectoral governance. The key challenge for proponents of sustaining groundwater resources is to engage stakeholders and decisionmakers outside the water sector in governance institutions.
\end{abstract}

J. Pittock $(\square) \cdot$ K. Hussey

Fenner School of Environment and Society, The Australian National University, Canberra, Australia

e-mail: Jamie.pittock@anu.edu.au

A. Stone

American Ground Water Trust, Concord, USA

(C) The Author(s) 2016

A.J. Jakeman et al. (eds.), Integrated Groundwater Management,

DOI 10.1007/978-3-319-23576-9_4 


\subsection{Introduction}

Increased demand for freshwater wrought by an increasing population, wealth and consumption of thirstier products will be exacerbated by climate change. While the direct impacts of climate change on groundwater recharge is uncertain, it is certain that climate change mitigation and adaptation policies will change. In some cases, shifts in policy will exacerbate the challenges associated with groundwater use and management. This chapter extends the detailed technical and governance information on groundwater in the following chapters (see especially Part II) to consider the implications of these significant and urgent global changes for the management of groundwater, and to suggest approaches to sustaining biodiversity while maintaining energy and food supplies under a changing climate.

In the next section, the little-appreciated synergies between climate mitigation policies and groundwater resources are explored. Energy demand management measures have positive synergies in reducing consumption of water, but the impacts of new energy technologies on groundwater are mixed: some increase and others decrease water consumption, the location of water use will change, and governments are being challenged to adequately regulate the rapid uptake of these new industries. Carbon sequestration in the landscape will have neutral impacts at best, but is more likely to have negative impacts on groundwater resources. In particular, the beguiling political appeal of tree planting and soil carbon heightens the risk that perverse impacts on groundwater will be poorly managed. Similarly, groundwater plays a significant role in climate change adaptation for water supply, food production and biodiversity conservation, due in part to the longer-term processes of recharge and storage that buffers aquifers from the short-term climatic and surface hydrology variability. These roles require more active and sustainable management of aquifers than has been achieved to date around the world.

The final section of this chapter considers options for meeting the challenge of more effectively managing groundwater to offset negative impacts of these global changes. The magnitude and location of tensions between groundwater, food and energy vary considerably from country to country and aquifer to aquifer. The drivers of groundwater depletion and demand for use vary at the local, regional and global scales. Thus, analysis of future impacts and associated solutions is complex and a range of disciplines is needed to understand how to manage the inter-linkages between the numerous drivers of groundwater use, from technology assessment through to the international political economy. It is with this multidisciplinary framing that we begin to step through issues and options for managing groundwater more sustainably in a growing world and under a changing climate. 


\subsection{Implications of Climate Change for Groundwater}

\subsubsection{Direct Impacts from Climate Change}

Modified weather patterns resulting from global climate change will affect rates of groundwater recharge differently in different parts of the world as outlined in Chap. 5. Precipitation will likely change in intensity, duration and frequency. In many areas, groundwater recharge may increase, as a result of increased precipitation totals, from more frequent large floods, or as a result of melting of permafrost (IPCC 2007a). In other regions, reduced precipitation and higher evapotranspiration are likely to decrease aquifer recharge. A number of these counter-veiling factors may occur in the same region making the outcome uncertain. For example, in the Murray-Darling Basin in south eastern Australia, while surface water availability may decline, under a changing climate, the infrequent but large floods may significantly contribute to aquifer recharge (CSIRO 2008; Hirabayashi et al. 2013).

Changes in vegetation land cover affecting runoff and recharge will occur due to climatic change and will exacerbate human impacts such as deforestation. Shifting of traditional climate and vegetation zones will result in alterations in the species composition of forests, rising snow lines, and more frequent wildfires. The latter may impact flood frequency and intensity, erosion, and dam siltation. The resultant effects on groundwater recharge will in turn affect rates and volumes of groundwater discharge to springs, stream base-flow and the availability of groundwater for pumping (Bates et al. 2008). The challenge for groundwater managers is to develop strategies that account for uncertainty, in a manner that can provide satisfactory outcomes for water use under a range of climate conditions (WWDR 2012). Example strategies range from conservative allocation limits to the use of threshold or contingency policies that trigger alternative management arrangements according to water availability conditions, and augmentation of storage through managed aquifer recharge (Chaps. 17 and 18).

In addition to the need for robust management that accounts for uncertainty, questions arise as to how climate change mitigation policies may avoid unsustainable impacts on groundwater, or how they may even benefit the resource.

\subsubsection{Climate Change Mitigation Policies}

Climate change mitigation policies typically fall into three categories: demand side, supply side and sequestration or storage focused strategies (IPCC 2007b). Demand side policies aim to reduce energy consumption and thus emissions of greenhouse gasses. Supply side policies shift the generation of energy away from fossil fuels to low-carbon sources. Sequestration approaches encourage the use of natural storage of greenhouse gasses in the landscape. Reducing greenhouse gas concentrations in the atmosphere to achieve an oft-expressed desire to limit global warming below $2{ }^{\circ} \mathrm{C}$ will require all of these approaches (Rogelj et al. 2013), and they all have implications for groundwater storage inventories. However, the groundwater 
consumption and storage implications of different mitigation measures vary considerably. Wallis et al. (2014) reviewed the water use implications of 74 mitigation measures for Australia and found that positive synergies existed between conserving energy and conserving water in a variety of demand management interventions. However, they also found that neutral and negative outcomes for water consumption are evident for a range of emerging low-emission energy technologies, and similarly, that very negative consequences could be expected from carbon sequestration measures. These findings are elaborated on below, specifically in relation to groundwater.

\subsubsection{New and Emerging Energy Technologies}

The quest for low-emission energy sources is driving rapid policy change as regulations, carbon pricing and technological innovation combine to favour rapid deployment of more modern energy technologies. The focus on reducing greenhouse gas emissions has meant that the impacts on water resources have received very little attention. Booming industries, such as biofuels in the United States (US) and unconventional gas production globally, have developed in advance of efforts by government regulators to require application of better practices, including sustaining groundwater resources (Hussey and Pittock 2012). In Australia, new financial incentives for low-emission energy sources have been adopted without fully considering how well carbon, energy and water markets are harmonised to avoid externalities (Pittock et al. 2013). To inform this analysis a number of cases with risks to groundwater from expansion of emerging energy technologies are considered, including biofuels, (hot-rock) geothermal, unconventional gas, solar thermal and ground-source heating and cooling systems.

\section{Biofuels}

First generation biofuels use crops that are frequently irrigated from groundwater like corn, sugar cane and beet to produce ethanol and oil palm and soy to generate biodiesel. Water consumption to grow these feed stocks means that these alternative fuels have water footprints several orders of magnitude higher than most conventional and renewable energy systems (Gerbens-Leenes et al. 2008). Yet, there has been a rapid expansion of these industries driven by subsidies and renewable fuel quotas in jurisdictions including Australia, Brazil, the European Union and the US (Pittock 2011).

There are reports that up to 281 of irrigation water are needed to produce enough soybeans to propel an average vehicle $1 \mathrm{~km}$. In comparison, water needs for gasoline (petrol) are merely $0.33 \mathrm{l}$ of water for each vehicle $1 \mathrm{~km}$ (King and Webber 2008). As is true for the agricultural sector generally, limiting the impacts on groundwater resource use by biofuels requires good governance, including allocation systems that cap extraction at sustainable levels and maximise social and economic benefits from the water consumed. However, the political power of biofuel industries in some countries may compel policies that encourage non-sustainable use and allocation (Notaras 2011). For example, the 2007 Energy Independence and Security Act in the US mandates an increase in annual biofuels 
production, requiring an additional 56.8 billion litres of ethanol by 2015 and an additional 60.6 billion litres of biofuels from cellulosic crops by 2022 (DominguezFaus et al. 2009). These mandated increases will likely increase the demand for groundwater resources, potentially pitting biofuel production against other irrigated agriculture, including food production. In the absence of appropriate governance arrangements to allocate water resources efficiently between uses, this increased competition could have deleterious effects on both the water supply base and commodity prices.

Simultaneously a number of transitions in less developed countries are beginning to revolve around biofuel related opportunities. Many producers are securing land and water resources in developing countries for production of crops, including for export of biofuels (Vermeulen and Cotula 2010; Zoomers 2010). In Africa, for example, agricultural proponents are pointing to little exploited groundwater resources as a major opportunity to expand production (MacDonald et al. 2012). To avoid the depletion of aquifers that has taken place in developed economies, groundwater governance will need to be strengthened in developing countries so as to manage these resources sustainably for both consumptive and non-consumptive purposes.

At the same time, there is a considerable global research effort into second generation biofuels from processing grass or timber cellulose (Sims et al. 2010) and third generation feedstock crops and techniques, which also raises interception questions for aquifer recharge. These 'wonder' crops, like jatropha, are untested. While these species may be able to grow on degraded lands and generate benefits for people in developing countries (Openshaw 2000), it is likely that widespread plantings would more effectively intercept precipitation and reduce aquifer recharge and surface runoff as land is cleared to establish the new crop (van Dijk and Keenan 2007). Proposals for third generation biofuels from farming microbes suggest that saline or wastewater may be used in these processes in the future (Yang et al. 2011), though commercial scale application has yet to be demonstrated. Each technological advance offers improvements in fuel production and may also meet other goals such as a reduction in GHG emissions, but biofuels are intrinsically linked with groundwater resources and can compete directly with agricultural food crops for water and land.

In essence, current commercial biofuel production consumes significant water, for crop production, processing and transport, and if production is increased then pressures to exploit aquifers globally will also increase. Biomass for fuel production where irrigation and crop chemicals are also used results in greater risks of aquifer contamination and hence a potential reduction of economically-usable groundwater. Given the complex and often uncertain knock-on consequences of biofuels, policy interventions which aim to increase biofuel production must account for these risks.

\section{Geothermal}

The generation of electricity from steam from underground aquifers where circulating groundwater is "boiled" by geological heat sources is a commercial 
energy technology and is sustainable in regions with substantial aquifer recharge, such as in Iceland and New Zealand. Geothermal energy proponents are now exploring ways of generating electricity from 'hot rock' sources, where aquifers are small or absent, by injecting water in one borehole to be heated through fractured strata, then extracted as steam up a parallel borehole to generate electricity. Geothermal generation may be sustainable in regions where there is plentiful water but in dry areas the source of water is uncertain. For example, much of the geothermal 'hot rock' resource in Australia is located in arid areas or in the wet-dry tropics where surface water resources are seasonal or absent (Goldstein et al. 2009).

Linking strata through boreholes and by fracking also raises the same questions (as for unconventional gas production) of managing potential risks of natural contaminants becoming incorporated in the production water and moving into previously constrained aquifers through fractures or borehole failures.

\section{Unconventional Gas}

Rising costs of petroleum on international markets, the political drive to achieve greater energy independence, and the development of directional drilling and hydraulic fracturing techniques have significantly improved the economics of natural gas as an energy source. Compared to conventional, free-flowing natural gas extraction, unconventional gas development involves production of methane from multiple types of geological strata where the deposits are dewatered and/or fractured (fracked) to enable withdrawal. This discussion will focus on the two most widespread resources, those in coal seams and those in shale (Cook et al. 2013).

Natural gas is a fossil fuel and governments around the world facilitate its exploitation for reasons of domestic energy security and to reduce greenhouse gas emissions. Scientists disagree on the extent to which unconventional gas production reduces greenhouse gas emissions owing to the risk of fugitive methane leaking from poorly maintained valves and connections in the surface storage and pipe-line infrastructure (Burnham et al. 2011). Nevertheless, in the best case scenario natural gas may reduce greenhouse gas emissions by around half compared to coal-fired generators (Burnham et al. 2011), thus receiving favourable treatment under carbon pricing schemes.

Coal seam, or coal bed, methane deposits are usually closer to the surface and production requires dewatering strata, resulting in the production of lower quality water. Shales with gas potential generally lie deeper in the earth, and gas development and most production methods currently used require the injection of large volumes of water. The directional drilling process and the subsequent hydraulic fracture of the shale target area involve the addition of various chemicals, compounds and proppants which are pumped under pressure to liberate natural gas from the rock formations. Contaminated flow-back water from hydraulic fracturing and 'produce water' (from the geological formations) over the lifetime of the gas well requires careful attention with respect to storage, treatment and disposal so as to avoid contamination risks to both surface and groundwater resources. 
Common concerns for aquifer management for coal seam, coal bed, and shale gas production identified by representatives from industry, researchers and regulators (Williams and Pittock 2012; Mauter et al. 2014), include potential for the creation of pathways for contaminant migration both at depth and from surface infrastructure, toxicity information for fracking chemicals, and to a lesser extent risks from induced seismicity. Fracking chemicals are used to develop and maintain boreholes and prop open the cracks in the strata to allow the gas to flow out. The toxicity of these chemicals is disputed, however many companies involved in the industry are supporting public disclosure laws and practices to demonstrate their confidence that the fluids will cause no harm. There are concerns that fracking may connect different rock strata and enable contaminated water and methane to migrate up into overlying freshwater aquifers, or even to the surface. The industry disputes this concern, saying that fracking is able to be limited to the target, gas producing coal seam or shale strata. However, industry and other stakeholder groups agree that inadequate borehole construction may enable methane and contaminated water to migrate into higher freshwater aquifer and to the surface.

There is a wealth of anecdotal accounts in the news media about the negative environmental impacts of shale-gas development. However, a common concern expressed by many groundwater specialists about gas production, is the lack of hard data and information in relation to migratory pathways. Knowledge and characterization about potential flow paths in the zone between the deep shale targets (usually 2-3 km beneath the surface) and the freshwater aquifer zones that may occur at depths up to $1 \mathrm{~km}$ is limited (Council of Canadian Academies 2014). At the same time, risks from gas related contamination appear to be low, to date very few instances of possible methane migration are documented in the US. Well blowouts (casing failure) are rare because industry standard operating practices require a test of vertical well casing integrity before proceeding with any hydraulic fracturing. Added to this is increased risk of earthquakes induced by the injection of fluids, which in turn compounds the risk of that injected fluid leaking into other aquifers, either during the production of gas or at some later date. However, while research undertaken in the US indicates that injection-via-disposal wells may cause tremors (National Research Council 2013), there is very little evidence hitherto of fault or fracture propagation resulting from hydraulic fracturing.

Industry and many researchers consider that the greatest risk to water resources from gas production is leaks from production water containment ponds and other spills on the surface, including accidents with fluid transport trucks on rural roads (Mauter et al. 2014; Williams and Pittock 2012). Once production water is at the surface it requires treatment, re-use or disposal. In the US, the reinjection of production waters into saline zones in deep geological formations is common practice but not all gas producing areas have the geologic conditions for disposal by injection, and there is increased environmental risk involved in transport to suitable areas. This raises questions as to the risk of polluting potentially beneficial aquifers in other locations. The practice of using closed or evaporative basins to treat production water, especially saline water, was abandoned in Texas as erosion often resulted in the breakdown of containment structures. 
This analysis exposes a number of risks to aquifers from unconventional gas production that each has a technical solution, but only if the industry is consistently well governed and adheres to the highest standards of practice. As a result of public and political concerns, and because of the economic costs related to water use and disposal, the US oil and gas industry is currently researching and field-testing many different on-site water treatment technologies. In addition, technologies that reuse water or actually use zero water for the hydraulic fracturing process are in development. However, until there is a rise in the market value of gas, many of the promising technologies are unlikely to achieve widespread implementation.

One concern that has not yet been well addressed in the development of the unconventional gas industry is the future of groundwater in depleted and abandoned gas fields. Aquifer depletion can be expected over long periods of time if associated with gas deposits, or fractured strata newly capable of holding water will recharge. What is unclear is how this will affect other water resources on basin scales, for example whether other surface and groundwater deposits may be depleted if they begin to fill the new, often deeper voids that are left behind.

\section{Solar Thermal}

Solar thermal power is an emerging technology that uses mirrors in large scale facilities to boil water and generate steam for electricity production. Currently deployed in California and Spain, these power stations work best when located in sunny, arid and semi-arid regions where water is naturally scarce. While the volumes of water required are modest compared with many other forms of energy technologies, sustainable groundwater availability may be a limiting factor for the location of these stations in deserts.

The world's largest solar thermal plant in the Mojave Desert near the border of California and Nevada is the 392-MW Ivanpah project. At the official opening in 2014, the US Energy secretary stated that the station's water needs for steam production "... will use roughly the same amount of water as two holes at the nearby golf course" (Phillips 2014). An additional water demand from the desert aquifers will be to regularly wash dust from the project's 347,000 mirrors.

As with all thermal power stations, there is the option of deploying dry rather than wet cooling technology. Dry cooling systems use less than $10 \%$ of the water of a wet cooling system but have several drawbacks, including a higher, upfront capital cost; reduction in energy generation of around $8 \%$; and less effective operation with higher air temperatures, such as the arid areas where these power stations are located (DoE 2008).

Ivanpah uses a directly heated steam cycle that can only generate power when the sun shines. In the future, large-scale solar plants will likely use an energy storage technology (such as the process that heats molten salt) so that energy can be stored and then 'released' whenever there is a load demand (Phillips 2014). Globally, large schemes have been proposed to power countries like Australia (BZE 2010) or whole regions such as northern Africa and Europe based on solar thermal power stations, though the economies of such ventures has yet to prove favourable. 
Production of hydrogen for use as a renewable fuel in fuel cells, from the electrolysis of water using solar generated electricity, is another possibility. If this hydrogen is combined with atmospheric nitrogen at high temperatures (which is possible in a solar thermal power station) to produce ammonia $\left(\mathrm{NH}_{3}\right)$ as a renewable energy fuel, it could regenerate the water, but some loss of water might be expected (Andrews and Shabani 2012; Balat 2008).

\section{Aquifer Thermal Energy Systems}

Aquifer thermal energy storage systems (ATES) are common in Europe and typically operate by running groundwater through a cooling tower in winter and returning it to the aquifer for storage. In summer, the chilled water is withdrawn, used for air conditioning and put back into the aquifer as warm water for use in winter to reduce heating costs. If closed loops are used to transfer heat the loop pipes are typically filled with food-grade glycol so that in the unlikely event of a leak, there is minimal risk to groundwater quality. Now, there is a growing trend in the US for using ground source heating and cooling technology for individual homes, schools, churches and office buildings. There are already over one million such installations in operation in the US. Ball State University in Muncie, Illinois has installed a ground source system involving 3,600 boreholes to service $622,450 \mathrm{~m}^{2}$ of building space which will save the burning of $36,000 \mathrm{t}$ of coal that was previously used each year (Roulo 2011).

When applied on a large scale for college campuses, military installations etc. this technology is providing a developing field for hydrogeologists to characterize subsurface heat transfer capabilities and to assess potential impacts on aquifers, particularly if the heat dissipation is dependent on groundwater flow. A concern is the potential build-up of groundwater temperatures which could progressively decrease heat transfer efficiency.

ATES technology and ground source heating and cooling raise a number of issues for future groundwater management. As with other technologies, their rapid increase in popularity since the 1990s has seen deployment in advance of adequate regulatory oversight (Bonte et al. 2011). Both systems can interfere with other underground infrastructure for electricity, water distribution and telecommunications technologies. The technology also raises questions of who owns the underground lands and waters and under what circumstances they can be exploited. The open systems risk diminishing biological and chemical water quality of aquifers through moving water about, and heating and cooling. The closed systems raise questions as to standards for containing the chemicals used and responsibilities for leaks and decommissioning.

\section{Fossil Substitution}

As the above examples illustrate, new energy technologies offer opportunities to reduce greenhouse gas emissions but with some risks for groundwater resources. A number of the proponents of these newer technologies argue that they can be substitutes for water-intensive fossil fuel-fired power stations and thus may free up water for other uses. For example, Beyond Zero Emissions argues that its 
proposal for a solar thermal power station in Port Augusta, Australia can be watered by decommissioning the local coal-fired power station (BZE 2010). Certainly in regions with high concentration of coal-fired power stations this may free up water, for example, in the Latrobe and Hunter valleys in Australia. However, this may also shift water consumption from places where water use is well-regulated to places where governance is poorer, for instance, from the two Australian coastal valleys to arid locations in the interior, where each litre of water may have more environmental and socio-economic value to other users. If governments and societies want this sort of water substitution to occur, then it will require active facilitation and regulation.

\subsubsection{Risks to Groundwater from Carbon Sequestration in the Landscape}

Carbon sequestration in the landscape, a subset of geoengineering proposals, is another component of mitigation policies that may impact on groundwater management and use. Two approaches to store greenhouse gases in the landscape are discussed here: geological carbon capture and storage, and carbon farming, including plantations.

Carbon dioxide $\left(\mathrm{CO}_{2}\right)$ capture and sequestration (CCS) is a process that involves underground injection and geologic storage (sequestration) of $\mathrm{CO}_{2}$ in deep underground rock formations that are overlain by impermeable rock that trap the $\mathrm{CO}_{2}$ and prevent it from migrating upward. CCS can significantly reduce emissions from industrial sources such as fossil fuel-fired power plants (EPA 2013). The US Department of Energy estimates that between 1,800 and 20,000 billion metric tons of $\mathrm{CO}_{2}$ could be stored underground in the US (c, 2012), a volume that is equivalent to 600-6,700 years of current level emissions from large stationary sources in the US (GHGRP 2012). Moreover, while sequestration removes $\mathrm{CO}_{2}$, that might otherwise impact the atmosphere, according to the US EPA Greenhouse Gas Reporting Program, $\mathrm{CO}_{2}$ capture for industrial reuse is currently occurring at over 120 facilities in the US. End users of $\mathrm{CO}_{2}$ include enhanced oil recovery, food and beverage manufacturing, pulp and paper manufacturing, and metal fabrication.

The success of CCS requires very low rates of leakage. The widespread drilling of gas wells has been cited as a risk to the security of potential CCS sites (Elliot and Celia 2012) and widespread bore-holes used previously in searches for oil and other minerals may also cause leakages. Thousands of such bore-holes were drilled in the early twentieth century, and their precise locations and seals are often unknown. In terms of groundwater, the primary concern is whether placement of waste gases underground will result in reductions of groundwater quality.

In contrast with CCS, sequestration of carbon in land and vegetation is practised internationally. In some nations, it is used either to earn or sell carbon credits in a formal market or in schemes to offset emissions in other sectors. As an example, many airlines now offer passengers the option of paying extra to offset the emissions from their flights through tree planting.

Planting trees to sequester carbon is the most common method advanced because of its many co-benefits, in terms of such services as biodiversity and soil 
conservation, production of non-timber forest products, and aesthetic improvements to the landscape. However, forests will normally intercept more precipitation than non-forested land uses, diminishing surface runoff into streams and aquifer recharge (van Dijk and Keenan 2007; Jackson et al. 2005). This inflow interception may not have significant impacts in wet environments such as in the wet tropics, but in the temperate zone significant reductions in flows are likely. In past decades in Australia, tree planting has been actively encouraged to reduce groundwater recharge in areas subject to salinity. Several means of reducing these impacts on water resources are possible, including: incorporating the plantation sector into cap and trade water markets, as occurs in South Australia and South Africa; limiting afforestation to landscapes where the impacts may be acceptable, such as the wet tropics and salinity prone lands; or scheduling planting over decades so that the impacts are spread over a longer period of time (Pittock et al. 2013).

A number of other methods are being actively promoted to sequester more carbon in soils, although there is little evidence of widespread application thus far. Incorporating more biomass into soils is promoted as a way of enhancing agricultural productivity by improving soil structure, fertility and water infiltration, as well as sequestering carbon (Henriksen et al. 2011). Biochar - adding charcoal to soils - has a very active group of promoters (Kleiner 2009; Sohi et al. 2009). A lot of research investment has focussed at the field scale on the longevity of the carbon sequestration with often disappointing results (Lam et al. 2013). A common claim is that by developing more friable soils that these methods will enable more precipitation to be stored in the soil and advantage crop growth. If this proves to be the case one potential outcome is diminished surface runoff and aquifer recharge.

Internationally, carbon sequestration in the landscape has a mandate under the umbrella of 'land use change and forestry' and it is being deployed through two programs of the UN Framework Convention on Climate Change. The Clean Development Mechanism and proposed REDD+ scheme (Reduced Emissions from Degradation and Deforestation plus) enable projects applying approved methodologies for reducing emissions or sequestering carbon in land and vegetation in developing countries to generate carbon credits (CDM Executive Board 2010; Pritchard 2009). However, the Clean Development Mechanism's current procedures for assessing and considering any negative impacts of proposed projects on water resources are token (Pittock 2010).

Australia is one nation that has legislated in the Carbon Credits (Carbon Farming Initiative) Act 2012 for market-based carbon sequestration in the landscape, based on the Clean Development Mechanism's approach of approved methodologies (Australian Government 2011). The Act's regulations attempt to limit the impact of carbon plantations on water by prohibiting commercial timber production and planting in areas within the $600 \mathrm{~mm} / \mathrm{year}$ and above rainfall isohyet, subject to a number of exemptions (DCCEE 2011). The $600 \mathrm{~mm} / \mathrm{year}$ rainfall isohyet was chosen as a threshold above which surface water runoff may be expected, however this may unreasonably restrict planting in environments where impacts may be insignificant, as in the tropics. The exemptions include planting for biodiversity conservation, and those agreed by poorly-resourced, state government mandated 
natural resource management organisations. National policy agreements to include significant inflow interception activities (including groundwater recharge) within cap and trade water markets have only been implemented by one of the eight states and territories (NWC 2011). Consequently this odd collection of half implemented policies and the exemptions mean that there is a strong prospect of perverse impacts on groundwater recharge.

Many other nations have prioritised reforestation in their climate mitigation policies, including China, India and Mexico, indicating that managing the tradeoffs between planting for carbon sequestration and water use is a growing global challenge (Pittock 2011). The links between the projected impacts of climate change and the sustainable management of surface and groundwater resources makes the challenge all the more complex. For example, with so many countries pursuing carbon sequestration through tree plantings, and the Intergovernmental Panel on Climate Change's projections for increased wildfire frequency and intensity, it is not inconceivable that governments may be increasing the risks of even bigger and more devastating wildfires by pursuing policies that are, ironically, attempting to mitigate the impacts of climate change. And, of course, the knockon consequences of more frequent and intense wildfires are insidious: denuded catchments which in turn lead to more floods, erosion and siltation of water storages, which has important implications for the sustainable use of groundwater resources.

\subsubsection{Climate Change Adaptation Policies}

Having discussed the implications of climate change mitigation on groundwater resources, we now turn to consider how groundwater may be used and sustained through climate change adaptation measures. Climate change is likely to impact surface water supplies in particular places in a number of ways, including: increasing or decreasing precipitation; changing seasonality of snowmelt and river flows; increasing evapotranspiration, the intensity of storms and frequency of floods and droughts. Groundwater resources have the potential to complement or buffer surface water shortages to deliver key services (Bates et al. 2008). Three examples are now elaborated, namely urban water supply, food production and freshwater biodiversity conservation.

\subsubsection{Water Supply}

Sustaining a reliable supply of drinking water to urban areas is essential for the well-being of the majority of the planet's people. Not only does good health depend on clean drinking water, but so too does the economic health of these communities. Climate change impacts, increasingly, jeopardise cities that depend on surface water catchments. Australia provides a salutary example. In the mid-1970s inflows into the city of Perth's water storages began a series of 'step changes' such that a decline in the order of $70 \%$ of the previous long-term average was experienced (Petrone et al. 2010). During the 2002-2010 Millennium Drought another five cities 
in southern Australia also saw their water storages reduced to perilously low levels. A common response of the impacted states was to diversify the supplies of water for these cities by adding reuse, groundwater, and desalination sources. In particular, Adelaide, Perth and Sydney each drew on new groundwater resources, applied managed aquifer recharge, or set aside aquifers as drought reserves.

This Australian example highlights the potential of aquifers to grow in importance as existing urban water storage and sources become more sensitive to increasingly variable climatic and surface hydrological conditions. This capacity can be enhanced through managed aquifer recharge, as detailed in Chaps. 17 and 18. These same storage characteristics will also make aquifers more attractive as a source of water for food production.

Additionally, an important buffering role of groundwater can be provided by individual on-site water wells. Private wells can reduce demand pressures on larger aquifers. In the US over 40 million people are supplied with their water needs from 15 million private wells (US Census Bureau 2007). In most instances homeowner wells (often in bedrock fractures) are accessing small discrete aquifer systems that are economically unusable for any major supply. Provided there is limited outside lawn watering, virtually all the pumped water is treated and returned to the sub-surface via septic systems and leach-fields. The key to continuing this harmonious use of groundwater is to ensure through zoning regulations that well density does not exceed renewability and that the rights of private well owners sharing access to aquifers with major pumpers are protected. "Deepest well wins" is not a good basis for groundwater management.

\subsubsection{Irrigated Food Production}

In 2007, the International Water Management Institute (IWMI)'s "Comprehensive assessment of water management in agriculture" (CAoWMiA) reviewed the world's future food needs and explored scenarios for how the required water may be sourced (CAoWMiA 2007). Around half of the globally accessible freshwater is already diverted for human uses and $70 \%$ of the world's water consumption is in agricultural production. CAoWMiA (2007) reported that food demand will double over the next 50-80 years, and that without improvements in productivity, water use in food production will need to increase by $70-90 \%$ under a changing climate (CAoWMiA 2007). From a business perspective, a McKinsey \& Company global report estimates "that the annual pace at which supply is added over the next 20 years in water and land would have to increase by $140 \%$ and up to $250 \%$, respectively, compared with the rate at which supply expanded over the past two decades. This expansion of supply could have a wide range of potentially negative effects on the environment. In this case, there would be an additional $1,850 \mathrm{~km}^{3}$ of water consumption by 2030, $30 \%$ higher than today's levels ..." (Dobbs et al. 2011: 8).

A study by Wada et al. (2012) shows that on a global basis non-renewable groundwater abstraction represents $18 \%$ of global gross irrigation water demand. In other words, on a global basis we are draining aquifer systems (see also Chap. 2 for more detail on aquifer depletion). This loss of groundwater inventory has 
greatly reduced the capacity of aquifers to serve as a buffer against current or future drought.

In the US over the last 100 years over $1,000 \mathrm{~km}^{3}$ of groundwater has been removed from major aquifers with the greatest losses from the High Plains Aquifer $\left(350 \mathrm{~km}^{3}\right)$ and California's Central Valley $\left(150 \mathrm{~km}^{3}\right)$ (Konikow 2013). These trends in groundwater depletions in the US have been observed and known for many years. However, effective and sustainable management strategies have eluded policy makers and only now, because of severe drought conditions, are end users and legislators in California, Texas and other impacted states beginning to talk about water metering and devising workable criteria for prioritizing allocations of the progressively scarce groundwater resources. These discussions are clouded by the issue of "water rights" and the spectre of litigation from end-users whose pumping might be curtailed.

The Asian Development Bank raises similar concerns. Noting "total annual sustainable freshwater supply remaining static at 4,200 billion cubic meters $\left(\mathrm{m}^{3}\right)$, the annual deficit for 2030 is forecasted to be 2,765 billion $\mathrm{m}^{3}$, or $40 \%$ of unconstrained demand, assuming that present trends continue. India and China are forecasted to have a combined shortfall of 1,000 billion $\mathrm{m}^{3}$ - reflecting shortfalls of $50 \%$ and $25 \%$, respectively. There is little evidence of changing trends. Signals of scarcity and stress have had little impact on policies, demand, or the market. On the supply side, there is little room for finding and abstracting more water. In areas with physical water scarcity (including north [China], south and northwest India, and Pakistan), demand needs to lessen" (ADB 2013: vi).

The increasingly frequent droughts predicted with climate change means that the greater security of food production afforded by irrigation will become increasingly popular. In Africa, for example, national governments have extensive plans to expand irrigated production (Sullivan and Pittock 2014). There has been extensive debate about why irrigated agriculture has performed very poorly in Africa, which points to a combination of problems with infrastructure, human capacity and economic viability (Lankford 2009). A number of researchers have pointed to extensive, but little used, groundwater resources in Africa as the basis for increased agricultural production (MacDonald et al. 2012). The arguments for greater use of groundwater are many, but the most compelling are the increased cost efficiencies and drought resilience gained over traditional small-scale rainwater harvesting, and the capacity for groundwater resources to be developed to support more people across the landscape compared to centralised, surface irrigation schemes (Stirzaker and Pittock 2014).

The obvious question about greater reliance in Africa on groundwater for agriculture is how to avoid the over-exploitation that has afflicted many parts of the world. The management of consumption using cap and trade groundwater markets as practised in Australia is unlikely to work in most of Africa where the reach of the state is not as strong. Work by the International Water Management Institute in regions of over-exploited groundwater in India indicates two examples of unconventional approaches that may be addressing the problem of over-exploitation of groundwater due to subsidized electricity for pumping. Reducing these 
power subsidies has not been politically feasible but other solutions have emerged. Over the past decade in Gujarat, India a USD \$260 million scheme called Jyotigram Yojana ("Lighted Village") has sought to overcome electricity theft and blackouts while rationing groundwater and ensuring the financial viability of utilities (IWMI 2011). Installation of a dual electricity distribution system has enabled one distribution system to be dedicated to providing reliable supplies to villages while the other system provides power for $8 \mathrm{~h} /$ day to groundwater pumps. This approach has curtailed energy consumption, encouraged more efficient groundwater pumping, and facilitated a tripling of agricultural production.

More recently the state government of West Bengal scrapped a permit system, instead connecting small pumps to the power grid at a fixed cost that only enables farmers to access annual monsoon recharge from shallow aquifers, conserving deeper groundwater resources. IWMI estimate that the area irrigated will expand in 3-5 years from 2.98 to 4.83 million hectares, increasing annual paddy rice production by 4.62 million tonnes (IWMI 2012).

\subsubsection{Freshwater Biodiversity Conservation}

Freshwater biodiversity has been significantly impacted by overexploitation of surface and groundwaters (MEA 2005; see also Chaps. 14 and 15). Current approaches to conserving freshwater biodiversity, including for climate change adaptation, have focussed on providing surface environmental flows and in some countries, environmental water demand management (also called environmental works and measures in Australia) (Poff and Matthews 2013; Pittock and Lankford 2010; Richter 2010). In countries like Australia, environmental flow programs have focussed on conserving large wetland systems, often in the lower reaches of river systems (Pittock and Finlayson 2011). An assumption is that surface water environment flows under conditions of short-term variability, and long-term climate change, will be sufficient to sustain the ecological character of these wetlands. Yet evidence is that desiccation and water quality impacts of drought events, exacerbated by climate change, are not adequately ameliorated by the current environmental watering programs (Pittock 2013; Pittock et al. 2010). In particular, these strategies assume that large wetlands in downstream reaches of river basins and ecosystems can be maintained in a similar state to the present.

Contrary to this approach, there is an emerging focus on the importance of conserving groundwater flows as a key strategy for retaining freshwater biota in refugia during severe drought and climate change (Pittock and Finlayson 2011). The potential exists for groundwater inflows into river channels to maintain reaches with sufficient volumes of water of acceptable quality to sustain biota that may otherwise perish. There are numerous management challenges if this adaptation option is to succeed, not least gaining community support to conserve connected aquifers for this purpose (Lukasiewicz et al. 2013). Importantly, these refugia are often different to the freshwater habitats currently prioritised for conservation. For instance, in Australia's Murray-Darling Basin, gaining reaches are often located in the mid and upper river systems rather than the downstream wetlands currently favoured (CSIRO 2008; Pittock and Finlayson 2011). 
This example of changing groundwater management priorities highlights the governance challenges brought on by global change.

\subsection{Discussion and Conclusion}

The need for Integrated Groundwater Management (IGM) is set out in the first chapter of this volume and defined as: "a structured process which promotes the coordinated management of groundwater and related resources (including conjunctive management with surface water), taking into account non-groundwater policy interactions, in order to achieve shared economic, social welfare and ecosystem outcomes."

Groundwater governance arrangements available to policy-makers vary from the local to global scales (see Part II which is devoted to governance issues). International scale processes, such as climate change, may have major impacts on groundwater at the national scale. Similarly policy decisions at the national scale on natural resources management, such as on the extent of forests, will impact on aquifers. Groundwater systems are usually sub-national in scale such that sound national policy will only be effective if it supports sustainable management at the regional or local levels. Implementation of effective policies will require fostering of human capacity and institutions at appropriate levels, international to local scale. The earlier discussion also highlights the importance of integrating interventions across sectors. For example, managing groundwater sustainably may require intervention in the food sector more than the water sector. What then are some of the key mechanisms that may facilitate sustainable groundwater management? Is there a case for IGM, to complement Integrated Water Resources Management (IWRM; and its various iterations)?

As this chapter has elucidated, sustainable management of aquifers across competing water-use sectors requires positive synergies to be seized and perverse impacts to be identified and minimised. IGM under global change requires four key interventions (Pittock et al. 2013; Hussey and Pittock 2012; Pittock et al. 2015):

1. Information. The often unseen nature of groundwater and the lack of a common currency with competing natural resource uses can lead to decisions with deleterious impacts on aquifers. We contend that making publicly available, and generating where necessary, compatible information on groundwater resources and major uses like the environment, energy, food and domestic water can facilitate integrated decision making. Examples of such information transparency include: publicly available water accounts, such as those of the Australian Bureau of Meteorology (BoM and ABS 2011); the Australian Government's online atlas of matters of national environmental significance that includes listed groundwater dependent biota (DOE n.d.); simple, online decision making models, such as one in Texas that enables businesses and regulators to match water resources to proposed power generators (Webber 
Energy Group n.d.); and 'traffic light' status reports on the state of aquifers and other resources (Pittock et al. 2013).

2. Technology. There are many technologies that may use less groundwater while facilitating climate change mitigation and adaptation, such as dry cooling thermal power stations (NETL 2008) and more efficient irrigation equipment (Mushtaq et al. 2009).

3. Market incentives. Establishing cap and trade water markets can create powerful incentives for using groundwater more efficiently and sustainably, as is now practised in many parts of Australia (Grafton et al. 2011). However, given the lower price of water per volume compared to many other natural resources and the potential for externalities, it is essential that markets for natural resources such as water, timber and carbon are harmonised to prevent negative impacts on groundwater (Pittock et al. 2013).

4. Reforming governance. Systematically integrating decisions across sectors like water and climate policy will expose many of the perverse outcomes identified in this chapter, though such integration is difficult to achieve. Pittock (2011) argues that there are five attributes of integrated governance, namely: (i) leadership; (ii) legal mandates for agencies to work across sectors in the interests of sustainability, for example, for electricity utilities to use fees to conserve water; (iii) mechanisms for vertical integration for local to national and international institutions, such as Australia's National Water Initiative (Commonwealth of Australia et al. 2004); (iv) horizontal integration between sectoral agencies, such as inter-departmental committees; and (v) accountability mechanisms such as periodic reviews, auditors, and capacity for third parties to challenge unsustainable decisions in the courts. As the examples discussed above with underground thermal energy systems and unconventional gas highlight, such integration is particularly required when new technologies emerge, to establish frameworks to govern their deployment.

Combined, actions in these four areas will go a long way to managing groundwater resources sustainably. However, the complexity of sustainable groundwater management raises the obvious question of whether an overarching conceptual framework is needed, as was deemed the case nearly 30 years ago when IWRM emerged. Indeed, espousing as it does "the coordinated development and management of water, land and related resources, in order to maximize the resultant economic and social welfare in an equitable manner without compromising the sustainability of vital ecosystems" (GWP 2000), IWRM does in principle at least incorporate groundwater resources. In practice, though, the emphasis of IWRM has been on surface water resources, with scant attention afforded to groundwater - a fact which is borne out by the excellent chapters in this book. However, advocates of an IGM framework should be aware of IWRM's limitations. While there is evidence of broad acceptance of IWRM principles, success has been limited. Three particular deficiencies will likely be relevant in any attempt at IGM. First, the acceptance of IWRM has not changed the underlying power differences between stakeholders that make integrated management, and more sustainable outcomes, so 
difficult to achieve. Second, as an all-encompassing framework IWRM is intellectually robust but practically very difficult to implement. Finally, conceptual frameworks do not address the underlying governance and institutional capacity challenges that beset many developing countries, and which are, arguably, the major barrier to more sustainable practices. It is salient that many proponents of IWRM have been calling for a new approach for the last decade (Biswas 2004).

There is value in an overarching framework to manage groundwater resources, but perhaps more importantly there is a need for the advocates of IGM to engage stakeholders 'out of the water box', with a view to advocating the four interventions listed above. Global changes are increasing the pressures on groundwater resources, but with these difficult problems and crises come policy reform windows. The challenge for decision-makers and water managers is to be prepared to seize the opportunities to implement more sustainable groundwater management.

Open Access This chapter is distributed under the terms of the Creative Commons AttributionNoncommercial 2.5 License (http://creativecommons.org/licenses/by-nc/2.5/) which permits any noncommercial use, distribution, and reproduction in any medium, provided the original author(s) and source are credited.

The images or other third party material in this chapter are included in the work's Creative Commons license, unless indicated otherwise in the credit line; if such material is not included in the work's Creative Commons license and the respective action is not permitted by statutory regulation, users will need to obtain permission from the license holder to duplicate, adapt or reproduce the material.

\section{References}

ADB (2013) Thinking about water differently: managing the water-food-energy nexus. Asian Development Bank, Manilla

Andrews J, Shabani B (2012) Re-envisioning the role of hydrogen in a sustainable energy economy. Int J Hydrogen Energy 37(2):1184-1203. doi:10.1016/j.ijhydene.2011.09.137

Australian Government (2011) Carbon Credits (Carbon Farming Initiative) Act 2011, No. 101, An Act about projects to remove carbon dioxide from the atmosphere and projects to avoid emissions of greenhouse gases, and for other purposes. Commonwealth of Australia, Canberra

Balat M (2008) Potential importance of hydrogen as a future solution to environmental and transportation problems. Int J Hydrogen Energy 33(15):4013-4029. doi:10.1016/j.ijhydene. 2008.05.047

Bates BC, Kundzewicz ZW, Wu S, Palutikof JP (eds) (2008) Climate change and water, Technical paper of the Intergovernmental Panel on Climate Change. IPCC Secretariat, Geneva

Biswas AK (2004) Integrated water resources management: a reassessment. Water Int 29(2): 248-256. doi:10.1080/02508060408691775

BoM, ABS (2011) Australian Government water accounting, Activities of the Bureau of Meteorology and the Australian Bureau of Statistics. Bureau of Meteorology and Australian Bureau of Statistics, Melbourne/Canberra

Bonte M, Stuyfzand PJ, Hulsmann A, Van Beelen P (2011) Underground thermal energy storage: environmental risks and policy developments in the Netherlands and European Union. Ecol Soc 16(1):22. http://www.ecologyandsociety.org/vol16/iss1/art22/ 
Burnham A, Han J, Clark CE, Wang M, Dunn JB, Palou-Rivera I (2011) Life-cycle greenhouse gas emissions of shale gas, natural gas, coal, and petroleum. Environ Sci Technol 46(2):619-627. doi:10.1021/es201942m

BZE (2010) Zero carbon Australia stationary energy plan. Beyond Zero Emissions, Melbourne

CAoWMiA (2007) Water for food, water for life. A comprehensive assessment of water management in agriculture. Earthscan and International Water Management Institute, London/ Colombo

CDM Executive Board (2010) Project design document form for afforestation and reforestation project activities (CDM-AR-PDD), version 05. UN Framework Convention on Climate Change, Bonn

Commonwealth of Australia, Government of New South Wales, Government of Victoria, Government of Queensland, Government of South Australia, Government of the Australian Capital Territory, Government of the Northern Territory (2004) Intergovernmental agreement on a national water initiative. Council of Australian Governments, Canberra

Cook P, Beck V, Brereton D, Clark R, Fisher B, Kentish S, Toomey J, Williams J (2013) Engineering energy: unconventional gas production. Australian Council of Learned Academies, Melbourne

Council of Canadian Academies (2014) Environmental impacts of shale gas extraction in Canada. Council of Canadian Academies, Ottawa

CSIRO (2008) Water availability in the Murray-Darling Basin, A report from CSIRO to the Australian Government. CSIRO, Canberra

DCCEE (2011) Carbon credits (carbon farming initiative) regulations 2011. Department of Climate Change and Energy Efficiency, Canberra

Dobbs R, Oppenheim J, Thompson F, Brinkman M, Zornes M (2011) Resource revolution: meeting the world's energy, materials, food, and water needs. McKinsey \& Company, Chicago

DoE (2008) Concentrating solar power commercial application study: reducing water consumption of concentrating solar power electricity generation, Report to congress. US Department of Energy, Golden

DOE (n.d.) Protected matters search tool. Department of the Environment, Canberra

Dominguez-Faus R, Powers SE, Burken JG, Alvarez PJ (2009) The water footprint of biofuels: a drink or drive issue? Environ Sci Technol 43(9):3005-3010. doi:10.1021/es802162x

Elliot TR, Celia MA (2012) Potential restrictions for $\mathrm{CO}_{2}$ sequestration sites due to shale and tight gas production. Environ Sci Technol 46(7):4223-4227. doi:10.1021/es2040015

EPA (2013) Carbon dioxide capture and sequestration. United States Environmental Protection Agency, Washington, DC

Gerbens-Leenes PW, Hoekstra AY, van der Meer TH (2008) Water footprint of bio-energy and other primary energy carriers, The value of water research report series no 29. UNESCO-IHE Institute for Water Education, Delft

Goldstein B, Hill A, Long A, Budd A, Holgate F, Malavazos M (2009) Hot rock geothermal energy plays in Australia. In: Proceedings of the 34th workshop on geothermal reservoir engineering, Stanford University, Stanford

Grafton RQ, Libecap G, McGlennon S, Landry C, O’Brien B (2011) An integrated assessment of water markets: a cross-country comparison. Rev Environ Econ Policy 5(2):219-239. doi:10. 1093/reep/rer002

Greenhouse Gas Reporting Program (GHGRP) (2012) EPA Greenhouse Gas Reporting datasubpart PP-suppliers of carbon dioxide. US Environmental Protection Agency, Washington, DC, http://www2.epa.gov/ghgreporting

Henriksen CB, Hussey K, Holm PE (2011) Exploiting soil-management strategies for climate mitigation in the European Union: maximizing "win-win" solutions across policy regimes. Ecol Soc 16(4). doi:10.5751/ES-04176-160422

Hirabayashi Y, Mahendran R, Koirala S, Konoshima L, Yamazaki D, Watanabe S, Kim H, Kanae S (2013) Global flood risk under climate change. Nature Clim Change, advance online publication. 
doi:10.1038/nclimate1911, http://www.nature.com/nclimate/journal/vaop/ncurrent/abs/ nclimate1911.html\#supplementary-information

Hussey K, Pittock J (2012) The energy-water nexus: Managing the links between energy and water for a sustainable future. Ecol Soc 17(1):31 [online]. doi:10.5751/ES-04641-170131

IPCC (2007a) Climate Change 2007: impacts, adaptation and vulnerability, Working Group II contribution to the fourth assessment report of the Intergovernmental Panel on Climate Change. International Panel on Climate Change, Geneva

IPCC (2007b) Mitigation of climate change: summary for policymakers, Contribution of Working Group III to the fourth assessment report of the Intergovernmental Panel on Climate Change. Intergovernmental Panel on Climate Change, Geneva

IWMI (2011) Innovative electricity scheme sparks rural development in India's Gujarat State. Success Stories (9). http://www.iwmi.cgiar.org/Publications/Success_Stories/PDF/2011/Issue_9-Innova tive $\% 20$ electricity\%20scheme\%20sparks.pdf

IWMI (2012) Boosting water benefits in West Bengal. Success Stories (14) http://www.iwmi. cgiar.org/Publications/Success_Stories/PDF/2011/Issue_14-Groundwater_in_West_Bengal. pdf

Jackson RB, Jobbágy EG, Avissar R, Roy SB, Barrett DJ, Cook CW, Farley KA, le Maitre DC, McCarl BA, Murray BC (2005) Trading water for carbon with biological carbon sequestration. Science 310(5756):1944-1947. doi:10.1126/science.1119282

King CW, Webber ME (2008) Water intensity of transportation. Environ Sci Technol 42(21): 7866-7872

Kleiner K (2009) The bright prospect of biochar. Nature (0906):72-74

Konikow LF (2013) Groundwater depletion in the United States (1900-2008). US Department of the Interior, US Geological Survey, Reston, pp 2013-5079. http://pubs.usgs.gov/sir/2013/5079/

Lam SK, Chen D, Mosier AR, Roush R (2013) The potential for carbon sequestration in Australian agricultural soils is technically and economically limited. Sci Rep 3. doi:10.1038/srep02179, http://www.nature.com/srep/2013/130710/srep02179/abs/srep02179.html\#supplementaryinformation

Lankford B (2009) Viewpoint - the right irrigation? Policy directions for agricultural water management in Sub-Saharan Africa. Water Altern 2(3):476-480

Lukasiewicz A, Finlayson CM, Pittock J (2013) Identifying low risk climate change adaptation in catchment management while avoiding unintended consequences. National Climate Change Adaptation Research Facility, Gold Coast

MacDonald AM, Bonsor HC, Dochartaigh BÉÓ, Taylor RG (2012) Quantitative maps of groundwater resources in Africa. Environ Res Lett 7(2):024009

Mauter MS, Alvarez PJJ, Burton A, Cafaro DC, Chen W, Gregory KB, Jiang G, Li Q, Pittock J, Reible D, Schnoor JL (2014) Regional variation in water-related impacts of shale gas development and implications for emerging international plays. Environ Sci Technol. doi:10.1021/ es405432k

Millennium Ecosystem Assessment (MEA) (2005) Ecosystems and human well-being: wetlands and water synthesis. World Resources Institute, Washington, DC

Mushtaq S, Maraseni TN, Maroulis J, Hafeez M (2009) Energy and water tradeoffs in enhancing food security: a selective international assessment. Energy Policy 37(9):3635-3644

National Research Council (2013) Induced seismicity potential in energy technologies. The National Academies Press, Washington, DC

NETL (2008) Estimating freshwater needs to meet future thermoelectric generation requirements, 2008 update. DOE/NETL-400/2008/1339, September 30. US Department of Energy, National Energy Technology Laboratory, Pittsburgh

Notaras M (2011) All biofuel policies are political. Our World, 18 Feb 2011) [online]

NWC (2011) The national water initiative - securing Australia's water future: 2011 assessment. National Water Commission, Canberra

Openshaw K (2000) A review of Jatropha curcas: an oil plant of unfulfilled promise. Biomass Bioenerg 19(1):1-15. doi:10.1016/S0961-9534(00)00019-2 
Petrone KC, Hughes JD, Van Niel TG, Silberstein RP (2010) Streamflow decline in southwestern Australia, 1950-2008. Geophys Res Lett 37(11), L11401. doi:10.1029/2010GL043102

Phillips A (2014) World's largest solar thermal plant uses as much water as two holes on nearby golf course. Climate Progress, 13 Feb 2014 [online]

Pittock J (2010) A pale reflection of political reality: integration of global climate, wetland, and biodiversity agreements. Climate Law 1(3):343-373

Pittock J (2011) National climate change policies and sustainable water management: conflicts and synergies. Ecol Soc 16(2):25 [online]

Pittock J (2013) Lessons from adaptation to sustain freshwater environments in the MurrayDarling Basin, Australia. Wiley Interdiscip Rev Clim Change 4(6):429-438. doi:10.1002/wcc. 230

Pittock J, Finlayson CM (2011) Australia's Murray-Darling Basin: freshwater ecosystem conservation options in an era of climate change. Mar Freshw Res 62:232-243

Pittock J, Lankford BA (2010) Environmental water requirements: demand management in an era of water scarcity. J Integr Environ Sci 7(1):75-93. doi:10.1080/19438151003603159

Pittock J, Finlayson CM, Gardner A, McKay C (2010) Changing character: the Ramsar convention on wetlands and climate change in the Murray-Darling Basin, Australia. Environ Plan Law J 27(6):401-425

Pittock J, Hussey K, McGlennon S (2013) Australian climate, energy and water policies: conflicts and synergies. Aust Geogr 44(1):3-22. doi:10.1080/00049182.2013.765345

Pittock J, Hussey K, Dovers, S (eds) (2015) Climate, energy and water. Cambridge University Press, Cambridge

Poff NL, Matthews JH (2013) Environmental flows in the Anthropocence: past progress and future prospects. Curr Opin Environ Sustain 5(6):667-675. doi:10.1016/j.cosust.2013.11.006

Pritchard D (2009) Reducing emissions from deforestation and forest degradation in developing countries (REDD) - the link with wetlands. Foundation for International Environmental Law and Development, London

Richter BD (2010) Re-thinking environmental flows: from allocations and reserves to sustainability boundaries. River Res Appl 26(8):1052-1063. doi:10.1002/rra.1320

Rogelj J, McCollum DL, Riahi K (2013) The UN's 'Sustainable Energy for All' initiative is compatible with a warming limit of $2^{\circ} \mathrm{C}$. Nat Clim Change 3(6):545-551. doi:10.1038/ nclimate 1806

Roulo C (2011) Ball State University's geothermal system will be largest in US Contractor (5 December 2011) [online]

Sims RE, Mabee W, Saddler JN, Taylor M (2010) An overview of second generation biofuel technologies. Bioresour Technol 101(6):1570-1580

Sohi S, Loez-Capel E, Krull E, Bol R (2009) Biochar's roles in soil and climate change: a review of research needs, CSIRO land and water science report 05/09. CSIRO, Canberra

Stirzaker R, Pittock J (2014) The case for a new irrigation research agenda for Sub-Saharan Africa. In: Pittock J, Grafton RQ, White C (eds) Water, food and agricultural sustainability in Southern Africa. Tilde University Press, Prahran, pp 91-107

Sullivan A, Pittock J (2014) Agricultural policies and irrigation in Africa. In: Pittock J, Grafton RQ, White C (eds) Water, food and agricultural sustainability in Southern Africa. Tilde University Press, Prahran, pp 30-54

U.S. Census Bureau (2007) American Housing Survey for the United States. Current Housing reports, Series H150/07. U.S. Government Printing Office, Washington, DC

van Dijk AIJM, Keenan RJ (2007) Planted forests and water in perspective. For Ecol Manage 251(1-2):1-9

Vermeulen S, Cotula L (2010) Over the heads of local people: consultation, consent, and recompense in large-scale land deals for biofuels projects in Africa. J Peasant Stud 37(4): 899-916. doi:10.1080/03066150.2010.512463

Wada Y, Beek L, Bierkens MF (2012) Nonsustainable groundwater sustaining irrigation: a global assessment. Water Resour Res 48(6):W00L06 
Wallis PJ, Ward MB, Pittock J, Hussey K, Bamsey H, Denis A, Kenway SJ, King CW, Mushtaq S, Retamal ML, Spies BR (2014) The water impacts of climate change mitigation measures. Clim Change 125(2):209-220. doi:10.1007/s10584-014-1156-6

Webber Energy Group (n.d.) Texas interactive power stimulator. University of Texas, Austin

Williams J, Pittock J (2012) Unconventional gas production and water resources, Lessons from the United States on better governance - a workshop for Australian Government officials. The Australian National University and United States Studies Centre, Canberra

WWDR (2012) Managing water under uncertainty and risk, Fourth world water development report. UNESCO, Paris

Yang J, Xu M, Zhang X, Hu Q, Sommerfeld M, Chen Y (2011) Life-cycle analysis on biodiesel production from microalgae: water footprint and nutrients balance. Bioresour Technol 102(1): 159-165. doi:10.1016/j.biortech.2010.07.017

Zoomers A (2010) Globalisation and the foreignisation of space: seven processes driving the current global land grab. J Peasant Stud 37(2):429-447. doi:10.1080/03066151003595325 


\title{
Linking Climate Change and Groundwater
}

\author{
Timothy Richard Green
}

\begin{abstract}
Projected global change includes groundwater systems, which are linked with changes in climate over space and time. Consequently, global change affects key aspects of subsurface hydrology (including soil water, deeper vadose zone water, and unconfined and confined aquifer waters), surface-groundwater interactions, and water quality. Research and publications addressing projected climate effects on subsurface water are catching up with surface water studies. Even so, technological advances, new insights and understanding are needed regarding terrestrial-subsurface systems, biophysical process interactions, and feedbacks to atmospheric processes. Importantly, groundwater resources need to be assessed in the context of atmospheric $\mathrm{CO}_{2}$ enrichment, warming trends and associated changes in intensities and frequencies of wet and dry periods, even though projections in space and time are uncertain. Potential feedbacks of groundwater on the global climate system are largely unknown, but may be stronger than previously assumed. Groundwater has been depleted in many regions, but management of subsurface storage remains an important option to meet the combined demands of agriculture, industry (particularly the energy sector), municipal and domestic water supply, and ecosystems. In many regions, groundwater is central to the water-food-energy-climate nexus. Strategic adaptation to global change must include flexible, integrated groundwater management over many decades. Adaptation itself must be adaptive over time. Further research is needed to improve our understanding of climate and groundwater interactions and to guide integrated groundwater management.
\end{abstract}

T.R. Green $(\square)$

USDA, Agricultural Research Service (ARS), Fort Collins, Colorado, USA

e-mail:Tim.green@ars.usda.gov 


\subsection{Introduction and Motivation}

Present understanding of how global change affects water resources around the world is limited. Potential impacts of global change on surface water, particularly projected regional climate patterns and trends have been studied in some detail. Studies of how subsurface waters will respond to climate change coupled with human activities have started to catch up only recently (Green et al. 2011; Taylor et al. 2013).

Challenges of understanding climate-change effects on groundwater are unique, because climate change may affect hydrogeological processes and groundwater resources directly and indirectly, in ways that have not been explored sufficiently (Dettinger and Earman 2007). Data limitations have made it impossible to determine the magnitude and direction of groundwater change due solely to climate change (Kundzewicz et al. 2007; Taylor et al. 2013). Even so, groundwater has been an historical buffer against climate variability, and our dependence on groundwater resources is likely to increase as water supplies are further stressed by population increase and projected increases in temperature and climatic variability over much of the globe.

Observational data and climate predictions provide abundant evidence that freshwater resources (both surface and subsurface water resources) are vulnerable and have the potential to be strongly affected by climate change, with wide-ranging consequences for society and ecosystems (Bates et al. 2008). According to Jorgensen and Yasin al-Tikiriti (2003) the effect of historical climate change on groundwater resources, which once supported irrigation and economic development in parts of the Middle East, is likely the primary cause of declining cultures there during the Stone Age. Climate change may account for approximately $20 \%$ of projected increases in water scarcity globally (Sophocleous 2004). Integrated groundwater management and planning into the future requires careful evaluation and understanding of climatic variability over periods of decades to centuries, while considering the increasing stresses on those groundwater resources from population growth and industrial, agricultural, and ecological needs (Warner 2007).

\subsubsection{Rising Interest in Impacts of Climate Change on Subsurface Water}

In recent decades, a wide array of scientific research has been conducted to explore how water resources might respond to global change. However, research has been focused dominantly on surface-water systems, due to their visibility, accessibility and more obvious recognition of surface waters being affected by global change. Only recently are water resources managers and politicians recognising the important role played by groundwater resources in meeting the demands for drinking water, agricultural and industrial activities, and sustaining ecosystems, as well as in the adaptation to and mitigation of the impacts of climate change and coupled human activities. 
Changes in global climate are expected to affect the hydrological cycle, altering surface-water levels and groundwater recharge to aquifers with various other associated impacts on natural ecosystems and human activities. Although the most noticeable impacts of climate change could be changes in surface-water levels and quality (Leith and Whitfield 1998; Winter 1983), there are potential effects on the quantity and quality of groundwater (Bear and Cheng 1999; Zektser and Loaiciga 1993).

\subsubsection{What Is Global Change?}

Global change may include natural and anthropogenic influences on terrestrial climate and the hydrologic cycle. Greenhouse gases are assumed to drive much of the contemporary climate change, and global atmospheric $\mathrm{CO}_{2}$ concentration is the primary indicator of greenhouse gases, as well as a primary regulator of global climate (Petit et al. 1999). Atmospheric $\mathrm{CO}_{2}$ concentration has been measured in the middle of the Pacific Ocean atop Mauna Loa, Hawaii at the National Centre for Environmental Prediction since 1958 (Keeling et al. 1976; Keeling et al. 2004; Thoning et al. 1989). Both $\mathrm{CO}_{2}$ concentration and its rate of change have increased continuously over most of our lifetimes. Green et al. (2011) showed a power-law increase in $\mathrm{CO}_{2}$ concentration with time, but projections of future greenhouse gas concentrations are based on complex "storylines" (IPCC 2007b) or Representative Concentration Pathways (RCPs) used in the Fifth Assessment Report (AR5) (IPCC 2013). Projected climate change is based primarily on simulated responses to these projected emissions and resulting greenhouse gases.

Atmospheric scientists are exploring complex interactions and causative factors using available data and climate models. Ice-core data have shown long-term correlation between entrapped atmospheric $\mathrm{CO}_{2}$ and (surrogate) temperature (Petit et al. 1999); however, $\mathrm{CO}_{2}$ changes lag behind temperature changes by approximately 1,300 years (Mudelsee 2001). The Earth's orbit and "Milankovitch cycles" seem to explain the apparent paradox, possibly working in tandem with global greenhouse warming and ocean circulation (Monnin et al. 2001). Loáiciga (2009) provided a helpful discussion of several factors in the debate over dominant drivers of climate as it relates to (ground)water resources. These types of issues in the theory and prediction of climate have not been fully resolved.

Although "global warming" is the topic of greatest public interest, changing patterns of surface level air humidity and precipitation are very important for predicting eco-hydrological impacts of multifaceted climate change. Projections from the Intergovernmental Panel on Climate Change (IPCC) show significant global warming and alterations in frequency and amount of precipitation in the twenty-first century (Le Treut et al. 2007; Mearns et al. 2007). 


\subsection{Climate Projections}

Aquifers are recharged mainly by precipitation or through interaction with surfacewater bodies. In order to quantify potential effects of climate change on groundwater systems, future projections of climate are needed at the scales of application.

\subsubsection{Global Climate Models}

Climate models come in different forms, ranging from simple energy-balance models to Earth-system models of intermediate complexity to comprehensive three-dimensional general circulation models of the atmosphere and oceans or global climate models (GCMs). GCMs are the most sophisticated tools available for simulation of the current global climate and future climate scenario projections. Over the last few decades, physical processes incorporated into these models have increased from simple rain and $\mathrm{CO}_{2}$ emissions to complex biogeochemical (including water vapor) feedbacks (Le Treut et al. 2007: Fig. 1.2). The dominant terrestrial processes that affect large-scale climate over the next few decades are included in current climate models. Some processes important on longer time scales (e.g., global glaciation), however, are not yet included. The spatial resolution of GCMs has improved, but the simulation of extreme precipitation is dependent on model resolution, parameterisation and the thresholds chosen. In general, GCMs tend to produce too many days with weak precipitation $\left(<10 \mathrm{~mm} \mathrm{~d}^{-1}\right)$ and too little precipitation during intense events $\left(>10 \mathrm{~mm} \mathrm{~d}^{-1}\right.$ ) (Randall et al. 2007).

Considerable advances in model design have not reduced the variability of model forecasts of climate, partially because climate predictions are intrinsically affected by uncertainty and deterministic chaos (Lorenz 1963). Lorenz (1975) defined two distinct kinds of prediction problems: (1) prediction of actual properties of the climate system in response to a given initial state due to non-linearity and instability of the governing equations, and (2) determination of responses of the climate system to changes in the external forcings. Estimating future climate scenarios as a function of the concentration of atmospheric greenhouse gases is a typical example of predictions of the second kind (Le Treut et al. 2007).

Uncertainties in climate predictions arise mainly from model uncertainties and errors. A number of comprehensive model intercomparison projects were set up in the 1990s under the auspices of the World Climate Research Programme to undertake controlled conditions for model evaluation (e.g., Taylor 2001). Use of multiple simulations from a single model (ensemble or Monte Carlo approach) is a necessary and complementary approach to assess the stochastic and chaotic behaviors of the climate system. Such single-model ensemble simulations clearly indicated a large spread in the climate projections (Le Treut et al. 2007).

The ability of any particular GCM to reproduce present-day mean climate and its historical characteristics with respectable realism and good overall performance in comparison with the other models are presumed to indicate that it can be used to project credible future climates IPCC (2007b). The atmosphere-ocean coupled 
climate system shows different modes of variability that range widely from intraseasonal to inter-decadal time scales. Successful simulation and prediction over a wide range of these phenomena increase confidence in the GCMs used for climate predictions of the future (Randall et al. 2007). In addition, the IPCC (2007a) showed that the global statistics of the extreme events in the current climate, especially temperature, are generally simulated well. However, GCMs have been more successful in simulating temperature extremes than precipitation extremes (Randall et al. 2007).

Uncertainty is expected with respect to what the future "picture" of global climate will be. GCMs are forced with concentrations of greenhouse gases and other constituents derived from various emissions scenarios ranging from non-mitigation scenarios to idealised long-term scenarios. The IPCC (2007b) considered six scenarios for projected climate change in the twenty-first century. These included a subset of three IPCC Special Report on Emission Scenarios (SRES; Nakićenović and Swart 2000) non-mitigation emission scenarios representing 'low' (B1), 'medium' (A1B) and 'high' (B1) scenarios. Green et al. (2011) discussed some potential spatial patterns of these scenarios across the globe. These include different projected changes in precipitation for the tropics (Neelin et al. 2006), subtropics (Wang 2005; Rowell and Jones 2006), and high latitudes (Emori and Brown 2005).

\subsubsection{Downscaling}

GCMs cannot provide information at scales finer than their computational grid (typically of the order of $200 \times 200 \mathrm{~km}$ ), yet processes at smaller unresolved scales are important. Thus, the usefulness of the raw output from a GCM for climate change assessment in specific regions is limited. To bridge the spatial resolution gaps for GCMs to produce realistic local climate projections, downscaling techniques are usually applied to the GCM output.

Downscaling addresses the disparity between the coarse spatial scales of GCMs and observations from local meteorological stations (Hewitson and Crane 2006; Wilby and Wigley 1997). GCMs do not accurately predict local climate, but the internal consistency of these physically-based climate models provides most-likely estimates of ratios and differences (scaling factors) from historical (base case) to predicted scenarios (Loaiciga et al. 1996) for climatic variables, such as precipitation and temperature.

Improvements to climate projections will likely come by developing regional climate models and GCMs that couple groundwater and atmospheric processes (Cohen et al. 2006; Gutowski et al. 2002). The primary challenge is the difference in scale between the large (continental) scale of GCMs and the local scale of groundwater or surface-water models, requiring daily data and spatial resolution of a few square kilometers (Bouraoui et al. 1999; Loaiciga et al. 1996).

A clearer picture of the robust aspects of regional climate change is emerging due to improvement in model resolution, the simulation of processes of importance 
for regional change, and the expanding set of available simulations (Christensen et al. 2007). Downscaling techniques are grouped into two main types: (1) dynamic climate modelling, and (2) empirical statistical downscaling.

A number of different approaches have been used to derive climate data series for hydrogeological studies. The complexity of approaches for obtaining the climate data series appears to have increased in recent years, ranging from the use of global averages (Loaiciga et al. 1996; Zektser and Loaiciga 1993) to the use of regional "bulk" projections (Allen et al. 2004; Brouyere et al. 2004; Vaccaro 1992; Yusoff et al. 2002) to the direct application of downscaled climate data (Jyrkama and Sykes 2007; Scibek and Allen 2006b; Scibek et al. 2007; Serrat-Capdevila et al. 2007; Toews and Allen 2009) to the use of regional climate models (Rivard et al. 2008; van Roosmalen et al. 2007, 2009). Some of the early efforts to assess potential hydrologic impacts were reviewed by Gleik (1986). Most of these hydrologic models used daily weather series generated stochastically, with climate change shifts applied for future climate scenarios. Many studies have considered a range of GCMs or the average projection from several GCMs, and a few studies have considered different downscaling methods.

Green et al. (2011) discussed dynamic and statistical downscaling as alternatives for applying GCM results at the local scales of interest. Downscaled daily temperature generally compares well with observed data, but daily precipitation amounts often do not, particularly seasonal amounts and durations of wet and dry periods. Such discrepancies are important because of the highly nonlinear responses and sensitivities of dynamic vegetation growth and water use (transpiration) to precipitation regimes (Green et al. 2007). Allen et al. (2010) used state-of-the-art downscaling methods to predict variations in recharge. They found that the variability in recharge predictions indicates that the seasonal performance of the downscaling tool is important, and that a range of GCMs should be considered for water management planning. Yang et al. (2005) noted that sufficient potential evaporation (PE) data are rarely available to identify long term trends. Thus, they made use of limited daily data to study sub-weekly structure, and used this information to downscale weekly sequences. In this way the dual objectives of downscaling weekly data and simulating daily PE sequences could both be achieved.

\subsection{An Holistic View of Groundwater Hydrology: Selected Studies}

This section summarizes the current state of research and understanding of climatechange effects on subsurface hydrology and surface-subsurface hydrologic interactions. Climate change, including anthropogenic-global warming and natural climate variability, can affect the quantity and quality of various components in the global hydrologic cycle in the space, time, and frequency domains (Holman 2006; IPCC 2007b; Loaiciga et al. 1996; Milly et al. 2005; Sharif and Singh 1999). 


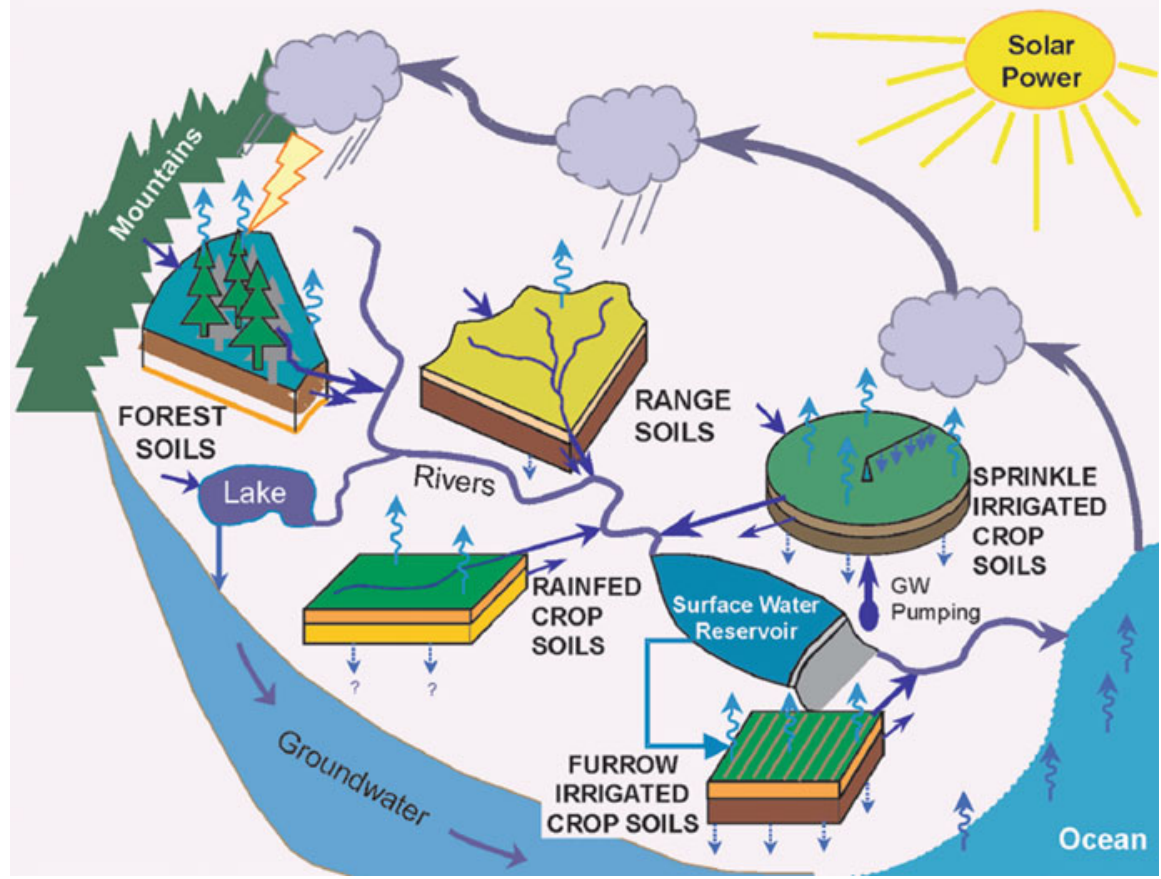

Fig. 5.1 Schematic illustration of the hydrologic cycle, including rainfed and irrigated agriculture with potential groundwater abstraction (Taken from Green and van Schilfgaarde 2006)

The components of the surface hydrologic cycle (Fig. 5.1) affected by climate change include atmospheric water vapor content, precipitation and evapotranspiration patterns, snow cover and melting of ice and glaciers, soil water content (SWC) and temperature, and surface runoff and stream flow (Bates et al. 2008). Such changes to the atmospheric and surface components of the global hydrologic cycle will likely result in changes to the subsurface hydrologic cycle within the soil, vadose zone, and aquifers of the world (Van Dijck et al. 2006). However, the potential effects of climate change on groundwater and groundwater sustainability are poorly understood. Gleeson et al. (2012) considered groundwater sustainability to include environmental, economic, or social consequences over multigenerational time scales (50-100 years). The relation between climate variables and groundwater is considered more complicated than with surface water (Holman 2006; IPCC 2007b). This understanding is confounded by the fact that groundwater-residence times can range from days to tens of thousands of years, which delays and disperses the effects of climate change, and challenges efforts to detect responses in the groundwater (Chen et al. 2004). 


\subsubsection{Precipitation, Evapotranspiration, and Surface Water Affect Groundwater}

Precipitation and evapotranspiration are particularly important because they directly affect groundwater recharge and indirectly affect human groundwater withdrawals or discharge. Even small changes in precipitation may lead to large changes in recharge in some semiarid and arid regions (Green et al. 2007; Sandstrom 1995; Woldeamlak et al. 2007). The current section describes recent research findings regarding how atmospheric and surface-water changes will generally affect subsurface hydrologic processes in the soil and vadose zone that control infiltration and recharge to groundwater resources.

Global warming is expected to increase the spatial variability in projected precipitation producing both positive and negative changes in regional precipitation, as well as changes in seasonal patterns (Cook et al. 2014; IPCC 2007b). There is little agreement on the direction and magnitude of predicted evapotranspiration patterns (Barnett et al. 2008). However, higher air temperatures are likely to increase evapotranspiration, which may result in a reduction in runoff and SWC in some regions (Chiew and McMahon 2002). In temperate regions where plants senesce during the winter, groundwater recharge and stream baseflow could be less affected than evapotranspiration would infer due to the seasonal timing of recharge events (e.g., Hunt et al. 2013). In seasons of above average precipitation, recharge is likely to increase, and water demand, such as for irrigated agriculture, will decline because of lower temperature and solar radiation and higher humidity in such periods (Rosenberg et al. 1999). In contrast, the spatial extent and temporal duration of extreme drought are predicted to increase under future climate change (Bates et al. 2008; IPCC 2007b).

The increased variability in precipitation, temperature, and evapotranspiration that is predicted under many climate-change scenarios will likely have variable effects on different aquifers and different locations within an aquifer depending on spatial variability in hydraulic properties and distance from the recharge area(s). Chen et al. (2002) observed that groundwater levels responded to precipitation variability in a mid-continent carbonate-rock aquifer differently from well to well because of the spatial differences in permeability of overlying sediments and recharge characteristics. Additionally, groundwater levels at some locations of the aquifer responded to high-frequency precipitation events while groundwater levels in other areas did not respond. The groundwater-level response to highfrequency events may indicate the existence of highly permeable channels or preferential-flow paths from land surface to the water table (Chen et al. 2002), or differences in thickness of the unsaturated zone (e.g., Hunt et al. 2008).

Other studies indicate that even modest increases in near-surface air temperatures will alter the hydrologic cycle substantially in snowmelt-dominated regions. Seasonal streamflow is altered because the snowpack acts as a reservoir for water storage (Barnett et al. 2008; Cayan et al. 2001; Hunt et al. 2013; Mote et al. 2005; Stewart et al. 2004; Tague et al. 2008). For example, Eckhardt and Ulbrich (2003) predicted a smaller proportion of the winter precipitation will fall as 
snow due to warming trends in mountainous regions of central Europe and that the spring-snowmelt peak will likely be reduced while the flood risk in winter will probably increase. Unless additional reservoir storage is created to account for the earlier snowmelt runoff, the use of groundwater may increase, where available, to offset the lack of surface water later in the season when water demands are typically higher.

Spatial differences in groundwater dynamics in mountainous regions also can play a substantial role in determining streamflow responses to warming (Tague et al. 2008; Tague and Grant 2009). Tague et al. (2008) suggested that groundwater dynamics, such as subsurface drainage, are as important as topographic differences in snow regimes in determining the response of mountain landscapes to climate change. The changes in streamflow, shifting spring and summer streamflow to the winter, will likely increase competition for reservoir storage and in-stream flow for endangered species (Payne et al. 2004) and lead to summer water shortage throughout the western United States (Tague et al. 2008) and other similar semiarid and arid regions globally.

In mountainous regions, how will forecasted changes to the surface hydrologic regime affect infiltration, evapotranspiration, SWC distribution, and ultimately recharge? Singleton and Moran (2010) noted that recharge mechanisms, storage capacity, and residence times of high elevation aquifers are poorly understood. The net change in recharge in mountain aquifers due to changes in the timing of snowpack melting is generally not known in direction or magnitude, making it difficult to predict the response of mountain groundwater systems to climate change (Singleton and Moran 2010). How will mountain-front recharge and recharge in other types of mountainous systems be affected by predicted changes in the snowmelt-dominated regions? A negative feedback between early timing of snowmelt and evapotranspiration may exist in snowmelt-dominated watersheds, as earlier snowmelt increases SWC in the season when potential evapotranspiration is relatively low (Barnett et al. 2008), which may increase infiltration and recharge in mountainous regions. Later in the year, when potential evapotranspiration is greater, the shift in snowmelt timing may reduce SWC, which again reduces the effect of evapotranspiration change but has an unknown effect on net infiltration and recharge. These and other questions remain regarding subsurface hydrologic responses to climate-change effects on surface-water hydrology.

\subsubsection{Soil Water and Vadose Zone Hydrology}

Climate-related variables that have a substantial control on soil water include spatiotemporal patterns in precipitation, evapotranspiration, and surface-water conditions. Land use, soil texture, slope, and other biological, chemical, and physical characteristics also are known to affect SWC (Jasper et al. 2006) with associated effects on groundwater and baseflow to streams (Wang et al. 2009). Seneviratne et al. (2010) provided an extensive review of interactions and 
feedbacks between SWC and climate, specifically atmospheric temperature and precipitation.

Climate change and variability are expected to have profound effects on soil water and temperature (Jasper et al. 2006; Jungkunst et al. 2008). Soil water content and temperature are important factors in terrestrial biogeochemical reactions, landatmosphere interactions, and a critical determinant of terrestrial climate. Variability in vadose-zone hydrology, shallow water tables that support SWC, and ultimately infiltration that feeds aquifers are also affected by SWC and temperature (Cohen et al. 2006; Fan et al. 2007). Spatial variations in SWC also influence atmospheric processes, such as the cumulus convective rainfall (Pielke 2001). Jungkunst et al. (2008) noted that some soil types, such as hydromorphic soils (i.e., soils which formed under prolonged periods of water saturation with seasonal aeration), will likely exhibit a higher climate-change feedback potential than other, wellaerated soils because soil organic matter losses in hydromorphic soils are predicted to be much greater than those from well-aerated soils.

Water evaporated from soils and transpired by plants is recirculated into the atmosphere, thus promoting a positive feedback mechanism for precipitation (Salas et al. 2014). The importance of this feedback depends upon the scale of interest. At the global scale, circulation of water between the land, atmosphere, and ocean is obviously important. Simulation of such circulation patterns is the basis for projecting future climates in GCMs. Moving down in scale, the coupling of landatmosphere interactions may become looser. For this reason, hydrologic models are typically driven by measured precipitation without considering feedbacks. However, regional-scale feedback has been shown to account for a "weakly dependent" pattern of annual rainfall via "precipitation recycling" in central Sudan (Elthahir 1989), the Amazon Basin (Eltahir and Bras 1994), and other regions of the world (e.g. Eltahir and Bras 1996). At watershed areas $<90,000 \mathrm{~km}^{2}$, however, the recycling ratio $(\mathrm{P} / \mathrm{ET})$ of a watershed is expected to be less than $10 \%$ based on simple scaling of annual precipitation in the Amazon basin (Eltahir 1993).

Koster et al. (2006) described the Global Land-Atmosphere Coupling Experiment (GLACE) as a model intercomparison study addressing how soil moisture anomalies affect precipitation at the GCM grid-cell resolution over the globe. The simulated strength of coupling between soil moisture and precipitation varied widely, but the ensemble multi-GCM results provided "hot spots" of relatively strong coupling based on a precipitation similarity metric. All studies indicate that the land's effect on rainfall is relatively small, though significant in places, relative to other atmospheric processes.

The vadose zone is the region between the land surface and saturated zone through which groundwater recharge occurs. It comprises complex interactions between thermal-hydrologic-geochemical processes that can affect groundwater quantity and quality. The timing and amount of groundwater recharge can be affected by the thickness of the vadose zone, as simulated for a temperate zone (Hunt et al. 2008). The vadose zone of some semiarid and arid regions responds slowly to terrestrial climate, and its long-term dynamics pose important challenges for understanding of the effects of climate change and variability on the vadose 
zone (Glassley et al. 2003; Phillips 1994). Glassley et al. (2003) showed that vadose-zone pore-water chemistries in the southwestern United States are still adjusting to relatively recent, post-glacial climate changes, and are not at a steady state (Phillips 1994).

\subsubsection{Saturated Zone/Groundwater}

Groundwater is an important component of the global water balance (Chap. 2). The use of groundwater can mitigate droughts, because many aquifers have a large storage capacity and are potentially less sensitive to short-term climate variability than surface-water bodies, which often rely on groundwater discharge to maintain baseflow conditions (Dragoni and Sukhija 2008). However, the ability to use groundwater storage to buffer rainfall deficits that affect surface-water resources will be constrained by the need to protect groundwater-dependent environmental systems (Skinner 2008).

Groundwater has and will continue to respond to changes in climate. Paleoclimate-change conditions and subsequent responses in recharge, discharge, and changes in storage are preserved in the records of groundwater major and traceelement chemistry, stable and radioactive isotope composition, and noble gas content (Bajjali and Abu-Jaber 2001; Castro et al. 2007; Hendry and Woodbury 2007). Other important components of hydrogeological systems include groundwater-fed lakes in arid and semiarid regions (Gasse 2000) and temperate climates (Hunt et al. 2013), pore-water chemistry of the vadose zone (Zuppi and Sacchi 2004), and subsurface-thermal regimes (Miyakoshi et al. 2005; Taniguchi 2002; Taniguchi et al. 2008).

Groundwater acts as a low-pass filter and provides long time-series of reconstructed temperatures and information on atmospheric-moisture transport patterns (Gasse 2000). Hiscock and Lloyd's (1992) paleohydrogeologic reconstruction of the North Lincolnshire Chalk aquifer in England revealed that recharge during the late Pleistocene (approximately the last 140,000 years) has been restricted to periods when the climate and sea-level position were similar to those of the present day. Forest clearance since about 5,000 years ago is likely to have resulted in increased recharge rates and enhanced the rate of Chalk permeability development (Hiscock and Lloyd 1992). Falling global sea levels during the last five glacial periods of the Pleistocene Ice Ages likely resulted in increased hydraulic heads in inland aquifers relative to those in the continental shelf, enhancing groundwater flow toward the coast (Faure et al. 2002). Faure et al. (2002) suggested that the "coastal oases" that formed from the groundwater discharge as springs along the exposed continental shelf had profound effects on biodiversity and carbon storage during periods of severe climatic stress. At present sea levels, submarine groundwater discharge is a well-established phenomenon that contributes substantial mass flux to oceans (Burnett et al. 2006). Gasse (2000) recommended that future paleohydrological research needs to develop solid chronologies, but also to analyze the mechanisms of water storage and losses in aquifers, obtain quantitative 
reconstructions of hydrological cycles, and identify atmospheric-moisture transport patterns at regional scales that affect groundwater resources.

Groundwater resources have been affected by a number of non-climatic forcings, such as contamination, reduction in streamflow (reduction in recharge), and lowering of the water table and decreased storage due to groundwater mining (primarily for irrigated agriculture). Kundzewicz et al. (2007) noted that climaterelated changes to groundwater have been relatively small compared with non-climate drivers. Juckem et al. (2008) demonstrated that changes in landuse influence how climate change is translated to the groundwater system. Additionally, groundwater systems often respond more slowly and have a more substantial temporal lag to climate change than surface-water systems (Chen et al. 2004; Gurdak 2008; Gurdak et al. 2007; Hanson et al. 2004, 2006; Kundzewicz et al. 2007). Persistent and severe dry periods have even altered the hydraulic properties of aquifers, such as the transmissivity of a regional karst aquifer in France (Laroque et al. 1998).

Current vulnerabilities in water resources are strongly correlated with climate variability, due largely to precipitation variability, especially for semiarid and arid regions (Kundzewicz et al. 2007; Ouysse et al. 2010). Such regions are particularly vulnerable to climate change if groundwater reservoirs are small or not available. Even if groundwater resources are currently available, communities become more vulnerable to climate change if the ratio of stored groundwater volumes to recharge is smaller and if there are no other local water resources, such as in the isolated alluvial aquifers of Yemen (van der Gun 2010). Groundwater levels correlate more strongly with precipitation than with temperature, but temperature becomes more important for shallow aquifers (Kundzewicz et al. 2007). The complexity is exacerbated because predictions of global precipitation spatiotemporal patterns are less certain than are predicted temperature patterns. As a result, the IPCC (2007a) stated that there is no evidence for ubiquitous climate-related trends in groundwater.

Green et al. (2011) discussed climate-change effects on components of the groundwater system in some detail, including recharge, discharge, flow and storage, surface-subsurface hydrological interactions, and groundwater quality. These topics are summarized below.

\subsubsection{Groundwater Recharge}

Predicting the dynamics and processes interactions affecting groundwater recharge over time requires a reliable prediction of critical climate variables (Gurdak et al. 2008; Herrera-Pantoja and Hiscock 2008; Jyrkama and Sykes 2007). Recharge occurs via two general pathways in many environments: diffuse recharge to the water table and focused recharge that occurs at locations where surface-water flow is concentrated at the land surface, including stream channels, lakes, topographic depressions, irrigated-agricultural land, and other macropore, preferential-flow pathways (Small 2005). Thus, recharge is a spatially and temporally complex, 
sensitive function of the climate regimes, local geology and soil, topography, vegetation, surface-water hydrology, coastal flooding, and land-use activities (Candela et al. 2009; de Vries and Simmers 2002; Green et al. 2007; Holman 2006; McMahon et al. 2006). Understanding of the controls on recharge is improving (Healy 2010; Scanlon et al. 2002, 2006), but knowledge of recharge rates and mechanisms is often poor (Kundzewicz et al. 2007).

Recharge will be affected by forecasted changes in precipitation patterns. Sharif and Singh (1999) divided groundwater resources into four categories:

1. confined aquifers with upper impermeable layers where recharge primarily occurs from precipitation where the water-bearing formations outcrop at land surface.

2. unconfined (phreatic) aquifers in wet regions where rainfall is high and evapotranspiration is low. These aquifers are highly renewable because precipitation exceeds evapotranspiration throughout much of year.

3. unconfined aquifers in semiarid and arid regions that are likely to have variable annual balances between precipitation and evapotranspiration and a general drying trend under most climate-change forecasts.

4. coastal aquifers vulnerable to rising sea levels (Döll 2009) and salt-water intrusion.

Climate change and variability will likely have variable long-term effects on recharge rates and mechanisms (Aguilera and Murillo 2009; Green et al. 2007; Kundzewicz et al. 2007; Vaccaro 1992). Many climate-change studies have predicted reduced recharge (Herrera-Pantoja and Hiscock 2008); however, the effects of climate change on recharge may not necessarily be negative in all aquifers during all periods of time (Döll 2009; Gurdak and Roe 2010; Jyrkama and Sykes 2007). Case studies (listed chronologically) included various predictions for recharge in Germany (2001), eastern England (2002), western Canada (2004) and Scibek and Allen (2006a), Ontario, Canada (Döll 2009; Gurdak and Roe 2010; Jyrkama and Sykes 2007), western United States (Dettinger and Earman 2007), Russia(Kovalevskii 2007), Australia (Green et al. 2007), and upper Midwestern United States (Hunt et al. 2013). Overall, simulated trends in recharge were highly variable depending upon the base climate zone and combinations of soil and vegetation types.

Temporal climate variability, especially variability in precipitation, can have substantial effects on recharge and groundwater levels. For example, Thomsen (1989) noted that recharge in most of western Denmark at the end of the nineteenth century was only half of the recharge during the period 1964-1983 because of much greater winter rainfall. A similar study of recharge sensitivity in Western Australia by Sharma (1989) concluded that a $\pm 20 \%$ change in rainfall would result in a $\pm 30 \%$ change in recharge beneath natural grasslands and $\pm 80 \%$ change in recharge beneath a pine plantation, indicating that recharge is greatly influenced by land use and precipitation variability. Subsequently, Green et al. (2007) demonstrated the potential importance of changes in the timing of rainfall regimes 
on evapotranspiration and recharge. Eckhardt and Ulbrich (2003) predicted that mean monthly recharge and streamflow will be reduced by up to $50 \%$ under changed precipitation regimes, that may lead to issues of local water quality, groundwater withdrawals, and hydropower generation.

Groundwater recharge and corresponding vulnerability indices have been mapped globally using a simple water balance model (Döll 2009). As noted above, estimates of recharge vary spatially with vegetation, soils and land use, and change in time depending upon the emissions scenario. For the mid-twenty-first century, Döll (2009) estimated that approximately $18 \%$ of the global population would be affected by decreased recharge of at least $10 \%$, and up to a third of the population may experience increased recharge of at least $10 \%$. The latter increases may have pronounced effects in areas with already shallow water tables, which may be more significant than sea level rise in coastal aquifers (Kundzewicz and Döll 2009).

Temperature-depth profiles in deep boreholes are useful for estimating groundsurface temperature history and recharge, because climate change at the ground surface is stored in the subsurface thermal regime (Miyakoshi et al. 2005; Taniguchi 2002). Taniguchi (2002) showed that subsurface thermal profiles near Tokyo, Japan reveal that recharge rates increased from the 1890 s to 1940 s and decreased from the 1940 s to 1990 s, in large part related to climatic variations in the precipitation regime. Climatic conditions affect the direction of groundwater flow and the relation between surface-water bodies and subsurface-water resources. and Dragoni (Cambi and Dragoni 2000; Dragoni and Sukhija 2008; Winter 1999).

Permafrost-groundwater dynamics respond to climate change at many scales, particularly in sub-permafrost groundwater that is highly climate dependent (Haldorsen 2010). Recharge is likely to increase in areas of Alaska that experience permafrost thaw (Dragoni and Sukhija 2008; Kitabata et al. 2006). Additionally, Walvoord and Striegl (2007) proposed that long-term (>30 year) streamflow records of the Yukon River in Alaska indicate a general upward trend in groundwater contribution to streamflow. In the Qinghai-Tibet Plateau of China, groundwater flow may play an important role in permafrost degradation (Cheng and $\mathrm{Wu}$ 2007), where degrading permafrost caused regional lowering of the groundwater table, which has resulted in falling lake levels, shrinking wetlands, and degenerating grasslands. Climate change is expected to reduce snow cover and soil frost in boreal environments of Finland, which will increase winter floods and cause the maximum recharge and water levels to occur earlier in the year in shallow unconfined aquifers (Okkonen et al. 2009; Okkonen and Kløve 2010).

Groundwater is a crucial component of the hydrologic cycle and many waterresource projects. Thus, potential effects of climate change on recharge deserve more attention (Dettinger and Earman 2007). Scientists currently lack the necessary tools and data, such as long-term continuous monitoring of recharge processes to confidently predict recharge responses to future climate change in most environments. In many regions of the world, it is unknown whether recharge will increase or decrease under predicted climate change (Green et al. 2007). The location and timing of recharge and associated effects on groundwater supplies 
are insufficiently understood under future climate change and variability (Gurdak et al. 2007; Sophocleous 2004). However, water resources, especially in many semiarid and arid regions, are particularly vulnerable to the effects of climate change (Aguilera and Murillo 2009; Barthel et al. 2009; Novicky et al. 2010).

\subsubsection{Groundwater Discharge}

Groundwater discharge is the loss of water from an aquifer to a surface-water body, the atmosphere, or abstraction for human uses. Groundwater depletion (see Chap. 3) occurs when rates of groundwater recharge are less than rates of discharge. Over the last 50 years, groundwater depletion from direct or indirect effects of climate change and human activities, such as groundwater pumping for irrigated agriculture or urban centers (Bouraoui et al. 1999; Dams et al. 2007), has expanded from a local issue to one that affects large regions in many countries throughout the world (Alley et al. 2002; Brouyere et al. 2004; Hsu et al. 2007; Martin-Rosales et al. 2007; Moustadraf et al. 2008). Changing global groundwater discharge has even contributed to sea-level rise during the past century (Taylor et al. 2013). In particular, the rise in sea level would have been even greater if substantial quantities of water had not been stored in land-surface reservoirs or channeled into aquifers by irrigation return-flow (Sahagian et al. 1994).

Some groundwater resources could be affected substantially by climate change even if the present groundwater pumping rates are not increased, such as in the Edward aquifer in Texas, USA (Loaiciga et al. 2000) and the Chalk aquifer in eastern England (Yusoff et al. 2002). Direct or indirect effects of climate change on groundwater discharge include soil degradation, changes in water demand, and changes in irrigation or land-use practices (Brouyere et al. 2004).

The notable increase in groundwater depletion beginning in the mid-1900s is consistent with increased population in many regions and the development of highcapacity well pumps that are used to support agricultural industries and public and private drinking-water supplies. For example, parts of the High Plains (or Ogallala) aquifer in the United States have had substantial water-level declines since the 1950s that range from 3 to more than $50 \mathrm{~m}$ depending on the relative magnitudes of discharge and recharge in the aquifer (McMahon et al. 2007). Declining baseflow in the Sand Hills of Nebraska, USA has also been correlated with soil texture (Wang et al. 2009).

Under some climate scenarios, many regions may receive more precipitation. Woldeamlak et al. (2007) showed that under wet-climate scenarios, runoff was the most sensitive component, and when combined with the predicted increases in groundwater discharge, may result in rising groundwater levels and winter precipitation that increase the risk of flooding. Under dry-climate scenarios, recharge was the most sensitive component and decreases in all seasons, resulting in annual groundwater level declines by as much as $3 \mathrm{~m}$. This could have adverse effects on local aquatic life in local wetlands and riverine ecosystems that rely on groundwater discharge to support baseflow (Woldeamlak et al. 2007). 
Submarine groundwater discharge (SGD), or the net groundwater discharge that occurs beneath the ocean, is a large component of the global hydrologic cycle, accounting for as much as $12,000 \mathrm{~km}^{3} /$ year (Speidel and Agnew 1988) and may otherwise provide fresh water for human needs (Burnett et al. 2006; Taniguchi 2000). Quantifying submarine groundwater discharge and the biogeochemical effects on the ocean has important implications for understanding climate-change effects on oceanic processes (Windom et al. 2006). For example, high dissolved nitrogen-phosphorus ratios in SGD relative to surface waters may drive the coastal oceans toward phosphorus limitation within the coming decades, perhaps changing the present nitrogen-limited coastal primary production (Slomp and Van Cappellen 2004; Taniguchi et al. 2008).

\subsubsection{Aquifer Flow and Storage}

Alley (2001) noted the critical importance of groundwater storage in successfully dealing with climate change and variability. In particular, changes in groundwater storage and agricultural groundwater pumping in active semiarid basins are substantial, yet poorly understood, components of the water balance (Ruud et al. 2004). The use of groundwater storage to moderate the effects of drought increases in importance as surface-water storage becomes more limited, especially during drought periods (Alley 2001).

Prior to development, the water in storage of most $\mathrm{s}$ worldwide was based on local-climate conditions, ecological demands, and interactions with surface water. Water-table declines and loss of storage worldwide during the second half of the twentieth century were consistent with the development of high-capacity well pumps, aquifer development for human use, and a warming climate (Kertesz and Mika 1999). Although some regions of the world, including parts of Russia (Dzhamalov et al. 2008), may have sufficiently reliable groundwater storage under future climate change and variability, the rate of global groundwater depletion was approximately $1.6 \times 10^{11} \mathrm{~m}^{3} /$ year during the second half of the twentieth century (Brown 2001). Postel (2001) estimated that if this rate of groundwater depletion continues, the number of people globally that will live in water-stressed countries will increase from 500 million to 3 billion by the year 2025. This problem will likely be compounded by future global-population growth, which correlates with higher groundwater pumping rates that further threaten the groundwater sustainability of many aquifers at the global scale (Loaiciga 2003). Taniguchi et al. (2008) showed that population growth and the associated increase in demand for water resources, groundwater pumping, and temporary loss of groundwater storage, have resulted in substantial land-subsidence problems for many Asian urban centers. Bultot et al. (1988) simulated changes in groundwater storage of three aquifers in Belgium in response to climate change (a doubling of $\mathrm{CO}_{2}$ in their study) that were largely dependent on aquifer specific hydrogeologic properties, such as transmissivity, presence of perched lens, or confining units. 
The water-table declines and loss of groundwater storage in the High Plains aquifer in the United States were consistently large from about the 1940s, when aquifer development became widespread across the aquifer, until about the early 1980s when rates of water-table drawdown diminished. Rosenberg et al. (1999) noted that this turn-around occurred despite a very large increase in the total acreage of irrigated agriculture between the early 1980s and mid-1990s. McGuire (2011) attributed the changes in water tables over this period to more efficient irrigation methods and economic factors, but also to the fact that precipitation in the High Plains was well above normal between 1980 and 1999 (Garbrecht and Rossel 2002).

The responsiveness of the High Plains aquifer, and other similar aquifers, is strongly suggestive that natural and human-induced changes in climate can profoundly affect the availability and future sustainability of groundwater resources. The above-normal precipitation across the High Plains aquifer region between 1980 and the late-1990s can be attributed to teleconnections from natural variations in sea-surface temperatures and atmospheric pressures across the Atlantic and Pacific Oceans (Garbrecht and Rossel 2002). During the 1980s and early 1990s, the Pacific Decadal Oscillation (PDO) (Mantua and Hare 2002) was in the positive phase of variability and the Atlantic Multidecadal Oscillation (AMO) (Kerr 2000) was in the negative phase of variability, which generally results in wetter conditions and lower frequency of drought for the High Plains region (McCabe et al. 2004).

Natural climate variability occurs on all time scales, from annual to decadal, centennial, and millennial time scales. Ghil (2002) noted that the complex nature of climate variability on multiple time scales is a major obstacle to the reliable characterisation of global climate change resulting from human activities. When anthropogenic effects on aquifers are on the same time scale as some natural climate variabilities, it is difficult to distinguish between the two (Gurdak et al. 2007; Hanson et al. 2004; Mayer and Congdon 2008). These natural variations in climate, when combined, can have profound effects on the surface-hydrologic cycle largely because of the magnitude and phase relation that can cause average or extreme climate forcings (Hanson and Dettinger 2005), such as drought, low flow in streams, changes to water quality, and adverse effects on stream ecosystems (Caruso 2002).

As a result, research efforts have characterised subsurface hydrologic and geochemical responses to climate variability on interannual to multidecadal time scales because variability on these time scales has the most tangible implications for water-resource management (Chen et al. 2002, 2004; Gurdak et al. 2007; Hanson and Dettinger 2005; Hanson et al. 2004, 2006). Climate forcings on these timescales, such as the PDO, AMO, and the El Niño/Southern Oscillation (ENSO), substantially control recharge and water-table fluctuations of the High Plains aquifer (Gurdak et al. 2007, 2008, 2009; McMahon et al. 2007), other aquifer systems of the southwestern United States (Barco et al. 2010; Hanson et al. 2006; Hanson et al. 2004), and a number of other aquifers worldwide (Ngongondo 2006), including those in many small, tropical islands in the Pacific, Indian, and Atlantic oceans (White et al. 2007). A few studies have relied on long-term historical 
hydrologic time series to identify climate-variability effects on groundwater levels (Chen et al. 2004; Gurdak et al. 2007; White et al. 2007).

Many questions remain regarding the control of natural climate forcings on subsurface hydrologic processes and how anthropogenic global warming may affect the frequency and magnitude of these forcings. Historical temporal patterns in the hydrologic cycle may not provide a reasonable guide to future climate conditions and hydrologic processes (Bates et al. 2008; IPCC 2007b). Future climate conditions may have substantial consequences for groundwater management and infrastructure (van der Gun 2010). Statistical stationarity of the temporal hydroclimatic dynamics is not a reasonable assumption under climate variability that has low-frequency and internal variability (such as ENSO, PDO, or AMO (McCabe et al. 2004)). Milly et al. (2008) suggested that stationarity assumptions must be replaced by nonstationary conceptual and statistical models for relevant variables in the hydroclimatic system to be properly analyzed. The concept of "shifts" instead of gradual changes in temporal statistics has been applied previously to hydrological systems (Salas and Boes 1980; Salas et al. 2014).

\subsubsection{Surface-Subsurface Hydrological Interactions}

Climate change has substantial implications for surface-water processes (Gosling et al. 2010), including groundwater/surface-water interactions. Some studies suggest that climate change will result in less surface-water availability, which will likely increase the need for groundwater development (Chen et al. 2004; Hsu et al. 2007). For example, climate change may extend the dry season of no or very low flows in some semiarid and arid regions, which can have a substantial effect on the overall water resources of the region if no deep or otherwise reliable groundwater resources are available (Giertz et al. 2006). Surface-water storage structures can play a vital role in augmenting groundwater recharge, especially in semiarid and arid regions (Sharda et al. 2006). Accurate low-flow stream measurements are important for groundwater-fed streams to assess the potential effects of climate change and variability, and to assess in-stream flow requirements and the nature of groundwater-surface interactions (Berg and Allen 2007). Cohen et al. (2006) showed that the responses in surface-water bodies to climate change were controlled in part by groundwater hydrodynamics and position within the watershed; water-table fluctuations were consistent and had larger-amplitude fluctuations with lake levels within the upland portions of a watershed in central Minnesota, USA. Groundwater-supported evapotranspiration varied with topography and aquifer-hydraulic conductivity, and small yet important feedbacks exist between groundwater and atmospheric processes on decadal and longer time scales. Moreover, hydrologic sensitivity of a watershed to climate change depends on feedbacks between groundwater, overland flow, and land-surface water and energy balance (Ferguson and Maxwell 2010) as well as the hydrologic regime such as lakes with and without stream outflows (e.g., Hunt et al. 2013). 
The magnitude and seasonality of groundwater feedbacks to surface hydrologic processes is highly sensitive to climate change (Ferguson and Maxwell 2010).

A projected increase in the frequency of droughts has implications for surfacegroundwater interactions. For example, the summer of 2003 was the hottest in Europe in more than 500 years, linked to an estimated 500 deaths in the Netherlands alone, but this could become a close-to-normal summer by about 2050 (Kabat et al. 2005). The extremely low freshwater discharge by the river Rhine in 2003 resulted in groundwater seepage of seawater to the low-lying delta, which threatened substantial areas of Dutch agriculture and horticulture. As a result, studies are underway to develop freshwater canals and additional summer water storage facilities for the region. Across regions of the High Plains aquifer in Kansas, USA, streamflow declines are historically caused by high rates of groundwater pumping, but also correlate with climate variability since the mid-1980s (Brikowski 2008). Projected climate change for the Kansas region will likely continue streamflow declines, resulting in severe consequences for surface-water supply and the strong possibility of unsustainable surface storage of water resources in the region. This will likely create even more pressure on the groundwater resources of the already-stressed High Plains aquifer. Similar findings have been identified in other climate regions, including humid, tropical and arctic catchments. Both observations and modelling suggest that climate-warming induced permafrost degradation will markedly increase baseflows of arctic and subarctic rivers and streams (Bense et al. 2009; St. Jacques and Sauchyn 2009; Walvoord and Striegl 2007).

Understanding future climate change effects will be crucial, especially for groundwater/surface-water resources already close to the limits of sustainability and under forecasted drought conditions. Groundwater withdrawals can affect streamflow strongly during dry periods (Lee and Chung 2007). Therefore, it is critically important to accurately understand the links between climate change and variations and the cycles of supply and demand that drive recharge and withdrawal of water resources. Accurate projections of climate change and variations and simulations of the responses in the water-resources system are required (Hanson and Dettinger 2005).

\subsubsection{Groundwater Quality}

Most studies of the effects of climate change and variability on groundwater have focused on processes that affect water quantity. Relatively few studies of climate change and variability effects on groundwater have focused on processes that will affect groundwater quality. Groundwater quality is a function of the chemical, physical, and biological characteristics of the resource. Thus, groundwater quality is expected to respond to changes in climate and human activities because of the influences of recharge, discharge, and land use on groundwater systems. The quality of water is related to specific water-use standards. The protection and enhancement of groundwater quality has been a high-priority environmental 
concern because of the direct implications for drinking-water health standards (Alley 1993). Also, water quality may be a limiting factor for other uses of groundwater, such as agriculture, industry, or ecosystem needs. Therefore, sustainability of water supplies under future climate change and variability is not only dependent on the quantity and quality of groundwater resources, but also on the physical hydrogeologic characteristics of the aquifer, laws, regulations, and socioeconomic factors that control the demand and use of groundwater (Reilly et al. 2008).

Global change may affect the quality of groundwater in many ways (Alley 2001; Dragoni and Sukhija 2008). Changes to recharge rates, mechanisms, and locations can affect contaminant transport, which may lead to erroneous conclusions about temporal trends in groundwater quality, particularly if only a few samples have been collected over time (Alley 2001). For example, recharge during relatively dry periods may have a greater concentration of salts and total-dissolved solids (TDS), while recharge during relatively wet periods may have a relatively lower TDS concentration (Sukhija et al. 1998). Climate variability on interannual to multidecadal timescales has been linked with changes in spatiotemporal-precipitation patterns that can result in substantial infiltration events that mobilise large, porewater chloride and nitrate reservoirs in the vadose zone of aquifers in semiarid and arid regions (Gurdak et al. 2007, 2008). Groundwater quality may deteriorate substantially if these large chemical reservoirs reach the water table.

Coastal regions support approximately one-quarter of the global population, but contain less than $10 \%$ of the global-renewable water supply and are undergoing rapid-population growth (Kundzewicz et al. 2007). Sea-level rise, spatiotemporal changes in precipitation and evapotranspiration, which affect recharge, and increased groundwater pumping will likely result in more groundwater salinisation in many coastal regions (Barrocu and Dahab 2010; Beuhler 2003; IPCC 2007a; Klein and Nicholls 1999; Kundzewicz et al. 2007; Moustadraf et al. 2008; Oude Essink 1996; Oude Essink 2001, 2004; Oude Essink et al. 2010; Pierson et al. 2001; Ranjan et al. 2006a, b; Sharif and Singh 1999; Yechieli et al. 2010). Vandenbohede et al. (2008) simulated a likely $15 \%$ increase in recharge across a Belgian coastal aquifer over the next 100 years. A $0.4 \mathrm{~m}$ sea-level rise increased simulated groundwater flow of fresh water toward low-lying inland areas and decreased groundwater flow toward the sea, while the increase in recharge resulted in more groundwater flow toward both low-lying inland areas and the sea. Therefore, brackish and salt water present in low-lying areas will be pushed back. Salt-water intrusion may occur from the low-lying areas into dunes, which could affect the ecology of the dunes and the drainage system used in most low-lying areas (Vandenbohede et al. 2008).

Lambrakis and Kallergis (2001) showed that over-pumping, combined with a dry period, has led to a substantial decline in groundwater quality of many Greek coastal aquifers. When simulated groundwater pumping was discontinued, the reverse process of groundwater freshening was a relatively long process, ranging from 15 to 10,000 years depending on the local geochemical conditions and flow regime (Lambrakis and Kallergis 2001). Such long periods of groundwater 
freshening highlight the importance of minimising the initial saltwater intrusion. The salinisation of groundwater may, in turn, affect the water quality in many rivers and estuaries (Burkett et al. 2002). Due to increasing human population, agricultural development and economic activities, the shortage of fresh groundwater for domestic, agricultural, and industrial purposes becomes more striking in coastal low-lying deltaic areas like the Mississippi, Nile, Mekong, Ganges, Po, and RhineScheldt deltas (Oude Essink 1996).

Reduced groundwater recharge and increased pumping may disrupt the current balance of the freshwater/saline water boundary, resulting in saline water intrusion in coastal basins, and even inland aquifers, such as the carbonate rock aquifer in the Winnipeg region of Canada (Chen et al. 2004; Grasby and Betcher 2002). Increased groundwater pumping could induce upward leakage of groundwater with poorerwater quality, such as in the High Plains aquifer (McMahon et al. 2007). Alley (2001) also noted that the combined effects of groundwater development and climate change may lead to less dilution of contaminants in streams during low flow (baseflow from groundwater) than was assumed in setting stream-discharge permits.

A wide range of additional climate-change effects on groundwater quality are possible. Kovalevskii (2007) showed that under projected climate change, many regions of Russia will likely have increased rates of recharge that may increase rates of contaminant transport and groundwater vulnerability to various distributed and point-source contamination. The combination of the heat-island effect from urbanisation and global warming on subsurface temperatures has implications for groundwater quality because of changes to subsurface biogeochemical reactions (Knorr et al. 2005; Taniguchi et al. 2008). Additional research is needed to understand and predict the full range of effects on groundwater quality from changes in the subsurface thermal regime and various biogeochemical reactions (Aureli and Taniguchi 2006). Climate change and the global trend of increasing urbanisation may also increase flood vulnerability (Aureli and Taniguchi 2006). Flooding in urban areas could increase loading of common urban contaminants like oil, solvents, and sewage to groundwater.

Nutrient transport rates beneath agricultural lands may also be sensitive to climate change. A study of nitrogen $(\mathrm{N})$ and phosphorus $(\mathrm{P})$ in Sweden (Destouni and Darracq 2009) illustrated subsurface controls on nutrient loading to coastal areas that were relatively insensitive to projected climate due to a lagged response to historical nutrient inputs. However, Destouni and Darracq (2009) noted groundwater-induced emissions of greenhouse gases such as $\mathrm{N}_{2} \mathrm{O}$ as a neglected feedback mechanism.

Relatively few studies have explored climate-change effects on pesticide fate and transport in the subsurface. Bloomfield et al. (2006) identified that the main climate drivers for changing pesticide fate and behavior are changes in rainfall seasonality and intensity, and increased temperatures. However, indirect impacts, such as land-use change are likely to have a more substantial effect on pesticides than the direct effects of climate change on pesticide fate and transport. Bloomfield et al. (2006) noted the overall effect of climate change on pesticide fate and 
transport is likely to be highly variable and challenging to predict because of the uncertainties associated with climate predictions.

Long-term monitoring efforts will likely provide the necessary data to observe and understand climate-related spatiotemporal trends in groundwater quality (McMahon et al. 2007; Dragoni and Sukhija 2008). Groundwater-remediation practices may consider climate-change prediction in site design. Warner (2007) noted that climate change, including shifting rainfall patterns, rising sea levels, and fluctuating river levels may affect the potential failure of a fixed-in-place remediation strategy, such as in-situ permeable reactive barrier, to capture its intended plume. The relatively short life expectancy of most engineered groundwaterremediation systems precludes the development of economically viable remediation systems for the long-term and uncertain nature of climate predictions. Warner (2007) suggested that flexibility in design of remediation systems may account for future shifts in the hydraulic gradient caused by climate change, or more likely, from human activities and groundwater pumping.

\subsection{Methods for Investigating Global Change Beneath the Surface}

Green et al. (2011) explored and reviewed a range of techniques for exploring subsurface effects of climate change, which are summarized here. Methods available to detect temporal changes in groundwater quantity and quality are numerous and range markedly in observation scale and "directness" of observation. The most direct, but also smallest-scale observations are obtained from head measurements in piezometers and water quality measurements of water samples obtained in wells. While in-situ measurements arguably provide the most accurate and reliable measures to detect change, spatial variability and transfer of information across scales (i.e., scaling) must be considered. Moreover, observation networks do not exist across large parts of the globe, and installing and maintaining measurement systems is expensive and labor intensive. To evaluate temporal trends at regional to global scales and to study their relationship to change in regional to global climate and human activities, studies of extensive data sets (monitoring networks) of such "point-data" are required. Hydroclimatically similar regions can be explored using a global database of historical climate data. Similarity between historical climates in different regions is a necessary starting point but may not be sufficient to constitute analogous climate change scenarios.

Most hydrogeophysical methods have the advantage that they allow detection of change over larger volumes of the subsurface, but at the expense of detail, notably regarding water chemistry. Remote sensing of systematic change in the recent past and future across the globe has limited ability to "see" watershed-scale groundwater. The major benefit of remote sensing technologies is their ability to access spatial information in remote areas where in-situ monitoring is sparse or non-existent. Furthermore, conjunctive use of well data, hydrogeophysics and remote sensing is essential. 


\subsubsection{Age Dating and Chemical Proxies}

Tracer methods are standard tools of hydrologists to obtain constraints on the age of groundwater and on the processes and conditions experienced during recharge and upon transit in the groundwater system (Clark and Fritz 1997; Cook and Herczeg 2000; Kooi 2008b; Loosli et al. 2001; Plummer 1993). Age dating refers to methods that aim to constrain the timing of recharge, often via the time since recharge. Groundwater ages can be estimated using radioactive isotopes with well-known, stable source concentrations (e.g., ${ }^{14} \mathrm{C}$ ), radioactive isotopes with variable source concentration and a daughter isotope that can be fairly uniquely linked to the mother species (e.g., ${ }^{3} \mathrm{H} /{ }^{3} \mathrm{He}$ ), or conservative chemical species which exhibit negligible decay and which have a well-known, systematically changing source concentration (e.g., ${ }^{85} \mathrm{Kr}, \mathrm{CFC}$ 's, $\mathrm{SF}_{6}$ ).

These "direct methods" of age dating, in principle, allow construction of a continuous record of water age with distance along a flow path, thereby potentially revealing temporal changes in recharge. Accuracy of age-dating methods covering time scales of 100-500 years is low, making temporal changes in this age-range difficult to resolve.

Several "indirect" age-dating methods provide additional useful constraints on groundwater age. These methods generally determine whether a water sample is recharged before or after a known event. An absolute age of a water sample can only be calculated when the sample corresponds to a distinct event marker. The nuclear bomb test peaks in ${ }^{3} \mathrm{H},{ }^{14} \mathrm{C}$ and ${ }^{36} \mathrm{Cl}$ are key examples. These indirect methods are most useful to study spatial variability in groundwater flow systems.

Several chemical proxies are used to trace changes in groundwater flow and changes in recharge conditions associated with climate change and surface environmental change in general. Key proxies are the stable isotopes of water (Clark and Fritz 1997) and noble gases dissolved in groundwater (Porcelli et al. 2002; Stute and Schlosser 1993). Also, chloride content of groundwater and, in particular in vertical SWC profiles collected in thick vadose zones in desert areas, have been exploited to infer changes in recharge conditions (e.g. Edmunds and Tyler 2002). Although noble gases have been applied primarily in paleohydrological reconstructions of long time scales (Kooi 2008a), they should also provide valuable constraints regarding changes in groundwater systems on timescales of decades to centuries.

\subsubsection{Hydrogeophysical Techniques}

Three hydrogeophysical methods are particularly relevant to the study of groundwater and the changes that arise from climate variability and change:

1. electrical/electromagnetic methods,

2. subsurface temperature logging, and

3. land-based gravity surveying. 
A wide range of electrical/electromagnetic imaging and logging methods can be used to study groundwater systems and their responses to climate-related phenomena. This group of methods includes spontaneous/self potential (SP), electrical resistivity, induced polarisation (IP), a range of time and frequency domain electromagnetic methods, and ground-penetrating radar (GPR). Their advantage over point sampling is that large areas can be covered either in land-based surveys or airborne surveys. Borehole logging methods can be used in a similar fashion to provide vertical profiles of these properties with depth and to constrain survey data.

Perhaps the most common application of these methods is to studies of saline water in aquifers (Dent 2007). Climate change is expected to result in higher sea levels, posing an even greater threat to coastal aquifers. Thus, these hydrogeophysical methods are ideally suited for monitoring changes in groundwater salinity over large coastal areas due to the effects of sea level rise. These techniques may prove invaluable for detecting changes in salinity over broad agricultural areas.

Subsurface temperature can be used to reconstruct climate change and land cover change, because the signal of surface temperature change is preserved in subsurface environment (e.g., Chapman et al. 1992; Davis et al. 2010; GonzálezRouco et al. 2009). Changes in surface temperature associated with changes in air temperature (Smerdon et al. 2009) can propagate into the subsurface, and can be detected by measuring ground temperatures up to several hundred meters deep (Beltrami and Mareschal 1995; Čermák et al. 1992). Temperature-depth profiles collected in boreholes can reveal and be used to help reconstruct the surface temperature changes due to climate change and land cover change during a few to several hundred years (Beltrami 2002; Huang et al. 2000; Roy et al. 2002). Effects of global warming on subsurface temperature subsequently affect the ecology and water quality.

Land-based gravity measurements have been used to detect changes in groundwater storage. Pool and Eychaner (1995) observed that measured gravity changes of about 13 microGal represented storage changes of about $0.30 \mathrm{~m}$ of water. Gravity meters are now sufficiently accurate to measure variations of about 2 microGal, and finer instrumental precision with temporal averaging. Gravity measurements have also been used to detect the changes in groundwater storage in situ (gravity profiling) and using the GRACE satellite data as discussed in the next section.

\subsubsection{Remote Sensing of Space-Time Trends}

Satellite remote sensing (RS) represents the most powerful method for detection and monitoring of environmental and climate change on a global scale. However, capabilities of RS to "look below the ground surface" and to detect properties that directly bear on groundwater conditions are extremely limited. Notable exceptions to this are satellite-based observations of the gravity field associated with changes in groundwater storage.

Remote sensing and earth observation technologies provide an important means of collecting groundwater-related data on a regional scale and to assess the state of 
the resource. Satellite remote sensing, despite drawbacks of temporal frequency and estimation errors, offers the advantages of global coverage, availability of data, metadata, error statistics, and the ability to provide meaningful spatial averages.

Aerial thermal infrared imaging is being used for mapping groundwater discharge zones in estuaries, rivers and oceans. Peterson et al. (2009) used aerial thermal infrared imaging to reveal that submarine groundwater discharge (SGD) along the western coast of the Big Island of Hawaii is often focused as point-source discharges that create buoyant groundwater plumes that mix into the coastal ocean.

Landsat, the Moderate-resolution Imaging Spectroradiometer (MODIS), the Advanced Very High Resolution Radiometer (AVHRR), and certain other instruments can resolve the location and type of vegetation, which can be used to infer a shallow water table. Altimetry measurements and Interferometric Synthetic Aperture Radar (InSAR) over time can show where subsidence is occurring, which is often an indicator of groundwater depletion. Microwave radar and radiometry measurements can be used to estimate snow and surface soil water, which further constrain groundwater assessments.

Perhaps the most valuable remote sensing technology for groundwater investigations is satellite gravimetry employed by the Gravity Recovery and Climate Experiment (GRACE) - a satellite gravimetry technology that may be used to assess groundwater storage changes. Since its launch in 2002, the GRACE satellites have been employed to detect tiny temporal changes in the gravity field of the Earth (Ramillien et al. 2008). Temporal changes in measured gravity are primarily caused by changes in total water (mass) storage (TWS) in the atmosphere, ocean and at and below the surface of the continents. GRACE is being used to generate time series of total terrestrial water variations (Tapley et al. 2004), which can be used to assess groundwater storage changes. Wahr et al. (2006) presented the first technique for deriving terrestrial water storage variations from global gravity field solutions delivered by GRACE. Rodell and Famiglietti (2002) showed in a pre-GRACElaunch study that interannual variations and trends in the High Plains aquifer water storage would be detectable by GRACE, pointing to new opportunities for groundwater remote sensing. Rodell et al. (2007) developed time series of groundwater storage variations averaged over the Mississippi River basin and its four major sub-basins using in situ data, and used these to evaluate GRACE-based estimates in which SWC and snow water equivalent fields output from a sophisticated land surface model were used to isolate groundwater from the GRACE terrestrial water storage data. At the smaller spatial scale of Illinois $\left(145,000 \mathrm{~km}^{2}\right)$, Swenson et al. (2006) showed that GRACE captures the signal of changes in total water storage very well, while Yeh et al. (2006) showed that GRACE-based estimates of groundwater storage variations compared well with borehole observations on seasonal timescales. Swenson et al. (2008) used Oklahoma Mesonet data and local groundwater level observations to further refine methods to remove the SWC signal from the total water storage change signal recorded by GRACE.

Post-launch studies using GRACE data have demonstrated that when combined with ancillary measurements of surface water and SWC, GRACE is capable of monitoring changes in groundwater storage with reasonable accuracy (temporal 
resolution 10 days to monthly, spatial resolution $400-500 \mathrm{~km}$, mass change $\sim 9 \mathrm{~mm}$ water equivalent). Syed et al. (2008) also found agreement between the storage changes estimated by GRACE and the Global Land Data Assimilation System (GLDAS), where GLDAS was used to disaggregate terrestrial water storage between soil, vegetation canopy and snow.

The need to better quantify potential changes in the water cycle associated with climate change $\left(\mathrm{GEWEX}^{1}\right.$; WATCH program $^{2}$ ) has provided a major stimulus for improvement of techniques to monitor key variables and components of the hydrological cycle using space-based platforms. Advances and new developments in monitoring of soil moisture (de Jeu et al. 2008; Liu et al. 2009), precipitation, and evapotranspiration (Anderson and Kustas 2008; Kalma et al. 2008) provide crucial elements to help constrain space-time trends in groundwater recharge. Future research will undoubtedly focus on the further integration of these multi-platform and multi-parameter observations, including GRACE data, in extensive hydrological models. Recent dedicated hydrological missions for improved monitoring of soil moisture (2009: SMOS/ESA; 2011: SMAP/NASA) and precipitation (2012: GPM/NASA) enhance RS capabilities of groundwater resources assessment.

The monthly temporal resolution of GRACE is an issue for many applications, but it should be sufficient for regional groundwater assessments. To address such scale issues, Zaitchik et al. (2008) used an advanced data assimilation approach to incorporate GRACE data into a land surface model, and hence merge them with other datasets and our knowledge of physical processes as represented in the model. In simulations over the Mississippi River basin, the GRACE-assimilation groundwater storage output fit observations better than output from the open loop, and they were of much higher spatial and temporal resolution than GRACE alone. Yamamoto et al. (2008) reported the larger difference, in particular at low latitude regions, between current terrestrial water models of global river basins and GRACE data. This technique may be the key to maximising the value of GRACE data for groundwater resources studies (e.g., Fukuda et al. 2009).

\subsection{Assessments of Subsurface Hydrology: Numerical Simulations}

Mathematical groundwater models play a central role, both for interpreting and integrating data and for generating general insight to the response of groundwater systems to climate change and other forcings on multiple spatial and temporal scales. While observations are essential to explore and document subsurface global change, numerical models provide key tools, not only to assist in developing a process-based understanding of observed changes (i.e., hindcasting), but also

\footnotetext{
${ }^{1}$ http://www.gewex.org/

${ }^{2}$ http://www.eu-watch.org/
} 
predict the future response of the subsurface parameters to climate change, land-use change and water management scenarios (forecasting). Distributed groundwater models simulate flow in the subsurface, both in saturated and unsaturated conditions, as well as for porous and fractured media. Specialised codes are used to simulate chemical processes, such as solute transport and reactions, heat transport, and density-dependent flow (e.g., for coastal regions). In addition to groundwater models, which form the basis for groundwater assessment, other potential models include coupled land surface-atmospheric models, biogeochemical models, surface-water hydrological models, coupled surface-water/groundwater models, and coupled land surface and variable-saturated groundwater models.

Process-based continental or global-scale hydrological models are rare. Thus, most studies develop watershed or smaller scale models, which are better constrained by available data and, thus, more easily calibrated. However, there remain challenges for coupling GCM predictions with hydrological models (Scibek and Allen 2006b; Toews and Allen 2009; Xu 1999), including issues discussed in the section Global Climate Projection.

The appropriate level of model complexity for a given problem may remain subjective, but some level of process interaction within the plant-soil-groundwateratmospheric system must be present. Tietjen et al. (2009) made a case for at least two soil layers in a soil-vegetation model that simulated soil-water dynamics under different climatic conditions. Others have applied relatively complex, spatially distributed subsurface models and coupled surface-groundwater models (Goderniaux et al. 2009; Hunt et al. 2013; van Roosmalen et al. 2007, 2009).

Numerical model-based studies continue to improve, but for the most part, the approaches are similar to the limited examples given above and more comprehensive case studies discussed by Green et al. (2011). Models used to predict terrestrial and subsurface effects of climate change must incorporate appropriate processes and their interactions in space and time. Integration studies encompassing changes in human or socio-economic scenarios (apart from emissions scenarios), such as land use and water demand are generally lacking (Holman 2006).

\subsection{The Role of Groundwater in the Water-Food-Energy- Climate Nexus}

Food and energy are inextricably linked through water in many important ways (see also Chap. 4). In most regions, agriculture uses a dominant share of water, often based on senior (possibly "grandfathered") water rights. Urban areas and industries, including the energy sector, have growing water demands and substantial financial resources that often lead to purchases of water rights from agricultural stakeholders. Thus, the price of water tends to rise from the demand side. In many water limited areas, projected reductions in supply will further raise prices. In this way, climate change enters the water-food-energy nexus as an additional complicating factor.

Various organisations and funding agencies are aiming to address the waterfood-energy nexus, by this or another term, including integrated modeling (Bazilian 
et al. 2011). A book by the World Economic Forum (Waughray 2011) covers the water-food-energy-climate nexus, including some discussion of groundwater issues. The interactive nature of problems related to this nexus will continue to spawn interest and exploration, hopefully with new innovations.

\subsection{Adapting to Climate Change: Integrated Groundwater Management}

Climate adaptation measures are developed to cope with the consequences of a changing climate and reduce future risks. Adaptation encompasses both national and regional strategies as well as practical measures taken at all political levels and by individuals.

In many parts of the world, groundwater is crucial to sustainable development through provision of low-cost, reliable and high-quality water supplies. About $70 \%$ of drinking water in the European Union, $80 \%$ of rural water supply in sub-Saharan Africa and $60 \%$ of agricultural irrigation in India depend on groundwater (IAH 2006). Groundwater also sustains ecosystems and landscapes in humid regions in supporting wetlands and riparian areas, and also supports unique aquatic ecosystems in more arid regions and in coastal environments. The largely hidden nature of groundwater means that development is often untallied and thus uncontrolled and not incorporated into overall water resource management, resulting in over-exploitation and contamination. Thus, even without considering climate change, sustainable management of groundwater is a major challenge. Groundwater is a widely distributed resource responding at basin scales, and local stakeholders (e.g., municipalities, industrial enterprises and farmers) are influenced by national policies determining land and water use. In general, governance systems, resource policies, innovation incentives, data collection and information provision need to relate to a wide range of scales (see Chap. 6), with different adaptive management approaches in rural and urban environments (IAH 2006).

Climate change challenges the traditional assumption that past hydrological experience provides a good guide to future conditions. In times of surface-water shortages during droughts, a typical response is for groundwater resources to be abstracted as an emergency supply. Under conditions of climate change, this response could be unsustainable, especially in areas expected to experience an increase in drought frequency and duration. Also, rising sea levels under climate change will further threaten coastal freshwater aquifers, especially those already experiencing salinisation due to over-exploitation.

Alley (2006) suggested that the effects of discharge and groundwater development often take many years to become evident. Thus, governments tend to neglect the data collection and analysis needed to support informed groundwater management until problems materialize. This type of reactionary stance to groundwater management is flawed because, although some groundwater systems are renewable, many groundwater resources contain "fossil" groundwater and thus are 
nonrenewable natural resources on human time scales. For example, the groundwater that is removed from storage in many arid and semiarid regions was recharged during wetter periods under paleoclimate conditions (Alley et al. 2002).

Adaptation approaches can be preventative or reactive and apply to natural and social systems. Ensuring the sustainability of investments in groundwater resources planning and development, over the entire lifetime of a scheme and taking explicit account of changing climate, is referred to as climate proofing (CEC 2007). At a minimum, and in the absence of reliable projections of future changes in hydrological variables, adaptation processes and methods can be implemented, such as improved water use efficiency and water demand management, offering no-regrets options to cope with climate change.

The Netherlands are investing in "climate proofing" (Kabat et al. 2005) that uses hard infrastructure and softer measures, such as insurance schemes or evacuation planning, to reduce the risks of climate change and hydrologic variability to a quantifiable level that is acceptable by the society or economy. The Netherlands and the rest of the world's coastal delta regions are vulnerable to climate change and sea-level rise. Rather than coping with extreme climatic events, as people from all over the world have done over human history, climate proofing is a proactive approach to develop precautionary measures to address the low-probability but high-magnitude hydroclimatologic events forecasted under climate change and variability (Kabat et al. 2005). Climate proofing should be driven by opportunities for technological, institutional, and societal innovations, rather than by the fear of climate-change induced threats. The climate-proofing approach could be used by water-resource scientists, engineers, and managers to develop forward-thinking, innovative solutions and precautionary measures for a range of probable hydroclimatic events under future climate change. The discredited stationarity of hydroclimatology (Milly et al. 2008) may promote innovation and suitable precautionary measures to protect the sustainability of groundwater resources under projected hydroclimatic regimes. Thus the process of adaptation to climate change must itself be adaptive over time.

Potential adaptive responses include some combination of technological (e.g., deepening of existing boreholes), behavioral (e.g., altered groundwater use), managerial (e.g., altered farm irrigation practices), and policy oriented (e.g., groundwater abstractions licensing regulations) approaches. The IPCC (2007a) argued that while most technologies and strategies are studied and developed in certain countries, the effectiveness of various options to substantially reduce risks for vulnerable waterstressed areas is not yet known, particularly at higher levels of warming and related impacts. Shah (2009) noted an indirect feedback of pumping on climate change due to energy use and associated carbon emissions. This is one obvious example of the interactions between potential groundwater-atmosphere feedbacks and adaptation to global change that must be considered.

For integrated water resources management, two types of decisions deal with: (1) new investments, and (2) the operation and maintenance of existing systems. Information is needed about future water availability and demand, both of which are affected by climate change at the river-basin scale (Ballentine and Stakhiv 
1993). As explained by the IPCC (2008), supply-side options generally involve increases in storage capacity or water abstraction. Demand-side adaptation options rely on the combined actions of individuals (industry users, farmers and individual consumers) and may be less reliable. Some options, such as those incurring increased pumping and treatment costs, may be inconsistent with climate change mitigation measures because they involve high energy consumption.

One of the major challenges facing water resources managers is coping with climate change uncertainty, particularly where expensive investment in infrastructure such as well-field design, construction and testing and laying of pipelines is required (Brekke et al. 2004; Taylor et al. 2013). Dessai and Hulme (2007) discussed this challenge and related questions, including: To what amount of uncertainty in climate change should we adapt? Are robust adaptation options socially, environmentally and economically acceptable and how do climate change uncertainties compare with other uncertainties such as changes in demand? The answers to these questions leading to robust adaptation decisions will require the development of probability distributions of specified outcomes (Wilby and Harris 2006) and negotiation between decision-makers and stakeholders involved in the adaptation process (Dessai and Hulme 2007). For lower income countries, availability of resources and building adaptive capacity are particularly important in order to meet water shortages and salinisation of fresh waters.

Examples of current adaptation to observed and anticipated climate change in the management of groundwater resources are few, with groundwater typically considered as part of an integrated water-supply system. Here, three examples serve to highlight the difference in approach in technically-advanced and developing country contexts. The ability of California's water supply system to adapt to longterm climate and demographic changes was examined by Tanaka et al. (2006) using a state-wide economic-engineering optimisation model of water supply management and considering two climate warming scenarios for the year 2100. However, recent drought conditions ${ }^{3}$ raised concerns regarding long-standing issues of groundwater quality and management in California. Even so, the prediction by Tanaka et al. (2006) that California's water supply system appears physically capable of adapting to significant changes in climate and population may remain valid, albeit at significant cost. Such adaptations would entail large changes in the operation of California's large groundwater storage capacity, significant transfers of water among water users and some adoption of new technologies. In the Sacramento Valley, California, Purkey et al. (2007) used four climate time series to simulate agricultural water management with adaptation in terms of improvements in irrigation efficiency and shifts in cropping patterns during dry periods leading to lower overall water demands in the agricultural sector with associated reductions in groundwater pumping and increases in surface-water allocations to other water use sectors. Land-use adaptation to projected climate change may include management changes within land-use classes (e.g., alternative

\footnotetext{
${ }^{3}$ http://www.water.ca.gov/waterconditions/declaration.cfm
} 
crop rotations) or changes in land classification (e.g., converting annual cropping systems to perennial grasslands or forests). Soil and water conservation programs already encourage some of these types of land-use changes.

A similar technological approach to that demonstrated for California is presented for the Mediterranean region of Europe. This region is experiencing rapid social and environmental changes with increasing water scarcity problems that will worsen with climate change. Iglesias et al. (2007) found that these pressures are heterogeneous across the region or water use sectors and adaptation strategies to cope with water scarcity include technology, use of strategic groundwater and better management based on preparedness rather than a crisis approach. Iglesias et al. (2007) also promoted the importance of local management at the basin level but with the potential benefits dependent on the appropriate multiinstitutional and multi-stakeholder coordination.

In contrast to the examples from North America and Europe, Ojo et al. (2003) discussed the downward trends in rainfall and groundwater levels, and increases in water deficits and drought events affecting water resources availability in West Africa. There, the response strategies needed to adapt to climate change emphasize the need for water supply-demand adaptations. The mechanisms needed to implement adaptation measures include: building the capacity and manpower of water institutions in the region for hydro-climatological data collection and monitoring; the public participation and involvement of stakeholders; and the establishment of both national and regional cooperation.

Furthermore, water resources management has a clear association with many other policy areas such as energy, land use and nature conservation. In this context, groundwater is part of an emerging integrated water resources management approach that recognises society's views, reshapes planning processes, coordinates land and water resources management, recognises water quantity and quality linkages, manages surface-water and groundwater resources conjunctively, and protects and restores natural systems while considering of climate change. Also, biofuel production has implications for groundwater recharge quantity and quality (IPCC 2008).

In summary, groundwater resources stored in aquifers can be managed given reasonable scientific knowledge, adequate monitoring and sustained political commitment and provision of institutional arrangements. Although there is no single approach to relieving pressures on groundwater resources, incremental improvements in resource management and protection can be achieved now and in the future under climate change. Sustainable management of groundwater will only be possible by approaching adaptation through the effective engagement of individuals and stakeholders at community, local government and national policy levels. Adaptative decision processes in the face of global change should be addressed even to improve management and decision making in an otherwise unchanging world. That is, natural and human-induced variability under historical conditions will be better quantified and managed using new scientific advances gained under the auspices of global change research, making such work a "winwin" proposition. 


\subsection{Future Directions}

Future work must build upon progress to date, and 12 key issues have been identified to improve understanding and guide integrated groundwater management (IGM) in light of climate change:

1. Knowledge of biophysical processes and their interactions must continue to increase, so that systems will be better understood, and estimates of projected groundwater changes and their potential feedbacks on climate will be refined, including quantification of uncertainty and associated risks.

2. Effects of projected climate change on hydrological fluxes (e.g., groundwater recharge) vary with different combinations of soils/aquifer materials, vegetation, and climate zone.

3. Long-term monitoring of terrestrial systems (groundwater, surface water, vegetation and land-use patterns) must be maintained and fortified to quantify baseline properties.

4. Shifts (versus gradual changes and linear trends) in the temporal means and variances of climate variables are probable forms of climate and groundwater changes which should be evaluated.

5. Higher spatial resolution is needed to make satellite-based gravity measurements more practical for regional groundwater management.

6. Long-term (multidecadal or greater) feedback from groundwater to atmospheric processes constitutes a knowledge gap. Paleohydrology indicates that contemporary groundwater-climate systems are not in equilibrium, due to the long memory of deep groundwater with long flow paths and large storage. Contemporary and projected climate change will have lagged and potentially amplified effects on many groundwater systems.

7. The nexus of climate change with food, water and energy security is linked directly to groundwater in many systems.

8. Issues of food and energy security, environmental protection, and social welfare all interact and depend upon improved understanding of terrestrial responses to climate change and feedback mechanisms.

9. Scaling fluxes of water and its constituents to the domains of interest for management and policy is an overarching theme for projecting groundwater responses and feedbacks with climate.

10. Information from intensive study areas must be transferred across the globe to other areas where monitoring infrastructure and research resources are not available. Mapping of global analogues in terms of climatic and terrestrial properties is a promising first-order approach.

11. Artificial recharge and managed storage and recovery projects may become more important components of many local water systems to bank excess renewable-water supplies

12. IGM needs to be both strategic and flexible over time (tactical) as projected climate-groundwater interactions become certainties, or otherwise unexpected realities. Climate proofing may offer no-regrets options to cope with climate 
change by developing precautionary measures that address low-probability but high-magnitude hydroclimatologic events.

Acknowledgments I wish to thank and acknowledge my colleagues who have contributed to the UNESCO International Hydrological Program's GRAPHIC (Groundwater Resources Assessments under the Pressures of Humanity and Climate change) Project since 2004. In particular, Makoto Taniguchi, Henk Kooi, Jason Gurdak, Diana Allen, Holger Treidel and Alice Aureli, who co-authored Green et al. (2011) contributed substantially to the basis for this chapter, and the authors of Taylor et al. (2013) provided updates and additional insights on key issues related to groundwater and climate change. I also thank Prof. Tony Jakeman and co-editors of this book for inviting me to write this chapter, particularly Dr. Randall Hunt for his thoughtful editing and help integrating it with other chapters.

Open Access This chapter is distributed under the terms of the Creative Commons AttributionNoncommercial 2.5 License (http://creativecommons.org/licenses/by-nc/2.5/) which permits any noncommercial use, distribution, and reproduction in any medium, provided the original author(s) and source are credited.

The images or other third party material in this chapter are included in the work's Creative Commons license, unless indicated otherwise in the credit line; if such material is not included in the work's Creative Commons license and the respective action is not permitted by statutory regulation, users will need to obtain permission from the license holder to duplicate, adapt or reproduce the material.

\section{References}

Aguilera H, Murillo J (2009) The effect of possible climate change on natural groundwater recharge based on a simple model: a study of four karstic aquifers in SE Spain. Environ Geol 57(5): 963-974

Allen DM, Mackie DC, Wei M (2004) Groundwater and climate change: a sensitivity analysis for the Grand Forks aquifer, southern British Columbia, Canada. Hydrogeol J 12(3):270-290

Allen DM, Cannon AJ, Toews MW, Scibek J (2010) Variabiltiy in simulated recharge using different GCMs. Water Resour Res 46:W00F03. doi:10.1029/2009WR008932

Alley WM (1993) Regional ground-water quality. Wiley, New York, 634 pp. ISBN: 978-0-47128453-6

Alley WM (2001) Ground water and climate. Ground Water 39(2):161

Alley WM (2006) Tracking U.S. groundwater reserves for the future? Environment 48(3):10-25

Alley WM, Healy RW, LaBaugh JW, Reilly TE (2002) Flow and storage in groundwater systems. Science 296:1985-1990

Alley WM, Reilly TE, Franke OL (1999) Sustainability of ground-water resources, U.S. geological survey circular 1186. U.S. Geological Survey, Denver, 79 pp

Anderson M, Kustas W (2008) Thermal remote sensing of drought and evapotranspiration. Eos 89(26):233-234

Aureli A, Taniguchi M (2006) Groundwater assessment under the pressures of humanity and climate changes - GRAPHIC. United Nations Educational Scientific and Cultural Organization, Paris

Bajjali W, Abu-Jaber N (2001) Climatological signals of the paleogroundwater in Jordan. J Hydrol 243(1-2):133-147

Ballentine TM, Stakhiv EZ (eds) (1993) Climate change and water resources management. In: Proceedings of the national conference on climate change and water resources management 
(1st), Albuquerque, New Mexico, November 4-7, 1991. US Army Corps of Engineers Institute of Water Resources, Washington D.C.

Barco J, Hogue TS, Girotto M, Kendall D, Putti M (2010) Climate signal propagation in southern California aquifers. Water Resour Res 46:W00F05. doi:10.1029/2009WR008376

Barnett TP, Pierce DW, Hidalgo HG et al (2008) Human-induced changes in the hydrology of western United States. Science 319(5866):1080-1083

Barrocu G, Dahab K (2010) Changing climate and saltwater intrusion in the Nile Delta, Egypt. In: Taniguchi M, Holman IP (eds) Groundwater response to changing climate, International Association of Hydrogeologists selected paper. CRC Press/Taylor and Francis Group, London, pp 11-25

Barthel R, Sonneveld BGJS, Goetzinger J, Keyzer MA, Pande S, Printz A, Gaiser T (2009) Integrated assessment of groundwater resources in the Oueme basin, Benin, West Africa. Phys Chem Earth 34(4-5):236-250

Bates B, Kundzewicz ZW, Wu S, Palutikof JP (2008) Climate change and water, Technical paper VI of the Intergovernmental Panel on Climate Change. Intergovernmental Panel on Climate Change Secretariat, Geneva, $210 \mathrm{pp}$

Bazilian M, Rogner H, Howells M et al (2011) Considering the energy, water and food nexus: towards an integrated modelling approach. Energy Policy 39(12):7896-7906

Bear J, Cheng HD (1999) Seawater intrusion in coastal aquifers - concepts methods and practices. Kluwer, Dordrecht/Boston/London, $625 \mathrm{pp}$

Beltrami H (2002) Climate from borehole data: energy fluxes and temperatures since 1500. Geophys Res Lett 29(23):2111. doi:10.1029/2002GL015702

Beltrami H, Mareschal JC (1995) Resolution of ground temperature histories inverted from borehole temperature data. Global Planet Chang 11(1-2):57-70

Bense VF, Ferguson G, Kooi H (2009) Evolution of shallow groundwater flow systems in areas of degrading permafrost. Geophys Res Lett 36, L22401

Berg MA, Allen DM (2007) Low flow variability in groundwater-fed streams. Can Water Resour J 32(3):227-246

Beuhler M (2003) Potential impacts of global warming on water resources in southern California. Water Sci Technol 47(7-8):165-168

Bloomfield JP, Williams RJ, Gooddy DC, Cape JN, Guha P (2006) Impacts of climate change on the fate and behaviour of pesticides in surface and groundwater - a UK perspective. Sci Total Environ 369(1-3):163-177

Bouraoui F, Vachaud G, Li LZX, Le Treut H, Chen T (1999) Evaluation of the impact of climate changes on water storage and groundwater recharge at the watershed scale. Climate Dynam 15(2):153-161

Brekke LD, Miller NL, Bashford KE, Quinn NWT, Dracup JA (2004) Climate change impacts uncertainty for water resources in the San Joaquin River Basin California. J Am Water Resour Assoc 40(1):149-164

Brikowski TH (2008) Doomed reservoirs in Kansas, USA? Climate change and groundwater mining on the Great Plains lead to unsustainable surface water storage. J Hydrol 354(1-4): 90-101

Brouyere S, Carabin G, Dassargues A (2004) Climate change impacts on groundwater resources: modelled deficits in a chalky aquifer, Geer basin, Belgium. Hydrogeol J 12(2):123-134

Brown L (2001) Running on empty. Forum Appl Res Public Policy 16:1-3

Bultot F, Coppens A, Dupriez GL, Gellens D, Meulenberghs F (1988) Repercussions of a $\mathrm{CO}_{2}$ doubling on the water cycle and on the water balance - a case study for Belgium. J Hydrol 99(3-4):319-347

Burkett VR, Zilkoski DB, Hart DA (2002) Sea-level rise and subsidence: implications for flooding in New Orleans, Louisiana, U.S. geological survey subsidence interest group conference. U.S. Geological Survey, Galveston, pp 63-71

Burnett WC, Aggarwal PK, Aureli A et al (2006) Quantifying submarine groundwater discharge in the coastal zone via multiple methods. Sci Total Environ 367(2-3):498-543 
Cambi C, Dragoni W (2000) Groundwater yield, climate changes and recharge variability: considerations arising from the modelling of a spring in the Umbria-Marche Apennines. Hydrogeologie 4:11-25

Candela L, von Igel W, Javier Elorza F, Aronica G (2009) Impact assessment of combined climate and management scenarios on groundwater resources and associated wetland (Majorca, Spain). J Hydrol 376(3-4):510-527

Caruso BS (2002) Temporal and spatial patterns of extreme low flows and effects on stream ecosystems in Otago, New Zealand. J Hydrol 257(1-4):115-133

Castro MC, Hall CM, Patriarche D, Goblet P, Ellis BR (2007) A new noble gas paleoclimate record in Texas - basic assumptions revisited. Earth Planet Sci Lett 257(1-2):170-187

Cayan DR, Kammerdiener SA, Dettinger MD, Caprio JM, Peterson DH (2001) Changes in the onset of spring in the Western United States. Bull Am Meteorol Soc 82:399-415

CEC (2007) Adapting to climate change in Europe - options for EU action. Green paper from the Commission to the Council, the European Parliament, the European Economic and Social Committee and the Committee of the Regions, Commission of the European Communities, Brussels

Čermák V, Bodri L, Šafanda J (1992) Underground temperature fields and changing climate: evidence from Cuba. Global Planet Chang 5(4):325-337

Chapman DS, Chisholm TJ, Harris RN (1992) Combining borehole temperature and meteorologic data to constrain past climate change. Global Planet Chang 6(2-4):269-281

Chen Z, Grasby SE, Osadetz KG (2002) Predicting average annual groundwater levels from climatic variables: an empirical model. J Hydrol 260(1-4):102-117

Chen Z, Grasby SE, Osadetz KG (2004) Relation between climate variability and groundwater levels in the upper carbonate aquifer, southern Manitoba. Can J Hydrol 290(1-2):43-62

Cheng G, Wu T (2007) Responses of permafrost to climate change and their environmental significance, Qinghai-Tibet Plateau. J Geophys Res 112:F02S03. doi:10.1029/2006JF000631

Chiew FHS, McMahon TA (2002) Modelling the impacts of climate change on Australian streamflow. Hydrol Process 16(6):1235-1245

Christensen JH, Hewitson B, Busuioc A et al (2007) Regional climate projections. In: Solomon S et al (eds) Climate change 2007: the physical science basis, Contribution of working group I to the fourth assessment report of the Intergovernmental Panel on Climate Change. Cambridge University Press, Cambridge/New York

Clark I, Fritz P (1997) Environmental isotopes in hydrogeology. Lewis Publishers, Boca Raton/New York, $328 \mathrm{pp}$

Cohen D, Person M, Daannen R et al (2006) Groundwater-supported evapotranspiration within glaciated watersheds under conditions of climate change. J Hydrol 320(3-4):484-500

Cook P, Herczeg AL (2000) Environmental tracers in subsurface hydrology. Kluwer, Norwell, $529 \mathrm{pp}$

Cook BI, Smerdon JE, Seager R, Coats S (2014) Global warming and 21st century drying. Climate Dynam 43:1-21

Dams J, Woldeamlak ST, Batelaan O (2007) Forecasting land-use change and its impact on the groundwater system of the Kleine Nete catchment, Belgium. Hydrol Earth Syst Sci Discuss 4 (6):4265-4295

Davis MG, Harris RN, Chapman DS (2010) Repeat temperature measurements in boreholes from northwestern Utah link ground and air temperature changes at the decadal time scale. J Geophys Res 115:B05203. doi:10.1029/2009JB006875

de Jeu R, Wagner W, Holmes T, Dolman A, van de Giesen N, Friesen J (2008) Global soil moisture patterns observed by space borne microwave radiometers and scatterometers. Surv Geophys 29(4):399-420

de Vries JJ, Simmers I (2002) Groundwater recharge: an overview of processes and challenges. Hydrogeol J 10(1):5-17

Dent D (2007) Environmental geophysics mapping salinity and water resources. Int J Appl Earth Obs Geoinf 9(2):130-136 
Dessai S, Hulme M (2007) Assessing the robustness of adaptation decisions to climate change uncertainties: a case study on water resources management in the East of England. Glob Environ Chang 17(1):59-72

Destouni G, Darracq A (2009) Nutrient cycling and $\mathrm{N}_{2} \mathrm{O}$ emissions in a changing climate: the subsurface water system role. Environ Res Lett 4(3):035008

Dettinger MD, Earman S (2007) Western ground water and climate change - pivotal to supply sustainability or vulnerable in its own right? Ground Water 4(1):4-5

Döll P (2009) Vulnerability to the impact of climate change on renewable groundwater resources: a global-scale assessment. Environ Res Lett 4(3):035006

Dragoni W, Sukhija BS (2008) Climate change and groundwater: a short review, Geological Society special publication. Geological Society, London, pp 1-12

Dzhamalov RG, Zektser IS, Krichevets GN, Safronova TI, Sotnikova LF, Gromova YV (2008) Changes in groundwater runoff under the effect of climate and anthropogenic impact. Water Resour 35(1):15-22

Eckhardt K, Ulbrich U (2003) Potential impacts of climate change on groundwater recharge and streamflow in a central European low mountain range. J Hydrol 284(1-4):244-252

Edmunds WM, Tyler SW (2002) Unsaturated zones as archives of past climates: toward a new proxy for continental regions. Hydrogeol J 10:216-228

Eltahir EAB (1989) A feedback mechanism in annual rainfall in Central Sudan. J Hydrol 110: 323-334

Eltahir EAB (1993) Interactions of hydrology and climate in the Amazon basin. Doctorate thesis, Massachusetts Institute of Technology, Cambridge, MA, $188 \mathrm{pp}$

Eltahir EAB, Bras RL (1994) Precipitation recycling in the Amazon basin. Q J Roy Meteorol Soc 120:861-880

Eltahir EAB, Bras RL (1996) Precipitation recycling. AGU Rev Geophys 34(3):367-378

Emori S, Brown SJ (2005) Dynamic and thermodynamic changes in mean and extreme precipitation under changed climate. Geophys Res Lett 32(17):L17706. doi:10.1029/2005GL023272

Fan Y, Miguez-Macho G, Weaver CP, Walko R, Robock A (2007) Incorporating water table dynamics in climate modeling: 1. Water table observations and equilibrium water table simulations. J Geophys Res 112:D10125

Faure H, Walter RC, Grant DR (2002) The coastal oasis: ice age springs on emerged continental shelves. Global Planet Chang 33(1-2):47-56

Ferguson IM, Maxwell RM (2010) Role of groundwater in watershed response and land surface feedbacks under climate change. Water Resour Res 46:W00F02. doi:10.29/2009WR008616

Fukuda Y, Yamamoto K, Hasegawa T, Nakaegawa T, Nishijima J, Taniguchi M (2009) Monitoring groundwater variation by satellite and implications for in-situ gravity measurements. Sci Total Environ 407(9):3173-3180

Garbrecht JD, Rossel FE (2002) Decade-scale precipitation increase in Great Plains at end of 20th century. J Hydrol Eng 7(1):64-75

Gasse F (2000) Hydrological changes in the African tropics since the last glacial maximum. Quat Sci Rev 19(1-5):189-211

Ghil M (2002) Natural climate variability. In: MacCracken MC, Perry JS (eds) Encyclopedia of global environmental change. Wiley, Chichester

Giertz S, Diekkruger B, Jaeger A, Schopp M (2006) An interdisciplinary scenario analysis to assess the water availability and water consumption in the Upper Oueme catchment in Benin. Adv Geosci 9:3-13

Glassley WE, Nitao JJ, Grant CW, Johnson JW, Steefel CI, Kercher JR (2003) The impact of climate change on vadose zone pore waters and its implication for long-term monitoring. Comput Geosci 29(3):399-411

Gleeson T, Alley WM, Allen DM, Sophocleous MA, Zhou Y, Taniguchi M, Vandersteen J (2012) Towards sustainable groundwater use: setting long-term goals, backcasting, and managing adaptively. Ground Water 50:19-26 
Gleick PH (1986) Methods for evaluating the regional hydrologic impacts of global climatic changes. J Hydrol 88(1-2):97-116

Goderniaux P, Brouyère S, Fowler HJ, Blenkinsop S, Therrien R, Orban P, Dassargues A (2009) Large scale surface-subsurface hydrological model to assess climate change impacts on groundwater reserves. J Hydrol 373(1-2):122-138

González-Rouco JF, Beltrami H, Zorita E, Stevens MB (2009) Borehole climatology: a discussion based on contributions from climate modeling. Clim Past 5(1):97-127

Gosling SM, Taylor RG, Arnell NW, Todd MC (2010) A comparative analysis of projected impacts of climate change on river runoff from global and catchment-scale hydrological model. Hydrol Earth Syst Sci Discuss 7:7191-7229

Grasby SE, Betcher RN (2002) Regional hydrogeochemistry of the carbonate rock aquifer, southern Manitoba. Can J Earth Sci 39:1053-1063

Green TR, van Schilfgaarde J (2006) Watershed approach, encyclopedia of soil science. Taylor \& Francis, London, pp 1874-1878

Green TR, Bates BC, Charles SP, Fleming PM (2007) Physically based simulation of potential effects of carbon dioxide-altered climates on groundwater recharge. Vadose Zone J 6(3): 597-609

Green TR, Taniguchi M, Kooi H, Gurdak JJ, Allen DM, Hiscock KM, Treidel H, Aureli A (2011) Beneath the surface of global change: impacts of climate change on groundwater. J Hydrol 405 (3-4):532-560

Gurdak JJ (2008) Ground-water vulnerability: nonpoint-source contamination, climate variability, and the High Plains aquifer. VDM Verlag Publishing, Saarbrucken

Gurdak JJ, Roe CD (2010) Review: recharge rates and chemistry beneath playas of the High Plains aquifer USA. Hydrogeol J 18(8):1747-1772

Gurdak JJ, Hanson RT, McMahon PB, Bruce BW, McCray JE, Thyne GD, Reedy RC (2007) Climate variability controls on unsaturated water and chemical movement, High Plains aquifer, USA. Vadose Zone J 6(3):533-547

Gurdak JJ, Walvoord MA, McMahon PB (2008) Susceptibility to enhanced chemical migration from depression-focused preferential flow, High Plains aquifer. Vadose Zone J 7(4): $1172-1184$

Gurdak JJ, Hanson RT, Green TR (2009) Effects of climate variability and change on groundwater resources of the United States, U.S. Geological Survey fact sheet 2009-3074. U.S. Geological Survey, Idaho Falls, Idaho, 4 pp.

Gutowski WJ, Vorosmarty CJ, Person M, Otles Z, Fekete B, York J (2002) A coupled landatmosphere simulation program (CLASP): calibration and validation. J Geophys Res 107(D16, 4283): $1-17$

Haldorsen S, Heim M, Dale B, Landvik JY, van der Ploeg M, Leijnse A, Salvigsen O, Hagen JO, Banks D (2010) Sensitivity to long-term climate change of subpermafrost groundwater systems in Svalbard. Quatern Res 73:393-402

Hanson RT, Dettinger MD (2005) Ground water/surface water responses to global climate simulations, Santa Clara-Calleguas Basin, Ventura. Calif J Am Water Resour Assoc 41(3): $517-536$

Hanson RT, Newhouse MW, Dettinger MD (2004) A methodology to assess relations between climatic variability and variations in hydrologic time series in the southwestern United States. J Hydrol 287(1-4):252-269

Hanson RT, Dettinger MD, Newhouse MW (2006) Relations between climatic variability and hydrologic time series from four alluvial basins across the southwestern United States. Hydrogeol J 14(7):1122-1146

Healy RW (2010) Estimating groundwater recharge. Cambridge University Press, Cambridge, $245 \mathrm{pp}$

Hendry MJ, Woodbury AD (2007) Clay aquitards as archives of Holocene paleoclimate: ${ }^{18} \mathrm{O}$ and thermal profiling. Ground Water 45(6):683-691 
Herrera-Pantoja M, Hiscock KM (2008) The effects of climate change on potential groundwater recharge in Great Britain. Hydrol Process 22(1):73-86

Hewitson BC, Crane RG (2006) Consensus between GCM climate change projections with empirical downscaling: precipitation downscaling over South Africa. Int J Climatol 26(10): 1315-1337

Hiscock KM, Lloyd JW (1992) Palaeohydrogeological reconstructions of the North Lincolnshire Chalk, UK, for the last 140,000 years. J Hydrol 133(3-4):313-342

Holman IP (2006) Climate change impacts on groundwater recharge-uncertainty, shortcomings, and the way forward? Hydrogeol J 14(5):637-647

Hsu KC, Wang CH, Chen KC, Chen CT, Ma KW (2007) Climate-induced hydrological impacts on the groundwater system of the Pingtung Plain, Taiwan. Hydrogeol J 15(5):903-913

Huang S, Pollack HN, Po-Yu S (2000) Temperature trends over the past five centuries reconstructed from borehole temperatures. Nature 403:756-758

Hunt RJ, Prudic DE, Walker JF, Anderson MP (2008) Importance of unsaturated zone flow for simulating recharge in a humid climate. Ground Water 46(4):551-560

Hunt RJ, Walker JF, Selbig WR, Westenbroek SM, Regan RS (2013) Simulation of climatechange effects on streamflow, lake water budgets, and stream temperature using GSFLOW and SNTEMP. Trout Lake Watershed. http://pubs.usgs.gov/sir/2013/5159/

IAH (2006) Groundwater for life and livelihoods - the framework for sustainable use. In: 4th World water forum invitation and briefing, Kenilworth

Iglesias A, Garotte L, Flores F, Moneo M (2007) Challenges to manage the risk of water scarcity and climate change in the Mediterranean. Water Resour Manag 21:775-788

IPCC (2007a) Climate change 2007: impacts, adaptation and vulnerability. In: Parry ML, Canziani OF, Palutikof JP, van der Linden PJ, Hanson CE (eds) Contribution of working group II to the fourth assessment report of the Intergovernmental Panel on Climate Change. Cambridge University Press, Cambridge/New York

IPCC (2007b) Climate change 2007: the physical science basis. In: Solomon S et al. (eds) Contribution of working group I to the fourth assessment report of the Intergovernmental Panel on Climate Change. Cambridge University Press, Cambridge/New York, p 996

IPCC (2008) Technical paper on climate change and water. Finalized at the 37th Session of the IPCC Bureau, Geneva

IPCC (2013) Climate change 2013: the physical science basis. In: Stocker TF, Qin D, Plattner G-K, Tignor M, Allen SK, Boschung J, Nauels A, Xia Y, Bex V, Midgley PM (eds ) Contribution of working group I to the fifth assessment report of the Intergovernmental Panel on Climate Change. Cambridge University Press, Cambridge/New York, p 1535

Jasper K, Calanca P, Fuhrer J (2006) Changes in summertime soil water patterns in complex terrain due to climatic change. J Hydrol 327(3-4):550-563

Jorgensen DG, Yasin al-Tikiriti W (2003) A hydrologic and archeologic study of climate change in Al Ain, United Arab Emirates. Global Planet Chang 35(1-2):37-49

Juckem PF, Hunt RJ, Anderson MP, Robertson DM (2008) Effects of climate and land management change on streamflow in the driftless area of Wisconsin. J Hydrol 355(1-4):123-130

Jungkunst HF, Flessa $\mathrm{H}$, Scherber C, Fiedler S (2008) Groundwater level controls $\mathrm{CO}_{2}, \mathrm{~N}_{2} \mathrm{O}$ and $\mathrm{CH}_{4}$ fluxes of three different hydromorphic soil types of a temperate forest ecosystem. Soil Biol Biochem 40(8):2047-2054

Jyrkama MI, Sykes JF (2007) The impact of climate change on spatially varying groundwater recharge in the grand river watershed (Ontario). J Hydrol 338(3-4):237-250

Kabat P, van Vierssen W, Veraart J, Vellinga P, Aerts J (2005) Climate proofing the Netherlands. Nature 438(7066):283-284

Kalma J, McVicar T, McCabe M (2008) Estimating land surface evaporation: a review of methods using remotely sensed surface temperature data. Surv Geophys 29(4):421-469

Keeling CD, Bacastow RB, Bainbridge AE (1976) Atmospheric carbon dioxide variations at Mauna Loa Observatory, Hawaii. TELLUS 28(6):538-551 
Keeling CD, Brix H, Gruber N (2004) Seasonal and long-term dynamics of the upper ocean carbon cycle at station ALOHA near Hawaii. Global Biogeochem Cycles 18(4):1-26

Kerr RA (2000) A North Atlantic climate pacemaker for the centuries. Science 288(5473): 1984-1986

Kertesz A, Mika J (1999) Aridification - climate change in South-Eastern Europe. Phys Chem Earth Solid Earth Geod 24(10):913-920

Kitabata H, Nishizawa K, Yoshida Y, Maruyama K (2006) Permafrost thawing in Circum-Artic and Highlands under climate change scenario projected by community climate system model (CCSM3). Sci Online Lett Atmosphere 2:53-56

Klein RJT, Nicholls RJ (1999) Assessment of coastal vulnerability to climate change. Ambio 28(2):182-187

Knorr W, Prentice IC, House JI, Holland EA (2005) Long-term sensitivity of soil carbon turnover to warming. Nature 433(7023):298-301

Kooi H (2008a) Groundwater palaeohydrology. In: Bierkens MFP, Dolman AJ, Troch PA (eds) Climate and the hydrological cycle, vol 8, IAHS special publication. International Association of Hydrological Sciences, Wallingford, UK, pp 235-254

Kooi H (2008b) Spatial variability in subsurface warming over the last three decades; insight from repeated borehole temperature measurements in the Netherlands. Earth Planet Sci Lett 270: 86-94

Koster RD, 25 others (2006) GLACE: the global land-atmosphere coupling experiment. Part I: overview. J Hydrometeorol 7:590-610

Kovalevskii VS (2007) Effect of climate changes on groundwater. Water Resour 34(2):140-152

Kundzewicz ZW, Döll P (2009) Will groundwater ease freshwater stress under climate change? Hydrol Sci J 54(4):665-675

Kundzewicz ZW, Mata LJ, Arnell NW et al (2007) Freshwater resources and their management. In: Parry ML, Canziani OF, Palutikof JP, van der Linden PJ, Hanson CE (eds) Climate change 2007: impacts adaptation and vulnerability. Cambridge University Press, Cambridge, pp 173-210

Lambrakis N, Kallergis G (2001) Reaction of subsurface coastal aquifers to climate and land use changes in Greece: modelling of groundwater refreshening patterns under natural recharge conditions. J Hydrol 245(1-4):19-31

Laroque M, Mangin A, Razack M, Banton O (1998) Contribution of correlation and spectral analyses to the regional study of a large karst aquifer (Charente, France). J Hydrol 205(3-4): 217-231

Le Treut H, Somerville R, Cubasch U, Ding Y, Mauritzen C, Mokssit A, Peterson T, Prather M (2007) Historical overview of climate change. In: Solomon S, Qin D, Manning M, Chen Z, Marquis M, Averyt KB, Tignor M, Miller HL (eds) Climate change 2007: the physical science basis, Contribution of working group I to the fourth assessment report of the Intergovernmental Panel on Climate Change. Cambridge University Press, Cambridge/New York

Lee KS, Chung ES (2007) Hydrological effects of climate change, groundwater withdrawal, and land use in a small Korean watershed. Hydrol Process 21(22):3046-3056

Leith RMM, Whitfield PH (1998) Evidence of climate change effects on the hydrology of streams in South-Central B.C. Can Water Resour J 23(3):219-230

Liu YY, van Dijk AIJM, de Jeu RAM, Holmes TRH (2009) An analysis of spatiotemporal variations of soil and vegetation moisture from a 29-year satellite-derived data set over mainland Australia. Water Resour Res 45(7):W07405

Loaiciga HA (2003) Climate change and ground water. Ann Assoc Am Geogr 93(1):30-41

Loaiciga HA (2009) Long-term climatic change and sustainable ground water resources management. Environ Res Lett 4(3):035004

Loaiciga HA, Valdes JB, Vogel R, Garvey J, Schwarz H (1996) Global warming and the hydrologic cycle. J Hydrol 174(1-2):83-127

Loaiciga HA, Maidment DR, Valdes JB (2000) Climate-change impacts in a regional karst aquifer, Texas, USA. J Hydrol 227(1-4):173-194 
Loosli HH, Aeschbach-Hertig W, others (2001) Isotopic methods and their hydrogeochemical context in the investigation of palaeowaters. In: Edmunds WM, Milne CJ (eds) Palaeowater in coastal Europe: evolution of groundwater since the late Pleistocene, Geological Society of London special publication 189. Geological Society of London, London, pp 193-212

Lorenz EN (1963) Deterministic nonperiodic flow. J Atmos Sci 20:130-141

Lorenz EN (1975) Climate predictability. In: The physical basis of climate and climate modelling, WMO GARP publication series no 16. WMO, Geneva, pp 132-136

Mantua NJ, Hare SR (2002) The Pacific decadal oscillation. J Oceanogr 58(1):35-44

Martin-Rosales W, Pulido-Bosch A, Vallejos A, Gisbert J, Andreu JM, Sanchez-Martos F (2007) Hydrological implications of desertification in southeastern Spain. Hydrol Sci J 52(6): 1146-1161

Mayer TD, Congdon RD (2008) Evaluating climate variability and pumping effects in statistical analyses. Ground Water 46(2):212-227

McCabe GJ, Palecki MA, Betancourt JL (2004) Pacifica and Atlantic Ocean influences on multidecadal drought frequency in the United States. Proc Natl Acad Sci 101(12):4136-4141

McGuire VL (2011) Water-level changes in the High Plains aquifer, predevelopment to 2009, 2007-08, and 2008-09, and change in water in storage, predevelopment to 2009, U.S. Geological Survey Scientific Investigations report 2011-5089, 13 p, available on the web at http://pubs.usgs.gov/sir/2011/5089/

McMahon PB, Dennehy KF, Bruce BW, Bohlke JK, Michel RL, Gurdak JJ, Hurlbut DB (2006) Storage and transit time of chemicals in thick unsaturated zones under rangeland and irrigated cropland, High Plains United States. Water Resour Res 42:W03314

McMahon PB, Dennehy KF, Bruce BW, Gurdak JJ, Qi SL (2007) Water-quality assessment of the High Plains aquifer, 1999-2004. U.S. Geological Survey. Professional Paper 1749, 136 pp., Reston, Virginia.

Mearns LO, Hulme M, Carter TR, Leemans R, Lal M, Whetton P (2007) Climate scenario development. In: Solomon S, Qin D, Manning M, Chen Z, Marquis M, Averyt KB, Tignor M, Miller HL (eds) Climate change 2007: the physical science basis, Contribution of working group I to the fourth assessment report of the Intergovernmental Panel on Climate Change. Cambridge University Press, Cambridge/New York, pp 739-768

Milly PCD, Dunne KA, Vecchia AV (2005) Global pattern of trends in streamflow and water availability in a changing climate. Nature 438:347-350

Milly PCD, Betancourt JL, Falkenmark M, Hirsch RM, Kundzewicz ZW, Lettenmaier DP, Stouffer RJ (2008) Stationarity is dead: whither water management. Science 319:573-574

Miyakoshi A, Taniguchi M, Okubo Y, Uemura T (2005) Evaluations of subsurface flow for reconstructions of climate change using borehole temperature and isotope data in Kamchatka. Phys Earth Planet In 152(4):335-342

Monnin E, Indermuhle A, Dallenbach A, Fluckiger J, Stauffer B, Stocker TF, Raynaud D, Barnola J-M (2001) Atmospheric $\mathrm{CO}_{2}$ concentrations over the last glacial termination. Science 291:112-114

Mote PW, Hamlet AF, Clark MP, Lettenmaier DP (2005) Declining mountain snowpack in western North America. Am Meteorol Soc 86(1):39-49

Moustadraf J, Razack M, Sinan M (2008) Evaluation of the impacts of climate changes on the coastal Chaouia aquifer, Morocco, using numerical modeling. Hydrogeol J 16:1411-1426

Mudelsee $\mathrm{M}$ (2001) The phase relations among atmospheric $\mathrm{CO}_{2}$ content, temperature and global ice volume over the past $420 \mathrm{ka}$. Quat Sci Rev 20:583-589

Nakićenović N, Swart R (2000) Special report on emissions scenarios, A special report of working group III of the Intergovernmental Panel on Climate Change. Cambridge University Press, Cambridge/New York

Neelin JD, Muennich M, Su H, Meyerson JE, Holloway CE (2006) Tropical drying trends in global warming models and observations. Proc Natl Acad Sci U S A 103(16):6110-6115 
Ngongondo CS (2006) An analysis of long-term rainfall variability, trends and groundwater availability in the Mulunguzi river catchment area, Zomba mountain, southern Malawia. Quat Int 148:45-50

Novicky O, Kasparek L, Uhlik J (2010) Vulnerability of groundwater resources in different hydrogeology conditions to climate change. In: Taniguchi M, Holman IP (eds) Groundwater response to changing climate, International Association of Hydrogeologists. CRC Press/ Taylor \& Francis Group, London, pp 1-10

Ojo O, Oni F, Ogunkunle O (2003) Implications of climate variability and climate change on water resources availability and water resources management in West Africa. In: Franks S, Bloschl S, Kumagai M, Musiake K, Rosbjerg D (eds) Water resources systems - water availability and global change. International Association of Hydrological Sciences, Wallingford, pp 37-47

Okkonen J, Kløve B (2010) A conceptual and statistical approach for the analysis of climate impact on ground water table fluctuation patterns in cold conditions. J Hydrol 388:1-12

Okkonen J, Jyrkama M, Kløve B (2009) A conceptual approach for assessing the impact of climate change on groundwater and related surface waters in cold regions (Finland). Hydrogeol J 18(2):429-439

Oude Essink GHP (1996) Impact of sea level rise on groundwater flow regimes, a sensitivity analysis for the Netherlands. Delft University of Technology, Delft, $411 \mathrm{pp}$

Oude Essink GHP (2001) Salt water intrusion in a three-dimensional groundwater system in the Netherlands: a numerical study. Transp Porous Media 43:137-158

Oude Essink GHP (2004) Modeling three-dimensional density dependent groundwater flow at the island of Texel, the Netherlands. In: Cheng AHD, Ouazar D (eds) Coastal aquifer management: monitoring, modeling, and case studies. Lewis Publisher, New York, pp 77-94

Oude Essink GHP, van Baaren ES, de Louw PGB (2010) Effects of climate change on coastal groundwater systems: a modeling study in the Netherlands. Water Resour Res 46:W00F04. doi:10.1029/2009WR008719

Ouysse S, Laftouhi NE, Tajeddine K (2010) Impacts of climate variability on the water resources in the Draa basin (Morocco): analysis of the rainfall regime and groundwater recharge. In: Taniguchi M, Holman IP (eds) Groundwater response to changing climate, International Association of Hydrogeologists selected paper. CRC Press/Taylor \& Francis Group, London, pp 27-48

Payne JT, Wood AW, Hamlet AF, Palmer RN, Lettenmaier DP (2004) Mitigating the effects of climate change on the water resources of the Columbia River Basin. Clim Chang 62:233-256

Peterson RN, Burnett WC, Glenn C, Johnson A (2009) Quantification of point-source groundwater discharges to the ocean from the shoreline of the Big Island, Hawaii. Limnol Oceanogr 54(3): 890-904

Petit JR, Jouzel J, Raynaud D et al (1999) Climate and atmospheric history of the past 420,000 years from the Vostok ice core, Antarctica. Nature 399(6735):429-436

Phillips FM (1994) Environmental tracers for water in desert soils of the American Southwest. Soil Sci Soc Am J 58:15-24

Pielke RA Sr (2001) Influence of the spatial distribution of vegetation and soils on the prediction of cumulus convective rainfall. Rev Geophys 39(2):151-177

Pierson WL, Nittim R, Chadwick MJ, Bishop KA, Horton PR (2001) Assessment of changes to saltwater/freshwater habitat from reductions in flow to the Richmond River estuary. Aust Water Sci Technol 43(9):89-97

Plummer LN (1993) Stable isotope enrichment in paleowaters of the Southeast Atlantic Coastal Plain, United States. Sci Total Environ 262:2016-2020

Pool DR, Eychaner JH (1995) Measurement of aquifer-storage change and specific yield using gravity surveys. Ground Water 33:425-432

Porcelli D, Ballentine CJ, Wieler R (2002) Noble gases in geochemistry and cosmochemistry, vol 47, Reviews in mineralogy and geochemistry. Geochemical Society and Mineralogical Society of America, Washington, DC

Postel S (2001) Growing more food with less water. Sci Am 284(2):46-51 
Purkey DR, Joyce B, Vicuna S, Hanemann MW, Dale LL, Yates D, Dracup JA (2007) Robust analysis of future climate change impacts on water for agriculture and other sectors: a case study in the Sacramento Valley. Clim Chang 87:S109-S122 Supplement

Ramillien G, Famiglietti JS, Wahr J (2008) Detection of continental hydrology and glaciology signals from GRACE: a review. Surv Geophys 29:361-374

Randall DA, Wood RA, Bony S et al (2007) Climate models and their evaluation. In: Solomon S, Qin D, Manning M, Chen Z, Marquis M, Averyt KB, Tignor M, Miller HL (eds) Climate change 2007: the physical science basis, Contribution of Working Group I to the Fourth Assessment Report of the Intergovernmental Panel on Climate Change. Cambridge University Press, Cambridge/New York, pp 589-662

Ranjan P, Kazama S, Sawamoto M (2006a) Effects of climate change on coastal fresh groundwater resources. Glob Environ Chang 16(4):388-399

Ranjan SP, Kazama S, Sawamoto M (2006b) Effects of climate and land use changes on groundwater resources in coastal aquifers. J Environ Manage 80(1):25-35

Reilly TE, Dennehy KF, Alley WM, Cunningham WL (2008) Ground-water availability in the United States, vol 1323. US Geological Survey, $70 \mathrm{pp}$

Rivard C, Paniconi C, Gauthier MJ, François G, Sulis M, Camporese M, Larocque M, Chaumont D (2008) A modeling study of climate change impacts on recharge and surface-groundwater interactions for the Thomas Brook catchment (Annapolis Valley, Nova Scotia). In: Proceedings of the GeoEdmonton, Canadian Gotechnical Society, International Association of Hydrogeologists, Canadian national chapter joint annual conference, Edmonton

Rodell M, Famiglietti JS (2002) The potential for satellite-based monitoring of groundwater storage changes using GRACE: the High Plains aquifer Central US. J Hydrol 263(1-4): 245-256

Rodell M, Chen J, Kato H, Famiglietti JS, Nigro J, Wilson CR (2007) Estimating groundwater storage changes in the Mississippi River basin (USA) using GRACE. Hydrogeol J 15(1): 159-166

Rosenberg NJ, Epstein DJ, Wang D, Vail L, Srinivasan R, Arnold JG (1999) Possible impacts of global warming on the hydrology of the Ogallala aquifer region. Clim Change 42(4):677-692

Rowell D, Jones R (2006) Causes and uncertainty of future summer drying over Europe. Climate Dynam 27(2):281-299

Roy S, Harris RN, Rao RUM, Chapman DS (2002) Climate change in India inferred from geothermal observations. J Geophys Res B: Solid Earth 107(7):5-1

Ruud N, Harter T, Naugle A (2004) Estimation of groundwater pumping as closure to the water balance of a semi-arid, irrigated agricultural basin. J Hydrol 297(1-4):51-73

Sahagian DL, Schwartz FW, Jacobs DK (1994) Direct anthropogenic contributions to sea level rise in the twentieth century. Nature 367:54-57

Salas JD, Boes DC (1980) Shifting level modeling of hydrologic series. Adv Water Resour 3: $59-63$

Salas JD, Rao GS, Anderson M, Arabi M, Francés F, Suarez W, Lavado-Casimiro WS, Green TR (2014) Introduction to hydrology. In: Wang LK, Yang CT (eds) Modern water resources engineering, Handbook of environmental engineering. Humana Press, New York, pp 1-126

Sandstrom K (1995) Modeling the effects of rainfall variability on groundwater recharge in semiarid Tanzania. Nord Hydrol 26:313-330

Scanlon BR, Healy RW, Cook PG (2002) Choosing appropriate techniques for quantifying groundwater recharge. Hydrogeol J 10(1):18-29

Scanlon BR, Keese KE, Flint AL, Flint LE, Gaye CB, Edmunds WM, Simmers I (2006) Global synthesis of groundwater recharge in semiarid and arid regions. Hydrol Process 20:3335-3370

Scibek J, Allen DM (2006a) Comparing modelled responses of two high-permeability, unconfined aquifers to predicted climate change. Global Planet Chang 50(1-2):50-62

Scibek J, Allen DM (2006b) Modeled impacts of predicted climate change on recharge and groundwater levels. Water Resour Res 42(11):W11405. doi:10.1029/2005WR004742 
Scibek J, Allen DM, Cannon AJ, Whitfield PH (2007) Groundwater-surface water interaction under scenarios of climate change using a high-resolution transient groundwater model. J Hydrol 333(2-4):165-181

Seneviratne SI, Corti T, Davin EL, Hirschi M, Jaeger EB, Lehner I, Orlowsky B, Teuling AJ (2010) Investigating soil moisture-climate interactions in a changing climate: a review. Earth Sci Rev 99(3-4):125-161

Serrat-Capdevila A, Valdes JB, Perez JG, Baird K, Mata LJ, Maddock Iii T (2007) Modeling climate change impacts - and uncertainty - on the hydrology of a riparian system: the San Pedro Basin (Arizona/Sonora). J Hydrol 347(1-2):48-66

Shah T (2009) Climate change and groundwater: India's opportunities for mitigation and adaptation. Environ Res Lett 4(3):035005

Sharda VN, Kurothe RS, Sena DR, Pande VC, Tiwari SP (2006) Estimation of groundwater recharge from water storage structures in a semi-arid climate of India. J Hydrol 329(1-2): 224-243

Sharif MM, Singh VP (1999) Effect of climate change on sea water intrusion in coastal aquifers. Hydrol Process 13(8):1277-1287

Sharma ML (1989) Impact of climate change on groundwater recharge conference on climate and water. Academy of Finland, Helsinki, pp 511-519

Singleton MJ, Moran JE (2010) Dissolved noble gas and isotopic tracers reveal vulnerability of groundwater in a small, high elevation catchment to predicted climate change. Water Resour Res 46:W00F06. doi:10.1029/2009WR008718

Skinner AC (2008) Groundwater: still out of sight but less out of mind. Q J Eng Geol Hydrogeol 41(1):5-19

Slomp CP, Van Cappellen P (2004) Nutrient inputs to the coastal ocean through submarine groundwater discharge: controls and potential impact. J Hydrol 295(1-4):64-86

Small EE (2005) Climatic controls on diffuse groundwater recharge in semiarid environments of the southwestern United States. Water Resour Res 41:W04012

Smerdon JE, Beltrami H, Creelman C, Stevens MB (2009) Characterizing land surface processes: a quantitative analysis using air-ground thermal orbits. J Geophys Res 114(D15):D15102

Sophocleous M (2004) Climate change: why should water professionals care? Ground Water 42(5):637-637

Speidel DH, Agnew AF (1988) The world water budget. In: Speidel DH, Ruedisili LC, Agnew AF (eds) Perspectives on water: uses and abuses. Oxford University Press, New York, pp 27-36

St.Jacques JM, Sauchyn DJ (2009) Increasing winter baseflow and mean annual streamflow from possible permafrost thawing in the Northwest Territories, Canada. Geophys Res Lett 36: L01401

Stewart IT, Cayan DR, Dettinger MD (2004) Changes in snowmelt runoff timing in western North America under a 'business as usual' climate change scenario. Clim Chang 62:217-232

Stute M, Schlosser P (1993) Principles and applications of the noble gas paleothermometer. In: Swart PK, Lohmann KC, McKenzie J, Savin S (eds) Climate change in continental isotopic records, vol 78, Geophysical monograph. American Geophysical Union, Washington, DC, pp 89-100

Sukhija BS, Reddy DV, Nagabhushanam P (1998) Isotopic fingerprints of paleoclimates during the last 30,000 years in deep confined groundwaters of southern India. Quatern Res 50(3): 252-260

Swenson S, Yeh PJF, Wahr J, Famiglietti J (2006) A comparison of terrestrial water storage variations from GRACE with in situ measurements from Illinois. Geophys Res Lett 33(16): L16401. doi:10.1029/2006GL026962

Swenson S, Famiglietti J, Basara J, Wahr J (2008) Estimating profile soil moisture and groundwater variations using GRACE and Oklahoma Mesonet soil moisture data. Water Resour Res 44:W01413. doi:10.1029/2007WR006057

Syed TH, Famiglietti JS, Rodell M, Chen J, Wilson CR (2008) Analysis of terrestrial water storage changes from GRACE and GLDAS. Water Resour Res 44(2):W02433 
Tague C, Grant GE (2009) Groundwater dynamics mediate low-flow response to global warming in snow-dominated alpine regions. Water Resour Res 45(7):W07421

Tague C, Grant G, Farrell M, Choate J, Jefferson A (2008) Deep groundwater mediates streamflow response to climate warming in the Oregon Cascades. Clim Change 86(1-2):189-210

Tanaka SK, Zhu TJ, Lund JR et al (2006) Climate warming and water management adaptation for California. Clim Change 76:361-378

Taniguchi M (2000) Evaluation of the saltwater-groundwater interface from borehole temperature in a coastal region. Geophys Res Lett 27(5):713-716

Taniguchi M (2002) Estimations of the past groundwater recharge rate from deep borehole temperature data. Catena 48(1-2):39-51

Taniguchi M, Burnett WC, Ness GD (2008) Integrated research on subsurface environments in Asian urban areas. Sci Total Environ 404(2-3):377-392

Tapley BD, Bettadpur S, Ries JC, Thompson PF, Watkins MM (2004) GRACE measurements of mass variability in the Earth system. Science 305:503-505

Taylor KE (2001) Summarizing multiple aspects of model performance in a single diagram. J Geophys Res 106:7183-7192

Taylor RG, Scanlon B, Döll P et al (2013) Ground water and climate change. Nat Clim Chang 3(4): 322-329

Thomsen R (1989) The effects of climate variability and change on groundwater in Europe. In: Conference on climate and water. Academy of Finland, Helsinki, pp 486-500

Thoning KW, Tans PP, Komhyr WD (1989) Atmospheric carbon dioxide at Mauna Loa Observatory. 2. Analysis of the NOAA GMCC data, 1974-1985. J Geophys Res 94(D6):8549-8565

Tietjen B, Zehe E, Jeltsch F (2009) Simulating plant water availability in dry lands under climate change: a generic model of two soil layers. Water Resour Res 45(1):W01418

Toews MW, Allen DM (2009) Evaluating different GCMs for predicting spatial recharge in an irrigated arid region. J Hydrol 374(3-4):265-281

Vaccaro JJ (1992) Sensitivity of groundwater recharge estimates to climate variability and change, Columbia Plateau, Washington. J Geophys Res 97(D3):2821-2833

van der Gun JAM (2010) Climate change and alluvial aquifers in arid regions: examples from Yemen. In: Ludwig F, Kabat P, Schaik H, Valk M (eds) Climate change adaptation in the water sector. Earthscan Publishing, London, pp 159-176

Van Dijck SJE, Laouina A, Carvalho AV et al (2006) Desertification in northern Morocco due to effects of climate change on groundwater recharge. In: Kepner WG, Rubio JL, Mouat DA, Pedrazzini F (eds) Desertification in the Mediterranean region: a security issue. Springer, Dordrecht, pp 549-577

van Roosmalen L, Christensen BSB, Sonnenborg TO (2007) Regional differences in climate change impacts on groundwater and stream discharge in Denmark. Vadose Zone J 6(3): 554-571

van Roosmalen L, Sonnenborg TO, Jensen KH (2009) Impact of climate and land use change on the hydrology of a large-scale agricultural catchment. Water Resour Res 45(7):W00A15

Vandenbohede A, Luyten K, Lebbe L (2008) Effects of global change on heterogeneous coastal aquifers: a case study in Belgium. J Coast Res 24(2 Suppl B):160-170

Wahr J, Swenson S, Velicogna I (2006) The accuracy of GRACE mass estimates. Geophys Res Lett 33:L06401. doi:10.1029/2005GL025305

Walvoord MA, Striegl RG (2007) Increased groundwater to stream discharge from permafrost thawing in the Yukon River basin: potential impacts on lateral export of carbon and nitrogen. Geophys Res Lett 34:L12402

Wang G (2005) Agricultural drought in a future climate: results from 15 global climate models participating in the IPCC 4th assessment. Climate Dynam 25(7):739-753

Wang T, Istanbulluoglu E, Lenters J, Scott D (2009) On the role of groundwater and soil texture in the regional water balance: an investigation of the Nebraska Sand Hills, USA. Water Resour Res 45(10):W10413 
Warner SD (2007) Climate change, sustainability, and ground water remediation: the connection. Ground Water Monit Rem 27(4):50-52

Waughray D (ed) (2011) Water security: the water-food-energy-climate nexus, World Economic Forum. Island Press, Washington, DC

White I, Falkland T, Metutera T, Metai E, Overmars M, Perez P, Dray A, Falkland AC (2007) Climatic and human influences on groundwater in low atolls. Vadose Zone J 6(3):581-590

Wilby RL, Harris I (2006) A framework for assessing uncertainties in climate change: low-flow scenarios for the River Thames, UK. Water Resour Res 42:W02419. doi:10.1029/ 2005WR00406

Wilby RL, Wigley TML (1997) Downscaling general circulation model output: a review of methods and limitations. Prog Phys Geogr 21:530-548

Windom HL, Moore WS, Niencheski LFH, Jahnke RA (2006) Submarine groundwater discharge: a large, previously unrecognized source of dissolved iron to the South Atlantic Ocean. Mar Chem 102:252-266

Winter TC (1983) The interaction of lakes with variably saturated porous media. Water Resour Res 19(5): 1203-1218

Winter TC (1999) Relation of streams, lakes, and wetlands to groundwater flow systems. Hydrogeol J 7(1):28-45

Woldeamlak ST, Batelaan O, De Smedt F (2007) Effects of climate change on the groundwater system in the Grote-Nete catchment, Belgium. Hydrogeol J 15(5):891-901

Xu C-Y (1999) From GCM's to river flow: a review of downscaling methods and hydrologic modelling approaches. Prog Phys Geogr 23(2):229-249

Yamamoto K, Hasegawa T, Fukuda Y, Nakaegawa T, Taniguchi M (2008) Improvement of JLG terrestrial water storage model using GRACE satellite gravity data. In: Taniguchi M, others (eds) From headwater to the ocean. CRC Press/Taylor and Francis Group, London, pp 369-374

Yang C, Chandler RE, Isham VS, Annoni C, Wheater HS (2005) Simulation and downscaling models for potential evaporation. J Hydrol 302(1-4):239-254

Yechieli Y, Shalev E, Wollman S, Kiro Y, Kafri U (2010) Response of the Mediterranean and Dead Sea coastal aquifers to sea level variations. Water Resour Res 46:W12550. doi:10.1029/ 2009WR008708

Yeh PJ-F, Swenson SC, Famiglietti JS, Rodell M (2006) Remote sensing of groundwater storage changes in Illinois using the Gravity Recovery and Climate Experiment (GRACE). Water Resour Res 42:W12203. doi:10.1029/2006WR005374

Yusoff I, Hiscock KM, Conway D (2002) Simulation of the impacts of climate change on groundwater resources in eastern England. In: Hiscock KM, Rivett MO, Davison RM (eds) Sustainable groundwater development. Geological Survey of London, London, pp 325-344

Zaitchik BF, Rodell M, Reichle RH (2008) Assimilation of GRACE terrestrial water storage data into a land surface model. J Hydrometeorol 9:535-548

Zektser IS, Loaiciga HA (1993) Groundwater fluxes in the global hydrologic cycle: past, present and future. J Hydrol 144(1-4):405-427

Zuppi GM, Sacchi E (2004) Hydrogeology as a climate recorder: Sahara-Sahel (North Africa) and the Po Plain (Northern Italy). Global Planet Chang 40(1-2):79-91 
Part II

Governance 


\title{
Groundwater Governance in Australia, the European Union and the Western USA
}

\author{
Andrew Ross
}

\begin{abstract}
Groundwater governance can be defined as the system of formal and informal rules, rule-making systems and actor networks at all levels of society that are set up to steer societies towards the control, protection and socially acceptable utilization of groundwater resources and aquifer systems. Groundwater resources are very diverse and groundwater governance is complicated by the common pool nature of most groundwater resources, information gaps, and the diversity of stakeholders and their interests. There are few comparative studies of groundwater governance. This chapter contributes to that literature by means of a high level comparison of groundwater governance in Australia, the European Union and the Western USA. The comparison is structured using the five categories of governance issues defined in the Earth System Governance Project; architecture, access and allocation, accountability, adaptiveness, and agency - defined in this case as management organisation. The EU WFD has gone furthest towards an integrated framework to manage groundwater quantity and quality objectives, but there are many implementation challenges. Australia's system of annually adjustable water entitlements and related water markets provides security, efficiency and flexibility but it is not yet clear how successfully environmental water allocations can be integrated within this framework. The system of prior appropriation in the Western US provides clearly defined priorities for water allocation, but lacks flexibility during extreme droughts. Fully integrated groundwater management, as intended by the WFD, is a very ambitious goal. The advantages of a strong central direction and coordination together with decentralised local management could be obtained through
\end{abstract}

\footnotetext{
A. Ross $(\bowtie)$

National Centre for Groundwater Research and Training, Fenner School of Environment and Society, Australian National University, Canberra, ACT, Australia e-mail: a.ross@unesco.org
} 
a decentralised system of collaborative planning and management at sub-basin scales nested within an overarching groundwater planning framework at the jurisdictional or basin scale. This system could take various forms in different countries depending on social preferences and institutional settings and capacity.

\subsection{Introduction}

Groundwater makes up $30 \%$ of the world's freshwater and $99 \%$ of the world's liquid freshwater. Groundwater supplies over $40 \%$ of global irrigation water and $50 \%$ of municipal water withdrawals. Two billion people depend on groundwater for drinking water. The consumption of groundwater is growing rapidly driven by increases in global population and agriculture and overextraction, and pollution of groundwater is increasing in many parts of the world. This is reducing groundwater reserves and harming rivers and lakes that are connected to groundwater (see Chap. 2 for more detail on the scale of the groundwater problem internationally). As groundwater is depleted supply costs increase leading to reduced access for the poor (Wijnen et al. 2012). Therefore good governance, protecting groundwater resources is crucial, for environmental, economic and social reasons.

Several features of groundwater and its use present challenges for its governance. Firstly, groundwater resources are not visible or well understood. The impacts of groundwater use and pollution are often hidden, and only become apparent over tens or even hundreds of years (Moench 2004, 2007; Wijnen et al. 2012). Secondly, groundwater governance has to allow and account for the large diversity of groundwater resources, users and use impacts. Groundwater is also subject to a diverse range of point source and diffuse pollution. Thirdly, groundwater is often subject to unsustainable levels of exploitation and depletion, because it is a common pool resource - individual users cannot exclude others (Ostrom 1990; Ostrom et al. 1994). Fourthly, even when individual groundwater users collaborate, they cannot be expected to manage remote impacts of groundwater pumping on other resources and the environment. Because of these features groundwater governance is a complex process that requires coordination across multiple spatial and time scales, sectors and administrative levels. Partnerships between governing authorities and water users are needed to address these problems (Schlager 2007; Blomquist and Schlager 2008).

The definition of groundwater governance in this chapter is adapted from the definitions in the Earth System Governance Project (Biermann et al. 2009) and the global diagnostic on groundwater governance (GEF et al. 2015). Groundwater governance is defined as the system of formal and informal rules, rule-making systems and actor networks at all levels of society that are set up to steer societies towards the control, protection and socially acceptable utilization of groundwater resources and aquifer systems.

There are few comparative studies of groundwater governance. This chapter contributes to that literature by means of a high level comparison of groundwater 
governance in Australia, the European Union and the Western USA. The comparison is structured using the five categories of governance issues defined in the Earth System Governance Project; architecture, access and allocation, accountability, adaptiveness and agency - defined in this case as management organisation.

The remainder of this chapter proceeds as follows. The next section introduces the importance and special features of groundwater. These features present a number of challenges for groundwater management. The following section discusses the challenges for groundwater governance in terms of the five issues defined in the Earth System Governance Project. The main part of the chapter includes a comparison of groundwater governance in Australia, the EU, and the western United States. This is followed by a summary assessment of the strengths and weaknesses of groundwater governance in the three regions and some governance difficulties and dilemmas.

\subsection{Framework for the Assessment of Groundwater Governance}

Groundwater governance involves collective action to ensure socially-sustainable utilisation and effective protection of groundwater resources for the benefit of people and groundwater dependent ecosystems (Foster et al. 2009). Groundwater governance as defined in this project refers to forms of steering societies that go beyond government policy-making and include a wide variety of decision-making structures and processes at all levels of society. These involve a wide variety of non-state actors representing industries, scientists, environmental interests and other parties interested in groundwater (Foster and Garduno 2013). In the remainder of this chapter groundwater governance is analysed using a framework based on the five issues defined in the Earth Systems Governance Project (Biermann et al. 2009).

The Earth Systems governance framework enables a large number of governance issues to be grouped into five major classes: architecture, access and use, accountability adaptation and agency and some links between the five issue classes are also established within the framework. Further details of this classification applied to groundwater are given in Table 6.1 and in the remainder of this section.

Table 6.1 Classification of earth system governance issues

\begin{tabular}{l|l}
\hline Architecture & $\begin{array}{l}\text { Central principles, policies and institutions that guide sustainable } \\
\text { groundwater use and protect groundwater quality, and interactions between } \\
\text { them }\end{array}$ \\
\hline Access and use & $\begin{array}{l}\text { Institutions and procedures that determine who has access to groundwater, for } \\
\text { what purposes and how groundwater is allocated }\end{array}$ \\
\hline Accountability & $\begin{array}{l}\text { Institutions and procedures that provide accountability for groundwater } \\
\text { protection and use }\end{array}$ \\
\hline Adaptation & $\begin{array}{l}\text { How groundwater users, governments and third parties respond and adapt to } \\
\text { changes and uncertainty in groundwater availability, use and governance }\end{array}$ \\
\hline Agency & Private and public sector responsibilities for groundwater management \\
\hline
\end{tabular}


The classification aligns with major themes of governance research and the framework has been subject to extensive peer review and has now been in use for several years.

\subsubsection{Architecture}

Groundwater extraction always creates an impact on other resources or the environment somewhere in a hydrological system. Before extracting groundwater a decision is required about the sustainable level of impact that can be accommodated by the system. A sustainable yield can be determined by a combination of two elements. Firstly, stakeholders negotiate a "consensus" or "acceptable" yield that enables them to set management goals. The acceptable yield may be defined in terms of specified resource condition targets. Secondly, scientists and engineers calculate the "operational" yield - the amount of groundwater available through different methods able to meet management goals (Richardson et al. 2011; Pierce et al. 2011). Decisions about acceptable groundwater yield and resource condition targets depend on political judgements about the weights that should be given to consumptive and environmental water consumption now and into the future.

The difficulty of establishing quality standards for groundwater increases with the variability of water quality and use over space and time. Groundwater quality regulation requires definition of well-defined groundwater and environmental quality standards, indicators/measures that enable the achievement of those standards to be assessed, criteria against which the success or failure of specific groundwater protection strategies or interventions can be evaluated (e.g. compliance with environmental quality standards) and evaluation of those interventions (Quevauviller 2008).

\subsubsection{Access and Allocation}

Comprehensive, well defined, secure legal entitlements provide incentives for investment and collective water management (Ostrom 2005; Bruns et al. 2005). A distinction needs to be made between appropriation of groundwater for private use and provision of groundwater for public benefit. Water property rights give individuals an incentive to make the best use of groundwater for their individual purposes, but individuals do not have an incentive to provide groundwater for the environment or to take account of "external" impacts of their use on resources that are remote in space or time.

The collective allocation of entitlements to access and use groundwater is appropriate because of the common property nature of groundwater resources and the external impacts of their use. Collective allocation may be undertaken by elected governments or by other organisations that represent stakeholders, both water users and others. Access and allocation rules can be set out in legal 
documents such as in water plans, or more informally in local agreements (Tang 1992).

Water allocation describes the process that sets out how, by whom and on what basis decisions are made about access to and use of water (Turner et al. 2004). Water allocation processes take place on different sectoral and administrative scales. Allocation refers to both the allocation of groundwater, and also responsibilities and risks related to groundwater management. Clear allocation principles and priorities are particularly important to deal with water scarcities.

Groundwater allocation can be assessed in terms of its effectiveness, efficiency and fairness. Effectiveness is indicated by whether water allocations are sustainable and meet quality standards. Efficiency is indicated by whether groundwater is allocated or can be transferred to its most economically efficient use. Fairness is indicated by whether people and communities have access to water of acceptable quality to meet their needs. The allocation of groundwater access and use entitlements is complicated by variation in legal authorities across administrative boundaries, conflicts between competing users and uncertainties about future biophysical and social conditions (Blomquist et al. 2004). The agriculture sector is the main user of groundwater in many countries, but many cities depend on groundwater. As agriculture develops and cities grow the access and allocation of groundwater becomes more challenging.

\subsubsection{Accountability}

Two important aspects of accountability can be distinguished. Democratic accountability refers to the institutions and procedures that provide public accountability for groundwater abstraction and groundwater quality standards. Technical accountability refers to processes of monitoring and reporting about groundwater condition and use. Both forms of accountability occur at multiple geographical and administrative scales.

Accountability and legitimacy issues have become increasingly important given the increasing complexity of groundwater management organisations, which include private actors and networks as well as elected governments. When central government agencies govern groundwater they are democratically accountable to the government of the country. However, centralised government agencies may be disconnected from water users and communities, who may perceive government decisions as not being consultative or legitimate (Gross 2011). When groundwater is governed by non-government bodies such as water user groups or watershed partnerships the lines of accountability are less clear. Such bodies may give disproportionate influence to particular groups such as farmers but may also offer opportunities for developing deliberative processes that are genuinely engage citizens (Huitema and Meijerink 2012).

Accountability requires the effective measurement and monitoring of groundwater use. This requires the installation of meters on individual wells and collation of use data by managing bodies - government or non-government. Measurement, 
monitoring and reporting of groundwater use is complicated by the large number and diffuse nature of groundwater users, and by the fact that many of the impacts of groundwater use only become evident after many years (Moench 2007). In many countries, the data available on both groundwater quantity and quality are poor and not standardised compared to the data available for surface water (Biswas 1999).

\subsubsection{Adaptation}

Adaptation can be encouraged by institutional design or implementation processes. Institutional adaptation allows for learning and change in response to unforeseen situations, such as unexpectedly severe droughts or floods, and changing knowledge and policy (Walters 1986; Pahl-Wostl 2007). Regulatory instruments and long-term plans provide direction and certainty to water users but they can be relatively inflexible in responding to change. Flexibility mechanisms such as adjustable shares of volumetric water entitlements, carryover arrangements, water trading and leasing have been built-in to groundwater regulations and plans in Australia and the Western USA to improve adaptability (Ross 2012).

Adaptation is also encouraged by collaborative groundwater governance processes that allow governments, water users and independent experts to collectively learn, negotiate and co-produce groundwater management arrangements (Emerson et al. 2012). It is not sufficient to get feedback through public seminars and discussions. Ongoing engagement of and effective collaboration between policy makers, scientists and practitioners is required (Letcher and Jakeman 2002).

\subsubsection{Agency}

A large variety of non-government as well as government organisations have been given authority to establish and implement groundwater policies and standards in different jurisdictions. Groundwater governance involves a large number of individuals and agencies exercising a wide range of roles and responsibilities. Groundwater governance has often been criticised as being too fragmented, including too many agencies with unclear roles and responsibilities. However attempts to streamline groundwater governance have proved difficult because of the wide diversity in groundwater resource and user attributes.

Groundwater governance poses a cross scale management dilemma. High-level governments can provide effective control, cross sectoral coordination and accountability, and can act flexibly to solve crises. However, hierarchical management can become very complicated at the river basin or sub-basin scale and may displace stakeholder and community action. Moreover, local governments and water users often understand groundwater resources and their importance to communities and the environment better than central governments (Ross 2012).

Special-purpose organisations, such as catchment management organisations in Australia and water districts in the USA may provide a better match with 
hydrogeological boundaries, better local coordination, and encourage engagement and innovation (Marshall 2005; Cech 2010). However, local organisations lack knowledge and incentives to manage intertemporal impacts of resource use at a river basin scale (Schlager 2007), and sometimes lack public accountability.

\subsection{Groundwater Governance in Australia, the European Union and the Western United States}

\subsubsection{The Context for Groundwater Governance}

Increasing groundwater use in Australia, the EU and the USA underlines the importance of good groundwater governance. Groundwater provides about $17 \%$ of water used in Australia, and much higher percentages in some regions and/or during dry periods. Groundwater use is increasing rapidly. For example between 1993-1994 and 1996-1997 groundwater use tripled in New South Wales and Victoria, the most populous states in Eastern Australia (the Australian Government 2001). By 2030 average groundwater use in the Murray-Darling Basin - which includes the majority of Australia's irrigated agriculture, is estimated to increase from an average of $14 \%$ to $27 \%$ of the total water used (CSIRO 2008).

Groundwater supplies about $65 \%$ of public water supplies in Europe (Jacques 2004), and $23 \%$ of agricultural water. There are wide variations between the EU states with a much larger proportion of agricultural water coming from groundwater in southern Europe (EASAC 2010). In many rivers across Europe more than $50 \%$ of annual flow is derived from groundwater, and in dry periods this can rise to more than $90 \%$ (European Commission 2008).

In 2000 groundwater provided about $20 \%$ of water consumed in the USA, $37 \%$ of public supply withdrawals and $51 \%$ of drinking water. There is substantial variation between the states, and in the arid Western USA there is substantial water scarcity, groundwater over drafting and related problems including land subsidence, saltwater intrusion and pollution. Groundwater use for irrigation has increased substantially. In 1950 only $23 \%$ of irrigation withdrawals were groundwater, by 2000 groundwater's share had risen to $42 \%$ (Kenney et al. 2009).

\subsubsection{Key Elements of Groundwater Governance in Australia, the EU and the Western USA}

Key elements of governance architecture, allocation and access, accountability, adaptation and agency in Australia, EU and the Western USA are summarised in Table 6.2 and described in the following sections of this chapter. 
Table 6.2 Key elements of groundwater governance in Australia, the EU and the Western USA

\begin{tabular}{|c|c|c|c|}
\hline & Australia & EU & Western USA \\
\hline Architecture & $\begin{array}{l}\text { National Water } \\
\text { Initiative (NWI) } \\
\text { Tradable property } \\
\text { rights } \\
\text { Water plans } \\
\text { Drinking water } \\
\text { standards }\end{array}$ & $\begin{array}{l}\text { EU water framework } \\
\text { directive (WfD) } \\
\text { Groundwater quantity } \\
\text { and quality standards } \\
\text { River basin } \\
\text { management plans }\end{array}$ & $\begin{array}{l}\text { No national strategy } \\
\text { Tradable property rights } \\
\text { Augmentation/ } \\
\text { mitigation plans } \\
\text { Drinking water } \\
\text { standards }\end{array}$ \\
\hline $\begin{array}{l}\text { Allocation and } \\
\text { access }\end{array}$ & $\begin{array}{l}\text { Return overallocated } \\
\text { basins to sustainable } \\
\text { use }\end{array}$ & $\begin{array}{l}\text { Maintain good } \\
\text { groundwater condition } \\
\text { (quantity and quality) }\end{array}$ & $\begin{array}{l}\text { Maintain property rights } \\
\text { of senior (surface water) } \\
\text { users - prior } \\
\text { appropriation system }\end{array}$ \\
\hline Accountability & $\begin{array}{l}\text { NWI consultation } \\
\text { principle } \\
\text { National monitoring of } \\
\text { NWI, State monitoring } \\
\text { of water plans }\end{array}$ & $\begin{array}{l}\text { WFD consultation } \\
\text { principle } \\
\text { Reporting on river } \\
\text { basin plans }\end{array}$ & $\begin{array}{l}\text { No national } \\
\text { accountability except for } \\
\text { drinking water standards }\end{array}$ \\
\hline Adaptation & $\begin{array}{l}\text { Variable "share" } \\
\text { allocations } \\
\text { Water markets }\end{array}$ & $\begin{array}{l}\text { EU/National drought } \\
\text { management plans } \\
\text { Flexible } \\
\text { implementation of } \\
\text { WFD }\end{array}$ & $\begin{array}{l}\text { Water "rationing" by } \\
\text { means of prior } \\
\text { appropriation system } \\
\text { Flexible implementation } \\
\text { of prior appropriation }\end{array}$ \\
\hline Agency & $\begin{array}{l}\text { Centralised } \\
\text { governance }\end{array}$ & $\begin{array}{l}\text { Subsidiarity principle } \\
\text { Wide range of national } \\
\text { settings }\end{array}$ & $\begin{array}{l}\text { Emphasis on local } \\
\text { governance by courts } \\
\text { and water users } \\
\text { monitored by States }\end{array}$ \\
\hline
\end{tabular}

\subsection{Governance Architecture: Principles, Policies and Institutions}

Australia and the EU have both adopted broad scale (continental) water management strategies with embedded groundwater components. The USA has not adopted a single comprehensive water management strategy and relies on a more decentralised approach using historical water allocation norms and principles prior appropriation in the case of the Western USA. Groundwater governance in Europe is largely based on regulation, Australia has developed a mixed system of regulation and markets, the USA has a polycentric groundwater governance system with a mixture of instruments.

\subsubsection{Australia}

Groundwater management in Australia has been strongly influenced the trajectory of surface water reform. Principles for water governance in Australia are contained in the 1994 and 2004 Council of Australian Government (COAG) agreements on 
water reform. The 1994 COAG agreement included full cost recovery, separation of water from land titles, integrated catchment management and the establishment of water markets and trading (COAG 2004). The 2004 Intergovernmental Agreement on a National Water Initiative (NWI), included the establishment of secure water access entitlements, water access planning with provision for environmental and other public benefit outcomes, the return of over allocated systems to sustainable levels of extraction and further development of water markets, best practice water pricing and national water accounting.

Section 23 of the NWI provides for "a nationally consistent market, regulatory and planning based system for managing surface water and groundwater resources", while 23 (x) recognises "the connectivity between surface and groundwater resources and connected systems managed as a single resource". Surface water and groundwater for human consumption and the environment are managed within this framework but water quality is managed separately.

Under Australia's federal system of government, the primary right to own or to control and use water is vested with the States and Territories (Lucy 2008). The States and Territories have enacted "mirror" legislation to incorporate the NWI in state laws and regulations. Groundwater is allocated in accordance with priorities established by the State governments. The 1992 Murray-Darling Basin agreement placed a cap on surface water use (MDBC 2006), and included a formula for allocating water among MDB jurisdictions, but there was no similar cap on groundwater use, which continued to expand for a further decade.

The Australian Government's Water Act 2007 requires that the new MurrayDarling Basin Authority prepare an integrated surface and groundwater plan for the basin. The Basin Plan was passed by the Australian Parliament on 26 November 2012. The plan includes sustainable diversion limits for groundwater resources, but these have been criticised insufficiently recognising surface water groundwater connectivity and for failing to take account of environmental impacts of groundwater pumping (Nelson 2012).

Groundwater quality is not included as a central objective or element in the NWI. Water quality is subject to a separate agreements between Australian governments, including the National Action Plan for Salinity and Water Quality and the National Water Quality Management Strategy (NWQMS). The NWQMS contains detailed standards for water that is to be used for specific human consumptive purposes, which are included in state legislation, but groundwater quality monitoring is generally poor. Groundwater salinity is increasing and groundwater dependent ecosystems are threatened by over-extraction and poor groundwater quality in some areas. Nitrate levels in some irrigated catchments exceed national drinking water standards and ecosystem protection guidelines (Geoscience Australia 2010). 


\subsubsection{The European Union (EU)}

The European Water Framework Directive (WFD) developed from a series of earlier water directives which were driven by concerns to ensure clean water supplies and to maintain environmental quality in the EU. The WFD is a legally binding policy that provides a common framework for integrated management of the quality of all types of water in Europe. The WFD came into force in December 2000.

The primary objectives of the WFD are to protect and enhance water quality and aquatic ecosystems and to promote sustainable water use. The WFD includes five key elements; river basin management based on river basin plans, a combined approach to pollution control linking emission limit values to environmental quality standards, definition of "good water status", the principle of full cost recovery for water and increasing public participation in policy making (Page and Kaika 2003). Good water status includes a focus on ecological status for surface water and quantitative status for groundwater i.e. groundwater levels linked to the achievement of ecological objectives (Wijnen et al. 2012).

The WFD is a supranational law which had to be transposed into domestic law of the EU Member States. Parts of the WFD, especially the chemical status of water bodies and the so-called priority substances contain specified standards. Environmental standards have been set for surface water for 33 substances. The ecological goal-setting process allows member states considerable freedom regarding both policy process and policy output, e.g. targets and end goals for water bodies. Implementation is flexible in several important ways including the designation of the relative "modification" of water bodies, the degree of formalisation of goals and environmental standards, scale of implementation, stakeholder participation, integration with other policy fields, and finally exemptions from general targets (Liefferink et al. 2011). If member states fail to transpose the WFD the European commission can initiate an infringement procedure before the European Court of Justice which may impose financial penalties (Mechlem 2012).

The WFD (Article 4.1(b) (i and ii) require member states to implement all measures necessary to prevent or limit the input of pollutants into groundwater, to prevent the deterioration of the status of all bodies of groundwater, and to protect enhanced and restore all bodies of groundwater, ensuring a balance between abstraction and recharge with the aim of achieving good groundwater status within 15 years.

Groundwater provisions of the WFD require member states to define and characterise groundwater bodies (within river basin districts), identify bodies at risk of not meeting WFD objectives, establish registers of areas where groundwater requires protection, establish groundwater threshold values (quality standards), pollution trends, and measures to prevent or limit inputs of pollutants into groundwater. Implementation of these provisions includes establishment of monitoring networks, and inclusion of groundwater protection in river basin management plans and programs of measures for achieving WFD objectives for each river basin district (European Commission 2008). 
River basin management plans were due to be submitted to the Commission by 2009 and programs of measures have to be in force by the end of 2013. However, there are large differences between member states in the enforcement of EU standards. More than $50 \%$ of groundwater bodies in some southern European states are at risk of not meeting WFP requirements because of the overpumping and pollution (EASAC 2010).

\subsubsection{Western USA}

There is no overarching national strategic framework for water management in the United States or across the western USA. Water for human use and the environment, and water quantity and water quality objectives are managed separately. Each individual state has "plenary control" over the waters within its boundaries and state of local governments set goals for regulating water use and water pollution.

In the Western USA the doctrine of prior appropriation was developed to set water allocation priorities and to address disputes among landowners. The doctrine includes four key elements; establishment of a water right by diverting water and applying it to a beneficial use, and (once beneficial use was established) the right to exclude others from using the same water, to use the water in allocation distant from the source and to sell the water to third parties (Jones and Cech 2009). Subsequently most western states adopted groundwater legislation that extended the doctrine to cover groundwater (Schlager 2006).

State law underpins the doctrine of prior appropriation (Kenney et al. 2005). If low stream flows prevent senior rights holders from diverting the water to which they are entitled, the seniors put a "call" on the river, requiring all upstream rights holders "junior" to the caller to stop diverting water until adequate streamflow is restored (Howe 2008). In the prior appropriation system most groundwater rights holders are relatively junior and have to make good their impacts on senior rights holders. In times of water scarcity this can result in groundwater pumping being terminated (Jones 2010).

Groundwater drawdowns and pollution have led to the choice between reducing the take of existing users or restricting new development. In some cases groundwater users have successfully lobbied against restrictions leading to the ongoing depletion of resources such as the High Plains aquifer (Sophocleous 2009).

The US Federal government has had a strong involvement in water development and distribution, through major water projects and more recently through federal environmental law (Kenney et al. 2005).

The Federal Clean Water Act (s102) provides for the development of comprehensive programs for preventing, reducing or eliminating the pollution of groundwater used for human consumption. The Act (s106) also allows for funding to support groundwater protection programs but in practice the costs of remediating source water pollution are met by municipal governments and industry (GWPC 2007). Federal pollution control laws including the Resource Conservation and Recovery Act and the Comprehensive Environmental Response Compensation and 
Liability Act provide for landowners to be liable for point source pollution including impacts on groundwater (Smith 2004). The Endangered Species Act provides for the conservation of threatened and endangered plants and animals and their Habitats, and is an important driver for environmental water provision.

Application of prior appropriation to groundwater has not prevented groundwater depletion in unconnected basins, while in connected basins it has prevented the use of groundwater when surface water is scarce (Schlager 2006), Groundwater quality controls are largely limited to point source pollution and sources of drinking water, there are no systematic controls on diffuse pollution. Thomas (2009) argues that the US would benefit from the adoption of a federal approach similar to the EU groundwater directive to protect its groundwater resources.

\subsection{Access and Allocation}

\subsubsection{Australia}

Under the NWI Australia has adopted a framework of water entitlements that are completely and transparently defined, separated from land wherever possible, specified in registers, monitored and enforced (NWC 2009). Entitlements to access water, to take water in a particular season/year and to use water at a particular place and time for a specific purpose are separated from land ownership.

Surface water allocations are made to satisfy these entitlements in each season/ year as defined in the relevant State water plan and depending on the amount of water available. During scarcities lower priority agricultural uses receive less than the face value of their water entitlement. In most Australian jurisdictions the separation of water entitlements from land promotes the development of water markets and trade in water.

The allocation of shares of total available groundwater is more difficult to clearly define. Groundwater availability is often defined according to proportion of longterm recharge that can be extracted without compromising the integrity of the water source and the ecosystems and communities that depend on it.

The use of groundwater has been restricted in a limited number of management areas on the basis of exploitation of, or stress in surface and/or groundwater resources. In some highly exploited stressed groundwater systems, annual allocations of a share of water entitlements have allowed authorities to control groundwater exploitation without compulsory reduction of entitlements (NWC 2006). Cease to pump rules are applied to some groundwater resources to maintain minimum flows in connected streams. However, there is no systematic national approach.

The efficient allocation of resources has been boosted by the development of water markets but the effectiveness of the protection of groundwater resources is complicated by the overallocation of water use entitlements (Young 2010), and the failure to properly account for impacts on groundwater use of surface water 
resources (Evans 2007). There are a range of community perceptions about fairness in water allocation, in particular there is some disagreement about the balance of allocations between water for the environment and irrigation (Connell et al. 2007).

\subsubsection{The EU}

In the EU the entitlement to use water is generally given by public authorities through licences and permits. Water allocation is carried out by different authorities and agencies at different levels. Authority to pump groundwater is generally given through permits that refer to the quantity of water abstracted and/or pumping capacity. Permits are issued for varying periods of time in different states. In some states including France, Germany and the UK environmental impacts are considered when granting permits.

National authorities have powers to restrict abstractions during times of water scarcity or drought. Some countries such as Netherlands, Spain and France determine restrictions according to a hierarchy of water users. Priority may also be given to particular sectors, or sometimes within sectors, for example for specific crops (European Commission 2012).

Also the WFD sets a "good quantitative status" for groundwater which implies an obligation to ensure a balance between (natural) recharge and abstraction over a river basin management cycle. However, the implementation of the programme of action that has followed the groundwater directive has concentrated on water quality issues rather than over abstraction.

Regulation of groundwater has not kept pace with the rapid growth in groundwater use in terms of both users and volumes used. Different member states use different combinations of instruments to manage groundwater resources. In some parts of the EU land-use control is the main instrument. For example in the UK environmental agencies have defined source protection zones for some 2000 groundwater sources. In many parts of the EU there are regimes for groundwater protection including the licensing of boreholes. However, in many of the southern European states the number of unlicensed users is growing rapidly (EASAC 2010).

The effectiveness of the Water Framework Directive is being reduced by slow implementation because of the different degrees of ambition and cohesion of the efforts of member states (Liefferink et al. 2011), and technical challenges including information processing (Hering et al. 2010). In southern Europe where the economic and social dependence on groundwater takes precedence over ecological considerations a difficult balance has to be struck between the social benefits of current consumption and the broader social and ecological benefits of conserving water dependent ecosystems (EASAC 2010). European water markets for quality or quantity are not well developed, reflecting a European emphasis on administrative water allocation and regulations on water quality. These institutions may be relatively efficient for European conditions, but there are opportunities for markets that can deliver greater amounts of cleaner water at lower costs (Zetland 2011). 


\subsubsection{The Western USA}

In the Western USA groundwater access and allocation has been regulated by the operation of the prior appropriation system. Water access and allocation reflects common-law courts decisions from the late 19th and early twentieth century. Surface water rights are generally senior to groundwater rights.

Prior appropriation has worked differently when applied to aquifers compared to surface waters. It has also applied differently to groundwater resources unconnected to surface water (non-tributary) and connected (tributary) resources (Schlager 2006).

In the case of non-tributary groundwater priority acts to limit the number of well permits issued but does not prevent declining water tables. Reasonable declines in water tables are allowed. It is up to state courts to determine what constitutes a reasonable decline on a case-by-case basis. State governments have not intervened to limit the issue of well permits until aquifer depletion and/or negative impacts on other users have become serious. In the case of tributary groundwater, prior appropriation has been adapted to allow some groundwater pumping while protecting senior surface rights. Groundwater pumpers have been allowed to pump water if they can provide water to augment stream flows to prevent injury to surface water users (or the environment). This system prevents long-term over abstraction of tributary groundwater, but it can discourage efficiency because water is forfeited if it is not used within the statutory time period (Neuman 2010) and it prevents the use of groundwater during droughts when it is most needed (Schlager 2006).

Further modifications of state water allocations based on prior appropriation have been needed to allow for the fact that hydrologic systems do not stop at state boundaries (GWPC 2007) and pumping can harm senior water rights in adjoining states. In order to deal with this problem interstate agreements have been negotiated to address cross-border impacts of water use.

Environmental water allocation is managed separately from water for consumptive use and the fairness of the prior appropriation system can be challenged in the sense that it does not service changing social preferences such as environmental water requirements. Federal environmental laws including the Clean Water Act and the Endangered Species Act provide the main driver for environmental water provision, often through an interstate compact. For example, the South Platte Compact requires that between April 1 and October 15 Colorado must ensure river flows do not fall below $120 \mathrm{cfs} .{ }^{1}$ Colorado has also committed to making 10,000 acre feet of water available between April and September of each year to assist recovery programs for three endangered birds and one endangered fish (Freeman 2011).

\footnotetext{
${ }^{1} 100$ cubic feet per second equals 2.82 cubic metres per second.
} 


\subsection{Accountability}

\subsubsection{Australia}

In Australia there are several levels of democratic accountability for groundwater management. The National Water Commission (NWC) has responsibility for reviewing the implementation of the NWI and reporting to the Australian government. The NWC has published biennial reviews of the NWI. State and Territory water authorities have responsibility for establishing groundwater management plans, and monitoring and enforcing these plans. These authorities report progress to their own government and also to the NWC.

The NWI provides that governments engage water users and other stakeholders in water planning and other reform processes in order to improve certainty and confidence, transparency and information sharing. State water legislation includes provision for consultation in relation to water plans, but consultation often appears more symbolic than real, because it takes place after policy changes have been made and/or does not take sufficient account of stakeholder views (Bowmer 2003). Australian and international experiences show how communities can use collaborative water planning processes to manage cuts to water allocations (Richardson et al. 2011) and for flood and drought risk management (Daniell et al. 2010).

The NWI requires all jurisdictions to ensure adequate measurement, monitoring and reporting systems are in place. The capacity of State and Territory governments to monitor groundwater resources and plans is mixed. Some resources, especially the most highly exploited resources, have relatively good metering and monitoring, but many resources lack basic metering, measurement and monitoring infrastructure. There is a national program to develop this infrastructure. Monitoring of groundwater quality is limited and carried out in an ad hoc manner. There is no consistent national program on groundwater quality monitoring and much of the monitoring has been short term (Geoscience Australia 2010).

\subsubsection{The EU}

Democratic accountability for the implementation of the WFD is complex with local areas reporting to national governments and parliaments who in turn report to the European Community and Parliament. EU member states and the European commission have jointly developed a Common Implementation Strategy (CIS) for supporting the implementation of the WFD. A Strategic Coordination Group (SCG) composed of Member States and stakeholder organisations coordinates cooperation on implementation.

Groundwater planning and allocation systems have high levels of democratic accountability to national governments, and the European Parliament, but sometimes are not perceived as legitimate at local levels because of lack of community participation and deliberative processes. The WFD requires governments to provide information about planned measures and to report on implementation to 
stakeholders and the general public. It remains a challenge to ensure public access to reliable and consistent information about measures, and to motivate and facilitate public participation (De Stefano et al. 2013).

The SCG has developed guidance documents on groundwater monitoring and groundwater protected areas and is developing guidance on compliance and impacts of land use on groundwater. Measurement, metering and monitoring capability varies substantially among the EU member states, and between regions within the states. EU wide coverage and long-term series of water quality data are not available, and the analysis of water quantity is insufficient in many river basin plans - only $25 \%$ of plans include water availability scenarios and less than $20 \%$ assess data uncertainty.

\subsubsection{Western USA}

State governments are accountable for groundwater management. There is no national accountability mechanism except in the case of transboundary aquifers where there are interstate agreements, and where federal courts or the Supreme Court are responsible for the agreements.

Water management in the US is fragmented, with many overlapping jurisdictions and agencies. Stakeholder engagement, information sharing and accountability is effective across parts of the system but it is very difficult to ensure good communication and consultation across the whole system. Groundwater is governed by a network of water users, water courts and administrative authorities. Groundwater management arrangements are accountable and are perceived as legitimate at a local level, but are not necessarily democratically accountable or perceived as legitimate at a broader level.

There are many gaps in information about groundwater availability and use and there is a need to improve the effectiveness of coordination of groundwater information and data. There is no regular national review or monitoring of groundwater use. The US Geological Service issues periodic reports. The latest covered groundwater use in 2010 (Maupin et al. 2014).

The Clean Water Act (s 106(e)) requires the USEPA to determine that a state is monitoring water quality including groundwater. Thirty states have included some groundwater monitoring in their water monitoring strategies but most of the emphasis is on surface water monitoring. ${ }^{2}$ From 1991 the US Geological Survey (USGS) has implemented a National Water Quality Assessment Program that includes groundwater assessments. The USGS has identified 62 regionally extensive aquifers and is carrying out assessments of about one third of them, but most aquifer assessment and monitoring is carried out by the states, and the quality of the programs is highly variable (GWPC 2007).

\footnotetext{
${ }^{2}$ GWPC-NGWA survey of State groundwater programs, 2006.
} 


\subsubsection{Monitoring - A Common Challenge}

Australia, Europe and the Western USA face similar technical accountability challenges because of shortfalls in groundwater metering and monitoring infrastructure. It is difficult to centrally manage groundwater monitoring because groundwater abstraction is very diffuse. On the other hand groundwater users and local governments often have insufficient mandate or resources to put broadscale monitoring programs in place.

\subsection{Adaptation}

\subsubsection{Australia}

Section 25 (iv) of the NWI provides for adaptive management of surface water and groundwater systems in order to meet productive, environmental and other public benefit outcomes. The National Water Commission undertakes biennial reviews of the implementation of the NWI, but it is left for states to determine how often to review water plans in their jurisdictions. Under the new Murray-Darling Basin plan the Murray-Darling Basin Authority will review state water resource plans, which will usually have a 10 year life cycle. ${ }^{3}$

In the Murray-Darling Basin flexibility is introduced into water allocation in three ways. Firstly water is allocated to entitlement holders on an annual basis depending on water availability. Secondly surface water and groundwater entitlement holders have a limited capacity to carryover water entitlements for later use. Thirdly, surface water and groundwater trading provides some extra flexibility for water users, including the potential to purchase additional water to make up shortfalls in allocations during dry periods, if there is water available for purchase. However, groundwater trading volumes have been relatively small in the MurrayDarling Basin and there has been no recorded surface water and groundwater trading (Ross 2012).

\subsubsection{The EU}

The EU WFD adopts an adaptive water planning approach. National water authorities adopt management plans, including quality standards and programs of measures for water districts for 6-year periods. These plans are monitored and evaluated and the WFD recognises that quality standards and programs of measures may need to be modified in the following 6-year period. However, the legal systems of some member states are not sufficiently flexible to respond to new situations and information.

\footnotetext{
${ }^{3}$ http://www.mdba.gov.au/draft-basin-plan/delivering-healthy-working-basin/ch03. Accessed 5 April 2013.
} 
The WFD recognises the importance of adaptive mechanisms but they are dealt with through parallel processes including the EU water scarcity and drought policy developments. In 2007 the European Commission released a communication on water scarcity and droughts that laid down a water hierarchy including demand management followed by alternative supply options once the potential for improving water efficiency had been exhausted. This text is, however, not legally binding.

A Commission review of this policy (European Commission 2012) found that while member states have established mechanisms for authorising groundwater use, illegal abstractions remain an important challenge in some parts of Europe. There has been only limited implementation of drought risk management plans, and cost recovery and price incentive mechanisms.

In practice the main flexibility mechanism in the WFD is the degree of freedom given to member states to set groundwater standards and implementation timetables. This approach reflects heterogeneity in the member states, but could result in slow improvements in standards which would reduce the effectiveness of the WFD.

\subsubsection{Western USA}

The prior appropriation system deals with uncertain water supply and shortages by setting clear priorities for allocation of scarce water based on seniority. Junior water entitlement holders must relinquish water in times of shortage. This system provides certainty in the face of changing water supplies but is not very flexible in responding to changing social preferences for the use of water such as demand for new urban development, provision for in stream flows or conjunctive water management. In addition conflicts are resolved by litigation which can be slow and not very responsive to unanticipated crises needing urgent responses.

Adaptive management is gaining a foothold in some agencies like the National Marine Fisheries Service and the U.S. Forest Service, but state water management agencies have a restricted role and responsibilities, to manage the allocation of water for consumptive use or to control water to ensure consumptive supplies. Water quality and water for the environment are managed separately. Because of these management settings water management agencies are not at the forefront of strategic adaptive management (Neuman 2010), although they do provide some leadership in information collection, monitoring and the development of local water allocation plans (Wolfe 2008).

In practice the law of prior appropriation has included provisions for reducing allocations of water to users in response to risks including water scarcity, wasteful or non-beneficial use or displacement by "public rights". On the other hand junior entitlement holders including municipalities and groundwater groups have obtained enough political power to secure continued allocations (Tarlock 2001). For example, local water plans in Colorado have enabled flexible implementation of the prior appropriation system, without requiring junior groundwater entitlement holders to 
cease production, except in the most extreme drought conditions (Blomquist et al. 2004).

Water trading and leasing provide further flexibility mechanisms. In Colorado there is a significant amount of water trading, mainly transfers from agricultural to municipal users (Howe and Goemans 2003). Water leasing has enabled farmers to lease part of their water portfolio to municipalities and to reduce their acreage temporarily through crop rotation or fallowing (Pritchett et al. 2008).

\subsection{Agency}

\subsubsection{Australia}

Historically, surface water and groundwater planning, rule development and administration have been separated in Australian jurisdictions. The historical separation of surface water and groundwater science (hydrology and hydrogeology) has reinforced the administrative separation. These separations have hindered the development of integrated water management. Water management and allocation in the Australian states is highly centralised in the hands of responsible ministers and their departments. Surface water and groundwater policy and planning are coordinated at the highest levels of decision-making, but often separate at lower levels.

Government representatives generally consider that policy and implementation functions are integrated effectively. But some water users consider that state water managers do not provide enough information and that some functions are poorly integrated. For example, in the Namoi region in New South Wales, users cited as examples of poor integration the separation of management of overland flows, stock and domestic bores, and issues related to water in the mining sector from other water planning and allocation processes. Local and regional bodies could play a more effective role in water planning and management if there were increased delegation of responsibility to these bodies, increased funding or fund raising capacity and support from high level leadership.

\subsubsection{The EU}

The EU Water Framework Directive initiated the move from national and local water management towards river basin planning, but generally EU member states adapted existing management and administrative bodies to implement the WFD maintaining long-standing water management institutions.

Groundwater governance in Europe is generally coordinated by national authorities, sometimes concentrated at the level of member states and sometimes decentralised to regional and local levels. There is a large diversity of management organisations. Many small states such as Denmark have a relatively top-down approach, whereas the large states exhibit a greater diversity of multilevel 
governance agencies. In Denmark the Minister for Environment is responsible for river basin management plans, whereas in the Netherlands the competent authority is the Minister for Transport, Water Management and Public Works. In the Netherlands regional water authorities and water boards have a strong role in implementing the WFD.

River basin authorities have a leading role in a small number of member states. France had already adopted a river basin approach before the WFD was conceived and adapted the existing structure of the river basin and sub-basin plans to implement the WFD (Liefferink et al. 2011). Water user groups play an important role in a limited number of countries including Spain. European countries will benefit from continued experiments with groundwater governance and representation from different levels of government, water users and experts.

\subsubsection{Western USA}

Federal water-related agencies and programs are fragmented and require better coordination. More than 30 federal agencies, boards, and commissions in the United States have water-related programs and responsibilities (Christian Smith et al. 2012). The allocation and distribution of water is subject to regulation by state water resource agencies, and is ultimately in the hands of thousands of farmers, hundreds of irrigation districts and a large number of municipalities and industries.

Local groundwater supply and distribution is managed by regional and local water entities, such as mutual water user companies and cooperatives, irrigation districts, conservancy and conservation districts. These organisations provide a crucial link between state laws and policies and individual water users. In some states water districts play an important role in encouraging regional coordination and innovation. In most cases organisation members democratically establish policy and elect management Boards. The organisations are non profit and raise revenue by assessments on shares (mutual companies), on acreage allotments (irrigation districts), or taxes on land or water sharing assessments (conservancy districts) (Freeman 2000). Municipal users and irrigators initiated the South Platte Water Related Activities Program to ensure that instream flow and endangered species obligations are met (Freeman 2011).

Decentralised groundwater management in the Western USA has encouraged many institutional innovations but management effectiveness could be could be improved by strategic watershed planning that integrated consumptive and environmental requirements, and gave governments and water users an opportunity to adjust the prior appropriation doctrine in order to achieve improved water management outcomes. 


\subsubsection{The Influence of Vested Interests}

In all three regions historically powerful water authorities and water users exert substantial influence and sometimes resist change. The protection of groundwater dependent ecosystems is an ongoing challenge. Strong leadership and broad community engagement are needed to progress reforms in groundwater management.

\subsection{Comparative Assessment of Groundwater Governance in Australia, the EU and the Western USA}

Drawing on the analysis in the previous section the main strengths and weaknesses in groundwater governance in Australia and the EU and the Western USA are summarised in Table 6.3.

Table 6.3 Strengths (+) and weaknesses (-) of groundwater (GW) governance in Australia, the EU and the Western USA

\begin{tabular}{|c|c|c|c|c|}
\hline & & Australia & EU & Western USA \\
\hline \multirow[t]{2}{*}{ Architecture } & + & $\begin{array}{l}\text { NWI provides for } \\
\text { comprehensive GW } \\
\text { governance }\end{array}$ & $\begin{array}{l}\text { WFD provides } \\
\text { comprehensive } \\
\text { GW protection }\end{array}$ & $\begin{array}{l}\text { Prior appropriation } \\
\text { system safeguards } \\
\text { senior water rights }\end{array}$ \\
\hline & - & $\begin{array}{l}\text { Weak GW quality } \\
\text { regulation (except for } \\
\text { drinking water) }\end{array}$ & $\begin{array}{l}\text { Variable } \\
\text { implementation of } \\
\text { GW standards }\end{array}$ & $\begin{array}{l}\text { Weak GW quality } \\
\text { regulation (except for } \\
\text { drinking water) }\end{array}$ \\
\hline \multirow[t]{2}{*}{$\begin{array}{l}\text { Access and } \\
\text { allocation }\end{array}$} & + & $\begin{array}{l}\text { Water plans set } \\
\text { sustainable GW use } \\
\text { limits }\end{array}$ & $\begin{array}{l}\text { GW allocation } \\
\text { included in river } \\
\text { basin plans }\end{array}$ & $\begin{array}{l}\text { Effective rationing of } \\
\text { scarce water }\end{array}$ \\
\hline & - & $\begin{array}{l}\text { Overallocation of } \\
\text { GW use entitlements }\end{array}$ & $\begin{array}{l}\text { Variable } \\
\text { implementation of } \\
\text { basin plans }\end{array}$ & $\begin{array}{l}\text { GW overuse in some } \\
\text { areas }\end{array}$ \\
\hline \multirow[t]{2}{*}{ Accountability } & + & $\begin{array}{l}\text { Democratic } \\
\text { legitimacy }\end{array}$ & $\begin{array}{l}\text { Democratic } \\
\text { legitimacy }\end{array}$ & Local legitimacy \\
\hline & - & $\begin{array}{l}\text { Use monitoring } \\
\text { variable, quality } \\
\text { monitoring poor }\end{array}$ & $\begin{array}{l}\text { Variable } \\
\text { monitoring and } \\
\text { reporting }\end{array}$ & $\begin{array}{l}\text { Accountability for } \\
\text { impacts at large scales, } \\
\text { variable monitoring }\end{array}$ \\
\hline \multirow[t]{2}{*}{ Adaptation } & + & $\begin{array}{l}\text { Variable annual } \\
\text { water allocation }\end{array}$ & $\begin{array}{l}\text { Flexible } \\
\text { implementation of } \\
\text { EU standards }\end{array}$ & $\begin{array}{l}\text { Local innovation, } \\
\text { flexible enforcement of } \\
\text { prior appropriation }\end{array}$ \\
\hline & - & $\begin{array}{l}\text { Centralised system } \\
\text { can discourage local } \\
\text { innovation }\end{array}$ & $\begin{array}{l}\text { Slow } \\
\text { implementation of } \\
\text { drought } \\
\text { management plans }\end{array}$ & $\begin{array}{l}\text { Rigidity of prior } \\
\text { appropriation during } \\
\text { droughts }\end{array}$ \\
\hline \multirow[t]{2}{*}{ Agency } & + & $\begin{array}{l}\text { Central coordination } \\
\text { and planning }\end{array}$ & $\begin{array}{l}\text { Central } \\
\text { coordination and } \\
\text { planning }\end{array}$ & $\begin{array}{l}\text { Local empowerment } \\
\text { and innovation }\end{array}$ \\
\hline & - & $\begin{array}{l}\text { Local delegation and } \\
\text { implementation }\end{array}$ & $\begin{array}{l}\text { Local delegation } \\
\text { (in most countries) }\end{array}$ & Strategic planning \\
\hline
\end{tabular}


The EU WFD has gone furthest towards an integrated framework to manage groundwater quantity and quality objectives and human and environmental uses of groundwater. The discretion for member states to set their own standards and implementation timetable provides flexibility but also threatens to undermine effectiveness of the WFD. Australia's comprehensive system of water entitlements and related water markets together with annual adjustment of entitlement shares provides security and flexibility for consumptive users and encourages efficient water allocation. But it is not yet clear how successfully environmental water allocations can be integrated within this framework. The system of prior appropriation in the Western US provides clearly defined priorities for water allocation, but lacks flexibility during extreme droughts. Neither the Australian nor the US systems effectively protect groundwater quality or groundwater dependent ecosystems.

Australia, the EU and the Western USA face common groundwater governance challenges. Firstly, the effectiveness of policy and plan implementation varies substantially within the regions. Secondly, there are substantial knowledge gaps, measurement and monitoring is expensive and is highly variable. Thirdly, powerful stakeholders conspire to prevent change when it threatens their interests.

\subsection{Some Groundwater Governance Difficulties and Dilemmas}

Experience with groundwater governance in the EU, Australia and the Western USA raises some unresolved dilemmas relating to relationships between aspects of groundwater governance.

\section{Is a Comprehensive Integrated Groundwater Governance Architecture Feasible or Desirable?}

A comprehensive system of groundwater governance would integrate the management of groundwater quantity and quality for consumptive and environmental purposes. Only the EU WFD attempts to integrate all four elements. This has proved to be an ambitious goal, and in practice full integration has not been achieved. In Australia the management of groundwater quantity and quality is carried out by separate institutions and in the Western USA all four elements are separated, with variable degrees of coordination in different regions. Degrees of separation of the four elements may be acceptable providing that there are effective coordination mechanisms, which raises the question of what those mechanisms would be.

\section{What Coordination Arrangements Are Appropriate for Groundwater Governance?}

Groundwater governance involves some particular coordination challenges. Firstly, groundwater resources and user groups are very diverse. Different management rules are appropriate for different resources and users. For example different rules will be appropriate for a shallow alluvial aquifer highly connected to a river 
compared with a fractured rock aquifer remotely connected with surface water. Secondly, the boundaries of groundwater resources, their flows and their interactions with surface water and the environment are often not well understood. Hence centralised groundwater governance can be very complicated, and groundwater governance is typically organised at multiple geographical, sectoral and jurisdictional scales. A multilevel groundwater governance model including elements of central control and accountability, together with decentralised, participative local agencies is discussed below.

Thirdly, long-term coordination raises special difficulties. The impacts of groundwater use on other resources and the environment can be delayed by many years, decades or even centuries. When long-term impacts are discounted using a "market" discount rate long term impacts have a negligible value. This implies that long-term impacts of groundwater overuse will be considered relatively unimportant compared to short-term impacts, and the maintenance of long-term stocks of groundwater will be considered less important than preserving jobs and environmental icon sites. If discount rates were chosen by means of a deliberative process involving commercial developers, community representatives and user groups as well as governments chosen rate could be lower (or higher) than the average market rate. Community discounting is not the current practice and could be expensive but it could better reflect community views and aspirations for the future (Ross 2012).

\section{How Can Central Control and Stability Be Balanced with Adaptiveness?}

Well defined, secure entitlements and rules about the use of groundwater increase confidence in and support for groundwater management. At the same time mechanisms that allow the flexible use, storage and exchange of groundwater over time are required to optimise groundwater use in response to changes in climatic and market conditions and new knowledge. There are some working examples of arrangements that combine security and flexibility. The allocation of tradable water entitlements coupled with annual calculation of water available to be used by water entitlement holders has proved to be an effective means of responding to drought in Australia, but requires the prior issue of individual tradable water entitlements - without overallocation. The wide variety of innovations introduced by water districts and communities in the Western United States show the potential for decentralised collaborative groundwater management, although these institutions may lack broad democratic accountability.

\section{How Can Central Direction Setting and Coordination Be Balanced with Local Agency and Responsibility for Groundwater Governance?}

In practice groundwater governance is typically polycentric, involving a network of governments and their agencies, and special purpose organisations. Participation by groundwater users in decision making is necessary to ensure that users understand each other and have the opportunity to craft mutually acceptable management arrangements taking account of relevant information and uncertainties (Emerson et al. 2012; Ross 2012). This can be achieved by a multilevel approach including both jurisdictional and/or basin wide overviews of water resources and uses and 
detailed management arrangements for individual resources. This multilevel approach can avoid the difficulties involved in drafting and communicating a fully detailed management plan at the river basin or jurisdictional scale, but at the same time ensure a coordinated approach to water management consistent with broader social and policy goals. Higher level governments will need to overcome their reluctance to give control to decentralized organisations (Marshall 2005; Ross 2008).

\subsection{Conclusions}

In this chapter groundwater governance in the EU, Australia and the Western USA has been compared using an analytical framework drawn from the Earth System Governance Project. While the high-level international comparison yields some interesting results, the analysis masks many regional and local variations in the study regions.

The EU WFD has gone furthest towards an integrated framework to manage groundwater quantity and quality objectives, but there are many implementation challenges. Australia's system of water entitlements and water markets coupled with variable annual water allocations provides security and flexibility for consumptive users. But neither it nor the US system protect GDEs or prevent diffuse pollution of groundwater. While the US system provides clearly defined priorities for water allocation, it lacks flexibility during extreme droughts.

Fully integrated management of all sources of water, as intended by the WFD, is a very ambitious goal. The advantages of a strong central direction and coordination together with decentralised local management might be obtained through collaborative planning and management at sub-basin scales nested within an overarching groundwater planning framework at the jurisdictional or basin scale. This system could take various forms in different countries depending on social preferences and institutional settings and capacity.

Open Access This chapter is distributed under the terms of the Creative Commons AttributionNoncommercial 2.5 License (http://creativecommons.org/licenses/by-nc/2.5/) which permits any noncommercial use, distribution, and reproduction in any medium, provided the original author(s) and source are credited.

The images or other third party material in this chapter are included in the work's Creative Commons license, unless indicated otherwise in the credit line; if such material is not included in the work's Creative Commons license and the respective action is not permitted by statutory regulation, users will need to obtain permission from the license holder to duplicate, adapt or reproduce the material.

\section{References}

Australian Government (2001) Australian water resources assessment 2000. National Land and Water Resources Audit, AGPS, Canberra 
Biermann F et al (2009) People, places and the planet: science and implementation plan of the earth system governance project. IHDP, Bonn

Biswas A (1999) Water crisis: current perceptions and future realities. In: Salman M, Salman A (eds) Groundwater-legal and policy perspectives, vol 456, World bank technical paper number. The World Bank, Washington, DC

Blomquist W, Schlager E (2008) Embracing watershed politics. University of Colorado Press, Boulder

Blomquist W, Schlager E, Heikkila T (2004) Common waters diverging streams. Resources for the Future, Washington, DC

Bowmer K (2003) Look after the land and the rivers: reflections on water sharing. Keynote paper 28th international hydrology and water resources symposium. The Institution of Engineers, Wollongong

Bruns B, Ringler C, Meinzem-Dick R (eds) (2005) Water rights reform: lessons for institutional design. International Food Policy Research Institute, Washington, DC

Cech T (2010) Written statement of Tom Cech, Executive director of the Central Colorado Water Conservancy District concerning managing water for the future: how federal, state and local entities are supporting agriculture. In: Sub-Committees of water and power of the house Committee on natural resources, US House of Representatives, Greeley, 17 May 2010

Connell D, Robins L, Dovers S (2007) Delivering the national water initiative: institutional roles, responsibilities and capacities. In: Hussey K, Dovers S (eds) Water for Australia: the social and institutional challenges. CSIRO, Canberra

Council of Australian Governments (2004) Intergovernmental agreement on the national water initiative. Council of Australian Governments, Canberra

CSIRO (2008) Water availability in the Murray-Darling Basin: a report from CSIRO to the Australian Government. CSIRO, Canberra

Daniell K et al (2010) Co-engineering participatory water management processes: insights from Australia and Bulgaria. Ecol Soc 15(4): Art 11

De Stefano L et al (2013) Easier said than done? The establishment of baseline groundwater conditions for the implementation of the water framework directive in Spain. Water Res Manage 27(7):2691-2707

Emerson K et al (2012) An integrated framework for collaborative governance. Public Adm Res Theory 22(1):1-29

European Academy's Science Advisory Council (2010) Groundwater in the southern member states of the European Union, and an assessment of current knowledge and future prospects, German National Academy of Sciences. EASAC Secretariat, Halle

European Commission (2008) Groundwater protection in Europe: the new groundwater directive consolidating the EU regulatory framework. European Commission, Luxembourg

European Commission (2012) Communication from the Commission to the European Parliament, the Council the European Economic and Social Committee and the Committee of the Regions: report on the review of the European water scarcity and droughts policy. COM (2012) 672, Brussels

Evans R (2007) The impact of groundwater use on Australia's rivers. Land and Water Australia, Canberra

Foster S, Garduno H (2013) Groundwater-resource governance: are governments and stakeholders responding to the challenge. Hydrogeol J 21:317-320

Foster S et al (2009) Groundwater governance: conceptual framework for assessment of provisions and needs, GW-MATE strategic overview series 1. World Bank, Washington, DC

Freeman D (2000) Wicked water problems: sociology and local water organisations in addressing water resource policy. J Am Water Resour Assoc 36(3):483-491

Freeman D (2011) Implementing the Endangered Species Act in the Platte Basin water commons. University Press of Colorado, Boulder

GEF, World Bank, UNESCO-IHP, FAO, IAH (2015) Global diagnostic on groundwater governance. http://www.fao.org/fileadmin/user_upload/groundwatergovernance/docs/general/ GWG_VISION.pdf. Accessed 10 June 2015 
Geoscience Australia (2010) Assessing the need to revise the guidelines for groundwater protection in Australia: a review report. Geoscience Australia, Canberra

Gross C (2011) Why justice is important. In: Connell D, Quentin Grafton R (eds) Basin futures. ANU Press, Canberra

Ground Water Protection Council (2007) Groundwater report to the nation: a call to action. Ground Water Protection Council, Oklahoma City

Hering D et al (2010) The European water framework directive at the age of 10: a critical review of the achievements with recommendations for the future. Sci Total Environ 408(19):4007-4019

Howe C (2008) Water law and economics: an assessment of river calls and the South Platte well shut down. Univ Denver Water Law Rev 12:181-196

Howe C, Goemans C (2003) Water transfers and the impacts: lessons from three Colorado water markets. J Am Water Resour Assoc 39(5):1055-1065

Huitema D, Meijerink S (2012) The politics of river basin organisations: coalitions, institutional design choices and consequences. In: Lund conference on earth system governance, 18-20 Apr 2012, Lund

Jacques P (2004) Introduction: Western Europe. In: Brentwood M, Robar S (eds) Managing common pool groundwater resources: an international perspective. Praeger, Westport

Jones A (2010) South Platte Well Crisis, 2002-2010. In the water report. Envirotech Publications, Eugene

Jones PA, Cech T (2009) Colorado water law for non-lawyers. University Press of Colorado, Boulder

Kenney D et al (eds) (2005) In search of sustainable water management: international lessons for the American west and beyond. Edward Elgar, Cheltenham

Kenney J et al (2009) Estimated use of water in the United States in 2005, circular 1344. US Department of the Interior, US Geological Survey, Washington, DC

Letcher RA, Jakeman AJ (2002) Experiences in an integrated assessment of water allocation issues in the Namoi river catchment, Australia. In: Rizzoli A, Jakeman A (eds) Proceedings of the 1st biennial meeting of the International Environmental Modelling and Software Society (iEMSs), Lugano

Liefferink D et al (2011) The EU water framework directive: a multi-dimensional analysis of implementation and domestic impact. Land Use Policy 28:712-722

Lucy J (2008) Water regulation: the laws of Australia. Thomson Reuters Australia Ltd, Sydney

Marshall G (2005) Economics for collaborative environment management: renegotiating the commons. Earthscan, London

Maupin MA et al (2014) Estimated use of water in the United States in 2010: U.S. Geological Survey Circular 1405, $56 \mathrm{p}$

Mechlem K (2012) Groundwater governance: a global framework for action: thematic paper 6: legal and institutional frameworks. FAO, Rome

Moench M (2004) Groundwater: the challenge of monitoring and management. In: Gleick P (ed) The world's water; the Biennial report on the world's water resources 2004-05. Island Press, Washington

Moench M (2007) When the well runs dry but livelihood continues: adaptive responses to groundwater depletion and strategies for mitigating the associated impacts. In: Giodarno M, Villholth K (eds) Agricultural groundwater revolution opportunities and threats to development. CABI International, Colombo

Murray Darling Basin Commission (2006) Murray Darling Basin agreement. Murray Darling Basin Commission, Canberra

National Water Commission (2006) 2005 National competition policy assessment of water reform progress. National Water Commission, Canberra

National Water Commission (2009) Australian water reform 2009: second biennial assessment of progress in implementation of the national water initiative. National Water Commission, Canberra 
Nelson R (2012) Submission to house of representatives standing committee on regional Australia's inquiry on certain matters relating to the proposed Murray Darling Basin plan: groundwater SDLs. Parliament of Australia, Canberra

Neuman J (2010) Are we there yet? Weary travellers on the long road to water policy reform. Nat Resour J 50:139-166

Ostrom E (1990) Governing the commons: the evolution of institutions for collective action. Cambridge University Press, Cambridge

Ostrom E (2005) Understanding institutional diversity. Princeton University Press, Princeton

Ostrom E, Gardner R, Walker J (1994) Rules, games and common-pool resources. The University of Michigan Press, Ann Arbor

Page B, Kaika M (2003) The EU water framework directive: part 2 policy innovation and the shifting choreography of governance. Eur Environ 13:328-343

Pahl-Wostl C (2007) Requirements for adaptive water management. In: Pahl-Wostl C, Kabat P, Moltgen J (eds) Adaptive and integrated water management: coping with complexity and uncertainty. Springer, Berlin

Pierce $\mathrm{S}$ et al (2011) Aquifer-yield continuum as a guide and typology for science-based groundwater management. Hydrogeol J 21:331-340

Pritchett J, Thorvaldson J, Frasier M (2008) Water as a crop: limited irrigation and water leasing in Colorado. Rev Agric Econ 30(3):435-444

Quevauviller P (2008) Groundwater science and policy: an international overview. The Royal Society of Chemistry, Cambridge

Richardson S et al (2011) Connecting science and engagement, and setting groundwater extraction limits using a stakeholder led decision-making process. In: Connell D, Quentin Grafton R (eds) Basin futures. ANU Press, Canberra

Ross A (2008) Australia. In: Jordan A, Lenschow A (eds) Innovation in environment policy: integrating the environment for sustainability. Edward Elgar, Cheltenham

Ross A (2012) Water connecting people adapting: integrated surface water and groundwater management in the Murray-Darling Basin, Colorado and Idaho. Australian National University, Canberra

Schlager E (2006) Challenges of governing groundwater in US western states. Hydrogeol J $14: 350-360$

Schlager E (2007) Community management of groundwater. In: Giordano M, Villholth K (eds) The agricultural groundwater revolution: opportunities and threats to development. CABI Publishing, Wallingford

Smith Z (2004) Groundwater: the US experience. In: Brentwood M, Robar S (eds) Managing common pool groundwater resources: an international perspective. Praeger, Westport

Sophocleous M (2009) Review: groundwater management practices, challenges, and innovations in the High Plains aquifer USA-lessons and recommended actions. Hydrogeol J 18:559-575

Tang SY (1992) Institutions and collective action: self-governance in irrigation. ICS Press, Lanham

Tarlock AD (2001) The future of prior appropriation in the new west. Nat Res Law J 41(4):761793

Thomas R (2009) The European directive on the protection of groundwater: a model for the United States. Pace J Environ Law 26:260-287

Turner K et al (2004) Economic evaluation of water resources in agriculture: from the sectoral to a functional perspective on natural resources management. FAO, Rome

Walters C (1986) Adaptive management of renewable resources. Macmillan, New York

Wijnen $\mathrm{M}$ et al (2012) Managing the invisible: understanding and improving groundwater governance. World Bank, Washington, DC

Wolfe D (2008) The future of water administration in Colorado. CBA-CLE, Denver

Young M (2010) Environmental effectiveness and economic efficiency of water use in agriculture: the experience of and lessons from the Australian water reform programme. OECD, Paris

Zetland D (2011) Water markets in Europe. Water Resour Impact 13(5):15-18 


\title{
Groundwater Law
}

\author{
Rebecca Nelson and Philippe Quevauviller
}

\begin{abstract}
This chapter reviews fundamental legal principles relating to groundwater quantity and quality in the United States, Australia and the European Union. It also examines legal approaches to three key "integration" challenges in groundwater law, which arise in relation to many of these foundational principles. First, groundwater law must deal with the relationship between groundwater and surface water-specifically, how abstraction of one should be controlled due to impacts on the other. A second and related challenge is making legal provision for integrating groundwater with its environment, that is, making legal provision for ecological water requirements. Finally, legal frameworks face the significant challenge of dealing with groundwater management in the cross-boundary context. By comparing and contrasting approaches to common and burgeoning legal challenges across different regions, this chapter seeks to highlight the key issues that regulators and groundwater users must consider and confront in dealing with them, and a range of potential legal solutions.
\end{abstract}

\subsection{Introduction}

Despite their many differences, Australia, the western US and Europe, and indeed major regions of the world, all rely on groundwater as an important water source for cities, agriculture, and ecosystems (Chap. 2). Their systems of groundwater law-a powerful tool for controlling access to groundwater, groundwater depletion, and

R. Nelson $(\bowtie) \cdot$ P. Quevauviller

Melbourne Law School, University of Melbourne, Melbourne, Australia

e-mail: rebecca.nelson1@unimelb.edu.au 
pollution - have proven to be useful for each other to consider, as well as for other nations worldwide (e.g. Garry 2007; Grafton et al. 2009; Thomas 2009; Folger 2010; Ross and Martinez-Santos 2010; Nelson 2011a). This chapter describes key aspects of the groundwater law systems of these three regions and the ways in which they deal with key emerging challenges, both as a guide and a caution to areas facing similar issues. In most countries, groundwater regulation has typically proceeded in "laissez faire mode" (Kemper 2007). But as varying combinations of population growth and its associated industry and agriculture, climate variability, and water quality challenges threaten groundwater in many places of the world (e.g. Bates et al. 2008), the importance of legal tools for dealing with these issues increasingly will come to the fore.

This chapter is structured in three parts. Part One deals with the fundamental legal nature of groundwater, and ownership of groundwater. Part Two describes key differences in the levels of government responsible for regulating groundwater quantity, and introduces key approaches to controlling the extraction of groundwater at two levels: the macro, or basin scale, and the micro scale of individual rights. This part also deals with four key emerging challenges in the context of groundwater extraction: permit- or licence-exempt wells; the emergence of a human right to water; integrated management of groundwater with hydrologically connected surface water and dependent ecosystems, and integrated management across political jurisdictions that share the same water source. These groundwater quantity issues have been particularly dominant in the legal discourse of the western US and Australia, where water scarcity is common and competition for water is high. Lastly, Part Three deals with groundwater quality protection, a regulatory concern in relation to both point-source pollution and, increasingly, diffuse sources of pollution.

The approaches taken in the western US, the EU and Australia to the groundwater law issues discussed here vary richly, not only in terms of the legal principles and tools available, but also in the extent to which they have developed and matured. The fundamental aim of this chapter is to highlight several key emerging issues that regulators, in particular, must consider and confront in groundwater management, and a range of potential legal approaches to these issues.

We draw on examples from each of the three focus regions in each part of the chapter, but in each part, emphasise the experience of jurisdictions in which the subject issue is particularly critical. Accordingly, in describing groundwater quantity concerns, we emphasise the experience of the western US and Australia, presenting these first; and in describing groundwater quality concerns, we emphasise the experience of the EU and the western US, presenting these first.

A final note: a comprehensive treatment of groundwater law, and notable subjects within it, lie outside the scope of this chapter. These include legal aspects of groundwater monitoring, trading, enforcement, pricing, managed aquifer recharge, stakeholder involvement in management, and non-regulatory aspects of groundwater law, such as private legal actions. 


\subsection{Envisioning Groundwater in Law: Its Nature and Ownership}

\subsubsection{What Is Groundwater, for the Purposes of the Law?}

Different legal systems conceive of groundwater differently. The way in which groundwater is defined is of central importance in groundwater law. Too narrow a legal definition can unduly constrain the reach of the law, putting important resources beyond its control. An overly broad definition could complicate administration of the law if it means that permission is required to undertake activities affecting resources that are not, in fact, subject to concern about depletion or contamination.

Definitions of groundwater vary along several dimensions. Key points of difference include whether the definition includes water in the unsaturated zone, as well as in the saturated zone of the soil profile; whether it includes saline water or only freshwater; whether there is a depth limit to the water that is considered "groundwater"; the extent to which the definition includes things that are associated with groundwater, like the aquifer structure; how to distinguish surface water and groundwater where they are subject to different allocation arrangements; whether to distinguish between naturally occurring groundwater and groundwater that has been "artificially" stored using managed aquifer recharge; and how different administrative units of groundwater are defined. While these issues are too numerous to discuss in detail here, some examples of this variation are given here to illustrate notable approaches.

Law plays a unique place in defining groundwater in western US statesbecause the legal view can differ so radically from the scientific view. Some western US states draw complex, narrow legal distinctions between different legal "types" of groundwater, treating some groundwater (often called "percolating" groundwater) differently to groundwater that is closely connected to a river (often called "underflow", "subflow" of a surface stream, or "underground streams"). These distinctions bear no resemblance to geological reality (Klein 2005). Different allocation regimes and rules can apply to each legal "type" of groundwater, and the geographical boundaries of these types are rarely clear. This can result in a troublesome lack of clarity about exactly what legal regime applies to groundwater in a particular location-confusion that may only be able to be resolved through extensive technical studies or litigation (Sax et al. 2006).

Among the regions under discussion here, arguably the broadest definition of groundwater is found in Australia's federal Water Act 2007. That legislation defines "ground water" as "(a) water occurring naturally below ground level (whether in an aquifer or otherwise); or (b) water occurring at a place below ground that has been pumped, diverted or released to that place for the purpose of being stored there; but does not include water held in underground tanks, pipes or other works". "Water resources", which are the basis of administrative planning units, are defined extremely broadly to include, among other things, "ground water", an aquifer whether or not it currently has water in it, and "all aspects of the water resource 
(including water, organisms and other components and ecosystems that contribute to the physical state and environmental value of the water resource" (sub-section 4 (1)). The broad definition of groundwater clearly includes water artificially stored in aquifers using managed aquifer recharge, and the broad definition of water resources clearly indicates the importance of dependent ecosystems, including those that depend on groundwater, within the Australian federal water governance framework.

Within the European Union, the EU Water Framework Directive (adopted by the Council representing EU Member States and the European Parliament) provides a framework for water management, including groundwater. It should be stressed that each country of the 28 EU Member States must transpose EU directives into their national laws but that the practical implementation remains each nation's responsibility. The WFD defines groundwater more narrowly than does Australia's federal Water Act, as "all water which is below the surface of the ground in the saturation zone and in direct contact with the ground or subsoil" (Article 2, item 2). The Directive also refers to a "Body of groundwater", which is a distinct volume of groundwater within an aquifer or aquifers. This volume is generally used to define administrative reporting units. Some Australian states take a similar approach, for example, defining groundwater as comprising only underground water in aquifers (e.g. sub-section 3(1), Water Act 1989 (Victoria), Schedule 4, Water Act 2000 (Queensland)).

\subsubsection{Who Owns Groundwater?}

The difficulty of conceiving of ownership in relation to water has been noted in very disparate jurisdictions as well as at the international level (Burke and Moench 2000; McKenzie 2009). Ownership of groundwater can be an emotion-charged issue: on the one hand, it is closely connected to land and ownership of land; on the other, it is often vital for public water supply systems and supporting ecosystems of high public value. In some places, groundwater has historically been treated very differently to surface water in relation to questions of ownership and allocation because its flowpath is less obvious, and even "secret" and "unknowable" (Klein 2005). This view was considered to justify the traditional English common law rule of absolute ownership of groundwater by overlying landowners, which was imported to both the US and Australia (Klein 2005; Gardner et al. 2009). Today, however, it may surprise some to know that across our three diverse focus regions, public or government ownership of groundwater is the norm, though principles for allocating it differ markedly between jurisdictions.

In the western US, with a few exceptions (as in Texas, where the English common law rule of absolute ownership still stands), the public as a whole owns the water and the state is its trustee. In other words, the state has a non-proprietary, regulatory interest in groundwater (Surett et al. 2013). A landowner generally has a proprietary right to use the water underlying the land, rather than ownership of the water itself (Surett et al. 2013). The question of whether water rights are property 
rights is not completely settled, however (e.g. Ross-Saxer 2010). Different states use different systems of allocation, relying on a variety of principles and procedures contained in statues and judge-made law. The doctrine of prior appropriation, which applies in most western US states, gives greater reliability to groundwater rights that developed earlier in time, rather than treating uses as generally equal in reliability and subject to correlative reductions in reliability in conditions of scarcity. Other systems are "correlative" groundwater rights among overlying landowners in California and Nebraska; and absolute ownership in Texas (Chapman et al. 2005). Judicial allocation necessarily involves court processes, and litigation has the potential to be lengthy and expensive-though this is not always the case, particularly where courts are used to formalise water rights in a basin, to which the parties have already agreed out of court.

Australian law also has its origins in the English common law, originally giving overlying landowners absolute, almost unrestricted rights to own and extract the resource. Legislative changes then vested groundwater in the Crown, and introduced a system of administrative regulation, under which the Crown grants individuals the right to use groundwater. Common law rights were generally abolished (Gardner et al. 2009). In some cases, statutes expressly sought to avoid the extensive water rights litigation that were perceived to occur under western US judicial allocation processes (Clark and Myers 1969). Rights to use groundwater in Australia are now generally considered property rights. Indeed, the creation of a highly regulated property rights system for water is an express premise of two decades of celebrated Australian water reforms aiming to improve economic efficiency and environmental sustainability (Gardner et al. 2009; McKenzie 2009).

Similar to Australia, in the EU, the entitlement to use groundwater (owned by the State) is given by public authorities through licences and permits which are issued for varying periods of time in different states. These are, however, not considered private property rights, but rather rights to exploit the resources in compliance with legally binding rules.

\subsection{Controlling Groundwater Extraction}

Establishing what groundwater is and who owns it is just part of the task of groundwater law. Its main function is to manage groundwater quantity by setting limits on total extraction to achieve a variety of objectives, and by controlling extraction as between individual users, in many cases by assigning individual rights to extract. The first step towards doing that is to decide what level of government to entrust with those regulatory tasks. The experiences of Australia and the EU show varying degrees of supra-state (federal and EU, respectively) involvement and coordination in certain high-level aspects of groundwater policy and law, but allocating water to individual users remains uniformly the task of lower levels of government. In the western US, the federal government has almost no formal role. 


\subsubsection{Who Regulates Groundwater Quantity?}

Different jurisdictions allocate responsibility for regulating groundwater differently as between local, state and federal governments. Broadly, the locus of responsibility for groundwater quantity regulation reflects the general degree of acceptance of centralised government in each region, with responsibility tending to lie higher in government hierarchies in the EU and Australia and lower in the western US.

Western US states are generally responsible for regulating groundwater quantity, though in some states (as in Nebraska and most regions of California), this role is assumed by local governments. The federal government is directly involved in groundwater quantity concerns to a much lesser degree, for example, through funding mechanisms (Leshy 2008b).

Until very recently, Australia approached groundwater quantity regulation in much the same way: states had carriage of water allocation issues, and federal influence was felt mainly through funding mechanisms. However, after over a decade of federal water policy driven by economic incentives offered to the states, the federal Water Act 2007 introduced a much more direct federal role. This is particularly so in the Murray-Darling Basin, an agriculturally and ecologically critical basin the size of France and Spain combined. Under arrangements that are yet to come fully into effect, the federal government sets Basin-wide limits on surface water and groundwater extraction, while states continue to allocate water to individual users within those overall caps.

In contrast to western US states (among which there is no coordination on groundwater quantity administration) and Australian states (among which there is coordination in policy, through the National Water Initiative, but relevant overarching law only in the Murray-Darling Basin), the EU's Water Framework Directive more strongly coordinates the regulation of groundwater quantity among Member States by establishing goals and planning processes in supra-national law. Actual water allocation is carried out by different authorities and agencies at different levels.

The issue of regulatory responsibility aside, the key substantive function of groundwater law is to manage groundwater extraction to achieve particular objectives. This can occur at both a macro- (i.e. basin-) scale, or at the level of individual rights to extract the resource. Though not discussed here, another focus of groundwater quantity law is requiring well spacing to control interactions between wells, and regulating well construction methods to prevent pollution.

\subsubsection{Macro-Level Controls: Establishing Groundwater Withdrawal Limits Through Plans and Other Means}

Jurisdictions use a variety of principles for establishing overall (e.g. basin-wide) withdrawal limits that restrict the allocation of groundwater rights-concepts like "safe yield" (western US), "good groundwater status" (EU), and "environmentally sustainable diversion limits" (Australia). In some cases, these overall withdrawal 
limits are established by management plans - an approach strongly favoured in Australia and the EU.

In most western US states, there is a weaker focus on overall basin extraction limits than in Australia or the EU, perhaps because of the absence of a water planning tradition (Chapman et al. 2005), and reliance on a common law tradition of water allocation. A disadvantage of the western US common law approach in contrast to Australia's water allocation planning approach is the relative difficulty of changing vital concepts like the principles that limit extraction, and how those principles are exercised in a particular year, to match changing water availability and also the modern recognition of the environmental water needs of groundwaterdependent ecosystems (Pilz 2010).

\section{Walnut Creek Intensive Groundwater Use Control Area, Kansas}

In the middle of Kansas, Cheyenne Bottoms lies on one of the busiest, globally significant shorebird migration paths. During their spring migration, about $45 \%$ of North America's shorebird population, up to 600,000 individuals, use these wetlands, which are the largest in the interior US. By 1989, groundwater pumping to support the agricultural economy surrounding the wetlands had depleted Walnut Creek, the source of a surface water right held by the Kansas Department of Wildlife and Parks to water the wetlands. They were completely dry during the height of spring migration (Hays 1990). In response to these effects, the Kansas water rights administrator, the State Engineer, took the unprecedented step of declaring an "intensive groundwater use control area" and establishing rules to ban new groundwater pumping, cut back on existing groundwater rights, and introduce a "cap and trade" system for irrigation water rights. At the time, farmers predicted that groundwater pumping restrictions would have devastating economic effects. However, a 2011 economic analysis suggests that the initially significant economic effects of these rules diminished rapidly, so that in the long-run, producers made the same amount of money from crops while using less water (Golden and Leatherman 2011).

Where they exist, water plans in the western US tend to be used as water supply planning tools "designed to insure that adequate water is available for certain kinds of uses" (Wadley and Davenport 2013) rather than tools for setting basin-scale limits on water allocation. California provides an example of this approach: the California Water Code provides for various kinds of water management plans, including groundwater management plans, but these generally do not affect groundwater allocation (Nelson 2011b). Some western US states that have made recent changes to their groundwater management regimes have introduced the concept of water plans that are capable of constraining groundwater allocation to within cumulative caps (as in groundwater planning processes that aim to achieve "desired future conditions" in Texas (Witherspoon 2010)). Some other western states have 
water plans that affect groundwater allocation in a few designated groundwater areas that are recognised to require special management (e.g. Intensive Groundwater Use Control Areas in Kansas (Sophocleous 2012; and see text box)). In some eyes, a water planning approach is highly controversial, interpreted as an attack on a "pure" prior appropriation system, where seniority and "beneficial use" are the major determinants in allocating water (Wilkinson 1991).

Rather than using a planning mechanism, western US states tend to express overall extraction limits through state statutes and sometimes through judicial precedent, though on occasion neither is particularly clear. Some western US state statutes explicitly limit extraction to "safe yield"-roughly, constraining groundwater extraction to the level of natural and artificial recharge (e.g. Arizona Revised Statutes section 45-561(12), 45-562) - or some variation of that concept. However, as a technical concept, safe yield has been discredited as a management tool capable only of protecting against groundwater over-exploitation, since it ignores discharge points at surface water bodies and ecological users of groundwater (Alley et al. 1999). Some states increase or decrease the allowable extraction above or below the level of recharge by qualifying the concept of safe yield to include other aspects, for example, those related to economics and water quality impacts. In Washington, safe yield prohibits the state from granting appropriative rights beyond the basin's capacity to yield water within a reasonable or feasible pumping lift in case of pumping developments, or within a reasonable or feasible reduction of pressure in the case of artesian developments (Revised Code of Washington $\S 90.44 .070$ ). In Utah, safe yield means extracting the amount of groundwater that can be withdrawn from a basin over a period of time without exceeding the long-term recharge of the basin or unreasonably affecting the basin's physical and chemical integrity (Utah Code Annotated § 73-5-15). Generally speaking, however, environmental considerations in relation to groundwater quantity (i.e. seeking to maintain some portion of natural basin discharge that supports ecosystems) have not yet become a prominent consideration in setting basin-scale limits on extraction in the western US.

In Australia, macro-scale extraction limits are set by statute, usually through legislatively prescribed water planning processes. Broadly, two major goals of national water policy are "to increase the productivity and efficiency of Australia's water use ... and to ensure the health of river and groundwater systems by establishing clear pathways to return all systems to environmentally sustainable levels of extraction." (Preamble, Intergovernmental Agreement on a National Water Initiative). National assessments of the progress of states in achieving these goals have repeatedly found shortcomings in relation to groundwater, however (e.g. National Water Commission 2009, National Water Commission 2011).

Australian water statutes generally cite both environmental and socio-economic objectives (e.g. section 3, New South Wales Water Management Act 2000). They limit extraction in a basin to a level that reflects a combination of environmental and economic principles, with the balance between the two varying depending on the jurisdiction. The federal Water Act 2007 gives an example of an environment-led 
limit: under that legislation, a legally binding federal management plan for the Murray-Darling Basin requires states to ensure that aggregate groundwater pumping does not exceed "sustainable diversion limits" set to reflect "an environmentally sustainable level of take" (section 23). Key elements of that term, however, remain undefined in the legislation, and have been the subject of contestation. By contrast, the state of Victoria provides for "permissible consumptive volumes" to be set for groundwater administrative units without detailing the criteria to be applied to set these limits (section 22A, Water Act 1989), and they have not traditionally been set with regard to ecological water requirements. While Australian jurisdictions strongly emphasise the value of pre-planning acceptable extraction volumes, and constraining allocation through licences accordingly, some states do not impose allocation plans and general controls on groundwater extraction in basins that are only lightly exploited, preferring to wait until more intensive exploitation occurs before undertaking the technical work necessary to nominate extraction limits (e.g. prescribed water resources in South Australia: sections 76, 125, Natural Resources Management Act 2004).

In the EU, the Water Framework Directive sets a groundwater quantity goal of achieving "good quantitative status" for all water bodies by 2015. This will be achieved if the long-term annual average rate of abstraction is compensated by the aquifer recharge. This definition is complemented by principles that go beyond traditional "safe yield" concepts. The status definition also implies that the abstraction should not lead to alterations in flow directions which would result in saltwater or other intrusion. In addition, the level of groundwater should not be subject to anthropogenic alterations such that it would result in failure to achieve the environmental objectives (good chemical and ecological status) for associated surface waters, any significant diminution in the status of such waters, and any damage to terrestrial ecosystems which depend directly on the groundwater body. The policy framework opens the possibility for the Member States to use artificial recharge, providing that this does not jeopardise the quality of the groundwater.

As a general observation, to a greater or lesser degree, depending on the state, there seems to be a general movement towards basin-wide withdrawal limits that take some account of the impacts of extracting groundwater on the environment. This is quite a historical shift, which has generally mirrored the inclusion of such considerations in earlier surface water frameworks, or in a few cases occurred alongside it. This shift is proving much more advanced in Australia and the EU, at least on paper, than is the case in the western US, where often highly developed environmental protections for surface water are not replicated in relation to groundwater. The ease of modifying overarching principles through statute- and water plan-based processes may be one factor explaining this. Another might be the political difficulty of constraining economically important and water-intensive agricultural sectors in the western US, which have a much greater dependence on groundwater than does agriculture in most European countries or Australia (van der Gun 2013). 


\subsubsection{Micro Level Controls: Rights, Entitlements and Licences}

Other than through basin-scale limits on extraction, the other major way in which groundwater law controls groundwater pumping is through rights, entitlements and licences at the scale of the individual groundwater user. Most jurisdictions within our focus regions require a person to obtain a right or entitlement to extract groundwater for particular end uses in all or many geographic areas. Notable exceptions to this are California and Texas in the western US, which do not generally require that a person obtain a permit to use groundwater, even for very large uses, except in small geographic areas. The requirements to obtain a permit or licence to use groundwater, and the processes involved, vary quite dramatically among our three focus regions, as well as within them (Patrick and Archer 1994; Bryner and Purcell 2003; Chapman et al. 2005; Gardner et al. 2009).

Western US groundwater allocation regimes tend to focus on a relatively narrow range of considerations that emphasise the human, rather than the environmental impacts of extracting groundwater. When considering an application for a permit, western US decision-makers commonly must consider: whether water is available for appropriation, the possibility of impairing existing rights, the applicant's ability to put the water to immediate beneficial use, public interest considerations, which are often undefined, and water conservation considerations (e.g. Idaho Code $\S$ 42-203A). A third party usually has strong rights of review; often, they not only have the right to protest a licensing decision, but in doing so, trigger a public hearing on the matter (e.g. Idaho Code $\S 42-203$ A, Montana Code Annotated $\S \S$ 85-2-308, 85-2-309). However, mirroring arrangements in relation to basin-scale extraction limits, in very few jurisdictions are environmental matters explicitly mentioned as a groundwater permitting consideration (e.g. Montana Code Annotated § 85-2-311(3)(b)(vi), Idaho Administrative Code $\S$ 37.03.08.045(e)(ii); North Dakota Century Code, $\S 61-04-06(4)(c))$, and in any case, it appears that these matters are rarely considered with great rigour in practice.

By contrast, Australian legislation tends to produce long lists of matters that a decision-maker must consider in determining whether to grant a licence, with a heavier focus on environmental impacts. A key consideration is whether granting the licence would be consistent with any applicable overall consumptive limit for the area or applicable management plan (e.g. section 147, Natural Resources Management Act 2004 (South Australia); section 40, Water Act 1989 (Victoria)), which may itself contain further location-specific considerations relevant to licensing. Additional statutory considerations relate to the impacts on third parties of granting the proposed right to extract, and impacts on elements of the environment, such as water quality; water conservation policies; impacts on the aquifer structure (e.g. sections 40, 53, Water Act 1989 (Victoria)); and impacts on connected resources, discussed further below. Opportunities for the public to be involved in the issuing of groundwater licences - and the emphasis that agencies place on this form of participation - are often relatively limited, with most of the focus of public participation being at the water planning stage (Nelson 2013). This may be problematic where the effects of extracting groundwater-particularly ecological 
effects-are very localised, and likely able to be anticipated only by locals. Localscale groundwater-dependent ecosystems (GDEs) are unlikely to have been captured in macro-scale planning processes, and are not guaranteed to be addressed by centralised decision-making (Nelson 2013). Recent efforts to map GDEs at a fine scale (Bureau of Meteorology (Australia) 2013) may go some way towards addressing this danger by making this information easily available to decisionmakers and the public.

The relative paucity of western US legal arrangements in relation to water planning, basin-scale caps, and even the brevity of permitting considerations can be explained in part by its very different conception of the role of time, compared with Australia. Rather than focusing heavily on prospective caps or groundwater permitting considerations, western US groundwater law deriving from prior appropriation principles controls the impacts of groundwater extraction primarily by looking backwards. That is, it seeks to avoid over-pumping by curtailing the exercise of a groundwater right that has been found to impair an earlier water right. Dangers with this approach lie in the political difficulty of reducing established uses, and dealing with the time lags that can separate ceasing to pump groundwater and the remediation of adverse impacts.

In the EU, authority to pump groundwater is generally given through permits that refer to the quantity of water abstracted and/or pumping capacity. The permits are closely linked to the risks of not achieving the Water Framework Directive's goal of "good quantitative status", i.e. implying that the level of groundwater in the groundwater bodies is such that the available groundwater resource is not exceeded by the long-term average rate of abstraction. This implies that issued exploitation licences are operated in such a way that they comply with the good status objectives (i.e. restrictions may be imposed in case of water scarcity).

\subsubsection{The Challenge of Exempt Uses}

Permit or licence-exempt groundwater uses can be a significant governance issue, in that they escape many standard legal controls, and may pose a cumulatively significant draw on the resource. Dealing with the potential impacts of such uses has been a particular issue in the western US and Australia (Bracken 2010; Sinclair Knight Merz et al. 2010). The particular end uses that are exempt from the general requirement to obtain a permit or licence vary from place to place. Uses of groundwater for domestic use and livestock watering are an important use category that rarely requires a permit in Australia and the western US (Bracken 2010; Sinclair Knight Merz et al. 2010).

In addition to the problem of many small exempt uses, sometimes even large individual uses of groundwater are exempt from regular groundwater licensing or permitting processes. An important example is groundwater produced as a by-product of extracting coal seam gas, or CSG (also known as coalbed methane). CSG production has raised concerns in relation to its groundwater impacts in both the western US and Australia (National Research Council (U.S.). Committee on 
Management and Effects of Coalbed Methane Development and Produced Water in the Western United States 2010; Nelson 2012b). Petroleum and gas legislation in the Australian state of Queensland, where much of Australia's CSG production occurs, explicitly enables CSG producers to withdraw an unlimited amount of groundwater as part of their CSG activities, without requiring a water entitlement (section 185(3), Petroleum and Gas (Production and Safety) Act 2004). The same position was recently reversed in Colorado after a state Supreme Court decision (Vance v. Wolfe, 205 P.3d 1165 (Colorado 2009)). Similar issues have arisen in other western states (Klahn and Tuholske 2010; Valorz 2010).

\subsubsection{The Challenge of a Human Right to Water}

Whereas exempt groundwater uses can challenge groundwater governance by evading regular controls, nascent concepts of a human right to water could add further complexity to groundwater administration by conferring a different sort of special status on select groundwater uses. There are many areas of uncertainty in the meaning and practical implementation of a human right to water, in general (Good 2011). Regardless of the jurisdiction, key issues in relation to operationalising a human right to water will be its possible fiscal implications, the precise obligations that it creates, on whom, and how the right would be enforced (Thor 2013). A human right to water seems likely to attach to relatively small uses, like direct consumption and sanitation, which likely already benefit from permit-exempt status in many areas. Accordingly, new governance issues associated with the right seem more likely to be associated with groundwater quality, than groundwater quantity. An exception to this might be situations in which large-scale groundwater pumping for other uses affects the availability of water sources that are used to satisfy the human right to water. In any case, a human right to water is an emerging issue which each of the focus regions will likely need to address in the future.

Internationally, various political statements acknowledge a "right to water", including a resolution by the UN General Assembly (Thor 2013). Our focus regions take different approaches to this issue. There is no explicit reference to a human right to water in EU law but the first recital to the Water Framework Directive says "Water is not a commercial product like any other but, rather, a heritage which must be protected, defended and treated as such", which is an implicit reference to human rights and principles of sustainability. Similarly, in Australia, a human right to water is not thought to be recognised at the federal level, but it has been argued that it could include principles of sustainability that would have a bearing on groundwater management, were it recognised (Good 2011).

California law has been more explicit. The state recently recognised a right to water in statute (Assembly Bill 685, codified as California Water Code $\S 106.3$ ), though its formulation is relatively weak. AB 685 declares that it is state policy that every human being has the right to clean, affordable, and accessible water for human consumption, cooking, and sanitary purposes. However, the only duty that AB 685 imposes is a duty of "relevant" state agencies to "consider" the state policy 
on the human right to water when revising, adopting, or establishing policies, regulations, and grant criteria. It does not expand any state obligation to provide water, require the development of additional water infrastructure, or create an enforceable right for water system customers to demand immediate access to safe and affordable water. Though the precise legal implications of the law are not yet clear, recent focus on the lack of access to clean water of many disadvantaged communities in California, who rely on contaminated groundwater (Salceda et al. 2013), promises that it will be an important area of future legal development.

\subsubsection{The Challenge of Connecting Groundwater Abstraction to Surface Water and Ecosystems}

Integrating different elements of the environment, institutions, and actors is a noted challenge in water and environmental law (Klein 2005; Godden and Peel 2010; Thompson 2011). A particular challenge for groundwater law is how to deal with the relationship between groundwater and surface water-specifically, how abstraction of one should be controlled due to impacts on the other-particularly where these connections are affected by significant technical uncertainty. In general, the key issue is how groundwater pumping impacts rivers (though withdrawing surface water may also affect groundwater systems). A major related challenge is making legal provision for integrating groundwater with its environment, that is, making legal provision for ecological water requirements, thereby extending the now well-established concept of protected in-stream flows to groundwater. In most jurisdictions, this is an emerging and unsettled area of law, which seeks to address the water requirements of species and ecosystems that depend entirely on groundwater, as well as those that are associated with streams that receive water from groundwater-derived baseflow. The experiences of our focus jurisdictions demonstrate that key issues in determining a regulatory response to integrating groundwater, surface water and ecosystems will be determining tradeoffs between using a complex, accurate, relatively certain, but administrative expensive mechanism (as in some states of the western US); and using broader, simpler, cheaper mechanisms, which offer arguably less certain results (as in Australia).

Western US mechanisms for integrating groundwater and surface water are arguably the most developed of the focus regions. They are also probably the most expensive to administer, since they require case-by-case technical assessments. Many western US states establish a threshold for the maximum proportion of the water withdrawn by a well that is predicted to be captured from a river over a certain period of time. States differ radically in the degree to which they will permit groundwater pumping to "impair" surface water rights. The relevant proportion in Colorado, for example, is $0.1 \%$ of the annual pumped volume within 100 years of continuous withdrawal (Hobbs Jr 2010). Oregon, on the other hand, adopts a default threshold assumption that a well would usually cause substantial interference with a river if it is located less than a mile from the 
river, and derives $25 \%$ of the withdrawal from the river within 30 days (Oregon Administrative Rules § 690-009-0040). States that have low regulatory thresholds for acceptable impairment of surface water rights tend to use flexible market-type mechanisms to enable groundwater pumpers to offset these impacts, and thereby meet the regulatory requirements for having their development proceed.

By contrast with protections for surface water rights, protections for (GDEs) are at a very early stage of development in the western US. They are achieved chiefly by way of principle-based thresholds for impairment, such as a "public interest" test for granting a groundwater permit that can include protections for fish and wildlife (e.g. Idaho Administrative Code \$37.03.08.045(e)(ii), North Dakota Century Code $\S 61-04-06(4)(\mathrm{c}))$. With more development, the public trust doctrine-which in most states applies only to certain surface waters, rather than groundwater-could provide a promising route to protecting GDEs (Craig 2010; Spiegel 2010).

\section{Protections for GDEs in the Blue Mountains, New South Wales}

Not far from the suburban sprawl of Sydney, Australia, lie the Blue Mountains, which have attained World Heritage status on account of their biodiversity values, cultural values, geodiversity, water production, and wilderness values. A key threat to the area's GDEs, particularly hanging swamps, comes in the form of new groundwater wells. The sensitivity of the ecosystems have warranted not only a ban on commercial wells in the Blue Mountains Sandstone Groundwater Management Area in 2007, but also short-term restrictions on the use of existing wells (NSW Office of Water 2011). Most significantly, given the generally high degree of reverence for domestic use of groundwater (see 'The challenge of exempt uses'), the Water Sharing Plan for the Greater Metropolitan Region Groundwater Sources (Sydney Basin Blue Mountains Groundwater Source) bans the granting or amending of bore approvals within $100 \mathrm{~m}$ of listed, high priority GDEs in the case of "bores used solely for extracting basic landholder rights", and $200 \mathrm{~m}$ for other uses; generally within $40 \mathrm{~m}$ from streams; and within $100 \mathrm{~m}$ from the top of an escarpment (clause 41).

Australian jurisdictions tend to use simpler volumetric or spatial thresholds to protect GDEs, such as clear drawdown limits or no-go zones for new wells around high-priority GDEs (see text box); or volumetric limits on groundwater pumping in a basin, where the limit is calculated to take into account acceptable impacts on rivers or other GDEs (Tomlinson 2011; Nelson 2013). In rare cases, caps on consumptive water use or rules that prevent extraction in response to water level triggers may cover both surface water and groundwater, where interaction effects happen over relatively short time-frames (e.g. Government of New South Wales 2010; Goulburn-Murray Water 2011). A further form of protection is offered by broad statutory considerations, such as requirements to have regard to environmental impacts when a decision-maker is considering a licence application (Nelson 
2013). These approaches tend to require less case-by-case technical analysis than in the western US, but may offer less certain local protections, either because they apply at a macro level (e.g. large-scale volumetric limits), or because their requirements are not specified in detail (e.g. broad statutory considerations).

The EU's Water Framework Directive addresses groundwater-surface water interactions by incorporating connections in its key goal: achieving "good quantitative status" implies that impacts of pumping groundwater should not result in alteration of status of associated surface waters or in any damage in groundwaterdependent terrestrial ecosystems. This regulatory mechanism is, in principle, well established. The extent to which it has been achieved will be evaluated in 2015 in consideration of these possible impacts.

\subsubsection{The Challenge of Connecting Groundwater Abstraction Across Boundaries}

In addition to integrating different water sources and users, groundwater law frameworks also face the significant challenge of dealing with groundwater management in the cross-boundary context. This manifests, first, as rules for sharing cross-boundary aquifers; and second, as an allocation of responsibility for surface water depletions experienced in one jurisdiction, caused by upstream pumping of connected groundwater in another jurisdiction. Our focus regions illuminate several regulatory options for making these connections: proactive formal legal arrangements designed to prevent conflict, which may or may not involve creating a new regional institution; litigation to resolve conflicts; or, in some cases, a lack of coordinated management.

In the western US, litigation-based solutions to cross-boundary groundwater issues tend to be relatively common, and pro-active formal legal arrangements, at least at the interstate level, fairly rare. In particular, the impact of pumping groundwater on interstate rivers has been a key issue subject to significant litigation. Lengthy litigation has dealt with how groundwater pumping affects surface water delivery obligations under multiple interstate agreements, which do not explicitly deal with groundwater (Hathaway 2011; Thompson 2011). In some cases, this litigation has resulted in multi-million dollar damages being paid by upstream groundwater pumping states to downstream states. Such litigation in some cases has been followed by comprehensive management arrangements that seek to avoid similar problems recurring, including integrated surface water-groundwater technical models and monitoring programs. This litigation has proven to be a key driver of intrastate efforts to integrate the management of groundwater and surface water (Nelson 2012a).

Although litigation-based management of transboundary groundwater-surface water resources has proven the norm in the western US, the recent agreement between eight US states and two Canadian provinces governing management of the Great Lakes, and connected groundwater and tributaries takes a promising, different approach (Great Lakes-St. Lawrence River Basin Water Resources 
Compact, effective 2008). The Compact applies to "Waters of the Basin", which are defined to include tributary groundwater (Article 103). The Compact establishes a central authority for management and implementation, and applies a common "decision-making standard" in relation to signatories regulating water uses within their territories (Article 203), but at the same time, grants them a relatively high degree of autonomy (Hall 2006).

In shared groundwater basins in the western US, which lack the complexity of highly connected surface water, "divided administration is the status quo" (Davenport 2008). Major interstate aquifers, like the High Plains Aquifer System (which includes the Ogallala Aquifer) underlying parts of South Dakota, Nebraska, Wyoming, Colorado, Kansas, Oklahoma, New Mexico, and Texas, are administered by each state under separate arrangements. There is no formal coordination of the sort found in interstate river basin commissions or compact arrangements (Sophocleous 2010; Hathaway 2011), and no Supreme Court litigation to apportion the groundwater (Leshy 2008a). Rather, a situation of "de facto groundwater allocation" through "a combination of unilateral actions and lack of action" occurs in many basins, for example the Hueco Bolson Basin underlying New Mexico, Texas and Mexico; in others, some mechanisms like data sharing exist, but cooperation is notably lacking (Hathaway 2011, p. 106). Commentators have noted that interstate groundwater conflicts are developing, particularly where groundwater use is growing (Hathaway 2011).

Australia's management challenges in relation to transboundary aquifers are relatively simple, since it lacks international groundwater boundaries and has relatively few states. The most significant aquifer that crosses interstate boundaries is the Great Artesian Basin, the world's largest artesian basin (Mackay 2007). Coordinated management of the basin occurs under the Great Artesian Basin Coordinating Committee, which has a largely advisory role, rather than regulatory functions. Its main focus has been a scheme to fund the capping of artesian wells that previously were allowed to run freely, causing a loss in aquifer pressure (Mackay 2007). At a smaller scale, a groundwater border agreement between the states of Victoria and South Australia, for example, controls depletion of a non-recharged aquifer by bores other than stock and domestic bores by setting zone-based caps on extraction and drawdown (Schedule 1, Groundwater (Border Agreement) Act 1985 (Victoria)). It takes effect through state-level licensing decisions within a $40 \mathrm{~km}$-wide cross-border area of the aquifer, which must be made consistent with the Agreement.

The EU Water Framework Directive deals with interjurisdictional groundwater issues in a notably more proactive and structured way than has been the case in either Australia or the western US. It requires Member States to establish international river basin districts, thus requiring cross-boundary cooperation for overall water management, including groundwater (article 13, items 2). It also recommends Member States to establish appropriate coordination with non-EU countries in river basins crossing the boundaries of the $\mathrm{EU}$ (this is however not as strict as the first regulation, as the article says: the Member States "shall endeavour to establish cooperation") (article 13, item 3). This is the only reference to cross-boundary 
aquifer situations concerning quantity aspects. In addition to this, the Groundwater Directive (daughter directive to the WFD) requests Member States to coordinate the establishment of threshold values (groundwater quality standards) in bodies of groundwater within which groundwater flows across a Member State's boundary. Similarly to the WFD, it also recommends ("shall endeavour") coordination with non-EU countries sharing a transboundary aquifer for the establishment of groundwater quality standards (threshold values).

\subsection{Controlling Discharges of Pollution to Groundwater}

Groundwater quality is a subject matter that regulation often treats separately to groundwater quantity. This occurs despite the physical connections between groundwater quantity and quality: polluting groundwater effectively reduces the quantity of usable groundwater, and pumping groundwater can cause quality problems in the form of spreading contaminant plumes and seawater intrusion. Groundwater quality and quantity are regulated under very different frameworks in Australia and the western US. This section briefly describes these frameworks, and introduces the EU's more integrated approach to controlling polluting discharges to groundwater. Key elements of regulatory frameworks for groundwater quality are setting quality goals, and regulating potentially polluting activities to achieve those goals-both point and diffuse sources of pollution.

\subsubsection{Macro-Level Groundwater Quality Goals}

Jurisdictions in each of our focus regions differ in the goals that they set for groundwater quality, the methods of setting those goals, and divisions of regulatory responsibility. In the EU, the goal and definition of "good chemical status" are given in the Water Framework Directive (article 2, item 25 and Annex V, Table 2.3.2) and elaborated in a "daughter directive" which was adopted in 2006 (Directive 2006/118/EC). In this context, the compliance regime is based on quality objectives (compliance with relevant standards, no saline intrusion) that have to be achieved by the end of 2015. The direction chosen is based on compliance with EU-wide groundwater quality standards (covering nitrates and pesticides) which reinforce the parent directives (i.e. the standards are to be applied across the EU). Regarding other pollutants, the adoption of numerical values at Community level was not considered to be a viable option, considering the high natural variability of substances in groundwater (depending upon hydrogeological conditions, background levels, pollutant pathways, and interactions with different environmental compartments). Consequently, the regime of the "daughter" Groundwater Directive requests Member States to establish their own groundwater quality standards (referred to as "threshold values"), taking identified risks into account and a list of substances given in an annex to the Directive. Threshold values must be 
established for all pollutants that characterise groundwater bodies at risk of not achieving the good chemical status objective and this should be done at the most appropriate level, e.g. national, river basin district or groundwater body level. They concern not only pollutants that may be naturally present in groundwater but also synthetic pollutants. Regarding compliance, evaluation will be based on a comparison of monitoring data with numerical standard values (EU-wide groundwater quality standards and/or threshold values set by individual Member States).

In contrast to the EU's single, comprehensive legislative approach to regulating groundwater pollution, the US federal approach has been characterised as an inadequate "patchwork" (Thomas 2009). In relation to groundwater, the main US federal approach has been to regulate key activities that have the potential to pollute groundwater, as described below, rather than to set quality standards, for which it provides in the case of surface water under the Clean Water Act. A form of macrolevel control is adopted, though, under the Safe Drinking Water Act. That Act provides for setting "maximum contaminant levels" for public water supply sources. In addition, its "sole source aquifer" program provides for the designation of aquifers that are the sole or principal source of drinking water for an area. The federal government may not fund a project that may contaminate such an aquifer, endangering public health. Under the Safe Drinking Water Act, states must also develop wellhead protection programs to prevent pollution near wellfields that provide public drinking water (Sax et al. 2006). A small number of US state laws mirror the Clean Water Act's approach to surface water protection, prohibiting the discharge of pollutants into groundwater (Thomas 2009). Australia's federal groundwater quality policy echoes, and has been influenced by, these approaches.

In Australia, the role of the federal government in groundwater quality is largely restricted to recommending policy, undertaking joint planning with states, and offering funding (Nelson 2011a). Though groundwater quality-mainly salinityhas been a traditionally strong concern in many parts of Australia, a recent decade of extreme drought ensured that most attention focused on groundwater quantity; federal groundwater quality policy is now significantly out of date. The Guidelines for Groundwater Quality Protection in Australia (GGQPA), a component of the National Water Quality Management Strategy, were published in 1995, and recent reviews have recommended that they be updated (Nelson 2010; Sundaram et al. 2010). Separate policies apply to protecting groundwater quality in specific contexts, such as managed aquifer recharge, the application of recycled water and drinking water standards. The basic approach promoted in the GGQPA is to assess a groundwater resource, set beneficial uses for the resource and accompanying quantitative or qualitative criteria, develop protection measures, and undertake monitoring (Chap. 5, GGQPA; Nelson 2010). Australian states shoulder the major regulatory burden in relation to groundwater quality. Goals for environmental quality (including groundwater quality) are generally set out in state-level environment protection policies, which may be binding or non-binding. They typically aim to protect region-specific "beneficial uses" or "environmental values" of the groundwater, consistent with national policy. 


\subsubsection{Micro-Level Controls: Diffuse and Point Sources}

Jurisdictions commonly control the discharge of point-source pollutants to groundwater, but controls over diffuse sources of pollution uniformly have proven more challenging. In the EU, the compliance regime of the Groundwater Directive implies that values of groundwater quality standards (threshold values) should not be exceeded at any monitoring points in groundwater bodies. However, it opens the possibility for exceeding concentrations at one or more monitoring points providing that an appropriate investigation shows that the exceeding concentrations (e.g. point source pollution) are not considered to present a significant environmental risk, nor endanger the uses of groundwater. In addition, Member States are required to assess the impacts of existing plumes of pollution in groundwater bodies that may threaten their overall quality objectives, in particular plumes resulting from point sources and contaminated land. The Directive requests Member States to carry out trend assessments for identified pollutants in order to verify that plumes from contaminated sites do not expand, do not deteriorate the chemical status of the groundwater body (or bodies in case of grouping) and do not present a risk to human health and the environment. Non-legally binding guidance documents are used to guide Member States on assessing the condition of groundwater and related matters (e.g. European Commission 2007; Quevauviller 2008; European Commission 2009).

In Australia, macro-level groundwater quality goals are operationalised through pollution licensing processes, which generally apply only to point sources. State laws regulate potentially polluting activities, often requiring that an authorisation to undertake such an activity only be granted consistently with, or considering, legislative instruments that set out the beneficial uses of groundwater (e.g. section 47(1)(e) Environment Protection Act 1993 (South Australia)). Water allocation planning processes may also include a requirement to consider beneficial uses (e.g. Tasmania Department of Primary Industries and Water 2009). Economic incentives to minimise pollution also appear in state laws in the form of fees for environmental authorisations that reward best practice (regulations 5CA, 5EA, Environment Protection Regulations 1987 (Western Australia)) and tradeable emissions schemes (e.g. Parts 9.3A Protection of the Environment Operations Act 1997 (New South Wales)). State laws (as opposed to policies or funding programs) dealing with non-point source pollution take several forms, but are much less developed than those for point sources. They can appear as general statutory duties not to pollute the environment or cause environmental harm, supported by codes of conduct or "best practice" guidelines for non-point source activities; and statutory matters that land use planners must consider when faced with land use decisions. Voluntary guidelines, codes of conduct and self-regulatory approaches tend to be used more commonly, in practice, than mandatory obligations (Nelson 2011a). Remedial measures take the form of environment protection or abatement orders (Bates 2006).

As alluded to above, the US federal government's key water quality legislation, the Clean Water Act, does not apply to groundwater in terms of licensing point 
source discharges, though this is a somewhat contentious matter in relation to groundwater that is hydrologically connected to navigable waters, which are covered (Thomas 2009; Makowski 2012). Rather, the potential for groundwater pollution is addressed by a collection of federal legislation that applies to particular activities that may pollute groundwater. The federal Safe Drinking Water Act applies to licensing underground injection activities, including aquifer storage; the Resource Conservation and Recovery Act regulates solid waste including hazardous waste, and applies to underground storage tanks; and the Comprehensive Environmental Response, Compensation and Liability Act deals with remediating past contamination using a strict liability approach (Sax et al. 2006). Non-point sources historically have been dealt with using voluntary control measures, but there is evidence that federal encouragement of states to use more rigorous enforcement mechanisms is producing promising results (Nelson 2011a).

At the state level, jurisdictions take a variety of approaches to seeking to prevent groundwater pollution. California provides an example of a state that is generally regarded as having a promising approach to non-point source groundwater pollution, in particular. Its Porter-Cologne Water Quality Control Act gives the state direct power to regulate nonpoint sources, including agriculture. Regional water quality control plans set out water quality objectives and beneficial uses; waste discharges are subject to either general (based on discharge category) or individualised requirements based on the relevant basin plan and other factors (sections, 13241, 13263 California Water Code). Any person discharging waste, including from non-point sources, must report the discharge and pay an annual fee, unless a waiver applies (section 13260, California Water Code). Unfortunately, the temptation to grant waivers to agricultural non-point polluters has historically been irresistible (Nelson 2011a; Smith and Harlow 2011). More recently, examples of stronger controls on agricultural non-point source pollution of groundwater have arisen, notably requirements for certain categories of farms to have a farm water quality management plan, monitor and report on groundwater conditions, monitor and report on discharges, and have a nutrient management plan (California Regional Water Quality Control Board Central Coast Region 2012). Concerns over nitrate pollution have been instrumental in driving this approach (California Regional Water Quality Control Board Central Coast Region 2012).

\subsection{Conclusion}

This chapter sets out a framework of key issues that arise in groundwater law, with an emphasis on regulatory approaches adopted in the western US, Australia, and the EU. It will be apparent that these regions, and the jurisdictions within them, differ in many ways in their approaches to groundwater law-both controlling groundwater extraction and controlling discharges of pollution to groundwater. These differences begin at the most basic level of defining what groundwater is and who should regulate it, and establishing limits to groundwater withdrawal and 
groundwater pollution at the level of the basin and of individual users and polluters, respectively.

It is not possible to deem any one approach universally most effective or desirable for all situations, and we do not attempt to do so. We do, however, suggest a series of key issues that are likely to pose challenges to effective groundwater management, and that decision-makers should consider in establishing, evaluating, and revising their groundwater laws. In the experience of our three focus regions, these basic challenges include: dealing with groundwater uses that are exempt from licensing requirements; interpreting and applying the emerging notion of a human right to water; connecting groundwater abstraction to impacts on surface water and ecosystems; connecting groundwater abstraction across boundaries; and dealing with both diffuse and point sources of pollution.

While some of these issues have been of regulatory concern for some time, others have arisen over only several years, more recently. Despite the many differences between jurisdictions, they have one regulatory requirement in common: groundwater law must continue to evolve and adapt to newly emerging and dynamic challenges in groundwater management in order to effectively manage groundwater quantity and quality, now and in the future.

Open Access This chapter is distributed under the terms of the Creative Commons AttributionNoncommercial 2.5 License (http://creativecommons.org/licenses/by-nc/2.5/) which permits any noncommercial use, distribution, and reproduction in any medium, provided the original author(s) and source are credited.

The images or other third party material in this chapter are included in the work's Creative Commons license, unless indicated otherwise in the credit line; if such material is not included in the work's Creative Commons license and the respective action is not permitted by statutory regulation, users will need to obtain permission from the license holder to duplicate, adapt or reproduce the material.

\section{References}

Alley WM, Reilly TE, Franke OL (1999) Sustainability of ground-water resources: U.S. geological survey circular 1186. U.S. Geological Survey, Denver

Bates G (2006) Environmental law in Australia, 6th edn. LexisNexis Butterworths Australia, Chatswood

Bates B, Kundzewicz ZW, Wu S, Palutikof J (2008) Climate change and water: intergovernental panel on climate change technical paper VI. IPCC Secretariat, Geneva

Bracken N (2010) Exempt well issues in the west. Environ Law 40:141-253

Bryner G, Purcell E (2003) Groundwater law sourcebook of the Western United States. Natural Resources Law Center, University of Colorado School of Law, Boulder

Bureau of Meteorology (Australia) (2013) National atlas of groundwater dependent ecosystems. http://www.bom.gov.au/water/groundwater/gde/. Accessed 19 May 2014

Burke JJ, Moench MH (2000) Groundwater and society: resources, tensions and opportunities. Themes in groundwater management for the twenty-first century. Department of International Economic and Social Affairs, Statistical Office, United Nations, New York 
California Regional Water Quality Control Board Central Coast Region (2012) Conditional waiver of waste discharge requirements for discharges from irrigated lands (Order No. R3-2012-0011). California Regional Water Quality Control Board Central Coast Region, San Luis Obispo

Chapman M, Glasser S, Gipsman J, Witte L (2005) U.S.D.A. forest service sourcebook of state groundwater laws in 2005. United States Department of Agriculture, Washington, DC

Clark SD, Myers AJ (1969) Vesting and divesting: the victorian groundwater act 1969. Melbourne Univ Law Rev 7:237-257

Craig RK (2010) A comparative guide to the western states' public trust doctrines: public values, private rights, and the evolution toward an ecological public trust. Ecol Law Q 37:53-198

Davenport JH (2008) Less is more: a limited approach to multi-state management of interstate groundwater basins. Univ Denver Water Law Rev 12:139-180

European Commission (2007) Common implementation strategy for the water framework directive (2000/60/EC): guidance on groundwater in drinking water protected areas. European Commission, Luxembourg

European Commission (2009) Common implementation strategy for the water framework directive (2000/60/EC): guidance on groundwater status and trend assessment. European Commission, Luxembourg

Folger JA (2010) From Australia to California: solving California's water crisis by applying lessons learned down under. Univ San Francisco Law Rev 45:243-264

Gardner A, Bartlett RH, Gray J, Carney G (2009) Water resources law. LexisNexis Butterworths, Chatswood

Garry T (2007) Water markets and water rights in the United States: lessons from Australia. Macquarie J Int Comp Environ Law 4:23-60

Godden L, Peel J (2010) Environmental law: scientific, policy, and regulatory dimensions. Oxford University Press, South Melbourne

Golden B, Leatherman J (2011) Impact analysis of the walnut creek intensive groundwater use control area. Kansas State University, Manhattan

Good M (2011) Implementing the human right to water in Australia. Univ Tasmania Law Rev 30: $107-143$

Goulburn-Murray Water (2011) Upper ovens river water supply protection area water management plan. Goulburn-Murray Water, Tatura

Government of New South Wales (2010) Water sharing plan for the peel valley regulated, unregulated, alluvium and fractured rock water sources 2010. Government of New South Wales, Sydney

Grafton RQ, Landry C, Libecap GD, O'Brien JR (2009) Markets—water markets: Australia's Murray-Darling Basin and the US Southwest, International centre for economic research, working paper no.15/2009. International Centre for Economic Research, Torino

Hall ND (2006) Toward a new horizontal federalism: interstate water management in the great lakes region. Univ Colorado Law Rev 77:405-455

Hathaway DL (2011) Transboundary groundwater policy: developing approaches in the Western and Southwestern United States. J Am Water Resour Assoc 47:103-113

Hays J (1990) Cheyenne bottoms fight pits farmers against fowl. Wichita Eagle, 2 Dec 1990: p 1A

Hobbs Jr (2010) Protecting prior appropriation water rights through integrating tributary groundwater: Colorado's experience. Idaho Law Rev 47:5-22

Kemper KE (2007) Instruments and institutions for groundwater management. In: Giordano M, Villholth KG (eds) The agricultural groundwater revolution: opportunities and threats to development. CABI, Wallingford, pp 153-171

Klahn SA, Tuholske J (2010) Coalbed methane produced groundwater: a survey of western water law regulation. Water Rep 77:1-8

Klein C (2005) On integrity: some considerations for water law. Alabama Law Rev 56:1009-1070

Leshy J (2008a) Interstate groundwater resources: the federal role. West-Northwest J Environ Law Policy 14:1475-1498 
Leshy JD (2008b) The federal role in managing the nation's groundwater. Hastings WestNorthwest J Environ Law Policy 14:1323

Mackay J (2007) Groundwater as the Cinderella of water laws, policies, and institutions in Australia. In: Ragione S (ed) The global importance of groundwater in the 21st century: In the proceedings of the international symposium on groundwater sustainability, Alicante, 24-27 Jan 2006, National Groundwater Association, Westerville, pp 317-329

Makowski A (2012) Beneath the surface of the clean water act: exploring the depth of the act's jurisdictional scope of groundwater pollution. Oregon Law Rev 91:495-526

McKenzie M (2009) Water rights in NSW: properly property? Sydney Law Rev 31:443-463

National Research Council Committee on Management and Effects of Coalbed Methane Development and Produced Water in the Western United States (2010) Management and effects of coalbed methane produced water in the Western United States. National Academies Press, Washington, DC

National Water Commission, Australia (2009) Australian water reform 2009: second biennial assessment of progress in implementation of the national water initiative. National Water Commission, Canberra

National Water Commission, Australia (2011) The national water initiative-Securing Australia's water future: 2011 assessment. National Water Commission (Australia), Canberra

Nelson R (2010) The guidelines for groundwater protection in Australia: regulatory review (prepared for Geoscience Australia). Geoscience Australia, Canberra

Nelson R (2011a) Regulating nonpoint sourt pollution in the US: a regulatory theory approach to lessons and research paths for Australia. Univ West Aust Law Rev 35:340-384

Nelson R (2011b) Uncommon innovation: developments in groundwater management planning in California. Stanford University, Palo Alto

Nelson R (2012a) Instituting integration: findings of the comparative groundwater law and policy program's workshop 1 . Stanford University, Palo Alto

Nelson R (2012b) Unconventional gas and produced water. In: Committee for economic development of Australia. Australia's Unconventional Energy Options, Committee for Economic Development of Australia, Melbourne, pp 27-40

Nelson R (2013) Groundwater, rivers and ecosystems: comparative insights into law and policy for making the links. Aust Environ Rev 28:558-566

NSW Office of Water (2011) Water sharing plan for the greater metropolitan region groundwater sources-background document. Government of New South Wales, Sydney

Patrick KL, Archer KE (1994) A comparison of state groundwater laws. Tulsa Law J 30:123-156

Pilz RD (2010) Lessons in water policy innovation from the world's driest inhabited continent: using water allocation plans and water markets to manage water scarcity. Univ Denver Water Law Rev 14:97-130

Quevauviller P (2008) Groundwater science and policy: an international overview. Royal Society of Chemistry, Cambridge

Ross A, Martinez-Santos P (2010) The challenge of groundwater governance: case studies from Spain and Australia. Reg Environ Chang 10:299-310

Ross-Saxer S (2010) The fluid nature of property rights in water. Duke Environ Law Policy Forum 21:49-112

Salceda A, Saied K, Zülow C, International Human Rights Law Clinic (2013) The human right to water bill in California. University of California, Berkeley, School of Law, Berkeley

Sax JL, Thompson BH Jr, Leshy JD, Abrams RH (2006) Legal control of water resources: cases and materials, 4th edn. Thomson/West, St. Paul

Sinclair Knight Merz, CSIRO, Bureau of Rural Sciences (2010) Surface and/or groundwater interception activities: initial estimates. National Water Commission, Canberra

Smith LN, Harlow LJ (2011) Regulation of nonpoint source agricultural discharge in California. Nat Resour Environ 26:28-32

Sophocleous M (2010) Review: groundwater management practices, challenges, and innovations in the High Plains aquifer, USA-lessons and recommended actions. Hydrogeol J 18:559-575

Sophocleous M (2012) The evolution of groundwater management paradigms in Kansas and possible new steps towards water sustainability. J Hydrol 414-415:550-559 
Spiegel D (2010) Can the public trust doctrine save western groundwater? New York Univ Environ Law J 18:412-453

Sundaram B, Nelson R, Coram J (2010) Assessing the need to revise the guidelines for groundwater protection in Australia: a review report. Geoscience Australia, Canberra

Surett E, Dietz L, Larsen S (2013) Waters. In American jurisprudence, 2nd edn. West Group, St Paul

Tasmania Department of Primary Industries and Water (2009) Water resources policy \#2005/1: generic principles for water management planning. Tasmania Department of Primary Industries and Water, Hobart

Thomas R (2009) The European directive on the protection of groundwater: a model for the United States. Pace Environ Law Rev 26:259-287

Thompson BH Jr (2011) Beyond connections: pursuing multidimensional conjunctive management. Idaho Law Rev 47:273-323

Thor E (2013) The human right to water in the United States: why so dangerous? Pac McGeorge Glob Bus Dev Law J 26:315-341

Tomlinson M (2011) Ecological water requirements of groundwater systems: a knowledge and policy review. National Water Commission, Canberra

Valorz NJ (2010) The need for codification of Wyoming's coal bed methane produced groundwater laws. Wyoming Law Rev 10:115-140

van der Gun J (2013) Groundwater abstraction estimates by country. In: Margat J, van der Gun J (eds) Groundwater around the world: a geographic synopsis. CRC Press, Leiden, pp 303-311

Wadley JB, Davenport JH (2013) The law of water. In: Powell on real property, vol 9. Matthew Bender \& Company, Inc, New York

Wilkinson CF (1991) In memoriam: prior appropriation. Environ Law 21:xxix-xlii

Witherspoon T (2010) Into the well: desired future conditions and the emergence of groundwater as the new senior water right. Environ Energy Law Policy J 5:166-182 


\title{
Groundwater Regulation and Integrated Water Planning
}

\author{
Philippe Quevauviller, Okke Batelaan, and Randall J. Hunt
}

\begin{abstract}
The complex nature of groundwater and the diversity of uses and environmental interactions call for emerging groundwater problems to be addressed through integrated management and planning approaches. Planning requires different levels of integration dealing with: the hydrologic cycle (the physical process) including the temporal dimension; river basins and aquifers (spatial integration); socioeconomic considerations at regional, national and international levels; and scientific knowledge. The great natural variation in groundwater conditions obviously affects planning needs and options as well as perceptions from highly localised to regionally-based approaches. The scale at which planning is done therefore needs to be carefully evaluated against available policy choices and options in each particular setting. A solid planning approach is based on River Basin Management Planning (RBMP), which covers: (1) objectives that management planning are designed to address; (2) the way various types of measures fit into the overall management planning; and (3) the criteria against which the success or failure of specific strategies or interventions can be evaluated (e.g. compliance with environmental quality standards). A management planning framework is to be conceived as a "living" or iterated document that can be updated, refined and if necessary changed as information and experience are
\end{abstract}

P. Quevauviller $(\bowtie)$

vrije universiteit, Brussel (VUB), Belgium

e-mail: Philippe.Quevauviller@ec.europa.eu

O. Batelaan

Strategic Professor Hydro(geo)logy, School of the Environment, Flinders University, GPO Box 2100, Adelaide, SA 5001, Australia

e-mail: okke.batelaan@flinders.edu.au

R.J. Hunt

United States Geological Survey, 8505 Research Lane, Middleton, WI 53562, USA

e-mail: rjhunt@usgs.gov 
gained. This chapter discusses these aspects, providing an insight into European Union (EU), United States and Australia groundwater planning practices.

\subsection{Introduction}

The complex nature of groundwater calls for emerging groundwater problems to be addressed through integrated management approaches designed to change the way people view and use the resource. Three levels of integration are concerned: (1) within the hydrologic cycle (the physical process) including the temporal dimension; (2) across river basins and aquifers (spatial integration); and (3) across socioeconomic sectors at regional, national and international levels (Mostert et al. 1999). A fourth level of integration concerns the way scientific knowledge is used (Quevauviller 2008). The great range of the natural variability inherent to groundwater systems obviously affects management needs and options, i.e. from highly local management approaches to regionally-based approaches. The management scale hence requires an encompassing evaluation of available policy choices and options for each particular setting. This is more complex than for example, river basin management delineated using land surface, owing to a three-dimensional structure of the aquifer systems with often unknown and unmapped boundaries, and complex temporal responses (e.g. lags) of aquifer systems. General principles of integrated water-resource management, address groundwater management in the context of a strategic framework that encompasses these and other characteristics. This chapter provides an insight into integrated groundwater planning, with examples taken from the European Union Water Framework Directive (WFD-http://ec.europa.eu/environment/water/waterframework/index_en.html) River Basin Management Planning (RBMP) as well as groundwater regulations in effect in Australia and USA.

\subsection{Challenges Linked to Groundwater Management}

Fully integrated approaches for groundwater management may precipitate massive data collection and planning efforts, which, given the potential large size and scope, may be out of date before they are completed. As a result, the level of integration must be balanced against practical limitations and the often superior effectiveness of immediate action to address developing problems. Whole-system perspectives and adaptive management approaches are generally considered to be more practical than the ideal "fully integrated" approaches. Both approaches require a strong conceptual understanding of the natural groundwater conditions while also encompassing a broad array of physical, social, economic and institutional factors affecting water management needs and options. Institutions are often required to be knowledgedriven with broad access to data and information, and need personnel capable of articulating a broad interdisciplinary understanding of water management issues.

Therefore there is a need for flexibility in groundwater management. Because social, economic and hydrological systems are dynamic rather than static, and 
factors directly or indirectly affecting groundwater conditions vary greatly from place to place, integrated groundwater management is not amenable to a one-sizefits-all approach. This implies the development of a management framework that acknowledges social, economic and physical resource conditions important in different management areas (Burke and Moench 2000). National frameworks that attempt to specify smaller scale management details (e.g. spacing of wells, specific prices for water) will often enumerate actions that are inappropriate or unworkable at the local or even regional level. In contrast, national frameworks that focus on broad principles and provide clear administrative and/or legal guidance enable local or regional managers to flexibly tailor more workable and efficient solutions. This also facilitates effective participatory planning involving scientists, resource management specialists, stakeholders, and decision-makers.

Groundwater management complexity tends to increase with increasing spatial and temporal scale, which in turn encompasses a wider range of conditions in the groundwater system. Therefore, management activities carried out at the smallest scale and at the lowest administrative level (at which they can effectively be carried out) are easier and most effective to tackle. This tenet needs to be balanced against management decisions related to the large and connected nature of groundwater systems - connections that propagate local management activities into the larger system. That is, institutional views of recognizing and accounting for resource management areas reflect the physical scale at which groundwater systems function and, in this respect, clear management units are as important for the development of effective management institutions as they are for scientific understanding (e.g. river basin or "water body" as defined in the EU Water Framework Directive, see Sect. 8.9). Therefore, local management actions have to reflect wholesale aquifer dynamics and fit within a management framework that recognizes the aquifer as the primary unit for management of the resource. The challenge is to manage large aquifer systems with a single overarching scientific framework and clear objectives that will facilitate overall aquifer management and ensuring that local approaches are consistent with the overarching framework.

\subsection{Integrated Water Management Framework}

\subsubsection{Water and Its Environment}

The surface-watershed constitutes the basis of river basin management (RBM) in the framework of which groundwater may be managed in an integrated way. Although the groundwater and surface-water divide may not exactly align (e.g., Hunt et al. 1998; Winter et al. 2003), the system can be defined for management as the geographical area determined by the surface-watershed limits of the system of waters, including surface water and groundwater. Strong interactions usually exist between groundwater and surface water in the basin, between water quantity and quality, and between land and water, upstream and downstream. This means that hydrologic basins can be managed not only as a geographical area but as a coherent 
social and ecological system (Burke and Moench 2000). Such entities are considered open systems in that these systems interact continuously with the atmosphere (precipitation and evaporation, airborne pollution) and terminal receiving waters (e.g., wetlands, lakes, oceans).

Waters within these systems fulfill many important functions, such as water supply for households, industry and agriculture, navigation, fishing, recreation and ecological niches. Economic and social development and even life itself cannot be sustained without sufficient water at the right time and place and of sufficient quality. In addition, water has shaped and continues to shape the environment, eroding mountain areas, creating karst, transporting sediment and creating delta areas. It is an essential element of nature while being subject to variability caused by human activities or natural causes, e.g. climate change, which can lead to floods or droughts. Effective RBM has to tackle all these issues, i.e. RBM is much broader than traditional water management as it includes land-use planning, policy (e.g. agricultural) and integrated management principles for groundwater. It also covers all human activities that use or affect surface water and groundwater systems.

\subsubsection{River Basin Management Objectives}

River basin management (RBM) principles aim at ensuring the multifunctional use of waters in rivers and their basins for the present and future generations. Since the capacity of river basins to accommodate different uses is always limited, with effective management, priorities have to be set. In particular, basic human needs have to be safeguarded (i.e. water supply for drinking and basic hygiene) and environmental protection should be given a full place in RBM. Apart from that, other priorities depend on the natural, social and economic conditions in the particular basin. Four different management levels can be distinguished according to Mostert et al. (1999): operational management, the institutional framework, planning and analytical support. Only operational management affects river basins directly. The following sections provide more details about these four components and issues relating to transboundary aquifer management and public participation.

RBM is closely linked to decentralization, i.e. government authorities are brought as close as possible to individual citizens, allowing for local variation in response to local circumstances and preferences for the notion of "subsidiarity" (a principle that is fully embedded into the EU Treaty). This is also more efficient as decentralized government tends to be less bureaucratic - simply because of its size - and better informed about local circumstances. Decentralization is not possible, however, for tasks such as establishing the institutional structure and formulating policies that apply to a large region or Nation as a whole. However, decentralized governments should be involved with RBM because of their superior information on local conditions and because of their (usually) closer contacts with the population within the river basin. Decentralization may also not be possible if the decentralized governments lack the necessary management capacity. Solutions could include local capacity building and advisory services by specialized central governments. 


\subsection{Operational Management}

Operational management embeds activities such as river regulation, constructing and operating water-supply infrastructure, reforestation projects, aquifer artificial recharge, etc. Operational management is linked to legal and policy requirements and guidelines and related measures. These may include emission controls of agricultural or industrial pollutants, abstraction controls, codes of good practices (e.g. Best Available Technologies, Best Environmental Practices, Best Management Practices), construction and/or rehabilitation projects and desalination plants. RBM may also address the behavior of different users/managers by explicitly forbidding, regulating or allowing certain activities (legislative or administrative instruments) in the basin and by offering economic (dis)incentives (economic or fiscal instruments) for some of these activities. Different resources are necessary to apply these instruments, such as financial, personnel, legal, appropriate policy directives and data.

\subsubsection{Pollution Control}

In a sustainable world, pollution control would be limited, i.e. emissions of contaminants of concern to the river basin would be close to zero. The main issue is how to approach this target and solve urgent pollution problems while ensuring that further pollution risks are prevented or limited. Regulations hence generally focus on programs for preventing or limiting inputs of pollutants into waters of the basin, e.g. control of point and diffuse sources of pollution through a combined approach based on emission controls using best available techniques, relevant emission values or best environmental practices (in the case of diffuse pollution) which are set out in relevant legislation (dealing with industrial, urban or agricultural sources of pollution). This may be complemented by a water-quality approach based on the establishment and compliance to water-quality standards, and the requirement to identify and reverse any statistically and environmentally significant pollution trends. There is no universally best approach, i.e. each situation may require tailor-made solutions which will be designed according to factors such as the urgency of pollution problems, the substance concerned, the pollution source and the capacity of the managers. In practice, the different approaches are often combined, e.g. minimum uniform emission standards combined with more stringent pollution controls if the water quality so requires.

\subsubsection{Voluntary Agreements}

Enforcement is a great concern in all regulatory instruments. Personnel and equipment are often insufficient for frequent monitoring, sometimes the different bodies responsible for enforcement may not co-operate effectively and political forces and lobbying may prevent strict sanctioning. Voluntary agreements and other 
communicative instruments may offer a partial solution, in particular with regard to agricultural activities. They are based on the co-operation of the (ground) water users or polluters: the latter are not forced but persuaded to do (or not to do) something. In this context, users and polluters may be willing to agree on quite ambitious goals, which may go beyond traditional regulatory incentives. This concerns not only groundwater regulations but also parent regulations (e.g. agriculture-related policies) directives which have to be effectively implemented to ensure a proper groundwater management planning.

\subsubsection{Cost Recovery}

Another operational issue is related to recovery of costs of water services, which takes into account that the polluter pays principle. It may require (like in the EU) authorities to establish water pricing policies, fixing adequate contributions of the different water uses, disaggregated into industry, households and agriculture. This policy depends on the price elasticity (the sensitivity of water use/pollution to the costs of the user/polluter), which is generally low in the case of drinking water use and high in the case of irrigated agriculture (the major water user in many countries). Charges that reflect the full economic and environmental costs of water use and pollution are economically efficient since they confront the water user/polluter with the real costs and promote an integral assessment of the costs and benefits. Moreover, they solve the financing problems of the providers of the water service concerned. However, this principle has to consider social, environmental and economic effects, as well as geographic and climatic conditions of the region or regions affected. In many instances, the cost recovery principle is not fully operational. An alternative approach is to fund particular preventive or remedial measures. This approach may be used, for example, if water becomes too expensive for poor populations. Indeed, very high charges and especially rapid increases may decrease the willingness to pay and may result in massive political opposition.

\subsubsection{Institutional Structure}

Mostert et al. (1999) illustrate different instruments for operational management that are applied in an institutional structure which consists of formal and informal working rules. Operational rules provide a framework for operational management, e.g. emission standards and (groundwater) policies. Collective choice rules deal with how operational rules should be developed, e.g. permitting and planning procedures. Constitutional rules determine who is entitled to make collective choice rules, setting up the organizational structure for RBM and allocate tasks and competencies (e.g. river basin district authorities). In this context, three basic RBM models are distinguished: 
- The hydrological model in which the organizational structure for water management is based on hydrological boundaries. In its extreme form all water management is in the hands of a single entity: the "river basin authority".

- The administrative model is in many respects the opposite of the hydrological model. In this model water management is the responsibility of provinces, municipalities and other bodies not based on hydrological boundaries.

- The coordinated model falls somewhere between the hydrological and the administrative model. In this model water management is not performed by river basin authorities, but public agencies, public coordination bodies or publicprivate partnerships or private river basin organisations coordinate river basin management.

Each model has advantages and disadvantages. In the hydrological model, administrative procedures coincide with hydrological boundaries, which limit the risk of upstream-downstream conflicts. However, since river basin authorities usually deal with water management only, this model may isolate water management from other relevant policy sectors, and inter-sectorial coordination may become a problem. In the administrative model water management, land-use planning and other relevant policy sectors can be kept together (but not necessarily). A major disadvantage is the serious risk of upstream-downstream conflicts and the lack of a platform to discuss these problems. Finally, an example of coordinated model is illustrated by river basin commissions (e.g. the International Commission for the Protection of the Danube River). The different bodies participating in these commissions may individually ensure co-ordination between water management and other policy sectors, and together, in the commission, they may coordinate their water management.

\subsection{Planning}

Whereas operational RBM constitutes the functional core of RBM, planning linked to policies has an important supportive role to play. As important as the plans and policies themselves is the way in which they are prepared: the "planning process" is a means to improve and support operational management.

\subsubsection{Functions of Plans and Policies}

Plans and policies can support operational RBM in several ways. Firstly, planning helps to assess the present situation in the basin, starting by an analysis of pressures and impacts and economic considerations, and measures required to meet predefined targets (e.g. quality and quantity objectives). It helps to orient operational management and set priorities. Secondly, it is impossible in practice to carry out policy analysis and organize public participation for each individual operational decision, and planning may provide the necessary framework. Thirdly, open and 
participatory planning processes may result in more public support or acceptance of the resulting plan/policy and (by extension) operational management. Fourthly, plans and planning may have a coordinating effect, i.e. bringing different river basin managers into discussion with each other with resulting plans and policies acting as common focal points.

\subsubsection{The Planning Process}

Planning requires extensive technical and scientific information, preparatory work and negotiation, considering different steps as described by Mostert et al. (1999):

1. Identification of planning needs, possibly involving some preliminary research;

2. Analysis of the institutional RBM framework and identification of the different operational decisions that can be taken, the bodies responsible for these decisions and their management capacity;

3. Identification of all the possible other stakeholders and their main interests;

4. Preparation of a process design, describing the scope of the planning exercise; the different phases; the different groups to be involved in each phase and the means to do so; the necessary research in each phase; and the project organization;

5. Implementation of the process design, resulting in the adoption of a plan; and

6. Implementation of the plan.

After a while, the plan and its implementation can be evaluated, and the process can start again. This form of planning cycle with review taking into account scientific progress is in force within the EU Water Framework Directive (see Sect. 8.9).

\subsubsection{Planning Systems}

Plans and policies relevant to RBM can differ on many dimensions-policy sectors, geographical scope, available funding, etc.- - which differ from country to country and from basin to basin. General guidelines may however be given, e.g. river basin planning should consider different interrelations within water systems (surface water and groundwater quantity and quality), the basin characteristics and their socioeconomic environment. This does not mean that each individual plan should have such a broad scope. Rather, the thinking should be in terms of planning systems: sets of interrelated types of planning, consisting of strategic and operational plans (e.g. linked to different regulatory frameworks concerning industrial, urban or agricultural activities). The more strategic a plan is, the more important it is that it covers complete river basins and all relevant policy sectors. Operational plans go more into detail and usually cover only one policy sector or part of a sector. 
The types of plans will depend on specific features, e.g. if in a specific basin there is one very urgent, very obvious issue, such as pollution of drinking water sources, there may be no need for integrated strategic planning that provides a complete integrated description of the basin and sets long-term goals. The resources could be much better used for making and implementing an operational plan that sets specific and concrete targets, proposes operational measures, and creates the necessary support linked to the specific feature.

Generally speaking, plans should be designed, taking into consideration the management capacity of the countries and basins. The number and scope of plans may be constrained by the amount of resources available for each planning exercise. Coordination between the plans can become problematic and transparency for the citizen is reduced. Moreover, resources that are spent on planning cannot be spent on operational management.

\subsection{Analytical Support}

River basin management is a complex task. Therefore, tools helping to assess the present situation and assist the development and evaluation of solutions are important. Two types of support may be distinguished: (1) support to operational management (e.g. action programs) and (2) support to strategic policy-making and planning (e.g. RBPM cycles). A second distinction is between (support) systems for monitoring, data collection and processing, oriented towards making facts and figures about the present situation and about possible trends; and tools or systems to support decision-making with a view to the future, typically oriented to the ex ante identification, analysis and evaluation of alternative allocations, policies or plans. These distinctions are not absolute. Operational management and strategic policymaking interact, and data collection and ex ante analysis support each other.

The development of information and computer technology over the last 30 years has enabled the design and application of a wide array of systems and modeling tools for supporting water managers. Most efforts in the field have so far concentrated on the technical and physical aspects of the (physical) river systems itself, and little attention has been paid to the development of systems and tools covering relevant aspects and processes in the river basin as a whole. This can be partly explained by the complexity of monitoring and analyzing of the interaction between natural and socioeconomic systems at the scale of a river basin, which are informed by on-going research trends and development of multidisciplinary synergies.

\subsubsection{Analytical Support for Operational Management: Main Challenges}

Many analytical tools have become available to support operational management. With respect to groundwater, efforts are still required to harmonize monitoring and 
analysis methods used by different organizations, especially in the case of international basins. A second challenge is to make the information available to anybody involved or interested. The development in database technology, often in combination with internet applications, can provide powerful tools for data retrieval and map visualization.

A more advanced type of operational support is to combine on-line monitoring with computer models in order to predict future conditions of the system. Examples are early warning systems, both for water-quantity issues (floods, droughts) and for water-quality issues (accidental spills). Flood early warning systems are already installed in many major basins in the world. An even more advanced form of support is the automation of infrastructure operation, such as weirs, pumps and sluices. In most cases such tools do not replace human operators: they provide the necessary information, but the decision is left to operators. This information is generated using monitoring data, often combined with computer models that describe the behavior of the natural system (water levels, discharges, etc.). The main challenge is to develop support systems that describe not only the natural system but also the use functions related to this system, thus enabling a weighing of all aspects involved.

\subsubsection{Analytical Support and the Strategic Level: New Directions}

At the level of strategic planning and policy-making, efforts so far are mainly related to the development of specific tools for specific problems in specific river basins, e.g. options for managing and cleaning up heavy metal pollution in a given groundwater body. Challenges for developing more generic and comprehensive tools at the river basin level are enormous as there is a lack of data and theories that may fully describe complex processes taking place in a groundwater body or groups of groundwater bodies within a river basin, taking socioeconomic issues into consideration. This does not allow one to include all relevant issues in a single model or tool. Yet, given the crucial importance and complexity of management at the basin level, it is of utmost importance that investments are made in the further development of analytical approaches and associated tools. Some possible tool development orientations are highlighted by Mostert et al. (1999):

- Tools for supporting integrated management and analyses at the river basin level describing not only the different aspects (quantity and quality) of the physical system, but also interactions with the socioeconomic system;

- Tools facilitating the linkage of (aggregated) strategies at the basin level and strategies at the regional and local levels to take account of processes and implementation aspects that have a regional rather than a basin-wide character. The challenge is to develop a family of tools operating at different geographical scales and levels of aggregation, linked to each other for overall consistency;

- Tools or models describing the costs and benefits of specific actions to the various actors involved, also helping to explore the possibilities for exchanges 
between actors, to assess the need to involve other actors in the process and possibly to identify potential linkages to other issues that would turn in a winlose situation into a win-win situation. Analysis of cost and benefits need to take account of recent developments in the estimation of unpriced values, especially environmental valuation;

- Support systems and tools that are better tuned to the dynamic and increasingly participatory nature of policy processes, i.e. accessible to non-specialists. For interactive learning settings there is a need for more flexible and transparent tools;

- Alternatives to the traditional tools based on "objective" system analytical approaches should be explored, e.g. striving to distinguish between "objective" knowledge and subjective judgments. Perceptions of problems and solutions are inevitably affected by differences in interests of participants, and arguments put forward in policy debates typically contain a mixture of "objective" facts and subjective viewpoints or perceptions. Argumentation analysis may be supported by tools specifically designed to describe, visualize and analyze policy arguments;

- Another novel approach is to use gaming as a vehicle for learning. In a policy game, participants interact as if they were playing the role of different parties involved in a real-world issue. Such games can be very instructive to both participants and observers as they include parts of the social and psychological dynamics of real policy processes, which cannot be included in more traditional systems. Policy games are generally supported by computer-based tools that take account of physical and other aspects in the process;

- New opportunities linked to developments of information and communication technology, e.g. geographical information systems (GIS) and interactive interfaces, allowing use of support tools by a broader group of users, and the development of the internet.

\subsection{Internationally Shared Aquifers}

A special management feature concerns internationally-shared aquifers. Natural and socioeconomic conditions, culture and language often differ significantly between different parts of the region where the aquifer is located, and consequently upstream-downstream conflicts may occur. More importantly, however, internationally shared aquifers are by definition located in different states. Consequently, international co-operation is needed in order to best manage the aquifer resources. This co-operation can be made more effective when required by law. In this respect, a major problem in the management of international basins is the so-called "lowest common denominator": Few obligations can be imposed on countries without their own consent in the absence of an international regulatory framework imposing coordination towards the achievement of common objectives. In the absence of such international law, many international agreements simply reflect the 
commonalities in the national policies of the states concerned or are very procedural and vague.

At the global level the normative system for the management of internationally shared aquifers focuses on the discretion of states and their sovereignty, rather than on their particular responsibilities in the process towards attaining sustainable water management, even if cooperation among those states is encouraged in conformity with existing agreements. Compliance regimes have now been included or are being developed in most multilateral environmental agreements, e.g. a procedure that entails that, at the request of a state, the commission coordinates negotiations among the parties and makes recommendations for an equitable solution to the dispute. While these recommendations are not binding in law, the parties to the dispute are to consider them in good faith. Such a procedure remains short of the compliance regimes included in multilateral environmental agreements in that it does not provide an automatic peer review system. It may, however, provide a mechanism through which the normative content of the international regime for groundwater management may be enhanced.

\subsection{Public Participation}

Public participation plays an essential role in planning and policy-making. It can be seen as a legal right of individuals and social groups, often resulting in procedural requirements for decision-making. Public participation can also be seen as a means for empowering individuals and groups and developing local communities. Furthermore it can be seen as a means of improving the quality and effectiveness of decision-making (REF). Public participation as a legal right is based on the notion that individuals and groups affected by decisions should have the opportunity to express their views and become involved in decision-making. Often three "pillars" of public participation are identified: access to information, involvement in the decision-making process (e.g. possibility to comment), and access to justice (right of legal review and redress). The danger of a purely legal approach to public participation is that it may become nothing more than an administrative requirement. Moreover, litigation is often time-consuming and expensive.

With regard to groundwater management, four groups stand out and should, as a basic principle, be involved in management initiatives:

- local stakeholders - water users and others whose interests are directly affected by groundwater management and whose actions often determine the effectiveness of any given initiative;

- policy-makers - those who have the ability to influence the institutional environment within which management approaches must evolve;

- public-sector organisations - these stakeholders often have their own internal agendas and control large programmes that either directly or indirectly have major impacts on water resources; and 
- private-sector organisations - these stakeholders are often major water users whose interests may or may not coincide with those of local stakeholders.

Stakeholder involvement and education are essential for any attempt to manage groundwater resources. It cannot, however, concern each individual but rather groups representing communities which may have a major impact on the resource (e.g. large water users such as municipalities, agricultural sector) and those whose interests will be significantly affected by management regimes (these groups are not mutually exclusive). The principle of stakeholder involvement is to start by being as inclusive as possible. The involvement and education will be all the more efficient if it is linked to a legal base, thus mixing stakeholder organisations with policy makers guiding discussions in relation to policy development, implementation and review needs.

\subsection{The EU Approach}

Groundwater planning within the EU regulatory context derives directly from the components of the Water Framework Directive, covering the following steps:

- Definition and characterisation of groundwater bodies (management units) within well-defined River Basin District which had to be carried out in the years 2004-2005. This involved an analysis of the pressures and impacts of human activity on the quality of groundwater with a view to identifying groundwater bodies at risk of not achieving WFD environmental objectives (of "good status", see below). This assessment has to evaluate risks linked to water uses and interactions with associated aquatic or terrestrial ecosystems in relation to the types of pressures and aquifer vulnerability;

- Establishment of registers of protected areas within each river basin district, which have been designated as requiring specific protection of their surface and ground waters or for the conservation of habitats and species directly dependent on water;

- Design and establishment of groundwater monitoring networks based on the results of characterisation and risk assessment to provide a comprehensive overview of groundwater chemical and quantitative status (this had to be done by EU Member States by the end of 2006). In this context, data monitoring constitutes an essential element of the overall management cycle;

- Development of river basin management plan (RBMP) for each river basin district, including a summary of pressures and impacts of human activity on groundwater status, a presentation in map form of monitoring results, a summary of the economic analysis of water use, as well as the implementation of the principle of recovery of costs for water services, including environmental and resource costs in accordance with the polluter pays principle, a summary of protection programmes, and control and remediation measures. The first RBPM 
has been published in December 2009. A review is then planned by the end of 2015 and every 6 years thereafter;

- Development and implementation of a programme of measures for achieving WFD environmental objectives (e.g. abstraction control, prevent or control pollution measures) operational since 2012. Basic measures include, in particular, controls of groundwater abstraction, controls (with prior authorisation) of artificial recharge or expansion of groundwater bodies (providing that it does not compromise the achievement of environmental objectives, meaning that the reuse of e.g. treated wastewater should not lead to a deterioration of the quality of receiving ground waters). Point source discharges and diffuse sources liable to cause pollution are also regulated under basic measures which are in force in other directives e.g. agriculture-related directives (Nitrates, Plant Protection Products), urban-related directives (Urban Wastewater Treatment) or chemical industry-related directives (Integrated Pollution Prevention and Control). Direct discharges of pollutants into groundwater are prohibited subject to a range of provisions listed in Article 11 of the WFD. The programme of measures has to be reviewed and if necessary updated by 2015 and every 6 years thereafter.

The Groundwater Directive (GWD) complements the above WFD components in establishing a regime which sets underground water quality standards and introduces measures to prevent or limit inputs of pollutants into groundwater (European Commission 2006). The directive establishes quality criteria that take into account local characteristics and allows for further improvements to be made based on monitoring data and new scientific knowledge. It thus represents a proportionate and scientifically sound response to the requirements of the Water Framework Directive (WFD) as it relates to assessments on chemical status of groundwater and the identification and reversal of significant and sustained upward trends in pollutant concentrations. In this context, EU Member States had to establish the standards (threshold values) at the most appropriate level, taking into account local or regional conditions. Complementing the WFD, the Groundwater Directive includes the following obligations:

- groundwater threshold values (quality standards) had to be established by Member States by the end of 2008 and revised on a regular basis in the light of scientific knowledge;

- pollution trend studies should be carried out using existing data and monitoring data which are mandatory under the WFD (referred to as "baseline level" data obtained in 2007-2008);

- pollution trends should be reversed so that environmental objectives are achieved by 2015 using the measures set out in the WFD (corresponding to a series of parent legislation setting legal rules for agricultural, domestic and industrial pollution risks and management);

- measures to prevent or limit inputs of pollutants into groundwater should be operational so that WFD environmental objectives can be achieved by 2015 ; 


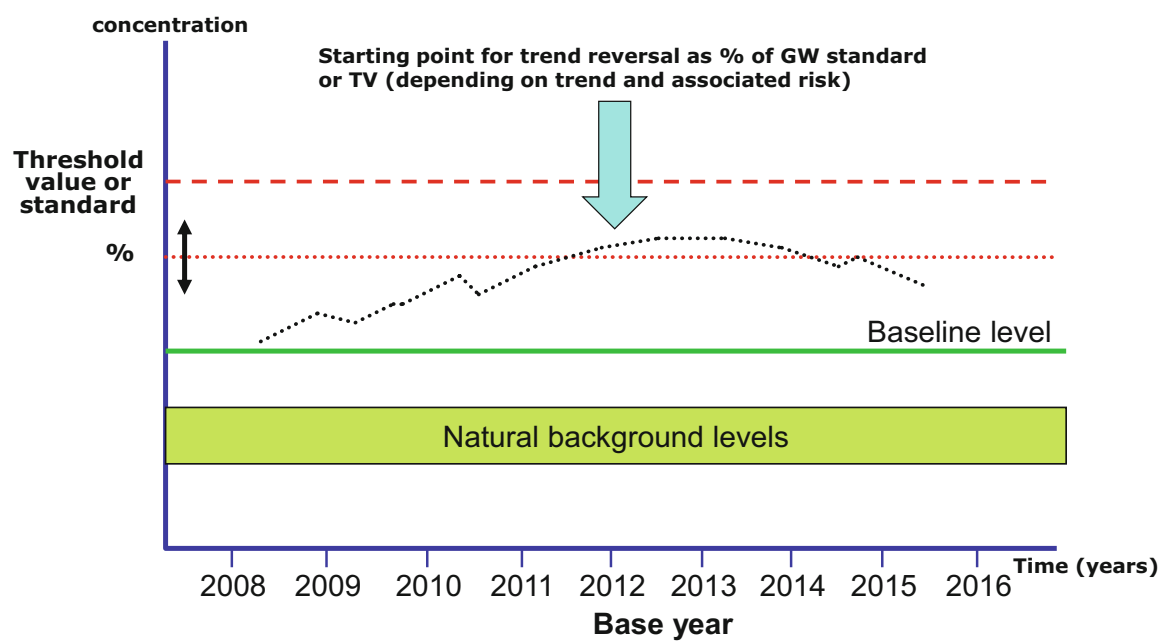

Fig. 8.1 Principle of the identification and reversal of statistically and environmentally significant upward trends. The 'Baseline Level' corresponds to the average value measured at least during the reference years 2007 and 2008 on the basis of monitoring programmes of the WFD, while the 'Background Level' means the concentration of a substance of the value of an indicator in groundwater corresponding to no, or only very minor, anthropogenic alterations to undisturbed conditions. TV stands for 'Threshold Values'

- compliance with good chemical status criteria (based on EU standards of nitrates and pesticides and on threshold values established by Member States) should be achieved by the end of 2015 .

The good chemical status achievement is based on quality objectives (compliance to relevant standards either EU-based or established by the Member States, no saline intrusion) that have to be achieved by the end of 2015 . The identification of sustained upward pollution trends and their reversal implies that trends will have to be identified for any pollutants characterising groundwater as being at risk (this is linked to the analysis of pressures and impacts carried out under the WFD). The reversal obligation establishes that any significant and sustained upward trend will in principle have to be reversed when reaching $75 \%$ of the values of EU-wide groundwater quality standards and/or threshold values (Fig. 8.1) through the programme of measures of the WFD where the parent legislations are the implementation tools for ensuring effective actions (e.g. Nitrates Directive, IPPC Directive, etc.).

Finally, measures to prevent or limit the introduction of pollutants into groundwater are related to the level of risks of different types of substances (some to be prevented, others to be limited). The principles are linked to conceptual modelling needs (Fig. 8.2). 


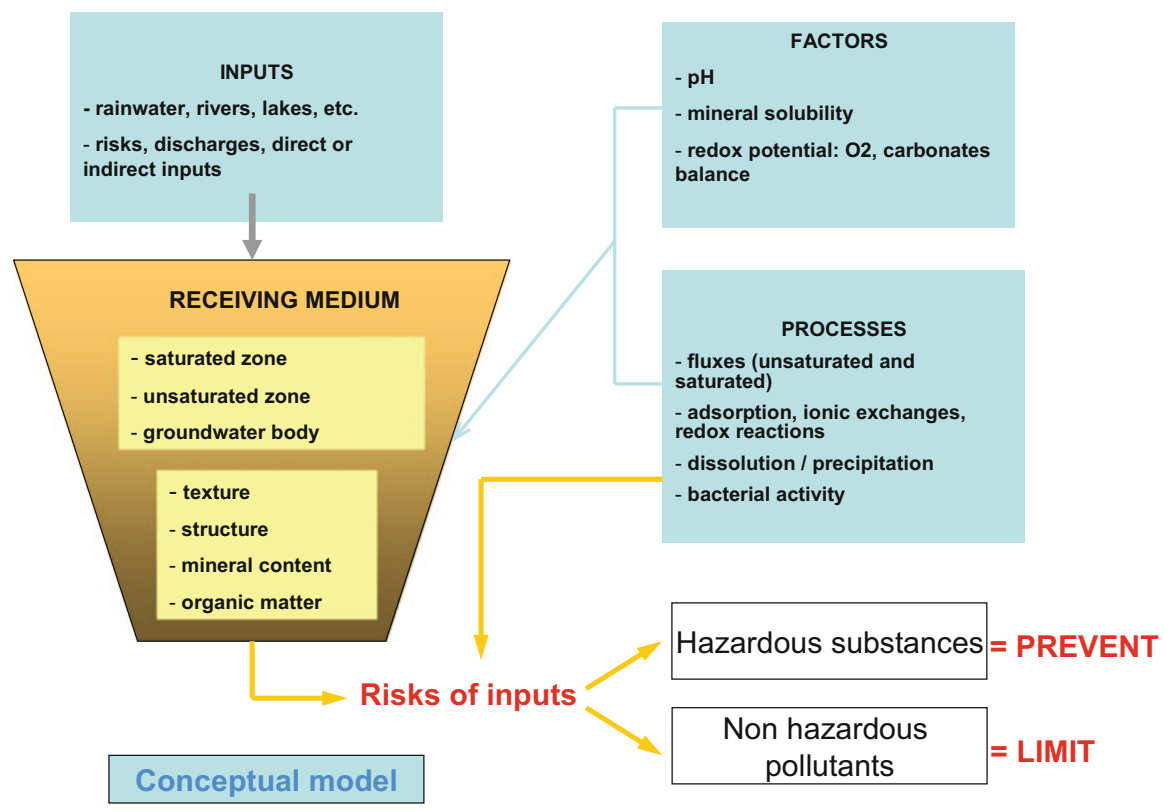

Fig. 8.2 The "Prevent and Limit" provisions linked to an evaluation of risks of inputs (and of the understanding of the groundwater system)

\subsection{An Example from Michigan, USA: A State Level Approach}

In contrast to an EU-scale approach, this section describes a statewide innovative management model for considering the ecological impact of groundwater and surface water withdrawals. The approach is notable for its focus on science-based tools and involvement from a range of stakeholders in the State of Michigan. The reader is directed to Steinman et al. (2011), and citations contained therein, for detailed coverage of the historical aspects and processes employed; Hamilton and Seelbach (2011) provide a comprehensive description of the withdrawal assessment process and Internet screen tool.

Groundwater management within the Michigan regulatory context derives directly from a series of governing laws, including:

- Definition and characterisation of groundwater bodies (management units) within well-were initially defined on an international scale. In 2001 and 2005, the governors and premiers of all United State Great Lakes states and Canadian provinces, respectively, committed to developing a progressive water management system to protect the waters of the Great Lakes basin. In 2005, the governors and premiers signed the "Annex 2001 Implementing Agreements" which banned diversions of water outside the Great Lakes (with limited 
exceptions). The Annex consisted of a good faith agreement between all parties, and a binding Compact among the eight US Great Lakes States. As a result, Great Lakes region has an overarching common regulatory framework, which is enforceable against the interstate movement of Great Lakes water due to its being ratified by the federal government;

- The Compact allows flexibility in each state's approach to implementation. A common, resource-based conservation standard applies to new or increased large-quantity (over 265 litres per minute (100,000 gallons per day)) water withdrawals from the Great Lakes basin. The intent of the standard is to avoid significant adverse individual or cumulative impacts on the quantity and quality of the waters and water-dependent natural resources of the Great Lakes basin;

- The states and provinces are also required to: establish programs to manage and regulate new or increased withdrawals; implement mechanisms for decision making and dispute resolution; develop an assessment approach for individual and cumulative impacts of water withdrawals; and augment scientific information in the Great Lakes basin and the impacts of the withdrawals on the ecosystems;

- To execute their responsibilities of the 2001 Annex agreement, the Michigan legislature passed Public Act 148 in 2003. The law's language formed the Groundwater Conservation Advisory Council and placed it within the Michigan Department of Environmental Quality (MDEQ), and explicitly denoted that its membership would consist of ten voting members from water using stakeholders and three non-voting (state agency) members. Public Act 148 also mandated a groundwater inventory and mapping effort.

- Initially, the 2003 Council was charged to: (1) study statewide sustainability and assess the need for additional oversight over groundwater withdrawals; (2) assess the state's implementation and statutory conformance with Annex 2001 requirements; and (3) assess the implementation and results from a dispute resolution program. The Council was given 2.5 years to submit a final report to the Michigan Legislature.

- After receiving the Council's final report, the Michigan Legislature enacted Public Act 34, legislation in 2006, legislation that for the first time regulated water withdrawals in the state and explicitly mandated that science should be used as the basis for decision making - a specific requirement of the overarching Compact. The 2006 law reconstituted the Council, which was then tasked to develop explicit criteria for judging sustainability, and to develop and design a water withdrawal assessment tool.

Criteria for Assessing Sustainability Efforts focused on development of characteristics of sustainability criteria and indicators. Criteria were defined as standards or points of reference that help in choosing indicators; they are more general and less detailed than indicators. Indicators were defined as measures that present relevant information on trends in a readily understandable way. Good indicators were defined as those that adequately represent the societal concern, be measurable, consistent, based on readily available or obtainable information, and 
comparable among various geographic regions (Steinman et al. 2011). Eleven indicators were identified (Table 8.1). Five environmental indicators focused on water quantity and quality. An indicator of the impacts of water withdrawal on groundwater-dependent biota was not developed because the state of the science was not sufficient to adequately relate the effect of withdrawals on these biota. Consensus was reached on three general economic indicators (Table 8.1), after considerable debate; three social sector indicators were identified (Table 8.1) that focused on public education, conservation and restricted groundwater access.

Development of a Water Withdrawal Assessment Tool The purpose of the water withdrawal assessment tool is to assist a large quantity user (threshold of 265 litres per minute/100,000 gallons per day defined using the Great Lakes Compact language) or the state discern if a proposed withdrawal is likely to cause an Adverse Resource Impact (ARI). An ARI is characterized in terms of an ecological functional impairment and defined by whether or not a water withdrawal impairs the ability of a surface-water body to support characteristic fish populations. Thus, fishery health was used as a biological proxy for overall stream functional integrity. The final water withdrawal assessment process provides outputs on two levels: (1) a screening tool, that is designed to 'screen in' (that is, to say yes to) those proposed withdrawals that are highly certain not to cause an ARI; and (2) for those withdrawals not initially 'screened in'. The applicant has a choice: they may either change the size, location, or depth of the proposed withdrawal in order to attain a 'screen in' decision or, if their application cannot pass using the tool, they may request the MDEQ to undertake a site-specific review. The applicant can provide site-specific measurements to assist with this review, but the expectation was that the review can be performed using readily available information.

The Internet-based (on-line) water withdrawal assessment tool comprises three models linked through a GIS. The models use information about streamflow, groundwater withdrawal and existing fish communities, with detailed resolution that allows site specific assessments of stream segments across Michigan. The streamflow model is a regression model that describes how much flow is in Michigan streams. An index flow is calculated from online data obtained from 147 established stream gages. Index flow is defined as the median flow for the summer month with lowest flow at a site. Summer months (usually August or September) were used because they commonly have the lowest flows and warmest temperatures, which result in the greatest stress to fisheries. A subsequent analytical withdrawal model estimates how much a proposed groundwater withdrawal will reduce streamflow in streams near the proposed pumping location. This model takes into account the amount and duration of pumping, well depth distance of well from stream, and aquifer properties (Reeves et al. 2009). The withdrawal assessment tool can also account for direct surface water withdrawal by subtracting it from the amount of available water.

The most critical component is the third model, a fish community statistical model that relates reduced streamflow to fish populations. This model leverages a 
Table 8.1 Recommended groundwater sustainability indicators and their associated measurement and criteria for the environmental economic and social sectors (Taken from Steinman et al. 2011)

\begin{tabular}{|c|c|c|}
\hline Indicator & Measurement & Criteria \\
\hline \multicolumn{3}{|l|}{ Environmental sector } \\
\hline $\begin{array}{l}\text { 1. Groundwater } \\
\text { contribution to stream } \\
\text { baseflow }\end{array}$ & $\begin{array}{l}\text { 1-1. Change in } \\
\text { groundwater contribution } \\
\text { over time }\end{array}$ & $\begin{array}{l}\text { 1-1. Adequate groundwater discharge to } \\
\text { maintain natural flow and temperature } \\
\text { regimes }\end{array}$ \\
\hline $\begin{array}{l}\text { 2. Groundwater } \\
\text { withdrawals }\end{array}$ & $\begin{array}{l}2-1 . \text { Volume of water use } \\
\text { by sector }\end{array}$ & $\begin{array}{l}\text { 2-1. Efficient use to maintain adequate } \\
\text { supply for public and private needs }\end{array}$ \\
\hline \multirow[t]{2}{*}{ 3. Land use/land cover } & $\begin{array}{l}\text { 3-1 Percentage natural } \\
\text { land use/land cover }\end{array}$ & 3-1. Increase \\
\hline & $\begin{array}{l}\text { 3-2. Percentage } \\
\text { impervious surface }\end{array}$ & $\begin{array}{l}\text { 3-2. Decrease below reference } \\
\text { impairment thresholds }\end{array}$ \\
\hline $\begin{array}{l}\text { 4. Groundwater } \\
\text { contamination }\end{array}$ & $\begin{array}{l}\text { 4-1. Number of at-risk } \\
\text { sites }\end{array}$ & 4-1. Decrease \\
\hline $\begin{array}{l}\text { 5. Groundwater- } \\
\text { dependent natural } \\
\text { communities }\end{array}$ & Not developed & Not developed \\
\hline \multicolumn{3}{|l|}{ Economic sector } \\
\hline $\begin{array}{l}\text { 6. Cost of groundwater } \\
\text { by relevant economic } \\
\text { sector }\end{array}$ & Not developed & Not developed \\
\hline \multirow[t]{2}{*}{$\begin{array}{l}\text { 7. Groundwater } \\
\text { dependent commerce }\end{array}$} & $\begin{array}{l}\text { 7-1. Product-revenue per } \\
\text { unit groundwater per } \\
\text { sector }\end{array}$ & 7-1. Increase \\
\hline & $\begin{array}{l}\text { 7-2. Efficiency of } \\
\text { groundwater use per } \\
\text { sector }\end{array}$ & 7-2. Increase \\
\hline \multirow[t]{2}{*}{$\begin{array}{l}\text { 8. Water usage from } \\
\text { alternative sources }\end{array}$} & $\begin{array}{l}\text { 8-1. Gallons of water } \\
\text { recycled }\end{array}$ & 8-1. Increase \\
\hline & $\begin{array}{l}\text { 8-2. Gallons of water } \\
\text { used from collection of } \\
\text { stormwater }\end{array}$ & 8-2. Increase \\
\hline \multicolumn{3}{|l|}{ Social sector } \\
\hline \multirow[t]{3}{*}{ 9. Public education } & $\begin{array}{l}\text { 9-1. Public knowledge of } \\
\text { groundwater resources }\end{array}$ & 9-1. Increase \\
\hline & $\begin{array}{l}\text { 9-2. Water resource } \\
\text { education }\end{array}$ & 9-2. Increase \\
\hline & $\begin{array}{l}\text { 9-3. Local government } \\
\text { training }\end{array}$ & 9-3. Increase \\
\hline \multirow[t]{2}{*}{ 10. Conservation } & $\begin{array}{l}\text { 10-1 Public water } \\
\text { systems using } \\
\text { groundwater }\end{array}$ & $\begin{array}{l}10-1 . \text { Efficient use to maintain adequate } \\
\text { supply for public and private needs }\end{array}$ \\
\hline & $\begin{array}{l}\text { 10-2 Water utilization by } \\
\text { sector }\end{array}$ & 10-2. Unspecified \\
\hline \multirow[t]{3}{*}{$\begin{array}{l}\text { 11. Restricted } \\
\text { groundwater access }\end{array}$} & $\begin{array}{l}\text { 11-1. Use restrictions due } \\
\text { to contamination }\end{array}$ & 11-1. Decrease \\
\hline & $\begin{array}{l}\text { 11-2. Adverse Resource } \\
\text { Impacts (ARIs) }\end{array}$ & 11-2. Decrease \\
\hline & 11-3. Water use conflicts & 11-3. Decrease \\
\hline
\end{tabular}




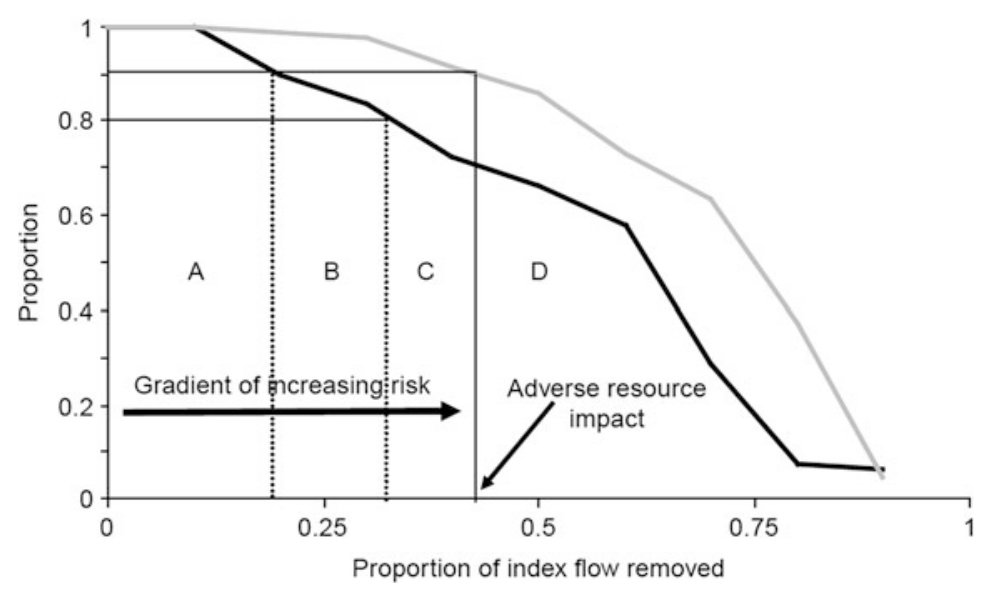

Fig. 8.3 Hypothetical example showing four policy zones (A-D), demarcated by increasing levels of index flow removal and functional response of fish populations (proportion of populations). The black curve represents the response of those fish whose needs are best suited to the stream temperature and flows. The gray line represents the response of more tolerant fish that require similar stream temperature and flows but are not as tied to the conditions as those represented by the dark line (From Steinman et al. 2011, used with permission)

large Michigan Department of Natural Resource's dataset of fish abundance at around 1700 stream locations in Michigan. Fish abundance is related to 11 river classes in Michigan, based on temperature type (cold, cold-transitional, cool, and warm) and size (large rivers, small rivers, and streams). This model estimates, for each of the 11 stream classes, the change in fish populations caused by reducing streamflow by using characteristic response curves.

Two curves were generated for each of the 11 stream classes in Michigan; these curves show how fish population responds as flow is incrementally reduced (Fig. 8.3). The leftmost curve shows the response of thriving species (fish best suited for stream conditions) and a rightmost curve that shows abundance reductions of other fish that more general and less dependent on the stream condition environmental niche (Zorn et al. 2008). This curve was divided using stakeholder and scientist input, and resulted in three vertical lines and four corresponding zones (A-D-Fig. 8.3). The far left vertical line (demarcating zones $\mathrm{A}$ and $\mathrm{B}$ ) showed the theoretical edge of minor impact, whereas the far right vertical line showed the theoretical start of an ARI (Fig. 8.3). That is, Zone A represents minimal measurable impact on fish populations, but as more flow is removed, there is a gradient of increasing risk to the point where notable replacement of fish species occurs, thereby constituting an ARI (Fig. 8.3).

According to 2006 Public Act 34, a person considering a new or increased large quantity withdrawal is not allowed to cause an ARI. A proposed user may either start the application process on-line by using the screening tool or they may work directly with MDEQ staff to conduct a site-specific analysis (Fig. 8.4). The screening tool estimates the amount of flow reduction for the appropriate stream segment 


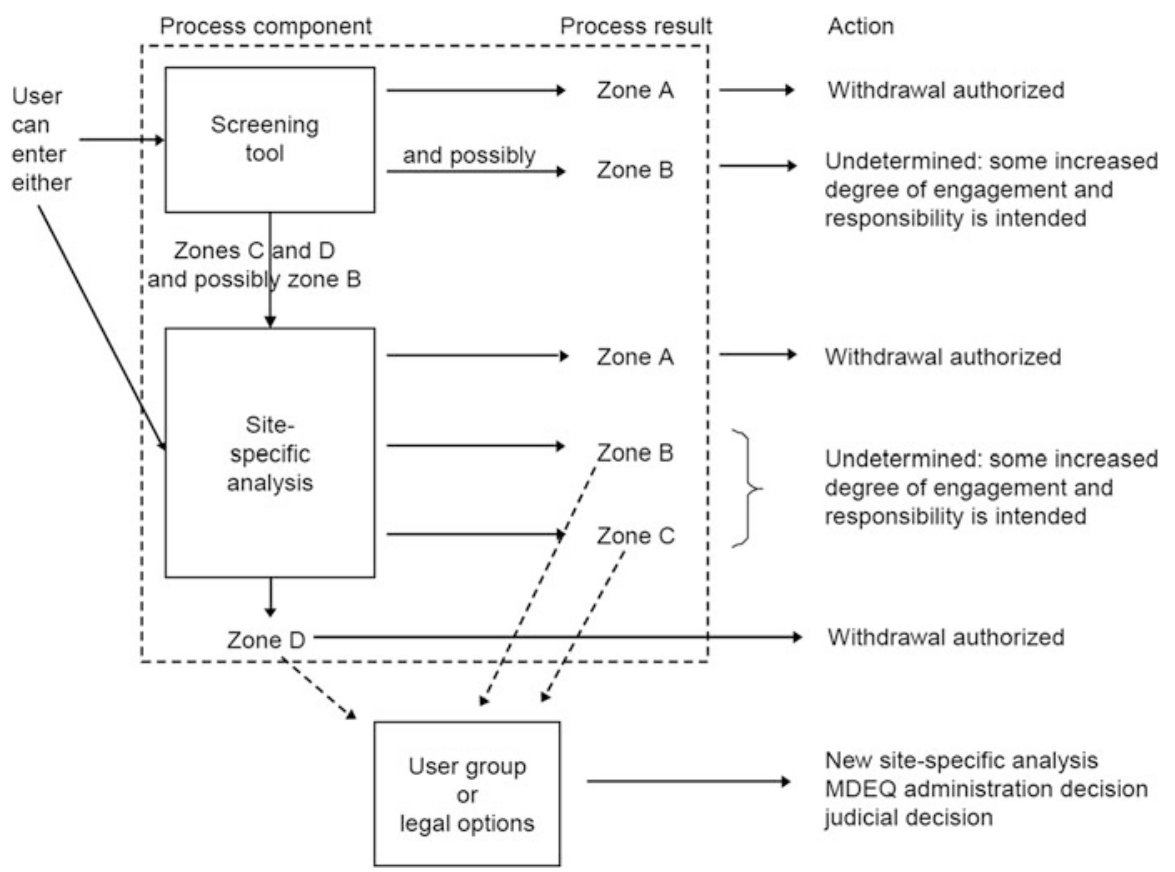

Fig. 8.4 Decision-making system associated with the water withdrawal process. Zones listed under process results correspond to Fig. 8.3 (From Steinman et al. 2011, used with permission)

and makes one of two determinations for the proposed withdrawal: (1) that it is not likely to cause an ARI and is authorized; or (2) that there is too much uncertainty in the outcome to determine whether or not the withdrawal would be likely to cause an ARI, and therefore the withdrawal may not proceed without a site-specific review. For a Zone A determination (ARI not likely; Figs. 8.3 and 8.4), the user would simply register the proposed withdrawal with MDEQ and receive authorization to proceed. For Zones B and C determination (ARI possible; Figs. 8.3 and 8.4), the applicant can modify the proposal and try the screening tool again or they can request the MDEQ to conduct a site-specific analysis of the withdrawal, with the expectation that a site-specific analysis will have less uncertainty associated with the withdrawal estimate than the screening tool. As of 9 July 2009, use of the screening tool is required by individuals proposing a large quantity withdrawal (265 litres per minute/100,000 gallons per day) from the groundwaters of Michigan. However, the Council recognized that the water withdrawal assessment tool is a work in progress (Steinman et al. 2011), specifically with the proposed the boundaries of Zones A and D (Fig. 8.3). They suggested that these were the starting points for further policy discussion, and recognizing that the social values of affected constituencies ultimately would influence the location of the boundaries. Indeed, the 2008 implementing legislation contained significant negotiated changes 
in the location of the Zone A and D lines for most of the 11 stream classifications (Steinman et al. 2011).

A new group, the Michigan Water Resources Conservation Advisory Council, was created as part of legislation passed in 2008. This group extends the earlier work but has a broader membership, and is charged with evaluating all water resources in the state, not just groundwater. Specifically, the new council is charged with: (1) evaluation of the water withdrawal assessment tool; (2) evaluation of the overall water withdrawal assessment process; (3) recommendations for inclusion of Great Lakes, inland lakes, and other waters in the process; (4) examining any potential legal conflicts within the process; and (5) recommendations for a new state water conservation and efficiency program (Steinman et al. 2011).

\subsection{The Australian Approach}

In comparison to the EU and US examples, this section reviews the background, past and current issues in groundwater regulation and integrated water planning for Australia.

\subsubsection{Early Approach}

In Australia water management has been dominated during most of the first 200 years of settlement by providing sufficient water for the growing population, agriculture and industry, hence aiming at increasing the exploitation of water. As Australia has high rainfall variability and is the driest continent on earth, exploitation of water resources has always been strongly linked to irrigation as it is the biggest water user (CSIRO 2011).

Irrigation started in 1886 in Mildura on the banks of the Murray River drawing on expertise from irrigation schemes in California to Victoria. Ownership of water and the rights to water use was setup according the model established by the Victorian Irrigation Act of 1886 and translated into State legislative arrangements. The legislation followed the principle that all streams were public property, and vested in the State or Crown the right to the use and flow, and to the control of water in any watercourse. Ownership and right of use of groundwater arose subsequently to that of surface water and hence the property in and the rights to the use, flow and control of all groundwater was vested in the Crown since 1910 by the different States, starting with Queensland (Acworth et al. 2009).

\subsubsection{The Murray-Darling Basin}

The Murray-Darling Basin covers more than 1 million $\mathrm{km}^{2}$ and spans most of the states of New South Wales, Victoria, and the Australian Capital Territory, and parts of the states of Queensland and South Australia. Agriculturally it is essential for the 
food production of Australia, while the management of irrigation in the basin has a long history and is still a politically sensitive issue. A drought period (1895-1902) and the Federation of Australia (1901) drove the government to start managing and regulating the Murray River system. The upstream states, Victoria and New South Wales, favoured the riparian doctrine, under which landowners are free to take water from streams flowing through their property. South Australia relied on agreements in the new Constitution on navigation along the Murray River to preserve flows in the South Australian section of the river (Wikipedia Contributors 2013).

The River Murray Waters Agreement (1915) did set out how flow and control is shared between New South Wales and Victoria and how South Australia is guaranteed of a minimum quantity of water or "entitlement". The agreement was also the starting point for construction of dams, weirs and locks on the main stream of the Murray to be managed by the River Murray Commission, which was established in 1917. As water is a state authority this agreement was an early example of federal cooperation on water, although limited to the management of water for irrigation and navigation (Wikipedia Contributors 2013).

As over the decades environmental problems due to overallocation of water for irrigation become seriously felt, the need for more coordination at the Basin level became evident. Updated and new versions of the Murray-Darling Basin Agreement were signed in respectively 1987 and 1992. The stated purpose of the MurrayDarling Basin Agreement was 'to promote and coordinate effective planning and management for the equitable, efficient and sustainable use of the water, land and other environmental resources of the Murray-Darling Basin'. To support the new Agreement, institutions at the political, bureaucratic and community levels were established, respectively (Wikipedia Contributors 2013):

- Murray-Darling Basin Ministerial Council;

- Murray-Darling Basin Commission; and

- Community Advisory Committee.

In 2012 finally after long negotiations the different Murray-Darling Basin states agreed on a new Murray-Darling Basin plan with as main result the promise to return 3200 gigalitres of environmental flows to the basin system annually, which is regarded essential to restore the strongly deteriorated health of the river's floodplains, and important large RAMSAR and other wetlands. The basin plan foresees setting up strategies for environmental watering, trading and sustainable diversion limits. The plan further encompasses state water resources planning, revision and review steps of the plan (Fig. 8.5).

\subsubsection{Groundwater Use}

In 2013 the total water consumption in Australia is estimated to be about 15,000 GL per year. Approximately one third of this amount comes from groundwater, with 


\section{BASIN PLAN implementation steps}

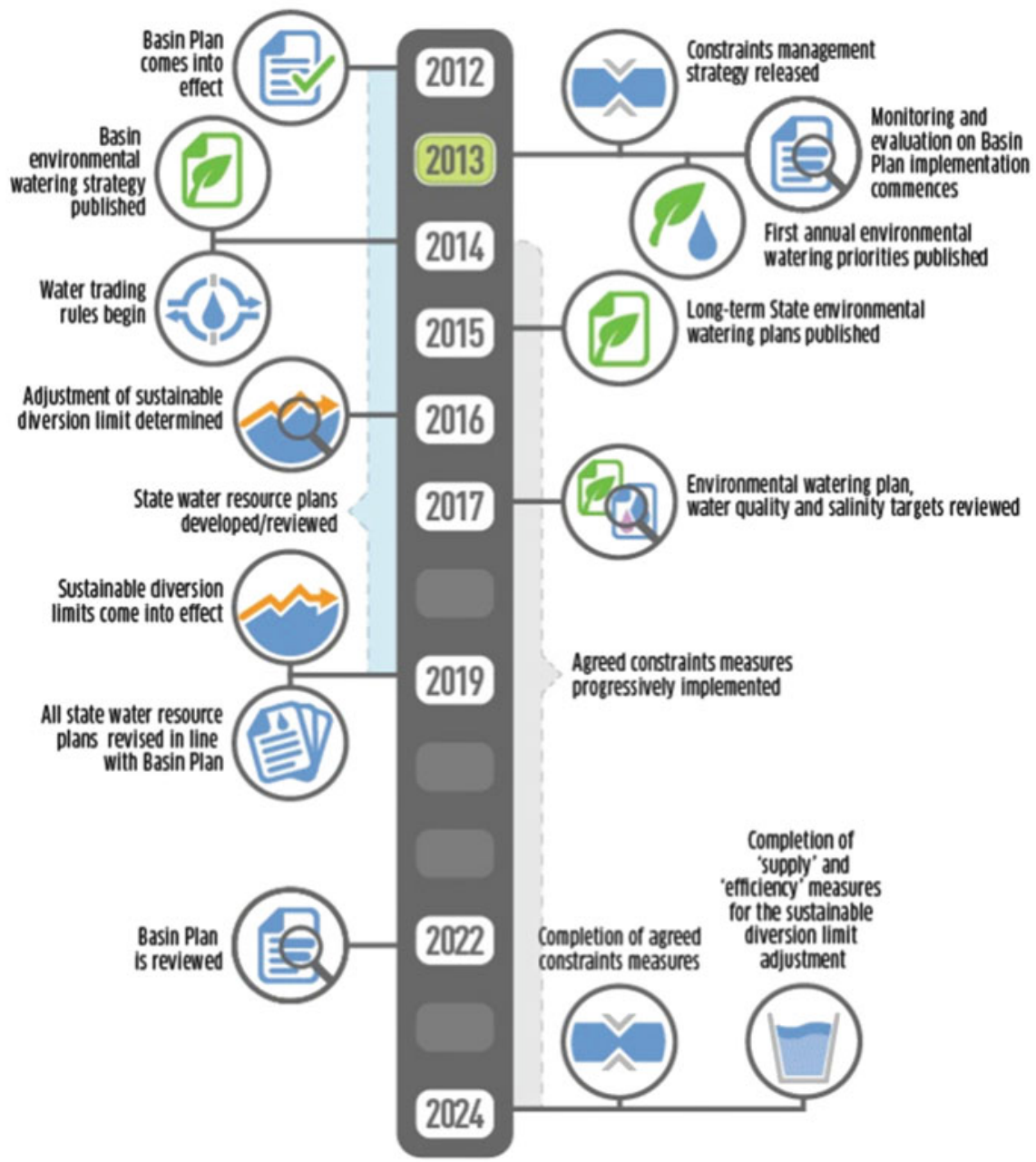

Fig. 8.5 Murray-Darling Basin Plan implementation steps (Murray-Darling Basin Authority 2013)

use doubling between 1983/1984 and 1996/1997 (AWRA 2000). These values have a high uncertainty as only a small fraction of abstraction wells are metered. The highest use of groundwater is in the Murray-Darling Basin, where over $1700 \mathrm{GL}$ of groundwater is abstracted annually in support of irrigated agriculture (NCGRT 2013; Murray-Darling Basin Authority 2010; CSIRO 2008).

The highest ratios of groundwater use to sustainable yield are found in Queensland (38\%), South Australia (33\%), New South Wales (26\%) and Western Australia (20\%). However, these statistics are misleading as they suggest scope for 
more groundwater extractions. While that is true in some areas, many major aquifers have been exploited up to or exceeding the sustainable yield, especially the Great Artesian Basin and alluvial aquifers of the Murray-Darling Basin. The lack of resource management and monitoring of groundwater systems have led to this overallocation and extraction, which was worsened by too little metering of groundwater extractions, provision of free or under-priced groundwater and not recognizing the importance of groundwater-surface water interaction (NWC 2013).

\subsubsection{National Level Policy}

\subsubsection{The National Water Initiative}

In 2004 a National Water Initiative was started as a consequence of the fact that the Murray-Darling Basin Agreement did not result in significant improvement in the environmental conditions in the basin as well as because of the growing number of other water policy issues elsewhere in Australia (Wikipedia Contributors 2013). As part of the National Water Initiative a National Water Commission was established through an intergovernmental agreement (Council of Australian Governments). The Commission provides independent and public advice to the Council of Australian Governments and the Australian Government by assessing, auditing and monitoring water reform progress. The main policy agreement is the National Water Initiative, Australia's enduring blueprint for water reform. The National Water Initiative agreement included objectives, outcomes and agreed commitments to (NWC 2013):

- prepare water plans with provision for the environment

- deal with overallocated or stressed water systems

- introduce registers of water rights and standards for water accounting

- expand the trade in water

- improve pricing for water storage and delivery

- meet and manage urban water demands.

Full implementation of the National Water Initiative aims to deliver (NWC 2013):

- effective water planning: transparent and statutory-based water planning that deals with key issues such as the natural variability of water systems, major water interception activities, the interaction between surface water and groundwater systems, and the provision of water to achieve specific environmental outcomes.

- clear, nationally compatible and secure water access entitlements: providing more confidence for those investing in the water industry through more secure 
water entitlements; better and more compatible registry arrangements; better monitoring, reporting and accounting; and improved public access to information.

- conjunctive management of surface water and groundwater resources: so that the connectivity between the two is recognised, and connected systems are managed in an integrated manner.

- resolution of overallocation and overuse: returning overallocated systems to sustainable levels of extraction as quickly as possible.

- clear assignment of the risks associated with changes in future water availability: ensuring that the risks arising from reductions in the pool of water available for consumptive use are shared between governments and water users according to an agreed framework, to provide investors and entitlement holders with certainty about how changes will be dealt with.

- effective water accounting: providing information on how much water there is, where it is, who has control of it, who is using it, and what it is being used for in order to support confidence about the amount of water being delivered, traded, extracted and managed for environmental and other public benefits.

- open water markets: removing artificial barriers to trading in water entitlements and allocations, bringing about more productive water use and enabling more cost-effective and flexible recovery of water to achieve economic, social and environmental objectives.

- effective structural adjustment ensuring that water policy, planning and management are facilitating and expediting adjustment, rather than impeding it.

Under the National Water Commission Act, the Commission has to report to the Council of Australian Governments on progress towards National Water Initiative objectives and outcomes. Reports were delivered in 2007, 2009 and 2011 and will further be delivered on a triennial basis (NWC 2013).

\subsubsection{National Groundwater Action Plan}

A National Groundwater Action Plan was initiated by the National Water Commission in 2007 as a consequence of the millennium drought (1997-2009). It had three elements (McKay 2012; NWC 2013):

- The National Groundwater Assessment Initiative: investigations to help overcome critical groundwater knowledge gaps.

- The National Centre for Groundwater Research and Training: a joint venture between the National Water Commission and Australian Research Council to build capacity in groundwater knowledge.

- A knowledge and capacity-building component: improvements in understanding and sustainable management of groundwater resources. 
Within the National Groundwater Action Plan groundwater reforms and investments were foreseen in eight priority themes (McKay 2012; NWC 2013):

- Harmonization of groundwater definitions and standards, and improved governance and management practices.

- Northern Australia Groundwater Stocktake.

- National assessment of sites suitable for managed aquifer recharge and recovery.

- Vulnerability assessment of groundwater-dependent ecosystems.

- Investigation of groundwater-surface water interconnectivity.

- Strategic aquifer characterization to quantify sustainable yields.

- National review of groundwater potential for deep fresh, saline and brackish waters.

- Managing risks to groundwater quality.

\subsubsection{Implementation of Policy at State and Local Levels}

As the different States are also responsible for the management of groundwater each bases it on their own legislation and regulates it via water management agencies, department of water or natural resources management agencies. The formulation of Natural Resource Management legislation has brought the integrated management of natural resources under one management portfolio in some States (Acworth et al. 2009).

Groundwater in Australia is governed by state policies mostly implemented through local area plans. However, a considerable part of Australia is still managed at statewide level because of either the low level of development or because of the general poor quality of the groundwater resources. Allocation of groundwater occurs via a system of renewable water access entitlements. Allocation planning requires assessment of sustainability, which is defined by the National Water Initiative as 'the level of water extraction from a particular system that, if exceeded, would compromise key environmental assets, or ecosystem functions and the productive base of the resource'. A range of methods is used to estimate the sustainable yield often reflecting the state of the knowledge of particular hydrogeological systems (NLWRA 2001; Acworth et al. 2009; NCGRT 2013). Options for optimization of use are (Acworth et al. 2009):

- Fixed water allocations, where licences can use up to a fixed amount. Penalties can be applied if use exceeds allocations.

- Announced allocations, where allocations are varied, usually from $75 \%$ to $125 \%$ of the fixed allocation, depending on the volume in storage at the start of the main demand period.

- A system of advanced draws, where licensees can "borrow" against next year's allocation, with that year's allocation being reduced (a gamble on next year's wet season). 
- A system of moving averages, whereby use is averaged with the two (or some other agreed number) preceding years, in order to average water use with the varying seasons.

- Temporary trading, where unused allocations can be transferred to other users, usually subject to some conditions. These transfers are usually private transactions, often financial, which must be sanctioned by the managing authorities.

- Permanent trading, where allocations can be sold permanently to others.

- Conjunctive allocations where groundwater and surface water allocations are tied.

\subsubsection{Groundwater Quality}

In terms of water quality the joint Australian-New Zealand National Water Quality Management Strategy of 1994 sets out the management process to achieve sustainable use of water resources, by protecting and enhancing their quality, while maintaining economic and social development (NWQMS 1994). As part of this National Water Quality Management Strategy the groundwater protection guideline details the principles for groundwater protection, which received comparably little attention over the decades. The protection framework involves the identification of specific beneficial uses and values for every major aquifer. Protection strategies include development of vulnerability maps, aquifer classification systems and wellhead protection plans, land-use planning measures and environmental management of modern waste management problems. All of these involve monitoring. Nearly all protection strategies will rely on government intervention, a public planning process and should be backed by community support (NWQMS 1995).

\subsubsection{Challenging Contemporary Groundwater Management Issues}

Australia faces currently and in the coming decades a number of highly challenging groundwater management issues. A robust policy framework is in place to address these, but it is likely that further adaptation and development of (ground)water policies will be required. Such issues include (Acworth et al. 2009; Tan et al. 2012; NCGRT 2013).

- Unsustainable groundwater extractions beyond natural recharge rates in some aquifer systems.

- As more than $85 \%$ of the Australian population lives in coastal areas $(<50 \mathrm{~km})$ salt-water intrusion into coastal aquifers is a real threat for some locations (Ivkovic et al. 2012). 
- Rising groundwater levels and resulting water logging/salinisation of soils due to irrigation is an on-going issue and needs sustained research and groundwater management.

- The use of water of marginal quality for irrigation and recycling causing salinity build-up in the underlying groundwater.

- Groundwater use by mining operations and especially the development of coal seam gas exploitation can introduce new groundwater related problems, which require groundwater research, monitoring and development of new management policies.

- Groundwater Dependent Ecosystems (GDEs) contribute significantly to social, economic, biodiversity and spiritual values (Murray et al. 2003). More knowledge of the specific requirements of GDEs is needed for effective management.

- The application of Managed Aquifer Recharge (MAR) is strongly increasing and has a number of benefits in terms of water management. However, as generally recycled or storm water is used for the recharge any risks of deteriorating water quality and health has to be managed. MAR guidelines have been established (NRMMC 2009).

- Analysis of the climate over the last 80 years shows a warming over most of Australia, increasing rainfall over northern, central and north-western Australia and decreasing rainfall in eastern, south-eastern and south-western Australia. As recharge is more variable than rainfall the effect of climate change on groundwater supplies will be more pronounced in areas of low recharge (Barron et al. 2011). Climate change will increase demand for water for irrigation, cities, wetlands, etc., intensifying the water scarcity.

- The value of water for indigenous Australians for culture, identity, as well as livelihood are poorly understood (CSIRO 2011; Jackson et al. 2012; Liedloff et al. 2013).

- As clearly groundwater management had in Australia a strong focus on quantitative aspects, further development of integrated quantitative-qualitative-ecological and publicly supported policies embedded in socio-economic plans is evident for long-term management of sustainable groundwater resources.

Open Access This chapter is distributed under the terms of the Creative Commons AttributionNoncommercial 2.5 License (http://creativecommons.org/licenses/by-nc/2.5/) which permits any noncommercial use, distribution, and reproduction in any medium, provided the original author(s) and source are credited.

The images or other third party material in this chapter are included in the work's Creative Commons license, unless indicated otherwise in the credit line; if such material is not included in the work's Creative Commons license and the respective action is not permitted by statutory regulation, users will need to obtain permission from the license holder to duplicate, adapt or reproduce the material. 


\section{References}

Acworth I, Hazel C, Laws T, Lawrence C (eds) (2009) Australian groundwater school, the notes. National Centre for Groundwater Research and Training, Adelaide

AWRA (2000) Australian water resources assessment 2000. http://www.anra.gov.au/topics/water/ pubs/national/water_use.html

Barron OV, Crosbie RS, Charles SP, Dawes WR, Ali R, Evans WR, Cresswell R, Pollock D, Hodgson G, Currie D, Mpelasoka PT, Aryal S, Donn M, Wurcker B (2011) Climate change impact on groundwater resources in Australia, vol 67, Waterlines report series. National Water Commission, Canberra

Burke JJ, Moench MH (2000) Groundwater and society: resources, tensions and opportunities. United Nations, New York. ISBN 92-1-104485-5

CSIRO (2008) Water availability in the Murray-Darling Basin a report to the Australian Government from the CSIRO Murray-Darling Basin Sustainable Yields project. CSIRO, Clayton South, $67 \mathrm{pp}$

CSIRO (2011) In: Prosser IP (ed) Water: science and solutions for Australia. CSIRO Publishing, Collingwood

European Commission (2006) Directive of the European Parliament and the Council on the protection of groundwater against pollution and deterioration. J Eur Comm L372:19

Hamilton DA, Seelbach PW (2011) Michigan's water withdrawal assessment process and internet screening tool. Michigan Department of Natural Resources, Fisheries special report 55, Lansing, $37 \mathrm{p}$

Hunt RJ, Anderson MP, Kelson VA (1998) Improving a complex finite difference groundwaterflow model through the use of an analytic element screening model. Ground Water 36 (6):1011-1017. doi:10.1111/j.1745-6584.1998.tb02108.x

Ivkovic KM, Marshall SM, Morgan LK, Werner AD, Carey H, Cook S, Sundaram B, Norman R, Wallace L, Caruana L, Dixon-Jain P, Simon D (2012) National-scale vulnerability assessment of seawater intrusion: summary report. Waterlines report no 85. National Water Commission, Canberra

Jackson S, Tan P-L, Mooney C, Hoverman S, White I (2012) Principles and guidelines for good practice in Indigenous engagement in water planning. J Hydrol 474:57-65

Liedloff AC, Woodward EL, Harrington GA, Jackson S (2013) Integrating indigenous ecological and scientific hydro-geological knowledge using a Bayesian network in the context of water resource development. J Hydrol 499:177-187

McKay J (2012) Groundwater management: looking to the future so there is a future. Water Int 37 (7):721-726

Mostert E, Van Beek E, Bouman NWM, Hey E, Savenije HHG, Thissen WAH (1999) River basin management and planning, proceedings of the international workshop on river basin management, The Hague, 27-29 Oct 1999, IHP-V, Technical Documents in Hydrology No 31, UNESCO, pp 24-55

Murray BR, Zeppel MJB, Hose GC, Eamus D (2003) Groundwater-dependent ecosystems in Australia: it's more than just water for rivers. Ecol Manag Restor 4(2):110-113

Murray-Darling Basin Authority (2010) Guide to the proposed basin plan: overview MurrayDarling Basin authority, Canberra. Available from http://www.mdba.gov.au

Murray-Darling Basin Authority (2013) Murray-Darling basin authority, Canberra. Website http:// www.mdba.gov.au/. Accessed 8 Sept 2013

NCGRT (2013) Groundwater in Australia. National Centre for Groundwater Research and Training, Adelaide

NLWRA (2001) National land and water resources audit, Australian water resources assessment 2000. Commonwealth of Australia, Canberra

NRMMC (2009) Natural resource management ministerial council, Environmental Protection and Heritage Council (EPHC) \& National Health and Medical Research Council (NHMRC) Australian guidelines for water recycling, managing health and environmental risks (phase 
2) - managed aquifer recharge, national water quality management strategy. Available at: http://www.ephc.gov.au/taxonomy/term/39

NWC (2013) National Water Commission. Available from http://www.nwc.gov.au/. Accessed 6 Sept 2013

NWQMS (1994) National Water Quality Management Strategy, document 1: water quality management-an outline of the policies. Available from http://www.environment.gov.au/ water/publications/quality/index.html

NWQMS (1995) National Water Quality Management Strategy, document 8: guidelines for groundwater protection. Available from http://www.environment.gov.au/water/publications/ quality/index.html

Quevauviller P (ed) (2008) Groundwater science and policy-an international overview. RSC Publishing, Cambridge, p 754. ISBN 978-085404-294-4

Reeves HW, Hamilton DA, Seelbach PW, Asher AJ (2009) Groundwater-withdrawal component of the Michigan water-withdrawal screening tool. United States Geological Survey Scientific Investigations report 2009-5003

Steinman AD, Nicholas JR, Seelbach PW, Allan JW, Ruswick F (2011) Science as a fundamental framework for shaping policy discussions regarding the use of groundwater in the State of Michigan: a case study. Water Policy 13:69-86

Tan P-L, Bowmer KH, Mackenzie J (2012) Deliberative tools for meeting the challenges of water planning in Australia. J Hydrol 474:2-10

Wikipedia Contributors (2013) Irrigation in Australia Wikipedia, The Free Encyclopaedia. http:// en.wikipedia.org/w/index.php?title=Irrigation_in_Australia\&oldid=551808498. Accessed 7 Sept 2013

Winter TC, Rosenberry DO, LaBaugh JW (2003) Where does the ground water in small watersheds come from? Ground Water 41:989-1000. doi:10.1111/j.1745-6584.2003.tb02440.x

Zorn TG, Seelbach PW, Rutherford ES, Wills TC, Cheng S, Wiley MJ (2008) A landscape-scale habitat suitability model to assess effects of flow reduction on fish assemblages in Michigan streams. Michigan Department of Natural Resources, Fisheries research report 2089, Ann Arbor 


\title{
Conjunctive Management Through Collective Action
}

\author{
Cameron Holley, Darren Sinclair, Elena Lopez-Gunn, \\ and Edella Schlager
}

\begin{abstract}
This chapter focuses on the interaction between conjunctive management and collective action. Collective action has several characteristics that provide a natural 'fit' with conjunctive management. These include building trust and ownership to enhance water user's acceptance of the need for better and more integrated management and resolving conflict and facilitating trade-offs between and across water users. But what are the opportunities and challenges for conjunctive management through collective action? And what types of settings encourage broadbased collective action by water users and governments? These questions are addressed through a comparative analysis of specific instances of groundwater governance in Australia, Spain, and the western United States of America. For each case, the diverse policy and institutional settings are explained, and consideration given to the motivators for, and successes of, conjunctive management and collective action. The chapter draws comparisons across the cases to suggest lessons on incentives for conjunctive management, as well as exploring its challenges, before identifying future directions for more effective integrated water management.
\end{abstract}

This research was partially funded by an ARC Discovery Early Career Researcher Award (DE140101216) and an ARC Linkage Grant (LP130100967).

C. Holley $(\bowtie)$

University of New South Wales, Kensington, Australia

e-mail: c.holley@unsw.edu.au

D. Sinclair

The Australian National University, Canberra, ACT, Australia

E. Lopez-Gunn

ICATALIST, Madrid, Spain

IE Business School, Madrid, Spain

E. Schlager

The University of Arizona, Tucson, AZ, USA

(C) The Author(s) 2016

A.J. Jakeman et al. (eds.), Integrated Groundwater Management,

DOI 10.1007/978-3-319-23576-9_9 


\subsection{Introduction}

Diverse policy and institutional settings provide different types of incentives for engaging in adaptive integrated cyclical management of surface water and groundwater (aka conjunctive management). This chapter's interest lies in the interaction between conjunctive management and collective action. In particular, it focuses on the opportunities for, and challenges of, conjunctive management and collective action as a combined strategy for managing variable water supply and incorporating options for environmental watering.

While there is no settled, precise definition of conjunctive management, it can be broadly conceived as involving the integration of water management decisionmaking and action to maximise the benefits arising from the innate characteristics of surface water and groundwater water use (e.g. surface water resources are more visible and measurable, but more variable and typically more difficult to store) (Evans et al. 2012; SKM 2011). Conjunctive management can take various forms, for example, engineered (e.g. aquifer storage and recovery; see Chaps. 16 and 17), non-engineered (e.g. integrated water planning; see Chap. 8 and Ross 2012a), bottom up (e.g. at the farm level of sourcing water from both a well and from an irrigation delivery canal, with some accompanying monitoring and evaluation to develop local management objectives) and top down (e.g. a more strategic approach where surface water and groundwater inputs are centrally managed/planned for) (Evans et al. 2012, pp. 4, 6).

Crucially, conjunctive management is not limited to the coordinated or joint use of surface water and groundwater, but rather the coordinated use of a portfolio of resources, of which groundwater is particularly important for three key reasons. First, groundwater has an in-built advantage during drought since it offers an important buffer to climate variability due to its relative stability (and thus lowers the risk). Second, it is a relatively inexpensive resource when compared to alternative climate independent sources such as desalinated or recycled water, with their comparatively high energy costs. Third, it affords enhanced agency or control to water users such as farmers through devolved decision-making (as compared to surface water systems).

The inherent appeal of conjunctive management lies in the unity (or connectedness) of the hydrological cycle. Recognising that the characteristics of water resources vary according to the relative and particular contributions of surface water and groundwater, this strengthens the case for examining opportunities for collective (and integrated or coordinated) management. Indeed, the use of connected groundwater and surface water systems can have significant implications for both water quantity and quality of each, respectively (Brodie et al. 2007). Abstraction from either can affect the quantity, quality and reliability/accessibility of abstraction from the other, as well as impacting on the water supply to conjunctive dependent ecosystems (e.g. low flows in rivers and certain wetlands) (SKM 2011, p. 4).

Alarmingly, the 'disjointed' use of groundwater can lead to undesirable effects (Lopez-Gunn et al. 2011) ranging from a rise in piezometric levels, increasing the risk of flooding and/or subsidence, problems of drainage and salinisation or marine intrusion, the lowering of piezometric levels and higher pumping costs, and if connected 
to surface water flows, to a reduction in flows which can negatively affect wetlands, springs, groundwater dependent ecosystems and river base flows. Conversely, conjunctive management in a conscious and coordinated way (Andreu et al. 2010) can ameliorate or even prevent many of these problems. This is where collective action comes into its own by engaging water users as key conjunctive management participants. Overseen by well-designed water rights systems, this can lead to better and more integrated management outcomes. In this respect, collective action can take various forms - between different tiers of government, between government and water users, and between groups of water users themselves (Holley et al. 2011).

Collective action has several characteristics that provide a natural 'fit' with conjunctive management. These include, in particular: the planning and day-today management of water; contributing local knowledge to assist in the development of a common understanding of water systems; building trust and ownership to enhance water user's acceptance of the need for better and more integrated management (Baldwin et al. 2012); and resolving conflict and facilitating trade-offs between and across water users (SKM 2011; Brodie et al. 2007, p. 78).

Given these potential attractions, what types of settings encourage broad-based collective action by water users and governments to deliver conjunctive management? And what are the opportunities and challenges for conjunctive management through collective action? These questions are addressed via a comparative analysis of specific instances of groundwater governance in Australia, Spain and the western United States of America, three leaders in water reform and conjunctive management approaches. Each national case study outlines the diverse policy and institutional settings, and considers the motivators for, and successes of, conjunctive management and collective action. Reflecting the diverse forms of conjunctive management, the national cases explore various conjunctive management approaches, including integrated basin and catchment planning in Australia, United States and Spain, as well as augmentation plans/agreements and large-scale water infrastructure projects involving storage and desalination in the United States and Spain. The chapter concludes by drawing comparisons across the cases to suggest lessons on incentives for conjunctive management, as well as exploring its challenges, before identifying future directions for more effective integrated water management.

\subsection{Conjunctive Management: Experiences from Australia, Spain and the United States of America}

\subsubsection{Australia}

By the latter stages of the twentieth century, significant weaknesses in Australia's water regulation began to emerge. In particular, state governments were granting many new water licences to irrigators and others, with generous extraction allocations attached (Bricknell 2010; Gray 2010). Under these arrangements surface water and groundwater resources were generally managed separately (Ross 2012a). Subsequent fears of over-allocation and severe water shortages soon 
emerged. Broadly speaking, this crisis motivated state and federal governments to come together and collaboratively address accelerating degradation of water sources (Godden and Foerster 2011).

The result was a new national water management regime. Commencing in 1994, and later taking shape under the National Water Initiative (NWI) in 2004, Australia came to recognise connectivity between surface water and groundwater resources and the need to manage connected systems as a single resource (Commonwealth of Australia and the Governments of New South Wales, Victoria, Queensland, South Australia, the Australian Capital Territory and the Northern Territory 2004, para 23 (x)). This included acknowledging hydrological connectivity considerations relating to trading of water rights (which have been separated from land), management of environmental water, and most importantly for present purposes, the use of collaborative planning for delivering integrated management of surface water and groundwater (IANWI, paras 58(i), 79(i) (c), Schedule E, 5(ii); NWC 2008, p. 2).

Collaborative planning is now central to the pursuit of conjunctive use management in Australia and is the primary instrument for achieving collective action between governments and water users. As such, NWI principles include consultation with stakeholders, adaptive management of surface water and groundwater systems and consideration of the level of connectivity between surface water and groundwater systems (IANWI, paras 23(x), 25(iv), Schedule E, 5(ii), 6(i)). The concept of connectivity has also been recognised in the recent Murray-Darling Basin Plan (Basin Plan, Cth, 2012, cl10.19).

Individual state jurisdictions have considerable flexibility in how they implement these principles (Tan et al. 2012). In practice, however, water plans commonly contain: rules for water allocation; rules for transferring water entitlements or allocations; environmental outcomes; limits on extraction in certain places or at certain times; and monitoring and reporting requirements (Gray 2012). Conjunctive management is taken into account across these various elements, including in identifying the environmental values and assets, setting the plan's objectives, and choosing the management tools to implement the plan (NWC 2011a, p. 99). Consequently, the number of water plans that recognise surface water and groundwater connectivity is growing (NWC 2011a, p. 99).

Despite this success, conjunctive water management has been piecemeal and slow. For instance, few groundwater dependent ecosystems have well-established environmental water requirements or effective monitoring programs (Lamontagne et al. 2012). Further, while available modelling and data is improving, the historical under-resourcing of data collection and analysis, and limited metering and enforcement of extraction, particularly of groundwater, have inhibited progress (Holley and Sinclair 2013a; Holley and Sinclair 2012; Baldwin et al. 2012, p. 75). Indeed, as the National Water Commission explains, "Quantifying surface and groundwater connectivity and aligning their management is unfinished business in most jurisdictions... While all jurisdictions have developed policies for managing connected surface water and groundwater systems, the implementation of effective conjunctive management remains limited and the understanding of connectivity in individual systems is still inadequate in many areas" (NWC 2011a, pp. 10, 100). 
Why has conjunctive management remained 'unfinished' in Australia? And what are the opportunities and barriers to conjunctive management and collective action? These issues remain unresolved, not least because answers are likely to vary between states and catchments. A comprehensive review of these experiences is beyond a chapter of this size, so we instead draw some general insights on the challenges and opportunities of conjunctive management through a collaborative planning case study (for further on this study and its methods, see Holley and Sinclair 2013b, pp. 37-38).

New South Wales (NSW) was selected because of its diverse range of surface water and groundwater resources, and it is at the forefront of integrated water management (Ross 2012a). Water sharing plans (WSPs) are employed to address competing demands through rules for water use and trading and are developed under the Water Management Act 2000 (NSW). The Act gives effect to the NWI goal of sustainable and integrated water management, including the role of the community in working with government to resolve water management issues (Water Management Act 2000, s 3). Most NSW WSPs take the form of 'Minister's Plans' rather than as a result of a formal collaborative committee process (Water Management Act 2000, ss 15, 50; Holley and Sinclair 2013b; Millar 2005). In making the WSP, the Minister has the power to set up advisory or other committees for the purposes of the Water Management Act and, as shown below, this was used in lieu of a more formal collaborative committee route (Water Management Act 2000, ss 387, 388).

The first of NSW's over 60 WSPs commenced in the early 2000s and were prepared using a local committee approach with stakeholder consultation (NWC 2011 b, p. 10). This study focuses on the development of one of these earlier plans in a small upper catchment in the Namoi Valley, chosen because its surface water channels exhibit a number of points of high connectivity with the local groundwater system (SWS 2012, pp. vii, 103; Parsons et al. 2008; Kelly et al. 2007). The particular 'zone' is subject to the Water Sharing Plan for the Upper and Lower Namoi Groundwater Sources 2003 (covering 13 zones in total).

The catchment has a single river flowing through it, but this is usually dry as it sits on top of a porous alluvial groundwater system, which is rapidly recharged from the surface river water. In short, it is a highly connected system. The catchment is populated by a comparatively small number of farmers (with 33 licence holders, but only around 15 active water users), with small holdings (around 40 ha). Other major stakeholders engaged in water management were a government department for water (the New South Wales Office of Water (NOW) (now known as DPI Water)), the Namoi Catchment Management Authority (CMA) (now known as North West Local Land Services), a number of local councils and other property holders who did not actively use the groundwater.

Notwithstanding that much of the groundwater resource is highly connected to the Namoi River, the development of our groundwater WSP case was separated from a surface WSP in the Namoi (NWC 2011b, p. 130). Both WSP's began as single resource drafts prior to the NWI being agreed at the national level. While the NWI was finalised before the groundwater WSP was completed, the ultimate plan provide little information on the potential connectivity between surface water and groundwater (NWC 2011b, p. 131). 
The groundwater planning process began with the release of a socioeconomic study into the region, followed by some initial consultation meetings in each zone of the Namoi Valley (approximately $42,000 \mathrm{~km}^{2}$ in total, containing 100,000 people) along with a series of related technical studies. With the Water Management Act in place in 2000, a groundwater management committee was established to cover the Namoi region. The committee included representatives from all the major stakeholder groups highlighted above, and other relevant department and fishing bodies, and had responsibility for developing the draft WSP, which it released in 2002 (Millar 2005, p. 9). Up to this point, there was little direct consultation with stakeholders outside of the committee process (Holley and Sinclair 2013b).

The draft WSP was scheduled to begin operation in 2003 and was to be made under s50 of the Water Management Act as a Minister's Plan. Following some controversy over the operation and amendment of s50 to exclude certain requirements relating to public consultation, and an unsuccessful legal challenge the WSP was put on hold while a review of the draft plan was undertaken (Millar 2005). This engaged representatives from peak irrigation bodies, and addressed in particular the issue of uniform and proportional reductions versus allocation based (at least partially) on 'history of use'. In order to execute this policy the implementation of six groundwater plans was deferred so the department could establish accurate information on the historical rates of extraction for all licensees (Gardner et al. 2009, p. 320). Subsequently, a new revised WSP was completed in 2005, and was scheduled to commence in 2006. In the interim, another far more comprehensive round of consultation was undertaken with the assistance of the existing stakeholder committee and the Namoi CMA. In terms of impact, the CMA consultation process amended approximately a third of the clauses in the draft WSP. The Minister approved the WSP, with the weighting of allocations favouring active users over inactive users (see also New South Wales Government NSWG 2011). The WSP came into force on 1 November 2006, and terminates on 30 June 2017.

While there were some disagreements over the mechanics of the above consultation process, there were also key differences and disputes over its nature and outcomes. These differing perceptions are fundamental to understanding the failure of conjunctive management in this instance, and reveal ongoing unresolved disputes between the different actors. Although there was, and remains, some tension regarding entitlement reductions, of fundamental relevance were disputes between government and non-government stakeholders. Holley and Sinclair's (2013b, pp. 44-50) research on the experiences of this case study zone reveal four key areas of contention.

First the zone's irrigators and NOW disagree as to the nature and content of the consultation process that led to final WSP. In particular, the irrigators reported that they were deceived by NOW as to a proposal for integrated water management involving variable groundwater allocations that reflected highly connected surface water and groundwater system and resulting rapid aquifer recharge by a stream in their zone. The underlying rationale of the irrigators' case was that the rapid aquifer recharge in their zone could have been better harnessed to optimise water use during wet and dry periods, including exploring storage options and more flexible annual allocations. In essence, this would have entailed management rules that were 
more responsive to changing aquifer levels via a seasonal allocation of the catchment as a whole, as opposed to a fixed sustainable yield as is common under WSPs. For the irrigators, a more integrated planning process would have allowed them to make trade-offs between flexibility and the security of water entitlements in order to make better use of existing water supplies. This would have required frequent monitoring of the catchment aquifer and river flows, such that water use protected environmental flows. The rationale for this approach was that farmers would be able to engage in a cooperative form of local governance (with external oversight), in particular, adapting their management strategies in response to changes in river flows and aquifer levels.

The irrigators believe they were given a firm undertaking by NOW (and its predecessors) to seriously consider their proposal to respond to their catchments biophysical conditions and put in place flexible integrated seasonally variable targets: "they said they would look at it". In contrast, the government claims no such undertaking was given, nor did they receive any written proposals to that effect from the irrigators. These different interpretations emerged from a decision-making and consultation process that saw significant mistrust and disconnection between government and the irrigators. One irrigator was of the view that "the [proposal] fell over because farmers were not respected by NOW, and were not trusted to manage the groundwater". Whilst not agreeing with the irrigators' interpretation of events, even NOW respondents acknowledged that shortcomings in the consultation process for the irrigators (discussed further below) had contributed to these fundamental divisions.

Despite the support of local farmers, in the end, the suggested management approach was not adopted. The opportunities for more flexible exchanges between different uses was instead overlooked in favour of groundwater only WSP, where water users were given annual allocations that were tied to groundwater levels in the catchment.

A second area of contention was the negotiation process in the lead up to the WSP zone allocations. On all accounts, the process was time consuming but had successfully involved many peak groups and, in the later stages, many farmers. Even so, smaller irrigators and local farmers believe they ultimately had little say (let alone an opportunity to contribute to a consensus agreement) in a decisionmaking process that was dominated by large, downstream cotton irrigators and governments. NOW respondents also acknowledged shortcomings in the consultation process for the case study's irrigators, particularly in earlier stages:

\footnotetext{
There wasn't a lot of consultation at local level with irrigators ... I don't know how up to date they were on what was happening and the decisions being made above them. They were out of the loop really. Government and peak irrigators were the main groups really throughout the entire process
}

Third, even when the CMA engaged local irrigators in the latter stages of the process, there were reportedly significant weaknesses in facilitating meaningful negotiation. Although NOW and the CMA had provided significant technical information on water conditions and hydrological modelling, and that some connectivity estimates were incorporated into their underlying hydrological models 
(NWC 2011b), sufficient information was not always available to properly account for groundwater-surface water interactions (Lamontagne et al. 2012). At the time, stakeholders raised questions about the information used to assist with complex decision-making. As one government respondent put it: "I guess by its nature, complicated was necessary". According to respondents, the lack of sufficient government assistance effectively precluded many local irrigators from fully understanding and inputting into issues of connectivity and the implications for conjunctive management. As one government respondent explained:

\footnotetext{
Another issue was the complexity of the model - because of this complexity, some irrigators never really got it ... You know you will always have people at one end of the room who are switched on, and then you will have others who enjoy farming but not following up issues and reading things. In hindsight some of the presentations could have been simpler.
}

Fourth, and finally, and perhaps the biggest weakness, was that despite models underpinning the WSPs, the resulting plan lacked sufficient provisions for integrated management of connectivity (NWC 2011b, p. 14). Arguably, this has constrained adaptation opportunities and the incorporation of conjunctive management approaches. Indeed, even if one has faith in the fact that hydrological models underpinning the plan continue to reflect aspects of connectivity modelling itself, sufficient information is reportedly not always available to account for groundwater-surface water exchanges in detail. Indeed, respondents pointed out that relevant government agencies have failed to generate and share relevant hydrological data, including an absence of information on their groundwater aquifer status and trends (Holley and Sinclair 2011). As one catchment management respondent noted, "they [NOW] are supposed to do Aquifer Status reports on a quarterly basis, but we are lucky if we get a report every three years".

There was a similar lack of sustained data sharing/dialogue between state and regional institutions and the water users themselves, namely, the farmers. Following the implementation of the WSP, it was claimed by catchment management respondents that at first "the Department came along with good reports, but then this stopped and people quickly lost interest". Consequently, the farmer consultation groups became dormant. Despite the availability of some data online, farmers said they lacked the time and skills to find, access, use and then interpret relevant information: "they tell us it's in the public domain but they can't find the time to show us how to get to it and look at it" (Holley and Sinclair 2011). In the absence of such data, effective water management (including ongoing monitoring and scrutiny of the WSP itself) is difficult, with minimal information reported on the achievement of environmental or cultural outcomes, or progress towards these (NWC 2011b, p. 131).

Despite recent recognition of these issues there is still a long way to go until successful conjunctive management of groundwater can be realised in catchments such as this case study. Certainty, there are limits to generalising from a single case (e.g. see the distinct history of developments relating to conjunctive management of seawater intrusion, Petheram et al. 2008). However many of these findings appear consistent with recent national evaluations (NWC 2011a). It is also important to 
remember that the case study was an early example of planning. The new Basin Plan (Basin Plan 2012, Cth, cl10.19), ongoing review of WSPs in NSW (NSW Office of Water 2013; NRC 2013) and new integrated and macro plans that aggregate water sources into broader management units (O'Rourke and Bailey 2010) provide evidence and opportunities for necessary refinement to management of groundwater surface water connections (NWC 2011b, p. 11). For example, the recent Water Sharing Plan for the Peel Valley Regulated, Unregulated, Alluvium and Fractured Rock Water Sources 2010 represents a substantial advancement in NSW's approach to integrated management of surface water and groundwater, including different sets of rules to manage water resources with varying degrees of connectivity (e.g. shallow alluvial groundwater below a river channel can be managed by the same rules as surface water, whereas groundwater remote from the river channel is managed as a separate resource) (Ross 2012b). Positive signs for conjunctive management are also evident in the growth of managed aquifer recharge (whose uptake in Australia has been patchy among different states, Dillon et al. 2009, 2010) and national efforts to improving resource condition data (Water Regulations 2008, Cth, Part 7). However, the full potential and impact of these developments is still some years away, and it is clear that despite over a decade of national objectives the implementation of conjunctive water systems through planning is lagging.

\subsubsection{Spain}

Conjunctive water use is widespread in Spain, both in the interior (e.g. Madrid's water supply as the capital region is now underpinned by conjunctive use) (Flores Montoya 1998), and along the Mediterranean coast, all the way from the internal basins of Catalonia, down to the Jucar, the Segura and finally the Almeria basin. Two features are peculiar to conjunctive use. The first is the role of water user groups in the management of this conjunctive use. The second is the fact that conjunctive use along the Mediterranean coastline (where there are high value crops and economically important tourism) is seeking to enlarge the portfolio of resources to reduce risk beyond surface water and groundwater, and is now incorporating desalinated, recycled and even recharged water (López-Gunn et al. 2012). This means that management is complex both from the perspective of resource management, and also in terms of coordination between a number of actors. The leading ones are, however, the water user groups as ground managers, and the respective river basin authority as the regulator.

Groundwater in Spain is a strategic resource in a number of basins and states (Sahuquillo 2009). It is not a particularly noticeable resource in the Northern part, whereas in parts of central Spain, like La Mancha or Almeria, it is the key water resource for the regional economy. In the case of Catalonia, conjunctive water use is part of day-to-day management, with a highly complex system of resource management. People and economic activity has concentrated along the coastline, where intensive groundwater use has led to problems with both marine intrusion 
and water quality, for example in the deltas of the Llobregat, Besos, Ter, Muga and Francoli rivers (Planas 2010). Intensive use affects the cities in the region, and has led to a complex management including built seawater barriers to prevent marine intrusion and projects for aquifer recharge. The experiences on aquifer recharge in the Besós and Llobregat rivers (Barcelona) are complemented with the pilot experience with the Río Belcaire (Castellón), which together represent $50 \mathrm{Mcm}^{3}$ / year for the whole of Spain (Andreu et al. 2010).

However in terms of resource use, what is noticeable is that rather than conjunctive use it is a case of 'alternate' use, i.e. surplus surface water is used to recharge local aquifers for times when there is low surface water availability. The case of the Cubeta de San Andreu is interesting because of the confluence between complex resource use and a complex institutional framework that is needed for the conjunctive use to run smoothly. The current plan for water resources is based on the joint use of surface, groundwater, re-used water and desalination and water transfers. This is a change from individual use to collective management, led under the umbrella groundwater user group for Catalonia, the specific one of the Cubeta de San Andreu, the public water supply company ATLL, and the regional water administration through specific agreements.

The agreement signed between users and the regional water agency provides a framework for a project of joint interest, e.g. aquifer recharge, covering technical, legal and economic aspects. It includes aspects related to aquifer recharge, inventory of water rights and the closing of some wells, the installation of water meters and monitoring, technical advice, a chemical monitoring network and preparatory work for the EU Water Framework Directive (WFD). Thus the goals or objectives are both public and private. The main obstacles have been to reach enough level of association and common vision, and closer links between administration agencies (like agriculture and water admin), as well as giving political voice and representation to users in the decision-making bodies.

The case of Andalusia, in particular, the region of Almeria, bears some similarities to the case of Arizona, except with one major difference: it is for use in the largest greenhouse area in the world, the so-called 'plasticulture'.

In the late 1990 s to early 2000 , with a lack of groundwater management in the southern Mediterranean coastal belt, authorities looked to divert water from the Ebro river in the north to help compensate for rapidly depleting aquifers (Llamas et al. 2007). Water agencies tend to build projects far in advance of their justifiable need on pure economic terms (Howe 2002). It is politically rational for decision makers to prefer users to continue pumping than to take the (unpopular) decision to cut allocations and instead opt for politically more popular water transfers. There are very few systems of explicit conjunctive management. Once the National Hydrological Plan of 2001 was derailed, Plan B centred on the construction of a series of desalination plants along the coast, including Almeria. However, Spanish farmers - like Arizona farmers - also balked at paying for expensive desalinated water in bulk to substitute groundwater abstractions. However, in an ironic twist, farmers do use desalinated water - which they consider 'fresh' to blend it with highly salinised groundwater with high conductivities, which is an optimal solution 
in terms of lowering the risk of no water, while ensuring optimal conductivity for high value tomato crops destined for export in Northern Europe. Farmers prefer cheaper groundwater to desalinated water, despite the fact that desalinated water prices are subsidised and do not reflect the true costs (which are borne by the taxpayer).

The case of Jaen in the Upper Guadalquivir basin offers a completely different narrative. Here, the discussion on conjunctive use is happening at the basin level, partly because groundwater farmers upstream started intensive use of relatively small aquifers, using water that technically was already 'allocated' to farmers downstream. However farmers downstream were more 'inefficient' in terms of Euros per drop (productivity) and also in terms of resource use $\left(\mathrm{m}^{3}\right.$ per crop) which has created a negotiation space. Intensive groundwater use upstream has meant the rapid development of a region that was economically depressed, and where there are now political pressures to keep these captured resources. Since in Spain, contrary to the United States, there is no prior appropriation doctrine, it is the river basin authority through basin planning that becomes the object of negotiation for groundwater user communities upstream and surface water communities downstream. In one case, defending what are rather tenuous 'use' rights as compared to full 'de jure' water rights. Yet it is an example where once this intensive groundwater use has happened (it is fait accompli), the most likely scenario is to upscale collective action to basin level in order to achieve the best possible 'conjunctive' use of both surface water and groundwater resources (Rica et al. 2014).

Looking at the Jucar case we see an interesting evolution in terms of conjunctive use, from really early experiences dating to the early twentieth century, all the way to current decisions being posed on conjunctive use on the river basin plan being prepared in 2013. In this context the case of the river Mijares and irrigation in the Plain of Castellon is a good example of conjunctive management, defined as consisting both of the joint (or alternate) use (resource organization) and joint use by users (social organization). An agreement was signed in 1970 to use water from the Mijares River (Convenio de bases para la ordenación de las aguas del río Mijares, 1970, OM-MOP-73), based on making use of the storage capacity of the aquifer (estimated at $600 \mathrm{Mcm}^{3}$ ) five times larger than the reservoirs of Sichar and Maria Cristina, which had filtrations. Thus during dry periods use is made of groundwater which is recharged during the wetter years by making use of surplus flows from surface irrigation in the acequias or canals (Andreu et al. 2010).

The Jucar case offers some similarities to the case of Colorado, in the United States, and to the case of the Guadalquivir, with a classic conflict between intensive use of groundwater upstream and impacts on surface water users downstream. In the first instance, like in other cases discussed in this chapter, there was a negotiation between farmers in the Eastern Mancha aquifer in Albacete with the Jucar river basin authority. However, during times of high water scarcity - in the midst of a drought - like in the case of Colorado, the temporary solution was an augmentation plan, to address the problem of low flows in the Jucar river, which eventually impacted downstream into the Acequia Real del Jucar (a traditional surface water irrigation area highly dependent on these flows). The Water Act of 1999 introduced 
Table 9.1 Results Ofertas Públicas de Adquisición de Derechos (OPAD)

\begin{tabular}{l|l|l}
\hline & 2007 & 2008 \\
\hline Applications submitted: & 119 & 234 \\
\hline Volume in rights $\left(\mathrm{Mcm}^{3}\right)$ & 56.8 & 109.6 \\
\hline Volume waived without economic compensation $\left(\mathrm{Mcm}^{3}\right)$ & 22.9 & 12.5 \\
\hline Volume offered $\left(\mathrm{Mcm}^{3}\right)$ & 27.3 & 50.6 \\
\hline Budget used $($ million $€)$ & 5.5 & 12.7 \\
\hline Reserved volume $\left(\mathrm{Mcm}^{3}\right)$ & 6.6 & 46.5 \\
\hline
\end{tabular}

Source: Ferrer and Garijo 2013

an important change by partially introducing market instruments under the figures of contract for the assignment of rights (Article 67 TRLA) and a centre for the exchange of water rights (Article 71 TRLA) (Ferrer and Garijo 2013). The first case has not been used frequently between users because it is fairly restrictive on the type of water right. Most groundwater rights are private and these are barred from participating in water rights exchanges. In the 2005-2008 drought, however, the river basin authority negotiated with Eastern Mancha farmers for an area of 28,000 ha on the basis of a series of criteria centred on impact on river flows and price offered. Exchange purchases went from $20 \%$ to $5 \%$ of the irrigation, securing $148 \mathrm{Mcm}^{3}$ bought with (temporary) reductions to prevent the drying up of the river bed as had occurred in the previous drought from 1994 to 1996.

It is important to stress that it is likely that this negotiation and agreement was facilitated to a large degree due to the existence of a well-organised and cohesive groundwater user group that acted as interlocutor with the river basin authority. Thus after the emergency meeting due to drought from the Spanish Council of Ministers in 2004, Centres for the Exchange of rights (art. 71) were set up in the Guadiana, Júcar y Segura which authorised these basins to undertake Public Offers for the (temporary) Acquisition of Rights (Ofertas Públicas de Adquisición de Derechos (OPAD)) (Table 9.1).

During the 2006-2008 drought other types of conjunctive management were undertaken in the Jucar, including the use of non-conventional resources like drainage flows from the Ribera del Jucar of up to $60 \mathrm{Mcm}^{3} /$ year via pumping (costs paid by users); and water re-use (up to $94 \mathrm{Mcm}^{3} /$ year) where treated water from Valencia city was partially exchanged for surface water in the Vega del Turia thus freeing up Jucar resources. These were initiatives for conjunctive use using all available resources and using a modelling programme to explore the different options, including leading to a better comprehension by users of the range of alternatives (Andreu et al. 2010).

The Jucar case is one of the best studied and most complex in Spain and one which highlights a range of available models for conjunctive use as discussed by Garduño et al. (2010). Equally, Andreu (a Spanish expert on conjunctive use (Andreu et al. 1996; Andreu et al. 2010)), highlights the diversity of experiences in Spain on conjunctive use not discussed here for reasons of space, and the common denominator for their durability: success centred on collective action 
and adequate rules of game, which have to envisage different scenarios, give particular emphasis to drought conditions and define the economic regime. What is particularly relevant at a more macro scale from the perspective of joint use and collective action is to make more flexible the opportunities for exchanges between different uses as argued by Ferrer and Garijo (2013). At the catchment level scale, conjunctive use of water opens up an interesting constellation of mutual interests between surface water and groundwater, public water supply and irrigation and the most suitable use of best quality water. Transfer of rents between sectors from those that have a higher capacity to pay could also solve one of the most intractable problems in the basin.

In conclusion, conjunctive management in Spain is a reality in many cases and it has become particularly valuable as a solution to complex problems, where in general the complexity of the resource use has been matched by the emergence of parallel social institutions and collective entities to address conjunctive management.

\subsubsection{United States of America}

In the United States, the primary authority over the allocation of ground and surface water resides with states. Each state has its own water laws and water administration system making it difficult to generalise about water policy in the United States (Getches 2008). Although the states are the lead actors in deciding whether and how conjunctive management occurs, the federal government is often a participant because of its authority over different activities that impact water. Beginning in the early twentieth century, the federal government began a long-term program of financing and building large surface water storage and delivery projects (Reisner 1993). The projects are often sources of water for conjunctive management programs. Later, in the 1970s, environmental laws extended the reach of the federal government. In particular, the Endangered Species Act has impacted how states and their water users place water to productive uses (Aiken 1999).

Since it is impossible to adequately address the water experiences of each of the 50 states, this section focuses on the experiences of three western states, Arizona, Colorado, and Nebraska. These three states were selected because of their variation in water administration that in turn has affected their experiences with conjunctive water management. Arizona's water arrangements are highly centralised within the Arizona Department of Water Resources (ADWR), which administers groundwater and conjunctive water management programs. Local jurisdictions, such as irrigation districts, cities and counties deliver water to end users, but have limited discretion in governing water (Colby and Jacobs 2007). In contrast, Nebraska's water arrangements are highly fragmented. Local natural resources districts have the primary authority to manage groundwater, whereas the Nebraska Department of Natural Resources has the authority to manage surface water (Harnsbarger 1984). Until very recently, the state held minimal decision making authority over groundwater, thus making it difficult to coordinate groundwater and surface water uses. 
Finally, Colorado may be characterised as more of a polycentric system. Concurrent and overlapping powers to govern water are shared across the three branches of government - specialised water courts, the state water engineer, and the legislature - with water users organised in irrigation districts and companies, well associations, and municipal water utilities (Blomquist et al. 2004). No single branch of government or local or regional water organization dominates water governance.

While each state's water laws, administration, and experiences are different, each state turned to conjunctive water management to provide solutions to a series of conflicts confronting water users and the state governments. It is the nature of the conflicts, combined with the state's water laws and water geography that shaped conjunctive water management responses. For Arizona, conjunctive water management emerged from conflicts over how to develop and use its allocation of Colorado River water. Allotted over 2 million acre feet of water annually from the river, it required a multi-billion dollar project of canals and pumping stations to deliver a substantial portion of that water to the most populous areas of the state. One of a number of conditions that Arizona accepted in order for the US Bureau of Reclamation to build the $\$$ (US) 4.8 billion Central Arizona Project was to adopt a new state groundwater code that would regulate groundwater pumping and limit the mining of groundwater (Leshy and Belanger 1988). The 1980 Arizona Groundwater Management Act established the framework for conjunctive management. It created four active management areas (AMAs), later expanded to five when one of the original AMAs was split in two, extending from central Arizona south to the international border with Mexico. Within the active management areas, agricultural groundwater rights were quantified and capped and municipalities were subject to limits and over time reductions in the amounts of groundwater they could pump to serve their residents (Leshy and Belanger 1988). The portions of Arizona not covered by active management areas continued under the historic groundwater regulatory regime of reasonable use (Colby and Jacobs 2007).

By the early 1990s, the Central Arizona Project was complete and began delivering water, however, the state faced a serious crisis. The state intended to repay its portion of the cost of constructing the project by selling water. The primary water users, irrigators, balked at purchasing the water because it was substantially more expensive than pumping groundwater. Over the course of several years, negotiations among the Federal government, state, and municipal, agricultural, and rural interests resulted in revisions to the 1980 Groundwater Management Act, some of which encouraged the recharge of Central Arizona Project water underground to be withdrawn at a later date (Glennon 1995). Large water districts, municipal utilities, and the Arizona Water Banking Authority have developed a series of direct and indirect recharge projects storing several million acre feet of water over the past decade. For instance, from 1997 to 2012, the Arizona Water Banking Authority which recharges 'surplus' Central Arizona Project water has accumulated over 3 million acre feet of recharge credits (Arizona Water Banking Authority 2013).

Arizona has a highly focused and directed conjunctive water management program - long term underground storage of its allotment of Colorado River 
water. The millions of recharge credits are likely to become an important source of water for irrigators and municipal water providers in the next couple of decades because of anticipated water shortages in the Colorado River Basin due to extended drought and climate change impacts.

Colorado, like Arizona, also has active conjunctive management programs and projects in place in the most heavily populated river basins in the state. However, the conflicts that stimulated a conjunctive management response and the resulting practice of conjunctive management are distinct. The first century of European settlement and economic development, roughly between 1849 and 1949, was supported by the construction of surface water storage and distribution systems. Water development was based on and supported by the prior appropriation doctrine in which water is allocated on a first in time, first in right basis. During times of scarcity, those water users most senior in time receive their water allotments while those more junior in time bear the water shortages. The State Water Engineer administers water rights and develops information for water courts to guide the creation, modification, and transfer of water rights. Water courts are the venue in which water users bargain, negotiate, and contest over water rights (Blomquist et al. 2004).

Beginning in the 1950s, irrigators began installing high capacity wells. Within a decade, groundwater pumping began to noticeably affect river and stream flows. Under Colorado water law, groundwater that is hydrologically connected to surface waters is governed under the prior appropriation doctrine. In practice, this meant that groundwater rights were junior to surface water rights and under the prior appropriation doctrine wells should not be pumped until surface water rights were satisfied. Such a strict application of the prior appropriation doctrine would shut off access to a major source of water, one that is particularly important during times of drought, and limit the expansion of irrigated agriculture and municipal and industrial development. Conflict between Colorado surface water and groundwater users also spilled across state borders as water users in downstream states claimed that they were being denied their rights to water by groundwater pumping occurring upstream in Colorado. Efforts to incorporate groundwater into the state's prior appropriation system and to ensure that interstate water allocation agreements are adhered to largely rest on conjunctive management programs and projects (Blomquist et al. 2004).

In Colorado, conjunctive management protects and maintains surface water flows while allowing for groundwater pumping. The state legislature passed a series of laws that gave the state water engineer the authority to engage in rule making and that allowed for the development and use of augmentation plans. Augmentation plans, which must be approved by water courts (as must any rules and regulations developed by the State Water Engineer), allow well owners to augment stream flows to cover the effects of groundwater pumping. Augmentation plans may take a variety of forms. Well owners may lease surface project water and make it available to the Colorado state water engineer to release to the stream or river when needed. Or, they may purchase surface water rights and leave the associated water in the stream to cover the effects of groundwater pumping. Or, some irrigation companies 
and districts run surface water in irrigation ditches and ponds, allowing it to percolate into the ground and eventually return to the river to cover the effects of groundwater pumping (Blomquist et al. 2004). Wells not covered by court approved augmentation plans have been shut down (Cowan 2012).

Like Colorado, Nebraska's conjunctive water management efforts have been directed at protecting and maintaining river and stream flows. Surface water is governed by the prior appropriation doctrine and is administered by the Department of Natural Resources. Groundwater is governed by local natural resources districts that have the authority to regulate groundwater access and use. Each district is governed by an elected board, and elected members are typically irrigators who pump groundwater. Until recently, the state had no authority over groundwater and natural resource districts were not required to pay attention to the effects of groundwater pumping on surface water flows (Schlager and Blomquist 2008).

The efforts to coordinate groundwater and surface water use occurred because of crises in relation to surface water users. In the Platte River Basin the surface water users were endangered species and in the Republican River Basin the surface water users resided in the downstream state who claimed that Nebraska groundwater pumpers were in violation of an interstate water sharing agreement. The endangered species in the Platte River Basin limited new water development and threatened existing water uses that required permits from federal agencies (Aiken 1999). Most importantly for Nebraska, the state's largest water and electric utility held permits issued by the Federal Electric Regulatory Commission to operate hydroelectric dams that were soon to expire. Permit renewal would require aggressive actions to protect endangered species. The two upstream states in the basin faced similar threats to their water projects as well. The three states and the federal government, over the course of a decade, negotiated an agreement that provided additional flows to the river for endangered species recovery and to cover all water development that affected the river from 1997 onward (Schlager and Blomquist 2008; Freeman 2010; Kenny 2011). One of the sticking points in achieving an agreement was Nebraska actively regulating groundwater wells and pumping in the basin. The upstream states did not want to provide additional water to the river only to have it diverted by irrigators in Nebraska (Freeman 2010). At about the same time, the 1990s, the state and irrigators in the Republican River Basin were gearing up for a US Supreme Court suit brought by Kansas, the downstream state claiming that Nebraska's well owners were diverting water that belonged to Kansas irrigators, causing Nebraska to violate its water sharing agreement. The Supreme Court found in favour of Kansas and required Nebraska to regulate groundwater pumping (Schlager et al. 2012).

Nebraska and its water users struggled to develop an agreed upon process for spanning the chasm between the surface water and groundwater management systems. Over the course of a decade (1994-2004), which witnessed a variety of experiments to settle the intense conflict between surface and groundwater users, the legislature finally adopted a statute that established an integrated water management planning process (Nebraska Department of Natural Resources 2006). The Nebraska Department of Natural Resources (NDNR) was granted the authority to 
declare river basins fully allocated or over allocated. Once such a designation occurred, the NDNR and the affected natural resources districts were required to collaborate to develop integrated management plans. The Platte and the Republican Rivers natural resources districts were the first to develop such plans (Nebraska Department of Natural Resources 2006).

Integrated Management Plans form the foundation for conjunctive water management in Nebraska. Well moratoria and strict pumping limits reduce the pressure on surface water flows. In addition, several districts in the Platte River Basin are experimenting with groundwater recharge projects by placing water in unlined canals and pits to percolate underground (Bradley 2011). While conflicts continue to simmer among the state's groundwater and surface water users and between water users and state agencies, the era of integrated or conjunctive management has arrived in Nebraska.

The form and function of conjunctive water management varies across the states as do the processes and outcomes of such management. The states differ on how broadly based collective action occurs, or to put it another way, the interests and values that are represented in decision-making processes. In Colorado, broad-based participation is built into the water administration system. Individuals, organizations, and state agencies who hold water rights or who regulate water rights have a seat at the table and that table is typically the water court. Any water rights holder who believes his or her water right will be affected by a decision may participate in court processes. Given such a process, the State Water Engineer, as a routine matter, convenes advisory groups consisting of water rights holders to guide the development of regulations before they are brought before a water court for approval. In Nebraska, participation occurs in a more ad hoc fashion. When substantive legislation is required to address water issues, the legislature often convenes commissions and task forces with representatives of different types of water uses from across the state to hold hearings, conduct investigations, and make proposals. In developing integrated management plans, temporary advisory committees may be established to participate in their development. The Arizona water administrative system allows for much more limited participation in conjunctive management processes. Participation involves organizations and agencies with access to Central Arizona Project water and with the financial wherewithal to engage in larger scale conjunctive management projects. A number of interests and uses have been excluded from pursuing different forms of conjunctive management, most notably those that are organised around perennial rivers outside of active management areas. Since state law does not recognise the hydrologic connection between ground and surface water, nor does it provide local jurisdictions with any policy tools to regulate groundwater, rivers are slowly being desiccated with little that surface water rights holders, recreationists, and environmentalists can do (Glennon 2002).

Conjunctive management represents a key form of adaptation to changing biophysical and societal demands among the three states. For Arizona, conjunctive management represented a response to a societal crisis, but later morphed into a response to changing biophysical demands. When the primary beneficiaries - 
groundwater irrigators - of a major surface water project were financially incapable of utilizing the project leaving the state in debt and with surplus water, conjunctive management was adopted. Now conjunctive management is viewed as a key tool in buffering water users against the effects of climate change.

For Colorado and Nebraska, conjunctive management was an important response to biophysical issues that generated conflict. The hydrologic connection between surface water and groundwater had to be actively managed in order to protect surface water flows and the users dependent on those flows. In addition, conjunctive management allows Colorado and Nebraska water users to make tradeoffs between flexibility and security of water rights in order to make better use of existing water supplies. For Colorado, augmentation plans provided flexibility allowing for groundwater use to occur, while also protecting surface water rights. Integrated management plans play a similar role in Nebraska - securing surface water rights and flows while allowing for continued use of groundwater. In turn, integrated management plans set the stage for the development of different forms of conjunctive management.

All three states - Arizona, Colorado, and Nebraska - have witnessed success with conjunctive management. Conjunctive management has allowed water users and the states to address various water related crises and makes possible more active forms of water management. However, each state's conjunctive water management programs also exhibit some limitations. First, environmental issues receive little attention. True, Nebraska is using conjunctive management to recover endangered species on the Platte River, however, that is the price the state must pay in order to protect existing water uses and allow for new water uses in the future. Coordinating the use of hydrologically connected ground and surface water would also allow Arizona to protect relatively rare riparian habitat and the rights of surface water users, but, thus far, the legislature has not been convinced to act. Second, the states have just begun to tap the potential of conjunctive management. The states could more actively coordinate groundwater and surface water use by allowing surface water users to move to groundwater during droughts, with water remaining in streams and rivers to provide for habitat and species protection and for downstream water uses, while limiting pumping and actively storing water underground during wet years. However, such flexibility would come at the potential cost of security of water rights as pumps may not be shut off during wet years.

\subsection{Discussion and Conclusion}

This chapter has shed light on specific instances of conjunctive management and collective action in Australia, Spain and the United States. The nature of these approaches varied, including examples of integrated basin and catchment planning in Australia, Nebraska and Upper Guadalquivir basin; large scale water infrastructure projects involving storage and desalination in Arizona and Almeria; as well as augmentation plans and other agreements in Colorado, Jucar and Catalonia. 
Each had considerable success. Australia's 'top down' water reforms involving national frameworks and state implementation gave rise to a suite of legislation and policy instruments and plans that recognise the importance of managing connected water systems as a single resource. In the United States, the more limited national role produced significant variation among states in their conjunctive management approach, but all three demonstrated success, not least facilitating water users and the states to address various water related crises through more active forms of water management. Finally, in Spain's hybrid and multilevel system, involving regulation, voluntary agreements and informal water markets/trading, conjunctive management is tackling various complex problems across a range of water resources. This approach encompasses the ability to engage with water users groups to create a shared vision and accommodate groundwater recharging through formal agreements. It also has facilitated links between administrative agencies to establish consistent conjunctive management approaches.

However, in their own ways, the experiences in each country also evidenced a number of limitations and challenges. In Australia, despite clear national objectives, the implementation of conjunctive water management via collaborative planning has been patchy. Groundwater and surface water remain siloed, science on connectivity was limited and key water user stakeholders were marginalised from integrated decision-making (Lamontagne et al. 2012, p. i). In terms of collective action, consultation was often inadequate, with a lack of meaningful dialogue, poor information and an absence of time and skill on the part of water users. Smaller users, in particular, felt disenfranchised from the process. In the United States, conjunctive management policy also lagged in some areas, including limited attention being given by the legislature and others to environmental issues, and an absence of more active coordination of groundwater and surface water use. In Arizona, in particular, collective action through the participation of water users in the management process was absent, and in Colorado, such participation was largely limited to the legal and regulatory development phase, as opposed to ongoing management. Although more advanced in pursuing collective action than Australian and the United States, Spain, too, has confronted conjunctive management challenges. There are lingering tensions between groundwater and surface water users, and between upstream and downstream users, both of which may be exacerbated in drought conditions. Further, the political voice of water user groups, and their subsequent participation in decision-making, has been less than ideal.

What broader comparative lessons can be gleaned from these case studies? While there are inherent dangers in generalizing from this type of research, nevertheless, a number of insights can be drawn from our findings across the different contexts and institutional arrangements of the three countries. They suggest some key lessons with regard to the types of settings that facilitate conjunctive management and collective action, and also associated challenges and limitations.

In terms of encouraging a participatory approach to conjunctive management, the case study findings support the proposition that governments and water users are more likely to pursue conjunctive management where social and environmental 
crisis arise. Such crises included over-allocation in Australia, fights spurned by endangered species (Platte River Basin in Nebraska), conflicts between water users in the United States (e.g. Colorado) and Spain (e.g. Jucar and Guadalquivir), battles over how to develop and use allocations (e.g. Arizona and Almeria) and a mix of pressing water problems including marine intrusion, water quality and low surface water availability (Catalonia). Certainly, the ultimate shape of the conjunctive water management responses may vary according to the nature of the crisis (as well as other institutional variables), however, collectively, the findings suggest that its presence is a powerful motivator for parties to engage in conjunctive management.

The case studies reveal a second condition that encourages and enables conjunctive management through collective action, that is, institutional recognition of hydrological connections (between ground and surface water), including, in particular, the devolution of management tools to water users on the ground. The importance of this condition was notable by the impact of its absence in the NSW case study from Australia, as well as limiting access to conjunctive management in Arizona in the United States. In NSW, the policy framework promoted a vision of connectivity and integrated management of surface water and groundwater, however this vision was not translated effectively into state government action and rules. Groundwater and surface water remained isolated with little provision in WSP for integrated management. This effectively stymied local water users in their desire for conjunctive management. Similarly, in Arizona, the failure of state law to recognise the hydrologic connection between ground and surface water effectively excluded different forms of conjunctive management in local jurisdictions outside of active management areas.

The importance of institutional recognition in facilitating conjunctive management was evident across other case studies, as well. There were examples of legal frameworks accommodating conjunctive management, be it through rights of participation in courts and legal recognition of augmentation plans and integrated management plans (United States), or policies that integrate resource management through conjunctive rules, a willingness of government agencies to work with water users groups and agreements tailored to different exchanges between water uses (Spain).

Beyond these pre-conditions, there are lessons about the challenges confronting the ongoing management of conjunctive use. While conjunctive management has the capacity to adapt to changing biophysical circumstances and societal demands, this was not always assured in the case studies. For example, it is apparent that conjunctive management struggles to accommodate a comprehensive suite of environmental issues - this is an issue that legislatures and government agencies need to progress further. This remains an issue in the Unites States, in particular in Arizona, where there has been little progress coordinating the use of hydrologically connected groundwater and surface water to advance the protection of rare riparian habitat. Similarly, in Australia and Spain, much work remains to be done to effectively manage the impacts on groundwater dependent ecosystems and establish environmental water requirements. Entrenching consideration of 
environmental issues within conjunctive programs is accordingly an area that demands policy attention.

Another obstacle to effective conjunctive management was a lack of meaningful engagement of water users in integrated water decision-making and implementation. In NSW, Australia, opportunities to incorporate local water users' knowledge, preferences and ideas relating to conjunctive management and connectivity were stymied by limited consultation, the provision of overly complex data and an inability of government and users to reach agreement. This contrast with Catalonia, Spain, where the political voice and representation of users was better able to contribute a common vision in support of conjunctive management. Meanwhile, the complete exclusion of surface water rights holders, recreationists and environmentalists from the regulation of groundwater outside of active management areas in Arizona, the United States, has undermined broader conjunctive management processes.

Overcoming this obstacle will require institutional settings that better facilitate water users participation in conjunctive management decision-making. While much will depend on context, a range of successful examples from the case studies include commission/taskforces/advisory committees in Nebraska, open court processes to those who hold water rights in Colorado, the use of modelling programmes to generate better comprehension by users of the range of alternatives and harnessing well-organised groundwater user groups to act as interlocutors with the government decision makers in Jucar.

In conclusion, conjunctive management through collective action remains a 'work in progress' across the case studies. While there are some encouraging green shoots appearing in a range of international jurisdictions, notably in terms of policy, legislative and regulatory recognition of groundwater and surface connectivity and integrated management, as is often the case, difficulties arise in effective delivery. Certainly, the presence of a 'crisis' can motive institutional actors, providing of course they have the necessary tools and resources. The greatest challenge is, however, how to effectively engage a broad suite of actors, particularly water users on the ground, to deliver conjunctive management through genuine collective action.

Open Access This chapter is distributed under the terms of the Creative Commons AttributionNoncommercial 2.5 License (http://creativecommons.org/licenses/by-nc/2.5/) which permits any noncommercial use, distribution, and reproduction in any medium, provided the original author(s) and source are credited.

The images or other third party material in this chapter are included in the work's Creative Commons license, unless indicated otherwise in the credit line; if such material is not included in the work's Creative Commons license and the respective action is not permitted by statutory regulation, users will need to obtain permission from the license holder to duplicate, adapt or reproduce the material. 


\section{References}

Aiken D (1999) Balancing endangered species protection and irrigation water rights: the Platte River cooperative agreement. Great Plains Nat Res J 3:119-158

Andreu J, Capilla J, Sanchis E (1996) Generalized decision support system for water resource planning and management including conjunctive water use. Great J Hydrol 177:269-291

Andreu J, Sahuquillo Herráiz A, Solera A, Pulido Velázquez M, Pulido Velázquez D, Paredes Arquiola J (2010) Ejemplo de gestión conjunta de aguas subterráneas y superficiales: la cuenca del Río Mijares. Paper presented at AEUAS, Garantías de la gestión de aguas subterráneas: diagnosis de la situación, Vila-Real, 4 Nov 2010

Arizona Water Banking Authority (2013) Background. http://www.azwaterbank.gov/Background. Accessed 18 June 2013

Baldwin C, Poh-Ling T, White I, Hoverman S, Burry S (2012) How scientific knowledge informs community understanding of groundwater. J Hydrol 474:74-83

Blomquist W, Schlager E, Heikkila T (2004) Common waters, diverging streams: linking institutions and water management in Arizona, California and Colorado. Resources for the Future, Washington, DC

Bradley J (2011) Conjunctive water management. Available via DNR. http://dnr.ne.gov/IWM/ Reports/ConceptualDesignConjunctiveMgmt_032811.pdf. Accessed 18 June 2013

Bricknell S (2010) Environmental crime in Australia. Australian Institute of Criminology, Canberra

Brodie R, Sundaram B, Tottenham R, Hostetler S, Ransley T (2007) An adaptive management framework for connected groundwater-surface water resources in Australia. Bureau of Rural Sciences, Canberra

Colby B, Jacobs K (eds) (2007) Arizona water policy: management innovations in an urbanizing, arid region. Resources for the Future, Washington, DC

Cowan J (2012) Physical and legal influences on groundwater. Available via Water. http://water. state.co.us/DWRDocs/Reports/Presentations/Pages/AtoZPresentations.aspx. Accessed 18 June 2013

Dillon P, Pavelic P, Page D, Beringen H, Ward J (2009) Managed aquifer recharge: an introduction. Waterlines report no 13, National Water Commission, Canberra

Dillon P, Toze S, Page D, Vanderzalm J, Bekele E, Sidhu J, Rinck-Pfeiffer S (2010) Managed aquifer recharge: rediscovering nature as a leading edge technology. Water Sci Technol 62 (10):2338-2345

Evans WR, Evans RS, Holland GF (2012) Conjunctive use and management of groundwater and surface water within existing irrigation commands: the need for a new focus on an old paradigm. Thematic paper, Global Environment Facility, GEF ID 3726. Available via Groundwater Governance. http://www.groundwatergovernance.org/fileadmin/user_upload/groundwatergovernance/ docs/Thematic_papers/GWG_Thematic_Paper_2_01.pdf. Accessed 10 May 2014

Ferrer J, Garijo L (2013) Mercados del agua y flexibilización del marco concesional (Confederación Hidrográfica del Júcar). Paper presented at XI Seminario Nacional Transparencia y concesiones, Observatorio del Agua de la Fundación Botín, 17 Jan 2013

Flores Montoya F (1998) Ventajas del aprovechamiento conjunto de aguas superficiales y subterráneas: el ejemplo de Madrid. In: Fernández Rubio R, Sánchez Fernández JA, López Camacho B, López Geta JA (eds) Aguas subterráneas y abastecimiento urbano. ITGE, Madrid

Freeman D (2010) Implementing the Endangered Species Act on the Platte Basin water commons. University Press of Colorado, Boulder

Gardner A, Bartlett R, Gray J (2009) Water resources law. LexisNexis, Chatswood

Garduño H, Foster S, Nanni M, Kemper K, Tuinhof A, Koundouri P (2010) Sustainable groundwater management: concepts and tools, GW-MATE Briefing note series; World Bank gestión sustentable del agua subterránea. Conceptos y herramientas; Serie de notas informativas Nota 10. World Bank, Washington, DC.

Getches D (2008) Water law in a nutshell, 4th edn. West Publishing, St Paul 
Glennon R (1995) Coattails of the past: using and financing the central Arizona project. Arizona State Law Rev 2(2):667-756

Glennon R (2002) Water follies. Island Press, Washington, DC

Godden L, Foerster A (2011) Introduction: institutional transitions and water law governance. J Water Law 22:53-57

Gray J (2010) Water trading and regulation in Australia. In: Saddy A, Linares Martínez A (eds) Dereito das infraestructuras: Um estudo dos distintos mercados regulados. Lumen Juris, Rio de Janerio, pp 753-792

Gray J (2012) The legal framework for water trading in the Murray-Darling Basin: an overwhelming success? Environ Plan Law J 29:328-349

Harnsbarger R (1984) Nebraska water law and administration. Butterworth Legal Publishers, Austin

Holley C, Sinclair D (2011) Collaborative governance and adaptive management: (mis) applications to groundwater, salinity and run-off. Aust J Nat Resour Law Policy 14(1):37-69

Holley C, Sinclair D (2012) Compliance and enforcement of water licences in NSW: limitations in law, policy and institutions. Aust J Nat Resour Law Policy 15(2):149-189

Holley C, Sinclair D (2013a) Non-urban water metering policy: water users' views on metering and metering upgrades in NSW. Aust J Nat Resour Law Policy 16(2):101-131

Holley C, Sinclair D (2013b) Deliberative participation, environmental law and collaborative governance: insights from surface and groundwater studies. Environ Plan Law J 30(1):32-55

Holley C, Gunningham N, Shearing C (2011) The new environmental governance. Earthscan, Abingdon

Howe C (2002) Policy issues and institutional impediments in the management of groundwater: lessons from case studies. Environ Dev Econ 7:625-641

Between the Commonwealth of Australia and the Governments of New South Wales, Victoria, Queensland, South Australia, the Australian Capital Territory and the Northern Territory (2004) Intergovernmental Agreement on a National Water Initiative (IANWI). Canberra

Kelly B, Merrick N, Dent B, Milne-Home W, Yates D (2007) Groundwater knowledge and gaps in the Namoi catchment management area. National Centre for Groundwater Management, University of Technology, Sydney

Kenny J (2011) Platte river recovery implementation program: four years into the first increment. Available via Prairie Fire. http://www.prairiefirenewspaper.com/2011/04/platte-river-recoveryimplementation-program-four-years-into-the-first-increment. Accessed 18 June 2013

Lamontagne S, Graham D, Household I, Middlemis H, Ross A (2012) Groundwater-surface water interactions: implications for water resources management. Workshop summary report, National Water Commission, Canberra

Leshy J, Belanger J (1988) Arizona law: where ground and surface water meet. Arizona State Law J 20(3):657-748

Llamas MR, Martinez-Santos P, de la Hera A (2007) Dimensions of sustainability in regard to groundwater resources development: an overview. In: Ragone S, de la Hera A, HernandezMora N, Bergkamp G, McKay J (eds) Global importance of groundwater in the 21st century: the international symposium in groundwater sustainability, Alicante, 24-27 Jan 2006. National Groundwater Association Press, Westerville

Lopez-Gunn E, Llamas MR, Garrido A, Sanz D (2011) Groundwater management. In: Rogers P (ed) Treatise in water science, vol 1. Elsevier, Amsterdam/Hackensack, pp 97-127

López-Gunn E, Rica M, van Cauwenbergh N (2012) Taming the groundwater chaos. In: De Stefano L, Llamas M (eds) Water, agriculture and the environment: can we square the circle? Taylor and Francis, Leiden, pp 227-240, Available at: http://www.fundacionbotin.org/file/ 44920/. Accessed 10 May 2014

Millar I (2005) Testing the waters: legal challenges to water sharing plans in NSW. In: Water Law in Western Australia, conference, July 2005. Available via EDOWA. http://www.edowa.org. au/files/presentations/wliwa.Millar.Testing.pdf. Accessed 10 May 2014

National Water Commission (NWC) (2008) Groundwater position statement. NWC, Canberra

National Water Commission (NWC) (2011a) National water planning report card 2011. Australian Government, Canberra 
National Water Commission (NWC) (2011b) The NWI-securing Australia's water future 2011 assessment. Australian Government, Canberra

Natural Resources Commission (NRC) (2013) Water sharing plan reviews. Available via NRC. http://nrc.nsw.gov.au/Workwedo/WaterSharingPlanReviews.aspx. Accessed 10 May 2014

Nebraska Department of Natural Resources (2006) Integrated water management planning process. Brochure, Lincoln

New South Wales (NSW) Office of Water (2013) Water sharing plans under review. Available via NSW Office of Water. http://www.water.nsw.gov.au/Water-management/Water-sharingplans/Plans-under-review/plans-remade. Accessed 10 May 2014

New South Wales Government (NSWG) (2011) Achieving sustainable groundwater entitlements. Available via Office of Water. http://www.water.nsw.gov.au/Water-management/Water-sharingplans/Plans-commenced/achieving-sustainable-groundwater-entitlements-program. Accessed 26 Nov 2013

O'Rourke M, Bailey A (2010) Peel valley water sharing plan, an integrated approach. In: National Groundwater conference, Canberra, 31 Oct-4 Nov 2010

Parsons S, Evans R, Hoban M (2008) Surface-groundwater connectivity assessment. A report to the Australian government from the CSIRO Murray-Darling Basin sustainable yields project. CSIRO, Canberra

Petheram C, Bristow K, Nelson P (2008) Understanding and managing groundwater and salinity in a tropical conjunctive water use irrigation district. Agric Water Manag 9(5):1167-1179

Planas JM (2010) Participación de los usuarios de aguas subterráneas en la gestión y planificación de los recursos hídricos. Paper presented at the symposium on user participation in groundwater management and water resources planning, Valladolid, 27 Jan 2010

Reisner M (1993) Cadillac desert, revised edn. Penguin Books, New York

Rica M, Dumont A, Villarroya F, Lopez-Gunn E, Rica M, Dumont A, Villarroya F, Lopez-Gunn E (2014) Whither collective action? Upscaling collective actions, politics and basin management in the process of 'legitimising' an informal groundwater economy. Water Int 39(4):520-533

Ross A (2012a) Easy to say, hard to do: integrated surface water and groundwater management in the Murray-Darling Basin. Water Policy 14:709-724

Ross A (2012b) Water connecting people adapting. PhD dissertation, Australian National University

Sahuquillo A (2009) La importancia de las aguas subterráneas (coste/uso intensivo/ almacenamiento subterráneo/uso conjunto/protección acuíferos). X Programa de Promoción de la Cultura Científica y Tecnológica. Rev R Acad Cienc Exact Fís Nat (Esp) 103(1):97-114

Schlager E, Blomquist W (2008) Embracing watershed politics. University Press of Colorado, Boulder

Schlager E, Heikkila T, Case C (2012) The costs of compliance with interstate agreements: lessons from water compacts in the western United States. Publius J Federalism. doi:10.1093/publius/ pjs017

Schlumberger Water Services (SWS) (2012) Namoi catchment water study independent expert interim final report. DTIRIS NSW, Orange

SKM (2011) National framework for integrated management of connected groundwater and surface water systems. Waterlines report 57. National Water Commission, Canberra

Tan PL, Bowmer K, Baldwin C (2012) Continued challenges in the policy and legal framework for collaborative water planning. J Hydrol 474:84-91 


\title{
The Social-Environmental Justice of Groundwater Governance
}

\author{
Marian J. Neal (Patrick), Francesca Greco, Daniel Connell, \\ and Julian Conrad
}

\begin{abstract}
Groundwater is but one component of the hydrological cycle. It interacts with and is dependent on how the other components of the hydrological cycle are managed. The rationale for sharing or allocating groundwater is guided by the principle of equitable and reasonable utilization. There is no universal theory of justice to which we can appeal, to help us operationalise this principle to the satisfaction of all water uses and users. Often the losers in allocation decisions are marginal communities or disempowered individuals or groups, and the natural environment. This results in the emergence of a variety of social and environmental injustices, especially if the burden falls continuously on the same group or ecosystem. Social - Environmental justice is a useful lens in the arsenal of researchers, policy makers and natural resource managers that can be used to highlight the importance of a systems approach when dealing with common pool resources such as groundwater.
\end{abstract}

M.J. Neal (Patrick) ( $₫)$

SIWI, Stockholm, Sweden

e-mail: marian.patrick@siwi.org

F. Greco

United Nations-World Water Assessment Programme-UN-WWAP, UNESCO, Perugia, Italy e-mail: francescagreco78@gmail.com

D. Connell

Crawford School, Australian National University, Canberra, ACT, Australia

e-mail: daniel.connell@anu.edu.au

J. Conrad

GEOSS - Geohydrological \& Spatial Solutions International (Pty) Ltd., Stellenbosch, South Africa

e-mail: jconrad@geoss.co.za; http://www.geoss.co.za 


\subsection{Why Justice Matters in Water Governance}

Water allocation is a fundamental part of water governance. It has been described as an unavoidable conflictual process because it is fundamentally a political process and it involves multiple, competing uses and users of water (Allan 2005). The scarcity of water resources, driven by anthropogenic or natural means, exacerbates an already politically sensitive process. Issues of justice arise when resources are, or are perceived to be, in short supply or when access to water resources is restricted or refused (Wenz 1988). In these situations individuals or groups are concerned about getting their fair share and arrangements are made, or institutions created, to manage, allocate and regulate the water resources in question.

This concern about getting one's fair share arises when an individual or group feel that others are either not contributing their fair share to a public good or are taking more than their fair share from a common or communal resource (Schroeder et al. 2003). In water governance this concern revolves primarily around the latter, and can (and has) resulted in winners and losers in water allocation and access. This uneven spread of benefits and burdens presents a problem because the burden of being the loser in a water sharing or allocation arrangement can impact negatively on one's livelihoods or can be detrimental to ecosystem health; and often results in some degree of discontent or even conflict. Often the losers are marginal communities or disempowered individuals or groups, and the natural environment. This results in the emergence of a variety of social and environmental injustices, especially if the burden falls continuously on the same group or ecosystem.

Groundwater resources are increasingly threatened (Chap. 2), with the recent data from the GRACE satellites depicting the rapid rate of decline in almost all the major aquifers in the arid and semi-arid parts of the world (Goldenberg 2014). The continued unsustainable extraction of groundwater is laying the foundation for more discontent and potential conflict over this resource. A recent study of international transboundary aquifers shows that $8 \%$ of transboundary aquifers worldwide are currently stressed due to human overexploitation (Wada and Heinrich 2013).

\subsection{Challenges of Groundwater Governance}

A focus on groundwater management and allocation is important yet it must not cloud the reality that groundwater is but one component of the hydrological cycle and that it interacts and is dependent on how the other components of the hydrological cycle are managed. It also cannot be regarded from a solely hydrological perspective (Chap. 3) - it is linked to other physical systems (soils, ecosystems, oceans, and atmosphere) and importantly to related social, cultural, economic, legal, institutional and political systems (UNESCO 2012).

Successful groundwater governance is challenging because of its interdependence with these other systems. These challenges are exacerbated because groundwater is a resource hidden from view and therefore the impacts of its use are difficult to monitor and evaluate. The importance of groundwater to society is 
overshadowed by the more visible surface water in rivers, lakes and reservoirs, yet the majority of the world's drinking water comes from groundwater and it supports an ever increasing agricultural sector (Giordano 2009). Groundwater allocation and sharing arrangements are further complicated by scientific uncertainties (Chap. 28) - the limited capacity to quantify surface water - groundwater interactions; aquifer recharge rates; and groundwater-dependent-ecosystem responses to fluxes in groundwater quantity and quality.

The rationale for sharing or allocating groundwater can draw on a variety of principles or values that we as human beings have constructed and developed over time to underpin our decision-making processes. In water management the call for equitable and reasonable utilization of water resources is a common guiding principle but it demands reflection on what we mean by equity and how this translates into practice. We need to be able to articulate what principles or values we draw upon to ensure that the outcome of water sharing is considered equitable or just. And herein lies an additional challenge - there is no one correct answer; there is no universal theory of justice to which we can appeal, to help us answer this question to the satisfaction of all water uses and users.

\subsection{Defining Justice}

Justice is a concept that most people commonly associate with the legal system justice will be served when a wrong is righted. In the ambit of ethics something is just if it adheres to the current sanctioned value discourse - the problem being of course is that there is always some disagreement on what that discourse is (Colquitt et al. 2001). The meaning of justice in the context of its role in decision-making and resource allocation is multifaceted and is described in many different disciplines. For the purposes of this chapter, a brief examination of the trends of justice research in the social psychology literature helps define the concept.

In the 1960s and 1970s much of the justice literature assumed that people's sense of justice was concerned with the distribution of outcomes or resources based purely on motivations of self-interest (Skitka and Crosby 2003). Equity theory provided the prominent distribution or outcome orientated viewpoint. Equity is achieved according to Adams (1963) when a person's rewards or outputs are perceived to be in proportion to that person's inputs or contributions. In other words equity is affected by what is termed the contributions rule (Leventhal 1976), where a person who contributes greater should receive higher rewards or outputs. ${ }^{1}$ There were some challenges to this mainstay theory. Deutsch (1975) introduced two additional rules that determine how rewards or outputs could be

\footnotetext{
${ }^{1}$ It is assumed that the use of terms 'equity' and 'equitable' in many water laws, regulations and strategies do not intend to use it in this narrow sense but rather in a broad justice sense- this however does contribute to some of the confusion over the use of term and its implications for water allocation.
} 
distributed, these are the needs rule, where a person who has a greater need should receive higher rewards or outputs; and the equality rule, where everyone should receive equal rewards or outputs regardless of their needs or contributions. Equity (or contributions), needs and equality are rules that are used to determine how resources or rewards could be distributed. They are often referred to in the literature as the distributive justice rules.

These 'rules' however all focus on the distribution of outcomes or allocation of resources. During the late 1970s and 1980s research shifted from distribution to procedural issues. Thibaut and Walker (1975) (and Deutsch and Leventhal) expanded the notion of justice to include not only distribution rules but also procedural rules. They contend that the manner or procedures in which the allocation of rewards or outputs are decided is also critical for determining what is just. The main premise of procedural justice is that the output or final distribution of resources is more likely to be accepted as just or fair ${ }^{2}$ if the manner in which the decision was made is deemed to be just or fair by the affected parties. In the 1980s and 1990s, since Thibaut and Walker's initial ideas on procedural justice, many more facets of procedural justice have been posited as important to defining procedural justice. They include inter alia the need for consistency, accurate information, opportunity to correct decisions, representation of all affected parties, interpersonal behaviour, articulation of reasons for allocation decisions, accountability and treating affected parties with respect (Brockner and Wiesenfeld 1996; Gross 2011).

Distributive and procedural justice provide some insight into the complexity of defining and understanding justice especially in the context of water resources governance where both distributional and procedural rules apply. If however we delve a little deeper into the literature, the concept of justice becomes even more textured and layered. There are many models of justice which attempt to provide an underlying or unifying explanation of why we make the decisions we do, and how we should make decisions in specific contexts. This Holy Grail - that there exists a unifying theory of justice - has not yet materialised, and is unlikely to in the near future (Wenz 1988). The reality is that there are many competing principles or perspectives of justice that can be used to make convincing arguments for the advocacy of quite contrary positions.

There is an extensive history and array of research that has contributed to the development of the many theories of justice; and a wide ranging review would not be appropriate for the purpose of this chapter. The aim here rather is to present a brief overview that provides sufficient background on the range of existing justice theories but also focuses on some that are relevant to groundwater governance. Bearing this in mind, four families of theories are described in Table 10.1: they are an economic family, a rights-based family, a social family and an environmental family. The description of each theory is a summary adapted from Wenz (1988) who provides a more detailed overview of a number of models and theories of justice.

\footnotetext{
${ }^{2}$ The terms fair or fairness is often used in the social psychology literature rather than the terms just or justice - in this chapter they are considered synonymous and are used interchangeably.
} 
Table 10.1 A non-exhaustive summary of the various justice theories, principles and models (Adapted from Wenz 1988)

\begin{tabular}{|c|c|c|}
\hline \multirow[t]{4}{*}{$\begin{array}{l}\text { The economic } \\
\text { family }\end{array}$} & \multicolumn{2}{|c|}{$\begin{array}{l}\text { Efficiency is the driving force behind this family of justice theories where } \\
\text { maximising surplus is advocated. This family is represented by the following: }\end{array}$} \\
\hline & $\begin{array}{l}\text { Libertarian } \\
\text { theory }\end{array}$ & $\begin{array}{l}\text { Provides an underlying rationale for settling all issues of } \\
\text { justice through the free market (and the courts). People } \\
\text { have the right to be able to buy and sell whatever they want } \\
\text { so long as they don't use force or fraud }\end{array}$ \\
\hline & $\begin{array}{l}\text { Efficiency } \\
\text { theory }\end{array}$ & $\begin{array}{l}\text { Is similar to libertarian theory in that it advocates a free } \\
\text { market where there is a minimal State that protects private } \\
\text { property but does not interfere with the economy. It differs } \\
\text { in the means to achieving this goal in that it advocates } \\
\text { maximum efficiency rather than the right to liberty and } \\
\text { private property as its central tenet }\end{array}$ \\
\hline & $\begin{array}{l}\text { Cost-benefit } \\
\text { analysis }\end{array}$ & $\begin{array}{l}\text { Although a technique rather than a theory, cost-benefit } \\
\text { analysis is often used in decision making. It is underpinned } \\
\text { by the principles of Efficiency and Utilitarian (see below) } \\
\text { theory. CBA analyses alternative courses of action based } \\
\text { on the costs and benefits (primarily expressed in monetary } \\
\text { terms) associated with each, and recommends the option } \\
\text { with the greatest benefits and/or lowest costs as the most } \\
\text { desirable choice }\end{array}$ \\
\hline \multirow{3}{*}{$\begin{array}{l}\text { The rights- } \\
\text { based family }\end{array}$} & & \\
\hline & Human rights & $\begin{array}{l}\text { Provides a means of settling disputes by appealing to } \\
\text { fundamental human rights. These comprise negative rights } \\
\text { which are rights to non-interference (e.g. people's life, } \\
\text { liberty, expression, religion or property) and positive } \\
\text { rights which are rights to assistance (e.g. health, education } \\
\text { and wellbeing). In } 2010 \text { the UN General Assembly } \\
\text { amended the Declaration of Human Rights to include the } \\
\text { right to water and sanitation as a human right (UN 2010) }\end{array}$ \\
\hline & Animal rights & $\begin{array}{l}\text { Provides a means of settling disputes by appealing to } \\
\text { fundamental animal (or non-human animal or subjects-of- } \\
\text { a-life) rights. Animal rights comprise negative rights such } \\
\text { as right to life and freedom, and apply to wild animals. In } \\
\text { most countries positive animal rights only come into play } \\
\text { when dealing with domesticated animals }\end{array}$ \\
\hline \multirow[t]{3}{*}{$\begin{array}{l}\text { The social } \\
\text { family }\end{array}$} & \multicolumn{2}{|c|}{$\begin{array}{l}\text { These theories generally reflect a concern for the welfare of society. Two of } \\
\text { the most popular and well known theories are: }\end{array}$} \\
\hline & $\begin{array}{l}\text { Utilitarian } \\
\text { theory }\end{array}$ & $\begin{array}{l}\text { Provides a rationale for making decisions, taking action } \\
\text { and designing policies that produce the greatest good. This } \\
\text { theory supports decisions that maximise happiness or } \\
\text { preference satisfaction, and is laudable in its aim to } \\
\text { improve the wellbeing of all people }\end{array}$ \\
\hline & $\begin{array}{l}\text { Rawls' theory } \\
\text { of justice }\end{array}$ & $\begin{array}{l}\text { Rawls offers a hybrid theory that reconciles the } \\
\text { consideration of rights and utility. The basic premise of the } \\
\text { theory is that decisions can be made based on which } \\
\text { alternatives offer the most help for the worst off or that the } \\
\text { worst possible outcome is made as good as it can be. Thus } \\
\text { decisions are made on principles that are considered fair } \\
\text { for everyone without any prejudice }\end{array}$ \\
\hline
\end{tabular}


Table 10.1 (continued)

\begin{tabular}{l|l|l}
\hline $\begin{array}{l}\text { The } \\
\text { environmental } \\
\text { family }\end{array}$ & $\begin{array}{l}\text { These theories focus on ecosystem and environmental concerns, values } \\
\text { and/or rights; and shine a light on the need to take the environment into } \\
\text { account when making decisions about natural resource management and } \\
\text { allocations; they are important when sustainability issues are taken seriously }\end{array}$ \\
\hline $\begin{array}{l}\text { Biocentric } \\
\text { individualism }\end{array}$ & $\begin{array}{l}\text { Is not a justice theory per se, but is a perspective that } \\
\text { contributes to the discussion. It is based on the belief that } \\
\text { there is value in every living thing and that people have an } \\
\text { obligation to take this value into consideration whenever } \\
\text { their actions affect living things }\end{array}$ \\
\hline $\begin{array}{l}\text { Ecocentric } \\
\text { holism }\end{array}$ & $\begin{array}{l}\text { Is a view that people should limit their activities out of } \\
\text { concern for the continued existence of a species and the } \\
\text { continued health of ecosystems. It is also not a theory per } \\
\text { se, but offers an additional view point that considers the } \\
\text { broader environment in decision making }\end{array}$ \\
\cline { 2 - 3 } & $\begin{array}{l}\text { Often referred to when development has the potential to } \\
\text { impact negatively on the environment. Where there is a } \\
\text { risk of irreversible harm or damage, the absence of } \\
\text { principle } \\
\text { developencent cannot be used as a reason to proceed with }\end{array}$ \\
\hline
\end{tabular}

The array of rules, theories and principles that can be called upon in order to determine on what basis water resources can be shared and allocated between users is vast and not only are they used in the allocation context, they are also used in determining who should be included or count as a potential water user and who is not, before any discussion on water allocation and access is initiated.

\subsection{Why Justice Should Be Considered in Groundwater Governance}

Even though justice is a complex, nebulous concept, it is imperative to give it due consideration since the consequences of not doing so can undermine the best groundwater management intentions. By articulating the practical meaning of equitable distribution of resources, the concept of justice also serves to illustrate the importance of a systems thinking approach when developing groundwater management plans or when managing conflict over scarce water resources.

The following case studies highlight the importance of considering groundwater as part of an inter-dependent web of systems, and the necessity of including local communities and the environment in the decision-making and allocation process in order to avoid or ameliorate potential social and/or environmental injustices.

\section{Case Study 1: The Daly River, Northern Territory, Australia}

Hydrological systems of the Northern Territory in Australia are currently the subject of a national debate about whether they should be used to support the expansion of irrigated agriculture in that region. A central focus is the Daly River 
catchment just south of Darwin. During the dry season it is one of the few rivers with flow. The Daly system does not have potential sites for large dams, therefore any expansion of irrigation would need to be based on withdrawals from groundwater or directly from the river itself which is sustained during the long dry season by groundwater inflows originating upstream. These groundwater systems currently support a mosaic of many dependent ecosystems with high biological diversity. They would be severely impacted if irrigation development goes ahead as proposed (Blanch et al. 2005).

When irrigation is supplied by releases from dams or directly from surface runoff it is usually the case that the greater the volume of extractions the more intense will be the impacts on the environment. With groundwater dependent ecosystems in the Northern Territory this pattern is reversed (DNREA 2006). It often takes only a relatively small level of extraction for the groundwater table to no longer intersect with the low lying parts of the land surface where it previously created permanent and semi-permanent wetlands. This can transform a landscape with many wetlands into a dry dusty semi desert (Blanch 2004).

The Daly River catchment includes the town of Katherine, the fourth largest in the Northern Territory and Pine Creek both with substantial Indigenous populations as well as Nauiyu, a wholly Indigenous community (Fig. 10.1). There are at least

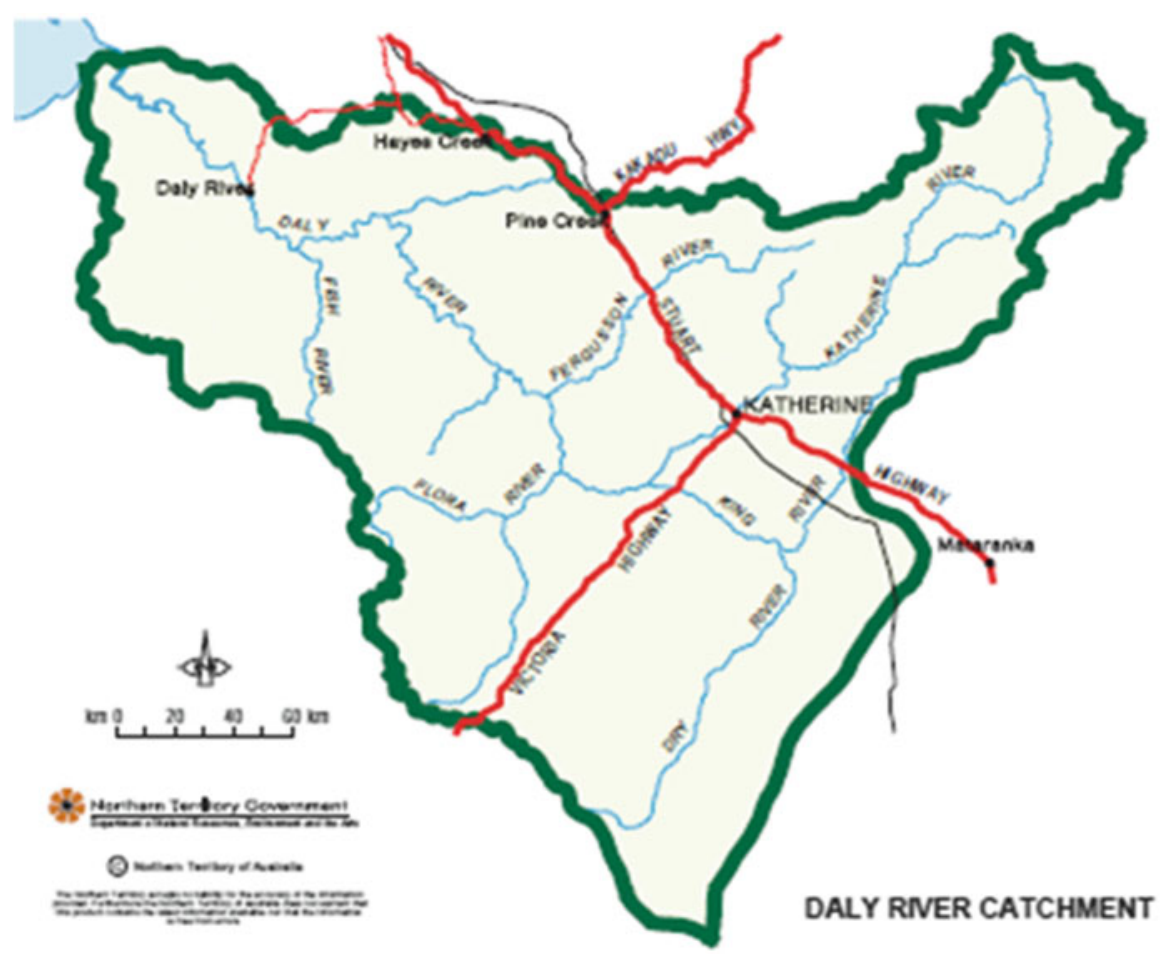

Fig. 10.1 Location of Daly River catchment, Northern Australia 
ten Indigenous language groups in the region. The current landscape with its many wetlands is of great cultural significance to the Indigenous peoples of the region. Indigenous people make up about $25 \%$ of the population of the Northern Territory and manage more than $30 \%$ of its area.

In addition to the threats from proposals for future development the clear waters of the Daly River are already under pressure from current agricultural and pastoral activities that are causing increased sedimentation. High levels of water clarity are needed to support the growth of aquatic plants such as Vallisneria nana - the key food source for pig-nosed turtles. A very significant species for the local Indigenous communities, this species of turtle is found in only a few rivers in Australia and Papua New Guinea. It is highly vulnerable because of its nutritional dependence on this single food source and its unusual breeding process. The favoured nest sites are fine sand riverine banks in the middle and lower reaches of the Daly River. Turtles rely on warm water discharged from springs to keep warm. During reproduction the females rarely move from these places. The sex of young turtles is determined by the temperature of the water within which they hatch. If water levels are reduced due to water extraction for irrigation, nests may dry out earlier and become hotter thereby reducing the percentage of males which only hatch in cooler nests (Blanch et al. 2005).

Indigenous interests in water are a complex mix of culture and economics, the latter term covering everything from traditional activities such as hunting, fishing and gathering wild plants to eco-tourism and to irrigated agriculture. The National Water Initiative (NWI) approved by the Council of Australian Governments in 2004, placed a very high priority on the need to take account of Indigenous interests in water planning and management. However, the NWI was frustratingly vague about how that should be done and some of its elements make it hard to achieve change. For example, the separation of entitlements to water from titles to land in order to promote water trading creates a serious challenge because it undermines the Indigenous conception that land and water are integrally connected. According to Jackson (2004), Indigenous interests do not translate easily into Western environmental management frameworks which are based on objectification and quantification. The concept of environmental flows, especially when costed in monetary terms, is an example of this tendency to define everything in quantifiable units so that they will be easy to compare and allocate.

Drawing on a large body of research, Jackson (2005) has described a relationship between water and Indigenous people which is more complex than that of European settlers in the region. She argues that in the latter case the cultural dimension is a diffuse and poorly articulated aesthetic and emotional response that tends to be secondary to the focus on economic goals defined in monetary terms. Indigenous connections are more complex and can only be reduced to monetary values with a significant loss of cultural meaning and richness. For example Western systems give priority to land as measured and allocated to particular owners as the basic unit for natural resource management. To a limited extent Indigenous interests in land can be taken into account with this approach but developing a similar approach for water has proved difficult. Jackson et al. (2005) have argued that this is one reason why there has been greater recognition of Indigenous relations with land rather than 
with water and the wider ecological system (Jackson 2006). Arguably this disproportionate emphasis on land rather than on the ecosystem as a whole has led to a serious underestimation of the importance of water to Indigenous people. This is despite the commitment contained in the National Water Initiative which states that water plans must take account of Indigenous issues by making arrangements for Indigenous representation in water planning 'wherever possible' and provision for indigenous social, spiritual and customary objectives 'wherever they can be developed'. They should also include allowance for 'the possible existence of native title rights to water in the catchment or aquifer area' (National Water Commission 2004, paras 52-54). Given the long delays in implementing these commitments it is likely that land and water policy in northern Australia will be highly contested in coming years.

The proposed extraction of groundwater within the Daly River region for increased agricultural production needs to weighed against the potential impacts on the groundwater dependent ecosystems, their supporting flora and fauna such as Vallisneria nana and pig-nosed turtles, and most especially the fragile links with sites and species of cultural significance to the local Indigenous communities. Disregard of the interdependencies of economic, social and environmental uses of water in Daly River catchment could result in social and environmental injustices with long term impacts.

\section{Case Study 2: The Disi Aquifer: Saudi Arabia and Jordan}

Jordan is one of the most arid countries on earth. The residents of Amman, the capital of Jordan, receive running water twice a week (prior to 2002 it was only once a week). The majority of the population lives in the Greater Amman area in the North, an urban conglomerate which is also a final destination for refugees from Iraq, Syria and, historically, from Palestine. The Disi Aquifer lies south of Amman, between the South of Jordan and the northern part of Saudi Arabia (Fig. 10.2). The majority of the aquifer is located in Saudi Arabia. By the 1990s, Saudi Arabia was extracting nine times as much water as Jordan and in 1992 Jordan accused the Saudis of overpumping, but the Saudi government did not respond in any way to the accusation (Shapland 1997).

The Disi Aquifer (called the Saq aquifer in Saudi Arabia) is a reservoir of fossil water, $3,000 \mathrm{~km}^{2}$ wide, with exploitable reserves estimated around 6,250 MCM (million cubic meters) (Foster and Loucks 2006), it has a minimal recharge such that it is considered 'non-renewable' in all major international classifications (USGS 2013). There is no bilateral treaty between Jordan and Saudi Arabia; despite that, a memorandum of understanding has long been due between the two countries, as they have so far not reached a formal agreement over the use of this shared water resource. During the 1980s and the 1990s, the Jordanian side of the overlying fields, around 10,000 ha, has been rented to agri-business companies in order to produce different export crops and, later on, also fruits and vegetables, consuming around $75 \mathrm{MCM} / \mathrm{year}$ and not paying any water fees (Ferragina and Greco 2008). When agri-business companies were granted the land in the 1980s, the concept of 'transboundary groundwater' barely existed. The agri-business companies exploiting the Disi aquifer on the Jordanian side were given incentives to exploit 


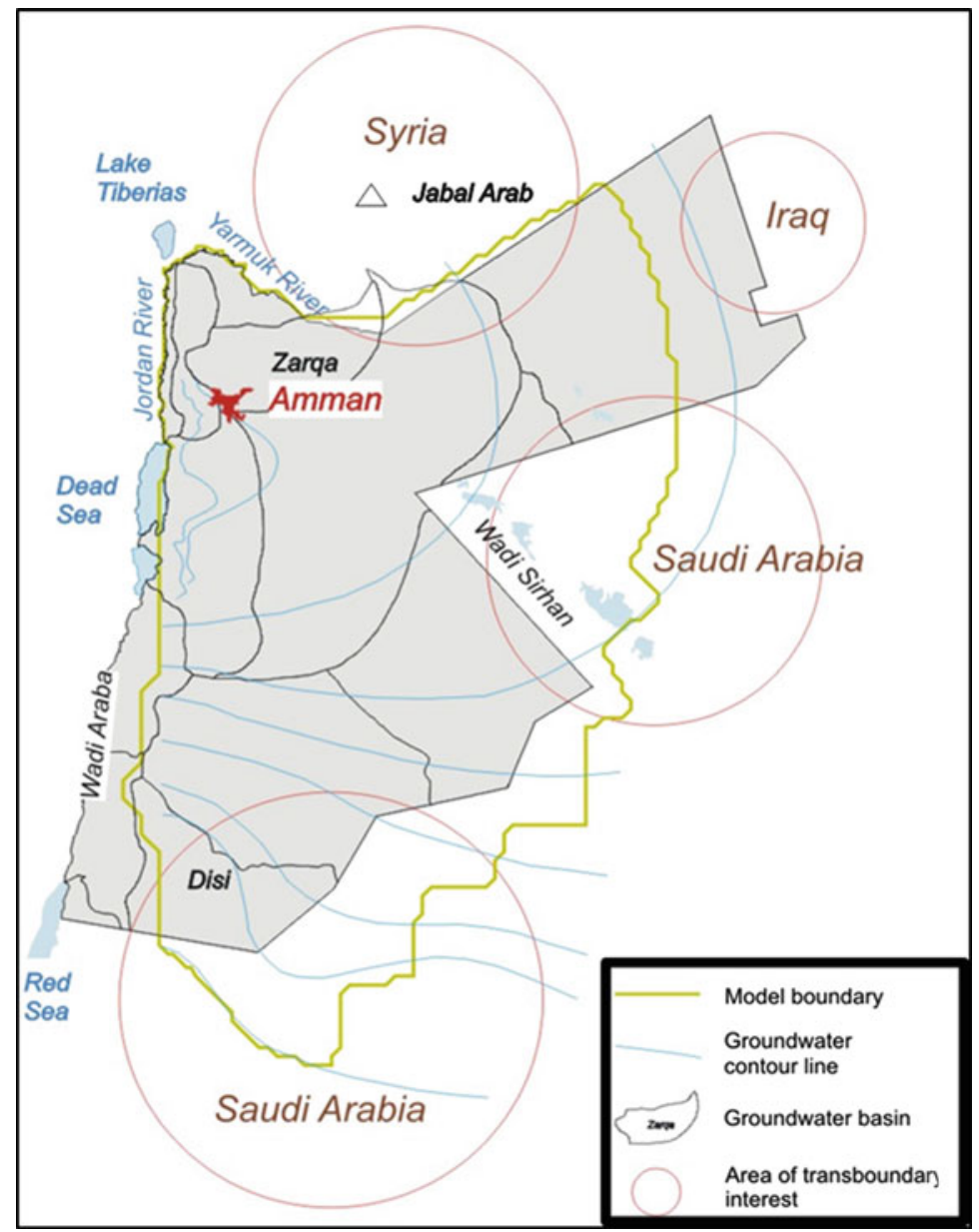

Fig. 10.2 Location of Disi Aquifer (Source: BGR 2013)

the resource in the $1980 \mathrm{~s}$, this encouragement ended in recent times due to a planned alternative use of the Disi water: to supply Amman via a $350 \mathrm{~km}$ long pipeline. When the planning for pipeline project was initiated, the agri-business companies were given a deadline; they were to cease farming before the end of 2012, in order to stop pumping the water from the aquifer, and in order to allow the diversion of all the resources to the capital city of Amman.

The World Bank did not agree to fund the pipeline project because of the lack of a bilateral treaty between Jordan and Saudi Arabia; which was judged by the bank as a preliminary condition for the good outcome of the project. Today, the pipeline is almost completed, funded by other international lenders such as Agence Française de Développement (AFD), the European Investment Bank (EIB), the Overseas Private Investment Corporation (OPIC), and the Promotion et Participation pour la Coopération économique (PROPARCO). The main problem with this 
project was that it was a top-down approach, where consultation with the local populations of the desert and the Bedouin groups remained very low. The construction of the pipeline has been contested, resulting in two workers being killed by the local Bedouins, who were asserting that the project company did not include them in the economic benefits of the work in general and, particularly by not renting their trucks for transportation tasks (BBC 2011).

Social considerations regarding the rights of local people were not taken into account; they feel they do not benefit enough from the water being abstracted and brought directly to the North, and have suggested a revision of the Project Company's Environmental and Social Management Plan. The legacy of social exclusion was also evident at the time when agri-businesses were using fossil water for irrigation, in order to export crops. The rights of the local Bedouins to benefit from that water were ignored; the rights of the agri-businesses and global consumer were prioritised over the local communities. The question of 'prior use rights' for local populations of arid countries over their non-renewable water resources were raised. 'Prior use, or historical right' is internationally recognized as a tool for negotiations of international treaties and agreements among States, however a 'prior use right' cannot be established at a lower scale: at the individual level. This is why a local Bedouin from the Disi area cannot claim any prior right over a foreign citizen consuming a watermelon irrigated from the Disi. International water law is promoting the principles of 'equitable use and no harm' in the management of shared water, but only among State-entities or sub-regional institutions, not among individuals. Herein lies the problem of how to deal with 'water rights' and 'environmental justice'. There exists a gap between the meaning of justice and equity for individuals and 'equitable use' in international water law.

Another important consideration that must not be ignored is the interaction of virtual water and the Disi groundwater dispute over time (Greco 2013). If we look at the storyline of the project, the agri-business companies can be considered a "virtual water flow" exporting Disi water outside the country. This virtual water flow started when there was no concern about the transboundary nature of the aquifer, but at a later stage of analysis, it is influencing the hydro-politics of this transboundary groundwater basin. As a matter of fact, after the creation of this virtual water flow, Jordan acquired a de-facto right to pump water over Saudi Arabia. While Saudi abstractions started earlier than on the Jordanian side, the virtual water flow has changed the position of Jordan forever, in view of a possible bilateral treaty between the two countries. The allocation of the Disi water will be switched from agriculture to urban supply, thus stopping the virtual water flow. Nevertheless, the Jordanian 'acquired right', created thanks to the virtual water flow, will be a 'de-facto' situation that will play a role in any future development of a bilateral agreement between the two countries. Even if the urban supply should start in 2014 or even later, Jordan will always be in a position to claim that Disi water had been pumped by Jordan since the 1980s. This is a good example of how virtual water can alter and drive power relations in transboundary water issues and, more in general, in hydro-political complexes (Greco 2012).

Social justice, environmental justice, the impact on future generations and the threat of a sudden depletion of the aquifer are all part of this emblematic case of 
groundwater exploitation. As long as there is no bilateral treaty in force, no precise projection of the duration regarding the water provision for Amman, no regulation of environmental and social balance between local, national and international water-consumers, and between current and future generations, the Disi will be "pumped to the bottom", until the very last drop.

\section{Case Study 3: The Sandveld, Cape West Coast, South Africa}

The northern Sandveld, situated approximately $250 \mathrm{~km}$ north of Cape Town, consists of a coastal plain along the west coast of South Africa (Fig. 10.3). It is bordered by the Olifants River catchment in the north and east, the Berg River in the south and the Atlantic Ocean in the west. It is a sandy area comprising granular primary aquifers and deeper fractured rock secondary aquifers, with a high degree of connectivity between the aquifers. The Sandveld is primarily comprised of three parallel seasonal river systems, namely the Jakkalsvlei River, the Langvlei River and the Velorenvlei, as well as a number of smaller systems. The catchments drain westwards through the Sandveld and consist of a combination of rivers, pans and wetland systems. The Ramsar designated Velorenvlei wetland system is the best known of the three systems (DWAF 2008).

The northern Sandveld $\left(4,827 \mathrm{~km}^{2}\right.$ in area) is a rural area with extensive farming, a few towns (Lambert's Bay, Elands Bay, Graafwater, Leipoldtville, Paleisheuwel and Redelinghuis), with fishing and tourism developments along the coastline. Most of the towns, as well as all agricultural developments in the region are supported from groundwater supplies. The main agricultural activity within the study area is the cultivation of potatoes. The water balance for the area (obtained by taking into account groundwater recharge minus discharge and abstraction estimates) ranges from $4 \%$ to $106 \%$ (i.e. significant over-abstraction). This is supported by observed dropping of groundwater levels in this over-abstracted area (DWAF 2006).

Potato farming, primarily is under centre-pivot irrigation systems and is the economic mainstay of the coastal plain. The potato industry employs some 3,250 workers. Between 6,000 and 7,000 ha of potatoes are planted annually in the Sandveld for the production of seed potatoes, potatoes for the fresh market and potatoes for the processing industry (French fries, crisps and frozen products). To limit the carry-over of soil borne diseases a rotation of up to 5 years is specified for the production of seed potatoes. In practice, a farmer wanting to cultivate 20 ha of seed potatoes would need to clear four 20 ha circles ( $80 \mathrm{ha}$ ) and would cultivate one circle per year, moving the centre pivot to the appropriate field each year. Nearly all plantings are irrigated. Farming input costs are high and environmental and other farming conditions often pose great challenges to the farmer in maintaining a viable enterprise (Knight et al. 2007).

Most of the native vegetation, which is being cleared for the cultivation of potatoes, is described as an open semi-succulent scrub of Fynbos form intermediate between Coastal Fynbos and Succulent Karoo (Acocks 1988). The total number of centre pivots in the potato production area of the Sandveld has been calculated as 1,773 (with a combined area of 30,740 ha) using satellite imagery (2003/2004) (Knight et al. 2007). Land clearing has a significant impact on the ecology of the 


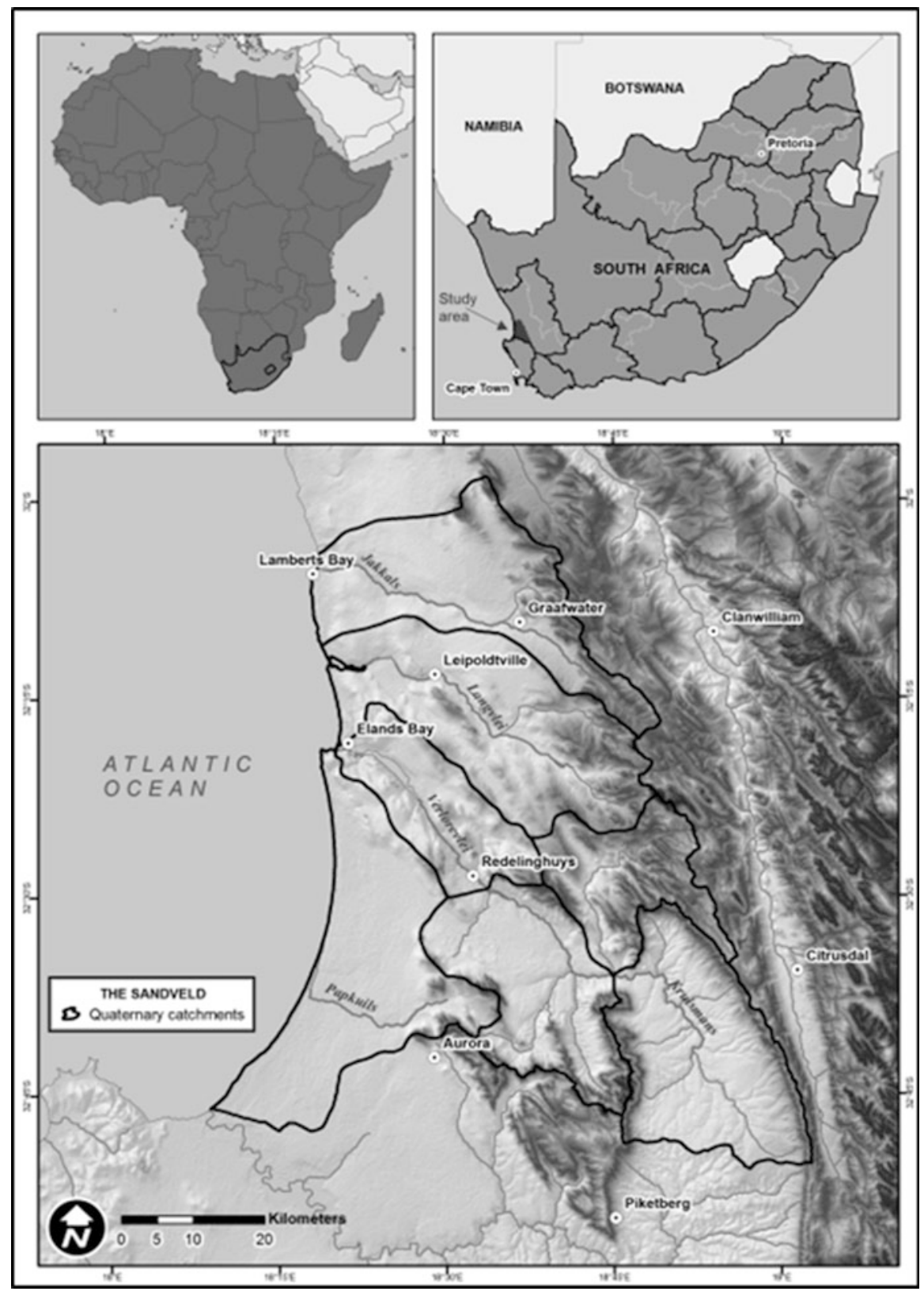

Fig. 10.3 Location of Sandveld, South Africa 
area because once the land is cleared it will never recover to its natural state. Based on broad water balance calculations for the northern Sandveld (which vary from year to year), approximately $64 \mathrm{Mm}^{3} / \mathrm{a}$ is received as groundwater recharge from precipitation; the amount of groundwater required for full ecological functioning is $\sim 29 \mathrm{Mm}^{3} / \mathrm{a}$, the volume of groundwater abstracted for irrigation is $\sim 51 \mathrm{Mm}^{3} / \mathrm{a}$ and the volume of groundwater abstracted for municipal supply equates to $\sim 1 \mathrm{Mm}^{3} / \mathrm{a}$. Thus it is evident that the agricultural abstraction impacts significantly on the ecological functioning of the area. It has been observed that certain wetlands have desiccated, certain spring flows have reduced, groundwater levels have dropped in places with an associated deterioration in groundwater quality and in one area salt water intrusion has occurred. These impacts are particularly noticeable at the lower end of the catchments where production boreholes are too closely spaced (and typically where groundwater is abstracted for multiple purposes e.g. town supply and agricultural needs).

The intense development of good to marginal quality groundwater in coastal aquifers makes the water resources vulnerable to long-term over-abstraction and the intrusion of poor quality groundwater and/or seawater. Proper resource assessment, abstraction plans and monitoring is crucial for sustainable use of groundwater in these coastal areas, where agricultural interests in the catchment must also be served.

There have been many initiatives to address and protect the long term viability of the resource. Some of them include: Environmental Water Reserve studies have been completed and approved; Water User Associations have been established; monitoring is being continued in the area and a Sandveld Integrated Water Resource Management (IWRM) Plan (that will give clear guidance on the way forward for an equitable and sustainable use of the water resources within the area), has been developed. In addition the umbrella organisation of the potato industry, Potatoes South Africa, has invested in the long term monitoring of the impacts of the potato agriculture on the groundwater resources of the Sandveld. The importance of responsible groundwater use has been emphasized to the farmers within the area and there is an increased awareness of the importance of groundwater and its conservation. The northern Sandveld is a complex area where social, economic and environmental water needs are all inter-dependent and a careful balance is required to meet all the demands on the water resources of the area to ensure its long term viability.

\subsection{Synthesis}

The case studies described above illustrate how the natural environment in general and the groundwater resource in particular underpins a broad range of social, political and economic activities, and why it is important to act cautiously when exploiting a resource with many unknowns, most especially unknown extraction limits before negative ecological impacts ensue. In both the Disi Aquifer and the Sandveld case studies it is apparent that the long term prospects of the social and 
economic activities will be undermined if there is no due consideration for the environmental limits of the underpinning groundwater resource. Not only are there direct injustices caused by environmental degradation and reduced groundwater for subsistence agriculture, but the injustices can also spill out of the environmental and social domain into the economic domain and impact on the long term sustainability of large agro- producers and exporters. In other words 'the ability to meet the needs of the present without compromising the ability of future generations to meet their own needs' (WCED 1987) is threatened.

The social dilemma posed by water allocation decisions centres on who or what use should get priority and in what circumstances. In the Daly River case study the dilemma is whether water should be distributed for environment and cultural uses or for irrigated agriculture. In the Disi Aquifer case study the allocation dilemma has arisen because of a change in allocation rules; initially the rationale for allocation was primarily economic driven but now increasing social demands (urban water use) is shifting the priority of use and is causing problems. The distributional dilemma can also be framed as one of long term vs short term, illustrating how important the temporal aspect is in justice considerations; for the Disi and the Sandveld it is a case of long term environmental sustainability of the resource vs the shorter term economic activity of irrigated agriculture.

The process of inclusion and exclusion of certain stakeholders or interests has been examined in the justice literature and falls within the discourse of procedural justice and public participation. Susan Opotow explores it in the context of environmental conflicts and has termed it the scope of justice (Opotow and Weiss 2000). The scope of justice, also known as the scope of moral exclusion, has been defined as the psychological boundary for fairness (Opotow and Weiss 2000) or the boundary within which justice is perceived to be relevant (Hafer and Olson 2003). Principles of justice govern our conduct towards those within our scope of justice, while moral exclusion rationalises the denial of those outside our scope of justice (Opotow and Weiss 2000) and thus enables and rationalises the application of justice principles (such as those described in Table 10.1) in an inconsistent or even in an unjust manner. In the Disi case study groundwater resources are being mined - this is old water i.e. a non-renewable resource - the significance of this fact and future environmental interests are not taken into account or included within the scope of justice. In addition the local communities' interests are not taken into account - i.e. not included in the scope of justice - therefore there are problems arising because procedural justice rules haven't been adhered to. In the Sandveld case study all interests have been taken into account - social inclusion and procedural justice issues are considered; the justice question here centres on whether long term needs vs short term gains will take priority.

Each case study has a number of proponents that will construct their argument for why they believe they should receive priority of water use from the families of justice outlined in Table 10.1 -the ultimate question is which one makes the case that will result in just and equitable outcomes and more importantly where the burdens of the unjust outcomes will fall if social and environmental justice is not the overarching goal. 


\subsection{Joining the Dots: Justice, Governance and Sustainability}

Water governance can be defined as a system for managing water according to objectives that reflect the goals of society. This system includes various organisations such as government departments, non-government organisations and civil society groups, and a range of institutions such as principles, policies, regulations, legislations and social norms that operate at a variety of levels (Ashton et al. 2005; North 1990). As environmental discourses and water management paradigms have evolved, so too have the structure and mandate of water governance systems.

The link between sustainability and justice has been explored at the conceptual level and has been termed Just Sustainability by Agyeman (2005a, b). Just Sustainability is best described by briefly recapping the origins of both environmental justice and sustainability. Environmental justice rose to prominence shortly after the civil rights movement in the United States of America and focused on the locating of toxic waste sites in close proximity to minority residential communities. Rallying around this and other forms of environmental racism led to the emergence of grassroots activism that protested against development and policy that did not embrace the principle that all people and communities are entitled to equal protection under environmental and public health laws and regulations (Towers 2000). The definition and scope of environmental justice has evolved since this initial movement around local environmental hazards and is now widely acknowledged and understood by many environmental justice organisations to include broader social justice considerations (Agyeman and Warner 2002). It does however run the risk of focussing too narrowly and solely on the community level in finding solutions to injustices.

The concept of sustainability emerged from the opposite end of the spectrum - a global rather than a grassroots phenomenon. Although its beginnings pre-date the 1972 United Nations Conference on the Human Environment in Stockholm, sustainable development was popularised through this event; and then progressively mainstreamed into our collective consciousness and policies through the 1983 World Commission on Environment and Development and the subsequent publication of Our Common Future in 1987; the 1992 World Summit in Rio de Janeiro and the publication of Agenda 21; the 2002 World Summit for Sustainable Development in Johannesburg and the publication of the Plan of Implementation, and lastly the 2009 World Conference on Education for Sustainable Development held in Bonn and the publication of the Bonn Declaration. Sustainable development emerged as a response to the recognition that many of the environmental problems that we currently face are now manifest at a global level and that individual NationStates or a piecemeal response to these problems would be unsuccessful in addressing them. Sustainability has now become a "higher order social goal" (Dovers 2005, p. 8). It aims to address the bigger picture but it can potentially lose sight of the social justice dimension of meeting the needs of current generations. 
One of the major tensions between the two concepts is scale related. Environmental justice claims are often initiated at the local - grassroots - community level, while calls for sustainability are usually more strategic in nature and are often initiated at the regional, national or international level. The proponents of sustainable development have recognised the conflict between the need for an overarching vision and the practical implementation of action plans at a more local level through the Local Agenda 21 programme and the Johannesburg Plan of Implementation; but there is still continuing and growing poverty and environmental degradation. This tension presents an opportunity for synergy between the two concepts - the strengths of one make up for the weaknesses in the other. It is clear that there exists an imperative to include justice issues into the higher social goal of sustainability, but it cannot be achieved if there is a perpetuation of social exclusion, be it racism or classism, or the exclusion of any other social, economic or environmental voice. Agyeman suggests this revised rationale for sustainability: "The need to ensure a better quality of life for all, now and into the future, in a just and equitable manner, whilst living within the limits of supporting ecosystems" (2005b, p. 17).

\subsection{Conclusion}

Social - Environmental justice is a useful lens in the arsenal of researchers, policy makers and natural resource managers that can be used to highlight the importance of a systems approach when dealing with common pool resources such as groundwater - it can highlight the inter-connectedness of systems and the potential social, economic and environmental consequences of disregarding this inter-dependency.

Three important and necessary questions that a justice perspective offers that are likely to improve groundwater governance if answered include:

1. What underlying 'rules' have been used to make a water allocation decision. Have both distributional justice and procedural justice rules been taken into account?

2. Which justice theory, model or principle has been used as the rationale for how the water resource is shared? Does the underlying rationale draw from the economic, social, rights-based or environmental family of justice theories (or a combination of families) and how does this potentially influence the outcome?

3. Who or what has been included and excluded from the scope of justice or scope of the decision-making process and for what reasons?

It is important to be explicit about answering these challenging questions because if the social, political, economic and environmental aspects of groundwater management are not taken into account, this could and has led to reduced groundwater levels to such an extent that sites of cultural significance are lost, local and small scale subsistence farmers have no access to water, tensions between countries might arise over shared water resources, native biodiversity is lost and the long term investment in commercial agriculture is threatened. 
Open Access This chapter is distributed under the terms of the Creative Commons AttributionNoncommercial 2.5 License (http://creativecommons.org/licenses/by-nc/2.5/) which permits any noncommercial use, distribution, and reproduction in any medium, provided the original author(s) and source are credited.

The images or other third party material in this chapter are included in the work's Creative Commons license, unless indicated otherwise in the credit line; if such material is not included in the work's Creative Commons license and the respective action is not permitted by statutory regulation, users will need to obtain permission from the license holder to duplicate, adapt or reproduce the material.

\section{References}

Acocks JPH (1988) Veld types of South Africa, 3rd edn. Memoirs of the botanical survey South Africa no 28. Government printer, Pretoria

Adams JS (1963) Toward an understanding of inequity. J Abnorm Soc Psychol 67:422-436

Agyeman J (2005a) Sustainable communities and the challenge of environmental justice. New York University Press, New York

Agyeman J (2005b) Where justice and sustainability meet. Environment 47:10-26

Agyeman J, Warner K (2002) Putting 'just sustainability' into place: from paradigm to practice. Policy Manag Rev 2:8-40

Allan JA (2005) Water in the environment/socio-economic development discourse: sustainability, changing management paradigms and policy responses in a global system. Gov Oppos 40 (2):181-199, Blackwell Publishing, Oxford

Ashton PJ, Patrick MJ, Mackay HM, Weaver A (2005) Integrating biodiversity concepts with good governance to support water resources management in South Africa. WaterSA 31:449-456

BBC (2011) BBC monitoring Middle East. BBC, London. http://search.proquest.com/docview/ 822342242. Accessed July 2013

BGR (2013) Groundwater basins and transboundary aspects in Jordan. www.bgr.bund.de. Accessed June 2013

Blanch S (2004) Submission-in-progress to the water allocation plan for the Daly region. World Wildlife Fund for Nature Australia, Darwin

Blanch S, Rea N, Scott G (2005) Aquatic conservation values of the Daly River catchment Northern Territory, Australia. A report prepared by World Wildlife Fund. Charles Darwin University, and the Environment Centre NT, WWF Sydney, Sydney

Brockner J, Wiesenfeld BM (1996) An integrative framework for explaining reactions to decisions: interactive effects of outcomes and procedures. Psychol Bull 120:189-208

Colquitt JA, Conlon DE, Wesson MJ, Potter COLH, Yee Ng K (2001) Justice at the millennium: a meta-analytic review of 25 years of organisational justice research. J Appl Psychol 86:425-445

Deutsch M (1975) Equity, equality, and need: what determines which value will be used as the basis of distributive justice? J Soc Issues 31:137-149

DNREA (2006) Conjunctive water management and Northern Territory water policy. Department of Natural Resources, Environment and the Arts, Northern Territory. www.connectedwater. gov.au/water_policy/nt_persepective.html. Accessed Dec 2006

Dovers S (2005) Environment and sustainability policy: creation, implementation, evaluation. The Federation Press, Sydney

DWAF (2006) Groundwater reserve determination for the Sandveld, Olifants-Doorn Water Management Area, Compilation of a high confidence ecological reserve for the groundwater, wetland and salt pan components. Consulting report for the Department of Water Affairs and Forestry. Compiled by Conrad J, and Munch Z, Pretoria

DWAF (2008) Integrated water resources management plan for the Sandveld, Olifants Doorn Water Management Area, Western Cape, Background information to management plan. 
Consulting report for the Department of Water Affairs and Forestry. Compiled by Belcher A, Conrad J, and Grobler D, Pretoria

Ferragina E, Greco F (2008) The Disi Project: an internal - external analysis. Water Int 33:451-463

Foster S, Loucks DP (2006) Non renewable groundwater resources, IHP VI - series on groundwater no 10. UNESCO, Paris

Giordano MA (2009) Global groundwater? Issues and solutions. Annu Rev Environ Resour $34: 153-178$

Goldenberg S (2014) Why global water shortages pose threat of terror and war. The Guardian. www.theguardian.com/environment/2014. Accessed 11 Mar 2014

Greco F (2012) Adding an historical perspective to virtual water flows: hydrometabolism and the history of virtual water rivers. AAG 2013. Available at http://bit.ly/ZUcDjo

Greco F (2013) Hegemony and counter-hegemony in virtual water trade: justice for indigenous people? In: Proceeding of the 6th Hydro Hegemony workshop on transboundary water justice, London

Gross C (2011) Why justice is important. In: Connell D, Grafton RQ (eds) Basin futures: water reform in the Murray-Darling Basin. ANU E Press, Canberra

Hafer CL, Olson JM (2003) An analysis of the empirical research on the scope of justice. Pers Soc Psychol Rev 7:311-323

Jackson S (2004) Preliminary report on aboriginal perspectives on land-use and water management in the Daly River region, Northern Territory. Report to Northern Land Council, CSIRO Sustainable Ecosystems, Darwin

Jackson S (2005) Indigenous values and water resource management: a case study from the Northern Territory. Aust J Environ Manag 12(3):136-146

Jackson S (2006) Compartmentalising culture: the articulation and consideration of indigenous values in water resource management. Aust Geogr 37:19-31

Jackson S, Storrs M, Morrison J (2005) Recognition of aboriginal rights, interests and values in river research and management: perspectives from northern Australia. Ecol Manag Restor 6:105-110

Knight F, Conrad J, Helme N (2007) Biodiversity: best practice guidelines for potato production in the Sandveld. Report compiled for Potatoes South Africa and CapeNature and funded by Conservation International, Potatoes SA and Woolworths, Pretoria

Leventhal GS (1976) What should be done with equity theory? New approaches to the study of fairness in social relationships. National Science Foundation, Washington, DC

National Water Commission (2004) National water initiative. Intergovernmental agreement on a National Water Initiative Council of Australian Governments (COAG)

North DC (1990) Institutions, institutional change and economic performance. Cambridge University Press, New York

Opotow S, Weiss L (2000) Denial and the process of moral exclusion in environmental conflict. J Soc Issues 56:475-490

Schroeder DA, Steel JE, Woodell AL, Bembenek AF (2003) Justice within social dilemmas. Pers Soc Psychol Rev 7:374-387

Shapland G (1997) Rivers of discord: international water disputes in the Middle East. Hurst, London

Skitka LJ, Crosby FJ (2003) Trends in the social psychological study of justice. Pers Soc Psychol Rev 7:282-285

Thibaut J, Walker L (1975) Procedural justice: a psychological analysis. Wiley, New York

Towers G (2000) Applying the political geography of scale: grassroots strategies and environmental justice. Prof Geogr 52:23-36

UN (2010) Declaration of water and sanitation as a human right. General Assembly GA/SHC/ 3987. Human Rights Council. www.un.org/en. Accessed Oct 2011

UNESCO (2012) Groundwater and global change: trends, opportunities and challenges. United Nations World Water Assessment Programme. UNESCO, Paris 
USGS (2013) Water data banks project, multilateral working group on water resources, middle east peace process. Overview of Middle East water resources. http://exact-me.org/overview/ p12.htm. Accessed June 2013

Wada Y, Heinrich L (2013) Assessment of transboundary aquifers of the world - vulnerability arising from human water use. Environ Res Lett 8:13pp

WCED (1987) Our common future. World Commission on Environment and Development. Oxford University Press, Oxford. Available online: http://www.un-documents.net/wced-ocf. htm

Wenz PS (1988) Environmental justice. State University of New York Press, New York 


\title{
Social Justice and Groundwater Allocation in Agriculture: A French Case Study
}

\author{
Jean-Daniel Rinaudo, Clémence Moreau, and Patrice Garin
}

\begin{abstract}
This chapter focuses on the design of rules for apportioning limited groundwater resources among agricultural users. It shows that different (often antagonist) conceptions of desirable water allocation rules co-exist within the agricultural community, reflecting farmers' differences in terms of economic self-interests, historical background and ethical values. Based on an empirical case study conducted in France, we disentangle the factors which determine the acceptability of alternative groundwater allocation rules by farmers, paying specific attention to the perception of their legitimacy, feasibility and social justice. We show that social justice plays a very significant role in the construction of the acceptability judgment, as already highlighted by a series of Australian studies.
\end{abstract}

\subsection{Introduction}

Since the latter part of the twentieth century, individual irrigation based on groundwater has experienced strong development in agriculture worldwide (Chap. 2; Giordano and Villholt 2007). In many countries, including those where groundwater use is now regulated (Australia, Chile, Spain, and Western US States) groundwater use has developed within a non-constraining institutional framework which often resembled a free-access regime. Farmers were granted abstraction licenses which specified a maximum pumping capacity or an area to be irrigated, generally without imposing (or enforcing) any effective constraint in terms of volume. Public

J.-D. Rinaudo $(\triangle) \cdot$ C. Moreau

French Geological Survey (BRGM), Montpelier, France

e-mail: Jd.rinaudo@brgm.fr

P. Garin

Irstea and UMR G-Eau, Montpelier, France

(C) The Author(s) 2016

A.J. Jakeman et al. (eds.), Integrated Groundwater Management,

DOI 10.1007/978-3-319-23576-9_11 
agencies in charge of issuing licenses favorably responded to farmers' demand without having accurate (if any) information, neither on the sustainable yields of the aquifers, nor actual abstractions by farmers. This resulted in groundwater overuse and related problems such as declining water tables, land subsidence, sea water intrusion in coastal aquifers, reduced river flows, springs dry-up and/or ecological deterioration of groundwater dependent ecosystems (Giordano and Villholt 2007, Chap. 2).

In many countries confronted with this evolution, in particular in the developed world, the response from policy makers consisted of a progressive shift from one of free access to a regulated abstraction regime. A review of case studies in Australia (Bennett and Gardner 2014), Spain (Ross and Martinez-Santos 2009; Garrido and Llamas 2009), Chile (Hearne and Donoso 2005), several Western States in the US (Blomquist et al. 2004; DuMars and Minier 2004; Schlager 2006) and France (Figureau et al. 2015) suggests that the establishment of regulated abstraction management regimes is a three stage process. The first one consists of imposing a status quo and characterizing the extent of the problem. No new licenses are issued, meters are installed to monitor actual groundwater use and studies are carried out to assess the sustainable yield of the aquifer. This stage can last several years, due to the time needed to conduct hydrogeological studies and political opposition from farm lobbies (denial of the problem, gap between scientific and lay knowledge, refusal to install meters, lobbying for the development of alternative resources). Time is also needed to allow for a change in prevailing mental models and the social representation of water. Indeed, as water becomes a limited resource, it takes on an economic dimension, creating incentives for private appropriation (the value of agricultural land increases if a groundwater use licence is attached to it), bringing about competition among users. In the rural world, this evolution may run against established social values (solidarity, mutual aid) and be relatively slow. The second stage corresponds to the design and negotiation with stakeholders of a new regulation framework that can theoretically ensure total abstraction does not exceed the sustainable yield. Public agencies estimate the percentage by which current water use must be reduced to align with aquifer sustainable yield. Rules for apportioning the authorized volume between sectors, then between users within each sector, are negotiated. The characteristics of the water use rights associated to individual allocation are also specified (validity period, transferability, etc.). A general approach concerning the role played by the different actors must also be stated (command and control, decentralized management involving users, market based mechanisms). The third stage consists of implementing the reform, raising many issues related to rule compliance and enforcement.

This chapter focuses on the second stage of this reform process and more specifically on the design of rules for apportioning the available volume of water among users. Not surprisingly, this is a very sensitive and often controversial step, which may impact the whole outcome of the reform process. Different (often antagonist) conceptions of desirable water allocation rules co-exist within the agricultural community, reflecting farmers' differences in terms of economic self-interests, historical background and ethical values. Crafting a groundwater 
allocation rule which can be accepted by the greatest possible number of farmers represents a major challenge for water managers. Indeed, a rule that would not be accepted would probably not be complied with, meaning that many farmers would abstract more than the share of water to which they are entitled. This outcome would raise the level of enforcement effort (control and sanction) required from the manager who may not be able to deliver it (public agency or water user association alike) in a context of increasingly limited human and financial resources. It would also result in increased tensions between the farming community and the administration.

One strategy for water managers to increase reform acceptability consists of performing an initial analysis of how stakeholders perceive different allocation rules, using hypothetical scenarios, before initiating any negotiation on groundwater allocation. The aim is to disentangle the factors which determine the acceptability of the different scenarios, paying specific attention to the perception of their legitimacy, feasibility and social justice (see also Chap. 10). Social justice plays a very significant role in the construction of the acceptability judgment, as highlighted by a series of Australian studies in the water sector (Syme and Nancarrow 1997; Nancarrow et al. 1998; Gross 2011). These studies suggest that an allocation rule is more likely to be accepted, together with the corresponding economic losses it implies, if users consider that the rule leads to an equitable apportionment of water resources (distributive justice) and if they consider the choice of the rule results from a fair decision making process (procedural justice) . Investigations conducted by Syme and Nancarrow have highlighted that water users construct their own definition of fairness by articulating different lay philosophies of justice. The resulting perception of what a "fair" allocation is thus varies in space and time. Consequently, since there is no dominant definition of justice, the way the notion is constructed should be assessed on a case by case basis, considering the history, economy, social organization and the prevailing ethical values of each local society as well as users' heterogeneity in terms of social preferences.

The research presented in this chapter contributes to this field of investigation through an empirical case study conducted in five French groundwater basins. Building on the results of the Australian studies, it goes further by attempting to articulate the notions of acceptability and social justice, the latter being considered as an important, but not the sole, determinant of acceptability. The study focuses on water allocation within the agricultural sector, while most previous studies have dealt with inter-sectoral allocation. The method chosen involves eliciting farmers' visions in regard to nine water allocation scenarios, each of which reposes one (or a combination) of a theoretical concept of social justice. The consultation, organized through semi-structured interviews, involved 76 farmers selected within the five French groundwater basins. From an operational perspective, this chapter proposes a method that is both original and readily implemented to evaluate a priori the acceptability of the different water allocation rules. 
The chapter is organized as follows. It begins with a presentation of various policy approaches implemented worldwide to manage water abstraction in overused or over-allocated groundwater basins, clarifying the underlying principle of justice. It then describes the French context, the method adopted and the case studies. Subsequently, we present the results obtained (perception of the nine scenarios), before discussing policy implications of the study.

\subsection{Groundwater Allocation Policies and Social Justice Principle}

\subsubsection{Philosophical Conceptions of Justice}

In many countries, policies consistently state that water resources need to be allocated with equity, without clearly defining how equity can actually be measured and how an equitable and fair allocation can be achieved in practice (Movik 2014; Roa-García 2014). The notion of distributive justice can indeed refer to very different interpretations and philosophical principles (Lamont and Favor 2012) such as prior appropriation or entitlement (Nozic 1974), strict egalitarianism (Nielsen 1979), the difference principle and equality of opportunity (Rawls 1971), the desert-based principle (Sadurski 1985), welfare based principles (Mill 1940) and libertarian principles (Nozic 1974).

According to the prior appropriation conception of justice, people who first use the resource are entitled to keep it (entitlements) provided they do not violate the rights of others. Strict egalitarianism assumes that all members of the society should be given access to the same amount of resources because "people are morally equal, and that equality in material goods and services is the best way to give effect to this moral ideal" (Lamont and Favor 2012). The difference principle assumes that inequalities in the distribution of resources are acceptable if they improve the situation of the worst-off in the society, whereas the "equality of opportunity" principle aims at attenuating inherited sources of inequalities (gender, race). The desert principle assumes that resources should be allocated considering the socially valuable efforts (i.e. leading to the production of goods and services desired by others) made by each individual. Welfare-based principles of justice assume that the allocation of resources should maximize social welfare, defined as the sum of individual satisfied preferences, and frequently interpreted in terms of economic wealth (utilitarian approach). Finally, libertarian theories assume that the allocation of resources resulting from market mechanisms is just because it results from transactions which are just in themselves; in that conception, no specific distributive pattern is required for justice, what matters is that acquisition and exchange conditions be right. 


\subsubsection{Existing Groundwater Policies and Underlying Conceptions of Justice}

In practice, policy approaches which have been implemented to manage overallocated groundwater systems frequently rely on a combination of several of the justice principles listed above. Based on an analysis of allocation policies implemented worldwide, we identify five archetypal policy approaches which we consider representative of the diversity of practices worldwide.

The first policy approach is based on the prior appropriation doctrine, based on a "first in time, first in right" philosophy. To align global abstraction with sustainable yield, the regulator curtails volumes granted to junior users while senior users do not suffer any (or a smaller) reduction. This approach implicitly considers that access to groundwater is subject to a priority order according to chronological possession. It considers individual water entitlements as property rights, valid in perpetuity, and which can be sold and purchased like any other property. Examples of such allocation policies can be found in Western States of the USA (Chap. 22; Blomquist et al. 2004; Schlager 2006).

An alternative policy approach consists of imposing on all users the same reduction in percentage of the volume they have been using during a recent reference period. It relies on two principles: an egalitarian principle, which refers to treating people identically (same cut-back in percentage), without regard to historical, social and economic circumstances; and an implicit recognition of the right to continue pre-existing use (grandfathering). The corollary is that water entitlement can be reduced when the volume specified in the license is not fully used (sleeping allocations). This reduction is undertaken without offering any financial compensation as there was no beneficial use of the corresponding volume. Policies reflecting this approach have been implemented in several Australian States (NRMSC 2002) and in the UK but also in some Water districts in the Western USA (e.g. California) who apply a "use it or lose it" condition. It remains attractive to policy makers in that it does not move too far away from the status quo, thereby minimizing political opposition to the reform and risks of social unrest during the implementation phase. Note that similar approaches have been implemented to allocate catch quotas in fisheries (Presser 1994; Khalilian et al. 2010).

A third policy approach embodies calculating the volume of water that would be theoretically needed by each farmer, assuming efficient irrigation technologies and considering the crops cultivated during a reference period. This theoretical volume then constitutes an individual reference to which the regulator applies an acrossthe-board cut-back to ensure sustainable use of the aquifer. Efficient farmers will thus have smaller cut-backs in allocation than others. This approach reflects a philosophy of justice based on the principle of desert or merit (those who made efforts to improve efficiency being rewarded while others are disadvantaged) and efficiency. It has been applied since the mid 1990s in a limited number of French groundwater basins.

In the three previous approaches, actual users benefit from an historical rent, whereas new users are denied access to the resource. This may result is inefficient 
water allocation if historical users have a low water marginal productivity as compared to new users. To solve that problem, a fundamentally different approach can be adopted to adjust allocation in over-allocated groundwater systems. It consists of cancelling all existing licenses before reallocating the available volume of water using an auction mechanism. This allows new users to enter the system while removing inefficient users. The underlying philosophy of justice is that users who maximize the added value of water, and who can pay for it, deserve using it (economic efficiency). This approach has not been used in practice, except in some Australian basins, where unused volumes of water are auctioned.

A fifth and last approach applies different allocation cut-back rates to users, depending on inherited historical equities that result in present inequitable opportunities. Reductions or no cut-backs will be imposed on farmers who have received limited water allocation due to late arrival in the zone, to inequitable past policies or to farmers affected by long lasting unfavorable market conditions. The objective is to protect economically fragile farmers who could possibly be ruled out of business with an egalitarian or an efficiency based approach, following Rawls' difference principle. In some French basins for instance, the regulator has decided to exempt small cattle breeders and certain fruit producers from seasonal allocation cut-backs, considering their high exposure to market risks. Farmers entitled with small water allocations are also exempted from cut-backs (France, Australia). The objective can also be to redress historical inequities or reduce poverty, as practiced for instance in South-Africa (Movik 2014; van Koppen and Schneiner 2014).

\subsubsection{The Construction of Fair Allocation Policies}

The five approaches described above represent archetypal policy options for managing over-allocated groundwater systems. They certainly do not represent off-theshelf solutions that would be directly applicable in a different context. However, because they illustrate the range of possible policy options, they can be used as hypothetical scenarios for engaging a debate between stakeholders. The virtue of using such scenarios as educational material is that it compels stakeholders to clarify why they support or reject a given policy option. This debate is expected to make explicit the diversity of principles advocated within the community (in particular social justice principles) for guiding the choice of a water allocation rule. While some of the principles enunciated will be incompatible, others can be combined to construct hybrid policy scenarios likely to be accepted by the greatest number. Critical scenario analysis is also expected to highlight how each individual articulates different principles of justice to reconcile their own self-interests and philosophical values. Understanding the complexity of individual constructions of a sense of justice is seen as a key asset for the regulator seeking to engage stakeholders in a negotiation over water allocation rules. This is now illustrated through the French case study. 


\subsection{Case Study and Methodology}

\subsubsection{Context and Objective}

The French situation illustrates the challenges related to the shift from an open access to a regulated groundwater abstraction regime, as described in the introduction. In France, the area irrigated increased from 1.8 to 2.7 million hectares between 1988 and 2000, mainly through the development of groundwater abstraction through private individual wells (Loubier et al. 2013). Until the mid-1990s, farmers were almost systematically granted groundwater use licenses which did not impose any ceiling on abstraction. In 1992, a new Water Act laid the foundations of a groundwater abstraction regulation regime, by imposing metering of all water uses and creating groundwater safeguard zones where government agencies could refuse granting new licenses. More sophisticated regulation regimes were experimentally introduced in a dozen basins, consisting of "capping" total water abstraction and assigning individual quotas (volume per year) to each farmer. The 2006 Water Act generalized this regulation regime to all basins characterized by over-abstraction. In these basins, hydro-geological studies were conducted to assess a sustainable yield. Government agencies calculated an available volume of water and apportioned it between sectors, priority being given to urban supply, industry then agriculture. The volume allocated to agriculture was then officially attributed to newly established Groundwater Users' Associations (GWUA- Organisme Unique de Gestion Collective in French). These Associations are made responsible for apportioning it among farmers, crafting their own rules for defining individual water allocation. Given the limited resources they have to enforce these rules, they are concerned about identifying options that are more likely to be accepted and complied with by farmers.

The empirical study presented in this chapter was conducted in this context. Its first objective was to design and test a methodology that could be used by GWUAs to assess the perception of various hypothetical water allocation rules, prior to engaging stakeholders in a negotiation. The second objective consisted in checking if there were any - or a limited number of - dominant conceptions of social justice within the French farming community, which could be used to define a French water allocation 'doctrine', potentially usable by all GWUAs.

\subsubsection{Overview of the Approach}

The methodology of this research comprises four stages. The first involves defining water sharing rules scenarios, each one being based on one (or a combination of) concepts of justice, in line with the archetypal approaches described above. Scenarios were adapted to the French context and presented in the form of a brief text which was sent to the farmers in advance. 


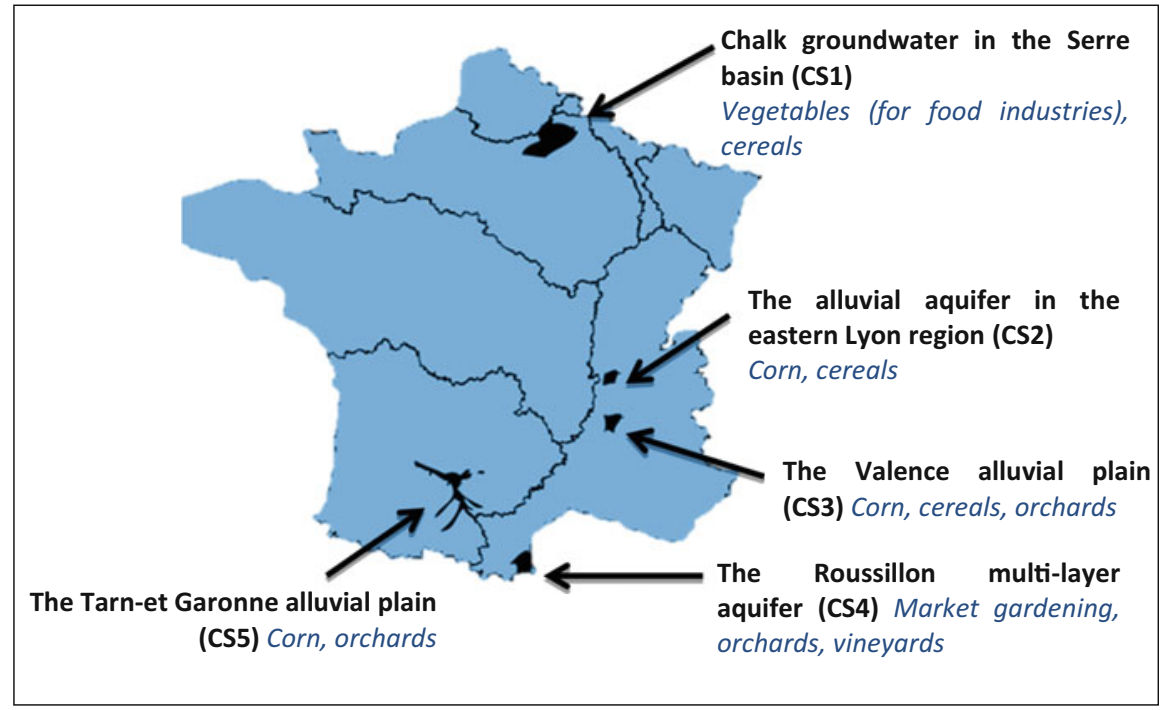

Fig. 11.1 Location and characteristics of the terrains in the study

The second stage entailed discussing these scenarios with farmers, through interviews conducted in five different groundwater basins (Fig. 11.1), and selected based on two criteria: dependency on irrigation from groundwater; and management of water scarcity. Face-to face interviews were conducted where possible (30 interviews) but some had to be made by telephone for practical considerations (17). Discussions were tape recorded to allow subsequent detailed analysis. Twenty-nine other farmers who were contesting the legitimacy of the reform process refused to answer the questionnaire. They however all explained their viewpoint and their arguments were subsequently analyzed. For each scenario, the individual was asked to explain why they felt that the scenario was acceptable or not, and secondly if and why they would consider it as fair and equitable. At the end of the interview, the preferred scenario, or a combination of several preferential scenarios, was to be indicated.

The third stage comprised a qualitative analysis of the discourse of participants and a quantitative analysis of their answers to the questionnaire. The arguments put forward by the farmers were re-transcribed word for word and used as a starting point for a qualitative analysis of the principles underlying the various visions of social justice in the agricultural community. The fourth stage was devoted to presenting the results to farmers to obtain a validation of our analysis and additional feedback. This was undertaken through organizing a meeting in each of the case study areas and disseminating a 4-page synthesis of the results to all interviewed farmers. 
Table 11.1 Description of allocation rules and corresponding principles of justice for the nine scenarios discussed with farmers

\begin{tabular}{|c|c|c|}
\hline \multicolumn{2}{|c|}{ Description of water allocation rule } & \multirow{2}{*}{$\begin{array}{l}\text { Underlying principles of justice } \\
\text { Historical entitlements/ } \\
\text { grandfathering (right to continue } \\
\text { preexisting use) }\end{array}$} \\
\hline \multirow{7}{*}{$\begin{array}{l}\text { Access } \\
\text { restricted to } \\
\text { historical water } \\
\text { users }\end{array}$} & $\begin{array}{l}\text { (1) The allocation is proportional to } \\
\text { past abstraction (last } 5 \text { years } \\
\text { average). }\end{array}$ & \\
\hline & $\begin{array}{l}2 \text { The allocation is based on usage } \\
\text { seniority, with priority given to those } \\
\text { whose usage dates back the furthest }\end{array}$ & $\begin{array}{l}\text { Prior appropriation (original date of } \\
\text { appropriation determines legitimacy } \\
\text { to use water) }\end{array}$ \\
\hline & $\begin{array}{l}\text { (3) The allocation is proportional to } \\
\text { the declared pumping capacity of } \\
\text { registered wells and independent of } \\
\text { actual use }\end{array}$ & $\begin{array}{l}\text { Merit (farmers who registered their } \\
\text { wells and properly declared the } \\
\text { pumping capacity are rewarded) } \\
\text { + grandfathering }\end{array}$ \\
\hline & $\begin{array}{l}(4 \text { The volume allocated per hectare } \\
\text { is inversely proportional to the size } \\
\text { of the farm: small farms get a greater } \\
\text { allocation per hectare }\end{array}$ & $\begin{array}{l}\text { Equality of opportunities (positive } \\
\text { discrimination to compensate } \\
\text { inherited inequalities) } \\
+ \text { grandfathering }\end{array}$ \\
\hline & $\begin{array}{l}\text { (5 The allocation depends on } \\
\text { production specialization: priority is } \\
\text { granted to high added value crops } \\
\text { (orchards, seeds) }\end{array}$ & $\begin{array}{l}\text { Economic efficiency } \\
+ \text { grandfathering }\end{array}$ \\
\hline & $\begin{array}{l}6 \text { The allocation depends on soil } \\
\text { type. Farmers cultivating soils with } \\
\text { low water retention capacity receive } \\
\text { a higher volume per ha, since crops } \\
\text { grown on these soils have greater } \\
\text { water requirements }\end{array}$ & $\begin{array}{l}\text { Equality of opportunity } \\
\text { (compensation of natural handicap) } \\
+ \text { grandfathering }\end{array}$ \\
\hline & $\begin{array}{l}\boldsymbol{8} \text { The allocation depends on the } \\
\text { accessibility of alternative water } \\
\text { supply sources. Groundwater is } \\
\text { granted proprietarily to those who } \\
\text { have access to no other resource } \\
\text { (rivers, reservoirs) }\end{array}$ & $\begin{array}{l}\text { Equality of opportunity } \\
\text { (compensation of naturally } \\
\text { unfavorable water supply situations } \\
\text { and differentiated treatment in } \\
\text { historical water resource } \\
\text { development policies) }\end{array}$ \\
\hline \multirow[t]{2}{*}{$\begin{array}{l}\text { Access open to } \\
\text { all farmers }\end{array}$} & $\begin{array}{l}\text { (8 The allocation is open to all } \\
\text { farmers, whether currently irrigating } \\
\text { or intending to do so in the } 5 \text { years to } \\
\text { come }\end{array}$ & $\begin{array}{l}\text { Equal treatment of all farmers (strict } \\
\text { egalitarian approach), no vested } \\
\text { rights linked to historical use }\end{array}$ \\
\hline & $\begin{array}{l}\text { (9 All existing licenses are cancelled. } \\
\text { The available volume of water is } \\
\text { auctioned (highest bids get water) }\end{array}$ & $\begin{array}{l}\text { Economic efficiency (maximization } \\
\text { of economic value of water) }\end{array}$ \\
\hline
\end{tabular}

\subsubsection{The Scenarios of the Initial Allocation Rule}

Nine allocation rule scenarios were used to support discussions with farmers during the interviews. Each one is implicitly based on one or several philosophies of justice, as indicated in Table 11.1 below. Two main groups of scenarios are differentiated: those of the first group all assume that only historical users can receive an allocation; whereas the second group considers that a fair allocation 
should provide all farmers with the possibility to access the resource, independently of historical circumstances.

This methodology is partly inspired from Syme and Nancarrow's studies in Western Australia who ask their respondents to assess a number of prominent philosophical statements (Syme and Nancarrow 1996, 1997) or water management scenarios (Nancarrow et al. 1998). Note that farmers were only provided with a detailed description of the first column of Table 11.1, expressed in lay terms.

\subsection{Results: The Acceptability of Allocation Rules Scenarios}

\subsubsection{Sticking Points to the Approach}

A first significant result is that nearly $40 \%$ of the farmers contacted refused to evaluate the scenarios. All of them justified their positions, using several arguments which are briefly presented hereafter. First, farmers contest the legitimacy of the reform on several grounds. They challenge the reality of water scarcity and the subsequent need for establishing a rationing system. Based on their own observations, they believe that water is more abundant in their area than the experts claim, and that there is no need to reduce abstraction. They also challenge the legitimacy of the volumes of water devoted to the environment (at the expense of agriculture) and/or consider that society should subsidize the construction of new resources (dams, hillside storage reservoir) to compensate for rationing groundwater use for farming. The farmers also refute the relevance of a system of individual volumetric quotas on the grounds that it introduces a rigidity that hinders their freedom to adapt their production strategy to a changing economic context. Moreover, they consider cut-backs as a violation of property rights, considering that historical use generated vested rights.

Overall, these farmers consider that participating in the survey and expressing their opinion on scenarios would mean that they recognize the existence of the problem, which is not the case. Second, some of these respondents refused to participate in the survey as they considered the research team had no legitimacy to discuss these issues, since we were not mandated by an institution defending farmers' interests. There was a general fear that the conclusions of the survey be used against them, to justify decisions already taken, leading them to refuse to participate. These types of reactions raise the issue of procedural justice. Last but not least, some farmers refused to express an opinion on the scenarios presented because it involved too distant a timeframe (difficulty in adopting a prospective stance). Overall, opposition was expressed in a manner that was radical but well justified. Despite this refusal to discuss the scenarios, the farmers took time to consider and make explicit their vision, showing that they adhere to being stakeholders reflecting on water management, and wish to extend the field of possibilities. 


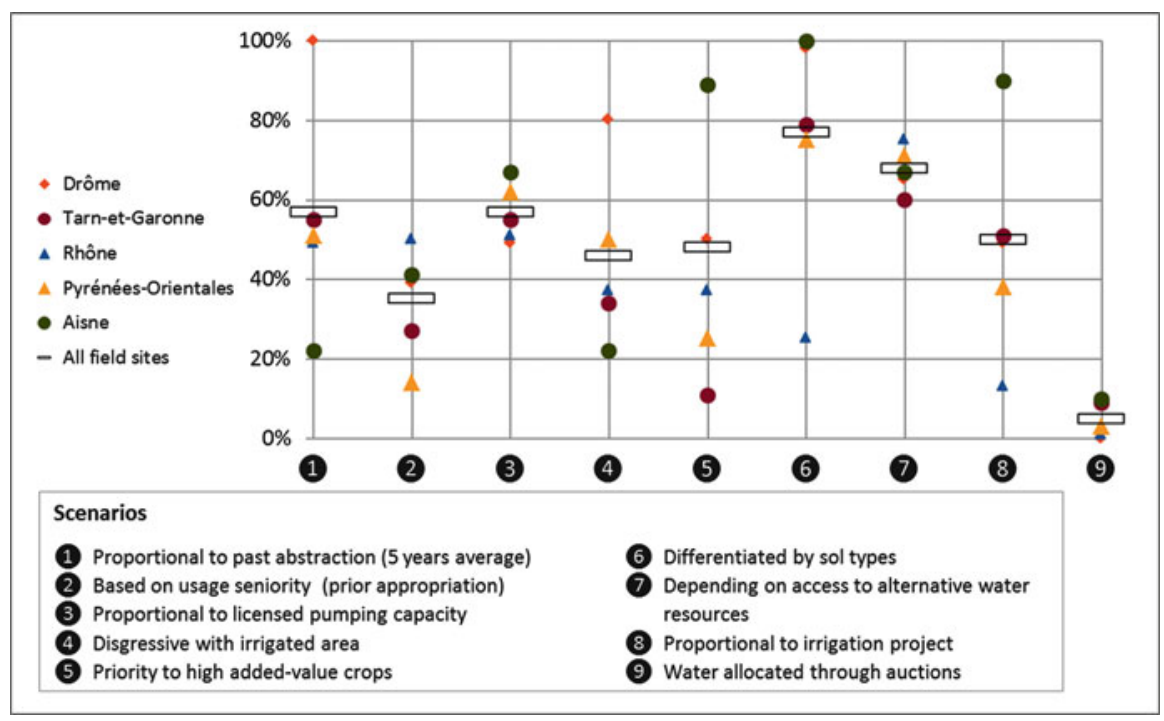

Fig. 11.2 Answer to the question: "Does this scenario seem acceptable to you?" (The numbers correspond to scenarios described in Table 11.1. Each colored sign corresponds to one of the five groundwater basins. The horizontal rectangle shows the average for the 47 farmers who accepted to assess the scenarios)

\subsubsection{Overall Scenario Perception}

A majority of the scenarios are the subject of highly contrasting opinions, and they are considered as acceptable by between $40 \%$ and $60 \%$ of the participants (Fig. 11.2). However, the two scenarios that compensate natural inequalities (allocation according to soil or access to surface water) received a higher approval rate of $77 \%$ and $70 \%$, respectively. Conversely, the rationales inspired from AngloSaxon models received more modest support from the panel: $35 \%$ (prior appropriation) and $4 \%$ (sold at auction). Figure 11.2 allows the results to be compared according to the case studies. Opinions converge for the following scenarios: "sold at auction," "allocation according to seniority," "according to pumping capacity" and "according to access to surface water". For the other scenarios, opinions differ widely. These disparities show that, in order to be acceptable, a solution must be adapted to the local context. The new French water law (2006) position of delegating the calculation of quotas to Groundwater Water Users' Associations, operating at the aquifer level would, in our opinion, promote the acceptability of such a measure.

Through these results, we see that the preferred solution is often the one that disturbs the existing order as little as possible. The criteria that should be taken into account relate to the region's specific characteristics in order to correct natural inequalities amongst irrigators (soil diversity, access to surface water), while at the same time recognizing the farmers' needs (reflected by pumping capacity and past 
consumption). Criteria relative to economic efficiency (protection of special crops, markets) or protection for the most vulnerable users (digressive allocation) trigger more reticence and strongly polarize the stances taken by farmers. Excluding certain irrigators, whether on the strength of a financial criterion (sold at auction) or seniority, resulted in a systematic refusal on the part of the irrigators.

\subsubsection{The Determinants of Acceptability: Justice Matters but Not Only!}

The detailed analysis of tape recorded interviews highlighted that farmers form their judgment of acceptability by articulating four main categories of arguments: ethical considerations, including those related to justice; implementation feasibility of the scenario; risks associated with the scenario; and unintended side effects. These four categories were spontaneously advocated by farmers, although they were initially asked to comment on the justice dimension only.

Most of the arguments enunciated by farmers during the interviews reflect ethical considerations and are related to social and philosophical values on which the scenarios are based. For instance, the auction scenario provokes strong reticence on ethical grounds due to rejection of the monetization of water ("water is not an economic good"). The "digressive" scenario elicits reactions that are either favorable in reference to the solidarity principle or unfavorable when the scenario is equated with the logic of assistantship or charity. Certain farmers worry that scenarios might give rise to new inequalities (past consumption would penalize farmers who had already adopted water conservation practices), or would reinforce existing inequalities (according to the seniority of the irrigation, since younger farmers are still in the process of reimbursing loans). On the other hand, the soils scenario came across as liable to legitimately attenuate a natural inequality already suffered.

A second category of argument relates to the feasibility of implementation. A scenario may be accepted for its underlying ethical principle and yet be invalidated because its operational implementation is thought to be too costly or too complex. This can be illustrated by the scenario suggesting varying allocation according to soil differences; while this scenario was virtually always validated in principle, it was often met with skepticism as to its implementation (lengthy and conflict-ridden negotiations for classifying land parcels, in particular where the soil is highly heterogeneous within short distances).

Many farmers were also concerned by the prospect of risk allocation rules being misused. They refer to the possibility that unexpected opportunistic behaviors appear, that rules be abused during their implementation phase, diverting them from their initial objective. This dimension is brought up spontaneously, probably because of many experiences where similar agricultural policy tools missed their mark (e.g. allocation of milk production quotas). Thus, an allocation that varies digressively according to surface area, and supposed to encourage small farms, would spur large enterprises to break up into a host of small entities. Similarly, the 
decision to grant larger allocation to high added value crops could encourage farmers to increase the planted area of such crops just to obtain a greater allocation which they would in reality use largely for other crops.

The fourth category of arguments relates to the unintended consequences that allocation rules might have on farms, the structure of farming systems, or the regional economy as a whole. For example, many farmers think that the digressive scenario would result in decreasing the region's agricultural performance, as the most competitive farms would be handicapped by reduced allocation. Similarly, selling at auction would encourage hyper-specialization in certain crops, removing from business small diversified farmers who play a key role in maintaining an economic activity in rural areas. Giving priority to high added value crops (vegetable, fruits and certified seeds) would provide incentives for farmers to increase the area under such crops at the expense of traditional production, impacting the regional industry. By introducing a territorial dimension in their analysis, farmers show that the evaluation of water allocation policies should be embedded in a wider context, giving ample thought to the agricultural development model sought for the region.

This typology of arguments is useful to disentangle motivations underlying the level of acceptance of our nine scenarios, as depicted in Fig. 11.2. Overall, we see that the ethical dimension is essential, since the scenarios that give rise to a favorable ethical judgment receive strong support, and conversely. However, the diversity of moral principles does not, alone, account for the large variety of preferences. Implementation difficulties are widely cited as well as the risk of seeing new unjust inequalities arise through abuses, and unintended developments in the system.

\subsubsection{Towards a Typology of Ethical Stance}

In our interviews, the farmers did not cite a theory or ideal of justice to validate or invalidate the different scenarios. The first reaction was affective in nature, with a very vigorous rejection, for example, for sale at auction, which sparked shock or anger. Sometimes, it was even hard to get beyond this affective relationship, because it was too strong and hard to justify: "I don't know how to explain it to you, but this scenario, I intuitively feel it will not work" (farmer 41). We thus sought to understand how this sentiment of justice or injustice forms, that prompts farmers to validate or invalidate the proposed scenarios. We noticed that the statements were underlain by various rationales, some of which conformed with the current notion of social justice, and others not. We have accordingly established a typology of ethical stances, or rationales, into which we have placed the 47 irrigators. To assign the farmers unambiguously to one of the rationales, we based our judgment on their reasoning in regard to the scenarios, performing a qualitative (somehow subjective) classification of the salient aspects of what they had to say (based on the material collected through interviews, we were not able to clearly define the rationale of 5 of the 47 farmers). The farmers are distributed relatively uniformly, 


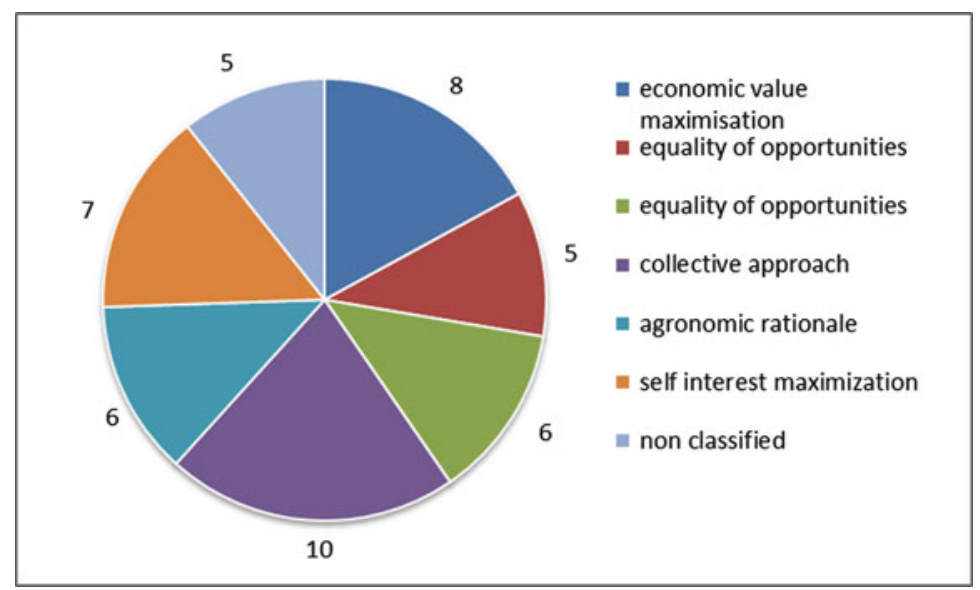

Fig. 11.3 Classification of interviewed farmers according to the typology of rationale

with each category containing between five and ten individuals (Fig. 11.3). Each of the rationales is described below and illustrated, when possible, with selected farmers' discourse quotations.

The Utilitarian Stance "In an emergency situation, irrigation of cereals should be reduced so as to irrigate crops produced under contract for the industry... The priority is to guarantee crops with a high added value" (farmer 38). These farmers believe that water should be allocated in such a way as to maximize its economic value and protect the security of irrigators. The scarcer water is, the greater its value; it is therefore logical to allocate it to crops that generate the highest revenue. Note that this stance is not only defended by the most efficient producers. Some farmers are willing to sacrifice personal earnings to increase social welfare. Farmers of this group came out strongly in favor of scenario "priority to special crops" (5). Yet they do set an ethical barrier to this principle, since very few of them accepted allocation via sale at auction $(\boldsymbol{9})$. Most farmers in this group rejected the "digressive allocation" scenario (4), considering it as being "too social".

The Egalitarian Stance "I don't like the idea of differentiating between Whites and Blacks, little and big guys" (farmer 28). In a context of restriction, these farmers associate justice with equality of treatment. "What is fairest, is to destabilize the economic system as little as possible with restrictions, it's better to apply the same restriction coefficient to everyone" (farmer 28), with the twofold advantage of creating no new inequalities and being easy to implement. The allocation scenarios that propose a single coefficient of restriction (194) were the ones that received strong support. Conversely, scenarios implying differential treatment are systematically rejected: sale at auction $(\boldsymbol{(})$, allocation according to seniority (2) and digressive allocation (4) all received $100 \%$ negative opinions. However, a majority in this group validate the principle of differentiation according to soil (6), 
probably motivated by an agronomical rationale rather than social justice consideration.

Equality of Opportunities "I' $m$ not a socialist, but I am sensitive to social issues. Everyone has to make an effort, but according to what he can. Nor should there be too great distortions, everyone has got to live" (farmer 17). For these farmers, the level of effort (in terms of allocation cut-back) should be differentiated according to the characteristics and situations in terms of opportunities and difficulties of different farm types. This comes down to accepting positive discrimination as a moral principle of justice. The allocation policy for the water resource is thus similar to a mechanism of social redistribution (references to unemployment insurance, the pension system, the right to housing). Applying a uniform coefficient of restriction would confirm existing inequalities or even give rise to new ones. " $A$ young farmer setting-up a new farm without initial capital is disadvantaged as compared to one inheriting from a family farm, he should therefore not be subjected to further prejudice" (farmer 11). This group widely approves the digressive allocation scenario (4) and the allocation differentiated by soil types $(\boldsymbol{6})$. Protection of special crops (⿹) is rejected, albeit differentiated. This system does not benefit the underprivileged.

The Collective Approach Rationale "It's hard to come to an agreement, but we've no choice. In the 1960s, they [the European Common Agricultural Policy] forced us to be individualistic, but there's no other way out for us but to reason collectively" (farmer 45). For this group of farmers, what matters is more the process leading to the choice of an allocation rule than the outcome in itself. In other words, this group is more concerned with procedural than distributive justice: if the decision making process is fair, final decisions on over-allocation will be accepted. They consider that the definition of a water allocation policy must not be reduced to the definition of individual water quotas, based on a negotiation where everyone defends their own individual or corporate interests. The design of water allocation rules should instead be taken as an opportunity for a societal debate on the type of agriculture to be promoted. Water allocation policy is a lever for a territorial and agricultural development policy. Farmers of this group consider that a user does not own water resources but merely is a custodian. These respondents defend the view, developed by Elinor Ostrom (1990), of a communitarian management of a common property, which can oppose management by the market or by the State effectively.

The Agronomical Rationale "I don't like what you're suggesting: water management isn't a social affair, it's an agronomic affair" (farmer 20). This group considers that irrigation is a farming practice, an act concurring with the production of crops like sowing, pruning or harvesting. It is determined by agronomic parameters (the plant's needs, the soil, the rainfall, etc.). Water allocation should be following the same rationale, i.e. be based on the same parameters; any other 
rationale constitutes an incursion of social and economic issues into a domain of technical agricultural efficiency. These farmers came out strongly in favor of allocation according to soil type (6), according to past consumption ((1)), and the pumping capacity (3) which they consider good indicators of crop water requirements. The other scenarios, responding to a social or economic line of rationale, are deemed poorly adapted and far removed from the objective of promoting an efficient use of water. These farmers call into question how we have formulated the terms of the debate, by presupposing that water allocation involves issues of social justice.

The Self-Interest Maximization Stance "Your questionnaire is doomed to failure, everyone will defend the scenario that suits him best" (farmer 10). These farmers examine the proposed scenarios in the light of the situation on their own farm. The scenarios are evaluated one by one, according to the advantages and threats it presents for the respondent's own interests. "I am one of the first farmers who developed irrigation in the region, I' $m$ going to speak up for my own" (farmer 22). This echoes some situations reported in Australian studies: "the forces of selfinterest among water users become pre-eminent, and public involvement merely becomes a game of each stakeholder presenting his or her interest in the most favorable light possible" (Syme et al. 1999). No scenario emerges clearly from this group as the choice reflects individual heterogeneous situations. However, scenarios based on seniority, which is generally rejected by all farmers, is widely approved in this group (which confirms the rationale of preserving what has been gained).

\subsubsection{The Individual Construction of a Hybrid Conception of Justice}

Assigning each farmer to only one of the rationales described above is however too simplistic. Indeed if some respondents do clearly fall into one type or another, most borrow arguments, successively or simultaneously, pertaining to different stances. When they have come to perceive a modality of allocation as being too far removed from their position on one or another of these "poles", they came forward with an argument to strengthen this "frustrated pole". Thus, farmers positioning with respect to the different rationales is not binary (opposition/adhesion), but rather suggests a gradation in terms of acceptance. Farmers can mobilize two, three or even four principles. They do not oppose the principles with each other, but rather combine them to make up a corpus of values that they mobilize successively. It is accordingly by this composition, this ongoing compromise, that the sentiment of justice is formed. 


\subsection{Discussion and Conclusion}

\subsubsection{Summary and Scientific Contribution}

This chapter proposes a method for evaluating the perception of justice and the acceptability of water allocation rules in over-used/over-allocated groundwater basins. We have endeavored to identify the factors determining acceptability for different principles of initial groundwater allocation. A first phase of this work was the design of contrasted scenarios depicting concrete rules for sharing the resource. These rules were inspired by an analysis of existing groundwater allocation practices in a selected number of countries and by a review of universal philosophies of justice. These scenarios were submitted to the scrutiny of 76 farmers from five French groundwater basins. The contribution of this study to the existing literature on justice and water allocation is threefold.

First, it complements existing Australian studies by providing empirical material relating justice issues to groundwater allocation problems in a European context. Moreover, the chapter focuses on the issue of water allocation within the farming community, whereas most of the existing literature deals with allocation between productive uses and the environment (a notable exception is (Nancarrow et al. 1998)). Our study confirms earlier findings that justice issues can be readily articulated by the farming community. We confirm that self-interest is only one of many different perspectives in the water allocation debate. We also invalidate our initial assumption on the existence of a limited number of dominant conceptions of social justice in the farming community, by showing that many different rationales coexist. The ways these principles are combined is likely to vary according to aquifer characteristics, land use and community culture (Syme and Nancarrow 2006).

Second, we highlight that acceptability of new water allocation rules is not only determined by how stakeholders perceive these rules in terms of distributive justice. Farmers' judgment is equally influenced by their perception of the legitimacy of the policy in which the question of allocation rule is embedded. Their arguments in that regard can be interpreted using the framework proposed by Suchman who distinguishes pragmatic, moral and cognitive legitimacy (Suchman 1995). Pragmatic legitimacy is determined by how farmers see their own activities and selfinterest being impacted by the policy reform. Pragmatic legitimacy exists when farmers perceive that groundwater depletion will affect their self-interest in the long term, making abstraction regulation desirable. This was not the case in our French case studies where farmers only perceive the short term negative impacts on their income of the proposed regulation policy. Moral legitimacy refers to the normative judgment on whether the objectives of water policy promote social welfare, in line with moral values of a society. In that respect, French farmers challenge, on macroeconomic grounds, the priority given to environmental issues over agricultural production. They also challenge the way the reform is implemented, with 
insufficient participation of stakeholders ("we know how to manage groundwater, we won't be dictated a solution by a bureaucrat looking at this from his desk": farmer 54) and the use of irrelevant policy models considered as universal by the administration ("they [government agencies] want to use the same model from Belfort [Swiss border of the Rhône river basin] to the Italian border, in situations which have nothing in common"; farmer 48). Finally, cognitive legitimacy is granted when the problem justifying a policy, the objectives and the means deployed to achieve them are understandable by concerned stakeholders. As explained in the result section, there was a clear lack of cognitive legitimacy in our French case studies, since many farmers were challenging the water scarcity assumption and refusing experts' evaluation of aquifer sustainable yield.

Our empirical results also show that acceptability of water allocation rules is also determined by their perceived implementation feasibility. Farmers make a very pragmatic evaluation of the difficulties that may arise with different allocation rules in terms of information acquisition and sharing, cost and complexity of operational functioning of the system, associated risks of conflicts, occurrence of deviant behaviors and unintended side-effect impacts. Overall, our empirical findings show that, when evaluating the different scenarios, farmers can alternatively use arguments related to social justice, legitimacy and implementation feasibility, in addition to self-interest considerations.

\subsubsection{Implications and Policy Recommendations}

Several policy recommendations can be derived from this empirical study, applying to the French context but also to other similar European contexts where groundwater abstraction regimes are currently being reformed.

First, there is a need to strengthen the cognitive and moral legitimacy of the groundwater abstraction policy reform before engaging stakeholders in a discussion of allocation rules. Stakeholders must first be convinced that a problem exists before discussing how to solve it. Government agencies and locally established GWUAs should ensure that stakeholders have a shared understanding of the groundwater situation, the extent of the overexploitation problem, of how sustainable yield was calculated and of the underlying trade-off made between environmental and economic objectives. Closing the gap between scientific experts' knowledge and farmers' lay knowledge is a prerequisite to engage farmers in a debate over how to share a limited resource among themselves.

Second, GWUA must also play a very proactive role in bringing out different viewpoints and perspectives held by farmers on distributive justice issues. Without a specific effort in that direction, there is a risk of seeing the debate play out not on the grounds of social justice, but rather on those of other dimensions of acceptability, and that the compromise on principles of justice give way to a balance of power. Such a shift occurred when fishing quotas were set in England (Gray et al. 2011). 
The authors showed that what were deemed to be the fairest modes of calculation were not the ones that were actually chosen, but rather those that guaranteed the sector's stability and reflected the balance of power amongst the players.

The third implication is that the discussion over allocation rules should be embedded into a broader evaluation of alternative agricultural development policies at the groundwater basin level. Discussing intra-agriculture water allocation rules brings farmers to raise the question of what ideal the agricultural community should endeavor to achieve, for which the quotas policy would be one of the levers of action. Water allocation is clearly perceived by farmers as one of the many policy tools that can be used to shape future agricultural developments. It therefore can't be discussed in isolation, without considering the other levers over agricultural development.

Fourth, there is an overall social preference for allocation rule scenarios that compensate natural inequalities (allocation according to soil or access to surface water). Conversely, the rationales inspired from Anglo-Saxon models, including prior appropriation and auctioning are far less accepted. Lay philosophies of French farmers do not seem compatible with the current trend towards market driven approaches which are increasingly promoted at the European level (Commission 2012). From a methodological perspective, the study also demonstrates the relevance of using scenarios to help farmers in presenting and justifying their own vision, the principles they want to promote, the technical approaches they consider feasible or not, and to communicate this vision with each other. In addition to facilitating mutual understanding of existing visions, scenarios are likely to help farmers involved in the negotiation over allocation rules to identify a limited set of principles on which they want to base their allocation rule. Scenarios then provide building blocks that can be combined to construct a rule that can be considered as just by the largest number.

Last but not least, the analysis presented in this chapter has focused on the distributive justice issue only. Two other dimensions of justice should also be considered when crafting groundwater allocation rules: procedural justice, which reflects whether stakeholders have been given a fair access to the decision making process, and interactional justice, which is related to how people have been treated during this process (e.g. trust and respect). Acceptance of groundwater allocation policies will also depend on these two other dimensions (Gross 2011)

Acknowledgements The authors wish to thank the Rhône Mediterranean and Corsica Water Agency for the financial support provided for this research project (SIMGDES project). The paper has been prepared with the financial support of BRGM research program 30 (Environmental and Risk economics). We also thank Marian Patrick and Geoff Syme for comments on an earlier version of this chapter.

Open Access This chapter is distributed under the terms of the Creative Commons AttributionNoncommercial 2.5 License (http://creativecommons.org/licenses/by-nc/2.5/) which permits any noncommercial use, distribution, and reproduction in any medium, provided the original author(s) and source are credited. 
The images or other third party material in this chapter are included in the work's Creative Commons license, unless indicated otherwise in the credit line; if such material is not included in the work's Creative Commons license and the respective action is not permitted by statutory regulation, users will need to obtain permission from the license holder to duplicate, adapt or reproduce the material.

\section{References}

Bennett M, Gardner A (2014) A regulatory framework for groundwater management in a drying South West: draft report for consultation. National Center for Groundwater Research and Training, Adelaide

Blomquist W, Schlager E, Heikkila T (2004) Common waters, diverging streams: linking institutions and water management in Arizona, California, and Colorado. Resources for the Future Press, Washington, DC

Commission E (2012) A blueprint to safeguard Europe's Water Resources. COM(2012) 673 final

DuMars C, Minier J (2004) The evolution of groundwater rights and groundwater management in New Mexico and the western United States. Hydrogeol J 12:40-51

Figureau A-G, Montginoul M, Rinaudo J-D (2015) Policy instruments for decentralized management of agricultural groundwater abstraction: a participatory approach. Ecol Econ 119:147157

Garrido A, Llamas MR (2009) Water management in Spain: an example of changing paradigms. In: Dinar A, Albiac J (eds) Policy and strategic behavior in water resources management. Earthscan, London

Giordano M, Villholt KG (2007) The agricultural groundwater revolution: opportunities and threat to development. CAB International

Gray T, Korda RC, Stead S, Jones E (2011) Quota discarding and distributive justice: the case of the under-10 m fishing fleet in Sussex, England. Mar Policy 35:122-129

Gross C (2011) Why justice is important. In: Connell D, Grafton Q (eds) Basin futures: water reforms in the Murray Darling basin. The National Australian University Press, Canberra, pp 149-162

Hearne RR, Donoso G (2005) Water institutional reforms in Chile. Water Policy 7:53-69

Khalilian S, Froese R, Proelss A, Requate T (2010) Designed for failure: a critique of the Common Fisheries Policy of the European Union. Mar Policy 34:1178-1182

Lamont J, Favor C (2012) Distributive justice. In: Zalta EN (ed) The Standford Encyclopedia of Philosophy. Standford University, http://plato.stanford.edu/

Loubier S, Campardon M, Morardet S (2013) L'irrigation diminue-t-elle en France ? Premiers enseignements du recensement agricole de 2010. Sciences, Eaux et Territoires 11:12-19

Mill JS (1940) Utilitarianism, liberty and responsive government. J. M. Dent, London (Original work published in 1861)

Movik S (2014) A fair share? Perceptions of justice in South Africa's water allocation reform policy. Geoforum 54:187-195

Nancarrow BE, McCreddin JA, Syme GJ (1998) Developping fair processes for the reallocation of groundwater for long term sustainability in the Namoi Valley. Consultancy report $98 * 40$. Australian Research Center for Water and Society, CSIRO Land and Water, Canberra

Nielsen K (1979) Radical egalitarian justice: justice as equality. Soc Theory Pract 5:209-226

Nozic R (1974) Anarchy, state and utopia. Blackwell, Oxford

NRMSC NRMSC (2002) Case examples of managing over-allocated groundwater systems. NRMM, Canberra

Ostrom E (1990) Governing the commons: the evolution of institutions for collective action. Cambridge University Press, Cambridge 
Presser J (1994) Distributive justice in allocating individual catch quota in a fishery. In: 38th conference of the Australian agricultural Economics Society, Australian agricultural Economics Society, Wellington

Rawls J (1971) A theory of justice. Harward University Press, Cambridge, MA

Roa-García MC (2014) Equity, efficiency and sustainability in water allocation in the Andes: trade-offs in a full world. Water Altern 7(2):298-319

Ross A, de Santos M (2009) The challenge of groundwater governance: case studies from Spain and Australia. Reg Environ Change 10(4):299-310

Sadurski (1985) Giving desert its due: social justice and legal theory. In: Law and philosophy library, vol 2. D. Reidel, Dordrecht

Schlager E (2006) Challenges of governing groundwater in U.S. western states. Hydrogeol J 14:350-360

Suchman MC (1995) Managing legitimacy: strategic and institutional approaches. Accad Manage Rev 20:571-610

Syme GJ, Nancarrow BE (1996) Planning attitudes, lay philosophies and water allocation: a preliminary analysis and research agenda. Water Resour Res 32:1843-1850

Syme GJ, Nancarrow BE (1997) The determinants of perceptions of fairness in the allocation of water to multiple uses. Water Resour Res 33:2143-2152

Syme GJ, Nancarrow BE (2006) Achieving sustainability in water reform: a Western Australia case study. Water Int 31:23-30

Syme GJ, Nancarrow BE, McCreddin JA (1999) Defining the components of fairness in the allocation of water to environmental and human uses. J Environ Manage 57:51-70

van Koppen B, Schneiner B (2014) Priority general authorisations in right-based water authorization in South Africa. Water Policy 59-77 


\section{Part III}

Biophysical Aspects 


\title{
Ecohydrology and Its Relation to Integrated Groundwater Management
}

\author{
Randall J. Hunt, Masaki Hayashi, and Okke Batelaan
}

\begin{abstract}
In the twentieth century, groundwater characterization focused primarily on easily measured hydraulic metrics of water storage and flows. Twenty-first century concepts of groundwater availability, however, encompass other factors having societal value, such as ecological well-being. Effective ecohydrological science is a nexus of fundamental understanding derived from two scientific disciplines: (1) ecology, where scale, thresholds, feedbacks and tipping points for societal questions form the basis for the ecologic characterization, and (2) hydrology, where the characteristics, magnitude, and timing of water flows are characterized for a defined system of interest. In addition to ecohydrology itself, integrated groundwater management requires input from resource managers to understand which areas of the vast world of ecohydrology are important for decision making. Expectations of acceptable uncertainty, or even what ecohydrological outputs have utility, are often not well articulated within societal decision making frameworks, or within the science community itself. Similarly, "acceptable levels of impact" are difficult to define. Three examples
\end{abstract}

\footnotetext{
R.J. Hunt $(\bowtie)$

Wisconsin Water Science Center, United States Geological Survey, 8505 Research Way, Middleton, WI 553562, USA

Department of Geoscience, University of Wisconsin-Madison, 1215 West Dayton Street, Madison, WI 53705, USA

e-mail: rjhunt@usgs.gov

M. Hayashi

Department of Geoscience, University of Calgary, 2500 University Drive Northwest, Calgary, AB, T2N 1N4, Canada

e-mail: hayashi@ucalgary.ca

O. Batelaan

School of the Environment, Flinders University, GPO Box 2100, Adelaide, SA 5001, Australia e-mail: okke.batelaan@flinders.edu.au
} 
are given to demonstrate the use of ecohydrological considerations for long-term sustainability of groundwater resources and their related ecosystem function. Such examples illustrate the importance of accommodating ecohydrogeological aspects into integrated groundwater management of the twenty-first century, regardless of society, climate, or setting.

\subsection{Introduction}

Groundwater resource characterization in the past was typically based on relatively easily estimated hydraulic metrics of water storage and flows within aquifers (see Chap. 3). This characterization occurred on smaller site scales to larger regional assessment, and employed well-established "classic" hydrogeological methods (Fig. 12.1). In the twenty-first century, however, such accounting approaches can miss a fundamental societal decision-making issue - there is no "unused" water in the environment (Hunt 2003). Because of mass balance, what is taken for a new use comes at the expense of an existing one. Recognizing the need to include this tradeoff, groundwater resources are now evaluated in terms of water availability. In such a view, a more holistic view of the groundwater system is required, one that includes non-hydraulic factors such as ecological degradation. For example, although a shallow unconfined aquifer might have a saturated thickness of $100 \mathrm{~s}$ of meters, even small drawdowns can markedly change groundwater discharge to surface water features and associated ecological functions valued by society (Reilly et al. 2008). Thus, the system is characterized by large groundwater storage, but the storage actually available for use, as decided by non-hydraulic factors, is much less (Alley 2007).

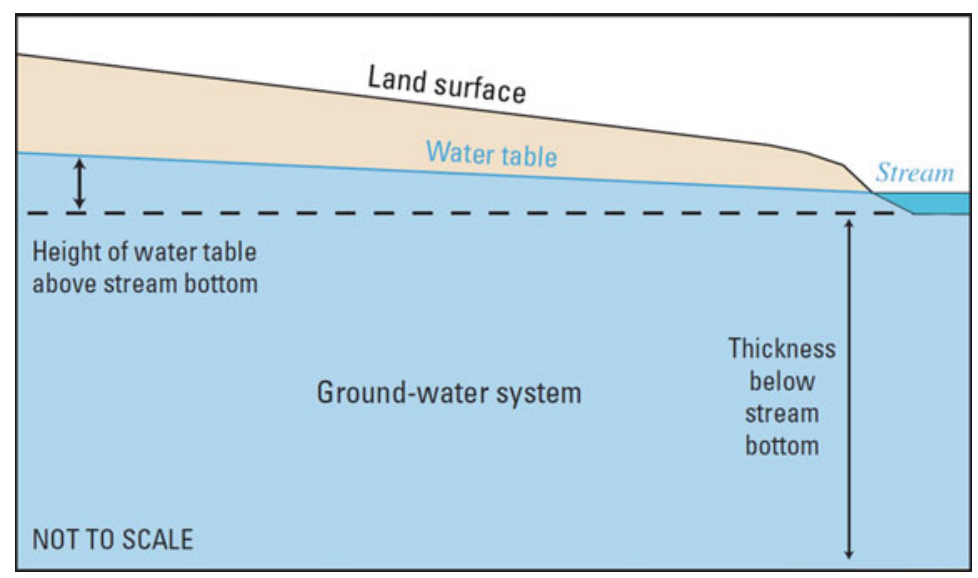

Fig. 12.1 An example of differences in water stored in an aquifer (large arrow on right) and the smaller amount of water available (small arrow on left) as determined by a societal desire to maintain surface water flow (Modified from Reilly et al. 2008) 
Unconsolidated sediments in humid climates typify this issue. These deposits are commonly characterized by a high water-table elevation and high degree of connectedness/interaction between groundwater and surface waters, and in turn, associated ecosystems. Groundwater withdrawals from unconfined aquifers not only intercept groundwater that would discharge to surface waters and associated ecosystems, but can directly capture water from the stream under certain pumping conditions (Fig. 13, Alley et al. 1999). In either case, associated diversion of groundwater by drainage and well abstraction can be expected to stress local groundwater-dependent ecosystems (GDEs). In arid areas, the importance of groundwater is also seen, where the landscape singularities of higher moisture drive high levels of ecosystem production (Springer and Stevens 2009). Thus, a very small portion of the land surface can be responsible for the majority of the arid ecosystems' value. In these ways, groundwater is not only a resource to be exploited, but is also a hidden connector across the landscape (Hunt 2003). This connection transmits stress within the aquifer itself, and across and between surface waters (Winter et al. 1998) and many aquatic and terrestrial ecosystems. For GDEs, where the water table intersects or comes close to the land surface, the timing and magnitude of groundwater flow and related nutrient fluxes can be critical to ecosystem formation and persistence. Consider that precipitation is the dominant source of water in nearly all wetland systems in humid climates, yet the influence of the groundwater flow component can be sufficient (from an ecological perspective) to yield an entire new type of wetland community often valued by society, the fen (e.g., Amon et al. 2002). Influxes of groundwater to lakes, rivers, and wetlands can change whole-system physico-chemical properties (e.g., Anderson and Bowser 1986) including temperature and salinity, while also providing more subtle influences on microenvironments and ecological processes such as (e.g., Hurley et al. 1985). Infiltration of water from surface aquatic ecosystems also has a significant effect on aquifer ecology, especially on microbes and invertebrates (e.g., Hunt et al. 2006). Moreover, surface ecological processes such as evapotranspiration have long been recognized as potentially influencing hydrological responses (e.g., Meyboom 1964, 1966) and related hydrochemical function. Thus, the relation of groundwater hydrology to patterns and processes in ecology is a 'two-way street' where understanding the feedback of one to the other serves as a powerful lens through which to evaluate and explain the functioning of natural ecosystems (Hancock et al. 2009).

One difficulty for standard application of broad ecohydrological concepts to integrated groundwater management is that types of groundwater-ecology links can be wide-ranging - they can include the well-recognized relations found at the groundwater/surface-water interface such as water-plant interactions or groundwater-temperature-fish relations, but also less well-known topics such as microbial community characterization at the periphery of a contaminant plume. Thus, it is perhaps not surprising that standard ecohydrological procedures and metrics do not exist, and the significance and power of this ecohydrological tandem has not always been followed with effective interdisciplinary science. That is, the encompassing ecological, hydrological, and physico-chemical links between 
groundwater, surface waters and associated ecosystems are seldom fully understood, even though true characterization and optimal management may require such an encompassing multidisciplinary view. Shortcomings in our ability to perform true characterization notwithstanding, overarching concepts of application to integrated groundwater management can be developed, and much can be learned from successful (and unsuccessful) attempts at ecohydrology.

One way to characterize the overarching interplay between ecology and hydrology is this: consideration of ecohydrological issues enhances understanding amongst biologists, as hydrogeology provides the abiotic "box", within which ecological processes play out. Biologists and ecologists articulate defining characteristics of groundwater flows required for their societally relevant target insight that requires the skills of hydrogeologists to attain. Hydrogeologists, in turn, must understand how and why groundwater influences ecological processes so that their expertise is effectively brought to bear on the ecological question (Hunt and Wilcox 2003a, b). Moreover, hydrogeologists have to recognize that the ecological system can influence the groundwater system most notably by evapotranspiration from shallow groundwater (Batelaan et al. 2003). Ecological factors help define important spatial and temporal scales, which in many cases are smaller than classical hydrogeologic characterization. In addition, ecological factors facilitate identification of qualitative levels of certainty needed in abiotic characterizations. Learning about ecological thresholds and tipping points for the societal question at hand helps define the work needed, and ensure it is tackled efficiently. An ecological threshold can be described as a system condition whereby a small change in external conditions causes a rapid change in an ecosystem, and passing the ecological threshold leads to rapid change of ecosystem health. An ecological tipping point is where the change moves from one stable state to another stable state, often irreversibly. To understand how a threshold can influence decision making, consider the selection of a pipe sized to convey a well's pumpage that is somewhat uncertain (Hancock et al. 2009): pipe sizes come in a set range of diameters so estimated pumpage is evaluated with the pipe-size thresholds in mind. If one is relatively certain that a pipe diameter (threshold) will not convey the estimated pumpage, then a larger diameter of pipe is chosen. Knowledge of pipe-size thresholds simplifies and directs the question into a form much different than trying to estimate the exact rate of well pumpage itself. In a similar ecohydrological context, the ecological threshold of a stream drying up is a very different abiotic forecast than estimating various degrees of low flow in a perennial stream. Therefore, the ecological threshold can simplify and direct the types of hydrogeological investigation brought to bear to characterize the system appropriately.

Identification of which thresholds and tipping points are societally important is often provided by the resource managers, and thus can be considered an important link for effective integrated groundwater management. A societal context for science has become increasingly important (e.g., Boland 2010; Guillaume et al. 2012); resource managers are better acquainted with competing needs and rank of societally valued ecosystem services. Thus, they are critical for including in the discussion of tradeoffs of one versus another, and ranking which areas of 
ecohydrology are societally relevant for decision making. Their input elucidates connections between groundwater and terrestrial/subterranean ecosystems that facilitate holistic management of natural systems, and helps create a complete listing of the threats and mitigation opportunities. Such input moves discussions of water availability to long-term sustainability of the resource and its ecosystem goods and services. Such a multi-discipline approach is needed to effect true integrated groundwater management.

In this chapter a historical background and examples of ecohydrology and integrated groundwater management are provided with these considerations in mind. Because the range of potential societally relevant ecological endpoints is vast, we focus on transferable elements contained within the examples rather than problem-specific insight. The chapter concludes with discussion of concepts and approaches for including ecohydrological considerations into integrated groundwater management. Using the dimensions of integrated groundwater management outlined in Chap. 1, ecohydrology can be seen as integration of multiple disciplines assessing natural and human systems across multiple scales of space and time. This integration, in turn, gives an encompassing foundation for discussion involving stakeholders, resource managers, and decision-makers. It should be noted that the topic of groundwater dependent ecosystems is sufficiently large and important for integrated groundwater management that it warrants its own chapter (Chap. 13). Therefore, these important systems are discussed only cursorily here.

\subsection{Background of Ecohydrology and Water Management}

In the last 10 years ecohydrology has been developed as a new scientific discipline. Recently its importance has been stressed in relation to hydro(geo)logy and ecology but also a wider range of ideas within the broad field of "ecohydrology". Elements of the history of ecohydrology are described here, which provide a foundation for the role of ecohydrology in groundwater management.

Several definitions of "ecohydrology" have been published:

- Wassen and Grootjans (1996): 'An application driven discipline aiming at a better understanding of hydrological factors determining the natural development of wet ecosystems, especially in regard of their functional value for natural protection and restoration'.

- Baird and Wilby (1999): 'Eco-hydrology is the study of plant-water interactions and the hydrological processes related to plant growth'.

- Eamus et al. (2006): 'Ecohydrology is the study of how the movement and storage of water in the environment and the structure and function of vegetation are linked in a reciprocal exchange.'

- Rodriguez-Iturbe (2000): 'Eco-hydrology seeks to describe the hydrological mechanisms that underlie ecological pattern and processes'. 
- Nuttle (2002): 'Eco-hydrology is ... concerned with the effects of hydrological processes on the distribution, structure and function of ecosystems, and on the effect of biological processes on the elements of the water cycle'.

- Hunt and Wilcox (2003a): 'ecohydrology (is) defined ... as tightly coupled research in which both (ecology and hydrology) disciplines are equally involved in the formulation of the research objective, design of the work plan, and on-going interpretation.'

The range of definitions clearly shows an imprint of the background from which different authors approach the field of ecohydrology, ranging from wetlands (nature protection), plant-water interaction, and, more recently, emphasis on bi-directional understanding provided by integrated application of hydrology, micrometeorology, and ecology.

Since 2000, ecohydrology has become popular in hydrological literature, including both dryland hydrology such as soil moisture-limited evapotranspiration processes (Rodriguez-Iturbe 2000; Eagleson 2002; Rodriguez-Iturbe and Porporato 2004), effects of streamflow and temperature on temperate climate biotic communities (e.g., Boulton and Hancock 2006; Hunt et al. 2006; Olson and Young 2009), and even using viruses as tracers of groundwater flow (Hunt et al. 2014). This recent interest in ecohydrology notwithstanding, much is to be gained by consideration of pre-2000 ecohydrological research roots, some of which have clear groundwater, and groundwater management, origins.

Early humans undoubtedly had some ecohydrological consciousness, as the recognition of certain plant species warned him of dangerous places where he could drown, or offered opportunities to find food. One of the earliest transcripts reporting on the topic comes from the Bible. Ross (2007) interprets and translates the Hebrew bible text of Isaiah 44 in modern language as: 'I will pour out My spirit as suddenly and overwhelmingly as a rainstorm in the desert. After such a storm, the willow does not fade like grass, but is kept green for many years by groundwater that recharges in the storm'. Obviously, this expresses some form of early 'ecohydrological' observations relating rainfall-recharge-groundwater with plant species occurrence. Vitruvius (15 BC) (1913), roman architect and engineer in the first century, wrote this concerning exploration of drinking water: 'One of the indications where groundwater can be found is the occurrence of small rushes, willows, alder, vitex, reeds and ivy'. Moreover he remarks: 'one must not rely on these plants if they occur in marshes, which receive and collect rain water'. Hence, he was well aware of the relativity of the plants as indicators for good quality groundwater, differences between sources of water, and the usefulness of ecological indicators for groundwater-drinking water management.

In tenth century AD, Mohammed ibn al-Hasan al-Hasib al-Karaji included a more holistic consideration of the subsurface into ecohydrology. Karaji was a mathematician and engineer who mainly lived and worked in Baghdad. In an effort to support the water resources exploration of his native Persia during the later stages of his career, he wrote the book 'The Extraction of Hidden Waters to the Surface', which is regarded the oldest textbook in hydrology/groundwater science (Nadji and 
Voigt 1972; Pazwash and Mavrigian 1980). In the book, Karaji includes techniques for the exploration of groundwater such as wells and qanats - techniques still used today in many parts of the Middle East and Asia. He also examines how plants indicate the presence of groundwater by studying the roots of plants and how they grow towards the water table, and includes a report of a well digger who found roots at a depth of $50 \mathrm{~m}$ (Nadji and Voigt 1972; Pazwash and Mavrigian 1980). From this treatise, it is clear that Karaji had a surprising good understanding of groundwater and hydrological processes, and used this understanding to further develop ecohydrological relationships with vegetation.

In the mid-nineteenth century, the famous work of engineer Henri Darcy revolutionized this early understanding of groundwater flow. Often overlooked in the pioneering work of Darcy (1856), however, is the fact that it contains a description for the search for drinking water by spring seeker Father Paramelle, in addition to the much better-known column tests. Darcy relates how Father Paramelle infers the probable presence of water, and even the approximate depth of the water below the ground surface, from the nature and strength of the plants. Paramelle (1859) documents his methods in detail, which are notable for using a multidisciplinary approach that includes careful observation and evaluation of geology, mineralogy, topography and vegetation. His methods provided water for many communities in France, where he identified more than 10,000 springs.

Later in the nineteenth century, botanist A.F.W. Schimper focused on the detailed knowledge of plants and their specific habitats, and illustrated an important distinction between wet, hygrophyte and dry, xerophyte plant species. The difference lies in the plant physiology: if a soil contains too much salt, the plants cannot absorb the water and hence it is physiologically dry. All soils which are physically dry are also physiologically dry; and hence only the physiological dryness or wetness of soils need be considered in ecology of plant communities near the ends of this gradient (Schimper 1898). O.E. Meinzer, the father of modern groundwater hydrology, was the first to define the term phreatophyte as a plant that habitually obtains its water supply from groundwater (Meinzer 1923). In 1927, he wrote an entire book about these phreatophytes (Meinzer 1927). In it, he describes the principal phreatophytic species, like common salt grass (Distilchlis spicata) and their occurrence in the arid and semi-arid regions of the US. With this understanding, Meinzer and other groundwater hydrologists could then use plants as indicators for locations of groundwater resources.

After the first half of the twentieth century, the use of phreatophytes in groundwater studies became less prominent in the hydrogeological literature; however, ecologists continued the study of plant habitat requirements (Londo 1988; Ellenberg et al. 1992). Ecologists interested in plant community composition, development, and species relations ("phytosociologists") started to research the relationship between vegetation types and groundwater dynamics in the 1950s. Ellenberg $(1948,1950,1952,1953,1974)$ and Tüxen (1954) systematically studied the relation between groundwater level and the occurrence of vegetation types. More recently, interest in phreatophytes again became a prominent topic of study following the interest and formal need for protection (European Union 2000, 2006) 
of groundwater dependent ecosystems (Batelaan et al. 2003; Witte and von Asmuth 2003; Loheide et al. 2005).

The first publication in which the word 'ecohydrology' is mentioned is from the Dutch author van Wirdum (1982), and came about through a groundwater management concern. In van Wirdum's annual report of the activities of the Dutch National Institute for Nature Research, one sees a growing recognition for ecological values of wetlands (Grootjans et al. 1988; Wassen et al. 1990; Mitsch and Gosselink 1993). This recognition was driven by an observed deterioration of high ecological functions of wetlands due to poor water management. For example, desiccation resulting from groundwater abstraction and agricultural drainage, along with water pollution (Schot et al. 1988) were identified as important factors reducing biodiversity. Hence, even with this early use of the word 'ecohydrology' it was understood that groundwater management could significantly influence ecological values.

\subsection{Examples of Ecohydrology and Water Management}

Groundwater has well-recognized ecological functions including: (1) sustaining stream base flow and moderating water-level fluctuations of groundwater-fed lakes and wetlands, (2) providing stable-temperature habitats, (3) supplying nutrients and inorganic ions, and (4) providing moisture for riparian and other groundwaterdependent vegetation (Hayashi and Rosenberry 2002). The importance of these functions is being incorporated in water management policies of European countries through the Water Framework and Groundwater Directives (European Union 2000, 2006), and has been gaining recognition in other parts of the world over the past decade or so. The following three examples explore how the considerations of the interaction of the ecosystem with the groundwater system influenced management of the resource.

\subsubsection{Temperate Climate: United Kingdom}

The European Water Framework and its progeny Groundwater Directive require assessment of the status of groundwater bodies with respect to various criteria including the condition of a groundwater-dependent terrestrial ecosystem. Using wetlands as an example of a groundwater-dependent ecosystem, Whiteman et al. (2010) describe a screening tool to assess wetland condition by examining three factors: (1) condition of source groundwater (rate of abstraction, concentration of contaminants, etc.), (2) connectivity between groundwater and the wetland, and (3) ecological response of the wetland to changes in hydrological condition. By assigning scores to the three criteria at 1,368 test sites in England and Wales, they identified 63 wetlands as having high risk from abstraction pressures and 117 from contamination pressures. Once a potentially high-risk site is identified, site-specific 
investigation is initiated to assess the actual condition of groundwater and, if poor condition is confirmed, potential mitigation measures are explored.

For example, Hurcott and Podmore Pools is a series of pools and marginal wetlands within a large alder wetland/woodland in Worcestershire (Whiteman et al. 2010). The main sources of water for the pools are surface water inflows from the upstream catchment and groundwater discharge from a major sandstone aquifer, which is also an important public water supply. Unsustainable groundwater abstraction from the aquifer caused a wide-scale drawdown of water levels in the aquifer (poor condition of source water), which significantly reduced stream inflows to the site and eliminated direct groundwater discharge to the site (poor connectivity), and which in turn resulted in a measurable change in vegetation community composition (ecological response). Detailed site assessment suggested that summer maximum water-table depths should be less than $0.45 \mathrm{~m}$ to support the ecosystem; however, water-table fluctuations up to $0.7 \mathrm{~m}$ were observed. Based on these observations and numerical groundwater modeling results, a Water Level Management Plan (Whiteman et al. 2010) was proposed and implemented to raise the water table and to potentially change the groundwater abstraction regime.

\subsubsection{Semi-Arid Climate: Kansas, United States}

The State of Kansas in the USA has a long history of integrated groundwater management, which provides a useful case study to demonstrate the paradigm shift in groundwater management. The following summary of the Kansas case study has been largely drawn from a major body of work by Marios Sophocleous at the Kansas Geological Survey. Irrigation is the largest user of water in Kansas, accounting for 80-85\% of total water use (KWO 2009), most of which comes from groundwater extracted from the High Plains aquifer. Groundwater abstraction rapidly increased after the enactment of the Kansas Water Appropriation Act in 1945, which permitted water rights to users for "beneficial use" (Sophocleous 2011). By the late 1960s, too many water rights had been permitted, enabling over-development of the High Plains aquifer resulting in the mining of groundwater resources (Sophocleous 1998). To prevent further mining of groundwater, five Groundwater Management Districts (GMDs) were established, covering most of the extent of the High Plains aquifer, and a "safe-yield" management policy was adopted in the GMDs (Sophocleous 2000).

The aim of this management policy was to balance groundwater withdrawals with aquifer recharge by limiting the total water abstraction in a $3.2-\mathrm{km}$ circle around any proposed new abstraction to be less than the long-term average annual recharge (Sophocleous 2000). This policy had an effect of slowing the rate of watertable declines in the aquifer, but the policy did not stop the decline. More importantly, the safe-yield concept was known to be problematic in practice (e.g., Thomas and Leopold 1964) as it gives no consideration to maintaining naturally occurring groundwater discharge that sustains the perennial flow of streams (Sophocleous 1997). As a result, stream flows and associated riparian and aquatic 
ecosystems in western and central Kansas steadily declined and the related ecosystem deteriorated (Sophocleous 1998).

Recognizing that streams and aquifers are closely linked and have to be understood and managed together, in the early 1990s some of the GMD's moved toward conjunctive stream-aquifer management by including baseflow in the evaluation (Sophocleous 2000). In other words, baseflow is considered a societal value that it has been given a water right on its own. This shifts the focus from the problematic aquifer safe-yield paradigm to a more holistic sustainable system water management paradigm. It was hoped that the new measure, together with the legal establishment of minimum-desirable streamflow standard in 1984, would provide needed protection to the riverine-riparian ecosystem (Sophocleous 2011). As a result of GMD actions, pumping rates of groundwater in Kansas leveled off after decades of increases. However, the aquifer had already been mined to a significant reduction of saturated thickness and many streams had deteriorated due to earlier over-development (Sophocleous 1998). The long-term goal of the GMDs is to reduce the rate of water use in order to prolong the life of the aquifer and maintain the remaining groundwater-dependent terrestrial ecosystem. Towards this goal, Intensive Groundwater Use Control Areas (IGUCAs) were established in locations where unfavorable conditions existed, including situations where groundwater use was adversely depleting streamflow and adversely affecting ecology (Sophocleous 2011). Such a tiered designation is a powerful tool that allows the use of a variety of measures, including the reduction in existing water rights, to solve groundwater and ecological issues.

In addition to the revised safe-yield policy explicitly considering baseflow and the use of IGUCAs, Kansas has been using innovative measures to enhance the riverine-riparian ecosystems. For example, private, not-for-profit water-bank systems are used to provide open-market approach for temporarily moving water rights from inactive users to active users (Stover et al. 2011). The Conservation Reserve Enhancement Program is used to give economic incentive to owners of irrigated land to retire lands located in sensitive areas, for example along river corridors of drying streams (Leatherman et al. 2006). In order to enhance integrated water management of groundwater-dependent ecosystems, Sophocleous (2007, 2011) suggests that: (1) the definition of "beneficial" water use must be expanded from traditional irrigation and other consumptive uses to include water conservation and instream flow needs; (2) domestic and other wells that are currently exempted must be included with regulated uses; and (3) increased flexibility of regulatory requirements regarding transferring water rights is needed.

\subsubsection{Arid Climate: Australia and United States}

The above examples demonstrate groundwater management efforts to support riverine-riparian ecosystems. In some water-scarce regions, however, riparian trees were deemed harmful to stream ecosystems because they take up and transpire groundwater that would otherwise be available to sustain baseflow. Doody 
et al. (2011) present a review of case studies from the western USA and southeastern Australia, where removal of non-native riparian vegetation has been attempted to reduce transpiration diversion and enhance stream flow. In the western USA, non-native phreatophyte, saltcedar (Tamarix spp.) had spread along many river bottoms by the 1950s and became a primary target of water "salvage" projects (Robinson 1965). Contrary to the original perception that saltcedar had a higher water use compared with native species, many years of studies including large-scale tree removal experiments have shown that the reduction in evapotranspiration by the removal of saltcedar had no measureable effect on streamflow. This surprising finding was due to similar transpiration rates between the non-native saltcedar and the vegetation community that was established after the saltcedar was removed. In this case, unexpected ecological aspects confounded the expected hydrologic response. Other ecohydrological work showed similar results: no large-scale removal experiments in arid settings have shown the expected return of increased stream flow.

In the Murray-Darling Basin in south-eastern Australia, colonization of the non-native phreatophyte, willow (Salix spp.) has also been associated with a number of undesirable impacts on stream ecosystems, including increased water uptake and transpiration, and subsequent reduction in streamflow. Similar to the United States saltcedar, site-scale studies have shown that willows growing in the riparian zone have evapotranspiration rates similar to native Eucalyptus spp., suggesting that removing willow from stream banks will have little effects on net stream flow (Doody et al. 2011). However, unlike saltcedar, willow growth has other hydrologic effects beyond capture and transpiration of groundwater that would discharge to streams. That is, it also grows within wet stream channels and reduces flow velocity. The reduction in velocity facilitates water capture, and because the willow is rarely water limited, they can transpire at a higher rate than open-water evaporation (Doody and Benyon 2011). Because the native Eucalyptus more commonly grows on river banks and not in the channel, the removal of willow from within stream channel is expected to result in significant water salvage. These examples indicate the importance of understanding eco-hydrological processes specific to the problem - in this case water uptake by trees - to design effective methods of integrated groundwater management.

\subsection{Incorporating Ecohydrology into Integrated Groundwater Management}

Taken as a whole, concepts and approaches discussed above lead to salient insight into how ecohydrological considerations can be integrated with groundwater management.

1. Groundwater availability constraints in highly connected groundwater and surface water systems are a function of both ecosystem degradation and water-use 
needs. Even though the latter is often an initial primary driver, aspects of the former often become key drivers for decisions of allowable water use. Therefore, sustainability of the groundwater resource can be expected to be tied to ecohydrological drivers.

2. Hydrologic measurements (e.g., streamflow statistics or water-table depth in a wetland) allow decision makers to obtain quick snapshots of the system of interest. These "sentinel metrics", however, are often an indirect measure of what is considered valuable. Therefore, these sentinels need to be formally recognized by stakeholders as surrogates for societally-relevant system qualities. The identification of a set of surrogate sentinel metrics is critical for integrated groundwater management because full system characterization after each management change is not feasible. Moreover, the real-time insight of properly identified sentinel metrics can move an adaptive management plan from simple monitoring to proactive actions that can mitigate ecosystem degradation.

3. Many integrated groundwater management questions are complex - both in ways systems interact as well as feedback mechanisms that mitigate or exacerbate the effect of potential change. Such questions may require hydrologic or ecologic characterizations that are more holistic and comprehensive than sentinel metrics. The goal of this higher level of ecohydrological work is development of a quantitative framework for how much degradation can be expected for differing levels of groundwater withdrawals (or diversions). This allows quantification of the trade-offs inherent to ecohydrology, which in turn can inform cost-benefit analyses conducted by stakeholders. Characteristic functions of ecosystem response, such as response curves (e.g., GCAC 2007; Chap. 6), thresholds, and tipping points, for species of interest give language and help visualize tradeoffs between water use and ecosystem degradation - evaluations inherent to integrated groundwater management.

4. There is a need to translate each science and resource manager concern into terms and metrics that are understandable to all involved. Ecologists may resist having their science being held to the precision that hydrogeologists routinely report, yet are comfortable focusing on thresholds and tipping points for their ecosystem. Successful integrated groundwater management will, in large measure, be a reflection of how well the interaction between ecology and hydrology aspects is articulated.

5. Similar to an adaptive management framework, integrated groundwater management must recognize that many of the underlying feedback loops and system complexity will never be fully understood, especially given the relatively short timeframe of most decision-making. Yet, just as with the adaptive management approach to handling confounding uncertainty, the integrated groundwater management framework can form the crucible of hypothesis testing, where it distills all possible ecohydrological research topics to a subset that can be prioritized. In this way, integrated groundwater management provides a relevance that may be missing in simple academic ecohydrological endeavours. An effective integrated groundwater management plan is expected to include aspects of applied research that focuses on spatial and temporal scales relevant to both the hydrogeological 
and the ecological process being studied. This is important to note since historically, hydrogeological studies often are performed on the aquifer or site scale, thus using approaches and generating data too broad for understanding many ecological processes on a site or smaller scale. Moreover, both hydrogeological and ecological foci may have not been optimally tuned for the resource management question of primary interest.

\subsection{Summary}

In summary, the demands of twenty-first century integrated groundwater management might be considered to precede the maturation of ecohydrological science, a view that might be concluded from the lack of dominant textbooks published or widely accepted common guidelines. However, we believe there are many necessary and common elements in current science methods that have direct application to today's integrated groundwater management. Moreover, formally including societal drivers as the basis for ecohydrological action provides an important foundation for effective ecohydrology in the twenty-first century. Such a focus can only help move the societally relevant and necessary science of ecohydrology into effective integrated management.

Open Access This chapter is distributed under the terms of the Creative Commons AttributionNoncommercial 2.5 License (http://creativecommons.org/licenses/by-nc/2.5/) which permits any noncommercial use, distribution, and reproduction in any medium, provided the original author(s) and source are credited.

The images or other third party material in this chapter are included in the work's Creative Commons license, unless indicated otherwise in the credit line; if such material is not included in the work's Creative Commons license and the respective action is not permitted by statutory regulation, users will need to obtain permission from the license holder to duplicate, adapt or reproduce the material.

\section{References}

Alley WM (2007) Another water budget myth: the significance of recoverable ground water in storage. Ground Water 45(3):251. doi:10.1111/j.1745-6584.2006.00274.x

Alley WM, Reilly TE, Franke OL (1999) Sustainability of ground-water resources, United States Geological Survey Circular 1186. Reston, VA. http://pubs.usgs.gov/circ/circ1186/

Amon JP, Thompson CA, Carpenter QJ, Miner J (2002) Temperate zone fens of the glaciated Midwestern USA. Wetlands 22(2):301-317

Anderson MP, Bowser CJ (1986) The role of groundwater in delaying lake acidification. Water Resour Res 22(7):1101-1108

Baird AJ, Wilby RL (1999) Eco-hydrology: plants and water in terrestrial and aquatic environments. Routledge, London

Batelaan O, De Smedt F, Triest L (2003) Regional groundwater discharge: phreatophyte mapping, groundwater modelling and impact analysis of land-use change. J Hydrol 275(1-2):86-108 
Boland M (2010) AGU congressional fellow outlines challenges for scientists. Eos Trans Am Geophys Union 91(48):461. doi:10.1029/2010EO480006

Boulton AJ, Hancock PJ (2006) Rivers as groundwater-dependent ecosystems: a review of degrees of dependency, riverine processes and management implications. Aust J Bot 54:1-12

Darcy HPG (1856) The public fountains of the City of Dijon. English translation by Bobeck P (2004) Kendall/Hunt Publishing Company, Dubuque, 506 pp

Doody TM, Benyon RG (2011) Quantifying water savings from willow removal in Australian streams. J Environ Manage 92:926-935

Doody TM, Nagler PL, Glenn EP, Moore GW, Morino K, Hultine KR, Benyon RG (2011) Potential for water salvage by removal of non-native woody vegetation from dryland river systems. Hydrol Process 25:4117-4131

Eagleson PS (2002) Ecohydrology: darwinian expression of vegetation form and function. Cambridge University Press, Cambridge

Eamus D, Hatton T, Cook P, Colvin C (2006) Ecohydrology: vegetation function, water and resource managemen. CSIRO Publishing Collingwood, Victoria, 360 pp. ISBN ISBN: 9780643068346

Ellenberg H (1948) Unkrautgesellschaften als Mass für den Säuregrad, die Verdichtung und andere Eigenschaften des Ackerbodens. Ber Landtech 4:2-18

Ellenberg H (1950) Landwirtschaftliche Pflanzensoziologie. I: Unkrautgemeinschaften als Zeiger für Klima und Boden. Ulmer, Stuttgart

Ellenberg H (1952) Landwirtschaftliche Pflanzensoziologie. II: Wiesen und Weiden und ihre standörtliche Bewertung. Ulmer, Stuttgart

Ellenberg H (1953) Physiologisches und ökologisches Verhalten derselben Pflanzenarten. Ber Deutsch Bot Ges 65:351-361

Ellenberg H (1974) Zeigerwerte der Gefässpflanzen Mitteleuropas, Scripta Geobotanica 9. Verlag Erich Goltze, Göttingen, pp 1-97

Ellenberg H, Weber HE, Düll R, Wirth V, Werner W, Pauliszen D (1992) Zeigerwerte der Gefässpflanzen (ohne Rubus), Scripta geobotanica. Verlag Erich Goltze, Göttingen, pp 9-166

European Union (2000) Directive 2000/60/EC of the European Parliament and of the Council of 23 October 2000 establishing a framework for Community action in the field of water policy. Available online at: http://ec.europa.eu/environment/water/water-framework/

European Union (2006) Directive 2006/118/EC of the European Parliament and of the Council of 12 December 2006 on the protection of groundwater against pollution and deterioration. Available online at: http://ec.europa.eu/environment/water/water-framework/groundwater. html

Grootjans AP, van Diggelen R, Wassen MJ, Wiersinga WA (1988) The effect of drainage on groundwater quality and plant species distribution in stream valley meadows. Vegetatio $75: 37-48$

Groundwater Conservation Advisory Council (2007) Report to the Michigan Legislature in response to 2006 Public Act 34. Available online at: http://www.isws.illinois.edu/iswsdocs/ wsp/MI_Groundwater_rpt.pdf

Guillaume JHA, Qureshi ME, Jakeman AJ (2012) A structured analysis of uncertainty surrounding modeled impacts of groundwater-extraction rules. Hydrogeol J 20:915-932. doi:10.1007/ s10040-012-0864-0

Hancock PJ, Hunt RJ, Boulton AJ (2009) Preface: hydrogeoecology, the interdisciplinary study of groundwater dependent ecosystems. Hydrogeol J 17(1):1-4. doi:10.1007/s10040-008-0409-8

Hayashi M, Rosenberry DO (2002) Effects of ground water exchange on the hydrology and ecology of surface water. Ground Water 40:309-316

Hunt RJ (2003) A water science primer. Wis Acad Sci Arts Lett Trans 90:11-21

Hunt RJ, Wilcox DA (2003a) Ecohydrology - why hydrologists should care. Ground Water 41 (3):289. doi:10.1111/j.1745-6584.2003.tb02592.x

Hunt RJ, Wilcox DA (2003b) Response to comment of ecohydrology - why hydrologists should care. Ground Water 41(5):562-563. doi:10.1111/j.1745-6584.2003.tb02393.x 
Hunt RJ, Strand M, Walker JF (2006) Measuring groundwater-surface water interaction and its effect on wetland stream benthic productivity, Trout Lake watershed, northern Wisconsin, USA. J Hydrol 320(3-4):370-384. doi:10.1016/j.jhydrol.2005.07.029

Hunt RJ, Borchardt MA, Bradbury KR (2014) Viruses as groundwater tracers: using ecohydrology to characterize short travel times in aquifers. Rapid Commun Groundw 52(2):187-193. doi:10. $1111 /$ gwat. 12158

Hurley JP, Armstrong DE, Kenoyer GJ, Bowser CJ (1985) Ground water as a silica source for diatom production in a precipitation-dominated lake. Science 227:1576-1578

Kansas Water Office (2009) Kansas water plan. http://www.kwo.org/Kansas_Water_Plan/ Kansas_Water_Plan.htm. Accessed 16 May 2014

Leatherman J, Golden B, Featherstone A, Kastens T, Dhuyvetter K (2006) Regional economic impacts of implementation of the conservation reserve enhancement program in the Kansas Upper Arkansas River Basin, Final interim report to Kansas Water Office, 74 pp. http://www. agmanager.info/policy/water/. Accessed 16 May 2014

Loheide SP II, Butle JJ, Gorelick SM (2005) Estimation of groundwater consumption by phreatophytes using diurnal water table fluctuations: a saturated-unsaturated flow assessment. Water Resour Res 41(7), W07030

Londo G (1988) Dutch phreatophytes (in Dutch). PUDOC, Wageningen

Meinzer OE (1923) Outline of ground-water hydrology with definitions, United States Geological Survey Water-Supply Paper 494. U.S. Government Printing Office, Washington, DC. http:// pubs.er.usgs.gov/publication/wsp494

Meinzer OE (1927) Plants as indicators of ground water, United States Geological Survey WaterSupply Paper 577. U.S. Government Printing Office, Washington, DC. http://pubs.er.usgs.gov/ publication/wsp577

Meyboom P (1964) Three observations on stream-flow depletion by phreatophytes. J Hydrol 2:248-261

Meyboom P (1966) Unsteady groundwater flow near a willow ring in hummocky moraine. J Hydrol 4:38-62

Mitsch WJ, Gosselink JG (1993) Wetlands. Van Nostrand Reinhold, New York

Nadji M, Voigt R (1972) "Exploration for hidden water" by Mohammad Karaji-the oldest textbook on hydrology? Ground Water 10(5):43-46

Nuttle WK (2002) Is ecohydrology one idea or many? Discussion. Hydrol Sci J 47(5):805-807

Olson DA, Young RG (2009) Significance of river-aquifer interactions for reach-scale thermal patterns and trout growth potential in the Motueka River, New Zealand. Hydrogeol J 17 (1):175-183. doi:10.1007/s10040-008-0364-4

Paramelle J (1859) L'Art de découvrir les sources. Dalmond et Dunod, Paris

Pazwash H, Mavrigian G (1980) A historical jewelpiece - discovery of the millennium hydrological works of Karaji. JAWRA J Am Water Resour Assoc 16(6):1094-1096

Reilly TE, Dennehy KF, Alley WM, Cunningham WL (2008) Ground-water availability in the United States, United States Geological Survey Circular 1323, 70 p. http://pubs.usgs.gov/circ/ $1323 /$

Robinson T (1965) Introduction, spread and areal extent of saltcedar (Tamarix) in the western United States, United States Geological Survey Professional Paper 491-A, 12 p. http://pubs.er. usgs.gov/publication/pp491A

Rodriguez-Iturbe I (2000) Ecohydrology: a hydrologic perspective of climate-soil-vegetation dynamics. Water Resour Res 36(1):3-9

Rodriguez-Iturbe I, Porporato A (2004) Ecohydrology of water controlled ecosystems: soil moisture and plant dynamics. Cambridge University Press, Cambridge

Ross B (2007) Phreatophytes in the Bible. Ground Water 45(5):652-654

Schimper AFW (1898) Pflanzen-Geographie auf physiologischer Grundlage. Fischer, Jena

Schot PP, Barendregt A, Wassen M (1988) Hydrology of the wetland Naardermeer: influence of the surrounding area and impact of vegetation. Agric Water Manag 14:459-470 
Sophocleous M (1997) Managing water resources systems: why "safe yield" is not sustainable. Ground Water 35:561

Sophocleous M (1998) On the elusive concept of safe yield and the response of interconnected stream-aquifer systems to development. In: Sophocleous M (ed) Perspectives on sustainable development of water resources in Kansas, Kansas Geological Survey Bulletin 239. Kansas Geological Survey, Lawerence, pp 61-85

Sophocleous M (2000) The origin and evolution of safe-yield policies in the Kansas Groundwater Management Districts. Nat Resour Res 9:99-110

Sophocleous M (2007) The science and practice of environmental flows and the role of hydrogeologists. Ground Water 45:393-401

Sophocleous M (2011) Groundwater legal framework and management practices in the High Plains aquifer, USA. In: Findikakis AN, Sato K (eds) Groundwater management practices, IAHR Monograph Series. CRC Press, Leiden, pp 325-366

Springer AE, Stevens LE (2009) Spheres of discharge of springs. Hydrogeol J 17(1):83-93. doi:10. 1007/s10040-008-0341-y

Stover S, 11 others (2011) Central Kansas Water Bank Association five year review and recommendations. http://www.kwo.org/reports_publications/Reports/Rpt_WaterBankReview_ 012011_ss.pdf. Accessed 16 May 2014

Thomas HE, Leopold LB (1964) Ground water in North America. Science 143(3610):1001-1006

Tüxen R (1954) Pflanzengesellschaften und Grundwasser-Ganglinien. Angew Pflanzensoz 8:64-97

van Wirdum G (1982) The ecohydrological approach to nature protection. In: Anonymus, Annual report 1981. Research Institute for Nature Management, Arnhem, Leersum and Texel, pp $60-74$

Vitruvius (15BC) Ten books on architecture/Book VIII. Translated by MH Morgan MH (1913). http://en.wikisource.org/wiki/Ten_Books_on_Architecture/Book_VIII

Wassen MJ, Grootjans AP (1996) Ecohydrology: an interdisciplinary approach for wetland management and restoration. Vegetatio 126:1-4

Wassen MJ, Barendregt A, Palczynski A, de Smidt JT, de Mars H (1990) The relationship between fen vegetation gradients, groundwater flow and flooding in an undrained valley mire at Biebrza, Poland. J Ecol 78:1106-1122

Whiteman M, Brooks A, Skinner A, Hulme P (2010) Determining significant damage to groundwater-dependent terrestrial ecosystems in England and Wales for use in implementation of the water framework directive. Ecol Eng 36:1118-1125

Winter TC, Harvey JW, Franke OL, Alley WM (1998) Ground water and surface water: a single resource, United States Geological Survey Circular 1139, 79 p. http://pubs.usgs.gov/circ/ circ1139/

Witte JPM, von Asmuth JR (2003) Do we really need phytosociological classes to calibrate Ellenberg indicator values? J Veg Sci 14(4):615-618 


\title{
Groundwater Dependent Ecosystems: Classification, Identification Techniques and Threats
}

\author{
Derek Eamus, Baihua Fu, Abraham E. Springer, and \\ Lawrence E. Stevens
}

\begin{abstract}
This chapter begins by briefly discussing the three major classes of groundwater dependent ecosystems (GDEs), namely: (I) GDEs that reside within groundwater (e.g. karsts; stygofauna); (II) GDEs requiring the surface expression of groundwater (e.g. springs; wetlands); and (III) GDEs dependent upon sub-surface availability of groundwater within the rooting depth of vegetation (e.g. woodlands; riparian forests). We then discuss a range of techniques available for identifying the location of GDEs in a landscape, with a primary focus of class III GDEs and a secondary focus of class II GDEs. These techniques include inferential methodologies, using hydrological, geochemical and geomorphological indicators, biotic assemblages, historical documentation, and remote sensing methodologies. Techniques available to quantify groundwater use by GDEs are briefly described, including application of simple modelling tools, remote sensing methods and complex modelling applications. This chapter also outlines the contemporary threats to the persistence of GDEs across the world. This involves a description of the "natural" hydrological attributes relevant to GDEs and the
\end{abstract}

\footnotetext{
D. Eamus

National Centre for Groundwater Research and Training, and School of Life Sciences, University of Technology Sydney, PO Box 123, Sydney, NSW 2007, Australia

B. Fu $(\bowtie)$

National Centre for Groundwater Research and Training, and Fenner School of Environment and Society, Australian National University, Canberra, ACT 0200, Australia e-mail: Baihua.fu@anu.edu.au
}

\section{A.E. Springer}

School of Earth Sciences and Environmental Sustainability, Northern Arizona University, P.O. Box 4099, Flagstaff, AZ 86011, USA

\section{L.E. Stevens}

Springs Stewardship Institute, Museum of Northern Arizona, 3101 N. Ft. Valley Rd, Flagstaff, AZ 86001, USA 
processes that lead to disturbances to natural hydrological attributes as a result of human activities (e.g. groundwater extraction). Two cases studies, (1) Class III: terrestrial vegetation and (2) Class II: springs, are discussed in relation to these issues.

\subsection{Introduction}

In order to sustainably manage groundwater in a truly integrated manner consideration needs to be given to the interaction of groundwater with ecology. Groundwater interacts with multiple classes of biome, including stygofauna of aquifers, rivers relying on base flow (the discharge of groundwater into rivers) and terrestrial ecosystems. Management plans that do not include such consideration are likely to negatively impact these groundwater dependent ecosystems.

In this chapter, we focus on the links between ecology and groundwater availability, rather than on groundwater resources and human demand. This is because we feel that environmental allocations of groundwater have generally received less attention than allocations to human demands and because we identify four important knowledge gaps to the sustainable management of environmental allocations of groundwater. These are:

1. How do we know where a GDE is in the landscape? If we do not know where they are, we cannot manage them and allocate groundwater resources appropriately.

2. How much groundwater is used by a GDE? If we do not know how much groundwater is used, we cannot allocate an appropriate quantity of the resource.

3. What are the threats to GDEs? Only by understanding the threats to GDEs can we ensure their sustainable management.

4. What are the likely responses of GDEs to over extraction of groundwater? Without knowing what to measure, we cannot regulate groundwater extraction in ways that do not negatively impact on GDEs.

\subsection{Classes of GDEs and Relevant Groundwater Attributes}

\subsubsection{GDE Classification}

Hatton and Evans (1998) were perhaps the first to attempt to categorise GDEs systematically. They recognised five classes of ecosystem dependency on groundwater:

1. Ecosystems entirely dependent on groundwater; or obligate GDEs. In these communities only small changes in groundwater availability or quality result 
in the total loss of the current ecosystem structure and function. Examples of entirely dependent ecosystems include the mound spring systems of the Great Artesian Basin of eastern Australia, karstic groundwater ecosystems of Western Australia and riparian vegetation along streams in central Australia.

2. Ecosystems highly dependent on groundwater. In these communities small to moderate changes in groundwater availability result in significant changes in ecosystem structure and function. Examples of highly dependent ecosystems in Australia include: Melaleuca swamp forests and woodlands of tropical northern Australia, base flow dependent ecosystems of temperate Australia and the damp lands of the Swan Coastal Plain.

3. Ecosystems with proportional dependence on groundwater. Such ecosystems do not exhibit the threshold-type responses of (1) and (2) above. As groundwater availability or quality changes, there is a proportional response in ecosystem structure and function and distribution. Examples include base flow and permanent lake ecosystems.

4. Ecosystems that are opportunistic users of groundwater. In these ecosystems groundwater has a significant role in their water balance occasionally and reliance is not obligate (so-called facultative dependency). Examples of opportunistic ecosystems include swamp forests of coastal floodplains along the fringe of the south-east uplands and Jarrah forests and Banksia woodlands of Western Australia.

5. Ecosystems that appear to be groundwater dependent, but are in fact entirely rain fed or dependent only on surface water flows. Examples of this type include seasonal floodplain lakes on small creeks in northern Australia and terminal drainage basin lakes in the Central Lowlands.

There are two major problems with this classification system. First, the determination of the degree of dependency is difficult and requires many years of study of a site. Establishing that an ecosystem is only an opportunistic user of groundwater may require a decade of waiting before a drought occurs and groundwater dependency becomes expressed. Second, establishing the presence or absence of a threshold response is extremely difficult and time consuming. Consequently, a simplified classification system was proposed by Eamus et al. (2006):

(I) Aquifer and cave ecosystems where stygofauna reside. This class also includes the hyporheic zones of rivers and floodplains.

(II) Ecosystems reliant on surface expression of groundwater. This includes base flow rivers, streams and wetlands, springs and estuarine seagrasses.

(III) Ecosystems reliant on sub-surface presence of groundwater within the rooting depth of the ecosystem (usually via the capillary fringe).

Application of this simple classification scheme assists managers in identifying the correct techniques for assessing GDE structure, function and management regime (Eamus et al. 2006). This classification scheme was recently adopted in the Australian National Atlas of Groundwater Dependent Ecosystems. 


\subsubsection{Classification of Springs Ecosystems as GDEs}

Springs occur in geomorphic settings that are far more complex than those of most wetlands, emerging from hill slopes, cliff faces, and beneath other bodies of water. Adding to their complex emergence environment, springs often support a wide array of microhabitats not observed in wetlands. The "sphere" into which the aquifer discharges was initially described by Meinzer (1923), and then simplified by Hynes (1970) into three classes: rheocrene (channel emergence), limnocrene (pool emergence), and helocrene (wet meadow emergence).

Springer et al. (2008) and Springer and Stevens (2009) reviewed literature and expanded this historical scheme to include 12 spheres of discharge of terrestrial springs, including: (1) springs that emerge in caves, (2) exposure springs, (3) artesian fountains, (4) geysers, (5) gushets, (6) contact hanging gardens, (7) helocrene wet meadows, (8) hill slope springs, (9) hypocrene buried springs, (10) limnocrene surficial lentic pools, (11) mineralized mounds, and (12) rheocrene lotic channel floors. This classification provides a more precise lexicon with which to describe groundwater emergence function in relation to ecosystem landform configuration and distribution.

Geomorphological variation among the 12 terrestrial springs types of Springer and Stevens (2009) leads to predictable variation in spring's vegetation, habitat structure, plant and faunal diversity, and ecosystem structure and function (Griffiths et al. 2008). For example, helocrene springs are typically dominated by wetland graminoid and shrub species, with little canopy cover by trees. Many hill slope springs typically occupy a position on the landscape where groundwater discharge has created a shallow concave depression due to low discharge rates winnowing away fine-grained sediments or groundwater sapping to create spring dependent headwater theatres for channels (Laity and Malin 1985; Meinzer 1923).

\subsubsection{Relevant Groundwater Attributes}

The persistence of GDEs relies on suitable groundwater attributes. Identifying these attributes is essential as this can help establish groundwater management targets and monitoring strategies (Kreamer et al. 2014). In general, the following groundwater attributes are important for GDEs (Clifton and Evans 2001):

1. Depth-to-groundwater, for unconfined aquifers;

2. Groundwater pressure - hydraulic head and its expression in groundwater discharge, for confined aquifers;

3. Groundwater flux - flow rate and volume of groundwater supply; flow direction;

4. Groundwater quality - including groundwater salinity, acidity and the concentrations of nutrients and pollutants. 
Importance of groundwater attributes to GDEs

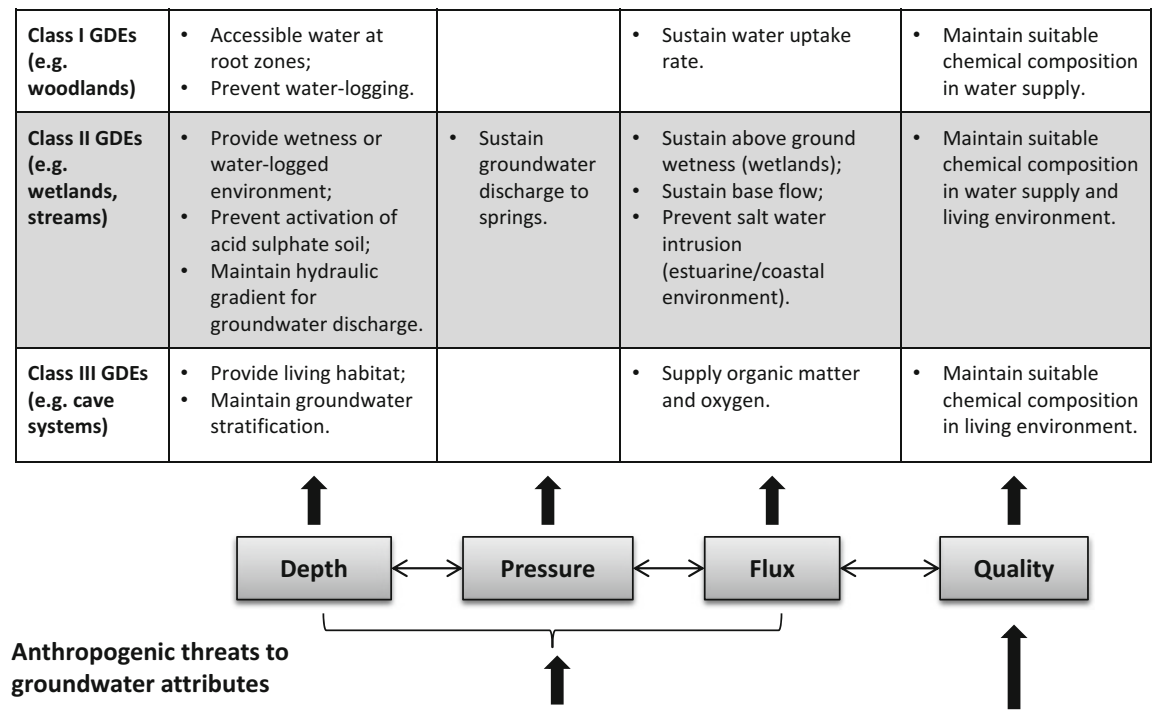

\begin{tabular}{|c|c|c|}
\hline $\begin{array}{l}\text { Agricultural } \\
\text { practices }\end{array}$ & $\begin{array}{l}\text { - Reduced groundwater level/pressure due to } \\
\text { excessive groundwater extraction to support } \\
\text { agricultural development; } \\
\text { - Reduced groundwater recharge due to surface } \\
\text { water pumping for irrigation; } \\
\text { - Water-logging due to vegetation clearing and } \\
\text { poorly managed irrigation. }\end{array}$ & $\begin{array}{l}\text { - Groundwater contamination from fertilisers, } \\
\text { pesticides and other agricultural chemicals. } \\
\text { - Soil and water salinisation due to vegetation } \\
\text { clearing and excessive irrigation. }\end{array}$ \\
\hline $\begin{array}{l}\text { Urban and } \\
\text { industrial } \\
\text { development }\end{array}$ & $\begin{array}{l}\text { Reduced groundwater level/pressure due to } \\
\text { excessive groundwater extraction to support } \\
\text { urban and industrial development. }\end{array}$ & $\begin{array}{l}\text { - Ground water contamination from urban facilities, } \\
\text { landfills, fertilisers and pesticides (e.g. for gardens } \\
\text { and parks), stormwater/sewage disposal, and } \\
\text { other industrial chemicals. }\end{array}$ \\
\hline $\begin{array}{l}\text { Mining } \\
\text { activities }\end{array}$ & $\begin{array}{l}\text { Reduced level, pressure and flux due to mine } \\
\text { dewatering; } \\
\text { - Reduced level due to channel incision (e.g. } \\
\text { gravel mining) }\end{array}$ & $\begin{array}{l}\text { - Change in groundwater stratification due to } \\
\text { dewatering; } \\
\text { - Groundwater contamination from tailings dams; } \\
\text { - Groundwater contamination through leaching of } \\
\text { acidic or toxic crushed rock storage sites; } \\
\text { - Groundwater contamination after mine closure, } \\
\text { due to water table rise and mine flooding. }\end{array}$ \\
\hline $\begin{array}{l}\text { Plantation } \\
\text { forestry }\end{array}$ & $\begin{array}{l}\text { - Reduced groundwater recharge and surface } \\
\text { flow; } \\
\text { - Increased groundwater discharge. }\end{array}$ & \\
\hline
\end{tabular}

Fig. 13.1 Importance of groundwater regime (depth-to-groundwater and groundwater pressure and flux) and quality on different classes of GDEs and the anthropogenic threats

Importance of these attributes to GDEs is summarised in Fig. 13.1. Depth-togroundwater (from the land surface) is perhaps one of the most important groundwater attributes for GDEs (Eamus et al. 2006). This is particularly the case for terrestrial ecosystems that rely on sub-surface provision of groundwater. Depth-togroundwater, with particular reference to the distance between the capillary fringe 
above the water table and plant roots, directly determines groundwater availability to vegetation. An increased depth-to-groundwater may lead to reduced plant growth, mortality and change in species compositions (Shafroth et al. 2000). Lowering a water table can also lead to loss of habitat for cave and aquifer ecosystems (Boulton et al. 2003; Heitmuller and Reece 2007). On the other hand, a rising water table may disadvantage those species vulnerable to water-logging and lead to succession to different plant communities (Naumburg et al. 2005). Changes in water table depth, coupled with other environmental factors, can also result in groundwater contamination. For example, lowering a water table beneath acid sulphate soils leads to oxidation of pyrite and subsequent acidification of the shallow aquifer (Ritsema et al. 1992; Nath et al. 2013).

Groundwater flux is important for Classes II and III GDEs because it sustains water uptake by vegetation (Shafroth et al. 2000). Reduced groundwater pressure and flux cause reduced groundwater discharge and subsequently reduced surface water availability to wetlands and GDEs that depend on base flow and springs (Zektser et al. 2005). In estuary or coastal areas reduced groundwater flux leads to seawater intrusion and contamination of coastal freshwater aquifers (Jayasekera et al. 2011; Lambrakis 1998), thereby reducing groundwater quality. For cave and aquifer ecosystems, appropriate groundwater flux is important to maintain a supply of organic matter and oxygen (Hancock et al. 2005) to stygofauna contained within these systems. Groundwater quality is critical for all types of GDEs to maintain suitable chemical composition in water supply and/or living environment. In some areas, groundwater is hydrochemically stratified. Disturbing the stratification may cause the chemical composition to be unsuitable for the associated aquifer ecosystems.

Depth-to-groundwater and groundwater pressure and flux naturally fluctuate. In unconfined aquifers, short-term fluctuations naturally occur in response to timevarying uptake of water by vegetation; whereas longer term fluctuations often reflect time-varying groundwater recharge as a result of wet and dry season cycles. GDEs that are developed at naturally highly fluctuating areas (e.g. areas with strong climatic seasonality) generally have adapted to the fluctuations of groundwater regime and hence can be more resilient to change in groundwater regime than those developed from areas with more constant regime. For example, in the Howard River catchment of the Northern Territory of Australia, natural intra-annual variation in groundwater depth is approximately $8 \mathrm{~m}$ (Cook et al. 1998). This large variation (arising through a combination of wet and dry season variation in rainfall, lateral sub-surface flow of groundwater to the Howard River and evapotranspirational discharge) is accommodated through changes in landscape leaf area index (LAI) and root depth.

These groundwater attributes can be altered due to human activities. The contemporary threats to the persistence of GDEs, including the processes that lead to disturbances to natural hydrological attributes as a result of human activities (e.g. groundwater abstraction), are described in Sect. 13.5. 


\subsection{Identifying GDEs}

Identifying the location of GDEs and assessing their dependency on groundwater is the vital first step to managing them. However, identifying their location across a landscape is often difficult, time-consuming and hence expensive and always requires a high level of technical expertise. In this section, a range of techniques that can be used to assist in this are discussed.

\subsubsection{Inferential Methods to Determine GDEs}

Early assessments of groundwater dependency frequently relied on inference (Clifton and Evans 2001; Eamus et al. 2006). Thus, answers in the affirmative to one or more of the following can be taken as supporting the hypothesis that at least some species in an ecosystem are using groundwater.

1. Does a stream/river flow all year, despite long periods of low or zero rainfall (and thus zero surface flows)?

2. For estuarine systems, do salinity levels fall below that of seawater in the absence of surface water inputs?

3. Does the total flux in a river increase downstream in the absence of inflow from a tributary or surface flow?

4. Are water levels in a wetland maintained during extended dry periods?

5. Is groundwater discharged to the surface for significant periods of time each year? If such a resource is present, evolution will ensure that some species will be using it.

6. Is the vegetation associated with the surface discharge of groundwater different (in terms of species composition, phenological pattern, leaf area index or vegetation structure) from vegetation close-by but which is not accessing this groundwater?

7. Is the annual rate of transpiration by vegetation at a suspected GDE significantly larger than annual rainfall at the site and the site is not a run-on site?

8. Are plant water relations (especially pre-dawn and mid-day water potentials and transpiration rates) indicative of less water stress (water potentials closer to zero; transpiration rate larger) than vegetation located nearby but not accessing the groundwater discharged at the surface? The best time to assess this is during rain-less periods.

9. Does the water balance of a site indicate that the sum of water-use plus interception loss plus run-off plus deep drainage is significantly larger that annual rainfall plus run-on?

10. Is occasional (or habitual) groundwater release at the surface associated with key developmental stages of the vegetation (such as flowering, germination, seedling establishment)? 
11. Does groundwater and hydrological modelling suggest that groundwater is either discharging to the surface or located within the likely rooting depth of the vegetation?

12. Is groundwater or the capillary fringe above the water table present within the rooting depth of any of the vegetation?

13. Does a proportion of the vegetation remain green and physiologically active (principally, transpiring and fixing carbon, although stem diameter growth or leaf growth are also good indicators) during extended dry periods of the year?

14. Within a small region (and thus an area having the same annual rainfall, temperature and vapour pressure deficit) and in an area not having access to run-on or stream or river water, do some ecosystems show large seasonal changes in leaf area index whilst others do not?

15. Are seasonal changes in groundwater depth larger than can be accounted for by the sum of lateral flows and percolation to depth (that is, is vegetation a significant discharge path for groundwater; (Cook et al. 1998))? Clearly, if the error terms in the estimation of lateral flow and percolation to depth are of similar magnitude or greater than the rate of vegetation water, this method may not be appropriate.

Affirmative answers to one or more of these questions leads to the inference that the system is a GDE. However, this does not provide any information about the nature of the dependency (obligate or facultative) nor about the groundwater regime (e.g. timing of groundwater availability, volume utilised, location of surface expression, the pressure of the groundwater aquifer required to support the surface discharge of groundwater) needed to support the ecosystem.

\subsubsection{Hydrological Indication of GDE Status}

In shallow unconfined aquifers where roots of vegetation are directly accessing the water table (via the capillary zone usually), it is possible to discern the diurnal pattern of vegetation water-use in sub-daily fluctuations in the depth-to-groundwater (Gribovszki et al. 2010). Although diurnal changes in atmospheric pressure or temperature (which induce changes in water volume, evaporation and condensation) and inputs of rainfall can cause changes in groundwater depth, it is still possible to identify and sometimes quantify the extraction of groundwater through transpiration (Gribovszki et al. 2010).

White, in 1932, was possibly the first to use sub-daily changes in groundwater depth to quantify transpiration use of groundwater (White 1932). An idealised representation of the deil pattern of groundwater depth in a shallow unconfined aquifer is shown in Fig. 13.2.

The solid continuous oscillating curve represents the cycle of groundwater drawdown (because of ET) during the day followed by the rebound of the water table when ET returns to zero (assuming no nocturnal transpiration) at night. The dashed straight line (with slope $=r$ ) is used to estimate the amount of water 
Fig. 13.2 A schematic representation of changes in depth-to-groundwater due to vegetation transpiration

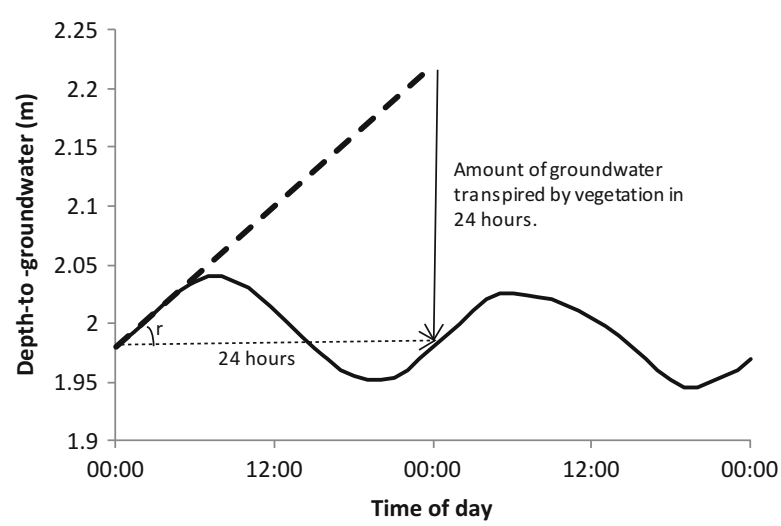

transpired by vegetation in $24 \mathrm{~h}(0: 00 \mathrm{~h}$ to $0: 0024 \mathrm{~h}$ later; indicated by the horizontal dotted arrow). This is represented by the vertical arrow which is the difference between the groundwater depth that would have occurred in the absence of vegetation water-use and the observed groundwater depth. By applying this methodology it is possible to identify the location of a GDE, thereby providing the first step in managing both the groundwater and the dependent ecology.

Lautz (2008) provides a detailed analysis of groundwater use using the White method of analyses of sub-daily changes in groundwater depth. She shows that spatial differences in groundwater use can be explained by differences in vegetation type (riparian wetland and grassland) and specific yield of the aquifer. As expected, the ratio of groundwater-to-soil water extraction increased as soil moisture content declined as a function of time since rain.

\subsubsection{Geochemical Indication of GDE Status: Tracers and Isotopes}

Geochemical studies, particularly isotopic analyses of water samples, can be used to distinguish groundwater sources from other water sources (e.g. atmospheric, soil water, or stream water sources), and used to identify source areas and groundwater residence time (e.g. Winograd et al. 1998; Monroe et al. 2005). Mineral deposition and helium isotope expression through groundwater discharge also can indicate groundwater discharge (Crossey and Karlstrom 2012), as attested to by the presence of certain plant species and invertebrates. For base flow systems (that is, rivers and streams showing significant flows during periods of zero surface or lateral flows), measurements of the chlorofluorocarbon, magnesium or radon concentrations of river and groundwater supply can identify and quantify the amount and timing of groundwater inflows into the river (Cook et al. 2003).

Stable isotopes (such as deuterium $\left({ }^{2} \mathrm{H}\right)$ and ${ }^{18} \mathrm{O}$ ) can be used for these systems too, as can artificial labelling with tracers, such as lithium. When tracers are added to the groundwater, the subsequent uptake into vegetation is usually conclusive 


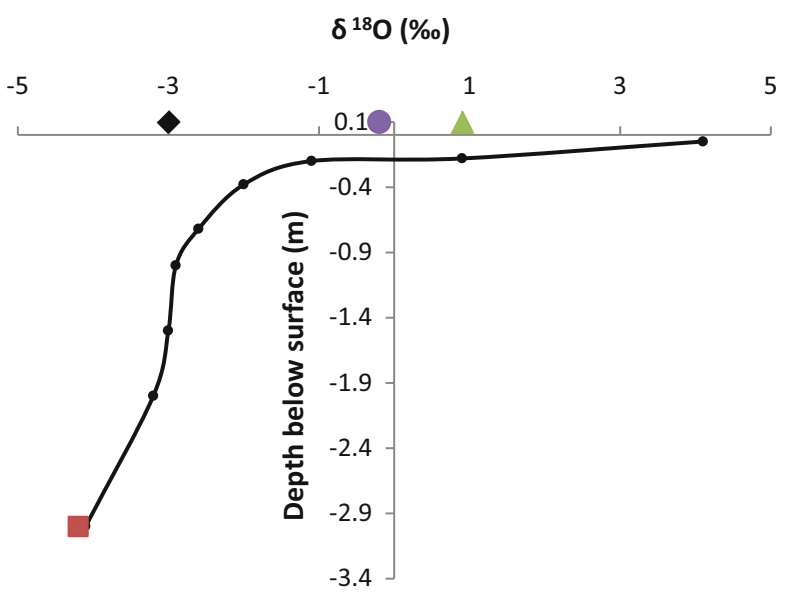

Fig. 13.3 An example of the use of ${ }^{18} \mathrm{O}$ analyses of xylem water, soil water and groundwater in a study of multiple species growing in northern Yucatan (Mexico). The ${ }^{18} \mathrm{O}$ content of soil declines with depth through the soil profile and eventually groundwater is reached (at $3 \mathrm{~m}$; brown square). The xylem ${ }^{18} \mathrm{O}$ content of three species (Ficus spp. green triangle; Spondias spp. purple circle; and Talisia spp. black diamond) is also presented. Ficus was the least reliant on groundwater whilst Talisia was the most reliant (Redrawn from Querejeta et al. 2007)

proof that access by that vegetation is occurring. However, the presence of a tracer in a shallow rooted species can occur if neighbouring deep rooted species exhibit hydraulic lift and the shallow rooted plants then "harvest" this water (Caldwell et al. 1998). When a close match between groundwater isotope composition and xylem isotope composition is made, we can conclude that the vegetation is using groundwater.

Direct evidence that vegetation is using groundwater can be obtained by comparing the stable isotope composition of groundwater, soil water, surface water (where relevant) and vegetation xylem water (Kray et al. 2012; Lamontagne et al. 2005; O'Grady et al. 2006; Thorburn et al. 1993; Zencich et al. 2002; Spałek and Pro-ków 2011). A direct comparison of periodic measurements was made by Hunt et al. (1996) who showed that time integration provided by measurements of isotopic composition was a valuable tool that provide insights not available from non-isotopic techniques. Where sufficient variation in isotopic composition among these sources occurs then it is possible to identify the single or the most dominant source of water being used by different species at different times of year (Zencich et al. 2002). An example of the use of ${ }^{18} \mathrm{O}$ isotope analyses of xylem water, soil water and groundwater is shown in Fig. 13.3.

Mixed-member models are available that allow estimation of the relative contribution of multiple sources of water to the water absorbed by roots (Phillips and Gregg 2003; Kolb et al. 1997). Thus the use of stable isotopes can provide information about spatial and temporal variation in groundwater dependency and rates of groundwater use within and between species and ecosystems. Application 
of stable isotope analyses to quantify the rate of water use is discussed in Sect. 13.4.4.

\subsubsection{Geomorphological Indicators of GDE Status}

The various springs spheres of discharge (springs types) generate characteristic geomorphology and soils that may indicate groundwater dependence. Travertine mound-forming springs and hanging gardens are obvious examples of distinctive GDE geomorphology. Aerial photographic analysis of spring channels is commonly used to plan springs restoration projects (e.g. Ramstead et al. 2012). Because the geometry of springs channels is often erratic and non-sinuous (Griffiths et al. 2008), detection of such channel configuration is one indication of a spring flow domination, rather than surface flow domination (Springer et al. 2008). In hypocrenes, excavation of shallow wells or soil pits/cores can help identify groundwater sources, and among other springs types, discrete particle size arrays may result from constancy of discharge from some types of springs.

Geochemical deposits such as travertine commonly indicate groundwater dependence in mound-forming, hypocrene, geyser, and other springs types. Montezuma Well, the massive travertines along the Colorado River, and collapsed travertine mounds in the Tierra Amarilla region of northern New Mexico, are all examples of springs-related landforms (Crossey and Karlstrom 2012; Johnson et al. 2011; Newell et al. 2005).

In arid regions, organic soil development at springs can be extensive, distinctive, and dateable using radiocarbon techniques. Groundwater dependent peat deposits may be massive and can persist for millennia (e.g. Haynes 2008). Peat deposits more than $2 \mathrm{~m}$ thick were mined commercially in the Upper Carson Slough in Ash Meadows, a spring fed tributary of the upper Amargosa River basin in southern Nevada (McCracken 1992). If site geomorphology has not been much altered, these distinctive groundwater-generated landforms and soils features may remain identifiable, even if the aquifer has been largely dewatered.

\subsubsection{Biotic Assemblages as GDE Status}

Throughout the world, both in terrestrial and subaqueous settings, springs are widely known to support unique aquatic and wetland plant species and unique assemblages. In one of hundreds of examples of unusual springs-dependent plant species, Spałek and Pro-ków (2011) reported a highly isolated population of springs-dependent Batrachium baudotii (Ranunculaceae) in a karst spring in central Poland. The few remaining mound springs between Guildford and Muchea in Western Australia support restricted wetland graminoid plant assemblages, with Cyperaceae, Juncaceae, and Restionaceae, as well as flooded gum (Eucalyptus rudis) and bracken fern (Pteridium esculentum) (Blyth and English 1996). 
In addition to springs-dependent aquatic and wetland species, the dendrochronology of trees from the periphery of springs also may be useful for establishing flow perenniality. Melis et al. (1996) used such data to evaluate flow variability of springfed Havasu Creek in Grand Canyon, reporting that the Fraxinus velutina cores revealed complacency of growth, indicating perennial flow over 80 years.

Surface-dwelling groundwater dependent species that indicate long-term groundwater flow perenniality include several groups of plants, invertebrates, fish, and amphibians. Among the plants in North America, such springs-dependent species are selected sedges (Caryophyllaceae), rushes (Juncaceae), and herbaceous taxa (e.g. some Primulaceae, Toxicoscordion spp., Flaveria mcdougallii). Among invertebrates, hydrobiid spring snails commonly are restricted to springs sources and channels, particularly the Pyrgulopsis and Tryonia (Hershler 1998, 2014), as are some members of the aquatic beetle families Elmidae and Dryopidae (Shepard 1993). In our studies of montane springs in the American Southwest, chloroperlid stoneflies and turbellarian flatworms are often springs-dependent species in coolcold natural waters. Among North American fish, the pupfishes (Cyprinodontidae) and goodeid topminnows (Goodeidae) are often springs-dependent, and often are tightly restricted to individual springs (e.g. Minckley and Deacon 1991; Unmack and Minckley 2008). Among southwestern amphibians, populations of native ranid frogs in the genus Lithobates (Rana) are often associated with groundwater dependent wet meadows (cienegas, GDE fens). The giant aquatic hellbender salamander, Cryptobranchus alleganiensis bishopi only occurs in clear water springfed stream segments in the Ozarks. Several turtle species in eastern North America hibernate on the periphery of coldwater springs, where they are cooled but are protected from freezing (Nickerson and Mays 1973; Ernst and Lovich 2009).

\subsubsection{Historical Documentation of GDE Status}

Historical documentation is often useful for establishing GDE status and the perenniality of springs flow. Many sources of historical information may be available for such documentation, such as historical photographs and diaries, and interviews with long-term stewards and community elders. Such historical information can be quite valuable for understanding change through time; however, locating, determining the validity of such information, and compiling and interpreting the information can be challenging.

\subsubsection{Remote Sensing}

Detection of GDEs through remote sensing (RS) includes the use of infrared and other aerial thermal imaging, and has been used successfully to locate groundwater sources, particularly during seasons with the greatest temperature differences between air and groundwater temperatures. Remote sensing (RS) provides a rapid and spatially extensive technique to assess vegetation structure (e.g. leaf area index, 
basal area), vegetation function (e.g. canopy temperature, rates of evapotranspiration and "greenness") and relationships amongst climate variables, vegetation function and vegetation structure.

An underlying conceptual model for the application of RS to identifying the location of GDEs has been that of "green islands". In this approach, the structure or function of one pixel in a RS image is compared to that of an adjacent pixel. If a GDE covers a significant fraction of the area of one pixel but not the other, it is assumed that during prolonged dry periods the structure/function of the two vegetation types will diverge. This is because the vegetation accessing groundwater is not experiencing soil dryness to the same extent (if at all) as the vegetation that is not accessing groundwater. Under the green islands conceptual model, assessments of vegetation structure or function are determined for the site of interest and compared to adjacent "control" sites, either at a single time, or preferentially, across several contrasting times (comparisons across "wet" and "dry" periods usually).

In the United States, aerial thermography surveys of the largest of Florida's springs, Silver Springs, were conducted along the spring-fed run out channel and detected new spring orifices over $1200 \mathrm{~m}$ below the first source (Munch et al. 2006). Remote sensing techniques can be successfully used in low-gradient terrain that is not covered by dense vegetation. The U.S. Forest Service conducted remote sensing analysis for fens in the Rocky Mountains to detect fens (U.S. Forest Service 2012), reporting good success in locating large fens that were exposed. However, a similar remote sensing effort in the topographically complex Spring Mountains of southern Nevada detected fewer than $50 \%$ of the more than 200 springs in that range (U.S. Forest Service 2012).

\subsubsection{Application of Vegetation Indices Derived from RS}

Münch and Conrad (2007) examined three catchment areas in the northern Sandveld of South Africa. They used Landsat imagery to identify the presence/ absence of wetlands and combined this with GIS terrain modelling to determine whether GDEs could be identified using a landscape "wetness potential". It is important to note that this application focused on Class II GDEs - those reliant on a surface expression of groundwater. They applied the "green island" philosophy and compared the attributes of potential GDEs with the attributes of surrounding land covers at three contrasting times: July when rains started at the end of a dry year, August, in the winter of a wet year and at the end of a dry summer. They concluded that RS data could be used to classify landscapes and when this was combined with a spatial GIS based model using landscape characteristics they could produce a regional-scale map of the distributions of GDEs. However, it is not known whether this approach could be applied to Class III GDEs (those reliant on sub-surface access to groundwater).

In arid and semi-arid regions, plant density is often correlated with water availability. When groundwater is available to vegetation, plant density tends to be larger than adjacent areas where groundwater is unavailable. Lv et al. (2012) used remotely sensed images of a vegetation index (the Normalised Difference 
Fig. 13.4 The relationship between NDVI and depth-togroundwater for the Hailiutu River catchment in northern China (Redrawn from Lv et al. 2012)

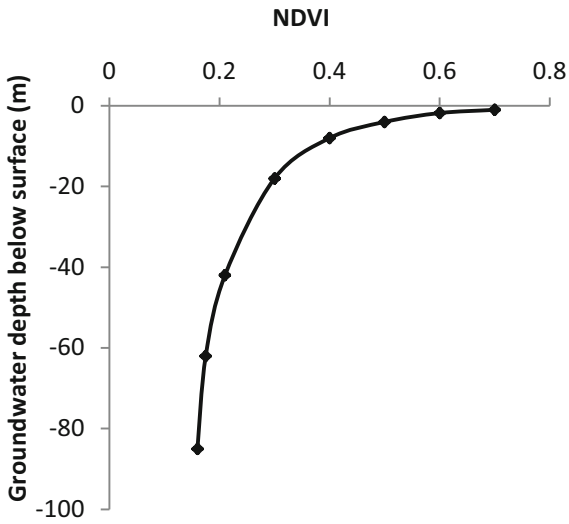

Vegetation Index; NDVI) to assess changes in NDVI as a function of depth-togroundwater in northern China. A $25 \mathrm{~m}$ resolution digital elevation model and groundwater bore data were used to generate a contour map of groundwater depths across the $2600 \mathrm{~km}^{2}$ catchment. Approximately 29,000 pixels of $300 \mathrm{~m}$ resolution of NDVI data were then used and the following relationship determined (Fig. 13.4):

This study demonstrated that the largest NDVI, a reliable measure of vegetation cover, occurred at the shallowest depths of groundwater and that cover declines curvilinearly with increasing depth-to-groundwater. They further analysed NDVI data and identified five land classes, including water bodies and bare earth as one land class, having a zero vegetation cover; and farmland and riparian zones as another class having the largest NDVI. The remaining three classes had intermediate values of NDVI. They then showed that the vegetated classes exhibited different responses to depth-to-groundwater. A cut-off of approximately $10 \mathrm{~m}$ depth-togroundwater was apparent; when the water table was lower than $10 \mathrm{~m}$, vegetation cover was insensitive to further increase in groundwater depth.

A similar method was applied by Jin et al. (2011) for the Ejina area in NW China. Despite much of the region being within the Gobi desert, with approximately $40 \mathrm{~mm}$ annual rainfall, an oasis located in the northern part of Ejina supports extensive agricultural and native vegetation. The NDVI was used by Jin and co-workers, along with 13 groundwater bores, from which relationships between NDVI and groundwater depth for three vegetation classes (grassland, woodland and scrubland) were established. Surprisingly, maximum NDVI were not observed at the shallowest groundwater sites for any vegetation class but at intermediate $(2.5-$ $3.5 \mathrm{~m}$ ) depths. A cut-off of $4.4 \mathrm{~m}$ depth-to-groundwater was observed such that vegetation was absent in regions where groundwater depth exceeded $5.5 \mathrm{~m}$.

Dresel et al. (2010) used geological, hydrogeological and ecological data to define regions having common physical and climatic profiles and which therefore should have similar RS signals. MODIS eVI and Landsat NDVI data were used and aridity thresholds (calculated as the Thornthwaite index) for individual regions developed based on a correlation analysis of Landsat summer NDVI images and 
MODIS eVI. Both of these are surrogate measures of productivity, with eVI generally performing better than NDVI (Campos et al. 2013).

Three methodologies were applied by Dresel et al. (2010). In the first, the MODIS eVI images identified pixels with a consistent photosynthetic activity throughout the year and pixels having variation across the year that was less than one standard deviation of the mean were deemed to show consistent productivity all year. For the second method, Landsat NDVI images were used to identify areas with contrasting photosynthetic activity for a wet year and a dry year. In the third method, an unsupervised classification of Landsat spectral data was used to identify spectral signatures of pixels that were deemed to be highly likely to use groundwater using expert local knowledge and then find other pixels with similar spectral signatures. Species specific differences in spectral signatures have been identified previously (Nagler et al. 2004). By combining all three methods within a GIS and finding pixels with a consistent productivity all year plus a high contrast between other local pixels plus a similar spectral signature to known GDEs, it was possible to identify all pixels across a catchment that had a very high probability of being a GDE. Ground truthing was then required.

An alternate approach to mapping the location of GDEs involves mapping of discharge zones, especially discharge through transpiration of vegetation and discharge to the ground surface. Discharge of groundwater to the surface (to swamps, wetlands and rivers) or through transpiration exerts a profound effect on the ecology of those systems utilising groundwater. To define the spatial extent of discharge across a landscape requires a multi-disciplinary approach that incorporates knowledge of geology, hydrology, ecology and climate (Tweed et al. 2007). Leblanc et al. (2003a, b) for example, used thermal, Landsat optical and MODIS NDVI data coupled to digital elevation models and depth-to-groundwater data to locate discharge areas in a large semi-arid basin in the Lake Chad basin in Africa. Tweed et al. (2007) examined discharge (and recharge) of the Glenelg-Hopkins catchment of southeast Australia. Discharge occurred through direct evaporation of the water table, with a likely limit of $5 \mathrm{~m}$ depth from which evaporation could occur; transpiration by vegetation from regions overlying a shallow unconfined aquifer and discharge to the ground surface to localised depression, break-of-slope localities and to wetlands, rivers and the ocean. The methodology they employed is summarised thus (from Tweed et al. 2007, Fig. 13.5).

Key indicators of groundwater discharge used in this study include:

1. Low variability of vegetation activity across wet and dry periods (seasons or years) using the NDVI as a measure of vegetation photosynthetic activity.

2. Topographic depressions and breaks of slope across the catchment, derived from a digital elevation model for the catchment to identify potential locations for surface discharge. A topographic wetness index $(w)$ was calculated from: $w=\ln$ $(1 / \tan \beta)$ where $\beta$ is the gradient of the slope of the land surface. Identification of concave slopes by identifying negative second-derivatives of slopes was used to identify areas where potential zones of saturation (arising from groundwater discharge) may occur across the landscape. 
Fig. 13.5 A schematic of the methodology used by Tweed et al. (2007) in the use of RS and GIS to identify the location of GDEs in a landscape

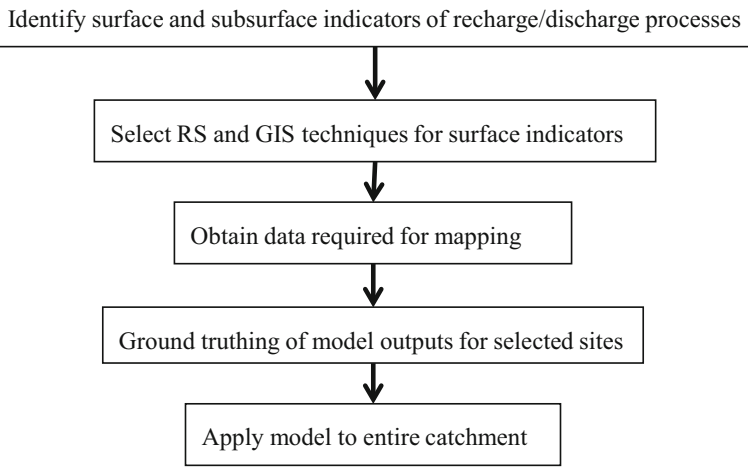

3. Groundwater depth data were used to produce a groundwater flow and these were combined with the digital elevation map to produce a depth-togroundwater map.

From this approach a detailed map of potential discharge zones across the entire $11,000+\mathrm{km}^{2}$ catchment was produced that far exceeded the ability if only the limited bore data had been used. A map of the standard deviation of the NDVI was able to identify locations where groundwater was supporting vegetation activity and thus identify GDEs across the catchment. A potential limitation to this method was that it tended to be most accurate in drier parts of the catchment where rainfall is more likely to limit vegetation activity. It was also found that identification of topographic depressions was a more reliable indicator for groundwater discharge than identification of break-of-slope.

\subsubsection{RS Derived Estimates of Water Fluxes}

The energy balance equation for land surfaces can be written thus: $L E+H=R_{n}-G$, where $L E$ is latent energy flux ( $=E T), H$ is sensible heat flux, $R_{n}$ is net radiation and $G$ is soil heat flux. Differences in temperature between boundary air temperature and canopy temperature can be used to estimate sensible heat flux. Assuming over a 24 h cycle $G=0$, and $R_{n}$ is either measured or derived from remote sensing data, then $L E$ (that is, ET) is calculated by difference. Li and Lyons (1999) used three models based on surface temperatures to estimate ET. The first model only used differences in surface and air temperature to calculate ET, the second model required NDVI data and surface temperature. This model requires the four extreme values of surface temperature and NDVI to be present within the area of study (i.e. patches of dry bare soils, wet bare soil, wet fully vegetated patches and dry (water stressed) fully vegetated surfaces). This makes its application problematic. The third method simply used the Priestley-Taylor equation (see Li and Lyons $1999)$ to estimate potential ET $\left(\mathrm{E}_{\mathrm{p}}\right)$.

Two of the key functional attributes of terrestrial ecosystems are the rates of water-use (either transpiration or evapotranspiration) and the rates of carbon 
fixation. Fluxes of transpired water and carbon uptake are coupled through the action of stomata, through which both gases must flow. It is because of the tight coupling of water and carbon fluxes that vegetation indices such as NDVI or eVI, which are good proxies of productivity and hence carbon flux, can be successfully applied in looking for GDEs, where it is an increase in water supply that drives their structural and functional differences (compared to adjacent no-GDEs).

\subsubsection{GDE Mapping and Database Challenges}

Information management constitutes a serious challenge for understanding and managing GDEs. Accurately georeferencing and archiving data on the distribution and ecohydrology of springs and other GDEs first involves developing a suitable database framework (Springs Stewardship Institute 2012). Some or many of the above methods for determining GDE distribution allows development of a geographic information system georeferenced map of springs within landscapes. However, a common problem in such mapping efforts is resolution of duplication error. We have repeatedly found that: (a) no single source of information (usually GIS layers or survey reports) provides a complete list of springs or other GDEs within a large landscape; (b) that each information source contains unique springs not found elsewhere; and (c) that the same GDEs may be mapped in multiple places with different names. Stevens and Ledbetter (2012) used 10 sources of information to identify 150 springs on the North Kaibab Forest District of northern Arizona, $50 \%$ more springs than had been documented by the managing agency, and field surveys increased the number of known springs in that landscape to more than 200. Development of an adequate map and database on the springs of large landscapes provides an essential tool for monitoring, modelling and further research on the status of the underlying aquifers.

\subsection{Estimating Rates of Groundwater Use by Class III GDEs}

Estimating groundwater needed to maintain GDE function is an essential step to the sustainable management of both GDEs and groundwater resources. However, it poses many methodological impediments, including:

1. Up-scaling from tree-scale measurements of tree water-use;

2. Partitioning total vegetation water-use into rain and groundwater sources;

3. Understanding seasonal/life-cycle variations in the rates of groundwater use;

4. Understanding the influence of climate at inter-annual time-scales on rates of tree water-use and the partitioning of water-use into rain and groundwater sources.

Moreover, what is required for the establishment and persistence of GDE function is often not well characterized; therefore the emphasis has been on 
Table 13.1 Three methods to estimate rates of groundwater discharge through vegetation in data poor areas, summarised from Leaney et al. (2011)

\begin{tabular}{l|l|l}
\hline Model & Input data & Method \\
\hline $\begin{array}{l}\text { Groundwater } \\
\text { risk model }\end{array}$ & $\begin{array}{l}\text { Climatic characterisation (rainfall, } \\
\text { evaporation), depth-to- } \\
\text { groundwater, soil profile } \\
\text { characterisation (depth, texture, } \\
\text { moisture holding), groundwater } \\
\text { salinity }\end{array}$ & $\begin{array}{l}\text { Uses a simple water balance } \\
\text { approach to estimate the probability } \\
\text { of groundwater use and estimate } \\
\text { groundwater discharge }\end{array}$ \\
\hline $\begin{array}{l}\text { Ecological } \\
\text { optimality } \\
\text { model }\end{array}$ & $\begin{array}{l}\text { Climatic characterisation (rainfall, } \\
\text { evaporation), long term average } \\
\text { Leaf Area Index (LAI) }\end{array}$ & $\begin{array}{l}\text { Estimates groundwater discharge } \\
\text { based on the difference between LAI } \\
\text { of GDE and theoretical LAI for a } \\
\left.\text { given climate wetness index (P/E } E_{0}\right)\end{array}$ \\
\hline $\begin{array}{l}\text { Groundwater } \\
\text { discharge- } \\
\text { salinity function }\end{array}$ & Groundwater salinity & $\begin{array}{l}\text { Estimates groundwater discharge } \\
\text { based on empirical relationship } \\
\text { between groundwater discharge and } \\
\text { groundwater salinity }\end{array}$ \\
\hline
\end{tabular}

measuring water use in existing GDEs and using this characterization as a basis for baseline conditions. A range of tools are available to estimate groundwater use by Class III GDEs. These are now briefly discussed.

\subsubsection{A Spreadsheet Tool}

Because of the paucity of data on points (1)-(4) above, Leaney and co-workers developed a novel, simple, but useful first-order method to estimate groundwater use of vegetation using a simple excel spreadsheet tool (Leaney et al. 2011). The excel spreadsheet includes three methods to estimate rates of groundwater discharge through vegetation:

(a) a groundwater risk model;

(b) an ecological optimality model; and

(c) a groundwater discharge salinity function.

These are summarised in Table 13.1.

The groundwater risk model is a simple water balance model that uses historical monthly rainfall and monthly evaporation data for any site. The soil profile is defined by the user and soil texture is used to estimate soil moisture characteristics for each layer. Groundwater discharge through vegetation is deemed to occur whenever evapotranspiration (ET) exceeds rainfall plus the soil water stores. 


\subsubsection{Sub-daily Fluctuation in Groundwater Depth}

In addition to being used to identify the location/presence of a GDE in a landscape, the White method (White 1932) described in Sect. 13.3.2 for analysing sub-daily changes in depth-to-groundwater can be used to quantify rates of groundwater use. The volume of water transpired is calculated from the change in volume of water in the aquifer that would account for the observed changes in the depth of the water table on an hourly or daily basis, assuming the specific yield of the aquifer is known with sufficient accuracy and confidence. Butler et al. (2007) examined the controls of variation in rates of groundwater use across several riparian sites in the High Plains region of the USA. They found that the principle drivers of vegetation water use were meteorological, vegetation attributes and the specific yield of the aquifer. Their estimates of groundwater use $\left(3-5 \mathrm{~mm} \mathrm{~d}^{-1}\right)$ agreed well with estimates derived from sapflow measurements of tree water use. For a detailed assessment of the technical problems inherent in application of the White method, the reader is referred to Loheide et al. (2005). Further examples of estimating rates of groundwater use using the White method can be found in Lautz (2008), Martinet et al. (2009) and Gribovszki et al. (2008).

\subsubsection{Using Remote Sensing to Estimate Groundwater Use}

Methods for remotely sensed estimates of groundwater discharge are being developed. It is important to quantify the water balance of arid and semi-arid groundwater basins to define safe yields for those resources. Obtaining accurate and spatially distributed estimates of discharge through vegetation is problematic, expensive and time consuming using field techniques. Consequently, Groeneveld and Baugh (2007) derived a new formulation of the standard NDVI which stretches the NDVI distribution for vegetation from zero to one. This new NDVI (NDVI*) can be calibrated to quantify actual rates of evapotranspiration $\left(E T_{a}\right)$ and the calibration only requires standard weather data from which to calculate $\left(E_{o}\right)$ (the grass reference ET calculated using the Penman-Monteith equation, as described in the FAO-56 method (Allen et al. 1998). The $N D V I^{*}$ is functionally equivalent to the crop coefficient $\left(K_{c}\right)$ commonly used in micrometeorology. This methodology is especially applicable to vegetated arid and semi-arid sites with a shallow water table where rainfall is low, often erratic but water supply to roots is relatively constant. Consequently $E T$ closely tracks $E T_{o}$, which varies as a function of solar radiation, wind speed and vapour pressure deficit.

Groeneveld et al. (2007) applied the $N D V I^{*}$ methodology to three disparate arid sites in the USA where annual $E T_{a}$ values were available through use of Bowen ratio or eddy covariance equipment. A linear correlation $\left(\mathrm{R}^{2}=0.94\right)$ between measured annual $E T_{a}$ and mid-summer $N D V I^{*}$ was obtained across the pooled, three-site data, despite very different vegetation composition and structure across the three sites. 
Deducting the contribution of annual rainfall to annual $E T_{a}$ yields the amount of groundwater that is transpired by the vegetation $\left(E T_{g w}\right)$. Thus, $E T_{g w}=\left(E T_{o}-\right.$ rainfall)NDVI* Across sites and across years, the average error in $E T_{g w}$ was estimated to be about $12 \%$, which in the absence of field assessments is a very valuable estimate of groundwater use.

Groeneveld (2008) applied the methodology of Groeneveld et al. (2007), using mid-summer NDVI data to estimate annual total ET of alkali scrub vegetation in Colorado. An estimate of annual groundwater use was then estimated as the difference between annual rainfall and annual ET for each year. On-site estimates of groundwater use were larger than those estimated using NDVI data and $E T_{o}$ because the remote sensing method does not include surface evaporation of groundwater. Annual $E T_{g w}{ }^{*}$ were compared to measurements made by Cooper et al. (2006) at the same site agreed to within $20 \%$. Similarly, as noted earlier in the discussion of RS methods to find ET, Scott et al. (2008) developed a numeric relationship for $E T_{a}$ and concluded that the difference between $E T_{a}$ and annual rainfall was groundwater use.

\subsubsection{Using Stable Isotopes to Estimate Rates of Groundwater Use}

Stable isotopes have been used extensively to provide estimates of the proportion of total vegetation water use that is derived from groundwater (Feikema et al. 2010; Kray et al. 2012; Máguas et al. 2011; McLendon et al. 2008; Querejeta et al. 2007). Thus, an independent estimate of rates of water use are required in addition to analyses of the stable isotope composition of soil water, groundwater and xylem water. Methods to estimate rates of vegetation water use include eddy covariance (Eamus et al. 2013), measurement of rates of sapflow (Zeppel et al. 2008) and remotely sensed estimates (Nagler et al. 2009). When only a single isotope is analysed $\left({ }^{2} \mathrm{H}\right.$ or $\left.{ }^{18} \mathrm{O}\right)$ a linear mixing model can distinguish between only two potential sources of water (groundwater and soil water). If both isotopes are used, spatial resolution is increased and one can distinguish between three sources of water, but only if the two isotopic compositions are independent of each other, which is often not the case. Interestingly, early work in 1996 established that the application of stable isotope analyses was found to be the most accurate method available in a comparative analysis of wetland groundwater inflows (Springs Stewardship Institute 2012).

Two generalities can be identified in the results of stable isotope studies of GDEs. First, as depth-to-groundwater increases, the proportion of total vegetation water-use that is derived from groundwater diminishes (O'Grady et al. 2006) although this can vary amongst different vegetation communities (McLendon et al. 2008). Second, the proportion of groundwater used by vegetation usually (McLendon et al. 2008) but not always (Kray et al. 2012) increases as time since last rain increases and soils dry out and thus seasonality of groundwater use may occur when rainfall is highly seasonal and groundwater availability is maintained throughout the dry season (O'Grady et al. 2006). 
Stable isotope composition varies as a function of depth (Fig. 13.3) and taking an average value to represent the entire rooting depth of the vegetation leads to errors. Even with two independent isotopes available for analyses, the relative contribution of only three sources can be determined. To overcome this limitation, Cook and O'Grady (2006) developed a simple model of water uptake whereby the relative uptake from different depths is determined by (1) the gradient in water potential between the soil and the canopy; (2) root distribution as a function of depth; and (3) a lumped hydraulic conductance parameter. Isotopic composition of water through the soil profile and of xylem water is then used to constrain root distributions (as opposed to measuring this destructively in situ). This model has several advantages over the more commonly used end-member (Phillips and Gregg 2003) analyses: (1) produces a more quantitative estimation of proportion of water extracted from different depths (including groundwater); (2) does not require distinct values of isotope composition for end-member analyses and therefore can deal with the more typical grading of isotope composition observed through the soil profile; and (3) is based on simple ecophysiological principles. Sapflow sensors were used to measure rates of tree water use across four species growing in a tropical remnant native woodland and this was up-scaled using plot basal area. Cook and O'Grady (2006) demonstrated that two species were sourcing 7-15\% of its transpirational water from the water table, a third species was accessing $100 \%$ of its water from the water table and a fourth species was accessing between $53 \%$ and $77 \%$ of its water from the water table - further confirmation of niche separation of patterns of water uptake for co-occurring species.

\subsection{Threats to GDEs}

Human activities threaten GDEs by disturbing habitats, depleting groundwater reserves, altering the groundwater regime at a site beyond the natural bounds of variation previously experienced at that site, and degrading groundwater quality. Globally, GDEs are and will continue to be threatened by groundwater depletion due to increasing water demands from growing populations and increased industrial demand (Danielopol et al. 2003). Wada et al. (2010) estimated that global groundwater depletion (i.e. groundwater abstraction in excess of recharge) in sub-humid to arid areas was approximately $280 \mathrm{~km}^{3} \mathrm{yr}^{-1}$ in 2000 , doubled from 1960. Increasing water demands was projected to greatly outweigh climate change in defining global water resource to 2025 (Vörösmarty et al. 2000). Locally, human activities have impacted GDE habitats through vegetation clearing, filling or draining of wetlands and alteration of surface water courses. Regionally, major anthropogenic threats to GDEs include

- alteration of surface water regime and quality through river regulation and landuse change; 


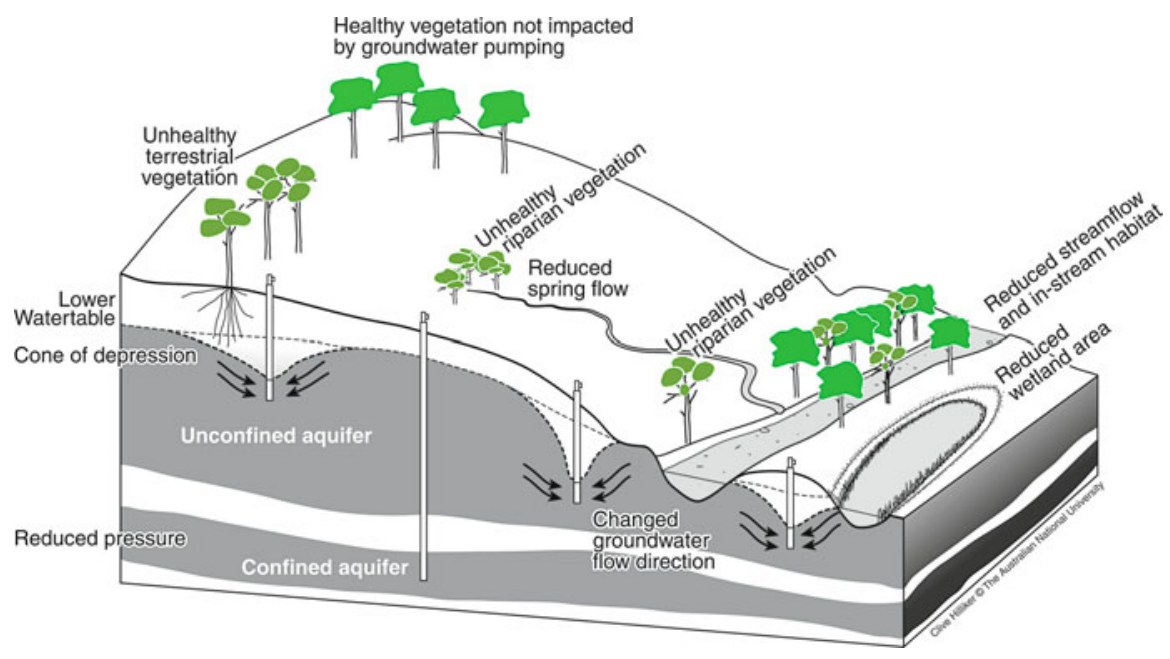

Fig. 13.6 Diagram showing the potential impacts of groundwater pumping on GDEs

- alteration of groundwater regime and quality as a result of agricultural practices, urban and industrial development, mining activities and plantation forestry (Fig. 13.1).

For GDEs that rely on both surface and groundwater sources, surface water regime (including flooding) and quality are considered the most important factor threatening GDEs (Eamus et al. 2006). Evidences of ecosystem change due to flow alteration and surface water quality decline have been reviewed elsewhere (Nilsson et al. 2005; DeFries et al. 2004). This section focuses on groundwater regime and groundwater quality.

\subsubsection{Anthropogenic Threats to Groundwater Regime}

Groundwater extraction is one of the major threats that alters groundwater regime. Groundwater has been extracted to support agricultural activities (especially irrigation), to satisfy residential water-use and to support urban and industrial development. In these cases, groundwater is often extracted through pumping wells in confined or unconfined aquifers. Excessive groundwater pumping in a confined aquifer will depressurise the entire confined aquifer and reduce groundwater discharge to springs (Weber and Perry 2006) (Fig. 13.6). The impact is at a regional scale. In contrast, impact of groundwater pumping from an unconfined aquifer is more localised. In unconfined aquifers, when extraction is faster than recharge, groundwater depth increases forming a "cone of depression" around the well that can extend for many hundreds of meters from the well (Fig. 13.6). In addition, groundwater flow direction can be changed because of the generation of new 
hydraulic gradients: groundwater may no longer flow into the local stream, and some water may be drawn from the stream to the well, thereby reducing stream flow. The time lag between extraction and a reduction in discharge to a stream vary from a few hours to many centuries, depending on extraction locations (relative to the stream), extraction volume and groundwater flux (Evans 2007).

Increased depth-to-groundwater and the disappearance of springs have been reported around the world and are associated with excessive groundwater pumping for agricultural and urban development, mining activities and plantation forestry (Fig. 13.1). Depth-to-groundwater has increased by $4-17 \mathrm{~m}$ in an irrigation region of northwest China, forming several cones of depression covering about $1000 \mathrm{~km}^{2}$ (Wang et al. 2003). Similarly, Burri and Petitta (2004) observed progressive disappearance of numerous springs in the Fucino Plain, Italy, due to increased agricultural water-use for water-intensive horticultural crops and second harvest practices. In some areas of extensive urban development, groundwater depletion has occurred at alarming rates. For example, in London the water table has dropped more than $70 \mathrm{~m}$ below the surface (Elliot et al. 1999); in Bangkok, the water table has dropped by $25 \mathrm{~m}$ since 1958; in Tamil Nadu, India, a $30 \mathrm{~m}$ decline in 15 years has occurred (Danielopol et al. 2003). Muñoz-Reinoso (2001) reported that the decline of water table in Doñana, Spain was primarily due to pumping for urban water supply of a tourist resort and secondarily due to the transpiration of large pine plantations. Mine dewatering (removal of water by pumping or evaporation) can have large impacts on aquifer and cave system locally, and springs close to mine sites. Cluster of mining operations can impact depth-to-groundwater at regional scales due to their cumulative effects (Clifton and Evans 2001).

In addition to groundwater extraction and mine dewatering activities, in-channel gravel or sand mining can cause the incision of a riverbed which lowers the alluvial water tables (Kondolf 1994). Scott et al. (1999) reported water table declines of more than $1 \mathrm{~m}$ at sites affected by gravel mining (compared to no significant decline at control sites). Sustained lowering of the water table greater than $1 \mathrm{~m}$ has led to significant declines in Populus growth and $88 \%$ mortality over a 3-year period (Scott et al. 1999). Water-logging, typically caused by forest clearing and poorly managed irrigation in agricultural lands can result in a rise in the water table, and associated impacts through impaired root function because of the development of anoxic conditions within the root zone (Pimentel et al. 1997).

\subsubsection{Anthropogenic Threats to Groundwater Quality}

Reports of groundwater contamination caused by human activities are abundant. Nitrate leaching from agricultural lands to shallow groundwater has been reported in many regions around the world (Andrade and Stigter 2009). Elevated nitrate levels in groundwater can be sourced from nitrogen fertilizers and manure, oxidation of organically bound nitrogen in soils, cattle feed lots, septic tanks and sewage discharge. Severity of contamination is modified by other factors such as lithology, 
dissolved oxygen levels and land-use. Andrade and Stigter (2009) reported that rice fields on fine-grained alluvium generally have low dissolved oxygen and minimal nitrate concentrations in groundwater due to denitrification. In contrast, areas with vegetable crops coupled with coarse grain lithology and high hydraulic conductivity have higher concentrations of nitrate in shallow groundwater. Discharge of nitrate enriched groundwater can alter nitrogen concentrations in the receiving water and hence increase the risk of eutrophication and algal blooms.

Pesticide contamination can be a problem for shallow groundwater. In the US, more than half of the wells in agricultural and urban areas contain one or more pesticide compounds (Gilliom et al. 2006). Using poor quality pesticides with low degradation rates, incorrect application of pesticides and inappropriate disposal methods can all lead to groundwater being contaminated by pesticides, among which herbicides are the most frequently detected in groundwater (Andrade and Stigter 2009).

Urban development can impair groundwater quality, thereby damaging urban ecosystems. Examples include leakage from septic tanks, underground fuel tanks, landfills, and use of fertilisers and pesticides for gardens and recreation areas. Animal rearing, horticultural activity, solid waste dumping, pit latrine construction and stormwater/sewage disposal have led to increased localised microbial and organic contamination of shallow groundwater (Kulabako et al. 2007; Massone et al. 1998). Foppen (2002) reported increased concentrations of almost all major cations and anions and acidification of groundwater at Sana'a, Yemen, due to continuous infiltration of wastewater into the aquifers via cesspits. More recently, urban groundwater in cities of Germany has been shown to be polluted with xenobiotics such as pharmaceuticals, personal care products (collectively known as PPCPs) and endocrine-active substances (Schirmer et al. 2011). However, their potential long-term effects on ecosystems and humans remain largely unknown.

Mining can contaminate groundwater during mining operation (e.g. leakage from tailings dams and crushed rock waste dumps, which can cover hundreds of hectares at a mine site), as well as the recovering phases after mine sites are abandoned (Younger and Wolkersdorfer 2004; Gao et al. 2011). Dewatering disturbs groundwater stratification, thereby altering the environment required by cave or aquifer ecosystems and associated stygofauna. Cidu et al. (2001) reported that mine closure and associated cessation of groundwater pumping and mine flooding may pose a contamination risk to shallow aquifers due to the rise of deep saline groundwater. Progressive mine flooding also causes groundwater contamination via weathering of ore minerals and remobilization of metals in the mine waste (Razowska 2001).

In summary, groundwater regime and quality are threatened by many human activities, including agricultural practices, urban and industrial development, mining activities and plantation forestry. These threats can have profound impact on GDEs in the short and long term, at local and regional scales. The impacts of groundwater abstraction on GDEs and their restoration are discussed below using two case studies. 
Shoot growth rate declines; root growth stimulated

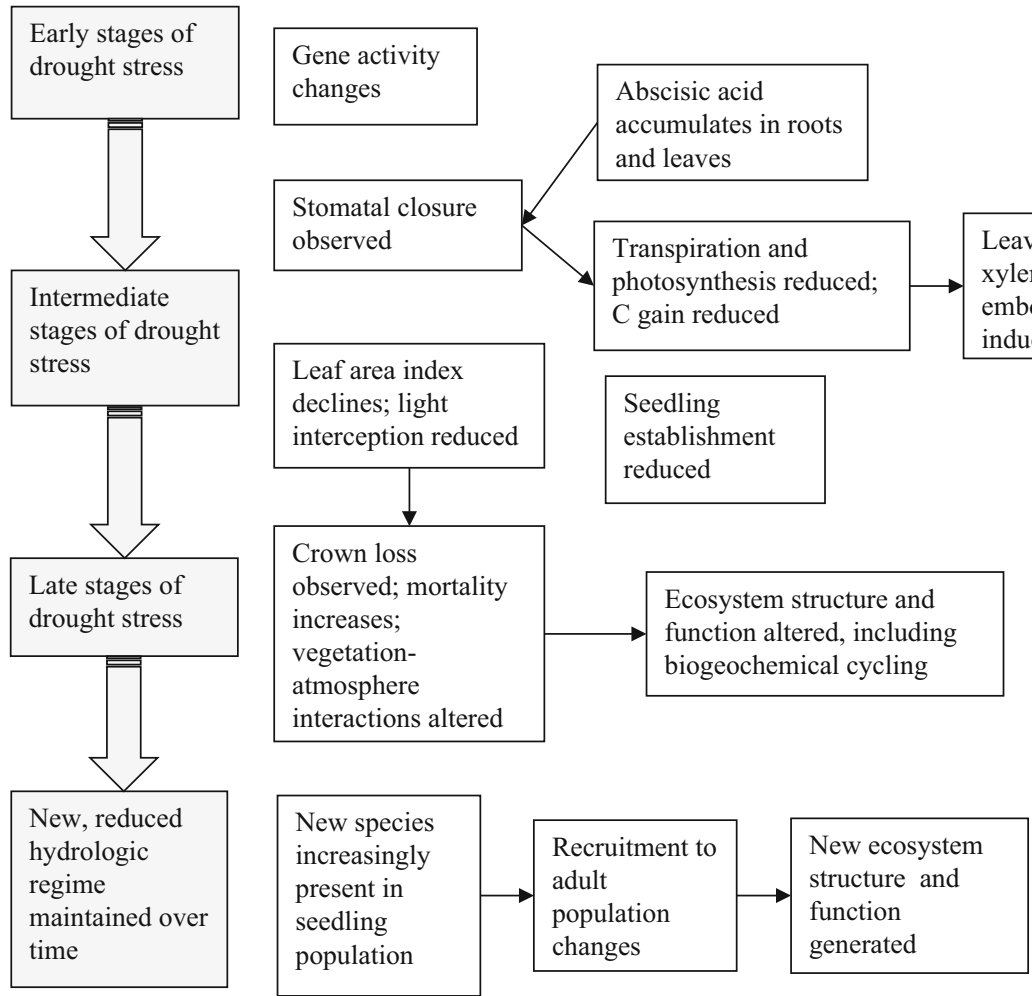

Fig. 13.7 Schematic outline of some of the changes in plant physiology, ecophysiology and ecology associated with short-, medium- and long-term changes in water availability

\subsubsection{Case Study 1: Terrestrial Vegetation}

The impacts of groundwater abstraction on woodlands has been documented for the Gnangara Mound, a shallow unconfined aquifer of the Swan Coastal Plain in Western Australia (Canham et al. 2009, 2012; Groom et al. 2000; Stock et al. 2012). Increased depth-to-groundwater is the result of a long-term decline in annual rainfall across the region, increased abstraction for human use and increased discharge (reduced recharge) arising from the development of a plantation industry in the region. A range of changes in plant physiology, ecophysiology and ecology are found associated with short-, medium- and long-term changes in water availability (Fig. 13.7).

In 1985 increased rates of summer abstraction in this Mediterranean climate resulted in increased and widespread mortality (up to $80 \%$ mortality close to the abstraction bores) of the native Banksia woodland. To determine longer-term 
floristic changes arising from groundwater abstraction, a series of transect studies were initiated in 1988. A $2.2 \mathrm{~m}$ increase in depth-to-groundwater, coupled to higher-than-normal summer temperatures resulted in a $20-80 \%$ adult mortality of overstory species and up to $64 \%$ mortality in the understory species, 2 years after the start of groundwater pumping (Groom et al. 2000). Control sites, not impacted by groundwater pumping, did not display increased mortality.

Because of the large inter-species differences in rates of mortality, a further study examined the vulnerability of different species to reduced water availability (Canham et al. 2009; Froend and Drake 2006). Using xylem embolism vulnerability curves as an indicator of sensitivity to water stress, Froend and Drake (2006) compared three Bankisa and one Melaleuca species. They found that xylem vulnerability reflected the broad ecohydrological distribution of the species across the topographic gradient present at the site and they were able to identify a threshold leaf water potential below which increased mortality was likely.

Similarly, Canham et al. (2009) examined Huber values (the ratio of sapwood to leaf area), leaf-specific hydraulic conductivity $\left(k_{l}\right)$ and xylem vulnerability of two obligate phreatophytes and two facultative phreatophytes. At sites were water availability was high (no increase in depth-to-groundwater) there were no interspecific differences in vulnerability to water stress. However, in a comparison of the upper and lower slopes (corresponding to larger and smaller depth-to-groundwater respectively) the two facultative phreatophytes (but not the obligate phreatophytes) were more resistant to xylem embolism at the upper slope than the lower slope, whilst one of the obligate phreatophytes did not alter its sensitivity (Canham et al. 2009).

In addition to differences in sensitivity of above-ground tissues to changes in water availability, it is likely that differences in the responses of root to changes in depth-to-groundwater contribute to the impact of changes in depth-to-groundwater on vegetation in GDEs. In a comparative study on two Banksia tree species, Canham et al. (2012) observed that root growth at sites with shallow depth-togroundwater was in synchrony with above-ground growth patterns. This was in contrast to patterns observed at depth, where root growth occurred all year and was independent of aerial climate. As depth-to-groundwater increased during the summer in this winter rainfall site, roots grew increasingly deeper, following the capillary fringe. As recharge occurred in the winter and depth-to-groundwater declined, anoxia resulted in root death at depth. These authors concluded that the ability to rapidly increase root depth during the summer is a critical attribute of phreatophytes occupying sites with seasonally dynamic depth-to-groundwater.

Long-term ( $>2$ years) studies of the influence of changes in depth-to-groundwater are relatively rare, despite the importance of such studies to the development of ecosystem response trajectories for the impact of groundwater abstraction. Froend and Sommer (2010) examined a rare, 40 year duration, vegetation survey data-set for the Gnangarra Mound in Western Australia. Although the long-term (1976-2008) average rainfall in $850 \mathrm{~mm}$, this has been declining for the past 40 years. Currently the annual average is about $730 \mathrm{~mm}$. This, along with increased groundwater abstraction, has resulted in increases in the depth-to-groundwater over 
the past 50 years of about $1 \mathrm{~m}$. Seasonally, depth-to-groundwater fluctuates about $0.5-3 \mathrm{~m}$, with a maximum depth occurring at the end of the summer. Two transects were used - a "control" transect where gradual increases in depth-to-groundwater $\left(9 \mathrm{~cm} \mathrm{y}^{-1}\right)$ have occurred as a result of the decline in annual rainfall over the past several decades; and an "experimental" transect where large rates of increase in depth-to-groundwater $\left(50 \mathrm{~cm} \mathrm{y}^{-1}\right)$ because of declining rainfall and extensive abstraction of groundwater have occurred. Three vegetation communities were identified with principal coordinate analyses and these were clearly associated with down-slope, mid-slope and upper-slope positions, corresponding to shallow, intermediate and deep depth-to-groundwater respectively. Species known to have a high dependency on consistent water supplies (mesic species) were dominant at the down-slope site whilst xeric species dominated the upper-slope sites.

On the control transect (slow rates of increase in depth-to-groundwater), the hypothesis that groundwater water abstraction would result in a replacement of the mesic by the xeric species was not supported. Most of the compositional and structural attributes of the three communities were unchanged. The principle community-scale response was a change in the abundance of mesic and xeric species rather than a complete replacement of one species for another. In contrast to the results of Shafroth et al. (2000), mesic species growing on sites with shallow groundwater were not more sensitive to increases in depth-to-groundwater than xeric species.

On the "experimental" transect where the increase in depth-to-groundwater was much faster $\left(50 \mathrm{~cm} \mathrm{y}^{-1}\right)$ changes in composition were far more pronounced and mass mortality observed across all classes (mesic to xeric) species. This result emphasises the importance of the rate of increase in depth-to-groundwater in determining the response of species and communities.

\subsubsection{Case Study 2: Restoration of Springs}

A systematic review of the literature of the restoration of arid-land springs was conducted by Stacey et al. (2011) to determine how successful projects were in restoring hydrology, geomorphology, and biological assemblage composition and structure in relation to those at natural springs with minimal anthropogenic disturbances. Unfortunately, the great inconsistency in the rationale for and in the implementation, monitoring, and reporting of springs restoration efforts globally made it impossible to conduct meta-statistical analyses of the quality of restoration. Stacey et al. (2011) recommended standardised ecosystem condition and restoration assessment protocols are needed to more clearly understand the success of projects. Because of the inability to report on a global summary of the success of restoration and management, we provide a case study by specific spheres of discharge to provide some lessons learned from restoration and management actions.

Hoxworth Springs is a rheochrene spring on the Mogollon Rim of the southwestern Colorado Plateau (Godwin 2004). This system is typical in both the morphology and degradation of many stream channels associated with rheochrene 
springs of the Southwestern USA. Causes for the channel down-cutting of the system are attributed to anthropogenic modification of the channel with the installation of a series of low-head dams and grazing of domestic animals and introduced, non-native wildlife in the channel and the drainage basin. In cooperation with land managers, channel restoration was completed to return the function and structure of the system. Restoration included stream channel morphologic reconstruction and hydrologic and vegetative monitoring. The channel was significantly incised and the sinuosity decreased resulting in greater flow velocities, steep channel banks, and flood flows which couldn't dissipate over the flood plain.

The restoration of Hoxworth Springs included reshaping of the channel based on morphologic patterns observed in abandoned reference sections of the channel on the flood plain surface and with similar runoff dominated rheocrene spring channels in the region (Griffiths et al. 2008). Re-vegetation was performed to stabilize the restored channel banks and large exclosures were constructed to manage grazing along the channel. A three-dimensional groundwater flow model was created to help interpret and predict effects of the restoration effort on perennial stream discharge, effectiveness of the restoration, and system response to climatic extremes. The model demonstrated that the length of perennial flow in the channel was dependent on the recent climate conditions. The use of a groundwater model to evaluate restoration efforts allows the user to modify recharge conditions based upon climatic or hydrologic perturbations and estimate impacts to the length of perennial flow and water availability to the riparian ecosystem.

\subsection{Concluding Remarks}

We now have, for the first time, a range of tools that cover the full temporal and spatial scales across which ecology moves (seconds-to-decades; from leaf-to whole-of-catchment). Measurements of stomatal or canopy conductance, sapflow, canopy temperature, leaf area index and rates of evapotranspiration and productivity can be made using ecophysiological techniques and remote sensing technologies. These data can be used in simple, moderate and complex models of ecosystem structure and function to identify the presence, areal extent and health of GDEs. What remains to be done? The three largest knowledge gaps are, in our opinion, (1) definition of the response function of ecosystems to changes in groundwater availability or groundwater quality; (2) determination of the threshold for GDEs beyond which unacceptable changes in GDE structure and function occur; and (3) a mechanistic understanding (and hence predictive capacity) of the interaction of future climate variability on GDEs.

Open Access This chapter is distributed under the terms of the Creative Commons AttributionNoncommercial 2.5 License (http://creativecommons.org/licenses/by-nc/2.5/) which permits any noncommercial use, distribution, and reproduction in any medium, provided the original author(s) and source are credited. 
The images or other third party material in this chapter are included in the work's Creative Commons license, unless indicated otherwise in the credit line; if such material is not included in the work's Creative Commons license and the respective action is not permitted by statutory regulation, users will need to obtain permission from the license holder to duplicate, adapt or reproduce the material.

\section{References}

Allen RG, Pereira LS, Raes D, Smith M (1998) Crop evapotranspiration-guidelines for computing crop water requirements. FAO Irrigation and drainage paper 56, FAO, Rome 300:6541

Andrade AIASS, Stigter TY (2009) Multi-method assessment of nitrate and pesticide contamination in shallow alluvial groundwater as a function of hydrogeological setting and land use. Agric Water Manag 96(12):1751-1765. doi:10.1016/j.agwat.2009.07.014

Blyth J, English V (1996) Endangered - tumulus springs. Landscope 11:47

Boulton A, Humphreys W, Eberhard S (2003) Imperilled subsurface waters in Australia: biodiversity, threatening processes and conservation. Aquat Ecosyst Health Manage 6(1):41-54

Burri E, Petitta M (2004) Agricultural changes affecting water availability: from abundance to scarcity (Fucino Plain, central Italy). Irrig Drain 53(3):287-299. doi:10.1002/Ird.119

Butler JJ, Kluitenberg GJ, Whittemore DO, Loheide SP, Jin W, Billinger MA, Zhan X (2007) A field investigation of phreatophyte-induced fluctuations in the water table. Water Resour Res 43(2):W02404. doi:10.1029/2005WR004627

Caldwell MM, Dawson TE, Richards JH (1998) Hydraulic lift: consequences of water efflux from the roots of plants. Oecologia 113(2):151-161

Campos GEP, Moran MS, Huete A, Zhang Y, Bresloff C, Huxman TE, Eamus D, Bosch DD, Buda AR, Gunter SA (2013) Ecosystem resilience despite large-scale altered hydroclimatic conditions. Nature 494(7437):349-352

Canham CA, Froend RH, Stock WD (2009) Water stress vulnerability of four Banksia species in contrasting ecohydrological habitats on the Gnangara Mound, Western Australia. Plant Cell Environ 32(1):64-72

Canham CA, Froend RH, Stock WD, Davies M (2012) Dynamics of phreatophyte root growth relative to a seasonally fluctuating water table in a Mediterranean-type environment. Oecologia 170(4):909-916

Cidu R, Biagini C, Fanfani L, La Ruffa G, Marras I (2001) Mine closure at Monteponi (Italy): effect of the cessation of dewatering on the quality of shallow groundwater. Appl Geochem 16 (5):489-502. doi:10.1016/S0883-2927(00)00046-9

Clifton CA, Evans R (2001) Environmental water requirements to maintain groundwater dependent ecosystems. Environmental flows initiative technical report number 2, Commonwealth of Australia, Canberra

Cook PG, O'Grady AP (2006) Determining soil and ground water use of vegetation from heat pulse, water potential and stable isotope data. Oecologia 148(1):97-107

Cook PG, Hatton TJ, Pidsley D, Herczeg AL, Held A, O’Grady A, Eamus D (1998) Water balance of a tropical woodland ecosystem, Northern Australia: a combination of micro-meteorological, soil physical and groundwater chemical approaches. J Hydrol 210(1-4):161-177. doi:10.1016/ S0022-1694(98)00181-4

Cook PG, Favreau G, Dighton JC, Tickell S (2003) Determining natural groundwater influx to a tropical river using radon, chlorofluorocarbons and ionic environmental tracers. J Hydrol 277 (1):74-88

Cooper DJ, Sanderson JS, Stannard DI, Groeneveld DP (2006) Effects of long-term water table drawdown on evapotranspiration and vegetation in an arid region phreatophyte community. J Hydrol 325(1):21-34 
Crossey LJ, Karlstrom KE (2012) Travertines and travertine springs in eastern Grand Canyon: what they tell us about groundwater, paleoclimate, and incision of Grand Canyon. Geol Soc Am Spec Pap 489:131-143

Danielopol DL, Griebler C, Gunatilaka A, Notenboom J (2003) Present state and future prospects for groundwater ecosystems. Environ Conserv 30(2):104-130. doi:10.1017/ S0376892903000109

DeFries RS, Asner GP, Houghton RA (2004) Ecosystems and land use change, vol 153. American Geophysical Union Geophysical Monograph Series, Washington, DC

Dresel P, Clark R, Cheng X, Reid M, Terry A, Fawcett J, Cochrane D (2010) Mapping terrestrial GDEs: method development and example output. Victoria Department of Primary Industries, Melbourne

Eamus D, Froend R, Loomes R, Hose G, Murray B (2006) A functional methodology for determining the groundwater regime needed to maintain the health of groundwater-dependent vegetation. Aust J Bot 54(2):97-114

Eamus D, Cleverly J, Boulain N, Grant N, Faux R, Villalobos-Vega R (2013) Carbon and water fluxes in an arid-zone Acacia savanna woodland: an analyses of seasonal patterns and responses to rainfall events. Agr Forest Meteorol. doi:10.1016/j.agrformet.2013.04.020

Elliot T, Andrews JN, Edmunds WM (1999) Hydrochemical trends, palaeorecharge and groundwater ages in the fissured Chalk aquifer of the London and Berkshire Basins, UK. Appl Geochem 14(3):333-363. doi:10.1016/S0883-2927(98)00060-2

Ernst CH, Lovich JE (2009) Turtles of the United States and Canada, 2nd edn. Smithsonian Institution Press, Washington/London

Evans R (2007) The effects of groundwater pumping on stream flow in Australia. Technical Report, Land \& Water Australia, Canberra

Feikema PM, Morris JD, Connell LD (2010) The water balance and water sources of a Eucalyptus plantation over shallow saline groundwater. Plant Soil 332(1-2):429-449

Foppen JWA (2002) Impact of high-strength wastewater infiltration on groundwater quality and drinking water supply: the case of Sana'a, Yemen. J Hydrol 263(1-4):198-216. doi:10.1016/ S0022-1694(02)00051-3

Froend R, Drake P (2006) Defining phreatophyte response to reduced water availability: preliminary investigations on the use of xylem cavitation vulnerability in Banksia woodland species. Aust J Bot 54(2): 173-179

Froend R, Sommer B (2010) Phreatophytic vegetation response to climatic and abstractioninduced groundwater drawdown: examples of long-term spatial and temporal variability in community response. Ecol Eng 36(9):1191-1200

Gao XB, Wang YX, Ma T, Hu QH, Xing XL, Yu Q (2011) Anthropogenic impact assessment of Niangziguan karst water. Proc Inst Civ Eng Water Manage 164(10):495-510, 10.1680/Wama. 1000070

Gilliom RJ, Barbash JE, Crawford CG, Hamilton PA, Martin JD, Nakagaki N, Nowell LH, Scott JC, Stackelberg PE, Thelin GP, Wolock DM (2006) Pesticides in the nation's streams and ground water, 1992-2001: the quality of our nation's waters. US Geological Survey, Reston, Virginia

Godwin TN (2004) Evaluation of streambed restoration and occurrence of Hoxworth Springs, Coconino County, Arizona. Northern Arizona University, Flagstaff

Gribovszki Z, Kalicz P, Szilágyi J, Kucsara M (2008) Riparian zone evapotranspiration estimation from diurnal groundwater level fluctuations. J Hydrol 349(1-2):6-17. doi:10.1016/j.jhydrol. 2007.10.049

Gribovszki Z, Szilágyi J, Kalicz P (2010) Diurnal fluctuations in shallow groundwater levels and streamflow rates and their interpretation - a review. J Hydrol 385(1):371-383

Griffiths RE, Anderson DE, Springer AE (2008) The morphology and hydrology of small springdominated channels. Geomorphology 102(3):511-521

Groeneveld DP (2008) Remotely-sensed groundwater evapotranspiration from alkali scrub affected by declining water table. J Hydrol 358(3):294-303 
Groeneveld DP, Baugh WM (2007) Correcting satellite data to detect vegetation signal for eco-hydrologic analyses. J Hydrol 344(1):135-145

Groeneveld DP, Baugh WM, Sanderson JS, Cooper DJ (2007) Annual groundwater evapotranspiration mapped from single satellite scenes. J Hydrol 344(1):146-156

Groom BPK, Froend RH, Mattiske EM (2000) Impact of groundwater abstraction on a Banksia woodland, Swan Coastal Plain, Western Australia. Ecol Manage Restor 1(2):117-124

Hancock P, Boulton A, Humphreys W (2005) Aquifers and hyporheic zones: towards an ecological understanding of groundwater. Hydrogeol J 13(1):98-111. doi:10.1007/s10040-004-0421-6

Hatton T, Evans R (1998) Dependence of ecosystems on groundwater and its significance to Australia, vol 12/98, Occasional paper. Land and Water Resources Research and Development Corporation, Canberra

Haynes V (2008) Quaternary cauldron springs as paleoecological archives. In: Stevens LE, Meretsky VJ (eds) Aridland springs in North America: ecology and conservation. University of Arizona Press, Tucson

Heitmuller FT, Reece BD (2007) Spatial data for Eurycea salamander habitats associated with three aquifers in south-central Texas. US Geological Survey, Austin, Texas

Hershler R (1998) A systematic review of the hydrobiid snails (Gastropoda: Rissoidea) of the Great Basin, western United States. Part I. Genus Pyrgulopsis. Veliger 41(1):1-132

Hershler R, Liu H-P, Howard J (2014) Springsnails: a new conservation focus in western North America. Bioscience 68:693-700. doi:10.1093/biosci/biu100

Hunt RJ, Krabbenhoft DP, Anderson MP (1996) Groundwater inflow measurements in wetland systems. Water Resour Res 32(3):495-507

Hynes HBN (1970) The ecology of running waters. University of Toronto Press, Toronto

Jayasekera DL, Kaluarachchi JJ, Villholth KG (2011) Groundwater stress and vulnerability in rural coastal aquifers under competing demands: a case study from Sri Lanka. Environ Monit Assess 176(1-4):13-30. doi:10.1007/s10661-010-1563-8

Jin XM, Schaepman ME, Clevers JG, Su ZB, Hu G (2011) Groundwater depth and vegetation in the Ejina area, China. Arid Land Res Manag 25(2):194-199

Johnson RH, DeWitt E, Wirt L, Arnold LR, Horton JD (2011) Water and rock geochemistry, geologic cross sections, geochemical modeling, and groundwater flow modeling for identifying the source of groundwater to Montezuma Well, a natural spring in central Arizona. U.S. Geological Survey Open-File Report 2011-1063, Reston, Virginia

Kolb TE, Hart SC, Amundson R (1997) Boxelder water sources and physiology at perennial and ephemeral stream sites in Arizona. Tree Physiol 17(3):151-160

Kondolf GM (1994) Geomorphic and environmental effects of instream gravel mining. Landsc Urban Plan 28(2-3):225-243. doi:10.1016/0169-2046(94)90010-8

Kray J, Cooper D, Sanderson J (2012) Groundwater use by native plants in response to changes in precipitation in an intermountain basin. J Arid Environ 83:25-34

Kreamer DK, Stevens LE, Ledbetter, JD. Groundwater dependent ecosystems-science, challenges, and policy. In: Adelana SM (ed) Groundwater. Nova Science Publishers, Hauppauge (NY), pp 205-230. ISBN: 978-1-63321-759-1

Kulabako NR, Nalubega M, Thunvik R (2007) Study of the impact of land use and hydrogeological settings on the shallow groundwater quality in a peri-urban area of Kampala, Uganda. Sci Total Environ 381(1-3):180-199. doi:10.1016/j.scitotenv.2007.03.035

Laity JE, Malin MC (1985) Sapping processes and the development of theater-headed valley networks on the Colorado Plateau. Geol Soc Am Bull 96(2):203-217

Lambrakis NJ (1998) The impact of human activities in the Malia coastal area (Crete) on groundwater quality. Environ Geol 36(1-2):87-92

Lamontagne S, Cook PG, O'Grady A, Eamus D (2005) Groundwater use by vegetation in a tropical savanna riparian zone (Daly River, Australia). J Hydrol 310(1):280-293

Lautz LK (2008) Estimating groundwater evapotranspiration rates using diurnal water-table fluctuations in a semi-arid riparian zone. Hydrogeol J 16(3):483-497 
Leaney F, Crosbie R, O'Grady A, Jolly I, Gow L, Davies P, Wilford J, Kilgour P (2011) Recharge and discharge estimation in data poor areas: scientific reference guide. CSIRO: Water for a Healthy Country National Research Flagship, CSIRO

Leblanc M, Leduc C, Razack M, Lemoalle J, Dagorne D, Mofor L (2003a) Applications of remote sensing and GIS for groundwater modelling of large semiarid areas: example of the Lake Chad Basin, Africa. IAHS Publ 278:186-194

Leblanc M, Razack M, Dagorne D, Mofor L, Jones C (2003b) Application of Meteosat thermal data to map soil infiltrability in the central part of the Lake Chad basin, Africa. Geophys Res Lett 30(19):1998. doi:10.1029/2003GL018094

Li F, Lyons T (1999) Estimation of regional evapotranspiration through remote sensing. J Appl Meteorol 38(11):1644-1654

Loheide SP II, Butler JJ Jr, Gorelick SM (2005) Estimation of groundwater consumption by phreatophytes using diurnal water table fluctuations: a saturated-unsaturated flow assessment. Water Resour Res 41(7):W07030

Lv J, Wang XS, Zhou Y, Qian K, Wan L, Eamus D, Tao Z (2012) Groundwater-dependent distribution of vegetation in Hailiutu River catchment, a semi-arid region in China. Ecohydrology 6:142-149

Máguas C, Rascher K, Martins-Loucao A, Carvalho P, Pinho P, Ramos M, Correia O, Werner C (2011) Responses of woody species to spatial and temporal ground water changes in coastal sand dune systems. Biogeosci Discuss 8(1):1591-1616

Martinet MC, Vivoni ER, Cleverly JR, Thibault JR, Schuetz JF, Dahm CN (2009) On groundwater fluctuations, evapotranspiration, and understory removal in riparian corridors. Water Resour Res 45(5):W05425

Massone HE, Martinez DE, Cionchi JL, Bocanegra E (1998) Suburban areas in developing countries and their relationship to groundwater pollution: a case study of Mar del Plata, Argentina. Environ Manage 22(2):245-254. doi:10.1007/s002679900100

McCracken RD (1992) The modern pioneers of the Amargosa Valley. Nye County Press, Tonopah

McLendon T, Hubbard PJ, Martin DW (2008) Partitioning the use of precipitation-and groundwater-derived moisture by vegetation in an arid ecosystem in California. J Arid Environ 72 (6):986-1001

Meinzer OE (1923) Outline of groundwater hydrology with definitions, vol 494, US Geology Survey Water supply paper. U.S. Govt. Print. Off, Washington, 71pp

Melis TS, Phillips WM, Webb RH, Bills DJ (1996) When the blue-green waters turn red: historical flooding in Havasu Creek, Arizona. U.S. Geological Survey water-resources investigations report 96-4059, Tucson, Arizona

Minckley WL, Deacon JE (eds) (1991) Battle against extinction: native fish management in the American West. University of Arizona Press, Tucson

Monroe SA, Antweiler RC, Hart RJ, Taylor HE, Truini M, Rihs JR, Felger TJ (2005) Chemical characteristics of ground-water discharge along the South Rim of Grand Canyon in Grand Canyon National Park, Arizona, 2000-2001. USGS scientific investigations report 2004-5146, Reston, Virginia

Munch DA, Toth DJ, Haung C, Fortich DM, Osburn WL, Phlips EJ, Quinlan EL, Allen MS, Woods MJ, Cooney P, Knight RL, Clarke RA, Knight SL (2006) Fifty-year retrospective study of the ecology of Silver Springs, Florida. St. Johns River Water Management District, Special Publication SJ2007-SP4, Palatka, Florida

Münch Z, Conrad J (2007) Remote sensing and GIS based determination of groundwater dependent ecosystems in the Western Cape, South Africa. Hydrogeol J 15(1):19-28

Muñoz-Reinoso JC (2001) Vegetation changes and groundwater abstraction in SW Doñana, Spain. J Hydrol 242(3-4):197-209. doi:10.1016/S0022-1694(00)00397-8

Nagler PL, Glenn EP, Lewis Thompson T, Huete A (2004) Leaf area index and normalized difference vegetation index as predictors of canopy characteristics and light interception by riparian species on the Lower Colorado River. Agr Forest Meteorol 125(1):1-17 
Nagler PL, Morino K, Didan K, Erker J, Osterberg J, Hultine KR, Glenn EP (2009) Wide-area estimates of saltcedar (Tamarix spp.) evapotranspiration on the lower Colorado River measured by heat balance and remote sensing methods. Ecohydrology 2(1):18-33

Nath B, Lillicrap AM, Ellis LC, Boland DD, Oldham CE (2013) Hydrological and chemical connectivity dynamics in a groundwater-dependent ecosystem impacted by acid sulfate soils. Water Resour Res 49:441-457. doi:10.1029/2012wr012760

Naumburg E, Mata-gonzalez R, Hunter R, McLendon T, Martin D (2005) Phreatophytic vegetation and groundwater fluctuations: a review of current research and application of ecosystem response modeling with an emphasis on great basin vegetation. Environ Manage 35 (6):726-740. doi:10.1007/s00267-004-0194-7

Newell DL, Crossey LJ, Karlstrom KE, Fischer TP, Hilton DR (2005) Continental-scale links between the mantle and groundwater systems of the western United States: evidence from travertine springs and regional He isotope data. GSA Today 15(12):4-10

Nickerson MA, Mays CE (1973) The hellbenders: North American "giant salamanders", vol 1. Milwaukee Public Museum, Milwaukee

Nilsson C, Reidy CA, Dynesius M, Revenga C (2005) Fragmentation and flow regulation of the world's large river systems. Science 308(5720):405-408

O'Grady A, Cook P, Howe P, Werren G (2006) Groundwater use by dominant tree species in tropical remnant vegetation communities. Aust J Bot 54(2):155-171

Phillips DL, Gregg JW (2003) Source partitioning using stable isotopes: coping with too many sources. Oecologia 136(2):261-269

Pimentel D, Houser J, Preiss E, White O, Fang H, Mesnick L, Barsky T, Tariche S, Schreck J, Sharon A (1997) Water resources: agriculture, the environment, and society. BioScience 47 (2):97-106. doi:10.2307/1313020

Querejeta JI, Estrada-Medina H, Allen MF, Jiménez-Osornio JJ (2007) Water source partitioning among trees growing on shallow karst soils in a seasonally dry tropical climate. Oecologia 152 (1):26-36

Ramstead KM, Allen JA, Springer AE (2012) Have wet meadow restoration projects in the Southwestern US been effective in restoring geomorphology, hydrology, soils, and plant species composition? Environ Evid 1(1):11

Razowska L (2001) Changes of groundwater chemistry caused by the flooding of iron mines (Czestochowa Region, Southern Poland). J Hydrol 244(1-2):17-32. doi:10.1016/S0022-1694 (00)00420-0

Ritsema CJ, Groenenberg JE, Bisdom EBA (1992) The transformation of potential into actual acid sulphate soils studied in column experiments. Geoderma 55(3-4):259-271. doi:10.1016/00167061(92)90087-N

Schirmer M, Reinstorf F, Leschik S, Musolff A, Krieg R, Strauch G, Molson JW, Martienssen M, Schirmer K (2011) Mass fluxes of xenobiotics below cities: challenges in urban hydrogeology. Environ Earth Sci 64(3):607-617. doi:10.1007/s12665-010-0880-0

Scott ML, Shafroth PB, Auble GT (1999) Responses of riparian cottonwoods to alluvial water table declines. Environ Manage 23(3):347-358. doi:10.1007/s002679900191

Scott RL, Cable WL, Huxman TE, Nagler PL, Hernandez M, Goodrich DC (2008) Multiyear riparian evapotranspiration and groundwater use for a semiarid watershed. J Arid Environ 72 (7): $1232-1246$

Shafroth PB, Stromberg JC, Patten DT (2000) Woody riparian vegetation response to different alluvial water table regimes. West N Am Naturalist 60(1):66-76

Shepard WD (1993) Desert springs - both rare and endangered. Aquat Conserv 3(4):351-359

Spałek K, Pro ków J (2011) Karst springs as habitats for rare and protected plant species: a new inland locality of a halophyte plant Batrachium baudotii (Ranunculaceae) in a karst spring in Central Europe. J Cave Karst Stud 73:158-162

Springer AE, Stevens LE (2009) Spheres of discharge of springs. Hydrogeol J 17(1):83-93

Springer AE, Stevens LE, Anderson DE, Parnell RA, Kreamer DK, Levin L, Flora S (2008) A comprehensive springs classification system: integrating geomorphic, hydrogeochemical, and ecological criteria. In: Stevens LE, Meretsky VJ (eds) Aridland springs in North America: ecology and conservation. University of Arizona Press, Tucson 
Springs Stewardship Institute (2012) Springs ecosystem inventory, assessment, and stewardship. Available on-line at: www.springstewardship.org. Accessed 1 Mar 2014

Stacey CJ, Springer AE, Stevens LE (2011) Have arid land springs restoration projects been effective in restoring hydrology, geomorphology, and invertebrate and plant species composition comparable to natural springs with minimal anthropogenic disturbance? CEE review 10002. Collaboration for Environmental Evidence. www.environmentalevidence.org/SR87.html

Stevens LE, Ledbetter JD (2012) Ecohydrology of springs on Kaibab National Forest to support forest planning. Springs Stewardship Institute, Flagstaff

Stock WD, Bourke L, Froend RH (2012) Dendroecological indicators of historical responses of pines to water and nutrient availability on a superficial aquifer in south-western Australia. For Ecol Manage 264:108-114

Thorburn PJ, Hatton TJ, Walker GR (1993) Combining measurements of transpiration and stable isotopes of water to determine groundwater discharge from forests. J Hydrol 150(2):563-587

Tweed SO, Leblanc M, Webb JA, Lubczynski MW (2007) Remote sensing and GIS for mapping groundwater recharge and discharge areas in salinity prone catchments, southeastern Australia. Hydrogeol J 15(1):75-96

U.S. Forest Service (2012) Groundwater-dependent ecosystem inventory using remote sensing. RSAC-10011-RPT1. Remote Sensing Evauation, Applications \& Training Center, Salt Lake City, Utah

Unmack PJ, Minckley WL (2008) The demise of desert springs. In: Stevens LE, Meretsky VJ (eds) Aridland springs in North America: ecology and conservation. University of Arizona Press, Tucson, pp 11-34

Vörösmarty CJ, Green P, Salisbury J, Lammers RB (2000) Global water resources: vulnerability from climate change and population growth. Science 289(5477):284-288. doi:10.1126/sci ence.289.5477.284

Wada Y, van Beek LPH, van Kempen CM, Reckman JWTM, Vasak S, Bierkens MFP (2010) Global depletion of groundwater resources. Geophys Res Lett 37(20), L20402. doi:10.1029/ $2010 \mathrm{~g} 1044571$

Wang GX, Cheng GD, Du MY (2003) The impacts of human activity on hydrological processes in the arid zones of the Hexi Corridor, northwest China, in the past 50 years. IAHS-AISH P 280:93-103

Weber K, Perry R (2006) Groundwater abstraction impacts on spring flow and base flow in the Hillsborough River Basin, Florida, USA. Hydrogeol J 14(7):1252-1264. doi:10.1007/s 10040006-0040-5

White WN (1932) A method of estimating ground-water supplies based on discharge by plants and evaporation from soil: results of investigations in Escalante Valley, Utah. Water supply paper 659-A. US Geological Survey, Utah

Winograd IJ, Riggs AC, Coplen TB (1998) The relative contributions of summer and cool-season precipitation to groundwater recharge, Spring Mountains, Nevada, USA. Hydrogeol J 6(1):77-93

Younger P, Wolkersdorfer C (2004) Mining impacts on the fresh water environment: technical and managerial guidelines for catchment scale management. Mine Water Environ 23(1):s2-s80. doi:10.1007/s10230-004-0028-0

Zektser S, Loáiciga HA, Wolf JT (2005) Environmental impacts of groundwater overdraft: selected case studies in the southwestern United States. Environ Geol 47(3):396-404. doi:10.1007/s00254-004-1164-3

Zencich SJ, Froend RH, Turner JV, Gailitis V (2002) Influence of groundwater depth on the seasonal sources of water accessed by Banksia tree species on a shallow, sandy coastal aquifer. Oecologia 131(1):8-19

Zeppel MJ, Macinnis-Ng CM, Yunusa IA, Whitley RJ, Eamus D (2008) Long term trends of stand transpiration in a remnant forest during wet and dry years. J Hydrol 349(1):200-213 


\title{
Interactions of Water Quality and Integrated Groundwater Management: Examples from the United States and Europe
}

\author{
Kelly L. Warner, Fabienne Barataud, Randall J. Hunt, Marc Benoit, \\ Juliette Anglade, and Mark A. Borchardt
}

\begin{abstract}
Groundwater is available in many parts of the world, but the quality of the water may limit its use. Contaminants can limit the use of groundwater through concerns associated with human health, aquatic health, economic costs, or
\end{abstract}

\section{K.L. Warner $(\varangle)$}

Illinois Water Science Center, United States Geological Survey, 405 North Goodwin Avenue, Urbana, IL 61801, USA

e-mail: klwarner@usgs.gov

\section{F. Barataud}

Research unit 055 SAD- ASTER, Institut National de Recherche Agronomique (Inra), 662, avenue Louis Buffet, 88500 Mirecourt, France

e-mail: fabienne.barataud@mirecourt.inra.fr

\section{R.J. Hunt}

Wisconsin Water Science Center, United States Geological Survey, 8505 Research Way, Middleton, WI 53562, USA

Department of Geoscience, University of Wisconsin-Madison, 1215 West Dayton Street, Madison, WI 53705, USA

e-mail: rjhunt@usgs.gov

\section{Benoit}

Research Unit 055 SAD- ASTER, Institut National de Recherche Agronomique (Inra), 662, avenue Louis Buffet, 88500 Mirecourt, France

e-mail: Marc.benoit@mirecourt.inra.fr

\section{J. Anglade}

UMR METIS, Biogeochemistry Department, University Pierre and Marie Curie (UPMC), 4 Place Jussieu, case 105, Tower 56.554 th floor-BP 105, 75252 Paris Cedex 05, France e-mail: Juliette.anglade@upmc.fr

M.A. Borchardt

Laboratory for Infectious Disease and the Environment, USDA-Agricultural Research Service, 2615 Yellowstone Drive, Marshfield, WI 54449, USA

e-mail: Mark.Borchardt@ARS.USDA.GOV 
even societal perception. Given this broad range of concerns, this chapter focuses on examples of how water quality issues influence integrated groundwater management. One example evaluates the importance of a naturally occurring contaminant Arsenic (As) for drinking water supply, one explores issues resulting from agricultural activities on the land surface and factors that influence related groundwater management, and the last examines unique issues that result from human-introduced viral pathogens for groundwater-derived drinking water vulnerability. The examples underscore how integrated groundwater management lies at the intersections of environmental characterization, engineering constraints, societal needs, and human perception of acceptable water quality. As such, water quality factors can be a key driver for societal decision making.

\subsection{Introduction}

Groundwater is commonly found in most parts of the world, but the quality of the water may be sufficiently poor to preclude or limit its use. Contaminants that affect groundwater use are related to human health, aquatic health, economic costs, or even societal perception. In this way, water-quality drivers might be considered different from factors of integrated groundwater management (IGM) covered in Chap. 1 and other chapters. For example, in their commentary on defining water quality, Chapelle et al. (2009) suggest the term "water quality" is inherently based on human judgments as to how water of given composition fits perceived needs, where the needs can be those of the individual, group, or ecosystem. At the same time, human judgments of water quality are dynamic. In the twentieth century water became cheap, safe, and widely available - something that had not happened before during the whole of human history (Fishman 2011). Such dynamic views can become drivers that inform current opinion and perceptions of water quality in the twenty-first century. In addition, constantly improving technology for water quality characterization identifies more contaminants at lower detection limits, which contributes to the dynamic perception of water quality, including whole new classes of contaminants (e.g., Focazio et al. 2008). How such issues are handled in a management framework can influence the subjective idea of water quality. In this way, IGM forms an important intersection of environmental characterization (e.g., water chemical analyses), engineering (e.g., water treatment and sanitation), societal needs (e.g., food supply), and human perception of water quality. This intersection of disparate drivers can, in turn, act as a key driver for societal cost-benefit analyses and other decision making.

How do we judge if water quality is limiting availability? For some contaminants and uses, objective water-quality criteria are available. For example, risk-based regulatory limits have set threshold quantities such as a "Maximum Contaminant Level (MCL)" or, a less stringent, "Preventative Action Limit" (PAL) used in the United States and similar thresholds in other countries (Table 14.1). Yet, subjective judgments can also affect perceptions of water quality, thus making acceptable water quality a dynamic interpretation. 
Table 14.1 Comparison of drinking water-quality standards and guidelines for the World Health Organization, European Union, Australia, United States, and Canada. All standards and guidelines in $\mathrm{mg} / \mathrm{L}$ (modified from Boyd (2006) with updates to United States as of $2013 \mathrm{http}: / /$ water.epa. gov/action/advisories/drinking/upload/dwstandards2012.pdf)

\begin{tabular}{|c|c|c|c|c|c|}
\hline Chemical & WHO & E.U. & Australia & U.S. & CANADA \\
\hline 1,1-Dichloroethylene & 0.03 & - & 0.03 & 0.007 & 0.014 \\
\hline 1,2-Dichlorobenzene & 1 & 0.0001 & 1.5 & 0.6 & 0.2 \\
\hline 1,2-Dichloroethane & 0.03 & 0.003 & 0.003 & 0.005 & 0.005 \\
\hline 1,4-Dichlorobenzene & 0.3 & 0.0001 & 0.04 & 0.075 & 0.005 \\
\hline 2,3,4,6-tetrachlorophenol & - & 0.0001 & - & - & 0.1 \\
\hline 2,4,6-trichlorophenol & 0.2 & 0.0001 & - & - & 0.005 \\
\hline $2,4-\mathrm{D}$ & 0.03 & 0.0001 & 0.0001 & 0.07 & 0.1 \\
\hline 2,4-Dichlorophenol & - & 0.0001 & 0.2 & - & 0.9 \\
\hline Aldicarb & 0.01 & 0.0001 & 0.001 & 0.003 & 0.009 \\
\hline Aldrin/Dieldrin & 0.00003 & 0.00003 & 0.00001 & - & 0.0007 \\
\hline Antimony & 0.02 & 0.005 & 0.003 & 0.006 & 0.006 \\
\hline Arsenic & 0.01 & 0.01 & 0.007 & 0.01 & 0.01 \\
\hline Atrazine & 0.002 & 0.0001 & 0.0001 & 0.003 & 0.005 \\
\hline Azinphos-methyl & - & 0.0001 & 0.002 & - & 0.02 \\
\hline Barium & 0.7 & - & 0.7 & 2 & 1 \\
\hline Bendiocarb & - & 0.0001 & - & - & 0.04 \\
\hline Benzene & 0.01 & 0.001 & 0.001 & 0.005 & 0.005 \\
\hline Benzo[a]pyrene & 0.0007 & 0.00001 & 0.00001 & 0.0002 & 0.00001 \\
\hline Boron & 0.5 & 1 & 4 & - & 5 \\
\hline Bromate & 0.01 & 0.01 & 0.02 & 0.01 & 0.01 \\
\hline Bromoxynil & - & 0.0001 & 0.03 & - & 0.005 \\
\hline Cadmium & 0.003 & 0.005 & 0.002 & 0.005 & 0.005 \\
\hline Carbaryl & - & 0.0001 & 0.005 & - & 0.09 \\
\hline Carbofuran & 0.007 & 0.0001 & 0.005 & 0.04 & 0.09 \\
\hline Carbon tetrachloride & 0.004 & 0.0001 & 0.003 & 0.005 & 0.005 \\
\hline Chloramines-total & - & - & 3 & 4 & 3 \\
\hline Chlorpyrifos & 0.03 & 0.0001 & 0.01 & - & 0.09 \\
\hline Chromium & 0.05 & 0.05 & 0.05 & 0.1 & 0.05 \\
\hline Cyanazine & 0.0006 & 0.0001 & - & - & 0.01 \\
\hline Cyanide & 0.07 & 0.05 & 0.08 & 0.2 & 0.2 \\
\hline Cyanobacterial toxins & - & - & 0.0013 & - & 0.0015 \\
\hline Diazinon & - & 0.0001 & 0.001 & - & 0.02 \\
\hline Dicamba & - & 0.0001 & 0.1 & - & 0.12 \\
\hline Dichloromethane & 0.02 & - & 0.004 & 0.005 & 0.05 \\
\hline Diclofop-methyl & - & 0.0001 & 0.005 & - & 0.009 \\
\hline Dimethoate & 0.006 & 0.0001 & 0.05 & - & 0.02 \\
\hline Dinoseb & - & 0.0001 & - & 0.007 & 0.01 \\
\hline Diquat & - & 0.0001 & 0.0005 & 0.02 & 0.07 \\
\hline Diuron & - & 0.0001 & 0.03 & - & 0.15 \\
\hline Ethylbenzene & 0.3 & - & 0.3 & 0.7 & - \\
\hline
\end{tabular}


Table 14.1 (continued)

\begin{tabular}{l|l|l|l|l|l}
\hline Chemical & WHO & E.U. & Australia & U.S. & CANADA \\
\hline Fluoride & 1.5 & 1.5 & 1.5 & 4 & 1.5 \\
\hline Glyphosate & - & 0.0001 & 0.01 & 0.7 & 0.28 \\
\hline Lead & 0.01 & 0.01 & 0.01 & 0.015 & 0.01 \\
\hline Malathion & - & 0.0001 & - & - & 0.19 \\
\hline Mercury & 0.001 & 0.001 & 0.001 & 0.002 & 0.001 \\
\hline Methoxychlor & 0.02 & 0.0001 & 0.0002 & 0.04 & 0.9 \\
\hline Metolachlor & 0.01 & 0.0001 & 0.002 & - & 0.05 \\
\hline Metribuzin & - & 0.0001 & 0.001 & - & 0.08 \\
\hline Monochlorobenzene & - & - & - & 0.1 & 0.08 \\
\hline Nitrate & 11 & 11 & 11 & 10 & 10 \\
\hline Nitrilotriacetic acid & 0.2 & - & 0.2 & - & 0.4 \\
\hline Paraquat & - & 0.0001 & 0.001 & - & 0.01 \\
\hline Parathion & - & 0.0001 & 0.01 & - & 0.05 \\
\hline Pentachlorophenol & 0.009 & 0.0001 & - & 0.001 & 0.06 \\
\hline Phorate & - & 0.0001 & - & - & 0.002 \\
\hline Picloram & - & 0.0001 & 0.3 & 0.5 & 0.19 \\
\hline Selenium & 0.01 & - & 0.01 & 0.05 & 0.01 \\
\hline Simazine & 0.002 & 0.0001 & 0.0005 & 0.004 & 0.01 \\
\hline Terbufos & - & 0.0001 & 0.0005 & - & 0.001 \\
\hline Tetrachloroethylene & 0.04 & 0.01 & 0.05 & 0.005 & 0.03 \\
\hline Toluene & 0.7 & - & 0.8 & 1 & - \\
\hline Trichloroethylene & 0.07 & 0.01 & - & 0.005 & 0.005 \\
\hline Trifluralin & 0.02 & 0.0001 & 0.0001 & - & 0.045 \\
\hline Trihalomethanes & - & 0.1 & 0.25 & 0.08 & 0.1 \\
\hline Uranium & 0.015 & - & 0.02 & 0.03 & 0.02 \\
\hline Vinyl chloride & 0.0003 & 0.0005 & 0.0003 & 0.002 & 0.002 \\
\hline Xylenes-total & 0.5 & - & 0.6 & 10 & - \\
\hline & & & & & \\
\hline
\end{tabular}

This chapter will present three examples that demonstrate how water quality factors can influence groundwater use and related management options. The examples are intended to present: (1) an overview of mechanisms of how water quality affects IGM; (2) a short listing of classes of contaminants that have affected groundwater use; and (3) a description of issues and associated IGM responses that have been used to address classes of water quality issues. Because the range of potential societally-relevant water quality issues is large, we focus here on transferable elements contained within the examples. Using the dimensions of integrated groundwater management outlined in Chap. 1, water quality can be seen as integration of both natural and human systems across multiple scales of space and time. Moreover, a definition of adequate water quality is highly dependent on stakeholders, as well as new methods of identifying and quantifying contaminants. It should be noted that some water quality topics are also covered separately in more detail elsewhere in this book, including salinity (Chap. 15). 


\subsection{Contaminants that Affect Acceptable Water Quality Determinations}

For convenience, contaminants are grouped into two broad categories that affect groundwater use: naturally occurring contaminants and human-introduced contaminants. Such a distinction cannot hold universally- for example, human activities such as high capacity pumping change the aquifer geochemical environment, which in turn can mobilize contaminants or transform them into different forms. Likewise, salinity is naturally occurring, but also can be a water quality concern in areas where it is not naturally occurring as a result of human use such as application of salt to prevent road icing. Our distinction is more robust, however, when considering the primary sources of contaminants and how they propagate to issues of water quality. Therefore, our discussion here follows this overarching criterion.

Table 14.2 lists a number of naturally occurring and human-introduced contaminants that can potentially influence groundwater management. Potential management actions to address water quality may include, but are not limited to, strategies involving:

- Source removal (e.g., centralized waste digesters, integrated pest management plans, organic farming)

- Tiered water quality designations that allow reuse of "grey water" or use of waters naturally having lesser quality (e.g., brackish groundwater)

Table 14.2 Common contaminants listed as a source of poor water quality

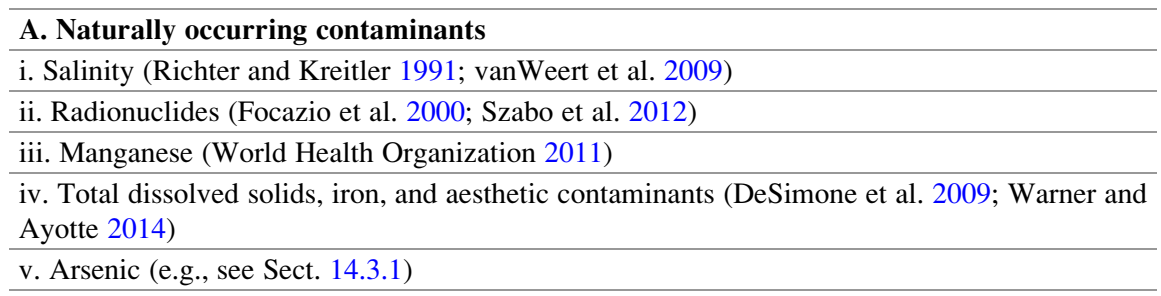

\section{B. Human-introduced contaminants}

\begin{tabular}{l} 
a. Non-pathogen \\
\hline i. Chloride (Granato 1996; Mullaney et al. 2009) \\
\hline ii. PCBs/PAHs \\
\hline iii. Nutrients/nitrate (Dubrovsky et al. 2010) \\
iv. Pesticides (e.g., see Sect. 14.3.2) \\
\hline v. Non-Aqueous Phase Liquids (Mayer and Hassanizadeh 2005) \\
\hline vi. Pharmaceuticals/personal care products (Barnes et al. 2008) \\
\hline vii. VOCs (Zogorski et al. 2006) \\
\hline b. Pathogens \\
\hline i. Bacteria (Hynds et al. 2014) \\
\hline ii. Viruses (e.g., see Sect. 14.3.3)
\end{tabular}


- Blending of water supplies from different sources to meet regulatory limits

- Modifying well open intervals or pumping regimes to minimize poor water quality

- Artificial aquifer recharge or aquifer storage and recovery systems

- Source minimization (e.g., landuse restrictions in wellfield capture areas, voluntary conservation)

- Water treatment at wellhead or point-of-use

- Wastewater treatment

These actions are often used in combination, and span a range of capital cost incurred during initial implementation as well as on-going cost of operation and maintenance. As might be expected given the range of cost and range of potential concerns shown in Table 14.2, there is no single or universally recommended approach for addressing water quality issues in an integrated groundwater management framework. Therefore, examples of groundwater management are used to illustrate applications where one or more of the actions described above were considered.

\subsection{Three Examples of Water Quality Issues and Integrated Groundwater Management}

In this Sect. 14.3 Case studies are presented here that use one naturally occurring and two human-introduced contaminants to illustrate the intersection of water quality and integrated groundwater management. Each will discuss the contaminant sources, health/aquatic/economic implications, factors affecting contaminant transport and transformation, and management solutions investigated.

\subsubsection{Naturally Occurring Contaminant: Arsenic}

Arsenic (As) is a contaminant that is commonly derived from natural sources and has affected the availability or use of groundwater. This case study of arsenic illustrates the importance of integrating water quality into groundwater management. People and policy makers in many parts of the world - but especially in South Asia and North China Plain-are aware of the dangers of drinking poor quality groundwater high in arsenic (Mukherjee et al 2006; Sharma et al. 2006; Singh et al 2014). Other studies predicting the occurrence of arsenic worldwide suggest that arsenic concentrations of human-health concern can be expected over large regions (Fig. 14.1) (Welch et al. 2000; Smedley et al. 2002; Amini et al. 2008; Winkel et al. 2008; Van Halem et al. 2009). Integrated groundwater management 


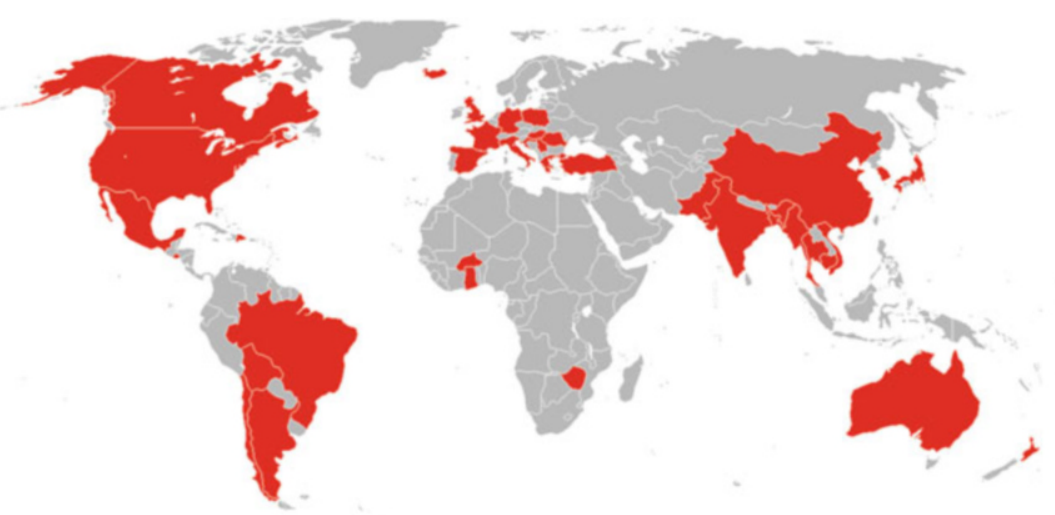

Fig. 14.1 Arsenic affected countries (red) of the world (From Van Halem et al. 2009)

for arsenic is a function of: (1) understanding the spatial and vertical extent of the problem by monitoring; and (2) managing human activities, such as pumping or locating landfills, that can change the geochemical conditions of the aquifer and mobilize arsenic.

Health effects from exposure to arsenic in drinking water include increased risk for bladder, skin, kidney, and lung cancers, and increased risk for diabetes and heart disease (National Research Council 2001). Research on the health effects of low-tomoderate concentrations of arsenic caused the U.S. Environmental Protection Agency (USEPA) in 2006 to lower the MCL from 50 to $10 \mu \mathrm{g} / \mathrm{L}$ illustrating how new research and information can change the perception of acceptable water quality. Many countries have similar drinking water-quality guidelines for arsenic and other contaminants (Table 14.1). The United States, European Union, and World Health Organization consider $10 \mu \mathrm{g} / \mathrm{L}$ of arsenic acceptable for drinking water (Boyd 2006).

Integrated groundwater management can mean appreciable resources are needed for monitoring and characterizing the extent and changes in arsenic concentration. For example, in the United States testing for arsenic in publicly-supplied drinking water is part of the Safe Drinking Water Act so public supplies are monitored regularly. Yet over 43 million people in the United States get their drinking water from privately owned household wells (DeSimone 2009). The quality and safety of these privately-owned water supplies are not regulated under Federal, or in most cases state, law. Individual homeowners are responsible for maintaining their water supply systems and for any routine water-quality monitoring. The U.S. Geological Survey National Water Quality Assessment Program (NAWQA) included sampling of more than 2100 privately owned wells in the United States (DeSimone 2009) and found that about $7 \%$ of privately owned wells contained arsenic greater than $10 \mu \mathrm{g} /$ L. In some areas, such as the methanogenic parts of the glacial aquifer system, up to $50 \%$ of the privately owned wells had arsenic concentrations greater than $10 \mu \mathrm{g} / \mathrm{L}$ (Thomas 2007). The publicly supplied drinking water is managed because routine 
monitoring identifies the high arsenic concentrations that need to be addressed, yet voluntary self-monitoring of privately owned wells is not routine. Identification of the problem is a first step for IGM.

Monitoring over time to assess seasonal changes in water-quality concentrations imply that there is not a one-size-fits-all solution to water-quality management over a year. A study in Albuquerque, New Mexico, shows that arsenic concentrations vary spatially and temporally in water from public-supply wells partly because groundwater with different arsenic concentrations migrates between different parts of the basin-fill aquifer within the wellbores of idle supply wells (Eberts et al. 2013). During times when the wells are not pumping, high-arsenic groundwater from deep within the aquifer moves up and out into the shallow parts of the aquifer in areas where hydraulic gradients are upward. When pumping resumes, arsenic-laden water enters these wells from both shallow and deep parts of the aquifer. Concentrations in the produced water are then elevated until the higharsenic water is purged from the shallow parts of the aquifer. Public-supply wells in this area are pumped less frequently in the winter than in the summer so arsenic concentrations are highest in winter water samples from the deepest wells in the parts of the aquifer having upward hydraulic gradients. Well construction (depth), well operation (duration of pumping), and position within the groundwater-flow system (location with respect to vertical hydraulic gradients) affect high arsenic concentrations in water from public-supply wells. Monitoring changes in pumping and arsenic concentrations over time will enable resource managers to better manage concentrations in the produced water by pumping existing wells for longer periods during the winter and by installing new supply wells at shallower depths in certain areas (Laura Bexfield, U.S. Geological Survey, written commun., 2012).

Naturally occurring contaminants like arsenic are ubiquitous in many aquifer systems and the identification of the processes that control their mobilization and transport could help water managers meet compliance standards (e.g., Gotkowitz et al. 2004). Solid-phase chemistry data are useful in understanding arsenic sources, but do not always correspond to the relative concentrations in ground water (Brown et al. 2007). The transport of arsenic to drinking water wells is controlled by physical and geochemical processes.

Physical processes such as preferential flow paths, human induced and natural, can result in faster travel times and higher concentrations of arsenic in publicsupply wells. Brown et al. (2007) identified preferential flow paths that include zones of high permeability in sand and gravel aquifers, conduit flow in karst aquifers, downward well-bore flow in a public-supply during periods of low or no pumping, and short-circuit pathways through wells and boreholes open to multiple aquifer layers. Methods using geophysical techniques, depth-dependent sampling, and sampling of monitoring wells adjacent to public supplies, improve the understanding of preferential flow paths and other factors such as redox chemistry and competing ions that affect the movement of arsenic to public-supply wells.

Groundwater age information is a tool that adds to our understanding of the processes resulting in elevated arsenic. For example, in the glacial aquifer system, arsenic concentrations above the drinking water standard (10 micrograms per liter 
$(\mu \mathrm{g} / \mathrm{L}))$ were most often associated with groundwater that recharged the aquifer system prior to the 1950s. Similarly, Eberts et al. (2013) found arsenic concentrations in water from public-supply wells in study areas in California, Connecticut, Ohio, Nebraska, Nevada, and Utah increased with increasing travel times to the wells (increasing groundwater age). The groundwater-age mixture for a well characterizes the complete range of time that it might take contaminants that are released to the groundwater to reach a well. An estimate for the groundwaterage mixture for a well is a useful measure of the potential for elevated arsenic in water from the well. In addition, public-supply well construction and operation (screen placement, pumping rates and schedules) can lead to differences in the age mixture of the groundwater pumped from different wells, including wells within the same aquifer. Many of the public supplies sampled as part of the NAWQA study showed a mixture of groundwater ages. This indicates that groundwater management practices need to consider natural and human-induced changes in the aquifer geochemistry over time.

Mixing of groundwater from different parts of the aquifer system can change the chemistry of the groundwater and the potential for elevated arsenic. Ayotte et al. (2011) show that pumping-induced hydraulic gradient changes and artificial connection of aquifers by well screens can mix chemically distinct groundwater. Chemical reactions between these mixed groundwater and solid aquifer materials can result in the mobilization of arsenic, with subsequent transport to water-supply wells. For example, near Tampa, Florida, much of the downward movement of groundwater is along flow pathways that follow natural conduits in the limestone bedrock (Jagucki et al. 2009). High-volume pumping from the wells in this study pulled shallow, oxic and low-pH water, which is capable of dissolving arsenicbearing minerals, into deeper, anoxic and high-pH parts of the aquifer system where arsenic can remain in solution. This accelerated mixing of dissimilar waters both mobilizes arsenic from the rocks and allows it to remain dissolved in the newly mixed water.

In many areas, dissolved oxygen is an easily determined concentration that indicates the likelihood of elevated arsenic in the water. In the glacial aquifer system, United States, geochemical conditions identified by presence or absence of dissolved oxygen (less than or greater than $0.5 \mathrm{mg} / \mathrm{L}$ ) is a good indicator of the likelihood of detecting (or not detecting) arsenic concentrations greater than the drinking-water standard (10 $\mu \mathrm{g} / \mathrm{L})$ (Warner and Ayotte 2014). Human activities can alter recharge or change groundwater flow in ways that lead to changes in the aquifer geochemical conditions (Eberts et al. 2013). These changes result in chemical reactions between the groundwater and the solid aquifer material, releasing naturally occurring arsenic into the groundwater. As a result, concentrations of arsenic in water from wells increases. Similarly, Gotkowitz et al. (2004) found that drawdowns resulting from pumping created conditions that mobilized naturally occurring mineralized arsenic quickly in drinking water wells that historically were not characterized as having arsenic contamination.

Other human activities can cause local and regional scale changes in aquifer geochemical conditions and indirectly increase arsenic concentrations in 
groundwater and in water from public-supply wells. For example, groundwater in the vicinity of a landfill can have elevated concentrations of arsenic, yet the source of the arsenic is not the contents of the landfill (Warner and Ayotte 2014). Rather the source is geologic - part of the solid aquifer material (Delemos et al. 2006). This type of situation occurs because microorganisms degrade large amounts of organic carbon derived from the waste within the landfills, creating anoxic conditions in the groundwater. Arsenic is then released from the solid aquifer material to the groundwater under the newly anoxic conditions, thus increasing arsenic concentrations in groundwater downgradient from the landfill.

Water managers who understand how redox conditions are distributed within an aquifer system are in a position to anticipate which chemical constituents in the groundwater (for example, nitrate, arsenic, iron, manganese, and certain VOCs or pesticides) would (or would not) be expected to occur in water from a particular well. In addition, knowledge about redox conditions in an aquifer system can help water managers select the most suitable water-treatment methods for water from their wells. Redox conditions of groundwater also are important because the oxidation state of some elements affects their toxicity. For example, the oxidized form of chromium (hexavalent chromium, $\mathrm{Cr} 6+$ ) is more toxic than the reduced form (trivalent chromium, Cr3+) (Mills and Cobb 2015). Another way that human activities can affect concentrations of natural contaminants in groundwater is by altering groundwater flow so that waters with different chemical characteristics mix.

Human-induced alteration of groundwater flow patterns can affect concentrations of naturally occurring trace elements like arsenic. Adverse waterquality impacts attributed to human activities are commonly assumed to be related solely to the release of the various anthropogenic contaminants at the land surface; yet, human activities including various land uses, well drilling, and pumping rates and volumes can adversely impact the quality of water in supply wells indirectly, when associated with naturally-occurring trace elements in aquifer materials (Ayotte et al. 2011). This occurs because subtle but significant changes in geochemistry are associated trace element mobilization as well as enhancing advective transport processes.

Sources of natural contaminants like arsenic are largely distributed and not usually mitigated with source remediation. The cost of treating for arsenic in large public-water utilities is an economic cost, but the human health cost of not treating for elevated arsenic in drinking water can be substantial. Costs, like that of public water suppliers using the glacial aquifer system in the United States, were estimated at 29 million dollars in 1999 to treat groundwater for a single issue of concern: elevated arsenic concentrations (Warner and Ayotte 2014). In the United States in 2006 when the drinking water standard was lowered to $10 \mu \mathrm{g} / \mathrm{L}$ the Illinois Environmental Protection Agency estimated that the initial cost to reduce arsenic concentrations to below the MCL of $10 \mu \mathrm{g} / \mathrm{L}$ for 50 of the community water supplies with elevated arsenic concentrations in Illinois (Fig. 14.2) could reach a total of $\$ 40$ million dollars, with the highest costs associated with small community supplies (Warner and Ayotte 2014; Warner et al. 2003; Warner 2001). On a national or worldwide scale, this is a large water-quality cost to consider. Understanding the 
Fig. 14.2 Cost of treating drinking water for elevated arsenic (From Warner and Ayotte 2014)

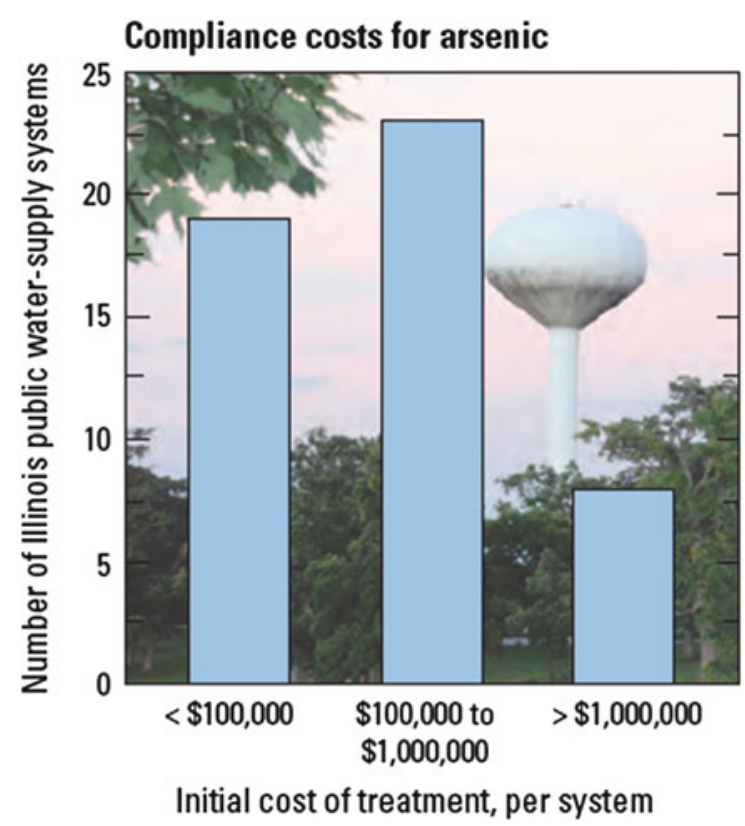

processes that affect the mobilization of arsenic in groundwater leads to more informed and integrated water management decisions in areas where arsenic is a concern, which in turn can provide cost savings.

\subsubsection{Human-Introduced Contaminant (Abiotic): Agricultural Inputs}

The pervasive use of organic and inorganic chemicals in agricultural areas has led to the deterioration of the quality of groundwater and surface water, and has become a concern for human consumption over the last decades. Water quality deterioration by pesticides, for example, is well recognized, for surface or drained water (Schiavon and Jacquin 1973; White et al. 1967) and groundwater (Muir and Baker 1978). Since the early identification of the concern, degradation of water quality by pesticides become widespread in Europe (Capriel et al. 1985; Heydel et al 1999; Réal et al. 2001, 2004; European Commission 2002, 2010). Many recent studies have reported the presence of pesticides higher than the European regulatory limits of $0.1 \mu \mathrm{g} / \mathrm{L}$ and $0.5 \mu \mathrm{g} / \mathrm{L}$ for surface water and groundwater, respectively. In one survey, total concentration of pesticides was over $0.5 \mu \mathrm{g} / \mathrm{L}$ in $18 \%$ of surface water samples and $3.8 \%$ of groundwater samples analyzed (SOeS 2010).

With the expected conflicting goals of crop production and preservation of surface and groundwater quality, an integrated water resources management approach is needed. Integrated groundwater management, specifically, must embrace spatial and temporal uncertainty both in the source (due to changing 
human application rates and chemical properties) and in the groundwater aquifers that embody a heterogeneous application and transport of that source. Even defining the groundwater system of interest can be problematic because: 1) groundwatersheds can be difficult to delineate accurately and often do not align with the easily delineated overlying surface watershed (e.g., Hunt et al. 1998; Winter et al. 2003); 2) the amount of effort expended on the characterization is likely not equal in space and time in an area of interest; and 3) the land surface encompasses different political boundaries, which may change the regulatory agency charged with the management of the water resource. Integrated groundwater management must also address the fact that a groundwater system is buffered by an unsaturated zone that separates the land surface where pesticides are applied from the aquifer used. This buffering can affect the timing and amount of recharge to the water table - effects that change as the unsaturated zone thickness changes (e.g., Hunt et al. 2008). Delays and lags between an activity, or change in activity like Best Management Practices, at the land surface and its appearance in the groundwater resource can confound simple cause-and-effect relations that underpin decision making.

For agricultural contaminants, integrated groundwater management is a function of: (i) changes in protective areas specified at land surface that can determine and influence the contaminant source; and (ii) the importance of lags and delays between the driving forces at the land surface and the change of the groundwater resource.

\subsubsection{Changing Protective Areas at the Land Surface}

Here we use two French groundwater systems as examples, the Vittel and Lons-leSaunier catchments located near the French-Swiss border. Vittel watershed is managed through voluntary agreements between diverse stakeholders and the private enterprise Nestlé Water (Benoît et al. 1997). The Vittel catchment has been the focus of a delineation process since 1925 (Barbier and Chia 2001). The catchment outline defined during negotiations with farmers and other stakeholders began in 1987 was 4200 ha. In 1994, new hydrological work increased the catchment to 4500 ha. In the case of Lons-Le-Saunier, the catchment is managed by the municipality and a group of priority catchment organizations; they are called the "Grenelle Catchments" because they were designated through the Grenelle Initiative - a collection of political meetings that occurred during the fall of 2007 to make long-term decisions on sustainable development. The Lons-le-Saunier catchment also will likely have multiple delineations (Hellec et al. 2013; Barataud et al. 2014a).

Areas identified for protection within the delineated groundwater resource have also evolved over time as a result of increasing awareness of contamination, negotiations with the farmers, and the evolution of the driving regulatory context (from Public Health Laws to a patrimonial management of water in the recent Environment Code). Today the management zone is divided into four zones (Fig. 14.3). The water wells zone (zone I) of about 7 ha, without any agricultural activity, was bought by the municipality in 1961 at the beginning of the wells' use. 


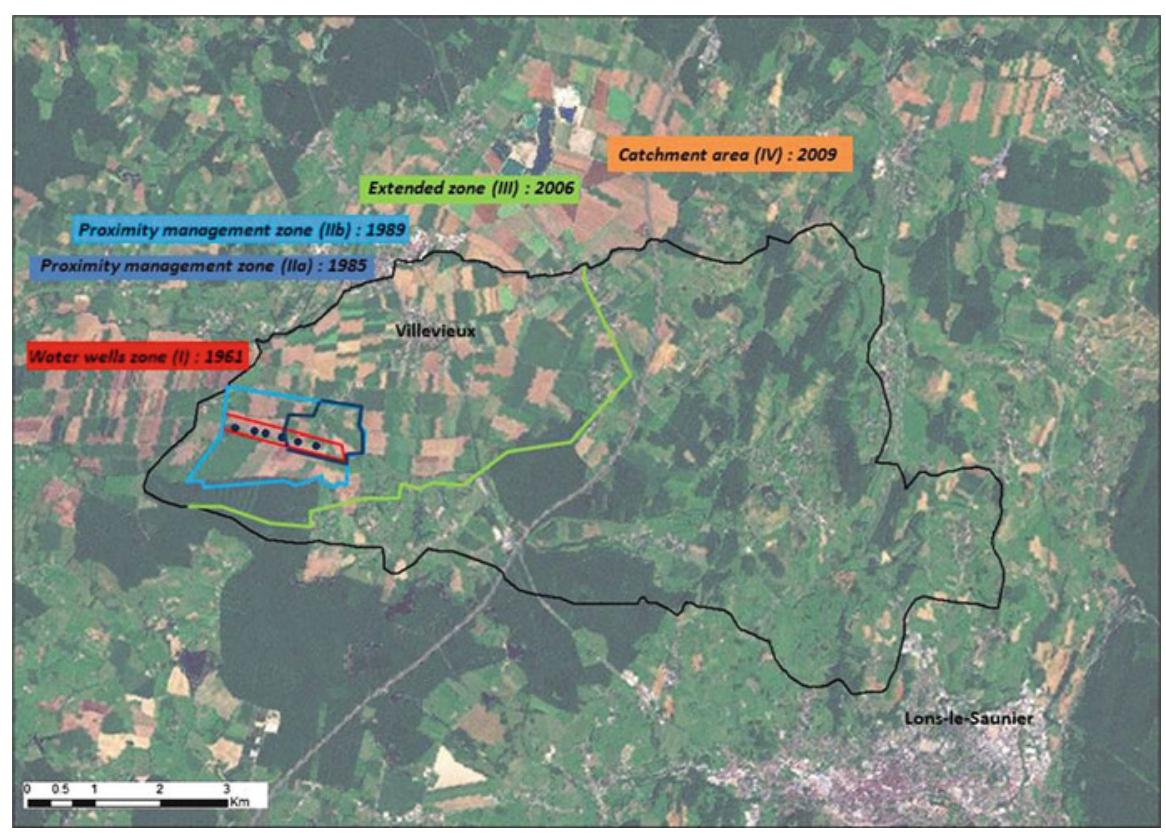

Fig. 14.3 Example of successive delimitation of the protection perimeters

A proximity management zone with two sub-divisions was then defined: contracts between the municipality and the farmers were primarily established on a zone IIa (63 ha) in 1985 when nitrates and atrazine were noted in the wells; zone IIa was extended to a zone IIb (220 ha) in 1989 and the contracts were re-negotiated in 2006 as a new French regulatory requirement imposed a more formalized definition of protection perimeters. In 2006 the zone was again extended to include an additional 1500 ha (zone III). Currently, the protection zones consist of slightly less than 1800 ha, corresponding to about $30 \%$ of the total catchment area. The total catchment was designated in 2009 as zone IV, defined using the hydrological report that resulted from the 2009 Grenelle Initiative.

Concurrently, a 1992 French law of the Public Health Code required a mandatory "Declaration of Public Utility" for water resources, which included a delineation of water protection areas in which conservation easements can restrict agricultural practices. In practice, the delineation of public utility is commonly delayed. A recent study showed that only two-thirds of catchments in the French Grenelle priority catchment were in conformity for the delineation of water protection areas (Barataud et al. 2014b), whereas a deadline of 5 years was given by the 1992 law . Local stakeholders noted a high level of inter-stakeholder conflict caused by these regulatory requirements. Using the catchments that are in conformity with the 1992 law, it is clear there is a wide range of management unit size (Fig. 14.4).

The size of the management unit can affect execution of protective measures. Perhaps most obviously, developing mutually agreeable solutions with the 


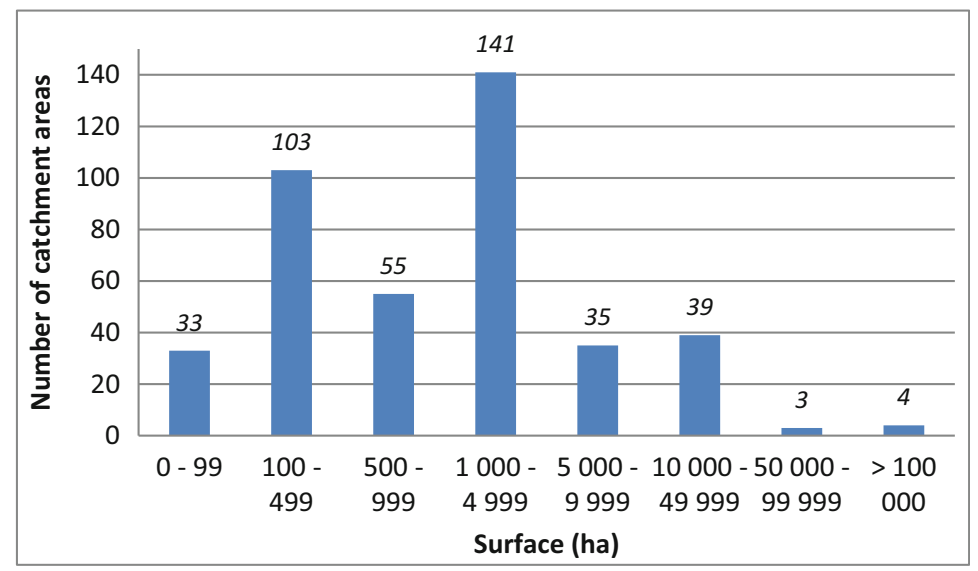

Fig. 14.4 Variability of the protection area size within the priority Grenelle catchment

agricultural producers and other stakeholders in large catchment areas is more difficult because there are more entities to include, and is often hindered by simple organization challenges such as identifying meeting-times and discussion frameworks. In large catchments, accounting for the interests and wide ranging viewpoints often requires designation of intermediaries to facilitate discussion that represent the whole of the stakeholder group. In small catchment areas, protective practices may be identified but often involve improved agricultural practices over only small parts of the catchment rather than major farming practice reforms. Several studies have questioned the effectiveness of partial measures for protecting and restoring target groundwater resources (Kunkel et al. 2010; Thieu et al. 2010; Lam et al. 2011; Posen et al. 2011).

\subsubsection{Temporal Characteristics of Groundwater Management}

Clearly the spatial area included or excluded from a protective action will influence the associated groundwater quality. Temporal aspects can also affect integrated groundwater management. The temporal aspects covered here include timing of human implementation of protective measures at the land surface, and time lags that result from the natural groundwater system itself.

An example of the human dimension is seen in the 2000 European Water Framework Directive (WFD), which proposed three new articles: preservation of water bodies as a whole (taking into account non-point pollution and not just pointsource pollution), an imposed schedule for adoption, and objectives defining quantified results for ecological restoration of the environment. This Directive is complex and ambitious, but is considered a cornerstone of the European Union's environmental policy (Bouleau and Richard 2009). France partially conformed to this directive 6 years after the Directive was signed through its Law on Water and Aquatic Environments (Loi sur 1'Eau et les Milieux Aquatiques [LEMA], 2006), where for the first time in French law the definition of non-point pollution appeared. 


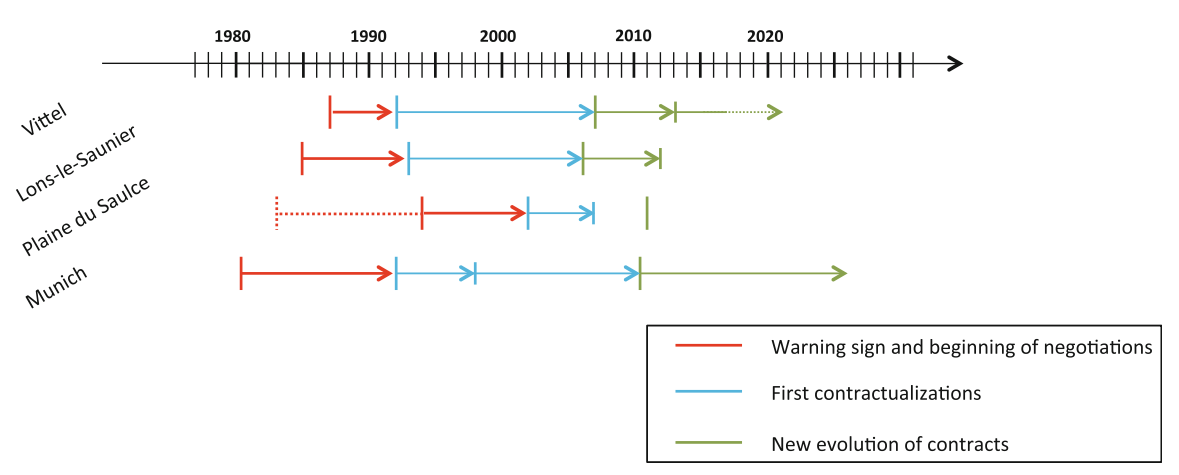

Fig. 14.5 Timelines of protection activities of catchments in four areas

However, it was not until the Grenelle Initiative in 2009 and the designation of the Grenelle priority catchments, that the notion of schedules, deadlines, and quantifiable results was written into French law. In the example of Lons-le-Saunier, 9 years were necessary to partially translate the WFD into application in one area of France, and the process was considered difficult by most all involved.

The human dimension also can result in unintended parallel protective actions. Faced with insufficient regulatory frameworks, many local water managers (municipalities, water utilities, private entities) outside of the Grenelle priority catchments have set up, or are currently setting up, their own coordination with farmers to promote protective practices to enhance local water resources quality. Each protective practice imposes various time frames for adoption, many of them distant into the future, as can be seen by comparing the timelines for the above mentioned Lons-le-Saunier and Vittel Catchments to two other European catchments (Fig. 14.5: La plaine du Saulce in western France and one near Munich, Germany). The Munich catchment is notable because it is an early example of protection of water quality internally developed after adoption of organic farming practices at a near catchment scale. The time from the identification of the problem and subsequent negotiations to formal protective measures can range between 5 and 20 years. Clearly lags in the adoption of protective measures will result in lags in obtaining the improved water quality that initially drove the adoption of protective measures.

Given the competing interests of the multiple stakeholders, problem scoping activities and protective action negotiations often require many months of discussion. For example, the mobilization of stakeholders, identification of needs and priorities, negotiations between stakeholders having conflicting interests, defining a consensus, and constructing adequate institutional forms, are all necessary stages which require different amounts of time and effort to execute. Even after protective measures are adopted, it is not uncommon to see delays of several years needed to coordinate and modify individual practices.

This temporal and spatial complexity of adopted protective measures then must then filter through the natural system to where the groundwater resource of interest 
is assessed. Nitrate pollution management in the Plaine du Saulce catchment discussed below exemplifies how the natural system dimensions can delay positive responses in the groundwater resources resulting from management intervention to reduce contamination. The water catchment area $\left(86 \mathrm{~km}^{2}\right)$ is situated $10 \mathrm{~km}$ south of the City of Auxerre, on a rural agricultural landscape consisting of 45 farms (4026 ha). In the early 1990s, high levels in nitrate concentration were recorded in the Auxerre groundwater wells in the early 1990s supplying one third of the 60000 inhabitants' water requirements. In 1994, peaks reaching $70 \mathrm{mgNO}_{3}{ }^{-} / \mathrm{L}$ (exceeding the European drinking standard of $50 \mathrm{mgNO}-/ \mathrm{l})$ precipitated a lively debate on management strategies to deal with this nitrate contamination. Various managing entities were brought to bear over the next three decades, with the first contract with farmers in 2002, 8 years after the first sign of severe degradation. The management strategy initially operating on a voluntary basis did not result in significant decrease in the nitrate concentrations. As a result, regulation was proposed in 2011 focusing on integrated agriculture, where adoption would become a mandatory after a period of 3 years. The proposed regulatory framework caused major tensions between stakeholders, made worse by a lack of understanding regarding the absence of improved water quality after many years of joint protective actions.

During 2012, a scientific committee met twice to update management strategies to account for the natural delay between changes in agricultural practices at the land surface and measurable improvements in water quality. One primary conclusion was that groundwater flow rates in the Sequanian limestone aquifer tapped by the wells are relatively longer than human timeframes considered in management actions. Water dating analysis through anthropogenic tracers $\mathrm{CFC}$ and $\mathrm{SF}_{6}$ estimated an aquifer residence time of around 25 years ( \pm 3 years) at the pumping wells (Anglade et al. 2013). As a result, nitrate levels observed at the wells reflected agricultural practices that occurred over two decades ago. Analysis of agricultural nitrate use also supported this assessment. Nitrogen inputs had sharply increased in the 1960s before stabilizing in the 1990s (Fig. 14.6); point-to-point comparison between nitrogen surplus and measured nitrate concentration also suggested an approximately 25 year lag in response at the wells.

This example underlines that when planning and implementing management actions, expected time lags need to be communicated to stakeholders and funding agencies in order to reduce short-term expectations that may impair long-term political and financial support. At this point in the Plaine du Saulce catchment, such knowledge has opened up new possibilities for organic farming, with recognition that changes are needed beyond the catchment borders.

Human-introduced pesticides also represent challenges to integrated groundwater management. They can affect the quality of drinking water; especially groundwater close to land surface (e.g., Schreiber et al. 1993). Many pesticides can persist for long periods in the environment - organochlorine insecticides, for example, were still detectable in surface waters 20 years after their use had been banned (Larson et al. 1997). Others studies documented measurable pesticide concentrations years after their last application on the land surface (Baran 

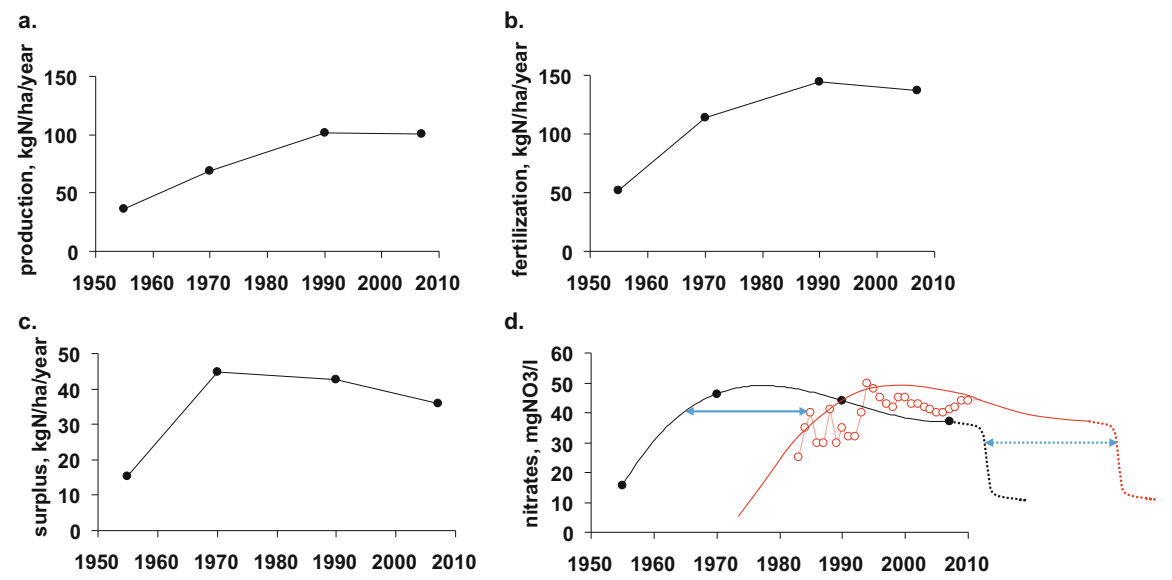

Fig. 14.6 (a) and (b) Evolution of harvested nitrogen and total nitrogen inputs (synthetics and organic fertilizers, atmospheric dry and wet deposition, biological nitrogen fixation) on arable land since 1950. (c) Calculation of $\mathrm{N}$ surplus (Harvested $\mathrm{N}$ - Total $\mathrm{N}$ inputs). (d) Resulting nitrates concentration (infiltration flux of $240 \mathrm{~mm} / \mathrm{year}$ ) and comparison with recorded nitrates levels in the wells (red points)

et al. 2008; Buhler et al. 1993; Jarczyk 1987; Novak et al. 1998; Reiml et al. 1989). In France, Atrazine was banned in 2003; yet, analysis of the Grenelle priority catchment area suggests that half of the protected catchments have measurable atrazine or atrazine degradation product, called a metabolite, in 2011 (Barataud et al. 2014b).

Site-scale studies have been used to help explain the persistence of pesticides in groundwater (Perrin-Ganier et al. 1996). In one case study by Schrack et al. (2009, 2012) from the Lorraine region of France, agricultural practices had been recorded annually for 40 years, including pesticides use during conventional crop management (date, product, application rate). From September 2004 to the present, no pesticides have been used on the study fields as a result of conversion to organic farming practices. During the 30 -year period prior to conversion to organic practices, many pesticides were applied on crops, including herbicides atrazine and 2,4-D (2,4-dichlorophenoxy acetic acid). Similar to the observations of Barataud et al. (2014b), measurable atrazine was documented over 10 years after atrazine application ceased. 2,4-D concentrations were higher than the regulatory limits in two water samples from drain tiles (Fig. 14.7), despite low detection frequency in point samples at the site. Thus it appears that even though the soil zone can reduce and transform pesticides applied to crops, it can also act as a diffuse source of groundwater contamination that persists after application ceases. That is, organic farming initiated in 2004 does not apply pesticides; however, more than 5 years after conversion to organic farming practices, pesticide concentration can still exceed the regulatory limit (e.g., 2,4-D drain water in Fig. 14.7). 


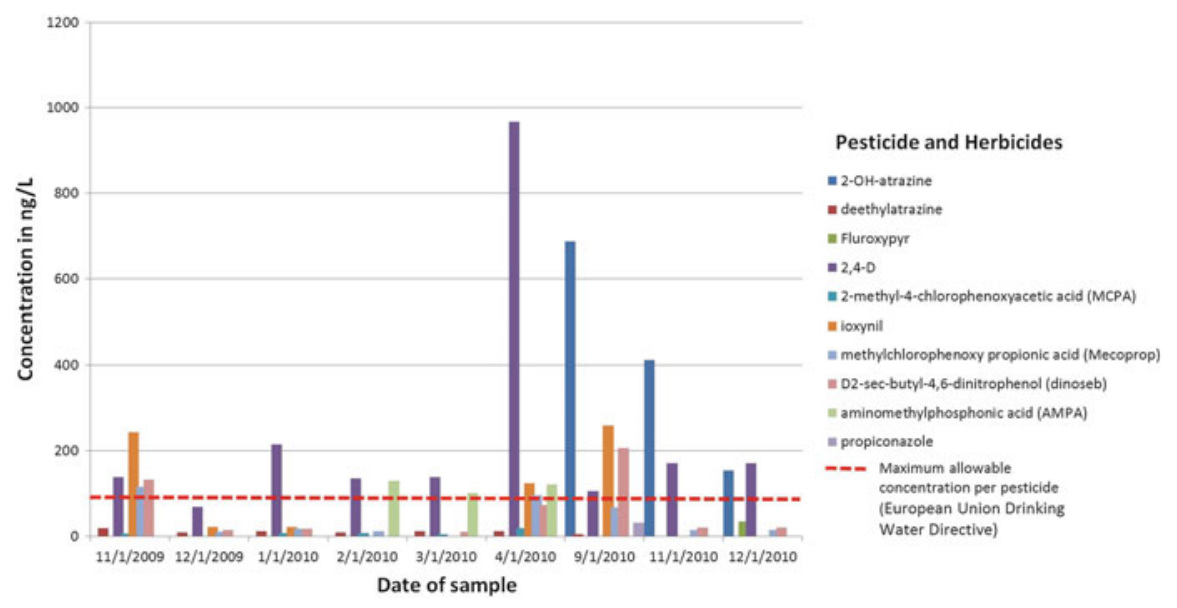

Fig. 14.7 Concentration of pesticides in experimental field after stopping their spreading on the experimental field (2,4-D: since 17 years; Ioxynil: since 13 years; Mecoprop: since 21 years; Dinosèbe: since 15 years; Atrazine: since 23 years; DEA: since 16 years; AMPA-glyphosate: since 17 years)

\subsubsection{Human-Introduced Contaminant (Biological): Human Enteric Viruses}

As shown in Tables 14.1 and 14.2 many types of human-source contaminants can influence groundwater management, and make an otherwise acceptable groundwater supply not suitable for an intended use. Agricultural contaminants, presented in Sect. 14.3.2 are a widely recognized example. Here we discuss a less known human contaminant - human enteric viruses, a subset of possible biological entities, called pathogens, that can affect drinking water suitability. Although the importance of viruses as a groundwater contaminant is primarily restricted to human drinking water, this example helps illustrate how recent advances in methodologies for detection and quantification provide new insights into vulnerability of groundwater supplies not provided by the traditional understanding of water quality contaminants. The material in this section is taken from Borchardt et al. (2004, 2012) and Hunt et al. (2005, 2010, 2014); the interested reader is directed there for additional information.

Viruses are infectious particles of nucleic acid wrapped in protein and sometimes an outer layer of lipid that replicate only within cells of living hosts. In the environment they are metabolically inert. Virus spread is facilitated by concentrated sources and the very low exposure needed for infection. For example, a gram of feces from an infected host can contain trillions of infectious viruses, yet only 1-10 viruses are required to infect a new host. The human health implications of waterborne virus contamination are multi-fold. Recent studies have demonstrated occurrence of human enteric viruses in domestic and municipal wells in the United States (Abbaszadegan et al. 2003; Borchardt et al. 2003; Fout 
et al. 2003; USEPA 2006). Of the 248 recorded drinking water outbreaks caused by untreated groundwater in the United States between 1971 and 2008, 32 (12.9\%) had a viral etiology. Moreover, in 135 outbreaks $(54.4 \%)$ the etiology was unidentified (Wallender et al. 2013), but believed to be viral as in the early years of outbreak surveillance the technology to detect waterborne viruses was less widely available than it is today. Outbreaks related to virus-contaminated groundwater have also been documented in other parts of the world (Gallay et al. 2006; Beller et al. 1997), suggesting widespread hydrologic conditions suitable for virus survival and transport.

Viruses are much smaller $(27-75 \mathrm{~nm})$ than bacterial and protozoan pathogens and thus are more easily transported through pores that physically filter larger pathogens. Virus adsorption onto sediment grains is a primary removal mechanism, although the strength of adsorptive forces depends on sediment and water chemistries (Borchardt 2006). These factors notwithstanding, viruses may still be transported some distance, even into confined aquifers at travel rates relevant for human-health concern (e.g., Borchardt et al 2007; Bradbury et al. 2013). As a result, the United States Environmental Protection Agency has listed several viruses on the third drinking water Contaminant Candidate List, emphasizing that waterborne viruses are a research priority (http://www.epa.gov/ogwdw000/ccl/ccl3.html).

There is also significant public and regulatory interest in understanding the vulnerability of water-supply wells to contamination by human enteric viruses (e.g., http://www.epa.gov/safewater/ccl/index.html; Unregulated Contaminant Monitoring Rule 3 - USEPA 2011). However, assessing well vulnerability to infectious pathogens is different because pathogen vulnerability assessments require knowledge of very fast $(<3$ year) times of travel - a timeframe not characterized by common groundwater age dating methods (Hunt et al. 2005, 2014). Therefore, a different conceptualization is needed to assess well vulnerability to pathogens.

Plume center-of-mass approaches of contaminant transport typically define risk from non-pathogen contaminants such as those listed in Tables 14.1 and 14.2; they reflect the bulk properties of the aquifer which control transport to a drinking well where risk is calculated using long-term exposure relevant for slowly moving plumes. Pathogen transport to groundwater-supply wells is different because adverse health effects can only occur while a pathogen is still infectious; viruses are reported to remain infectious in groundwater for time periods less than 3 years (Seitz et al. 2011). However, unlike dissolved contaminants, as particles pathogens tend to follow fast preferential flow pathways with minimal matrix diffusion (McKay et al. 1993; DeBorde et al. 1999). Thus, rather than well vulnerability assessment based on decade-scale water movement, it is the fast pathway properties of the aquifer that are most important for understanding the vulnerability to pathogens and the risk for disease transmission.

For many groundwater systems, a 1-3 year travel time might be considered of little importance because distances traveled in many unstressed groundwater systems in even 3 years are short. But this is not true for all groundwater systems; large distances can be traveled in short timeframes in karst and fractured rock 
aquifers (e.g., Borchardt et al. 2011). Even in porous media aquifers, high capacity water-supply wells significantly depressurize local groundwater systems and create large hydraulic gradients. These gradients, in turn, result in faster local groundwater velocities than occur in natural groundwater flow systems. This could explain, in part, why virus contamination frequency tends to be greater in high capacity wells than in private domestic wells (Borchardt et al. 2003). More surprising, in the confined aquifer supplying drinking water to Madison, Wisconsin USA, there are pathways sufficiently fast that virus transport to deep supply wells cased through the aquitard can occur in several weeks (Bradbury et al. 2013).

Viruses can only be a contaminant of concern, however, if there is an infectious human fecal source. One common source is leaking sanitary sewers (Hunt et al. 2010). Reported estimates of sanitary sewer leakage, or "exfiltration", range from $1 \%$ to $56 \%$ of the dry weather flow (Rutsch et al. 2008). In the United States, exfiltration has been estimated as $30 \%$ of system flow as a result of infrastructure deterioration, and in local areas, sanitary sewer leakage has been reported to be as high as $50 \%$ of the system flow (USEPA 1989). The exfiltration rate for a European sanitary sewer has been reported on the order of $1 \mathrm{l} / \mathrm{m}$ of sewer line per day (Lerner and Halliday 1994). Exfiltrated volumes for large municipalities are thought to reach tens of thousands of cubic meters per day (millions of gallons per day), exceeding the capacity of the sediments to filter, absorb, and immobilize contaminants carried therein (Amick and Burgess 2000). Even though more research is needed to make general system predictions (Rutsch et al. 2008; Tafuri and Selvakumar 2002), local sanitary sewers have been related to drinking-water associated outbreaks of gastroenteritis (e.g., see Amick and Burgess 2000; Bishop et al. 1998). Older, non-maintained systems are thought to be more susceptible to exfiltration, as well as systems including pressurized by sewage lift stations (Decker 1994a, b). For example, of the wells sampled by Borchardt et al. (2004), the highest number of positive virus samples was obtained from a drinking water well near a pressurized lift station. When the water table is below the utility infrastructure, exfiltrated sewage is often concentrated and transported in the trenches surrounding sanitary sewers, especially during conditions of rainfall-induced infiltration, such that they can threaten drinking-water supplies (Tafuri and Selvakumar 2002). Sanitary sewer infrastructure is often located near municipal wellheads, and carries a high viral load during periods of infections in a community (e.g., Sedmak et al. 2003; Bradbury et al. 2013). From an IGM perspective, this presents management action options: a groundwater-supplied municipality could work to minimize sewer contamination of its urban aquifer by integrating its management teams for wastewater and drinking water, making sure both teams are aware of each other's activities that might affect the aquifer.

From a contaminant monitoring perspective, total coliform bacteria and E. colistandard microbiological indicators of water sanitary quality - are rarely correlated with viruses (Wu et al. 2011), likely due to their differences in transport/ filtering and survival characteristics in an aquifer. Even with direct analysis, virus occurrence is commonly temporally sporadic when viruses are analyzed at the wellhead. Therefore, assessing drinking well vulnerability can involve a multiple samplings, 
perhaps more than might be used for traditional contaminant vulnerability assessments. Fortunately, water samples for viruses can now be collected inexpensively and routinely (Lambertini et al. 2008; Gibbons et al 2010; Mull and Hill 2012), which allows affordable collecting of larger sample numbers. In the early 2000 s, results from viral analysis by conventional polymerase chain reaction (PCR) usually included only virus identification and presence/absence; virus quantification could only be accomplished by culture methods and these are laborious, expensive, and restricted to only a few virus groups. Now, with the advancement of real-time quantitative PCR (qPCR), the quantities of many virus types can be reliably measured with high-throughput, low cost, and less labor. Detailed genetic information on virus subtypes can also be obtained with high-throughput sequencers widely available. Therefore, from a practical standpoint, this newly developed technology has created a capability to assess well vulnerability that was not available to groundwater managers even 15 years ago.

These available technologies have also allowed the advent of a new concept in groundwater management, using viruses as tracers of young-age groundwater (Hunt et al. 2014). Because the maximum survival time for viruses in groundwater is approximately 3 years, a positive virus signal in mixed-age groundwater, in effect, zeros-out the contribution of older water and indicates young water must be present. Moreover, because different virus types infect and then disappear from the host population over time as the number of susceptible and resistant hosts changes, this creates a time-varying signal that can be tracked in the environment. When fecal waste from an infected population is released to the environment, whether from people, livestock or wildlife, the combination of virus identities and quantities in the waste becomes a "virus snapshot" for a specific point in time. Measuring this "snapshot" at suspected virus sources and waiting for it to appear at "downstream" receptors, such as a supply well, can be used to make inferences about time-oftravel to the well; wells with very young water are typically considered more susceptible to all water quality contaminants. Unlike traditional well vulnerability assessments that are relevant for contaminants carried by "high-yield slowpathways" in the aquifer to the well, viruses as tracers for well vulnerability assessment gives information on the less-studied leading edge and early arrival of a pathogen contaminant, which is driven by preferential flowpaths that provide "low-yield fast-pathways" to the well (Hunt et al. 2010).

In areas where groundwater supplies for drinking water are not disinfected, the economic cost of virus contamination can be considerable. In an epidemiological study of 14 groundwater-supplied communities in Wisconsin that did not practice disinfection, Borchardt et al. (2012) determined that $6 \%$ to $22 \%$ of the acute gastrointestinal illnesses (AGI) in these communities resulted from their viruscontaminated drinking water. The economic cost of these groundwater-borne illnesses can be roughly estimated from US data on healthcare utilization and costs for AGI in young children (Cortes et al. 2009) and extending the assumption these data apply to the rest of the population. Such an assumption is likely justified for American adults 18-54 years old because in this age group the prevalence and severity of gastrointestinal illness is not much lower than that for young children 
(Jones et al. 2006). From Cortes et al. (2009), for children less than 5 years old the national hospitalization rate for AGI is $0.5 \%$, the emergency room visit rate is $1.8 \%$, and the outpatient visit rate is $13.3 \%$. The United States median payments for AGI treatment by hospitalization, ER visit, and outpatient is $\$ 3135, \$ 332$, and $\$ 90$ (reported in 2009 USD), respectively. The number of people drinking non-disinfected municipal groundwater in Wisconsin is about 100,000. If the baseline AGI rate in Wisconsin is 1 episode/person-year, about the national average, and using the midpoint of $14 \%$ of AGI attributable to virus-contaminated groundwater, the healthcare costs in Wisconsin are approximately $\$ 500,000$ USD per year. This only includes direct payment to healthcare providers. It does not include costs to the economy from work lost either by the ill person or their caregiver, nor does it include the cost of death. It also does not consider the most disease-vulnerable populations, the immunocompromised and elderly. Moreover, this estimate can be considered conservatively low because it does not account for the legal, social, and economic costs if virus-contaminated groundwater resulted in a disease outbreak. The AGI reported in the study by Borchardt et al (2012) only measured sporadic non-outbreak illnesses.

Studies by Borchardt et al. (2012) and Lambertini et al. $(2011,2012)$ were part of a large United States government funded epidemiological study (the Wisconsin Water And Health Trial for Enteric Risks, or WAHTER Study), designed to measure the level of illness in communities that rely on non-disinfected groundwater as their source for drinking water. Concurrent with the study, the Wisconsin Department of Natural Resources (DNR), the state agency ceded the authority for regulation of drinking water quality, was preparing to implement the United States Federal Groundwater Rule. As it became clear the 14 Wisconsin communities enrolled in the WAHTER Study had significant virus contamination of their groundwater supplies, the DNR decided to incorporate into their statewide implementation plan a change to the State drinking water code to require disinfection for all groundwater-source municipal drinking water systems in the state. The code change was approved by the DNR oversight board. However, after a statewide election in 2010, the State legislature reversed the DNR's decision and passed a bill prohibiting the DNR from requiring drinking water disinfection (http://docs.legis. wisconsin.gov/2011/proposals/ab23, accessed August 12, 2014). The bill was signed into law in 2011 (http://docs.legis.wisconsin.gov/2011/related/acts/19, accessed August 12, 2014). This statewide action was taken despite expert testimony describing the WAHTER study results and associated estimated costs to its citizens.

In an IGM context, there were factors associated with human enteric viruses that may have influenced the decision making process. A new contaminant, viruses, and a new technology, qPCR, were unfamiliar to many drinking water utilities and policymakers. People viewed the traditional pathogen indicators total coliform and E. coli tests as the "gold standard" for sanitary quality; if these traditional indicators were negative the water was considered acceptable. Positive tests for traditional indicators, when they occurred, were interpreted as a distribution system problem not a quality problem associated with the groundwater source itself. Such 
assumptions were deemed reasonable because non-disinfecting communities were not required by State code to collect microbiological samples from their drinkingwater production wells, and a common perception is that the groundwater must be clean because it is filtered by soil and aquifer material, and thus can be considered microbiologically pure. Waterborne disease may have also been viewed as being events that only occurred as disease outbreaks as reported by news headlines; the concept of low-level, but measurable, sporadic disease transmission was unfamiliar. Lastly, the actions were consistent with a public view that State government should not supersede local control of drinking water regulation. A second independent study has since corroborated the WAHTER Study findings and showed heavy precipitation events result in more children seeking medical treatment for AGI in groundwater-supplied communities in Wisconsin that do not practice disinfection compared to those communities that do (Uejio et al. 2014). This study prompted a bill to reverse the disinfection prohibition but it did not move forward (Wisconsin Assembly Bill 545, https://docs.legis.wisconsin.gov/2013/proposals/ ab545, accessed August 12, 2014).

\subsection{Implications for IGM}

Groundwater is under increasing threat from over-development, over-extraction and pollution, due to increasing population pressure, increasing living standards, industrialization, and a lack of proper management to match the demands and use patterns (see Chap. 2 for more detail). This is a global trend, although there are regional differences. The availability of groundwater with adequate quality to meet ecological and human health needs is often in direct and immediate conflict with strategies of livelihood. Competing demands for quantity and quality of groundwater can be result in fragmented management policies. These competing needs present a problem for researchers and managers to communicate the complexity of groundwater-quality changes with changing demands and uses. There is a strong need to close the gap between the perceptions of groundwater quality and understanding.

The latest technologies and approaches in groundwater modeling, laboratory analytical methods, engineering design, and economic modeling can all inform decision-making in an IGM framework, but societal subjective perceptions of water quality and societal behavior can be equally important in some circumstances. In the context of an IGM framework, water quality issues can require regulators to devote appreciable resources to managing societal perceptions and societal behavior - additional resources beyond that needed to perform the more easily recognized components of IGM such as monitoring, engineering, and risk assessment. Moreover, additional dimensions of acceptable water quality can appear as new technology becomes available, which in turn can become important forcing functions on IGM activities. In addition to changing technology, increasing the sampling frequency used in traditional groundwater monitoring assessments can influence IGM 
activities. For example, infrequent sampling (often once a year) and long-term exposure risk assessment approaches may not adequately represent the dynamism of the groundwater system quality - for either pathogen or non-pathogen concerns (e.g., Hunt et al. 2010). New advances in monitoring continuous water quality, such as specific conductance and other parameters, show that changes can occur within hours or days of a precipitation event depending on the system. On the other hand, the time lag between actions at the land surface and expression in the groundwater system must also be accounted. Clearly identifying and characterizing potential water quality drivers is the first step for a successful IGM framework. From such an understanding associated risks can be estimated, which in turn can form the basis of societal discussion of costs and benefits that will form the foundation for all IGM activities that follow.

Open Access This chapter is distributed under the terms of the Creative Commons AttributionNoncommercial 2.5 License (http://creativecommons.org/licenses/by-nc/2.5/) which permits any noncommercial use, distribution, and reproduction in any medium, provided the original author(s) and source are credited.

The images or other third party material in this chapter are included in the work's Creative Commons license, unless indicated otherwise in the credit line; if such material is not included in the work's Creative Commons license and the respective action is not permitted by statutory regulation, users will need to obtain permission from the license holder to duplicate, adapt or reproduce the material.

\section{References}

Abbaszadegan M, LeChevallier M, Gerba CP (2003) Occurrence of viruses in US groundwaters. J Am Water Works Assoc 95:107-120

Amick RS, Burgess EH (2000) Exfiltration in sewer systems. US EPA report EPA/600/R-01/034, 34 p. http://www.epa.gov/nrmrl/pubs/600r01034/600r01034.pdf

Amini M, Abbaspour KC, Berg M et al (2008) Statistical modeling of global geogenic arsenic contamination in groundwater. Environ Sci Technol 42:3669-3675

Anglade J, Billen G, de Marisly G, Benoît M, Barraqué B, Vergnaud V (2013) Le BAC de la Plaine du Saulce (Auxerrois): Analyse de la pollution agricole diffuse et esquisse de propositions pour un plan d'action à long terme. In: Quelle agriculture pour demain? (pp. 1-32). Rapport d'activité PIREN-Seine 2012, pp. 1-32. http://www.sisyphe.upmc.fr/piren/?q=rapports_ 2012/agriculture

Ayotte JD, Szabo S, Focazio MJ, Eberts SM (2011) Effects of human-induced alteration of groundwater flow on concentrations of naturally-occurring trace elements at water-supply wells. Appl Geochem 26:747-762. doi:10.1016/j.apgeochem.2011.01.033

Ayotte JD, Gronberg JM, Apodaca LE (2011) Trace elements and radon in groundwater across the United States, 1992-2003. U.S. Geological Survey Scientific Investigations report 2011-5059: 115 p. http://pubs.usgs.gov/sir/2011/5059

Baran N, Lepiller M, Mouvet C (2008) Agricultural diffuse pollution in a chalk aquifer (Trois Fontaines, France): influence of pesticide properties and hydrodynamic constraints. J Hydrol 358:56-69 
Barataud F, Aubry C, Wezel A, Mundler P (2014a) Management of drinking water catchment areas in cooperation with agriculture and the specific role of organic farming: experiences from Germany and France. Land Use Policy 36:585-594

Barataud F, Durpoix A, Mignolet C (2014b) Broad analysis of French priority catchment areas: a step toward adaption of the water framework directive? Land Use Policy 36:427-440

Barbier M, Chia E (2001) Negotiated agreement on underground water quality management. A case-study of a private contractual framework for sustainable farming practices. In: Agriculture use of groundwater. Towards integration between agricultural policy and water resources management, Kluwer Academic Publisher, Dordrecht (NLD), pp. 195-212. 11 p. 51th EAAE seminar, Zandvoort, I-2-6, BMAK

Barnes KK, Kolpin DW, Furlong ET et al (2008) A national reconnaissance of pharmaceuticals and other organic wastewater contaminants in the United States - I. Groundwater Sci Total Environ 402(2-3):192-200. doi:10.1016/j.scitotenv.2008.04.028

Beller M, Ellis A, Lee SH, Drebot MA, Jenkerson SA, Funk E, Sobsey MD, Simmons OD III, Monroe SS, Ando T, Noel J, Petric M, Middaugh JP, Spika JS (1997) Outbreak of viral gastroenteritis due to a contaminated well. International consequences. J Am Med Assoc 278:563-568

Benoît M, Deffontaines JP, Gras F, Bienaimé E, Riela-Cosserat R (1997) Agriculture et qualité de l'eau. Une approche interdisciplinaire de la pollution par les nitrates d'un bassin d'alimentation. Cahiers Agric 6:97-105

Bishop PK, Misstear BD, White M, Harding NJ (1998) Impacts of sewers on groundwater quality. CIWEM 12:216-223

Borchardt MA (2006) Biologically active contaminants in aquitards. In: Cherry JA, Parker BL, Bradbury KR, Eaton TT, Gotkowitz MG, Hart DJ, Borchardt MA (eds) Contaminant transport through aquitards: a state-of-the-science review. American Water Works Association Research Foundation, Denver Colorado, p 126

Borchardt MA, Bertz PD, Spencer SK, Battigelli DA (2003) Incidence of enteric viruses in groundwater from household wells in Wisconsin. Appl Environ Microbiol 69:1172-1180

Borchardt MA, Haas NL, Hunt RJ (2004) Vulnerability of municipal wells in La Crosse, Wisconsin, to enteric virus contamination from surface water contributions. Appl Environ Microbiol 70:5937-5946

Borchardt MA, Bradbury KR, Gotkowitz MB, Cherry JA, Parker BL (2007) Human enteric viruses in groundwater from a confined bedrock aquifer. Environ Sci Tech 41:6606-6612

Borchardt MA, Bradbury KR, Alexander EC, Kolberg RJ, Alexander SC, Archer JR, Braatz LA, Forest BM, Green JA, Spencer SK (2011) Norovirus outbreak caused by a new septic system in a dolomite aquifer. Ground Water 49(1):85-97. doi:10.1111/j.1745-6584.2010.00686.x

Borchardt MA, Spencer SK, Kieke BA Jr, Lambertini E, Loge FJ (2012) Viruses in non-disinfected drinking water from municipal wells and community incidence of acute gastrointestinal illness. Environ Health Perspect 120:1272-1279

Bouleau G, Richard S (2009) Les lois sur l'eau à la lumière de la directive cadre, Edition AgroParisTech ENGREF, GovAgua, $125 \mathrm{p}$

Boyd DR (2006) The water we drink: an international comparison of drinking water standards and guidelines. David Suzuki Foundation, Vancouver

Bradbury KR, Borchardt MA, Gotkowitz M, Spencer SK, Zhu J, Hunt RJ (2013) Source and transport of human enteric viruses in deep municipal water supply wells. Environ Sci Technol 47(9):4096-4103. doi:10.1021/es100698m

Brown CJ, Jurgens BC, Katz BG, et al (2007) Arsenic and uranium in four aquifer settings: occurrence, distribution, and mechanisms for transport to supply wells. Paper presented at National Groundwater Association naturally occurring contaminants conference - arsenic, radium, radon, uranium, Charleston, 22-23 Mar 2007

Buhler DD, Randall GW, Koskinen WC, Wyse DL (1993) Water quality - arazine and alachlor losses from subsurface tile drainage of a clay loam soil. J Environ Qual 22:583-588 
Capriel P, Haisch A, Khan SU (1985) Distribution and nature of bound (nonextractable) residues of atrazine in a mineral soil nine years after the herbicide application. J Agric Food Chem 33:567-569

Chapelle FH, Bradley PM, McMahon PB et al (2009) What does "water quality" mean? Ground Water 47(6): 752-754

Cortes JE, Curns AT, Tate JE, Parashar UD (2009) Trends in healthcare utilization for diarrhea and rotavirus disease in privately insured US children $<5$ years of age, 2001-2006. Pediatr Infect Dis J 10:874-878. doi:10.1097/INF.0b013e3181a653cd

DeBorde DC, Woessner WW, Kiley QT, Ball P (1999) Rapid transport of viruses in a floodplain aquifer. Water Res 33(10):2229-2238

Decker J (1994a) Environmental hazard by leaking sewers. In: Proceedings of water quality international, IAWQ 17th biennial international conference, Budapest Hungary

Decker J (1994b) Pollution load of subsoil, groundwater, and surface water by leaky sewers. In: Proceedings from Hydrotop 94, Marseille

Delemos JL, Bostick BC, Renshaw CE et al (2006) Landfill-stimulated iron reduction and arsenic release at the Coakley Superfund Site (NH). Estuar Coast Shelf Sci 40(1):67-73

DeSimone LA (2009) Quality of water from domestic wells in principal aquifers of the United States, 1991-2004. U.S. Geological Survey Scientific Investigations report 2008-5227:139 http://pubs.usgs.gov/sir/2008/5227

DeSimone LA, Hamilton PA, Gilliom RJ (2009) Quality of water from domestic wells in principal aquifers of the United States, 1991-2004 - overview of major findings. US Geol Surv Circ 1332:48

Dubrovsky NM, Burow KR, Clark GM et al (2010) Nutrients in the Nation's streams and groundwater, 1992-2004. US Geol Surv Circ 1350:174. http://water.usgs.gov/nawqa/ nutrients/pubs/circ1350

Eberts SM, Thomas MA, Jagucki ML (2013) Factors affecting public-supply well vulnerability to contamination-understanding observed water quality and anticipating future water quality. US Geol Surv Circ 1385: 120. http://pubs.usgs.gov/circ/1385/

European Commission (2002) Implementation of Council Directive 91/676/EEC concerning the protection of water against pollution caused by nitrates from agricultural sources. Synthesis from year 2000 Member States reports. COM (2002) 407 fin. European Commission, Brussels

European Commission (2010) Report from the Commission to the Council and the European Parliament on implementation of Council Directive 91/676/EEC concerning the protection of waters against pollution caused by nitrates from agricultural sources based on Member State reports for the period 2004-2007 SEC(2010)118/* COM/2010/0047 final */. European Commission, Brussels

Fishman C (2011) The big thrist : the secret life and turbulent future of water. Free Press, New York, p 402

Focazio MJ, Szabo Z, Kraemer TF (2000) Occurrence of selected radionuclides in ground water used for drinking water in the United States - a reconnaissance survey, 1998. U.S. Geological Survey Water-Resources Investigation Report 00-4273, 46 p., http://pubs.usgs.gov/wri/ wri004273/

Focazio MJ, Kolpin DW, Barnes KK et al (2008) A national reconnaissance for pharmaceuticals and other organic wastewater contaminants in the United States - II) untreated drinking water sources. Sci Total Environ 402:201-216

Fout GS, Martinson BC, Moyer MWN, Dahling DR (2003) A multiplex reverse transcription-PCR method for detection of human enteric viruses in groundwater. Appl Environ Microbiol 69:3158-3164

Gallay A, De Valk H, Cournot M, Ladeuil B, Hemery C, Castor C, Bon F, Mégraud F, Le Cann P, Desenclos JC (2006) A large multi-pathogen waterborne community outbreak linked to fecal contamination of a groundwater system, France, 2000. Clin Microbiol Infect 12:561-570

Gibbons CD, Rodríguez RA, Tallon L, Sobsey MD (2010) Evaluation of positively charged alumina nanofibre cartridge filters for primary concentration of noroviruses, adenoviruses and male-specific coliphages from seawater. J Appl Microbiol 109:635-641

Gotkowitz MB, Schreiber ME, Simo JA (2004) Effects of water use on arsenic release to well water in a confined aquifer. Groundwater 42:568-575. doi:10.1111/j.1745-6584.2004.tb02625.x 
Granato GE (1996) Deicing chemicals as source of constitutents of highway runoff. Transportation research record 1533, Transportation Research Board, National Research Council, Washington, DC, pp. 50-58

Hellec F, Barataud F, Martin L (2013) Protection de l'eau et agriculture: une négociation au long cours. Natures, Sciences, Sociétés 21(2):190-199. In Dossier « Ecologisation des politiques publiques et des pratiques agricoles » doi:10.1051/nss/2013097

Heydel L, Benoît M, Schiavon M (1999) Reducing atrazine leaching by integrating reduced herbicide use with mechanical weeding in corn (Zea mays). Euro J Agron 11:217-225

Hunt RJ, Anderson MP, Kelson VA (1998) Improving a complex finite difference groundwaterflow model through the use of an analytic element screening model. Ground Water 36 (6):1011-1017. doi:10.1111/j.1745-6584.1998.tb02108.x

Hunt RJ, Coplen TB, Haas NL, Saad DA, Borchardt MA (2005) Investigating surface water-well interaction using stable isotope ratios of water. J Hydrol 302(1-4):154-172. doi:10.1016/j. jhydrol.2004.07.010

Hunt RJ, Prudic DE, Walker JF, Anderson MP (2008) Importance of unsaturated zone flow for simulating recharge in a humid climate. Ground Water 46(4):551-560. doi:10.1111/j.17456584.2007.00427.x

Hunt RJ, Borchardt MA, Richards KD, Spencer SK (2010) Assessment of sewer source contamination of drinking water wells using tracers and human enteric viruses. Environ Sci Technol 44 (20):7956-7963. doi:10.1021/es100698m

Hunt RJ, Borchardt MA, Bradbury KR (2014) Viruses as groundwater tracers: using ecohydrology to characterize short travel times in aquifers. Rapid Commun Groundwater 52(2):187-193. doi:10.1111/gwat. 12158

Hynds PD, Thomas MK, Pintar KDM (2014) Contamination of groundwater systems in the US and Canada by enteric pathogens, 1990-2013: a review and pooled-analysis. PLoS One 9(5), e93301. doi:10.1371/journal.pone.0093301

Jagucki ML, Katz BG, Crandall CA, Eberts SM (2009) Assessing the vulnerability of publicsupply wells to contamination - Floridan aquifer system near Tampa, Florida. U.S. Geological Survey Fact Sheet 2009-3062:6

Jarczyk HJ (1987) Studies on the leaching characteristics of crop protection chemicals in monolith lysimeter installation. Pflanzenschutz-Nachrichten Bayer 40:49-77

Jones TF et al (2006) A population-based estimate of the substantial burden of diarrheal disease in the United States; FoodNet, 1996-2003. Epidemiol Infect 135:293-301

Kunkel R, Kreins P, Tetzlaff B, Wendland F (2010) Forecasting the effects of EU policy measures on the nitrate pollution of groundwater and surface waters. J Environ Sci 22(6):872-877

Lam QD, Schmalz B, Fohrer N (2011) The impact of agricultural best management practices on water quality in a North German lowland catchment. Environ Monit Assess 183:351-379

Lambertini E, Spencer SK, Bertz PD, Loge FJ, Kieke BA, Borchardt MA (2008) Concentration of enteroviruses, adenoviruses, and noroviruses from drinking water by use of glass wool filters. Appl Environ Microbiol 74(10):2990-2996

Lambertini E, Spencer SK, Kieke BA Jr, Loge FJ, Borchardt MA (2011) Virus contamination from operation and maintenance practices in small drinking water distribution systems. J Water Health 9:799-812

Lambertini E, Borchardt MA, Kieke BA Jr, Spencer SK, Loge FJ (2012) Risk of viral acute gastrointestinal illness from non-disinfected drinking water distribution systems. Environ Sci Technol 46:9299-9307

Larson SJ, Capel PD, Majewski MS (1997) Pesticides in surface waters-distribution, trends, and governing factors. Ann Arbor Press, Chelsea

Lerner DN, Halliday D (1994) The impact of sewers on groundwater quality. In: Wilkinson, WB (ed) Groundwater problems in urban areas. Thomas Telford, London

Mayer AS, Hassanizadeh SM (2005) Introduction. In: Mayer AS, Hassanizadeh SM (eds) Soil and groundwater contamination: nonaqueous phase liquids-principles and observations. American Geophysical Union, Washington, DC. doi:10.1029/17WM01

McKay LD, Cherry JA, Bales RC, Yahya MT, Gerba CP (1993) A field example of bacteriophage as tracers of fracture flow. Environ Sci Technol 27(6):1075-1079 
Mills PC, Cobb RP (2015) Hexavalent and total chromium at low reporting concentrations in source-water aquifers and surface waters used for public supply in Illinois, 2013. U.S. Geological Survey Scientific Investigations Report 2015-5020, 58 p., http://dx.doi.org/ $10.3133 / \operatorname{sir} 20155020$.

Muir DCG, Baker BE (1978) The disappearance and movement of three triazine herhicides and several of their degradation products in soil under field conditions. Weed Res 18:111-120

Mukherjee A, Sengupta MK, Hossain MA et al (2006) Arsenic contamination in groundwater: a global perspective with emphasis on the Asian scenario. J Health Popul Nutr 24(2):142-163

Mull B, Hill VR (2012) Recovery of diverse microbes in high turbidity surface water samples using dead-end ultrafiltration. J Microbiol Methods 91:429-433

Mullaney JR, Lorenz DL, Arntson AD (2009) Chloride in groundwater and surface water in areas underlain by the glacial aquifer system, northern United States. U.S. Geological Survey Scientific Investigations report 2009-5086:41

National Research Council (2001) Arsenic in drinking water - 2001 update. Subcommittee to update the 1999 Arsenic in Drinking Water report, Committee on Toxicology, Division on Earth and Life Studies. National Academy Press, Washington, DC: 226 http://www.nap.edu/ catalog.php?record_id=10194

Novak SM, Portal JM, Morel JL, Schiavon M (1998) Mouvement des produits phytosanitaires dans le sol et dynamique de transfert par l'eau. Comptes Rendus De L'Academie D'Agriculture de France 84:119-132

Perrin-Ganier C, Portal JM, Benoît M, Schiavon M (1996) Monitoring isoproturon leaching in the field by drainage and porous cup sampling. Chemosphere 32:2043-2048

Posen P, Hutchins M, Lovett A, Davies H (2011) Identifying the catchment size at which robust estimations of agricultural land use can be made, and implications for diffuse pollution modelling. Appl Geogr 31(3):919-929

Réal B, Dutertre A, Gillet JP (2001) Transfert des produits phytosanitaires par drainage et ruissellement. Résultats de sept campagnes d'expérimentation. COLUMA Journées Internationales sur la lutte contre les mauvaises herbes, Toulouse

Réal B, Dutertre A, Eschenbrenner G, Bonnifet AP, Mulher JM (2004) Transferts de produits phytosanitaires par drainage et ruissellement. Résultats de 10 campagnes d'expérimentation. In: ANPP (ed) COLUMA, XIX ${ }^{\text {èmes }}$ Journées Internationales sur la lutte contre les mauvaises herbes, Dijon

Reiml D, Scheunert I, Korte F (1989) Leaching of conversio products of ${ }^{14} \mathrm{C}$ Buturon from soil during 12 years after application. J Agric Food Chem 37:244-248

Richter BC, Kreitler CW (1991) Identification of sources of ground-water salinization using geochemical techniques. U.S. Environmental Protection Agency EPA/600/2-91/064: 273

Rutsch M, Rieckermann J, Cullmann J, Ellis JB, Vollertsen J, Krebs P (2008) Towards a better understanding of sewer exfiltration. Water Res 42(10-11):2385-2394. doi:10.1016/j.watres. 2008.01.019

Schiavon M, Jacquin F (1973) Etude de la présence d'atrazine dans les eaux de drainage. Compte rendu des journées d'études sur les herbicides COLUMA, Versailles, pp 35-43

Schrack D, Coquil X, Ortar A, Benoît M (2009) Rémanence des pesticides dans les eaux issues de parcelles agricoles récemment converties à l'Agriculture Biologique. In: Colloque Dinabio: développement et innovation en agriculture biologique; 2008/05/ 19-20; Montpellier(FRA). Innovations Agronomiques 4:259-268

Schrack D, Ortar A, Benoît M (2012) La longue rémanence des pesticides et de leurs résidus dans les eaux du sol issues de drainage et de bougies poreuses. Cas d'une population de parcelles agricoles en Lorraine après usage de leur utilisation (Installation Expérimentale de Mirecourt). Research report, $111 \mathrm{p}$

Schreiber JD, Smith S, Cullum RJ (1993) Pesticides and nutrients in sourther U.S. shallow ground water and surface water. Water Sci Technol 28(3-5):583-588

Sedmak G, Bina D, MacDonald J (2003) Assessment of an enterovirus sewage surveillance system by comparison of clinical isolates with sewage isolates from Milwaukee, Wisconsin, collected August 1994 to December 2002. Appl Environ Microbiol 69(12):7181-7187 
Seitz SR, Leon JS, Schwab KJ, Lyon GM, Dowd M, McDaniels M, Abdulhafid G, Fernandez NL, Lindesmith LC, Baric RS, Moe CL (2011) Norovirus infectivity in humans and persistence in water. Appl Environ Microbiol 77(19):6884-6888

Sharma BR, Villholth KG, Sharma KD (eds) (2006) Groundwater research and management. Integrating science into management decisions. In: Proceedings of IWMI-ITP-NIH international workshop on creating synergy between groundwater research and management in south and southeast Asia, Roorkee 8-9 Feb 2005. Colombo: International Water Management Institute: 282 (Groundwater Governance in Asia Series - 1)

Singh SK, Ghosh AK, Kumar A et al (2014) Groundwater arsenic contamination and associated health risks in Bihar, India. Int J Env Res 8(1):49-60

Smedley PL, Kinniburgh DG (2002) A review of the source, behaviour and distribution of arsenic in natural waters. Appl Geochem 17:517-568

SoeS (2010) L'environnement en France, édition 2010. Commissariat Général au Développement Durable. $150 \mathrm{p}$

Szabo Z, dePaul VT, Fischer JM, et al (2012) Occurrence and geochemistry of radium in aquifers used for drinking water in the United States. Appl Geochem 27:729-752. doi:10.1016/j. apgeochem.2011.11.002

Tafuri AN, Selvakumar A (2002) Wastewater collection system infrastructure research needs in the USA. Urban Water J 4:21-29

Thieu V, Billen G, Garnier J, Benoît M (2010) Nitrogen cycling in a hypothetical scenario of generalized organic agriculture in the Seine, Somme and Scheldt watersheds. Reg Environ Chang 11:359-370. doi:10.1007/s10113-010-0142-4

Thomas MA (2007) The association of arsenic with redox conditions, depth, and ground-water age in the glacial aquifer system of the Northern United States. U.S. Geological Survey Scientific Investigations report 2007-5036: 26

Uejio CK, Yale SH, Malecki K, Borchardt MA, Anderson HA, Patz JA (2014) Drinking water systems, hydrology, and childhood gastrointestinal illness. Am J Public Health 104:639-646

US Environmental Protection Agency (1989) Results of the evaluation of groundwater impacts of sewer exfiltration. Engineering-Science Pb95-158358

US Environmental Protection Agency (2006) Occurrence and monitoring document for the final ground water rule. Office of Water (4606-M), EPA 815-R-06-012

US Environmental Protection Agency (2011) Revisions to the unregulated contaminant monitoring regulation. UCMR 3) for public water systems. Fed Regist 76(42):11713-11737

Van Halem D, Bakker SA, Amy GL, et al (2009) Arsenic in drinking water - a worldwide water quality concern for water supply companies. Drinking Water Eng Sci 2:29-34 www.drinkwater-eng-sci.net/2/29/2009/

vanWeert F, van der Gun J, Reckman J (2009) Global overview of saline groundwater occurrence and genesis. International groundwater resources assessment centre report nr. GP 2009-1, Utrecht, July 2009: 107

Wallender EK, Ailes EC, Yoder JS, Roberts VA, Brunkard JM (2013) Contributing factors to disease outbreaks associated with untreated groundwater. Groundwater. doi:10.1111/gwat. 12121

Warner KL (2001) Arsenic in glacial drift aquifers and the implication for drinking water -Lower Illinois River Basin. Ground Water 39(3): 433-442. doi:10.1111/j.1745-6584.2001.tb02327.x

Warner KL, Ayotte JD (2014) The quality of our Nation's waters - water quality in the glacial aquifer system, northern United States, 1993-2009. US Geol Surv Circ 1352: 116. doi:10. 3133/cir1352

Warner KL, Martin A, Arnold TL (2003) Arsenic in Illinois ground water - community and private supplies. U.S. Geological Survey Water-Resources Investigations report 03-4103: 12 http://il. water.usgs.gov/pubs/wrir03_4103.pdf.

Welch AH, Westjohn DB, Helsel DR et al (2000) Arsenic in ground water of the United States: occurrence and geochemistry. Ground Water 38:589-604 
Winkel L, Berg M, Amini M, Hug SJ, Johnson CA (2008) Predicting groundwater arsenic contamination in Southeast Asia from surface parameters. Nat Geosci 1:536-542. doi:10. 1038/ngeo254

Winter T, Rosenberry DO, LaBaugh JW (2003) Where does the ground water in small watersheds come from? Ground Water 41(7):989-1000

White AW, Barnett AD, Wright BG, Holladay JH (1967) Atrazine losses from fallow land caused by runoff and erosion. Environ Sci Technol 1:740-744

World Health Organization (2011) Manganese in drinking-water - background document for development of WHO Guidelines for drinking-water quality. World Health Organization, Geneva, WHO/SDE/WSH/03.04/104/Rev/1: 21. http://www.who.int/water_sanitation_health/ dwq/chemicals/manganese.pdf

Wu J, Long SC, Das D, Dorner SM (2011) Are microbial indicators and pathogens correlated? A statistical analysis of 40 years of research. J Water Health 9:265-278

Zogorski JS, Carter JM, Ivahnenko T et al (2006) The quality of our Nation's waters - volatile organic compounds in the Nation's ground water and drinking-water supply wells. US Geol Surv Circ 1292:101 


\title{
Soil and Aquifer Salinization: Toward an Integrated Approach for Salinity Management of Groundwater
}

\author{
Richard Greene, Wendy Timms, Pichu Rengasamy, \\ Muhammad Arshad, and Richard Cresswell
}

\begin{abstract}
Degradation of the quality of groundwater due to salinization processes is one of the key issues limiting the global dependence on groundwater in aquifers. As the salinization of shallow aquifers is closely related to root-zone salinization, the two must be considered together. This chapter initially describes the physical and chemical processes causing salinization of the root-zone and shallow aquifers, highlighting the dynamics of these processes and how they can be influenced by irrigation and drainage practices, thus illustrating the connectivity between soil and groundwater salinization. The processes leading to aquifer salinization in both inland and coastal areas are discussed. The roles of extractive resource industries, such as mining and coal bed methane operations, in causing aquifer salinization are also outlined. Hydrogeochemical changes occurring during salinization of aquifers are examined with the aid of Piper and Mixing Diagrams. The chapter then illustrates the extent of the problem of groundwater salinization as influenced by management and policy using two case studies. The first is representative of a developing country and explores management of salt-affected soils in the Indus Valley, Pakistan, while the second looks at a developed country, and illustrates how through monitoring we can deduce
\end{abstract}

R. Greene $(\square) \cdot$ M. Arshad

Fenner School of Environment and Society, Australian National University, Canberra, ACT 0200, Australia

e-mail: Richard.greene@anu.edu.au

W. Timms

UNSW School of Mining Engineering, Kensington, NSW 2033, Australia

P. Rengasamy

School of Agriculture, Food and Wine, Adelaide University, PMB 1, Glen Osmond, SA 5064, Australia

R. Cresswell

Eco Logical Australia, Suite 1, Level 1, 101 Sussex Street, Sydney, NSW 2000, Australia 
causes of shallow aquifer salinity in the Namoi Catchment of NSW, Australia. Finally, there is a section on integration and conclusions where we illustrate how management to mitigate salinization needs to be integrated with policy to diminish the threat to productivity that occurs with groundwater degradation.

\subsection{Introduction}

Globally the increased dependence on groundwater to maintain societies and their economies is mediated by threats to supplies of groundwater from a range of environmental and economic pressures, including depletion of supplies (Chap. 2), degradation of the water quality (Chaps. 2 and 14) and the energy issues associated with groundwater extraction and usage (Chap. 4). The criticalities and potential impacts of poorly-managed water resources are nowhere more divisive than where the balance between surface water and groundwater fluxes are upset and excessive amounts of salt are concentrated at the surface and in the shallow sub-surface. This can be caused both by excessive use of water, infiltrating to recharge shallow aquifers that fill to the surface where evapotranspiration concentrates salts in the near-surface, or through inadequate supply of water which does not flush salts beyond the root zone, hence also salinizing the sub-surface. This chapter addresses the degradation of water quality as it relates to salinization of resources and in particular the environmental degradation that occurs as a result of salinization processes. This degradation from salinization can be due to a combination of natural and anthropogenic processes, but these can be closely related. Specifically, this chapter addresses salinization as it affects agricultural productivity and does not consider naturally saline lands, though the consequence of anthropogenic mistreatment of landscapes containing salt stores can result in a similar situation that can prove extremely difficult to rectify and may require timeframes that prohibit economic recovery.

A report by FAO in 2000 estimated that globally the area of salt-affected soils including saline and sodic soils was 831 million ha (Martinez-Beltran and Manzur 2005). It extended over all the continents including Africa, Asia, Australasia and the Americas. This salinization results from the accumulation of water soluble salts in the upper layers of the stratigraphy. It has a major impact on agricultural productivity, environmental health and economic welfare. These salt stores in the stratigraphy can also cause increases in the salinity of groundwater, as salts can be mobilised through irrigation, deep drainage and recharge events. Thus the salinization of surface soils and groundwater supplies are intimately related.

This chapter will first describe the physical and chemical processes causing salinization of the root-zone and shallow aquifers, highlighting the dynamics of these processes and how they can be influenced by irrigation and drainage practices and thus illustrate the connectivity between soil and groundwater salinization. Conceptual diagrams will be used to depict fluxes of water and salt between the different compartments of the integrated system. Two case studies will then illustrate the extent of the problem of groundwater salinization as influenced by 
management and policy. The first is representative of a developing country and explores management of salt-affected soils in the Indus Valley, Pakistan, while the second looks at a developed country, and illustrates how through monitoring we can deduce causes of shallow aquifer salinity in the Namoi Catchment of NSW. Finally, this chapter will show how management to mitigate salinization needs to be integrated with policy to diminish the threat to productivity and groundwater degradation.

\subsection{Major Types of Soil Salinity Based on Groundwater and Soil Processes}

Three major types of salinity may be identified globally, determined by relative interactions between soil and groundwater processes (Rengasamy 2006), as shown in Fig. 15.1. Thus, these types include:

1. Groundwater associated salinity (GAS) where fluctuations in shallow groundwater levels lead to salt discharge into root zone layers

2. Non-groundwater associated salinity (NAS) caused by poor leaching due to restricting hydraulic properties of some soil layers (also referred to as transient salinity), and

3. Irrigation associated salinity (IAS) which is due to the input of salts in the irrigation water and their accumulation in the root zone due to inadequate drainage.

\section{SALINE LAND}
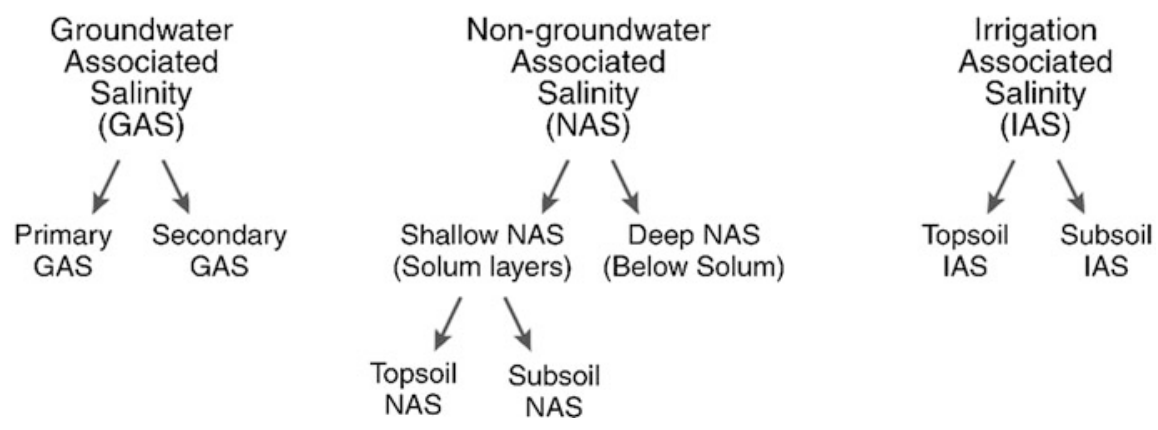

Fig. 15.1 Major types of salinity based on salinization processes 
Irrigation associated salinity may also arise from excessive leaching of applied water that causes a rise in water tables and subsequent salt discharge and thus presents as groundwater associated salinity.

\subsubsection{Groundwater Associated Salinity (GAS)}

Salt accumulation in soil layers occurs when the water tables are shallow, particularly when they are $<4 \mathrm{~m}$ from the surface and the salinity of groundwater becomes progressively higher due to evapotranspiration. Usually this situation occurs in foot slopes and valley floors of the landscape. Human activities, such as clearance of native deep-rooted perennial vegetation and subsequent agricultural practices, disturb the equilibrium levels of the water tables allowing increased recharge and salt movement from upper regolith layers that increases the salinity of the groundwater. Salts ultimately reach the surface via the discharge zone through capillary rise and high salinity levels in the soils can develop that are not conducive for agricultural production. Figure 15.2, for example, depicts an area of agricultural land in the Boorowa region of S.E. NSW badly affected by GAS.

\subsubsection{NAS and Transient Salinity}

Salt accumulation in root zone layers where water tables are deep, is termed transient salinity and generally salt concentrations fluctuate due to soil processes

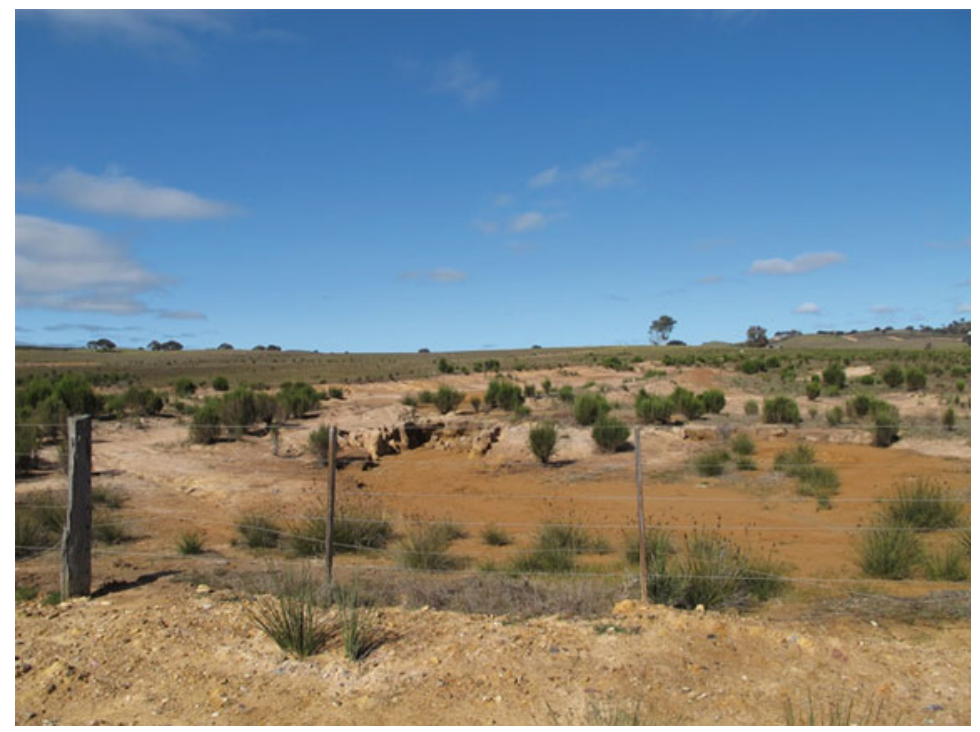

Fig. 15.2 Agricultural land in SE NSW badly affected by GAS 
and seasonal variability. Several sources of salts (as outlined in subsequent sections) contribute to the salts in the soil profile and these are concentrated due to evapotranspiration and the lack of sufficient leaching. The low hydraulic conductivity of many soil layers, which commonly occur in sodic subsoils, leads to poor drainage. Salt levels can be moderate to high and depend strongly on local soil and environmental conditions. Soil management and drainage options thus have to be specific for each site.

\subsubsection{Irrigation Induced Salinity}

The quality of irrigation water determines the amount and composition of salts which are stored in soil layers, while the relative hydraulic conductivity of the soil profile will determine the time taken for a specific area to salinize due to insufficient leaching. Irrigation management and drainage options are therefore also generally site specific.

\subsection{Physical and Chemical Processes Causing Salinization of Root Zone Layers and Aquifers}

While the processes of root zone and shallow aquifer salinization are inter-related, they have nevertheless traditionally been treated separately by agronomists and hydrogeologists, respectively. While attempts have been made to integrate our collective knowledge, the general disparity in ultimate drivers (agricultural productivity for agronomists and water supply for hydrogeologists) and scales of operation $(<2 \mathrm{~m}$ depth at paddock scale for the former and $>2 \mathrm{~m}$ depth and catchment scale for the latter) results in differing approaches; however these approaches ultimately converge where soil profiles and aquifers intersect. It is therefore instructive to approach salinization from these two directions to determine the intersection and synergies that exist.

\subsubsection{Soil Processes and Salt Accumulation in the Root Zone}

Accumulation of soluble salts above a certain level in the root zone of agricultural soils interferes with the crop production by either directly affecting the physiological functions of the plants and/or indirectly by disturbing soil physical and chemical conditions. The commonly used terms 'Primary' and 'Secondary' salinity are based on whether salt accumulates by natural phenomena or as a consequence of mismanagement of natural resources (viz. soil and water). There are several sources of salts causing soil salinization including natural weathering of soil minerals, salts added through precipitation (e.g. Blackburn and McLeod 1983) and salts associated with aeolian dust (e.g. Shiga et al. 2011). Other natural salinization processes 
include discharge of naturally saline groundwaters and saline groundwater intrusion. Agronomic practices such as fertiliser and pesticide application will also add salts to the soils, as will irrigation and dumping of waste materials. In addition to requiring a source of salts, climatic, hydrological and landscape features, combined with human activities and plant interactions, determine the specific location of salinization in the root zone and also the quantity and quality of salts accumulating.

\subsubsection{Salinization of the Root-Zone}

Figure 15.3 illustrates typical processes leading to salt accumulation in the root zone of a sodic soil, including the specific case of development of transient salinity (Fig. 15.3b). These salt stores in the root zone can have major effects on plants growth and soil processes (Fig. 15.3a) and can also affect groundwater supplies deeper in the landscape if recharge conditions change and a net downward flux of water and hence salt occurs.

\subsubsection{Effects on Plant Growth}

Irrespective of how the salts have accumulated in soil layers, the concentrations of soluble salts affect plant growth through the osmotic and ionic effects (Munns and Tester 2008). Thus, as salinity increases, the osmotic potential required to extract water into plant cells decreases and inhibits the water uptake by plants (water always moving from a higher to lower potential energy level). Increasing salinity
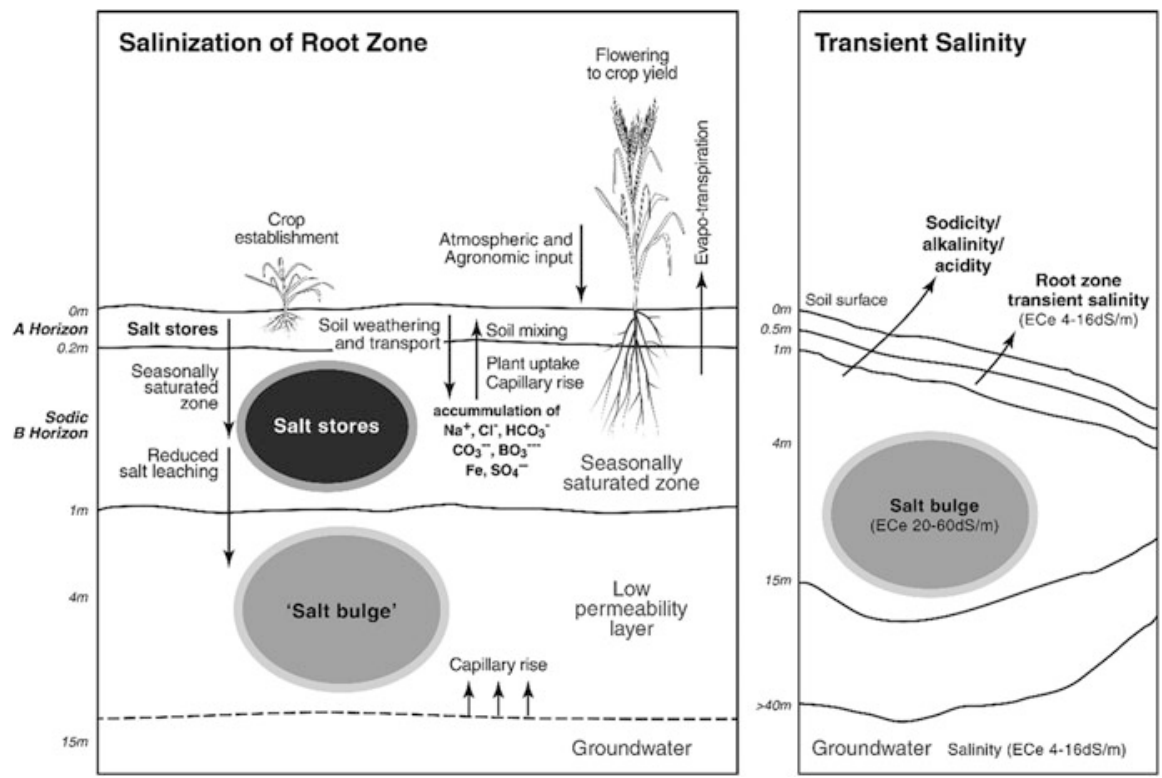

Fig. 15.3 (a) Salt accumulation in the root zone and effects on plant growth and soil processes. (b) Development of transient salinity (After Rengasamy 2006) 
also leads to accumulation of ions in the plant over a period of time and leads to ion toxicity or ion imbalance.

\subsubsection{Effects on Soil Processes}

Salts can also affect many soil processes, such as soil water dynamics, soil structural stability, and solubility of plant nutrients under different hydrogen ion concentrations $(\mathrm{pH})$ and electron conditions ( $\mathrm{Eh}$, or redox) of the soil water. Different categories of salt affected soils can therefore be distinguished based on the ionic composition of soil solution, each affecting soil properties and the mechanism of plant growth in different ways (Table 15.1).

\subsubsection{Effect of Cations and Anions on Soil Structure}

It has been well established that when the amount of soil adsorbed sodium ions, commonly measured as exchangeable sodium percentage (ESP) in soils (or estimated through the sodium adsorption ratio (SAR) of the soil solution), increases above a critical value (ESP $>6$ in Australia and ESP $>15$ in USA and other countries), and the EC of the soil solution decreases below a critical threshold value, the soil structure deteriorates severely due to dispersion of the clay microaggregates or quasi-crystals (Greene et al. 1973; Quirk and Schofield 1955; Rengasamy et al. 1984). With clay dispersion and concomitant blockage of the soil pores, permeability is reduced; this effect is particularly pronounced in smectite dominant clay soils (Turner et al. 2008). As a consequence water and air movement and water storage are highly restricted thereby affecting root environments and, consequently, plant growth (Rengasamy 2013). SAR is readily determined from the major cation composition of soil water and hence used as an indicator of sodium effects on soils.

$$
\mathrm{SAR}=\mathrm{Na}^{+} /\left(\mathrm{Ca}^{2+}+\mathrm{Mg}^{2+}\right)^{0.5}
$$

where the concentrations of $\mathrm{Na}^{+}, \mathrm{Ca}^{2+}$ and $\mathrm{Mg}^{2+}$ in soil solutions are expressed as mmol.L ${ }^{-1}$.

SAR, however, has a number of limitations which distil its effectiveness in predicting soil effects. Potassium $\left(\mathrm{K}^{+}\right)$ions, for example, are not considered in this SAR model, even though adsorbed potassium has been found to affect soil structure (Rengasamy and Sumner 1998). This is partly because $\mathrm{K}^{+}$has traditionally been hard to quantitatively measure and fortunately has been found to occur at relatively low concentrations $(<5 \%)$ in most waters. Recently, Marchuk and Rengasamy (2011) derived ionicity indices of clay-cation bonding and showed that the dispersive effects (which causes soil structural problems) of $\mathrm{Na}^{+}$and $\mathrm{K}^{+}$, and the flocculating effects (which promote soil structural integrity) are highly related to ionicity, or covalency, of the clay-cation bondings.

Further, the effects of $\mathrm{Ca}^{2+}$ and $\mathrm{Mg}^{2+}$ in reducing monovalent adsorption are considered to be equal in the SAR equation. However, Rengasamy and Sumner 
Table 15.1 Categories of salt-affected soils based on $\mathrm{EC}_{\mathrm{e}}(\mathrm{dS} / \mathrm{m}), \mathrm{SAR}_{\mathrm{e}}$ and $\mathrm{pH}_{1: 5}$ of soil solutions and possible mechanisms of impact on plants. Toxicity, deficiency or ion-imbalance due to various ions will depend on the ionic composition of soil solution

\begin{tabular}{|c|c|c|c|}
\hline No. & $\begin{array}{l}\text { Category of } \\
\text { saline soil }\end{array}$ & Criteria & Possible mechanisms of impact on plants \\
\hline 1 & $\begin{array}{l}\text { Acidic-saline } \\
\text { soil }\end{array}$ & $\begin{array}{l}\mathrm{EC}_{\mathrm{e}}>4 \\
\mathrm{SAR}_{\mathrm{e}}<6 \\
\mathrm{pH}<6\end{array}$ & $\begin{array}{l}\text { Osmotic effect; microelement }(\mathrm{Fe}, \mathrm{Al}, \mathrm{Mn} \text { etc. }) \\
\text { toxicity; } \mathrm{SO}_{4}{ }^{2-} \text { toxicity in very low } \mathrm{pH}\end{array}$ \\
\hline 2 & $\begin{array}{l}\text { Neutral saline } \\
\text { soil }\end{array}$ & $\begin{array}{l}\mathrm{EC}_{\mathrm{e}}>4 \\
\mathrm{SAR}_{\mathrm{e}}<6 \\
\mathrm{pH} 6-8\end{array}$ & $\begin{array}{l}\text { Osmotic effect; toxicity of dominant anion or } \\
\text { cation other than } \mathrm{Na}^{+}\end{array}$ \\
\hline 3 & $\begin{array}{l}\text { Alkaline-saline } \\
\text { soil }\end{array}$ & $\begin{array}{l}\mathrm{EC}_{\mathrm{e}}>4 \\
\mathrm{SAR}_{\mathrm{e}}<6 \\
\mathrm{pH} 8-9\end{array}$ & Osmotic effect; $\mathrm{HCO}_{3}{ }^{-}$and $\mathrm{CO}_{3}{ }^{2-}$ toxicity; \\
\hline 4 & $\begin{array}{l}\text { Highly alkaline- } \\
\text { saline soil }\end{array}$ & $\begin{array}{l}\mathrm{EC}_{\mathrm{e}}>4 \\
\mathrm{SAR}_{\mathrm{e}}<6 \\
\mathrm{pH}>9\end{array}$ & $\begin{array}{l}\text { Osmotic effect; } \mathrm{HCO}_{3}{ }^{-} \text {and } \mathrm{CO}_{3}{ }^{2-} \text { toxicity; } \\
\text { microelement ( } \mathrm{Fe}, \mathrm{Al}, \mathrm{Mn} \text { etc.) toxicity }\end{array}$ \\
\hline 5 & $\begin{array}{l}\text { Acidic-saline- } \\
\text { sodic soil }\end{array}$ & $\begin{array}{l}\mathrm{EC}_{\mathrm{e}}>4 \\
\mathrm{SAR}_{\mathrm{e}}>6 \\
\mathrm{pH}<6\end{array}$ & $\begin{array}{l}\text { Osmotic effect; } \mathrm{Na}^{+} \text {and microelement }(\mathrm{Fe}, \mathrm{Al}, \mathrm{Mn} \\
\text { etc.) toxicity }\end{array}$ \\
\hline 6 & $\begin{array}{l}\text { Neutral saline- } \\
\text { sodic soil }\end{array}$ & $\begin{array}{l}\mathrm{EC}_{\mathrm{e}}>4 \\
\mathrm{SAR}_{\mathrm{e}}>6 \\
\mathrm{pH} 6-8\end{array}$ & $\begin{array}{l}\text { Osmotic effect; } \mathrm{Na}^{+} \text {toxicity; toxicity of dominant } \\
\text { anion }\left(\mathrm{Cl}^{-} \text {or } \mathrm{SO}_{4}{ }^{2-}\right)\end{array}$ \\
\hline 7 & $\begin{array}{l}\text { Alkaline-saline- } \\
\text { sodic soil }\end{array}$ & $\begin{array}{l}\mathrm{EC}_{\mathrm{e}}>4 \\
\mathrm{SAR}_{\mathrm{e}}>6 \\
\mathrm{pH} 8-9\end{array}$ & $\begin{array}{l}\text { Osmotic effect; } \mathrm{Na}^{+} \text {toxicity; } \mathrm{HCO}^{-} \text {and } \mathrm{CO}_{3}{ }^{2-} \\
\text { toxicity }\end{array}$ \\
\hline 8 & $\begin{array}{l}\text { Highly alkaline- } \\
\text { saline-sodic soil }\end{array}$ & $\begin{array}{l}\mathrm{EC}_{\mathrm{e}}>4 \\
\mathrm{SAR}_{\mathrm{e}}>6 \\
\mathrm{pH}>9\end{array}$ & $\begin{array}{l}\text { Osmotic effect; } \mathrm{Na}^{+} \text {toxicity; } \mathrm{HCO}^{-} \text {and } \mathrm{CO}_{3}{ }^{2-} \\
\text { toxicity; microelement }(\mathrm{Fe}, \mathrm{Al}, \mathrm{Mn} \text { etc.) toxicity }\end{array}$ \\
\hline 9 & $\begin{array}{l}\text { Acidic-sodic } \\
\text { soil }\end{array}$ & $\begin{array}{l}\mathrm{EC}_{\mathrm{e}}<4 \\
\mathrm{SAR}_{\mathrm{e}}>6 \\
\mathrm{pH}<6\end{array}$ & $\begin{array}{l}\text { Indirect effect due to soil structural problems; } \\
\text { seasonal waterlogging can induce microelement } \\
\text { (Fe, } \mathrm{Al}, \mathrm{Mn} \text { etc.) toxicity }\end{array}$ \\
\hline 10 & $\begin{array}{l}\text { Neutral sodic } \\
\text { soil }\end{array}$ & $\begin{array}{l}\mathrm{EC}_{\mathrm{e}}<4 \\
\mathrm{SAR}_{\mathrm{e}}>6 \\
\mathrm{pH} 6-8\end{array}$ & $\begin{array}{l}\text { Indirect effect due to soil structural problems; } \\
\text { seasonal waterlogging; } \mathrm{Na}^{+} \text {toxicity at high } \mathrm{SAR}_{\mathrm{e}}\end{array}$ \\
\hline 11 & $\begin{array}{l}\text { Alkaline-sodic } \\
\text { soil }\end{array}$ & $\begin{array}{l}\mathrm{EC}_{\mathrm{e}}<4 \\
\mathrm{SAR}_{\mathrm{e}}>6 \\
\mathrm{pH} 8-9\end{array}$ & $\begin{array}{l}\text { Indirect effect due to soil structural problems; } \\
\text { seasonal waterlogging; } \mathrm{Na}^{+} \text {toxicity at high } \mathrm{SAR}_{\mathrm{e}} \text {; } \\
\mathrm{HCO}_{3}{ }^{-} \text {and } \mathrm{CO}_{3}{ }^{2-} \text { toxicity }\end{array}$ \\
\hline 12 & $\begin{array}{l}\text { Highly alkaline- } \\
\text { sodic soil }\end{array}$ & $\begin{array}{l}\mathrm{EC}_{\mathrm{e}}<4 \\
\mathrm{SAR}_{\mathrm{e}}>6 \\
\mathrm{pH}>9\end{array}$ & $\begin{array}{l}\text { Indirect effect due to soil structural problems; } \\
\text { seasonal waterlogging; } \mathrm{Na}^{+} \text {toxicity at high } \mathrm{SAR}_{\mathrm{e}} \text {; } \\
\mathrm{HCO}_{3}{ }^{-} \text {and } \mathrm{CO}_{3}{ }^{2-} \text { toxicity; microelement }(\mathrm{Fe}, \mathrm{Al} \text {, } \\
\text { Mn etc.) toxicity }\end{array}$ \\
\hline
\end{tabular}

(1998) showed the flocculation efficiency of $\mathrm{Mg}$ is actually about 0.6 times that of $\mathrm{Ca}$.

Based on these recent discoveries, Rengasamy and Marchuk (2011) proposed an alternative "cation ratio of soil structural stability" (CROSS) to replace SAR. CROSS incorporates the differential effects of $\mathrm{Na}^{+}$and $\mathrm{K}^{+}$in dispersing soil 
clays, and also the differential effects of $\mathrm{Ca}^{2+}$ and $\mathrm{Mg}^{2+}$ in flocculating soil clays. CROSS is defined as:

$$
\text { CROSS }=\left(\mathrm{Na}^{+}+0.56 \mathrm{~K}^{+}\right) /\left(\mathrm{Ca}^{2+}+0.6 \mathrm{Mg}^{2+}\right)^{0.5}
$$

where the cation concentrations are expressed in mmol.L $\mathrm{L}^{-1}$.

CROSS estimated in soil solutions can be used as a better indicator of potential soil structural effects when compared to SAR (Marchuk and Rengasamy 2012; Marchuk et al. 2013). The actual effects on soil structure depend on the total electrolyte concentration, generally measured as electrical conductivity (EC). When the ionic strength, or EC, of the soil solution is below a critical threshold level (see Table 15.1), the cationic effects on soil structure are predominant.

Anions, even in low ionic strength solutions, critically contribute to the $\mathrm{pH}$ of the soil solution. This alters the net charge on soils and thereby affects the influence of cations. Thus, sulphates and chlorides tend to contribute to acidic $\mathrm{pH}$ levels while bicarbonate and carbonate ions generally promote alkaline conditions. Notably, the dispersive effects of $\mathrm{Na}^{+}$and $\mathrm{K}^{+}$are enhanced when the soil $\mathrm{pH}$ is above 8.5 (Marchuk et al. 2013).

\subsubsection{Management of Salt-Affected Soils}

Sustainable agriculture in salt-affected soils, whether in dryland or irrigated regions, will depend on maintaining low levels of salinity as well as maintaining the proper balance of cations and anions. Accurate, spatially explicit data on soil water chemistry is vital and consideration of the potential effects of differing sources and expressions of salinity is required to make informed assessment of appropriate remediation strategies. While application of fresher waters may serve to dilute salt-affected lands, if the inherent conditions are highly sodic, or have high acidity, or alkalinity, then reduction in salinity alone my result in further degradation of soil condition (Turner et al. 2008) (Table 15.1).

\subsubsection{Processes Leading to Salinization of Aquifers}

\subsubsection{Aquifer Salinization in Inland Areas}

Foster and Chilton (2003) have summarised decades of investigations into salinization of aquifers and consolidated several processes leading to salinization of aquifers in inland areas (Fig. 15.4). These processes include: (i) rising groundwater tables due to inefficient surface irrigation and inadequate drainage, (ii) natural salinity mobilized from the landscape due to land clearing of native vegetation, and (iii) disturbance of natural groundwater salinity stratification by well construction and groundwater extraction. Some of these processes of groundwater salinization are discussed in more detail in the case studies below of (i) the management of salt-affected soils in the Indus Valley, Pakistan, and (ii) the monitoring and investigation of the causes of shallow aquifer salinity in the Namoi Catchment of NSW. 


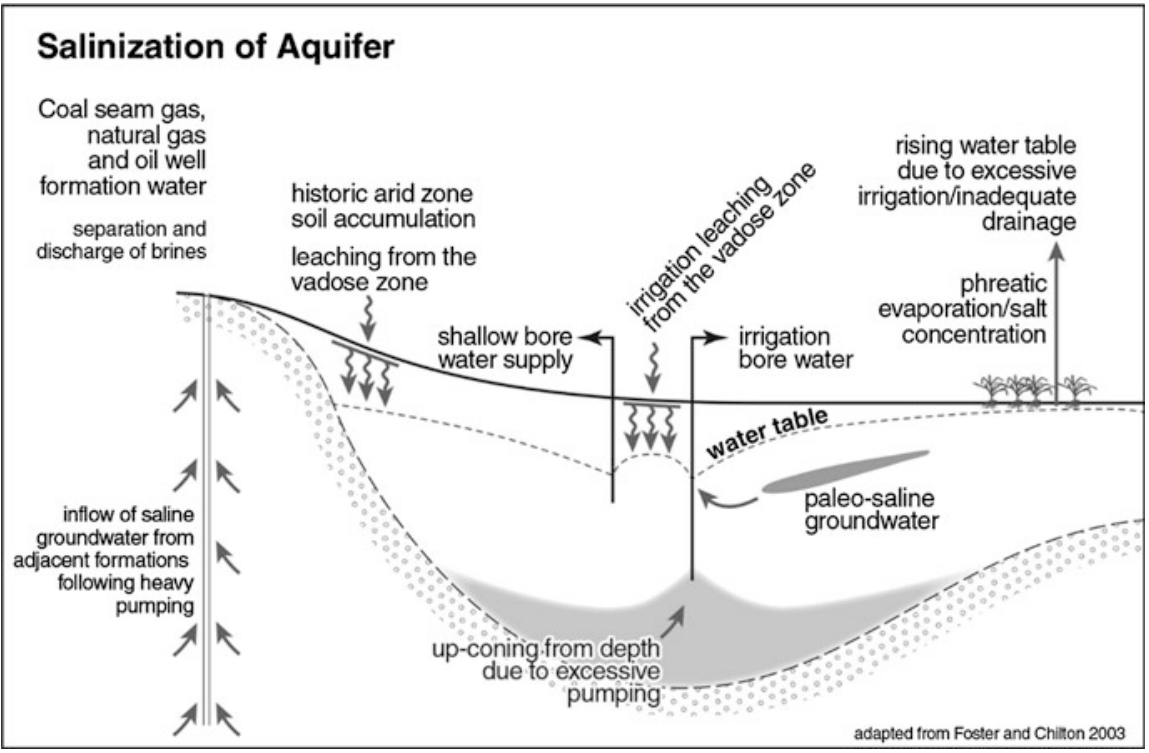

Fig. 15.4 Processes leading to salinization of aquifers in inland areas (After Foster and Chilton 2003)

\subsubsection{Aquifer Salinization in Coastal Areas Due to Intrusion of Salt Water}

Coastal floodplains around the globe constitute prime agricultural areas that generally rely on conjunctive use of surface water and groundwater, and this is largely controlled by the strong seasonality expressed in surface water supplies. As agricultural productivity has increased, traditional seasonal, opportunistic irrigation has been replaced by year-round development with seasonal surface waters augmented by groundwater during low-flow periods. Excessive pumping during groundwater extraction in coastal areas, however, can lead to salinization due to induced sea water intrusion. The hydraulic head of inland groundwaters is reduced by excessive pumping allowing seawater to encroach further inland, and thus salinizing the landscape (Fig. 15.5).

Once seawater intrudes and causes coastal salinization, it is almost impossible to remediate. Salinization of fresh groundwater in coastal aquifers is a global issue that is exacerbated by excessive groundwater extraction as well as by sea level rise (Werner et al. 2013). Under natural hydraulic equilibrium, a sloping interface between fresh and saline pore waters within an aquifer is located beneath the coastal plain (Fig. 15.5). Groundwater extraction at rates exceeding up-stream recharge by freshwater allows the interface to progress inland and locally may cause increased upwards and landward flow of saline seawater. The natural groundwater equilibrium is further susceptible to changes in recharge and discharge caused by climate change. Khan et al. (2006) have discussed how increasing rates 


\section{Seawater intrusion}

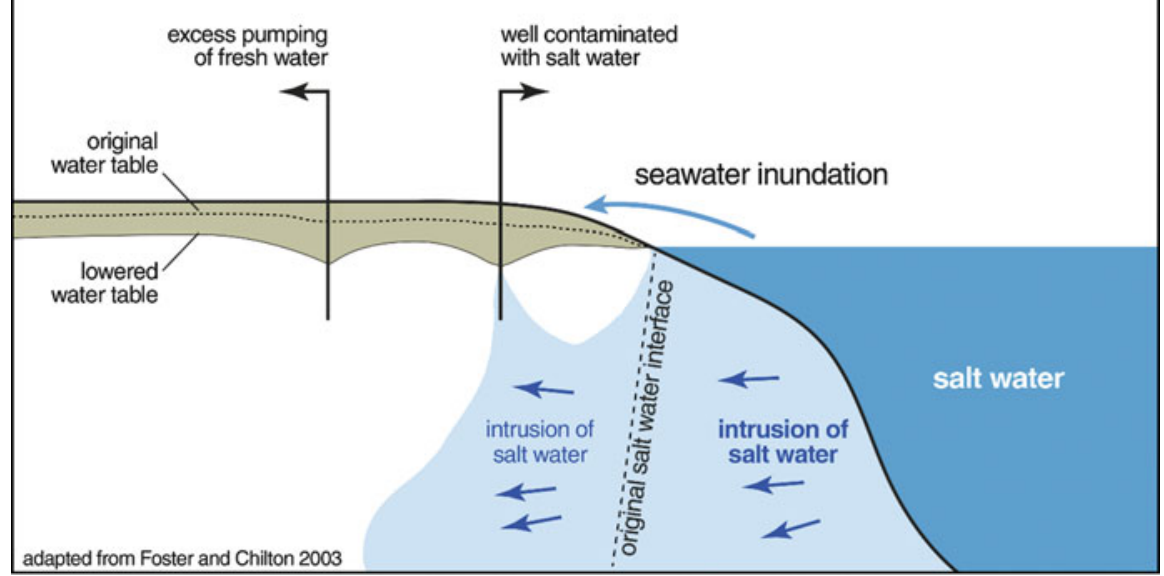

Fig. 15.5 Process leading to salinization of fresh groundwater in coastal aquifers due to the intrusion of salt water from the sea

of sea level rise due to global warming will increase the potential for intrusion of salt water in coastal areas of Bangladesh.

Critically, fresh water that is contaminated by only $5 \%$ of seawater renders it unsuitable for many beneficial uses without treatment. In low lying areas, salinization of fresh coastal aquifers commonly also occurs by inundation (Fig. 15.5), where seawater floods across the surface during storm surges or tsunami or as the land surface subsides. Seawater inundation infiltrates through soil to underlying aquifers as unstable lobes of saline water. Wong et al. (2015) also described how storm surges and sea-level rise resulted in the short-term inundation of low level coastal floodplain sediments. The inundation by either brackish water or seawater results in a decline in surface water quality due to increase liberation of acidity and trace metals.

\subsubsection{Aquifer Salinization Related to Extractive Resource Industries}

Resource extraction industries may also affect groundwater salinity as they physically interfere with existing aquifers and rock formations that are saturated with groundwater. Commonly, groundwaters associated with mineral resources (e.g. coal, oil and gas) exhibit high salinity and appropriate management is required to mitigate any contamination of fresher water supplies, soils and the environment.

Although the volume of water used by mining is typically small relative to other users, such as agriculture and the environment, cumulative volumes of groundwater that may require disposal can be large and, if challenges in managing salinity can be adequately addressed, this produced water presents significant opportunities as an 
alternative water supply for communities, industry, and the environment, albeit potentially short-lived (Timms and Bourke 2014).

As an example, management of salt at coal mining operations in the Hunter Valley involves multiple strategies to protect fresh surface waters. Farmers, concerned that increasing river salinity was impacting the irrigation of food and fodder crops, worked together with the mining and power generation industries to develop a world leading salt trading scheme. The Hunter River salt trading scheme (HRSTS) involves 13 mines and 3 power stations that trade salt credits permitting controlled release of saline water to the river during high flow events (Selman et al. 2009; Vink et al. 2013). Discharge volumes, salt concentrations and dilution factors are continuously monitored to achieve salinity targets at key points along the river. Allowable maximum salinity in the river during discharge events is set as $900 \mu \mathrm{S} / \mathrm{cm}$ at the most downstream monitoring point of the scheme. Thus, mine-site contribution to the salt load in the Hunter River, via controlled discharges, was contained to $3 \%$ of total river load under the HRSTS between 1995 and 2001 (David et al. 2003). Ultimately, however, if salt containment and dilution strategies are unable to achieve water quality objectives, active treatments such as desalination are required at some mine sites.

An additional salinity concern relates to final voids left following mine closure. These voids act as a point of groundwater recharge, or a hydraulic sink for local groundwater flow depending on local conditions. Evaporative concentration of saline groundwater in open voids often occurs, with the salinity of the void water increasing until salt solubilities are exceeded and precipitation occurs. This is a rare event however, as inputs of fresh runoff will delay the salinization. Geochemical modelling estimates of water quality in an open mine in the Hunter Valley, for example, indicates that it would take over 400 years for water salinity to exceed $4,000 \mathrm{mg} / \mathrm{L}$ (Hancock et al. 2005). A recent Environmental Impact assessment for a proposed open cut coal mine in the semi-arid Gunnedah Basin estimates $30,000 \mathrm{mg} / \mathrm{L}$ after $\sim 420$ years of evaporative concentration of inflowing groundwater at a salinity of $5,000 \mathrm{mg} / \mathrm{L}$ (Shenhua Watermark EIS 2013).

The recently developed water accounting framework for the minerals industry in Australia (MCA 2012), provides a common method to compare water balance and quality on a site-by-site basis and identifies three categories of water with respect to salinity to guide water use options, which may include dust suppression, industrial use or being suitable for potable supplies (Table 15.2).

Coal bed methane (CBM) operations, known as coal seam gas (CSG) in Australia, can generate large volumes of groundwater that may be quite saline and requires careful management to ensure that the risk of salinization to other groundwater and surface water supplies is negligible (Williams et al. 2012). Groundwater salinity could be impacted by CBM operations via a number of mechanisms including: mobilisation of saline groundwater through enhanced hydraulic gradients towards gas wells; leakage of saline groundwater through poorly sealed exploration bores and aging water supply bores; and surface spills from pipelines and storages for produced water and associated production fluids. Produced water volumes are typically highest during the early stages of CBM well 
Table 15.2 Water types and salinity classes

\begin{tabular}{l|l|l|l}
\hline Water type & EC $(\mathrm{dS} / \mathrm{m})$ & TDS $(\mathrm{mg} / \mathrm{L})$ & Mine Water ${ }^{\mathrm{a}}$ TDS $(\mathrm{mg} / \mathrm{L})$ \\
\hline Pure rainwater & $<0.015$ & $<10$ & \\
\hline Freshwater & $0.015-0.8$ & $100-1,000$ & $<1,000($ Category 1$)$ \\
\hline Slightly brackish water & $1.6-4.8$ & $1,000-3,000$ & $1,000-5,000($ Category 2$)$ \\
\hline Brackish water & $4.8-16$ & $3,000-10,000$ & $>5,000($ Category 3) \\
\hline Saline water & 16 & $>10,000$ & \\
\hline Seawater & 51.5 & 35,000 & \\
\hline Hyper saline & $>51.5$ & $>35,000$ & \\
\hline
\end{tabular}

${ }^{\mathrm{a}} \mathrm{MCA} 2012$

development as the system is depressurised to allow gas to desorb from the coal matrix. Risks to groundwater quality can typically be managed to reduce the risk of impacts to very low or negligible issues, although some concerns remain to be addressed. Disposal via evaporation and seepage ponds are no longer permitted in eastern Australian states and thus removes one of the highest risks to aquifer salinization. Temporary storage ponds, however, are still required and must be designed to minimise the risk of spills and seepage losses.

The salt content in produced CBM water varies widely, from nearly freshwater $(10-500 \mathrm{mg} / \mathrm{L})$ to salt levels up to ten times higher than seawater $(300,000 \mathrm{mg} / \mathrm{L})$. Lower concentrations tend to be associated with shallow coal seams exposed to recent fresh surface water recharge (Khan and Kordek 2014). In the Sydney Basin, existing CBM operations currently produce $<4.5 \mathrm{ML} /$ year of water with a salinity between 7 and $15 \mathrm{dS} / \mathrm{m}$ (i.e. TDS of 4,700-10,000 $\mathrm{mg} / \mathrm{L}$ ). The produced water is reused in drilling operations and the excess treated at a licensed water treatment facility. By contrast, CSG operations in the Surat Basin in South-east Queensland are projected to produce $20,000 \mathrm{ML} /$ year of water for 50 years with a TDS of 14,500-31,000 mg/L (OGIA 2012).

Produced water that is in excess of operational requirements will generally be treated by reverse osmosis desalination with discharge of suitably treated water for beneficial use. Beneficial use of mixed or treated water, for example to augment irrigation and environmental flows to rivers, is currently encouraged by regulatory agencies. Table 15.3 indicates water salinity limits for selected beneficial uses in Australia for irrigation of crops and for stock water. Water that is not suitable for drinking water $(>1.2 \mathrm{dS} / \mathrm{m})$ for example, is fit for the purpose of irrigating crops that are tolerant to brackish water.

Brine produced by desalination would be concentrated and recrystallized, typically for disposal to landfill. An alternative method of disposal of saline produced water by deep well injection could provide a local and permanent disposal solution for produced water or brine concentrates (National Research Council 2010). Commonly practiced in some parts of the US, deep well injection targets naturally saline formations that are hydraulically disconnected from fresh water aquifers (Yeboah and Burns 2011). 
Table 15.3 Salinity guidelines for key beneficial uses

\begin{tabular}{|c|c|c|c|}
\hline \multirow[t]{6}{*}{ Irrigation } & $\mathrm{EC}(\mu \mathrm{S} / \mathrm{cm})$ & Comments & Source \\
\hline & 8,000 & Unsuitable for barley irrigation & \multirow{10}{*}{$\begin{array}{l}\text { ANZEEC } \\
(2000)\end{array}$} \\
\hline & 7,700 & Unsuitable for cotton irrigation & \\
\hline & 5,500 & Unsuitable for sunflower irrigation & \\
\hline & 6,000 & Unsuitable for wheat irrigation & \\
\hline & 1,500 & $\begin{array}{l}\text { If used on early season cotton, the final yields could } \\
\text { be diminished }\end{array}$ & \\
\hline \multirow[t]{5}{*}{ Livestock } & $14,920^{\mathrm{a}}$ & $\begin{array}{l}\text { Loss of production and a decline in beef cattle } \\
\text { condition and health }\end{array}$ & \\
\hline & $10,450^{\mathrm{a}}$ & $\begin{array}{l}\text { Loss of production and a decline in dairy cattle and } \\
\text { horses condition and health }\end{array}$ & \\
\hline & $11,940^{\mathrm{a}}$ & $\begin{array}{l}\text { Loss of production and a decline in pigs condition } \\
\text { and health }\end{array}$ & \\
\hline & $5,970^{\mathrm{a}}$ & $\begin{array}{l}\text { Loss of production and a decline in poultry } \\
\text { condition and health }\end{array}$ & \\
\hline & $19,400^{\mathrm{a}}$ & $\begin{array}{l}\text { Loss of production and a decline in sheep condition } \\
\text { and health }\end{array}$ & \\
\hline \multirow{5}{*}{$\begin{array}{l}\text { Drinking } \\
\text { water }^{\mathrm{b}}\end{array}$} & $<120^{\mathrm{c}}$ & Excellent drinking water quality & \multirow{5}{*}{$\begin{array}{l}\text { ADWG } \\
(2008)\end{array}$} \\
\hline & $120-750^{\mathrm{c}}$ & Good drinking water quality & \\
\hline & $750-1,200^{\mathrm{c}}$ & Fair drinking water quality & \\
\hline & $1,200-1,490^{\mathrm{c}}$ & Poor drinking water quality & \\
\hline & $>1,490^{c}$ & Unacceptable drinking water & \\
\hline
\end{tabular}

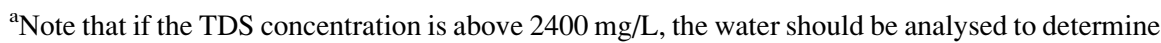
the concentrations of specific ions to avoid possible toxication (ANZEEC 2000)

${ }^{b}$ Bruvold and Daniels (1990) in Australian Drinking Water Guidelines (2008)

${ }^{\mathrm{c}} \mathrm{TDS}$ values converted to EC using equation: $\mathrm{EC}(\mu \mathrm{S} / \mathrm{cm}) \times 0.67=\mathrm{TDS}(\mathrm{mg} / \mathrm{L})($ ANZEEC 2000)

\subsubsection{Hydrogeochemical Changes During Salinization}

Examination of the changing proportions of dissolved ions in groundwater can reveal more information about the processes that lead to increased salinity or EC. Mixing and geochemical reactions that are common along a flow path change specific ion concentrations, or hydrochemical facies. Water recharged from meteoric sources is typically represented by fresh, bicarbonate-type water with mixed cation composition. Geochemical interactions between water and sediment, or rock, along a flow path typically results in evolution towards either a sodium bicarbonate water or sodium chloride water. Hypothetically, a series of hydrochemical facies occurs along a flow path, depending on the nature of sediment and rock encountered, that can indicate the maturity of a groundwater system.

A Piper diagram, as shown in Fig. 15.6, is a common method by which hydrochemical facies are represented. Relative concentrations of major cations are plotted in the lower left hand ternary plot, and relative concentrations of major anions are plotted in the lower right hand ternary plot. Both these sets of points are then projected to the central diamond, to intersect at a point that is indicative of hydrochemical facies. For example, Fig. 15.6 depicts facies change 


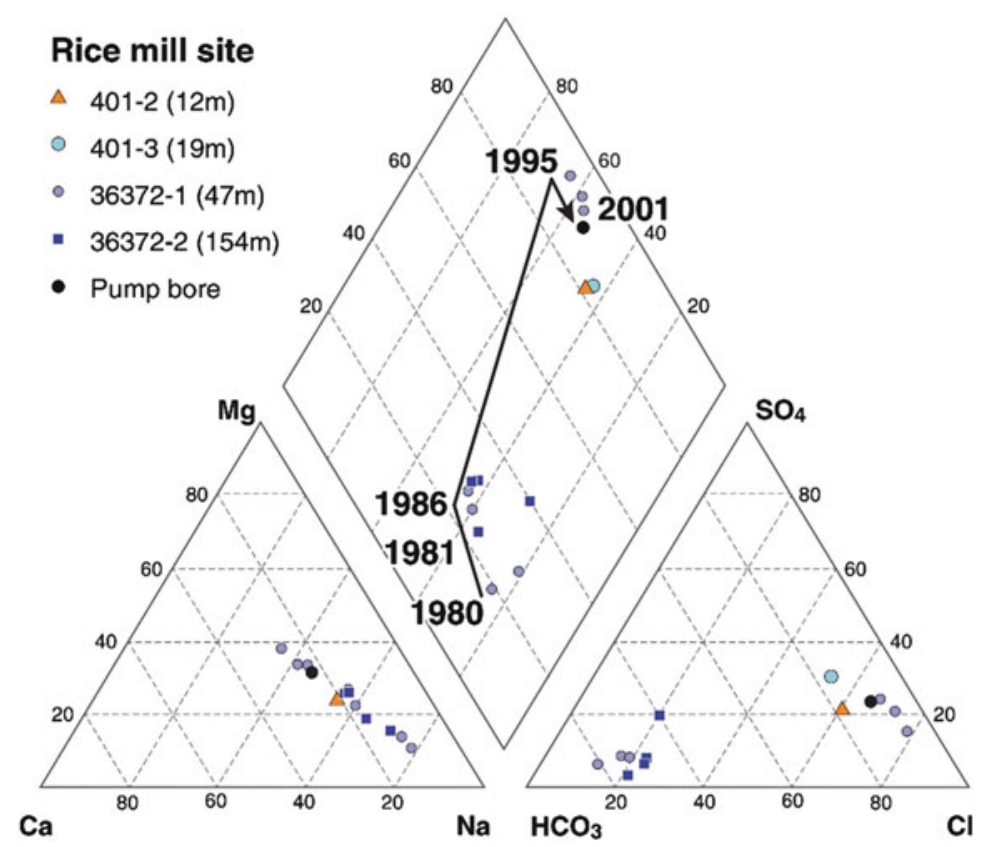

Fig. 15.6 Piper diagrams showing changes in major ion composition of groundwater at the Rice Mill site between 1980 and 2001 (After Timms 2001)

during salinization over two to three decades at a site (Rice Mill) in the Murrumbidgee Irrigation Area (MIA) of Australia's Murray-Darling Basin. At this site, groundwater in alluvial sediments at a depth of approximately $50 \mathrm{~m}$ increased in EC from $<0.5 \mathrm{dS} / \mathrm{m}$ to between 1.3 and $4.1 \mathrm{dS} / \mathrm{m}$. Concomitant with this change in EC, bicarbonate type water changed towards a chloride type water. The major ion composition of the deep groundwater also trended towards a similar composition, though less pronounced, and this was attributed to a downwards hydraulic gradient caused by groundwater extraction from the underlying aquifers, causing the leakage of groundwater from salt laden shallow sediments (Timms and Acworth 2002).

The primary geochemical reactions include dissolution of salts; ion exchange with clay minerals and surface sorption and desorption reactions. These geochemical reactions proceed towards chemical equilibrium and can therefore be assessed using models based on thermodynamic chemical databases. A simple approach utilises a water mixing diagram that can be developed prior to geochemical modelling based on conservative ion (e.g. chloride) concentrations of end members such as saline and fresh groundwater. Figure 15.7, for example, illustrates that at high mixing ratios, based on conservative ion mixing, $\mathrm{HCO}_{3}$ and $\mathrm{SO}_{4}$ concentrations are non-linear indicating processes other than mixing controlling concentration. A relative increase of $\mathrm{Na}$ in fresh water samples is evident, 


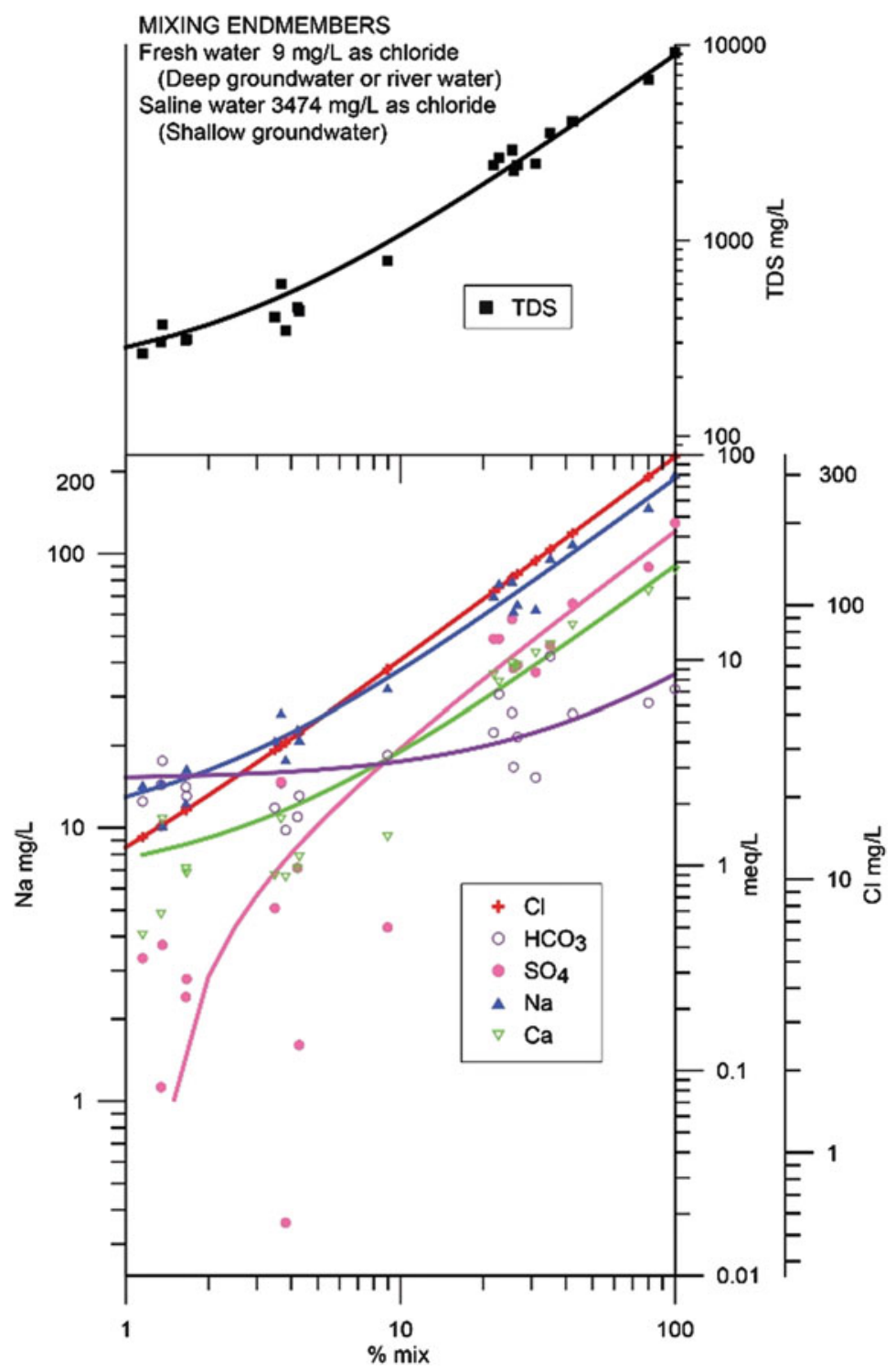

Fig. 15.7 Mixing diagram for groundwaters $(N=44)$ arranged along the $X$ axis in terms of $\%$ mix of saline groundwater of $3,474 \mathrm{mg} / \mathrm{L}$ chloride in fresh water of $9 \mathrm{mg} / \mathrm{L}$ chloride (After Timms 2001)

indicating ion-exchange is an important geochemical process that occurs during mixing. Incorporation of geochemical mixing models to help understand salinization processes can aid in determination of appropriate mitigation strategies and management controls. 


\subsection{Salinization Case Studies}

This section illustrates the scale of the problem of groundwater salinization as influenced by management and policy through two case studies in a developing and a developed country, i.e. Pakistan and Australia, respectively. The case study from Pakistan focuses mainly on soil salinization, whilst the case study from the Namoi catchment particularly assesses aquifer salinization.

\subsubsection{Case Study 1: Rehabilitation of Salt Affected Lands in the Wheat-Cotton Zone of Pakistan; a Physical and Economic Approach to Water Logging and Irrigation Salinity}

\subsubsection{Overview}

In Pakistan approximately $80 \%$ of the agricultural production comes from irrigated agriculture. However, waterlogging and irrigation salinity are major land degradation problems that result in severe economic and social consequences. Out of the total 16.3 million ha of irrigated land in Pakistan about 6.2 million ha (38\%) are waterlogged, and 2.3 million ha $(14 \%)$ are saline. The irrigation salinity results from the intensive use of surface irrigation, where the salt accumulates in the soil surface layers due to a major imbalance in the amount of salt entering and leaving the soils. As a consequence yields and production of crops are adversely affected, resulting in severe economic losses. In 2001 these losses were estimated to be 350 million US\$ annually. Thus salinity management can offer opportunities to alleviate poverty and improve rural livelihoods. Economically, a viable choice of the salinity management is needed to guide decisions for future salinity investments.

Eastern Sadiqia South region in the wheat-cotton zone of Punjab province has been used as a case study. The aim of this study was to (i) conduct a cost benefit analysis of implementing three management strategies, i.e. no intervention, an engineering approach, and an agronomic approach, on four land types, and (ii) compare the Net Present Values (NPV) of the three strategies on the four land types over a period of 25 years, using a discount rate of $6 \%$. The results of the study will enable us to define criteria and set out rules for investment in the rehabilitation of salt-affected lands.

\subsubsection{Background}

The Fordwah canal command area of Eastern Sadiqia South (FESS) region is located in the wheat-cotton zone of Punjab province, and forms part of the Indus Basin irrigation system. The area is situated on the left bank of the River Sutlej (Fig. 15.8).

The climate of the regions is arid (PARC 2002), with annual evaporation of $2,000 \mathrm{~mm}$, far in excess of the annual rainfall of $240 \mathrm{~mm}$ (Sarwari et al. 2000). The soils of the area are comprised mainly of a wide range of coarse to fine textured 


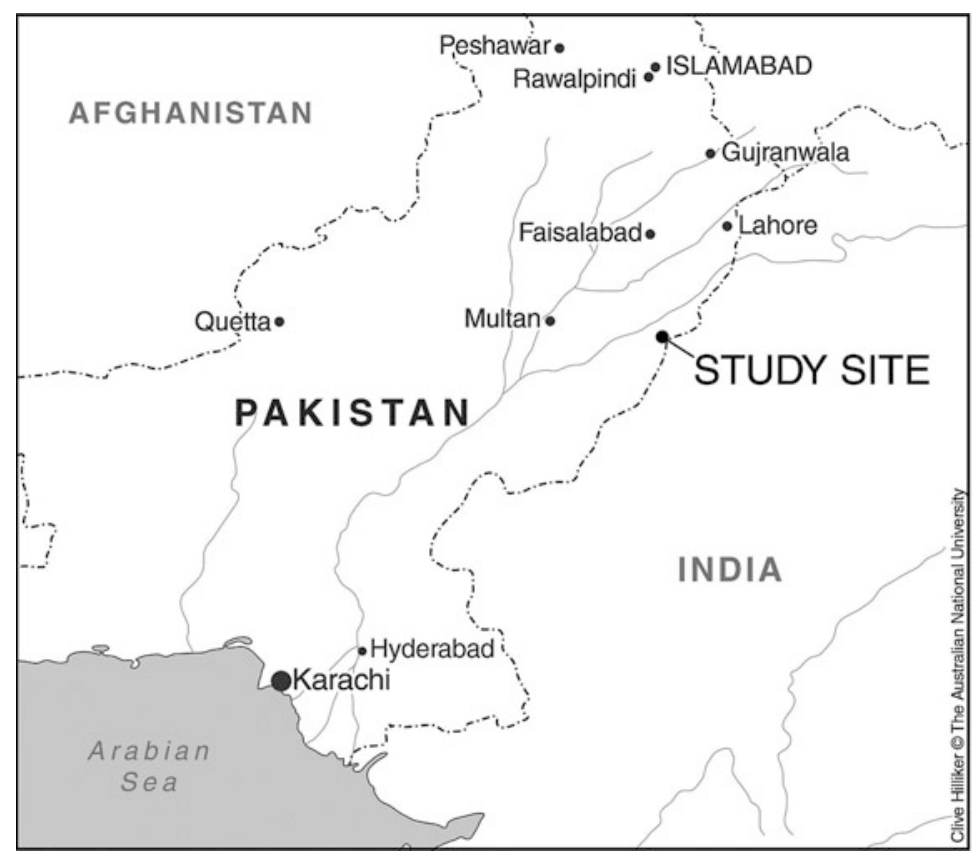

Fig. 15.8 Location of Eastern Sadiqia region, the study area (Source: Pakistan Agriculture Research Council 2002)

alluvial deposits, dominated by medium textured silty loams, with a low to medium water holding capacity (Sarwari et al. 2000). In the majority of cases, farmers use flood irrigation (Kijne 1996), sourced from canal water with an average EC value of $0.3 \mathrm{dS} / \mathrm{m}$ (IWMI 2007). Groundwater in most of the region, however, is saline with EC $>4 \mathrm{dS} / \mathrm{m}$ (Aslam and Prathapar 2006), making groundwater mostly unsuitable for irrigation purposes. Deep percolation from the irrigation system of canals, combined with general lack of good drainage, has resulted in water logging and a major imbalance in the amount of salt entering and leaving the soils. The water logging and salt accumulation have caused various degrees of degradation (Fig. 15.9) (Kahlown and Azam 2002).

Four different land categories were identified (Fig. 15.9) based on the severity of water logging (depth of water table) and soil salinity (ECe) (Table 15.4). They ranged from Land Class D1 which was extremely degraded land through to Land Class 4 which was normal land. Three different salinity management strategies were investigated, i.e. 1. no intervention and use of existing land-use cropping activities, 2. an engineering approach where excessive water is drained from the irrigated land, and 3. an agronomic approach whereby crop diversification, e.g. kallar grass and sesbania, and planting of deep rooted vegetation, e.g. River Red Gum, were used. 


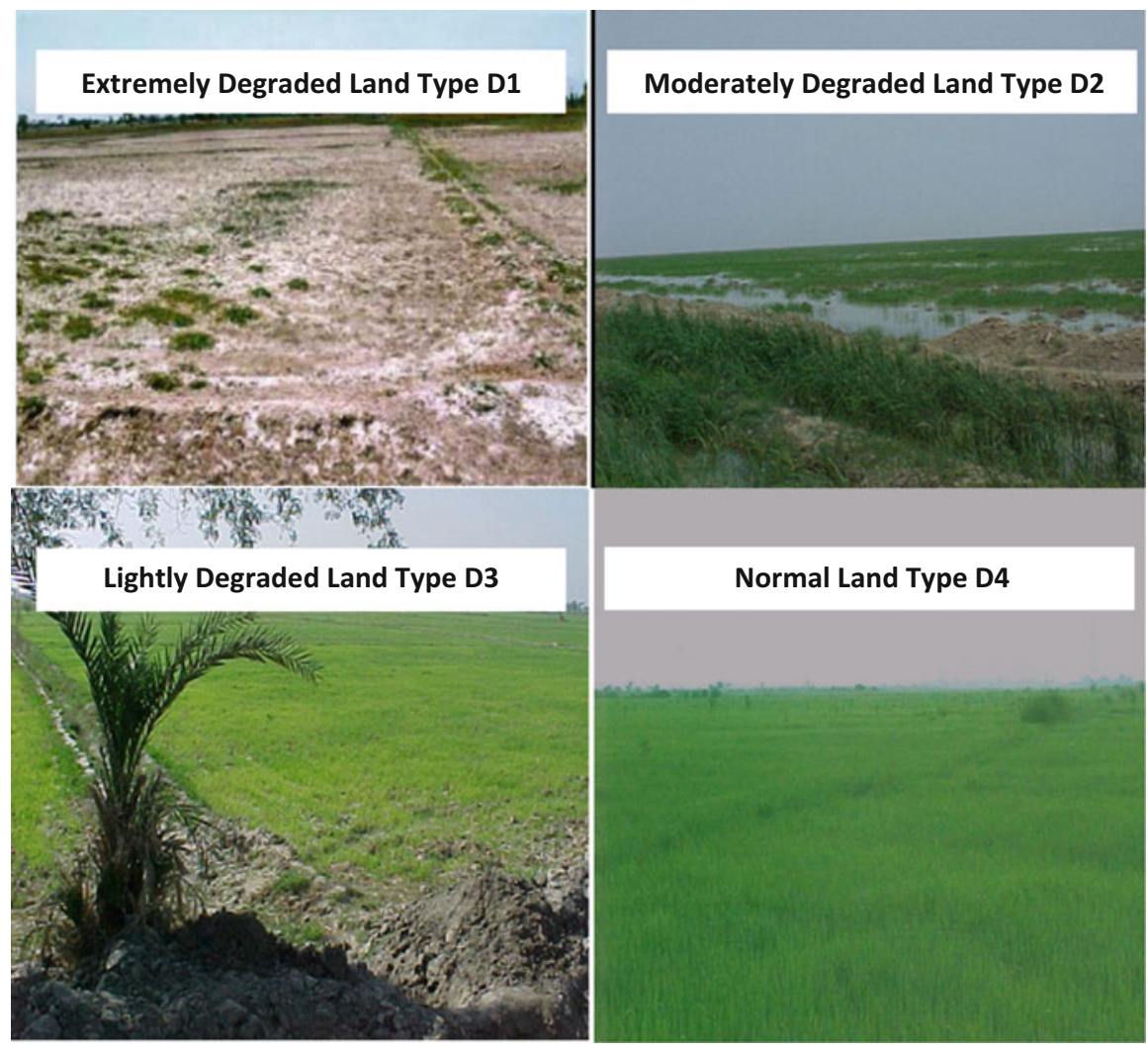

Fig. 15.9 Land types of the Eastern Sadiqia region (Compiled from IWMI 2007)

Table 15.4 Criteria for land categories in the Eastern Sadiqia (FESS) region (Adapted from PARC 2002)

\begin{tabular}{l|l}
\hline Land category & Description \\
\hline D1 Extremely degraded land & Watertable $<1 \mathrm{~m}$ and ECe $>12 \mathrm{dS} / \mathrm{m}$ \\
\hline D2 Moderately degraded land & Watertable $1-2 \mathrm{~m}$ and ECe between 8 and $12 \mathrm{dS} / \mathrm{m}$ \\
\hline D3 Lightly degraded land & Watertable $2-3 \mathrm{~m}$ and ECe between 4 and $8 \mathrm{dS} / \mathrm{m}$ \\
\hline D4 Normal land & Watertable $>3 \mathrm{~m}$ and ECe between 0 and $4 \mathrm{dS} / \mathrm{m}$ \\
\hline
\end{tabular}

\subsubsection{Physical Analysis of Effects of Salinity on Soils and Crops}

A salt balance model proposed by Hillel (2000) (Fig. 15.10) was used to calculate the rate of salt accumulation under the four land categories. The model identifies five sources of salt inputs: the salt already present in the mineral soils; the salt entering the root zone from irrigation water; salt addition through land management practices such as fertilizers; salt addition through rainwater; and the salt entering 


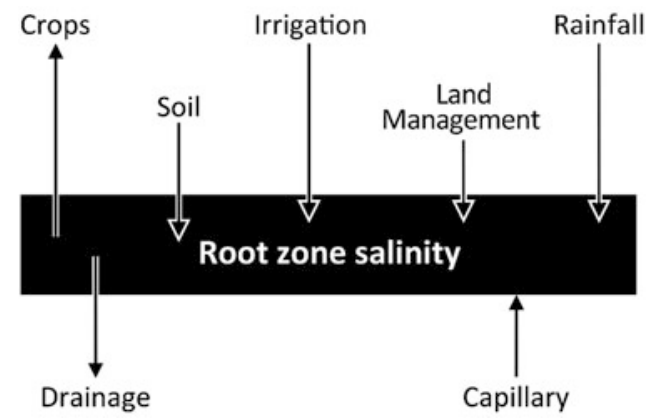

Fig. 15.10 Salt balance calculation model proposed by Hillel (2000)

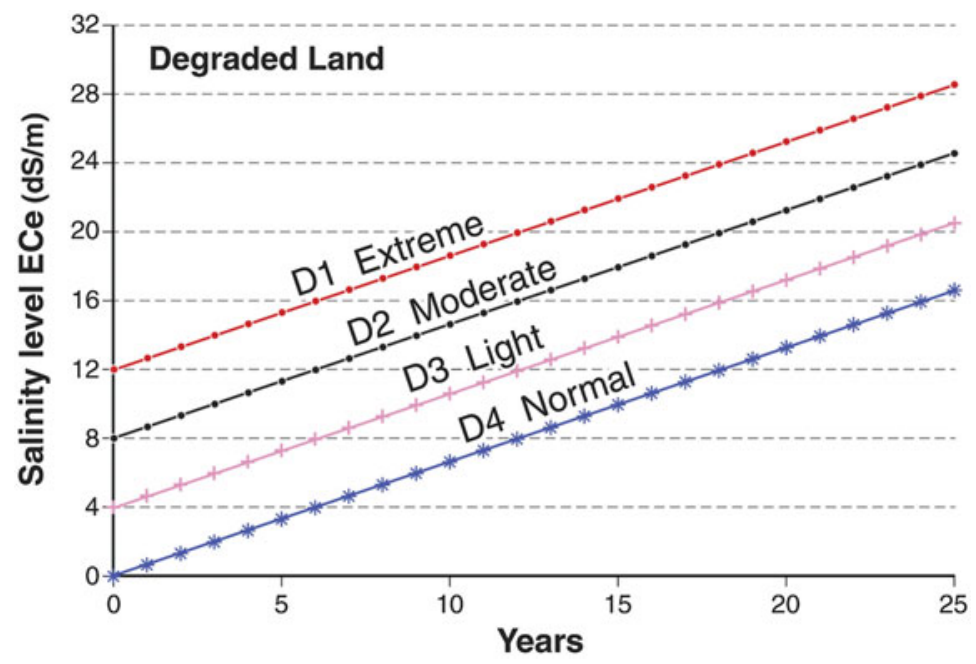

Fig. 15.11 Salinity projections for the next 25 years in the study area

the root zone from groundwater through capillary rise (Fig. 15.10). The factors of salt removal include removal by the crops and by natural drainage.

Figure 15.11 indicates the increasing trend of land salinity for the next 25 years in the four major categories of land (D1, D2, D3, and D4) present in the study area under irrigated agriculture and with no management strategy in place. The annual rate of salt accumulation was calculated to be $0.420 \mathrm{~kg} / \mathrm{m}^{2}$ or $0.66 \mathrm{dS} / \mathrm{m}$ (Arshad 2007). Wheat and cotton crop yields start to decrease with the increase in the salinity levels for each year. Figure 15.12 shows the trend of wheat and cotton crop yields under the influence of salinity. There is no effect of salinity on both crops up to an ECe of $4 \mathrm{dS} / \mathrm{m}$; however, after an ECe of $4 \mathrm{dS} / \mathrm{m}$, yield of both crops show a rapid decrease with increase in ECe, with wheat being the most affected. 


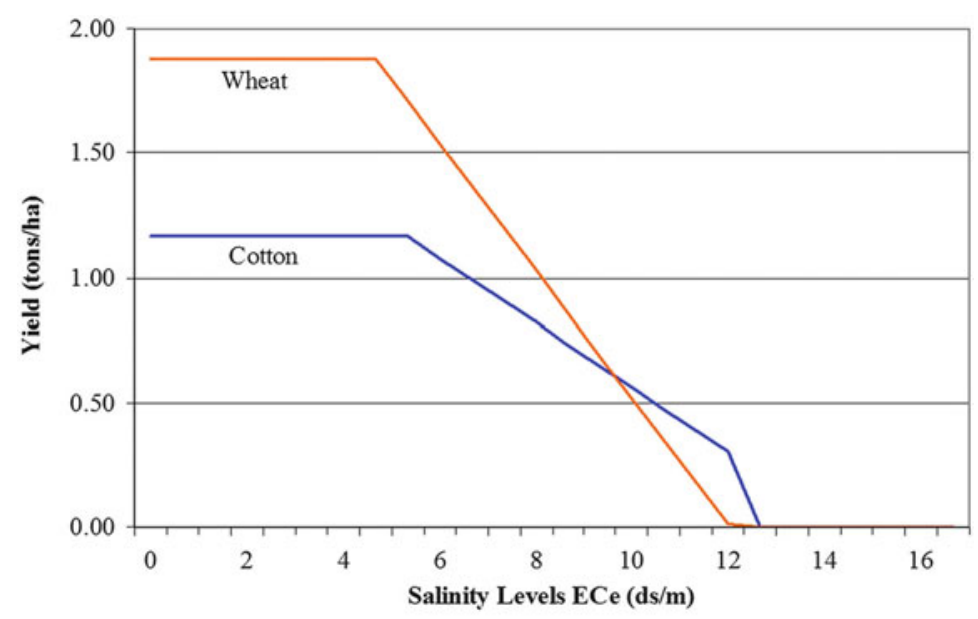

Fig. 15.12 The effect of increasing salinity levels on wheat and cotton yields in the study area

Table 15.5 Net present values (NPV) for three salinity management strategies (US \$/ha)

\begin{tabular}{l|l|l|l}
\hline Land type & $\begin{array}{l}\text { No management } \\
\text { strategy }\end{array}$ & $\begin{array}{l}\text { Engineering } \\
\text { strategy }\end{array}$ & $\begin{array}{l}\text { Agronomic } \\
\text { strategy }\end{array}$ \\
\hline $\begin{array}{l}\text { D1 Extremely degraded } \\
\text { land }\end{array}$ & -408 & 673 & 1,078 \\
\hline $\begin{array}{l}\text { D2 Moderately degraded } \\
\text { land }\end{array}$ & 57 & 1,042 & 477 \\
\hline D3 Lightly degraded land & 1,544 & 1,074 & 477 \\
\hline D4 Normal land & 3,500 & 49 & 95 \\
\hline
\end{tabular}

\subsubsection{Results of the Cost Benefit Analysis}

By considering the four land types (D1, D2, D3, and D4) this desktop study compares the Net Present Values (NPV) of the two diverse management strategies, of engineering and agronomic options, with the no intervention strategy. Table 15.5 highlights the rehabilitation strategies that maximise Net Present Values for the four land types over a period of 25 years. A discount rate of $6 \%$ was applied to all three strategies analysed.

The results of the cost benefit analyses in the study area indicate several important outcomes:

Firstly, for the extremely degraded land type D1, the agronomic strategy will result in the highest farm benefits in the next 25 years. Managing extremely degraded land type D1 with the engineering strategy ranked 2nd, and with the no management strategy ranked 3rd. Secondly, for the moderately degraded land type D2, the engineering strategy provides the best economic solution, when compared with the agronomic strategy which ranked 2nd, and the no management strategy which ranked 3rd. Thirdly, for the lightly degraded land type D3, no management is the best economic strategy. After the no management strategy, the engineering 
strategy ranked 2nd and the agronomic strategy ranked 3rd. Fourthly, for the normal land type D4, the no management strategy provided the highest benefits followed by the agronomic strategy which ranked 2 nd and the engineering strategy which ranked 3rd.

One limitation of the previous analysis, where the criteria for the rehabilitation of salt affected lands are purely economic, is that it will encourage farmers to maximise profits at the cost of soil and land degradation. For example results in Table 15.2 suggest that the No Management Strategy for Land types D3 (NPV, 1,544 \$/ha) and D4 (NPV 3,500 \$/ha) is the best economic option. This implies that both the productive Normal and Lightly Degraded Lands under irrigation should be managed according to normal practice without any additional salinity management. However, following only this economic criteria, the two land types D3 and D4 will become extremely salinized by the end of years 12 and 18 respectively, with salinity levels $\mathrm{EC}_{\mathrm{e}}$ exceeding $12 \mathrm{dS} / \mathrm{m}$ (Table 15.4 and Fig. 15.11). Thus a long term farm plan considering $\mathrm{a} \geq 50$ year scenario may encourage farmers to initially degrade the productive lands (D3 and D4) in the first 25 years and concurrently restore the degraded lands (D2 and D1) via an engineering and agronomic strategy respectively. However, in the second 25 year period, theoretically the initially productive lands (D3 and D4) which have now become degraded due to salinization, should undergo active rehabilitation via an engineering or agronomic strategy. Similarly land types D1 and D2 which were initially extremely and moderately degraded respectively and became productive after 25 years, should in the next 25 years be managed without any additional inputs.

In summary, this study serves as a decision support tool for funding agencies to undertake future investments in salinity management. The study informs two guiding principles for the salinity management policy in Pakistan: first, highly degraded lands such as D1 and D2 should be given priority for salinity rehabilitation (via an engineering and agronomic strategy respectively) over the relatively productive lands such as D3 and D4; and second a longer period of analysis of at least 50 years should be adopted for determining economic viability of salinity investment strategies. However even though a $\geq 50$ year scenario may be adopted such an approach is still limited because it only considers economic criteria and doesn't take into account broader environmental factors such as (i) climate change, and (ii) the problem of how to dispose of the salt in the long term and how to prevent this salt contaminating other areas. Such factors may adversely impact on the long-term sustainability of irrigated agriculture in the region.

\subsubsection{Case Study 2: Groundwater Salinity Changes in the Namoi Catchment}

\subsubsection{Overview}

The salinity of alluvial aquifers in the Namoi catchment, located in the north-west of Australia's Murray-Darling Basin, has changed over the last several decades. Since the mid-1980s, groundwater from some bores has become more saline, while 
in others groundwater has become fresher (Badenhop and Timms 2012). Aquifer salinization processes in the Namoi catchment area could be attributed to several processes that mobilize salt from shallow soils and aquifers. These are investigated below.

\subsubsection{Background}

The Namoi catchment covers an area of approximately $42,000 \mathrm{~km}^{2}$ and is located in northeast New South Wales in a semi-arid to arid setting with summer-dominant rainfall. In the Namoi catchment, 112,000 ha of land is irrigated to grow cotton, wheat and other crops, using a combination of surface-water and groundwater supplies depending on water availability (CSIRO 2007). Groundwater resources occur primarily in semi-confined, alluvial aquifers up to $100 \mathrm{~m}$ depth and exhibit complex hydraulic connectivity pathways (Kelly et al. 2014). Relatively low, fresh to saline, groundwater yields are achieved from multiple watertable alluvial aquifers with additional supplies from porous and fractured rock aquifers accessed on ridges above the black soil plains, and from beneath the alluvial aquifer system.

Low salinity groundwater is required for the environment, stock water and for irrigation in the Namoi Catchment, to support an industry worth at least $\$ 380$ million each year. In addition, potable drinking water supplies are sourced almost exclusively from groundwater in this semi-arid region. Continued extraction has resulted in a clear trend of falling groundwater levels, with up to $14 \mathrm{~m}$ drawdown in some areas since the beginning of the groundwater withdrawals in the 1960s, with the growth of the irrigation industry and development of groundwater management approaches in the area and response to historic and recent flooding (Kelly et al. 2013).

\subsubsection{Groundwater Salinity Changes over Time}

In the late 2000s, the Namoi Catchment Management Authority (CMA) commissioned a study to evaluate groundwater salinity changes across both the Lower and Upper Namoi catchments (Timms et al. 2009). Historic data was compiled and at-risk and representative bores across the region were re-sampled (Timms et al. 2009; Badenhop and Timms 2012). In that study, the variability of groundwater quality across the catchment and over time was augmented with new data. Standard protocols were used to test $\sim 60$ samples at 45 bores on three occasions during 2009 with a total of 189 field parameter records and 121 major ion analyses. Groundwater salinity was found to be relatively stable at most sites where sufficient historic data was available (105 monitoring pipes), although significant groundwater salinity increases occurred over the past two decades at about $20 \%$ of sites. Salinity increases were most concentrated to the east and southeast of Gunnedah (Fig. 15.13). This is an area with intensive groundwater extraction and where naturally high salt stores within three metres of the surface occur (Fig. 15.13). One of the worst cases was a bore screened at $80 \mathrm{~m}$ depth where the average EC from monitoring in 2000-2009 (8.8 dS/m) was $156 \%$ higher than the average from 1980 to 1999 (3.5 dS/m). In contrast, groundwater in other bores in the area was found to be fresh. An update to the original analysis (Badenhop and 


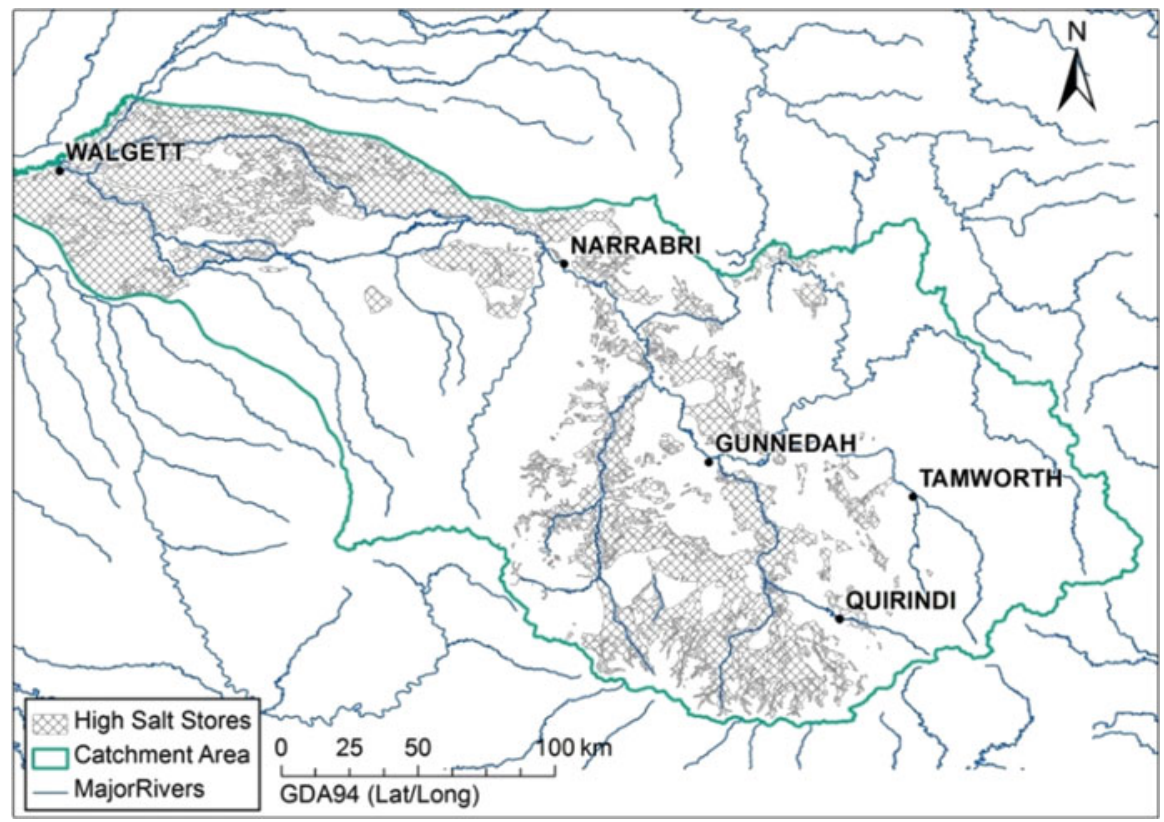

Fig. 15.13 Salt store in upper $3 \mathrm{~m}$ of soil in Namoi catchment (Namoi CMA)

Timms 2012) found that freshening had occurred at about $25 \%$ of sites that had sufficient data over the same period (Fig. 15.14). This figure shows the lack of comparative EC data in many areas, and the spatial non-uniformity in salinization and freshening.

Earlier studies of groundwater salinity changes focused on processes at research sites or were limited in scope to restricted parts of the Namoi catchment. Agriculture-induced salinity is a well-documented soil and land management issue on the adjacent Liverpool Plains, a part of the Upper Namoi catchment (e.g. RingroseVoase et al. 2003) and broad trends of aquifer salinization since the 1980s have been identified by Lavitt (1999) in the Mooki River area, to the east of Gunnedah. These are attributed to extraction of groundwater and increased downwards flux of saline water from clayey silt deposits. In areas dominated by groundwater fed irrigation, complex hydrochemical variations occur to a significant depth in the system during and after significant periods of groundwater extraction (Timms and Acworth 2002; Timms and Ackworth 2009).

The potential for mixing of fresh and saline groundwaters induced by groundwater pumping is a major concern for both the Lower and Upper Namoi catchments. Studies by McLean et al. (2011) indicate that salinity is increasing at several hotspots, due to several factors including changing hydraulic gradients, and leaching of salt-laden sediments. The beneficial use of groundwater was found to have deteriorated since monitoring began, with some bores no longer suitable for 


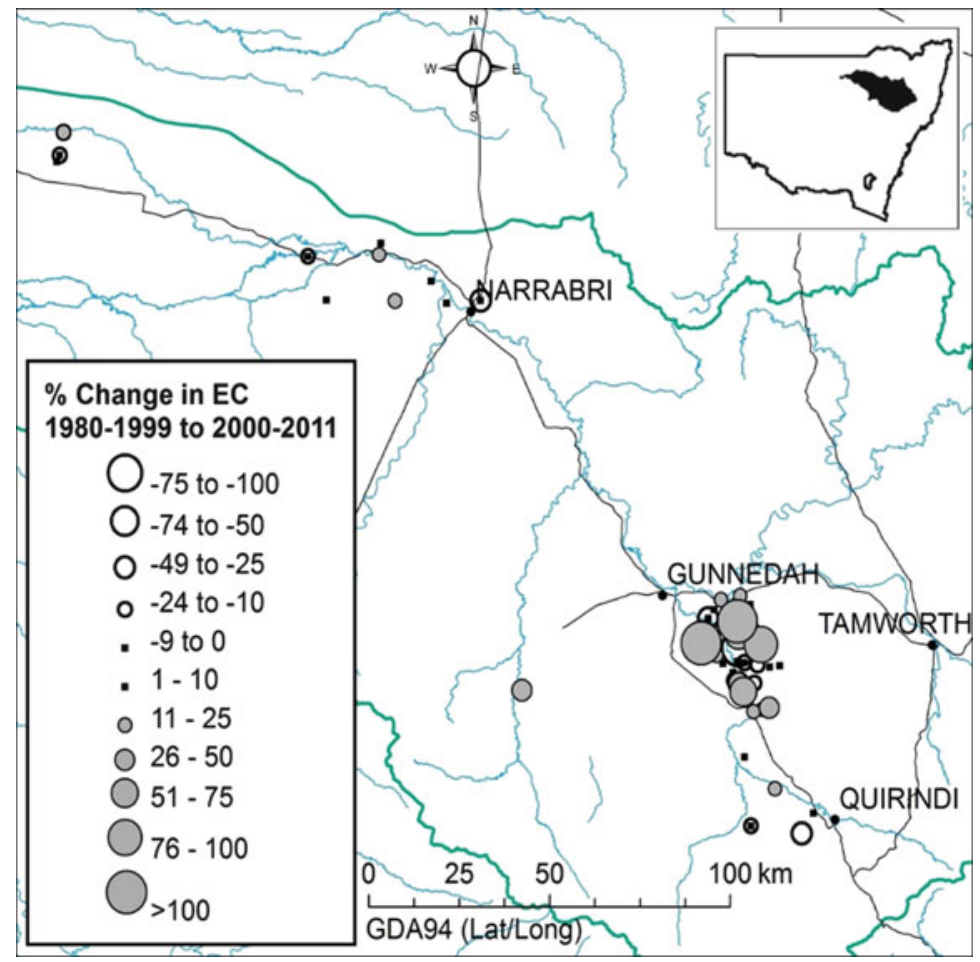

Fig. 15.14 Hot spot of groundwater salinity changes near Gunnedah showing a non-uniformity in salinization and freshening (After Badenhop and Timms 2012)

stock (generally noted in shallow bores), or no longer suitable for irrigation of some crops, including cotton (notably in the deeper bores).

Groundwater chemistry changes due to mixing induced by irrigation pumping were also observed in the Lower Namoi irrigation area by Barrett et al. (2006). The increase in salinity in this area, however, remained within the beneficial use limits for irrigation. In the western, arid parts of the Namoi, there is no irrigation to mobilize salts, but there is evidence (Timms et al. 2012) that clearing of native vegetation has caused a salt bulge in the soil to leach downwards. Total salt loads of 91-229 t/ha $\mathrm{NaCl}$ equivalent were measured for deep salt stores (from the ground surface to $10 \mathrm{~m}$ depth) for both perennial vegetation and cropping sites, despite salinity not being detected by shallow soil surveys, that are typically limited to $2-3 \mathrm{~m}$ depth. Groundwater salinity varied spatially from $0.9 \mathrm{dS} / \mathrm{m}$ to $2.4 \mathrm{dS} / \mathrm{m}$ at $21-37 \mathrm{~m}$ depth $(\mathrm{N}=5)$, whereas deeper groundwater remained less saline $(0.3 \mathrm{dS} / \mathrm{m})$.

\subsubsection{Salinization and Freshening Processes in Aquifers}

Aquifer salinization in this inland groundwater system has been attributed to several processes. Multiple processes are required to explain the isolated and patchy nature of the temporal trends across the catchment. The most significant aquifer 
salinization processes in this area thus include: (i) leaching of saline soils with increased recharge; (ii) downward and lateral flow of shallow saline groundwater into deeper fresh aquifers as hydraulic gradients are enhanced by extraction of deep fresh alluvial aquifers for irrigation, and (iii) possible leakage that occurs at some locations via aging and poorly constructed bores whereby water from shallow saline aquifers leaks into deeper fresh aquifers.

All processes suggested by Foster and Chilton (2003) (Fig. 15.4) may have affected salinization of shallow groundwater in localised areas of the Namoi catchment. However, the processes that have led to salinization of deeper alluvial aquifers used for irrigation still require further investigation. Leaching of saline soils is likely to be more significant in areas with relatively high permeability soils and where ponding occurs in areas of relatively low surface elevation (Timms et al. 2012).

Shallow, saline groundwater has long been an issue for land management in the Namoi (Abbs and Littleboy 1998; Ringrose-Voase et al. 2003) and is also a threat to salinization of deeper fresh aquifers (Badenhop and Timms 2012). Mobilization of saline groundwater that occurs in stratified sediments, either via lateral flow, or from leakage from overlying sediments with variable salt content, could account for the patchy and localised nature of the groundwater salinity trends observed (Badenhop and Timms 2012). The degree of dilution of saline groundwater by fresh groundwater within aquifers is unknown, though mixing within pore waters of the layered sedimentary alluvium may be limited. Enhanced hydraulic gradients due to groundwater pumping for irrigation influence aquifers with good hydraulic connectivity, although there can be significant time delays for changes to occur is less hydraulically connected aquifers (Kelly et al. 2013).

Due to the possible leakage from aging, or poorly constructed, bores (Fig. 15.15) causing salinization of groundwater (Santi et al. 2006), newly revised construction guidelines (NUDLC 2012) for water bores in Australia emphasise the need for appropriate annulus seals, rehabilitation and decommissioning procedures (Timms and Acworth 2009). However, there is anecdotal evidence of irrigation bores having been recently constructed in the Namoi area with gravel pack filling the annulus between the deep alluvial aquifer to the surface, potentially allowing shallow saline groundwater a conduit for leakage into deeper fresh aquifers. For example, the salinity of fresh groundwater could double from 0.2 to $0.4 \mathrm{dS} / \mathrm{m}$ by mixing with just $1.7 \%$ of saline groundwater at $12 \mathrm{dS} / \mathrm{m}$. The National Water Commission estimated that NSW has a liability to replace at risk monitoring bores at a cost in the order of $\$ 35.6$ million, mainly for $\sim 800$ monitoring bores constructed of steel casing or screen that are aging (NWC 2012). Although many of the monitoring bore casings in the Namoi are PVC rather than steel that is susceptible to failure, no account has been taken of the failure of bentonite seals in the NWC (2012) review of groundwater monitoring infrastructure.

\subsubsection{Freshening processes}

Freshening of groundwater observed by Timms et al. (2009) at some bores near the river was attributed to changes in gaining and losing stream patterns. Many 


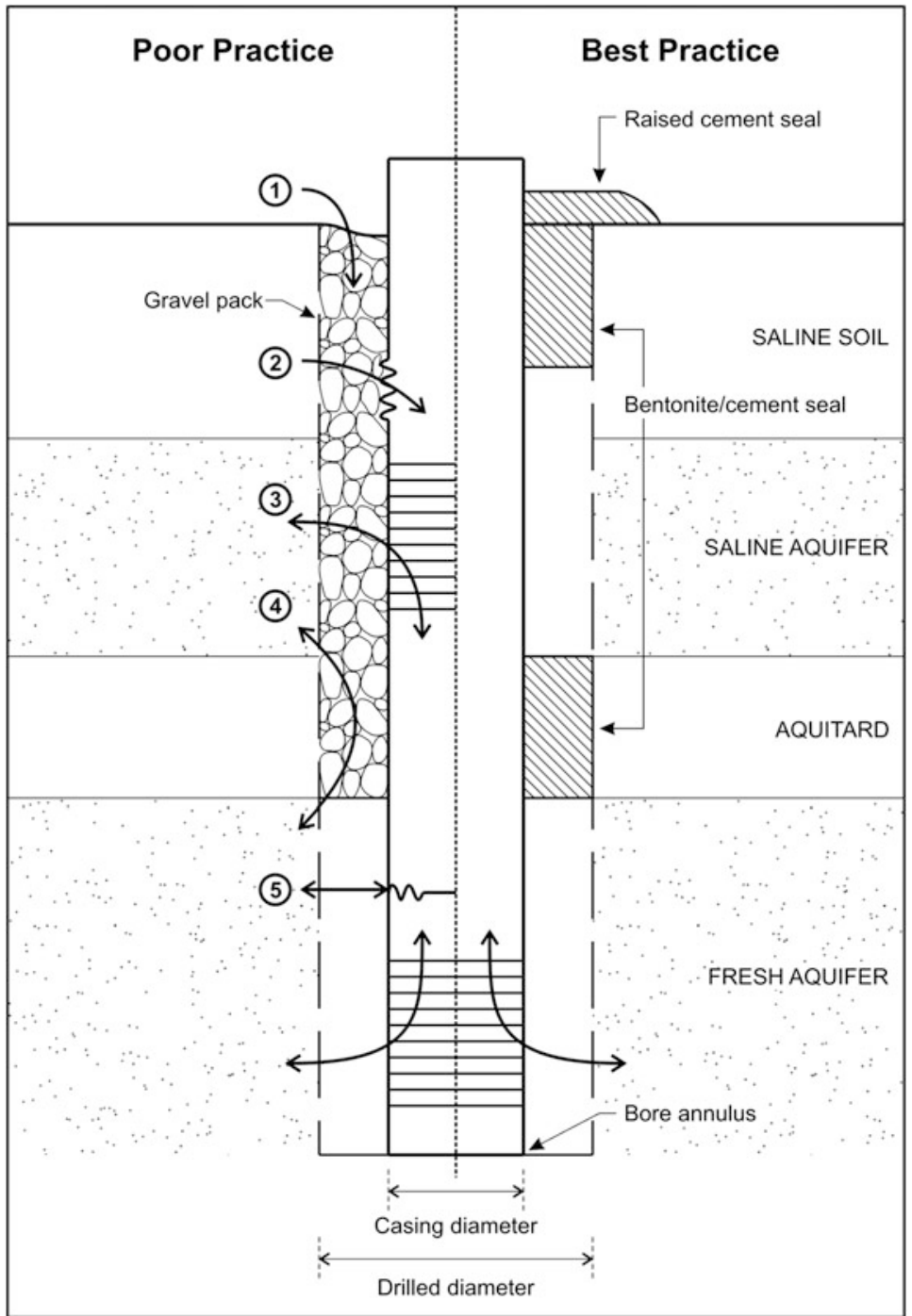

(1) Leakage from ground surface/storm runoff

(2) Leakage through corroded casing

(3) Leakage within bore with multiple or long intake screens

(4) Leakage through non-sealed annulus (eg. gravel pack)

(5) Leakage via leaky casing join

Fig. 15.15 Leakage pathways for groundwater in poorly constructed, or failed, groundwater bores (After Timms and Acworth 2009) 
locations that were once gaining streams are now losing streams due to development of the groundwater resources (CSIRO 2007; Andersen and Acworth 2009; McCallum et al. 2014). Prior to extensive development of the Lower Namoi alluvium, recharge from stream losses would have been about 9 GL/yr., whilst from 1980 to 1998 stream loss accounted for an average of $41 \mathrm{GL} / \mathrm{yr}$. This enhanced stream loss could lead to freshening of groundwater as river water is typically of lower salinity. The impacts of current levels of extraction on stream loss are yet to be fully realised (Kelly et al. 2013), and further changes in flow rates and salt fluxes will occur in the future.

\subsubsection{Beneficial Use Impact}

The NSW Groundwater Protection Policy contains the management principle that "All groundwater systems should be managed such that their most sensitive identified beneficial use (or environmental value) is maintained" (NSW DLWC 1998). Average EC for the period 2000-2005 was used by Timms et al. (2009) to assess the beneficial use across the catchment as a reference to determine if changes had occurred. The majority of waters across the Namoi Catchment were found to be suitable for drinking water, with waters only suitable for irrigation and livestock in selected areas of the Upper Namoi, and in the north-west as well as those areas furthest from the Namoi River in the Lower Namoi alluvium.

An analysis was completed by Timms et al. (2009) to determine if there had been any recent changes in beneficial use, comparing data from 2000 to 2005 to data from 2006 to 2009. Unfortunately, only 27 of 1,268 monitoring bores had sufficient data for both time periods. Of these bores, only one showed a degraded beneficial use category within the broad definitions of drinking, irrigation and poultry, and livestock (Table 15.2). However, if the resolution of beneficial use category is increased to define changes that inhibit the growth of specific crops, the findings change. While mature cotton can be irrigated with water EC up to $7.7 \mathrm{dS} / \mathrm{m}$, early season cotton tolerates only water with $\mathrm{EC}<1.5 \mathrm{dS} / \mathrm{m}$ (Fig. 15.16). A risk assessment of groundwater resources in the Namoi identified four areas where changes in salinity might occur in the future that require strategic monitoring and management strategies.

\subsubsection{Integrated Management Responses}

Management responses to groundwater quality issues include: local initiatives; regional efforts to understand and raise awareness, and state-based regulatory approaches. These approaches include policy and compliance functions consistent with Murray-Darling Basin Authority and National water reforms (Holley and Sinclair 2012 and Chap. 9).

\section{Local Level}

At a local level, the keys to efficient on-farm irrigation water management are knowing how much water in the soil profile is available to the crop and how much water the crop needs (Charlesworth 2005). This will minimise accessions of surface water and potential salt leaching into lower fresh aquifers. 


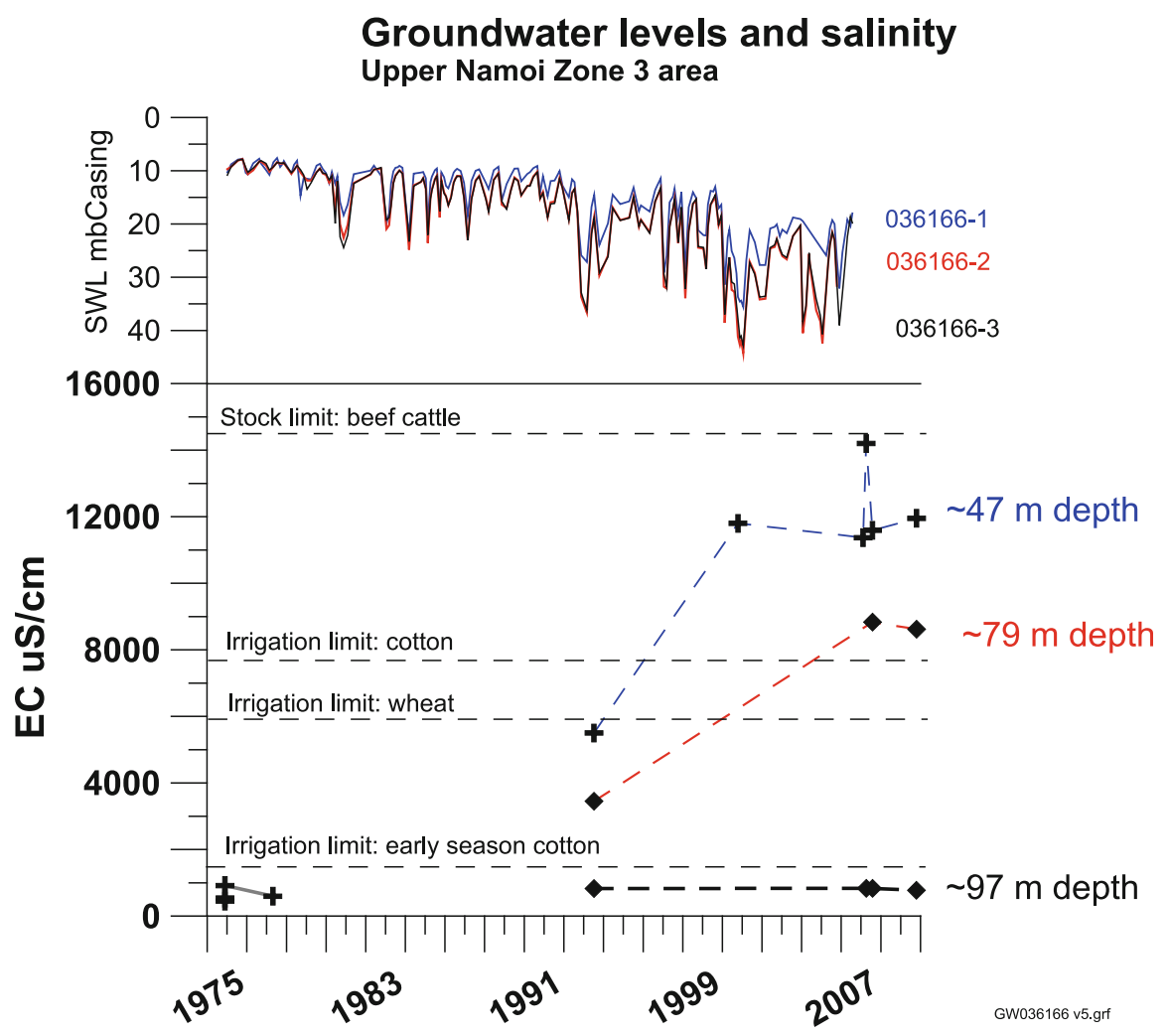

Fig. 15.16 Groundwater level and salinity changes over time compared to beneficial use guidelines at site GW036166 (After Timms et al. 2009)

Measuring and monitoring soil water status should be essential parts of an integrated management program. Irrigation managers and the irrigation service sector now have a large range of equipment available for measuring the soil water status, with favourable cost-benefits, water savings and crop yields. The Cotton industry has developed best management practices for irrigation (CRDC 2008) for irrigators, which includes a protocol for monitoring the salinity of bore water (Timms et al. 2009). Recommendations for management responses include calls for more strategic monitoring, improving data integrity and archiving, understanding of processes and numerical modelling of aquifer salinity changes that could occur in the future (Timms et al. 2009; McLean et al. 2011; Kelly et al. 2013).

Assessing and managing irrigation salinity on a farm by farm basis includes a range of possible investigations, including soil type and EM surveys, water salinity and depth to water table monitoring. Best practice irrigation requires scheduling to match plant water requirements at differing stages of the season and taking into account soil type and salinity. Excess drainage is to be avoided, or reduced, in salt prone areas, or managed with more efficient irrigation methods such as drip and spray application. 
Strategic groundwater monitoring guidelines were developed by Timms et al. (2009) with a 4 level Best Management Practice (BMP) for irrigation bores, and a 3 level guideline for sub-catchment and regional scale. For example, a level $2 \mathrm{BMP}$ for irrigation bores is to maximize crop yields by using bore water within appropriate salinity guidelines.

\section{Regional Level}

At a regional level, the existing State Government Water Sharing Plan has set a sustainable yield (also referred to as the diversion limit) of 86,000 ML per year (NSW 2008; Smithson 2009). Kelly et al. (2013) demonstrated (at the $90 \%$ confidence interval) that under this rate of withdrawal the groundwater level will continue to fall, which is to be expected given that groundwater hydrographs indicate that dynamic equilibrium has not been reached. The sustainable-yield groundwater flow modelling undertaken by CSIRO (2007) indicates that under some climatic scenarios dynamic equilibrium will not be reached within at least 100 years. Thus, the current Namoi Catchment Action Plan 2010-2020 (NCAP 2010) goal of not allowing the groundwater levels to fall cannot be achieved without reducing groundwater withdrawals, or changing the way both surfacewater and groundwater are distributed and used throughout the whole of the Namoi Catchment. Kelly et al. (2013) argue that if groundwater is allocated and managed only in the context of point of use, or in assumed isolation from surface water, sustainable access to groundwater for all existing irrigation farms will be difficult to attain while minimising the impact on groundwater-dependent ecosystems. This will only be achieved if surface-water and groundwater are managed as a single resource at the catchment scale.

\section{State Level}

The NSW State Groundwater Policy Framework (NSW DLWC 1997) highlights the need to manage the access to groundwater within the sustainable yield of a system so that the availability of the resource is sustained for all consumptive uses as well as the dependent ecological processes. Groundwater quantity, groundwater quality (NSW DLWC 1998) and groundwater dependent ecosystems are specifically addressed in the framework. Status reports are regularly prepared on the basis of monitoring in groundwater management areas and zones. Local groundwater allocations and trading rules are decided on the basis of groundwater level and quality status assessments. Emphasis is placed on addressing hotspot issues and on salinity management in areas where downwards leakage of saline water is occurring due to extraction. For example, Smithson (2009) used saturated thickness depletion limits and water level constraints to define local impact management rules in the Lower Namoi alluvium.

In 2012, the Aquifer Interference Policy (AIP) was introduced to clarify rules for groundwater licencing, with particular implications for coal bed methane and mining projects (NSW 2012). The AIP covers activities that interfere with an aquifer including penetration, obstructing flow, taking or disposing of water. The AIP also includes considerations for dewatering for infrastructure and injection of waste into 
groundwater systems for both individual and cumulative impacts. The assessment criteria are called 'minimal impact considerations' and include impacts on water table levels, water pressure levels and water quality in different types of groundwater systems.

The state Office of Water (NOW), a stand-alone regulator, has responsibility for regulation under the Water Act 1912 (NSW) which is gradually being superseded by the Water Management Act 2000 (NSW) (WMA 2000). Holley and Sinclair (2012) reviewed compliance and enforcement of water licences in NSW and deduced that over 24,000 surface and groundwater licences were covered under the WMA, accounting for $95 \%$ of all water extracted in NSW. The WMA 2000 details a range of breaches with potential application to groundwater, including taking water that is not authorised by a licence, constructing a bore without approval, not maintaining a water meter and interfering with an aquifer.

\subsection{Integration and Conclusions}

Given the increased dependence of groundwater globally to maintain societies and their economies, it is critical to combat the various types of degradation threatening groundwater supplies. This chapter has looked at the issue of groundwater salinization, one of the major forms of aquifer degradation, from a theoretical and practical view.

Assessment of the physical and chemical processes causing salinization of the rootzone and shallow aquifers identified three major types of salinity based on soil and groundwater processes: (i) groundwater associated salinity, (ii) transient salinity and (iii) irrigation induced salinity (Rengasamy 2006). These types of salinity all result in accumulation salt stores in the root zone which can have major effects on plant growth and soil processes. The salt stores can also affect groundwater supplies deeper in the landscape. Three processes were specifically recognised as causing salinization of aquifers: (i) rising groundwater tables due to inefficient surface irrigation and inadequate drainage, (ii) natural salinity mobilized from the landscape due to land clearing of native vegetation, and (iii) disturbance of natural groundwater salinity stratification by well construction and groundwater extraction (Foster and Chilton 2003).

The extent of the salinization problem, including the influence of management and policy, was explored using two case studies representative of a developing country (Pakistan) and developed country (Australia).

The Indus Valley (Pakistan) case study highlighted deep percolation from the irrigation system of canals and lack of drainage that resulted in a major imbalance in the amount of salt entering and leaving the soils and hence salt accumulation in the shallow soils. A cost benefit analysis of implementing three management strategies (no intervention, an engineering approach, and an agronomic approach) on four land categories was carried out. The four land categories ranged from extremely degraded land through to normal land and were based on the severity of waterlogging (depth of water table) and the soil salinity. The Net Present Values (NPV) of the three strategies on the four land categories were compared over a period of 25 years, using a discount rate of $6 \%$. The results indicated that some 
strategies can maintain farm profitability in the long run, provided that the right kind of treatment is given to the right type of land at the right time.

The Namoi catchment (Australia) study demonstrated that aquifer salinization occurs from salt remobilisation in the landscape, with redistribution by changing groundwater flows. The source of salt for shallow aquifers that are located inland, far from possible sea-water intrusion, includes salt naturally accumulating in the soil, or leakage from saline aquifers located overlying, adjacent to, or below freshwater aquifers. A detailed monitoring program indicated that both salinization and freshening processes occurred in aquifers at different depths. The most significant aquifer salinization processes in this area include: (i) leaching of saline soils with increased recharge; (ii) downwards and lateral flow of shallow saline groundwater into deeper fresh aquifers as hydraulic gradients are enhanced by extraction of deep fresh alluvial aquifers for irrigation, and (iii) possible leakage that occurs at some locations via aging and poorly constructed bores.

Both the case studies from the Indus Valley and the Namoi Catchment involved examples of how management strategies and policy can be integrated to reduce salinization of the root zone and aquifers respectively. Thus:

(i) The Indus Valley case study demonstrated how it is now feasible for planners to make informed decisions on the rehabilitation of salinized surface soil. Previously, investments in salinity had not provided economic returns. Therefore, despite great interest, funding agencies had little confidence in making investments for salinity management. The approach taken in this case study linked viable policy management that has economic credibility to welldocumented, and practical, salinity management.

(ii) In the Namoi case study, management responses to groundwater quality issues require both local initiatives and regional efforts to understand and raise awareness and inform state-based regulatory approaches. These approaches include policy and compliance functions consistent with Murray-Darling Basin Authority and National water reforms (Holley and Sinclair 2012).

In summary this chapter on root zone and groundwater salinization processes has indicated that as the surface root zone can be a major source of salts that lead to aquifer salinization, it is critical that both the interactions within and between these zones (i.e. root zone and aquifers) are understood if salinization of valuable groundwater supplies is to be prevented.

It is important to note that this chapter has focussed on the biophysical processes in the root zone and aquifers and their interactions that are likely to cause groundwater salinization. As demonstrated by the two case studies, management strategies to reduce salinity both in the root zone and/or in aquifers, also need to be carefully integrated with policy. Such integration needs to consider the following:

(i) Land use policies to reduce salinity need to take into account the suitability of the soil and the type of crop;

(ii) The nature of local and regional water allocation policies need to be integrated; 
(iii) Agricultural and agronomic policies that encourage groundwater use in salinity affected areas can accelerate the processes of aquifer salinization.

(iv) There is a need to understand and closely monitor catchment scale processes and their feedback on each other for sustainability of land and water resources. Related to land and aquifer salinization such catchment scale processes may include the clearing of deep rooted native vegetation for agricultural extension, over extraction of groundwater, and the use of saline and sodic water for irrigation. The feedbacks from each of these processes can accelerate land and aquifer salinization.

(v) It is important not to degrade the resources (land and water) in the first place as some processes such as soil salinization and aquifer degradation can be non-reversible.

(vi) Integrated catchment management is urgently required.

Other chapters in this book deal in more detail with the issue of how to integrate management strategies to reduce salinity with policy, e.g. Chap. 2.

Acknowledgements The assistance of Clive Hilliker with the illustrations is gratefully acknowledged.

Open Access This chapter is distributed under the terms of the Creative Commons AttributionNoncommercial 2.5 License (http://creativecommons.org/licenses/by-nc/2.5/) which permits any noncommercial use, distribution, and reproduction in any medium, provided the original author(s) and source are credited.

The images or other third party material in this chapter are included in the work's Creative Commons license, unless indicated otherwise in the credit line; if such material is not included in the work's Creative Commons license and the respective action is not permitted by statutory regulation, users will need to obtain permission from the license holder to duplicate, adapt or reproduce the material.

\section{References}

Abbs K, Littleboy M (1998) Recharge estimation for the liverpool plains. Aust J Soil Res 36:335-357

ADWG (2008) The Australian drinking water guidelines, Water quality protection note, Department of Water, Government of WA

Andersen MS, Acworth RI (2009) Stream-aquifer interactions in the Maules Creek catchment, Namoi Valley, New South Wales, Australia. Hydrogeol J 17(8):2005-2021

ANZEEC (2000) Australian and New Zealand guidelines for fresh and marine water quality, vol 1. Australian and New Zealand Environment and Conservation Council, Canberra

Arshad M (2007) Improving investment decisions for rehabilitation of salt-affected lands: a case study from the wheat-cotton zone of Pakistan. Major research essay (unpublished), Australian National University

Aslam M, Prathapar SA (2006) Strategies to mitigate secondary salinisation in the Indus basin of Pakistan: a selective review, vol 97, IWMI research report. International Water Management Institute, Colombo 
Badenhop AM, Timms WA (2012) Long-term salinity changes in an Inland Aquifer, NSW, Australia. Paper presented at the 34th hydrology \& water resources symposium, Sydney, 19-22 Nov 2012

Barrett C, Williams RM, Sinclair P (2006) Groundwater chemistry changes due to mixing - Lower Namoi Valley, New South Wales. Paper presented at the Murray Daling Basin Groundwater conference, Canberra, ACT

Blackburn G, McLeod S (1983) Salinity of atmospheric precipitation in the Murray - Darling Drainage Division, Australia. Aust J Soil Res 21:411-434

Bruvold WH, Daniels JL (1990) Standards for mineral content in drinking water. Am Waterworks Assoc J 82(2):59-65

Charlesworth P (2005) Soil water monitoring. Irrigation insights, vol 1. Land and Water Australia

CRDC (2008) WATERpak - a guide for irrigation management in cotton. Cotton Research and Development Corporation. http://www.cottoncrc.org.au/industry/Publications/Water/WATERpak/ WATERpak_Forward_Disclaimer

CSIRO (2007) Water availability in the Namoi. A report to the Australian Government from the CSIRO Murray-Darling Basin sustainable yields project, Canberra, ACT

David K, Prathapar S, Creelman B, Hanckok GR, Voller T (2003) Management of salinity issues for the closure of open cut coal mines. ACARP report $\mathrm{C} 11050$

Foster SSD, Chilton P (2003) Groundwater: the processes and global significance of aquifer degradation. Philos Trans R Soc Lond B 358:1957-1972

Greene RSB, Posner AM, Quirk JP (1973) Factors affecting the formation of quasi-crystals in montmorillonite. Soil Sci Soc Am Proc 31:457-460

Hancock GR, Wright A, De Silva H (2005) Long-term final void salinity prediction for a postmining landscape in the Hunter Valley, New South Wales, Australia. Hydrol Process 19:387-401. doi:10.1002/hyp.5538

Hillel D (2000) Salinity management for sustainable irrigation: integrating science. Environment and Economics, World Bank, IBRD, Washington, DC

Holley C, Sinclair D (2012) Compliance and enforcement of water licences in NSW: limitations in law, policy and institutions. Australas J Nat Res Law Policy 15(2):149-189

International Water Management Institute (IWMI) (2007). IWMI technical reports on salinity management in Pakistan: multiple issues, IWMI, Colombo. Available from: http://www.iwmi. cgiar.org/Publications/Pakistan_Reports/index.aspx\#. Accessed 14 Aug 2007

Kahlown MA, Azam M (2002) Individual and combined effect of waterlogging and salinity on crop yields in the Indus Basin. Irrig Drain 51:329-338

Kelly BFJ, Timms WA, Andersen SM, McCallum AM, Blakers RS, Smith R, Rau GC, Badenhop A, Ludowici K, Ackworth RI (2013) Aquifer heterogeneity and response time: the challenge for groundwater management. Crop Pasture Sci 64:1141-1154

Kelly BFJ, Timms W, Comunian A, McCallum AM, Andersen MS, Acworth RI, Baker A, Blakers RS, Ralph TJ, Giambastiani BMS (2014) A reassessment of the Lower Namoi Catchment aquifer architecture and hydraulic connectivity with reference to climate drivers. Aust J Earth Sci 61:501-511

Khan S, Kordek G (2014) Coal seam gas: produced water and solids. Prepared for the office of the NSW Chief Scientist and Engineer (OCSE). School of Civil and Environmental Engineering, University of New South Wales

Khan ZH, Mohal N, Khan AS (2006) Salinity intrusion, coastal and fluvial flood modelling. Workshop on climate change prediction modelling, Dhaka

Kijne JW (1996) Water and salinity balances for irrigated agriculture in Pakistan, vol 6, IWMI research report. Inernational Water Management Institute, Colombo

Lavitt N (1999) Integrated approach to geology, hydrogeology and hydrogeochemistry in the Lower Mooki River Catchment. Ph.D thesis, University of New South Wales

Marchuk A, Rengasamy P (2011) Clay behaviour in suspension is related to the ionicity of claycation bonds. Appl Clay Sci 53:754-759

Marchuk A, Rengasamy P (2012) Threshold electrolyte concentration and dispersive potential in relation to CROSS in dispersive soils. Soil Res 50:473-481 
Marchuk A, Rengasamy P, McNeil A (2013) Influence of organic matter, clay mineralogy and pH on the effects of CROSS on soil structure is related to the zeta potential of the dispersed clay. Soil Res 51:34-40

Martinez-Beltran J, Manzur CL (2005) Overview of salinity problems in the world and FAO strategies to address the problem. In: Proceedings of the International Salinity Forum, Riverside, pp 311-313

MCA (2012) Water accounting framework for the minerals industry. Minerals Council of Australia, Forrest, ACT

McCallum A, Andersen M, Rau GC, Larsen J, Acworth I (2014) River-aquifer interactions in a semi-arid environment investigated using point and reach measurements. Water Resour Res 50:2815-2829

McLean W, Brown S, Scarff S, Rochford L (2011) Characterisation of hydrogeochemistry and risks to groundwater quality - impact of groundwater pumping on groundwater quality. National Water Commission - Raising National Water Standards Programme, report by Parsons Brinkerhoff to NSW Office of Water

Munns R, Tester M (2008) Mechanisms of salinity tolerance. Annu Rev Plant Biol 59:651-681

NCAP (2010) Namoi Catchment Action Plan 2010-2020. Namoi Catchment Management Authority of New South Wales Government, Gunnedah, NSW

NRC (2010) Management and effects of coalbed methane produced water in the western United States. National Research Council, Washington, DC

NSW (2008) Water sharing plan for the upper and lower Namoi Groundwater Sources NSW legislation. New South Wales Government, Sydney

NSW (2012) NSW Aquifer Interference Policy (2012), Department of Primary Industries, Office of Water, Parramatta

NSW DLWC (1997) The NSW state groundwater policy framework document: NSW department of land and water conservation, Sydney

NSW DLWC (1998) Groundwater quality protection policy: NSW department of land and water conservation, Sydney

NUDLC (2012) Minimum construction guidelines for water bores. National Uniform Drillers Licensing Committee (NUDLC). http://adia.com.au/wp-content/pdf/MCR3RD2012B.pdf

NWC (2012) An assessment of groundwater management and monitoring costs in Australia. Waterlines report, Sinclair Knight Merz for the National Water Commission, Canberra

OGIA (2012) Office of groundwater impact assessment, Underground water impact report for the Surat cumulative management area. Queensland Water Commission

Pakistan Agriculture Research Council (2002) National action programme to combat desertification in Pakistan. Ministry of Environment Government of Pakistan and United Nations Environment Programme UNEP (ESCAP), Islamabad

Quirk JP, Schofield RK (1955) The effect of electrolyte concentration on soil permeability. J Soil Res 6:163-178

Rengasamy P (2006) World salinization with emphasis on Australia. J Exp Bot 57:1017-1023

Rengasamy P (2013) Salt-affected soils: sustainable agriculture. In: Jorgensen SE (ed) Encyclopedia of environmental management. Taylor and Francis, New York, pp 2349-2356

Rengasamy P, Marchuk A (2011) Cation ratio of soil structural stability (CROSS). Soil Res 49:280-285

Rengasamy P, Sumner ME (1998) Processes involved in sodic behaviour. In: Sumner ME, Naidu R (eds) Sodic soils: distribution, properties, management, and environmental consequences. Oxford University Press, New York, pp 35-50

Rengasamy P, Greene RSB, Ford GW, Mehanni AH (1984) Identification of dispersive behaviour and the management of red-brown earths. Aust J Soil Res 22:413-431

Ringrose-Voase AJ, Young RR, Paydar Z, Huth NI, Bernardi AL, Cresswell HP, Keating BA, Scott JF, Stauffacher M, Banks RG, Holland JF, Johnston RM, Green TW, Gregory LJ, Daniells I, Farquharson R, Drinkwater RJ, Heidenreich S, Donaldson S (2003) Deep drainage under different land uses in the Liverpool Plains catchment. Report 3, Agricultural resource management report series. NSW Agriculture, Tamworth, NSW 
Santi PM, McCray JE, Martens JL (2006) Investigating cross-contamination of aquifers. Hydrogeol J 14:51-68

Sarwari A, Bastiaansseni WGM, Bores M, Van Dam JC (2000) Evaluating drainage design parameters for the fourth drainage project Pakistan using SWAP model part I calibration. Irrig Drain Syst 14:257-280

Selman M, Greenhalgh S, Branosky E, Jones C, Guiling J (2009) Water quality trading programs. An International Overview, Washington, DC

Shenhua Watermark (2013) Watermark coal project environment impact statement. NSW Planning and Environment, Sydney, NSW

Shiga Y, Greene RSB, Scott KM, Stelcer E (2011) Recognising terrestrially- derived salt $(\mathrm{NaCl})$ in SE Australian dust. Aeolian Res 2:215-220

Smithson A (2009) Lower Namoi groundwater source: groundwater management area 001 groundwater status report - 2008. NSW Department of Water and Energy, Sydney

Timms WA (2001) The importance of aquitard windows in development of alluvial groundwater systems: lower Murrumbidgee, Australia. Ph.D thesis, University of New South Wales, School of Civil and Environmental Engineering, Kensington, NSW

Timms WA, Acworth RI (2002) Induced leakage due to groundwater pumping and flood irrigation at the Pullaming Agricultural Field Station, vol 208, Liverpool Plains research report. University of New South Wales Water Research Laboratory, Manly Vale, NSW

Timms WA, Ackworth RI (2009) Quantifying the potential impact of leaky boreholes. In Proceedings groundwater in the Sydney basin symposium, International Association of Hydrogeologists NSW Branch, Sydney, 4-5 Aug 2009

Timms W, Bourke S (2014) Tackling the complexities of mine dewatering. Queensland Mining and Energy Bulletin Autumn (20)

Timms WA, Badenhop A, Rayner D, Mehrabi S (2009) Namoi groundwater monitoring and evaluation. Report no. 2. Part A: results of 2009 groundwater monitoring and recommendations for future best practice monitoring framework. Part B: groundwater user survey. Technical report 2009/25. UNSW Water Research Laboratory, Manly Vale, NSW

Timms W, Young R, Huth N (2012) Implications of deep drainage through saline clay for groundwater recharge and sustainable cropping in a semi-arid catchment, Australia. Hydrol Earth Syst Sci 16:1203-1219

Turner ML, Greene RSB, Knackstedt M, Senden TJ, Sakellariou A, White I (2008) Use of gamma emission CT to study the effect of electrolyte concentration on regions of preferred flow and hydraulic conductivity in deep regolith materials. Aust J Soil Res 46:101-111

Vink S, Hoey D, Robbins S, Roux E (2013) Regulating mine water releases using water quality trading. In: Wolkersdorfer Ch, Brown A, Figueroa L (eds) Reliable mine water technology, Golden, CO. International Mine Water Association (IMWA), Wendelstein, Germany, pp 71-76

Werner AD, Bakkerk M, Post VEA, Vandenbohedec A, Lua C, Ataie-Ashtiani B, Simmons CT, Barry DA (2013) Seawater intrusion processes, investigation and management: recent advances and future challenges. Adv Water Resour 51:3-26

Williams J, Stubbs T, Milligan A (2012) An analysis of coal seam gas production and natural resource management in Australia. A report prepared for the Australian Council of Environmental Deans and Directors by John Williams Scientific Services Pty Ltd, Canberra, Australia

WMA (2000) Water Management Act. NSW Government legislation. http://www.legislation.nsw. gov.au/xref/inforce/?xref=Type\%3Dact\%20AND\%20Year\%3D2000\%20AND\%20no\%3D92\& nohits $=\mathrm{y}$

Wong VNL, Johnston SG, Burton FD, Hirst P, Sullivan LA, Bush RT, Blackford M (2015) Seawater inundation of coastal floodplain sediments: short-term changes in surface water and sediment geochemistry. Chem Geol 398:32-45

Yeboah NNN, Burns SE (2011) Geological disposal of energy-related waste KSCE. J Civ Eng 15 (4):697-705. doi:10.1007/s12205-011-0010-x 


\title{
Managed Aquifer Recharge: An Overview of Issues and Options
}

\author{
Joël Casanova, Nicolas Devau, and Marie Pettenati
}

\begin{abstract}
As covered in Chap. 2, many of the world's aquifers are rapidly being depleted. Nearly one quarter of the world's population -1.7 billion people - live in regions where more water is being consumed than nature can renew (Gleeson et al. 2012). Over-exploitation occurs when groundwater abstraction is too intensive, for example for irrigation or for direct industrial water-supply like extracting fossil fuels (Pettenati et al. 2013; Foster et al. 2013). When groundwater is continuously over-pumped, year after year, the volume withdrawn from the aquifer cannot be replaced by recharge. Eventually, the groundwater level is much lower than its initial level and even when pumping stops, the aquifer has trouble rising once again to its original level. In continental zones, overexploitation can lead to groundwater drawdown and, ultimately, to subsidence through development of sinkholes when underground caverns or channels collapse. In coastal areas, the decrease in groundwater recharge results in saltwater intrusion into the aquifer formation (Petalas and Lambrakis 2006; De Montety et al. 2008). Preserving local groundwater resources is an environmental and economic issue in coastal zones and is vital in an island context. The increasing demand for water caused by a growing population can lead to the salinization of groundwater resources if these are systematically over-exploited. Limiting the salinization of coastal aquifers is consistent with the groundwater objective of the European Union Water Framework Directive, which is to achieve a good qualitative and quantitative status by 2015 . The economic advantage of preserving these threatened water resources is that, when there is a growing demand, a local water resource is sustained and there is no need to import water. Transporting water can cost 2-10 times more than limiting the intrusion of saltwater into a coastal aquifer.
\end{abstract}

J. Casanova $(\bowtie) \cdot$ N. Devau $\bullet$ M. Pettenati

BRGM, Orléans, France

e-mail: j.casanova@brgm.fr 


\subsection{Introduction}

As covered in Chap. 2, many of the world's aquifers are rapidly being depleted. Nearly one quarter of the world's population -1.7 billion people - live in regions where more water is being consumed than nature can renew (Gleeson et al. 2012). Over-exploitation occurs when groundwater abstraction is too intensive, for example for irrigation or for direct industrial water-supply like extracting fossil fuels (Pettenati et al. 2013; Foster et al. 2013). When groundwater is continuously overpumped, year after year, the volume withdrawn from the aquifer cannot be replaced by recharge. Eventually, the groundwater level is much lower than its initial level and even when pumping stops, the aquifer has trouble rising once again to its original level. In continental zones, over-exploitation can lead to groundwater drawdown and, ultimately, to subsidence through development of sinkholes when underground caverns or channels collapse. In coastal areas, the decrease in groundwater recharge results in saltwater intrusion into the aquifer formation (Petalas and Lambrakis 2006; De Montety et al. 2008). Preserving local groundwater resources is an environmental and economic issue in coastal zones and is vital in an island context. The increasing demand for water caused by a growing population can lead to the salinization of groundwater resources if these are systematically overexploited. Limiting the salinization of coastal aquifers is consistent with the groundwater objective of the European Union Water Framework Directive, which is to achieve a good qualitative and quantitative status by 2015. The economic advantage of preserving these threatened water resources is that, when there is a growing demand, a local water resource is sustained and there is no need to import water. Transporting water can cost 2-10 times more than limiting the intrusion of saltwater into a coastal aquifer.

All over the world, the problems related to groundwater withdrawal from coastal aquifers are usually complicated because they associate the notion of quantity with that of quality (Werner et al. 2013). They are even more complex given that there is often a high demand for water in coastal areas. Population growth and the development of agriculture, industry and tourism are leading to increased groundwater abstraction, while the effects of global climate change are increasing seasonal variations. The deterioration of groundwater quality and quantity as demand increases is becoming more pronounced. In order to prevent this salinization, long-term operational management measures must be taken.

In such various contexts, technologies for Managed Recharge Aquifer (MAR) are of particular interest (see also Chap. 17). Indeed, these technologies aim to increase the available quantities of groundwater by increasing groundwater infiltration to aquifer formations. Together with rain, treated wastewater and desalinated seawater, it is one of the unconventional sources of water that is most often included in integrated water management schemes. MAR is one of the measures that can be implemented to secure water supply, compensate for some effects of climate change and, more generally, handle the quantity and quality of groundwater bodies. It is not, however, a substitute for groundwater management based on decreasing abstraction and adapting withdrawal to resource availability. 
Due to its relatively high cost (Khan et al. 2008), MAR has been practised, over the last four decades, mainly in developed countries. It is commonly carried out in the United States, and now increasingly in Europe (Levantesi et al. 2010). Large cities, especially, most often use this management method (Berlin, Paris suburbs, Lyon, Dunkirk, Geneva). In these cities, MAR is used to manage stormwater by collecting surface runoff waters in infiltration basins. However, stormwater can be one of the main sources of pollutants (heavy metals, hydrocarbons and other organic compounds) produced by cities. Consequently, traditional urban drainage systems now cause many technical and environmental problems, notably the pollution of the surface receptor media (Chocat et al. 2007). Nevertheless, some MAR technologies can also be used to limit the pollution of surface water by infiltrating some of the polluted water and monitoring the geo-purification and/or attenuation processes. Therefore, MAR can also be undertaken to protect the environment by limiting the level of pollution in sensitive receptor media. In Mediterranean countries, MAR has in some cases been taken into account in reservoir design in order to limit losses by evaporation. In coastal contexts, the MAR objective is to move from passive management of saltwater intrusion (by reducing abstraction for the drinking water supply) to dynamic management optimising pumping and natural and artificial recharge as a function of aquifer model predictions and the results of continuous, in-situ monitoring of the water table. The principal objective of MAR here is to create a hydraulic barrier to prevent the intrusion of pollutants and saltwater (Casanova et al. 2007, 2008).

Based on the large number of existing reviews already published about MAR technologies (e.g. Dillon et al. 2009a, b; Page et al. 2010; Chap. 17), the present book chapter summarizes the main managed recharge measures (types of artificial recharge systems, hydrogeological and regulatory restrictions, health and environmental risks) and makes recommendations concerning site selection, technical feasibility and monitoring methods. As an illustrative purpose of MAR technologies, there is a focus on French MAR installations.

\subsection{MAR Technologies}

\subsubsection{Infiltration Methods}

Infiltration methods are designed to facilitate the infiltration of water to the aquifer by means of infiltration basins (ponds, tanks), while improving the quality of the recharge water by natural attenuation in the aquifer's unsaturated zone. They are usually used to recharge water table aquifers or, in some cases, to create hydraulic barriers. One of the main advantages of these methods is that they are inexpensive and relatively easy to implement and maintain. The "infiltration ponds" method includes installations such as dams and small reservoirs, as well as various improvements and installations designed to manage stormwater (or runoff) and individual wastewater treatment units. This category also includes reservoir 
pavements, recharge pits, drainage trenches, vegetated ditches, mounds systems, sand filters and septic drain fields.

With all of these techniques, the water passes through the unsaturated zone before reaching the aquifer. The water can thus be potentially purified by contact with the soil, which enables the elimination not only of certain pathogenic agents but also of potentially harmful inorganic and organic substances. Infiltration ponds are often used in MAR projects, notably in places where there are frequent water shortages. Depending on which technique is being considered (infiltration ponds, percolation tanks, Soil Aquifer Treatment (SAT) Dillon 2005), basin characteristics such as the desired infiltration rate are adapted to the local objectives and can vary significantly. If the objective is quantitative, the chosen infiltration rate might be relatively high (several meters per day), whereas a lower infiltration rate (an average of $0.5 \mathrm{~m} . \mathrm{day}^{-1}$ ) would be recommended when the objective also includes the geo-purification of the infiltrating water.

The geo-purification capacity of the filtering layer is in some cases improved when plants are grown on this layer. Indeed, the presence of plants in the filtering layer protects the surface of the basin from erosion and clogging and is carriers for bacteria that act for biodegradation of some inorganic and organic pollutants. On summer, plants can improve the purification of the infiltrated water by enhancing phytoremediation.

The water temperature also has an influence on the infiltration rate. Colder water infiltrates more slowly due to an increase in viscosity. The volume of water that infiltrates below a basin can therefore decrease significantly in winter. Water that has not been greatly treated is also rich in organic matter, which fosters the development of bacteria. This might decrease the porosity, notably by the formation of biofilms.

To avoid, or rather slow down this clogging process several processes are available, depending on the application (Le Coustumer 2008). The first is to pre-treat the water that will infiltrate. Settling ponds or sand filters can be installed upstream from the infiltration basin, or the chemical properties of the recharge water can be modified by adding various chemical compounds, mostly inorganic. The second solution is to operate infiltration basins alternately, following "wetting-drying" cycles, in order to enable the decompacting and/or maintenance of the basin floor.

\subsubsection{Direct Injection Method}

Direct injection methods using injection wells are the methods most often used throughout the world. Aquifer Storage and Recovery (ASR) and Aquifer Storage Transfer and Recovery (ASTR) are installed mainly to meet two objectives: (i) to recharge confined (or semi-confined) aquifers and/or (ii) to create hydraulic barriers. The quality of the injected water must be closely monitored to prevent any contamination. They might also be preferred when space is limited because their footprint, only several tens of $\mathrm{m}^{2}$, is small compared to that of infiltration basins. Moreover, their wellhead protection zone is small. 
The principle behind ASR is the injection of water into an aquifer followed by its recovery by pumping from the same well at a later date. This method involves distinct and alternating periods of storage of excess water and of its consumption (Pyne 2006). ASR is therefore generally used for aquifers that are relatively invulnerable to non-point source pollution and in which groundwater moves slowly, i.e. confined or semi-confined aquifers. This method is used mainly for the seasonal storage of good quality water (sometimes potable), as a "pocket of fresh water" in an aquifer containing non-potable water. From a technical point of view, there are two advantages to this method. First of all, it entails alternating phases of injection and abstraction in the same well. This results in an inversion of the water circulation in the well screen and in the surrounding aquifer, thereby reducing clogging (Dillon et al. 2006; Pyne 2005, 2006). Secondly, the use of the same well for injection reduces investment costs.

As opposed to ASR, ASTR involves injection in one well and recovery by pumping from a second well located several hundred metres down-gradient from the injection well. The injected water is transferred through the aquifer before being abstracted. The specific technical characteristics of this set up require that the water in the aquifer be of relatively good quality. ASTR is therefore used mainly when the pumped water is a supply for human consumption.

\subsubsection{Filtration Methods}

Induced recharge called riverbank filtration, involves increasing the infiltration of water from a river to its alluvial aquifer by pumping in wells located near the riverbank. A string of wells are installed parallel to and near the river. Pumping in the wells lowers the water table, creating a difference in head between the river and the groundwater. This draws the surface water through the riverbank, as long as the riverbank is not clogged and/or the pumping rate is sufficient. The principal aim of this technology is to use the geo-purifying capacity of the riverbank to filter and purify the recharge water. Due to the high concentration of suspended matter in surface water, riverbanks rapidly become clogged. In order to prevent this, the infiltration rate must be relatively low and the riverbanks must be periodically maintained. Another method called dune filtration consists of infiltrating water from ponds constructed in dunes. The water is then extracted from wells or ponds at lower elevation (Dillon 2005).

\subsection{Sources of Water Used for MAR}

The first basic criterion concerning the feasibility of a MAR project is the availability of recharge water near the injection site in order to ensure a steady supply and limit potential transport costs. An aquifer can be recharged with several types of 
water. Several types of water are used for recharge: surface water from rivers, stormwater and treated wastewater.

The inventory of MAR installations still active in France showed that almost all of these use surface water, notably due to the availability of this resource. Indeed, surface water is abundant in temperate countries where rainfall adequately replaces water lost by evapotranspiration and flow to the sea. There are three other reasons for the predominant use of surface water. Firstly, the chemical and microbiological quality of this water is adequate, even when the water is not pre-treated, which enables its use for both quantitative and/or qualitative objectives. Secondly, surface water can be used with different existing MAR techniques, from infiltration or indirect injection to direct injection. Thirdly, the laws that enable the use of surface water for recharge systems already exist.

Intermittent surface water bodies can also be used, although their hydrological cycle is somewhat random and water availability depends on climate events that only occur over several days or weeks each year. It is important to note that the duration of these climate events can vary from year to year. Historically, this type of surface water has been little used for MAR due to its intermittent character. Recently, new techniques, notably for direct injection, have been developed in order to use this type of water. Most of these are new ASR techniques developed in semi-arid and arid Mediterranean climate zones.

Desalinated water made from seawater or brine is an alternative. First developed to produce drinking water, industrial water and water for agriculture, desalinated water can also be used for MAR. Initially used only in energy-rich countries like Saudi Arabia, the United Arab Emirates or Bahrain (Ahmed et al. 2001; Al-Zubari 2003; Chafidz et al. 2014), all of which produce drinking water from seawater, desalinated water is increasingly used elsewhere in the world thanks to improved desalination techniques that have decreased production costs (Shatat et al. 2013; Feitelson and Rosenthal 2012; Moatty 2001; Palomar and Losada 2010). Because of the relatively small quantities produced and their very high cost (Dabbagh 2001), desalinated water is almost never used for MAR, the aim of which is to significantly increase the volume of groundwater. However, the stability of desalinated water production might be a favourable argument for its use in some arid countries as a secondary source of recharge water for installations whose objective is quantitative. Desalination techniques confer particular chemical properties on this type of water. The principal characteristic is that it contains very little salt. When water is produced by distillation, it usually has a dissolved salt content of between 5 and $30 \mathrm{mg} . \mathrm{L}^{-1}$. Due to its low salt content, this water does not meet drinking water standards. It is therefore necessary to remineralize it until its salt content reaches ca. 300 mg. $\mathrm{L}^{-1}$.

At present, treated wastewater is used in MAR systems in many countries. Although very common in countries with limited water resources, wastewater is rarely reused in France (about 40 projects developed experimentally for irrigating crops, watering golf courses and forests or prairies) and there are no MAR installations that specifically use treated urban wastewater. It is important to point out that in France the use of wastewater for MAR is forbidden (Miquel 2003). 
The volumes of reclaimed treated wastewater are slightly higher than those of desalinated water but are still lower than those of surface water. Like that of desalinated water, the production of treated wastewater is relatively stable over time. It is, however, important to point out that the production of wastewater increases drastically during tourist seasons in holiday resorts. Therefore, treated wastewater is usually used for both recharge systems whose objective is to significantly increase the volume of groundwater and those whose objective is to improve groundwater quality.

In this context, MAR using infiltration of treated wastewater might be one of the possible solutions for recycling water to its natural medium while making it possible, for example, to recharge over-exploited aquifers, prevent saltwater intrusion into coastal aquifers, or store water without the loss by evaporation that occurs in open-air reservoirs, and make it available during periods of high demand. Treated wastewater is therefore an alternative resource that is available throughout the year and, in particular, during low water stages when the demand for conventional resources is highest, or when they are unavailable. It is of particular interest when the natural resource is scarce, notably in coastal areas and on islands. Moreover, the infiltration of treated wastewater through an unsaturated zone to recharge an aquifer benefits from the purifying capacity of the sub-surface in which naturally occurring processes enable the degradation or filtering of a certain number of the water's pollutants (Bekele et al. 2011).

Industrial water comes from factories, manufacturing plants and farms. The discharge of this water is subject to a specific study and preliminary treatment is usually required. It can contain both easily degradable organic compounds and substances that do not degrade easily such as organohalogenated compounds or heavy metals. Compared to treated urban wastewater, industrial water which contains more specific contaminants (organic molecules, trace metals and contaminants of emerging concern (CECs)) is generally not used for MAR. Indeed, most companies have their own treatment plants to treat the specific effluents of their industrial processes. This means that this water is not systematically discharged to the municipal wastewater system, thus limiting its use. However, this water can be used for MAR if there is a system to route the water to the MAR site and its chemical quality has been specifically studied.

\subsection{Hydrogeological and Regulatory Constraints}

The feasibility of an MAR system depends for the most part on local hydrogeological conditions (Dillon 2005). In the case of infiltration methods, the unsaturated zone must allow the water to infiltrate to the aquifer and the aquifer must be able to store the infiltrated water. Preference is therefore given to sites that have a rather low diffusivity, i.e. relatively low permeability and high storage capacity. These conditions can be found in aquifer formations with interstitial porosity (e.g. sandy, sandstone formations) or with both interstitial and fracture 
porosity (e.g. chalk). As concerns water quality, when choosing an MAR site, one must be sure that the quality of the recharge water is compatible with the reactive potential of the aquifer matrix and especially that of the unsaturated zone.

Current French regulations state that an MAR system is subject to prior approval in compliance with the environmental code and an impact assessment must be carried out. It must comply with French and European water laws, in particular with respect to the prevention and mitigation of discharge of pollutants to groundwater. In the specific case of MAR systems, the environmental code prohibits the use of treated wastewater in France.

Wells used to supply drinking water can be located down-gradient of the sector targeted for MAR with water whose quality is degraded. It is therefore essential that the safety for public health and the environment of the artificial recharge, induced by the addition of water to a parcel and its transport to the aquifer through the unsaturated zone, is ensured. The regulatory "wellhead protection zone" tool, described in the French public health code (Water law of the 3th January 1992, article L-1321-2) is, in most hydrogeological contexts, poorly suited to preventing pollution. Additional measures have therefore been taken in protection zones. These must now be implemented at the scale of an entire well or well-field catchment area, which is the most appropriate spatial unit for combating nonpoint source pollution (Vernoux et al. 2010). If this catchment area includes an MAR installation, the restrictions on the quality of the infiltrated water are even stricter.

\subsection{Health and Environmental Risks}

Depending on the quality and the efficiency of the treatments given to the recharge water, it can contain various amounts of pollutants such as trace metals, nutrients and microorganisms, including pathogenic microorganisms and contaminants of emerging concern (CECs) (Lapworth et al. 2012). Using different waters that have different origins and different qualities, notably treated wastewater, for MAR systems might therefore create high risks for public health. The complexity of reactive transport processes in the unsaturated zone highlights two of the main stumbling blocks that must be taken into consideration if treated wastewater is being considered for MAR: one specific challenge is to have numerical models that can include all of the hydro-biogeochemical processes involved in reactive transport, while a second, more operational, is the need to have a complete biogeochemical and hydrogeological characterisation specific to each MAR site.

\subsubsection{Trace Metals}

The problem posed by metals in recharge water concerns first of all the use of treated wastewater since the concentrations of many trace metals are very low in 
most natural waters. Several studies have shown that trace metal concentrations can vary greatly in runoff and surface water but that, except for iron and lead, they are, the most part of the time, below acceptable levels (Haeber and Waller 1987). Iron and lead present relatively few health risks. Recharge water coming from water treatment plants might also contain trace metals, the most abundant of which are iron, zinc, copper and lead. Other trace metals can also be found: manganese, aluminium, chrome, arsenic, selenium, mercury, cadmium, molybdenum, nickel, etc. They are of various origins. They come from products consumed by the population at large, from the corrosion of material in the water distribution and treatment systems, from service activities (health, automobile) and possibly from industrial effluents (Cauchi et al. 1996). Trace metals can be dissolved in recharge water from the aquifer material by modification of natural geochemical conditions. The recharge water, rich in nutrients and organic matter leads to the creation of new redox conditions in the system driven by the microbial community (Hunter et al. 1998; Kloppmann et al. 2012; Pettenati et al. 2012).

Several countries (the United States and Australia, for example) have developed guidelines for the use of treated wastewater for recharge (USEPA 2004, 2012; WHO 2006a, b). These guidelines focus mainly on the health and environmental risks that result from the presence of pathogenic microorganisms, suspended solids and dissolved organic carbon in this water. There are few recommendations concerning trace element contents in water (e.g. USEPA 2012), except as concerns five trace metals. These are: (i) arsenic, for which the drinking water limit is $10 \mu \mathrm{g} /$ L in France; (ii) nickel, which is only weakly toxic but which accumulates in plants; (iii) cadmium, which is considered to be the metallic pollutant of greatest concern due to its rapid accumulation in plants and its proven toxicity even at low concentrations (acceptable daily intake (ADI) $0.057 \mathrm{mg} /$ day/individual); (iv) mercury, which can be highly mobile; and (v) lead, the injection of which, even at low doses, can cause neurotoxic and hepatotoxic disturbances (Dillon et al. 2009a).

\subsubsection{Emerging Pollutants}

Water quality and societal wellbeing are currently threatened by emerging pollutants and pathogens including antibiotic resistant bacteria and viruses. The recharge water that is most likely to be contaminated by pharmaceutical products is treated wastewater. Indeed, there are several sources of pharmaceutical products discharged to water bodies. The excretion of pharmaceutical products by patients following their ingestion is the main source of wastewater contamination. Hospital wastewater therefore contains high levels of pharmaceutical products, essentially antibiotics. Moreover, anaesthesia products, disinfectants and diagnostic products are also present in this wastewater.

Some pharmaceutical products in their active forms, and/or their metabolites if these are also active, can be hazardous for the environment from an eco-toxicological point of view. They are then found in wastewater. When wastewater is treated, the elimination of these pharmaceutical products and/or their 
metabolites varies depending on both the nature of the drug under consideration and on the characteristics of the treatment methods used in the treatment plant (Joss et al. 2005; Yu et al. 2006). Furthermore, the elimination of pharmaceutical products does not mean their total destruction. They can degrade into products that are also active (Kümmerer et al. 1997; Zwiener et al. 2002). Several studies have identified the presence of various pharmaceutical products in treated wastewater (Steger-Hartmann et al. 1996; Kümmerer et al. 1997; Ternes et al. 1998). For example, Ternes et al. (1998) showed that the most abundant pharmaceutical products in wastewater are beta blockers, contrast media and pain relief/antiinflammatory drugs.

Like that of trace metals, the mobility of pharmaceutical products can be reduced with infiltration basins and indirect injection methods because the presence of an unsaturated zone enhances the trapping of these pollutants. In the unsaturated zone, geochemical and microbiological processes can indeed decrease the concentration of both pathogenic and non-pathogenic microorganisms and CECs by (i) biodegradation and (ii) adsorption. To a lesser extent, adsorption can also limit the mobility of organic pollutants. Pharmaceutical products can be adsorbed on several solid phases in the unsaturated zone, such as oxyhydroxides, mineralogical clays and humic substances. This adsorption of pharmaceutical products requires the creation of a chemical or electrostatic link between the functional groups present on a pharmaceutical product and the functional groups present on the solid phases in the unsaturated zone. The adsorption of these pharmaceutical products might or might not result in the release of chemical compounds to the aqueous phase.

\subsubsection{Risk Assessment}

At present, most studies have focused mainly on notions of environmental risk (Devaux 1999; Wintgens et al. 2012; Dillon et al. 2009b). These risk assessment studies consider three types of risks: (i) potential theoretical risk, (ii) potential experimental risk, and (iii) real risk.

Potential theoretical risk is related to all of the disruptions that might affect the various characteristics of the aquifer as a result of the installation of an MAR system. These include, for example, groundwater contamination by recharge water that contains pollutants (trace metals, metalloids, microorganisms, pharmaceutical products, etc.). The assessment of theoretical risk therefore requires the determination of: (i) the possible sources of contamination of the recharge water used, such as prolonged contact with minerals rich in trace metals, industrial discharge, or the presence of a nearby hospital; and (ii) the intrinsic chemical and microbiological quality of the recharge water.

Potential experimental risk corresponds to the risk that the disruptions affecting the recharged aquifers might be transferred to humans or to the environment. This experimental risk corresponds, for example, to the probability that a pollutant present in the recharge water will reach humans. In this case, the experimental 
risk will depend not only on the theoretical risk associated with the contamination of the recharge water but also to other factors such as the volumes of recharge water injected, the efficiency of pre-treatments, and the geo-purification capacity of the unsaturated zone in the case of infiltration structures (infiltration basin and indirect injection techniques).

The last type of risk that is considered by studies assessing the impacts of recharge systems is the real risk, which is the probability that one member of an exposed population will be contaminated (Devaux 1999). This risk broadens the notion of potential environmental risks by considering other factors that are specific to individuals exposed to disruptions caused by MAR such as the specific immunesystem capacity of a given individual (natural or acquired), age, sex, health, nutrition, hygiene and the diagnostic ability of health personnel (e.g. serology).

Although many risk assessment studies have made it possible to define the conceptual framework of the risks associated with MAR, the complexity of the developed markers, and the lack of knowledge concerning some of the components of these markers, means that the dangers associated with the disruptions caused by this activity are hard to quantify. For example, the water consumption of individuals, which is needed for assessing the real risk, is difficult to estimate because it can be influenced by many factors such as age or access to drinking water resources.

\subsection{Implementing MAR}

\subsubsection{Hydrogeology Study}

The feasibility of an MAR system depends largely on local hydrogeological conditions (Dillon 2005). Understanding of natural recharge, of its evolution, and therefore of the storage capacity of the sub-surface will be a fundamental criterion for decision support in the choice of an artificial recharge site. This step of feasibility needs a closely hydrogeological analysis with the help of hydrogeologic experts that can advise about the drawbacks or benefit of the future considered MAR site.

\subsubsection{Biogeochemical Processes Evaluation}

In the case of artificial recharge systems that involve infiltration techniques, geochemical and microbiological processes might occur in the unsaturated zone that enables the purification of the recharge water. Furthermore, the unsaturated zone must allow the water to infiltrate to the aquifer, the aquifer must be able to store the infiltrated water, and then release it without excessive "dissipation", which would cancel the storage effect. 
It is, however, possible to identify the main criteria that can affect the geochemical and microbiological processes that enhance the purification of the recharge water as it moves through the unsaturated zone: (i) $\mathrm{pH}$, (ii) redox potential, (iii) organic matter content, and (iv) mineralogy (Johnson et al. 1999; Rinck-Pfeiffer et al. 2000; Pettenati et al. 2012):

(i) In order to limit trace metal mobility and optimize organic contaminant degradation, it is preferable that the $\mathrm{pH}$ of recharge water interacting with the aquifer matrix and/or soil presents a range of values between 5 and 8 . In general, adsorption processes (surface complexation and ion exchange reactions) of cations such as trace metals and degradation reactions are usually weaker at extreme $\mathrm{pH}$ values. Under acidic conditions $(\mathrm{pH}<4)$, the adsorption of protons on negatively charged adsorption sites neutralises the charges of these sites, or even gives them a positive charge, which decreases the adsorption capacity of the components of the medium for cations. Under alkaline conditions $(\mathrm{pH}>8)$, cations do not remain in the form of free ions but form aqueous complexes involving anions, usually the oxyhydroxides group, that are present in the solution.

(ii) Geo-purification processes (adsorption, dissolution/precipitation, biodegradation) are strongly influenced by the redox potential. For example, a decrease in the redox potential can cause dissolution of oxide and/or hydroxide carrier phases and therefore the release of adsorbed trace metals at their surface or in their crystal matrix. Furthermore, a decrease in the redox potential modifies the aqueous speciation of trace metals, which can increase their toxicity (for example, by transforming $\mathrm{As}(\mathrm{V})$ into As(III)).

(iii) The natural attenuation processes occurring in the soil and sub-soil, particularly in the unsaturated zone, have been shown to be quite effective with respect to trace organic removal (Ternes et al. 1998). The biodegradation process is also influenced by organic matter. Organic matter is the main source of energy for microorganisms in the unsaturated zone. In order to enhance the metal adsorption reactions and microbiological reactions including the degradation of organic pollutants or the reduction of nitrates, recharge systems should be installed on sites having significant relatively-insoluble organic matter content.

(iv) Another criterion that makes it possible to evaluate the geo-purification capacities of unsaturated zones during artificial recharge is their mineralogy. Indeed, mineralogy can strongly influence the geochemical processes that control the mobility of pollutants in the unsaturated zone. Analysing the mineralogy of the unsaturated zone makes it possible to determine the concentrations of oxyhydroxides and clay minerals, which are the solid phases that have the greatest affinity for pollutants. 


\subsubsection{Particular Case of SAT: Methodology of Purification Processes Evaluation}

An initial, generic approach should, however, make it possible to roughly identify and quantify the potential biological activity (of the soil itself, or of the injected water) that will play a role in the evolution of the main mineral phases of interest as concerns: the physical and chemical characteristics of the soil (dissolution/precipitation), and on certain global reactions that must be defined (organic matter decomposition, redox reactions of $\mathrm{Fe}, \mathrm{S}, \mathrm{Mn}$, etc.) depending on the nature of the injected water and the soil (Azaroual et al. 2008, 2009; Pettenati et al. 2012).

Once the MAR site has been identified, taking into account constraints such as the availability of water, hydrogeological characteristics and regulations, five steps are usually necessary:

- a preliminary evaluation of the feasibility of a recharge system on the chosen site based on existing data or modelling

- designing the recharge system

- carrying out a detailed study of the site in order to validate or supplement the results obtained in the first step

- building a pilot or experimental system at a scale that makes it possible to carry out preliminary tests

- extrapolation to an operational scale

Since the aim of SAT is to optimise the upstream treatment of residual water and the natural geo-purification of the sub-surface, a preliminary analysis of the chosen site must be carried out since the characteristics of the recharge water and of the mineralogical assemblage making up the sub-surface are site-specific. The water quality monitoring programme recommended by Ollivier et al. (2013) include the following:

- measuring physical-chemical parameters: water saturation, water pressure, temperature, conductivity, redox potential, $\mathrm{pH}$ of the infiltration water

- sampling and analysis of the gas in the unsaturated zone

- sampling and analysis of the water in the unsaturated zone

- sampling of the soil for mineralogical and microbiological analyses

- permeability testing of the soil and sub-soil on the recharge site

\subsubsection{Cost-Benefit Study}

The costs and benefits of the different management solutions (including environmental costs and benefits) must be systematically assessed in close collaboration with hydrogeological study (Shah 2014). The concept of water foot-printing needs to be deepened, establishing practical methods and certifiable systems. Innovative concepts for water resources management need to be developed, with the aim of 
providing science-proof solutions to societal water challenges. On the basis of French feedback (Casanova et al. 2013), the feasibility of implementing MAR strongly depends on developing new approaches for water management aiming at setting up innovative alternatives suitable for decision making. These approaches should be ideally based on: (i) the broad participation of stakeholders; (ii) multidisciplinary research; and (iii) the development of scenarios to support short to long term decision making.

\subsection{Case Study of the MAR in France}

Groundwater can be found in two thirds of France which has about 200 large aquifers and 6,300 small aquifers, and at least 6 billion $\mathrm{m}^{3}$ are withdrawn every year $-59 \%$ for drinking water supply, $19 \%$ for agriculture (irrigation) and $22 \%$ for industry (not including the water used by nuclear power plants) (SOeS 2012). When there is a rainfall deficit for several successive years (e.g. between 2006 and 2011), or during periods of long summer drought particularly in the southern half of France (Giuntoli et al. 2013), groundwater levels drop significantly, in particular in aquifers that are near the surface and in the large aquifers in the Paris Basin. These critical periods are usually limited in time and space.

Water resources are a crucial element in the analysis of the impacts of climate change and the suitable responses that can be proposed (Roux 1995). Indeed, climate change directly modifies both the spatial and temporal dynamics of the water cycle. The aim of the French National Plan for Adaptation to Climate Change (PNACC) is to develop concrete and operational measures to prepare France, over the next 5 years, between 2011 and 2015, for confronting and even benefitting from new climate conditions (MEDDE 2011).

The impacts of climate change on water resources are numerous (see Chap. 5) and concern both the offer and the demand, both quantitatively and qualitatively (Armandine Les Landes et al. 2014). Climate change predictions indicate that surface runoff will decrease in almost all of France's catchment basins. In particular, the decrease in runoff will be greater in areas that are already affected by structural deficits. Therefore, one of the main challenges of the future will be how to ensure the water supply that, already in some places, is not adequate and will increase due to global warming (IPCC 2014).

The Explore 2070 project aimed to determine the impacts of climate change on aquatic environments and water resources between now and 2070 in order to anticipate the main challenges to be met and rank the risks incurred (MEDDE 2013). As concerns groundwater hydrology, this project showed that there will be an almost universal lowering of the water table in France together with a 10-25\% decrease in recharge, with two zones more severely affected - the Loire catchment basin with a 25-30\% decrease in recharge over half of its surface area, and especially the Southwest of France with decreases ranging from 30-50\%. 


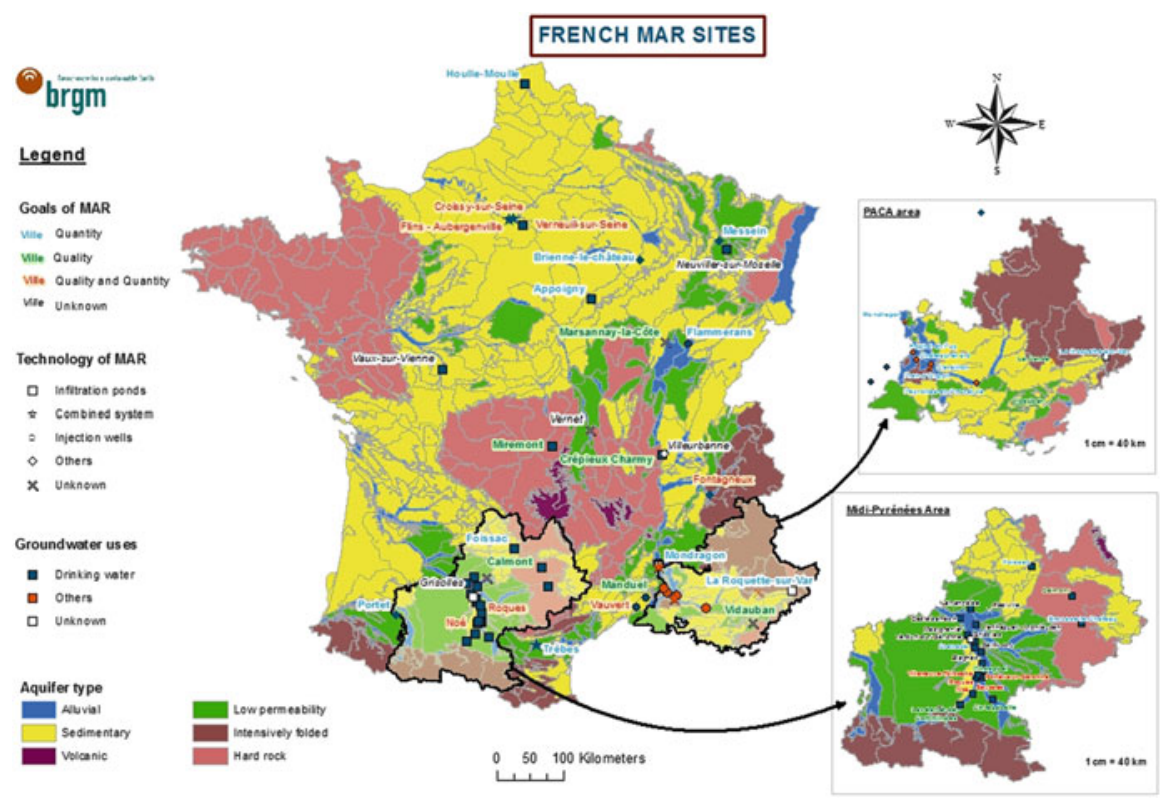

Fig. 16.1 State of MAR facilities in France

The integrated management of water resources by catchment basins must be done comprehensively, taking into account various water needs, including those of the environment. At present, it aims, within the framework of water development and management directives, to reach the objectives of the European Water Framework Directive (WFD, Directive 2000/60/EC of the European Parliament establishing a framework for Community action in the field of water policy). The anticipated impacts of climate change will affect, first of all, regions that are already encountering conflicts over water resources. It is therefore necessary to begin immediately to prevent all situations of diminishing water resources and develop strategies that promote water conservation and optimised use. MAR is one of the tools that can be used for an integrated quantitative (and/or qualitative) management of ground- and surface water resources.

A recent inventory of MAR facilities in France (Casanova et al. 2013) enabled us to identify 75 installations. The current operational status of 48 of these is known with certainty, while there is some uncertainty concerning the operational status of 8 others, and the state of 19 sites could not be determined. Two thirds of the first group are located in the Nord-Pas-de-Calais, Midi-Pyrenees and PACA regions and only about 20 of these are still active today (Fig. 16.1). Many sites have been abandoned when towns find other sources of water for their drinking water supply. In some cases, MAR was no longer needed or the quality of the recharge water no longer enabled the system to function correctly.

In most of the cases identified in France (Casanova et al. 2013), the main objective of MAR is to sustain an over-exploited groundwater aquifer. The second 
objective is to improve the quality of the groundwater by significantly decreasing the concentrations of some chemicals by dilution (e.g. nitrate, pesticides), thereby enabling the use of simpler and cheaper water treatment methods to reach drinking water standards. More precisely, in France, the objective most often sought in MAR projects is quantitative. More than half of the sites inventoried by Casanova et al. (2013) had a quantitative objective, a quarter of them had no clearly defined objective, while the others aimed at improving water quality or had an objective that was both qualitative and quantitative.

MAR is also undertaken to protect the environment by limiting the level of pollution in sensitive receptor media. In 2009, $41.4 \%$ of France's surface water bodies was assessed as having a good ecological status and $43.1 \%$ a good chemical status. In addition, $58.9 \%$ of its groundwater bodies possessed a good chemical status and $89.4 \%$ a good quantitative status (MEDDE 2012a). The quality of France's groundwater is better than that of its surface water $(60 \%$ of the groundwater bodies in France and $80 \%$ in Europe having "good" chemical status). For this reason, groundwater is often used as a source of drinking water. However, the number of French groundwater bodies that have been disqualified for drinking water supply due to nitrates and pesticides is rather large (higher than the European average, the cause of the poor status being divided equally between pesticides and nitrates) (MEDDE 2012b). In France, MAR is therefore often used to dilute pollution in groundwater bodies that are tapped for drinking water such as the MAR installation of Lavelanet-de-Commingues (Haute Garonne, France). This MAR is assigned to decrease the nitrate concentration $\left(>50 \mathrm{mg} \mathrm{l}^{-1}\right)$ of groundwater. Recharge water is abstracted from the upstream Tuchan canal and transport to the water catchment in decantation ponds previous to infiltration ponds. This system permits to maintain a nitrate concentration in the groundwater around $30 \mathrm{mg} \mathrm{l}^{-1}$ (Wuilleumier and Seguin 2003).

Conversely, in France, MAR can also be used to limit the pollution of surface water by infiltrating some of the polluted water and monitoring the geo-purification processes. MAR is used to manage stormwater in many French cities where surface runoff is collected in infiltration basins. However, stormwater is one of the main sources of pollutants (heavy metals, hydrocarbons and other organic compounds) produced by cities. In consequence, traditional urban drainage systems now cause many technical and environmental problems, notably the pollution of the surface receptor media (Chocat et al. 2007).

\subsection{Conclusions}

Recurrent water resources crises call for a better understanding of hydrological processes and improved technical and socioeconomic groundwater management. In many areas of Europe, including France, growing freshwater scarcity currently emphasizes the need to close the water cycle gap by reconciling water supply with demand both in quantity and quality terms. The demand for closed water 
systems is obvious in semiarid areas, where research institutes are currently developing new concepts and technologies. MAR is one of the strategies that can be used for quantitative and qualitative water management and adaptation to climate change in the field of water resources. The various methods used at the sites currently in activity in France and elsewhere in the world use technologies that, for the most part, have been relatively well perfected over the last 20 years.

Water resources observation and modelling are required to better understand hydrological processes and to analyse and forecast the effect of management options. This technological and environmental research must be systematically combined with a socio-economic approach investigating the questions of participation, behaviour and commitment of stakeholders. The choice of a method for artificial recharge depends on numerous factors such as the objective (quantitative and/or qualitative), the local hydrogeological context, the type and volume of recharge water available, and the chemical and microbiological characteristics of this water. Laws regulate the construction and operation of recharge systems. One criterion common to all identified artificial recharge French sites is that they have all been built using a multi-step procedure. Independently of the social, economic and environmental impact that must be taken into account, this chapter highlights the challenge that must be overcome upstream of any regulatory modifications that aim to facilitate the use of these technologies.

Because of the specific local characteristics of each MAR site (Fig. 16.2), there is no universal solution that can be recommended and any change in laws must take this into account. It seems, however, possible to break down artificial recharge installations into two groups based on the quality of recharge water. Water whose quality is similar to drinking water standards is better-suited to direct or indirect injection into the aquifer, whereas for water whose quality is degraded, preference should be given to infiltration methods that enhance additional natural treatment in the subsurface. In both cases, post-treatment, the intensity of which depends on the foreseen use of the pumped water, is necessary before distribution.

Therefore, the initial objective is often to sustain an over-exploited aquifer with other induced benefits such as improved groundwater quality with a significant decrease in the concentrations of some reactive chemicals (i.e. iron, manganese, ammonium, nitrate, organic pollutants, etc.). This enables the use of simpler and cheaper water treatment methods to reach drinking water standards. At the same time, the contamination of the infiltrated water can be reduced naturally if the procedure used to site the installation includes the identification of reactive zones and/or buffer zones and zones that are favourable to the development of microorganisms. Indeed, clay minerals, iron and manganese hydroxides, and microorganisms present in the different zones have great capacities for decontaminating (i.e. biodegradation of organic compounds, etc.) and fixing metallic pollutants and metalloids. Choosing a MAR site therefore requires that the quality of the recharge water is compatible with the soil's reactive processes, especially in the unsaturated zone. In this context, the final treatment of the water might be optimised and hence become less costly. 


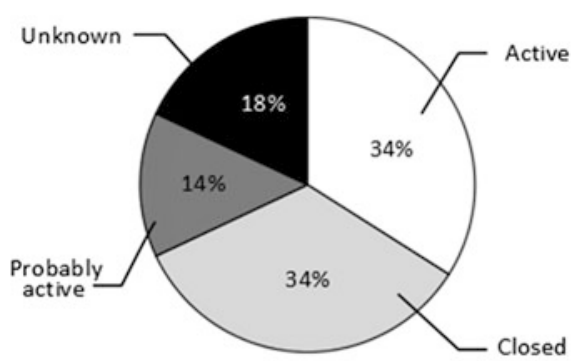

State of the french MAR sites

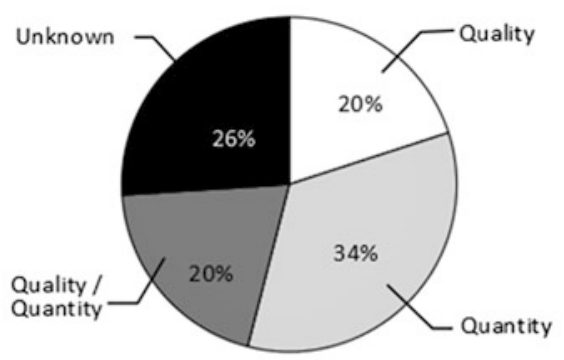

Goals of the french MAR sites

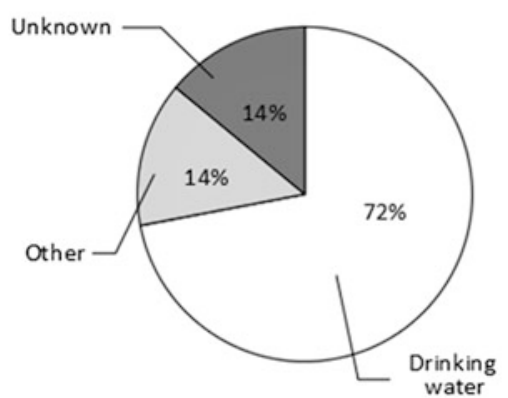

Use of groundwater in the french MAR sites

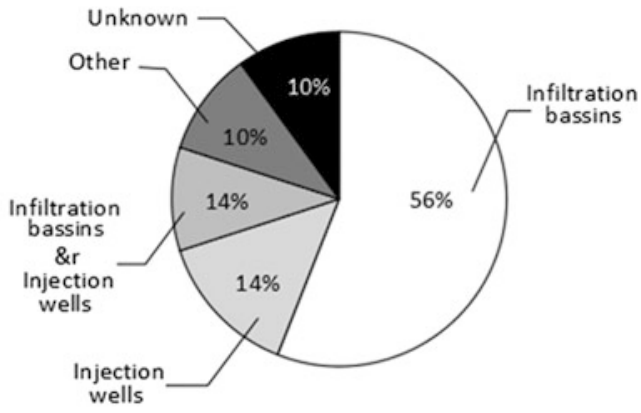

MAR tehcnologies in the french sites

Fig. 16.2 Characteristics of the French MAR sites

In order to meet WFD challenges, links between pressures and water resources have to be established through research activities aiming at elucidating specific connections between water resources, pressures and uses. The combination of observations and hydrological modelling (water bodies, overland flow, unsaturated zone, groundwater and land cover) might be targeted to ensure proper conceptualization of the involved processes. In Europe MAR implementations are being widely reapplied and developed using current technologies. However, French examples of quantified assessments of their effectiveness are limited. Improved understanding of how recharge structures actually function and the impact they have on water availability, water quality, sustainability as well as on the local and downstream environment, need to be gained and disseminated to promote cost-effective implementation.

It is generally assumed that MAR systems will be used throughout the world, including in France, due to the fact that MAR is a pragmatic and potentially 
eco-responsible response to climate change, and our need to adapt to it in a systemic approach to environmental management. Moreover, it is economically attractive for water resource management. It is however difficult to quantify the exact cost of the construction, use and profitability of these systems. Regardless of which technical solution is chosen for recharge, the costs of pre- and/or post-treatment depend strongly on the quality of the injected water. Systems that give preference to slow infiltration and an optimisation of the geo-purification capacities of the sub-surface, therefore, make it possible to minimise the costs inherent in recharge water treatment and enhance the profitability of the project.

Open Access This chapter is distributed under the terms of the Creative Commons AttributionNoncommercial 2.5 License (http://creativecommons.org/licenses/by-nc/2.5/) which permits any noncommercial use, distribution, and reproduction in any medium, provided the original author(s) and source are credited.

The images or other third party material in this chapter are included in the work's Creative Commons license, unless indicated otherwise in the credit line; if such material is not included in the work's Creative Commons license and the respective action is not permitted by statutory regulation, users will need to obtain permission from the license holder to duplicate, adapt or reproduce the material.

\section{References}

Ahmed M, Shayya WH, Hoey D, Al-Handaly J (2001) Brine disposal from reverse osmosis desalination plants in Oman and the United Arab Emirates. Desalination 133(2):135-147

Al-Zubari WK (2003) Assessing the sustainability of non-renewable brackish groundwater in feeding an RO desalination plant in Bahrain. Desalination 159(3):211-224

Armandine Les Landes A, Aquilina L, De Ridder J, Longuevergne L, Pagé C, Goderniaux P (2014) Investigating the respective impacts of groundwater exploitation and climate change on wetland extension over 150 years. J Hydrol 509:367-378

Azaroual M, Lassin A, Pettenati M, André L, Casanova J, Rampnoux N (2008) Reactive transport simulation of the pollutant transfer through the unsaturated soil zone in the framework of an aquifer artificial recharge process. In: Proceedings of "Water Down Under 2008", IBSN 0858 25735 1, Engineers Australia, Apr 2008, p 12

Azaroual M, Pettenati M, Casanova J, Rampnoux N (2009) Reactive transport modelling of pollutant transfer through the unsaturated soil zone in the framework of the artificial recharge of an aquifer under seawater intrusion constraints. In: Proceedings of "REUSE09", Brisbane, 22-25 Sept 2008, p 3

Bekele E, Toze S, Patterson B, Higginson S (2011) Managed aquifer recharge of treated wastewater: water quality changes resulting from infiltration through the vadose zone. Water Res 45 (17):5764-5772

Casanova J, Rampnoux N, Lauras P (2007) Le projet REGAL (REcharge artificielle et Gestion Active des nappes Littorales): une réponse adaptée à l'impact des changements climatiques dans le Sud de la France. Résumé in: L'impact des Changements Climatiques sur les Régions Arides et Semi Arides, 15-17 Décembre 2007, Biskra, Algérie, p 1

Casanova J, Béchu E, Bouzit M, Leroy P, Maton L, Pettenati M (2008) Appui au projet de REcharge artificielle et Gestion Active des nappes Littorales (REGAL). Rapport intermédiaire BRGM/RP - 56836 Ŕ FR, Décembre 2008, 63 pages, 20 illustrations 
Casanova J, Cagnimel M, Devau N, Pettenati M, Stollsteiner Ph (2013) Recharge artificielle des eaux souterraines: état de l'art et perspectives. Rapport final. BRGM/RP-61821-FR. p 99, 16 ill., 18 ann

Cauchi H, Nakache SD et al (1996) Dossier : la réutilisation des eaux usées après épuration. TSM 2:81-118

Chafidz A, Al-Zahrani S, Al-Otaibi MN, Hoong CF, Lai TF, Prabu M (2014) Portable and integrated solar-driven desalination system using membrane distillation for arid remote areas in Saudi Arabia. Desalination 345:36-49

Chocat B, Bertrand-Krajewski J-L, Barraud S (2007) Chapitre: Les eaux pluviales urbaines et les rejets urbains de temps de pluie. Les techniques de 1'Ingénieur. Edition T.I. Doc. W6 800 Ŕ 8-2007, p 17

Dabbagh TA (2001) The management of desalinated water. Desalination 135(1-3):7-23

De Montety V, Radakovitch O, Vallet-Coulomb C, Blavoux B, Hermitte D, Vincent Valles V (2008) Origin of groundwater salinity and hydrogeochemical processes in a confined coastal aquifer: case of the Rhône delta (Southern France). Appl Geochem 23:2337-2349

Devaux I (1999) Intérêts et limites de la mise en place d'un suivi sanitaire dans le cadre de la réutilisation agricole des eaux usées traitées de l'agglomération clermontoise. Thèse univ. Joseph Fourier, Grenoble, p 257

Dillon P (2005) Future management of aquifer recharge. Hydrogeol J 13:313-316

Dillon P, Pavelic P, Toze S, Rinck-Pfeiffer S, Martin R, Knapton A, Pidsley D (2006) Role of aquifer storage in water reuse. Desalination 188:123-134

Dillon P, Pavelic P, Page D, Beringen H, Ward J (2009a) Managed aquifer recharge: an introduction. Waterlines report series $n^{\circ} 13$, February 2009. The National Water Commission, Australian Government

Dillon P, Kumar A, Kookana R, Leijs R, Reed D, Parsons S, Ingleton G (2009b) Managed aquifer recharge: risks to groundwater dependent ecosystems. A review. Water for a healthy country flagship report to land and water, May 2009. The National Water Commission, Australian Government

Feitelson E, Rosenthal G (2012) Desalination, space and power: the ramifications of Israel's changing water geography. Geoforum 43(2):272-284

Foster S, Chilton J, Nijsten G-J, Richts A (2013) Groundwater, a global focus on the 'local resource'. Curr Opin Environ Sustain 5(6):685-695

Giuntoli I, Renard B, Vidal J-P, Bard A (2013) Low flows in France and their relationship to largescale climate indices. J Hydrol 482:105-118

Gleeson T, Wada Y, Bierkens MFP, van Beek LPH (2012) Water balance of global aquifers revealed by groundwater footprint. Nature 488:197-200

Haeber RH, Waller DH (1987) Water quality of rainwater collection systems in the Eastern Caribbean. Third international rainwater catchment systems conference proceedings. http:// www.eng.warwick.ac.uk/ircsa/

Hunter KS, Wang YF, Van Cappellen P (1998) Kinetic modeling of microbially-driven redox chemistry of subsurface environments: coupling transport, microbial metabolism and geochemistry. J Hydrol 209:53-80

IPCC (2014) Climate change 2014: synthesis report. Contribution of working groups I, II and III to the fifth assessment report of the intergovernmental panel on climate change [Core Writing Team, RK Pachauri and LA Meyer (eds)]. IPCC, Geneva, p 151

Johnson JS, Baker LA, Fox P (1999) Geochemical transformations during artificial groundwater recharge: soil-water interactions of inorganic constituents. Water Res 33:196-206

Joss A, Keller E, Alder AC et al (2005) Rermoval of pharmaceuticals and fragrances in biological wastewater treatment. Water Res 39:3139-3152

Khan S, Mushtaq S, Hanjra MA, Schaeffer J (2008) Estimating potential costs and gains from an aquifer storage and recovery program in Australia. Agric Water Manag 95(4):477-488

Kloppmann W, Aharoni A, Chikurel H, Dillon P, Gaus I, Guttman J, Kraitzer T, Kremer S, Masciopinto C, Miotlinski K, Pavelic P, Pettenati M, Picot-Colbeaux G (2012) Use of 
groundwater models for prediction and optimisation of the behaviour of MAR sites. In: Christian K, Thomas W, Peter D (eds) Water reclamation technologies for safe managed aquifer recharge. IWA Publishing, London, pp 311-349

Kümmerer K, Steger-Hartmann T, Meyer M (1997) Biodegradability of the anti-tumout agent ifosafamide and its occurrence in hospital effluents and communal sewage. Water Res $31: 2705-2710$

Lapworth DJ, Baran N, Stuart ME, Ward RS (2012) Emerging organic contaminants in groundwater: a review of sources, fate and occurrence. Environ Pollut 163:287-303

Le Coustumer (2008) Colmatage et rétention des éléments traces métalliques dans les systèmes d'infiltration des eaux pluviales. Thèse de Docteur de l'INSA de Lyon et de Monash University, p 427

Levantesi C, La Mantia R, Masciopinto C, Böckelmann U, Ayuso-Gabella M-N, Salgot M, Tandoi V, Van Houtte E, Wintgens T, Grohmann E (2010) Quantification of pathogenic microorganisms and microbial indicators in three wastewater reclamation and managed aquifer recharge facilities in Europe. Sci Total Environ 40(21):4923-4930

MEDDE (2011) Plan national d'adaptation de la France aux effets du changement climatique 2011 Ŕ 2015. Juillet 2011. www.developpement-durable.gouv.fr

MEDDE (2012a) Mise en oeuvre de la directive cadre sur l'eau : position de la France en Europe en 2009. Observation et statistiques $n^{\circ} 367$. Nov 2012, p 10. www.statistiques.developpementdurable.gouv.fr

MEDDE (2012b) Guide d'évaluation de l'état quantitatif des masses d'eau souterraine. Annexe V de la circulaire relative à l'application de l'arrêté du 17 décembre 2008 établissant les critères d'évaluation et les modalités de détermination de l'état des eaux souterraines et des tendances significatives et durables de dégradation de l'état chimique des eaux souterraines NOR : [DEVL1227826C]. Sept 2012, p 26

MEDDE (2013) Synthèse du projet Explore 2070. Hydrologie souterraine. http://www. developpement-durable.gouv.fr/Evaluation-des-strategies-d.html

Miquel G (2003) La qualité de l'eau et de l'assainissement en France. Rapport de l'Office parlementaire d'évaluation des choix scientifiques et technologiques, Sénat n²15, Assemblée Nationale $\mathrm{n}^{\circ} 705,2$ tomes

Moatty N (2001) Water management and desalination in Israel. Desalination 136(1-3):101-104

Ollivier P, Surdyk N, Azaroual M, Besnard K, Casanova J, Rampnoux N (2013) Linking water quality changes to geochemical processes occurring in a reactive soil column during treated wastewater infiltration using a large-scale pilot experiment: Insights into Mn behavior. Chem Geol 356:109-125

Page D, Dillon P, Vanderzalm J, Bekele E, Barry K, Miotlinski K, Levett K (2010) Managed aquifer recharge case study risk assessments. CSIRO water for a healthy country flagship report series, ISSN: 1835-095X

Palomar P, Losada IJ (2010) Desalination in Spain: recent developments and recommendations. Desalination 255(1-3):97-106

Petalas C, Lambrakis N (2006) Simulation of intense salinization phenomena in coastal aquifers the case of the coastal aquifers of trace. J Hydrol 324:51-64

Pettenati M, Croiset N, Casanova J, Azaroual M, Besnard K, Rampnoux N (2012) Optimisation of waste water treatments through combined geomaterials and natural soil filter: modelling tools. J Water Reuse Desalin 2(4):185-193

Pettenati M, Perrin J, Pauwels H, Ahmed S (2013) Simulating fluoride evolution in groundwater using a reactive multicomponent transient transport model: application to a crystalline aquifer of Southern India. Appl Geochem 29:102-116

Pyne D (2005) Aquifer storage recovery. A guide to groundwater recharge through wells. CRC Press, Boca Raton, p 620

Pyne RDG (2006) Aquifer storage recovery: a guide to groundwater recharge through wells, 2nd edn. Published by ASR Press, Florida 
Rinck-Pfeiffer SM, Ragusa S, Szajnbok P, Vandevelde T (2000) Interrelationships between biological, chemical and physical processes as an analog to clogging in aquifer storage and recovery (ASR) wells. Water Res 34:2110-2118

Roux J-C (1995) The evolution of groundwater quality in France: perspectives for enduring use for human consumption. Sci Total Environ 171(1-3):3-16

Shah T (2014) Towards a Managed Aquifer Recharge strategy for Gujarat, India: an economist's dialogue with hydro-geologists. J Hydrol. Available online 20 Dec 2013, ISSN 0022-1694. doi:10.1016/j.jhydrol.2013.12.022.

Shatat M, Worall M, Riffat S (2013) Opportunities for solar water desalination worldwide: review. Sustain Cities Soc 9:67-80

SOeS (2012) - Les prélèvements en eau en 2009 et leurs évolutions depuis 10 ans. Chiffres \& Statistiques $\mathrm{N}^{\circ} 290$, p 4

Steger-Hartmann T, Kümmerer K, Schecker J (1996) Trace analysis of the antineoplasics ifosfamide and cyclophosphamide in sewage water by two-step solid phase extraction and GS-MS. J Chromat A 726:179-184

Ternes TA, Stumpf M, Scuppert B et al (1998) Simultaneous determination of antiseptics and acidic drugs in sewage and river water. Wom Wasser 90:295-309

USEPA (2004) Guidelines for water reuse. U.S. Environmental Protection Agency, Report No. EPA/625/R-04/108, Cincinnati, p 445

USEPA (2012) Guidelines for water reuse. EPA/600/R-12/618. National risk management research laboratory office of research and development, U.S. Agency for International Development, Cincinnati, p 643

Vernoux JF, Buchet R, Blum A, James O (2010) Améliorer la protection des captages d'eau souterraine destinée à la consommation humaine. Editions du BRGM, p 66. ISBN 978-2-71592484-0 BRGM

Werner AD, Vincent MB, Post EA, Vandenbohede A, Lu C, Ataie-Ashtiani B, Simmons CT, Barry DA (2013) Seawater intrusion processes, investigation and management: recent advances and future challenges. Adv Water Resour 51:3-26

Wintgens T, Hochstrat R, Kazner C, Jeffrey P, Jefferson B, Melin T (2012) Managed aquifer recharge as a component of sustainable water strategies-a brief guidance for EU policies. In: Kazner C, Wintgens T, Dillon P (eds) Water reclamation technologies for safe managed aquifer recharge. IWA Publishin, London, pp 411-429. ISBN 9781843393443

World Health Organization (WHO) (2006a) Guidelines for the safe use of wastewater, Excreta and Greywater, volume 2: wastewater use in agriculture. WHO, Geneva

World Health Organization (WHO) (2006b) Guidelines for the safe use of wastewater, Excreta and Greywater, volume 4: excreta and greywater use in agriculture. WHO, Geneva

Wuilleumier A, Seguin JJ (2003) Réalimentation artificielle des aquifères en France. Une Synthèse. Rapport final BRGM/RP-55063-FR, p 119

Yu JT, Bouwer EJ, Coelhan M (2006) Occurrence and biodegradability studies of selected pharmaceuticals and personal care products in sewage effluent. Agric Water Manag 86:72-80

Zwiener C, Seeger S, Glauner T et al (2002) Metabolites from the biodegradation of pharmaceutical residues of ibuprofen in biofilm reactor and batch experiment. Anal Bioanal Chem 372:569-575 


\title{
Managed Aquifer Recharge in Integrated Water Resource Management
}

\author{
Peter Dillon and Muhammad Arshad
}

\begin{abstract}
Managed aquifer recharge (MAR) is one tool in integrated water resources management which can restore over-allocated or brackish aquifers, protect groundwater-dependent ecosystems, enhance urban and rural water supplies, reduce evaporation losses and improve water supply security. This chapter describes the ways in which MAR is used around the world and presents two Australian case studies, with a focus on economics. Aquifer storage and recovery of urban stormwater via a confined limestone aquifer is shown to provide a viable alternative to use of existing mains water or desalinated seawater for public open space irrigation. The second case study is a desk-top evaluation of the potential for recharge of harvested floodwater via infiltration basins for irrigation of cotton and faba bean crops. Based on assumptions about scale of operations, component and maintenance costs, and evaporation losses, the net benefits of infiltration basins for a range of infiltration rates were compared with those of surface water storage and of aquifer storage and recovery wells. Infiltration basins with moderate to high rates of infiltration $(>0.15 \mathrm{~m} / \mathrm{d}) \mathrm{had}$ the highest net benefits and warrant testing in a pilot program. Water treatment costs make ASR with flood waters unattractive for crop irrigation, in comparison with both basin infiltration and surface storage. Selection of the most economic method of storage depends on availability of an aquifer, soil and subsurface hydraulic characteristics, available quantity and quality of surface water, land value and end use of the water. MAR is shown to offer a range of options that
\end{abstract}

P. Dillon $(\bowtie)$

Honorary Fellow, CSIRO Land and Water, Glen Osmond, SA, Australia

e-mail: pdillon500@gmail.com

M. Arshad

Fenner School of Environment and Society, Australian National University, Canberra, ACT,

Australia

e-mail: muhammad.arshad@anu.edu.au 
warrant investigation in comparison with conventional supply alternatives to enable the most effective water resources management to be implemented.

\subsection{Introduction}

This three-part paper describes the role of managed aquifer recharge (MAR) in integrated water management, and then provides two case studies. The first is the storage of urban stormwater for later reuse to irrigate public open space in the City of Salisbury in South Australia. This has been practised in a confined brackish limestone aquifer for 20 years and the number of aquifer storage and recovery wells continues to grow. The second case study is a desktop evaluation of the potential for storing flood water in a rural catchment to allow irrigated crop production to be expanded or to achieve environmental goals by replenishing a depleted aquifer (Rawluk et al. 2013; Arshad et al. 2012). That desktop study suggested that managed aquifer recharge via infiltration basins may be viable.

\subsection{Managed Aquifer Recharge to Date}

Managed aquifer recharge is defined as the purposeful recharge of water to aquifers for subsequent recovery or for environmental benefit (Dillon et al. 2009a). MAR may be used to replenish depleted aquifers, in association with demand management strategies to bring aquifers back into hydrologic equilibrium while minimising adverse impacts on livelihoods of irrigation communities. A series of examples from India and Australia are shown in Dillon et al. (2009b) that illustrate coupling MAR with demand management to achieve groundwater supplies with aquifer storage hydrologic equilibrium. Managed aquifer recharge augments groundwater with available surface water and acts alongside conjunctive use of surface waters and groundwater to sustain water supplies and achieve groundwater and surface water management objectives such as protection of ecosystems (Fig. 17.1).

Fig. 17.1 Roles of managed aquifer recharge and conjunctive use in integrated water resources management

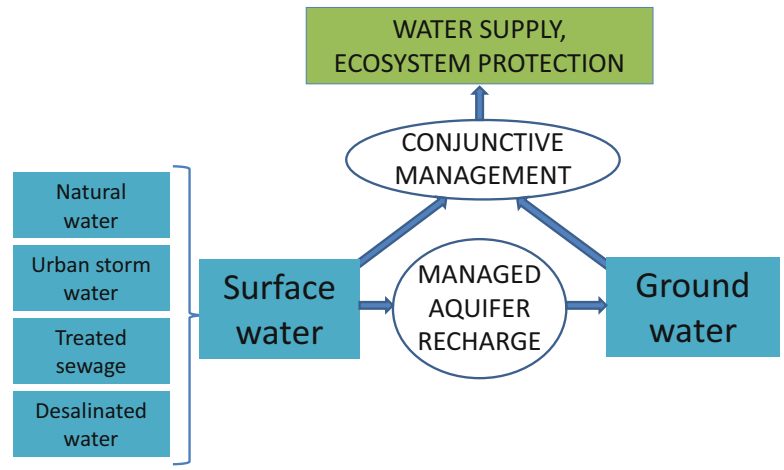


There are countless examples around the world that demonstrate the value of managed aquifer recharge. India leads the world in recharge enhancement with about $3 \mathrm{~km}^{3} /$ year, almost exclusively to unconfined aquifers through infiltration structures to help sustain groundwater supplies predominantly for agriculture and increasingly in urban areas. This volume does not keep up with groundwater storage depletion in northern India, but does help to prolong the resource and allow a window of opportunity for adaptive management. Water quality is rarely intentionally managed so it can be claimed that this recharge is not yet managed aquifer recharge. The same can be said for many parts of the world where untreated sewage and industrial effluent, stormwater or blends are allowed to infiltrate and contaminate aquifers and diminish the useable resource. If appropriately treated, this water would have supply benefits as well as environmental and health improvements.

Roof top rainwater and urban stormwater have been recharged in Australia, Germany, India, Jordan, USA and in many locations with permeable soils or karstic aquifers. There is now a progression underway from uncontrolled disposal via sumps, basins, wells and karst features to managed aquifer recharge through implementing measures to improve and protect water quality. In coastal locations in California, China, and Bangladesh replenishment of aquifers using injection wells has protected urban and irrigation supplies from salinization and in some places has been claimed to assist in mitigating against land subsidence. Treated sewage effluents have been used to augment and secure groundwater supplies in Australia, Belgium, Germany, Israel, Italy, Mexico, Namibia, South Africa, Spain, USA and elsewhere. Desalinated water is also used in UAE and USA for recharge primarily to build secure reserves of mains water. In a few locations groundwater from one aquifer is stored in another to secure supplies.

Riverbank filtration is another widespread technique to improve water quality and security of drinking water supplies. Being a low energy method for water treatment its popularity will grow as the treatment effectiveness of alluvium becomes better understood. Recharge has also been practiced for protection of groundwater dependent ecosystems (Berry and Armstrong 1997; Dillon et al. 2009c). There are many technical papers on managing aquifer recharge available from the IAH-MAR web site www.iah.org/recharge and some of these (in English and Spanish) are stored on our companion Spanish web site accessed from the same URL.

Figure 17.2 demonstrates how managed aquifer recharge can act alongside demand management and conjunctive use to bring an over-exploited aquifer back into hydrologic equilibrium. A corollary of this is that in areas where the climate is drying, causing natural recharge rate to decline and irrigation demand to increase, managed aquifer recharge may provide an adaptive strategy to help re-establish hydrologic equilibrium.

It is logical that at any location the most economic option available would be adopted first, and then the next most economic, and so on until the volume by which demand is decreased, or the volume of managed aquifer recharge or supply substitution is increased so that hydrologic equilibrium is achieved. Invariably, some strategies for increasing water use efficiency will be among the most economic options.

Figure 17.3 represents the actual sequence of options for restoring the aquifers of the Swan Coastal Plain and continuing to supply Perth's growing need for water. 


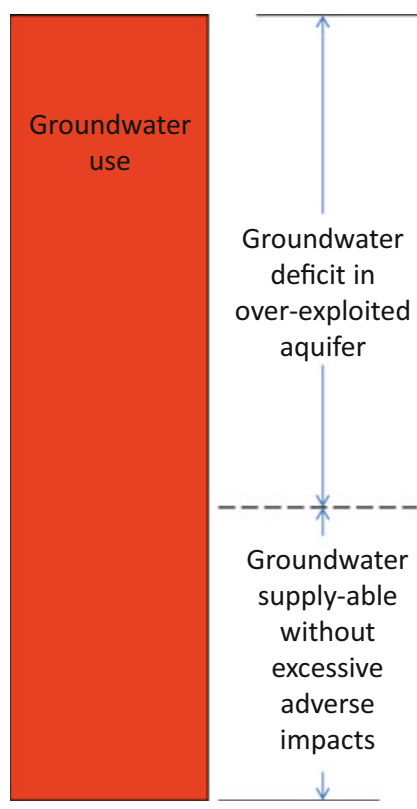

Initial situation

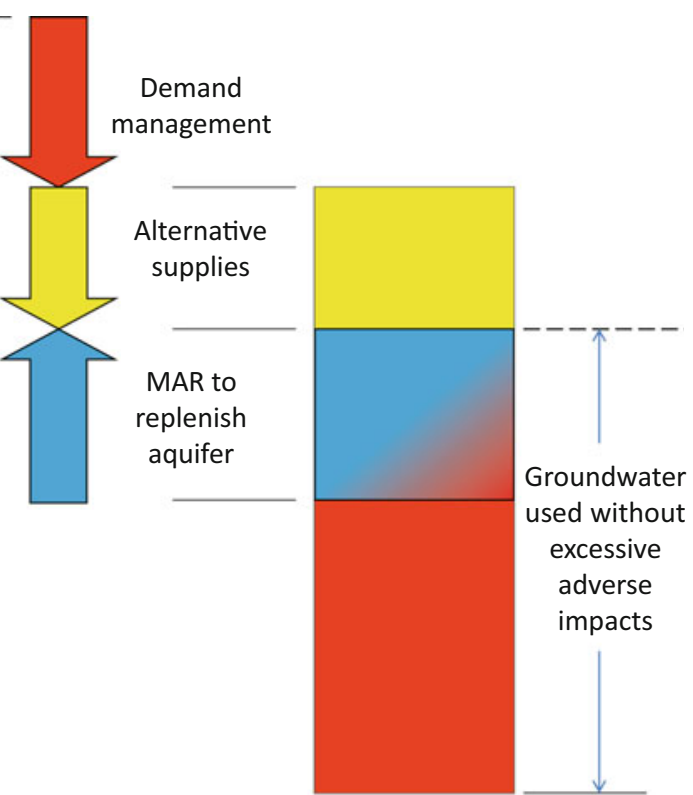

Final situation

Fig. 17.2 An aquifer can be brought into hydrologic equilibrium by either reducing extraction, or augmenting supplies, either through groundwater replenishment or providing alternative supplies (conjunctive use) (From Dillon et al. 2012)

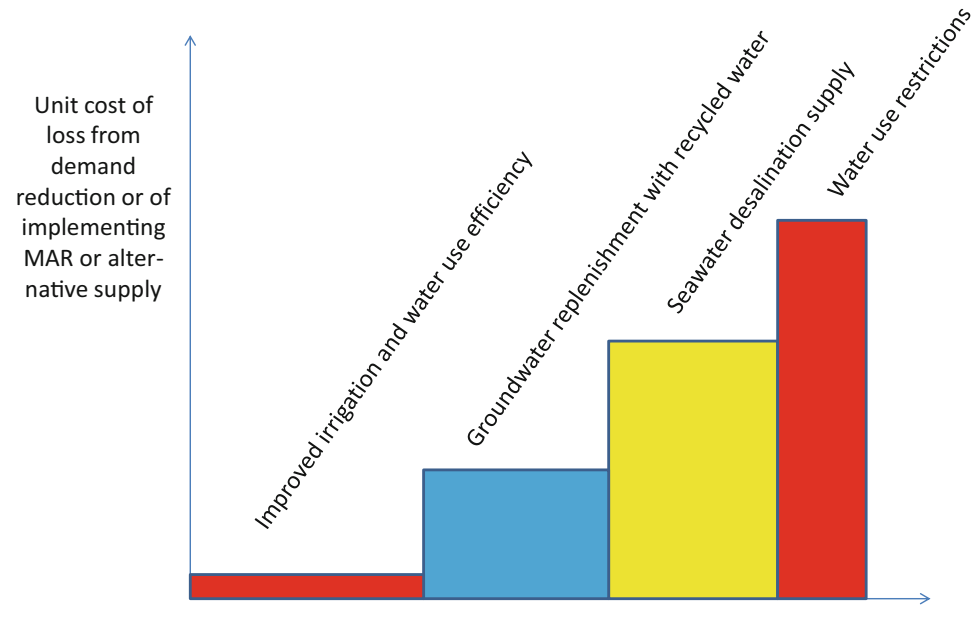

Cumulative volume saved or supplied

Fig. 17.3 A logical sequence of demand reduction (red), MAR (blue) and conjunctive use (yellow) to reign in groundwater depletion and sustain supplies (in this case for Perth, Western Australia). Options, their relative costs and volumes are location-specific. Improved irrigation efficiency is frequently the least costly option and should be implemented first (Adapted from Dillon et al. 2012) 
The Water Corporation in the state of Western Australia imposed a series of water conservation measures, such as mandatory restrictions on the hours during which parks and gardens may be irrigated to avoid high rates of evaporation, and reducing the frequency of irrigation to once or twice a week. It also encouraged water efficient household appliances such as washing machines, showers, and toilets. An extensive investigation and demonstration trial of the use of recycled water for groundwater replenishment was undertaken, and the Western Australian Minister for Water announced in 2013 that this would be the next water supply for Perth, based on safety, economic efficiency and public acceptance. The value of the research was that it showed the costs of groundwater replenishment with recycled water were approximately half those of harnessing seawater desalination, the alternative (conjunctive supply) previously regarded as the cheapest acceptable source of supply. Prior to that, onerous water restrictions were the only option, and these were regarded as politically unsustainable, and caused failures in garden supplies industries.

This framework of integrated water management is used in this chapter to explore two case studies of the potential for managed aquifer recharge, one harnessing urban stormwater in a city for public open space irrigation and industrial use. The other is a desktop study for a rural area that assesses the opportunities to harvest from large floods in order to sustain agricultural irrigation. These studies focus on the economic aspects of MAR in relation to alternatives.

\subsection{Potential for Managed Aquifer Recharge from Urban Stormwater in a Suburban Area of SA, Australia}

The driver for this case study is not the need to reduce groundwater demand. In fact the aquifer originally contained brackish groundwater and demand was negligible prior to aquifer storage and recovery (ASR) with stormwater. The purpose of recharge was to store fresh urban stormwater runoff during wet winters and recover it for irrigation in dry summers in an area with a Mediterranean climate. The costs of MAR water supplies for local councils were cheaper than the costs of purchasing mains water from the state government-owned water utility. This supply met with the approval of the State at that time as it reduced demand on drinking water supplies and hence had a positive effect on the security of those supplies in a system that had little storage capacity and was drought-prone.

The costs of producing these supplies were calculated in AUD 2008 as shown in Table 17.1, based on data from consultants and owners of eight ASR systems with capacities between 75 and 2,000 ML/year. Costs exclude value of land occupied by wetlands used for water harvesting. In all cases the proponent of the project already owned this land. In most cases a wetland was required as a detention basin to prevent increased peak flow rates during storms as a result of new urban developments. Hence the land for the wetland was considered as contributing to the flood mitigation benefit, and the remaining costs, including wetland 
Table 17.1 Mean levelised costs (in AUD 2008) for components of urban stormwater ASR projects for irrigation supplies in the size range 75-2000 ML/year (Adapted from Dillon et al. 2009a)

\begin{tabular}{l|l|l|l}
\hline Project component & $\begin{array}{l}\text { Number of sites } \\
\text { with costs }\end{array}$ & $\begin{array}{l}\text { Component cost as \% } \\
\text { of total cost }\end{array}$ & $\begin{array}{l}\text { Mean levelised } \\
\text { cost }(\mathrm{A} \$ / \mathrm{kL})\end{array}$ \\
\hline Investigations & 7 & 11 & 0.12 \\
\hline $\begin{array}{l}\text { Capital costs of water } \\
\text { harvesting }\end{array}$ & 5 & 25 & 0.28 \\
\hline $\begin{array}{l}\text { Capital costs of treatment, } \\
\text { ASR, distribution }\end{array}$ & 5 & 39 & 0.44 \\
\hline Total capital costs & 8 & 64 & 0.72 \\
\hline $\begin{array}{l}\text { Total initial costs (minus } \\
\text { land) }\end{array}$ & 7 & 74 & 0.84 \\
\hline $\begin{array}{l}\text { Operation, maintenance and } \\
\text { management }\end{array}$ & 8 & 26 & 0.28 \\
\hline $\begin{array}{l}\text { Total levelised cost (minus } \\
\text { land) }\end{array}$ & 8 & 100 & 1.12 \\
\hline
\end{tabular}

construction, were attributed to producing a water supply via ASR. Levelised cost, expressed in $\$ / \mathrm{KL}$, was calculated as annualised cost to amortise capital cost components over their expected working life added to the annual operating and maintenance expenses and divided by the annual volume of supply. In this case for eight stormwater ASR projects in South Australia, the adopted discount rate was $7 \%$ and the working life of ASR wells was assumed to be 15 years, for wetland systems 25 years, and for distribution systems 50 years. It was also assumed that only $80 \%$ of injected water could be recovered at the salinity required for its intended use.

The mean levelised cost for ASR (A \$1.12) compared favourably with independently provided figures by consultants for two seawater desalination options ranging from A $\$ 2.45$ to $3.76 / \mathrm{KL}$ levelised cost. The ASR energy intensity of $0.10 \mathrm{KWh} /$ KL compared favourably with seawater desalination and distribution of 4.2 to 5.3 KWh/KL (Dillon et al. 2009a). That is, the mean levelised cost from the sample of stormwater ASR projects was found to be between $30 \%$ and $46 \%$ of that of seawater desalination, and greenhouse gas emissions were less than $3 \%$ of seawater desalination.

Levelised costs for ASR reduced as recharge rate increased. The eight projects costed had injection rates from $\sim 10$ to $\sim 30 \mathrm{~L} / \mathrm{s}$ per well. Hence sites with higher well yields and transmissivities are preferred. For low permeability formations the levelised costs of recharge are elevated due to the capital and operating costs being amortised over smaller volumes of water and because additional water treatment may be required in order to avoid clogging of the well. An example in south-east Melbourne is reported in Dillon et al. (2010) where levelised costs of ASR exceed A $\$ 8 / \mathrm{KL}$ in a formation with a transmissivity of $\sim 1 \mathrm{~m}^{2} /$ day, sustaining an injection rate of $0.4 \mathrm{~L} / \mathrm{s}$ and requiring ultrafiltration and granular activated carbon filtration as pre-treatments to avoid clogging for recharge of 4ML/year. 
A more recent study of stormwater recharge on the Northern Adelaide Plains (Dandy et al. 2013) revealed levelised costs of A \$1.57/KL (in 2012-2013) including land value of the harvesting facility and capital and operating costs of the distribution system for public open space irrigation. The same study found that recovery for potable use of treated stormwater had a levelised cost of between $\mathrm{A} \$ 1.47$ and $\mathrm{A} \$ 2.51 / \mathrm{KL}$ depending on whether the water was pumped to an existing dam and treatment plant or was treated locally in a decentralised treatment plant. These costs include the costs of treatment and implementation of a risk-based management plan appropriate to the end use. Equivalent financial results for water recycling from treated sewage effluent via aquifers to various end uses will be available in 2015 from the Australian Water Recycling Centre of Excellence.

ASR sites with higher ambient groundwater salinity generally allow a smaller proportion of injected water to be recovered at a salinity that is acceptable for its intended use. This is exacerbated where native groundwater has sufficiently high salinity that density-affected flow occurs (Ward et al. 2009) and a freshwater injection lens forms at the top of the aquifer. This is difficult to recover without also entraining some of the saline water underneath. Recovery efficiency therefore also influences the levelised cost of ASR operations and needs to be taken into account wherever the native groundwater is not fit for the intended use of recovered water.

\subsection{Potential of Managed Aquifer Recharge from Large Floods Events in a Rural Irrigation Area of NSW, Australia}

Groundwater in the Namoi River Catchment in the Australian state of New South Wales supports an irrigation industry worth in excess of AU\$ 380 million per annum (Namoi CMA 2013). According to The Australian Cotton Grower (2012), in the wetter year of 1998/1999 about 60,000 ha of cotton were grown in the Lower Namoi, whereas in the drought year of 2003/2004 only 26,300 ha were planted due to limited surface water supplies.

In response to groundwater overdraft, State governments in Australia have reduced current groundwater irrigation entitlements in stressed aquifer systems (Smithson 2009). For the Lower Namoi Valley, a highly developed cotton irrigation district in NSW, this gradual cutback of $10 \%$ each year, translates to a reduction of 21 gigalitres (GL)/year in groundwater entitlements for irrigation by 2015 and beyond. Reduced water availability under droughts and reduction in water allocation have significant financial impact on the farming communities.

A typical Namoi valley farm holds enough water in storage (600-900 ML) for 1 year of irrigation (Powell and Scott 2011). All irrigation water is stored and routed from surface storages before application to the field, resulting in substantial evaporation losses. On average, evaporation losses from surface water storages range between 1.2 and $1.8 \mathrm{~m} /$ year (Wigginton 2011), this represents a loss of approximately $35 \%$ to $50 \%$ of the total on-farm storage capacity. 
Aquifer storage via Managed Aquifer Recharge (MAR) was investigated as a way of minimising evaporative losses and increasing farm profitability. MAR can serve the purpose of increasing groundwater storage in wet periods in order to support irrigation and environmental use of water during dry periods. The case study highlights the availability of water from high flood events that may be used for aquifer recharge and examines the financial costs and benefits of storing floodwater underground (via infiltration basins or injection wells) compared with the current method using surface storages.

Assessing the feasibility of MAR requires the integration of many types of data and information from many disciplines to assessing hydrologic, hydrogeologic, social, institutional factors and environmental risks. Carrying out a comprehensive feasibility assessment is essential; the first step in establishing an MAR scheme requires assessing the feasibility of technical and economic factors, to provide a basis for other investigations to proceed. An overview of the basic requirements and feasibility guidelines for MAR is available in Dillon et al. (2009a)

Before conducting costly technical feasibility studies through geophysical and hydrogeological investigations, a first step is to explore the potential of MAR through a desktop case study to address two questions that are of major concern to the irrigation farmers of the Lower Namoi;

I. Is a reliable source of water for aquifer storage available? and

II. Is underground storage financially better than surface storage?

Identifying water for the purpose of MAR will be challenging, particularly in the Murray-Darling Basin where irrigators must operate within existing entitlements to water and where flood waters are typically considered as environmental water. Under these arrangements only existing entitlements for consumptive use can realistically be considered as a source of water for MAR in rural catchments. Within existing entitlements for consumptive uses, Rawluk et al. (2013) discussed the potential sources of water for MAR in the Murray Darling Basin.

The potential sources for MAR water in the Lower Namoi may include;

i. Water diverted from rivers under existing entitlements to take water during high floods or periods of high streamflow, known as supplementary water.

ii. Locally captured farm run-off.

iii. Water used in coal seam gas mining could be treated (desalinated) and reused for MAR.

In many areas of Australia, including the Lower Namoi, supplementary water and local run-off is captured and stored in farm dams for stock supply and irrigation. Currently, farm dams across the Murray-Darling Basin have a combined capacity of 2,000 GL (CSIRO 2007). Craig et al. (2005) estimated that up to $40 \%(800 \mathrm{GL})$ of this storage volume can be lost each year to evaporation. Most situations in which there are opportunities for such water capture are on floodplains in the lower parts of major catchments, including the Lower Namoi. In these 
situations the alluvial sediments offer storage opportunities either through surface recharge or deep injection into alluvial aquifers, depending on local hydrogeology. MAR can provide a low or no evaporation option for storage of water under these circumstances (Ross and Arshad 2013); however some water may not be recoverable, termed as recovery losses, if native groundwater is not of a suitable quality for irrigation or if there is leakage from the aquifer to other aquifers or to surface water bodies.

The Namoi River follows an irregular flow pattern with moderate to large variability in inter-annual and inter-decadal flows. Figure 17.4 highlights floods from the river flow data (1970-2008) at the Mollee gauging station where recorded mean daily flows in months during flood events in 1964, 1971, 1974, 1976, 1984, 1998 and 2000 were between 100 and $200 \mathrm{GL} /$ day. This is a huge volume of water when compared to the long term median flow of $0.53 \mathrm{GL} / \mathrm{day}$, indicated by the horizontal bar in Fig. 17.4. Such peaks could be more frequent in future under climate change (Barron et al. 2011; Chiew et al. 2011).

From the flood frequency and magnitude data, it appears that a significant volume of water could be made available for MAR provided that environmental flows and ecological requirements are met. The Water Sharing Plan (The Plan) for the Upper Namoi and Lower Namoi Regulated River Water Sources (NSW DIPNR 2003) states the extraction rules for supplementary water entitlements held by irrigators. Under The Plan, flood water that is not already allocated is assumed to be environmental water, except that holders of the supplementary access licences can extract water during the announced supplementary periods. Such access periods are typically during floods and periods of high streamflow, when dams spill and flows are in excess of licensed obligations and environmental needs (Burrell et al. 2011).

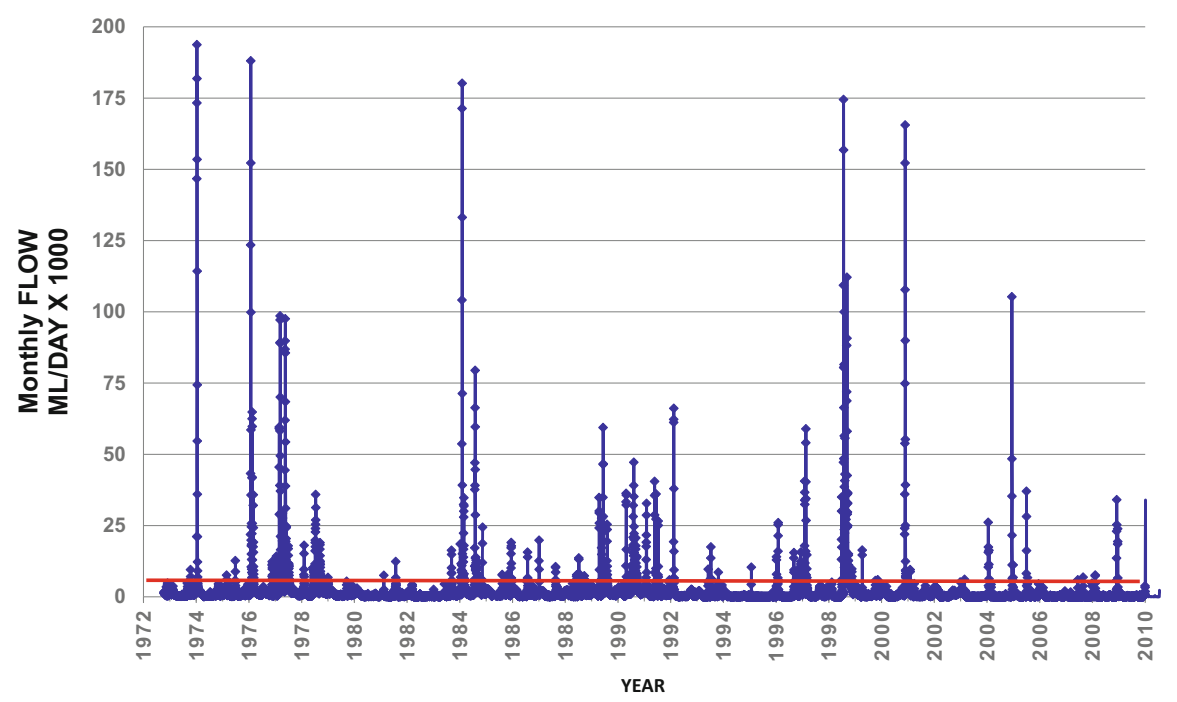

Fig. 17.4 Flood peaks in the Namoi River at Mollee (1970-2008) (Source: NSW, Office of Water 2008) 
Under The Plan the volume of water that may be taken from a supplementary access event depends on the time of year. The Plan provides all the basic rules for capture of water during each supplementary event. However, the rules defining the threshold for the announcement of a supplementary access event are complex and depend on many factors. The rules in The Plan detail the various start, stop and flow triggers for different locations and the different scenarios that apply depending on the volumes of water allocations in the regulated river. In addition, the available volume of water for extraction varies for different times of the year, that is up to $10 \%$ of the event volume between 1 July and 31 October and up to $50 \%$ during other times. A water user is only able to extract supplementary water when, amongst other things, their supplementary water account balance is in credit.

After meeting all other requirements, supplementary access is only available when the uncontrolled flows are surplus to other needs and is only permitted in accordance with announcements made by the Minister's Office of Water. Arshad et al. (2012) made a quantitative assessment of the volume of water from high flow events. This was achieved by analysing daily streamflow data (NSW, Office of Water 2008), from 1972 to 2012 at the Mollee gauging station.

In the absence of any published threshold volume that could be used to establish the start of a supplementary event, Arshad et al. (2012) adopted a threshold of $37.8 \mathrm{GL} /$ day. This threshold was based on the peak flow of the Namoi River on 1 August 2011 at Gunnedah when the river level was more than one metre higher than the river bank (Burrell et al. 2011). With this level of inundation in the floodplain it is assumed that all the basic environmental and ecological requirements are met locally and downstream.

Figure 17.5 shows the share of irrigation and environmental water for each of the supplementary water events in the Lower Namoi from 1972 to 2012. As is indicated

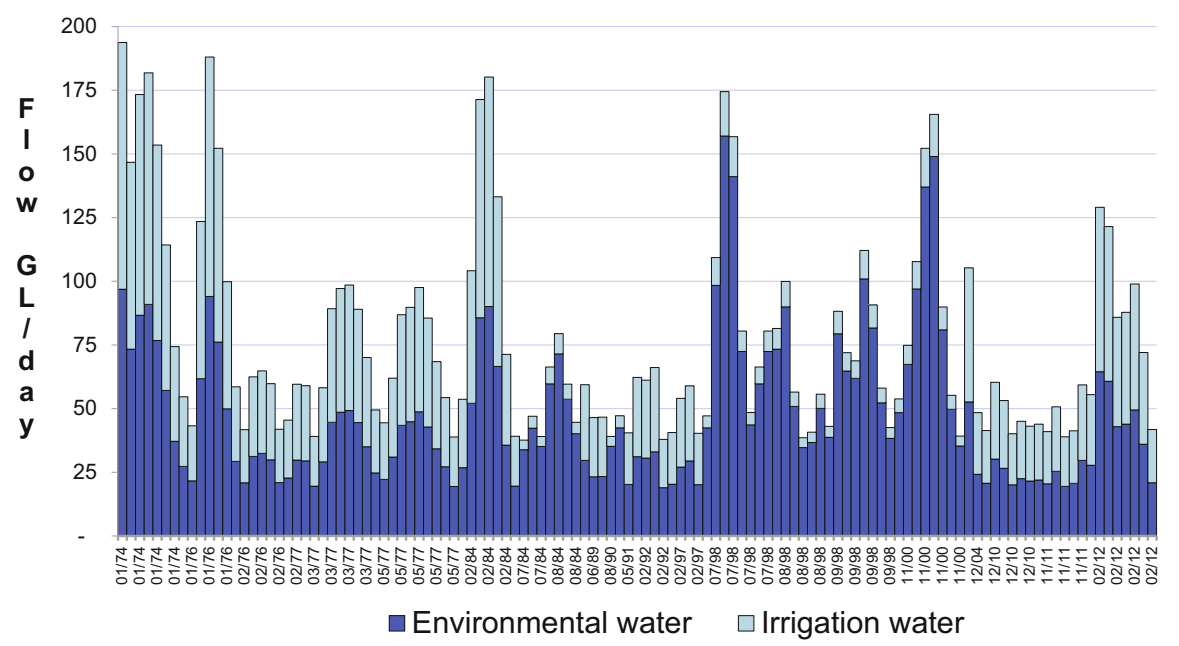

Fig. 17.5 Shares of irrigation and environmental water (1972-2012). Supplementary access set at a threshold of 37.8 GL/day, Namoi at Mollee (Data Source: NSW, Office of Water 2012) 
in Fig. 17.5, in the 40 years between 1972 and 2012, there were 120 high flow events exceeding the threshold of $37.8 \mathrm{GL} /$ day. These flows provided an average $85 \mathrm{GL}$ of water per year for irrigation that may be available for aquifer storage which is a significant amount of water.

There is sufficient space in the main aquifers in the Lower Namoi to store this volume of supplementary irrigation water. Historical groundwater extraction, supporting the irrigation industry since the 1960s, has been in excess of groundwater recharge. This has generated a huge storage space within the alluvial aquifer. The captured supplementary water could be placed in either the shallow unconfined aquifer, or the semi-confined aquifers from which the irrigation bores extract groundwater.

Periods of high streamflow and floods offer a significant opportunity for diverting river water, and storing it in the aquifers of the Lower Namoi. However, the amount of flood water is highly variable from year-to-year, ranging from $11 \mathrm{GL}$ in 1990 to 691 GL in 1977. This large variability in the volume of flood water will require temporary storages to capture, stabilise and/or treat the water before recharging it into the aquifers. Before establishing institutional mechanisms to implement MAR in Lower Namoi, a financial comparison of the costs and benefits of surface storage and underground storage using MAR would be needed.

The cost of MAR depends on number of factors such as local hydrogeology; e.g. infiltration and injection rates, cost of physical infrastructure and its maintenance, cost of acquiring source water, level of required water treatment, cost of land and cost of pumping to recover stored water. Arshad et al. (2013) carried out a costbenefit analysis of surface and aquifer storage of $600 \mathrm{ML} / \mathrm{year}$ in Lower Namoi for a typical cotton irrigation farm. The study estimated all the irrigation related costs and benefits and compared net irrigation benefits under three different water storage scenarios: surface storage in farm dams, aquifer storage using basin infiltration, and aquifer storage using aquifer storage and recovery (ASR) wells. In a typical Lower Namoi farm all the surface water allocations, including flood water, is stored in farm dams before application to the fields.

Surface storages have significant evaporation losses reported as high as 35-45\% from surface farm dams annually (Craig 2006; Craig et al. 2005). MAR can be an option to minimize evaporation losses by storing water in aquifers and recovering that water when needed. This would allow additional land to irrigate with saved water and possibly additional farm benefits. Increased costs are however incurred on establishing MAR infrastructure and its ongoing operation and maintenance. The annual irrigation water allocation from all sources for an average cotton farm in Lower Namoi is approximately 1,350 ML. However, in this analysis we only consider and report costs and benefits of $200 \mathrm{ML}$ of flood water, which is only $25 \%$ of flood water allocation and is based on recent statutory allocations of flood water (800 ML/year) in the study area.

One limitation of the study of (Arshad et al. 2013) was that it assumed average basin infiltration and ASR well injection rates that could be possible in areas with favourable hydrogeological conditions and may be uncertain at other places due to hydrogeological heterogeneity. The following section extends the analysis by 
considering a range of infiltration rates. The analysis also considers the comparative cost advantage of using an existing borehole for an ASR facility.

\subsubsection{More Detailed Costings for the Case Study}

Cost estimates of aquifer recharge are scarce and can vary considerably with location. Itemized costs for this study which are identified in subsequent paragraphs were estimated by combining current market rates of earthworks, services and materials for water infrastructure projects in Australia and were adjusted to the local situation and market rates in the Lower Namoi. Cost estimates were also compared with published data and technical reports including Khan et al. (2008), Dillon et al. (2009a) and Pyne (2010).

Capital costs of basin infiltration were estimated by assuming a range of infiltration rates $(0.1-0.3 \mathrm{~m} /$ day) and calculating the required land area to achieve $2 \mathrm{ML}$ of recharge per day. The target flood water harvested volume of $200 \mathrm{ML}$ would generally appear in four or more episodes in a flood year. The flood water is collected and temporary held in farm dams before recharge. An infiltration pond with surface area of 1 ha and infiltration rate $0.2 \mathrm{~m}$ per day would recharge $50 \mathrm{ML}$ of floodwater in a cycle of 25 days. For an infiltration rate of $0.1 \mathrm{~m} /$ day a pond with surface area of 2 ha would be required to recharge $50 \mathrm{ML}$ in the same period.

The cost of underground storage primarily depends on the hydrogeological features of the target aquifer and the choice of method considered suitable to accomplish recharge. Apart from quality of source water, infiltration and injection rates can highly influence the cost of any aquifer recharge and storage facility. Bouwer (1999) provides typical infiltration rates for surface infiltration systems in the range from 0.3 to $3 \mathrm{~m} /$ day with relatively clean and low turbidity river water. For systems that are operated year-round, long-term infiltration rates vary from 30 to $500 \mathrm{~m} /$ year, depending on soil type, water quality and climate.

ASR can potentially achieve injection rates between 0.5 and $8 \mathrm{ML} /$ day per borehole. In a modelling study Khan et al. (2008) assumed an injection rate of $8 \mathrm{ML}$ per day per borehole for an ASR facility in the alluvial aquifers of the Murrumbidgee catchment. In the absence of accurate well injection rates based on field monitoring, Pyne (2005) observed that the injection rates of ASR increase with increasing aquifer transmissivities. For the Lower Namoi Williams (1989) reported that the main aquifers which are tapped for irrigation extraction are associated with the Gunnedah and Cubbaroo Formations with transmissivities in the range of 1,000-2,000 $\mathrm{m}^{2} /$ day. The yields from bores tapping these aquifers vary up to $250 \mathrm{~L} / \mathrm{s}$ in the Gunnedah Formation at depths of $60-90 \mathrm{~m}$ and in the deep Cubbaroo Formation at depths of 80-120 m. The shallow Narrabri Formation has transmissivities less than $250 \mathrm{~m}^{2} /$ day. For this study an assumed injection rate of $25 \mathrm{~L} / \mathrm{s}$ (2.2 ML/day) is considered likely for an ASR well.

The analysis assumed $40 \%$ evaporative losses from surface storage and $5 \%$ from basin infiltration and ASR. In the base case the only cost considered is the cost of harvesting $200 \mathrm{ML}$ of flood water and the cost of annual maintenance of the farm 
dam. The capital cost of basin infiltration includes the cost of earth works and laying of pipes. Ongoing costs include operation and maintenance of water harvesting and recovery and the cost of basin de-silting. An existing bore is assumed to be available for recovery after basin infiltration or for injection and recovery in ASR. The capital cost of an ASR facility on an existing farm primarily includes setting up a coagulation and filtration pre-treatment facility, with capital cost assumed as A \$ 250/ML. Ongoing operation and maintenance costs for ASR include well flushing and cleaning, flood water harvesting, water treatment and recovery. The analysis assumed a 30 year life span for surface storage and basin infiltration and 20 years for ASR and $7 \%$ uniform discount rate for all options. All capital costs estimates are exclusive of land value.

With the additional $70 \mathrm{ML}$ of water saved from evaporation through MAR, farmers in the Namoi have a choice to irrigate additional land with cotton, faba bean or some combination of the two crops that yields the highest returns. Value brought by the flood water under each option is estimated from the useable volume of flood water, after evaporative and recovery losses, times the gross margin per megalitre of mixed cropping of cotton and faba bean on equal land area. On average, for a typical lower Namoi irrigation farm average gross margins for cotton and faba bean are estimated as $\$ 310$ and $\$ 435$ respectively, averaging $\$ 342.3 / \mathrm{ML}$ of irrigation water. Details of farm benefits are available in Powell and Scott (2011) and their estimation is in Arshad et al. (2013). Table 17.2 summarises the costs and value addition of $200 \mathrm{ML}$ of flood water with each water storage option in A $\$ / M L$.

The cost and value addition of basin infiltration depends highly on the infiltration rates; as the infiltration rates increase the capital costs decrease and value of saved water increases. Basin infiltration at an infiltration rate of $0.10 \mathrm{~m} /$ day proves to be uneconomical with $15 \%$ less benefits than surface storage. With infiltration rates of $0.15 \mathrm{~m} /$ day basin infiltration is marginally profitable, while with infiltration rates of $0.2 \mathrm{~m} /$ day and above basin infiltration becomes economically viable. The breakeven point, where the added value of basin infiltration exceeds the additional costs occurs at an infiltration rate of $0.14 \mathrm{~m} /$ day.

In the Lower Namoi, areas with floodwater infiltration rates of $0.2 \mathrm{~m} /$ day and above can potentially benefit from aquifer storage of floodwater using basin infiltration. Basin infiltration systems could be piloted in areas where river-aquifer connectivity exists, particularly in zones where the river system is losing to the aquifer. Basin infiltration systems could be feasible to recharge unconfined shallow aquifers. A high cost of treatment of relatively turbid floodwaters was conservatively assumed for ASR, although testing is warranted to determine the level of treatment required for sustainable operation. Under the current assumptions even using existing wells, ASR appears to uneconomical due to the high cost of water treatment.

In the Lower Namoi, the opportunity for aquifer storage can be advantageous for two reasons: (a) under existing rules, large quantities of floodwater are available to harvest in wet periods and can be stored underground; (b) the existing on-farm storage dams avoid the need for building temporary storage of floodwater before 


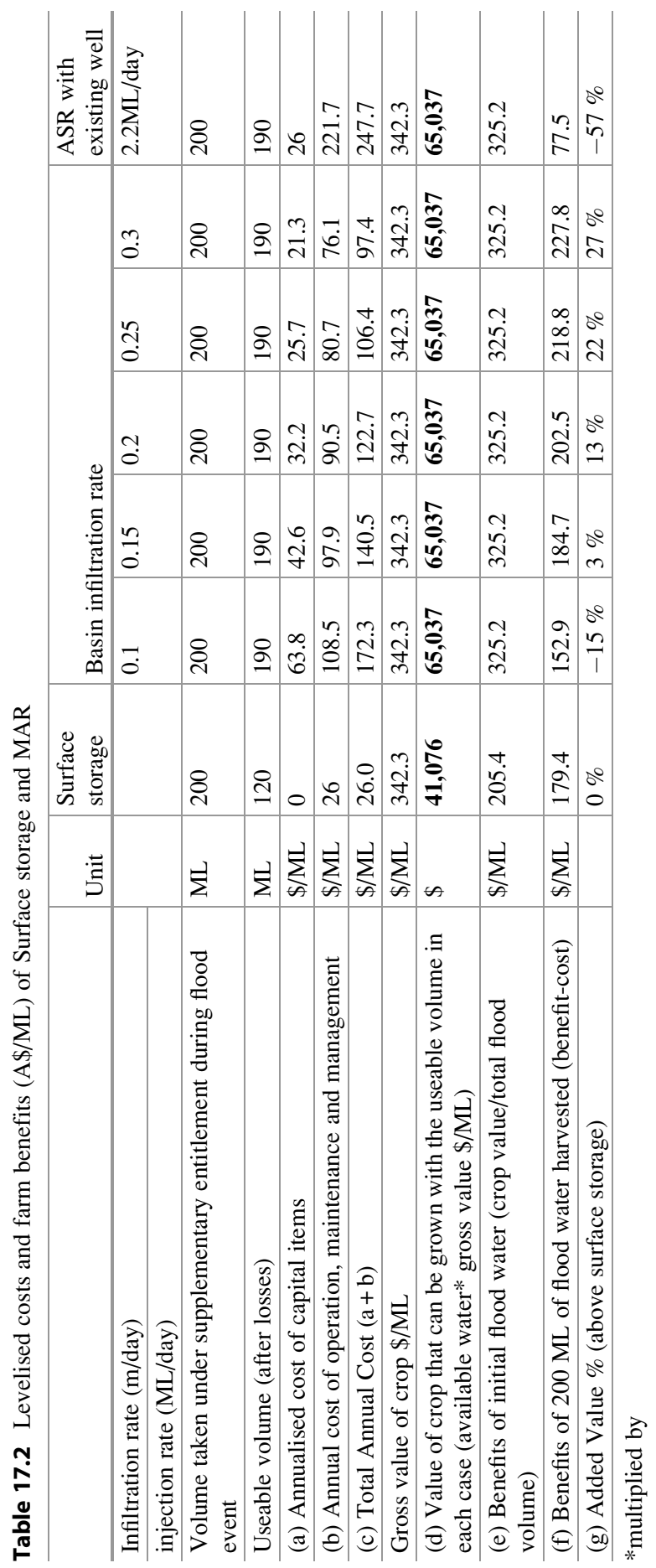


recharging it underground. If the assumptions of this study are validated, aquifer storage using infiltration ponds would be financially viable.

\subsection{Conclusion}

Managed aquifer recharge can be a useful element of integrated water resource management. It can help to conserve surface water resources and improve groundwater quality (eg Adelaide case study), and minimize the evaporative loses and increase the volume of groundwater available for use (eg Namoi case study).

The economics depend on site-dependent factors. In general, recharge is least expensive where soils are permeable and aquifers are unconfined and fresh. Levelised costs may be approximately an order of magnitude less than the costs of recharge via wells. ASR is most cost efficient in aquifers that are transmissive and contain fresh or only mildly brackish ambient groundwater. It is attractive in urban areas where the value of recovered water is very high, it requires very small land area and if storing water in confined aquifers the groundwater resource is protected from overlying land uses.

MAR options have been shown to be economic in comparison with seawater desalination for urban substitutional supplies, and cheaper than use of mains water for public open space irrigation. Stormwater ASR has now been operational for 20 years in South Australia and the capacity is continually being expanded. For rural supplies the price of water is significantly lower than for urban supplies. And where infiltration rates are high and aquifers are unconfined, transmissive and contain fresh groundwater, it is possible for basin infiltration harvesting of supplementary entitlements during flood flows and their subsequent storage in aquifers to be a more efficient supply than harvesting in detention ponds alone that are exposed to significant evaporation losses. The Namoi desktop case study suggests that field validation of infiltration rates and maintenance requirements is warranted to determine the economics of MAR for flood water harvesting. Other such studies of recharge of flood waters such as Pavelic et al. (2012) in Thailand suggest that applications could potentially be very widespread.

Acknowledgements The information reported in this chapter is derived from studies undertaken by CSIRO for the National Water Commission, Goyder Institute for Water Research, City Of Salisbury, and Adelaide and Mount Lofty Ranges Natural Resources Management Board, and from the PhD. study under the Australian Government's Endeavour Scholarships and Fellowships programme, and National Centre for Groundwater Research and Training (NCGRT) Australia.

Open Access This chapter is distributed under the terms of the Creative Commons AttributionNoncommercial 2.5 License (http://creativecommons.org/licenses/by-nc/2.5/) which permits any noncommercial use, distribution, and reproduction in any medium, provided the original author(s) and source are credited. 
The images or other third party material in this chapter are included in the work's Creative Commons license, unless indicated otherwise in the credit line; if such material is not included in the work's Creative Commons license and the respective action is not permitted by statutory regulation, users will need to obtain permission from the license holder to duplicate, adapt or reproduce the material.

\section{References}

Arshad M, Jakeman AJ, Kelly BFJ, Qureshi ME, Croke BFW, Blakers RS, Ross AJ, Curtis A, Rawluk A (2012) Assessing the potential of managed aquifer recharge: preliminary hydrological findings from a scoping study in the Lower Namoi Valley, Australia. In: Kulkarni PS, Mayilswami C, Thangarajan M, Sing VP (eds) Proceedings of the fifth international groundwater conference on the assessment and management of groundwater resources in hard rock systems with special reference to basaltic terrain, vol II. Department of Geology, Maulana Azad College, Aurangabad, pp 58-70

Arshad M, Qureshi M, Jakeman A (2013) Cost-benefit analysis of farm water storage: surface storage versus managed aquifer storage. In: Piantadosi J, Anderssen RS, Boland J (eds) MODSIM2013, 20th international congress on modelling and simulation, Modelling and simulation society of Australia and New Zealand, December 2013, pp 2931-2937. ISBN: 978-0-9872143-3-1. www.mssanz.org.au/modsim2013/L16/arshad.pdf

Australian Cotton Growers (2012) A bi-monthly magazine providing technical and marketing information to the Australian cotton industry. http://www.greenmountpress.com.au/ cottongrower

Barron O, Crosbie R, Charles S, Dawes W, Ali R, Evans W, Cresswell R, Pollock D, Hodgson G, Currie D, Mpelasoka F, Pickett T, Aryal S, Donn M, Wurcker B (2011) Climate change impact on groundwater resources in Australia, Waterlines report. National Water Commission, Canberra

Berry KA, Armstrong D (1997) Olympic dam project water supply - environmental constraints. In: Proceedings of the 6th international mine water association congress, vol 1. Bled, pp 261-271

Bouwer H (1999) Artificial recharge of groundwater: systems, design, and management. In: Mays LW (ed) Hydraulic design handbook. McGraw-Hill, New York, pp 24.21-24.44

Burrell M, Moss P, Green D, Ali A, Petrovic J, Nguyen K (2011) General purpose water accounting report 2010-2011: Namoi catchment. NSW Department of Primary Industries, Sydney

Chiew FHS, Young W, Cai W, Teng J (2011) Current drought and future hydroclimate projections in southeast Australia and implications for water resources management. Stoch Env Res Risk A 25(4):601-612

Craig I, Schmidt E, Green A, Scobie M (2005) Controlling evaporation from on-farm storages, Irrigation Australia 2005: Irrigation Association of Australia National Conference and Exhibition: Restoring the Balance. Irrigation Australia Ltd., Townsville

Craig IP (2006) Comparison of precise water depth measurements on agricultural storages with open water evaporation estimates. Agricultural Water Management 85(1-2):193-200. doi:10. 1016/j.agwat.2006.04.010

CSIRO (2007) Water availability in the Namoi. A report to the Australian Government from the CSIRO Murray-Darling Basin Sustainable Yields project, CSIRO, Australia, $154 \mathrm{pp}$

Dandy G, Ganji A, Kandulu J, Hatton MacDonald D, Marchi A, Maier H, Mankad A, Schmidt CE (2013) Managed aquifer recharge and stormwater use options: net benefits report. Goyder Institute for Water Research technical report series no. 14/1, 181 p. http://goyderinstitute.org/ index.php?id=20 
Dillon P, Pavelic P, Page D, Beringen H, Ward J (2009a) Managed aquifer recharge: an introduction. Waterlines series report no. 13. National Water Commission, Canberra. http://archive. nwc.gov.au/library/waterlines/13

Dillon P, Gale I, Contreras S, Pavelic P, Evans R, Ward J (2009b) Managing aquifer recharge and discharge to sustain irrigation livelihoods under water scarcity and climate change. IAHS Publication 330:1-12, http://hydrologie.org/redbooks/a330/iahs_330_0001.pdf

Dillon P, Kumar A, Kookana R, Leijs R, Reed D, Parsons S, Ingleton G (2009c) Managed aquifer recharge - risks to groundwater dependent ecosystems - a review. Water for a healthy country flagship report to land \& water Australia. www.clw.csiro.au/publications/ waterforahealthycountry/2009/wfhc-managed-aquifer-recharge-risks.pdf

Dillon P, Pavelic P, Page D, Miotlinski K, Levett K, Barry K, Taylor R, Wakelin S, Vanderzalm J, Molloy R, Lennon L, Parsons S, Dudding M, Goode A (2010) Developing Aquifer Storage and Recovery (ASR) opportunities in Melbourne - Rossdale ASR demonstration project final report. WfHC report to Smart Water Fund, June 2010. http://www.clw.csiro.au/publications/ waterforahealthycountry/2010/wfhc-Rossdale-ASR-demonstration.pdf

Dillon P, Fernandez EE, Tuinhof A (2012) Management of aquifer recharge and discharge processes and aquifer storage equilibrium. IAH contribution to GEF-FAO Groundwater Governance thematic paper 4, 49p. www.groundwatergovernance.org/resources/thematic-papers/en/

Khan S, Mushtaq S, Hanjra MA, Schaeffer J (2008) Estimating potential costs and gains from an aquifer storage and recovery program in Australia. Agric Water Manag 95(4):477-488

Namoi CMA (2013) Namoi Catchment Action Plan 2010-2020; 2013 Update. NSW Government, Namoi Catchment Management Authority. http://archive.lls.nsw.gov.au/_data/assets/pdf_ file/0005/496364/archive-namoi-catchment-action-plan-2010-2020-2013-update.pdf

NSW DIPNR (2003) Water sharing plan for the Upper Namoi and Lower Namoi regulated river water sources. http://www.legislation.nsw.gov.au/viewtop/inforce/subordleg+179+2003 $+\mathrm{FIRST}+0+\mathrm{N} /$

NSW Office of Water (2008) Historic data DVD "PINNEENA" for continuous monitoring, version 2.8. Office of Water, Parramatta. http://www.water.nsw.gov.au/Realtime-reports/ hydro_rivers/default.aspx

NSW Office of Water (2012) Real-time surface water data, rivers and streams. Office of Water, Parramatta

Pavelic P, Srisuk K, Saraphirom P, Nadee S, Pholkern K, Chusanathas S, Munyou S, Tangsutthinon T, Intarasut T, Smakhtin V (2012) Balancing-out floods and droughts: opportunities to utilize floodwater harvesting and groundwater storage for agricultural development in Thailand. J Hydrol 470-471:55-64. doi:10.1016/j.jhydrol.2012.08.007

Powell J, Scott F (2011) A representative irrigated farming system in the Lower Namoi Valley of NSW: an economic analysis. Economic research report no. 46. Industry \& Investment NSW, Narrabri

Pyne RDG (2005) Aquifer storage recovery: a guide to groundwater recharge through wells, 2nd edn. ASR Press, Gainesville

Pyne RDG (2010) Aquifer storage recovery: economics and recent technical advances in achieving ground water supply sustainability \& reliability through managed aquifer recharge. In: Proceedings of the 7th international symposium of managed aquifer recharge ISMAR 7, IAH, Abu Dahbi

Rawluk A, Curtis A, Sharp E, Kelly BFJ, Jakeman AJ, Ross A, Arshad M, Brodie R, Pollino CA, Sinclair D, Croke B, Qureshi ME (2013) Managed aquifer recharge in farming landscapes using large floods: an opportunity to improve outcomes for the Murray-Darling Basin? Aust J Environ Manag i:1-15

Ross A, Arshad M (2013) Underground water storage and banking: benefits, barriers and ways forward. Paper presented to the 8th international symposium on managed aquifer recharge, ISMAR 8, IAH, Beijing

Smithson A (2009) Lower Namoi groundwater source: groundwater management area 001. Groundwater status report 2008. NSW Department of Water and Energy, Sydney 
Ward JD, Simmons CT, Dillon PJ, Pavelic P (2009) Integrated assessment of lateral flow, density effects and dispersion in aquifer storage and recovery. J Hydrol 370:83-99

Wigginton D (2011) Research: Irrigation Research - How Leaky Are Those Dams? Irrigation Australia: The Official Journal of Irrigation Australia 26(1):22-23

Williams RM, Merrick NP, Ross JB (1989) Natural and induced recharge in the Lower Namoi Valley, New South Wales. In: Sharma ML (ed) Groundwater recharge, proceedings of the symposium on groundwater recharge, Mandurah, 6-9 July 1987. A.A Balkema, Rotterdam, pp 239-253 


\section{Part IV}

Socioeconomics 


\title{
Towards Integrated Groundwater Management in China
}

\author{
Jie Liu and Chunmiao Zheng
}

\begin{abstract}
This chapter is intended to provide an overview of groundwater policy development in China, analyze the integration dimensions in current policy, identify the missing pieces and major challenges of integration in groundwater management, and offer suggestions towards more integrated groundwater management. The average groundwater recharge in China is about 880 billion $\mathrm{m}^{3} /$ year, $70 \%$ of which is unevenly distributed in the south. Groundwater exploitation has doubled over the past three decades, and agriculture is the largest consumer at approximately $60 \%$. The exploitation of groundwater sustains a steady increase in agricultural production, but also brings about a multitude of eco-environmental problems. Since the founding of the People's Republic of China, the focus of groundwater work has changed from investigating and exploiting to managing and protecting groundwater, and the viewpoint that groundwater is a single natural resource has gradually given way to that regarding groundwater as an environmental element with multiple functions. Integrated considerations of groundwater quantity, quality and its eco-environmental effects have been reflected in several programs aimed at prevention and control of groundwater contamination and land subsidence. Integration of surface water and groundwater by managed aquifer recharge and water transfer projects has been implemented. In the future, improvement of the legislation system, strengthening of institutional control, building-up of professional management teams, and increasing stakeholder involvement and
\end{abstract}

J. Liu

Center for Water Research, College of Engineering, Peking University, Beijing, China

C. Zheng $(\square)$

School of Environmental Science and Engineering, South University of Science and Technology of China, Shenzhen, China

Department of Geological Science, University of Alabama, Tuscaloosa, AL, USA

e-mail: czheng@ua.edu 
public participation are all needed facets towards a more integrated groundwater management.

\subsection{Introduction}

As an important part of water resources, groundwater plays an essential role in securing domestic uses, supporting socioeconomic development and maintaining ecological balance. Especially in the arid and semi-arid northern and northwestern parts of China with relative limited surface water, groundwater is non-substitutable. Indeed, China's groundwater situation is very grim (see also Chap. 2). Many areas are experiencing storage depletion with the water table continually declining, which further induces geologic hazards such as land subsidence, karst collapse and sea water intrusion; groundwater quality degradation and contamination is also becoming severe (Qiu 2010; Zheng et al. 2010). The conventional emphasis of groundwater management studies usually includes engineering and technological measures, modeling approaches (Demetriou and Punthakey 1999; Barthel et al. 2008; Liu et al. 2008; Shu et al. 2012; Cao et al. 2013; Qin et al. 2013), and economic leverage (Yang and Zehnder 2007; Zhang et al. 2008; Wang et al. 2010a). However, comprehensive studies that integrate legislative and administrative dimensions have often been ignored. To ensure that scientists understand what kinds of knowledge are required by policy makers and how hydrological expertise can be translated into real actions, it is essential to have an understanding of the current groundwater management system in China.

The objective of this chapter is to depict how groundwater policy has been progressively implemented in China, the existing gaps between the current and integrated groundwater policy, and possible steps towards more integrated groundwater management. The present state of China's groundwater resources is first described, and the historical groundwater development and management is then reviewed. This is followed by analysis of the integration dimensions in current groundwater policy and the existing major integration challenges. Finally, the authors offer suggestions towards more integrated groundwater management in China. Considering the size of the nation and the severity of the groundwater situation in China, this study not only has practical significance for improving China's groundwater development and management, but also can provide important implications for global groundwater governance. 


\subsection{State of China's Groundwater Resources}

\subsubsection{Types of Groundwater Resources and the Distribution}

Based on the occurrence of groundwater, China's aquifers can be divided into four major categories: (1) alluvial deposits in plains and basins; (2) groundwater in loess regions; (3) karstified limestone aquifers; and (4) bedrock aquifers in mountainous regions (Fig. 18.1).The first type is stored in porous and poorly consolidated sediments with an abundant amount of water, mainly distributed in alluvial plains, large river valleys, and the piedmont of inland basins. The total area is about 2.74 million $\mathrm{km}^{2}$ and provides groundwater around 168.6 billion $\mathrm{m}^{3} / \mathrm{year}$, accounting for $46 \%$ of the total exploitable groundwater. Groundwater in loess regions is a special type stored in unconsolidated sediments, mainly distributed in the loess plateau region in northern Shaanxi, southern Ningxia, western Shanxi and southeastern Gansu provinces. The total area is about 0.17 million $\mathrm{km}^{2}$, with the total exploitable groundwater in the amount of 9.7 billion $\mathrm{m}^{3} / \mathrm{year}$, about $3 \%$ of the nation's total exploitable groundwater. Karstified limestone aquifers occur in karst caves or fractures, with a total area of about 0.82 million $\mathrm{km}^{2}$. The total exploitable groundwater resource of this type is about 87 billion $\mathrm{m}^{3} / \mathrm{year}$, accounting for $24 \%$ of total exploitable groundwater resources. The bedrock aquifers mainly occur in the fractures of magmatic rocks, metamorphic rocks, and clastic rocks. The total area is about 5.75 million $\mathrm{km}^{2}$, with total exploitable groundwater in the amount of 97 billion $\mathrm{m}^{3} /$ year, accounting for $27 \%$ of the total exploitable groundwater resources (China's Groundwater Information Center 2014).

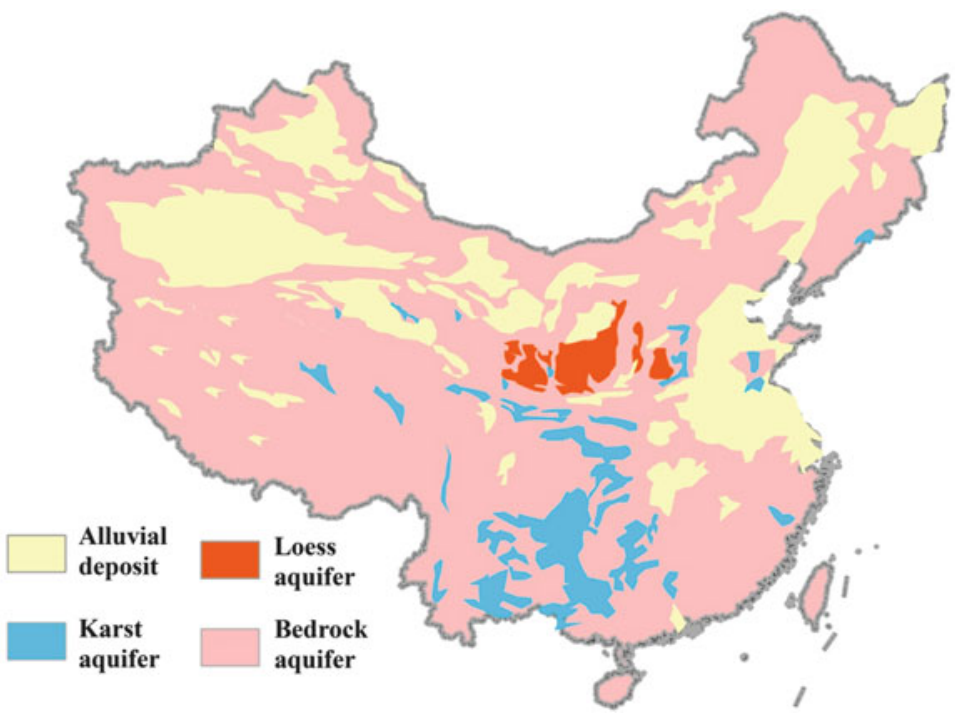

Fig. 18.1 China's major aquifer types and their spatial distribution 


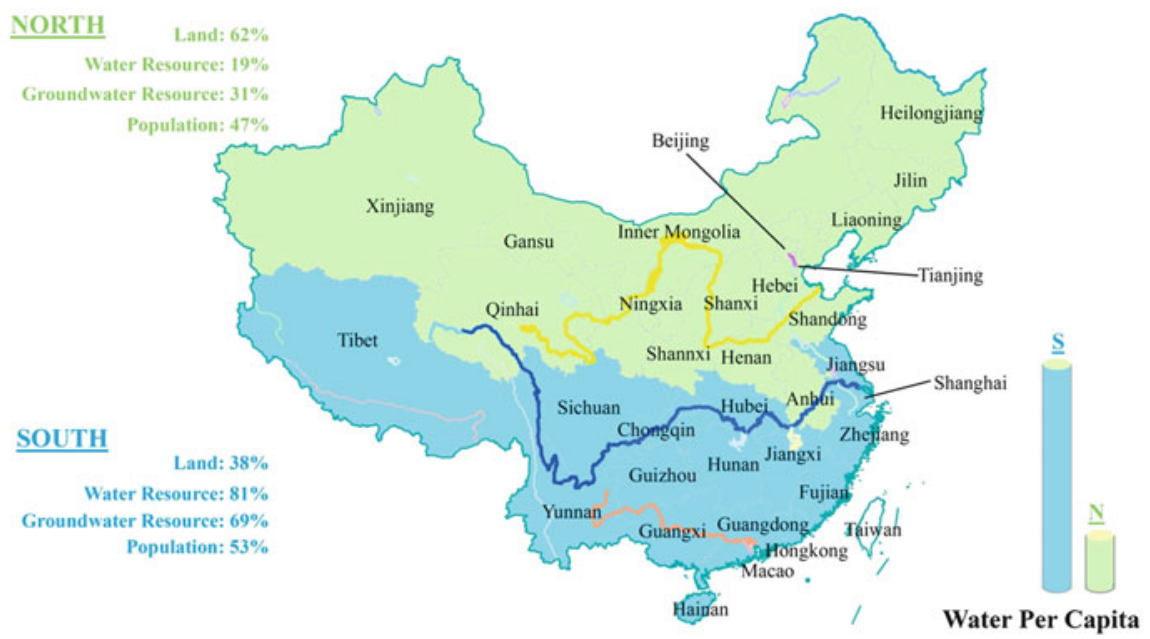

Fig. 18.2 Spatial distribution of groundwater resources in China (Data Source: The Ministry of Water Resources)

Table 18.1 Total amount and spatial distribution of China's groundwater resources $\left(10^{8} \mathrm{~m}^{3}\right)$

\begin{tabular}{l|l|l|l|l}
\hline Area & \multicolumn{2}{|l|}{ Total } & \multicolumn{2}{l}{ Exploitable } \\
\hline Nation-wide & 8837 & 3527 & \\
\hline North & 2743 & $31 \%$ & 1536 & $44 \%$ \\
\hline South & 6094 & $69 \%$ & 1991 & $56 \%$ \\
\hline & & & & \\
\hline Plain area & 2276 & $26 \%$ & 1561 & $44 \%$ \\
\hline Mountain area & 6561 & $74 \%$ & 1966 & $56 \%$ \\
\hline
\end{tabular}

According to the latest round (2000-2002) national groundwater resource assessment by the Ministry of Land and Resources, the average annual natural groundwater recharge in China is 884 billion $\mathrm{m}^{3} / \mathrm{year}$, accounting for nearly one-third of the nation's total water resources. The spatial distribution of groundwater resource in China is quite uneven. Nearly $70 \%$ of its groundwater resource is in southern China (38\% of the country's total land area) while only $30 \%$ is in northern China (62\% of the total land area). In general, the abundance of the groundwater resource decreases gradually from the southeast to the northwest (Fig. 18.2). Moreover, $74 \%$ of the groundwater resource is in the mountainous areas and $26 \%$ in plain areas, which adds difficulty and restriction in its exploitation and utilization (Table 18.1) (Zhang and Li 2004).

\subsubsection{Groundwater Exploitation and Overdraft Issues}

With fast economic development and population increase over the past three decades, groundwater exploitation in China has increased dramatically. Since the 


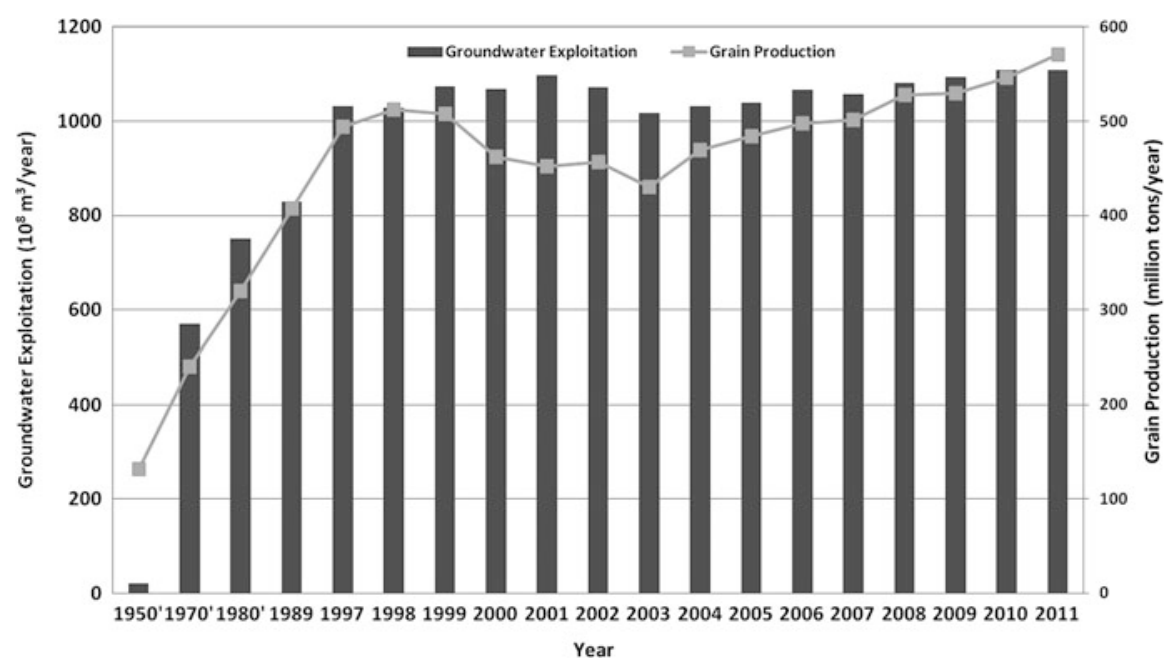

Fig. 18.3 Groundwater exploitation and total grain production from 1950s to 2011 in China (Data Source: The Ministry of Water Resources, China Statistical Yearbook)

1970s groundwater exploitation has grown at an average rate of 2.5 billion $\mathrm{m}^{3} /$ year. The total amount of groundwater exploitation was 57 billion $\mathrm{m}^{3} / \mathrm{year}$ in the $1970 \mathrm{~s}$, 75 billion $\mathrm{m}^{3} /$ year in the 1980s, and reached 111 billion $\mathrm{m}^{3}$ by 2011 , accounting for more than $18 \%$ of total water supply (Ministry of Water Resources 2011) (Fig. 18.3). Agricultural water use accounts for the largest percentage of the total groundwater use, although it has decreased from $88 \%$ in the 1980 s to $62 \%$ in the late 1990s; industrial and municipal water use has increased from $12 \%$ in the $1980 \mathrm{~s}$ to $38 \%$ in the late $1990 \mathrm{~s}$, and this trend will likely continue to keep pace with the acceleration of industrialization and urbanization.

Among the 657 cities in China, more than 400 (61\%) cities use groundwater as their major water supply. In rural areas of China, people generally use groundwater as their drinking water source, and $40 \%$ of the total farmland is irrigated by groundwater. In northern regions, $65 \%$ of domestic water, $50 \%$ of industrial water and $33 \%$ irrigated water come from groundwater (Ministry of Environment Protection 2011). The exploitation of groundwater has allowed a steady increase in grain production. Figure 18.3 shows the relationship between groundwater exploitation and total grain production in China from the 1950s to 2011. All those indicate that China's economic development and people's livelihoods depend greatly on groundwater.

With the increasing groundwater abstraction rate, most aquifers in northern China have been over-drafted, among which the entire Hebei Province, the aquifers in mega or middle-sized cities such as Beijing, Tianjin, Shenyang, Haerbin, Jinan, Taiyuan and Zhengzhou are all over-pumped. More than 100 regional groundwater cones of depression have been formed with total area exceeding $150,000 \mathrm{~km}^{2}$. In the North China Plain, the cone of depression has spanned from Hebei to Beijing, Tianjin, Shandong, with the groundwater level in an area of $70,000 \mathrm{~km}^{2}$ lower than 
sea level (Liu et al. 2001). The regional groundwater level decline has also impacted groundwater dependent ecosystems, such as the shrinking or disappearing of wetlands and degradation of vegetation coverage. Land subsidence occurred in more than 40 cities because of groundwater overdraft, among which Shanghai, Tianjin and Taiyuan have the maximum accumulative land subsidence over $2 \mathrm{~m}$. In coastal areas such as Dalian, Qinhuangdao, Cangzhou, Qingdao, and Beihai, sea water intrusion has caused degradation of groundwater quality in a total area of nearly $1000 \mathrm{~km}^{2}$, among which Shandong and Liaodong Peninsula are the most seriously affected. In addition, aquifer salinization has been caused by intensive irrigation in the North China Plain (Foster et al. 2004), the middle stream of the Yellow River and inland basins of northwestern China.

\subsubsection{Groundwater Quality Issues}

The overall quality of groundwater has deteriorated rapidly in recent years. According to the latest well sampling campaign in 2012 in nearly 200 cities and administrative regions by China's Ministry of Land and Resources, some $57.4 \%$ of over 4,900 samples indicated groundwater of category IV or V - on a scale of I-V from the best to poorest quality (Ministry of Environmental Protection 1994, 2012). The spatial information of groundwater quality is shown in Fig. 18.4, from which it can be seen that groundwater contamination in Taihu basin, Liaohe basin, Haihe basin and Huaihe basin is the most severe, with $91 \%, 85 \%, 76 \%$ and $68 \%$, respectively, of their total sampled areas with groundwater of category IV or V (Ministry of Environment Protection 2011).

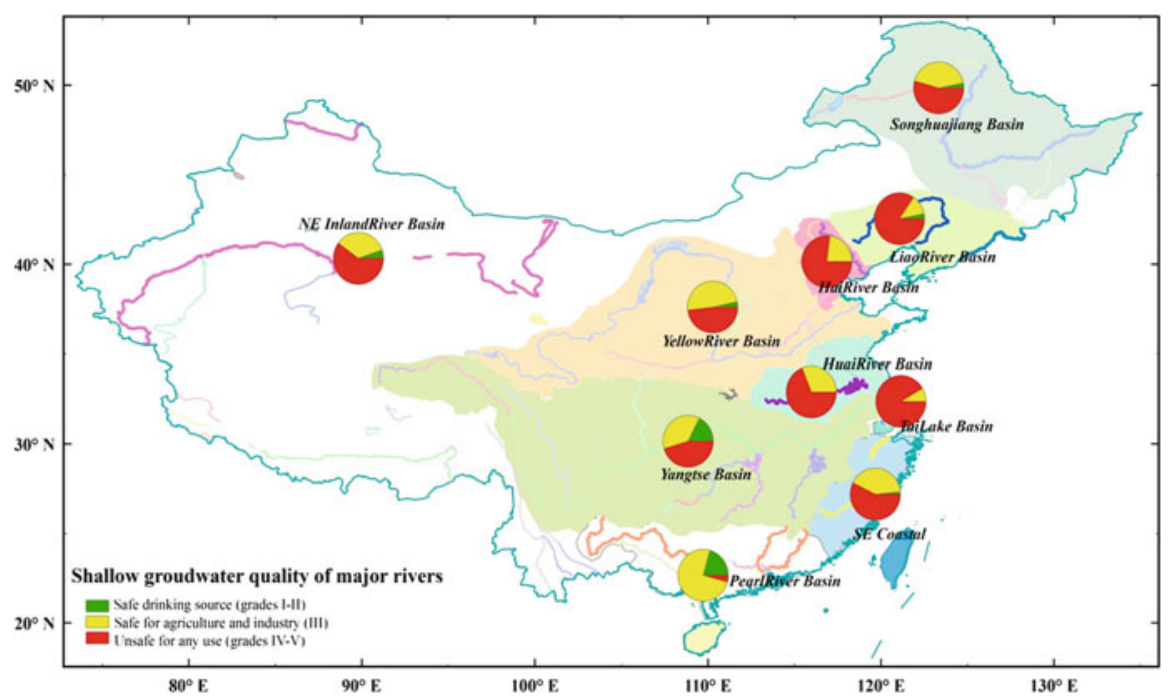

Fig. 18.4 Groundwater quality in major plains and basins of China. Categories I and II: good, category III: moderate, and categories IV and V: poor (Based on Tang et al. 2006) 
China Geological Survey conducted an investigation and assessment of groundwater contamination in the North China Plain from 2006 to 2011. Based on 7,451 groundwater samples, shallow aquifers show more serious contamination than deep aquifers. The major pollutants include nitrates, heavy metals, and toxic organic compounds. The nitrate pollutant has a planar distribution surrounding villages and cities, and the major sources include unregulated disposal of polluted water from industries, and the overuse of fertilizer in agricultural activities. $\mathrm{Pb}, \mathrm{Cr}$ and $\mathrm{As}$ are the major heavy metals with a high rate of exceeding environmental standards, and have a spotty or linear distribution pattern around cities and industries. The unregulated disposal of polluted water and poorly managed wastes are the major cause of heavy metal pollution. Toxic organic compounds have a low rate of exceeding standards but a high detection rate, mainly in shallow aquifers. The major source comes from the production, process, storage and use of those organic compounds by petrochemical industries (Zhang et al. 2012).

"It is estimated that 190 million Chinese fall ill and 60,000 die because of water pollution. According to the World Bank, such illnesses cost the government \$23 billion a year, or $1 \%$ of China's gross domestic product. And that doesn't factor in the impact on China's ecosystems and food supply" (Qiu 2011). The degradation of groundwater quality and groundwater contamination accidents also provokes sociopolitical unrest from the public. In the year of 2013, business owners in Shandong province were accused of disposing waste water through injection wells and contaminating shallow groundwater, which ignited a firestorm on the Internet (Zheng and Liu 2013).

\subsection{Historical Perspectives on Groundwater Development and Management in China}

China has a long history in utilizing groundwater resources. The earliest ancient well was found in Hemudu village of Yuyao, Zhejiang Province more than 5000 years ago (Liu 1987). Back to 2000 years ago, the Chinese began to use tube wells to exploit shallow groundwater. Systematic development of groundwater started after the founding of the People's Republic of China in 1949, and the development and management of groundwater in China has been closely related to the country's economic development. More than 60 years of groundwater development and management in China can be divided into the following five distinct stages (Ji and Wang 2009).

\subsubsection{9-1958: Initial Development}

China's hydrogeological work was launched right after the People's Republic of China was founded in 1949, closely linked with the demands of the nation's reconstruction and socioeconomic development. During this stage, groundwater 
was managed as a type of geological resource by the Ministry of Geology back then (later changed to the Ministry of Geology and Mineral Resources, and now the Ministry of Land and Resources). The major task of this stage was to conduct hydrogeological investigations for the major industrial and urban construction projects. In 1956, a regional hydrogeological investigation was initiated in the main basins, such as the Chaidamu Basin in Qinghai Province, the Hexi Corridor in Gansu Province and the Yangtze River basin. Groundwater protection was mentioned for the first time in the "Interim Regulations on Mineral Resources Protection" (1956), which states that: hydrogeological investigations and reasonable extraction plans should be enforced to prevent groundwater resources from being damaged; and the relevant departments should adopt effective measures to prevent groundwater contamination from the discharged industrial, medical or municipal wastewater. The discipline of Hydrogeology has been set up since 1952 in colleges, and academic activities have been carried out since the late 1950s. At this stage, many working methods were learnt and adopted from the former Soviet Union.

\subsubsection{9-1978: Growth Period}

Since 1959, hydrogeology has entered a growth period in China. Every province (autonomous region and municipality) built up their own hydrogeological and engineering geological teams. With the extensive development of agricultural activities and railway construction, hydrogeological investigations was conducted accordingly. Great progress was achieved in finding groundwater sources for areas with severe water shortage and endemic diseases. The academic and teaching activities also developed rapidly. In 1964, hydrogeological maps for the HuangHuai-Hai (which means the Yellow River, Huai River and Hai River in Chinese) Plain and the Song-Liao Plain (at a scale of 1:1,000,000) were completed. The national hydrogeologic maps were compiled by the Institute of Hydrogeology and Engineering Geology in the late 1970s, which integrated the previous hydrogeological investigations in different plains and basins. In 1977, a geological survey team for karst areas was formed, whose name was then changed to the Institute of Karst Geology in 1979. In 1962, land subsidence appearing in Shanghai led to the concerns over geo-environmental issues and the study of environmental geology as an important subject followed. Rational groundwater development and protection to prevent groundwater level decline, quality deterioration, land subsidence and collapse have been studied in many large and middle cities and the North China Plain since then.

\subsubsection{8-1998: Comprehensive Research and New Technologies}

In the 1980s comprehensive investigation and mapping of hydrogeological conditions started, based on natural geographical units. The major achievements 
include the hydrogeological maps of the Yangtze River Basin and the Yellow River Basin. By the mid-1980s, the first round of national groundwater resources assessment had been completed (Zhang and Li 2004). Following that, the groundwater resource assessment in the northern karst region was conducted. In 1996, the regional hydrogeological survey of the entire country was completed, with two-thirds of the national territory at the scale of 1:200,000 and the rest at the scale of 1:1,000,000. New concepts and technologies in hydrogeological research and practice from western developed countries were introduced to China during this period; and some technologies such as drilling and geophysical technologies were also actively developed in China as well.

In 1988, the first comprehensive national Water Law was enacted. Before then there was no systematic management structure and no specific regulations or laws for groundwater. The only regulation directly related to groundwater resources is the Interim Regulations on Mineral Resources Protection enacted in 1956. Following the Water Law, Regulations on Water Pollution Prevention and Control in Drinking Water Source Protection Area, and Regulations on Urban Groundwater Development and Management were formulated in 1989 and 1993, respectively. The Mineral Resources Law was amended in 1986, and the specific rules for the Implementation of the Mineral Resource Law were formulated in 1994 (Department of Water Resources 2008). During this stage, the Ministry of Construction was in charge of urban groundwater management; the Ministry of Land and Resources was responsible for groundwater investigations; and groundwater quality management was under the jurisdiction of the Ministry of Environmental Protection.

\subsubsection{9-2008: Large-Scale Land and Resources Survey and Assessment}

The second round of national groundwater resource and environmental assessment was conducted by the China Geology Survey (CGS) from 2000 to 2002. The CGS finished the regional hydrogeological survey in 11 major plains and basins in northern China (Fig. 18.5) and published a series of reports (Zhang and Li 2004). Groundwater recharge, runoff and discharge as well as their changes over the past 20 years were investigated. At the same time, geo-environmental issues related to groundwater such as land subsidence and seawater intrusion were also investigated comprehensively. A basin-scale digital groundwater information system was developed. Investigation of karst groundwater resources was conducted in eight provinces, including Yunnan, Guizhou, Guangxi, Hunan, Chongqing, Hubei, Guangdong, Sichuan, involving nearly 80 million people and a total area about 1 million $\mathrm{km}^{2}$.

From 2005 groundwater quality investigations and assessments were conducted in the eastern plains, including Zhujiang Delta, Yangtz Delta, Huaihe River Basin and the North China Plain. Questions such as the state of the nation's groundwater, how the groundwater quality evolves over time, and how natural factors and human activities impact the quality of groundwater were addressed. The groundwater pollution investigation in the Pearl River Delta, Yangtze River Delta, the plains 


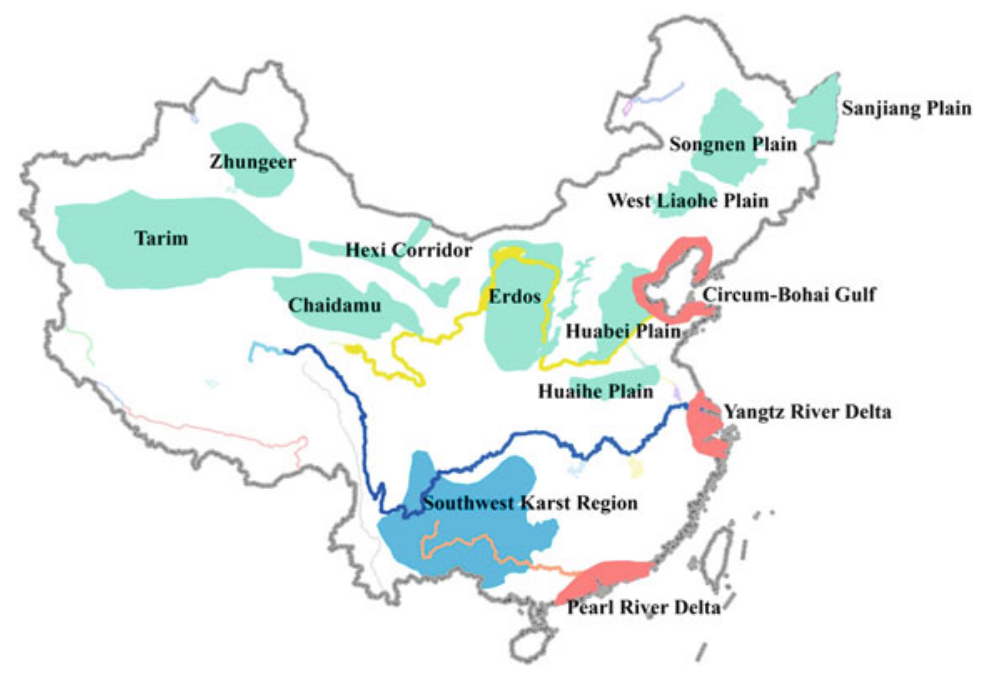

Fig. 18.5 Regional hydrogeological surveys in major plains conducted by China Geological Survey (Data Source: China Geological Survey)

area of the Huaihe Basin, the North China Plain, the lower Liaohe Plain and the eastern plain with an area of $430,000 \mathrm{~km}^{2}$ targeted inorganic to organic components. This provided important background information on groundwater quality for subsequent national groundwater pollution prevention and control efforts.

Groundwater exploration and exploitation in water-shortage and endemic areas was also been conducted. In the arid northwest region, and the so-called "red soil region" in the southwest, as well as areas with endemic diseases, the CGS carried out hydrogeological surveys and groundwater supply demonstration projects, and solved the drinking water supply problem for more than 20 million people.

The national monitoring network for the dynamic changes of groundwater level and quality has been under construction (Zhou et al. 2013). Currently, there are 24,417 groundwater monitoring stations, mainly distributed in the northern part of China. In the near future another 20,455 monitoring stations are planned to be constructed or reconstructed, which will cover $3,500,000 \mathrm{~km}^{2}$ and dynamically monitor the groundwater level and quality changes of major plains, basins, karst areas and ecologically vulnerable areas. Figure 18.6 shows the density of monitoring stations in each province of China (China Groundwater Information Center 2014).

\subsubsection{9-Present: Attempt at Integrated Water Management}

The integration dimensions of groundwater development and management have been considered to a greater extent during this stage. Back to 2000, the administrative management functions on groundwater resources of both the Ministry of 


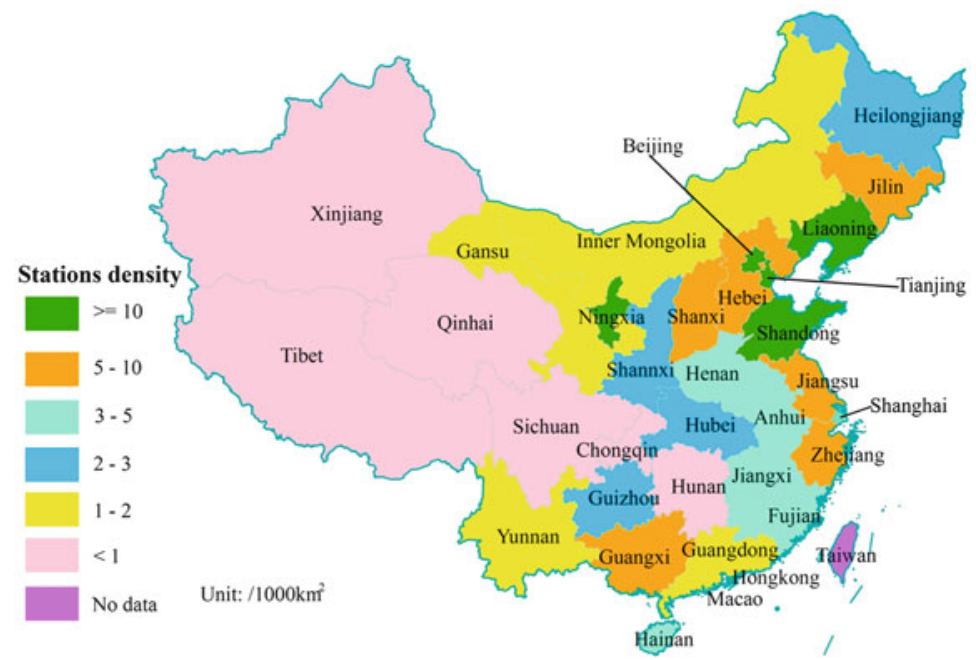

Fig. 18.6 National groundwater monitoring network in China (Data Source: China Institute of Geo-Environment Monitoring)

Construction (now the Ministry of Housing and Urban-rural Development) and the Ministry of Land and Resources have been moved to the Ministry of Water Resources. The Water Law was amended in 2002 to further strengthen the MWR's administrative power over groundwater. In 2011, the Plan of Groundwater Pollution Control and Remediation was issued, which was a joint effort of the Ministry of Environmental Protection, the Ministry of Water Resources, the Ministry of Land and Resources and the Ministry of Housing and Urban-rural Development. In 2012, the Land Subsidence Control Program (2011-2020) was launched by the Ministry of Land and Resources and the Ministry of Water Resources. Following those, the Working Plan of Groundwater Pollution Control and Remediation in the North China Plain was issued in 2013, which was also a joint effort by the Ministry of Environmental Protection, the Ministry of Water Resources, the Ministry of Land and Resources and the Ministry of Housing and Urban-rural Development. Integrated considerations of surface water and groundwater, water quantity and quality, groundwater exploitation and its subsequent consequences were reflected to some extent in the various programs mentioned above.

\subsection{Analysis of the Integration in China's Groundwater Management}

Although groundwater development and management in China has made great strides in the past decades, the outlook for groundwater management is still not optimistic. In major pumping areas like the North China Plain, groundwater 
overdraft is still severe. The average water table decline rate from 1980 to 1985 was about $0.5 \mathrm{~m} /$ year, slowed down in 1986-1995, but increased to more than $0.5 \mathrm{~m} /$ year from 1996 to 2008. The average annual groundwater storage depletion for the NCP is approximately 4 billion $\mathrm{m}^{3}$ (Cao et al. 2013). The overdraft of groundwater caused further eco-environmental problems, such as land subsidence, sea water intrusion and groundwater quality deterioration. Based on groundwater sampling in the NCP by the China Geological Survey, $58 \%$ of the samples showed poor quality (category IV or V). Land areas subsiding more than $200 \mathrm{~mm}$ extended $60,000 \mathrm{~km}^{2}$, with the estimated economic loss at about 330 billion RMB.

The major challenges of integration in groundwater management come from both the defining characteristics of groundwater itself and the particular social, cultural and political contexts of China. Groundwater, by its very nature, has multifunctional characteristics: it is an important part of the hydrologic cycle and important resource; at the same time it occurs in geological media and is also a type of mineral resource. In addition, groundwater has environmental values, the quality of which significantly affects human health and ecosystems. As a commonpool resource, groundwater is easily appropriated simply by capturing it, and the negative externalities associated with its use as well as the difficulty to measure this invisible resource add to the complexity of groundwater management (Wijnen et al. 2012). Cooperation among users is promoted as a means of achieving better management, internalizing the damages of users' activities and reducing extractions (Esteban and Dinar 2011).

Through this historical review of groundwater development and management in China, it can be seen that "integration" has been gradually taking place in the nation's groundwater policies due to the increasing intensity of groundwater exploitation and its subsequent problems. The integration dimension has been reflected in the legal framework and the changes of the institutional system in charge of groundwater management, but challenges still exist.

\subsubsection{Integration of Groundwater Quantity, Quality and Dependent Ecosystems}

In the initial phase of groundwater development, the major task facing China was to identify groundwater sources by conducting hydrogeological investigations. With the fast exploitation of groundwater in the 1960s-1980s for agricultural activities and economic development, groundwater-related geo-environmental issues started to emerge. The land subsidence in Shanghai started from the 1960s, and initiated the concerns over environmental issues caused by groundwater overdraft. Environmental Geology became a major field of research and practice at that time aimed at the protection of groundwater from water table decline, quality deterioration, land subsidence and collapses, and seawater intrusion. In addition, changes in groundwater quantity and quality can adversely impact many ecosystems in China that rely on groundwater to survive. 
Although the concerns over groundwater related environmental issues started in the 1960s, most of the work that has been done is scientific research in nature and has not been explicitly reflected in laws or regulations. In 2011, the State Council issued the National Plan for Groundwater Pollution Prevention and Control (2011-2020), which became an important official directive for groundwater quality management; in 2012, the National Plan for Land Subsidence Prevention and Control (2011-2020) was issued by the Ministry of Land and Resources and the Ministry of Water Resources, providing the official guidelines for the management of land subsidence. In this Plan, it is required to strictly restrict groundwater overdraft by controlling total groundwater pumping amount and the groundwater level. A water resources evaluation system is required if construction projects such as city construction and mining need to pump groundwater. The areas to limit or prohibit groundwater pumping need to be delineated. Based on the requirement of land subsidence control of a specific area, the goal of groundwater pumping control and reduction should be determined. At the same time, the construction of substitute water sources should be expedited to guarantee the requirement of domestic and industrial water uses.

In 2013, the Working Plan of Groundwater Pollution Prevention and Control in the North China Plain was issued to make specific provisions of groundwater protection in the NCP as a pilot study, and the Ministry of Environmental Protection, Ministry of Land and Resources, Ministry of Housing and Urban-rural Development, and Ministry of Water Resources were all involved. The working plan mandates that MEP constructs the monitoring network of groundwater quality and organizes routine groundwater quality monitoring, which should be linked up with the" National Groundwater Monitoring Project" implemented by the MLR and the MWR with all obtained information shared. The working plan is closely linked with the existing plans of water pollution prevention and control in the Haihe River Basin, the Yellow River Basin and other large river basins to manage surface water and groundwater quality jointly. The management of waste water outlets to rivers/ lakes, water permits and environmental evaluation should be coordinated. The plan also mentions that the coordination of the relevant laws and regulations of groundwater pollution prevention and control should be enhanced, and that groundwater quality standards should be formulated and linked with the Standards for Drinking Water Quality. The enactment of regulations about the responsibility and compensation of groundwater contamination should be speeded up. Sound and diversified funding and financing mechanisms for groundwater remediation should be constructed with stakeholders, local and central government all involved. The responsibility of stakeholders and local governments is strengthened, and the executive leadership responsibility system is implemented, and therefore the groundwater pollution prevention and control is brought into the planning of local social and economic development. The MEP coordinates and supervises the implementation of the Working Plan in coordination with other relevant organizations such as the MLR, National Development and Reform Commission, Ministry of Finance, Ministry of Housing and Urban-rural Development, and the MWR. 


\subsubsection{Integration of Surface Water and Groundwater}

"Integration of surface water and groundwater use" is explicitly mentioned in the Water Law, with the understanding that they are one single resource of the hydrologic cycle, but there are no specific and detailed regulations on how to integrate them. Most of the work related to integration of surface water and groundwater remains mainly at the technical level, such as characterizing the spatial and temporal connection of the major river-aquifer systems, and development of generic approaches/tools to identify and quantify the nature and extent of interaction between the surface and groundwater (Liu et al. 2014; Huang et al. 2012). However, the policy challenges have rarely been addressed; for example, how to integrate extraction limits in highly connected river-aquifer systems, and how to address groundwater extraction to meet environmental flow requirements of rivers. Substantial technical investigation and policy development are still needed towards integrated groundwater and surface water management.

Managed aquifer recharge (MAR) is one of the methods to integrate surface water and groundwater (see Chaps. 16 and 17). MAR uses excess runoff or reused urban waste water to recharge aquifers and offsets the decreased recharge that has been caused by reservoir construction or overdraft of groundwater. China has a long history in managed aquifer recharge. Dating back to the Qing Dynasty (1644-1911), people in the Huantai County of Shandong Province excavated subsurface channel-wells along the Wuhe River and used river water to recharge groundwater. Since the 1960s, cooling water and tap water were used to recharge groundwater to recover groundwater level in Shanghai as well as to prevent and control land subsidence. Before the 1990s the well-channel irrigation system was popularized in northern rural China with a combination of groundwater exploitation and recharge. In the 1990s, lots of facilities, such as underground reservoirs in coastal areas, were built to prevent sea water intrusion by groundwater recharge with surplus floods (Wang et al. 2010b). In the North China Plain, Xu et al. (2009) identified specific regions that could be targeted for MAR, all of which are alluvial fans in the piedmont of the Taihang Mountains, where regional recharge occurs (Currell et al. 2012). The South-to-North Water Transfer project has been under construction to transfer a billion cubic meters of surface water from southern China to northern China which is plagued by groundwater overdraft. This would be a good example to use surface water and groundwater conjunctively over a large spatial scale. With the transferred surface water satisfying parts of the water demands, groundwater can be conserved and protected to some extent.

\subsubsection{Incompleteness of Legal Framework}

The incompleteness in the current legal framework in China has limited the implementation of integrated groundwater management. Article 12 in the Water Law (issued in 1988 and amended in 2002) regulates the administrative system of water resources, which is to integrate watershed management with the management 
of administrative regions. The department of water administration under the State Council, that is, Ministry of Water Resources (MWR), is in charge of the integrated administration and supervision of water resources throughout the country. MWR establishes watershed management organizations for the major rivers and lakes, which perform the managing and supervising duties in their jurisdiction. The department of water administration under the local governments at or above the county level is responsible for the integrated management and supervision within their respective administrative regions.

Water planning is listed as an independent chapter (Article 14-19) in the Water Law to emphasize the importance of planning and its legal status. It is emphasized that integrated water planning should be done based on watersheds and regions, with the regional planning complying with watershed planning, and professional planning (such as flood control, irrigation, shipping, water supply, hydropower generation, and fisheries) complying with integrated planning (the overall arrangements of water exploitation, utilization, conservation and protection). The planning should be based on a comprehensive scientific survey and an investigation and assessment co-organized by the department of water administration at or above the county level in conjunction with the relevant departments at the same level.

Article 23 indicates that local governments at different levels should utilize surface water and groundwater conjunctively and make a rational and integrated exploitation of water based on the actual conditions of the local water resources. Article 36 mentions that groundwater abstraction should be strictly controlled in overdraft areas by the local government at and above county level. Scientific studies should be conducted and measures adopted if pumping groundwater in coastal areas in order to prevent land subsidence and sea water intrusion.

Although the Water Law has explicitly mentioned the "integration" issue in several of its articles, the legal regime is still far from complete and fails to capture important issues such as the necessity for integrated management and control of water quantity and quality. Article 32 mentions that the departments of water administration at or above the county level or watershed management organizations should evaluate the pollutant carrying capacity of a certain watershed and then provide suggestions of the total pollution discharge to the administrative department of environmental protection. The departments of water administration at or above the county level or watershed management organizations undertake the water quality monitoring task, and need to report to the administrative department of environmental protection. This segmentation in managing water quantity and quality will inevitably hinder the realization of integrated groundwater management.

\subsubsection{Defective Institutional System}

An integrated institutional system that is a good fit for the characteristics of groundwater resources has not been established in China. A coordinating organization is lacking and both segmentation and overlapping exist in the function of the 
major water management departments. Even though the amended Water Law indicates that the MWR has the right to govern water resources in an integrated fashion, including the protection and management of water resources, there is no further definition of what exactly the department is in charge of in the law. The multi-sectoral management system has caused undue overlaps, conflict of interests and additional complexity in solving problems (Department of Water Resources Management 2008). The Ministry of Land and Resources and its subordinate units take on the basic hydrogeological survey tasks and gather the basic geological data and information. In the meantime, the administrative function of groundwater management belongs to the Ministry of Water Resources, which is in charge of issuing groundwater abstraction permits and owns the information on groundwater utilization. The groundwater quality and pollution issue is under the jurisdiction of the Ministry of Environmental Protection. This has caused significant difficulties in data sharing and use, and prevented the hydrogeological surveys and groundwater contamination assessment to achieve the best outcomes.

Although watershed management organizations have been constructed and their legal status has been defined in the amended Water Law, the actual situation is that the management power of watershed management organizations is very limited. At present the major tasks of the watershed management organizations center on construction and management of river flood control systems and development of some ad hoc projects at the watershed scale, but they do not play a substantive role in the development and management of water resources, especially groundwater resources, at the watershed scale.

The current situation of water management authority has left "policy implementation ... fragmented and disjointed" (Foster et al. 2004). Many local governments have been slow to embrace the laws and regulations; as a result enforcement of the laws varies widely among the localities. In addition, as an institutional setting, each administrative division has its own water resource management departments. A local bureau only reports to its corresponding local government, not the bureaus or ministry above it. A higher bureau has no mandatory power over the lower one (the broken arrows in Fig. 18.7 showing the indirect leadership). Furthermore, a bureau is financially supported by the local government whose budget mostly depends on its local GDP. All these tend to promote local protectionism which affects policy implementation, and also breaks the integrity and integration of watershed management (Saleth and Dinar 2000).

\subsubsection{Lack of Information Sharing and Public Participation}

As a public resource, groundwater governance cannot continue without public participation. In western countries such as the European Union and Australia, the system of public participation is specified in legal documents, and the public plays an important role in groundwater protection. In the United States, since the "Love Canal" incident and largely spurred by it, citizen groups have demanded more inclusion in decision processes that affect their communities, such as the cleanup of 


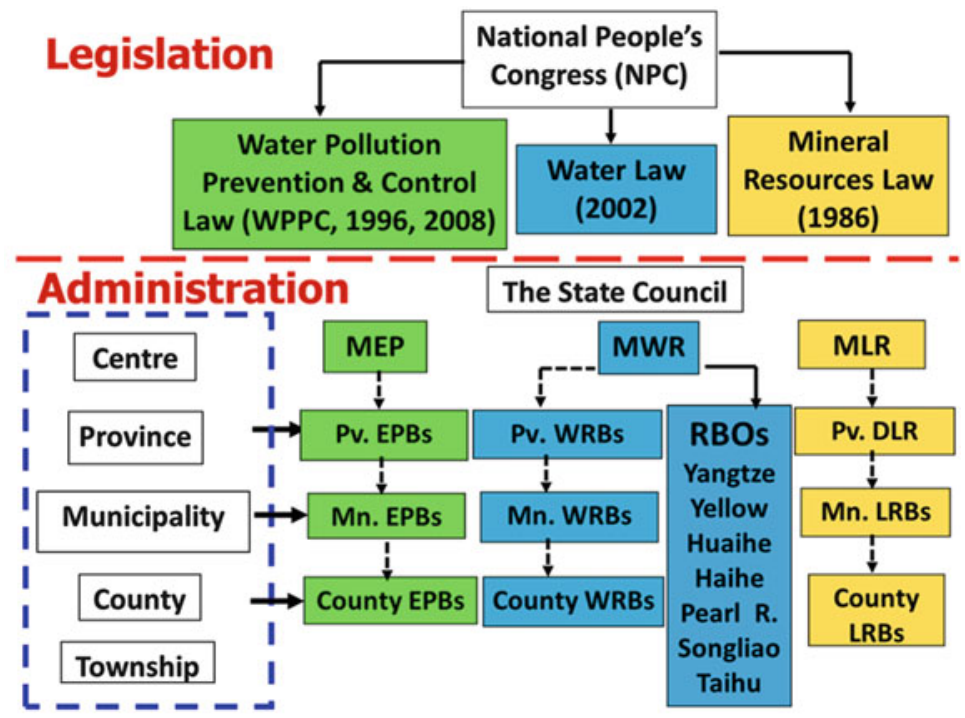

Fig. 18.7 Legislation, administrational and institutional system of groundwater management in China (Acronyms: $M W R$ Ministry of Water Resources, MEP Ministry of Environmental Protection, MLR Ministry of Land and Resources, WRB Water Resources Bureau, EPB Environmental Protection Bureau, DLR Department of Land and Resources, $L R B$ Land and Resources Bureau, $R B O$ River Basin Organizations)

The solid arrows depict the political dependency

The broken arrows indicate indirect leadership - mainly professional guidance from higher-level authorities without any hierarchical subordination

Superfund sites. But in China the public participation system has not been defined in current groundwater-related laws and regulations. Public awareness of the importance of groundwater and the status of groundwater quantity and quality is lacking. One prerequisite for public participation is to have a transparent institutional structure and accessible information (Winalski 2009). Data publishing and information sharing should be promoted; education of the public regarding groundwater protection is needed. "Any law lacks teeth unless public involvement fostered by education and media coverage promotes and accelerates the implementation process as an external factor" (Beyer 2006).

\subsection{Recommendations Towards More Integrated Groundwater Management in China}

China's State Council warned in 2007 that by 2030 China's water use will reach or approach the total volume of exploitable water resources. The country will consume 750 billion $\mathrm{m}^{3}$ of water per year by 2030 , about $90 \%$ of the total amount of usable water resources in the country (Qiu 2010). With changing climate and intensifying 
human activities, groundwater will continue to be used intensively in China, putting groundwater management under increasing stresses. The wide-ranging spatial and temporal scales of groundwater resources in China necessitate an integrated approach for exploitation and management. Implementing integrated groundwater management is a question of getting the "three pillars" right: (1) moving towards an enabling environment of appropriate legislation, policies and strategies; (2) putting in place the institutional framework through which policies can be implemented; and (3) setting up the management instruments required by these institutions to do their job (Water Partnership Program 2014). This has provided a general instruction for implementing integrated groundwater management in China.

Over the past 60 years, China has made great progress towards the integrated management of groundwater. However, there is still much work that needs to be done to continue the integration. Firstly, the legislation system should be improved. China still has no groundwater-specific laws and regulations, only with some provisions in general terms (the Water Law and the WPPC Law) regulating groundwater management. The overlapping of the WPPC Law and the Water Law leads to the confusion of institutional responsibilities of the MWR and the MEP as well as their local counterparts. In addition, the groundwater legal regime is far from complete and fails to capture important issues such as the necessity for integrated management and control of water quantity and quality. The formulation of specific "Groundwater Management Regulations" and the technical standards on groundwater development should be speeded up to enhance groundwater governance and protection in accordance with laws. The vague statutory language and general terms of the present laws and regulations also create obstacles to the implementation process, and need to be more clarified and specific.

Secondly, institutional reforms are needed to straighten out several critical relationships, including the relationship among different organizations with water-related jurisdiction, the relationship between the national and local governments, and the relationship between watershed based and administrative division based management approaches. The responsibilities, authorities and interests of each side should be clarified. Under the current institutional system, the management of water quantity and water quality is divided and is under the administration of the MWR and the MEP separately. A suggestion to resolve this separation is to construct an integrated water resources management system led by the MWR, and a supervision system on water environment protection led by the MEP. To improve watershed management, the relationship between watershed management organizations and the regional management authorities should be carefully defined. Different levels should be differentiated for the watershed management and regional management. In general, the institutional reforms involve the distribution of important resources and are closely related to the national political system. Information sharing and collaborations among those related organizations and at different levels are essential for integrated groundwater management.

Thirdly, it is urgently needed to set up the management instruments and build up professional management teams to guarantee the implementation of integrated groundwater management. Currently the MWR has led integrated water resources 
management, but for a long period the MWR has mainly managed surface water and lacks experience in managing groundwater. It is important to build up the capacity in managing groundwater, including the formation, distribution, transformation of groundwater and its interaction with surface water. A dynamic national groundwater monitoring network should be constructed with improved metering techniques to collect information and provide the scientific foundation for groundwater management. Data dissemination and access, and information sharing should also be greatly improved. In addition it is essential to improve participation of stakeholders and to enhance public awareness and education of groundwater utilization and problems.

Finally, China should rethink its economic development strategy, population policy, and food security policy. China has been attaching primary importance to the development of the economy in the past three decades. Environmental quality and ecosystem health have not been given sufficient consideration, although the situation has been improving recently. It is essential to integrate the eco-environmental factors into its sustainable development strategy. Agriculture is the largest groundwater consumer among the various water using sectors, and therefore how to optimize certain agricultural water use requirements without threatening the food security policy will be an important issue. With the population exceeding 1.3 billion, nearly $20 \%$ of the world's population, China is facing unprecedented challenges in managing its limited water resources. In general, to manage China's groundwater resources effectively and sustainably, various aspects discussed in this chapter must be considered, including philosophical, legal, scientific and technological. This is a long-term goal that needs continuous and relentless efforts.

Acknowledgements The authors greatly appreciate the valuable comments by Jean-Daniel Rinaudo and Randy Hunt which have led to significant improvement of the presentation. The support for this work was provided by the National Natural Science Foundation of China (No. 41271032 and No. 91225301).

Open Access This chapter is distributed under the terms of the Creative Commons AttributionNoncommercial 2.5 License (http://creativecommons.org/licenses/by-nc/2.5/) which permits any noncommercial use, distribution, and reproduction in any medium, provided the original author(s) and source are credited.

The images or other third party material in this chapter are included in the work's Creative Commons license, unless indicated otherwise in the credit line; if such material is not included in the work's Creative Commons license and the respective action is not permitted by statutory regulation, users will need to obtain permission from the license holder to duplicate, adapt or reproduce the material.

\section{References}

Barthel R, Jagelke J, Gotzinger J et al (2008) Aspects of choosing appropriate concepts for modeling groundwater resources in regional integrated water resources management examples from the Neckar (Germany) and Oueme catchment (Benin). Phys Chem Earth 33:92-114 
Beyer S (2006) Environmental law and policy in the people's Republic of China Chinese. JIL 5 (1):185-211

Cao G, Zheng C, Scanlon BR et al (2013) Use of flow modeling to assess sustainability of groundwater resources in the North China Plain. Water Resour Res 49:159-175. doi:10. 1029/2012WR011899

China Ministry of Environmental Protection (1994) National quality standard for ground water (GB/T 14848-93)

China's Groundwater Information Center (2014) http://www.cigem.gov.cn. Accessed 20 Apr 2014

Demetriou C, Punthakey JF (1999) Evaluating sustainable groundwater management options using the MIKE SHE integrated hydrogeological modeling package. Environ Model Software 14:129-140

Department of Water Resources Management, the Ministry of Water Resources (2008) The collection of groundwater laws, regulations and standards. China Standard Press (in Chinese), Beijing

Esteban E, Dinar A (2011) Collective action and the commons: are cooperative groundwater institutions stable in the presence of environmental externalities? Water Science and Policy Center, Riverside

Foster S, Garduno H, Evans R et al (2004) Quaternary aquifer of the North China Plain - assessing and achieving groundwater resource sustainability. Hydrogeol J 12:81-93

Han D, Chen Z et al (2012) Sustainability of groundwater usage in northern China: dependence on palaeowaters and effects on water quality, quantity and ecosystem health. Hydrol Process. doi:10.1002/hyp. 9208

Huang L, Zheng C, Liu J et al (2012) Application of distributed temperature sensing to study groundwater-surface water interactions in the Heihe river basin. Hydrogeol Eng Geol 39(2):611 (in Chinese)

Ji C, Wang Z (2009) Sixty years retrospect and prospect of China's hydrogeology and engineering geology. Paper presented at the 21st conference of committee of geological history, geological society of China, China University of Geosciences (Beijing), Beijing, Oct 2009

Liu Z (1987) Introduction of groundwater utilization in ancient China. Ground Water 3:186-187 (in Chinese)

Liu C, Yu J, Kendy E (2001) Groundwater exploitation and its impact on the environment in the North China Plain. Water Int 36(2):265-272

Liu J, Zheng C, Zheng L et al (2008) Ground water sustainability: methodology and application to the North China Plain. Ground Water 46:897-909

Liu C, Hu Y, Liu J et al (2014) Advances in the use of temperature data for study of surface watergroundwater interactions. Hydrogeol Eng Geol 41(5):5-10

Ministry of Environment Protection (2011) National pollution groundwater prevention plan (2011-2020). Index No. 000014672/2015-00539

Ministry of Environmental Protection (2012) China's Environmental Bulletin. Index No. 000014672/2015-00539

Ministry of Water Resources (2011) China Water Resources Bulletin (1997-2011). China Water Power Press, Beijing. ISBN 7508490797, 9787508490793

Qin H, Cao G, Kristensen M et al (2013) Integrated hydrological modeling of the North China Plain and implications for sustainable water management. Hydrol Earth Syst Sci 17:3759-3778

Qiu J (2010) China faces up to groundwater crisis. Nature 466:308

Qiu J (2011) China to spend billions cleaning up groundwater. Science 334:11

Saleth R, Dinar A (2000) Institutional changes in global water sector: trends, patterns, and implications. Water Policy 2:175-199

Shu Y, Villholth K, Jensen K et al (2012) Integrated hydrological modeling of the North China Plain: options for sustainable groundwater use in the alluvial plain of Mt. Taihang. J Hydrol 464-465:79-93

Tang K, Wu Y, Hou J (2006) Assessment of groundwater quality in China: groundwater quality and pollution analysis. Water Resour Prot 22(3):1-4 (in Chinese) 
Wang J, Huang J, Zhang L et al (2010a) Water governance and water use efficiency: the five principles of WUA management and performance in China. J Am Water Resour Assoc 46(4): $665-685$

Wang W, Sun X, Xu Y (2010b) Recent advances in managed aquifer recharge in China. 2010. In: International conference on challenges in environmental science and computer engineering, vol 2, pp 516-519. doi:10.1109/CESCE.2010.100

Water Partnership Program (2014) www.gwpforum.org. Accessed 20 Apr 2014

Wijnen M, Augeard B, Hiller B et al (2012) Managing the invisible - understanding and improving groundwater governance. Water Partnership Program. http://water.worldbank.org/sites/water. worldbank.org/files/publication/ESW_Managing-the-invisible.pdf. Accessed 20 Apr 2014

Winalski D (2009) Cleaner water in China? The implications of the amendments to China's law on the prevention and control of water pollution. J Environ Law Litig 24:181-202

Xu G, Liu L, Fei Y et al (2009) Research on the adjustment of groundwater storage in the North China Plain. Resour Sci 31:375-381 (in Chinese)

Yang H, Zehnder A (2007) "Virtual water": an unfolding concept in integrated water resources management. Water Resour Res 43:W12301. doi:10.1029/2007WR006048

Zhang Z, Li L (eds) (2004) Groundwater resources of China. SinoMaps Press, Beijing. ISBN 7-5031-3418-6

Zhang L, Wang J, Huang J et al (2008) Development of groundwater markets in China: a glimpse into progress to date. World Dev 36(4):706-726

Zhang Z, Fei Y, Guo C et al (2012) Regional groundwater contamination assessment in the North China Plain. J Jilin Univ (Earth Sci Ed) 42(5):1456-1461

Zheng C, Liu J (2013) China's "Love Canal" moment? Science 340:810

Zheng C, Liu J, Cao G et al (2010) Can China cope with its water crisis? - perspectives from the North China Plain. Ground Water 48(3):350-354

Zhou Y, Dong D, Liu J et al (2013) Upgrading a regional groundwater level monitoring network for Beijing Plain, China. Geosci Front 4:127-138 


\title{
Social Science Contributions to Groundwater Governance
}

\author{
Allan Curtis, Michael Mitchell, and Emily Mendham
}

\begin{abstract}
All environments have been modified by human activity and those interactions produce "winners" and "losers". Improvements require changes in human behaviour, especially when these activities deny opportunities for future generations. However, changing human behaviour can be difficult to accomplish. We need to establish better ways to reach and implement sound decisions. For social researchers, a key assumption is that complex and difficult natural resource management (NRM) issues are often best addressed by engaging stakeholders in processes that involve dialogue, learning and action - that is, by engaging and building human and social capital. In this chapter we identify some of the social research principles and practices that will enhance groundwater governance. Social researchers have developed principles and approaches for effective stakeholder engagement, social impact assessment, collaborative approaches for NRM governance and changing the use and management of land and water by rural landholders. We conclude with a discussion of some of the challenges for social scientists contributing to larger integrated programs.
\end{abstract}

\footnotetext{
A. Curtis $(\varangle) \cdot$ E. Mendham

Graham Centre for Agricultural Innovation, Wagga Wagga, NSW, Australia

National Centre for Groundwater Research and Training, Flinders University, South Australia, PO Box 789, Albury, NSW 2640, Australia

e-mail: acurtis@csu.edu.au

M. Mitchell

Landscapes and Policy Hub, National Environmental Research Program, University of Tasmania, PO Box 789, Albury, NSW 2640, Australia
} 


\subsection{Introduction}

Research to improve groundwater management is increasingly recognising the value of drawing on theory and methods from social research. In part, this trend reflects the increasing maturity of those disciplines; and builds on an acceptance that all environments have been modified by human activity and function as co-evolving social-ecological systems (SES), as discussed in Chap. 3. Improvements in environmental condition require changes in human behaviour, especially when these activities deny opportunities for future generations. However, changing human behaviour can be difficult to accomplish. Environmental management is complex because: cause and effect is often uncertain; effective intervention often requires substantial effort over a considerable period of time; it is often difficult to link an intervention with change in resource condition; and in many instances, no single actor is capable of addressing these issues on their own (Curtis and Lefroy 2010). That is, we are often dealing with "wicked problems" (Rittel and Webber 1973). Changing the behaviour of individuals and groups of people is necessary, but not always sufficient. It is also clear that land and water degradation frequently results from deficiencies in governance arrangements (Lockwood et al. 2009). We need to establish better ways to reach and implement sound decisions.

The introductory paragraph above sets out much of the rationale for a chapter that focuses on the social dimensions of groundwater governance. The chapter will provide a review of relevant literature in the social sciences with the aim of identifying the ways those disciplines can contribute to improved ground water governance.

\subsection{Responding to Complexity and Uncertainty}

For social researchers, a key assumption is that "wicked problems" are best addressed by engaging stakeholders in processes that involve dialogue, learning and action - that is, by engaging and building human and social capital. We deliberately distinguish 'engage and build' on the basis that we believe that all people possess inherent abilities and agency (ability to take action to meet their needs). By human capital we mean the skills and abilities of individuals (Castle 2002); and social capital refers to the social relations, networks, trust, norms and institutions (rules) that arise between people when they interact, and which can then lead to further benefits (Sobels et al. 2001). Social researchers typically support more inclusive approaches to Natural Resource Management (NRM) that move beyond government where decisions are largely influenced by markets and bureaucracies to governance where a wider set of actors and arrangements are embraced (Lockwood et al. 2010).

The social research team in Australia's National Centre for Groundwater Research and Training (NCGRT) recently completed a comprehensive review of 
social research focused on groundwater governance. That literature turned out to be a relatively small but expanding body of published work (Mitchell et al. 2011). Almost 300 potentially relevant publications were identified, sorted thematically and assessed for quality in terms of having sound theoretical underpinning and providing credible evidence to support key findings (Mitchell et al. 2012). Some of the ground breaking research identified included Ostrom's publications around the role of social norms in NRM governance that built on her doctoral thesis examining groundwater management in California (Ostrom 1965, 1990). In Australia, the work on justice principles by Syme and colleagues (e.g. Syme et al. 1999) is partly based on research involving reforms in groundwater allocations. This process also enabled the authors to identify some of the key social research principles and practices that will enhance groundwater governance; and identify future social research directions. Those topics are the main foci for this chapter. We will also reflect on our experiences as social researchers contributing to larger integrated research programs which we think are essential if "wicked problems" are to be addressed effectively.

\subsection{Effective Community/Stakeholder Engagement}

For political scientists, civic engagement is a fundamental right and responsibility of citizenship thought to enhance individual's sense of self and well-being. From the 1960s, public engagement became accepted practice with legislation in the USA mandating public involvement in all federal agency decision making (Stankey and Hendee 1975). Public participation was expected to provide an effective means of articulating and incorporating community values in decisions (Creighton 1983), legitimise planning outcomes, reduce conflict, provide feedback on program implementation and outcomes, contribute to community education and improve accountability of government (Daneke 1983; Grima 1983). Of course, the reality and outcomes were often very different. The public often perceived engagement as tokenistic because they thought decisions had already been made; existing inequalities were often entrenched because the privileged with better networks were more likely to be engaged; it was unlikely to be fully representative; those attempting to engage had little idea of how to do that effectively; and the expectation of resolving conflict was unrealistic and ill formed (Kweit and Kweit 1981; Priscoli 1983; Sewell and Phillips 1979; Stankey and Hendee 1975).

Those working in NRM often focus their engagement on local, place-based communities. The local scale can be appropriate for interventions that seek to address local manifestations of environmental problems and to do so by engaging and building human and social capital. However, that focus can also result in the marginalisation of others, including communities of practice, interest and identity (Harrington et al. 2008). There are also questions about the extent the concept of community is used by those with limited understanding or commitment to sound engagement principles and practices. For those operating at larger scales, 
stakeholder engagement might be a more appropriate conceptualisation of the task at hand.

We employ the term "stakeholder" to indicate the range of people who might participate, encompassing those who are influenced by a particular action, organisation or phenomenon, and those who influence that action, organisation or phenomenon (Freeman 1984). In the groundwater context, stakeholders can include scientists, policy makers, farmers, Indigenous people and environmental interests, and there are clear benefits from not excluding key actors (Knüppe and Pahl-Wostl 2011).

There is now abundant advice about how to implement participatory processes (Aslin and Brown 2002). Broad principles for effective stakeholder engagement include: ensure transparency about the purpose of engagement and the level of decision making offered; be inclusive of the range of stakeholders and empower the less advantaged to participate; and develop processes that enable participants to see other perspectives and, therefore, to act "reasonably" rather than "rationally" (Perlgut 1986).

Community self-regulation of groundwater, such as treated in Chap. 9, exemplifies the "citizen control" end of Arnstein's (1969) ladder of citizen participation. However, Arnstein's typology has been criticised for idealising “citizen control", potentially disparaging a wider range of participation approaches that might be appropriate in different contexts (Collins and Ison 2009; Ross et al. 2002). Baldwin (2008), for example, investigated an irrigation community's effort to initiate a system of co-management of groundwater with government through a water planning process in the Lockyer Valley of southern Queensland, Australia. She concluded that groundwater management should draw on values-based rules developed by stakeholders to reflect Ostrom's principles for improving self-governance of common pool resources, but that these should be enforced by government. Taylor et al. (2009) also concluded that government authorities should maintain a role in groundwater management.

In the groundwater literature there are examples where stakeholders have been engaged in planning through participatory modelling (Martínez-Santos et al. 2008), agent-based modelling (Zellner 2008), integrated assessment modelling (Letcher and Jakeman 2003) or cooperative modelling (Tidwell and van den Brink 2008). Henriksen and Barlebo (2008) and more recently Ticehurst et al. (2011) assess the use of Bayesian Networks (BNs) as a tool to enable stakeholder engagement in policy implementation and evaluation. They have also been used as a tool to integrate local ecological knowledge with scientific-based knowledge (Liedloff et al. 2013). BNs are particularly suited to participatory processes because stakeholders are engaged in processes to establish a common language and a shared understanding of causality. In this sense the use of BNs contributes to a process of social learning (Reed et al. 2010; Schusler et al. 2003). The largely hidden and complex nature of groundwater governance provides an ideal context for engagement that embraces social learning. 


\subsection{Social Impact Assessment}

Changes in access to water resources have been a key element of government responses to environmental degradation and water scarcity. In relation to groundwater, these reforms have included reductions in groundwater entitlements and annual allocations, the introduction of trading in groundwater, and changes in rules to allow for the "banking" of surplus water in aquifers for later recovery and use (Contor 2009; Schlager 2006; Thompson et al. 2009). Of course, these changes have the potential to have substantial impacts on stakeholders, including irrigators, industries dependent on irrigation and the nearby towns and cities.

Social impact assessment (SIA) explores how particular events or policies affect people's way of life, their culture and their community (Vanclay and Esteves 2011). SIA may draw on economic assessments, but emphasises the non-monetary effects of an intervention. SIA uses a range of social science disciplines to anticipate the consequences of proposed actions compared to a "no change" scenario. While there are limits to the capacity of the social sciences to predict impacts, plausible scenarios can be constructed, including by drawing on experience with similar interventions in other contexts.

Australian researchers have been at the forefront of developing solid theoretical foundations for SIA (Howitt 1989; Syme and Nancarrow 2006; Syme et al. 1999; Vanclay and Esteves 2011). An important aspect of SIA is the identification of social groups which may be impacted in both negative and positive ways (winners and losers), in particular in relation to individual and community well-being. Amongst other things, SIA examines the unequal distribution of benefits and costs; changes in power structures; implications for family life, health and education; and effects on community cohesion and local organisations. SIA considers impacts on basic human needs (e.g. food, shelter, health, education, work), but extends to consider all of the key aspects of contemporary life in a particular society (e.g. access to banking services; recreation opportunities and infrastructure; quality of information and communication technology; aspirations for the future, including for family succession and education of children).

SIA provides policy makers with a process for identifying and working through issues with stakeholders. A key assumption is that SIA will enable stakeholders (including governments and communities) to identify strategies to mitigate impacts and to monitor impacts over time. Public engagement is a fundamental part of SIA. While there are likely to be benefits from engagement through an SIA in terms of providing a sound information base, clarifying issues, articulating values (i.e. what is important), identifying alternatives and clarifying tradeoffs, and enhancing agency credibility and reducing conflict, these outcomes cannot be assumed. These objectives are reflected in the steps that an SIA typically involves (Vanclay and Esteves 2011).

Public engagement can be costly, requires expertise and, in the case of contentious issues, takes some time (from a few months to years). The scale and duration of the SIA will depend on an initial assessment of the extent of likely impacts 
(e.g. minimal/substantial/transformational), the extent that the intervention will be contentious and the time/resources available.

Despite the potential of SIA, there is always the concern that governments will offer to undertake SIA to placate disgruntled stakeholders and that SIA will occur after a decision has been made. This has largely been the case so far in the past decade with the major water reform process in Australia (Baldwin et al. 2009).

Notwithstanding those remarks, there are international examples where social researchers have been able to make recommendations that have been empowering and proactive (Howitt 1989; Vanclay and Esteves 2011). Of course, social researchers can examine the social impacts of interventions without undertaking a formal SIA. Budds (2009) was able to expose the extent a hydrological assessment undertaken by a contractor for a Chilean government agency enabled wealthier and better educated farmers upstream to secure groundwater allocation rights, including substantial additional amounts of water. Those additional allocations came at the expense of the majority of groundwater users who were peasants located downstream. Apparently, modelling by the contracting agency had failed to consider the widespread illegal use of groundwater, an amount that was estimated to be almost twice that of actual legal extractions. The illegal groundwater use was predominantly by peasant farmers.

Syme et al. (1999) focused on the concepts of fairness and justice as part of their research examining water reform processes, and employed rigorous empirical research to explore these ideas. These authors developed a set of fairness principles and a fairness heuristic that can be used to assess the justice of such decisions. Syme et al. (1999) found that the public considered both distributional and procedural justice when deciding whether water allocation processes were fair. Additionally, they concluded that most of the community assessed fairness as both situational relating to specific water allocation decisions and each community's unique context; and universal - relating to overarching principles, such as a community's rights to have a say in allocation decisions, adherence to principles of procedural justice in the decision-making process, and rights of the environment. These topics have been pursued through subsequent studies by Lukasiewicz et al. (2013).

\subsection{Collaborative Approaches to Groundwater Governance}

Governance involves the interactions between social structures, processes and traditions that determine how power in society influences how decisions are made, how responsibilities are exercised and who has a say in all of this (Lockwood et al. 2010). The shift to governance reflects an approach to decision making that moves beyond markets and bureaucracies to be inclusive of a wider set of actors and arrangements (Lockwood et al. 2010). For Mukherji and Shah (2005) "groundwater governance" implied a shift from expert-driven processes derived from the 
"mathematical model-building exercises" of hydrologists and "the formulation and implementation of groundwater laws" by water managers. In part, the move towards governance reflects the need to establish better ways to reach and implement sound decisions. But groundwater governance has its own challenges, including those related to incomplete property rights, compliance with rules when the resource is largely invisible, lack of knowledge about the interconnections with surface and groundwater, the impact of groundwater use at considerable distance from where extraction occurs (Bolin et al. 2008), and conflicting interpretations over sustainable use of groundwater (Shriver and Peaden 2009; Weber et al. 2011) derived in part from the problematic construct of sustainable yield (Richardson et al. 2011; Seward et al. 2006).

There is increased interest in exploring the potential for community selfregulation of groundwater given the trend to devolve responsibilities away from centralised authorities (Chap. 9; Wilder and Lankao 2006), problems associated with privatisation (Bluemling et al. 2010), and the difficulties government agencies face in regulating groundwater use and preventing over extraction (van Steenbergen 2006). Defined as the "collective management of groundwater by water users" (López-Gunn 2003; Wester et al. 2011), the concept is also referred to as local, community-based and/or participatory management (Sandoval 2004; van Steenbergen 2006; Yamamoto 2008). In Gujarat, India, for example, government agencies in partnership with local non-governmental organisations have nurtured the development of farmer cooperatives and other credible local organisations (Tewari and Khanna 2005). Drawing on examples from developing economies, van Steenbergen (2006) concluded that informal norms based on moral imperatives (or "injunctive" social norms) have been the most effective means to limit the negative consequences of excessive private development of groundwater resources. Others have examined the difficulties that can be faced when authorities attempt to promote self-regulation of groundwater (López-Gunn and Cortina 2006; Mustafa and Qazi 2007; Wester et al. 2011).

Our review of the literature suggests that self-regulation is most effective when it evolves through collective action, building on the strength of existing social capital. Ross and Martinez-Santos (2010) confirmed Ostrom's (1990) conclusion that selfregulation is more likely to work for smaller scale groundwater systems than larger ones. Existing literature has little to say about how to build and engage community capacity for self-organisation. Yet there is a body of research exploring attributes of social capital that could provide researchers examining groundwater management with a rich pool of theory and research tools to draw upon. For example, de Vos and van Tatenhove (2011) described the evolution of trust relationships between fishers and government through the development of co-management arrangements in the Netherlands. In their evaluation of regional NRM governance in Australia, Lockwood et al. (2010) identified seven governance principles and provided a set of examples of how the elements of each principle could be evaluated. 


\subsection{Influencing the Use and Management of Land and Water by Rural Landholders}

In developed and developing economies rural landholders are key stakeholders in groundwater governance. Groundwater access and the quality of that water are often critical factors influencing human wellbeing (e.g. food security, incomes, employment and health). The land use and management actions of rural landholders also influence the integrity of aquifers and in turn, the condition of key environmental assets. However, groundwater research has focused mostly on the resource, rather than the actors who use and manage the resource (Hammani et al. 2009). Bekkar et al. (2009), Kuehne et al. (2008) and Albrecht (1990, 1995) are some of the small set of researchers who have explored the links between landholder behaviour and influences on landholder adoption in the groundwater context.

Engaging rural landholders in practice change is complex and difficult, not least because there is a potentially large set of factors (personal, societal) influencing their decisions (Mazur et al. 2013; Pannell et al. 2006); and these vary according to each technology, each landholder, each farming context and over time (Curtis and Mendham 2011). Figure 19.1 provides a useful framework for those attempting to identify the most relevant factors in any context. Even the concept of adoption is problematic. For example, when does a trial of a new practice become a change that represents adoption/implementation?

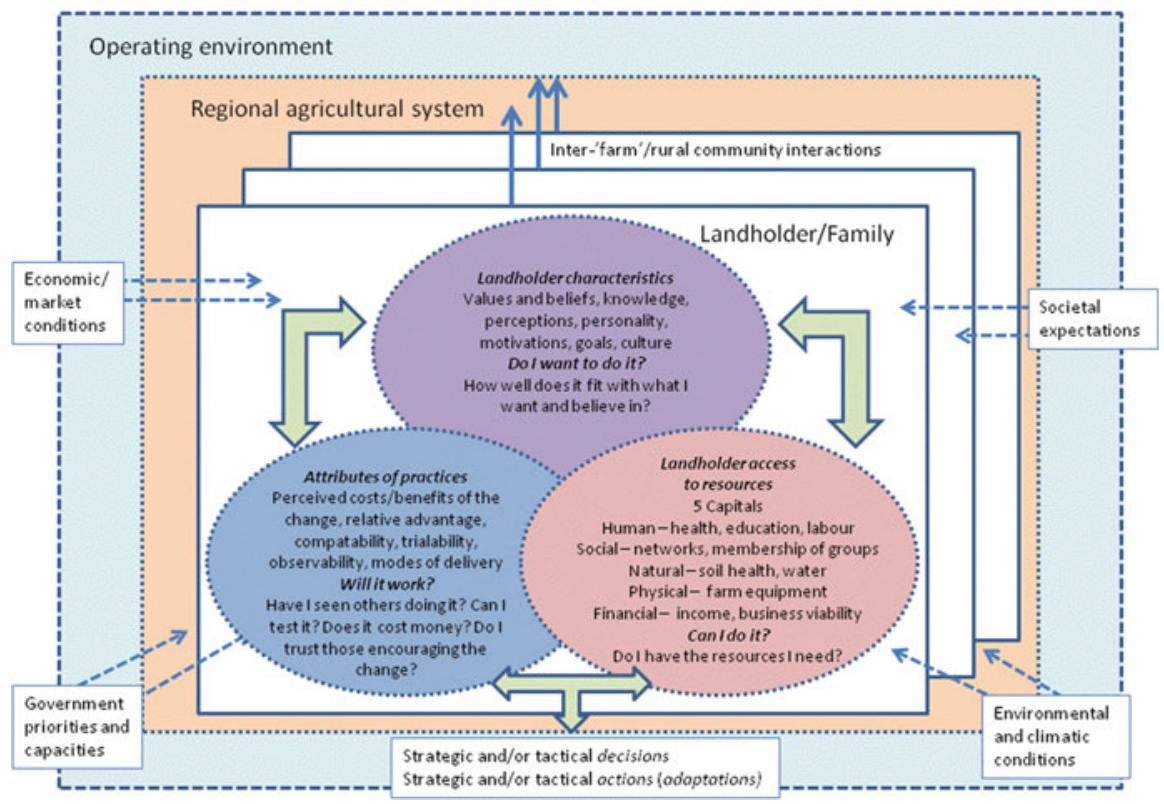

Fig. 19.1 Understanding landholder decision making (Adapted from Mazur et al. 2008) 
Personal engagement with individual landholders can be very effective. However, personal engagement is not always possible or necessary and it may be sufficient to develop a suite of policy instruments from across the "five P's: prescription, penalty, persuasion, property rights (and markets) and payment that meet the diverse needs of landholders (Salzman 2005).

The selection of policy instruments should be based on an assessment of the extent we are confident in the science underpinning decisions about "where we are headed and how to get there" (Curtis and Lefroy 2010); the adoptability of the technology (landuse or management practice); and the relative costs of different approaches, including transaction costs (Pannell 2011).

Where we are reasonably confident about the appropriateness of the outcomes we are seeking and the science that links the proposed intervention and desired outcomes, we can apply best-practice recommendations. If that is the case, we then need to make an assessment of the adoptability of those practices by rural landholders. For example, if awareness, knowledge or management skills are the issue, then activities that address those issues are appropriate. If the issue is lack of confidence in a recommended practice, perhaps because elements of the technology might be unproven or complex, then activities to trial those practices in the local area might be appropriate. If the issue is that the change involves considerable expense and appears to offer limited financial returns to landholders, then some form of cost-sharing between government and private landholders might be appropriate. Of course, even the implementation of best practices should be undertaken within an adaptive management framework.

We live in an increasingly modified environment. Having accepted that reality, it makes little sense to base NRM around the objective of restoring the environment to "pristine" condition. We must also recognise that concepts such as "pristine," "safe" or "sustainable yield" are human constructs that are changing over time (Alley and Leake 2004; Pierce et al. 2013).

A way forward is to bring stakeholders together to negotiate desired condition outcomes for specific environmental assets or systems (e.g. a water catchment) and for these condition targets to be the basis for developing and adapting strategies to move towards more desirable futures (Curtis and Lefroy 2010).

Rural landholders would be a key stakeholder in these processes and would be actively engaged in the dialogue, learning and action (not just on their property) that would occur in such an iterative process. The literature around resilience thinking and social learning provides important theoretical foundations and much practical guidance for those contemplating this type of engagement with rural landholders.

While improved environmental condition or health is the desired outcome of NRM interventions, considerable focus will be on engaging and building human and social capital that underpin much of the capacity of any community to respond to the challenges of sustainability. These concepts were introduced earlier and we expand those explanations here. Human capital embraces the attributes of a population, its training and skills, health and cultural diversity. Social capital refers to the attributes of relationships established in a community that enables participants to act together more effectively. These attributes include the structural social capital 
of networks and partnerships; and the cognitive social capital of trust, norms, institutional arrangements and reciprocal relationships that predispose people to cooperative behaviour and reduce transaction costs (Sobels et al. 2001). A focus on developing positive social norms is one strategy that can be used to influence adoption of new practices (Minato et al. 2010). Of course, if changes in human and social capital are part of our intermediate objectives as we strive to achieve our environmental condition targets, we must develop measures to evaluate those outcomes.

There is a trend in social research focused on environmental behaviour to draw on Values-Beliefs-Norms (personal) (VBN) theory (Stern et al. 1999). Our view is that this and related theories arising from the Theory of Planned Behaviour (Ajzen 1991) are adequate for explaining the conservation behaviours of the general public, but do not adequately account for the larger set of factors influencing decisions by rural landholders (Pannell et al. 2006). These additional factors include attributes of specific practices; government interventions to influence landholder decisions; global commodity prices; and the existence/development of social norms through local organizations [refer to Fig. 19.1]. It is also important to note that while values, beliefs and personal norms (VBN) may mediate or moderate some of these other factors, it is difficult to change these attributes in the short or medium term. At the same time, we know from research that interventions that focus on engaging and building human and social capital, including through one-toone extension, involvement in short courses and participation in field days have positive effects on adoption (Curtis and Mendham 2011). An additional layer of complexity is emerging as a result of the trend to non-farmer (by occupation) rural landholders, and a substantial cohort of absentee owners (Mendham and Curtis 2010).

\subsection{Conclusions}

\subsubsection{Future Research}

Drawing on our review, our knowledge of the more expansive social research contributions to NRM, and our understanding of the groundwater context, we have identified a number of research topics that could be pursued by social researchers in order to achieve more integrated groundwater management. Sustainable yield remains a problematic concept for groundwater managers and scientists. Social researchers could make an important contribution here by describing, explaining, and perhaps assisting in reconciling the different ways stakeholders define or interpret "sustainable yield" and how those different interpretations affect their attitudes and behaviours, and in turn, policy and management.

The contemporary proliferation of coal seam gas (CSG) developments in Australia, Canada, the United States and elsewhere, which has the potential to impact negatively on aquifer integrity and water quality, also provides a context to 
examine stakeholder perceptions of risk and trust. A key issue and one of considerable theoretical interest would be the nature of any relationships between risk interpretation and trust and their influence on the social acceptability of CSG by different stakeholders. While there is an established body of research into the social acceptability of carbon capture and storage (e.g. van Alphen et al. 2007) and risk perceptions associated with groundwater contamination (e.g. Vandermoere and Vanderstraeten 2014), research into stakeholder perceptions of risks associated with CSG is in its infancy (Jacquet 2009; Shackley et al. 2006). Given the scale of public controversy over CSG mining, we believe there is considerable scope to inform those policy debates by investigating how CSG risks are interpreted and communicated.

Theoretical constructs and frameworks associated with justice, collective action, trust and social norms can be explored further as researchers contribute to efforts to undertake social impact assessment processes, develop improved collaborative management and community self-regulation, and identify interventions designed to influence landholder behaviour. In this way, developments in theory will be underpinned by practice.

\subsubsection{Social Scientists Contributing to Integrated Research}

Working as social researchers contributing to multi-disciplinary and interdisciplinary research programs has had many benefits. Regular and structured interactions with scientists have increased our understanding of ecology and hydrogeology and the assumed links between property management and environmental condition outcomes. As part of research teams we have found it easier to access informants and data layers held by spatial scientists. There have also been benefits in terms of being exposed to different perspectives and approaches that have led to improved problem definition and the interpretation of results. These interactions improved the efficiency of the research process, the quality of research outcomes and the extent research has influenced policy and management.

At the same time, our experience has been mixed in that offers to engage with other disciplines have often been ignored. That has typically occurred at the start when research priorities are being developed and resources allocated. Our experience has been that over time, most researchers develop an appreciation of the relevance of social research and the capacity of the social sciences to contribute to integrated approaches. So, it is critical for social researchers to be engaged from the outset in problem definition and setting research priorities. It is also important for social researchers to articulate what they see as the cutting-edge social research rather than being considered as service providers who can support the tasks of stakeholder engagement or social impact assessment. Of course, social researchers must be open to offers to contribute to these research teams and to explain and justify their research approaches. 


\subsection{Summarised Points}

1. Difficult or 'wicked' natural resource management (NRM) issues are often best addressed by engaging stakeholders in processes that involve dialogue, learning and action to build and engage social and human capital.

2. Human and social capital underpins much of the capacity of any community to respond to the challenges of sustainability.

3. Principles and practices developed by social researchers that will enhance groundwater governance include: approaches for effective stakeholder engagement, social impact assessment, collaborative approaches for NRM governance and changing the use and management of land and water by rural landholders.

4. When conducting integrated research, it is critical for social researchers to be engaged from the outset in problem definition and setting research priorities.

Open Access This chapter is distributed under the terms of the Creative Commons AttributionNoncommercial 2.5 License (http://creativecommons.org/licenses/by-nc/2.5/) which permits any noncommercial use, distribution, and reproduction in any medium, provided the original author(s) and source are credited.

The images or other third party material in this chapter are included in the work's Creative Commons license, unless indicated otherwise in the credit line; if such material is not included in the work's Creative Commons license and the respective action is not permitted by statutory regulation, users will need to obtain permission from the license holder to duplicate, adapt or reproduce the material.

\section{References}

Ajzen I (1991) The theory of planned behavior. Organ Behav Hum Decis Process 50(2):179-211. doi:10.1016/0749-5978(91)90020-T

Albrecht DE (1990) The adaptations of farmers in an era of declining groundwater supplies. South Rural Sociol 7:46-62

Albrecht DE (1995) A comparison of the views of farmers and the nonfarm public regarding resource use the case of Texas groundwater. South J Rural Sociol 11(1):1-15

Alley WM, Leake SA (2004) The journey from safe yield to sustainability. Ground Water 42 (1):12-16. doi:10.1111/j.1745-6584.2004.tb02446.x

Arnstein S (1969) A ladder of citizen participation. J Am Inst Plann 35(4):216-224. doi:10.1080/ 01944366908977225

Aslin H, Brown V (2002) Terms of engagement: a toolkit for community engagement for the Murray-Darling Basin. Bureau of Rural Sciences, Canberra. http://adl.brs.gov.au/brsShop/ html/brs_prod_90000002788.html. Accessed 30 July 2011

Baldwin C (2008) Rules for the magic pudding: managing Lockyer groundwater. Soc Altern 27 (3):26-31

Baldwin C, O'Keefe VO, Hamstead M (2009) Reclaiming the balance: social and economic assessment - lessons learned after ten years of water reforms in Australia. Australas J Environ Manag 16(2):70-83

Bekkar Y, Kuper M, Errahj M et al (2009) On the difficulty of managing an invisible resource: farmers' strategies and perceptions of groundwater use, field evidence from Morocco. Irrig Drain 58(S3):S252-S263. doi:10.1002/ird.527 
Bluemling B, Pahl-Wostl C, Yang H et al (2010) Implications of stakeholder constellations for the implementation of irrigation rules at jointly used wells: cases from the North China Plain, China. Soc Nat Resour 23(6):557-572. doi:10.1080/08941920903376998

Bolin B, Collins T, Darby K (2008) Fate of the Verde: water, environmental conflict, and the politics of scale in Arizona's central highlands. Geoforum 39(3):1494-1511. doi:10.1016/j. geoforum.2008.02.003

Budds J (2009) Contested $\mathrm{H}_{2} \mathrm{O}$ : science, policy and politics in water resources management in Chile. Geoforum 40(3):418-430. doi:10.1016/j.geoforum.2008.12.008

Castle EN (2002) Social capital: an interdisciplinary concept. Rural Sociol 67(3):331-349

Collins K, Ison R (2009) Jumping off Arnstein's ladder: social learning as a new policy paradigm for climate change adaptation. Environ Policy Gov 19(6):358-373. doi:10.1002/eet.523

Contor BA (2009) Groundwater banking in aquifers that interact with surface water: aquifer response functions and double-entry accounting. J Am Water Resour Assoc 45 (6):1465-1474. doi:10.1111/j.1752-1688.2009.00378.x

Creighton JL (1983) The use of values: public participation in the planning process. In: Daneke GA, Garcia MW, Priscoli JD (eds) Public involvement and social impact assessment. Westview Press, Boulder, pp 143-160

Curtis A, Lefroy EC (2010) Beyond threat- and asset-based approaches to natural resource management in Australia. Aust J Environ Manag 17(3):6-13

Curtis AL, Mendham E (2011) Bridging the gap between policy and management of natural resources. In: Vanclay F, Pannell DJ (eds) Changing land management: adoption of new practices by rural landholders. CSIRO Publishing, Collingwood, pp 153-176

Daneke A (1983) Public involvement: what, why, and how. In: Daneke GA, Garcia MW, Priscoli JD (eds) Public involvement and social impact assessment. Westview Press, Boulder, pp 11-34

de Vos BI, van Tatenhove JPM (2011) Trust relationships between fishers and government: new challenges for the co-management arrangements in the Dutch flatfish industry. Mar Policy 35 (2):218-225. doi:10.1016/j.marpol.2010.10.002

Freeman RE (1984) Strategic management: a stakeholder approach. Pitman, Boston

Grima AP (1983) Analyzing public inputs to environmental planning: a summary and discussion of public involvement in Great Lakes management. In: Daneke GA, Garcia MW, Priscoli JD (eds) Public involvement and social impact assessment. Westview Press, Boulder, pp 111-119

Hammani A, Hartani T, Kuper M et al (2009) Paving the way for groundwater management: transforming information for crafting management rules. Irrig Drain 58(S3):S240-S251. doi:10.1002/ird.521

Harrington C, Curtis A, Black R (2008) Locating communities in natural resource management. J Environ Policy Plan 10(2):199-215

Henriksen HJ, Barlebo HC (2008) Reflections on the use of Bayesian belief networks for adaptive management. J Environ Manage 88(4):1025-1036. doi:10.1016/j.jenvman.2007.05.009

Howitt R (1989) Social impact assessment and resource development: issues from the Australian experience. Aust Geogr 20(2):153-166. doi:10.1080/00049188908702987

Jacquet J (2009) Energy boomtowns and natural gas: implications for Marcellus Shale local governments and rural communities. NERCRD Rural Development paper no. 43, Northeast Regional Center for Rural Development, Pennsylvania State University, University Park

Knüppe K, Pahl-Wostl C (2011) A framework for the analysis of governance structures applying to groundwater resources and the requirements for the sustainable management of associated ecosystem services. Water Resour Manag 25(13):3387-3411. doi:10.1007/s11269-011-9861-7

Kuehne G, Bjornlund H, Cheers B (2008) Identifying common traits among Australian irrigators using cluster analysis. Water Sci Technol 58(3):587-595. doi:10.2166/wst.2008.681

Kweit MG, Kweit RW (1981) Implementing citizen participation in a bureaucratic society. Praeger, New York

Letcher R, Jakeman A (2003) Application of an adaptive method for integrated assessment of water allocation issues in the Namoi River catchment. Australia. Integr Assess 4(2):73-89 
Liedloff AC, Woodward EL, Harrington GA et al (2013) Integrating indigenous ecological and scientific hydro-geological knowledge using a Bayesian Network in the context of water resource development. J Hydrol 499:177-187. doi:10.1016/j.jhydrol.2013.06.051

Lockwood M, Davidson J, Stratford E et al (2009) Multi-level environmental governance: lessons from Australia for natural resource management. Aust Geogr 40(2):169-186

Lockwood M, Davidson J, Curtis A et al (2010) Governance principles for natural resource management. Soc Nat Resour 23(10):986-1001. doi:10.1080/08941920802178214

López-Gunn E (2003) The role of collective action in water governance: a comparative study of groundwater user associations in La Mancha aquifers (Spain). Water Int 28(3):367-378. doi:10.1080/02508060308691711

López-Gunn E, Cortina L (2006) Is self-regulation a myth? Case study on Spanish groundwater user associations and the role of higher-level authorities. Hydrogeol J 14(3):361-379. doi:10. 1007/s10040-005-0014-z

Lukasiewicz A, Syme GJ, Bowmer KH et al (2013) Is the environment getting its fair share? An analysis of the Australian water reform process using a social justice framework. Soc Justice Res 26:231-252

Martínez-Santos P, Llamas MR, Martínez-Alfaro PE (2008) Vulnerability assessment of groundwater resources: a modelling-based approach to the Mancha Occidental aquifer, Spain. Environ Model Software 23(9):1145-1162. doi:10.1016/j.envsoft.2007.12.003

Mazur N, Curtis A, Thwaites R et al (2008) Rural landholder adaptation to climate change: social research perspectives. Landscape Logic Research report no. 5, University of Tasmania, Hobart. http://athene.riv.csu.edu.au/ acurtis/reports/No\%205_P2_Mazur_climate\%20change.pdf

Mazur N, Curtis A, Rogers M (2013) Do you see what I see? Rural landholders' belief in climate change. Soc Nat Resour 26(1):75-85. doi:10.1080/08941920.2012.686650

Mendham E, Curtis A (2010) Taking over the reins: trends and impacts of changes in rural property ownership. Soc Nat Resour 23(7):653-668. doi:10.1080/08941920801998893

Minato W, Curtis A, Allan C (2010) Social norms and natural resource management in a changing rural community. J Environ Policy Plan 12(4):381-403. doi:10.1080/1523908X.2010.531084

Mitchell M, Curtis A, Sharp E et al (2011) Social research to improve groundwater governance: Literature review. ILWS report no. 66, Institute for Land, Water and Society, Charles Sturt University, Albury. http://www.csu.edu.au/research/ilws/research/reports2011.htm

Mitchell M, Curtis A, Sharp E et al (2012) Directions for social research to underpin improved groundwater management. J Hydrol 448-449:223-231. doi:10.1016/j.jhydrol.2012.04.056

Mukherji A, Shah T (2005) Groundwater socio-ecology and governance: a review of institutions and policies in selected countries. Hydrogeol J 13(1):328-345. doi:10.1007/s 10040-005-0434-9

Mustafa D, Qazi MU (2007) Transition from karez to tubewell irrigation: development, modernization, and social capital in Balochistan, Pakistan. World Dev 35(10):1796-1813. doi:10.1016/ j.worlddev.2007.06.002

Ostrom E (1965) Public entrepreneurship: a case study in ground water basin management. Dissertation, University of California, Los Angeles

Ostrom E (1990) Governing the commons: the evolution of institutions for collective action. Cambridge University Press, Cambridge

Pannell D (2011) Policy perspectives on changing land management. In: Pannell D, Vanclay F (eds) Changing land management: adoption of new practices by rural landholders. CSIRO Publishing, Melbourne, pp 177-187

Pannell DJ, Marshall GR, Barr N et al (2006) Understanding and promoting adoption of conservation technologies by rural landholders. Aust J Exp Agric 46(11):1407-1424

Perlgut D (1986) Introduction. In: Sarkissian W, Perlgut D, Ballard E (eds) The community participation handbook: resources for public involvement in the planning process. Impact Press, Roseville, pp 1-6

Pierce SA, Sharp JM, Guillaume JA et al (2013) Aquifer-yield continuum as a guide and typology for science-based groundwater management. Hydrogeol J 21(2):331-340. doi:10.1007/ s10040-012-0910-y 
Priscoli JD (1983) The citizen advisory group as an integrative tool in regional water resources planning. In: Daneke GA, Garcia MW, Priscoli JD (eds) Public involvement and social impact assessment. Westview Press, Boulder, pp 79-87

Reed MS, Evely AC, Cundill G et al (2010) What is social learning? Ecol Soc 5(4):r1. [online] URL: http://www.ecologyandsociety.org/vol15/iss4/resp1/

Richardson S, Evans R, Harrington G (2011) Connecting science and engagement: setting groundwater extraction limits using a stakeholder-led decision-making process. In: Connell D, Grafton RQ (eds) Basin futures: water reform in the Murray-Darling Basin. ANU e-press, Canberra, pp 351-366

Rittel HWJ, Webber MM (1973) Dilemmas in a general theory of planning. Policy Sci 4 (2):155-169. doi:10.1007/BF01405730

Ross A, Martinez-Santos P (2010) The challenge of groundwater governance: case studies from Spain and Australia. Reg Environ Chang 10(4):293-310. doi:10.1007/s10113-009-0086-8

Ross H, Buchy M, Proctor W (2002) Laying down the ladder: a typology of public participation in Australian natural resource management. Aust J Environ Manag 9(4):205-217

Salzman J (2005) Creating markets for ecosystem services: notes from the field. N Y Univ Law Rev 80:870-961

Sandoval R (2004) A participatory approach to integrated aquifer management: the case of Guanajuato State, Mexico. Hydrogeol J 12(1):6-13. doi:10.1007/s10040-003-0311-3

Schlager E (2006) Challenges of governing groundwater in U.S. western states. Hydrogeol J 14 (3):350-360. doi:10.1007/s10040-005-0012-1

Schusler TM, Decker DJ, Pfeffer MJ (2003) Social learning for collaborative natural resource management. Soc Nat Resour 16(4):309-326. doi:10.1080/08941920390178874

Seward P, Xu Y, Brendonck L (2006) Sustainable groundwater use, the capture principle, and adaptive management. Water SA 32(4):473-482

Sewell WRD, Phillips SD (1979) Models for the evaluation of public participation programs. Nat Resour J 19:337-358

Shackley S, Mander S, Reiche A (2006) Public perceptions of underground coal gasification in the United Kingdom. Energ Policy 34(18):3423-3433. doi:10.1016/j.enpol.2005.07.010

Shriver TE, Peaden C (2009) Frame disputes in a natural resource controversy: the case of the Arbuckle Simpson Aquifer in south-central Oklahoma. Soc Nat Resour 22(2):143-157. doi:10. 1080/08941920801973789

Sobels J, Curtis A, Lockie S (2001) The role of Landcare group networks in rural Australia: exploring the contribution of social capital. J Rural Stud 17(3):265-276. doi:10.1016/S07430167(01)00003-1

Stankey GH, Hendee JC (1975) Applied social research can improve public participation in resource decision making. Rural Sociol 40(1):67-74

Stern PC, Dietz T, Abel T et al (1999) A value-belief-norm theory of support for social movements: the case of environmentalism. Hum Ecol Rev 6(2):81-97

Syme GJ, Nancarrow BE (2006) Achieving sustainability and fairness in water reform: a Western Australian case study. Water Int 31(1):23-30. doi:10.1080/02508060608691911

Syme GJ, Nancarrow BE, McCreddin JA (1999) Defining the components of fairness in the allocation of water to environmental and human uses. J Environ Manage 57(1):51-70. doi:10.1006/jema.1999.0282

Taylor B, de Loe R, Kreutzwiser R et al (2009) Local groundwater management studies in Ontario, Canada: a case for retaining a role for the state in community-based water research. Aust $\mathrm{J}$ Water Resour 13(1):69-80

Tewari DD, Khanna S (2005) Building and energizing water institutions: a case study of irrigation management transfer in Gujarat. J Environ Syst 31(3):201-221. doi:10.2190/ES.31.3.a

Thompson CL, Supalla RJ, Martin DL et al (2009) Evidence supporting cap and trade as a groundwater policy option for reducing irrigation consumptive use. J Am Water Resour Assoc 45(6):1508-1518. doi:10.1111/j.1752-1688.2009.00384.x 
Ticehurst JL, Curtis A, Merritt WS (2011) Using Bayesian Networks to complement conventional analyses to explore landholder management of native vegetation. Environ Model Software 26:52-65

Tidwell VC, van den Brink C (2008) Cooperative modeling: linking science, communication, and ground water planning. Ground Water 46(2):174-182. doi:10.1111/j.1745-6584.2007.00394.x

van Alphen K, van Voorst tot Voorst Q, Hekkert MP et al (2007) Societal acceptance of carbon capture and storage technologies. Energ Policy 35(8):4368-4380. doi:10.1016/j.enpol.2007. 03.006

van Steenbergen F (2006) Promoting local management in groundwater. Hydrogeol J 14 (3):380-391. doi:10.1007/s10040-005-0015-y

Vanclay F, Esteves AM (eds) (2011) New directions in social impact assessment. Edward Elgar, Cheltenham

Vandermoere F, Vanderstraeten R (2014) Back and forward to the future: an explorative study of public responses to urban groundwater contamination. J Environ Plan Manag 57(5):720-732. doi:10.1080/09640568.2013.763773

Weber EP, Memon A, Painter B (2011) Science, society, and water resources in New Zealand: recognizing and overcoming a societal impasse. J Environ Policy Plan 13(1):49-69. doi:10. 1080/1523908x.2011.564414

Wester P, Sandoval R, Hoogesteger J (2011) Assessment of the development of aquifer management councils (COTAS) for sustainable groundwater management in Guanajuato, Mexico. Hydrogeol J 19(4):889-899. doi:10.1007/s10040-011-0733-2

Wilder M, Lankao PR (2006) Paradoxes of decentralization: water reform and social implications in Mexico. World Dev 34(11):1977-1995. doi:10.1016/j.worlddev.2005.11.026

Yamamoto S (2008) Groundwater management in rice terraces: a case study of a lakeside community in Shiga Prefecture, Japan. Local Environ 13(5):449-460. doi:10.1080/ 13549830701809775

Zellner ML (2008) Embracing complexity and uncertainty: the potential of agent-based modeling for environmental planning and policy. Plan Theory Pract 9(4):437-457. doi:10.1080/ 14649350802481470 


\title{
Lessons to Be Learned from Groundwater Trading in Australia and the United States
}

\author{
Sarah Ann Wheeler, Karina Schoengold, and Henning Bjornlund
}

\begin{abstract}
This chapter provides an overview of the issues and challenges facing policy makers intending to establish groundwater markets. It studies in detail two developed countries that have introduced groundwater trading and have some experience in its implementation-Australia and the United States of Americaand draws out lessons from these countries that need to be considered for the development of groundwater markets around the world. The key lessons that this chapter stresses are: the importance of establishing institutions and regulations; investing in high quality economic and scientific research; that opportunities arise from crises; and that social concerns are not always the most important considerations to be aware of for efficient and effective groundwater markets.
\end{abstract}

\subsection{Groundwater Global Over Extraction and Shortage}

Globally, groundwater extraction is the outcome of decisions by organisations and individuals; there is little control or planning involved with its management. Groundwater withdrawals supply a large percentage of the world's population. It accounts for about $50 \%$ of global drinking water and $43 \%$ of global irrigation (van der Gun 2012). As detailed in Chap. 2, its overuse is associated with several

\author{
S.A. Wheeler $(\square)$ \\ Global Food Studies, University of Adelaide, Adelaide, SA, Australia \\ e-mail: sarah.wheeler@adelaide.edu.au \\ K. Schoengold \\ Agricultural Economics and School of Natural Resources, University of Nebraska, Lincoln, NE, \\ USA \\ H. Bjornlund \\ School of Commerce, University of South Australia, Adelaide, SA 5000, Australia
}


negative externalities including: water drawdown and groundwater depletion; land subsidence; loss of biodiversity; reduced dilution and assimilation of contaminants; increased salinity; pollution; and seawater intrusion into coastal aquifers (Moreaux and Reynaud 2004; Goesch et al. 2007). In some of the world's most important food producing regions, such as Punjabi in India, Northern Plains in China and the Ogallala aquifer in the United States, over extraction has now reached levels where it is apparent that it will not be possible in the longer term to support irrigation at current levels (Shah 2009). It is thus a major threat to food security.

The extraction of groundwater during the twentieth century was mainly for irrigation. Given the increasing impact of climate change on surface water availability, it is likely the pressure on groundwater will increase in the future (van der Gun 2012). The Brundtland report in 1987 increased the awareness that there had been over-allocation of water reserves and that groundwater was being drained more quickly than it could be replenished. This led to the emergence of the concept of 'safe yields', which set upper limits on the available water for use without depleting storage. However, this did not protect the interests of other users of water, notably the environment (Richardson et al. 2011).

\subsubsection{Groundwater Features}

Aquifers are recharged by rainwater, snow melt and returns from irrigated agriculture. Sometimes water moves considerable distances underground. Aquifers can be depleted if more water is extracted than the annual recharge. For several decades, aquifers in arid and semi-arid regions have been stressed with a growing gap between extraction and recharge. This has direct economic impacts because of increased pumping costs for consumptive users and water degradation and ecosystem damage (Esteban and Albiac 2012). Stocks of groundwater in aquifers are often larger than surface water stocks. This makes them important buffers during prolonged dry spells where, with reduced surface water availability and increased demand, groundwater use typically increases during droughts (van der Gun 2012; Goesch et al. 2007).

Groundwater management is more challenging than surface water management because it is less visible and recharge is more difficult to measure than stream inflows. Also, the hydraulic interconnectedness between different aquifers and between aquifers and surface water is still not fully understood in many regions. Groundwater is much more poorly monitored relative to surface water. It is only in recent years that authorities in many countries have started to require meters to be installed and monitored on bores (i.e., wells). For example, in Australia, by 2007 only 20-40 \% of major groundwater users were monitored (Goesch et al. 2007).

Another feature of groundwater is its 'shared water' component; that is, the interconnectedness of aquifers and streams. Shared water is that component that feeds into a stream or river from an aquifer (gaining stream) or that discharges into an aquifer from a river (losing stream). In some areas, a single river can gain and lose water (Goesch et al. 2007). Some ecosystems, such as wetlands, small streams, rivers, and lakes, are fed by aquifers (Esteban and Albiac 2012). 
Managing the quality of groundwater also poses a challenge, as problems such as salinity are common (Chap. 15). The susceptibility to quality pollution depends on the properties of the soil, climatic conditions, location of aquifers and factors such as rainfall frequency. The type of cropping, as well as fertilizer and pesticide application, also influence the risk of pollution. Short duration crops lead to greater levels of leaching (Arthukorala and Wilson 2012). Further, certain irrigation practices, failure to dispose of waste water properly and land clearing can all decrease groundwater quality (NWC 2012).

To understand groundwater use, a model of groundwater flow systems is required, including its sources and the spatial nature of natural and induced or imposed recharge and discharge. Quantifying recharge from all sources is difficult, as is determining the amount of water extracted. Thus where overuse is suspected, regular measurement is essential (Athukorala and Wilson 2012).

\subsection{Groundwater Policy Frameworks}

In the 1990s there was a shift in thinking about water within the international community. It was generally recognised that the possibilities of increasing water supplies had ended and there should be a shift in focus to managing water demand and reallocation. The global document Agenda 21, emerging from the Rio Convention in 1992, reflected this thinking and its main elements for dealing with water shortage included the notions that:

- users should pay the full cost of water;

- water markets should be established;

- the community should be involved in the decision making process

- water use should be more efficient; and

- the environment must be recognized as a legitimate stakeholder (Sitarz 1993).

Strategies must be found to more purposefully allocate water in ways that respond to competing demands, promote sustainability, prevent environmental damage and generate economic efficiency. In general, existing diversions can be reallocated or reduced through an administrative reallocation of water rights, information approaches or market-oriented policy approaches (Bennett 2008). Government managed 'command and control' approaches can be unpopular, while market based instruments are frequently regarded as politically neutral, and as an efficient means of managing water under conditions of scarcity (Skurray et al. 2013). However, many countries are heavily influenced by political influences which means second-best policy approaches are often chosen when first-best policies are available (for example, see Crase (2011) for a discussion of the Australian water situation). Markets, by contrast, allow for voluntary action informed by price signals and market forces. 


\subsubsection{Water Market Conditions}

Before the establishment of water markets in any area, four broad elements are needed to drive efficient use and outcomes. These are:

- A fixed limit to resource availability (set consumptive pool) that is ideally: (i) credible and based on accurate science; (ii) monitored and enforced; and (iii) consistent with sustainable levels of extraction;

- Users are provided with secure property rights in the form of an access entitlement to a share of that consumptive pool;

- These shares, and the water allocated to them each season, are tradeable under low transaction costs and entry/exit barrier conditions, such that ownership, control and use can change over time; and

- Prices for these shares and allocations that take into account externality costs to third-parties are established in a market that uses the value placed on water use by a large pool of well-informed buyers and sellers (NWC 2011; Bjornlund et al. 2013; Loch et al. 2013).

For groundwater markets in particular, there need to be well-defined rights with limited groundwater use allocations and monitoring of groundwater extraction by all users. These rights and allocation levels need to be based on a good understanding of the hydrogeology of a groundwater area, groundwater mobility and its sustainable yield, along with knowledge of dependent ecosystems and the way the aquifer responds to extraction. However, caution needs to be taken that property rights to water can be reduced when necessary for environmental or climate purposes, or due to uncertainty about watershed hydrology. It has been proposed that sustainable yield be managed by defining lower and upper bounds for water table levels and monitor them (Anderson and Snyder 1997). Entrenching property rights in water can be problematic. Firstly, there is the issue of dozer and sleeper rights (e.g. unused or unutilized water rights). For example, establishing water markets in Australia activated many unused licences, and reduced the water left in the river. Secondly, enshrining property rights holds dangers if there is incomplete knowledge of riverine ecosystems and future environmental needs for water (Crase et al. 2004; Young 2014).

\subsubsection{Difficulties in Establishing Groundwater Markets}

Bauer (1997) argues that establishing markets in water resources is difficult. Water markets are not natural or self-maintaining. Further, the institutional frameworks, the political and economic conditions, as well as geographic context are important influences on market function. Regulation is necessary to prevent third party effects and externalities. Despite the need to clearly define property rights, some aspects of water resources are inherently public goods and represent collective interests. Government oversight is also very important for markets to work effectively, 
particularly in relation to assessing trade applications, monitoring and reporting on the state of ground and surface water resources and market performance, revising trading rules as appropriate and ensuring water management plans are adequate (GHD et al. 2011). However, markets are embedded in institutions which can either facilitate or impede their optimal functioning. High transaction costs can be a significant disincentive to trade and they are likely to be particularly relevant when establishing new markets since they involve a change from historical systems of water management. Such costs can arise from the transaction itself or they can be generated by the institutional factors that are necessary in enabling trade (Skurray et al. 2013; Garrick et al. 2009).

\subsubsection{Property Right Issues}

The characteristics of groundwater and surface water and their interaction differ in ways that lead to various challenges in defining property rights to each type of resource. These differences also affect the complexities involved in developing water markets.

With surface water, movement across boundaries can be difficult to control. Moreover simultaneous and sequential users of water make exclusion difficult and create numerous interdependencies. Thus, multiple parties can be affected by surface water trading. Also, in some countries, individuals do not own water; it is owned by the state and held in trust for individual citizens, creating a legal impediment to developing property rights. There is also a chronological hierarchy in claims to water (similar to the framework of high, medium and low security water rights used in countries such as Australia) which may not be correlated to the value of its use (Brewer et al. 2008).

Surface water markets also depend on conveyance opportunities and the absence of canals, or rivers, to move water can decrease arbitrage opportunities. Markets tend to be local because of regulation between different states and the cost of transporting water over long distances (Brewer et al. 2008). It is essential that market boundaries are clearly defined; this relates to physical boundaries as well as volumetric ones. Finally, Crase et al. (2004) suggest that efficiency improvements may not return water to the environment unless there are institutional mechanisms to direct saved water to environmental flows.

In contrast, groundwater aquifers have many of the characteristics of a common property resource where the location of the user is important. Early work on groundwater management (e.g., Gisser and Sanchez 1980; Gisser 1983) modelled groundwater as a spatially homogeneous common property resource (i.e., the "bathtub" model), where one individual's groundwater use immediately affected all other users equally. More recent work (e.g., Brozović et al. 2010) shows that while groundwater aquifers have some characteristics of a common property resource, the impact of one individual's use on other users varies over space and time from one aquifer to another, depending on hydrological characteristics. This distinction is important for the appropriate definition of property rights and the region where trading is permitted. It is important for policymakers to first set the 
total level of groundwater use rights for an aquifer to a sustainable level, then the important task is the distribution of those rights over the aquifer.

Given the inherent and manifold difficulties in specifying property rights in groundwater, greater specification of rights and their conditions seems a tempting option. However, greater specification decreases the ease of transferability of rights. The greater the degree of specification, the thinner the market and the less benefits it will generate. The alternative to extensive specification of property rights is introducing other measures to prevent environmental and other third party effects (Skurray et al. 2013).

Aquifers can vary markedly in terms of their hydrogeological properties, with consequent variation in the ease of extracting water, the capacity for recharge, the difficulty of specifying property rights and the external costs associated with accessing groundwater from them. Therefore, it may be difficult to expect management regimes to be applied to a number of different aquifers. Furthermore, management regimes are often embedded in administrative jurisdictions that do not necessarily align with the boundaries of aquifers. Decision making must therefore address and integrate interconnected natural systems. A further element of flexibility relates to the temporal variation in aquifer 'behaviour'. Responsiveness to changing conditions should override a reliance on rigidly applied and upheld regulations (Skurray et al. 2013).

The physical differences between surface water and groundwater systems also affect the ease of monitoring water use. Well-defined property rights that are quantifiable and can be monitored are essential for a water market. Surface water systems are more likely to have (but note this is far from certain) a well-developed infrastructure of rivers and canals that make quantifying water use relatively straightforward. Water flows can be measured at each point of diversion to determine water use by individuals or communities. By contrast, groundwater is generally extracted through a network of individual wells, which are interconnected horizontally depending on geology. Quantifying water use can require installing flow meters at each well and collecting information on actual water use. Quantifying use also can be estimated by a range of various models. While the monitoring technology is readily available to collect this information for groundwater use, the cost of doing so is higher for groundwater than for surface water systems. The higher monitoring cost is one reason that many areas have been slower to limit groundwater than surface water. In addition, the interconnectedness of groundwater and surface water adds to the complexity of establishing property rights. Property rights to surface water and groundwater need to be coordinated to incorporate the physical connection between the two resources.

\subsubsection{Externalities}

Due to the common pool ownership of aquifers, and the unique physical properties of aquifers, externalities are easily created. Because of the spatially-dynamic nature of groundwater flow, the extent of various externalities depends on the quantity, location and time of extraction and the strategic behaviour of users. In a competitive and unregulated setting, the temporal and spatial profile of external effects results in 
inefficient pricing and misallocation; users take too much, too quickly and from what may be considered the wrong locations (e.g. closer to surface water rivers). Individual users of groundwater have, in the absence of regulation or other incentives, little reason to consider the increased pumping costs for other users as a result of the extraction they undertake (Katic and Grafton 2012). Nor is there much incentive to consider future costs associated with reduced stock. Finally, they have little reason to consider the impact of their activities on surface water, where groundwater extractions can decrease the amount of surface water available (Goesch et al. 2007). Regulation is needed. Groundwater is not used optimally by individuals who do not internalize the part of the extraction costs and environmental externalities in their pumping decisions. Extraction by one user will deplete the water supply and, because users believe competitors will not conserve water, there is little incentive to protect the storage. This is a significant reason for market failure and highlights the need for institutional arrangements. A key issue is therefore whether markets are capable of achieving balanced inter-temporal allocation of resources (Esteban and Albiac 2012).

\subsection{Actual Groundwater Trade}

Notwithstanding the complexity of the physical influences on groundwater, its use is also inextricably linked with socio-economic, legal, institutional and political systems. There are several drivers of groundwater access and use: other water sources; demographic and socio-economic factors; science and technological innovation; policies, laws and financial conditions; climate variability and market changes (changed demand, changed renewal, availability of other sources) (van der Gun 2012).

Surface water markets around the world occur mainly in semiarid areas and include: United States (mostly in the western states), Chile (Limarí River Valley), Australia (Murray-Darling Basin), Spain, Canada (South Saskatchewan River Basin), South Africa, China, Brazil, Mexico and Tanzania (Loch et al. 2013; Wheeler et al. 2014). All water markets can be hampered by political, technical, social and administrative factors. However, markets in groundwater face some particular challenges, including the three dimensional nature of aquifers, boundary uncertainties, water quality variation and local drawdown impacts. Groundwater markets are less common than surface water markets but some exist in Australia (Skurray et al. 2013; Skurray and Pannell 2010), China (Zhang et al. 2008; Wang et al. 2007), Oman (Zekri and Al-Marshudi 2008; Al-Marshudi 2007), the Indian Subcontinent (Meinzen-Dick 1998; Shah 1993; Easter et al. 1998) and the United States (Colby 2000; Colby and Bush 1987; Anderson and Snyder 1997; Griffin 1998).

The specific details of markets can vary by location. For example, in China, Oman, and India groundwater trading typically occurs when water is sold and transported to be used on non-adjacent land. In Australia and the United States groundwater trading generally involves selling the right to pump water from a 
shared aquifer. However, some of the major groundwater transfers in the US have taken place by purchasing water farms and pumping the water to distant cities, especially in Arizona, with detrimental impact on exporting regions This distant pumping has also taken place in California and Texas (Colby and Bush 1987; Anderson and Snyder 1997). The Omani and Indian/Pakistan groundwater markets provide some interesting insights on groundwater opportunities and problems. A brief discussion is provided in Box 20.1.

\section{Box 20.1: Examples of Groundwater Markets in Developing Countries India and Pakistan}

Informal groundwater markets have developed in India and Pakistan where irrigation water is supplied from deep tubewells which are costly to install (Meinzen-Dick 1998; Shah 1993; Easter et al. 1998). This excludes small farmers from accessing water. However, many of them can buy water from large farmers with excess capacity. There are various arrangements for payment: (i) the buyer pays an agreed amount or works for the larger farm in exchange for water; (ii) two-way share farming: one party supplies the water, the other the land and labour and all share net profits; (iii) three-way share farming: one party supplies the water, another the land and the third the labour and all share net profits.

These groundwater markets increase availability and reliability of water supplies; but the ability to sell water, combined with subsidized electricity prices, encourages over-extraction of groundwater. This results in increased pumping costs, elimination of use of shallow wells, and increased saline aquifers.

Oman

A unique groundwater market has developed in Oman within the falaj irrigation systems (Zekri and Al-Marshudi 2008; Al-Marshudi 2007; Bjornlund and Bjornlund 2010). There are 1,000 year old underground water mobilization systems tapping water from the top of mountain aquifers and transporting it by gravity-driven tunnels and canals to villages and fields (with domestic use given first priority). The system can only tap the aquifer's overflow, and access is granted in flow time only; hence access is correspondingly reduced in times of shortage. In most systems, the majority of water is controlled by the village community and semi-public charity organizations, such as the mosques. Many farmers are dependent on buying water access either on a weekly or annual basis. The proceeds from the weekly auctions are used to pay for the administration and maintenance of the falaj system, while the water controlled by semi-public organizations is sold annually and the proceeds go towards community activities. Many of the systems are currently under threat due to external encroachment on this communal resource (e.g. farmers have sunk tube wells into aquifers supplying the falaj systems).

The remainder of this paper studies in detail two of the most advanced countries in the world in terms of groundwater trading: Australia and the United States. 


\subsubsection{Australia}

In Australia, groundwater has typically been: (i) unmetered; (ii) provided free or at low prices; and (iii) 'managed' by management plans, which have not properly considered the connectivity between surface and groundwater (NWC 2012). Groundwater use almost doubled between 1983/4 and 1996/7, but this average masks a tripling in the states of New South Wales, Victoria and Western Australia (where much of Perth's drinking water supply comes from groundwater). Under the National Water Initiative (NWI), Australian governments are committed to:

- improving knowledge of ground-surface water connectivity;

- returning all over-allocated systems to sustainable levels of extraction;

- improving understanding of what is a sustainable extraction rate; and

- improving understanding of the relationship between groundwater and groundwater dependent ecosystems (NWC 2008).

The National Groundwater Action Plan, arising from the 2007 evaluation of progress of the NWI, seeks to take the actions needed to achieve these outcomes. The National Water Commission (NWC) concluded in 2008 that ongoing use of groundwater for consumptive use from 'stressed' aquifers and connected systems is an 'unacceptable risk'. They then developed a set of principles to guide subsequent action (NWC 2008). Developing water markets in groundwater was one such consideration, though there were many considerations that needed addressing first (Goesch et al. 2007).

In 2004-05, ABS (2006) estimated that groundwater access entitlements accounted for 146,185 (or $65 \%$ ) of all water access entitlements and 6,998 GL of water allocated in Australia. As at June 2012, NWC (2013) suggested there were 81,719 groundwater entitlements issued, covering about 6,600 GLs (the majority are in New South Wales, followed by Western Australia, Victoria, Queensland and South Australia) (Table 20.1).

Table 20.1 Groundwater entitlements on issue at 30 June 2012

\begin{tabular}{l|c|c}
\hline Jurisdiction & Number & Volume (GL) \\
\hline New South Wales (NSW) & 47,835 & 2,056 \\
\hline Queensland (Qld) & 8,153 & 1,008 \\
\hline Victoria (Vic) & 8,956 & 950 \\
\hline Western Australia (WA) & 11,400 & 1,713 \\
\hline South Australia (SA) & 4,911 & 620 \\
\hline Tasmania (Tas) & 0 & 0 \\
\hline Northern Territory (NT) & 232 & 125 \\
\hline Australian Capital Territory (ACT) & 262 & 76 \\
\hline Total & $\mathbf{8 1 , 7 1 9}$ & $\mathbf{6 , 5 9 6}$
\end{tabular}

Source: NWC (2013) 
Table 20.2 Groundwater entitlement and allocation trading in 2011-12

\begin{tabular}{|c|c|c|c|c|c|c|c|c|}
\hline & Qld & $N S W$ & Vic & $S A$ & $W A$ & $N T$ & Tas & $A C T$ \\
\hline Entitlement (no) & 0 & 208 & 304 & 202 & 68 & 0 & 0 & 0 \\
\hline $\begin{array}{l}\text { Entitlement volume } \\
\text { (ML) }\end{array}$ & 0 & 84,377 & 35,325 & 15,725 & 11,004 & 0 & 0 & 0 \\
\hline Allocation (no) & 62 & 134 & 97 & 41 & 29 & 0 & 0 & 0 \\
\hline $\begin{array}{l}\text { Allocation volume } \\
(\mathrm{ML})\end{array}$ & 3,688 & 26,972 & 7,524 & 2,147 & 4,255 & 0 & 0 & 0 \\
\hline
\end{tabular}

Source: NWC (2013)

Groundwater entitlement trading made up only about $12 \%$ of total trade in Australia in 2011-12 (NWC 2013). The number and volume of entitlement and allocation trade is shown in Table 20.2.

\subsubsection{Murray-Darling Basin (MDB) Groundwater Trade}

In the MDB, most surface and groundwaters are hydraulically linked; meaning that overuse of surface water will deplete aquifers, while increased groundwater extraction will adversely affect the supply of surface water. Groundwater comprises about $15 \%$ of irrigation water in the MDB, but this can increase to over $70 \%$ in some catchments in extended dry conditions (Richardson et al. 2011).

As of 2012, annual groundwater extractions from the MDB were 1,744 GL per annum. However, the MDB Plan allows for an increase up to a total of 4,340 GLs annually. Of this increase, $760 \mathrm{GL}$ is due to be extracted from aquifers that need to have extractions reduced or capped. In some areas of the MDB, extraction exceeds recharge capacity with poor long term outcomes for groundwater levels (Wentworth Group of Concerned Scientists 2012).

Policies and guidelines for sustainable groundwater extraction are currently being developed. In the past, an extraction limit was defined as part of a technical process and then announced via a water plan. This has worked reasonably well, but has led to some tensions. These tensions were mainly about the over-extraction of groundwater because of a development imperative, unchecked by knowledge of the ecological needs served by, and dependent on, groundwater (Richardson et al. 2011).

In some areas people use groundwater in dry periods to augment the supplies they receive from surface water (NWC 2011). Groundwater trade is permitted in New South Wales, South Australia, Victoria, the Northern Territory and Western Australia. However only a small amount of trade has occurred (e.g. Tables 20.2, 20.3, and 20.4).

Table 20.4 indicates that groundwater and unregulated trade only made up $2 \%$ of total MDB water allocation trade in 2011-12, while Table 20.3 shows it made up $14 \%$ of total MDB water entitlement trade. Overall, groundwater trading within the southern MDB increased significantly during the 2000s from 2-5\% of total groundwater use to 10-20\% (NWC 2010).

One of the first active groundwater markets was in the Northern Adelaide Plains, where urban encroachments into market gardening areas left many ground water 
Table 20.3 Australian water trade volumes

\begin{tabular}{l|c}
\hline (GL) in 2011-12 & Water entitlements \\
\hline MDB regulated & 1,065 \\
\hline MDB unregulated and groundwater & 153 \\
\hline Other water systems & 218 \\
\hline Australia total & 1,437 \\
\hline
\end{tabular}

Source: Adapted from data in NWC (2013)

Table 20.4 Water allocation trading volumes (GL), Australia, 2007-08 to 2011-12

\begin{tabular}{l|c|c|c|c|c}
\hline & $2007-08$ & $2008-09$ & $2009-10$ & $2010-11$ & $2011-12$ \\
\hline MDB Regulated & 1,376 & 1,663 & 2,118 & 3,340 & 4,127 \\
\hline $\begin{array}{l}\text { MDB Unregulated and } \\
\text { groundwater }\end{array}$ & 17 & 290 & 183 & 76 & 89 \\
\hline MDB total & 1,393 & 1,953 & 2,301 & 3,417 & 4,216 \\
\hline Other water systems & 201 & 205 & 194 & 77 & 81 \\
\hline Total Australia & 1,594 & 2,158 & 2,495 & 3,493 & 4,297 \\
\hline
\end{tabular}

Source: NWC (2013)

licenses unused. Trading was allowed to enable this water to move to remaining market gardeners. However, this caused water extraction to concentrate withdrawal in the most productive region and after only 4 years of trading a large cone of depression developed in this area. This resulted in the introduction of zones and trade limitation between some zones (Boyd and Brumley 2004).

Access to groundwater for irrigation is governed by entitlement and is usually separate from land and other property rights. Generally, each entitlement specifies the volume that irrigators can extract in a given year. But some entitlements specify daily pumping rates, while others specify additional volumes that can be withdrawn during droughts. Extraction in some areas is not sustainable. Sustainability is formulated by assessing extractions against sustainable yield. There is variation in the definition of sustainable yield. The National Groundwater Committee defines it as an extraction regime that allows acceptable levels of stress and protects economic, social and environmental values. This recognizes the trade-offs between competing uses (Goesch et al. 2007).

In the Namoi groundwater area in NSW, there is well developed trading in groundwater because of several initiatives. Firstly, over-allocation was addressed. This has allowed the setting of total extraction limits, with annual allocations announced at the beginning of the year. The key elements of successful trading activity in NSW are:

- high demand for groundwater;

- water sharing plans for aquifers based on sound scientific knowledge;

- access to perpetual licenses for users;

- transparent trading rules;

- efficient approval processes; and

- a system for metering and monitoring is in place (NWC 2011). 
Table 20.5 Groundwater and surface water allocation trade volumes, Namoi, 2006-07 to 2011-12 (ML)

\begin{tabular}{l|l|l|l|l|l|c}
\hline & $2006-07$ & $2007-08$ & $2008-09$ & $2009-10$ & $2010-11$ & $2011-12$ \\
\hline $\begin{array}{l}\text { Groundwater } \\
\text { allocation trade }\end{array}$ & 12,155 & 12,543 & 10,210 & 9,102 & 6,096 & 3,997 \\
\hline $\begin{array}{l}\text { Surface water } \\
\text { allocation trade }\end{array}$ & n.a. & 5,598 & 12,581 & 12,151 & 17,516 & 23,462 \\
\hline
\end{tabular}

Source: NWC (2013)

Table 20.5 illustrates the trade in groundwater and surface water allocations over the past 6 years. It highlights that groundwater trade was highest in the drought years of 2006-07 and 2007-08, while surface water trade is higher in years of higher rainfall (and higher water allocations).

Groundwater trade is comparatively much less developed in Victoria than in NSW. There seem to be a number of reasons for the under-developed trade in Victoria: (1) historical reliance on bulk water supply provider systems; (2) some groundwater regions are not fully allocated; (3) incomplete resource planning; and (4) underdeveloped market rules and institutions. In Victoria, just less than half of the groundwater management units are considered over-allocated, while $12 \%$ are considered less than $50 \%$ allocated. Within under-allocated units, new licenses are being issued and there is little incentive for trade. Furthermore, many 'sleeper' licenses have been issued. This would limit trade even in over-allocated areas, as many current licence holders already have the capacity to expand. However, there is compelling evidence that groundwater levels are declining in Victoria. Therefore, if increasing groundwater extraction continues, the predicted consequences of climate change eventuate and there is lack of recharge following drought, demand for trade should increase (NWC 2011).

A second barrier to trade in Victoria is lack of planning for management of groundwater resources. In areas designated as Water Supply Protection areas, trading in or out is not permitted until a management plan for the area has been developed. There have been delays in developing such plans because of lack of knowledge about aquifers and sustainable yields (again due to historical reliance on surface water systems and a lack of development on groundwater). In other areas, where trade in groundwater has been developed, or has the potential for such development, caps need to be set to ensure the volume that can be taken from a given groundwater management area in a given period is established. This requires defining the boundaries of the area so that they align with the hydrogeological boundaries of the aquifer and ensure that the boundaries of groundwater and surface water align. Without this consistent establishment of boundaries, it is difficult to properly manage the asset. There are a number of administrative barriers to groundwater trade in Victoria. These include unbundled licenses, licenses that are of short duration, lack of clarity about the basis for reducing seasonal allocations and complex and restrictive trading rules (NWC 2011). 


\subsubsection{Western Australia}

In 2011-12, there were over 11,000 ML of groundwater entitlements traded nationally and 4,255 ML of these groundwater allocations were traded in Western Australia (NWC 2013). In the Gnangara aquifer of Western Australia, the legal rights associated with a 10 year licence for a volume of groundwater are significantly attenuated because unused portions of water may be reclaimed by the relevant Minister. Rights can also be 'amended' by the Minister in order to protect third parties. In addition, the Government can amend a license if the reason for the use of water is not appropriate. Further, licences are time limited and do not represent an unconditionally owned asset. There are up to 80 conditions that relate to well depth, monitoring, infrastructure, reporting and time of use requirements (Skurray et al. 2013). Thus the property rights entailed by having a licence for Gnangara groundwater is administratively restricted, purpose limited, and time limited with conditional rights that are vulnerable to cancellation or amendment. While it might be argued that the Government control of certain aspects of water rights is a means to guarantee sustainable management of the resource, this has not proved to be the case. The current arrangements do not meet the NWI's guidelines for the creation of effective markets, despite the fact that the WA government is a signatory to the agreement. Transfers of water can only be made to a person who either owns, or occupies, the land on which the water will be used, or they must have written permission from the land owner to use the land for activities which are deemed appropriate under the conditions of the water licence. These significantly constrain the transferability of licences. The process for applying to transfer water is cumbersome, expensive and does not adequately maintain confidentiality. Moreover, even where transfers are approved by the Minister's office, they can be overridden by local regulations (Skurray et al. 2013).

\subsubsection{United States of America (US)}

Of critical importance in understanding the existence and potential for groundwater trading in the United States is the fact that water law is generally determined at the state level, as opposed to the federal level. There are some exceptions (e.g. the Endangered Species Act, which trumps state-level decisions when the habitat of an endangered species is at risk, or compacts that regulate interstate rivers such as the Colorado River). However, most groundwater law, including the rights structure, regulation, and the potential for groundwater trading varies by state and some states have further devolved groundwater management to regions, counties, or basins. For example, Texas groundwater law has historically given landowners an absolute right to use groundwater below the land, while Nebraska law is defined by "reasonable use" and "correlative" rights, which mean that groundwater users are expected to manage the resource jointly and restrictions affect all users equally.

The Edwards Aquifer in Texas has implemented regulation that restricts groundwater use and allows trading but the changes are not comprehensive across the state. In fact, in 2011 the Texas Legislature passed a bill that upheld the interpretation that 
landowners that are not in the Edwards Aquifer management area have "a vested ownership interest in and right to produce groundwater below the surface" (Eckhardt 2013). Kansas and Idaho use appropriative rights for groundwater so that groundwater is managed based on a "first in time, first in right" basis. Arizona regulates groundwater use based on a state law that requires an assured water supply for users (Megdal 2012), while California has little groundwater regulation at the state level, but allows local areas to develop more restrictions (Hanak 2003; Jacobs 2006).

States in the western parts of the US enshrined the environment's right to water under common law doctrines. However, given that these regulatory and administrative regimes are implemented by individual states, the result is very uneven in terms of the amount of reform achieved in each jurisdiction. Increasingly, private entities have engaged in buying or leasing high security water for the environment. As this activity has increased, so too has monitoring, scrutiny of transfer and enforcement of regulations (Garrick et al. 2009). While most of the purchases of water for environmental benefits have been for surface water, there are some cases where protecting environmental quality also helps groundwater resources. For example, protecting natural wetlands such as the playa system in the Southern High Plains has environmental benefits via the provision of important habitat and also helps recharge groundwater aquifers (Bolen et al. 1989).

Another important distinction between surface and groundwater rights is the incentive to use water. While the details vary by state, western states in the United States generally use the prior appropriation system for surface water. Under prior appropriation, failure to continue using water can result in rights being lost; this is a disincentive to using less water and those who save water often see it forfeited to others. This creates a situation in which there are rewards for using a lot of water to grow low value crops. California eliminated this disincentive with a regulation that allowed water saved to be sold, leased or transferred (Brewer et al. 2008). However, Garrick et al. (2009) suggests that the prior appropriation doctrine establishes an implicit cap on the amount of water available, which has been an incentive to the development of trading. In contrast, groundwater rights are more frequently determined on the basis of land ownership and are less likely to be subject to a "use it or lose it" clause. ${ }^{1}$ While this reduces the incentive for overuse, it fails to provide the implicit cap on available water.

Brewer et al. (2008) found in their review of surface water markets in the US that:

1. Agriculture is the origin for many of the transactions;

2. The annual flow of water traded and the amount of water committed for transfer show different patterns;

\footnotetext{
${ }^{1}$ This varies by state. In some states (e.g., Idaho, Montana) groundwater rights are based on prior appropriation and can be lost if unused. Other states (e.g., Arizona, California, Nebraska, and Texas) base rights on land ownership, making it difficult to lose a right if the land or pumping right is not sold.
} 
3. Number of trade transactions is increasing (mainly accounted for by agricultureto-urban trades);

4. Sales and multi-year leases are growing, while 1 year leases are not;

5. Arizona, Texas and California are among the top four states on any measure of trading;

6. Agriculture -to-urban trades account for most permanent trades on committed trade measures, while agriculture -to- agriculture trades account for most of the annual leases;

7. In comparing sales and leases across a number of US western states, prices varied more across states than across sectors and this differential reflects differences in demand and supply characteristics, transaction type, transaction costs and regulatory restrictions that prevent arbitrage across states. Sales are more common than leases of water (because of the greater security they provide) and this is reflected in increasing sales prices while those for leases have declined relatively; and

8. Finally, the price data reveal that urban users pay considerably more for water than agricultural users.

In contrast to surface water, in most places groundwater rights are not quantified; that is, there is no legal right for users to withdraw a specific amount of water. Thus there is a general right for all those who are located above the aquifer to pump from it. Basins where the rights to groundwater are specified are located primarily in urban areas. They usually charge pumping fees and manage recharge programs. The development of clearly defined and limited property rights to groundwater is a necessary condition for further development of groundwater trading.

\subsubsection{California}

While surface water markets were introduced in California in the late 1970s, the factors leading to their expansion in the 1990s were severe drought and government mandated environmental flows. Trade was initially spurred by dry years, but has persisted since the return of normal precipitation. In its early stages, most transfers were short term trades such as 1 year leases, but the percentage of longer term leases and permanent sales has increased. The proportion of sales has fluctuated but the trend in longer term leases is sustained. Since the late 1980s, the percentage of water bought or leased for cities and the environment has continued to increase relative to other uses (Hanak and Stryjewski 2012). However, there is some indication that overall trade has slowed in recent years (Hanak and Stryjewski 2012).

California provides an interesting example of water regulation and trading, with surface water laws clearly defined and a thriving surface water market, while groundwater regulation and associated trading is extremely limited and very little data exist. While groundwater management is improving in the state overall, it is still largely a voluntary system and groundwater regulations are primarily determined at a local level (Hanak and Stryjewski 2012). Groundwater is an important source of 'wet water' in California and groundwater transfers are subject to less 
oversight by the state than surface water since the state's water code does not cover groundwater (Hanak and Stryjewski 2012). Historically this meant that there was little regulation over groundwater use. This was highlighted after many surface water irrigators sold their water rights to the state in the drought of the late 1980s and early 1990s, only to respond by pumping groundwater as a substitute. This trend has not changed and the same pattern of irrigators substituting groundwater for limited surface water availability was also seen in the late 2000s (Famiglietti et al. 2011).

Groundwater banking has emerged as an important tool in California's water management, which involves the deliberate storage of surface water in aquifers during wet years (Hanak 2005). Since 2000, the state has been making active attempts to facilitate groundwater storage, which is part of the strategy to encourage conjunctive use of water as part of a diversification process (Hanak and Stryjewski 2012). The term "groundwater banking" is a misnomer: while a useful tool for managing water, in most parts of the state it is really a conjunctive management system although the details are case-specific. For example, some districts that use groundwater are purchasing surface water to augment local aquifers for local use. In other cases, municipalities are purchasing storage space in existing aquifers to store surface water. Groundwater banking describes the practice of storing surface water in natural or created aquifers during wet periods to save the water for dry periods. There are many benefits of groundwater banking for overall water management. It is a relatively cost-effective way to bolster water supplies especially in drought times. It also will help mitigate the loss of seasonal storage provided historically by the Sierra Nevada snowpack, which is expected because of climate change. Groundwater banking has become common in California (Hanak and Stryjewski 2012) and in Arizona (Megdal 2012) but typically does not actually involve the transfer of existing (i.e. natural) groundwater. However, any transfer of the banked water is often limited by local ordinances, limiting the benefits of water trading (Hanak and Stryjewski 2012).

There is a history of aquifers being drained, with adverse consequences for other users in California. This background helps to explain the development of local ordinances and the contemporary resistance to groundwater export from local communities. Many of the local ordinances restrict the export of groundwater. These ordinances are a significant deterrent to groundwater trade, which in many areas make groundwater transfers more difficult than surface water trades (Hanak 2003; Hanak and Stryjewski 2012). The efficiency of the approvals process for handling transfers is an important determinant of benefits of a market. Some counties place restrictions on groundwater exports and limitations on groundwater substitution transfers, while some aim to restrict groundwater banking with non-local parties. There are no state level 'no injury' groundwater protection statutes that can regulate groundwater (Hanak and Stryjewski 2012). In addition, there is local resistance to recent attempts by the state to collect information on groundwater use and groundwater levels. Without such information it is nearly impossible to develop a well-managed system of regulated groundwater rights that can facilitate groundwater trading. 
In summary, California provides an interesting example that shows strong differences in the approach to developing trade in groundwater versus surface water. However, despite the growing maturity of the surface water market, overall trade has been declining since 2003, despite some drought years since 2000. A number of factors appear to explain the reduction in surface water trade. New pumping restrictions since 2007 have impeded north to south and east to west transfers around the Delta. Aspects of the approval process have also impeded transfers (Hanak and Stryjewski 2012). At the same time, county ordinances have limited groundwater transfers. These transfers are subject to environmental strictures over and above those related to the 'no injury' to environmental flows. In both surface and groundwater, recent high commodity prices are associated with a reluctance to lease/sell water. Finally, the existence of different kinds of water rights with separate approval processes has dampened the market. Overall, developing a more robust groundwater market will require additional restrictions to limit groundwater use and well-defined property rights that are streamlined across different counties.

\subsubsection{Nebraska}

Nebraska has developed a system where groundwater law is developed at the state level but administered and managed at a local level. Groundwater law follows a system of correlative rights, which means that all groundwater users have equal rights to use the resource. The state is divided into 23 natural resource districts, or NRDs. The NRD boundaries are determined by watersheds and each NRD has responsibility for managing natural resources such as groundwater and soil. Each NRD has substantial autonomy in choosing how to interpret and apply any state groundwater laws, and they frequently impose additional regulations above state limits. In contrast, surface water use is managed by the state using a prior appropriation system.

Unlike states such as California that rely primarily on surface water, ${ }^{2}$ groundwater is the major source of water for Nebraska, providing approximately $85 \%$ of total water used (Kenny et al. 2009). Historically surface water and groundwater law in the state were separate. However, legal changes since the mid-1990s have provided legal recognition to the many hydraulically-connected surface and groundwater systems in the state. Much of the state's groundwater is connected to surface water basins, including the Platte River Basin and the Republican River Basin. A law passed in 2004 (Legislative Bill 962) requires many of the NRDs to cooperatively develop integrated management plans (IMPs) to specify how hydraulically connected groundwater and surface water will be jointly managed. One outcome of this change is that groundwater wells need to be certified, registered, and metered in much of the state. In addition to metering, many NRDs have set groundwater allocations for each well, establishing binding property rights for groundwater users. This combination of factors has allowed some of the NRDs to

\footnotetext{
${ }^{2}$ Approximately $80 \%$ of total water use in California is from surface water (Kenny et al 2009).
} 
permit groundwater trading to be used to improve the economic efficiency of groundwater use. However, variation exists between the approaches used by different NRDs:

Upper Republican Natural Resource District (URNRD): The URNRD was an early adopter of groundwater regulation. This primarily rural district, located in southwest Nebraska, initially required all irrigation wells to install flow meters in 1979. Use restrictions were also implemented in the same year, although the initial allocation levels were sufficiently high that users were not constrained. Allocations are determined for a multi-year period (typically for 5 years) and the allocations have gradually decreased. Initial water allocations were set at $5,610 \mathrm{~m}^{3} /$ year/hectare and current allocations are $3,315 \mathrm{~m}^{3} /$ year/hectare $(\mathrm{RRB}$ 2013). The expansion of acres is controlled, setting a cap on total water use. The allocation rights are allocated to each field based on the size of the field. Given the binding allocations and history of monitoring, the URNRD is well-suited for groundwater trading.

In the URNRD, an irrigator can transfer part of his/her water allocation to another irrigator if the water will be used within a confined geographical region (9,324 hectares). This constraint has advantages and disadvantages. The advantages are that it reduces regional economic impacts associated with the transfer of groundwater and can reduce the chance of cones of depression, where groundwater pumping is concentrated in a small area. Disadvantages accrue from limiting potential trading partners, reducing the potential economic benefits of trade. Relative to surface water, groundwater transfers have few technical impediments since the right to pump is transferred as opposed to the wet water. One impediment to groundwater transfers has been high transaction costs. There is no mechanism to help prospective buyers and sellers find trade partners. In addition to formally transferring allocation, the URNRD also allows an irrigator to combine the pumping rights to all of his/her land in a limited geographical area. This creates a defined set of fields (referred to as a "pool"). Total groundwater use is limited for the pool of fields, but the irrigator can choose how to distribute the total allocation between fields. This allows flexibility to move water from one field to another due to differences in soil type or crop choice. Many producers use pools to help manage their water allocation, and this suggests that reducing the transaction costs for formal trading would lead to more trades and greater economic benefits. In a recent analysis, Juchems (2013) found that indicators of profitability such as soil type, depth to groundwater, and pumping capacity are strong indicators of the direction of trade in both formal trades and within-pool transfers.

Lower Republican Natural Resource District (LRNRD): As with the URNRD, the LRNRD establishes multi-year groundwater allocations for irrigators. Due to changes in state law, the NRD began metering and limiting groundwater allocations in 2005. Unlike the URNRD, transfers of groundwater allocation are not permitted. Research suggests that modifying the rules to allow groundwater 
transfers would have economic benefits, and would allow the NRD to reduce overall groundwater use at a very low cost (Palazzo and Brozović 2014).

Central Platte Natural Resource District (CPNRD): The motivation for improved water management is different in the Platte River Basin than in the Republican River Basin. Both are interstate rivers and restrictions on hydraulically connected groundwater in the Republican River Basin have been necessary to provide enough water to Kansas (the downstream state). In contrast, restrictions on hydraulically connected groundwater in the Platte River Basin are designed to improve instream flow for endangered species. A series of interstate agreements and legislative changes between 1997 and 2006 led to the current restrictions and water management plan for the CPNRD.

The CPNRD has developed a number of tools to help groundwater users manage their water allocation. First, the CPNRD allows groundwater users to transfer (trade) the right to pump groundwater to another location. Transfers are permitted between the NRD and other NRDs as long as the transfer is approved (CPNRD 2012). The permitting process is designed to ensure that any transfer does not lead to additional depletion from the river. As seen in the URNRD, oneto-one transfers can have high transaction costs due to the difficulty of finding a trading partner. In addition to one-to-one transfers, the CPNRD has developed a water bank. To date most of the water bank activities have been permanent buyouts of irrigated land (both groundwater and surface water). However, the water bank has been designed to also permit some flexibility, with individual producers able to purchase water. While the program is still fairly new, the centralized system is expected to lead to lower transaction costs, more trades, and higher economic benefits from water use.

While each of the 23 NRDs differs in their approach to managing groundwater, these three examples highlight some of the groundwater trading activities that are already occurring. Jointly, these three case studies show evidence that there is demand for transfers and flexibility when it is permitted. The URNRD, which is fairly restrictive with formal transfers, had approximately 40 transfers during the 2005-2011 period (Juchems 2013). Transfers within a pool of fields are extremely common. The CPNRD has a more established system for transfers, and has approved many transfers. Thus, a key lesson from these experiences is that even with high transaction costs, there are economic benefits from groundwater transfers. While local control of groundwater resources is politically important across the state, the differences between districts illustrate how economic efficiency may be improved by relaxing constraints on groundwater trading and reducing transaction costs. Transferring the right to pump water, instead of moving water, reduces transportation costs but without oversight may lead to the problem of more intensive pumping in a small area, resulting in cones of depression.

\subsubsection{Edwards Aquifer (Texas)}

Texas has historically had a rule of capture for groundwater, where a landowner has the right to use groundwater below his or her land. While some of the state still 
operates under a 'rule of capture', the Edwards Aquifer in south-central Texas provides an example of groundwater management that includes some restrictions on use and permits groundwater trading. Motivated by threats to endangered species' habitat that depend on aquifer flow, the Texas legislature passed Senate Bill 1477 (SB 1477, known as the Edwards Aquifer Authority Act) in 1993 (Boadu et al. 2007). SB 1477 changed the water rights structure for groundwater users, created a permit system that gave a right to use a specified quantity of water, and created the Edwards Aquifer Authority (EAA). While some initial rights were allocated in the late 1990s, many water users felt the allocation was unjust, leading to extensive litigation (Colby 2000). A series of legal challenges delayed the assigning of most water rights until 2001 and 2002, when the legal authority of the EAA to restrict groundwater use was upheld by the Texas Supreme Court (Eckhardt 2013). Legal challenges have continued to lengthen the process of regulating the Edwards Aquifer, reducing the benefits of water permits and trading, and increasing stress on endangered species.

An analysis of the potential changes due to the regulation in SB 1477 finds that without regulation, low water flow will significantly affect habitat for endangered species (Gillig et al. 2004; Boadu et al. 2007). A recent analysis of proposed legislative changes has compared expected water flows and economic benefits with and without regulation and water markets. Results show that under regulation, flows are higher without water markets but that regulated water markets are necessary for habitat needs and that the economic loss due to regulation is reduced when trading is permitted (Gillig et al. 2004; Boadu et al. 2007). Results also show that unregulated groundwater use is expected to lead to insufficient water flow for endangered species.

The experience in the Edwards Aquifer shows that legal battles can reduce the benefits of water trading and regulation. In 2013, almost 20 years after the initial legislation to regulate groundwater and create tradable permits was passed, the expected benefits have still not been realized.

\subsection{Lessons Learned from Groundwater Trade in Australia and the US}

There are a number of lessons that can be learned from this review of groundwater trade in Australian and the US. They include:

1. Institutions matter: While there are physical limits on the operation of groundwater markets, in Australia it appears that institutional barriers are as significant an impediment to trade as hydrogeological factors. While groundwater trading is permitted everywhere, only in a few states is there much market activity and there are few trades relative to the number of entitlements held; this is largely because trades are concentrated in particular areas. There is no consistency about whether products are unbundled across states (NWC 2011). Variation in the 
rules established by Nebraska's different NRDs affects the frequency and feasibility of groundwater trading. The legal institutions involved in the management of the Edwards Aquifer in Texas have played a role in impeding the development of a viable water market.

2. Science matters: Before groundwater markets can be established, it is critical to understand and specify the boundaries of a groundwater management system. Groundwater systems should be based on physical aquifers, have clearly defined boundaries based on hydrogeological features. Interactions between surface water and groundwater need to be understood and incorporated, as well as the water quality of the system and the social and environmental externalities. Entitlement and extraction limits must be as accurate as possible, as should processes for changing long term entitlement and extraction limits, determining allocation limits and restricting extractions during periods of shortage (GHD et al. 2011).

3. A crisis can be an opportunity: Several examples of successful restructuring of water rights and the development of water trading are due to necessity. For example, a major impetus for the development and expansion of surface water markets in both Australia and California was a multi-year drought in the late 1980s and early 1990s (Bjornlund and McKay 2000; Hanak 2003). In California, where statewide groundwater legislation does not exist, courts have adjudicated radical changes to groundwater rights, management and trading in examples of severe stress, such as in the Tehachapi Basin and Mojace Basin north of Los Angeles (Anderson and Snyder 1997). Interstate legal conflicts in Nebraska led to legislative changes in the joint management of hydraulically connected surface and groundwater.

4. Economics matters: As well as the need to put proper institutions in place, there is a need for economics in groundwater management. There is a need to consider how many users there are in a management area, the value to be gained from trading groundwater, and the costs involved in establishing a market. A properly established market will grow in trade over time, and optimal water prices achieve efficient management by balancing benefits and costs across users and across time (Hansen 2012). Rural water users in the western USA have typically paid only for conveyancing and pumping cost of water, not its scarcity value. Markets will allow the movement of water to high value users.

5. Society's concerns do not always matter: Although policy needs to be concerned with social externalities from water markets, it is not something that should always be considered for designing efficient groundwater markets. This is where other policy needs to be put in place to address those rural social concerns; water markets should not be used as a second-best tool to address their problems. There have been a myriad of concerns about equity, low income impacts, rural community depopulation and the belief that water is a public good that have led commentators to imply that water should not be commodified (NWC 2012). However, setting water prices artificially low will result in inefficient pumping and consumption, and not allowing water markets to develop will deny rural users a valuable adaptation and risk measure (Hansen 2012). 
Finally, the most important point that needs elaborating upon is that flexibility matters. Flexibility in institutions, in policy, in scientific and social science research is needed to continually deal with changes in the environment, the climate and in rural conditions. There is an element of path dependence that has resulted in the way institutions in each country are established and policy prescriptions for a variety of environmental and water scarcity problems are made. In California, water marketing and groundwater banking are essential tools for helping water users to manage their scarce water resources more efficiently and sustainably. The continual development of such tools augments the ability to cope with future droughts (Hanak and Stryjewski 2012). In Australia, the decision to institute water markets, the setting of the initial Cap on water use and the inability to recognise that this would activate many unused water rights by such water owners selling their water, has led to the situation in the 2000s where governments are buying back billions of dollars of surface water entitlements in the MDB. By significantly increasing the demand for water entitlements (and paying what is perceived to be higher prices for water), this has also activated many farmers selling their surface water, and increasingly turning to their groundwater entitlements to support their farm production. It is predicted that this growth in groundwater use is unsustainable in the MDB. Such a situation highlights the importance of history, and of how various policy decisions play a part in creating further externalities down the line. It also highlights that policy needs to be flexible to deal with unintended externalities that have resulted from previous attempts to solve water issues.

Acknowledgements We are grateful for the research assistance of Jane Edwards in helping to prepare this manuscript. This research was supported by an ARC Discovery project DP140103946 and ARC Future Fellowship FT140100773.

Open Access This chapter is distributed under the terms of the Creative Commons AttributionNoncommercial 2.5 License (http://creativecommons.org/licenses/by-nc/2.5/) which permits any noncommercial use, distribution, and reproduction in any medium, provided the original author(s) and source are credited.

The images or other third party material in this chapter are included in the work's Creative Commons license, unless indicated otherwise in the credit line; if such material is not included in the work's Creative Commons license and the respective action is not permitted by statutory regulation, users will need to obtain permission from the license holder to duplicate, adapt or reproduce the material.

\section{References}

ABS (Australian Bureau of Statistics) (2006) Water account Australia: 2004-05. Australian Bureau of Statistics, Canberra

Al-Marshudi A (2007) The falaj irrigation system and water allocation markets in Northern Oman. Agric Water Manage 91:71-77 
Anderson T, Snyder P (1997) Water markets: priming the invisible pump. Cato Institute, Washington, DC

Athukorala W, Wilson C (2012) Groundwater overuse and farm-level technical inefficiency: evidence from Sri Lanka. Hydrogeol J 20:893-905

Bauer C (1997) Bringing water markets down to earth: the political economy of water rights in Chile, 1976-95. World Dev 25:639-656

Bennett J (2008) Defining and managing environmental flows: inputs from society. Econ Papers 27:167-183

Bjornlund V, Bjornlund H (2010) Sustainable irrigation: a historical perspective. In: Bjornlund H (ed) Incentives and instruments for sustainable irrigation. WIT Press, Southampton, pp p13-p24

Bjornlund H, McKay J (2000) Are water markets achieving a more sustainable water use? In: Proceedings from the Xth world water conference, Melbourne, 11-17 Mar

Bjornlund H, Wheeler S, Rossini P (2013) Water Markets and Their Environmental, Social and Economic Impact in Australia. In: Maestu J (ed) Water Trading and Global Water Scarcity: International Perspectives. RFF Press, Abingdon, pp 68-93

Boadu FO, McCarl B, Gillig D (2007) Empirical investigation of institutional change in groundwater management in Texas: the Edwards Aquifer case. An Nat Resour J 47:117-163

Bolen E, Smith M, Schramm H (1989) Playa lakes: prairie wetlands of the southern high plains. BioScience 39:615-623

Boyd T, Brumley J (2004) Optimising sustainable use of groundwater: a challenge for science and water markets. In: Paper presented at the 1st international conference on sustainability engineering and science, Auckland, 6-9 July 2004. Available at www.thesustainabilitysociety.org. nz. Accessed 4 July 2013

Brewer J, Glennon R, Ker A et al (2008) Water markets in the west: prices, trading and contractual forms. Econ Inq 46:91-112

Brozović N, Sunding D, Zilberman D (2010) On the spatial nature of the groundwater pumping externality. Res Energy Econ 32:154-164

Colby B (2000) Cap-and-trade policy challenges: a tale of three markets. Land Econ 4:638-658

Colby S, Bush D (1987) Water markets in theory and practice. Market transfer. Water values and public policy. Studies in water policy and management. Westview Press, Colorado

Crase L (2011) The fallout to the guide to the proposed basin plan. Aust J Publ Admin 70:84-93

Crase L, Pagan P, Dollery B (2004) Water markets as a vehicle for reforming water resource allocation in the Murray-Darling Basin. Water Resour Res 40:1-10

CPNRD (Central Platte Natural Resource District) (2012) Integrated management plan. http:// www.cpnrd.org/IMP\%20Final.pdf. Accessed 5 May 2013

Easter K, Dinar A, Rosengrant M (1998) The performance of water markets: transaction costs, interjurisdictional barriers and institutional options. In: Just R, Netanyahu S (eds) Conflict and cooperation on trans-boundary water resources. Kluwer, Boston, pp 299-313

Eckhardt G (2013) The Edwards Aquifer website. http://www.edwardsaquifer.net/rules.html. Accessed 3 July 2013

Esteban E, Albiac J (2012) The problem of sustainable groundwater management: the case of La Mancha aquifers, Spain. Hydrogeol J 20:851-863

Famiglietti J, Lo M, Ho S et al (2011) Satellites measure recent rates of groundwater depletion in California's Central Valley. Geophys Res Lett 38:L03403. doi:10.1029/2010GL046442

Garrick D, Siebentritt M, Alyward B et al (2009) Water markets and freshwater ecosystem services: policy reform and implementation in the Columbia and Murray-Darling Basins. Ecol Econ 69:366-379

GHD et al (2011) A framework for managing and developing groundwater trading. Waterlines report. National Water Commission, Canberra. http://archive.nwc.gov.au/_data/assets/pdf_ file/0019/10378/52_framework3.pdf. Accessed 10 May 2014

Gillig D, McCarl B, Jones L et al (2004) Economic efficiency and cost implications of habitat conservation: an example in the context of the Edwards Aquifer region. Water Resour Res. doi:10.1029/2003WR002749 
Gisser M (1983) Groundwater: focusing on the real issue. J Polit Econ 91:1001-1027

Gisser M, Sanchez D (1980) Competition versus optimal control in groundwater pumping. Water Resour Res 16:638-642

Goesch T, Hone S, Gooday P (2007) Groundwater management: issues affecting the efficient allocation of groundwater. Aust Commod 14:200-211

Griffin R (1998) The application of water market doctrines in Texas. In: Easter K, Rosengrant M, Dinar A (eds) Markets for water. Potential and performance. Kluwer, Boston, pp 51-64

Hanak E (2003) Who should be allowed to sell water in California? Third-party issues and the water market. Public Policy Institute of California, San Francisco

Hanak E (2005) Stopping the drain: third-party responses to California's water market. Contemp Econ Policy 23:59-77

Hanak E, Stryjewski E (2012) California's water markets, by the numbers: update 2012. Public Policy Institute of California, San Francisco

Hansen J (2012) The economics of optimal groundwater management in Southwestern USA. Hydrogeol J 20:865-877

Jacobs N (2006) California: groundwater management, conjunctive use and water banking. West Water Law Policy Rep 10:122-125

Juchems E (2013) Predicting groundwater trading participation in the Upper Republican River Natural Resource District. Masters Dissertation, University of Nebraska-Lincoln

Katic P, Grafton R (2012) Economic and spatial modelling of groundwater extraction. Hydrogeol J 20:831-834

Kenny J, Barber N, Hutson S et al (2009) Estimated use of water in the United States in 2005. U.S. Geological Survey Circular, Reston, 1344

Loch A, Wheeler S, Bjornlund $\mathrm{H}$ et al (2013) The role of water markets in climate change adaptation. National Climate Change Adaptation Research Facility, Gold Coast

Megdal S (2012) Arizona groundwater management. The water report. http://www.cwi.colostate. edu/southplatte/files/TWR_AZGroundWaterManagement.pdf. Accessed 10 May 2014

Meinzen-Dick R (1998) Groundwater markets in Pakistan: institutional development and productivity impacts. In: Easter K, Rosengrant M, Dinar A (eds) Markets for water-potential and performance. Kluwer, Boston, pp p207-p222

Moreaux M, Reynaud A (2004) Optimal joint management of a coastal aquifer and a substitute resource. Water Resour Res 40:W06S18. doi:10.1029/2003WR002166

NWC (2008) National water commission groundwater position statement. http://www.nwc.gov. au/_data/assets/pdf_file/0009/9729/Groundwater-position_statement.pdf. Accessed 26 Apr 2013

NWC (2010) The impact of water trading in the southern Murray Darling basin: an economic, social and environmental assessment. NWC, Canberra

NWC (2011) Strengthening Australia's water markets. NWC, Canberra

NWC (2012) Groundwater essentials. NWC, Canberra

NWC (2013) Australian water markets: trends and drivers 2007-08 to 2011-12. NWC, Canberra

Palazzo A, Brozović N (2014) The role of groundwater trading in spatial water management. Agric Water Manage. http://dx.doi.org/10.1016/j.agwat.2014.03.004

Richardson S, Evans R, Harrington G (2011) Connecting science and engagement: setting groundwater extraction limits using a stakeholder led decision-making process. In: Grafton Q, Connell D (eds) Basin futures: water reform in the Murray-Darling basin. Australia National University Press, Canberra

RRB (Republican River Basin) (2013) Sustainability steps - previous and planned actions in the republican basin to preserve water. Available at: http://www.urnrd.org/. Accessed 10 May 2014

Shah T (1993) Groundwater markets and irrigation development. Political economy and practical policy. Oxford University Press, Bombay

Shah T (2009) Taming the anarchy: groundwater governance in South Asia. Resources for the Future, Washington, DC 
Sitarz D (1993) AGENDA 21: the earth summit strategy to save our planet. Earth Press, Boulder Skurray J, Pannell D (2010) Potential approaches to the management of third-party impacts from groundwater transfers. Hydrogeol J 20:879-891

Skurray J, Pandit R, Pannell D (2013) Institutional impediments to groundwater trading: the case of the Gnangara groundwater system of Western Australia. J Environ Plan Manag $56: 1046-1072$

van der Gun J (2012) Groundwater and global change: trends, opportunities and challenges. UNESCO, Paris

Wang J, Huang J, Blanke A et al (2007) The development, challenges and management of groundwater in rural China. In: Giordano M, Giordano M, Vilholth K (eds) The agricultural groundwater revolution: opportunities and threats to development. CABI, Wallingford/ Cambridge, MA

Wentworth Group of Concerned Scientists (2012) Statement on the 2011 Draft Murray-Darling Basin Plan. http://wentworthgroup.org/wp-content/uploads/2013/10/Statement-on-the-2011Draft-Basin-Plan.pdf. Accessed 10 May 2014

Wheeler S, Loch A, Zuo A, Bjornlund H (2014) Reviewing the adoption and impact of water markets in the Murray-Darling Basin, Australia. J Hydrol 518:28-41

Young M (2014) Designing water entitlement regimes for an ever-changing and ever-varying future. Agric Water Manag. http://dx.doi.org/10.1016/j.agwat.2013.12.002

Zekri S, Al-Marshudi A (2008) A millenarian water rights system and water markets in Oman. Water Int 33:350-360

Zhang L, Wang J, Huang J et al (2008) Development of groundwater markets in China: a glimpse into progress to date. World Dev 36:706-726 


\title{
Integrated Assessment of Economic Benefits of Groundwater Improvement with Contingent Valuation
}

\author{
Cécile Hérivaux and Jean-Daniel Rinaudo
}

\begin{abstract}
This chapter investigates the potential and limits of the contingent valuation method for assessing the benefits of groundwater remediation or protection programs. The discussion is based on a review of the literature and on two original contingent valuation surveys conducted in France and in Belgium, in contexts where groundwater was expected to be particularly unfamiliar to respondents. Particular attention was paid to (i) people's perception and understanding of the resource under study, and (ii) type and quantity of information provided by the questionnaire. In both cases, we show that the population is concerned about groundwater remediation or protection, especially to guarantee the wellbeing of future generations. Overall, we highlight that assessing willingness to pay through contingent valuation surveys is helpful for conducting an integrated valuation of groundwater protection benefits. However, we also point out two main limits which might restrict the relevance of the results obtained: (1) the respondents' limited prior knowledge of groundwater and the risk that information provided by the questionnaire biases the elicitation process; and (2) two types of embedding effect, with the difficulty for respondents in considering the geographic extension of an aquifer and disentangling benefits derived from groundwater quality improvement from other environmental benefits.
\end{abstract}

C. Hérivaux $(\square)$

BRGM, New resources and economics Unit, 1039 rue de Pinville, 34000 Montpellier, France e-mail: c.herivaux@brgm.fr

J.-D. Rinaudo

Water Department, BRGM, French Geological Survey, Montpellier, France

e-mail: jd.rinaudo@brgm.fr 


\subsection{Introduction}

Since the industrial revolution, the development of industrial and other economic activities has generated significant pressures on groundwater resources, in developed and in developing countries. Many aquifers were contaminated by point and non-point source pollution or were over-abstracted, sometimes leading to irreversible damages, such as sea water intrusion or land subsidence (see Chap. 2). Groundwater deterioration went relatively unnoticed for decades, due to the invisible nature of the resource, lack of knowledge, inexistent monitoring networks and insufficient institutional frameworks (Chap. 1). Yet, over time, a growing number of users were affected by this "silent" groundwater deterioration. The cost to society became tangible as municipalities, households, industries or farmers were forced to shut down contaminated wells. This progressively triggered response from public authorities including the elaboration of more comprehensive legal frameworks for groundwater protection (see Chaps. 6 and 22) and the implementation of groundwater protection and reclamation programs.

Due to difficulties in identifying the actors who caused groundwater deterioration (e.g. diffuse pollution), or because they no longer exist (e.g. abandoned industrial sites), costs of groundwater remediation projects often have to be borne by public agencies. Because of limited available financial resources, economic considerations have increasingly played a key role in setting priorities between competing groundwater protection programmes or remediation projects. Costbenefit analysis (CBA) has been used to identify groundwater basins where groundwater decontamination or protection is likely to generate the highest return on investments for society. This rationale for instance underlies the Superfund programme in the USA (Kiel and Zabel 2001). Alternatively, CBA is also used to identify sites where no action should be undertaken because remediation costs are outweighed largely by the expected benefits. This approach is implemented in Europe where CBA can be used to waive the general requirement to restore good chemical and quantitative status imposed by the Water Framework Directive (Brouwer 2008; Quevauviller 2008; Rinaudo and Aulong 2014).

This paper focuses on two main "integration" challenges faced by economists trying to assess in monetary terms the benefits of groundwater remediation or protection. The first one lies in integrating in their analysis the full range of positive impacts of such programs. Restoring groundwater quality or quantity is likely to improve the economic situation of many economic actors who directly use groundwater, including drinking water utilities, households depending on private wells, farmers irrigating their crops, industries using groundwater in their process (direct use values). It will also generate indirect benefits, often related to recreational activities (e.g. swimming, angling, canoeing) for users of groundwater dependent ecosystems (e.g., rivers, wetlands, gravel pit lakes) where ecological status is improved together with groundwater (indirect use values). Last but not least, groundwater remediation may also generate benefits not related to a particular use of the resource: these benefits refer to non-use values such as those associated with the possibility for others to use a groundwater in good status (altruistic value), 
or to the protection of the groundwater resources for itself (existence value). Economic valuation aims at integrating all these positive impacts into one single monetary estimate.

The second challenge lies in integrating in monetary valuation the long term dimension of groundwater protection benefits and in particular the value of groundwater for future generations. Indeed, restoring groundwater quality not only provides a flow of benefits for present generations. It also represents an increase of natural capital which might become a source of wealth in the future. Economists usually distinguish the option value associated with potential future use for present generations from bequest value associated with the preservation of an environmental good (natural heritage) for future generations.

This paper investigates the potential and limits of a specific economic valuation methodology - the contingent valuation method - which has often been recommended for conducting an integrated economic assessment of groundwater restoration benefits. The main objectives of the chapter are: (1) to present to non-economists how the contingent valuation method can be used for conducting an integrated economic assessment of groundwater protection and restoration benefits; and (2) to discuss the advantages and caveats of this method. The discussion is based on a review of the literature and on two original case studies to feed the debate.

The chapter is organised as follows. In the next section, we describe the different methods that can be used to assess the economic benefits of groundwater protection and remediation, with a specific focus on the contingent valuation method which is increasingly used in environmental economics. The paper then presents two original groundwater valuation studies conducted in Belgium and France, based on the contingent valuation method and using a similar protocol. Materials and methods are presented in Sect. 21.3 and results obtained in Sect. 21.4. We then discuss in Sect. 21.5 the limitations of the method in the context of groundwater valuation studies before concluding the chapter.

\subsection{Valuing the Benefits of Groundwater Protection with Contingent Valuation: A Review}

\subsubsection{Methodological Approaches for Valuing Groundwater Protection Benefits}

A popular approach among practitioners to assess the benefits of groundwater protection is the avoidance-cost method (e.g., see Abdalla 1994; Rinaudo et al. 2005). It consists of assessing the cost of actions undertaken by economic agents to cope with groundwater degradation, and pollution in particular. Typical avoidance costs are those related to the closure and displacement of contaminated drinking water wells (public or private), the installation of sophisticated water treatment units (municipal or domestic) or the purchase of bottled water when 
groundwater can no longer be used as a safe source of drinking water. One of the main advantages of this method is that it measures tangible costs that correspond to real expenditures made by concerned economic agents (investment, operation and maintenance costs). Results obtained are thus easy to grasp by policy makers and stakeholders. Its main weakness is that it only focuses on direct use benefits. It does not consider less tangible benefits related to: the possible uses of groundwater in the future (option value); the positive impact on groundwater dependent ecosystems (indirect use benefits); the transmission of a well-protected natural heritage to future generations (bequest value); the opportunity for other individuals to use groundwater in good status (altruistic value); and the protection of the groundwater resource for its own integrity (existence value). Benefits assessed with avoidance cost methods are thus generally considered as lower bound estimates.

An alternative method, widely used for practical applications in the United States, is the contingent valuation method (CVM). Unlike the avoidance-costs technique, this method is not based on the observation of actual behaviours of economic agents to cope with existing groundwater deterioration. Instead, it relies on the implementation of surveys to elicit people's willingness to pay (WTP) for hypothetical environmental improvement scenarios. The assumption is that individual-stated WTP reflects the intensity of the benefits each respondent derives from the scenario. After the survey is completed, stated WTP can be aggregated over the sample, and then extrapolated to the entire population concerned by the groundwater remediation scenario, in order to produce an estimate of the total economic benefits of the restoration scenario. The information provided to respondents should describe the full range of benefits they will derive from the groundwater protection/restoration scenario, including direct and indirect use, for present and future generations. In theory, the main advantage of this method is its ability to integrate all the benefits - direct and indirect, present and future - in a single monetary indicator. Let us now look at how the method has been used in practice.

\subsubsection{The Integrative Capacity of Contingent Valuation Method}

The CVM was first, and predominantly, applied to assess groundwater restoration and protection benefits in the USA (see Table 21.1). The use of the method was recommended by the US Water Resources Council in 1983. Its use was fostered by the increasing number of groundwater contamination cases, affecting a very large number of households relying on private wells for drinking water supply. The first study was conducted by Edwards (1988) in a small Massachusetts community where water supply was fully dependent on groundwater. A survey was conducted to elicit the population's WTP for reducing the probability of water supply contamination. This seminal research was followed by a number of similar studies conducted in the 1990s. Overall, this first wave of groundwater contingent valuation studies primarily aimed at assessing people's WTP for an improvement in the quality of their domestic water supply (see for example Shultz and Lindsay 1990; 


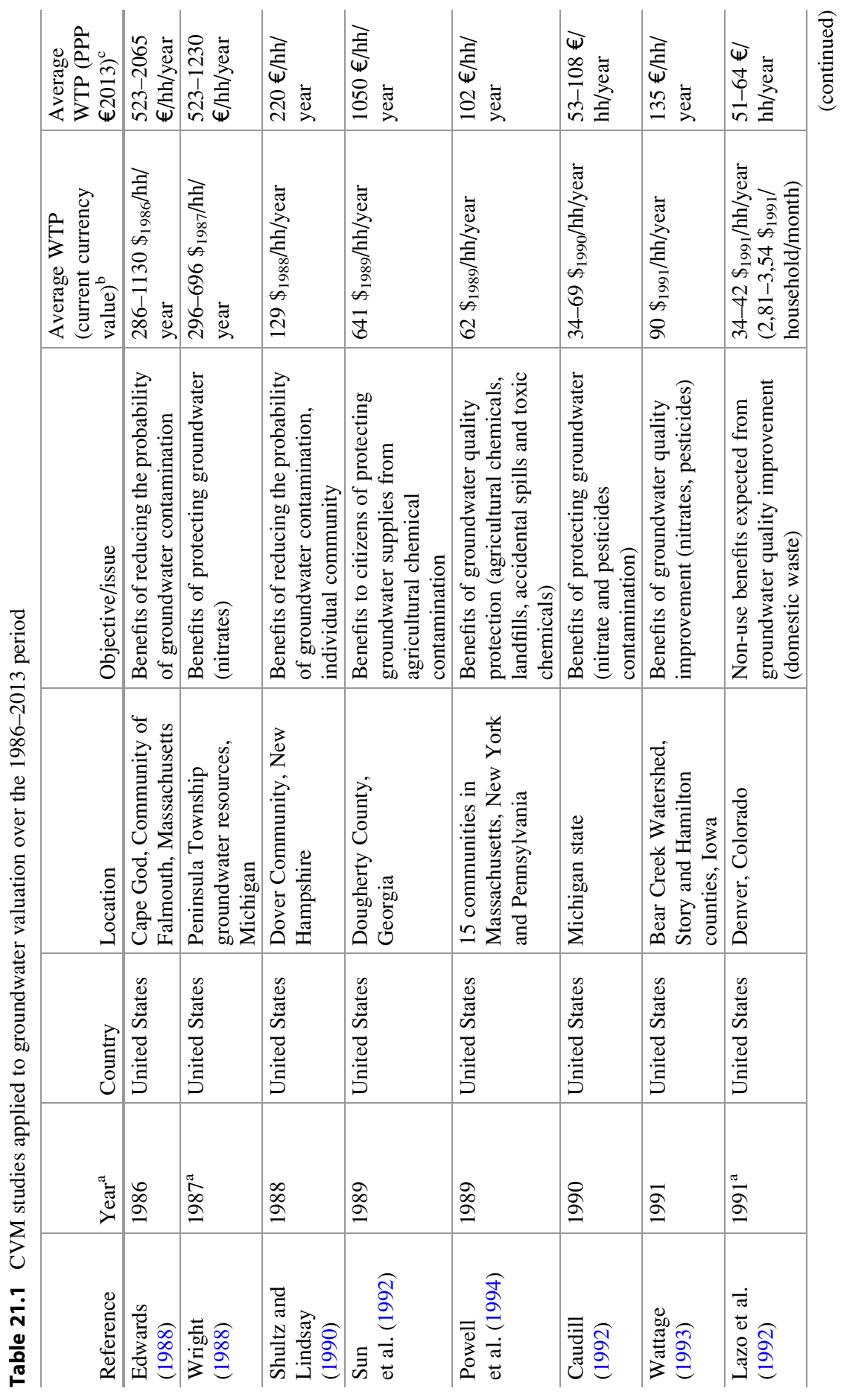




\begin{tabular}{|c|c|c|c|c|c|c|c|}
\hline 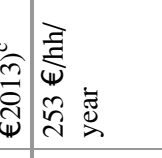 & 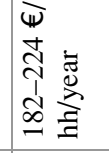 & 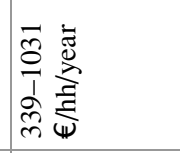 & 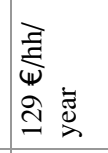 & 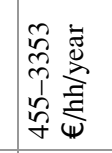 & 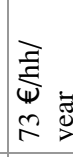 & 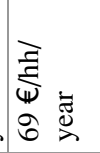 & 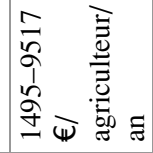 \\
\hline 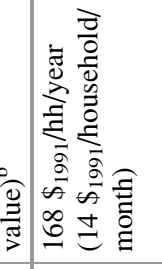 & 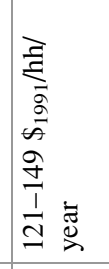 & 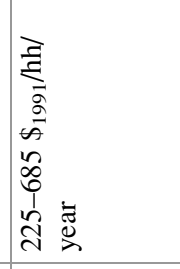 & 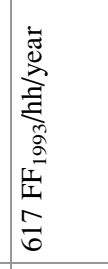 & 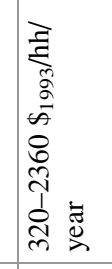 & 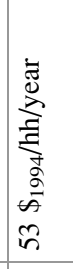 & 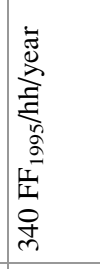 & 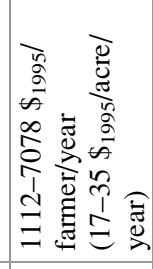 \\
\hline 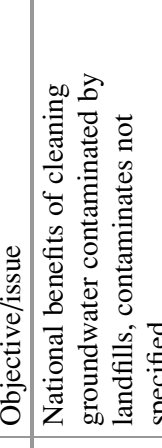 & 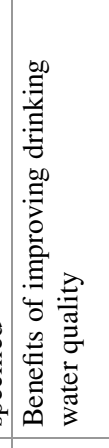 & 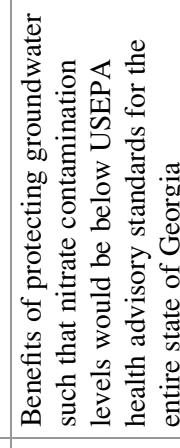 & 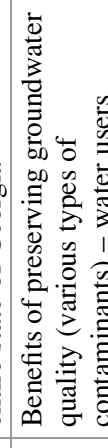 & 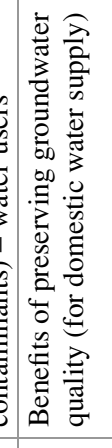 & 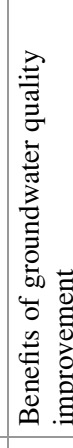 & 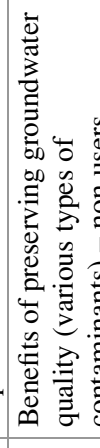 & 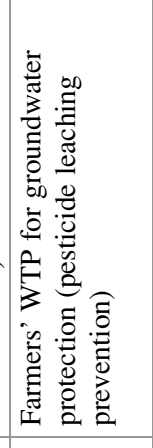 \\
\hline 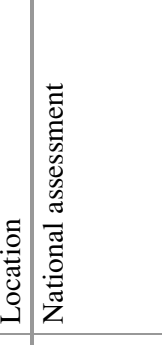 & 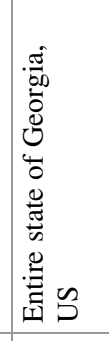 & 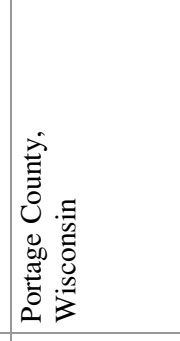 & 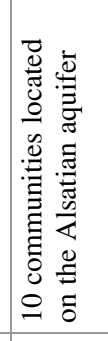 & 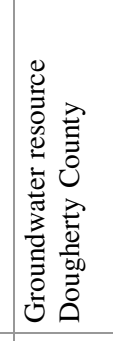 & 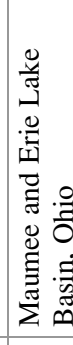 & 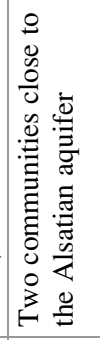 & 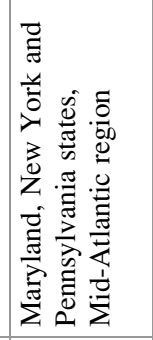 \\
\hline 童 & 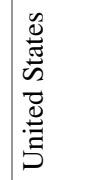 & 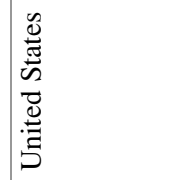 & 遵 & 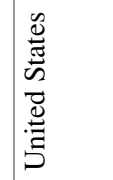 & 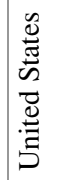 & 总 & 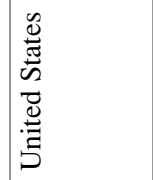 \\
\hline 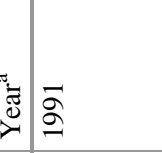 & $\bar{\Xi}$ & $\begin{array}{l}\delta \\
\frac{\sigma}{\partial} \\
\frac{\partial}{\alpha}\end{array}$ & مू & ఏ̊ & 离 & 命 & 崩 \\
\hline 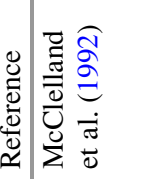 & 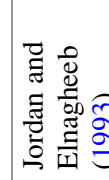 & $\begin{array}{ll}0 \\
0 \\
0 \\
0 \\
0\end{array}$ & 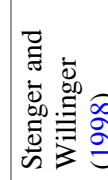 & 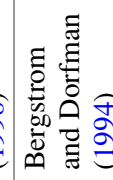 & & 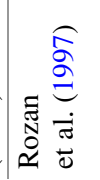 & 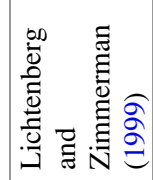 \\
\hline
\end{tabular}




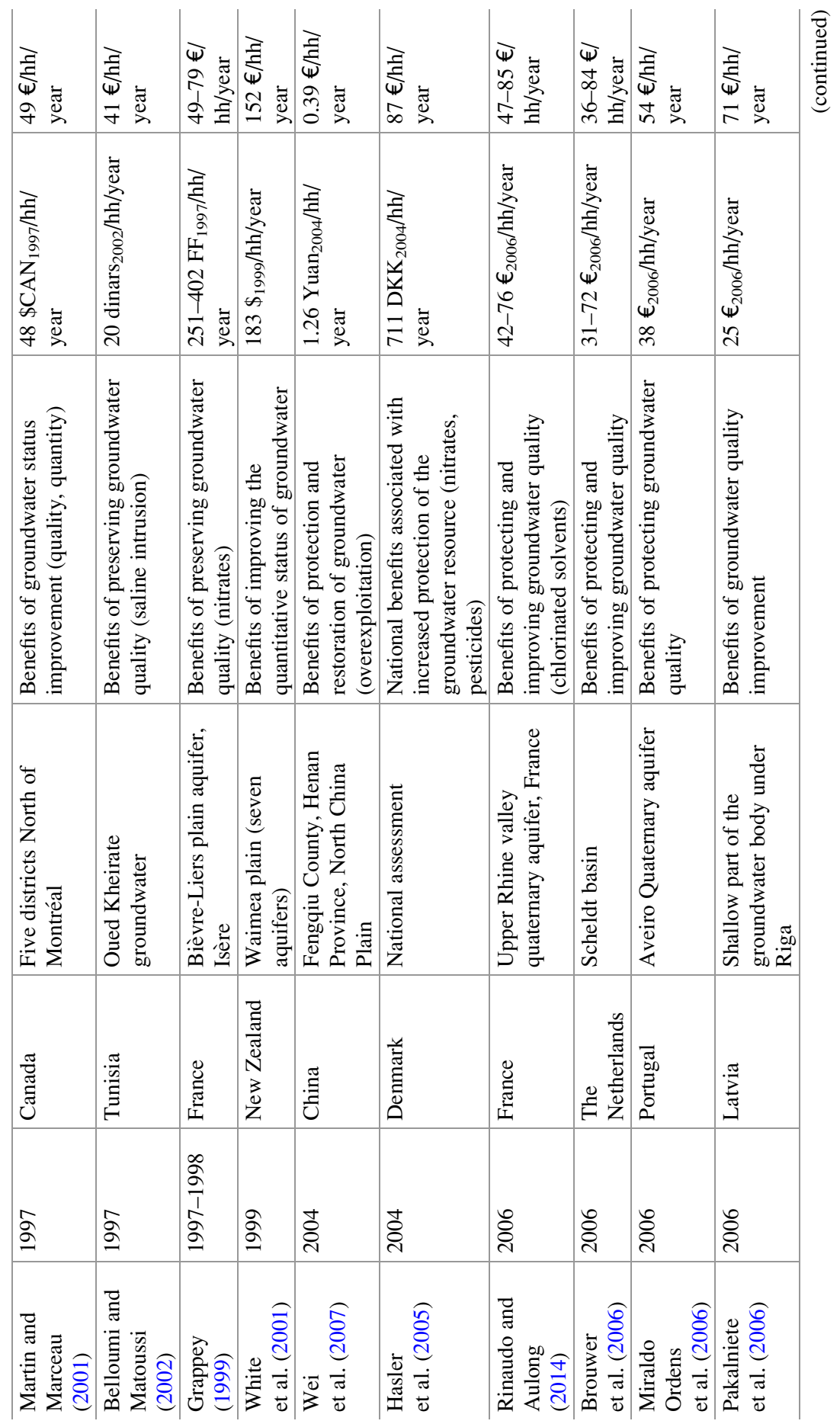




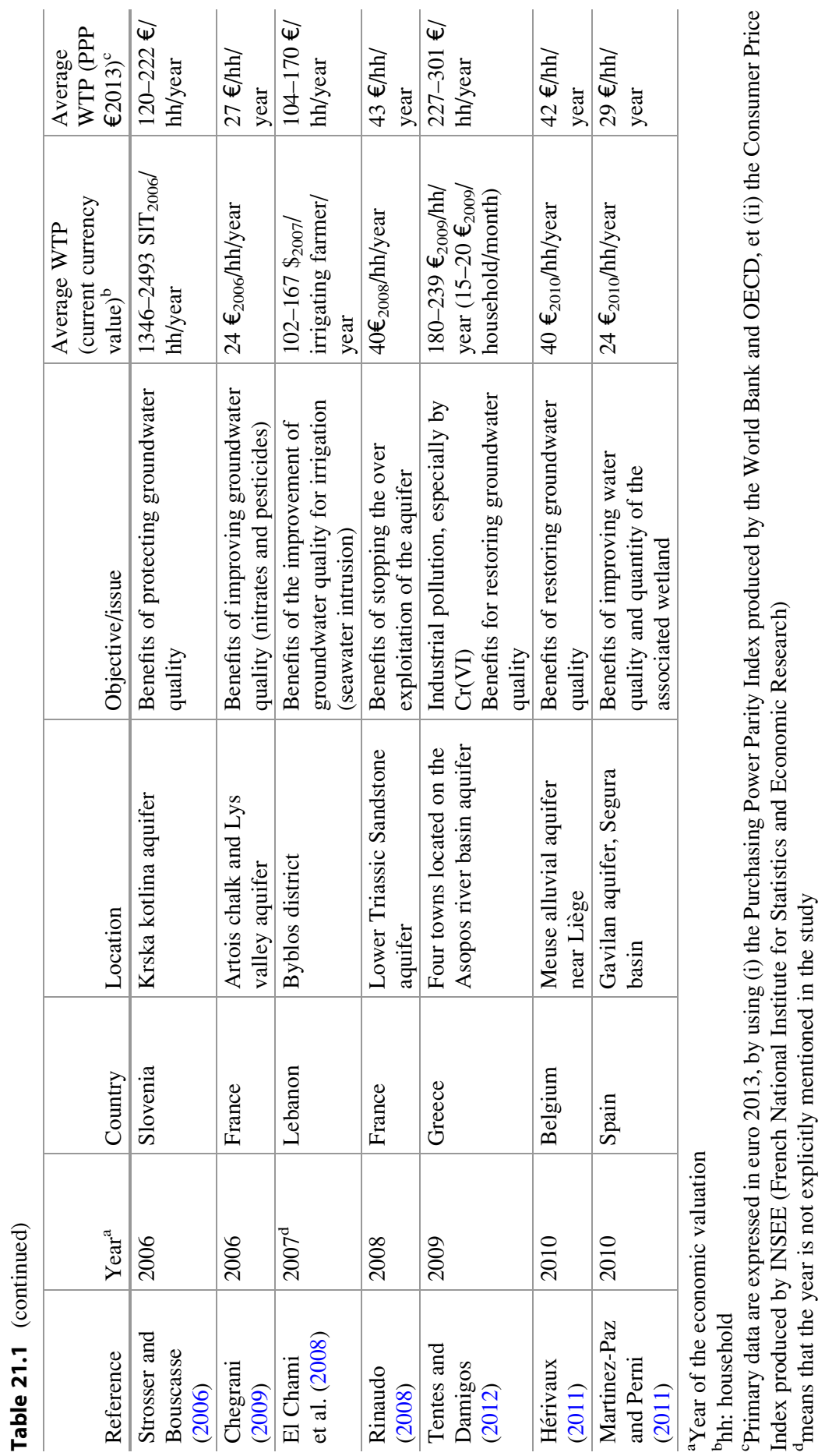


Sun et al. 1992; Powell et al. 1994; Caudill 1992; Jordan and Elnagheeb 1993; Poe and Bishop 1993; Lichtenberg and Zimmerman 1999). Estimated WTP were thus not reflecting the total value of groundwater improvement. Several studies have also shown that an important part of the elicited WTP may be related to the improvement of the groundwater resource itself or to the ecological services it provides through sustaining dependent ecosystems (see for example Lazo et al. 1992; McClelland et al. 1992).

In Europe, the use of the CVM to assess the economic value of groundwater protection has been more integrative. Studies were generally designed to capture a wider range of benefits and they were not solely focusing on the benefits associated with domestic water supply. In the first study, Stenger and Willinger (1998), followed by Rozan et al. (1997), designed a survey to assess the "patrimonial value" of the upper Rhine valley aquifer (Eastern France), explicitly considering the multi-generational dimension of groundwater. Their study was designed to elicit WTP of groundwater users and non-users. This integrative approach was further extended in the 2000s, following the publication of the Water Framework Directive, with a series of studies explicitly considering a wide range of potential benefits in Denmark (Hasler et al. 2005), France (Chegrani 2009; Rinaudo and Aulong 2014), the Netherlands (Brouwer et al. 2006), Portugal (Miraldo Ordens et al. 2006), Latvia (Pakalniete et al. 2006); Slovenia (Strosser and Bouscasse 2006), Greece (Tentes and Damigos 2012) and Spain (Martinez-Paz and Perni 2011). Similar studies have also been conducted in New Zealand (White et al. 2001), in China (Wei et al. 2007) and in Lebanon (El Chami et al. 2008).

One of the main findings of groundwater contingent valuation studies was to show that an important part of the elicited WTP may be associated with indirect use values or non-use values. In 1985, the USEPA reported that "numerous cases have occurred where communities and public officials argue heatedly for complete clean-up of contaminated aquifers which are not even presently being taped" Poe et al. (2000) shows in a meta-analysis that studies focusing only on use values had significantly lower WTP than studies that elicited total WTP for groundwater protection programs. Several studies have also shown that bequest values were quoted among the main reasons to contribute to a program of groundwater protection and may also statistically influence the willingness to contribute (e.g., Rinaudo and Aulong 2014).

\subsubsection{The Limits of CV for Groundwater Economic Valuation}

One of the main concerns with applying CVM to groundwater is that respondents may have a very limited knowledge of the environmental asset they are asked to value. In theory, CVM should only be used when respondents have what Lazo et al. (1992) call "perfect information," defined as: (i) a clear perception of the environmental asset they are asked to value; (ii) existing substitute commodities if any; and (iii) a good understanding of how changes in the level of provision of the commodity will affect them (e.g. the individual benefits of the scenario). 
Evidence from various surveys shows that this is rarely the case. People generally have a very limited knowledge of groundwater resources and related management issues, even when they have a direct link to the resource through private wells. This is illustrated by the results of a survey conducted in 1995 in Massachusetts (Stevens et al. 1997) where $47 \%$ of the respondents declared they knew little or nothing about groundwater, although half of the respondents had private wells and the second half was supplied by a municipal utility using groundwater. This knowledge problem is even worse in contexts where the population is supplied by public water networks and where "the only link that exists between groundwater quality and households is the price they pay for the drinking water supply" (Rinaudo and Aulong 2014). This is illustrated by the results of a series of European surveys: in the Netherlands, Brouwer et al. (2006) found that $40 \%$ of the respondents were not familiar at all with groundwater; in Latvia, $46 \%$ of the respondents connected to the domestic water supply network did not know the origin of their water and that $48 \%$ of the respondents were not informed about the groundwater contamination problem (Pakalniete et al. 2006); in Eastern France, $82 \%$ of respondents declared not being well-informed of groundwater management problems (Rinaudo and Aulong 2014).

In such situations, CVM specialists acknowledge that the method can still be used (Arrow et al. 1993). The burden of informing respondents about all the aspects of the environmental asset being evaluated then falls with the survey instrument. To avoid information bias, special attention should be paid to design the survey protocol and questionnaire, especially to select the nature, format and quantity of information provided to respondents. The researcher should ensure that this information is correctly understood by respondents by implementing a careful pretesting of the contingent valuation questionnaire. Complementary techniques can also be implemented. McClelland et al. (1992) for instance used a process of cognitive survey design, based on the pretesting of a 30-40 page perfect information questionnaire with randomly chosen people who were asked to speak continuously into a tape recorder as they completed the survey, in order to identify potential information problems. Mitchell and Carson (1989) conducted several focus groups to explore in-depth people's groundwater knowledge, concerns and preferences for groundwater protection. If sufficient information is provided "in a way that is plausible, understandable and meaningful to respondents" (Carson et al. 2001), some authors do not consider unfamiliarity as a problem for conducting a CV survey. 


\subsection{Empirical Case Studies: Objectives and Methodology \\ 21.3.1 Context and Motivation for Conducting Two Additional Case Studies}

The empirical research presented in this section was triggered by practical problems arising from the implementation of the European Water Framework Directive. In several European river basin districts, a number of groundwater bodies were so severely affected by human activities (overdraft or pollution) that stakeholders would not support the implementation of costly clean-up or replenishment programs. Clean-up or remediation costs were considered excessive as compared to financial capacities of actors and/or to the benefits that could be derived by potential groundwater improvement. However, justifying that benefits were much lower than remediation costs had to be supported by some evidence, which economists were asked to provide. The use of the contingent valuation method was advocated and several studies implemented in the framework of European and national research programs (see for example the Bridge-WFD program and the FRAC-WECO Belgian research project). The two case studies presented here were initiated in this context, with the intention of answering the following questions:

- Is contingent valuation an appropriate method for monetary valuation of benefits associated with groundwater protection and restoration, in locations where (1) people do not directly use groundwater through wells, and (2) where they have a very limited knowledge of groundwater resources?

- If appropriate, what type of information should be provided to respondents to make sure that they properly understand the multidimensional nature of the benefits associated with groundwater protection and restoration?

- Finally, what are people's stated preferences for the different components of groundwater protection and restoration benefits? Do they integrate use and non-use benefits, short and long term benefits?

\subsubsection{Case Studies}

The two selected case studies are complementary in terms of type of territory, type of resource and use, and management problem (see Table 21.2). The Meuse alluvial aquifer (MAA) case study (under the city of Liège, Belgium, 360,000 inhabitants) focuses on a large urban section of an alluvial aquifer which is no longer used due to historical industrial pollution. If implemented, a clean-up program (decontamination of brownfields) would not only restore groundwater quality but also contribute to improving the ecological status of the Meuse River (indirect use benefit). It would also generate a moral satisfaction in transmitting to future generations a 
Table 21.2 Main characteristics of the two aquifers selected as case studies

\begin{tabular}{l|l|l}
\hline Characteristics & $\begin{array}{l}\text { Meuse alluvial aquifer (MAA) } \\
\text { Liège region, Belgium }\end{array}$ & $\begin{array}{l}\text { Lower Triassic Sandstone (LTS) } \\
\text { Lorraine region, France }\end{array}$ \\
\hline $\begin{array}{l}\text { Aquifer type } \\
\text { and scale }\end{array}$ & $\begin{array}{l}\text { Shallow alluvial aquifer (15 } \mathrm{m} \\
\text { depth) } \\
\text { Local resource }\end{array}$ & $\begin{array}{l}\text { Deep confined aquifer (0-800 } \mathrm{m} \\
\text { depth) } \\
\text { Regional resource }\end{array}$ \\
\hline $\begin{array}{l}\text { Type of } \\
\text { territory }\end{array}$ & Densely populated urban area \\
\hline $\begin{array}{l}\text { Management } \\
\text { problem }\end{array}$ & Rural area \\
\hline $\begin{array}{l}\text { Groundwater } \\
\text { use }\end{array}$ & $\begin{array}{l}\text { Industrial } \\
\text { Drinking water wells abandoned } \\
\text { due to pollution } \\
\text { Very few private wells }\end{array}$ & $\begin{array}{l}\text { Main resource for municipal supply, } \\
\text { food and beverage industry, industrial } \\
\text { water bottling and cattle farms }\end{array}$ \\
\hline $\begin{array}{l}\text { Expected } \\
\text { benefits }\end{array}$ & $\begin{array}{l}\text { Ecological improvement of } \\
\text { dependent ecosystems (indirect } \\
\text { benefit) } \\
\text { Improvement of natural heritage } \\
\text { (bequest value) and potential future } \\
\text { use (option value) }\end{array}$ & $\begin{array}{l}\text { Continued long term access to } \\
\text { groundwater implying continuation of } \\
\text { cheap municipal supply in the future; } \\
\text { and reduced risk in case of drought or } \\
\text { contamination of superficial water } \\
\text { resources }\end{array}$ \\
\hline
\end{tabular}

better environment cleared from historical pollution, and potentially offering an alternative to currently used superficial water supplies.

The Lower Triassic Sandstone (LTS) case study (Lorraine region, in Eastern France) deals with a large confined aquifer that is increasingly depleted $(-68 \mathrm{~m}$ between 1968 and 2000). This aquifer has a strategic role at the regional level, since over 100,000 inhabitants depend on it for their water supply. A programme of measures aiming at restoring a balance between recharge and abstraction is currently being considered. In the absence of remediation action, a number of wells will run dry in the medium term (15-50 years) and local communities will have to switch to surface water supply, entailing higher investment and operation cost and a greater exposure to drought and surface water contamination risk. Note that the restoration program would not have any indirect ecological impact since this confined aquifer does not interact with surface ecosystems.

\subsubsection{Overview of the Common Methodology Deployed in the Case Studies}

The methodology deployed in the two case studies comprises the four following steps (Hérivaux 2011; Rinaudo 2008): (1) preliminary social survey; (2) questionnaire design and test; (3) survey implementation; and (4) data analysis.

Step 1 consists of a series of qualitative interviews to analyse people's perception and understanding of the groundwater resource under study. In the LTS, a total 
of 72 semi-structured face-to-face interviews were conducted to capture the lay vision of the reservoir, its characteristics and geographic extension; and to assess the level of understanding of the water cycle underground, with specific attention being paid to the understanding of exchanges between ground and surface water. Respondents were also asked to identify the services provided by groundwater to society. In the MAA case study, the same issues were addressed through informal discussion during the pre-test of the questionnaire and several open-ended questions administered at the beginning of each interview.

The results of this first step were used to construct a structured questionnaire, which was then carefully tested with about 50 respondents in each case study (step 2). Although differing in their contents, to be adapted to each case study, the contingent valuation questionnaires were similarly structured into four main sections. Section 21.1 consists of the presentation of the aquifer under study and it is followed by a series of questions aiming at assessing respondent's prior knowledge of this resource. Section 21.2 summarizes the groundwater management problem today and in the future if no action is undertaken. Impacts of groundwater overexploitation/ pollution on the current uses of the resources are also presented. Respondents are asked about their prior knowledge of this situation. Section 21.3 presents the groundwater improvement scenario. Proposed measures and expected impacts on groundwater quality and groundwater uses are listed. Respondents are asked if they would be willing to contribute financially (each year for 10 years) for such a scenario using the water bill as a payment vehicle. Those who agree are asked to specify an amount in euros per year on a payment card (for the household). Respondents are then asked to explain their motivations for accepting or refusing to contribute. Section 21.4 deals with socio-economic characteristics of the respondents (gender, age, employment, education, size of the household, income, perception of environmental problems, etc.).

The quantitative survey was then completed, with respectively 530 and 650 respondents in the MAA and LTS case studies (step 3). Face-to-face interviews were used in the MAA case study and a mail survey in the French LTS case study. Both methods have their advantages and their limits. For the MAA case study, the in-person survey seemed to be the most appropriate to collect answers to openended questions on groundwater and to minimize the non-response rate which was expected to be particularly high in this "non-use context". The mail survey method was chosen for the LTS case study to ensure that respondents would have sufficient time to get to know an unfamiliar subject and think about their preferences. The return rate was about $11 \%$.

Data obtained were then statistically analysed to check the consistency of responses and to identify factors determining stated WTP for groundwater protection (step 4). Different econometric models were estimated. Further detail on this part of the work is provided in the Appendix. 


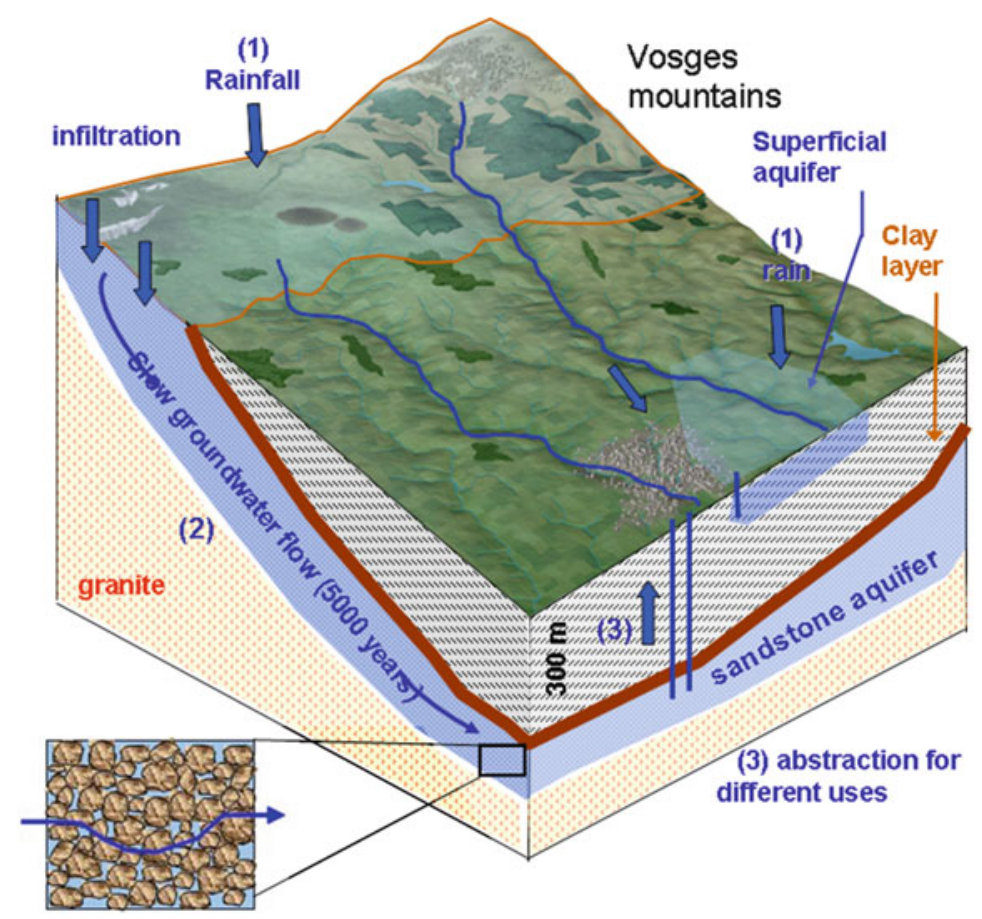

Fig. 21.1 Simplified representation of the Lower Triassic Sandstone aquifer (diagram used in the CV survey) (Source: Rinaudo 2008)

\subsubsection{Sending Clear Messages About the Benefits of Groundwater Protection}

When designing our CV survey, the main difficulty we had to address was to send clear messages about the benefits associated with the groundwater protection plan presented in the questionnaire. Given the complexity of the issue, we adopted a stepwise approach consisting of: progressive delivery of information on the groundwater resource itself and its current problems (Sect. 21.1); expected future evolution with a no-action scenario and possible consequences over time (Sect. 21.2); and a groundwater protection/restoration scenario, accompanied with a description of the potential benefits (Sect. 21.3).

In Sect. 21.1, we developed several simplified schemes depicting the geometry of the aquifer and the circulation of water and/or pollution loads within the reservoir (Fig. 21.1). The understanding of these visual supports as well as of the vocabulary used was checked during the pre-test phase. Maps were also used to delineate the spatial extent of the management problem so that each respondent could see if they 


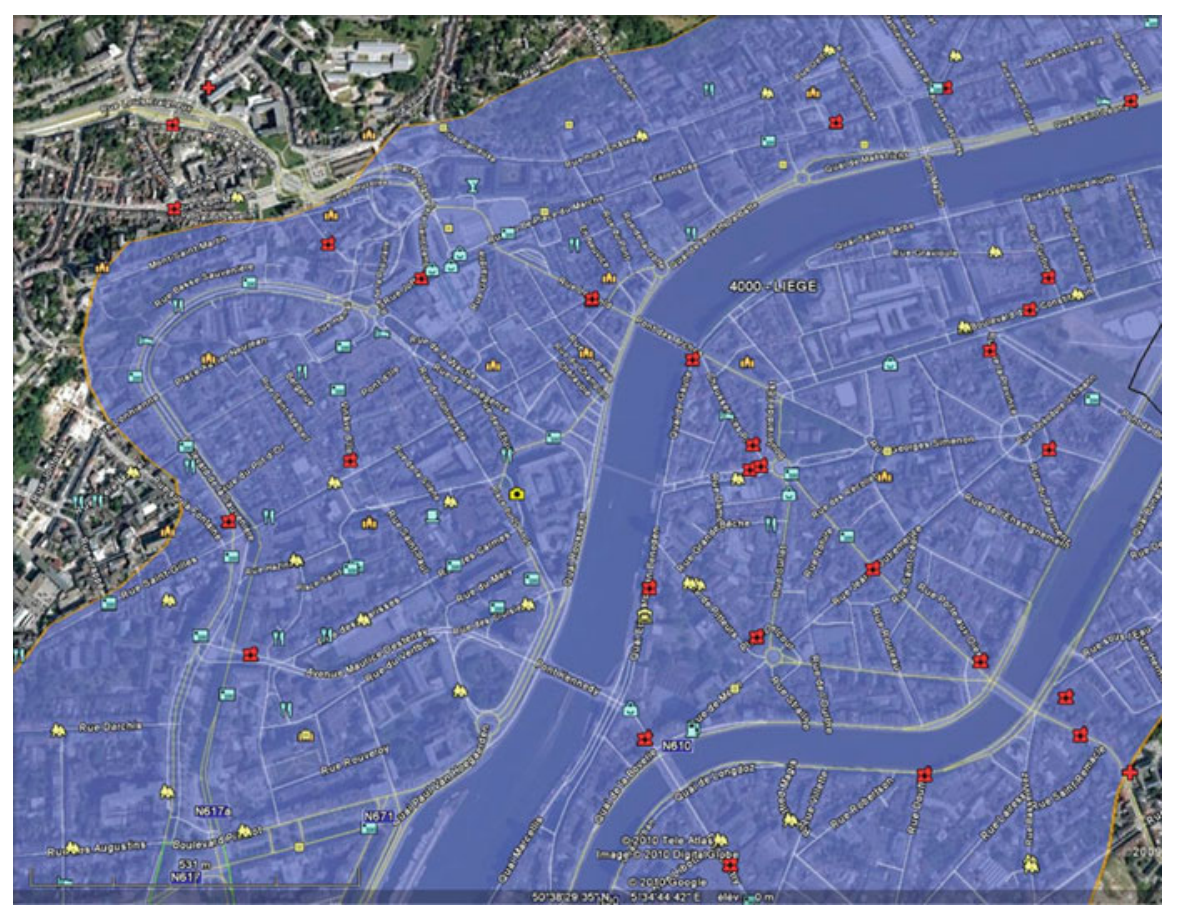

Fig. 21.2 Example of map combining aerial photographs and aquifer boundaries used during the survey (Source: Hérivaux 2011)

live above the aquifer or not, close or far from it. For the MAA case study, a series of maps combining Google Earth views and the aquifer boundaries were used during the survey to know if the respondent lives above the MAA (Fig. 21.2). Specific supports (maps or tables) were also used to show the origin of tap water for each municipality of the sample so that respondents could know if their water supply relies on the groundwater under study (Fig. 21.3).

When designing the questionnaire, specific efforts were made to describe the temporal dimension of groundwater deterioration (under the no-action scenario) or improvement (under the restoration scenario). In the LTS case study for instance, respondents were presented a map showing the date at which they would be impacted by groundwater depletion with the no action scenario (see Fig. 21.4). This map was elaborated based on the results of groundwater model simulations (Vaute et al. 2007). It was intended to help respondents in understanding if they would be personally concerned by groundwater protection benefits or if benefits would accrue to future generations. 


\begin{tabular}{|c|c|c|c|}
\hline \multicolumn{4}{|c|}{$\begin{array}{l}\text { Département de la Meurthe et } \\
\text { Moselle (54) }\end{array}$} \\
\hline Barbonville & $\square$ & Remenoville & 口 \\
\hline Charmois & - & Remereville & 0 \\
\hline Diarville & 0 & $\begin{array}{l}\text { Saint-Nicolas- } \\
\text { de-Port }\end{array}$ & $\Delta$ \\
\hline $\begin{array}{l}\text { Dombasle- } \\
\text { sur-Meurthe }\end{array}$ & $\Delta$ & Seichamps & 0 \\
\hline Einvaux & $\square$ & Tantonville & 0 \\
\hline Haussonville & a & Varangeville & $\Delta$ \\
\hline Herimenil & $\Delta$ & Villacourt & 口 \\
\hline Laloeuf & 0 & Virecourt & 0 \\
\hline Lamath & - & Xirocourt & 0 \\
\hline Lunéville & a & & \\
\hline
\end{tabular}

\begin{tabular}{|c|c|c|c|c|c|}
\hline \multicolumn{6}{|c|}{ Département des Vosges (88) } \\
\hline Auzinvilliers & $\Delta$ & Dompaire & $\mathrm{O}$ & Monthureux-le-sec & 口 \\
\hline Bulgneville & $\Delta$ & Evaux et Menil & $\Delta$ & Nomexy & 0 \\
\hline Charmes & 0 & Floremont & $\Delta$ & Oelleville & 曰 \\
\hline $\begin{array}{l}\text { Châtel-sur- } \\
\text { Moselle }\end{array}$ & 0 & $\begin{array}{l}\text { Gircourt les } \\
\text { Vieville }\end{array}$ & $\Delta$ & Poussay & $\triangle$ \\
\hline Chatenois & $\square$ & $\begin{array}{l}\text { Gironcourt sur } \\
\text { Vraine }\end{array}$ & $\square$ & Rainville & a \\
\hline Contrexeville & $\Delta$ & Hagecourt & $\Delta$ & Remoncourt & 口 \\
\hline Crainvilliers & $\Delta$ & Houecourt & 0 & $\begin{array}{l}\text { Rouvres en } \\
\text { Xaintois }\end{array}$ & $\Delta$ \\
\hline Dombrot sur Vair & $\Delta$ & Mandres sur Vair & $\Delta$ & Suriauville & $\Delta$ \\
\hline Domjulien & $\Delta$ & Mattaincourt & $\Delta$ & Ubexy & $\Delta$ \\
\hline & & Mirecourt & $\Delta$ & Vittel & $\Delta$ \\
\hline
\end{tabular}

The water you receive at your tap is pumped:
$\Delta$ In the lower triassic
- in the LTS aquifer for one part. and in rivers and other a
for another part
only from rivers and other resources.
and not from the LTS aquifer

Fig. 21.3 Table showing where tap water comes from in the municipalities selected for case study (used in the questionnaire) (Source: Rinaudo 2008)

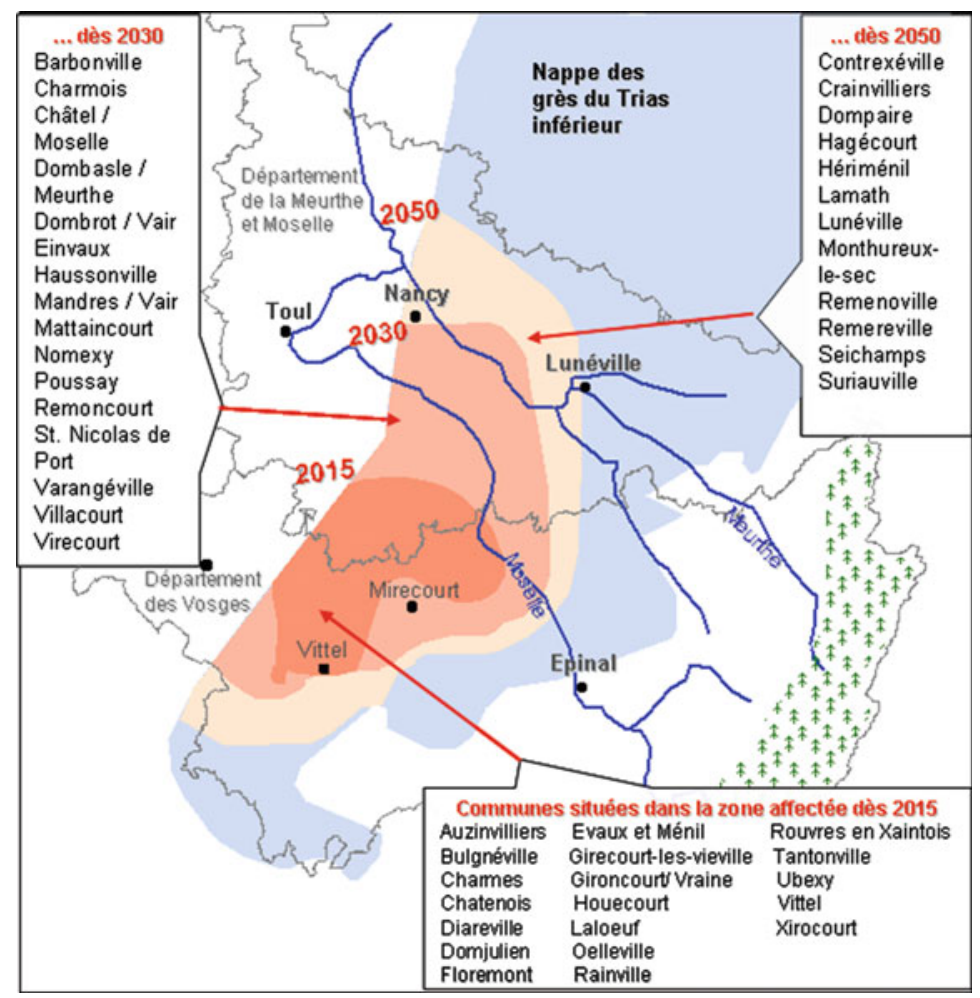

Fig. 21.4 Map depicting the area likely to be affected by the decline of water tables at three different dates. A list of municipalities included in each coloured pocket is provided so that respondents can locate themselves on the map (Source: Rinaudo 2008) 


\subsection{Empirical Results}

\subsubsection{The Impact of Prior Knowledge and Information Supply on WTP}

In line with past research conducted in similar European contexts, these two case studies confirm that respondents are quite unfamiliar with groundwater. Many of them discovered the existence of the resource and its management problems as they completed the questionnaire (LTS) or answered the interviewer (MAA). In both case studies, there is a large percentage of the population that does not even know of the existence of the groundwater body presented in the survey - $80 \%$ in the MAA case study and $46 \%$ in the LTS. Few respondents were also aware of the pollution or overexploitation problems threatening local groundwater (76\% and $54 \%$ of the respondents for the MAA and LTS case studies). And less than half of them knew if their water supply was dependent or not on groundwater (see Fig. 21.5).

One of the reasons for this limited knowledge is obviously that most respondents have no direct use of groundwater. Their lack of interest for groundwater is further accentuated by the limited coverage of this issue by the media and local political

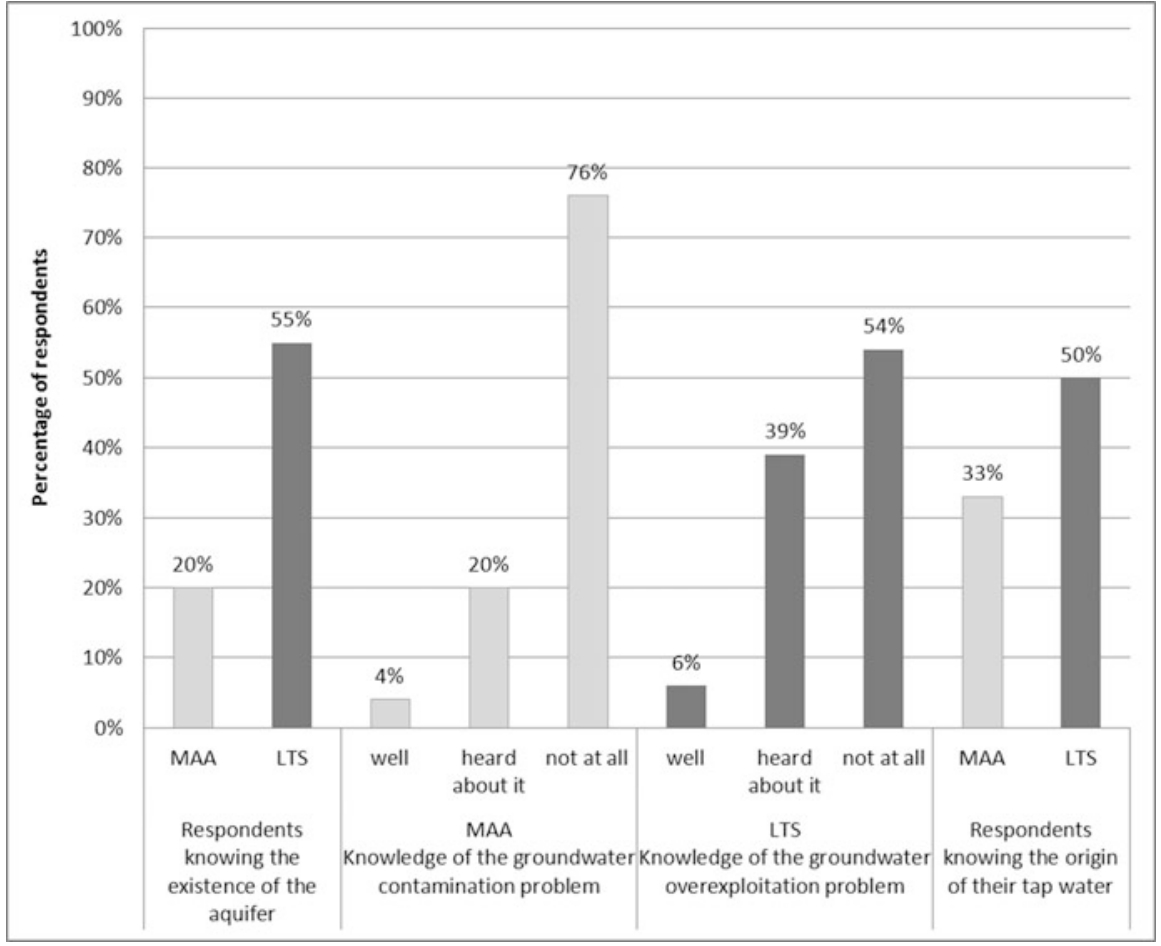

Fig. 21.5 Respondents' prior knowledge level (MAA Meuse alluvial aquifer, LTS Lower Triassic Sandstone aquifer) 
debate. The second reason, identified through semi-structured interviews conducted in the LTS case study relates to the public's mental representation of groundwater. Although lay people have a general understanding of what groundwater is, they do not spontaneously grasp the concept of an aquifer, defined as a three-dimensional geological reservoir and the water it contains. Laymen can hardly locate water resources on a map and find it very difficult to explain how and why water moves underground, eventually reaching the surface through springs or river banks. Groundwater is generally perceived as a ubiquitous resource, not as a well spatially-defined object.

Despite limited prior knowledge, the two case studies show that it is possible to supply adequate information during a survey, either through face-to-face interviews (MAA case study) or postal surveys (LTS). Maps and diagrams presented to respondents present no major understanding challenges because "they echo what they learnt on the water cycle at secondary school" (quote from several respondents). The information provided was considered by respondents as sufficient to inform their decision to contribute financially to groundwater restoration (e.g., $84 \%$ in the MAA).

However, one can wonder how the information supplied influences stated WTP. While the questionnaires provide the same information to the respondents through a detailed description of the aquifer, its uses, its management problem and the benefits expected from a good status, the appropriation of this complex information can be different between those who discovered the aquifer under study during the survey (situation of preferences construction) and those who had a prior knowledge of the aquifer and its management problem (situation of established preferences). This was actually tested in the two case studies by comparing the average WTP of respondents with and without prior knowledge of the problem. No statistically significant impact was found in the MAA. By contrast, respondents' prior level of information had a significant negative impact on WTP in the LTS case study (see the statistical results in the Appendix). Variable "info" in the OLS model has a negative sign. It is significant at the $5 \%$ level. This suggests that the information provided in the questionnaire may have a WTP enhancing effect. Similar findings were reported by Venkatachalam (2004) who found that additional information, provided about drinking water quality to respondents who possessed different levels of information about the water quality, can significantly influence the WTP values.

\subsubsection{Motivations Underlying WTP}

In the two case studies, about two third of the respondents accepted paying, revealing a real concern for groundwater protection. The average stated WTP was approximately $40 € /$ household/year over 10 years in each of the two case studies. This value lies at the lower bound of the range of WTP reported in the literature. Multivariate regression analyses were performed using several econometric models 
Table 21.3 Willingness to pay and underlying motivations in the two case studies (motivation statements were listed in the questionnaire and selected by respondents)

\begin{tabular}{|c|c|c|c|c|}
\hline & \multicolumn{2}{|l|}{ Meuse Alluvial Aquifer } & \multicolumn{2}{|l|}{ Lower Triassic Sandstone aquifer } \\
\hline & $\begin{array}{l}\text { Willingness to pay } \\
\% \text { accepting to pay } \\
\text { Average WTP/year/ } \\
\text { household }\end{array}$ & $\begin{array}{l}66 \% \\
40 €\end{array}$ & $\begin{array}{l}\text { Willingness to pay } \\
\% \text { accepting to pay } \\
\text { Average WTP/year/household }\end{array}$ & $\begin{array}{l}67 \% \\
39 €\end{array}$ \\
\hline & Main motivation for paying & & Main motivation for paying & \\
\hline $\begin{array}{l}\text { Bequest } \\
\text { value }\end{array}$ & $\begin{array}{l}\text { To pass on to future } \\
\text { generation groundwater of } \\
\text { better quality }\end{array}$ & $49 \%$ & $\begin{array}{l}\text { Groundwater is what my } \\
\text { grandchildren will drink in } \\
40 \text { years }\end{array}$ & $52 \%$ \\
\hline $\begin{array}{l}\text { Indirect } \\
\text { use } \\
\text { value }\end{array}$ & $\begin{array}{l}\text { To improve the quality of } \\
\text { dependent ecosystems (fauna, } \\
\text { flora) in the Meuse valley }\end{array}$ & $22 \%$ & & \\
\hline $\begin{array}{l}\text { Option } \\
\text { value }\end{array}$ & $\begin{array}{l}\text { To make possible future use } \\
\text { of the aquifer for the city of } \\
\text { Liège if needed }\end{array}$ & $22 \%$ & $\begin{array}{l}\text { I prefer to pay now for } \\
\text { groundwater protection than } \\
\text { later to bring water from far } \\
\text { away }\end{array}$ & $19 \%$ \\
\hline $\begin{array}{l}\text { Direct } \\
\text { use } \\
\text { value }\end{array}$ & $\begin{array}{l}\text { To keep the possibility of } \\
\text { using groundwater through a } \\
\text { private well }\end{array}$ & $3 \%$ & $\begin{array}{l}\text { I accept to pay because I use } \\
\text { this aquifer/my drinking water } \\
\text { supply depends on it } \\
\text { Depleting this aquifer would } \\
\text { represent a handicap for the } \\
\text { local economy }\end{array}$ & $\begin{array}{r}20 \% \\
9 \%\end{array}$ \\
\hline
\end{tabular}

to check the consistency of answers. Some three models were estimated: a logistic regression model to explain the yes/no response to the WTP question; an ordinary least square regression model to explain the positive WTP amounts; and a Tobit regression model to explain positive or true zeros WTP amounts. Results of various multivariate regression models are presented in the Appendix. The analysis was useful in understanding how various motivations for paying influence the stated amount.

The main motivations underlying the decision to pay are given in Table 21.3. These motivations are helpful in identifying to which component of the total economic value different individuals are sensitive. Looking at the main motivation quoted, we can distinguish four groups of respondents:

- In the first group, the concern for future generations is the main motivation for paying (respectively $49 \%$ and $52 \%$ of the MAA and LTS samples). Groundwater is clearly perceived as a natural heritage which should be preserved to guarantee future generations wellbeing, either as a clean, cheap and protected drinking water source or as a support of the local economy. For these respondents, higher WTP may reflect a feeling of moral responsibility for contributing to the protection of groundwater for future generations. WTP reflects altruism more than economic self-interest. In the LTS, the econometric analysis shows that respondents ranking by future generation as a first 
motivation have an $11 \%$ higher WTP (variable "futgen" significant at the $1 \%$ level, see Appendix).

- The second group comprises respondents whose main motivation is protecting (LTS) or restoring (MAA) the groundwater resource which they could personally be using in the future. WTP stated by these respondents thus reflects the option value of groundwater, defined as the benefits that could be derived from potential future use. Their WTP is not statistically different from the average.

- The third group is mainly motivated by the protection of a resource which they already use, either directly through a private well, or indirectly when their municipal water supply depends on groundwater. They represent approximately $20 \%$ of respondents in the LTS, but only $3 \%$ in the MAA where the aquifer is not usable in its current status. In LTS, these respondents have a statistically lower WTP than the sample average.

- The fourth groups say their main motivation is to contribute to the environmental improvement of dependent ecosystems. They represent $22 \%$ of the MAA sample. This motivation is not expressed in the LTS due to the confined nature of the aquifer, and the absence of an impact on surface dependent ecosystems.

Overall, these results highlight that stated WTP is an indicator that actually captures the different dimensions of groundwater protection benefits: direct use benefits; indirect use benefits (dependent ecosystems); option value (opportunity to use in the future); and bequest value (value for future generations).

\subsubsection{Mental Models and Embedding Effects}

An abundant literature describes the potential bias associated with the use of contingent valuation for valuing environmental goods (Venkatachalam 2004). Our case studies suggest that there are additional problems related to the specific characteristics of groundwater and to what environmental economists call an embedding effect or a part-whole effect. This embedding effect seems to be closely related to the "mental model" of joint products highlighted by Schulze et al. (1998): respondents may have different mental models, often strongly held, which will replace whatever mental model the researcher intended to impose on the respondent. Some respondents will accept the implicit mental model used by the researcher in designing the survey while others will not. Increased information does not address the possibility that individuals may have different mental models. Our results highlight two kinds of potential embedding effects:

- Due to insufficient knowledge, some respondents perceive groundwater as a ubiquitous and uniformly distributed resource, rather than a collection of welldefined and spatially delineated reservoirs. These respondents are thus not able to make a clear distinction between protecting groundwater in a broad sense on 
the one hand, and protecting a specific aquifer on the other hand. This remains true even if maps and schemes are provided in the survey. The existence of such an embedding effect is supported by much evidence in our two case studies: in the MAA, we asked respondents who accepted to contribute if they would be willing to contribute for any other groundwater body. The answer was positive for $71 \%$, with $41 \%$ declaring the same WTP. In the LTS, $44 \%$ of the respondents declared they would consent to pay a similar amount for the protection of any other aquifer in France. Such results cast doubts on the meaning of elicited WTP values, which could be considered as the WTP to protect groundwater resources in general (and not specifically the groundwater body under study).

- The second embedding effect is more specifically linked to situations where groundwater protection or restoration programs generate a wide range of environmental benefits. This effect is observed mainly in the MAA case study where some respondents faced difficulties in clearly disentangling those benefits derived from groundwater quality improvement from those of other environmental benefits. Especially in the context of orphan brownfields management, it is clear that actions aiming at improving groundwater quality will also bring other types of benefits to the population (positive landscape amenities, improvement of soil quality, etc.). Even if a survey clearly focuses on groundwater resources we cannot be sure that all respondents accept the implicit mental model used by the researcher in designing the survey. Results provide evidence of this risk: respondents who declare being concerned by a high number of environmental problems have a higher probability of accepting to pay, and a greater WTP. This reflects a difficulty for respondents to disconnect groundwater resources from other environmental compartments (air, soil, surface water, etc.). The survey may have influenced them in that direction by explaining the link between contaminated soil and groundwater quality on the one hand, and groundwater quality and surface ecosystems on the other hand. Such a result raises doubts as to the meaning of the WTP value, which could be considered as their WTP to improve the environment quality in general in their community (and not specifically the groundwater resource).

\subsection{Discussion, Conclusions and Recommendations}

In a context of mounting financial constraints, policy makers and the managers of river basins increasingly tend to use economic appraisal techniques to screen and compare competing groundwater protection and remediation projects. This generally involves assessing and comparing the costs and benefits associated with such projects. One of the main difficulties reported by economists is conducting an integrated assessment of the wide range of benefits generated by groundwater 
protection. Indeed groundwater protection or remediation not only improves the welfare of economic agents exploiting this resource (households, municipalities, industries, farmers), it also contributes to improving ecological services produced by groundwater dependent ecosystems (e.g. rivers and wetlands). Moreover, there are clear long term benefits associated with the protection of groundwater resources for future generations, considering their buffering role in situations of drought or extreme pollution events for instance.

One of the methods recommended and widely used to assess all these benefits is contingent valuation. The method comprises eliciting people's WTP for improving groundwater and the associated benefits. One of the strengths of this method is providing a single monetary estimate that theoretically includes direct and indirect use values as well as option and bequest values. A number of applicative studies, reviewed in this chapter, illustrate the integrative potential of the method. They also highlight some of its limitations and caveats. In particular, doubts exist about the validity of the method when applied to situations where respondents have a very limited knowledge of groundwater; and where direct uses being limited, most of the benefits are linked to indirect impacts on dependent ecosystems.

Two original case studies representative of this situation are presented in the chapter. They show how the method can be used in contexts where respondents are not familiar with groundwater. Overall, selected results highlight that WTP is an indicator that captures the whole range of groundwater protection benefits. Assessing WTP through contingent valuation surveys therefore is helpful for conducting an integrated valuation of groundwater protection benefits. Based on the results from the surveys, the message to water planners and policy makers is that people do care for groundwater protection and remediation, especially to guarantee the wellbeing of future generations.

However, the studies also point out some limits that might restrict the relevance of the results obtained. The first limit is related to the respondents' limited prior knowledge of groundwater. Our case studies suggest that it is possible to convey sufficient information to support respondents' contribution decision. However, there is a clear risk that this information biases the elicitation process, either enhancing or reducing WTP. This statement also raises doubts as to the representativeness of the sample of CVM respondents, as the survey sample on average is more informed about groundwater than the public in general. The second limit is related to two types of the so-called embedding effect: (1) because lay people often perceived groundwater as a uniformly distributed resource, some of them may be unable to assess the benefits associated with the protection of a distinct aquifer, considering its geographic location and extension and its specific hydrogeological properties; and (2) in situations where the groundwater management actions are expected to bring a wide range of environmental benefits (e.g. on water quality but also on landscape amenities and soil quality), respondents may face difficulties to clearly disentangle benefits derived from groundwater quality improvement from other environmental benefits. 
This leads us to formulate two main recommendations. The first one is that a 30-min or so face-to-face interview or an eight-page questionnaire, say, may not be sufficient for people to correctly understand the characteristics of the aquifer under study and the benefits ensuing from its protection. More time should be dedicated to this preliminary step to ensure that respondents adopt the "mental model" used by the survey designers. Techniques such as focus groups could be used to achieve this objective. The second recommendation is to favor assessing the benefits of groundwater protection programs for the full range of expected environmental improvements at the local scale (rather than only for the groundwater quality improvement), either by the use of the CVM or by the use of other types of revealed preferences methods such as choice experiments which could be more appropriate.

Acknowledgements The authors wish to thank the Belgian Federal Science Policy Programme BELSPO for the financial support provided for the FRAC-WECO research project, and the European Commission for the financial support provided for the BRIDGE-WFD research project. The chapter has been prepared with the financial support of BRGM research program 30 (Environmental and Risk economics).

Open Access This chapter is distributed under the terms of the Creative Commons AttributionNoncommercial 2.5 License (http://creativecommons.org/licenses/by-nc/2.5/) which permits any noncommercial use, distribution, and reproduction in any medium, provided the original author(s) and source are credited.

The images or other third party material in this chapter are included in the work's Creative Commons license, unless indicated otherwise in the credit line; if such material is not included in the work's Creative Commons license and the respective action is not permitted by statutory regulation, users will need to obtain permission from the license holder to duplicate, adapt or reproduce the material.

\section{Appendix}

\section{Detailed Description of Survey Results}

Tables 21.4 and 21.5 provide the results of the estimated econometric models. The logistic model aims at identifying variables determining the probability that a given respondent accepts contribution. The dependent variable is 1 if the respondent is willing to pay, 0 otherwise.

The Ordinary Least Square (OLS) regression model aims to identify the variables that determine the amount respondents are willing to pay. The OLS model only uses strictly positive WTP, zeros being excluded. The Tobit model is a variant of this model, which accounts for zeros. 


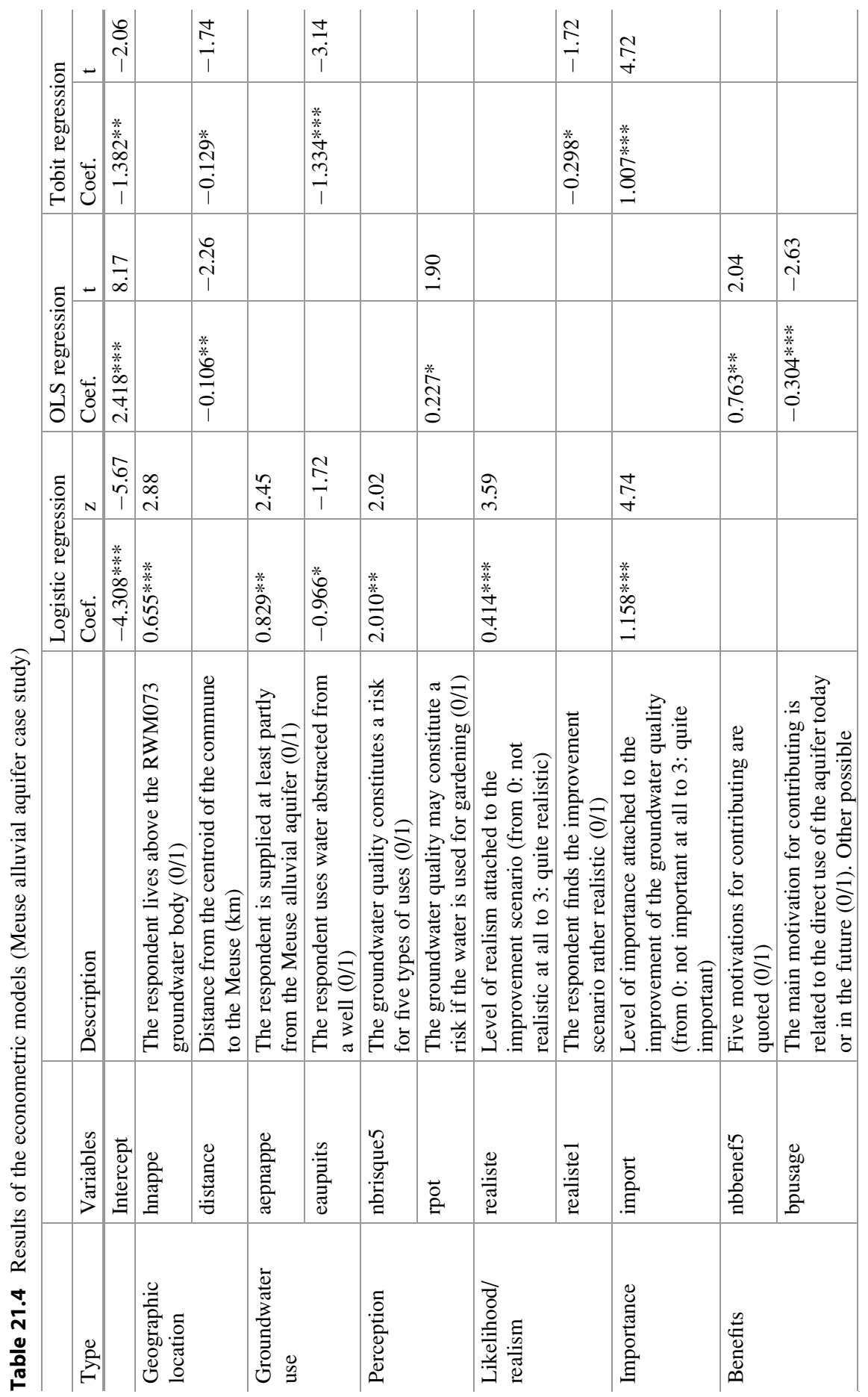




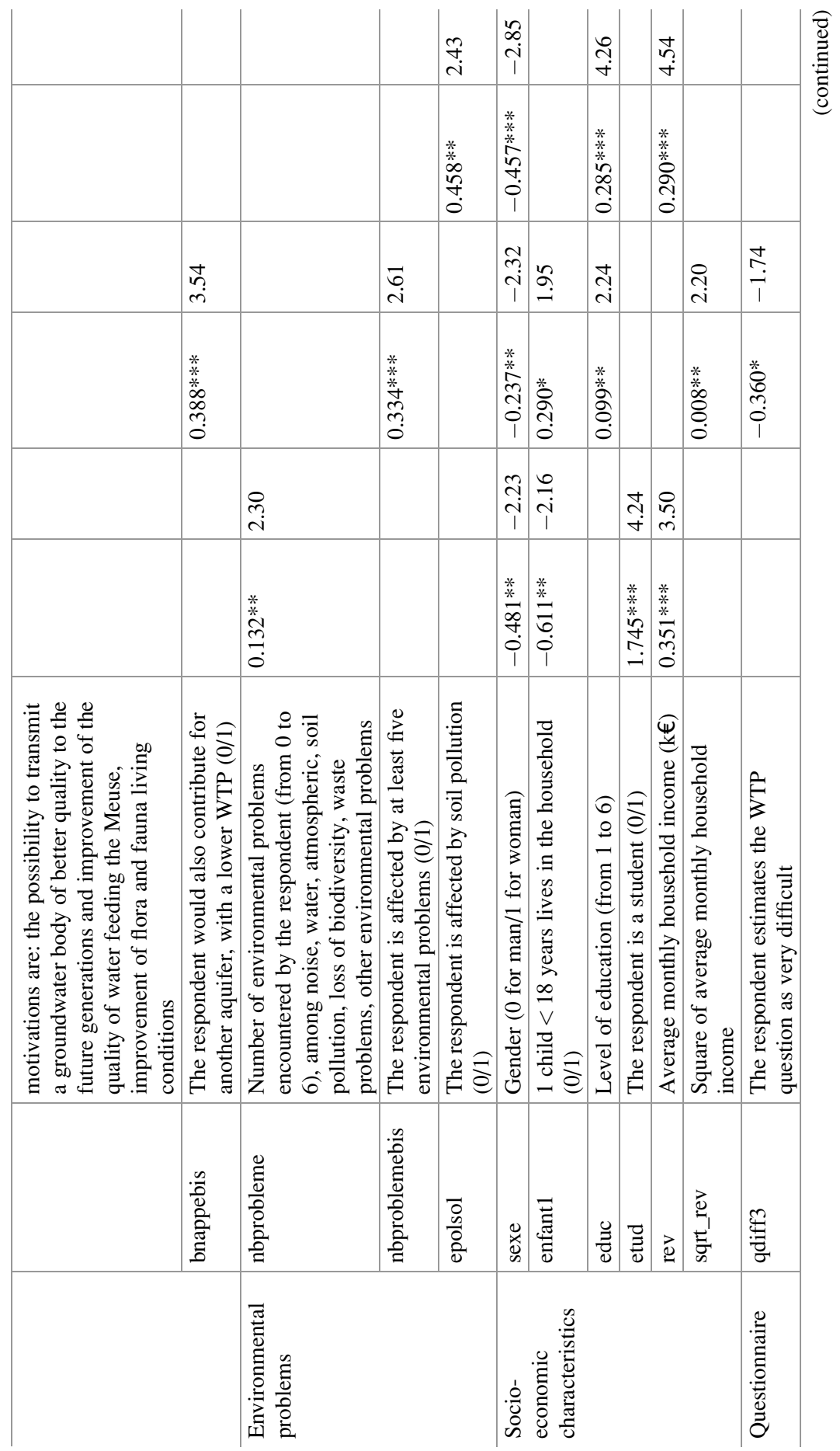




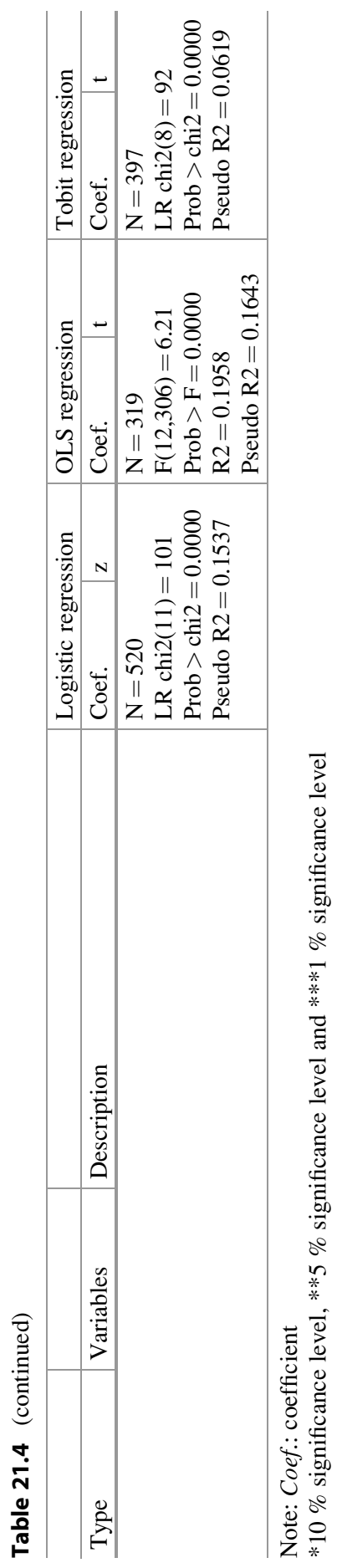




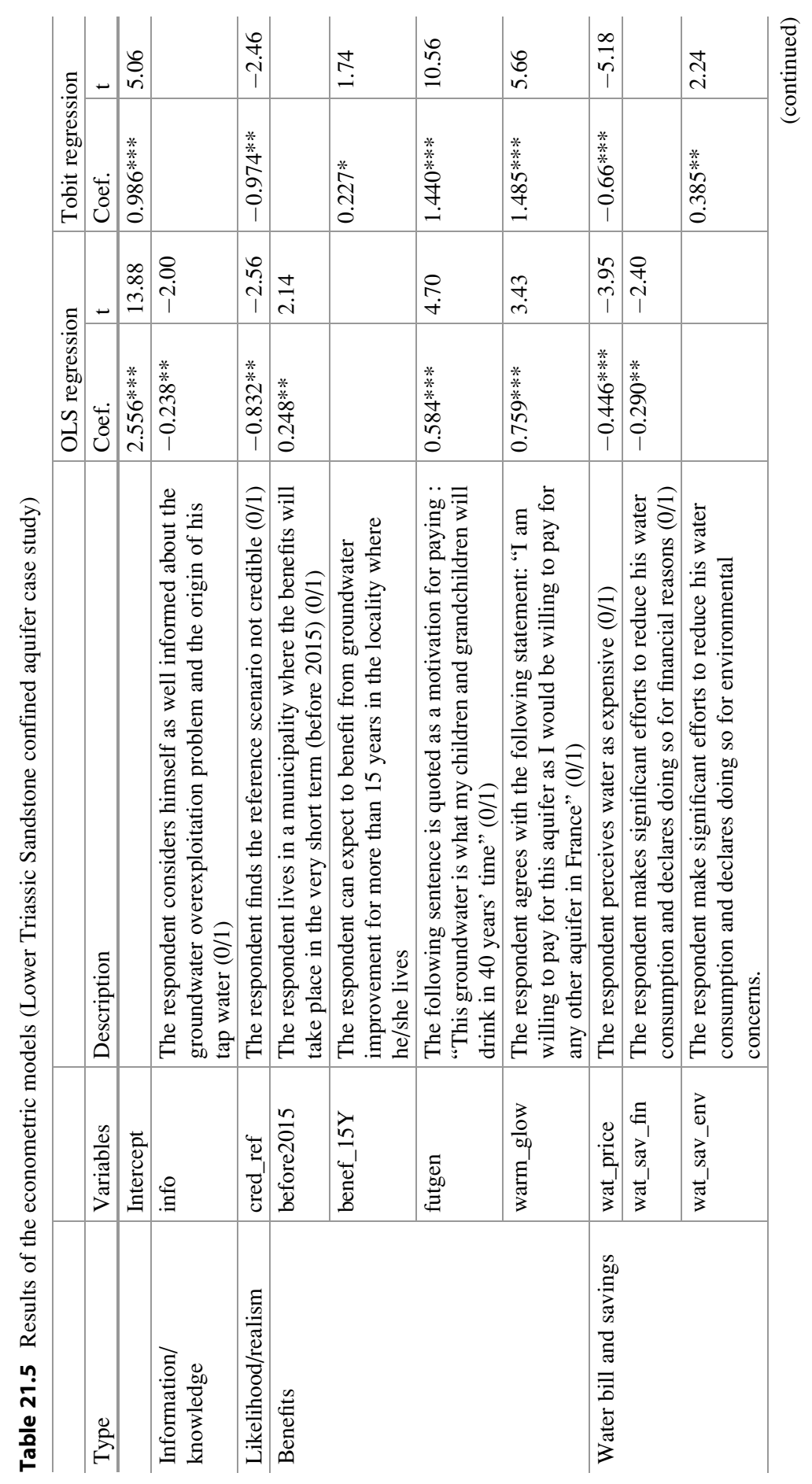




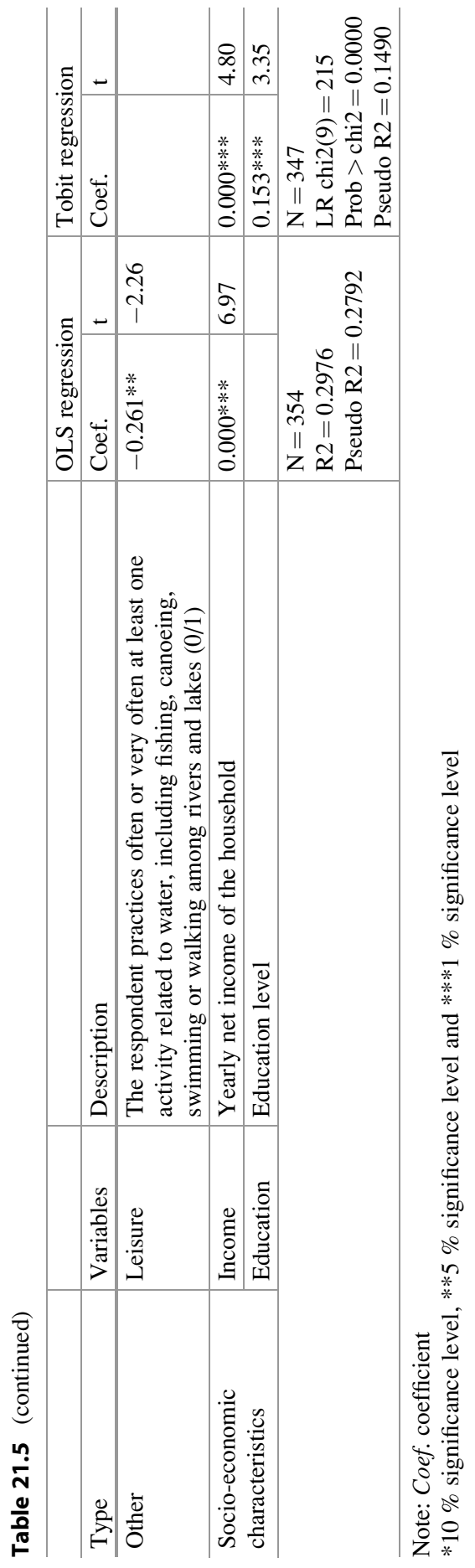




\section{References}

Abdalla CW (1994) Groundwater values from avoidance cost studies: implications for policy and future research. Am J Agric Econ 76:1062-1067. doi:10.2307/1243392

Arrow K, Solow R, Portney PR, Leamer EE, Radner R, Schuman H (1993) Report of the NOAA panel on contingent valuation. Fed Regist 58(10):4601-4614

Belloumi M, Matoussi MS (2002) Evaluation de la valeur de préservation de la qualité de la nappe d'Oued Kheirate. New Medit 1(4):39-45

Bergstrom JC, Dorfman JH (1994) Commodity information and willingness to pay for groundwater quality protection. Rev Agric Econ 16:413-425

Brouwer R (2008) The potential role of stated preference methods in the Water Framework Directive to assess disproportionate costs. J Environ Plan Manag 51:597-614

Brouwer R, Hess S, Bevaart M, Meinardi K, (2006) The socio-economic costs and benefits of environmental groundwater threshold values in the Scheldt basin in the Netherlands, November 2006. Deliverable D26 of the BRIDGE EU funded research project, Amsterdam, the Netherlands

Carson RT, Flores NE, Meade NF (2001) Contingent valuation: controversies and evidence. Environ Resour Econ 19:173-210. doi:10.1023/A:1011128332243

Caudill JD (1992) The valuation of groundwater pollution: the differential impacts of prevention and remediation. PhD thesis, Department of Agricultural Economics, Michigan State University, East Lansing, the United States

Chegrani P (2009) Restaurer les eaux souterraines: quels coûts ? quels avantages ? Cas de la nappe de la craie de l'Artois et de la vallée de la Lys. Etudes et documents CGDD n², Mars 2009

de Zoysa ADN (1995) A benefit evaluation of programs to enhance groundwater quality, surface water quality and wetland habitat in Northwest Ohio. Dissertation, The Ohio State University, Columbus, the United States

Edwards SF (1988) Option prices for groundwater protection. J Environ Econ Manag 15:475-487

El Chami D, El Moujabber M, Scardigno A (2008) The Contingent Valuation Method for the economic assessment of Groundwater: a Lebanese case study. New Medit 7:19-24

Grappey C (1999) Fiabilité des résultats de la méthode d'évaluation contingente et modes d'interrogation, Une application à la ressource en eau souterraine. Economie Rurale 254:45-53

Hasler B, Lundhede T, Martinsen L, Neye S, Schou JS (2005) Valuation of groundwater protection versus water treatment in Denmark by Choice Experiments and Contingent Valuation. NERI technical report $n^{\circ} 543$

Hérivaux C (2011) Economic analysis applied to groundwater degradation due to contaminated sites, Public perception and willingness to pay for the RWM073 groundwater quality improvement. Deliverable 5.5 of the FRAC-WECO project. BRGM-RP-59800-FR

Jordan JL, Elnagheeb AH (1993) Willingness to pay for improvements in drinking water quality. Water Resour Res 29:237-245

Kiel K, Zabel J (2001) Estimating the economic benefits of cleaning up superfund sites : the case of Woburn, Massachussetts. J Real Estate Financ Econ 22:163-184

Lazo JK, Schulze WD, McClelland GH, Doyle JK (1992) Can contingent valuation measure nonuse values? Am J Agric Econ 74:1126-1132

Lichtenberg E, Zimmerman R (1999) Farmers' willingness to pay for groundwater protection. Water Resour Res 35:833-841. doi:10.1029/1998WR900066

Martin M, Marceau R (2001) The economic value of groundwater. Working document, Access to the results via the EVRI database

Martinez-Paz JM, Perni A (2011) Environmental cost of groundwater: a contingent Valuation Approach. Int J Environ Res 5:603-612

McClelland GH, Schulze WD, Lazo JK, Waldman DM, Doyle JK, Elliot SR, Irwin JR (1992) Methods for measuring non-use values: a contingent valuation study of ground water cleanup. Final report, Office of Policy, Planning and Evaluation, U.S. Environmental Protection Agency, Cooperative Agreement \#CR-815183, 1992 
Miraldo Ordens C, Bertin S, Brouwer R, Condesso Melo T (2006) Assessing the costs and benefits of groundwater quality improvements in the Aveiro Quaternary Aquifer in Portugal, December 2006. Deliverable D28 of the BRIDGE EU funded research project

Mitchell RC, Carson RT (1989) Existence values for groundwater protection. Draft final report to US Environmental Protection Agency. Resources for the Future, Washington, DC

Pakalniete K, Bouscasse H, Strosser P (2006) Assessing socio-economic impacts of different groundwater protection regimes, Latvian case study report, November 2006. Deliverable D29 of the BRIDGE EU funded research project

Poe GL, Bishop RC (1993) Information, risk perceptions and contingent values for groundwater protection. In: Bergstrom JC (comp.) Western Regional Research Publication, W-133. Benefits $\&$ costs transfer in natural resource planning. Sixth interim report. University of Georgia, Athens. http://fes.forestry.oregonstate.edu/sites/fes.forestry.oregonstate.edu/files/PDFs/W133\% 206th\%20Interim\%20Report\%201993.pdf

Poe GL, Boyle KJ, Bergstrom JC (2000) A meta analysis of contingent values for groundwater quality in the United States. http://econpapers.repec.org/paper/agsaaea00/21871.htm

Powell JR, Allee DJ, McClintock C (1994) Groundwater protection benefits and local community planning: impact of contingent valuation information. Am J Agric Econ 76:1068-1075. doi:10. 2307/1243393

Quevauviller P (2008) From the 1996 groundwater action programme to the 2006 groundwater directive - what have we done, what have we learnt, what is the way ahead? J Environ Monit 10:408-421

Rinaudo J (2008) Assessing the benefits of groundwater protection. A case study in the Rhine district, France. Deliverable of the EU funded AQUAMONEY project

Rinaudo J-D, Aulong S (2014) Defining groundwater remediation objectives with cost-benefit analysis: does it work? Water Resour Manag 28:261-278

Rinaudo J-D, Arnal C, Blanchin R, Elsass P, Mailhac A, Loubier S (2005) Assessing the cost of groundwater pollution: the case of diffuse agricultural pollution in the Upper Rhine valley aquifer. Water Sci Technol 52(9):153-162

Rozan A, Stenger A, Willinger M (1997) Valeur de preservation de la qualite de l'eau souterraine: une comparaison entre usagers et non-usagers. Cahiers d'economie et sociologie rurales, INIST-CNRS, France, pp 61-92

Schulze WD, McClelland GH, Lazo JK, Rowe RD (1998) Embedding and calibration in measuring non-use values. Resour Energy Econ 20:163-178. doi:10.1016/S0928-7655(97)00034-1

Shultz SD, Lindsay BE (1990) The willingness to pay for groundwater protection. Water Resour Res 26:1869-1875. doi:10.1029/WR026i009p01869

Stenger A, Willinger M (1998) Preservation value for groundwater quality in a large aquifer: a contingent-valuation study of the Alsatian aquifer. J Environ Manage 53:177-193. doi:10. 1006/jema.1998.0197

Stevens TH, Barrett C, Willis CE (1997) Conjoint analysis of groundwater protection programs. Agric Resour Econ Rev 26:229-235

Strosser P, Bouscasse H (2006) Assessing socio-economic impacts of different groundwater protection regimes, Slovenian case study report, November 2006. Deliverable D42 of the BRIDGE EU funded research project

Sun H, Bergstrom JC, Dorfman JH (1992) Estimating the benefits of groundwater contamination control. South J Agric Econ 24:63-71

Tentes G, Damigos D (2012) The lost value of groundwater: the case of Asopos River Basin in Central Greece. Water Resour Manag 26:147-164. doi:10.1007/s11269-011-9910-2

Vaute L, Nguyen-The D, Gigleux S (2007) Eaux souterraines du département des Vosges: caractérisation des principales ressources exploitables et révision du modèle de gestion de la nappe des grès du Trias inférieur. Report BRGM RP 55653-FR

Venkatachalam L (2004) The contingent valuation method: a review. Environ Impact Assess Rev 24:89-124. doi:10.1016/S0195-9255(03)00138-0 
Wattage PM (1993) Measuring the benefits of water resource protection from agricultural contamination: results from a contingent valuation study. Dissertation, Iowa State University, Ames, The United States

Wei Y, Davidson B, Chen D, White R, Li B, Zhang J (2007) Can contingent valuation be used to measure the in situ value of groundwater on the North China Plain? Water Resour Manag 21:1735-1749. doi:10.1007/s11269-006-9123-2

White PA, Sharp BM, Kerr GN (2001) Economic valuation of the Waimea Plains groundwater system. J Hydrol (New Zealand) 40:59-76

Wright C (1988) An economic assessment of groundwater pollution. Master thesis, Central Michigan University, Mount Pleasant, the United States 


\title{
Controlling Groundwater Exploitation Through Economic Instruments: Current Practices, Challenges and Innovative Approaches
}

\author{
Marielle Montginoul, Jean-Daniel Rinaudo, Nicholas Brozović, \\ and Guillermo Donoso
}

\begin{abstract}
Groundwater can be considered as a common-pool resource, is often overexploited and, as a result, there are growing management pressures. This chapter starts with a broad presentation of the range of economic instruments that can be used for groundwater management, considering current practices and innovative approaches inspired from the literature on Common Pool Resources management. It then goes on with a detailed presentation of groundwater allocation policies implemented in France, the High Plains aquifer in the USA, and Chile. The chapter concludes with a discussion of social and political difficulties associated with implementing economic instruments for groundwater management.
\end{abstract}

\subsection{Introduction}

As detailed in Chap. 2 and elsewhere in this book, groundwater abstraction has increased considerably over the last few decades for both agricultural and urban uses. In many parts of the world, government agencies have not paid sufficient

\footnotetext{
M. Montginoul $(\bowtie)$

Irstea - UMR G-Eau, Montpellier, France

e-mail: marielle.montginoul@irstea.fr
}

J.-D. Rinaudo $(\bowtie)$

Water Department, BRGM, French Geological Survey, Montpellier, France

e-mail: Jd.rinaudo@brgm.fr

N. Brozović

Robert B. Daugherty Water for Food Institute, University of Nebraska, Lincoln, NE, USA

G. Donoso

Department of Agricultural Economics, Pontificia Universidad Católica de Chile, Santiago, Chile 
attention to this 'silent revolution'. Groundwater development has thus taken place in an institutional setting that placed no or few limits on groundwater use. Tens of thousands of wells and boreholes were constructed by small private agricultural or urban economic actors, leading to overdraft and associated environmental impacts (e.g. sea water intrusion, declining water tables, impacts on dependent ecosystems). In countries where groundwater has long been considered as an open access good, the establishment of new rules for governing access to groundwater and its use is increasingly perceived as necessary. This calls for the design of innovative institutional frameworks, involving the redistribution of responsibilities between the State and user communities, and an increased use of economic instruments providing incentives and theoretically leading to higher water use efficiency.

In practice, the shift from an open access to a regulated use regime has been implemented with three distinct policy approaches, depending on the local or national economic, legal and social context. The first approach (command and control) consists of establishing or reinforcing direct administrative regulation, with systematic registration of abstraction points, the issuance of pumping permits, and the award and enforcement of individual volumetric quotas. This approach is illustrated by the case of France, described in detail in Sect. 22.3 of this chapter. The second approach is founded on private appropriation of the resource, and involves the allocation of water use rights (the nature of which can differ significantly from one country to another) which can be traded amongst users, under supervision of a State agency. Such groundwater markets exist in several countries including the USA, Chile (see Sects. 22.4 and 22.5 of this chapter), Australia (Skurray et al. 2012), China (Zhang et al. 2008) and Spain (Garrido et al. 2012), among others. The third approach is founded on the decentralization of water allocation policies and the devolution of a number of State responsibilities to Water Users Communities or Associations. This model has been implemented with varying level of success in Spain or Mexico (Mukherji and Shah 2005), and underlies the recent evolution of groundwater policy in France.

In each of these three policy approaches, water managers are dealing with similar issues, including: the definition of the nature of water use rights; the control of free riding behaviors and the access to information on abstraction points and actual water withdrawals. In the following sections, we illustrate how these issues have been addressed in three different contexts in France, the USA and Chile. We also describe existing economic instruments and innovative ones that could be implemented to control access to and the use of groundwater.

The chapter is organized as follows. It starts with a broad presentation of the range of economic instruments that can be used for groundwater management, considering current practices and innovative approaches inspired from the literature on Common Pool Resources management (Sect. 22.2). The chapter then goes on with a detailed presentation of groundwater allocation policies implemented in France (Sect. 22.3), the High Plains Aquifer in the USA (Sect. 22.4), and Chile (Sect. 22.5). The chapter ends with a discussion of social and political difficulties associated with implementing economic instruments for groundwater management. 


\subsection{Economic Instruments for Groundwater Management: Approaches and Challenges}

Since the 1980s, there has been a growing recognition that economic instruments should be used to regulate the access to and the use of water resources. However, a review of existing practices shows that situations resembling Hardin's tragedy of the commons still prevail in most places around the world (see Chap. 23). This situation reflects the significant difficulties encountered by policy makers and managers to deploy economic instruments, in particular due to the lack of information on water users, abstraction points and water withdrawals, as well as the difficulties in enforcing allocation rules and instruments. This first part of the chapter proposes to look at existing and innovative tools that are, or could be, deployed to ensure sustainable management of overexploited aquifers.

\subsubsection{The Information Problem}

One of the main challenges faced by water managers attempting to control groundwater use is the lack of information regarding the hydrology of the aquifer and the abstractions. More specifically, well developed and calibrated models are not usually available, which does not facilitate estimation of the stock and recharge levels. In Chile, for example, there is little to no knowledge of the aquifers south of Central Chile. Moreover, the number of abstraction points, their location, the average volume pumped and the period at which the pumping takes place are often unknown. Indeed, the control of groundwater - a three-dimensional system - is more complex than for surface systems (one-dimension). The existence of undeclared or illegal wells remains an issue even in developed countries, both in the urban and agricultural sectors. When abstraction points are known, meters are not always installed or they can be temporarily removed or tampered with. This is illustrated with several agricultural and urban case studies selected in southern Europe such as in Spain or in France (de Stefano and Lopez-Gunn 2012; Montginoul and Rinaudo 2011), and elsewhere in the world.

In such contexts, groundwater abstraction control policies have focused on circumventing the monitoring problem by using readily observable information that can be used as a proxy for groundwater abstraction. Four different levels of information can be targeted depending on the effort made.

- On the first level, the agency decides to rely on aggregate information which provides a proxy for the overall groundwater abstraction - for instance the measurement of groundwater table levels. A decline of water table (adjusted considering climatic conditions) indicates an increase of water abstraction and can trigger temporary bans on irrigation, for instance. Sophisticated groundwater models can also be used to assess total abstraction with better accuracy. 
- The second level consists of identifying and locating all abstraction points and users. This can be done in a deterministic way (through field surveys for instance) or based on self-declaration.

- This information can be improved (third level) by collecting technical information on the characteristics of the wells (pump capacity), on irrigated areas and type of crops grown by farmers and on the type of irrigation system used (drip or furrow irrigation). Rough estimates of individual abstraction can then be derived from this information.

- The fourth level of information is when water use is fully metered, the agency knowing who uses how much water in which place at different periods of the year.

\subsubsection{Current Policies}

Policies currently implemented by groundwater management agencies to reveal groundwater use information mostly rely on command and control mechanisms. The most frequently used approach relies on random control and penalties. Two main constraints usually limit the efficiency of this type of system: first, the agency often lacks the required human resources to inspect a significant proportion of users; second, fines imposed are kept low for political reasons. Overall, the risk of running an illegal well or under-declaring water abstraction is perceived as very limited by users who are facing little incentives to comply with the regulatory framework (cost of non-compliance is lower than cost of compliance). The efficiency of the inspection and sanction system can however be improved in several ways. The first one consists of increasing inspection probability or the fine for users who were caught in fraud. The second one could consist of providing incentives for all users getting involved in the monitoring of groundwater abstraction, in order to increase the probability of control. The cost of decentralized monitoring is expected to be lower, since agents possess information on the actions of other agents (areas and crops irrigated, irrigation practices and frequencies, etc.). The incentive to participate in a decentralized monitoring system can be provided by redistributing a share of the fine to the person who discovers the violator. This system has been used for centuries for regulating access to common pastures and forests in the Italian Alps (Casari and Plott 2003). It may however be strongly assimilated to denouncement and thus rejected in many cultural contexts.

The second policy approach, mainly used in the agricultural sector, consists of assessing individual water abstractions through indirect information, such as the observation of cropping patterns with satellite images (Castaño et al. 2010) or electricity bills (when wells are electric-powered). An illustration can be found in Mancha Oriental (Spain), where a groundwater user association (Junta Central de Regantes de la Mancha Oriental) uses satellite images to assess monthly groundwater use for each individual farmer. If the estimated water abstraction exceeds the quota allocated to the farmer $\left(4000 \mathrm{~m}^{3} / \mathrm{ha}\right)$, a field inspection is carried out and a fine is charged to the farmer in the case of non-compliance (Martin de Santa Olalla et al. 1999, 2003). 
Desprats et al. (2011) suggested that a similar approach could be used to identify unlicensed urban groundwater users. This would apply to low density urban areas where households use private wells for watering lawns and gardens and filling swimming pools. Their method consists of using high resolution aerial photographs to assess irrigated lawn areas and swimming pools and to compute the corresponding outdoor water use for each single family house. They then compare estimated outdoor water requirements with metered water bills to identify households using private wells. The method is applied to a southern France case study to detect undeclared domestic boreholes.

Another way to incentivise users to reveal more accurate information is the charging of a high flat rate when users refuse to declare information on abstraction. This is actually used by the Rhône Water Agency in France, which charges high irrigation water fees on a per hectare basis (crop differentiated) to farmers who refuse to meter water abstraction. However, in spite of the economic incentives, some farmers prefer paying high charges for preserving the information asymmetry, fearing that water fees may rise in the future once meters have been installed everywhere. This echoes the "ratchet principle" enunciated by Weitzman (1980): economic agents may refuse higher rewards for better current performance by fear of future assignment of more ambitious targets.

A fourth policy approach comprises linking groundwater management with other economic policies. In Europe for instance, the grant of subsidies under Common Agricultural Policies is conditioned by full compliance with environmental regulations (eco-conditionality). This compels farmers to declare their wells to the relevant authorities and to demonstrate that appropriate metering devices are installed. Similar constraints are imposed on farmers by supermarkets through the use of certification standards (e.g. Global Gap) which aim at providing consumers the security that the products they purchase have been produced in conformity with existing environmental regulations.

\subsubsection{Alternative Policy Options Based on Incentives}

Several other proposed instruments have been suggested in the Common Pool Resources literature to force users to reveal information on harvesting level. Although none of them have been applied to groundwater management, they can theoretically be considered as possible options worth being assessed in terms of efficiency, equity and acceptability.

One of these theoretical options involves combining an upfront payment with compliance rebate. The mechanism is inspired from the "guilty until proven innocent" principle enunciated by Swierzbinski (1994) in his work on pollution control. Applied to groundwater abstraction, it could work as follows. Every user is requested to declare what his groundwater abstraction is (self-reporting principle) and he pays an initial fee or tax that depends on what he reports. The agency in charge then conducts random inspections and quantifies actual water abstraction, based on costly audit. In the case of proven non-compliance, the user is punished with a dissuasive fine; if findings of the audit are consistent with the initial declaration, the user is rewarded with a rebate. Auditing probability is inversely 
correlated to the declared intensity of groundwater use (in $\mathrm{m}^{3}$ per hectare for instance). The relative values of the fine and of the rebate determine on which of the two mechanisms (sanction or reward) the incentive structure depends.

A variant of this instrument can be proposed if we assume that the audit cost can be lowered through active cooperation of the user (e.g. weekly on-line recording of water uses). In that case, voluntary agreements could be signed between users willing to be audited and the regulator. The main advantage of this system is that it shifts the burden of proof from the regulator to the user. This mechanism is similar to deposit-refund systems which have been advocated to control other environmental problems.

\subsubsection{Instruments for Groundwater Abstraction Control}

Based on Salzman's classification, five instruments can be used to control groundwater abstraction (Salzman 2005): (1) command and control; (2) penalty (including tax); (3) payment (including subsidies); (4) appropriation (tradable property rights); and (5) persuasion. Some of them are incentive-based instruments (2-3-4), others aim to manage groundwater abstraction through an administrative or concerted share of available water, or through influencing withdrawers taking into account psychological and social aspects. Although this chapter is primarily dedicated to economic instruments, these five instruments are presented here because they can be combined to increase the efficiency of incentive-based instruments or are in competition.

\subsubsection{Command and Control}

The command and control approach relies on the definition of restrictions of use that can take different forms depending of the level of available information. When abstraction points are known and water uses fully metered, a system of individual abstraction quotas can be implemented. Quotas can be adjusted every year to account for variability of groundwater recharge. Enforcement requires a system of control (meter reading) which can be costly. This allocation procedure is a source of economic inefficiency, quotas being frequently allocated based on historical records. More simple restriction approaches are used when information is lacking, such as a temporary ban on irrigation when groundwater levels fall below certain pre-specified threshold level. An intermediate approach lies in restricting the pumping capacity of users while granting pumping licenses. Water abstraction can also be controlled through rationing energy used for pumping, a current practice in several Indian States (Shah 2008). An alternative is non-tradable water rights (water use rights) that specify maximum allowable extraction water flows for each abstraction point. The advantage of this command and control instrument is that it allows the taking into account of geographical differences in water abstraction levels for the same aquifer. As with the quota system, non-tradable water rights require a costly system of control. Chile's 1951 Water Code (Ley 9909, 1951) employed this instrument. 


\subsubsection{Abstraction Tax Systems}

The tax approach assumes that consumption (households) or production decisions (farmers) can be influenced by the cost of water supply. The type of tax system that can be implemented again depends on the level of information available to the regulator.

If water abstraction is metered, an individual (Pigouvian) tax system can be used. The tax can also be levied on inputs used for pumping such as electricity. In both cases, the choice of an efficient tax level is not trivial, in particular where demand and available resource significantly fluctuate over time. If the tax level is set to ensure that no over-exploitation takes place in a normal climatic year, it will not allow meeting this objective in drought years, when farmer's willingness to pay for water is extremely high. If on the contrary, the tax level is set taking drought years into consideration, it will represent an unacceptable economic burden for farms during normal years. The choice of an efficient tax level is further complicated by conjunctive use of surface and groundwater, farmers' decisions to use one or the other resource being influenced by the relative level of taxes charged for the two different resources (Lenouvel and Montginoul 2010).

If abstraction points are unknown or if water use is unmetered, the regulator can charge all actors using groundwater with an ambient tax with level proportional to the aggregate over-exploitation level (Segerson 1988). The regulator can assess the aggregate abstraction level based on simple observation of groundwater level decline, or use more sophisticated groundwater models that account for climatic and other natural recharge conditions. Each user is then charged with the same tax level, irrespective of his or her actual groundwater use. To cope with the risk of excessive fines, Segerson also proposed to supplement ambient taxes with a lump sum subsidy which ensures that the correct group of users remain in production.

\subsubsection{Payment}

The payment approach assumes that water demand can be curved downwards by subsidies which reduce the profitability of activities using a lot of water. The instrument can be implemented even in the absence of accurate information on water use, since the payment is based on observable characteristics (crop choice or irrigation equipments) that are assumed to be strongly linked with groundwater use. This approach has been implemented in Europe where farmers agreeing to stop irrigation are granted significant subsidies during a 5-year period in order to reorganize their farm for rainfed crops. The payment can be offered on an individual basis or made dependent on collective change, for instance in terms of irrigation practices by all farmers in a specific groundwater recharge area. The payment is generally part of a contract signed between the regulator and one or several groundwater users (Salzman 2005). The main difficulty of such an instrument lies in its sustainability: funds must be provided and once subsidies are stopped, farmers may once again increase their water consumption to maintain their income. 


\subsubsection{Tradable Abstraction Water Rights}

Appropriation is a fourth approach. It assumes that the distribution of individual or collective property rights may support the development of rules and associated micro-institutions (Ménard 2003) to enforce those rights by local communities (in particular in the case of collective appropriation); the main assumption is that this local regulation will facilitate coordination between actors and reduce transaction costs. Appropriation through tradable water rights enables the development of water markets through which water can be reallocated among users, theoretically leading to improved water use efficiency. This policy approach is illustrated with the US High Plains case study below.

\subsubsection{Persuasion}

Persuasion is the fifth approach. It assumes that water use can be significantly reduced by providing users with information on the consequences of over-exploitation (in particular when irreversibility occurs with implication for future generations) and by increasing transparency on who uses what. This is supported by recent developments in psychological research dealing with common dilemmas, which highlight "that people are not just motivated by narrow (economic) selfinterest but that they also consider the broad implications of their decisions for others and for the natural environment" (Van Vugt 2009).

\subsection{From Command and Control to Self-Regulation: The Case of France}

The case of France is illustrative of a transition from command and control to a decentralized groundwater management policy, where economic incentives play a very limited role and appropriation is still resisted by policy makers and the society in general.

\subsubsection{Legal and Institutional Framework}

In France, as in many other EU countries, groundwater development has occurred in an institutional setting that imposed few if any limits on groundwater use. Until the 1992 water law, existing regulation mainly focused on surface waters and on objectives related to minimum in-stream flow and aquatic ecosystems protection. Few constraints were imposed on groundwater development until the 1990s. Wells were not always notified and authorized discharges were not complied with. A rapid development of agricultural groundwater use ensued. Since 2000, half of the total agricultural irrigated area in France depends on groundwater (Garin et al. 2013). In several parts of France, this has resulted in declining water tables, with significant impacts on dependent rivers and ecosystems. 
The situation started to evolve with the 1992 water law which strengthened the well licensing system and imposed the use of meters. The law also established the concept of "water scarcity zones"1 where local regulators could ban the construction of new wells and restrict pumping through allocating individual abstraction ceilings (in volume per year). This new regulatory framework was implemented in several groundwater basins (Fig. 22.1), the most well-known being the Beauce aquifer in central France.

Public water utilities were given priority over other uses in water allocation. Concerning agriculture, the allocation of individual volumes was made by governmental agencies, based on environmental impact considerations, after consultation with the Chamber of Agriculture. The State kept the sole responsibility for enforcing water allocation, although it lacked the human and financial resources to conduct the required controls. Conflict resolution relied fully on judicial procedures, but court cases were often abandoned and penalties charged to offenders were not dissuasive. Overall, this "command and control" institutional set-up established by the 1992 law did not succeed in averting over-exploitation. The frequency of water crises increased and temporary restrictions and even total irrigation bans were promulgated every year in many groundwater basins.

The regulatory framework was again reformed in 2006 with the promulgation of a new Law on Water and Aquatic Ecosystems. In aquifers considered at risk of over-exploitation, hydrogeological studies need to be conducted to assess the total maximum volume that can be abstracted (capping procedure). This volume (which can be much lower than current aggregate use) must then be shared among users. Urban water supply is still given priority. Concerning agricultural use, Groundwater User Associations ${ }^{2}$ (GWUAs) must be established locally to share the available amount of water among farmers (Fig. 22.1). GWUAs also have the option to raise water fees, and to implement new instruments to enforce allocation. This opens an interesting space for testing innovative instruments, inspired from theoretical research and from on-going experiences in other countries.

This brief historical description shows two main transformations underlying groundwater policy reform. First, the focus is shifted from command and control to a decentralized management approach. The State is progressively transferring responsibilities to farmers, through the establishment of micro-institutions which are "inserted between global rules that circumscribe the environmental context on the one hand, and agents, organizations and contractual agreements they are tied with on the other hand" (Ménard 2003). Such intermediary institutions adapt general institutional rules to effective local organizations and allow transaction costs to be reduced. As for groundwater, it is assumed that a locally-designed institution will be more efficient than the government at enforcing a groundwater quota system. The second transformation relates to allocation procedures. The

\footnotetext{
1 «Zones de Répartitions des Eaux» in French.

${ }^{2}$ Organisme Unique de Gestion Collective (OUGC) in French.
} 

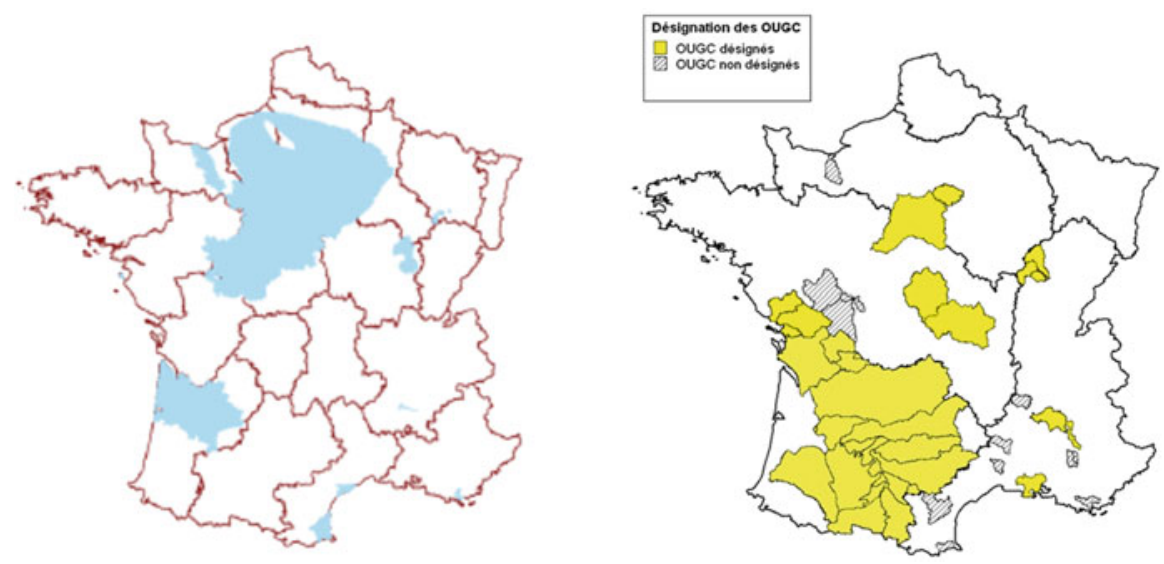

Fig. 22.1 Groundwater scarcity areas (left) and areas where Water Users associations have been established (surface and groundwater)

establishment of individual quotas can be considered as a first move towards an appropriation approach. In theory, quotas are very far from being property rights, since they can be reduced or even suppressed without any compensation. In practice, administrative pumping authorizations remain attached to the land in the case of land transactions, which implies that the land price reflects the value of the rent attached to the water quota. Appropriation is well underway, although this is not recognized officially.

\subsubsection{Economic Instruments in Place}

As shown in the previous section, groundwater allocation is mainly driven by command and control instruments, including temporary restrictions and individual quotas in "water scarcity zones". And since the 1964 Water Law an abstraction tax is also charged by Water Agencies. The main objective of this tax is not to signal scarcity, but to raise revenues that can be used to subsidize water related projects. The tax level is regulated by the National Parliament which sets a maximum level for different uses (see Table 22.1). Tax levels are far too low to provide any real incentive to reduce groundwater extraction. For instance, the average rate charged for irrigation (traditional gravity systems excluded) is only $3.6 €$ per thousand cubic meters. Although it is doubled in "water scarcity zones", it does not signal water scarcity. Moreover, the abstraction fee is not recovered from small water users (less than $10,000 \mathrm{~m}^{3}$ per year). Small economic enterprises and domestic users who directly pump groundwater are therefore exempted from the tax. 
Table 22.1 Maximum tax level $\left(€ / \mathrm{m}^{3}\right)$ on water resource extraction (applied from January 2013)

\begin{tabular}{l|l|l}
\hline Uses & $\begin{array}{l}\text { Normal rate }(€ / \\
\left.\mathrm{m}^{3}\right)\end{array}$ & $\begin{array}{l}\text { Water scarcity zone } \\
\left(€ / \mathrm{m}^{3}\right)\end{array}$ \\
\hline Irrigation (except by gravitary) & 0.036 & 0.072 \\
\hline Gravitary irrigation & 0.005 & 0.01 \\
\hline Potable use & 0.072 & 0.144 \\
\hline $\begin{array}{l}\text { Industrial cooling (with more than 99\% of water } \\
\text { restitution) }\end{array}$ & 0.005 & 0.01 \\
\hline Canal alimentation & 0.0003 & 0.003 \\
\hline Other economic uses & 0.054 & 0.108 \\
\hline
\end{tabular}

Source: Code de l'Environnement, articles L213-14-1 et L213-10-9

\subsubsection{Issues and Problems}

The main problems and policy issues in current groundwater policies are now covered in this subsection. The first problem relates to law enforcement. Since 1997 all wells and borewells should be declared and equipped with meters. There are however still a number of places where this does not happen. Field investigations conducted by the authors in the Roussillon plain, Southern France, showed that only $1 \%$ of domestic boreholes and 40-63\% of agricultural boreholes have been declared (Montginoul and Rinaudo 2009; Desprats et al. 2011). In that case study area, the Chamber of Agriculture collects the information on wells from farmers but they withhold it fearing that it can be used against them in the future. And when wells are declared, farmers prefer continuing to pay the flat rate abstraction fee to the Water Agency rather than declaring the volumes they actually used, even though this would clearly be favorable to them. The situation persists because sanctions are not dissuasive, the probability of control is too low, offenders are not systematically prosecuted (many cases are abandoned in overburdened courts), and due to a general lack of political will.

The second problem relates to water allocation efficiency. Water quotas have generally been granted based on records of historical use. In certain areas, like in the Tarn et Garonne county, the "use it or lose it" rule that should theoretically prevail in France, where water is considered as a public trust, is not applied. This results in situations where farmers may keep control over water quotas which they do not use, at the expense of other farmers who are queuing-up to obtain a quota from the government agency in charge. The corollary is a progressive feeling of private appropriation of water by farmers (and other users) who have been benefiting from a quota for years. The value of land reflects the existence and the magnitude of the attached water quotas, meaning that the water rent is appropriated by the land owner. This trend reflects current administrative practices which are in contradiction with the foundations of the 1992 and the 2006 water laws, both stating that water is a Nation's common heritage.

The third problem is that of perceived (un)fairness of water allocation. Many of the farmers in various French basins contest current water allocation which they find unfair and not equitable. They particularly contest the priority given to urban areas 
first before environment and agriculture. Another issue of controversy is around the rules for sharing water among farmers. The grandfathering principle, advocated by those benefiting from a quota based on historical use, is contested by other users who would like to enter the groundwater economy. This is nicely shown by a survey on water allocation rules conducted in five French regions, where the diversity of positions defended by farmers on this issue can only be understood by analyzing self-interest economic motivations jointly with ethical beliefs and values (Chap. 11).

Last but not least, groundwater policy reform is somehow blocked by lobbying efforts made by agricultural stakeholders who try to obtain public subsidies to construct small reservoirs as a substitute for groundwater use.

\subsubsection{Options for Future Policy}

In France, policy makers are at a crossroads where three different approaches can be chosen to develop national groundwater regulation.

\section{- Pursuing decentralization}

The first policy approach consists of pursuing decentralization. It requires strengthening the legal status and the internal capacity of newly established GWUAs to setup and implement their own groundwater regulation. GWUAs would become more involved in conflict resolution, for instance through establishing a "groundwater tribunal" composed of elected farmers and government representatives and who would arbitrate conflicts and charge penalties on offending farmers. GWUAs would also need to design their own rules for allocating water among their members and facilitating (monetary or non-monetary) exchanges between their members, in search of flexibility and efficiency. Contract-based instruments may play a significant role in decentralized management. For instance, Figureau et al. (2015) have proposed a "pooling agreement" through which farmers would agree to mutualize their quotas, in search of greater flexibility. The contract is favorable to the agents as a team relative to the standard penalty system provided that the team does not exceed the targeted abstraction level, but unfavorable to the team if the target is exceeded. Participating in a group remains a voluntary decision and not all farmers are expected to engage in these types of agreements.

As shown by the abundant literature on common pool resources, the main advantage of decentralized groundwater management is that rules are likely to be adapted to the local context. In France, this would respond to a real demand from farmers, as shown by the above-mentioned recent farm survey (Chap. 11) in five very different French counties. It highlights that farmers have highly diverging views concerning which criteria should be used to share water and how frequently allocation should be revised. For instance, while fruit farmers in the west (Tarn et Garonne) are asking for 15-20 years of water use concessions, cereal and vegetable growers in the north (Aisne county) would like allocation to be revised every year. 


\section{- Strengthening administrative regulation}

The second approach involves strengthening direct administrative regulation, with systematic registration of abstraction points, the issuance of pumping permits, and the awarding and enforcement of individual volumetric quotas. Water quotas are granted for a duration compatible with irrigation investments (e.g. 15 years) and have the status of concessions as practised under the Spanish law. Beneficiaries of concessions must report detailed information to government agencies on where they use water and for which crop, using an internetbased geographic information system similar to what is currently required by the Common Agriculture Policy subsidies. Automated reading meters such as those used in the drinking water sector help solve the information problem. The enforcement problem is dealt with by the use of sophisticated remote-sensing technology coupled to field inspections. A fine, proportional to the excess water used, is applied in case of non-compliance. One of the drawbacks of this policy approach is the lack of flexibility: newcomers (young farmers) are unable to obtain a concession until another farmer relinquishes a license - possibly providing incentives for farmers to drill illegal wells or to engage in informal water trading. Water use efficiency is obviously another issue. And enforcement is likely to be problematic in a context where scarce financial resources are allocated to government agencies in charge of water and environmental policies.

- Using incentive-based economic instruments

The third model gives more importance to incentive-based economic instruments, which can be implemented by the State or within GWUAs. Several tools have been proposed and tested experimentally by French economists.

- The establishment of markets where water quotas could be traded has been advocated since the early 2000s (Strosser and Montginoul 2001) and more recently evaluated through consultation with farmers in different regions (Rinaudo et al. 2012, 2014). Creating markets would not require many institutional changes if water abstraction is properly capped (as suggested in the second approach) and they could even operate without privatizing water, based on a concession system as currently is happening in Spain.

- Lenouvel et al. (2011) tested an instrument combining an ambient tax with a contract. The ambient tax is indexed according to groundwater level, and it is charged to all farmers of the area. Farmers are offered the option to sign a contract with the GW basin agency in which they commit to provide true information to the agency concerning the location of their wells, irrigated fields, and volume pumped, and to facilitate the control of this information. These farmers are exempt from the ambient tax. The information they provide is verified using remote sensing and field inspections.

- Figureau et al. (2015) have proposed combining payments and fines. Farmers exceeding their quota pay an increasing block fine for the extra volume pumped. The sum of the fines collected is then shared between those farmers who use less than their entitlement, the received amount being proportional to the water saving effort made. This instrument, which is expected to meet water and budget balance simultaneously, is currently being tested through experiments with farmers. 


\subsubsection{Social Expectations}

Considering a 20-year time horizon, the three paths represent alternative feasible options, provided significant evolution of the legal framework occurs. However, future evolution may be strongly determined by social expectations. A series of workshops conducted with 80 farmers and 44 institutional stakeholders suggest that there is a strong social preference for decentralized solutions and cooperative arrangements, while economic instruments like taxes and market are strongly rejected mainly based on ethical considerations (Figureau et al. 2015; Rinaudo et al. 2014). Similar conclusions were reached by Montginoul and Rinaudo (2009) from a survey conducted in southern France by Rinaudo et al. (2014). Overall, water remains perceived as a free access good and implementing economic instruments is considered to be a drastic shift in paradigm. Transition towards a mature water economy will necessarily take place as climate changes and demand increases, but this will take time.

\subsection{From Command and Control to Markets: Examples from the High Plains Aquifer, USA}

\subsubsection{Background on Groundwater Management in the United States}

In the United States, the connections between groundwater pumping, local economies, and freshwater ecosystems that are fed by groundwater have been the subject of extended study and litigation over the last decade (e.g. Hathaway 2011; Van Kirk and Naman 2008; Scanlon et al. 2012; Gleeson and Cardiff 2013; Steward et al. 2013). Importantly, there is no national water policy related to groundwater use in the United States (see also Chaps. 6, 7, and 8). Instead, groundwater regulations are often set and implemented locally and not at a state or federal level. Changes in regulations are primarily driven by legal impositions on local groundwater management districts, or by a desire to preserve a rural way of life for future generations.

Common concerns about the sustainability of groundwater use may be divided into three broad categories: concerns over aquifer depletion (Konikow 2013; Laukaitis 2013; Steward et al. 2013; Terrell et al. 2002; Wines 2013), concerns over damages to transboundary surface water resources resulting from surface water-groundwater interaction (Kuwayama and Brozović 2013; McCarl et al. 1999), and concerns over damages to groundwater-dependent ecosystems and endangered species from surface water-groundwater interaction (Van Kirk and Naman 2008).

As a result, there is a very fine-scale heterogeneity of regulations related to groundwater use. Whereas large portions of the United States do not have any meaningfully binding restrictions on groundwater use, there is also a growing 
number of areas where quantification, monitoring, and enforcement of pumping rights have been implemented. Moreover, there are also examples where markets in groundwater pumping rights are emerging. Finally, in at least one case, voluntary changes in water rights that allow binding reductions in agricultural groundwater pumping have occurred (Kuwayama and Brozović 2013; NE DNR and MRNRD 2010; NE DNR and TBNRD 2012; NE DNR and URNRD 2010; Thompson et al. 2009). In the remainder of the section, we will focus on describing some of these recent, innovative approaches to groundwater management.

\subsubsection{Introduction to the High Plains Aquifer Region}

The High Plains aquifer system is one of the largest groundwater aquifers in the world (McGuire et al. 2012; Fig. 22.2). It supports endangered species, ecosystems, and rural economies in an area covering multiple states (Gutentag et al. 1984; Rosenberg et al. 1999; Dennehy et al. 2002) and a variety of hydrologic and climatic settings. As a result, both the management concerns and institutional responses to these concerns vary enormously across the region.

Each state above the High Plains aquifer has its own groundwater administration areas. These areas are called Natural Resources Districts (NRDs) in Nebraska, Groundwater Management Districts (GMDs) in Kansas, and Groundwater Conservation Districts (GCDs) in Texas. All three categories of groundwater-related conflict discussed in the previous section are observed in the High Plains (Fig. 22.2). First, the major concern over groundwater may be related to declining well yields as pumping reduces saturated thicknesses (e.g. Northwest Kansas GMD\#4, North Plains GCD). Second, stream depletion related to groundwater pumping may lead to conflict between groundwater users and downstream surface water users (e.g. the Upper and Middle Republican NRDs, Big Bend GMD\#5). Finally, stream depletion may negatively impact endangered species and instream habitat (e.g. the Twin and Central Platte NRDs).

Effective groundwater management requires monitoring and enforcement of groundwater use. In the High Plains region, a large portion of the states of Kansas and Nebraska requires that all irrigation wells are metered and pumping reported annually. Meters are less common in Texas, but some groundwater management districts such as the North Plains Groundwater Conservation District are now phasing-in meter installation.

As noted above, monitoring of groundwater use is only meaningful to resource management to the extent that there is enforcement when violations occur. Where reporting of metering data is voluntary and without sanction, there is little incentive to provide timely or accurate readings. Conversely, in some groundwater management districts, paid district employees do the meter reading, with fines for broken meters and severe penalties for violators. For example, in 2010, the Upper Republican Natural Resources District in Nebraska revoked groundwater pumping rights, estimated to be worth in excess of $\$ 3$ million, for several groundwater users who 


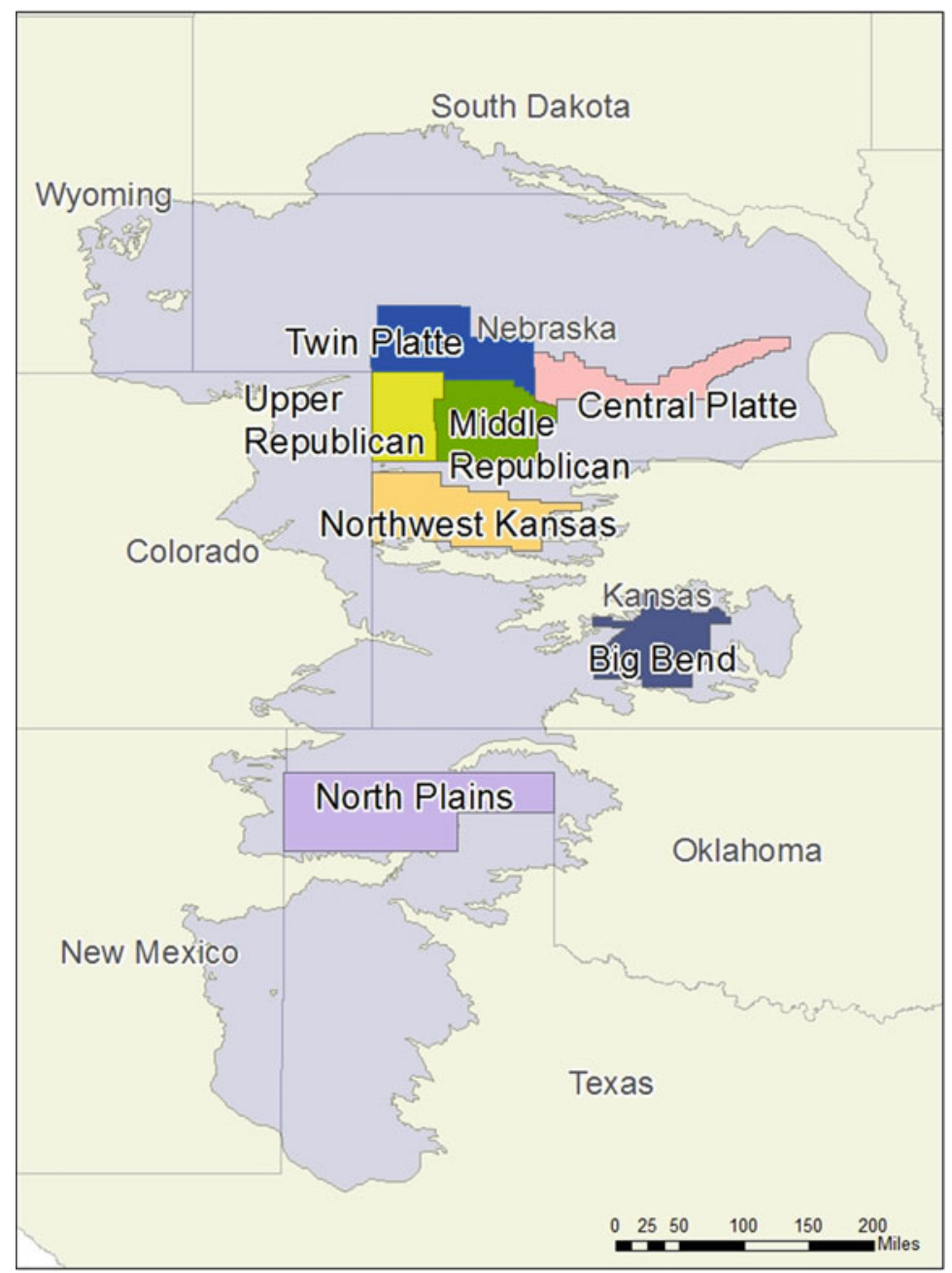

Fig. 22.2 High Plains Aquifer region, with key administrative areas in Kansas, Nebraska, and Texas

had attempted to increase their water use illegally through bypassing their well flow meters.

Note that even without metering of groundwater use, it is possible to estimate groundwater use, and depending on the situation, imperfect monitoring may be sufficient for management. For example, some natural resources districts in Nebraska quantify and enforce the right to irrigate a certain area of land, but do not meter water use (e.g. the Twin Platte and Central Platte NRDs). If crop water demands on a per-area basis are similar, then the estimation error from not metering may be small. Thus, depending on the goals of groundwater management, it may be 
preferable to avoid the potential difficulties associated with metering. However, there is still a need to enforce limits on the irrigated areas for such systems to succeed.

\subsubsection{Transferable Schemes for Groundwater Pumping Rights}

Policies that seek to reallocate groundwater pumping rights must deal with a number of issues. While some of these are well-known from markets for surface water rights (Chong and Sunding 2006; Saliba 1987; Young 1986), others are specific to groundwater pumping. Groundwater pumping leads to several kinds of spatial and intertemporal externalities (Brozović et al. 2010; Kuwayama and Brozović 2013). Indeed, groundwater management schemes that reallocate water between alternate pumping locations are often explicitly designed to change the distribution and magnitude of pumping externalities. Reallocation may be designed to minimize unwanted impacts on third parties or to encourage trades that reduce the magnitude of externalities (Palazzo and Brozović 2014; Brozović and Young 2014).

Externalities arising from groundwater pumping depend on local hydrologic properties and are spatial and intertemporal (Brozović et al. 2010). In principle groundwater pumping produces well interference and induces drawdown in adjacent wells. However, to date interference between adjacent wells with different ownership has not obviously restricted groundwater trading in the High Plains region. One possible explanation is that existing well spacing regulations are enough to prevent significant well interference between adjacent wells. Because trading of the right to pump groundwater changes the location of pumping but does not involve the physical transfer of water above ground, in general no water conveyance system is needed. Note that this is different to most surface water markets, where the need for water conveyance may be a major limitation to trading. Moreover, in groundwater management areas where there are already binding restrictions on groundwater use, water users that are looking to purchase additional pumping rights often have excess pumping capacity and may be able to use any permits they purchase without needing any further capital investment.

Existing groundwater permit trading schemes typically use applied water, rather than consumptive water use, as the unit of trade. Again this is in contrast to surface water markets, where it is common for only consumptive water use to be tradable. The main reason for the difference is likely pragmatic. Well metering quantifies applied water rather than consumptive use and represents a unit of transfer that is politically acceptable to water user groups. Moreover, in many cases both buyers and sellers of groundwater use rights have the same irrigation technology (typically centre pivot systems in the High Plains region of the United States). Consequently, differences in consumptive use between buyers and sellers may be negligible. Conversely, in surface water markets where water is moved outside of basins, or between agricultural and urban water users, the need to quantify consumptive use is much greater. 


\subsubsection{Innovations in Groundwater Management: Nebraska}

Management of groundwater in Nebraska is undertaken by Natural Resources Districts (NRDs). The NRDs are operated as local government agencies but may be thought of as large groundwater user associations. The NRDs have a relatively large amount of autonomy, and determine their rules and regulations in consultation at the state level through the Nebraska Department of Natural Resources. As a result, a wide variety of groundwater management institutions have evolved at an NRD level, reflecting local concerns about water use (Fig. 22.2). For example, (NE DNR and MRNRD 2010; NE DNR and TBNRD 2012; NE DNR and URNRD 2010) in the Platte River Basin in Nebraska, groundwater regulation is driven by stream depletion impacting endangered species habit for fish and migratory birds (Fig. 22.2). There is currently no metering of wells in the NRDs within the Platte River Basin. The Twin Platte, Central Platte, and Tri-Basin (Platte River portion) NRDs currently allow transfers of groundwater pumping rights. Each of these NRDs uses certification of irrigated acres to place an upper bound on the land area that can be irrigated. Then, transfers of certified irrigated acreage are allowed. Stream depletion is calculated over a 50-year horizon and, depending on the NRD, transfers may be adjusted if acreage is transferred to a location with higher stream depletion than the original location. There are also additional spatial limits on trading, such as constraints that trades cannot move water upstream (Twin Platte and Central Platte NRDs) or outside of specified zones (Tri-Basin NRD). Note that the use of certified irrigated acres as the unit of transfer corresponds to an imperfect monitoring of groundwater pumping. However, when the primary concern is stream depletion, encouraging trading to move water further from the river is desirable and, over short to medium management timescales, the benefits of this spatial reallocation may outweigh modest increases in total pumping.

Conversely, groundwater regulation in the Republican River Basin of Nebraska has been driven by interstate litigation between Kansas, Nebraska, and Colorado over the allocations of surface water to each state from the Republican River (McKusick 2002; Figure 2). As a result of a long litigation between the states, all wells in the Nebraska portion of the Republican River Basin are metered, with mandatory annual reporting and moratoria on new wells. The Upper Republican NRD completed metering in 1982, and the remaining NRDs completed metering in 2005. There are pumping quotas in place with complex and changing intertemporal carry forward provisions that allow banking of unused rights for future use. Current updates of the integrated management plans for three of the NRDs in the Republican River Basin, the Upper (UR) and Middle (MR) Republican and Tri-Basin (TB) (Republican River portion) NRDs, allow for some trading of groundwater pumping rights.

The Republican River Basin NRDs that allow trading each have slightly different rules that constrain trading. For example, in the Upper Republican NRD, trades must stay within an area equal in size to a township (36 mile or around $90 \mathrm{~km}^{2}$ ). In the Middle Republican NRD, trading is limited to groundwater users within certain distances from streams. In years in which the Middle Republican NRD is concerned 
about meeting its stream depletion targets under the Republican River Compact, trading may be suspended at the discretion of the NRD. In each of the NRDs, there is an adjustment for differences in stream depletion if pumping rights are transferred to a location where stream depletion is greater than the original pumping location. However, if pumping rights are transferred to a location with lower stream depletion than the original location, no adjustment to the rights takes place.

\subsubsection{Innovations in Groundwater Management: Kansas}

Kansas is unusual in having appropriative, rather than correlative, rights for groundwater. This complicates any policy that seeks to reallocate groundwater pumping between users as any transfer must not demonstrably impact any senior rights holders. Thus, it is possible that concerns over well interference might restrict the potential applicability of groundwater trading schemes. Despite this, groundwater trading has been established in two areas of the state. First in the Big Bend Groundwater Management District (GMD) No. 5, the Wet Walnut Creek Intensive Groundwater Use Control Area is metered with pumping allocations, and transfers are allowed, though they have not yet occurred. GMD No. 5 also operates a groundwater bank through which transfers may occur, subject to large conservation offsets and regulatory complexity. One trade has occurred in the bank.

Second, in the Northwest Kansas Groundwater Management District No. 4, a portion of the district (the Sheridan-6 area) was designated a Local Enhanced Management Area (LEMA) in early 2013. This is the first such area in the state. The LEMA is self-regulating, and has chosen to equalize the seniority of its water rights and reduce the total water allocation by $20 \%$ relative to historic use. Trading is allowed and will be on a volumetric basis without adjustment, as the primary concern is aquifer depletion and not stream depletion.

\subsubsection{Innovations in Groundwater Management: Texas}

Although metering is slowly being introduced to groundwater conservation districts in Texas, conveyance is an impediment to trading in Texas. Under current groundwater law, trading is allowed but the buyer is expected to pump the water at the location of purchase, on the seller's land. Portions of land overlying the Edwards Aquifer (not a part of the High Plains Aquifer) are an exception to this rule, where trading is allowed to change the location of pumping as it is assumed that the area encompassing all potential transfers is small enough that impacts on third parties will not be altered significantly by transfers. The Edwards Aquifer Authority in Texas has implemented well permitting and metering programs and allows transfers of the right to pump up to 1 acre-foot/acre of certified irrigated land (EAA 2012). Both permanent transfer and lease markets exist. 


\subsection{From Command and Control to Markets: Examples from Chile}

The case of Chile is illustrative of a transition from command and control to market based groundwater management policy, where economic incentives play a significant role in allocation of water use rights.

\subsubsection{Legal and Institutional Framework (an Historical Perspective and Recent Evolution)}

The first Chilean text to regulate the use of water is an 1819 Executive Decree which defined the dimensions of an irrigation water use right and responsibility for water intakes. The 1855 Civil Code was the first legal instrument to define that "the rivers and all waters running within natural channels are national goods of public use." In addition, it establishes that access to water is obtained by means of wateruse rights (WUR) "granted by the competent authority." The concept of WUR was further developed in the 1930 Water Code proposal and 1951 Water Code. The latter code defines WUR as follows: "A water use right is an actual right that falls on publicly owned waters which consists in the use, possession and disposal of such waters fulfilling the requirements and in accordance with the rules prescribed herein" (Hearne and Donoso 2005). The 1967 Water Code, implemented in a more centralized political context, reinforces the concept of water as being within the public domain and changed the legal nature of WUR, stressing that these were administrative rights where the State grants the use of the waters, subject to public regulation. These WUR could expire, and the process of water reallocation was to be based on regional water-use plans executed by means of studies that determined the rate of rational and beneficial use (Hearne and Donoso 2005).

The Water Code of 1981 (WC 1981) maintained water as "national goods of public use," but granted permanent, transferable WUR to individuals so as to reach an efficient allocation of the resource through market transactions of WUR. The holder of the WUR is the owner of the right in perpetuity, ownership that is protected constitutionally. However, it is important to note that granted WUR do not constitute a transfer of ownership of the water. The WC 1981 allowed for freedom in the use of water to which an agent has WUR; thus, WUR are not sector specific and can be transferred between sectors as well as within economic sectors. Similarly, the WC 1981 abolishes the water use preferential lists, present in the Water Codes of 1951 and 1967. Additionally, WUR do not expire and do not consider a "use it or lose it" clause.

The WC 1981 specifies consumptive and non-consumptive WUR for both surface and groundwater. Non-consumptive use rights allow the owner to divert water with the obligation to return the same water unaltered to its original source. Consumptive use rights do not require that the water be returned once it has been used. Consumptive and non-consumptive WUR are, by law, specified as a volume per unit of time. In addition, consumptive and non-consumptive rights can be 
exercised in a permanent or contingent manner and in a continuous, discontinuous or alternating mode. Permanent use rights are rights specified as a volume per unit of time, unless there is water scarcity in which these WUR are recognized as shares of water flows. Contingent rights are specified as a volume per unit of time and only authorize the user to extract water once permanent rights have extracted their rights. Continuous rights are those use rights that allow users to extract water continually over time. On the other hand, discontinuous rights are those that only permit water to be extracted at given periods. Finally, alternating rights are those in which water extraction is distributed among two or more persons.

Groundwater in Chile is regulated in Book I, Title VI of the WC 1981 in Articles 58-68. In addition, groundwater is administratively regulated by Resolution No. 425 of the Dirección General de Aguas (DGA - General Water Directory) approved in 2008. Article 58 establishes that any person can explore in order to find groundwater on their property. Exploration on public property requires an authorization by the DGA; should two or more petitions for exploration be presented for the same geographic area, the DGA will define who receives the exploration right based on an auction. If groundwater is found, the user can petition the DGA for a new groundwater use right. The groundwater use right petition must meet the following requirements:

(a) Identification of the aquifer from which the water is to be extracted;

(b) Definition of the quantity of water to be extracted, expressed in liters per second;

(c) Yield and depth of the extraction well;

(d) Specification of the water extraction points and the method of extraction; and

(e) Definition of whether the right is permanent or contingent, continuous, discontinuous or alternating.

The administrative procedure requires that this WUR petition be published in the Diario Oficial, in a daily Santiago newspaper, and in a regional newspaper, where applicable. Previous to the WC 1981 reform of 2005, the DGA could not refuse to grant new water rights without infringing a constitutional guarantee, provided there was technical evidence of the availability of water resources and that the new use would not harm existent rights holders. ${ }^{3}$ At present, if the petition is found to be for speculative reasons the DGA can refuse to grant the solicited WUR. If there is competition for solicited water rights, they are to be allocated through an auction with an award to the highest bidder. This allocation rule between competing WUR petitioners allows water to be allocated to its highest use value.

The Law $\mathrm{N}^{\mathrm{o}} .20,017$ of 2005 amended the procedure to grant new WUR of the WC 1981 and introduced a non-use tariff (patente de no-uso). Due to the difficulties of monitoring the effective use of all WUR, the non-use tariff is applied to all

\footnotetext{
${ }^{3}$ But, the DGA can declare certain aquifers to be fully exploited and refuse to grant new groundwater use rights.
} 
consumptive permanent groundwater WUR that do not count with water intake infrastructure, and to all non-consumptive WUR that do not have water intake and return infrastructure (Law $\mathrm{N}^{\mathrm{o}}$. 20,017 of 2005, art. 129 bis 4-6).

Groundwater resources can be classified as: free, under restriction, and under prohibition. A groundwater resource classified as free implies that new WUR can be granted to petitioners. Groundwater declared under restriction ${ }^{4}$ only allows provisional WUR to be granted; meanwhile, if it is under prohibition, ${ }^{5}$ no new WUR can be granted. ${ }^{6}$ In Chile, the possibility of limiting withdrawals has been contemplated since 1983 (Res DGA 207 of 1983). However, this resolution does not indicate how these restricted groundwater resources were to be managed. DGA Res 186, which establishes that groundwater user communities (GUC) will manage restricted groundwater resources, clarifies this in 1996; additionally, DGA Res 186 establishes that all restricted groundwater resources must have a GUC. At present Res 341 of 2005, Article 63 of the WC 1981, and Article 39 of Resolution 425 of the DGA establishes that GUC are responsible for the management of groundwater resources and of water extractions.

Approximately $70 \%$ of Chilean territory presents no restrictions for groundwater exploitation. There are at least 50 aquifers with a declaration of restriction, all located from the Region of Arica and Parinacota to O'Higgins (Fig. 22.3). There are only two aquifers under prohibition: the first is the aquifer of San José de Azapa in the Region of Arica and Parinacota and the second is the aquifer of Copiapó in the Atacama Region. Even though there could be over 50 GUC, only two GUC exist at present in Chile; one manages groundwater in the restricted aquifer of Copiapó Province and the second one can be found in the Yali sector of the Melipilla Province of the Metropolitan Region.

\subsubsection{Economic Mechanisms/Instruments in Place}

The WC 1981 established that WUR are transferable in order to facilitate WUR markets as an allocation mechanism. Although private water use rights existed in Chile prior to 1981, the previous water codes restricted the creation and operation of efficient water markets. The framers of the 1981 Water Code sought to achieve the efficiencies of market reallocation of water, "the objective of the governmental

\footnotetext{
${ }^{4}$ The DGA can declare an aquifer under restriction if there is a risk of negative impacts of new WUR on existing WURs.

${ }^{5}$ The DGA can declare an aquifer under prohibition if there is clear evidence of a risk of resource depletion due to over-extraction.

${ }^{6}$ The DGA has the authority to provisionally grant groundwater use rights in those areas that have been declared under restriction. The effects of these provisional WUR on other groundwater use rights holders are studied. Should negative impacts be identified in these areas, these provisional WUR are anulled by the DGA; i.e. groundwater may no longer be extracted with these WUR. However, if no effects are identified after 5 years of water extraction, these provisional WUR can become definite WUR.
} 


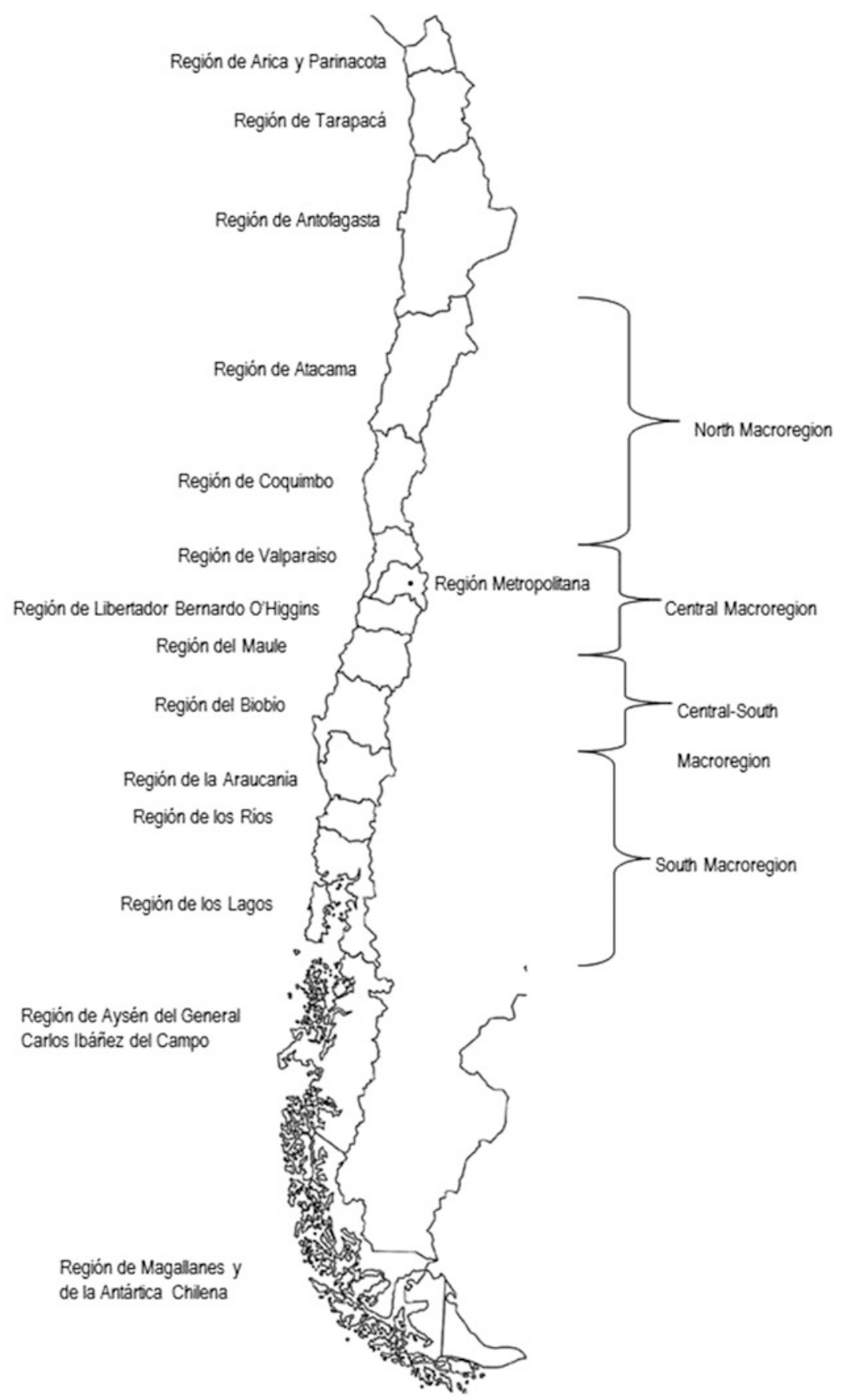

Fig. 22.3 Map of Chile showing different regions 


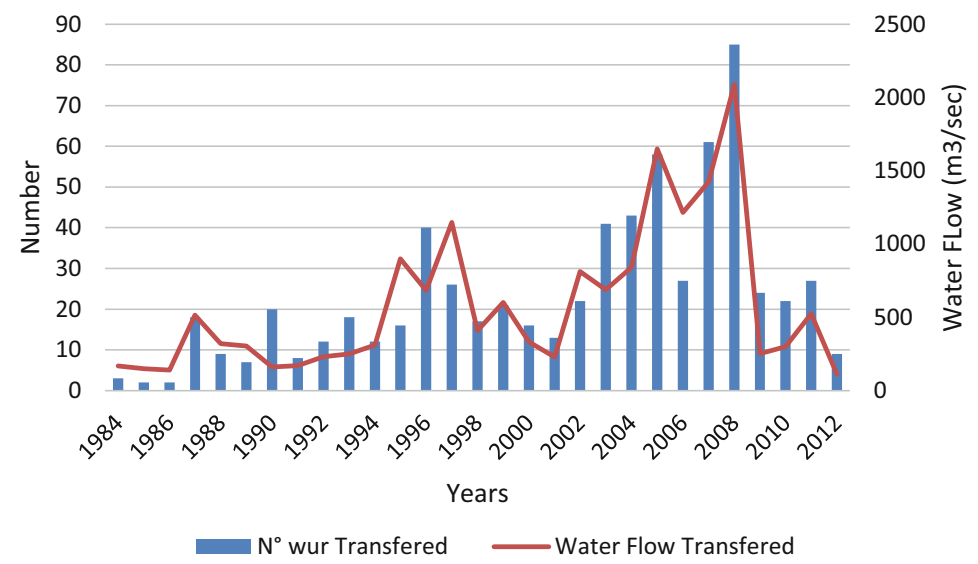

Fig. 22.4 Water flow and number of WUR traded in the Copiapó Aquifer (CNR 2012)

action in this field was to create solid WUR in order to facilitate the proper operation of the market as an allocation mechanism" (Buchi 1993, pp. 85-87). Thus the WC 1981 was designed to protect traditional and customary WUR and to foster economically beneficial reallocation through market transfers (Bauer 2004; Buchi 1993; Hearne and Donoso 2005).

Although market reallocation of water has not been common throughout most of Chile, the existence of water markets has been documented. As Donoso (2012) concludes, studies have shown active trading for WUR in the Copiapó aquifer where water is scarce with a high economic value, especially for the mining sector and the high valued agricultural export sector (CNR 2012). Inter-sectoral trading has transferred water to growing urban areas in the Elqui Valley (Hearne and Easter 1997) and the upper Mapocho watershed, where water companies and real estate developers are continuously buying water and account for $76 \%$ of the rights traded during the 1993-1999 period (Donoso et al. 2002). Other studies have shown limited trading in the Bío Bío, Aconcagua, and Cachapoal Valleys (Bauer 1998; Hadjigeorgalis and Riquelme 2002).

A key conclusion of these studies is that water markets are driven by demand from relatively high-valued water uses, and facilitated by low transactions costs in those aquifers that the DGA has declared as restricted or protected and where there are GUCs present that assist in the transfer of water. For example as Fig. 22.4 shows, in the Copiapó basin, the volume of water and number of WUR traded began to increase as of 1994, when the DGA declared the aquifer under protection (CNR 2012). There was a second increase as of 2002 when the DGA maintained the prohibition for Sectors 1-4 and declared restrictions for Sectors 5 and 6. This resolution reinforced the signal to water users that new WUR were not available for the Copiapó aquifer and, thus new water demands must be satisfied through the market for WUR.

In the absence of these conditions, trading has been rare and water markets have not become institutionalized in most aquifers. It should be noted that during the 
2000s, the market was more active than in the previous two decades, that is in the 1980s and 1990s (Donoso 2012).

\subsubsection{Issues and Problems}

The WC 1981 did not pay much attention to the sustainable management of groundwater because at that time groundwater extraction was marginal during the early 1980s. Recognizing the need to improve groundwater management regulation due to increased groundwater pumping, the 2005 amendment of the WC 1981 introduced procedures to reach a sustainable management of underground water resources. The main provisions are: (a) extraction restrictions when third parties are affected; (b) authorization for the DGA to impose the installation of extraction measurement equipment in order to monitor extractions effectively; (c) the establishment of areas subject to extraction prohibitions and restrictions; and (d) the need to consider the interaction between surface water and groundwater when analyzing petitions for new surface or groundwater WUR.

However, a World Bank study (2011) concluded that there exist various problems associated with groundwater management. A major concern is the general lack of information about groundwater and insufficient knowledge about its dynamics, in particular its interaction with surface waters. There are significant gaps in the registry of wells, extraction and quality measurements, recharge balances, and identification of pollution sources. In general, information systems are not linked to the measurement and monitoring of aquifers to estimate groundwater withdrawals. An effective information system is a prerequisite to be able to control and sustainably manage an aquifer.

The sustainability of northern aquifers is compromised due to the over-provision of WUR related to the practice of allocating WUR based on foreseeable use. The foreseeable use considers the probable effective water extraction of different sectors when analyzing whether there is sufficient water to grant new WUR. For example, an agricultural WUR does not extract water in winter months, whereas a mining WUR extracts water all year round. In this case, the authority would consider a lower pressure on water resources of an agricultural WUR with respect to the pressure of a mining WUR. This practice commits the mistake of not considering the transferable nature of WUR. Thus, when water scarcity increases and inter-sectoral WUR transactions increase, water resources will be overexploited and unsustainable. Additionally, the over-provision of WUR gave rise to increased water conflicts as WUR are transferred to users with a more intensive water use, such as from agriculture to mining in the northern basins.

An additional challenge for a sustainable groundwater management is the fact that at present ground and surface waters are managed independently despite their recognized interrelations even though the 2005 reform of the WC 1981 establishes that surface and groundwater must be jointly managed. This implies that at present there is no conjunctive management of surface and groundwater, which has proven to be an effective adaptation mechanism for climate change. 
There are, in general, no GUCs that manage groundwater user rights; the only exception is in some sections of the over-exploited Copiapo aquifer. There should exist a GUC at least for all aquifers that have a restriction or prohibition declaration by the DGA. The fact that users have not yet organized themselves in GUCs to take over the management of groundwater reflects the lack of understanding of a large proportion of users of the long term effects that uncontrolled exploitation of aquifers may cause. In the absence of GUCs, the WC 1981 establishes that the DGA is responsible for controlling and monitoring groundwater withdrawals. Evidence has shown that the DGA does not have the necessary resources (human, technical, and financial) to monitor all groundwater extractions.

There is an incentive for the adoption of water saving technologies by farmers (Law No. 18,450). This program subsidizes small scale, private irrigation investments. It has supported much of the installation of drip irrigation systems in the dry north and spray systems in the humid south. However, there has been no assessment of the impacts of this incentive instrument on groundwater recharge and sustainability. Hence, it is essential to strengthen the coordination between sectoral policies and water management policies.

\subsection{Conclusions}

One of the lessons learnt from the three case studies is that policies implemented in practice often combine instruments which text books often present as competing options. In Chile, France and the High Plain case studies, policy makers and local managers are actually trying to combine (i) instruments which provide economic incentives and allow for reallocating water with (ii) the development of water user associations and, to some extent, (iii) the formalization of water (use) rights. There is nothing in reality that looks like a pure "market" approach.

Another key lesson is that monitoring and control remains an issue in the three very different contexts, even where full property rights have been established for decades. It is also interesting to note that solutions implemented to solve information problems are somewhat the same in the different countries - all assume that perfect information on water abstraction (e.g. metering) is not a prerequisite and that management can work with less precise information such as a measurement of irrigated area for instance.

A third lesson is that economic instruments enter the management tool box only when water scarcity becomes a real problem or, to use Randall's terminology, when the water economy matures. The High Plain case study shows that different "maturity" levels may co-exist in the same State. Put differently, this implies that the choice of economic instruments that can be used in each specific situation is far from being fully determined by the national legal, institutional, societal and economic framework. Therefore there is probably plenty of room for manoeuvre for local stakeholders to explore the potential for innovative approaches.

Table 22.2 synthesizes the main characteristics of groundwater management in the three case studies. It highlights that incentive-based instruments are framed 
Table 22.2 Comparison of groundwater management in the three case studies

\begin{tabular}{|c|c|c|c|}
\hline & Chile & France & USA - high plains aquifer \\
\hline $\begin{array}{l}\text { Level of } \\
\text { aquifer } \\
\text { regulation }\end{array}$ & $\begin{array}{l}\text { A national policy locally } \\
\text { translated }\end{array}$ & $\begin{array}{l}\text { A national policy } \\
\text { locally translated }\end{array}$ & $\begin{array}{l}\text { No federal policy } \\
\text { regulation. May be some } \\
\text { state oversight. } \\
\text { Groundwater regulation at } \\
\text { local level, which can } \\
\text { differ from one State to } \\
\text { another }\end{array}$ \\
\hline $\begin{array}{l}\text { Groundwater } \\
\text { areas }\end{array}$ & $\begin{array}{l}\text { Free ( } 70 \% \text { of aquifers), } \\
\text { under restriction }(\sim 50 \\
\text { aquifers), under } \\
\text { prohibition ( } 2 \text { aquifers })\end{array}$ & $\begin{array}{l}89 \% \text { of aquifers } \\
\text { reputed in good } \\
\text { status (Vial } \\
\text { et al. 2010) }\end{array}$ & $\begin{array}{l}\text { Most aquifers with no } \\
\text { restrictions, but a growing } \\
\text { number of active } \\
\text { management areas } \\
\text { Three types of problems: } \\
\text { aquifer depletion, } \\
\text { damages to transboundary } \\
\text { surface water resources or } \\
\text { to ecosystems }\end{array}$ \\
\hline Water rights & $\begin{array}{l}\text { Ancient (1855) water-use } \\
\text { rights -WUR- based on } \\
\text { maximal consumptive } \\
\text { levels. Constitutionally } \\
\text { protected. No "use it or } \\
\text { lose it" clause }\end{array}$ & $\begin{array}{l}\text { No water right. } \\
\text { Only yearly and } \\
\text { revocable water } \\
\text { abstraction } \\
\text { authorizations. } \\
\text { Presently, } \\
\text { definition of an } \\
\text { upper limit to } \\
\text { water abstraction } \\
\text { per groundwater } \\
\text { basin to be shared } \\
\text { between users }\end{array}$ & $\begin{array}{l}\text { Generally no or very few } \\
\text { limits on groundwater use. } \\
\text { In some regions, water } \\
\text { rights defined with or } \\
\text { without water meters. } \\
\text { Kansas: appropriative } \\
\text { rights; other States: } \\
\text { generally correlative } \\
\text { rights }\end{array}$ \\
\hline $\begin{array}{l}\text { Groundwater } \\
\text { withdrawals' } \\
\text { management }\end{array}$ & $\begin{array}{l}\text { Water markets authorized } \\
\text { since } 1981 \text {. Active only in } \\
\text { scarcity areas, when there } \\
\text { exist high-valued water } \\
\text { uses and low transactions } \\
\text { costs }\end{array}$ & $\begin{array}{l}\text { A fee paid to } \\
\text { Water Agency. } \\
\text { Creation of water } \\
\text { users' associations } \\
\text { charged to share } \\
\text { global water } \\
\text { quota. No water } \\
\text { market }\end{array}$ & $\begin{array}{l}\text { A variety of mechanisms } \\
\text { including no restrictions, } \\
\text { well moratoria, limits on } \\
\text { irrigated acreage, limits } \\
\text { on pumping, water } \\
\text { markets }\end{array}$ \\
\hline $\begin{array}{l}\text { Water users' } \\
\text { associations }\end{array}$ & $\begin{array}{l}\text { Compulsory in scarcity } \\
\text { areas since } 1983\end{array}$ & $\begin{array}{l}\text { Compulsory in } \\
\text { scarcity areas } \\
\text { since } 2014 \\
\end{array}$ & Yes, in some areas \\
\hline Problems & $\begin{array}{l}\text { No conjunctive ground } \\
\text { and surface water } \\
\text { management and more } \\
\text { generally no coordination } \\
\text { between sectoral policies } \\
\text { Lack of information on } \\
\text { groundwater dynamics } \\
\text { Few WUA (2) and lack of } \\
\text { monitoring in other cases } \\
\text { Water markets lead an } \\
\text { unsustainable increase of } \\
\text { water consumption }\end{array}$ & $\begin{array}{l}\text { Levels of water } \\
\text { fees not incentive } \\
\text { Law enforcement } \\
\text { Water allocation } \\
\text { efficiency } \\
\text { A perceived unfair } \\
\text { allocation }\end{array}$ & $\begin{array}{l}\text { Generally there are few } \\
\text { restrictions on } \\
\text { groundwater use } \\
\text { Generally, no conjunctive } \\
\text { ground and surface water } \\
\text { management } \\
\text { Extended litigation is } \\
\text { often a prerequisite for } \\
\text { management changes }\end{array}$ \\
\hline
\end{tabular}


taking into account local contexts, in particular historical, institutional and cultural aspects. Where groundwater was traditionally considered as an open access resource, introducing regulations represents a shift in paradigm and is likely to raise significant opposition. Moreover, the level of involvement of users in the definition of groundwater sharing rules is key to understanding the type of instrument chosen and its efficiency. All these aspects explain the current institutions for groundwater management that have developed in the three case studies: the external imposition of water markets in Chile which do not function as expected, a management mostly based on quantitative sharing in France (with few economic instruments), and nascent market instruments in the High Plains Aquifer of the United States.

To conclude, economic instruments are used to encourage groundwater users to adopt water saving behaviours and then to not overexploit groundwater resources while maximising water efficiency. However, using economic instruments for groundwater management is challenging due to the nature of the resource: it is often complicated to define satisfactorily the level of abstraction that allows a sustainable exploitation; it is also difficult to detect groundwater usage, especially where surface water can also be used. Together, this explains why economic instruments sometimes do not function as anticipated because of incomplete information.

Apart from such difficulties, the three case studies point out two main challenges to be able to control groundwater over-exploitation through economic instruments. First of all is the acceptability challenge. For instance, in France, water markets are nowadays not acceptable mainly for ethical reasons; water taxes can also be rejected, a taxable user finding unfair such an instrument which is seen to unduly increase State receipts. Similarly, over most of the United States, restrictions on groundwater use are currently not acceptable to key user groups. The second challenge is enforcement. An example is given by the Chile case where an enforceable property rights' system combined with an appropriate information level of groundwater availability and demand is still lacking; in France, sanctions applicable in respect of non-registered withdrawals are sometimes not applied. Threats cannot be credible, and then an instrument based on them will not function at all.

Open Access This chapter is distributed under the terms of the Creative Commons AttributionNoncommercial 2.5 License (http://creativecommons.org/licenses/by-nc/2.5/) which permits any noncommercial use, distribution, and reproduction in any medium, provided the original author(s) and source are credited.

The images or other third party material in this chapter are included in the work's Creative Commons license, unless indicated otherwise in the credit line; if such material is not included in the work's Creative Commons license and the respective action is not permitted by statutory regulation, users will need to obtain permission from the license holder to duplicate, adapt or reproduce the material. 


\section{References}

Bauer C (1998) Against the current: privatization, water markets, and the state in Chile. Kluwer, Boston

Bauer C (2004) Siren song: Chilean water law as a model for international reform. Resources for the Future Press, Washington, DC

Brozović N, Young R (2014) Design and implementation of markets for groundwater pumping rights. In: Easter K, Huang Q (eds) Water markets for the 21st century: what have we learned? Springer, Netherlands

Brozović N, Sunding DL, Zilberman D (2010) On the spatial nature of the groundwater pumping externality. Resour Energy Econ 32(2):154-164

Buchi H (1993) La transformación económica de Chile. Del Estatismo a la libertad económica. Norma, Bogota

Casari M, Plott CR (2003) Decentralized management of common property resources: experiments with a centuries-old institution. J Econ Behav Organ 51(2):217-247. doi:10. 1016/S0167-2681(02)00098-7

Castaño S, Sanz D, Gómez-Alday J (2010) Methodology for quantifying groundwater abstractions for agriculture via remote sensing and GIS. Water Resour Manag 24(4):795-814. doi:10.1007/ s11269-009-9473-7

Chong H, Sunding D (2006) Water markets and trading. Annu Rev Environ Resour 31(2):239-264

CNR (2012) Capacitación y Apoyo a Comunidades de Aguas Subterráneas, en el Valle de Copiapó. Report Comisión Nacional de Riego (CNR), Ministerio de Agricultura, Chile

de Stefano L, Lopez-Gunn E (2012) Unauthorized groundwater use: institutional, social and ethical considerations. Water Policy 14(S1):147-160

Dennehy KF, Litke DW, McMahon PB (2002) The High Plains Aquifer, USA: groundwater development and sustainability. Geol Soc Lond Spec Publ 193(1):99-119

Desprats J-F, Rinaudo J-D, Montginoul M (2011) Analyse de la relation entre le type d'urbanisation et la consommation en eau des ménages - Le cas de l'agglomération de Perpignan. BRGM, Orléans

Donoso G (2012) The evolution of water markets in Chile. In: Maetsu J (ed) Water trading and global water scarcity: international perspectives. RFF Press, Washington, DC, pp 111-129

Donoso G, Montero JP, Vicuña S (2002) Análisis de los Mercados de Derechos de Aprovechamiento de Agua en las Cuencas del Maipú y el Sistema Paloma en Chile: Efectos de la Variabilidad de la Oferta Hídrica y de los Costos de Transacción. In: Embid A (ed) El Derecho de Aguas en Ibero América y España: Cambio y Modernización en el Inicio del Tercer Milenio. Civitas, Madrid, pp 109-151

EAA (2012) Edwards aquifer authority rules. http://www.edwardsaquifer.org/files/download/ $2 \mathrm{~b} 4674 \mathrm{cbea} 20 \mathrm{e} 5 \mathrm{~b}$

Figureau A-G, Montginoul M, Rinaudo J-D (2015) Policy instruments for decentralized management of agricultural groundwater abstraction: a participatory evaluation. Ecological Economics 119:147-157, http://dx.doi.org/10.1016/j.ecolecon.2015.08.011

Garin P, Loubier S, Campardon M (2013) Irrigation individuelle - irrigation collective: état des lieux et contraintes. Revue SET 11:86-89

Garrido A, Rey D, Calatrava J (2012) Water trading in Spain. In: De Stefano L, Llamas MR (eds) Water, agriculture and the environment in Spain: can we square the circle? CRC Press, Botín Foundation, London, pp 205-216

Gleeson T, Cardiff M (2013) The return of groundwater quantity: a mega-scale and interdisciplinary "future of hydrogeology"? Hydrogeol J 21(1169-1171). doi:10.1007/s10040-013-0998-8

Gutentag ED, Heimes FJ, Krothe NC, Luckey RR, Weeks JB (1984) Geohydrology of the High Plains aquifer in parts of Colorado, Kansas, Nebraska, New Mexico, Oklahoma, South Dakota, Texas, and Wyoming. US Department of the Interior, Geological Survey, Washington, DC

Hadjigeorgalis E, Riquelme C (2002) Análisis de los Precios de los Derechos de Aprovechamiento de Aguas en el Río Cachapoal. Ciencia e Investigación Agraria 29(2):91-99 
Hathaway D (2011) Transboundary groundwater policy: developing approaches in the Western and Southwestern United States. J Am Water Resour Assoc 47(1):103-113

Hearne R, Donoso G (2005) Water institutional reforms in Chile. Water Policy 7(1):53-69

Hearne R, Easter KW (1997) The economic and financial gains from water markets in Chile. Agric Econ 15:187-199

Konikow LF (2013) Groundwater depletion in the United States (1900-2008). US Department of the Interior, US Geological Survey, Reston, Virginia

Kuwayama Y, Brozović N (2013) The regulation of a spatially heterogeneous externality: tradable groundwater permits to protect streams. J Environ Econ Manag. doi:10.1016/j.jeem.2013.02. 004

Laukaitis AJ (2013) Drought's toll on groundwater is steepest on record. Lincoln J Star. http:// journalstar.com/news/local/drought-s-toll-on-groundwater-is-steepest-on-record/article_8c3d377d7dd1-5d11-bdce-7498476a032f.html. Accessed 9 May

Lenouvel V, Montginoul M (2010) Groundwater Management Instruments in a Conjunctive Use System: assessing the Impact on Farmers' Income Using a Mixed Integer Linear Programming (MILP). Ger J Agric Econ 59(3):158-172

Lenouvel V, Montginoul M, Thoyer S (2011) From a blind truncheon to a one-eyed stick: testing in the lab an optional target-based mechanism adapted to groundwater withdrawals. Paper presented at the 18th annual conference of European Association of Environmental and Resource Economists, Rome, 29 June-2 July 2011

Martin de Santa Olalla F, Brasa Ramos A, Fabeiro Cortés C, Fernández González D, López Córcoles H (1999) Improvement of irrigation management towards the sustainable use of groundwater in Castilla-La Mancha, Spain. Agric Water Manag 40(2-3):195-205. doi:10. 1016/s0378-3774(98)00121-8

Martín de Santa Olalla F, Calera A, Domínguez A (2003) Monitoring irrigation water use by combining Irrigation Advisory Service, and remotely sensed data with a geographic information system. Agric Water Manag 61(2):111-124. doi:10.1016/s0378-3774(02)00169-5

McCarl B, Dillon C, Keplinger K, Williams R (1999) Limiting pumping from the Edwards Aquifer: an economic investigation of proposals, water markets, and spring flow guarantees. Water Resour Res 35(4):1257-1268

McGuire B, Lund K, Densmoe B (2012) Saturated thickness and water in storage in the High Plains Aquifer, 2009, and water- level changes and changes in water in storage in the High Plains Aquifer, 1980 to 1995, 1995 to 2000, 2000 to 2005, and 2005 to 2009. U.S. Geological Survey Scientific Investigations Report 2012-5177, 28 p

McKusick V (2002) State of Kansas v. State of Nebraska and State of Colorado: joint motion of the states for entry of proposed consent judgement and approval and adoption of final settlement stipulation. Supreme Court of the United States, Washington DC

Ménard C (2003) L'approche néo-institutionnelle: des concepts, une méthode, des résultats. Cahiers d'Economie Politique 44:103-118

Montginoul M, Rinaudo J-D (2009) Quels instruments pour gérer les prélèvements individuels en eau souterraine? Le cas du Roussillon. Economie Rurale 310:40-56

Montginoul M, Rinaudo J-D (2011) Controlling households' drilling fever in France: an economic modeling approach. Ecol Econ 71:140-150

Mukherji A, Shah T (2005) Groundwater socio-ecology and governance: a review of institutions and policies in selected countries. Hydrogeol J 13(1):328-345. doi:10.1007/s10040-005-0434-9

NE DNR, MRNRD (2010) Integrated management plan. Nebraska Department of Natural Resources and Middle Republican Natural Resource District, Nebraska

NE DNR, URNRD (2010) Integrated management plan. Nebraska Department of Natural Resources and Upper Republican Natural Resource District, Nebraska

NE DNR, URNRD (2012) Integrated management plan. Nebraska Department of Natural Resources and Tri-Basin Natural Resources District, Nebraska

Palazzo A, Brozović N (2014) The role of groundwater trading in spatial water management. Agric Water Manag 145:50-60. doi:10.1016/j.agwat.2014.03.004 
Rinaudo J-D, Montginoul M, Varanda M, Bento S (2012) Envisioning innovative groundwater regulation policies through scenario workshops in France and Portugal. Irrig Drain 61 (1):65-74

Rinaudo J-D, Montginoul M, Hérivaux C, Figureau A-G (2014) Quels instruments pour une gestion collective des prélèvements agricoles individuels en eau souterraine ? Mise en débat de scénarios avec des acteurs du territoire dans 5 départements français. BRGM/RP-63259-FR, Montpellier, February, p 93

Rosenberg NJ, Epstein DJ, Wang D, Vail L, Srinivasan R, Arnold JG (1999) Possible impacts of global warming on the hydrology of the Ogallala aquifer region. Clim Change 42(4):677-692

Saliba BC (1987) Do water markets "work"? Market transfers and trade-offs in the Southwestern States. Water Resour Res 23(7):1113-1122

Salzman J (2005) Creating markets for ecosystem services: notes from the field. N Y Univ Law Rev 80(6):870-961

Scanlon BR, Faunth CC, Longuevergne L, Reedy RC, Alley WM, McGuire VL, McMahon PB (2012) Groundwater depletion and sustainability of irrigation in the US High Plains and Central Valley. Proc Natl Acad Sci. doi:10.1073/pnas.1200311109

Segerson K (1988) Uncertainty and incentives for nonpoint pollution control. J Environ Econ Manag 15(1):87-98

Shah T (2008) Taming the Anarchy: Groundwater Governance in South Asia. Resources for the Future Press (RFF Press), Washington, p 310

Skurray JH, Roberts EJ, Pannell DJ (2012) Hydrological challenges to groundwater trading: lessons from south-west Western Australia. J Hydrol 412-413(0):256-268. doi:10.1016/j. jhydrol.2011.05.034

Steward DR, Bruss PJ, Yang X, Staggenborg SA, Welch SM, Apley MD (2013) Tapping unsustainable groundwater stores for agricultural production in the High Plains Aquifer of Kansas, projections to 2110. Proc Natl Acad Sci 110(37):E3477-E3486

Strosser P, Montginoul M (2001) Vers des marchés de l'eau en France ? Quelques éléments de réflexion. Annales des Mines, Responsabilité et Environnement 23:13-31

Swierzbinski JE (1994) Guilty until proven innocent-regulation with costly and limited enforcement. J Environ Econ Manag 27(2):127-146

Terrell B, Johnson P, Segarra E (2002) Ogallala aquifer depletion: economic impact on the Texas high plains. Water Policy 4(1):33-46

Thompson CL, Supalla RJ, Martin DL, McMullen BP (2009) Evidence supporting cap and trade as a groundwater policy option for reducing irrigation consumptive use. J Am Water Resour Assoc 45:1508-1518

Van Kirk RW, Naman SW (2008) Relative effects of climate and water use on base-flow trends in the lower Klamath basin. J Am Water Resour Assoc 44(4):1035-1052

Van Vugt M (2009) Averting the tragedy of the commons: using social psychological science to protect the environment. Curr Dir Psychol Sci 18(3):169-173

Vial I, Lalement R, Deronzier G (2010) De l'état des eaux en 2009 aux objectifs 2015. Office national de l'eau et des milieux aquatiques (Onema) Paris

Weitzman ML (1980) The "ratchet principle" and performance incentives. Bell J Econ 11 (1):302-308

Wines M (2013) Wells dry, fertile plains turn to dust. New York Times 19 May

World Bank (2011) Chile: Diagnóstico de la gestión de los recursos hídricos. The World Bank, Washington, DC

Young RA (1986) Why are there so few transactions among water users? Am J Agric Econ 68:1144-1151

Zhang L, Wang J, Huang J, Rozelle S (2008) Development of groundwater markets in China: a glimpse into progress to date. World Dev 36(4):706-726. doi:10.1016/j.worlddev.2007.04.012 


\title{
Liberation or Anarchy? The Janus Nature of Groundwater Use on North Africa's New Irrigation Frontiers
}

\author{
Marcel Kuper, Nicolas Faysse, Ali Hammani, Tarik Hartani, \\ Serge Marlet, Meriem Farah Hamamouche, and Fatah Ameur
}

\begin{abstract}
Two contrasting views prevail on groundwater use in situations of predominantly state-led irrigation development. The first considers 'groundwater as liberation', i.e., how, by capturing the irrigation initiative, farmers liberated themselves from 'state' water, enabling more intensive and productive agriculture. The second view - 'groundwater as anarchy' - considers groundwater as a
\end{abstract}

M. Kuper $(\triangle)$

Cirad, Umr G-Eau, Montpellier, France

IAV Hassan II, Rabat, Morocco

e-mail: Marcel.kuper@cirad.fr

N. Faysse

Cirad, Umr G-Eau, Montpellier, France

National Agronomy School (ENA), Meknes, Morocco

A. Hammani

IAV Hassan II, Rabat, Morocco

T. Hartani

ENSA, El Harrach, Algeria

S. Marlet

Cirad, Umr G-Eau, Montpellier, France

National Research Institute in Rural Engineering, Water Management and Forestry (INRGREF), Tunis, Tunisia

M.F. Hamamouche • F. Ameur

Cirad, Umr G-Eau, Montpellier, France

IAV Hassan II, Rabat, Morocco

ENSA, El Harrach, Algeria 
declining resource, overexploited by millions of individualistic farmers in the absence of effective groundwater governance with mounting inequalities in groundwater use. We analyse the Janus nature of groundwater in the expanding groundwater economy in Morocco, Algeria and Tunisia. Groundwater has redesigned irrigation frontiers, and caters to over $60 \%$ of the total irrigated area, supplying more than 500,000 farms with irrigation water. However, more than half of the aquifers are overexploited, and typically only 40-50\% of farmers in a given area access groundwater. We conclude that groundwater use in North Africa cannot be qualified as anarchy, but rather as a negotiated disorder where the interests of farmers, the private sector, and the state, are continuously realigned. Groundwater 'liberated' farmers only partially from 'state' water, as the state has remained present in groundwater economies. Moreover, groundwater concerned a minority of farmers, who are often keen to get state support when facing resource depletion or harsh agricultural markets. Breaking the current conundrum will require creating space for change, by making visible the current and future effects of groundwater dynamics to local actors, and supporting the building of coalitions of actors towards a sustainable agricultural use of groundwater.

\subsection{Introduction: Private Groundwater Use in a Context of State-Led Irrigation Development}

The development of irrigation in North Africa in the twentieth century was long associated with state-implemented large-scale surface irrigation schemes. This masked the less visible but continuously increasing exploration and development of groundwater resources (Swearingen 1987; Côte 2002; Mamou and Kassah 2002). The increase in the use of groundwater probably remained more or less unseen from the State's point of view - because groundwater was used by private settlers or communities, "without order or specific plan" (Chevalier 1950). The rapid and massive development of groundwater use, especially since the 1980s, has changed this viewpoint. Today, groundwater is delivered through hundreds of thousands of mostly private (tube-) wells to more than 500,000 farm holdings in Algeria, Morocco and Tunisia, irrigating more than 1.75 million ha, and opening up new irrigation frontiers every day.

Two contrasting views prevail in the literature on the emergence of a groundwater economy, especially in countries with predominantly State-led irrigation development (Shah 2009). The first considers 'groundwater as liberation', i.e., how, by recapturing the irrigation initiative, farmers 'liberated' themselves from State water, and consequently from increasingly inadequate irrigation services, compulsory cropping patterns, and more generally from the "implacable order of an extraordinary authority that is at the origin of the distribution of life" (Pascon 1978). According to this view, private groundwater use enabled more intensive and 
productive agriculture. Siebert et al. (2010) estimated that 113 out of 300 million ha in the world are currently irrigated with groundwater. Groundwater-based systems generate annual revenues of \$210-230 billion (Lopez-Gunn and Llamas 2008; Shah 2009), and are economically three to ten times more efficient than surface water systems (Llamas and Martinez-Santos 2005). Groundwater also provides social status, as farmers who are part of the groundwater economy qualify themselves as 'modern' (Quarouch et al. 2014). Finally, groundwater has a pro-poor aura as it has enabled the survival of many small-scale farms with insufficient access to surface irrigation (Penov 2004; Kuper et al. 2012).

The second view - 'groundwater as anarchy' - considers groundwater as a declining resource, overexploited by millions of individualistic farmers in the absence of effective groundwater governance (Shah 2009). More than $10 \%$ of the world's food production depends on aquifers that are overexploited and threatened (Postel 1999). In addition, inequalities in groundwater access, often building on the individual's position in society, were shown to contribute to marginalization of certain categories of farmers and to favour social differentiation (Prakash 2005; Amichi et al. 2012). According to this view, the growing anarchy in the exploitation of groundwater for irrigation is due to 'inherent' features of the groundwater economy, i.e. the rapid development of mostly 'illicit' tube-wells at the initiative of private farmers, the diffuse and relatively cheap access to groundwater through individual pumps, limited scientific knowledge and data, and the political weight of groundwater users (Allan 2007; Moench 2007; Shah 2009). Such features make conventional management responses to groundwater overexploitation, including administrative regulation, economic instruments, water markets, community management, generally at best a theoretical exercise far from reality in the field (Moench 2007). In India for example, such "policy measures. . . have all been discussed ad nauseum. . . as the groundwater situation is turning from bad to worse" (Shah et al. 2003).

Both views acknowledge the weaknesses of the state in controlling the dynamics of groundwater economies; the first one praises this situation, while the second one laments it. They describe the state as the main absentee of these new dynamics. But is this really the case in Algeria, Morocco and Tunisia, where the state had such a prominent role in earlier surface irrigation development? In this chapter, we want to explore the dynamics of groundwater economies: their growth and the new irrigation frontiers they set, what takes place at farm level, and the imminent risks at farm and aquifer level. This will help us reconsider whether the state is as absent as it seems at first sight, and whether it should remain so. To do so, we acknowledge the Janus nature of groundwater, as both an "enabler of important rural socio-economic transition", but which is exploited by "short-term water-using practices" and presided over by passive political economies (Allan 2007). We provide a brief history of the emergence and size of the groundwater economy at national level, and we analyse the pathways of some contrasting local groundwater economies in order to engage the debate on current groundwater use practices, the actors involved (and those who are excluded). 


\subsection{The Emergence of the Groundwater Economy}

\subsubsection{Groundwater Use Was Long Masked by Large-Scale Irrigation Development (1920-1980)}

Algeria, Morocco and Tunisia have a long-standing tradition of using groundwater for irrigated agriculture. Communities created and managed irrigation systems, including groundwater-based systems such as the foggara or khettara systems, which are "subterranean aqueducts engineered to collect groundwater and channel it to surface canals" (Lightfoot 1996), but also through artesian wells and springs. In the twentieth century, surface and groundwater resources were progressively placed in the public domain, thereby limiting traditional water rights in time and in space, and liberating water resources for "State water" (Pascon 1978; Riaux 2013). This allowed the different States, first under French (in)direct rule, then after Independences, to develop State-managed large-scale irrigation. Not a single drop was to go to the sea (Swearingen 1987), and 980,000 ha of large-scale irrigation schemes were developed in Algeria, Morocco and Tunisia from 1920 to 1980, providing access to irrigation water to hundreds of thousands of farmers (Benmoufok 2004; El Gueddari 2004; Al Atiri 2007).

These large-scale State-led projects masked the more discreet exploration and development of groundwater resources mainly by French settlers, who installed tube-wells from the late nineteenth century and beginning of the twentieth century onwards, often encouraged by the States themselves (Swearingen 1987; Côte 2002; Mamou and Kassah 2002). In Algeria, for instance, there were about 12,000 tubewells operational by 1960 (MRE 2009). The attention of the State was only episodically drawn to groundwater resources for two main reasons. First, the exploitation of groundwater resources was increasingly considered a profitable economic activity. ${ }^{1}$ Hydro-geologists undertook several studies to determine the potential yield of aquifers, and the economic interest of exploiting them for irrigation. These studies were followed by public programmes to drill tube-wells of considerable depth (100-200 m), for example during the 'artesian campaigns' in the oases in southern Algeria from 1856 to 1878 (Jus 1878), or the Moroccan programme in the 1920s to encourage private settlers (Célérier and Charton 1925). Second, by 1950 the first problems of overexploitation of aquifers appeared, especially in the coastal areas, where export-oriented horticulture had led to intensive groundwater use. This led to a drop in groundwater tables and even to problems of marine salt intrusion (Monition and de Lesguise 1954). Similarly, there were concerns about the loss of artesianism of sources, for example in oases in southern Tunisia (Mamou and Kassah 2002). In the early twentieth century, the

\footnotetext{
${ }^{1}$ From a more political perspective, Swearingen (1987) described how providing access to groundwater was thought to help pacify rebellious areas. In 1929, "wells of security" were installed to "fix to the soil" nomadic tribes in the Tadla area (Morocco): "As one newspaper editor paraphrased a Lyauté maxim: A well is worth a battalion".
} 
States reacted by incorporating groundwater resources in the public domain, by establishing procedures for the authorization and payment of water fees, and by conducting scientific studies to find solutions to the problems that were beginning to appear.

\subsubsection{Development of an Informal 'Groundwater Economy' (1980 to Date)}

From the early 1980s onwards, large-scale exploitation of groundwater for agriculture began in Algeria, Morocco, and Tunisia (Mamou and Kassah 2002; Hammani et al. 2009). The State initially encouraged groundwater exploitation to compensate for severe droughts by drilling deep state-owned tube-wells. Stimulated by expanding agricultural markets, on their own initiative, farmers rapidly took over and hundreds of thousands of private (tube-) wells were created (Mamou and Kassah 2002). Farmers increasingly preferred tube-wells to wells. The rapid expansion of tube-wells was due to declining water tables, but also to relatively cheap technologies both for installing them, which was generally handled by informal service providers capable of drilling deep tube-wells in only a few days, and for running them. The supply of energy for the tube-wells was often indirectly subsidized (butane gas in Morocco, electricity in Algeria and Tunisia), and the cost of equipping the tube-well (pump, engine) went down. Rural development programmes enabled the electrification of many tube-wells.

The flexible use of groundwater allowed the intensification and diversification of existing farming systems, and strengthened farmers' economic conditions. At the same time, farmers also became exposed to new risks, related for instance to fluctuating market prices for agricultural products. Intensive groundwater use in Algeria, Morocco and Tunisia enabled the development of a "vibrant wealthcreating agriculture', to which Shah (2009) - in the South-Asian context- referred to as the 'groundwater economy'. This represents a social-ecological system (see also Chap. 3), where socio-economic and biophysical dynamics are interdependent. The system combines two extremely complex systems: (1) the aquifer system, where 'virgin' recharge and discharge mechanisms and groundwater abstraction through tube-wells are intimately intertwined; and (2) a "people's irrigation economy' in which the initiative, investment, and management have come primarily from farmers" (Shah 2009). Farmers stimulated the development of a huge grey support sector through their ever-increasing demand for services, including the installation of tube-wells, the supply of inputs (seeds, fertilizers, herbicides and pesticides) and farm equipment (including irrigation equipment), counselling, and the sales of agricultural products (Poncet et al. 2010). This support sector in turn accompanied and even stimulated the expansion of groundwater-based agriculture.

The groundwater economy in Algeria, Morocco and Tunisia involves different territories. First, access to groundwater converted pastoral land, land dedicated to rain-fed agriculture, and even waste land into land used for irrigated agriculture, thereby creating new irrigation frontiers. Referred to as 'private irrigation', this is 
the context in which the most rapid and extensive growth of the groundwater economy occurred. From the mid-1990s onwards, the increasing use of groundwater was often accompanied by pressurized piped irrigation (particularly drip irrigation) in a mutually reinforcing process. Access to groundwater enabled farmers to increase their irrigated area without connecting to existing surface irrigation systems, and pressurized irrigation could be practiced in areas where surface irrigation could not (sandy soils, unsuitable relief).

Second, paradoxically, groundwater use also involved large-scale surface irrigation systems, which were affected by water scarcity. For instance, in the 100,000 ha Tadla irrigation scheme in Morocco, the number of (tube-) wells rose from a few hundred in the early 1980s to about 8,300 in 2008 (Hammani et al. 2009). This marked the transition from irrigation overwhelmingly based on flow irrigation to irrigation also, and increasingly, relying on pump irrigation (Shah 2009). This transition can be explained by the increasing demand for water for intensive agriculture in these schemes, as the droughts in the 1980s had affected the surface water supply, but also by the fact that the groundwater economy "liberated" farmers from State-led agriculture, in which even cropping patterns were imposed (Kuper et al. 2009). Nevertheless, farmers generally continued to use both water resources, as surface water was usually cheaper, and farmers were also keen to maintain a relationship with the State (ibid.).

Third, a number of community-managed irrigation schemes continued to rely on groundwater resources. This was the case of the khettara/foggara systems in the Atlas and Saharan areas, and of the irrigation systems in the piedmont, which relied on springs. A considerable number of public tube-well irrigation schemes also continued to function in Algeria and Tunisia. These were generally deep tubewells, installed on State initiative, with collective access to groundwater for farmers' associations. However, community-managed irrigation schemes are increasingly faced with individual initiatives of farmers or private investors installing tube-wells, either inside these systems, or (more often) in the vicinity of these systems. For instance, in southern Tunisia, Mekki et al. (2013) reported that both the irrigated area and the total water abstraction increased fivefold from 1970 to 2008. The appearance of pump irrigated 'modern' agriculture often jeopardized 'traditional' flow irrigated systems, sometimes leading to their destruction (Popp 1986).

\subsection{Magnitude of the Groundwater Economy Today}

\subsubsection{Observing a Furtive Groundwater Economy}

Official statistics on groundwater-based systems, and more particularly those pertaining to individual pump irrigation, are generally difficult to obtain. The data are fragmented and diffuse, mirroring the image of the furtive groundwater economy itself. The information is in the hands of different administrations, who 
commission private consultants to conduct surveys whose results are not always made public. The FAO Aquastat database, for instance, which we accessed on July 15th 2013, provided figures for groundwater-irrigated areas that date back to 2000 (Morocco, Tunisia), and 2001 (Algeria)! A scholar who wishes to understand the magnitude of the groundwater economy faces a number of problems, which we discuss further below: (1) the groundwater economy is often considered to be a private business by its protagonists, and the legitimacy of the State to even collect data is frequently challenged; (2) the diffuse, and often informal nature of the rapidly developing groundwater economy makes it an extremely complex system to observe; and (3) aquifer dynamics are complex, even more so when they are intertwined with human practices.

\subsubsection{A Furtive Economy}

The groundwater economy is mainly a private irrigation economy developed during a period when the dominant paradigm called for the State, already in the process of disengaging, to get out of the way of private initiative. Not only did the State install fewer public pumping schemes, but even controlling the development of individual wells and tube-wells was often impossible. "Illegal" private (tube-) wells, which are often not included in official statistics, account for the vast majority of pumping devices. Many actors of the groundwater economy are "invisible", since they crop and irrigate the land under informal contracts as lessees or tenants, while equally informal intermediaries provide inputs, credit, and sell their agricultural products (Daoudi and Wampfler 2010). In the Mitidja plain (Algeria), for instance, Imache et al. (2010) estimated that $23 \%$ of the volume of irrigation was used to irrigate horticultural crops grown by lessees whose presence is not officially acknowledged, through informal water transactions. Even when farmers declare their tube-well, they tend to make their declaration conform to current legislation, and not to field realities. This may lead to tube-wells installed inside wells, so they can be declared as wells. This also often leads to farmers under-declaring the depth of their tubewell. For example, a farmer we met in Kairouan (Tunisia) in 2012 had a 120-m deep tube-well, which he had declared as being $50 \mathrm{~m}$ deep. Fifty metres is the limit for water-lifting devices to qualify as 'surface wells', which were tolerated by the administration. As we met him after the Tunisian "revolution" in 2011, he was proud to show us his tube-well, which in his view almost qualified as an act of resistance against the previous regime: "in the past, I had to cover it with plastic, but now I am free to show you my tube-well". This is a good example of law breaking (i.e. ignoring the official ban on drilling beyond a depth $50 \mathrm{~m}$ ), but is also symptomatic of the continuous negotiation between the State and irrigators, which certainly influenced the expansion of groundwater use.

\subsubsection{Surveys Are Out of Date the Day They Are Published}

The 'atomistic' informal nature of the groundwater economy, which relies on individual and diffuse access to groundwater, along with its extremely rapid development makes it difficult to monitor (Shah et al. 2003; Moench 2007). In addition, in Algeria, Morocco and Tunisia, mixing resources is common; for 
example, in large-scale surface irrigation schemes most farmers also have access to groundwater through private pumps, or in Saharan oases, making it difficult to distinguish between areas irrigated with surface water or groundwater. Occasionally, extensive regional or national surveys have been undertaken to count the number of (tube-) wells and determine the areas irrigated by groundwater. A survey on 'private' irrigation financed by the World Bank was conducted in Morocco in 2002, while in Algeria a survey was conducted in 2009 (Bouchedja 2012), and in Tunisia in 2010. These surveys are often incomplete, and are out of date the day they are published. At any time, farmers may close wells which run dry, deepen them, or convert wells into tube-wells, while ever increasing numbers of farmers join the groundwater economy each day by installing new tube-wells. Others obtain access to groundwater through informal water transactions, which are difficult to account for without close observation. Then again, even when the number of wells and tube-wells is known, this does not provide information on groundwater use. Field observations in the Tadla (Morocco) revealed considerable differences in the use of similar tube-wells (depth, discharge, source of energy) between neighbouring small and medium-scale farmers (Kuper et al. 2003). The annual utilization rate varied from 600 to $1,870 \mathrm{~h}$, and the annual volumes pumped from 32,000 to $101,000 \mathrm{~m}^{3}$, depending on the crops grown, irrigation practices, the area served, and the number of farmers who relied on the tube-well. The inherent complexity of groundwater use means it is often estimated for regional water balances rather than established in the field.

\subsubsection{Overexploitation, an Established Fact?}

Aquifer dynamics are extremely complex and the values of different hydrological parameters vary considerably under different scenarios of change, including climate change, and human practices such as pumping. This makes modelling groundwater and predicting the behaviour of a particular groundwater system a difficult exercise (Rojas et al. 2010). Whether groundwater comes from renewable or nonrenewable sources, and to what extent specific aquifers are overexploited is the subject of lively debate (Konikow and Kendy 2005). While major uncertainties remain on the hydrological impact of recent rapid changes, including groundwater pumping, hydro-geologists agree that the "present development of agriculture is.. . unsustainable" (Leduc et al. 2007). River basin agencies routinely present graphs of declining groundwater tables. Perhaps more surprisingly, most groundwater users are also aware of the coming groundwater crisis (Bekkar et al. 2009), and some even anticipate their exit from groundwater-related agriculture. Groundwater resource overdraft is no longer an issue only pointed out by hydro-geologists (e.g. Llamas 1998), but has become common discourse. But up to now, this apparent consensus has not led to using existing information for better management of groundwater use in the region (Hammani et al. 2009). This pleads for more attention to be paid to the use of information, as much as to the production of information, and hence to obtaining more insights into the users' point of view of groundwater exploitation (Mitchell et al. 2012). 


\subsubsection{Official Figures: Redrawing the Irrigation Map in North Africa}

Despite the difficulties of obtaining data on the groundwater economy in Algeria, Morocco and Tunisia, and the doubt surrounding the accuracy and utility of such data, we synthesized - to the best of our knowledge - some figures based on the different national statistics (Table 23.1). This exercise is fraught with danger, and

Table 23.1 Official figures concerning the groundwater economy in Algeria, Morocco and Tunisia

\begin{tabular}{l|l|l|l}
\hline & Algeria & Morocco & Tunisia \\
\hline Total irrigated area (ha) & $1,006,198^{\mathrm{a}}$ & $1,458,160^{\mathrm{b}}$ & $404,375^{\mathrm{c}, \mathrm{d}}$ \\
\hline $\begin{array}{l}\text { Area irrigated by groundwater pumps (in ha and } \\
\text { as \% of total area) }\end{array}$ & $\begin{array}{l}883,004^{\mathrm{a}, \mathrm{e}} \\
88 \%\end{array}$ & $\begin{array}{l}615,881^{\mathrm{b}, \mathrm{f}} \\
42 \%\end{array}$ & $\begin{array}{l}258,547^{\mathrm{c}, \mathrm{g}} \\
64 \%\end{array}$ \\
\hline $\begin{array}{l}\text { Total annual renewable groundwater resources } \\
\left(\mathrm{km}^{3}\right)\end{array}$ & $7.1^{\mathrm{h}, \mathrm{i}}$ & $4.1^{\mathrm{j}}$ & $2.2^{\mathrm{k}}$ \\
\hline $\begin{array}{l}\text { Annual groundwater withdrawal for irrigation } \\
\left(\mathrm{km}^{3}\right)\end{array}$ & $8.1^{1, \mathrm{~m}}$ & $3.5^{\mathrm{j}}$ & $2.0^{\mathrm{k}}$ \\
\hline $\begin{array}{l}\text { Annual groundwater withdrawal for drinking } \\
\text { water }\left(\mathrm{km}^{3}\right)\end{array}$ & $1.6^{\mathrm{a}}$ & $0.4^{\mathrm{j}}$ & $0.4^{\mathrm{c}}$ \\
\hline $\begin{array}{l}\text { Number of overexploited aquifers/total number } \\
\text { of aquifers }\end{array}$ & $\begin{array}{l}\text { North: } \\
23 / 38^{\mathrm{i}} \\
\text { South: all }\end{array}$ & $57 / 99^{\mathrm{j}}$ & $71 / 273^{\mathrm{n}, \mathrm{o}}$ \\
\hline $\begin{array}{l}144,050 \\
\text { wells }\end{array}$ & $\begin{array}{l}62,967 \text { tube- } \\
\text { wells }\end{array}$ & $100,000^{\mathrm{b}}$ & $\begin{array}{l}137,709 \\
\text { wells } \mathrm{k}, \mathrm{p} \\
6,167 \text { tube- }^{\mathrm{a}} \\
\text { wells }\end{array}$ \\
\hline
\end{tabular}

${ }^{\mathrm{a}} \mathrm{MRE}(2011)$

${ }^{\mathrm{b}}$ MAPM (2012)

${ }^{\mathrm{c}}$ DGGREE (2006)

'The total irrigated area of 'intensive' irrigated agriculture in 2013 was 416,000 ha (DGGREE). The area irrigated by groundwater is certainly underestimated, as farms in public surface irrigation schemes $(138,248$ ha in 2006) may use groundwater

${ }^{\mathrm{e}}$ This includes the area irrigated by wells (316,198 ha) and tube-wells (486,806 ha) in small- and medium-scale irrigation schemes, and pump irrigation in large-scale irrigation schemes $(-80,000$ ha; Benblidia 2011)

fThis includes "private irrigation" (435,881 ha), and pump irrigation in large- as well as small- and medium-scale irrigation schemes $(-180,000 \mathrm{ha})$

${ }^{\mathrm{g}}$ This includes 180,283 ha of private irrigation and 78,264 ha of public tube-well schemes

${ }^{\mathrm{h}}$ Bouchedja (2012)

${ }^{\mathrm{i}}$ This includes $5 \mathrm{~km}^{3} /$ year of non-renewable or little renewable groundwater resources in the Sahara

${ }^{\mathrm{j}}$ Ziyad (2007), ABH (2011)

${ }^{\mathrm{k}} \operatorname{DGRE}(2005,2008)$

${ }^{\mathrm{l}}$ MRE (2009)

${ }^{\mathrm{m}}$ Value estimated on the basis of cropped areas and theoretical crop water requirements

${ }^{\mathrm{n}}$ TICET (2009)

${ }^{\circ}$ Tunisia identified a higher number of aquifers than the other countries as it privileged a local management perspective (Faysse et al. 2011)

${ }^{\mathrm{p}}$ According to the Ministry of Agriculture, only 94,691 out of 137,709 wells were 'equipped' with a pump/engine (DGGREE 2006) 
the figures should be interpreted with great caution. Despite these reservations, we feel this is a useful exercise, as it provides some idea of the comparative importance of the groundwater economy in the three countries. If considered in conjunction with more detailed local studies, these figures provide an interesting perspective of the rapidly evolving, informal, atomistic groundwater economy.

Three conclusions can be drawn from this table. Firstly, it shows the importance of the groundwater economy in these three countries. According to these data, the groundwater economy caters to more than 1.75 million ha of irrigated land (more than $60 \%$ of the total irrigated area), farmed by probably more than 500,000 farm holdings (293,033 farm holdings in Algeria alone). The countries regularly publish information on the substantial added value of irrigated agriculture for which groundwater has become indispensable. In Morocco, the High Commission for Planning (2008) stated that in an average year, the irrigated sector, while only accounting for $13 \%$ of the agricultural area, contributes about $45 \%$ of agricultural added value, and $75 \%$ of agricultural exports and accounts for $35 \%$ of rural employment. The irrigated sector is responsible for all citrus and sugar production, and supplies $80 \%$ of horticultural products, fodder and milk. Twenty per cent of meat and cereals come from irrigated areas. At the same time, the groundwater economy appears to benefit a minority of farmers. From the official agricultural census in the different countries, it can be deduced that only $20-30 \%$ of all farmers have access to groundwater.

Secondly, the official data show that the current status of aquifers is not good. More than half the aquifers in Algeria and Morocco, and about one quarter of the aquifers in Tunisia are overexploited, and the potential of aquifers in Tunisia is severely limited by salinity. All three countries rely to a considerable extent on groundwater resources, especially Algeria (88\% of the total irrigated area, Table 23.1) and Tunisia (64\%). Morocco (42\%) benefits from more generous (renewable) surface water resources. This is probably why, as opposed to Algeria and Tunisia, Morocco never developed many public tube-well schemes. In Tunisia public tube-well schemes officially still account for $30 \%$ of the pump-irrigated area. This figure is certainly overestimated, as farmers installed private tube-wells even inside public irrigation schemes. According to official statistics the groundwater economy in Algeria, Morocco and Tunisia is served by about 450,000 (tube-) wells for a total withdrawal for irrigation of $13.6 \mathrm{~km}^{3}$; these values are probably the most questionable figures in the table due to the difficulty of keeping track of the (tube-) wells, and of monitoring the withdrawals. In all three countries, farmers are increasingly turning to tube-wells, whereas the total number of wells is not progressing, or is even declining. Farmers are accessing deeper (confined) aquifers, where the supply - in the short term - is better, but where the water resources are even less renewable. Finally, some of the most rapidly growing irrigated areas were based on the mining of non-renewable groundwater resources (Margat 2008).

Thirdly, when comparing these data with earlier official data, (available on the FAO database) it appears that the groundwater economy has expanded at a remarkable pace. Nowhere is this clearer than in Algeria, where the irrigated area increased from 228,000 ha in 1985 to slightly over a million ha in 2011. While the latter figure 
may be optimistic, there is no doubt about the galloping development of Algeria's groundwater economy. Algeria's irrigation map was redrawn after the exploitation of huge groundwater reserves in the south, ranking the country second only to Libya in terms of available groundwater resources in Africa (MacDonald et al. 2012).

\subsubsection{Policy Measures}

Irrigated agriculture has been consistently and "disproportionately prominent in national water allocation policy discourse" in the Middle East and North Africa's political economies (Allan 2007). Irrigated farming was not only a "deeply entrenched social phenomenon" (ibid.), but was also considered to be a political priority in building the independent Nation (Akesbi and Guerraoui 1991). Policies initially focused on building dams for surface irrigation but, from the 1970s on, groundwater resources were included in water master plans, as surface resources gradually became insufficient (Al Atiri 2007).

For many years, groundwater was mainly seen as a complementary resource that could be used for more intensive irrigated agriculture. Following the 1992 Dublin conference, international discourse on integrated water resources management gained importance in the Mediterranean area and coincided with increasing awareness of the limits of existing water resources (Margat and Vallée 1999). These debates inspired recent water laws and strategies in Algeria, Morocco and Tunisia, leading to institutional reforms (e.g. the creation of river basin agencies), and to a series of measures promoting the rational use of water (El Alaoui 2006; Al Atiri 2007; Benblidia 2011). Basically, the idea was to promote water demand management as opposed to a supply-based approach, as the latter had led to ever-increasing pressure on water resources (Margat and Vallée 1999). Agriculture was specifically targeted as a sector in which water was 'wasted.' Water demand management meant identifying possible ways of saving water, so water could be used more productively, while decreasing the existing pressure on water resources. However, the different economic, regulatory and participatory instruments proposed and debated never focused on water demand management alone, and the different states continued to explore ways to increase the water supply, for example through desalination (Benblidia 2011).

Faysse et al. (2012) conducted an inventory of the different policy instruments focused on groundwater, implemented and discussed in Algeria, Morocco and Tunisia on the basis of the expected impacts: (1) direct regulation of the water demand (authorization, control of extracted volumes); (2) incentives for water demand management (tariffs, subsidies for micro-irrigation); and (3) measures for increased water availability (desalination, groundwater recharge). In addition, a limited number of initiatives on participatory instruments were identified, including groundwater users associations in Tunisia, and aquifer contracts in Morocco (ibid.). There has been little public debate on the environmental, social, and economic sustainability of the groundwater economies in the region. The question is whether the future pathways of these groundwater economies only concern farmers who are 
currently overexploiting them? Or do they also concern farmers who currently have no access? When dealing with groundwater overexploitation today, it is probably more realistic to first involve farmers who pump large volumes. If the stakes related to equity, rural poverty or agricultural productivity were taken into account, the debate could extend to rural areas, or even to society at large.

After more than a decade of lively debate and policy initiatives promoting water demand management, paradoxically, irrigated agriculture appears to be no longer in the 'dock' for wasting water, even though in the meantime the pressure on groundwater resources has increased. This increased pressure may be partly due to recent ambitious agricultural policies (e.g. the 2008 Green Morocco Plan), which promote modern "excessively intensive" agricultural models with increased pressure on water resources (Akesbi 2014). In parallel, the agricultural sector started several subsidy programmes for water saving irrigation technologies, especially drip irrigation. The amount of water saved as a result of these programmes has rarely been evaluated (Benouniche et al. 2014), but the programmes were probably essential in providing agriculture with a more positive image of "efficiency, productivity and modernity" (Venot et al. 2014). Through the "alignment of farmers' interests and those of the political class" (Allan 2007), solutions are once again being sought in supply management approaches (desalination, inter-basin transfers) or in technological inventions, such as water saving irrigation technologies.

\subsection{Illustrating the Rapid Massive Development of North Africa's Groundwater Economy}

We use two contrasting case studies to illustrate the diversity of the different local groundwater economies encountered in North Africa, focusing on the three issues mentioned in the introduction, i.e. the apparent contradiction of groundwater as an "enabler of an important rural socio-economic transition", used with "short-term water-using practices" and presided over by passive political economies (Allan 2007). The first case study concerns the Biskra district in the Algerian Sahara (less than $150 \mathrm{~mm}$ of rain annually), where the rapid irrigation development relies almost exclusively on non- or little renewable groundwater resources (Fig. 23.1). The second case study was conducted in the rich agricultural Saiss plain in northwestern Morocco (with 400-600 mm rainfall regime), where farmers turned to irrigated agriculture by exploiting a rich but overexploited aquifer system (Fig. 23.2).

\subsubsection{Biskra: Why Deal with the Problems Now?}

Groundwater experts put North African countries such as Algeria and Libya on the map as the most water-rich countries of the continent thanks to enormous, but not very actively recharged, sedimentary Saharan aquifers (MacDonald et al. 2012). 


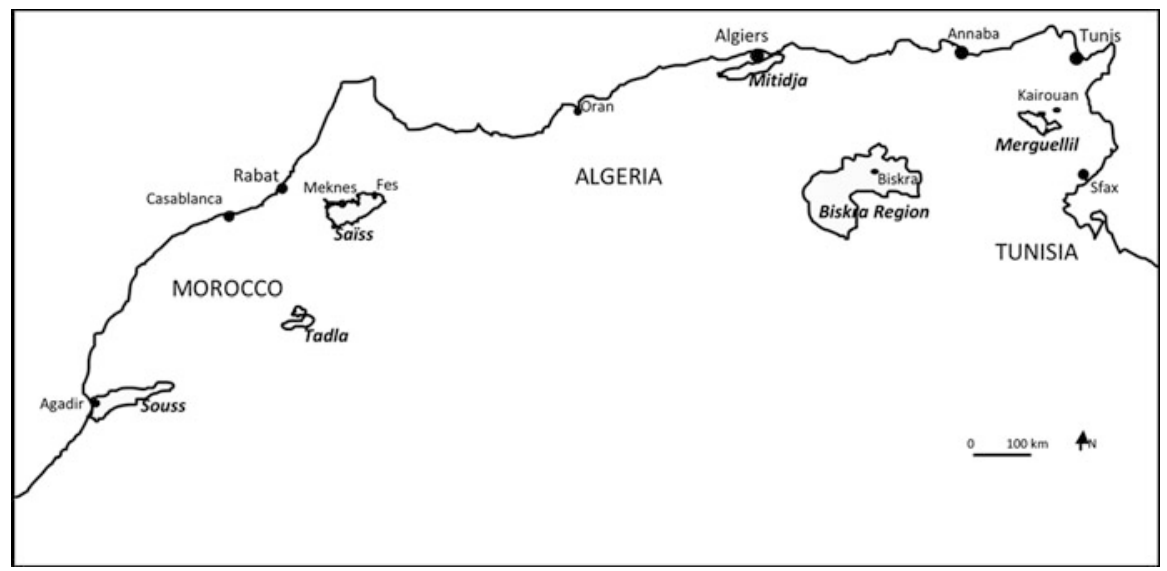

Fig. 23.1 Location of the case studies in North Africa

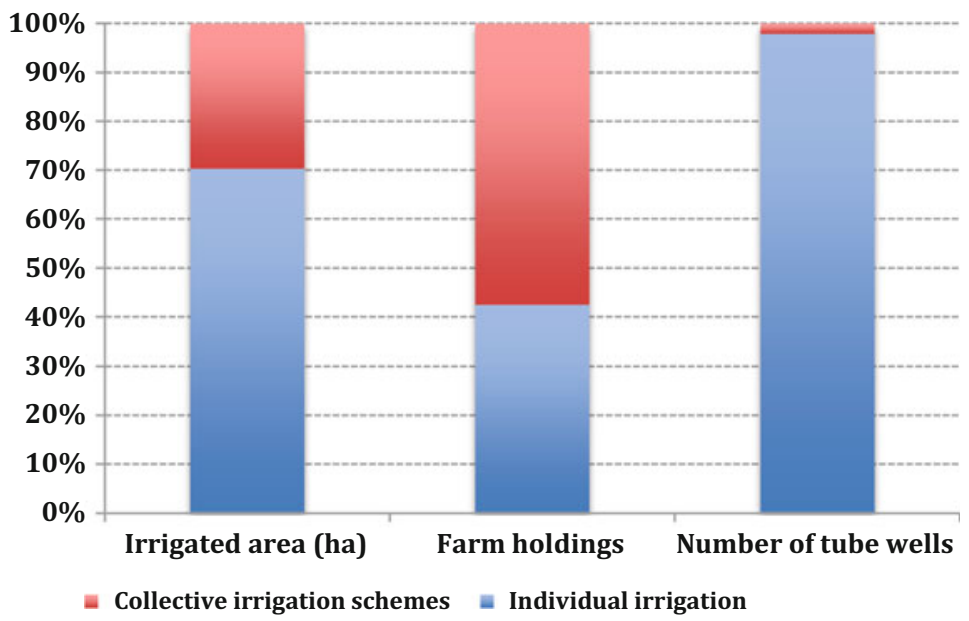

Fig. 23.2 Private and collective irrigation in the Biskra district (Source: MRE 2009)

These countries did not stand out in FAO irrigation statistics in the past due to limited development of State-led irrigation, but rapid private irrigation expansion linked to groundwater is changing the outlook and scale of the irrigated sector. In Algeria, groundwater is shifting the balance between traditional irrigated areas in the North, and rapidly developing irrigated agriculture in the Sahara.

Oases had been declining since the sixteenth century with the demise of TransSaharan trade when an astonishing agricultural revival started in the early twentieth century linked first to the exploration of new artesian tube-wells, and more recently to pump irrigation. Groundwater allowed the rapid expansion of palm groves in the Algerian Sahara, which increased from 5.5 million palm trees in 1959 to 12 million 
in 2000, and to 17 million in 2011 (Côte 2002; Benziouche et Cheriet 2012). The rapid agricultural development of the Biskra district made it one of the most important Saharan agricultural regions in Algeria. The irrigated area increased fivefold from 16,615 ha in 1969 to 83,350 ha in 2008 and $94 \%$ of the irrigation water is currently supplied by groundwater through 4,293 wells and 9,075 tubewells (MRE 2009).

While palm groves were traditionally irrigated through community-managed collective irrigation schemes around artesian wells, springs, or diverted river flow, more than $70 \%$ of the total irrigated area is now qualified as private or individual irrigation areas (Fig. 23.2). The figure confirms the rapid expansion of private irrigation, which took place mostly outside the traditional oases. However, collective irrigation schemes continued to serve almost $60 \%$ (19,305 farms) of the total number of irrigated farm holdings in the Biskra district. These collective schemes are served by powerful tube-wells $(>100 \mathrm{l} / \mathrm{s})$ or more rarely, by artesian wells, in some cases enhanced by surface water or springs. This explains the limited number of tube-wells in these schemes, according to official data (Fig. 23.2).

In the next two sections, we will show first how groundwater was integrated into the existing farmer-managed surface irrigation system of the oasis of Sidi Okba through a complex mix of private and collective (tube-) wells. The state played an important role in unlocking the access to groundwater. We will then present the new irrigation frontiers, outside of the oases, where groundwater is accessed through private tube-wells enabling commercial date production and greenhouse horticulture.

\subsubsection{Traditional Oases: Integrating Groundwater in the Existing Farmer-Managed Irrigation System}

Access to water resources in traditional oases is rather complex. We analysed changes in access to groundwater in the 970 ha Sidi Okba palm grove, situated in the Biskra district. This mythical palm grove, laid out around the 686 mosque commemorating the Arab conqueror Oqba Ibn Nafaa, was traditionally supplied by surface water (Oued El Abiod), but increasingly relies on groundwater (Fig. 23.3). Officially, the palm grove is irrigated by surface water (Foum El Gherza dam) and five functioning state-created tube-wells managed by a farmers' cooperative. However, there is also a large number of individual or community-owned collective tube-wells. In 2013, a total of 71 State and private tube-wells (collective or individual) were counted of which only 42 were functioning.

Access to groundwater started in the 1920s, when farmers dug hand-operated wells, which they mechanized from 1950 onwards (Fig. 23.3). These wells were progressively abandoned in the 1960s and 1970s. In 1979, access to the confined aquifer was initiated by the State to compensate for dwindling surface water resources following droughts. The State had two-tube-wells drilled to great depths (632 and $807 \mathrm{~m}$, respectively), followed by six more later on. Farmers followed suit and drilled 63 collective and individual tube-wells.

The figure illustrates three main issues of Biskra's groundwater economy. Firstly, the different groundwater resources were successively unlocked over a 


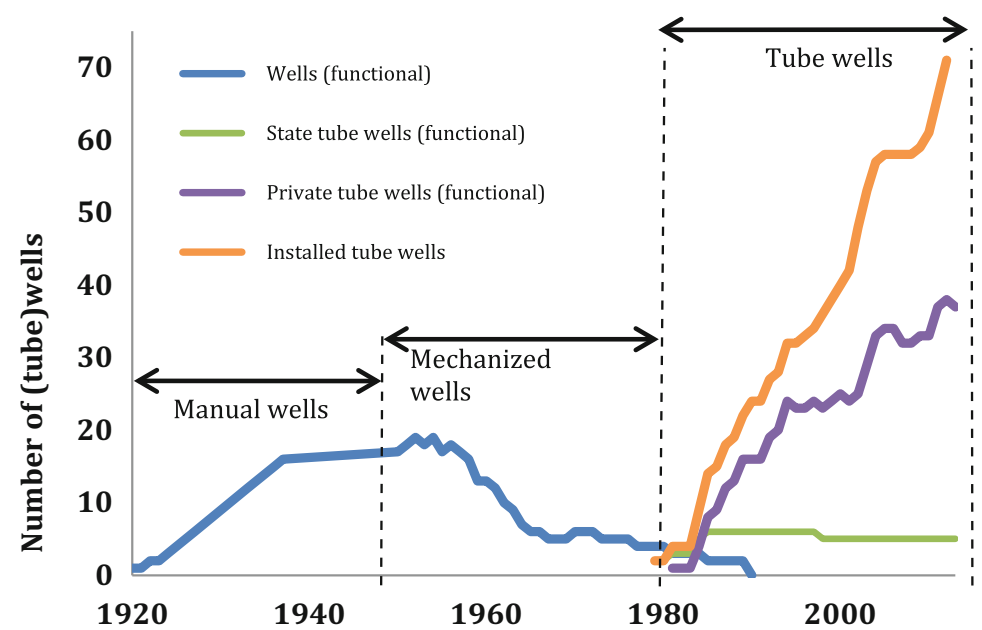

Fig. 23.3 Development of wells and tube-wells in the Sidi Okba palm grove (Biskra region)

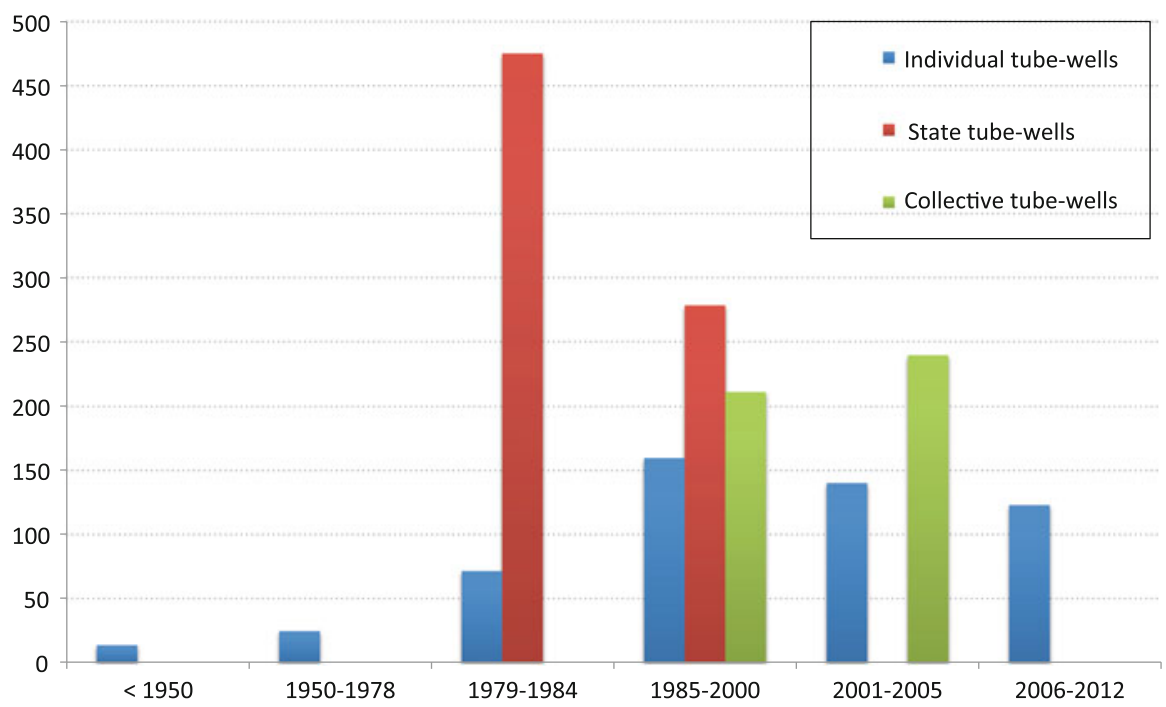

Fig. 23.4 Changes in the depth of (tube-)wells drilled in the Sidi Okba palm grove (Biskra region)

long period of time. Farmers look for water at increasing depth, and as a result, they may even change an aquifer's behavior (Fig. 23.4). While they initially exploited the phreatic aquifer using 10-30-m deep wells or relatively shallow tube-wells $(50-70 \mathrm{~m})$, they started drilling deep tube-wells in the early $1980 \mathrm{~s}$ thereby accessing the first confined aquifer. The State-led drilling of deep tube-wells having a high discharge, and delivering relatively good quality water, prompted farmers to 
drill individual tube-wells to a depth of 100-150 m. Some even drilled to a depth of $200 \mathrm{~m}$ for individual tube-wells, and to $280 \mathrm{~m}$ for collective tube-wells. From 2002 onwards, the State managed to impose some norms on the depth of tube-wells, at least on those that were subsidized: individual tube-wells should not exceed $150 \mathrm{~m}$, and collective tube-wells should not exceed $250 \mathrm{~m}$. Groundwater also "liberated" farmers, and especially the former sharecroppers, to go beyond the frontiers of the traditional palm grove, and settle on new lands to establish new farming systems, including commercial dates and horticulture.

Secondly, the State as well as the irrigation community continued to play an important role in managing groundwater, and access did not become entirely private. In the Sidi Okba palm grove, 30 tube-wells (out of 71) were either installed or subsidized by the State, of which 12 were collective tube-wells. The existing farmer-managed irrigation cooperative was able to integrate progressively (part of the) groundwater resources in the collective management of the surface irrigation system. The cooperative continued to distribute surface water, but also included the state tube-wells in the water distribution programme. The irrigation community installed a further 10 collective tube-wells, which were shared by neighbours or relatives. The community even created three larger informal tube-well associations (using four collective tube-wells), where farmers were supplied with water according to the shares they had in the tube-well. This collective organization (20-60 members per association) is perhaps due to the fact that the irrigation community already managed a collective surface irrigation scheme at the time. Collective action is probably also linked to the high cost of accessing confined aquifers at substantial depth. However, in the past 10 years, only individual tubewells were drilled in the palm grove, encouraged by individual State subsidies.

Thirdly, farmers faced many hazards in accessing groundwater. They progressively abandoned the 37 wells in the palm grove, due to the drop in groundwater levels, and the increasing salinity of the phreatic aquifer. Another problem was the limited know-how of private companies who improvised the installation of tubewells in the 1980s and 1990s. Some tube-wells became obsolete after only functioning for a few years. Twenty-nine (out of 63) individual and collective tubewells drilled between 1979 and 2000 stopped functioning (Fig. 23.3), mainly due to the poor quality of the equipment (tubing, pump). The State-installed tube-wells also often broke down because of age and the high cost of repairs. Three out of eight tube-wells in this category are no longer functional today.

\subsubsection{Outside the Oases: Exploring New Irrigation Frontiers}

Outside the traditional oases, palm groves no longer followed the classical threestage oasis system, but were new mono-cropped plantations focused on the production of deglet nour, a readily marketable date for the domestic and export market. More surprisingly, groundwater also enabled new farming systems, in particular greenhouse horticulture (tomatoes, peppers, chillies, aubergines, (water) melons), which arrive early on the domestic markets thanks to favourable climatic conditions. Greenhouse horticulture started in the 1980s, and expanded rapidly (Khiari 2002). Recent figures from the Ministry of Agriculture mention almost 
100,000 greenhouses (about 4,000 ha) in 2010. New palm groves and greenhouses spread rapidly in the Biskra district, following the availability of groundwater resources. The region ranks second in Algeria in agricultural production (around 1.24 billion $€$ in 2012), only behind another Saharan region (El Oued). In 2012, Biskra accounted for $37 \%$ of dates grown in Algeria, and for $25 \%$ of tomatoes.

The question is what are the limits to the development of this Saharan groundwater economy? On the one hand, official data imply serious overexploitation of groundwater resources, and ever-increasing numbers of tube-wells. Groundwater use for irrigation in Biskra is estimated to be around $1.2 \mathrm{~km}^{3}$ per year (MRE 2009), which is $467 \%$ of the volume of the renewable groundwater resources that can be exploited $\left(0.26 \mathrm{~km}^{3} /\right.$ year). However, the different actors largely ignore this "safe yield" (Alley and Leake 2004), and continue to overexploit the different aquifers, including the Continental Intercalaire aquifer, which is non- or little renewable, but represents an enormous reserve $\left(91,900 \mathrm{~km}^{3}\right.$; MacDonald et al. 2012). Farmers are confronted with decreasing groundwater tables, and frequently deepen their tubewells.

On the other hand, the Saharan groundwater economy continues to grow rapidly, mainly through private investment and 'resource pooling' (Amichi et al. 2013). Farmers come from hundreds of kilometres away, attracted by the abundant land and water resources of the area, and bring know-how, energy and financial resources. These integrative farming systems continue to attract new financial, and human resources which, in turn, further extend the irrigation frontiers of Saharan agriculture. The State contributed to this development enabling access to land and water by providing agricultural subsidies, but also, and perhaps most importantly, by developing the basic infrastructure to ensure the logistics for intensive agriculture, and support the newcomers (wholesale markets, roads, health facilities and schools, electricity supply).

This illustrates not only Biskra's attraction for private investment in agriculture, but also how private investment is supported by ambitious public policies and investments aiming to "transform the Algerian Sahara into an agricultural Eldorado" (Otmane and Kouzmine 2013). In a survey of 150 farmers, $84 \%$ declared they had made substantial investments since 2000 (plantations, pumping station, drip irrigation), and $52 \%$ said they had obtained subsidies for these investments (MRE 2009). However, this mainly concerned established farmers. Most informal actors, particularly in the horticultural sector (tenants, lessees), may not even have been interviewed, as they are generally not registered as farmers. They manage without subsidies, because of buoyant agricultural markets and a strong national demand for fresh vegetables.

In sum, Biskra's thriving groundwater economy continues to develop at a breathtaking pace both inside and outside the traditional oases. The limiting factors which generally limit the development of agriculture (markets, capital, labour, land, water) will surely surface sometime, but in the meantime, business as usual - that is rapid expansion - is likely to continue. 


\subsubsection{Saiss: "He Has Committed the Crime Who Profits by It" (Seneca)}

The Saiss plain is a well-known rich agricultural area in Morocco in the vicinity of Fes and Meknes, covering about 220,000 ha. In the past, the Saiss plain was known for rain-fed crops (cereals, vineyards, olive trees). Some small communitymanaged irrigation schemes, which depended on springs, made it possible to irrigate certain crops (tobacco, fodder, vegetables). The Saiss always attracted newcomers because of its rich productive resources, and its proximity to Fes and Meknes. During the first half of the twentieth century, French settlers occupied some of the best lands accounting for about one third of the total surface area. Some stayed until 1971. This land was then partly redistributed to landless farmers or labourers who formerly worked on colonial farms. Some lands were grouped in agrarian reform cooperatives under close State supervision, and some were converted into State farms. Both types of agrarian structures disappeared over the past 10 years following structural reforms and State disengagement from direct agricultural production.

Droughts in the early 1980s along with a liberalisation of the agricultural sector prompted a series of rapid transformations whereby the groundwater economy rapidly gained momentum. There was a tremendous increase in pump-irrigated area, but also a decrease in the area irrigated by small-scale surface irrigation schemes. A survey by the Ministry of Agriculture in 2012 showed a total irrigated area of 49,677 ha (out of 220,000 ha), of which 45,316 ha depended on pump irrigation. Today, irrigation caters principally for orchards (olives, plums, peaches, apples), and vineyards, horticulture (onions, potatoes), and fodder crops.

Saiss' rich aquifer system is composed of a phreatic aquifer and the Lias confined aquifer; its potential was explored early on, and some (tube-)wells were installed during the protectorate. According to the river basin agency, groundwater tables have decreased considerably (ABH 2011). Groundwater levels in the phreatic aquifer, generally between 10 and $40 \mathrm{~m}$, decreased by about $10 \mathrm{~m}$ between the early 1980 s and 2005, with a sharper decline after 2000 when water levels decreased by about $1 \mathrm{~m}$ per year. The decline in groundwater tables was even more marked in the confined aquifer. In the west (Meknes area), the decline was about $65 \mathrm{~m}$ between 1979 and 2004, i.e. $2.6 \mathrm{~m}$ per year. In the east, the decline was about 20-25 m over the same period.

Field observations conducted in an area of 4,153 ha in the Saiss near the town of El Hajeb illustrate the rapid transformations (Fig. 23.5). In 1989, the area was characterized by the contrast between an irrigated State farm (1,374 ha) and a large collective agrarian reform cooperative (1,888 ha), growing rain-fed cereals. In the cooperative, the land was not attributed to individual farmers, and the assignees basically had the status of labourers working under State supervision. There was no room for private initiative to grow other crops, or change to irrigated agriculture, whereas on a nearby smaller agrarian reform cooperative (340 ha), assignees had been attributed individual plots. They were supposed to work the land together with other assignees, but in practice managed to progressively install wells to irrigate 
(a)

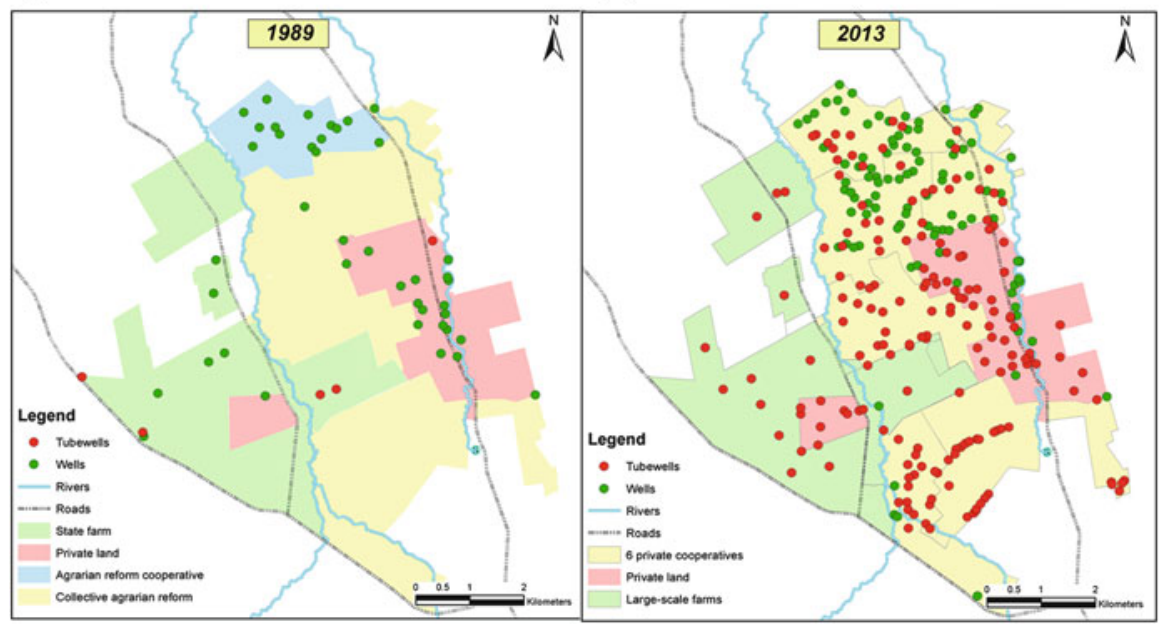

Fig. 23.5 Maps showing the proliferation of wells and tube-wells in the study area (4,153 ha) in the Saiss in 1989 (a) and 2013 (b)

part of their land in the context of State disengagement. Farmers on private land in the study area (551 ha) also installed wells. In 1989, the total number of pumping stations in the study area was 67 , of which 62 were wells, i.e. a density of about 1 (tube-) well for every 62 ha.

In 2013, the situation had drastically changed due to liberalisation. The State farm had been split in two, and leased out to private investors, who continued pump irrigation for orchards and vineyards. In 1991, the collective agrarian reform cooperative was split into small cooperatives with individual plots attributed to the assignees. Assignees diversified cropping patterns, and progressively gained access to groundwater through wells. In 2005, a government decree set off a process of land privatization of the agrarian reform cooperatives; once they had paid off all their debts, assignees could obtain a private land title. During this process, a lively land market emerged, resulting in the massive arrival of newcomers to these oftenrich lands. Assignees sold part of their land to pay their debts; some even sold all of their land. Large numbers of farmers (especially newcomers) joined the groundwater economy, but this time mainly through tube-wells which accessed both aquifers. The groundwater-based agricultural boom had considerable consequences for the groundwater availability. In 2013, half the wells (96 out of 193), mostly belonging to former assignees, were no longer functional, largely because they had run dry. But sometimes the farmers did not have the resources to make them function because they had ventured into more risky market crops, and ended up with debts. Other assignees managed to install tube-wells and ensure their access to groundwater. Newcomers generally invested in orchards, which required a tubewell usually with a drip irrigation kit. The total number of functional pumping 
stations amounted to 275 , of which 178 were tube-wells. The density of (tube-) wells in this study area increased to 1 (tube-)well for every 15 ha.

The antagonism between newcomers and local farmers is nowhere more clearly expressed than in the former agrarian reform cooperatives, where different farming models exist side by side. While most of the former assignees practise diversified cropping (cereals, horticulture, fodder) and both irrigated and rain-fed agriculture, newcomers prefer mono-cropped irrigated trees. The assignees mostly rely on wells, and have increasing difficulty in running their well, while the newcomers largely invest in tube-wells. Most of the local farmers, who were previously assignees in the different agrarian reform cooperatives, therefore tend to blame the newcomers, who are referred to as "investors", "buyers", or simply as "foreigners" (to the area), for causing their wells to run dry.

In two former cooperatives in the study area (here referred to as Alif and Ba), we investigated this mounting feeling of inequity in access to groundwater. To our surprise, the vast majority of farmers did have access to groundwater (respectively $88 \%$ and $75 \%$; Table 23.2), which, in other regions in North Africa, had been shown to be a first order inequity where this rate is usually much lower (Hammani et al. 2009). This high rate was probably for the following reasons: (1) the phreatic aquifer was rather shallow, particularly in the 1980s and 1990s; (2) farm holdings were relatively large compared to Moroccan standards, due to the recent distribution of land; (3) some assignees obtained access through tenancy arrangements, whereby the tenant or lessee obtained the land for a period of 5-6 years, and installed a (tube-)well, which reverted to the owner once the lease ended; and (4) the State subsidized the access to groundwater and the irrigated agriculture depending on groundwater.

A second order inequity concerned the pump equipment of farmers. The wells of most assignees were not adequately equipped (second-hand engine, vertical axial flow pumps), and could consequently only irrigate about 1-2 ha of land (mainly onions or potatoes). In addition, many of the wells of the assignees are running dry (about $50 \%$ and $25 \%$, respectively in both cooperatives; Table 23.2). Newcomers, on the other hand, used well-equipped tube-wells, and could easily irrigate 5-8 ha

Table 23.2 Access to groundwater of farmers in agrarian reform cooperatives Alif and Ba (Saiss plain)

\begin{tabular}{l|l|l}
\hline & Cooperative Alif & Cooperative Ba \\
\hline Surface area & 340 ha & 392 ha \\
\hline Number of farmers & 33 & 51 \\
\hline Number of farmers having access to groundwater & $29(88 \%)$ & $38(75 \%)$ \\
\hline Number of tube-wells & 12 & 19 \\
\hline Number of wells & 43 & 31 \\
\hline$\quad$ Functional & 22 & 23 \\
\hline$\quad$ Non-functional & 21 & 8 \\
\hline Irrigated area & $33 \%$ & $41 \%$ \\
\hline Rainfed area & $67 \%$ & $59 \%$ \\
\hline
\end{tabular}


of orchards. The cost of a fully equipped tube-well was $15,000-25,000 €$. The newcomers often had an off-farm income and usually obtained subsidies for investments. As a consequence, in the Alif cooperative, almost all farmers had access to groundwater but only one third of the land was irrigated. In the $\mathrm{Ba}$ cooperative, fewer farmers had access to groundwater but the percentage of irrigated land was slightly higher $(41 \%)$. The newcomers had more land (53 ha of arboriculture) than in the Alif cooperative (6 ha of arboriculture), which explains the difference in irrigated area.

Groundwater use is likely to increase in the near future, as tube-wells progressively replace wells. Tube-wells in the study area pump at least twice as much water (up to $40,000-65,000 \mathrm{~m}^{3} /$ year) as wells. The extra volumes of water available will likely extend the irrigated area, as almost two-thirds of the area is not yet irrigated. Moreover, newcomers have a mainly economic view of agriculture, with offensive strategies to maximize profits (Bekkar et al. 2009).

A third order inequity in the study area related to the economic situation of different social categories of farmers. Assignees had problems obtaining the other agricultural inputs required for irrigated agriculture, which limited their use of groundwater. This has an impact on the volume of water extracted by each category (Fig. 23.6).

Figure 23.6 shows that $3.6 \%$ of the farmers ( $>20$ ha) own more land $(44 \%)$ than $82.5 \%$ of the farmers ( $<10 \mathrm{ha}$ ) who own only $40.3 \%$ of the land. In the literature, this well-known skewed landownership is rarely interpreted in terms of the differential contribution of these farm holdings to the overexploitation of groundwater. Instead, this overexploitation is generally attributed to the agricultural sector as a

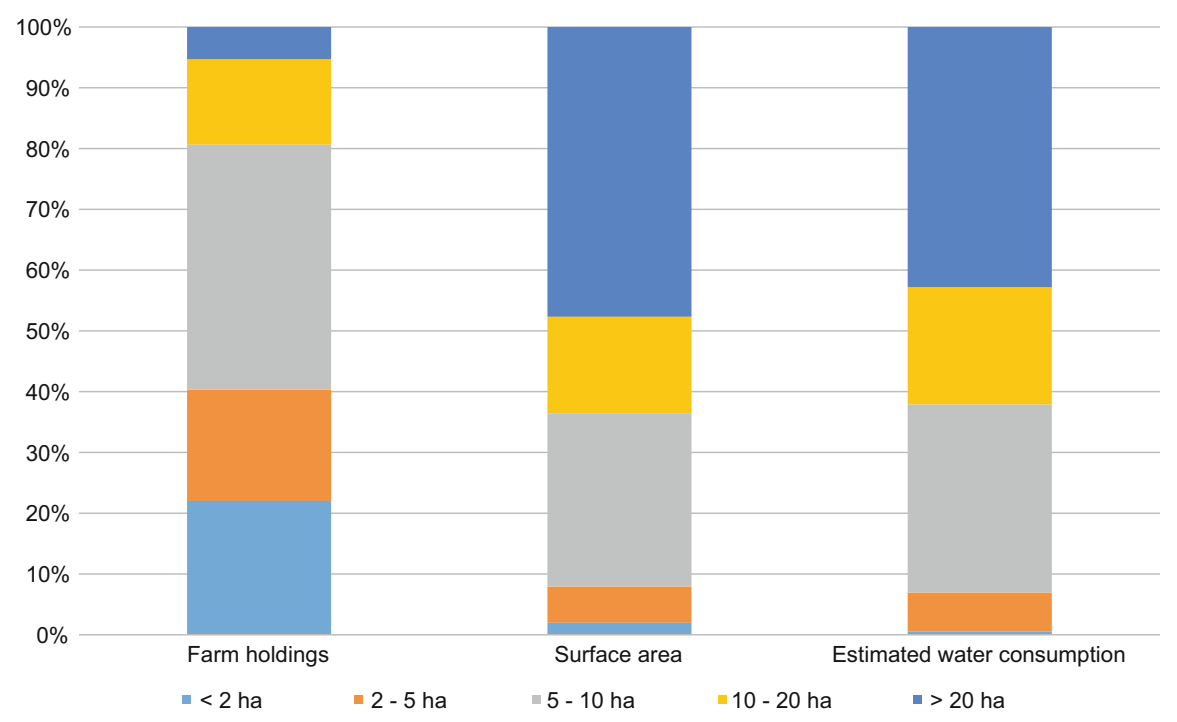

Fig. 23.6 Estimated water consumption (in \%) per class of farm holding in the study area, located in the Saiss 
whole. Distinguishing the contribution of the different categories of farmers to overexploitation is not easy due to complex agrarian structures and the mobility of farmers, and farmers' irrigation practices, which may lead to fourfold differences in irrigation volumes per ha (Benouniche et al. 2014). This explains the question mark in Fig. 23.6, which we are addressing in our on-going research. In the context of groundwater overexploitation, the question is then, who benefits from groundwater use, and who loses out?

\subsection{Three Issues Related to the Rapid and Massive Development of Groundwater Use}

\subsubsection{Will Overexploitation Continue? Current Groundwater Use Practices in North Africa's Groundwater Economies}

Current groundwater use practices have led to overexploitation of a large number of North Africa's aquifers, including some non- or little renewable aquifers. Due to the interplay between the different pathways of local groundwater economies, and the hydraulic characteristics of specific aquifers supporting them, groundwater practices will evolve differently in different situations.

Three main types of groundwater economies can be identified. First, the established medium-sized groundwater economies in northern and central Morocco, Algeria and Tunisia are based on renewable, but overexploited, groundwater resources, sometimes in addition to surface water resources which are exploited in existing irrigation schemes. Most of these groundwater economies have existed for more than 30 years, and each supports several tens of thousands of ha of irrigated agriculture. The groundwater economy of the Souss (Morocco) is probably the oldest and most threatened of all due to the marginalization of certain types of farming and social conflict (Popp 1986; Houdret 2012), brought about by a long history of intensive agriculture (orange trees, horticulture), and limited rainfall and recharge. But tensions have appeared even in more recent groundwater economies with higher precipitation rates like the Mitidja, in Algeria (Imache et al. 2010), Merguellil, in Tunisia (Leduc et al. 2007) or the Saiss (this study).

Second, the burgeoning groundwater economies of the Saharan areas, for example Nefzaoua (Tunisia) and Biskra (Algeria), are based on the exploitation of huge mostly non-renewable groundwater resources. Water is mined in quite a similar way as in the nearby oil fields (Margat 2008), while the local groundwater economy incorporates increasing numbers of farmers and other supporting actors in the current agricultural boom (Côte 2002; Mekki et al. 2013).

Third, minor volatile groundwater economies depend on often-overexploited small aquifers. They can be distinguished from the first type by their smaller size, which brings the tipping point beyond which a groundwater economy enters in a crisis situation much closer. Coastal horticultural groundwater economies are a typical example. Taking advantage of temperate climatic conditions, light soils and 
shallow groundwater, horticulture is widespread in many locations along the Atlantic and Mediterranean coasts. This led to many critical situations, particularly seawater intrusion, for example around Casablanca (Morocco) in the 1950s, around Azemmour (Morocco) in the 1980s (Berahmani et al. 2012), and north of Sfax (Tunisia) in the 1990s (Trabelsi et al. 2005). So far mainly individual adaptive strategies have been observed. Farmers reacted by piping good quality water in from nearby areas to continue horticulture, but in many cases had to change cropping systems by switching to more salinity tolerant crops or even quit (Berahmani et al. 2012). Local actors also looked to the State to save these groundwater economies, by providing additional surface water resources. However, as yet, there have been no 'success stories' concerning the restoration of the balance of such groundwater economies.

These North African aquifers can be positioned in the successive temporal stages of the rise and fall of groundwater economies, if adopting the frameworks of Shah et al. (2003) and Llamas and Martinez-Santos (2005). These frameworks propose a sequence in the life cycle of a groundwater economy, starting with a first stage in which the groundwater economy slowly emerges ("silent" revolution). The second stage corresponds to an era of groundwater-based agricultural prosperity. In the third stage, the first signs of groundwater overdraft or degradation become apparent, but farmer lobbies generally successfully defend the considerable interests generated by the groundwater economy. During the fourth stage, the decline in the groundwater economy causes social conflict. Conservation lobbies may prevent the groundwater economy entering this stage.

Most established medium-sized, partly renewable, groundwater economies are already positioned beyond the middle of the curves, meaning that there are early symptoms of groundwater overdraft with farmer lobbies defending their share and pushing the government to look for additional supplies, as is the case in the Saiss (Morocco), in the Mitidja (Imache et al. 2010) and in the Merguellil (Leduc et al. 2007). In the case of the Souss, clear signs of decline and social conflict are already apparent (Popp 1986; Houdret 2012). As in South Asia, these groundwater economies generally reached the later stages of the curves in less than 40 years. In these established groundwater economies, overexploitation will probably continue for the time being, while coalitions of privileged farmers and the State actively search for additional water resources, for example through desalination or interbasin water transfer.

The Saharan groundwater economies appear to be stably positioned in an earlier stage of the curves, that is in the stage of the groundwater-based agrarian boom. In these aquifers, there are signs of overexploitation; in some confined aquifers the water tables have dropped as much as $100 \mathrm{~m}$ in the past 20 years (MRE 2009). However, the water reserves are huge, and few actors appear to be worried about the finite nature of groundwater resources. It is hard to see how, in the context of the alignment of interests between the States promoting agricultural growth, and the different private actors with direct economic and social interest in these new irrigation frontiers, overexploitation will even remain at current levels. As with 
other mining resources, the question will then be how the benefits of such unsustainable groundwater economies will be reinvested.

Finally, some of the minor groundwater economies, such as the coastal horticultural systems, have already reached the final stages of their life cycle. Dealing with overexploitation in such situations could be a good test case for managing groundwater resources sustainably, as the size of these economies is limited. Technical solutions (artificial recharge, pumping barriers) that exist to deal with this issue will need to be embedded in a larger management framework negotiated with all the actors. Otherwise short-term water use practices are likely to continue (Llamas and Martinez-Santos 2005).

While farmers and public institutions agree on the general overdraft in the different aquifers, ${ }^{2}$ no supporting coalitions have emerged to deal with groundwater overexploitation (Faysse et al. 2012). Groundwater overdraft had dramatic shortterm consequences in some specific aquifers, but actors reacted individually or looked to the State to supply more water. In all other groundwater economies, to most local actors the crisis appeared far away. Proposed measures to deal with the crisis, through aquifer contracts for instance, mostly concerned increasing water supplies, through desalination units, inter-regional water transfer, or the construction of dams. Water saving in agriculture was promoted by subsidizing irrigation technologies such as drip irrigation. In reality, drip irrigation may even increase water demand as farmers turn to more intensive agriculture or extend the irrigated area (Berbel et al. 2013; Batchelor et al. 2014). The question is what will be the consequences of current water use practices, and how long will it take to deal with the looming groundwater crisis?

Alley and Leake (2004) took a long-term and multi-perspective view of "sustainable" groundwater development, including the environmental, economic and social consequences. They showed that groundwater use might go through stages that are environmentally unsustainable, but that propel social and economic development which would not have been possible without such use. This means that groundwater use should be thought out and, perhaps more importantly, negotiated in all the different stages in the life cycle of a groundwater economy. This is very difficult due to the State interest in increasing agricultural productivity, the inherent characteristics of the rapidly expanding and diffuse groundwater economy, and existing social power relations. However, putting off dealing with these issues may lead to extremely difficult situations, given the economic, social and political proportions that groundwater economies have taken.

\footnotetext{
${ }^{2}$ Issues related to groundwater pollution in North Africa are widely acknowledged in scientific studies and in government documents but, except for salinity problems, are rarely mentioned by local actors.
} 


\subsubsection{Groundwater as the Enabler of a Socio-economic Transition: Who Are Left Behind?}

The different North African States, the private sector, and farmers alike acclaimed groundwater as an enabler of more productive agriculture, and a safety net for small-scale agriculture threatened by droughts. Groundwater is associated with 'modern' agriculture, improving the social status of farmers. Quarouch et al. (2014) showed that farmers look on groundwater as a means of gaining access to "unlimited horizons," where water no longer censors their existence. This can be compared with observations made in large-scale irrigation schemes, where farmers experienced access to groundwater as emancipation from State water (Kuper et al. 2009).

The recent boom in agricultural production was supported by a recent cycle of ambitious public policies aimed at agricultural productivity. The opportunities offered by the rapid development of the groundwater economy attracted many newcomers. In Morocco, the Green Morocco Plan had the clearly stated objective of facilitating access to land and water for 'modern' investors, who would be able to exploit these resources in line with new ambitions. The State granted substantial subsidies for irrigation (tube-wells, drip irrigation) and plantations to stimulate private investment by new entrepreneurs. There is even a discourse claiming that certain categories of farmers, such as the former assignees of agrarian reform cooperatives, do not "participate in the economic development of the Nation" (Papin-Stammose et al. 2013). In Algeria, the Saharan 'Eldorado' attracted many newcomers; investors who were keen to take advantage of the interesting returns of the Saharan farming systems, but also young people for whom the rapid socioeconomic promotion represented an exciting opportunity.

While the groundwater economy brought undeniable social and economic progress to some, other groups of actors were marginalized. We have shown three orders of inequality in groundwater access and use. Firstly, large numbers of farmers did not obtain access to groundwater. In the Tadla irrigation scheme (Morocco), only $50 \%$ of the farmers have access to groundwater. It is mainly small-scale farmers $(<2$ ha) who are left behind (Kuper et al. 2012). A recent study in the Cheliff irrigation scheme (Algeria) showed that only $38 \%$ of farmers had access to groundwater, while the remaining farmers were "trapped in a process of impoverishment" (Amichi et al. 2012). The second source of inequality is the pump equipment as we showed for the Saiss. Farmers with poorly equipped wells, which are running dry, have difficulty competing with those who drill deep tubewells and invest in high-value agriculture. The third source of inequality is the economic status of different categories of farmers in the skewed access and use of groundwater (ibid.). This may lead to similar social and economic differentiation to that reported in Gujarat (Prakash 2005). Social inequity may also undermine the development of local agriculture, as the majority of farmers (and their offspring) may be tempted to give up farming. Finally, the trend to increasing socio-economic inequality is a threat in the strained political context of North Africa, as most groundwater economies rely on overexploited aquifers. 
However, different, often informal, mechanisms exist to deal with unequal access to groundwater. This contradicts common perceptions, as the groundwater economy is always presented as a private affair. "A farmer, a well" farmers in Morocco replied when asked whether they would be willing to share a (tube-) well (Quarouch et al. 2014). In India, Shah (1993) showed how thriving informal water markets provide access to those that do not have their own tube-well. Shah and Bhattacharya (1992) reported another interesting mechanism - the 5-7,000 informal 'tube-well companies' in Gujarat where farmers jointly invest in deep tubewells. In North Africa, such mechanisms can also be found. In Biskra, we observed informal tube-well associations that reminded us of the Gujarati tube-well companies. More importantly, informal water markets, often intertwined with access to other production factors (land, capital, labour) ensure the integration of large numbers of small-scale farmers in the groundwater economy (Ammar Boudjellal et al. 2011). Unlike in South Asia, selling water directly and independently from a larger contractual but informal arrangement is generally (still) not done. Investigating these different mechanisms and their evolution may be an interesting way to contribute to the debate on how to deal with mounting inequalities. Finally, there are still areas where collective access to groundwater enables more generalized access to groundwater. These are mainly communitymanaged irrigation schemes and public tube-well schemes. In Tunisia, for instance, almost $30 \%$ of the groundwater-based irrigated area depend (in part) on public tube-wells. However, both types of systems appear to be declining, because of diminishing investments in collective irrigation schemes, resulting in degraded equipment, and the proliferation of private tube-wells in these schemes, as farmers want to obtain a more secure access to groundwater.

\subsubsection{The Groundwater Economy Is an Informal Economy, Should It Remain So?}

The global groundwater economy emerged in a period when rural development was no longer considered to be the sole responsibility of the State. "Less state, more market" aptly described the general opinion of how development should take place, and the State was basically asked to get out of the way of private initiative (Shah 2009). Since the initiative, investment and management of the groundwater economy is mainly a private affair, the State's "writ does not run" in such informal water economies (Shah 2009). The groundwater economy that emerged in Algeria, Morocco and Tunisia is dominated by informal arrangements for access to water, land and other resources, and by actors whose role is not formally acknowledged (Ammar Boudjellal et al. 2011). If farmers remain in the invisible world of informal groundwater economies, this may increase the risk of domination by opportunist investments, which are both socially and ecologically unsustainable (Errahj et al. 2009). On the other hand, State intervention will not necessarily lead to improved social, economic and environmental sustainability of the groundwater 
economy. Formalizing access to groundwater could cement existing inequalities, and should thus be considered with caution (Mukherji 2006).

In North Africa, groundwater is now firmly associated with productive irrigated farming. By extension, groundwater became an important part of what remained a national priority for North Africa's political economies (Allan 2007). Interestingly, our results showed that the State was an active but not always very visible actor in the groundwater economy through different (in) direct mechanisms. First, the State provided water to a substantial number of farmers through public tube-wells, although the importance of these schemes has declined. Second, the three States have made considerable efforts to provide basic infrastructure in rural areas, thus facilitating the deployment of the groundwater economy. The electrification of rural areas, for example, enabled the spread of more powerful tube-wells. Third, many authors deplored the fact that the existing regulations on groundwater use were not applied. We do not entirely agree. The "tolerant" State allowed the private sector to appropriate access to groundwater resources (Brochier-Puig 2004). However, the rules-in-use were continuously evolving in a negotiated process between the State and the private actors. In Morocco for instance, this led to an increasing number of tube-wells registered by river basin agencies. On the other hand, the volumes extracted are not regulated anywhere, thereby revealing the limits of the on-going negotiations. Fourth, the different states subsidized the groundwater economies directly (through tube-wells) and indirectly (through energy, drip irrigation, fruit trees).

We have shown, in particular, that the subsidies for micro-irrigation were an important stimulus for the groundwater economy. Fifth, experience shows that the protagonists of groundwater economies who are in peril will sooner or later call on the State to find solutions (Houdret 2012). Private actors look for public protection by claiming, for instance, to include their land in a public irrigation scheme; the State thus becomes co-responsible for finding solutions to declining water resources. This happened in the Souss (Morocco) where citrus farmers had overexploited groundwater resources, and (by calling on the State) managed to obtain access to surface water by means of a $90 \mathrm{~km}$ pipeline, thereby marginalizing a large number of small-scale farmers (Houdret 2012). This appears to contradict earlier tough talk by the administration, as documented in the 1974 Water Master Plan of the Souss: "If the private sector should continue to disregard bans on planting (orchards) or pumping, it should be prepared in the future to fully support the most disastrous consequences" (Nhrira 2011).

In sum, while at first sight the groundwater economies in North Africa appear to be based on private initiative, the presence of the State remains important through different formal and informal channels. However, there are very few examples in the region of substantial discussions between the different actors on the future of the different groundwater economies. 


\subsection{Conclusions: Privatization of Groundwater?}

Groundwater is now an important resource in North Africa - for farmers, the private sector, and the State. Over the past 30 years it has gradually become a lifeline for farmers engaged in irrigated agriculture. It saved farmers from structural droughts, and enabled them to intensify farming systems. It created many jobs in the grey support sector which developed in the wake of, and contributed to, the mounting groundwater economy. It enabled the different States to continue promoting irrigated agriculture as a national priority and a credible rural development option, for as long as the overexploited aquifers will continue to provide water.

The groundwater economy in the region emerged during a period of State disengagement following structural adjustments in the 1980s. It is tempting to define this as a transition from State-led surface irrigation development to private groundwater exploitation, amounting to a "privatization" of this resource. Groundwater access did end up in the hands of a minority of farmers, who are overexploiting the aquifers. However, we argue that there is also continuity in this transition or, in other words, that the trajectory of change is path-dependent. This explains why the State remained (and was held) legally but also morally 'responsible' for groundwater by users who had become dependent on groundwater. It intervened in many (in-) direct ways in what at first sight may appear to be private exploitation of groundwater. When private wells ran dry, the State even looked for additional water resources for the rolling groundwater economies, ignoring water demand management options.

So what conclusions can be drawn regarding the pathways of North Africa's groundwater economies, and the Janus nature of groundwater use (liberation or anarchy)? In our opinion, these pathways did not lead to 'anarchy' but rather to negotiated disorder in which the different interests of the farmers, the private sector, and the State were continuously realigned through various (in)formal channels. This disorder explains why groundwater continues to be overexploited in the shortor medium-term interest of those who use groundwater, those who provide services to the booming groundwater economies, and that of the permissive State looking for food security, social stability and economic development. At the same time, groundwater 'liberated' farmers only partially from State water. Groundwater was available for only a minority of farmers, with many inequalities. And even farmers who were able to obtain groundwater access were quickly confronted with other challenges, including harsh agricultural markets. In times of crisis, these farmers therefore often turned towards the State for support.

Finally, in a context of structural overexploitation of aquifers, crisis situations are likely to occur frequently in the next decade or so. This is not only the case in North Africa, but in many other parts of the world. Most actors depending on groundwater are well aware of these imminent crises. However, there are few examples of concerted and negotiated strategies to deal with such crises. Perhaps, the wider implications of this study relate to giving more visibility and importance to the short and medium-term effects of current dynamics and the impending decline of groundwater economies in order to create "space for change" (Leeuwis 
and Aarts 2011). This may in particular entail building coalitions of actors around the definition and analysis of scenarios of change pertaining to how the groundwater economy may evolve in the future. Research has certainly a major role to play in enabling such reflections.

Acknowledgments Research for this study was carried out in the framework of the 'Groundwater Arena' project, funded by the French National Research Agency (CEP S 11/09), and the Sirma collaborative agreement.

Open Access This chapter is distributed under the terms of the Creative Commons AttributionNoncommercial 2.5 License (http://creativecommons.org/licenses/by-nc/2.5/) which permits any noncommercial use, distribution, and reproduction in any medium, provided the original author(s) and source are credited.

The images or other third party material in this chapter are included in the work's Creative Commons license, unless indicated otherwise in the credit line; if such material is not included in the work's Creative Commons license and the respective action is not permitted by statutory regulation, users will need to obtain permission from the license holder to duplicate, adapt or reproduce the material.

\section{References}

Akesbi N (2014) Le Maghreb face aux nouveaux enjeux mondiaux. Les investissements verts dans l'agriculture au Maroc. IFRI, Paris. http://dev.ocppc.lnet.fr/sites/default/files/IFRI_ noteifriocpnakesbi.pdf

Akesbi N, Guerraoui D (1991) Enjeux agricoles: évaluation de l'expérience marocaine. Editions le Fennec, Casablanca

Al Atiri R (2007) Evolution institutionnelle et réglementaire de la gestion de l'eau en Tunisie: Vers une participation accrue des usagers de l'eau. In: Bouarfa S, Kuper M, Debbarh A (eds) L'avenir de l'agriculture irriguée en Méditerranée. Nouveaux arrangements institutionnels pour une gestion de la demande en eau. 3rd Wademed seminar. Cirad, Montpellier

Allan JAT (2007) Rural economic transitions: groundwater uses in the Middle East and its environmental consequences. In: Giordano M, Villholth KG (eds) The agricultural groundwater revolution: opportunities and threats to development, vol 3. CABI, Wallingford, UK

Alley M, Leake SA (2004) The journey from safe yield to sustainability. Ground Water 42 (1):12-16

Amichi H, Bouarfa S, Kuper M, Ducourtieux O, Imache A, Fusillier JL, Bazin G, Hartani T, Chehat F (2012) How does unequal access to groundwater contribute to marginalization of small farmers? The case of public lands in Algeria. Irrig Drain 61(S1):34-44

Amichi F, Bouarfa S, Hartani T, Lejars C, Belhamra M, Daoudi A, Amichi H, Kuper M (2013) Le maraîchage au service de la phoeniciculture pour développer de nouvelles frontières agricoles à El Ghrouss. In: Hartani T, Kuper M, Belhamra M (eds) Proceedings of the seminar on the governance of groundwater in the Maghreb. ENSA-CRSTRA-Cirad, Biskra

Ammar Boudjellal AA, Bekkar Y, Kuper M, Errahj M, Hammani A, Hartani T (2011) Analyse des arrangements informels pour l'accès à l'eau souterraine sur les périmètres irrigués de la Mitidja (Algérie) et du Tadla (Maroc). Cah Agric 20(1-2):85-91

Batchelor C, Reddy VR, Linstead C, Dhar M, Roy S, May R (2014) Do water-saving technologies improve environmental flows? J Hydrol 518:140-149 
Bekkar Y, Kuper M, Errahj M, Faysse N, Gafsi M (2009) On the difficulty of managing an invisible resource: farmers' strategies and perceptions of groundwater use, field evidence from Morocco. Irrig Drain 58(S3):252-263

Benblidia M (2011) L'efficience d'utilisation de l'eau et approche économique. Plan Bleu, Sophia Antipolis

Benmouffok B (2004) Efforts de l'Algérie en matière d'économie de l'eau et de modernisation de l'irrigation. In: Hammani A, Kuper M, Debbarh A (eds) Proceedings of the seminar on the modernisation of irrigated agriculture, Rabat, 19-22 April 2004. 1st Wademed seminar. IAV Hassan II, Rabat

Benouniche M, Kuper M, Hammani A, Boesveld H (2014) Making the user visible: analyzing irrigation practices and farmers' logic to explain actual drip irrigation performance. Irrig Sci. doi:10.1007/s00271-014-0438-0

Benziouche SE, Cheriet F (2012) Structure et contraintes de la filière dattes en Algérie. New Medit 11:49-57

Berahmani A, Faysse N, Errahj M, Gafsi M (2012) Chasing water: diverging farmers' strategies to cope with the groundwater crisis in the coastal Chaouia region in Morocco. Irrig Drain 61 (5):673-681

Berbel J, Pedraza V, Giannoccaro G (2013) The trajectory towards basin closure of a European river: Guadalquivir. Int J River Basin Manag 11(1):111-119

Bouchedja A (2012) La politique nationale de l'eau en Algérie. In: Euro-RIOB 2012, $10^{\text {ème }}$ Conférence Internationale, Istanbul, 17-19 Oct 2012

Brochier-Puig J (2004) Société locale et État face aux limites de la ressource eau (Nefzaoua, SudOuest tunisien). In: Picouët $\mathrm{M}$ et al (eds) Environnement et sociétés rurales en mutation, Approches alternatives. Éditions IRD, Paris, pp 307-321

Célérier J, Charton A (1925) Les grands travaux d'hydraulique agricole au Maroc. Annales de Géographie 34(187):76-80

Chevalier L (1950) Le plan de modernisation et d'équipement pour l'Afrique du Nord. Population $5(1): 166-170$

Côte M (2002) Des oasis aux zones de mise en valeur: l'étonnant renouveau de l'agriculture saharienne. Méditerranée 99(3-4):5-14

Daoudi A, Wampfler B (2010) Le financement informel dans l'agriculture algérienne: les principales pratiques et leurs déterminants. Cah Agric 19:243-248

El Alaoui M (2006) Développement de l'agriculture irriguée, dispositif juridique et institutionnel et stratégie de gestion de l'eau au Maroc. In: Bouarfa S, Kuper M, Debbarh A (eds) L'avenir de l'agriculture irriguée en Méditerranée. Nouveaux arrangements institutionnels pour une gestion de la demande en eau. 3rd Wademed seminar. Cirad, Montpellier

El Gueddari A (2004) Economie d'eau en irrigation au Maroc: Acquis et perspectives d'avenir. Hommes, Terre et Eaux 130:4-7

Errahj M, Kuper M, Faysse N, Djebbara M (2009) Finding a way to legality, local coordination modes and public policies in large-scale irrigation schemes in Algeria and Morocco. Irrig Drain 58(S3):358-369

Faysse N, Hartani T, Frija A, Tazekrit I, Zairi C, Challouf A (2011) Agricultural use of groundwater and management initiatives in the Maghreb: challenges and opportunities for sustainable aquifer exploitation. AfDB Econ Brief 1-24. http://www.afdb.org/en/documents/document/ economic-brief-agricultural-use-of-groundwater-and-management-initiatives-in-the-maghrebchallenges-and-opportunities-for-sustainable-aquifer-exploitation-25496/

Faysse N, El Amrani M, El Aydi S, Lahlou A (2012) Formulation and implementation of policies to deal with groundwater overuse in Morocco: which supporting coalitions? Irrig Drain 61(S1):126-134

Hammani A, Hartani T, Kuper M, Imache A (2009) Paving the way for groundwater management: transforming information for crafting management rules. Irrig Drain 58(S3):240-251

Houdret A (2012) The water connection: irrigation and politics in southern Morocco. Water Altern 5(2):284-303 
Imache A, Hartani T, Bouarfa S, Kuper M (2010) La Mitidja, 20 ans après: réalités agricoles aux portes d'Alger. Editions Alpha, Algiers

Jus H (1878) Les forages artésiens de la province de Constantine: résumé des travaux éxécutés de 1856 à 1878. Impr. Nouv., Paris

Khiari A (2002) Une région pionnière dans le Sahara algérien: El Ghrouss. Méditerranée 99 $(3-4): 27-30$

Konikow LF, Kendy E (2005) Groundwater depletion: a global problem. Hydrogeol J 13 (1):317-320

Kuper M, Hammani A, Zemzam S, Bouarfa S, Thomas V (2003) Stratégies d'utilisation conjuguée des eaux de surface et souterraine pour l'irrigation: le cas du périmètre irrigué du Tadla au Maroc. In: Proceedings of the 3rd Pcsi seminar on the Integrated water management in river basins. Cirad, Montpellier

Kuper M, Dionnet M, Hammani A, Bekkar Y, Garin P, Bluemling B (2009) Supporting the shift from "state" water to "community" water: lessons from a social learning approach to design joint irrigation projects in Morocco. Ecol Soc 14(1):19

Kuper M, Hammani A, Chohin A, Garin P, Saaf M (2012) When groundwater takes over: linking 40 years of agricultural and groundwater dynamics in a large-scale irrigation scheme in Morocco. Irrig Drain 61(S1):45-53

Leduc C, Ben Ammar S, Favreau G, Béji R, Virrion R, Lacombe G, Tarhouni J, Aouadi C, Zénati Chelli B, Jebnoun N, Oï M, Michelot JL, Zouari K (2007) Impacts of hydrological changes in the Mediterranean zone: environmental modifications and rural development in the Merguellil catchment, central Tunisia. Hydrol Sci J 52(6):1162-1178

Leeuwis C, Aarts N (2011) Rethinking communication in innovation processes: creating space for change in complex systems. J Agric Educ Ext 17(1):21-36

Lightfoot DR (1996) Moroccan Khettara: traditional irrigation and progressive desiccation. Geoforum 21(2):261-273

Llamas MR (1998) Groundwater overexploitation. In: Proceedings of the UNESCO-IHP conference on world water resources at the beginning of the 21 st century, Paris

Llamas MR, Martínez-Santos P (2005) Intensive groundwater use: silent revolution and potential source of social conflicts. J Water Resour Plan Manag 131(5):337-341

Lopez-Gunn E, Llamas MR (2008) Re-thinking water scarcity: can science and technology solve the global water crisis? Nat Res Forum 32(3):228-238

MacDonald AM, Bonsor HC, Dochartaigh BEO, Taylor RG (2012) Quantitative maps of groundwater resources in Africa. Environ Res Lett 7(2):024009

Mamou A, Kassah A (2002) Eau et développement dans le Sud tunisien: projet national mobilisateur 'potentialités et gestion de l'eau dans le Sud tunisien'. CERES, Tunis

Margat J (2008) Exploitations et utilisations des eaux souterraines dans le monde, vol 52. Unesco/ BRGM, Paris

Margat J, Vallée D (1999) Vision méditerranéenne sur l'eau, la population et l'environnement au XXIème siècle. Plan Bleu, Sophia Antipolis

Mekki I, Jacob F, Marlet S, Ghazouani W (2013) Management of groundwater resources in relation to oasis sustainability: the case of the Nefzawa region in Tunisia. J Environ Manage 121:142-151

Mitchell M, Curtis A, Sharp E, Mendham E (2012) Directions for social research to underpin improved groundwater management. J Hydrol 448-449:223-231

Moench M (2007) When the well runs dry but livelihood continues: adaptive responses to groundwater depletion and strategies for mitigating the associated impacts. In: Giordano M, Villholth KG (eds) The agricultural groundwater revolution: opportunities and threats to development. CABI Head Office, Oxford, pp 173-192

Monition L, de Lesguise MN (1954) Contribution à l'étude du drainage naturel des nappes aquifères. In: Proceedings Ass. Int. Hydrol. Sa., CR Assembl. Gén., Rome, pp 499-519

Mukherji A (2006) Political ecology of groundwater: the contrasting case of water-abundant West Bengal and water-scarce Gujarat, India. Hydrogeol J 14:392-406

Nhrira A (2011) La sauvegarde des eaux souterraines dans le Bassin du Souss Massa. In: Proceedings of the groundwater conference, 14-16 March 2011. Afeid, Orléans 
Otmane T, Kouzmine Y (2013) Bilan spatialisé de la mise en valeur agricole au Sahara algérien Mythes, réalisations et impacts dans le Touat-Gourara-Tidikelt. Cybergeo: European Journal of Geography, Espace, Société, Territoire 632

Papin-Stammose C, Petit O, Kuper M (2013) Résilience des paysanneries marocaines dans un contexte de mutations de l'accès aux ressources productives: cas du Saiss. In: Hartani T, Kuper M, Belhamra M (eds) Proceedings of the seminar on the governance of groundwater in the Maghreb. ENSA-CRSTRA-Cirad, Biskra

Pascon P (1978) De l'eau du ciel à l'eau de l'état: psychosociologie de l'irrigation. Hommes, Terre et Eaux 8(28):3-10

Penov I (2004) The use of irrigation water in Bulgaria's Plovdiv region during transition. Environ Manage 34(2):304-313

Poncet J, Kuper M, Chiche J (2010) Wandering off the paths of planned innovation: the role of formal and informal intermediaries in a large scale irrigation scheme in Morocco. Agr Syst 103 (4):171-179

Popp H (1986) L'agriculture irriguée dans la vallée du Souss. Formes et conflits d'utilisation de l'eau. Méditerranée 59(4):33-47

Postel S (1999) Pillar of sand: can the irrigation miracle last? WW Norton, New York

Prakash A (2005) The dark zone: groundwater irrigation, politics and social power in North Gujarat. PhD thesis, Wageningen University and Research Centre

Quarouch H, Kuper M, Abdelaoui E, Bouarfa S (2014) Eaux souterraines, sources de dignité et ressources sociales. Cas d'agriculteurs dans la plaine du Saïss au Maroc. Cahiers Agricultures. doi:10.1684/agr.2014.0699

Riaux J (2013) Engager la construction d'un regard sociohydrologique: des archives catalyseurs de l'interdisciplinarité. Nat Sci Soc 21(1):15-23

Rojas R, Kahunde S, Peeters L, Batelaan O, Feyen L, Dassargues A (2010) Application of a multimodel approach to account for conceptual model and scenario uncertainties in groundwater modelling. J Hydrol 394(3):416-435

Shah T (1993) Water markets and irrigation development: political economy and practical policy. Oxford University Press, Bombay

Shah T (2009) Taming the anarchy: groundwater governance in South Asia. Resources for the Future Press, Washington, DC

Shah T, Bhattacharya S (1992) Farmer organisation for lift irrigation: irrigation companies and tubewell co-operatives of Gujarat. In: Singh K, Ballabh V (eds) Symposium on management of rural co-operatives. Institute of Rural Management, Anand

Shah T, Deb Roy A, Qureshi AS, Wang J (2003) Sustaining Asia's groundwater boom: an overview of issues and evidence. Nat Res Forum 27(2):130-141

Siebert S, Burke J, Faures JM, Frenken K, Hoogeveen J, Doll P, Portmann FT (2010) Groundwater use for irrigation - a global inventory. Hydrol Earth Syst Sci 14:1863-1880

Swearingen WD (1987) Moroccan mirages: agrarian dreams and deceptions, 1912-1986. IB Tauris Publishers, London/New York

Trabelsi R, Zaïri M, Smida H, Ben Dhia H (2005) Salinisation des nappes côtières: cas de la nappe nord du Sahel de Sfax, Tunisie. Comptes Rendus Geosci 337(5):515-524

Venot JP, Zwarteveen M, Kuper M, Boesveld H, Bossenbroek L, Van Der Kooij S, Wanvoeke J, Benouniche M, Errahj M, De Fraiture C, Verma S (2014) Beyond the promises of technology: a review of the discourses and actors who make drip irrigation. Irrig Drain 63(2):186-194

Ziyad A (2007) Renouvellement de la politique de l'eau au Maroc: quel apport du débat national sur l'eau? Hommes Terre Eaux 137:59-61

\section{Official Data}

Agences de Bassin Hydraulique (ABH) (2011) Plan directeur d'aménagement intégré des ressources en eau (PDAIRE), Rabat, Morocco 
Direction Générale des Ressources en Eau (DGRE) (2005) Situation de l'exploitation des nappes phréatiques. Tunis, Tunisia

Direction Générale des Ressources en Eau (DGRE) (2008) Annuaire de l'exploitation des nappes profondes. Tunis, Tunisia

Direction Générale du Génie Rural et de l'hydraulique agricole (DGGREE) (2006) Computer data base, accessed on 23/9/2013. Tunis, Tunisia

High Planning Commission (HCP) (2007) Prospective Maroc 2030: Quelle agriculture pour le Maroc? Rabat, Morocco

Ministère de l'Agriculture et de la Pêche Maritime (MAPM) (2012) Situation de l'agriculture marocaine. Rabat, Morocco

Ministère des Ressources en Eau (MRE) (2009) Etude d'inventaire et de développement de la PMH. Algiers, Algeria

Ministère des Ressources en Eau (MRE) (2011) Note sur l'activité de l'hydraulique agricole. Algiers, Algeria

TICET (2009) Institutional framework and decision making practices for water management in Tunisia. Project report of the CITET. Tunis, Tunisia 


\section{Part V}

Modeling and Decision Support 


\title{
Incorporating Human Aspects into Groundwater Research and Policy Making: A Soft and Critical Systems Thinking Approach
}

\author{
Sondoss Elsawah and Joseph H.A. Guillaume
}

\begin{abstract}
Groundwater management issues present a serious challenge partly because of the complexity and uncertainty that human elements (i.e. cognitive, social, cultural and political) bring into the problem, as well as our limited capacity to fully comprehend and deal with such elements and their interactions with the biophysical systems. Whereas there is a wide recognition of the importance of stakeholder participation for the design and implementation of effective policies, the ongoing depletion of groundwater and disputes surrounding management policies suggest the need for better participatory mechanisms. This raises the question of how human elements can be incorporated into groundwater policies. Whereas there is no single discipline that can provide answers for such crucial research and policy questions, this chapter argues that systems thinking (especially soft and critical approaches) has the potential to provide a framework of theories, methods and example applications to help incorporate human elements into groundwater management and research. This chapter aims to give an overview of systems thinking by firstly describing the theory, distinguishing between hard, soft and critical systems thinking approaches. Secondly, we discuss the importance of mixing methods from these approaches and evaluating
\end{abstract}

\footnotetext{
S. Elsawah $(\bowtie)$

School of Engineering and Information Technology, University of New South Wales, Canberra, Australia

Integrated Catchment Assessment and Management Centre, Fenner School of Environment and Society, Australian National University, Canberra, Australia e-mail: S.elsawah@adfa.edu.au
}

J.H.A. Guillaume

Integrated Catchment Assessment and Management Centre, Fenner School of Environment and Society, Australian National University, Canberra, Australia

Water and Development Research Group (WDRG), Aalto University, Tietotie 1E, Espoo 02150, Finland 
'process' and 'outcomes' when applying them. Thirdly, we review four example applications, and highlight their relevance to groundwater management systems.

\subsection{Introduction}

Groundwater research and policy making are grappling with many interconnected and interdependent issues including:

- Finding ways to anticipate and adapt to climate change impacts on groundwater resources, and dependent social-ecological systems, including severe impacts from climatic hazards such as prolonged droughts;

- Allocating available water among competing consumptive and environmental water needs especially at times of scarcity;

- Identifying and dealing with risks to groundwater health (quantity and quality) caused by cumulative and delayed impacts of human activities;

- Establishing the public's trust and acceptance of management decisions, and the credibility of underpinning science in situations where values and science are highly contested, and data are limited;

- Building the adaptive capacity of individuals, communities, and institutions to communicate, learn, and self-adjust in order to respond timely to incremental and abrupt changes in resource conditions

There is a wide consensus that contemporary water and groundwater management issues are defined as wicked problems (Rittel 1972), messes (Ackoff 1974), or resource dilemmas (Ison et al. 2007). These terms express the observation that managing groundwater issues is a vexing challenge owing to a constellation of reasons, many of which are caused and/or amplified by the human rather than the biophysical elements of the system. First, the resource behaviour is driven by the collective outcomes of decisions and actions made by different actor groups (i.e. stakeholders, policy makers, and scientists) where individuals and agencies within and across groups interact at different levels of the governance system (see Fig. 24.1). Second, there is no well-defined set of goals or priorities. Stakeholders have multiple, many times conflicting, views about the resource. For example: how they envisage the future of the groundwater resource systems, how much weight is to be given to different knowledge sources and viewpoints, what are considered feasible and acceptable management decisions. Third, managed systems, both human and biophysical, do not respond to management initiatives in ways that are consistent or predictable. Implementing a management intervention may create a new set of problems that may only become evident when considering the problem situation across broader spatial and temporal ranges (Mason and Mitroff 1981). For example, effects of a single mine on groundwater levels might seem to be acceptable. However, aggregated effects from multiple mining sites may interact with 


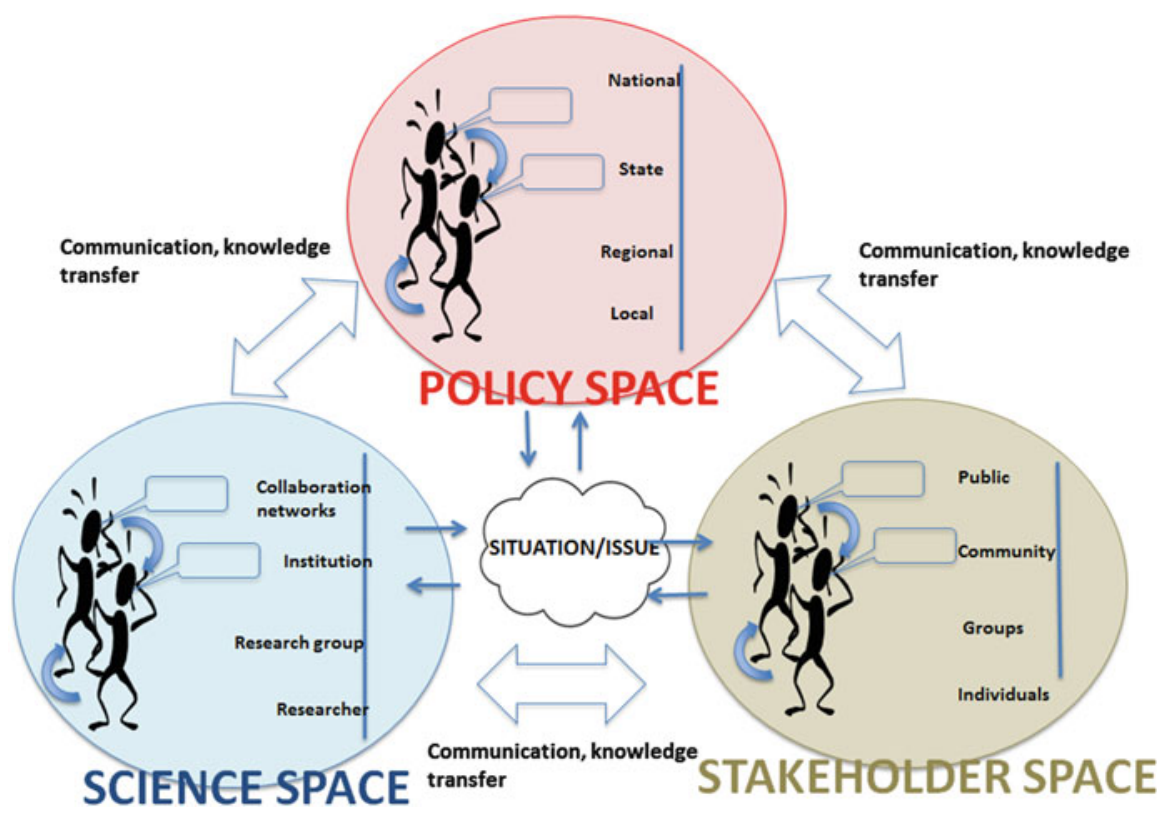

Fig. 24.1 In resource dilemmas, the resource behaviour is driven by the collective outcomes of decisions made by multiple groups at different levels of the governance system

other pressures (e.g. other development activities) leading to cumulative and long term effects at a regional level. Fourth, there is no silver bullet or a final solution for managing wicked problems. Groundwater policies (e.g. allocation plans) need to be continuously monitored and periodically reviewed to cope with emergent changes in the resource conditions and stakeholder values. Finally, we (as scientists, resource users, managers, and policy makers) have limited capacity (e.g. cognitive, social) to understand and manage such complexity and uncertainty. Reynolds (2011) argues that we often fall into three conventional thinking traps that hinder us from appreciating the nature of the situations on hand:

1. Reductionism: our tendency to focus on individual parts and symptoms of a problem, and overlook root causes and interrelationships. For example, traditional groundwater allocation policies are often framed around identifying hydro-geological aquifer limits, and marginalising the cognitive and sociocultural context at which the policy is embedded.

2. Dogmatism: our tendency to take a single perspective on the system, and overlook other viewpoints. This leads to excluding or marginalising policy impacts on particular stakeholder or interest groups.

3. Managerialism: our tendency to overlook the limited capacity of employed interventions (e.g. instruments, measures, methods) in dealing with the sheer uncertainty and complexity of the whole situation. 
The motivation for this chapter stems from two premises. First, the field of systems thinking (especially soft and critical) has the potential to improve our capacity to understand and manage the human (i.e. cognitive, social, cultural, and political) elements in wicked water and groundwater issues. Systems thinking approaches provide a holistic framework (of theories, methods, and tools) that can help unlock key management issues and interrelationships from multiple perspectives. In systems thinking, the key assumption is that bringing together different views may lead to building shared, multi-dimensional, and rich understanding of the situation, which may therefore, lead to developing sustainable (i.e. economically-viable and socially-accepted) policies. This assumption presents an opportunity for groundwater policies that cry out for better and more explicit ways of incorporating and linking the human aspects to the groundwater conditions (Richardson et al. 2011).

The second premise motivating this chapter is the perceived lack of studies that explicitly address the systems applications in sustainability problems (including groundwater). Midgley and Reynolds (2004) argue that for every paper on environment management that is explicit about the use of Operations Research/Systems Thinking (OR/ST) methods, there are "at least" five that use similar OR/ST methods, claiming "methodological innovation" without referencing OR/ST. The ideas are clearly useful. Even for authors who mention a systems approach as a research framework (e.g. Bosch et al. 2007), the discussion is often limited to the conceptual idea of systems thinking without explicitly explaining the in-depth implementation details, and how the work links to existing theories and methodologies. Therefore, we aim to promote use of systems methods in groundwater management explicitly rather than reinventing the wheel, and with rigorous reference to theory rather than referring to vague concepts.

The chapter is structured as follows. First, we trace the evolution of the systems idea through the hard, soft, and critical developments (Sect. 24.3). Next, we discuss two important topics in systems approaches: multi-methods and evaluation (Sect. 24.4). In Sect. 24.5, we complement the theoretical overview with a set of selected case studies to shed some light on different implementations of systems thinking and their relevance to groundwater research and management. Finally, we wrap up by drawing some lessons from systems thinking literature and case studies.

\subsection{The "Systems" Idea}

The systems idea is not new, but can be originally traced back to Aristotle's dictum that "the whole is greater than sum of the parts." The contemporary notion of systems can be found in General Systems Theory (GST) which recognizes the importance of interactions and organization (Von Bertalanffy 1950). Since the formulation of GST, the systems idea has developed in two main directions. The first applied the systems idea in biology and ecology. The second resulted in the development of problem solving methodologies, which have evolved through three 
Table 24.1 Summary of the three waves of development in systems thinking approaches

\begin{tabular}{l|l|l|l}
\hline $\begin{array}{l}\text { Point of } \\
\text { comparison }\end{array}$ & Hard & Soft & Critical \\
\hline System & $\begin{array}{l}\text { A system is a } \\
\text { well-defined } \\
\text { entity that has } \\
\text { clear function }\end{array}$ & $\begin{array}{l}\text { A system is a cognitive and } \\
\text { social construct that is not } \\
\text { independent from the } \\
\text { observer }\end{array}$ & $\begin{array}{l}\text { A system is defined by a } \\
\text { boundary that may be } \\
\text { alienating individuals or a } \\
\text { particular social group }\end{array}$ \\
\hline Purpose & $\begin{array}{l}\text { Predicting, } \\
\text { optimising, and } \\
\text { controlling } \\
\text { outcomes }\end{array}$ & $\begin{array}{l}\text { Develop a meaningful } \\
\text { understanding, learning }\end{array}$ & $\begin{array}{l}\text { Empowering stakeholders } \\
\text { to overcome power } \\
\text { imbalances and social } \\
\text { inequities }\end{array}$ \\
\hline Researcher & $\begin{array}{l}\text { Outside } \\
\text { observer }\end{array}$ & Participant & $\begin{array}{l}\text { Participant, and sometimes, } \\
\text { enabler for change }\end{array}$ \\
\hline Models & $\begin{array}{l}\text { Accurate } \\
\text { representation of } \\
\text { the real world } \\
\text { system }\end{array}$ & $\begin{array}{l}\text { Interpretations or } \\
\text { intellectual construct to } \\
\text { inform debate and learning } \\
\text { about possible changes }\end{array}$ & $\begin{array}{l}\text { Interpretations that are used } \\
\text { to surface and question } \\
\text { assumptions about values, } \\
\text { power, and knowledge } \\
\text { during a public or corporate } \\
\text { dialogue }\end{array}$ \\
\hline
\end{tabular}

waves of thinking: hard, soft, and critical (see Table 24.1). We give an overview of these developments in the following sub-sections.

\subsubsection{Hard Systems Approaches}

During and after World War II, hard systems thinking approaches (optimisation, simulation, systems engineering, systems analysis) appeared as powerful analytical methodologies for solving real world problems. Hard system approaches have been long and widely used to analyse groundwater problems, such as Ayvaz and Elçi (2014). Hard approaches share the following assumptions (Checkland 1981):

- There is a "problem" that can be exhaustively formulated in terms of welldefined objectives and actions that can be optimised or (at least) improved.

- Success in applications depends on quantification of variables and the creation of mathematical formulations that specify the relationships between variables.

- Our knowledge (including models) and language perfectly describe the real world.

- Systems have objective boundaries which are "given" by the structure of reality (Checkland 1983).

- Stakeholders are passive entities who share common views, values and objectives (Rosenhead and Mingers 2001).

- An analyst is an independent observer who perceives the world as a set of interacting components or sub-systems. The analyst's efforts are directed in a systematic search for the most efficient means to achieve objectives. 
In the early 1970s to the mid 1980s, hard systems approaches came under a lot of criticism for their inability to deal with problems that arise in contexts that are highly complex and involve multiple stakeholders (Dando and Bennett 1981). Many authors, such as Churchman (1970a), reject the view that a system has an objective boundary that is independent of human perspectives. System boundaries are social and subjective constructs. Thus, setting a system's boundary is a critical choice about what the study considers to be relevant knowledge and legitimate decision makers. To account for multiple perspectives, the analysis boundary should be pushed out by "sweeping in" divergent views (Churchman 1970b).

\subsubsection{Soft Systems Approaches}

In response to the attack on hard approaches, soft systems thinking appeared as an alternative approach capable of addressing complex and unstructured situations as it places human and social considerations at the core of systems management. The fundamental distinction between hard and soft systems thinking lies in the way they address the philosophical question about the nature of reality and the nature of knowledge (Checkland 1999). In soft systems thinking, the word systemic is no longer applied to the world but to the inquiry process to explore this world. This view implies that systems thinking remains only as a way of describing knowledge about the world rather than an objective reality (Checkland 1983). For more details, we refer the reader to Mingers (2003) who presented and compared the philosophical and methodological assumptions underpinning a multitude of hard and soft systems approaches.

In the soft view, it is necessary to engage in an iterative process of systemic inquiry and learning (which may be ongoing) to develop a meaningful understanding of the situation (Checkland 1985). To build a meaningful understanding, we need to understand the cultural and social aspects of the situation, as well as the purpose, interpretations, and actions of stakeholders. This includes all people who may affect or be affected by the action outcomes, including the researcher(s). The soft approach takes the view that scientists bring their own values and subjective interpretations with the aim of intervening within the system. Intervention is defined as "purposeful action by an agent to make change" (Midgley 2000). Active stakeholder engagement and an active researcher role are common pillars of soft systems and also action research. For a detailed discussion about the links between systems approaches and action research, readers are referred to Flood (2010).

Within the soft systems approach, several methodologies, known as Problem Structuring Methodologies (PSM), have been developed in the literature, including:

- Soft Systems Methodology (SSM) (Checkland 2001)

- Cognitive Mapping (CM) for Strategic Options Development and Analysis (SODA) (Eden and Ackermann 1998)

- Viable System Model (Beer 1989)

- Visioning choice methodology (O’Brien and Meadows 2007) 
Whereas PSMs have different forms, they share four generic phases (Mingers 2000):

1. Appreciation of the situation as perceived by stakeholder groups

2. Analysis of the structure that generates the perceived situation

3. Assessment of ways of changing the situation into more desirable conditions

4. Action to implement change, and achieve desired outcomes.

PSMs use models/modelling in a heuristic fashion, as learning aids or artefacts that help system stakeholders to co-construct a meaningful understanding, but are never taken to represent reality.

\subsubsection{Critical Systems Thinking}

Soft systems thinking and PSMs have been criticized for not being able to address the question of power relations, how they influence the problem situation, and how they are perceived by system actors. This has resulted in a third wave of systems approaches: Critical Systems Thinking (CST) (Ulrich 2000; Jackson 2006). CST rests on the key notion of "boundary judgment", and how it determines how people perceive and judge a particular situation (in relation to what is and what ought to be the case) (Midgley 2000). Setting a system boundary is a critical choice about what the study considers to be relevant knowledge and legitimate decision makers. Ulrich (1994) argues that exploring boundaries through dialogue among stakeholders make the analysis more "rational" and robust than an external group of experts (e.g. scientist and policy makers) imposing their own values. Midgley (2000) argues that boundary setting is deeply underpinned by a value judgment; and conflict arises when two or more value/ethical systems come into tension. Boundary selection therefore has ethical implications (Midgley 1992). People draw a boundary around issues they perceive as sacred or central. Issues outside their boundary are regarded as subsidiary, which marginalises people that hold that view. From this perspective, CST aims to explore and make explicit different boundary judgments, and help justify why a particular boundary judgment is selected. It proposes a dialogical framework to allow for collective reflection to acknowledge and negotiate sources of motivation, power, knowledge and legitimation.

Inspired by the critical systems idea, several methodologies have been developed in the literature including:

- Critical systems heuristics (CSH, (Ulrich 1994))

- System of systems methodologies (Jackson 1999)

- Systemic intervention (Midgley 2000) 


\subsection{Multi-Method and Evaluation in Systems Approaches}

The design and implementation of systems thinking interventions depends on choosing effective methods and allowing for an adaptive process. In this section, we discuss two key topics to achieve this aim: use of a multi-method approach and evaluating systemic interventions.

\subsubsection{Use of a Multi-Method Approach}

The debate about the three waves of systems thinking has moved away from arguing the strength of each wave to recognizing that the three waves take different, but not incompatible, perspectives on the world. This view has resulted in the rise of multi-method/multi-methodology as a framework to accommodate different views of systems (Mingers and Leroy 2010). In the context of this chapter, we will use the term multi-method to denote the broad idea of combining methodologies and/or methods (i.e. hard, soft, and critical) within a real-world intervention (Mingers 2000). Multi-method is increasingly regarded as an essential framework for dealing with wicked and turbulent environments (Mingers 1997).

Wicked problems have multiple dimensions: physical or material, personal and social dimensions. Multi-method strengthens the inquiry process and provides multiple lenses for exploring different aspects of multi-dimensional situations. Whereas the intervention process passes through a number of phases, some methods however can be more useful than others for different phases. Pulling the two ideas together, Mingers and Brocklesby (1997) developed a framework to map out how systems methods can be used to examine the problem dimensions across the different intervention phases. Several research directions have stemmed from the multi-method idea, such as: "coherent pluralism" (Jackson 1999), "pragmatic pluralism" (White and Taket 1997), and "creative design of methods" (Midgley 1990). Whereas these approaches share the idea of using multi-method, they have different view about how methods are selected and employed. Kotiadis and Mingers (2006) identified two strands in multi-method research: (1) those who think that methods and methodologies can be effectively mixed-and-matched to strengthen the inquiry (sometimes referred to as pragmatists); and (2) others who are concerned about the incommensurability of paradigms, and accept multimethod legitimacy only under the condition that it respects the theoretical underpinning of the process used to combine methods. For an overview about the evolution of multi-method theory, readers are referred to Zhu (2011). In practice, there have been different forms of applying multi-methods, such as using methods in parallel (e.g. use of two problem structuring methods at the same time to inform each other) or in series (e.g. use of outputs from problem structuring to inform the design of a numerical model). 


\subsubsection{Evaluating Systemic Interventions}

The topic of evaluating systemic methods has gained increasing attention in the literature (Midgley et al. 2013). A similar trend is observed in environmental studies (e.g. Matthews et al. 2011; Bellamy et al. 2001). Several reviews on systemic research have concluded that although projects claim to have achieved some kind of value, the evidence is merely based on the author's own reflection with minimal formal evaluation (Midgley 2007). Howick and Ackermann (2011) conducted a comprehensive review of multi-method systems applications, and concluded there is often a limited link between a project's rationale, process, and actual outcomes.

Similar to the debate about hard and soft system approaches, there exist two main positions for evaluating systemic interventions (White 2006): Positivist and interpretive positions. Positivist evaluation aims to collect objective data about the efficiency and effectiveness of the methods in practice. This can lead to "universal" evaluations that may applicable across multiple interventions (Rowe and Frewer 2004). On the other side, an interpretive evaluation approach argues that objective evaluation has limited practicality and relevance to gaining insights into worldviews and interpretations. Instead, it frames evaluation as a continual learning process about the methods and how they have been applied in reality (i.e. what worked, what did not work, why). Along the same lines, Checkland and Holwell (1998) argue that recoverability rather than repeatability (of process and results) is to be used as the criterion for evaluating systemic research. For 'recoverability' to be achieved, the whole research activity or intervention, including the methodology to be employed must be made explicit for an outsider.

Recent developments have argued that there is a need for new evaluation theories or frameworks that combine both positivist and interpretive positions into the systemic intervention, such as (Midgley 2007). Towards this goal, a few evaluation frameworks have been developed, such as White's pragmatic theorybased framework (White 2006). Whereas systemic evaluation frameworks have different forms, they can share some common ideas or principles:

- The need to focus on the purpose of the evaluation and how it is meaningful and relevant to the intervention's purpose and participants' worldviews

- The researcher has to be pragmatic about what they can and cannot measure in complex, contested and resource-limited contexts

- Both quantitative information and qualitative insights are essential and complementary means of establishing evidence

- Use of established theories (e.g. a behavioural theory) to support the design of evaluation and/or explain results add rigor and enrich findings

- The evaluative inquiry itself is a systemic and learning process that involves multiple perspectives (e.g. who and what determines successful outcomes). The process needs to involve continuous exploration of the: purpose, context, and methods and how they link together. 


\subsection{Systems Approaches in Practice and Learning Lessons}

So far, we have given a theoretical overview of systems approaches. Now, we complement the picture by giving the reader a feel for applications of systems approaches in natural resource management in general because of the very lack of groundwater-specific studies. Paucar-Caceres and Espinosa (2011) surveyed systems applications in environment and sustainability areas published in leading OR/MS journals, and concluded that the majority of applications belong to the hard view, with very few soft and critical approaches.

In this section, we present a selection of case studies. We aim to shed some light on elements in the context of each case study (i.e. purpose and methods) that can be relevant in groundwater systems. We hope that this may encourage the reader to think whether and how they can make use of the systems approach in their groundwater applications. We selected case studies to represent different forms and purposes of systems methodologies (See Table 24.2) where:

- Form: single and multi-method interventions where multi-method cases present different combinations of methods (hard, soft, and critical)

- Purpose: intervention's aim is to develop an end-product (e.g. decision support tool), or a process (e.g. a medium for learning and exchanging views)

\subsubsection{Support Community Engagement in Water Conservation Policies in New Zealand (Foote et al. 2006)}

\subsubsection{Context, Purpose, and Design}

The study takes place in a water-stressed town in New Zealand where water security stands as a contentious issue between government agencies and the local community as a result of the failure of successive policies to provide a satisfactory solution to ongoing water shortages. The study starts with the premise that effective implementation of water conservation policies depends on the collaboration of all stakeholders and interest groups. The purpose of the study is to provide a legitimate participatory process for engaging stakeholder groups in evaluating water conservation policies employed. Legitimacy is sought by involving independent third party scientists who are trusted to bring different views to the negotiation table.

Table 24.2 Summary of case studies reviewed as part of this chapter

\begin{tabular}{l|l|l|l|l}
\hline & & & $\begin{array}{l}\text { (Powell and } \\
\text { Osbeck } \\
2010)\end{array}$ & $\begin{array}{l}\text { (Larsen } \\
2011)\end{array}$ \\
\hline Form & $\begin{array}{l}\text { (Foote et al. 2006) } \\
\text { Multi-method } \\
\text { boundary critique } \\
\text { +rich picture) }\end{array}$ & $\begin{array}{l}\text { Multi-method (system } \\
\text { dynamics + cognitive } \\
\text { mapping) }\end{array}$ & $\begin{array}{l}\text { Soft systems } \\
\text { methodology }\end{array}$ & $\begin{array}{l}\text { Critical } \\
\text { systems } \\
\text { heuristics }\end{array}$ \\
\hline Purpose & Process-driven & Product-driven & $\begin{array}{l}\text { Product- } \\
\text { driven }\end{array}$ & $\begin{array}{l}\text { Process- } \\
\text { driven }\end{array}$ \\
\hline
\end{tabular}


In response to the perceived tension, authors foresee the potential of using a boundary critique (Midgley 2000) method to: (1) make the problem definition explicit from a variety of viewpoints; (2) identify areas of agreement, disagreement, marginalisation, and sources of conflicts among stakeholder groups; and (3) guide how problem structuring methods are selected, used and mixed in the case study, and identify implications for inclusion, exclusion, and marginalisation of issues and stakeholders. Authors used interviews, rich pictures and scenario planning workshops to identify and share a multi-perspective evaluation of water policies. Results from using boundary critique show that the conflict about the effectiveness of water conservation measures is rooted in the tension between the pro-development and anti-development values of citizens, and that the debates about water policies cannot be "decoupled" from the "wider debate on the desirability of economic development."

Later in the process, authors reported facing an "ethical dilemma" about the credibility of their research given the decision of policy officers to overlook issues raised by the community (i.e. economic development impacts on water security), and their unwillingness to discuss all the information identified through the engagement process. However, authors decided to think strategically by keeping the process alive, building strategic relationships with key parties, and exploring potential opportunities to establish more open dialogue in the future.

\subsubsection{Evaluation}

Reflecting on the methods used, authors noted that systemic intervention can establish a "sound process" of stakeholder engagement, but it does not necessarily guarantee "win-win outcomes for all." They found that boundary critique provides a useful way for exploring values and boundaries. However, results should not be taken for granted in that there are limits to the method's capacity to elicit values and boundaries.

Whereas the paper is transparent about the methods used, it does not justify how the boundary critique method informed the choice to use rich pictures as problem structuring, although the justification of how methods were selected was as an explicit objective at the outset.

Reflecting on the process outcomes, authors perceived the project as a success because it improved understanding and dialogue as expressed by participating groups. Quotes are used to establish evidence, for example: "The decision-making tools...have allowed a wide range of stakeholders to be actively involved in the decision-making process. The methods employed have provided a non-threatening environment for stakeholders to express their views and this participation has led to general acceptance of the consultation outcomes." In addition, the evidence that the client invited the authors to do more work in the area supported the project's success.

\subsubsection{Relevance to Groundwater Research and Management}

This work has a strong relevance for community engagement in groundwater planning. For example, the concept of acceptable or sustainable aquifer yield is 
underpinned by a judgment about the spatial boundaries (e.g. geographic area, aquifer), temporal boundaries (e.g. planning cycle), administrative and institutional boundaries (e.g. government levels), value boundaries (e.g. social, economic, and environmental groups), and knowledge boundaries (e.g. scientific vs. local). Who makes these judgments? How are these judgments made? Are judgments and their implications transparent to all stakeholders or hidden and scattered across the governance system? In a sound and legitimate planning process, these questions need to be identified and negotiated among stakeholder and interest groups. Boundary critique can be a useful method to facilitate these discussions.

\subsubsection{Communicating About Water Security Issues in the Australian Capital Territory (EISawah 2010)}

\subsubsection{Context, Purpose, and Design}

The study is based on three premises: (1) people have over-simplified mental models about the causal interactions that drive the behaviour of a water resource; (2) flawed and inaccurate mental models may lead to less informed decisions and attitudes towards water management policies and conservation measures; and (3) the design of effective communication tools needs to be based on sound understanding of such mental models, and best ways to improve them. The purpose of this work was to develop an interactive dynamic simulator that could be used to inform and improve the mental models that water users and managers have about the complexity and uncertainty surrounding the future of water security in the Australian Capital Territory. A cognitive mapping method was used to elicit, analyse, and visualise the mental models of water users and managers, specifically in relation to misperceptions and erroneous assumptions, sources of conflicts and communication gaps.

Although managers frequently point out the need to "get the community on board" and for two-way communication, they were reluctant to engage in open discussion groups, indicating that to do so would be overly confronting and excessively time consuming. Yet, they welcome the use of a model as an online educational tool to improve public understanding about the complexities of water management. Given that the primary purpose of the project was developing a modelling tool, the author had to find other data collection and validation methods (e.g. interviews and electronic data sharing methods) to share results and gain feedback. Based on these data, a series of conceptual and numerical system dynamics models were used to develop an interactive simulator that can be used to check the dynamic coherence of elicited mental models and views. A transparent flow of information from cognitive mapping, to conceptual, and then numerical system dynamics models helps users relate their thinking to the end product, and makes the modeller be explicit about the modelling assumptions. 


\subsubsection{Evaluation}

The author uses both self-reflection and pilot experiments to evaluate the modelling process (e.g. transparency, relevance) and its outcomes (e.g. improving the mental models that water users and managers have before and after interacting with the simulator). The author reported that the process allowed for identifying the different perspectives and mental model without prior assumptions. However, the process was limited to only two stakeholder groups, and did not address any of the power relationships in the system and how they may affect policy making. The use of rigorous experiments to evaluate the learning outcomes gives an understanding of what particular perceptions the model can influence.

\subsubsection{Relevance to Groundwater Research and Management}

This work has two key implications for communication and modelling in groundwater management systems. First, the invisible nature of groundwater resources compounded by lack of scientific understanding about the system breeds misconceptions among lay people about the resource's nature, and how it changes (e.g. the myth of underground rivers). Grounded on cognitive psychology, cognitive mapping enables in-depth understanding of these mental models and their implications for attitudes and behaviours.

Secondly, from a modelling viewpoint, modellers often select the boundary of the system to be modelled (what to model) through "ignorance and/or politics" (Eden 1994). The ignorance option is the default for most modellers who decide to ignore the problem complexity and model what they think important to model. Or alternatively, modellers may choose what to model based on how individuals or groups in power (e.g. experts, policy makers and scientists) define the problem. As an alternative, cognitive mapping provides a cognitive approach for modelling where the modeller starts the modelling process by seeking the idiosyncratic views of problem owners. The decision of "what to model" naturally flows from the way problem owners think about the problem. The modelling progression provides better ways of incorporating stakeholder's views and mental models into models.

\subsubsection{Stakeholder Realities in Mangrove Rehabilitation Processes in Southeast Asia (Powell and Osbeck 2010)}

\subsubsection{Context, Purpose, and Design}

The project starts with the premise that "underlying problem definition" significantly affects the design of initiatives to rehabilitate the mangrove forests in East Kalimantan, Indonesian Borneo. Soft systems methodology is used to support the critique of the rehabilitation planning process from the perspective of different stakeholders in the system. 


\subsubsection{Evaluation}

The authors did not reflect thoroughly on the choice and use of their method, but the general impression is that the method was successful in eliciting multiple perspectives and understanding the differences between them.

\subsubsection{Relevance to Groundwater Research and Management}

Groundwater planning is often evaluated from a policy compliance perspective, judging its success from a policy maker's viewpoint. The use of SSM may provide multiple lenses for incorporating other views, especially of those who will implement and be affected by the policy. Some of the differences in viewpoint in this mangrove rehabilitation case transfer to a groundwater management context. There is conflict in objectives between scales, particularly national, state, district and individual, and between groups. Each group adjusts their behaviour to cope with this conflict, leading to unintended consequences and failure to meet objectives. This paper concludes: "The owners' worldview has been shaped by the widely accepted regional assumption that there are strong linkages between the ecological services provided through the rehabilitation of mangroves and the livelihoods of local coastal communities contrary to the assumption, the implementation of this worldview has led to a transformation that neither promotes the cause of conservation nor contributes to sustainable livelihoods of local community. Rather, the beneficiaries have been a private elite. The victims have been the most marginalized in the community and ultimately the ecosystem in which these processes are nested." The distributed nature of groundwater pumping and use can lead to similar self-organising behaviour at multiple scales. Understanding the points of view of different groups can help the plan to avoid such failures.

\subsubsection{Facilitate Stakeholder Dialogue About Coastal Conservation Policies in the Philippines (Larsen 2011)}

\subsubsection{Context, Purpose, and Design}

The study takes place in the northern Philippines where there are growing concerns about overfishing, a declining fisheries industry, low community engagement in integrated coastal management, and hidden agendas overshadowing coastal planning. Within the context of existing involvement in stakeholders in planning, the study aims to facilitate dialogue as a process of social learning, to allow sharing of multiple perspectives on defining the problem and its solutions. The ultimate social learning aim is to enable "stakeholder self-organization." The researcher planned to use Critical Systems Heuristics (CSH, (Ulrich 1994)) to facilitate boundary critique and "provide a 'liberating language' for citizens." However, "participants commented about the rigidity [of $\mathrm{CSH}$ ] and felt constrained by [its] structure". The author decided to use CSH in an exploratory sense with some communicative tools, such as Venn diagrams and mind mapping. 


\subsubsection{Evaluation}

The researcher reflected on the process and concluded that the success of any method is highly dependent on context and implementation. The process was modified as it progressed based on feedback from participants. Underlying boundary problems were identified. However, the paper does not say how the process ended.

The research is built on solid theory, states a clear goal to be evaluated and maintains a reflective approach to both. While we do not know the end outcome, this is a good representation of a well-performed system intervention

\subsubsection{Relevance to Groundwater Research and Management}

Fisheries and groundwater resources are both shared resources, resulting in similar problems of degradation of the resource in a 'tragedy of the commons' when individuals do not have strong feedback on the effect of their actions on the resource. In both fisheries and groundwater management, this has commonly been dealt with through "command-and-control management," where individual actions are regulated by law. Opposition to this arrangement has led to "a shift towards increased stakeholder participation." However, these altered arrangements have their own weaknesses. This paper's attempt to support "social learning for self-organisation" can therefore also be useful in groundwater management, to establish new relationships or restructure existing ones to allow people affected by resource degradation or resource management to participate. The paper supports the claim that tools that help stakeholders participate in management must be used within a broader systems approach, allowing the process to evolve as new information is gained. Addressing the complexity of the human dimension cannot be a simple recipe, "a continuous reconstruction of the process and its assumptions was necessary."

\subsection{Lessons Learnt}

In this section, we share some of the lessons for applying systems thinking interventions, which are manifested in the presented case studies.

First, no single discipline can provide all the answers to addressing human aspects of groundwater management. In particular, systems practitioners and researchers should not think or present their methodologies as being the "most effective", or most comprehensive, pluralistic or holistic (otherwise, they would have fallen into the managerialism thinking trap themselves!). Instead, researchers should have a reflective spirit where they fully understand the strengths and limitations of different methods, and communicate openly about implications for the process and its outcomes.

Second, the effectiveness of a method is strongly dependent on purpose, context and implementation. Whereas most (if not all) systems interventions end up developing both processes and products, it is essential for the researcher to have a clear 
understanding of the primary focus of the intervention (i.e. process-driven or product-driven). This influences process design, including: choices of methods, ways to mix them, evaluation design, as well as strategies to cope with gatekeepers and lack of information.

Third, existing literature on the theory and practice of systems approaches provide rich guidance on how to select, design and implement methods. While practitioners and researchers need to be aware and be explicit about their research's theoretical and methodological stance, they still need to be creative about how they adapt and localise the approach for their case study requirements and constraints.

Finally, incorporating human elements into analysis brings up challenges that often need to be overcome by modifying the existing approach. For example, there may be times where stakeholder groups (as individuals or groups) will act as gatekeepers and try to influence or even block the process and its potential outcomes. It is essential for researchers undertaking this type of research to identify those gatekeepers and develop techniques to work around challenges, such as by looking for other information sources, building trust with key parties, and instituting flexible arrangements to accommodate concerns.

\subsection{Conclusions}

Groundwater management issues present a serious challenge partly because of the complexity and uncertainty that human elements (i.e. cognitive, social, cultural and political) bring into the problem, as well as our limited capacity to fully comprehend and deal with such elements and their interactions with the biophysical systems. Whereas there is a wide recognition of the importance of stakeholder participation for the design and implementation of effective policies, the ongoing depletion of groundwater and disputes surrounding management policies suggest the need for better participatory mechanisms. This raises the question of how human elements can be incorporated into groundwater policies. Whereas there is no single discipline that can provide answers for such crucial research and policy questions, this chapter argues that systems thinking (especially soft and critical approaches) has the potential to provide a framework of theories, methods and example applications to help incorporate human elements into groundwater management and research. This chapter aims to give an overview of systems thinking by firstly describing the theory, distinguishing between hard, soft and critical systems thinking approaches. Secondly, we discussed the importance of mixing methods from these approaches and evaluating 'process' and 'outcomes' when applying them. Thirdly, we reviewed four example applications, and highlighted their relevance to groundwater management systems. Together, these three elements indicate how the framework of systems thinking can help with a number of issues that manifest themselves in groundwater management and research, including: understanding and learning to account for different points of view in planning; understanding how groups affected by a change might respond; helping to enhance 
participants' view of the problem; exploring conflict; and critiquing existing management and groundwater use arrangements with a view to improving them.

Open Access This chapter is distributed under the terms of the Creative Commons AttributionNoncommercial 2.5 License (http://creativecommons.org/licenses/by-nc/2.5/) which permits any noncommercial use, distribution, and reproduction in any medium, provided the original author(s) and source are credited.

The images or other third party material in this chapter are included in the work's Creative Commons license, unless indicated otherwise in the credit line; if such material is not included in the work's Creative Commons license and the respective action is not permitted by statutory regulation, users will need to obtain permission from the license holder to duplicate, adapt or reproduce the material.

\section{References}

Ackoff R (1974) Redesigning the future: a systems approach to societal problems. Wiley, New York

Ayvaz MT, Elçi A (2014) Groundwater recharge rate and zone structure estimation using PSOLVER algorithm. Ground Water 52(3):434-447

Beer S (1989) Viable system model. Wiley, Chicester

Bellamy JA, Walker DH, Mcdonald GT et al (2001) A systems approach to the evaluation of natural resource management initiatives. J Environ Manage 63:407-423

Bosch OJH, King CA, Herbohn JL et al (2007) Getting the big picture in natural resource management-systems thinking as 'method' for scientists, policy makers and other stakeholders. Syst Res Behav Sci 24:217-232

Checkland P (1981) Systems thinking, systems practice. Wiley, Chichester

Checkland P (1983) O.R. and the systems movement: mappings and conflicts. J Oper Res Soc 34:661-675

Checkland P (1985) From optimizing to learning: a development of systems thinking for the 1990s. J Oper Res Soc 36:757-767

Checkland P (1999) Soft systems methodology in action. Wiley, New York

Checkland P (2001) Soft systems methodology. In: Rosenhead J, Mingers J (eds) Rational analysis for a problematic world. Wiley, Chichester, pp 61-89

Checkland P, Holwell S (1998) Action research: its nature and validity. Syst Pract Action Res 11:9-21

Churchman CW (1970a) The design of inquiring systems. Basic Books, New York

Churchman CW (1970b) Operations research as a profession. Manag Sci 17:B37-B53

Dando M, Bennett P (1981) A Kuhnian crisis in management science? J Oper Res Soc 32:91-103

Eden C (1994) Cognitive mapping and problem structuring for system dynamics model building. Syst Dyn Rev 10:257-276

Eden C, Ackermann F (1998) Making strategy: the JOURNEY of strategic management. Sage Publications, London

ElSawah S (2010) The use of integrated modelling for learning and communicating about water issues in the Australian Capital Territory. University of New South Wales, Canberra

Flood RL (2010) The relationship of 'systems thinking' to action research. Syst Pract Action Res 23:269-284

Foote JL, Gregor JE, Hepi MC et al (2006) Systemic problem structuring applied to community involvement in water conservation. J Oper Res Soc 58:645-654

Howick S, Ackermann F (2011) Mixing OR methods in practice: past, present and future directions. Eur J Oper Res 215:503-511 
Ison R, Röling N, Watson D (2007) Challenges to science and society in the sustainable management and use of water: investigating the role of social learning. Environ Sci Pol 10:499-511

Jackson MC (1999) Towards coherent pluralism in management science. J Oper Res Soc 50:12-22

Jackson MC (2006) Creative holism: a critical systems approach to complex problem situations. Syst Res Behav Sci 23:647-657

Kotiadis K, Mingers J (2006) Combining PSMs with hard OR methods: the philosophical and practical challenges. J Oper Res Soc 57:856-867

Larsen R (2011) Critical systems thinking for the facilitation of conservation planning in Philippine coastal management. Syst Res Behav Sci 28:63-76

Mason R, Mitroff I (1981) Challenging strategic planning assumptions: theory, cases and techniques. Wiley, New York

Matthews KB, Rivington M, Blackstock K et al (2011) Raising the bar?-The challenges of evaluating the outcomes of environmental modelling and software. Environ Model Software 26:247-257

Midgley G (1990) Creative methodology design. Systemist 12:108-113

Midgley G (1992) Pluralism and the legitimation of systems science. Syst Pract Action Res 5:147-172

Midgley G (2000) Systemic intervention: philosophy, methodology, and practice. Springer, New York

Midgley G (2007) Towards a new framework for evaluating systemic and participative methods. In: 51st annual meeting of the ISSS pp 1-21

Midgley G, Reynolds M (2004) Systems/operational research and sustainable development: towards a new agenda. Sustain Dev p 57

Midgley G, Cavana RY, Brocklesby J et al (2013) Towards a new framework for evaluating systemic problem structuring methods. Eur J Oper Res 229:143-154

Mingers J (1997) Multi-paradgim multimethodology. In: Mingers J, Gill A (eds) Multimethodology. Wiley, Chichester, New York, pp 1-20

Mingers J (2000) Variety is the spice of life: combining soft and hard OR/MS methods. Int Trans Oper Res 7:673-691

Mingers J (2003) A classification of the philosophical assumptions of management science methods. J Oper Res Soc 54:559-570

Mingers J, Brocklesby J (1997) Multimethodology: towards a framework for mixing methodologies. Omega 25:489-509

Mingers J, Leroy W (2010) A review of the recent contribution of systems thinking to operational research and management science. Eur J Oper Res 207:1147-1161

O'brien F, Meadows M (2007) Developing a visioning methodology: visioning choices for the future of operational research. J Oper Res Soc 58:557-575

Paucar-Caceres A, Espinosa A (2011) Management science methodologies in environmental management and sustainability: discourses and applications. J Oper Res Soc 62:1601-1620

Powell N, Osbeck M (2010) Approaches for understanding and embedding stakeholder realities in mangrove rehabilitation processes in Southeast Asia: lessons learnt from Mahakam Delta, East Kalimantan. Sustain Dev 18:260-270

Reynolds M (2011) Bells that still can ring: systems thinking in practice. In: Tait A, Richardson K (eds) 1st international workshop on complex systems thinking and real world applications. Emergent Publications, Litchfield Park, pp 327-349

Richardson S, Evans R, Harrington G (2011) Connecting science and engagement: setting groundwater extraction limits using a stakeholder-led decision-making process. In: Connell D, Grafton RQ (eds) Basin futures water reform in the Murray-Darling Basin. ANU, Canberra

Rittel H (1972) On the planning crisis: systems analysis of the 'first and second generations'. Bedrifts Okonomen 8:390-396

Rosenhead J, Mingers J (2001) A new paradigm of analysis. In: Rosenhead J, Mingers J (eds) Rational analysis for a problematic world. Wiley, Chichester, pp 1-19 
Rowe G, Frewer L (2004) Evaluating public participation exercises: a research agenda. Sci Technol Hum Values 29:512-556

Ulrich W (1994) Critical heuristics of social planning: a new approach to practical philosophy. Wiley, Chichester

Ulrich W (2000) Reflective practice in the civil society: the contribution of critically systemic thinking. Reflect Pract 1:247-268

Von Bertalanffy L (1950) An outline of general system theory. Br J Philos Sci 1:134-165

White L (2006) Evaluating problem-structuring methods: developing an approach to show the value and effectiveness of PSMs. J Oper Res Soc 57:842-855

White L, Taket A (1997) Critiquing multimethodology as metamethodology: working towards pragmatic pluralism. In: Mingers J, Gill A (eds) Multimethodology: the theory and practice of combining management science methodologies. Wiley, Chichester, pp 379-405

Zhu Z (2011) After paradim: why mixing-methodology theorising fails and how to make it work again. J Oper Res Soc 62(4):784-798 


\title{
Decision Support Systems and Processes for Groundwater
}

\author{
Suzanne A. Pierce, John M. Sharp Jr, and David J. Eaton
}

\begin{abstract}
Information and knowledge management challenges abound in groundwater sciences. Groundwater problems of interest to society are characteristically complex and exceed our ability to solve them without the aid of computational analysis. Yet discipline specific problems that are of interest to hydrogeologists frequently do not directly address the immediate decision making needs of policy makers, groundwater managers, and stakeholders. It is the immediate societal needs that drive the demand for science-based information for common problems in which groundwater figures as a prominent element. Integrated Assessment and Modeling (IAM) presents an approach for merging discipline and case-specific knowledge, such as those in hydrogeological sciences, with social drivers for use in decision support applications. Moreover, decision support systems (DSS) that are constructed and applied using integration as a guiding principle and design ethic can advance groundwater DSS beyond passive support toward active and, eventually, proactive support for implementations to achieve real world integrated groundwater management.
\end{abstract}

S.A. Pierce $(\bowtie)$

Texas Advanced Computing Center, The University of Texas, Austin, Texas, USA

e-mail: sawpierce@gmail.com

J.M. Sharp Jr

Jackson School of Geosciences, The University of Texas, Austin, TX, USA

D.J. Eaton

Johnson School of Public Affairs, The University of Texas, Austin, TX, USA

(C) The Author(s) 2016

A.J. Jakeman et al. (eds.), Integrated Groundwater Management,

DOI 10.1007/978-3-319-23576-9_25 


\subsection{Introduction}

Groundwater is a critical water resource that must be managed effectively while meeting the demands of society. The behavior and response of groundwater systems to natural and human influences are best understood through scientific analyses using data and models. In groundwater resource management, as with all water resources, disputes can be compounded by misconceptions about the meaning of data and scientific models, as well as social and political misunderstandings among the various interests. The complexity of groundwater management creates the need for computational assistance to support reasoned consideration of available scientific knowledge in conjunction with the preferences of the resource users.

Decision support systems (DSS) are computational systems that use data and models interactively to aid in the formulation, analysis, and selection of management strategies. The design, architecture, and implementation of DSS are extensive, highly variable, and, ultimately driven by the needs of the decision problem and instance that is under evaluation. At the simplest levels, DSS may provide repositories of data and information in accessible formats and could offer tools to search and discover repository content. At the other end of the spectrum, DSS may incorporate sophisticated simulations, link with optimization algorithms, or other intelligent systems components to enhance decision making. Regardless of the level of sophistication, DSS are well suited for application to integrated groundwater problems because they can provide a set of applications, methodologies, and tools to cope with the inherent complexity and uncertainty. They can also be part of an Integrated Assessment and Modelling (IAM) process (Jakeman and Letcher 2003) providing distinct advantages for facilitating the IAM process, its transparency and its legacy. Indeed if constructed appropriately, DSS can provide ways of exploring and explaining tradeoffs, provide a tool for adoption and adaptation, create a repository to document the project methods, archive a library of integrated data sets, models, methods, visualization and other tools, a focus for integration across researchers and stakeholders, and act as a training and education tool (Jakeman and Letcher 2003). While the use of DSS for groundwater problems poses potential for improved outcomes, in practice DSS technologies are rarely implemented.

Conceptually, the use and adoption of DSS for groundwater is straightforward. Yet the adoption of DSS may be limited due to scientific, social and technical challenges (McIntosh et al. 2011). Groundwater decision support combines collections of scientific data and models that are inherently uncertain, so that drawing robust recommendations for policy or management is difficult. The creation of DSS is also a multi-disciplinary process that engages subject matter expertise with stakeholder interests across a wide range of sectors in society. Framing DSS applications so that the inputs and outputs are relevant for multiple perspectives is an added hurdle between theory and practice. While the level of effort for developing hybridized computer architectures for DSS is decreasing, the length of time, costs, and computational intensity remain barriers to regular use for groundwater.

This chapter evaluates the state of DSS applications that incorporate groundwater modules with the aim of informing researchers and practitioners interested in designing, developing, and deploying DSS for use in integrated groundwater management. 


\subsection{Decision Support Systems in Relation to Groundwater}

Population is increasing around the globe with over 9.5 billion individuals projected by 2050 (United Nations 2010). The concomitant water resource demands for these 9.5 billion water users are expected to lead to disputes over the finite global water supply. To address future water demands, groundwater science needs to provide adequate characterization of the physical systems to assure that policy limits, and management strategies for water allocation are feasible. Simultaneously, scientists and managers need to incorporate the concerns and priorities as defined by stakeholders and the policy context for any aquifer early in design and assessment of options. In effect, knowledge related to both aquifer performance and groundwater governance needs to be explicitly provided in usable formats, such as DSS, in order to achieve integrated groundwater management (Pierce et al. 2013).

Integrated methods that incorporate considerations beyond hydrogeologic analyses using a strict disciplinary focus can be employed to assess the factors of aquifer management or policy defined by both science and consensus conditions (Pierce et al. 2013). The continuum view of aquifer yields (Pierce et al. 2013) fits within an integrated water resources management approach to groundwater science and lends itself to decision support applications. It also requires an adjustment to the underlying framework hydrogeologists use to describe and categorize types of yields. Every DSS is built using datasets and models that represent the problem domain and key elements of interest to decision makers and stakeholders. Building on the concept of interrelated knowledge processes, Fig. 25.1 highlights the relationship between decision

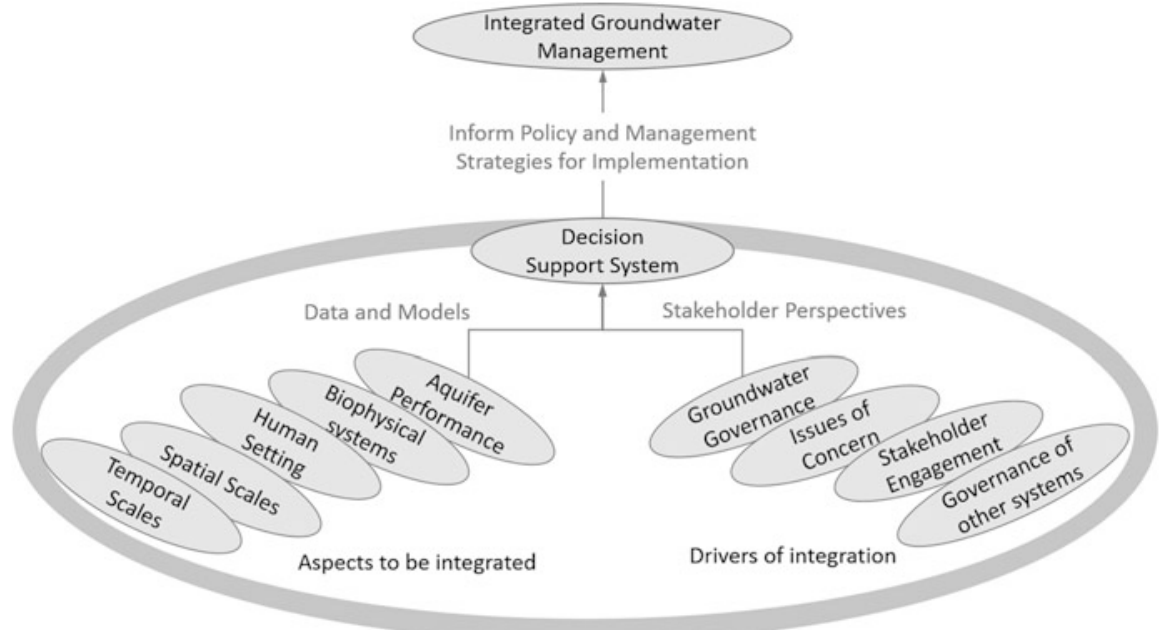

Dimensions of Integrated Assessment and Modelling

Fig. 25.1 The conceptual relationship between decision support, aquifer performance, and groundwater governance in integrated groundwater management (Modified from Hamilton et al. 2015; Pierce et al. 2013) 
support and the knowledge processes of aquifer performance and groundwater governance. It depicts an expanded scope of DSS for applications in integrated groundwater management by combining framing elements from hydrogeological sciences and an aquifer continuum approach (Pierce et al. 2013) and the primary dimensions of IAM (Chap. 1 and Hamilton et al. 2015).

Beyond the content, disciplinary expertise and relationship among the interacting parts of a DSS process, the type of support can vary from informative to normative. The targeted approach distinguishes between providing access to explanatory or analytical information about a decision problem (informative) versus approaches that provides guidance on candidate solutions (normative). This distinction is a factor in determining the selection, incorporation, and interaction with the scientific information and knowledge that becomes part of the DSS build for each application.

\subsubsection{Aquifer Performance}

Science-based decision making depends upon an acceptable understanding of groundwater systems. Hydrogeology describes aquifers and groundwater flow principally through the use of data and models. Aquifer performance factors reflect physical processes commonly assessed through geological observations, and field measurements of flow conditions that are encoded and integrated into simulation models by subject matter experts (Pierce et al. 2013). Groundwater science has made significant strides towards measuring, describing and quantifying the nature of aquifer behavior. Some traditional hydrogeological methods for measuring or estimating groundwater parameters (see also Chap. 3) include water budgeting, numerical modeling, optimization, simulation, chemical tracing, chemical mixing models, flow-net construction, pump testing, slug testing, and geophysical methods (Weight and Sonderegger 2001).

Field observations and the principles of flow that are used to evaluate groundwater response also provide a set of natural attributes that are common to hydrogeologic problems. Hydrogeologic attributes (shown in Table 25.1, Sect. 25.3.1 of this chapter) are the most basic unit of information for describing groundwater systems. As such, hydrogeologic attributes form the cornerstone elements in an ontology for groundwater decision support. Ontologies are formal representations of knowledge. The set of vocabulary, concepts, and the relationships between them are defined within a domain. In this case, the hydrogeology domain has established a set of information within an ontology to describe how groundwater systems function. A first step towards designing, developing, and using hydrogeological information to support decisions depends on identifying what kind of information and knowledge is necessary to describe the problem adequately. Physical system attributes for groundwater are the first necessary elements. A secondary set of necessary elements includes the considerations related to stakeholder concerns and revolves around the topic of groundwater governance. 
Table 25.1 Natural attributes for a hydrogeologic system ${ }^{\mathrm{a}}$

\begin{tabular}{|c|c|c|c|c|}
\hline $\begin{array}{l}\text { State } \\
\text { conditions }\end{array}$ & Inflows & Storage & Outflows & $\begin{array}{l}\text { Model } \\
\text { considerations }\end{array}$ \\
\hline $\begin{array}{l}\text { Aquifer } \\
\text { type }^{b} \\
\text { (m) }\end{array}$ & $\begin{array}{l}\text { Natural recharge } \\
\text { spatial } \\
\text { component }\left[\mathrm{R}_{\mathrm{n}}(\mathrm{x},\right. \\
\mathrm{y})]\end{array}$ & $\begin{array}{l}\text { Specific } \\
\text { storage } \\
\left(\mathrm{S}_{\mathrm{s}}\right)\end{array}$ & $\begin{array}{l}\text { Natural discharge } \\
\text { spatial component } \\
{\left[Q_{n}(i, j)\right]}\end{array}$ & $\begin{array}{l}\text { Planning } \\
\text { Horizon } \\
(\mathrm{g})\end{array}$ \\
\hline $\begin{array}{l}\text { Boundary } \\
\text { conditions }\end{array}$ & $\begin{array}{l}\text { Natural recharge } \\
\text { rate } \\
{\left[\mathrm{R}_{\mathrm{n}}(\mathrm{t})\right]}\end{array}$ & $\begin{array}{l}\text { Saturated } \\
\text { thickness } \\
\text { (b) }\end{array}$ & $\begin{array}{l}\text { Natural discharge } \\
\text { rate } \\
{\left[Q_{n}(t)\right]}\end{array}$ & $\begin{array}{l}\text { Stress Period } \\
(\mathrm{p})\end{array}$ \\
\hline $\begin{array}{l}\text { Areal extent } \\
\text { of aquifer } \\
\text { (A) }\end{array}$ & $\begin{array}{l}\text { Artificial } \\
\text { recharge spatial } \\
\text { component }\left[\mathrm{R}_{\mathrm{a}}(\mathrm{x},\right. \\
\mathrm{y})]\end{array}$ & $\begin{array}{l}\text { Storage } \\
\left(\mathrm{S}_{\mathrm{T}}\right)\end{array}$ & $\begin{array}{l}\text { Pumping well } \\
\text { spatial component } \\
{\left[\mathrm{Q}_{\mathrm{a}}(\mathrm{i}, \mathrm{j})\right]}\end{array}$ & $\begin{array}{l}\text { Time Step } \\
(\mathrm{t})\end{array}$ \\
\hline $\begin{array}{l}\text { Porosity } \\
(\varnothing)\end{array}$ & $\begin{array}{l}\text { Artificial } \\
\text { recharge rate } \\
{\left[\mathrm{R}_{\mathrm{a}}(\mathrm{t})\right]}\end{array}$ & $\begin{array}{l}\text { Specific yield } \\
\left(\phi_{\text {eff }} \text { or } S_{y}\right)\end{array}$ & $\begin{array}{l}\text { Pumping well } \\
\text { discharge rate } \\
{\left[\mathrm{Q}_{\mathrm{a}}(\mathrm{t})\right]}\end{array}$ & $\begin{array}{l}\text { Cell } \\
(\mathrm{i}, \mathrm{j}, \mathrm{k}, \mathrm{z})\end{array}$ \\
\hline $\begin{array}{l}\text { Hydraulic } \\
\text { conductivity } \\
\text { (K) }\end{array}$ & Return flow $(\alpha)^{\mathrm{e}}$ & $\begin{array}{l}\text { Storativity } \\
{[-]}\end{array}$ & $\begin{array}{l}\text { Evapotranspiration } \\
{\left[\mathrm{Q}_{\mathrm{e}}(\mathrm{t})\right]}\end{array}$ & $\begin{array}{l}\text { Zone } \\
(\mathrm{z})\end{array}$ \\
\hline $\begin{array}{l}\text { Land } \\
\text { Surface } \\
\text { Elevation } \\
\left(\mathrm{m}_{\mathrm{ij}}\right)\end{array}$ & $\begin{array}{l}\text { Lateral or vertical } \\
\text { influx }(\mathrm{V})^{\mathrm{e}}\end{array}$ & $\begin{array}{l}\text { Hydraulic head } \\
{[\mathrm{h}(\mathrm{x}, \mathrm{y}, \mathrm{z})]}\end{array}$ & $\begin{array}{l}\text { Lateral or vertical } \\
\text { outflux }(\mathrm{V})^{\mathrm{e}}\end{array}$ & $\begin{array}{l}\text { Bottom } \\
\text { confining unit } \\
\text { elevation } \\
\left(\mathrm{n}_{\mathrm{ij}}\right) \\
\end{array}$ \\
\hline \multirow[t]{2}{*}{$\begin{array}{l}\text { Drain } \\
\text { elevation } \\
\text { (d) }\end{array}$} & $\begin{array}{l}\text { Unrecoverable } \\
\text { Storage } \\
\left(\mathrm{S}_{\mathrm{u}}\right)\end{array}$ & $\begin{array}{l}\text { Minable } \\
\text { Storage } \\
\left(\mathrm{S}_{\mathrm{m}}\right)\end{array}$ & $\begin{array}{l}\text { Replenishable } \\
\text { Storage } \\
\left(\mathrm{S}_{\mathrm{r}}\right)\end{array}$ & $\begin{array}{l}\text { Diffusivity } \\
\text { (T/S) }\end{array}$ \\
\hline & & $\begin{array}{l}\text { Transmissivity } \\
\text { (T) }\end{array}$ & & $\begin{array}{l}\text { Acceptable } \\
\text { variance }(\mathrm{X})\end{array}$ \\
\hline
\end{tabular}

Notes:

${ }^{\mathrm{a}}$ Table excerpted from Pierce 2006 showing a list of influential hydrogeologic parameters as indicated by Feinerman and Knapp 1983; Gisser and Sánchez 1980; Bredehoeft and Young 1970; Freeze and Massmann 1990; Alley et al. 1999; Kresic 1997; Harbaugh and McDonald 1996; Kalf and Wooley 2005 - this list is not necessarily comprehensive

${ }^{\mathrm{b}}$ Such as fractured/porous; consolidated/unconsolidated; stratigraphic position and extent (after Freeze and Massmann 1990)

${ }^{\mathrm{c} C}$ Conditions can include no flow boundaries (lateral), surface impermeabilities, constant heads, differences between geologic units, etc.

${ }^{\mathrm{d}}$ An areal extent may be subdivided into zones of confinement, unconfined, and artesian

${ }^{e}$ Return flow and lateral influx or outflux can be counted within the artificial or natural recharge and natural discharge components respectively or split apart as separate components of recharge to the system as shown here

${ }^{\mathrm{f}}$ Presented in the context of finite difference modeling, such as in MODFLOW packages

${ }^{\mathrm{g}}$ Diffusivity is an indication of the rate of movement through a system and the capacity to sustain localized drawdowns without resulting in long-term storage depletion. An aquifer's diffusivity is probably a good indicator of the relationship to an appropriate planning horizon 


\subsubsection{Groundwater Governance}

Management of water resource demands requires the incorporation of legal and regulatory rules for allocation (Part II of this book) as well as community preferences for risk sharing of the potential consequences of water shortages. In short, the interdependency of community drivers and science-based analyses must be recognized and integrated to determine the actual availability of a resource under various management policies as depicted in Fig. 25.1.

Aquifer governance includes the social and contextual aspects of a case that may be used by groundwater managers, together with operational definitions, to implement management regimes (Pierce et al. 2013). Participatory processes are one of many stakeholder engagement and modelling approaches that are well suited for unravelling the issues of aquifer governance. A review of design methodologies, approaches, and guidance on common stakeholder modelling techniques and typologies are discussed broadly in the literature on decision support processes and stakeholder engagement (e.g. Voinov and Bousquet 2010; Margerum 2008). Combining scientific knowledge with stakeholder perspectives, preferences, and concerns generates opportunities to (1) address misconceptions about the science content, (2) establish a shared learning and visioning environment, and (3) increase the likelihood of adoption for solutions that may be identified. DSS offer mechanisms and methods for merging a plurality of views and information that are needed to achieve effective groundwater governance and reduce the potential for conflict.

\subsubsection{Decision Support Systems and Processes}

The use of DSS represents a systematic approach to often divisive and intractable issues, such as groundwater availability and its allocation. Defined as interactive computer models, DSS incorporate data relative to a problem and, through programmed analyses, aid the formulation and selection of an appropriate management strategy. The development of a DSS is inherently systemic and multi-disciplinary which differs from traditional analytical approaches that are discipline specific and tend to isolate variables. In addition, the design and development of DSS benefit from engagement and participatory inclusion of stakeholders and decision makers.

Research into the behavior of decision makers demonstrates that the complexity of many decision problems quickly outstrips a decision makers' unaided cognitive capacity (Gregory et al. 2005). Complex socio-technical decisions, such as those needed for groundwater management, are based on large quantities of evidence that is frequently assembled and analyzed by multi-disciplinary teams. The meaning and implications for developing management strategies or actions are evaluated and compared through the eyes of stakeholders. DSS that combine aquifer performance and groundwater governance, as shown in Fig. 25.1, create a more transparent lens 
through which complex groundwater problems may be viewed without overwhelming stakeholders.

Decisions about aquifer yields are the most common to groundwater problems, though a wide range of other common decision making contexts exist. A non-comprehensive list of examples includes decisions about groundwater availability, such as defining acceptable pumping limits, pump locations, or determining the influence of pumping on threshold flows for groundwater dependent ecosystems (Chap. 15). Another segment of decision contexts include groundwater quality decisions (Chaps. 14 and 15), such as those related to remediation and risk prevention. And decision contexts related to groundwater monitoring stations, sampling locations, or waste management are all good examples of the numerous sets of decision contexts that cross sectors, from industrial to environmental management or domestic and agricultural use cases.

The following sections delve into a more detailed discussion of performance, governance, and decision support elements as they relate to groundwater applications.

\subsection{Data and Modeled Attributes for Aquifer Performance}

Information and knowledge management challenges abound in groundwater sciences. Every DSS is built using datasets and models that represent the problem domain and key elements of interest to decision makers and stakeholders. The domain of hydrogeology is comprised of significant data collections that span spatial and temporal scales across many orders of magnitude with variable resolutions (Narasimhan 2005).

While the scales and extent of groundwater information are vast, the datasets often are sparse considering the complexity in the systems. The resultant uncertainty, paired with inherent variability in groundwater systems limit the predictive value of groundwater models that form the core of decision support systems (Chap. 28). Regardless, offsets of parameters are derived from direct measurements and field observations to quantify and describe groundwater system behavior. These data are used by groundwater modelers to populate, extrapolate, and define a numerical simulation to represent the natural behavior of aquifer systems. Modeled outputs then form the core information for any undertaking in integrated groundwater decision support.

While groundwater modelers are concerned with the low predictive value of numerical simulations for aquifers, from a DSS perspective the focus revolves around (1) linking groundwater with ancillary components in the integrated models (e.g. land use, climatic conditions, and surface water, etc.), and (2) communicating the level of uncertainty as it relates to the decision context. 


\subsubsection{Natural Hydrogeologic Attributes and Uncertainty}

Identifying natural attributes of a groundwater system is a vital step in determining a method for calculating relevant performance indicators for decision contexts related to both groundwater response and linkages with ancillary or related aspects for integration.

Parameter uncertainty is a key consideration for assuring that the representative groundwater model reflects actual aquifer behavior. Hydrogeologists have established a myriad of approaches for addressing uncertainty with domain-centric groundwater models (Matott et al. 2009; Banta et al. 2006; Doherty and Skahill 2006; Doherty 2003, 2004; Hamby 1994; Hill 1998; Poeter and Hill 1998). Yet direct assessment and treatment of uncertainty as it relates to integrated groundwater models, such as those that inform DSS applications are less common and recent (Guillaume et al. 2012; Guillaume and Pierce 2011). Integrated modelling is beginning to establish methods and approaches to creating and testing IAMs (e.g. Bennett et al. 2013) and groundwater modelling practice reflects these advances. A key issue is the problem of the low predictive value of groundwater models, particularly when they are combined within an IAM, and the central element of concern is related to the variables and parameters that are used to define the systems of interest, or the attributes. The measurements used to describe and monitor a groundwater system serve as the basic units of knowledge that define performance for decision problems. A natural attribute, defined by Keeney (1992), is a measurable quantity or criterion that has a common interpretation and can indicate the level of achievement of goals or objectives. A review of natural attributes that are common to hydrogeologic problems, compiled by Pierce (2006) and shown in Table 25.1, reveals approximately 37 measures, variables and descriptive parameters.

The units of information shown in Table 25.1 are central to an ontology and scientific understanding of groundwater, as well as being core to the design of groundwater-related decision problems. For example, defining an actual rate of yield or extraction rate, along with primary natural attributes, must begin with the master equation for hydrology, where changes in storage $(S)$ over time $(t)$ can be defined as the difference between inputs (such as recharge) $[\mathrm{I}(\mathrm{t})]$ and outputs (such as discharge) $[\mathrm{O}(\mathrm{t})]$. Determining the response of an aquifer to variations in any one of the variables for this equation is key to defining the volumes of groundwater that may be available for extraction. In turn, defining groundwater availability is a quintessential hydrogeology decision problem (Pierce et al. 2013) that may be bounded by limiting constraints for population growth, water demand, and total use of the resource for example.

Natural attributes provide the cornerstone for quantifying and valuing groundwater resources and for developing integrated groundwater management strategies. The natural attributes also serve as the parameters that represent groundwater response in simulation models. Collecting the information needed to understand and model groundwater systems is a necessary first step to decision support. 
A DSS links together raw data, empirical calculations, numerical models, and other qualitative factors to analyze decision problems. DSS can help decisionmakers conceptualize a problem in a new way, as well as allowing for the rapid conversion of the vast sets of data typically associated with groundwater problems into understandable reports that can provide guidance and insight (Kersten 2000).

\subsection{Addressing Stakeholder Perspectives for Groundwater Governance}

While a great deal of data may exist to inform appropriate analytical or numerical analyses for groundwater resources, the ultimate influences of scientific uncertainty and the issue of complexity require the inclusion of stakeholder perspectives and concerns. Moreover a primary problem as far as DSS is concerned is the communication of this uncertainty to stakeholders and decision makers. The value-based considerations that can only be gleaned from interactions with stakeholders must guide the identification and prioritization of management options that fit with available scientific knowledge and social concerns. In fact, modeling efforts that engage qualitative methods and stakeholder input tend to create more informative problem formulations than traditional efforts without stakeholder advice ( $\mathrm{Li}$ et al. 2013). These participatory processes are frequently referred to as a co- design and co-creation approach.

Decision support provides a mechanism that interactively bridges the theoretical and methodological gaps between physical systems, analytic outcomes, knowledge interactions and interfaces with users, as well as providing computational support for science-based exploration, dialogue, and/or deliberation. Research on applied, participatory, decision support recognizes that science dialogue is simply another means of communicating ideas or knowledge (Welp et al. 2006) and provides rich qualitative inputs for modeling of complex problems.

Application of fundamental scientific and engineering principles alone can identify a set of management alternatives that are efficient across a number of performance metrics. Yet, technically sound solutions may, in fact, yield options that lead to an unacceptable political price (Allan 1999) because without the aid of a decision support process they neglect social values and process. The MurrayDarling River Basin provides a real world example where farmers protested a technically sound water plan that was unveiled by the Australian Government without adequate stakeholder consultation (Sullivan 2014). Therefore, approaches that recognize the difference between the measurable components of physical systems and the underlying values and preferences that influence management decisions are also needed. Clearly delineating the objective components of a problem from the value-based, or subjectively-judged, components is crucial to assure a final set of decisions that can be implemented without exacerbating disputes (Focazio et al. 2002). For example, a strategic path forward might include efforts to strengthen institutional capacity for managing over-pumped groundwater 
resources in order to prevent irrevocable damage to an aquifer system. Such governance depends on effective communication with, and advice from, stakeholders and water users.

Effective communication about decision problems follows a recognized set of conventional stages (Mintzberg et al. 1976):

\section{Problem formulation or definition \\ 2. Identification of decision objectives \\ 3. Generation and analysis of options \\ 4. Choice of a preferred option \\ 5. Implementation \\ 6. Monitoring and feedback \\ 7. Iteration and problem redefinition.}

Groundwater decisions frequently involve a distributed set of stakeholders who need assistance to work through the various stages of decision making and DSS may be of assistance at any of these stages or for multiple stages. Decision support for groups includes processes that enable cooperation among decision makers and stakeholders, while assuring that each participant has a clear stake in the problem that needs to be solved and guides the group towards a shared vision.

Processes may range from informative to strongly normative approaches. Informative approaches attempt to improve the quality of a decision by providing information to help decision makers analyze a situation and assess alternatives. Normative support aims to recommend options based on expected outcomes, rather than strictly explaining information or knowledge.

Regardless of the approach, there is broad agreement that successful processes engage participants and build capacity (van Kerkhoff and Lebel 2006). Consensus building remains the dominant process for creating a shared vision with participatory engagement. Systems thinking (Chap. 24) frequently informs the development of group goals, targets, and criterion. In the context of groundwater governance, consensus yield is a concept that is used for the most common decision making context for groundwater whereby the acceptable range of extraction from an aquifer is bounded by the preferences of affected stakeholders (Pierce et al. 2013; Mace et al. 2001). Consensus yield has become a recognized concept within hydrogeology, yet there are many instances and decision contexts, as discussed previously, where decisions about groundwater and the systems that are naturally linked, or integrated with aquifers, are aided by DSS applications. The preference sets and prioritization of candidate solutions then defines a feasibility space within which technically viable strategies for operational yield and management can be designed. Figure 25.2 shows a conceptualization and example of mapping aquifer performance with the overlay of stakeholder preference points to define a feasible solution space (modified from Pierce 2006). It depicts the intersection between the integrated system response measures, or performance metrics, as generalized groundwater storage response to pumping, and defines the feasibility space. 


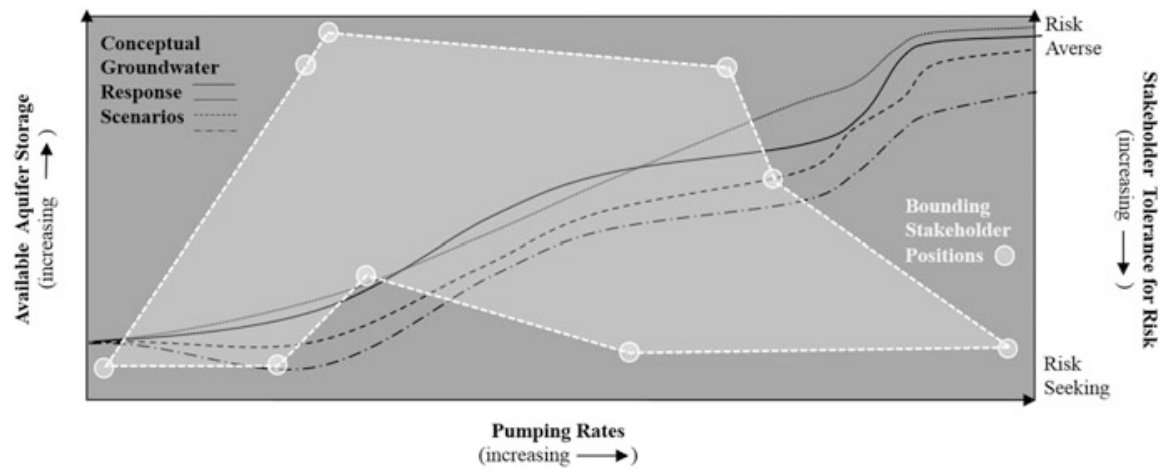

Fig. 25.2 Conceptual mapping of a feasibility space as defined by hypothetical aquifer performance across multiple scenarios bounded by hypothetical stakeholder preference points (Modified from Pierce 2006)

Framing the problem is a pivotal aspect for capturing principle stakeholder concerns, as well as defining the initial terms of focus for negotiation or deliberation (Chap. 24). Bridging the gap between problem formulation stages and groundwater model development provides an area with potent research potential and opportunities to improve the applicability of research products to real-world groundwater management problems (Borowski and Hare 2007).

\subsection{Decision Support Systems: Background and Types}

As research related to science-based decision making has evolved, increasing levels of insight and understanding are expected to be generated from the application and use of DSS. The field of decision support is constantly advancing at the boundary between theory and application. Theoretically DSS research begins with the premise that improving knowledge management will result in superior outcomes for decisions. For that reason, DSS development activities that target improvements in knowledge management are expected to foster meaningful advances when the DSS are deployed in practice.

Proponents of DSS further claim that activities striving for the most advanced levels will achieve effective knowledge management leading to the generation of 'new' knowledge. The history of DSS development provides a foundation from which to create concrete applications in a specific domain. In assessing DSS case studies that include groundwater, it becomes clear that the level of effort for applying DSS knowledge is significant even while we are able to preview from the broader DSS literature what future advances may achieve. 


\subsubsection{The Emergence of Decision Support}

While some practitioners credit Simon (1960) with the presentation of basic management decision processes, Little (1970) was the first to define a DSS as part of the concept of decision calculus. The first international conference on DSS was held in Atlanta, GA in 1981 (Power 2003). DSS literature recognizes that DSS models are simplified representations of problems addressed within a society that assist with the development and evaluation of alternatives. They use multiobjective planning to simultaneously consider various aspects of the decisionmaking paradigm (Haith and Loucks 1976), such as environmental quality, optimization, and economic cost-benefit analyses.

Since the inception of DSS, theories and applications have evolved to ever more sophisticated approaches over time by leveraging technological advances and transitioning toward improved functionalities and applied competencies on a case-by-case basis.

In the context of groundwater science and governance, the epitomy of groundwater DSS applications will communicate the extent and influence of scientific uncertainty while also enabling interactive deliberation among a plurality of stakeholders. In effect, an idealized DSS for groundwater will provide an advanced level of negotiation and facilitation support. Progressing from fundamental DSS applications to a full DSS with the capability to support live negotiation among groups of stakeholders requires a series of transitions that have been characterized by Kersten and Lai (2008). The progression of DSS types, depicted in Fig. 25.3, identifies transitions among DSS types that range from passive to active, and ultimately proactive applications with the relative level of effort that is necessary

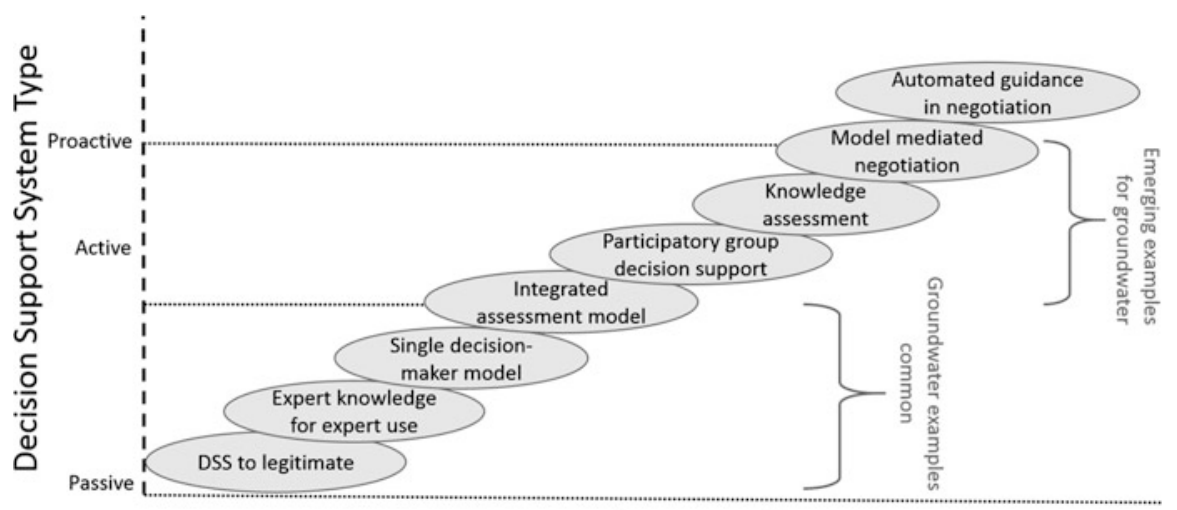

Development Effort

Fig. 25.3 Evolution of decision support systems for proactive support of science-based deliberation and negotiation (Modified from Kersten and Lai 2008; Pereira and Quintana 2002) 
for development, (modified from Kersten and Lai 2008; Pereira and Quintana 2002). The concept of DSS types and tiers (Kersten and Lai 2008) is helpful for assessing the state of use in groundwater cases. The following sections describe the DSS types and evaluate the state of groundwater DSS through this lens.

\subsubsection{Passive}

Passive DSS are tools that aid communication, calculation, and visualization in direct response to the input of a user. These systems augment users' ability to interact or analyze information, but interactivity is limited to direct selection and specification by a user (Kersten and Lai 2008).

The majority of groundwater modeling and management applications reported in the literature can be considered passive type systems from a DSS perspective. Case examples for integrated assessment that include groundwater are beginning to emerge (for example see various cases listed in Table 25.2), with the most advanced case studies transitioning from passive to active style applications.

\subsubsection{Active}

DSS assistance that helps users formulate, evaluate, and solve difficult problems is considered an example of an active system. Active systems provide utilities that support construction and processing of solutions for users (Kersten and Lai 2008). Active DSS may include some automatic knowledge capture or search techniques.

Integrated models and assessment provide the transitional DSS type between passive and active. Jakeman and Letcher (2003) discuss the basic features of integrated assessment models (IAMs), yet little consensus on a generalized framework for the use of IAM's within decision support contexts has been achieved (van Evert et al. 2005; Mysiak et al. 2005). Various approaches and frameworks are presented in the literature (Villa 2007; Khaiter 2005; Moore et al. 2004; Rahman et al. 2004; Sydelko et al. 2001; Argent and Grayson 2003; Segrera et al. 2003; Leavesley et al. 2002). They range from: generalized modeling frameworks that are more accessible to non-programmers but limit specific model implementation; to model-specific frameworks, or implementation-level frameworks, that require a higher level user group, usually with programming experience and result in increased development effort.

\subsubsection{Proactive}

Systems that can evaluate aspects of a decision problem independently with the ability to provide feedback to facilitators/mediators and users during a negotiation process are proactive. These systems are similar to active systems with the addition of facilitator and mediator centric utilities, as well as algorithms with embedded assessment of user inputs in order to derive, or recommend, alternative options. Proactive DSS are expected to provide capabilities to aid group facilitation or mediation, along with the ability to access and use information in real time for the purpose of supporting the facilitators or negotiators. Proactive systems will make suggestions and critiques for improving the outcome of a DSS supported deliberation or negotiation. 


\begin{tabular}{|c|c|c|c|c|c|}
\hline 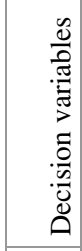 & 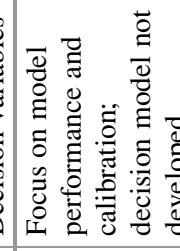 & 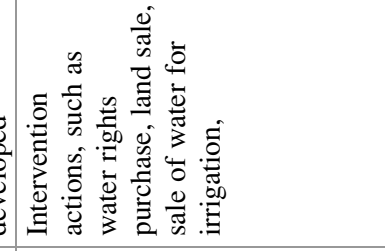 & 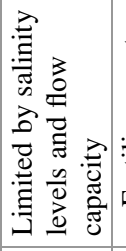 & 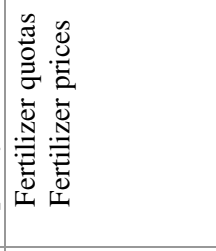 & 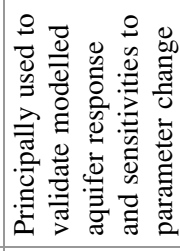 \\
\hline 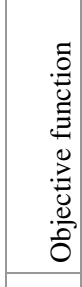 & 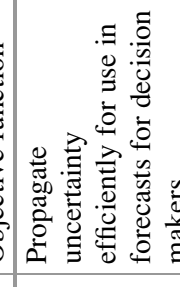 & 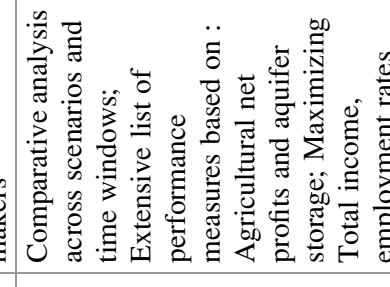 & 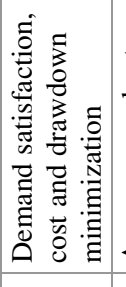 & 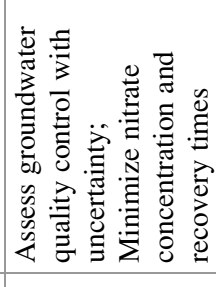 & 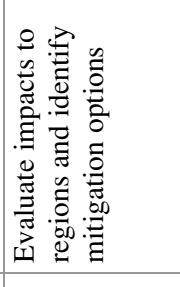 \\
\hline 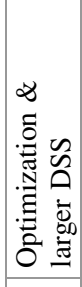 & 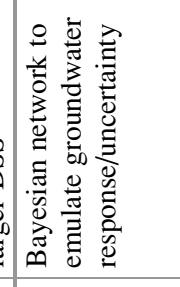 & 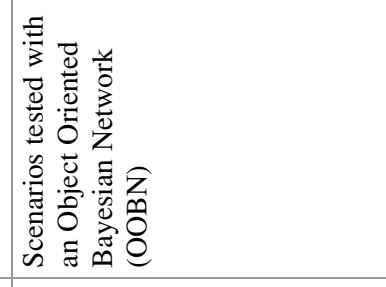 & 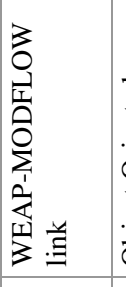 & 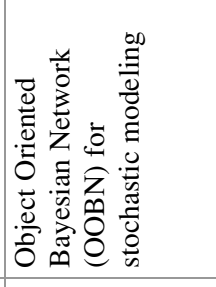 & 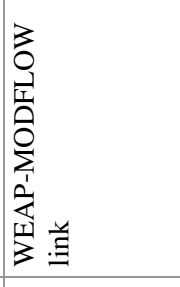 \\
\hline $\begin{array}{l}:= \\
0 \\
z \\
0\end{array}$ & 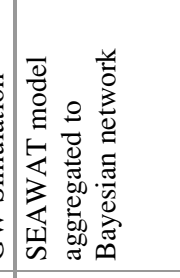 & 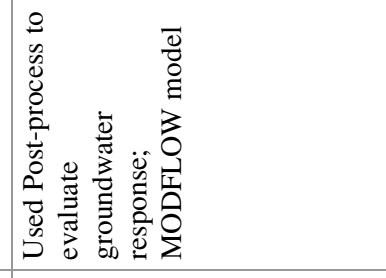 & 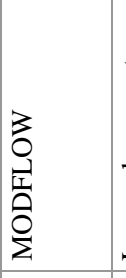 & 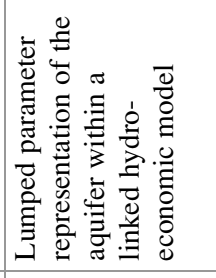 & 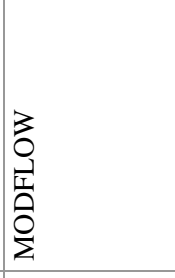 \\
\hline $\begin{array}{l}\frac{0}{\tilde{J}} \\
\underline{\omega}\end{array}$ & & 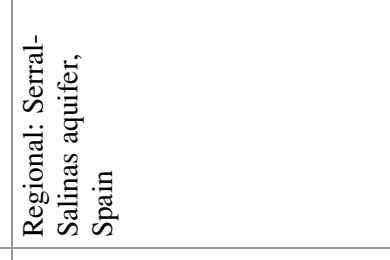 & 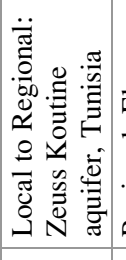 & 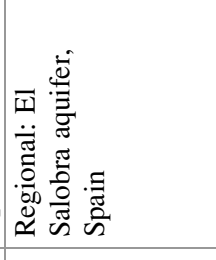 & 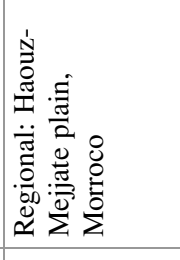 \\
\hline$\stackrel{0}{2}$ & 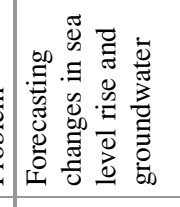 & 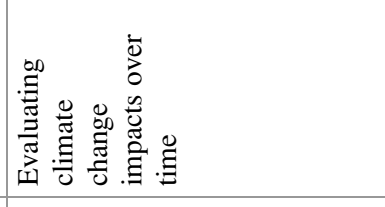 & 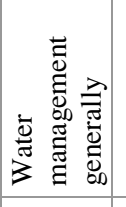 & & 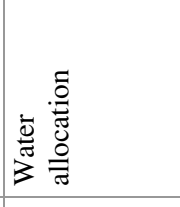 \\
\hline & : & 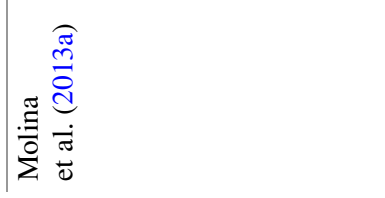 & 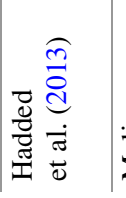 & 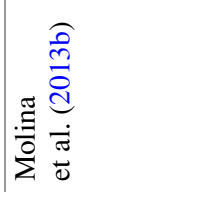 & 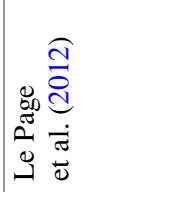 \\
\hline
\end{tabular}




\begin{tabular}{|c|c|c|c|}
\hline 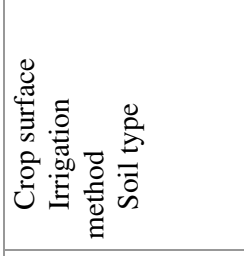 & 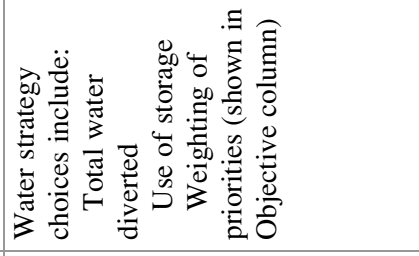 & 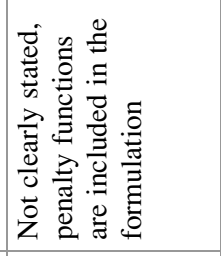 & 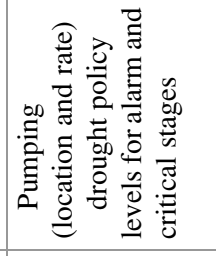 \\
\hline 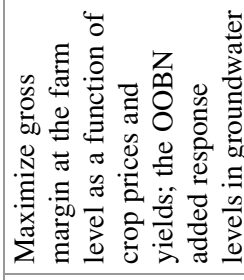 & 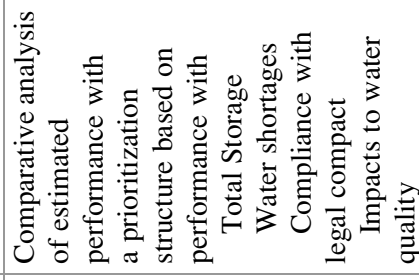 & 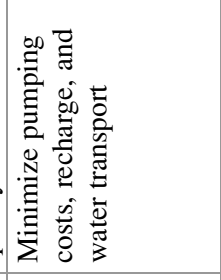 & 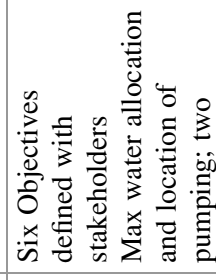 \\
\hline 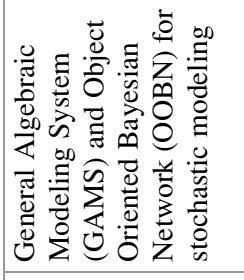 & 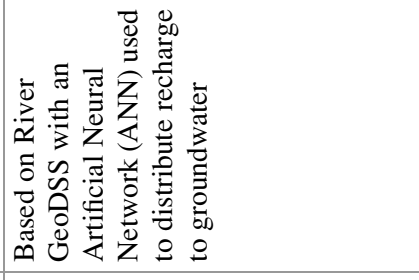 & 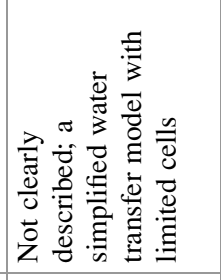 & 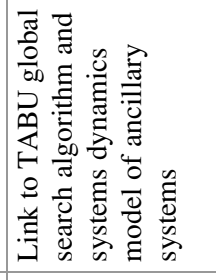 \\
\hline 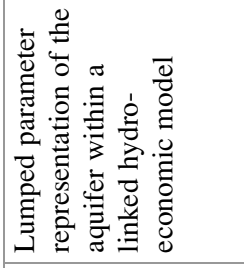 & 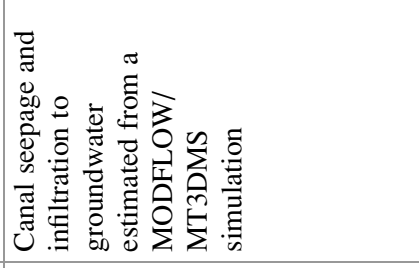 & 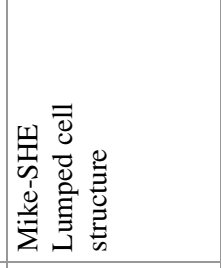 & 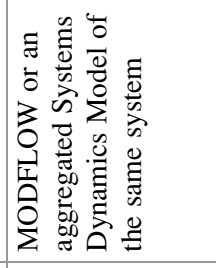 \\
\hline 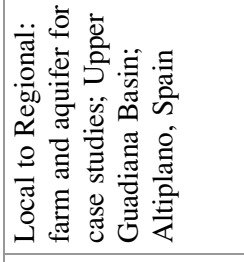 & 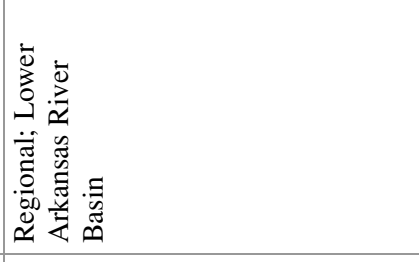 & 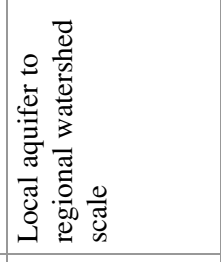 & 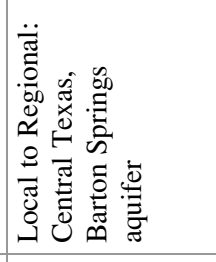 \\
\hline 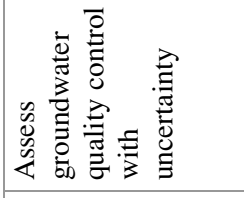 & 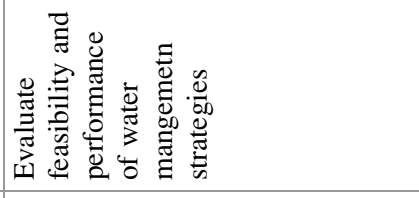 & 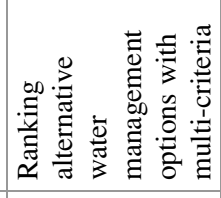 & 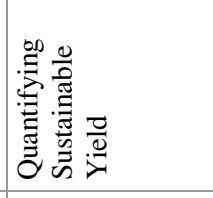 \\
\hline 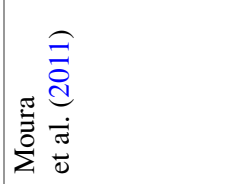 & 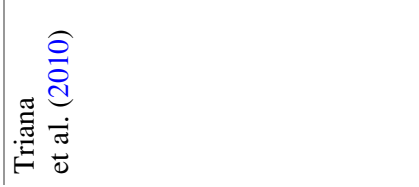 & 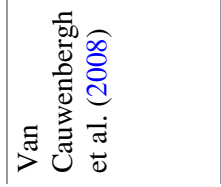 & 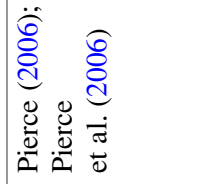 \\
\hline
\end{tabular}




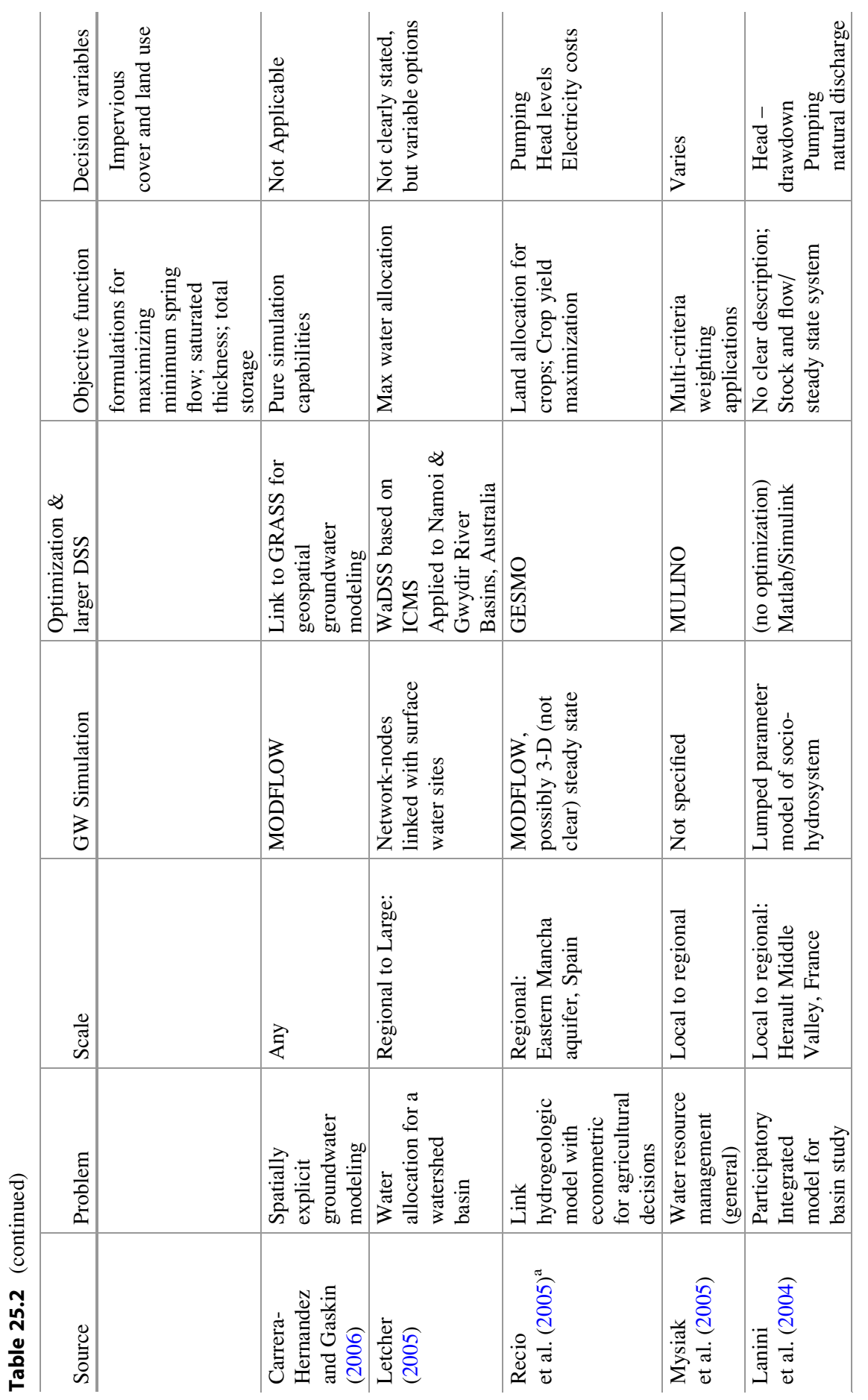




\begin{tabular}{|c|c|c|c|c|c|c|}
\hline 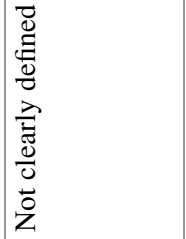 & 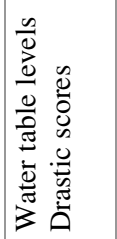 & 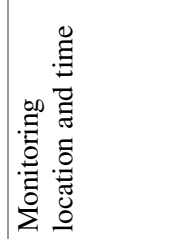 & 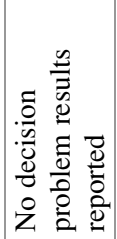 & . & 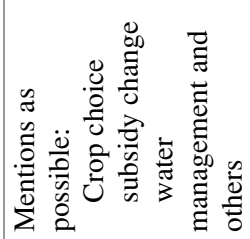 & 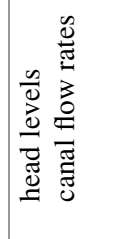 \\
\hline 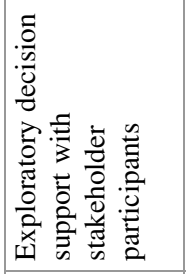 & 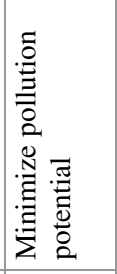 & 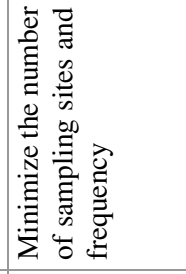 & 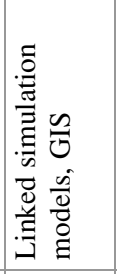 & 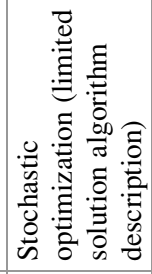 & 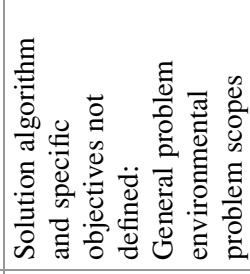 & 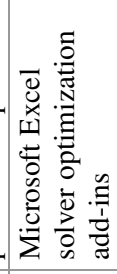 \\
\hline 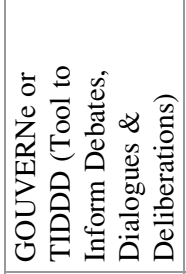 & 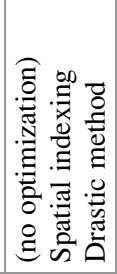 & $\begin{array}{l}2 \\
0 \\
2 \\
2 \\
\Sigma\end{array}$ & 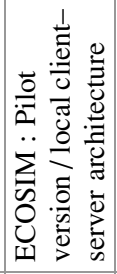 & 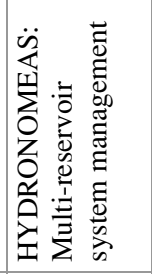 & 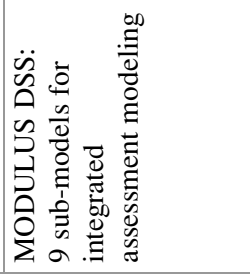 & 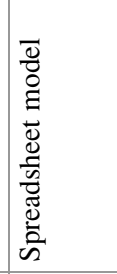 \\
\hline 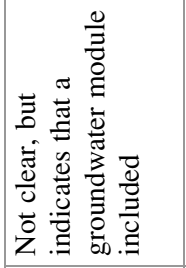 & 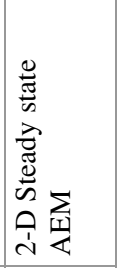 & 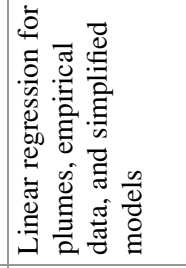 & 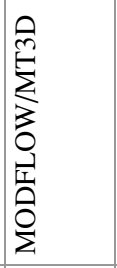 & 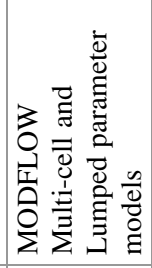 & 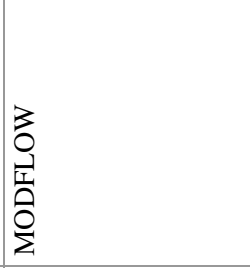 & 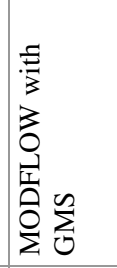 \\
\hline 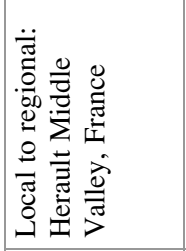 & 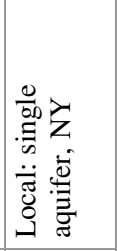 & 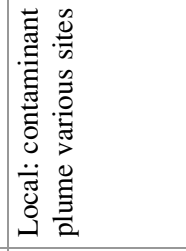 & 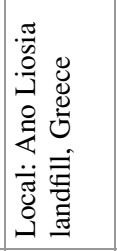 & 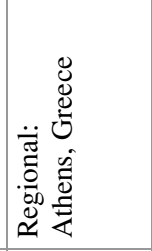 & 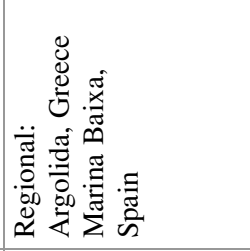 & 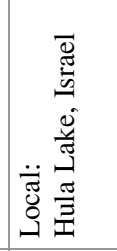 \\
\hline 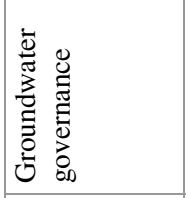 & 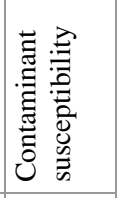 & 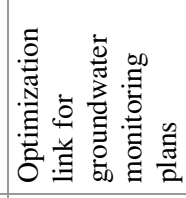 & 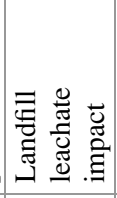 & 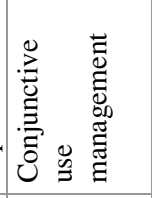 & 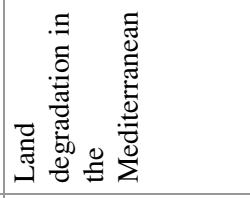 & 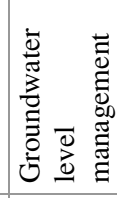 \\
\hline 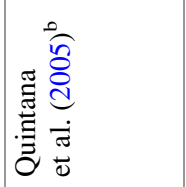 & 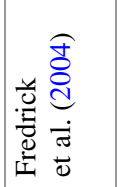 & 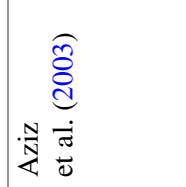 & 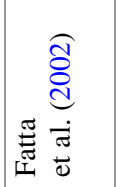 & 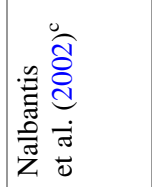 & 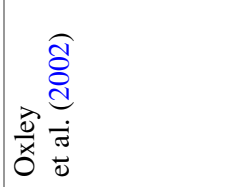 & 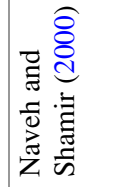 \\
\hline
\end{tabular}




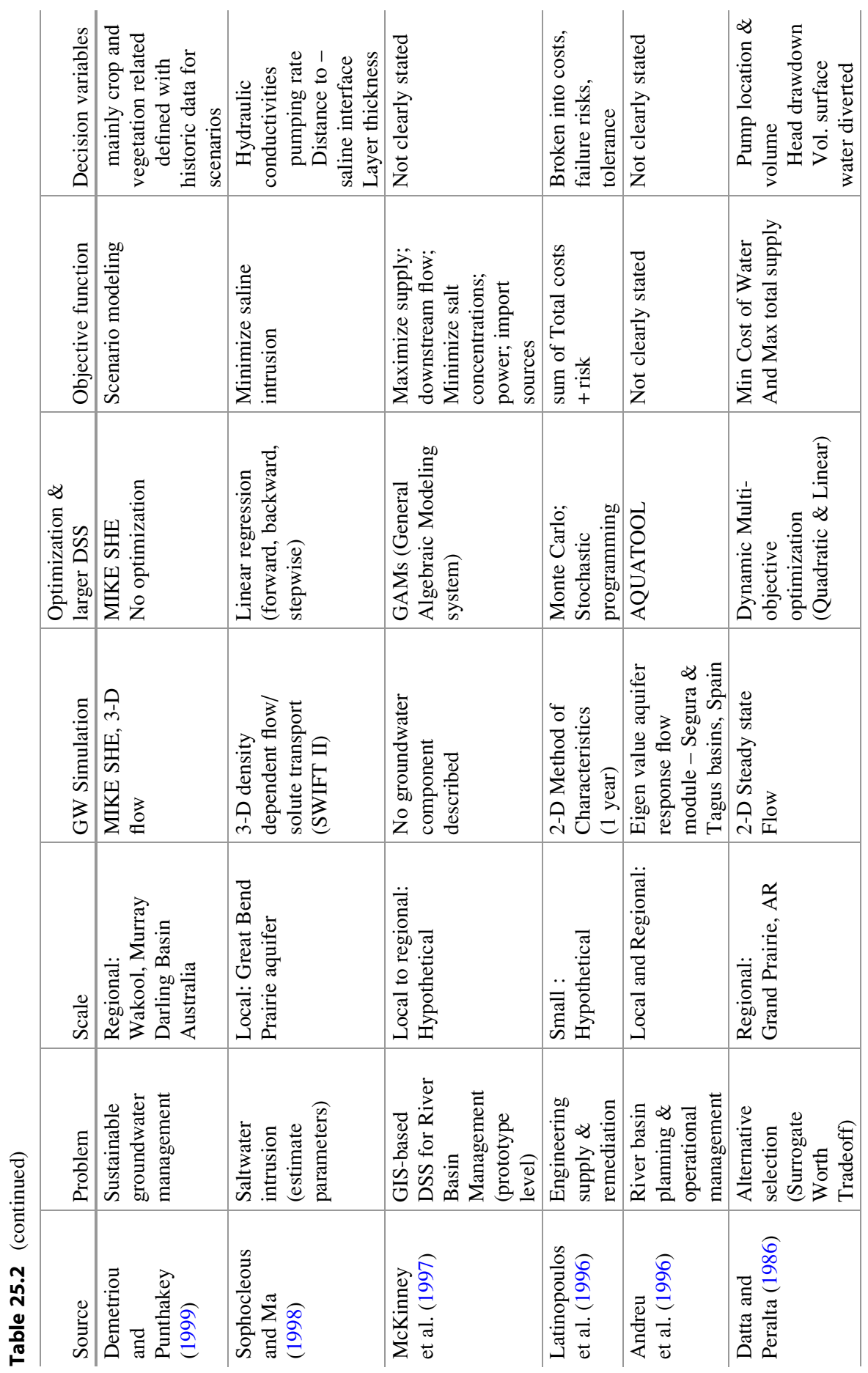


Due to the nature of groundwater systems, decision problems for these resources tend to fall into the category of emergent decision contexts (i.e. problems that are ill-defined and lack a common heuristic for identifying solutions). Groundwater management problems will likely require the application of proactive support of science-based deliberation and negotiation DSS. Application of proactive DSS tools for real world groundwater cases are not reported, yet case studies demonstrate transitions from passive toward progressively more active use of DSS tools for groundwater problems. In the future, the field of groundwater decision support systems can be expected to evolve toward increasingly proactive type DSS.

\subsubsection{Applications of Decision Support to Groundwater Cases}

While distributed groundwater modeling approaches have advanced significantly, their incorporation in decision support processes remains limited, and the inclusion of groundwater cases within IAMs or participatory processes is largely absent. The following sections review the use of decision analytic techniques and decision support as reported in the literature for a range of groundwater problems, most frequently discussed in relation to health and environmental quality concerns. Risk assessment techniques have been applied to groundwater problems associated with petroleum spills, waste site leachates, agricultural contaminants, and radioactive materials control (Correll and Dillon 1993).

Control and management of groundwater supply is a primary topic in groundwater research and application, yet few DSS have been developed specifically to address this topic. An evaluation of decision-analysis with hydrogeological applications was put forth by Freeze et al. (Freeze and Massmann 1990; Freeze 1992) for project evaluation. Freeze's paper was timely, preceding the development of a wide-array of DSS for applications to groundwater, particularly contamination and remediation problems (Camara and Cardoso da Silva 1990; Xiang 1993; Lovejoy et al. 1997), but little work can be found applying the same concepts to aquifer yield. A few lumped system approaches without spatial considerations are reported (Naik and Awahthi 2003; National Research Council 1997), or with dimensional approximation (Miles and Chambet 1995), but these efforts lack the credibility of a distributed groundwater model that has been vetted scientifically. To address this issue, advances in linking groundwater with geospatial utilities are streamlining approaches for incorporating spatially detailed models (CarrerraHernandez and Gaskin 2006). Spatially-distributed models have been used for permitting and operation decisions while lumped-parameter models are typically used to evaluate socioeconomic relationships.

Sophocleous and Ma (1998) provide one of the earliest groundwater DSS that evaluates the impact of salt water intrusion on aquifer yield. Since 1997 interest in decision support applications has increased (Jamieson 1997). Table 25.2 presents a summary of the literature regarding decision applications and support systems related to groundwater management. Examples include articles that list specific 
tools or decision analysis applications, as well as integrated models for environmental decisions that include a groundwater component.

Groundwater decision support systems ought to be capable of providing alternative means for approaching water resource management operations through adaptive management for water resources. Table 25.2 also lists decision support and decision analysis projects reported in the literature with groundwater, environmental, optimization, multi-criteria analysis, and other relevant features.

The examples in Table 25.2 demonstrate progressively higher levels of sophistication in the integration of groundwater in DSS applications, yet groundwater DSS have attained primarily passive type DSS and active type cases are emerging. GESMO (Recio et al. 2005) incorporates a steady-state MODFLOW model to evaluate econometric problems for agricultural use on a regional scale. MIKESHE (Demetriou and Punthakey 1999) addresses the problem of sustainable groundwater management, but does not incorporate optimization techniques, and instead pure scenario modeling is used. Hydroanemas (Nalbantis et al. 2002) incorporates stochastic programming to address uncertainty and evaluate conjunctive use problems with an embedded MODFLOW model to simulate groundwater response. Gouverne (Quintana et al. 2005) focuses strictly on policy questions to date and incorporates the media-based input from stakeholder participants, but does not clearly describe the groundwater component of the system. WaDSS (Letcher 2005) addresses the problem of water resource distribution on a regional scale linking surface-water and groundwater through a nodal network.

To achieve proactive type guidance tools for DSS, computational advances in areas such as artificial intelligence, optimization algorithms, real-time sensing, informatics, and science visualization will be needed. In the case of groundwater, it is common for subject matter experts to pair models of groundwater response with optimization algorithms. Yet the most advanced algorithmic support remains limited to use by technical experts with particular emphasis on applications for parameterization of numerical models rather than DSS applications.

Development and advances of optimization techniques are integral to the potential for achieving advanced decision support applications. Reviews of optimization applications for groundwater management (Reed et al. 2013; Singh 2012) reveal that the use of traditional optimization and global search techniques have been applied to support decisions related to quantity and quality problems. For example, the groundwater decision support system (GWDSS) presents a hybridized example for water allocation that includes both simulation-optimization and lumped parameter modelling tools (Pierce 2006; Pierce et al. 2006). Artificial Neural Networks (ANN), such as the River GeoDSS (Triana et al. 2010) and Bayesian networks (Molina et al. 2013a, b; Fienen et al. 2013) present an advanced area of research that leverages algorithms to generate potential candidate solutions. The first report of an immersive environment is implemented for a case in the Sichuan Province, China demonstrating a framework that links virtual environments with models (Zhang et al. 2013). As the algorithms and computing capacity have advanced the problems and approaches have also evolved to increasing levels of complexity. 
An important indicator of advances and maturity in the field of DSS applications to groundwater problems will be the replication and reuse of DSS methods and software application tools. The application of Bayesian networks (Moura et al. 2011; Molina et al. 2013a, b; Fienen et al. 2013) across multiple cases demonstrates a replicable methodology, and the WEAP-MODFLOW software tool (Le Page et al. 2012; Hadded et al. 2013) is gaining traction across several applications.

Tools and methods are emerging that provide more generalized approaches to DSS for groundwater with some cases shown in Table 25.2 that can be categorized as active type DSS. The pinnacle of applications for model mediated negotiation, or proactive DSS, will require continued advances in computation and algorithm support to identify tradeoffs and candidate solutions among the myriad of complex alternatives.

\subsection{Factors Related to Adoption of DSS}

The complex nature of groundwater resources often overwhelms decision-makers and inhibits the creation of clear management strategies. The possible number of management permutations can be almost innumerable, even for small scale aquifers, which in current accepted practice results in the inefficient evaluation of management alternatives. DSS can provide the computational tools and methodologies to address the complexity of groundwater problems.

Ideally a DSS will consider scientific knowledge, social process, operational constraints, as well as technology system performance. The potential to improve upon current groundwater management and policy practices through the use of science-based DSS is significant. Yet bridging the gaps to advance toward widespread adoption and usefulness of groundwater DSS requires explicitly addressing a myriad of factors (see also McIntosh et al. 2011), such as:

- Financial costs - because implementing a DSS system limits groundwater management districts frequently requires software licenses and staff or consultant time.

- Knowledge to implement - use of a DSS system requires the technical capacity to operate and use advanced software products.

- Adaptability of DSS - every decision situation has contextual elements and situation-specific considerations. DSS systems must be easy to adapt to each case before use.

- Multi-disciplinary team - the range of knowledge and expertise necessary to represent a groundwater problem can be very broad and requires expertise across domains.

- Adequate governance structures - without appropriate authority to manage the resources or infrastructure to support a DSS long-term the likelihood of adoption and use drops

- Trust - DSS deployment depends on trust among collaborators. 
Groundwater systems frequently cross political boundaries, are exposed to multiple hazards, and affect a broad range of stakeholder groups. Before DSS can be expected to flourish in groundwater use there is the need to: (1) develop new tools that are increasingly transparent to the user groups; (2) improve the integration of tools into daily use by decision makers; and (3) continue collection of input parameter data and improve data measurement. Successful DSS for groundwater management will need to remain flexible and simple enough to explain to various user and decision-making groups while addressing key barriers to adoption.

\subsection{Conclusions}

Groundwater management involves both the facets of an aquifer's behavior as well as the preferences of its users. Users who presume sovereignty over their water rights and withdraw water to meet their individual social-economic needs without considering potentially adverse consequences to others may be following local allocation norms, even as they create the potential for disputes.

In order to address the projected future demands of society for fresh water, groundwater science must provide adequate characterization of the physical system to assure that policy limits for feasible allocation are achievable. Realistic projections of resource demand require incorporating the preferences of the community that depends upon that resource. The interdependency of community drivers and science-based analyses must be recognized and integrated in order to determine the actual availability of a resource under various management schemes.

DSS can provide a set of applications, methodologies, and tools to identify aquifer sensitivity, evaluate inter-relationships among parameters, test alternative management scenarios, and define levels for decision variables that can guide policy making and, ideally, reduce conflict over the resource.

Aquifer decision support is a multi-disciplinary field of study because it relies upon physical models of aquifer behavior, contemporary groundwater data collection systems, rapidly developing simulation and optimization software, as well as qualitative methods to engage and learn from resource users. While the idea of interactive, knowledge-based decision support for groundwater is straightforward, the combination of technical challenges, multi-disciplinary complexity, and scientific uncertainty create significant barriers to implementation. Today, decision support is experiencing a revival in many fields of interest, particularly land use planning and other physical science disciplines. Whether or not the field begins to take form in groundwater sciences will depend in large measure upon the ability of the theoretical techniques to live up to conceptual expectations of the users and the ability of researchers to link theoretical advances to practice.

To meet future water demand scenarios it will be necessary for groundwater aquifers to be managed more effectively and sustainably. Current methods used to 
determine groundwater allocation and management strategies are neither equitable nor efficient, frequently resulting in the over-abstraction of aquifer systems. Decision support systems (DSS) provide a means for water managers to evaluate complex data sets that include hydrogeologic, economic, legal and environmental elements to calculate available yield for aquifers or estimate levels of risk, resulting in improved policies for groundwater management that may, eventually, help ensure the long-term sustainability of water use by society. Water and humans are inextricably linked. As burgeoning human populations stress existing water resources, civilization needs to manage water. This need highlights the inseparable link between scientific knowledge and human interpretation of the environment. Societies interpret the state of the world around them, and take certain actions upon the physical systems based upon that interpretation. As resource constraints grow and the potential consequences of mismanagement increase, improved methods and DSS for people to convert information into knowledge are vital to ensure long-term resource stability.

Acknowledgments Sections of this chapter were initially completed as part of a doctoral thesis by Suzanne A Pierce with funding from The Jackson School of Geosciences, The University of Texas at Austin and the STAR Fellows program of the U.S. Environmental Protection Agency (Agreement number FP91632001-0). The authors would like to thank the editors, Muhammed Arshad and Dr. Anthony Jakeman for their patience and constructive comments throughout the editorial process.

Open Access This chapter is distributed under the terms of the Creative Commons AttributionNoncommercial 2.5 License (http://creativecommons.org/licenses/by-nc/2.5/) which permits any noncommercial use, distribution, and reproduction in any medium, provided the original author(s) and source are credited.

The images or other third party material in this chapter are included in the work's Creative Commons license, unless indicated otherwise in the credit line; if such material is not included in the work's Creative Commons license and the respective action is not permitted by statutory regulation, users will need to obtain permission from the license holder to duplicate, adapt or reproduce the material.

\section{References}

Allan T (1999) Productive efficiency and allocative efficiency: why better water management may not solve the problem. Agric Water Manag 40:71-75

Alley WM, Reilly TE, Franke LO (1999) Sustainability of ground-water resources: U.S.Geological Survey, U.S. Geological Survey Circular 1186, Denver, Colorado

Andreu J, Capilla J, Sanchis E (1996) AQUATOOL, a generalized decision-support system for water-resources planning and operational management. J Hydrol 177:269-291

Argent R (2003) A modelling shell for participatory assessment and management of natural resources. Environ Model Software 18:541-551

Aziz JJ, Ling M, Rifai HS, Newell CJ, Gonzales JR (2003) MAROS: a decision support system for optimizing monitoring plans. Ground Water 41(3):355-367 
Banta ER, Poeter EP, Doherty JE, Hill MC (2006) JUPITER: joint universal parameter identification and evaluation of reliability - an application programming interface (API) for model analysis. U.S. Geological Survey Technical Methods TM 6-E1, Denver, Colorado

Bennett ND, Croke BFW, Guariso G, Guillaume JHA, Hamilton SH, Jakeman AJ, MarsiliLibelli S, Newham LTH, Norton JP, Perrin C, Pierce SA, Robson B, Seppelt R, Voinov AA, Fath BD (2013) Characterising performance of environmental models. Environ Model Software 40:1-20

Borowski I, Hare M (2007) Exploring the gap between water managers and researchers: difficulties of model-based tools to support practical water management. Water Resour Manag 21:1049-1074

Bredehoeft JD, Young RA (1970) The temporal allocation of groundwater: a simulation approach. Water Resour Manag 6:3-21

Camara AS, Cardoso da Silva M (1990) Decision support system for estuarine water-quality management. J Water Resour Plan Manag 116(3):417-432

Carrera-Hernandez JJ, Gaskin SJ (2006) The groundwater modeling tool for GRASS (GMTG): open source groundwater flow modeling. Comput Geosci 32:339-351

Correll RL, Dillon PJ (1993) Risk assessment as a framework for management of aquifers - a literature review. J Aust Geol Geophys 14(2/3):155-159

Datta B, Peralta RC (1986) Interactive computer graphics-based multiobjective decision-making for regional groundwater management. Agric Water Manag 11:91-116

Demetriou C, Punthakey JF (1999) Evaluating sustainble groundwater management options using the MIKE SHE integrated hydrogeological modelling package. Environ Model Software $14: 129-140$

Doherty J (2003) Ground water model calibration using pilot points and regularization. Ground Water 41(2):170-177

Doherty J (2004) PEST: model-independent parameter estimation. User manual, 5th edn. Watermark, Brisbane

Doherty J, Skahill BE (2006) An advanced regularization methodology for use in watershed model calibration. J Hydrol 327(3-4):564-577

Fatta D, Naoum D, Loizidou M (2002) Integrated environmental monitoring and simulation system for use as a management decision support tool in urban areas. J Environ Manage 64:333-343

Feinerman E, Knapp KC (1983) Benefits from groundwater management: magnitude, sensitivity, and distribution. Am J Agric Econ 65(4):703-710

Fienen MN, Masterson JP, Plant NG, Gutierrez BT, Thieler ER (2013) Bridging groundwater models and decision support with a Bayesian network. Water Resour Res 49:6459-6473

Focazio MJ, Reilly TE, Rupert MG, Helsel DR (2002) Assessing ground-water vulnerability to contamination providing scientifically defensible information for decision makers. U.S. Geological Survey Circular 1224, Denver, Colorado

Fredrick KC, Becker MW, Flewelling DM, Silavisesrith W, Hart ER (2004) Enhancement of aquifer vulnerability indexing using the analytic-element method. Environ Geol 45 (8):1054-1061

Freeze RA (1992) Hydrogeological decision analysis. Ground Water 30:574-588

Freeze RA, Massmann J (1990) Hydrogeological decision-analysis: 1. A framework. Ground Water 28(5):738-766

Gisser M, Sánchez DA (1980) Competition versus optimal control in groundwater pumping. Water Resour Res 16(4):638-642

Gregory RS, Fischoff B, McDaniels T (2005) Acceptable input: using decision analysis to guide public policy deliberations. Decis Anal 2(1):4-16

Guillaume JHA, Pierce SA (2011) Groundwater management: what methods have we used to address uncertainty when making decisions? MODFLOW \& More 2011, Golden, Colorado, 5-8 June 2011

Guillaume JHA, Qureshi ME, Jakeman AJ (2012) A structured analysis of uncertainty surrounding modeled impacts of groundwater extraction rules. Hydrogeol J. doi:10.1007/s10040-012-0864-0 
Hadded R, Nouiri I, Alshihabi O, Maßmann J, Huber M, Laghouane A, Yahiaoui H, Tarhouni J (2013) A decision support system to manage the groundwater of the Zeuss Koutine aquifer using the WEAP-MODFLOW framework. Water Resour Manag 27:1981-2000

Haith DA, Loucks DP (1976) Multiobjective water-resources planning. In: Biswas AK (ed) Systems approach to water management. McGraw Hill, New York, pp 365-397

Hamby DM (1994) A review of techniques for parameter sensitivity analysis of environmental models. Environ Monit Assess 32(2):135-154

Hamilton SH, ElSawah S, Guillaume JHA, Jakeman AJ, Pierce SA (2015) Integrated assessment and modelling: overview and synthesis of salient dimensions. Environ Model Software 64:215-229

Harbaugh AW, McDonald MG (1996) User's document for MODFLOW-96, an update to the U.S. Geological Survey modular finite-difference ground-water flow model. US Geological Survey Open-File Report 96-485, $56 \mathrm{p}$

Hill MC (1998) Methods and guidelines for effective model calibration. US Geological Survey Water Resources Investigation Report 98-400

Jakeman AJ, Letcher RA (2003) Integrated assessment and modelling: features, principles and examples for catchment management. Environ Model Software 18:491-501

Jamieson DG (1997) Special Issue on decision-support systems (DSS). J Hydrol 199:211-212

Kalf FRP, Wooley DR (2005) Applicability and methodology of determining sustainable yield in groundwater systems. Hydrobiol J 13:295-312

Keeney RL (1992) Value-focused thinking: a path to creative decisionmaking. Harvard University Press, Cambridge, MA, $416 \mathrm{p}$

Kersten GE (2000) Decision making and decision support, decision support systems for sustainable development: a resource book of methods and applications. Kluwer, Boston, $423 \mathrm{p}$

Kersten GE, Lai H (2008) Negotiation support and e-negotiation systems. In: Burstein F, Holsapple CW (eds) Handbook on decision support systems 1: basic themes. Springer, Berlin, pp 469-508

Khaiter PA (2005) Simulation modelling in quantifying ecosystem services and sustainable environmental management. In: MODSIM 2005 international congress on modelling and simulation. York University, Canada, pp 347-353

Kresic N (1997) Quantitative solutions in hydrogeology and groundwater modeling. Lewis Publishers, Boca Raton, $461 \mathrm{p}$

Lanini S, Courtois N, Giraud F, Petit V, Rinaudo JD (2004) Socio-hydrosystem modelling for integrated water-resources management - the Herault catchment case study southern France. Environ Model Software 19:1011-1019

Latinopoulos P, Mylopoulos N, Mlopoulos Y (1996) Risk-based decision analysis in the design of water supply projects. J Hydrol 177:263-281

Le Page M, Berjamy B, Fakir Y, Bourgin R, Jarlan L, Abourida A, Benrhanem M, Jacob G, Huber M, Sghrer F, Simonneaux V, Chehbouni G (2012) An integrated DSS for groundwater management based on remote sensing. The case of a semi-arid aquifer in Morocco. Water Resour Manage 26:3209-3230

Leavesley GH, Markstrom SL, Restrepo J, Viger RJ (2002) A modular approach to addressing model design, scale, and parameter estimation issues in distributed hydrological modelling. Hydrol Process 16(2):173-187

Letcher RA (2005) Implementation of a water allocation decision support system in the Namoi and Gwydir valleys. In: MODSIM 2005 international congress on modelling and simulation, Canberra, pp 1546-1552

Li JP, Chen R, Lee J, Rao HR (2013) A case study of private-public collaboration for humanitarian free and open source disaster management software deployment. Decis Support Syst 55:1-11

Little JDC (1970) Models and managers: the concept of a decision calculus. Manag Sci 16(8): B466-B485

Lovejoy SB, Lee JG, Randhir TO, Engel BA (1997) Research needs for water quality management in the 21st century: a spatial decision support system. J Soil Water Conserv 52(1):18-22

Mace RE, Mullican WF, Way TS-C (2001) Estimating groundwater availability in Texas. In: 1st annual Texas Rural Water Association and Texas Water Conservation Association Water Law Seminar: Water Allocation in Texas: The Legal Issues, Austin 
Margerum RD (2008) A typology of collaboration efforts in environmental management. Environ Manage 41(4):487-500

Matott LS, Babendreier JE, Purucker ST (2009) Evaluating uncertainty in integrated environmental models: a review of concepts and tools. Water Resour Res 45. doi:10.1029/2008WR007301

McIntosh BS, Ascough JC II, Twery M, Chew J, Elmahdi A, Haase D, Harou JJ, Hepting D, Cuddy S, Jakeman AJ, Chen S, Kassahun A, Lautenbach S, Matthews K, Merritt W, Quinn NWT, Rodriguez-Roda I, Sieber S, Stavenga M, Sulis A et al (2011) Environmental decision support systems (EDSS) development - challenges and best practices. Environ Model Software 26:1389-1402

McKinney DC, Cai X, Maidment DR (1997) A prototype GIS-based decision support system for river basin management. ESRI user conference, Austin, Texas

Miles JC, Chambet PD (1995) Safe yield of aquifers. J Water Resour Plan Manag 121(1):1-8

Mintzberg H, Raisinghani D, Theoret A (1976) The structure of "Unstructured" decision processes. Adm Sci Q 21(2):246-275

Molina JL, Pulido-Velázquez D, García-Aróstegui JL, Pulido-Velázquez M (2013a) Dynamic Bayesian networks as a decision support tool for assessing climate change impacts on highly stressed groundwater systems. J Hydrol 479:113-129

Molina JL, Pulido-Velázquez M, Llopis-Albert C, Pe na-Haro S (2013b) Stochastic hydroeconomic model for groundwater quality management using Bayesian networks. Water Sci Technol 67(3):579-586

Moore R, Tindall I, Fortune D (2004) Update on the Harmonit project - the OpenMI Standard for model linking. In: 6th international hydroinformatics conference, Singapore

Moura P, Barraud S, Baptista MB, Malard F (2011) Multicriteria decision-aid method to evaluate the performance of stormwater infiltration systems over the time. Water Sci Technol 64 (10): 1993-2000

Mysiak J, Giupponi C, Rosato P (2005) Towards the development of a decision support system for water resource management. Environ Model Software 20:203-214

Naik PK, Awahthi AK (2003) Groundwater resources assessment of the Koyna River basin, India. Hydrogeol J 11(5):582-594

Nalbantis I, Rozos E, Tentes GAE, Koutsoyiannis D (2002) Integrating groundwater models within a decision support system. National Technical University of Athens, Athens

Narasimhan TN (2005) Hydrogeology in North America: past and future. Hydrogeol J 13(1):7-24

National Research Council (1997) Valuing ground water: economic concepts and approaches. National Academy Press, Washington, DC, $189 \mathrm{p}$

Naveh N, Shamir U (2000) Decision support system for managing the Hula project (only summary available). Israel Institute of Technology, Haifa, $19 \mathrm{p}$

Oxley T, Winder N, McIntosh B, Mulligan M, Engelen G (2002) Integrated modelling and decision support tools: a mediterranean example. In: Integrated Assessment and Decision Support, Proceedings of the first biennial meeting of the international environmental modelling and software society, Manno

Pereira AG, Quintana SC (2002) From technocratic to participatory decision support systems: responding to the new governance initiatives. J Geogr Inf Decis Anal 6(2):95-107

Pierce SA (2006) Groundwater decision support: linking causal narratives, numerical models, and combinatorial search techniques to determine available yield for an aquifer system. Dissertation, The University of Texas at Austin

Pierce SA, Dulay MM, Sharp JM, Lowry TS, Tidwell VC (2006) Defining tenable groundwater management: integrating stakeholder preferences, distributed parameter models, and systems dynamics to aid groundwater resource allocation. In: MODFLOW and More 2006: Managing groundwater systems, Golden, p 810

Pierce SA, Sharp JM, Guillaume JHA, Mace RE, Eaton DJ (2013) Aquifer-yield continuum as a guide and typology for science-based groundwater management. Hydrogeol J 21:331-340

Poeter EP, Hill MC (1998) Documentation of UCODE: a computer code for universal inverse modeling. US Geological Survey Water Resources Investigation report 98-4080, Denver, Colorado 
Power DJ (2003) Decision support systems hyperbook, DSSResources.com, HTML version: Cedar Falls, IA, Power, D. J, Cedar Falls, Iowa

Power DJ (2007) A brief history of decision support systems. DSSResources.COM, World Wide Web, http://DSSResources.COM/history/dsshistory.html, version 4.0.

Quintana SC, Pereira AG, Funtowicz S (2005) GOUVERNe: new trends in decision support for groundwater governance issues. Environ Model Software 20:111-118

Rahman JM, Cuddy SM, Watson FGR (2004) Tarsier and ICMS: two approaches to framework development. Math Comput Simul 64(3-4):339-350

Recio B, Ibanez J, Rubio F, Criado JA (2005) A decision support system for analysing the impact of water restriction policies. Decis Support Syst 39:385-402

Reed PM, Hadka D, Herman JD, Kasprzyk JR, Kollat JB (2013) Evolutionary multiobjective optimization in water resources: the past, present, and future. Adv Water Resour 51:438-456

Segrera S, Ponce-Hernandez R, Arcia J (2003) Evolution of decision support system architectures: applications for land planning and management in Cuba. J Comput Sci Technol 3(1):40-46

Simon HA (1960) The new science of management decision. Harper and Row, New York

Singh AJ (2012) An overview of the optimization modeling applications. J Hydrol 466-467:167-182

Sophocleous M, Ma T (1998) A decision support model to assess vulnerability to salt water intrusion in the great bend prairie aquifer of Kansas. Ground Water 36(3):476-483

Sullivan CA (2014) Planning for the Murray-Darling Basin: lessons from transboundary basins around the world. Stochastic Environ Res Risk Assess 28:123-136

Sydelko PJ, Hlohowskyj I, Majerus K, Christiansen J, Dolph J (2001) An object-oriented framework for dynamic ecosystem modeling: applications for integrated risk assessment. Sci Total Environ 274:271-281

Triana E, Gates T, Labadie J (2010) River GeoDSS for agroenvironmental enhancement of Colorado's Lower Arkansas River Basin. II: evaluation of strategies. J Water Resour Plann Manage: 190-200. doi:10.1061/(ASCE)WR.1943-5452.0000021

United Nations (2010) World population prospects: 2010 revision population database. http:// www.un.org/esa/population/unpop.htm. Accessed 15 July 2013

van Cauwenbergh N, Pinte D, Tilmant A, Frances I, Pulido-Bosch A, Vanclooster M (2008) Multiobjective, multiple participant decision support for water management in the Andarax catchment, Almeria. Environ Geol 54:479-489

van Evert F, Holtzworth D, Muetzelfeldt R, Rizzoli A, Villa F (2005) Convergence in integrated modeling frameworks. In: MODSIM 2005 international congress on modelling and simulation, Canberra, pp 1539-1545

van Kerkhoff L, Lebel L (2006) Linking knowledge and action for sustainable development. Ann Rev Environ Res 31:12.11-12.33

Villa F (2007) A semantic framework and software design to enable the transparent integration, reorganization and discovery of natural systems knowledge. J Intell Inf Syst 29:79-96. doi:10.1007/s10844-006-0032-x

Voinov A, Bousquet F (2010) Modelling with stakeholders. Environ Model Software 25 (11): $1268-1281$

Weight WD, Sonderegger JL (2001) Manual of applied field hydrogeology, professional engineering. McGraw-Hill, New York, 608 p

Welp M, de la Vega-Leinert A, Stoll-Kleemann S, Jaeger CC (2006) Science-based stakeholder diablogues: theories and tools. Glob Environ Chang 16:170-181

Xiang WN (1993) A GIS method for Riparian water quality buffer generation. Int J Geogr Inf Syst 7(1):57-70

Zhang SH, Xia ZX, Wang TW (2013) A real-time interactive simulation framework for watershed decision making using numerical models and virtual environment. J Hydrol 493:95-104 


\title{
Integrated Groundwater Data Management
}

\author{
Peter Fitch, Boyan Brodaric, Matt Stenson, and Nate Booth
}

\begin{abstract}
The goal of a data manager is to ensure that data is safely stored, adequately described, discoverable and easily accessible. However, to keep pace with the evolution of groundwater studies in the last decade, the associated data and data management requirements have changed significantly. In particular, there is a growing recognition that management questions cannot be adequately answered by single discipline studies. This has led a push towards the paradigm of integrated modeling, where diverse parts of the hydrological cycle and its human connections are included. This chapter describes groundwater data management practices, and reviews the current state of the art with enterprise groundwater database management systems. It also includes discussion on commonly used data management models, detailing typical data management lifecycles. We discuss the growing use of web services and open standards such as GWML and WaterML2.0 to exchange groundwater information and knowledge, and the need for national data networks. We also discuss crossjurisdictional interoperability issues, based on our experience sharing groundwater data across the US/Canadian border. Lastly, we present some future trends relating to groundwater data management.
\end{abstract}

P. Fitch $(\bowtie) \bullet$ M. Stenson

Commonwealth Scientific Industrial Research Organisation (CSIRO), Canberra, ACT, Australia e-mail: Peter.fitch@csiro.au

B. Brodaric

Geological Survey of Canada, Calgary, AB, Canada

N. Booth

United States Geological Survey (USGS), Reston, VA, USA

(C) The Author(s) 2016 


\subsection{Introduction}

There is a growing recognition that many environmental/hydrological management questions cannot be adequately answered by single discipline studies. This has led a push towards a systems view (Chap. 24), which includes integrating many aspects of the hydrological cycle (Chaps. 1 and 3). The push for integration has significant implications for data management. It requires that data are not only well stored, but also well described, easily discoverable and accessible, and in consistent form for use in the different models in an integrated modeling system. The development of the proto-operational Australian Water Resource Assessments (AWRA) (Van Dijk et al. 2011) system in Australia and a similar system under development by the USGS (Alley et al. 2013) are good examples of this, along with many other studies reported in the literature (Schou et al. 2000; Croke et al. 2006; Krol et al. 2006).

In addition to the focus on integration, new technologies in monitoring and computing, such as advances in computational power and storage, have allowed for an increase in the complexity of studies undertaken. For example, groundwater modeling is increasingly being undertaken at larger scales and groundwater flow is being incorporated into earth system modeling - fully coupled biogeochemical climate models - reflecting the growing awareness of the importance of groundwater systems to society. Therefore, there is a growing need to share data across different jurisdictional and groundwater management areas.

All of these factors mean that groundwater data management, and its support of groundwater modeling, is changing rapidly. It is shifting from discrete standalone data management processes and systems, to connected open and shared data systems that support integrated modeling and decision support (Chap. 25). The chapter is organized as follows: first the concepts of data management are discussed, and then current practices with existing toolsets. This is followed up with case studies and last is some discussion on future directions and trends.

This chapter is not directed at organizations that are responsible for data management; rather it aims to inform the research practitioner who is responsible for an integrated modeling study.

\subsection{Data Management Lifecycle}

\subsubsection{What Is Data Management?}

Data management means different things to different practitioners, and often the varying views reflect the differing roles of the actors in the system. The World Meteorological Organization (WMO) Guide to Hydrological Practices (WMO 2008) provides the following definition: 
We define data management as the set of processes or procedures together with a defined workflow and tools, roles and governance arrangements to ensure secure storage ease of discovery and access as well as ensuring the quality and integrity of the data. These data processes and workflows tend to be formally represented in data management models of which there are many examples. In addition, the implementation of a data management model is with a data management plan.

This definition provides the context for following discussion on groundwater data management.

\subsubsection{Data Management Models}

The task for a data management model is to define the data management workflow and process. It does not necessarily define the governance, nor does it specify how things are to be done. These models are typically defined using graphical representation or formal modeling notation such as Business Process Modeling Notation ${ }^{1}$ (BPMN). Here we present two data management models.

The first data management model is presented below in Fig. 26.1, and comes from the WMO Guide to Hydrological Practices (WMO 2008). This model describes a data management scheme where the roles, tools, processes and data products are defined in an abstract manner. This model has been subject to significant input from many practitioners, and is useful as a high-level framework for applications such as integrated groundwater modeling studies. The workflow is described by following the sequence of processes from top to bottom, with the tools used for each of the process connected by dashed lines, and the actors performing particular roles are associated with the tools. In the last column, a range of data inputs and outputs are identified.

The second model is illustrated in Fig. 26.2 using BPMN notation. It is taken from the Data Documentation Initiative (Thomas et al. 2009), which defines a combined cycle including data management processes as well as the associated workflow.

The workflow flows from left to right commencing at the "Start" symbol. Each of the rectangular boxes defines a process and the arrows represent transitions through the workflow from one process to the next.

\footnotetext{
${ }^{1}$ www.bpmn.org.
} 


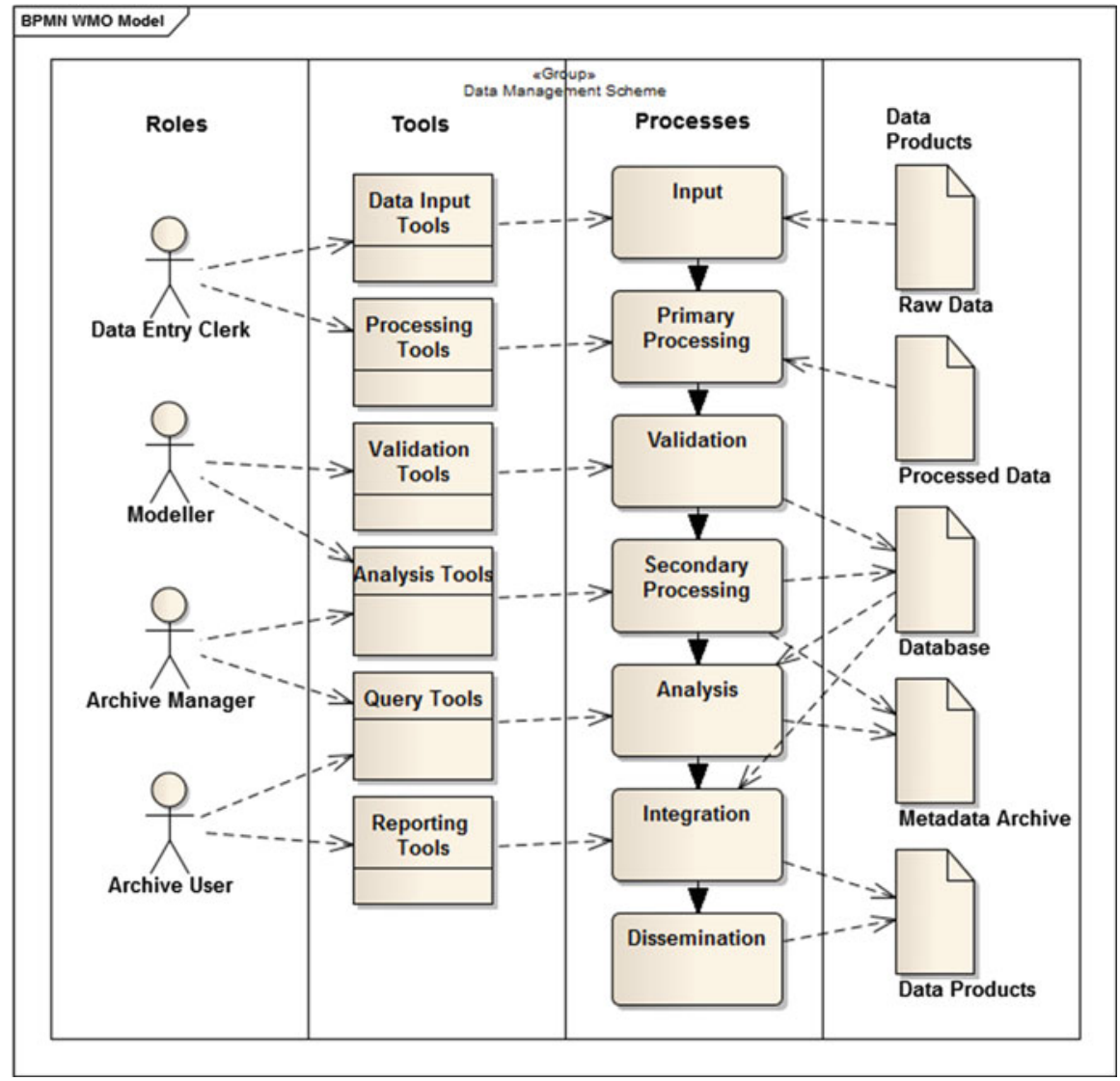

Fig. 26.1 WMO data management scheme

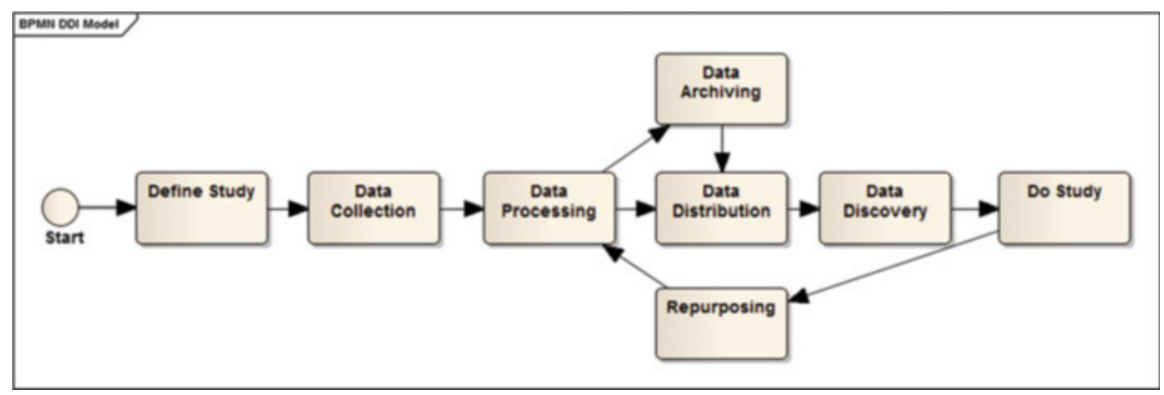

Fig. 26.2 DDI data lifecycle model 
This model can be applied to integrated groundwater studies as follows:

Define Study For collection of integrated data, the first goal is to define study objectives, the models to be integrated, and the associated data requirements.

Data Collection The next process involves collection of all the data for the integrated study.

Data Processing In this step, the data is preprocessed into appropriate resolutions and formats such that it is suitable for the integrated models. Typically at this stage, a number of quality assurance and checks are undertaken.

Data Archiving Next, the data is archived in preparation for further distribution and use.

Data Distribution Prior to the study being undertaken, the data are made available through a distribution mechanism. This is very consistent with enterprise data management models where centralised data storage is used, either by way of databases or fileservers. These data stores are then accessed for the study by way of a data discovery process. More contemporary methods of data distribution using web services are now gaining favor.

Data Discovery In this step, the data are located for the groundwater study.

Do Study This is the step in the model where the study is performed. Note groundwater studies, especially modeling studies, almost always are iterative, and this iteration is reflected in the subsequent repurposing of the data.

Repurposing The final step in this workflow, takes the data generated by the groundwater study and repurposes it for another use. This could either be another integrated study, or simply another iteration within the current study.

It is worth noting that this data management model can be modified depending upon the purpose of the study and is provided as a general-purpose model. For example an additional feedback loop can be drawn between 'Do Study' and 'Data Collection' if during the study additional data needs have been identified.

\subsubsection{The Data management Challenge}

Data management is successful when data are discoverable, available, accessible, understandable, and usable (Robbins 2012). This perspective comes from the ecological community and their long-term ecological research (LTER) program. It recognizes that successful studies depend on the development of integrated databases and data sets, many of which are collected by different teams over 
different timescales and are required to be brought together to tackle integrated scientific challenges (Costello 2009), such as integrated groundwater modeling studies. However, while management of data is a core part of the mission of large organizations such as USGS and Bureau of Meteorology in Australia, it is often the case that even within these organizations it is difficult to establish good data management practices in research projects.

Data management is beset with multifaceted problems characterized by social, cultural, and technical dimensions. The social and cultural issues associated with data management are often overlooked and can often be the reason why organizations, research project teams, and individuals, struggle with it.

Leadership heavily influences the culture of an organization, by modeling and defining behavior and values. This is particularly evident in many research projects and integrated modeling studies. It therefore follows that perhaps the most important single driver for good data management within an organization, project or study is the priority placed on it by leadership. This begins with individual practitioners recognizing the value of data, and its management, and cascades to project leaders and senior managers, who include and enforce data management in project plans through policies and adequate resourcing (Costello 2009). Efforts in this area are also augmented by leadership from national agencies such as the US National Science Foundation (NSF) and UK National Environment Research Council (NERC), which now require a data management plan to be prepared with all research funding applications.

\subsubsection{Data Quality Assurance and Quality Control}

The concepts of data Quality Assurance (QA) and Quality Control (QC) are profoundly critical any study. This topic is mentioned here because of its importance, but the reader is referred to WMO 2008 for a detailed treatment of the practical issues and approaches to ensuring QA/QC of hydrological data. In this section we will provide definitions of QA and QC, illustrating the differences, which are not always well understood.

QC is defined as a procedure or set of procedures intended to ensure that data adheres to a defined set of quality criteria, typically accuracy and reliability. These checks are usually done post data acquisition. QA is a more systematic approach to ensuring that the data will meet quality requirements, typically undertaken prior to data acquisition. To illustrate these differences, we will use a manufacturing example. Say a plastic part is manufactured with specific dimensions and tolerance of $10 \mathrm{~mm}$ square plus or minus $0.1 \mathrm{~mm}$. A quality control is to check these dimensions with a micrometer to confirm that the part meets specification. In this case the dimension and tolerances are the quality criteria. For data quality control, checks could include bounds checking (not exceeding known maximum or minimum criteria) and that it conforms to some expected distribution and so on.

QA is defined as a procedure or a systematic set of procedures intended to ensure quality controlled data. These are procedures undertaken before data acquisition, 
intended to improve/ensure quality once checked for. In our manufacturing example, these might include regular maintenance of the machine that manufactures the part, training for the operator, etc. Examples of this for data measurement systems can include instrument calibration procedures, operator training and so on.

QA and QC are usually bundled together as QA/QC without a good understanding of the differences and are commonly now tackled together by organisations implementing a quality management framework such as ISO $9001 .^{2}$

For more information, the reader is directed to WMO (2008, Chap. 9) for details on data processing and quality control.

\subsubsection{Data Licensing}

There is a growing push towards the idea of open data across the research and government sectors, particularly for data supported by publically funded programs. Opendefinition.org provides the following definition: "a piece of data or content is open if anyone is free to use, reuse, and redistribute it - subject only, at most to the requirement to attribute and/or share - alike." Examples of the growing interest in open data are the open data agendas of the United States, Canada, United Kingdom and Australia. These are manifest in data discovery and access portals such as data. gov, data.gov.au, and others. Many of these data initiatives use open data licensing such as Open Data Commons (opendatacommons.org) and Creative Commons (creativecommons.org.au). The intent of all of these open license formats is to maintain copyright with the data creator, ensure attribution, and to transfer risk of use to the user. The interest in Opendata is driven by the assumption that making data freely available generates greater value to society. The authors of this chapter subscribe to this view.

Much data used in integrated studies are subject to a restrictive data license. This is particularly the case in environmental studies where there has been significant cost to collect hydrogeological data, lithological data, and so on. There are potentially other concerns that may limit availability such as commercial interests (eg. storage levels within a hydro-electricity scheme) or potential security concerns. In our work with large scale integrated surface and groundwater modeling, the majority of data have come from state jurisdictions and water management authorities, and is subject to strict licensing conditions. It is often the case for the data to be licensed for a particular study, and in some cases with conditions stipulating deletion once the study is complete (Hartcher and Lemon 2008). Any data management initiative thus needs to be fully cognizant of the many and varied and often strict data licensing requirements.

\footnotetext{
${ }^{2}$ http://www.iso.org/iso/iso_9000.
} 


\subsubsection{Data Management and Analysis Tools}

Integrated groundwater studies have a specific set of requirements for data types and their specific data management needs. For integrated groundwater modeling studies, these are well described by Refsgaard et al. (2010). Typical data include borehole data containing general descriptions, location, lithology, borehole geophysics, water level and water chemistry. This is supplemented with surface geophysical data, which might include seismic, electromagnetic and electrical data from which the hydrogeology and conceptual models of the groundwater systems can be developed. Most groundwater data management systems have separate tools, processes, and mechanisms for storage of time series, GIS, and spatial data, metadata, and conceptual models.

\subsection{Time Series Data Management}

There exist many commercial time-series data management systems, which specialize in the storage, dissemination and management of surface and groundwater data (e.g. WISKI, ${ }^{3}$ Schlumberger ${ }^{4}$ and Aquatic Informatics ${ }^{5}$ ). These types of software packages typically allow ingestion of a variety of data sources including telemetry from automated gages, perform quality assurance, and usually are coupled to integrated analysis tools. They are also able to store a broad set of other hydrological, meteorological and climate data. Most of these systems use relational database technology as the persistence mechanism, which is then attached to a series of tools, as can be seen in the abstract model of a timeseries data management system in Fig. 26.3 below. In this diagram, we map the functional elements described by WMO in Fig. 26.1 above to this abstract model. For these systems, the data output toolsets are increasingly being used to deliver data outside the enterprise using web services and open standards such as WaterML2.0 (Taylor et al. 2013).

This ability to deliver data outside the enterprise becomes very useful for integrated studies and allows time series systems to become part of a web-based data network, which is discussed further below in web-based data management and modeling section.

\footnotetext{
${ }^{3}$ http://www.kisters.eu/english/html/homepage.html.

${ }^{4}$ http://www.slb.com/services/software.aspx.

${ }^{5}$ http://aquaticinformatics.com.
} 


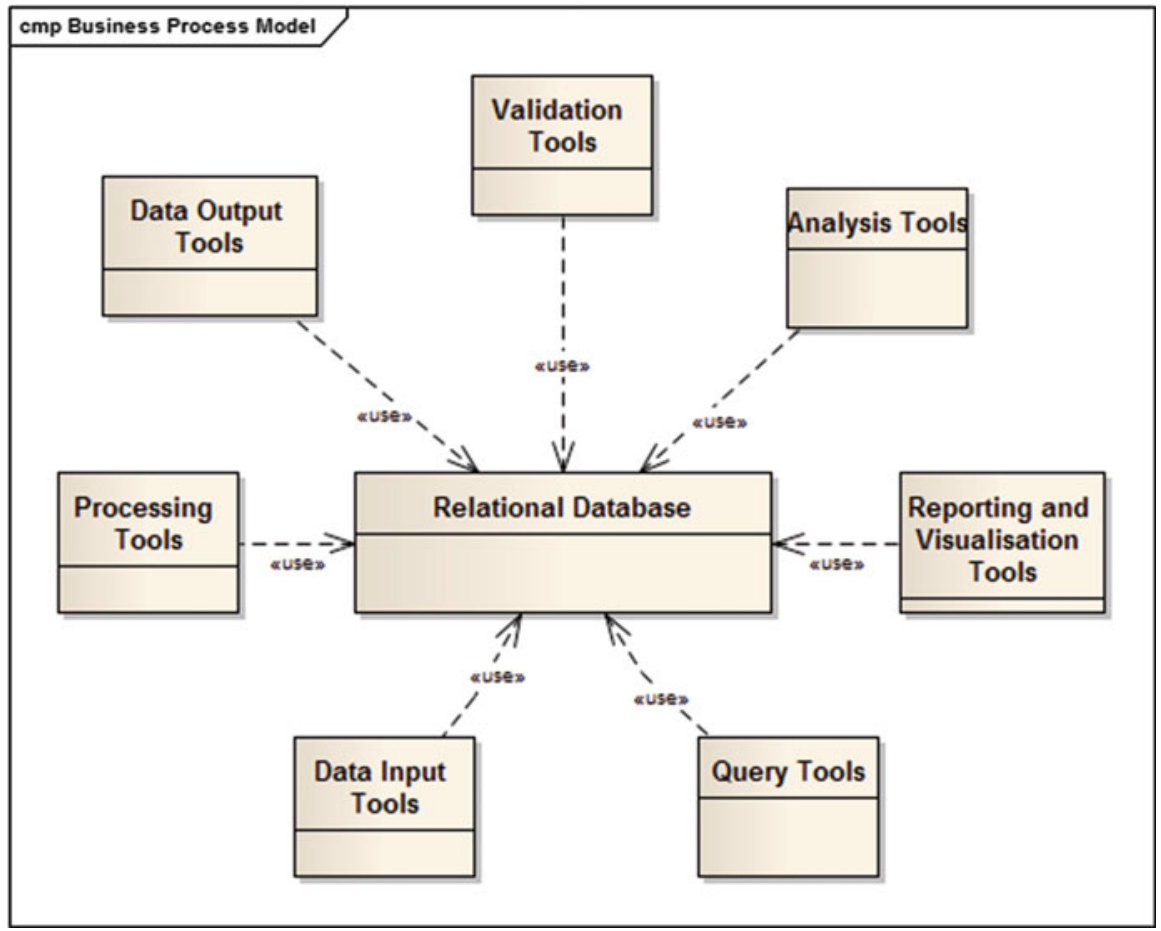

Fig. 26.3 Abstract model of a time series data management system

\subsection{GIS toolsets}

GIS systems are a core tool for integrated environmental modeling and are widely used (Argent 2003; Gogu et al. 2001; Whiteaker et al. 2006). GIS toolsets are used for spatial and temporal data management, spatial data-processing and analysis, and they can form a software framework for integrated modeling scenarios (Ames et al. 2012).

In Fig. 26.4 above, Argent (2003) describes how GIS systems can be used for integrated modelling application. Two workflows are described, one simply uses GIS for spatial data management (diagram on the right) and the other (on the left) describes a more integrated use of GIS toolsets. In this workflow, the GIS becomes the integration tool, where various modeling applications are created and run. For a good example of this type of workflow, see Gogu et al. (2001). 

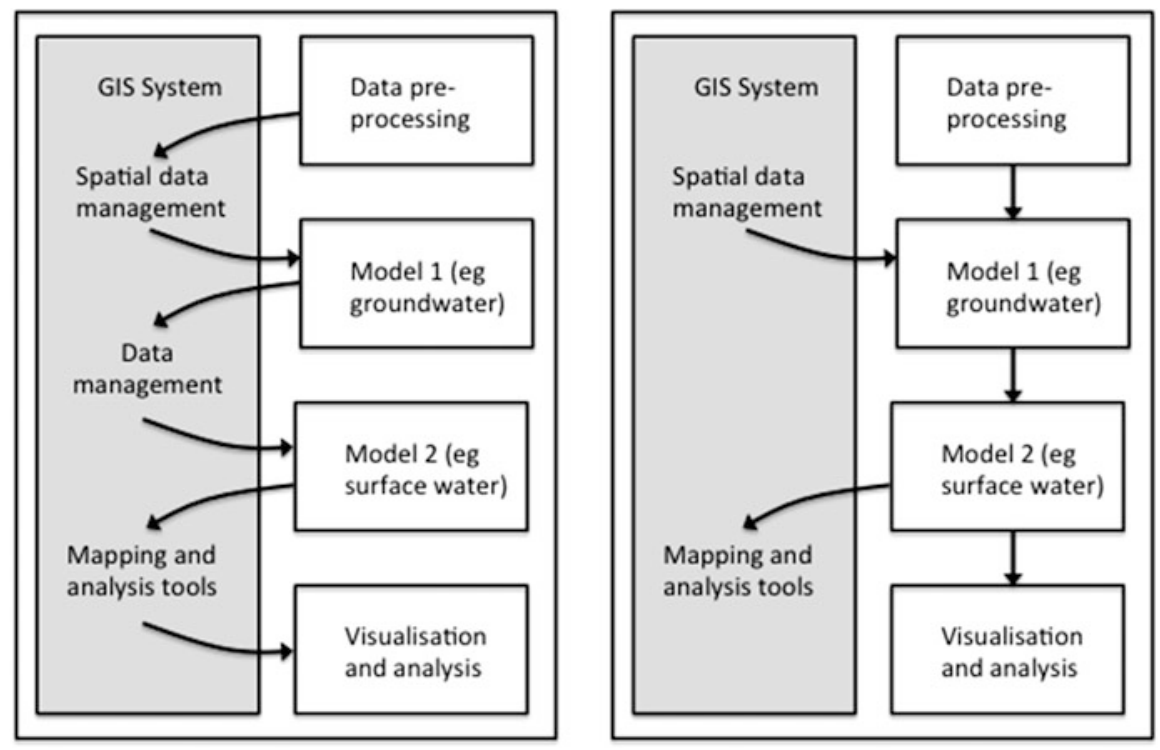

Fig. 26.4 GIS workflow for integrated modelling after Argent (2003)

\subsection{Examples of GIS Data models}

The widespread use of GIS systems as a data management and data integration tool has led to the development of domain specific geospatial databases, called GeoDatabases. These are optimized for the sorts of data commonly used in geospatial studies, in this case with integrated groundwater studies. These Geodatabase models (Strassberg et al 2004; Jarar Oulidi et al 2009; Chesnaux et al 2011; Yang et al 2010b) represent the features and properties of hydrogeological systems, in ways that allow storage, integration and manipulation of the spatial and time series data. In the hydrology domain, the two most widely used models are ARCHydro (Maidment 2002) for surface water studies, and ARCHydroGW (Strassberg et al. 2004) for groundwater studies.

ARCHydro is a geographical data model for hydrological systems designed to support a cartographic representation of hydrological features. It is designed to provides a unified model for geospatial and time series data in support of integrated hydrological modeling and analysis (Strassberg et al. 2004). It allows different aspects of the water-resource systems, such as a drainage system, hydro-network and channel system, to be linked to time series flow observations and managed within the GIS system.

ARCHydroGW provides a data model for hydrogeologic units, boreholes and other aspects of groundwater systems that can be used for integrated modelling. 
There are many studies which have successfully used these types of models (Whiteaker et al. 2006) in conjunction with GIS toolsets.

One issue that arises concerns unique identifiers in these types of systems (called HydroID in ARCHydro-GW), which identify features in the geospatial databases. Usually these identifiers have local scope, meaning that they are assigned to be unique within a GeoDatabase, and are most usually non-unique when combining or integrating databases. As a result, it becomes difficult to automatically merge databases when conducting integrated studies, requiring significant effort to match or differentiate hydro-geological features based other information.

Another issue concerns the assignment of a fixed geometry to a feature type. For example, a borehole might be represented by a point, in one particular GeoDatabase, and by a line in another GeoDatabase. Thus integrating the different representations between GeoDatabases becomes problematic. This has led to the development of the Hy-Features (Atkinson et al. 2012) conceptual model, in which the features are defined independently of representation. The difference may seem to be esoteric, but defining features in this way allows for easier integration of data for a particular feature type, and greatly eases integrated studies.

\subsection{Metadata Requirements}

For the integrated modeler, the discovery of data suitable for modeling studies always depends on the availability of suitable metadata and an ability to search across it. Most organizations with data management programs will have metadata standards or profiles defined. Examples include the Australian and New Zealand Land Information Council (ANZLIC) in Australia, and the Federal Geographic Data Committee (FGDC) in the US. In general, there is a significant international adoption of the ISO/TC $211^{6}$ standards, and many of the emerging national metadata standards are now using ISO as a core, with profiles or extensions as required. Because of this standardization, many tools are appearing which support these standards and leverage them to allow federated searching capabilities. Examples of these include GeoNetwork (http://geonetwork-opensource.org), GI-Cat (http://essi-lab.eu/do/view/GIcat), and Esri Geoportal (http://www.esri. com/software/arcgis/geoportal). In all of these examples, the tools support a number of different metadata profiles and have the ability to harvest metadata records from other catalogs. This federated search ability distributes the responsibility and burden for the generation and management of metadata to data providers, and then allows federated catalogs to be easily assembled and queried by users.

\footnotetext{
${ }^{6}$ http://www.isotc211.org/.
} 


\subsection{Conceptual Models}

In hydrological modeling the need for a scientific conceptual model is well known (Refsgaard et al. 2010). Though related, scientific conceptual models are distinguished from information conceptual models (discussed in semantics below). Information conceptual models consist of theoretical knowledge (consistent with the scientific conceptual model), such as feature types and scientific theories, whereas scientific conceptual models are essentially re-constructions of a physical area and consist of representations of actual features. Scientific conceptual models provide a description of the agreed understanding of the system under study. Refsgaard et al. (2010) argue for a scientific conceptual model repository to help combine knowledge effectively. We argue that defining both scientific and information conceptual models, and having them discoverable and readily available, is a key requirement for integrated studies.

\subsection{Web-Based Data Management and Modeling}

Integrated studies by their very nature have significant data management and integration challenges. When coupled with the rapidly growing data holdings (for example, in national agencies), an environment is created where discovery access and use of data becomes increasingly difficult. As a result, an interest in interoperability has grown, and practitioners are increasingly looking to the web for help in data management and modeling, such that web-based data access and management is now common place (Granell et al. 2009; Frehner and Brändli 2006). Much of the recent advances in this area have been precipitated by the more than a decade's interest in Spatial Data Infrastructures (SDI; Masser 2010), which has directly led to the development of pan-national standards such as INSPIRE in Europe (http:// inspire.jrc.ec.europa.eu), and the construction of associated data networks, including those for hydrology and hydrogeology. In this model of data management, organizations are responsible for management of data and making it discoverable, accessible and available by way of a data network. This approach has significant benefits for integrated studies.

In the next section, we discuss challenges and approaches to building and coupling groundwater data networks, and describe several examples: one example from Canada, two from the US, a unified Canada-US example, and a US example from academia. 


\subsection{Groundwater Data Networks}

Groundwater data networks are becoming an important source of data for groundwater studies, due to the increased breadth and depth of their data holdings (Refsgaard et al. 2010). In data networks, autonomous data sources are federated into a composite entity, which behaves as a unified single enterprise. For example, regional groundwater monitoring networks, water well databases, aquifer maps, and other relevant data, are being variously integrated into larger networks in Australia, Canada, and the US (Booth et al. 2011; Brodaric et al. 2011; Dahlhaus et al. 2012). Such networks are typically arranged in some form of distributed architecture, which dynamically retrieves data from original sources, thus ensuring access to current data. They also typically enable users to query and obtain data via a unified common view, shielding users from the heterogeneity of the original sources. In this way, more data, and more data types, are more readily accessed by those studying groundwater, including modelers.

\subsection{Challenges: Data Interoperability in Groundwater Data Networks}

Data access is a key issue faced by all groundwater data users, including modelers, particularly those carrying out integrated studies using multiple data sources. Barriers to data access involve data availability, fragmentation, and heterogeneity: i.e. not all data are available online, and groundwater data are divided unevenly amongst multiple providers, such that the structure and content of the data is quite heterogeneous. This leads to problems in its usage, because data are hard to find, and once found are difficult to exploit due to the immense work required to re-format the data into a common usable structure. Figure 26.5 illustrates an example of heterogeneity in the lithology descriptions of water well databases from two adjacent Canadian provinces: note the differences in language (French/ English), structure (one field/many fields), and content (sand/fine and medium sand).

Overcoming the data access barrier thus requires a solution to the alignment of multiple heterogeneous and distributed data sources, i.e. to the data interoperability problem. Spatial Data Infrastructures (SDI) are a leading approach to this problem, and they are actively being adopted by various water data networks, including those for groundwater. Solutions to data interoperability typically require alignment of the data at five levels: systems, syntax, structure, semantics and pragmatics (Brodaric 2007). Ideally, SDI standards are used at each level, and in the water domain these are being developed in coordination with the Open Geospatial Consortium (OGC), the International Organization for Standardization (ISO), and professional bodies such as the World Meteorological Organization (WMO) (Zaslavsky et al. 2011): 


\begin{tabular}{|c|c|c|c|c|c|c|}
\hline & $\begin{array}{l}\text { cle_noseq } \\
\text { integer }\end{array}$ & $\begin{array}{l}\text { epaisseur } \\
\text { double precis }\end{array}$ & $\begin{array}{l}\text { matprim } \\
\text { character vaı }\end{array}$ & $\begin{array}{l}\text { fiss_prim } \\
\text { character vaı }\end{array}$ & $\begin{array}{l}\text { mat_sec } \\
\text { character vaı }\end{array}$ & $\begin{array}{l}\text { fiss_sec } \\
\text { character val }\end{array}$ \\
\hline 1 & 1 & 1.5 & SABL/BLO & INCO & & INCO \\
\hline 2 & 1 & 3.4 & SABL/BLO & INCO & & INCO \\
\hline 3 & 1 & 3.4 & ARGL/GRA & INCO & & INCO \\
\hline 4 & 1 & 2.7 & SABL/GRA & INCO & & INCO \\
\hline 5 & 1 & 0.3 & TERR & INCO & & INCO \\
\hline
\end{tabular}

\begin{tabular}{|c|c|c|c|c|c|c|}
\hline & $\begin{array}{l}\text { materialcolor } \\
\text { character vaı }\end{array}$ & $\begin{array}{l}\text { material_1 } \\
\text { character vaı }\end{array}$ & $\begin{array}{l}\text { material_2 } \\
\text { character vaı }\end{array}$ & \begin{tabular}{|l|} 
material_3 \\
character vaı
\end{tabular} & $\begin{array}{l}\text { topdepth } \\
\text { real }\end{array}$ & $\begin{array}{l}\text { bottomdepth } \\
\text { real }\end{array}$ \\
\hline 1 & & Topsoil & & & 0 & 0.3048 \\
\hline 2 & Black & Muck & & & 0.3048 & 0.9144 \\
\hline 3 & & Medium Sand & & & 0.9144 & 1.524 \\
\hline 4 & & Fine Sand & Silt & Clay & 1.524 & 7.3152 \\
\hline
\end{tabular}

Fig. 26.5 Heterogeneous water well data from the Canadian Groundwater Information Network (www.gw-info.net)

- The systems level involves the deployment of standard web interfaces to the data, typically web services such as WFS (Web Feature Service), SOS (Sensor Observation Service), and WMS (Web Map Service), which transmit features (e.g. wells), observations (e.g. groundwater levels), and map images, respectively (Boring et al. 2012; De La Beaujardière 2006; Panagiotis 2005).

- The syntax level involves the use of standard data languages, such as GML (Geographical MarkUp Language; Portele 2007), which can be used to encode data.

- The structure level includes standard data schema, such as OGC Observations and Measurements (O\&M), WaterML2 (WML2), and GroundwaterML (GWML), which are built with GML and constitute a common structure for observations, water time series, and groundwater features, respectively (Boisvert and Brodaric 2012; Cox 2011; Taylor et al. 2013). Standard schemas are typically diagrammed using well-constrained methods, such as UML, and can be expressed in a variety of formats, such as XML.

- The semantics level refers to the use of standard concepts and related terms. The terms are typically organized in vocabularies or codelists, and the concepts are typically organized in computational ontologies. Both can be applied to (1) data content, such as common rock type terms and their definitions, and (2) data structure, such as a commonly defined lithology field containing rock type terms. However, they can also refer to scientific knowledge in general, distinct from data, that is to the components of a scientific conceptual model. This includes definitions for the types of entities in the model, and expressions of underlying theories that drive the model.

- The pragmatics level includes standard tools and methods, so that data are collected and processed using common scientific protocols. 
As an example, the heterogeneous rock type descriptions from Fig. 26.5 can be resolved via transformations of the data at each level: a query in a web browser, for example wells possessing certain rock types, is translated into requests to WFS web services layered over each database (systems); the web services return water well records, by transforming the structure of the databases into standard GWML (syntax, schema), which uses one field to hold rock types, and the content of this field is populated with the rock types in the logs transformed into a standard English vocabulary (semantics). Community agreed protocols are used to determine how rock type terms correlate between the source data and the standard vocabulary (pragmatics). Finally, the results from each web service are integrated, producing a single unified GWML file that is returned to the modeler.

Note that data networks can vary according to where the transformations occur, for example locally at the source, or centrally, and some networks utilize a hybrid strategy that includes local transformations for some network nodes and centralized transformations for the remainder. Likewise, the degree of data centralization can also vary, as evident by the rise of hybrid approaches that use frequently updated central data caches as access points for some, but not all, of the data in a network. Lastly, the location of catalogs can also be centralized, distributed or hybrid; catalogs contain metadata that enable data to be found in the network and that facilitate data transformations, for example by serving local and standard vocabularies and ontologies. However, regardless of the architectural placement of these items within a network, data interoperability cannot be fully achieved without alignment at each of the five levels.

\subsection{Examples}

This section presents five examples. Example 26.1 is the Canadian Groundwater Information Network and Example 26.2 the US National GroundWater Monitoring Network. These are presented as examples of the trend towards large scale national groundwater data networks. Example 26.3 details an emergent North American Groundwater Data Network and discusses how individual networks, if constructed the right way, can be federated into a single federated groundwater data network. Example 26.4 is that of an academic surface water hydrological data network. Lastly, Example 26.5 discusses the use of integrated hydrological data provided from data networks in a national water assessment system. These five examples illustrate approaches that variously utilize hybrid methods for the placement of data, transformations, and related data catalogs. 


\section{Example 26.1: Canadian Groundwater Information Network}

The Canadian Groundwater Information Network (GIN; Brodaric et al. 2011) is a national federation of groundwater data sources managed by Canadian provinces and some federal departments. At present, it contains water well records for most of Canada, monitoring records (groundwater levels) for some selected provinces, and some key regional aquifer and geology maps. As shown in Fig. 26.6, GIN is an example of an architecture in which a centralized approach is used for data transformation and catalogs, and a hybrid approach is used for data placement, that is it is a mix of centralized data caches and distributed data sources such that some data are obtained from the centralized caches and others directly from the distributed data sources.

GIN consists of three tiers. The bottom tier comprises provincial and federal data sources, exposed online ideally via standard web services and data exchange formats, or occasionally via bulk file downloads in non-standard local formats. The top tier consists of potentially many distributed web portals that provide various user interfaces to the data - included among these is the GIN portal itself (www.gw-info.net). The middle tier connects the top and bottom tiers, in that it (1) carries out the necessary transformations between these tiers, and (2) houses the data caches and catalogs required by the transformations. The data caches and

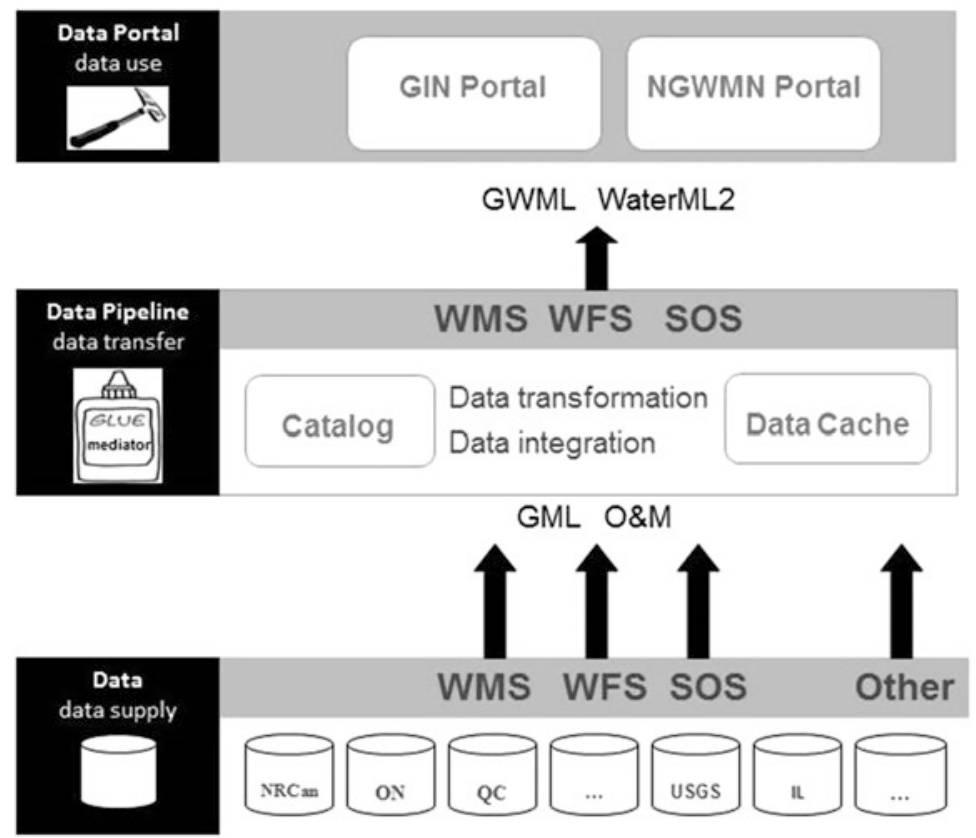

Fig. 26.6 Architecture for GIN and NGWMN - local data sources in the lowest tier, central data caches, catalogs, and transformations in the middle tier, and distributed web portals in the upper tier 
catalogs are updated from local sources either dynamically online via the web services, or manually via file download. The transformations occur in both directions as the middle tier transforms requests from the portals to the local requirements of individual web services or data caches, and conversely transforms the retrieved data to a community standard, either GWML or WaterML2, as required. It also integrates the standardized data, retrieved from potentially multiple sources, into a single unified result, and returns this result to the requester in a choice of several possible file formats such as GML, KML, shape file, ESRI GeoDatabase, or PDF. Significantly, the middle tier is presented online as three web services (WFS, WMS, SOS), which effectively serve as a central data pipeline. Requests for data can thus be made in two ways: through a web portal which issues requests to the data pipeline; or the web portal can by bypassed completely and requests can be sent directly to the data pipeline, for example from an online modeling application.

The GIN architecture has proven to be efficient and effective, returning moderate amounts of data relatively quickly (e.g. hundreds of wells in several seconds), which is adequate for typical usage. Retrieval of large data amounts is enabled via bulk download of pre-packaged files.

\section{Example 26.2: US National GroundWater Monitoring Network}

The US National Groundwater Monitoring Network (NGWMN; ACWI, 2013) is a recently initiated national federation of US groundwater data. In collaboration with groundwater agencies from US states, the NGWMN links federal and state data in a virtual environment, providing a single online entry point to groundwater data holdings across the nation. NGWMN data include waterwell records, water level and water-quality measurements, and references to related aquifers where possible. The NGWMN architecture is very similar to GIN's (Fig. 26.6), utilizing a three-tier portal-pipeline-data architecture, as well as centralized data transformations and catalogs. However, NGWMN differs from GIN in the extent of its data cache, as NGWM caches all data to improve speed of online usage: a data request to NGWMN will thus always retrieve data from its central cache and never directly from the original data sources. The middle tier pipeline implements the same standards as GIN, i.e. GWML, WaterML2, WFS, SOS, and WMS, and also similarly the harvester that populates the cache from local data sources uses these as well as other local standards to ensure that barriers to participation are low. At present NGWMN has completed a pilot stage and adoption continues, incorporating data from more than 20 states and enabling access to this data via an online portal (http:// cida.usgs.gov/ngwmn). 


\section{Example 26.3: An Emergent North American Groundwater Data Network}

Coupling of the Canadian and US groundwater data networks is highly desirable, due to the potential for high impact on cross-border groundwater studies. Encouragingly, the coupling of technologies is relatively straightforward, due to the implementation of compatible architectures, and the adherence to common standards across the bottom three interoperability levels (i.e. systems, syntax, and schema), which ensure the use of common web services and related schema. Note that discrepancies at the remaining levels (semantics, pragmatics), which involve differences between vocabularies largely caused by variations in data collection procedures, are managed through data transformations. This is feasible because each network exposes a single data pipeline, which is treated as just another data source by the consuming network. For example, NGWMN is consumed by GIN as if it were another provincial data source, one that requires mapping of vocabularies only, with that mapping taking into account procedural differences.

The coupling of the GIN and NGWMN networks has been tested in two pilot studies carried out in the course of standards development activities at the OGC. In the Groundwater Interoperability Experiment (GWIE; Brodaric and Booth 2010), water level time-series and associated wells across the US-Canada border were found, viewed and downloaded. The Climatology-Hydrology Information Sharing Project (CHISP; Brodaric et al. 2013) was more ambitious, as it involved both surface water and groundwater monitoring gauges, and addressed both water quantity and quality concerns. CHISP enabled cross-border flood risk determination and alerting through dynamic monitoring of gauges upstream from a point of interest, and it also dynamically estimated nutrient loads for any one of the mutually managed Great Lakes.

The GWIE and CHISP studies not only demonstrated that the two groundwater data networks can be successfully coupled, they also directly led to improvements in the networks and to the identification of gaps in the standards, which are subsequently being addressed. Also significantly, they showed that key organizational mandates could be enhanced through the deployment of open standards and the resultant interoperability of the data networks. The end result is the nascent emergence of a North American groundwater data network, which is facilitating access to data for modelers and others in both countries.

\section{Example 26.4: CUAHSI-HIS and HydroDesktop}

The Consortium of Universities for the Advancement of Hydrological Science (CUAHSI) is a research collaboration of more than 100 US universities and affiliated international research organizations. Apart from its significant scientific contributions, a key achievement of CUAHSI is its hydrological information system (HIS), which enables researchers to publish, manage, and use largely surface water data online (Tarboton et al. 2011). The published data are integrated into the wider HIS data network, which links academic data with 
major government data sources, such as the USGS, EPA and NOAA. HIS is by far the most de-centralized architecture examined herein, as its data holdings, transformations, catalog and portals are all distributed. Data distribution is achieved, at the moment, using custom "WaterOneFlow" web-services layered over 70 data sources. Data transformation takes place at each data source as an integral component of the web services, and is minimized as standard database structures are encouraged. For data discovery, transformation includes the semantic level, as time series parameters are mapped to a common vocabulary, enabling specific types of data to be identified within the network. However, data retrieval occurs only up to the structure level, as parameters are not mapped to a standard, but served 'as is' from the sources; moreover, data from multiple sources are not integrated into a unified file, but served individually. A central catalog tracks and publishes metadata about the data sources, which can be discovered by online tools. However, in contrast to previous data networks described herein, which are web-centric, HIS emphasizes desktop tools as primary interfaces to the data network. The cornerstone is HydroDesktop, which contains a rich suite of functions for data discovery, management, analysis and modeling. At present, plans are in place to develop HydroShare which will be an online portal that not only incorporates some key HydroDesktop functionality, but will in addition enable many types of collaborative online interactions, most notably the sharing of data and models amongst various research teams (Tarboton 2013).

\section{Example 26.5: Australian National Water Resource Assessment System7}

Following a period of extended drought within Australia the federal government initiated a national plan for water security, enacted as legislation through the Water Act of 2007. ${ }^{8}$ An outcome of the Water Act was that the Australian Bureau of Meteorology (BoM) would become the custodian of national water information, and would be required to produce several new water information products, including the annual National Water Accounts and sub-annual National Water Resources Assessments. The AWRA integrated modelling system was developed to support the production of these continental-scale products and integrates three models - landscape processes (AWRA-L), groundwater (AWRA-G) and surface water routing and use (AWRA-R for rivers)

In the proto-operational version of AWRA, where possible, data fetching, pre-processing and loading of input data streams are treated as independent processes, decoupling the modelling system from the data and data management systems. In a complex modelling system such as AWRA, there are many input

\footnotetext{
${ }^{7}$ Note this section refers to the proto-operational development of AWRA, the final operational version my change in design, scope and implementation.

${ }^{8}$ http://www.environment.gov.au/topics/water/australian-government-water-leadership/water-leg islation/key-features-water-act-2007.
} 


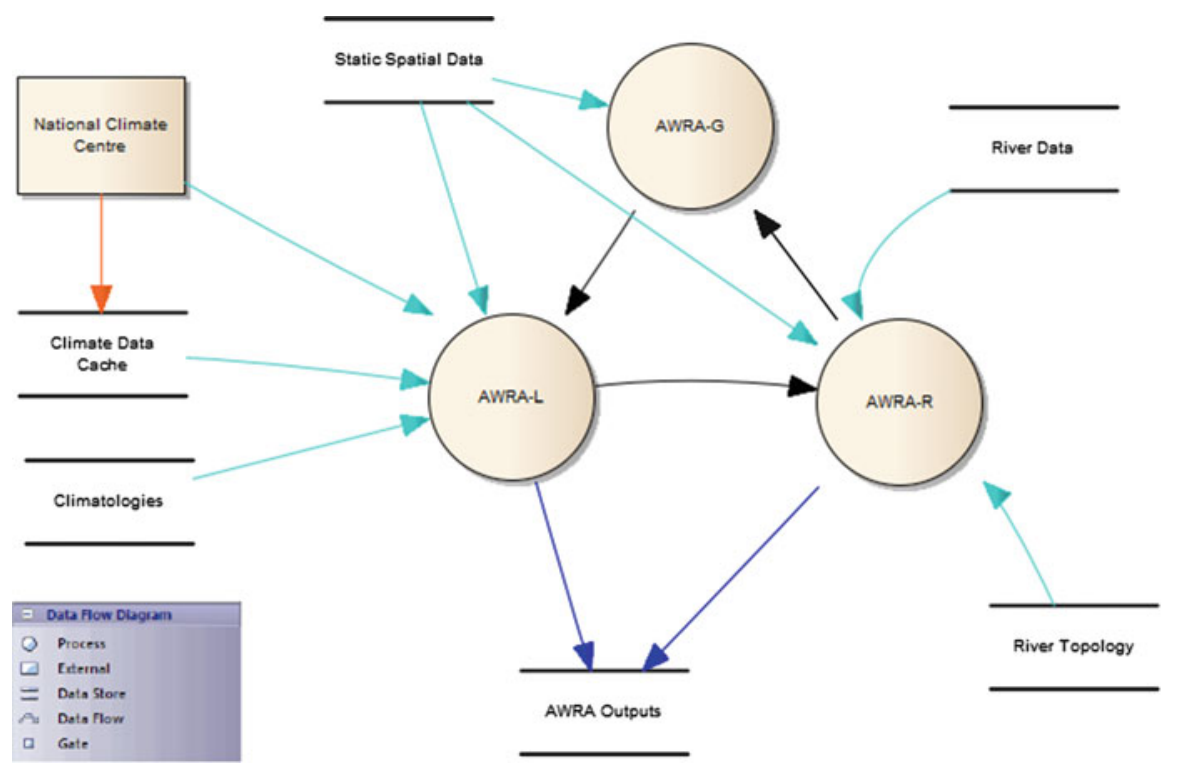

Fig. 26.7 High level representation of data flows within the AWRA system. Note the barred data sources are internal ad hoc rather than operational data sources. Orange arrows are ASCII grids via FTP delivery, teal arrows are binary files via direct transfer, blue arrows are NetCDF export to THREDDS server and black arrows are PI-XML via Delft-FEWS internal data store

data streams, some are standard products and use standardized formats and associated metadata; and they are often supported by a government mandate or service level agreement. These can be considered high trust data streams and have guaranteed availability, and are used in preference to alternatives.

In a real-time modelling system such as AWRA the data fetching is done asynchronously, to both reduce wasted time in the workflow waiting for fetch and pre-processing, and to facilitate future historic runs. The data retrieval process makes use of a local file based data store (Fig. 26.7), which it keeps up to date through both checking for new data, and updating existing data as it is re-published by the data provider following re-processing such as when updated observations become available.

While the fetching of published, operational data streams is preferable from a systems perspective, often the data are incomplete and have gaps either in space or time. In AWRA these gaps are filled through purpose developed data interpolation algorithms or by lookup default values in a post-processing step.

Figure 26.7 shows a high level view of the AWRA modelling system. The diagram shows both the flow of data into and out of the system, and internally between the three major model components. In the original design of the system many of the input data streams were hosted operationally by the Bureau, supported by its new mandate as the custodian of water information. Due to the rapid development of AWRA, and the significant technical and organizational hurdles 
faced by the Bureau in streamlining the data ingestion process, none of the operational data streams, apart from climate data, are currently available for real-time use by the AWRA system. This has caused complications in the management and updating of the system, and diverted development resources. Once the data network is completed, this problem will be significantly reduced.

Ideally, work on data ingestion would have involved adhering to standards such as WaterML2 (Taylor et al. 2013) for observations, and GML (Portele 2007) for spatial data such as contributing catchments and river network topology. Instead, substantially greater work has been diverted to the collection, checking, re-purposing, re-formatting and management of input data, with all the complications of storage, deployment, duplication, broken provenance chains and a greater number of potential points where errors could be introduced. Once the data services are available through the water data network, AWRA's modular design will allow migration to these new data sources with minimal disruption.

The data sources that will benefit most from availability using a data network approach are those where identity is important such as the naming of river gauges, and those that will need to be extended in their temporal coverage such as river observations. In the current conceptual design of AWRA, the location and identity of river gauges are crucial. The location is used to identify contributing flow from the AWRA-L model and is based largely on the positioning of infrastructure within the river network, rather than by river confluences, although they may be co-located. Over time, as more river reaches are added to the model, gauges are moved or retired; or as the number of gauges used in the model are consolidated, the relationship between river reach models in AWRA-R and the contributing areas used to apportion flow from AWRA-L into those reach models will need to be updated, checked, and incorporated into the model, a time consuming and error prone task. Additionally the mix of points used to define reach models is crucial in the ingestion of observational data such as flow, extractions, diversion and storages, as the identity of those points will be used to resolve the inputs. Currently the network of points, their identities and the related observational data are compiled manually, an even more costly and error prone process than the contributing areas, as the identities are often unique to the agency tasked with monitoring them. The temporal data when collected will often be in different formats that require processing and consolidation, but more crucially the semantic definition of terms is often subtly different, requiring at least a unit conversion, and at worst a conceptual transformation.

Figure 26.8 shows the future idealised data flows into and out of the AWRA system in which the two most important data streams have been replaced by operational web services. These include the network geometry and topology, and associated contributing areas via the GeoSpatial Fabric, and the temporal observation data such as gauged river flow, storage levels and diversion via the AWRIS data warehouse. Crucially, some of greatest headaches in preparing and ingesting input data for the AWRA system will be solved using this approach. The GeoFabric will provide a resolution of identity between the spatial network, the jurisdictional agencies that collect the data, and the AWRIS data warehouse. AWRIS itself will 


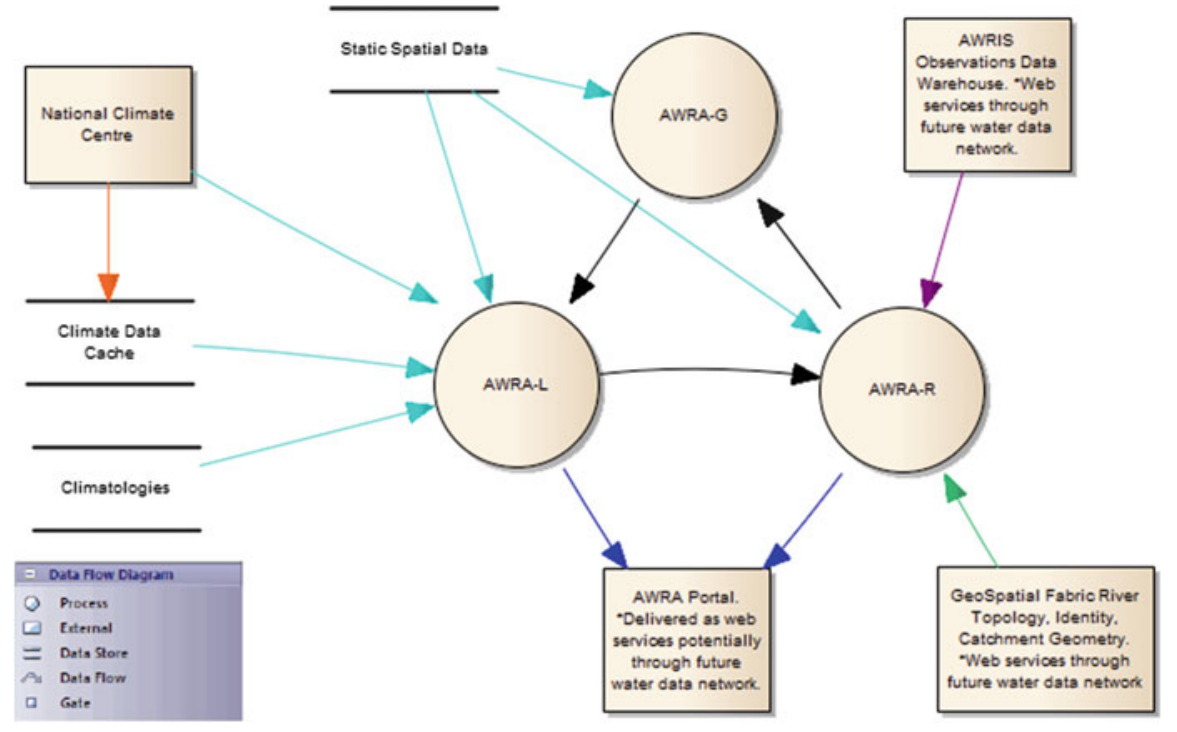

Fig. 26.8 High-level representation of future idealized data flows for the AWRA system, showing the current ad-hoc data streams replaced by operational services. Note the barred data sources are internal ad hoc, rather than operational, data sources. Orange arrows are ASCII grids via FTP delivery, Teal arrows are binary files via direct transfer, blue arrows are NetCDF export to THREDDS server, green arrows are GML via web services, mauve arrows are WaterML2 via web services and black arrows are PI-XML via Delft-FEWS internal data store

handle the ingestion, consolidation and semantic matching between the diverse sources, as well as proving a trusted data source complete with metadata, and a convenient web services interface supplying data in standardised formats such as WaterML2.

AWRA is a significant national integrated modeling application that has many data management challenges. The current system makes use of many semiautomated steps for the discovery, access, integration and use of data. We have learned that:

- Integrated modeling systems cannot be developed in isolation from the data availability and management needed to support them

- Models need to be managed and governed similarly to data

- Management of data needs to be approached from a dataset by dataset perspective

- A web-based data network would significantly ease the burden of the data management challenge for integrated modeling studies like AWRA. 


\subsection{Discussion of Future Trends}

As noted above, it is becoming commonplace to deliver groundwater data online, typically via web services, and to incorporate such data into groundwater studies and modeling activities, also variously occurring online in workflow environments. The totality of these online resources and activities is often referred to as cyberinfrastructure. We anticipate that for integrated modelling studies the cyberinfrastructure paradigm will continue to evolve and grow, likely exponentially.

Furthermore, as cloud-computing technology is also becoming commonplace, it is likely that the processes of data storage, management and integration will occur within the "cloud" (Yang et al. 2010a). This essentially outsources the provision of the hardware side of the data management challenge, with expected gains in efficiencies, reduction of costs and potentially risks. We expect that cloudcomputing technology will become an important enabler for delivery of integrated groundwater data in data networks.

Open standards (data and services) are likely to become more common-place with some good current examples being GWML, WaterML2.0 and the underlying GML and XML formats.

Finally, linked data implementations will continue to evolve and grow. Linked data is a term which refers to a set of standards and approaches for publishing and connecting data on the web (Bizer et al. 2009). Linked data is made available on the web in a standard format, usually RDF, which enables links to other datasets, or contextual data including metadata. Because linked data methods use the standard web-based linking approach of Universal Resource Identifiers (URI's), it becomes very easy to discover new data and information on the web. As a result, linked data methods are migrating from the research community and starting to become mainstream, albeit with varying levels of conformance to core linked data principles (Hogan et al. 2012). Examples are appearing in a number of countries, such as the UK location program (http://data.gov.uk/location), in which the identity of features and their corresponding properties can be easily determined.

Two related issues remain a challenge for linked data - these are particularly evident in the water domain. The first is the massive volume of data stored in legacy databases: because linked data approaches, at the moment, almost universally deploy RDF as a format, it still remains a research objective how best to layer linked data methods over non-RDF databases (Marjit et al. 2013). The second associated issue concerns granularity: what is the appropriate granule to be assigned an URI? For example, a particular measurement in a time series, the time series itself, the monitoring site, or even a specific pixel in a remote sensed image? In many of these cases the level of granularity would result in enormous and likely impractical volumes of linked entities. Thus, it becomes important to be able define a certain level of granularity, and have web-friendly mechanisms to delve deeper if required. Nonetheless, we expect that linked data approaches will continue to grow and become an integral part of data networks. 
Open Access This chapter is distributed under the terms of the Creative Commons AttributionNoncommercial 2.5 License (http://creativecommons.org/licenses/by-nc/2.5/) which permits any noncommercial use, distribution, and reproduction in any medium, provided the original author(s) and source are credited.

The images or other third party material in this chapter are included in the work's Creative Commons license, unless indicated otherwise in the credit line; if such material is not included in the work's Creative Commons license and the respective action is not permitted by statutory regulation, users will need to obtain permission from the license holder to duplicate, adapt or reproduce the material.

\section{References}

Advisory Committee on Water Information (2013) A national framework for ground-water monitoring in the United States, Prepared by the Subcommittee on Ground Water of the Advisory Committee on Water Information, First Release June 2009, Revised July 2013, 169 pp. http://acwi.gov/sogw/ngwmn_framework_report_july2013.pdf

Alley WM, Evenson EJ, Barber NL, Bruce BW, Dennehy KF, Freeman MC, Freeman WO, Fischer JM, Hughes WB, Kennen JG, Kiang JE, Maloney KO, Musgrove MaryLynn, Ralston B, Tessler S, Verdin JP (2013) Progress toward establishing a national assessment of water availability and use. U.S. Geological Survey Circular 1384, 34 p, available at http://pubs. usgs.gov/circ/1384

Ames DP, Horsburgh JS, Cao Y, Kadlec J, Whiteaker T, Valentine D (2012) HydroDesktop: web services-based software for hydrologic data discovery, download, visualization, and analysis. Environ Model Software 37:146-156

Argent RM (2003) An overview of model integration for environmental applications components, frameworks and semantics. Environ Model Software 19:219-324

Atkinson R, Dornblut I, Smith D (2012) An international standard conceptual model for sharing references to hydrologic features. J Hydrol 424-425:24-36

Bizer C, Heath T, Berners-Lee T (2009) Linked data-the story so far. Int J Seman Web Infor Sys (IJSWIS) 5(3):1-22

Boisvert E, Brodaric B (2012) Ground Water Markup Language (GWML) - enabling groundwater data interoperability in spatial data infrastructures. J Hydroinf 14(1):93-107

Booth NL, Brodaric B, Lucido JM, Kuo I-L, Boisvert E, Cunningham WL (2011) Development of an interoperable groundwater data exchange network between the United States and Canada. GeoHydro 2011, Quebec, 28-31 Aug

Boring A, Stasch C, Echterhoff J (eds) (2012) OGC sensor observation service interface standard. Open Geospatial Consortium, OGC 12-006, version 2.0, 163 pp. https://portal.opengeospatial.org/ files/?artifact_id=47599

Brodaric B (2007) Geo-pragmatics for the geo-spatial semantic web. Trans GIS 11(3):453-477

Brodaric B, Booth N (2010) OGC groundwater interoperability experiment final report. Open Geospatial Consortium, Groundwater Data Management, 44 pp. http://portal.opengeospatial.org/ files/?artifact_id=43545\&version $=1$

Brodaric B, Sharpe D, Boisvert E, Logan C, Russell H, Julien H, Smirnoff A, Létourneau F (2011) Groundwater information network: recent developments and future directions. Proceedings, GeoHydro 2011, Quebec, 28-31 Aug

Brodaric B, Dabolt T, Booth N, Vretanos P (2013) CHISP-1 pilot project introduces open architecture for watershed observatories. Cana Water Resour Assoc, Water News 33(1):6-12

Chesnaux R, Lambert M, Walter J, Fillastre U (2011) Building a geodatabase for mapping hydrogeological features and 3D modeling of groundwater systems: application to the Saguenay-Lac-St.-Jean region, Canada. Comput Geosci 37:1870-1882 
Costello MJ (2009) Motivating online publication of data. dx.doi.org

Cox S (ed) (2011) Observations and measurements - XML implementaion. Open Geospatial Consortium, OGC 10025r1, version 2.0, 77 pp. http://portal.opengeospatial.org/files/?artifact_id=41510

Croke BFW et al (2006) Integrated assessment of water resources: Australian experiences. Water Resour Manag 21(1):351-373

Dahlhaus PG, MacLeod AD, and Thompson HC (2012) Federating hydrogeological data to visualise Victoria's groundwater. In: Lambert I, and Gordon AC (eds) 34th international geological congress: proceedings, 5-10 Aug 2012, Brisbane, Australian Geoscience Council, p 592

De La Beaujardière J (ed) (2006) OpenGIS web map server implementation specification. Open Geospatial Consortium, OGC 06-042, version 1.3.0. http://portal.opengeospatial.org/ files/?artifact_id=14416

Frehner M, Brändli M (2006) Virtual database: spatial analysis in a web-based data management system for distributed ecological data. Environ Model Software 21(11):1544-1554

Gogu R, Carabin G, Hallet V, Peters V, Dassargues A (2001) GIS-based hydrogeological databases and groundwater modelling. Hydrogeol J 9(6):555-569

Granell C, Gould M, Manso MÁ, Bernabé MÁ (2009) Spatial data infrastructures. In: Karimi H (ed) Handbook of research on geoinformatics. Information Science Reference, Hershey, pp 36-41. doi:10.4018/978-1-59140-995-3.ch005

Hartcher M, Lemon D (2008) Data management for the Murray-Darling Basin sustainable yields project, pp 1-40. https://publications.csiro.au/rpr/download?pid=procite:51d8dcdf-203b-4cda932e-9480ac8b2cda\&dsid=DS1

Hogan A, Umbrich J, Harth A, Cyganiak R, Polleres A, Decker S (2012) An empirical survey of linked data conformance. Web Semant Sci Serv Agents World Wide Web 14:14-44

Jarar Oulidi H, Löwner R, Benaabidate L, Wächter J (2009) HydrIS: an open source GIS decision support system for groundwater management (Morocco). Geo-Spat Inf Sci 12(3):212-216. http://doi.org/10.1007/s11806-009-0048-9

Krol M, Jaeger A, Bronstert A, Güntner A (2006) Integrated modelling of climate, water, soil, agricultural and socio-economic processes: a general introduction of the methodology and some exemplary results from the semi-arid north-east of Brazil. J Hydrol 328(3):417-431

Maidment DR (ed) (2002) Arc Hydro: GIS for water resources. ESRI Press, Redlands

Marjit U, Sharma K, Sarkar A, Krishnamurthy M (2013) Publishing legacy data as linked data: a state of the art survey. Library Hi Tech 31(3)

Masser I (2010) Building European spatial data infrastructures, 2nd edn. ESRI Press, Redlands, $108 \mathrm{pp}$

Panagiotis AV (ed) (2005) Web feature service implementation specification. Open Geospatial Consortium, OGC 04-094, version 1.1.0, 117 pp. http://portal.opengeospatial.org/files/?arti fact_id $=8339$

Portele C (2007) Geography Markup Language (GML) encoding standard. Open Geospatial Consortium, OGC 07-036, version 3.2.1, 427 pp. http://portal.opengeospatial.org/files/?artifact_id= 20509

Refsgaard JC, Højberg AL, Møller I, Hansen M, Søndergaard V (2010) Groundwater modeling in integrated water resources management - visions for 2020. Ground Water 48(5):633-648

Robbins R (2012) Data management for LTER: 1980-2010. NSF, pp 1-59. Available at: http:// www.nsf.gov/pubs/2012/bio12002/bio12002.pdf

Schou JS, Skop E, Jensen JD (2000) Integrated agri-environmental modelling: a cost-effectiveness analysis of two nitrogen tax instruments in the Vejle Fjord watershed, Denmark. J Environ Manage 58(3):199-212

Strassberg G, Maidment DR, Jones N (2004) Arc Hydro groundwater data model. In: Geographic information systems in water resources III, AWRA spring specialty conference, Nashville, May 2004, pp 17-19 
Tarboton, D (2013) HydroShare: an online, collaborative environment for the sharing of hydrologic data and models. Proceedings: 2013 CAUHSI conference on hydroInformatics and modeling. http://www.cuahsi.org/pageFiles/DavidTarboton.pptx

Tarboton DG, Maidment D, Zaslavsky I, Ames D, Goodall J, Hooper RP, Horsburgh J, Valentine D, Whiteaker T, Schreuders K (2011) Data interoperability in the hydrologic sciences, The CUAHSI hydrologic information system. In: Proceedings of the environmental information management conference 2011, pp 132-137, http://eim.ecoinformatics.org/eim2011/eimproceedings-2011/view

Taylor P, Cox S, Walker G, Valentine D, Sheahan P (2013) WaterML2. 0: development of an open standard for hydrological time-series data exchange. IWA Publishing http://www. iwaponline.com/jh/up/jh2013174.htm

Thomas W, Gregory A, Gager J, Kuo I-L, Wackerow A, Nelson C (2009). Data Documentation Initiative (DDI) technical specification part I: overview, pp 1-103. Retrieved from http://www. ddialliance.org/

Van Dijk A, Bacon D, Barratt D (2011) Design and development of the Australian water resources assessment system. In: Water information research and development alliance, Science symposium proceedings, Melbourne, 1-5 Aug 2011

Whiteaker T, Schneider K, Maidment D (2006) Applying the ArcGIS Hydro data model. http:// www.crwr.utexas.edu/gis/gishydro01/support/schematutorial.pdf

World Meteorological Organization (WMO) (2008) Guide to hydrological practices. WMO, Geneva, pp 1-296

Yang C, Raskin R, Goodchild M, Gahegan M (2010a) Geospatial cyberinfrastructure: past, present and future. Comput Environ Urban Syst 34(4):264-277

Yang X, Steward DR, de Lange WJ, Lauwo SY, Chubb RM, Bernard EA (2010b) Data model for system conceptualization in groundwater studies. Int J Geogr Inf Sci 24(5):677-694. doi:10. 1080/13658810902967389

Zaslavsky I, Williams M, Aufdenkampe A, Lehnert K, Mayorga E, Horsburgh J (2011) Data infrastructure for the Critical Zone Observatories (CZOData): an EarthCube design prototype. National Science Foundation EarthCube White Paper: Designs Category. http://earthcube.org/ file/4024/download?token=HGb9YhHv 


\title{
Hydroeconomic Models as Decision Support Tools for Conjunctive Management of Surface and Groundwater
}

\author{
Manuel Pulido-Velazquez, Guilherme F. Marques, Julien J. Harou, \\ and Jay R. Lund
}

\begin{abstract}
Conjunctive use (CU) of surface and groundwater storage and supplies is essential for integrated water management. It is also a key strategy for supporting groundwater-dependent ecosystems, and for adapting water systems to future climate and land use changes. CU has become increasingly sophisticated and integrated with other innovative and traditional water management techniques, such as water transfers, water reuse, demand management, and aquifer remediation. CU adds value for society (increasing average yield and reliability) but can also induce costs to some parties, such as damaging senior water rights of surface water users when pumping from the aquifer reduces streamflow. Groundwater overexploitation also can produce a host of undesirable economic and environmental impacts. Successful CU implementation typically requires changes in infrastructure and operations, but also changes in institutions and institutional arrangements to offset potential third party costs and protect ecosystems. This chapter analyses first the management and economic implications of $\mathrm{CU}$,
\end{abstract}

M. Pulido-Velazquez ( $\square$ )

Research Institute of Water and Environmental Engineering (IIAMA), Universitat Politècnica de València, Valencia, Spain

e-mail: mapuve@hma.upv.es

G.F. Marques

Instituto de Pesquisas Hidraulicas, Universidades Federal do Rio Grande do Sul, Porto Alegre, RS, Brazil

e-mail: guilherme.marques@ufrgs.br

J.J. Harou

School of Mechanical, Aerospace and Civil Engineering, The University of Manchester, Manchester, UK

e-mail: julien.harou@manchester.ac.uk

J.R. Lund

Center for Watershed Sciences, University of California, Davis, Davis, CA, USA

e-mail: jrlund@ucdavis.edu 
addressing advantages, costs and limitations, as well as the potential contribution of economic instruments to the conjunctive operation of groundwater and surface storage and resources. $\mathrm{CU}$ management models are then classified according to the $\mathrm{CU}$ problem, their formulation and solution techniques. Different applications of hydroeconomic models are reviewed in a wide range of $\mathrm{CU}$ problems. A few applications are discussed more in-depth, using cases from California and Spain. Then, we discuss the relevance of these models in decision-making, and the policy and institutional implications. Finally, we address limitations and challenges, and suggest future directions.

\subsection{Introduction: Conjunctive Use Overview}

Most regions in the world depend on a mixture of surface and groundwater to supply their water demands. This mix of supplies is especially important in semiarid and arid regions, where seasonal and annual variability in surface water is more pronounced, but humid regions also have seen increased importance of mixed surface and groundwater supplies as populations, environmental concerns, and water demands increase (Downing 1998). Historically, surface and groundwater sources have largely been developed, managed and used independently. However, as water resources in a region become increasingly exploited, population continues to grow, and water transfers become more controversial, the potential benefits of coordinated management of surface and groundwater supplies offer significant incentives for change.

Conjunctive use $(\mathrm{CU})$ of surface and groundwater resources has long been recognized as essential for integrated water management (Buras 1963; Burt 1967; Coe 1990). CU implies the coordinated management and use of surface and groundwater resources, taking advantage of their complementary properties. Although both surface and groundwater storages are used to redistribute water over time to match supply and demands, they differ in storage capacity, recharge and depletion rates, water quality, capital and operating costs, and physical, operational and institutional constraints. Jointly operating all manageable water resources in a region can increase the yield, efficiency, supply reliability and cost-effectiveness for a system. CU is also a key strategy for supporting groundwater-dependent ecosystems (Chap. 13; Kløve et al. 2011 and 2013), as well as for the adaptation of water resource systems to future climate and land use changes (Chaps. 4 and 5; Hanson et al. 2012).

Compared with surface storage, groundwater storage offers vast storage reserves, usually orders of magnitude larger than available surface storage in most watersheds. These reserves can help reduce or eliminate water shortages, acting as a "buffer stock" that provides a reliable, although informal, insurance system (Perez and Gómez 2013) Moreover, the great natural storage capacity of aquifers can be used to store excess surface water in wet periods, increasing ground water levels for use in subsequent dry periods. This could be achieved by artificial recharge techniques (Chaps. 16 and 17), or simply by alternating surface and groundwater use for irrigation, and taking advantage of the recharge coming from 
river and reservoir losses and the percolation of irrigated water (Sahuquillo and Lluria 2003). Aquifers provide a natural long-term water storage reservoir, without evaporation losses (except from very shallow aquifers). Efficient conjunctive operation increases supply by reducing losses from the freshwater system through reduced flow to the ocean or salt sinks and reduced evaporation from surface reservoirs (Coe 1990).

Groundwater bodies provide additional resources, but also means for water storage, distribution and treatment, which can be combined advantageously with surface water resources and facilities. $\mathrm{CU}$ can reduce drainage and salinity problems in irrigated and coastal areas, and water quality improvement is possible with more opportunities for blending water of different qualities and use of soil/aquifer media to treat water (SAT - soil aquifer treatment; see Fox et al. 2001). Initiatives in the US include the use of Aquifer Storage and Recovery (ASR) technologies in Florida, in the ambitious Comprehensive Everglades Restoration Plan (NRC 2012). The costly ASR component in the CU operations was avoided in Al Khamisia et al. (2013) by combining reclaimed water use directly with groundwater to meet irrigation demands. Conjunctive use may also facilitate the integration of reclaimed water to meet urban landscape irrigation demands (green strips and public gardens).

Despite all these advantages, the potential for $\mathrm{CU}$ of surface and groundwater has not been fully developed and implemented in many water systems. Traditionally, groundwater has been used only as a backup supply for times of shortage. Perhaps reflecting the bygone eras of their design, most large water supply systems continue to depend exclusively on surface water. Some physical, institutional and legal constraints make implementation of efficient conjunctive use management difficult. Physical and institutional factors promote, shape, and limit conjunctive management (Blomquist et al. 2004).

Conjunctive use operations involve diverse environmental, economic and social aspects, given that alterations in the natural cycle of surface water and groundwater are likely to cause costs and benefits not only to the directs users, but also the neighboring uses. The goals of the $\mathrm{CU}$ should be transparent and built with stakeholders' involvement and consensus, to avoid later conflicts. Communication is also critical for success. For example, conjunctive use operations using water banking will affect groundwater pumping costs to both users and neighbors due to the water table fluctuations during the refill and drawdown stages, causing both negative and positive externalities. If not properly taken into account and communicated, these may cause later litigation.

Further opportunities for conjunctive management can be exploited when an elaborate network of water infrastructure, water rights and institutions is present. Examples of these opportunities are found in California, where complex surface and groundwater problems have stimulated development of new approaches for conjunctive use. These approaches are focused mostly on integrating storage and conveyance infrastructure to allow more efficient and flexible water allocation and conservation, to broaden the range of beneficiaries and minimize water conflicts. The contemporary application of $\mathrm{CU}$ has become increasingly sophisticated and integrated with other innovative and traditional water management techniques, such 
as water transfers, water reuse, demand management, and aquifer remediation. The complexity of integrated water resources management in general, and conjunctive use in particular, requires methods and tools for predicting impacts and developing efficient and sustainable strategies.

In this chapter, after reviewing some economic and hydrologic tradeoffs of conjunctive management, we analyze the role of models and systems analysis techniques in the design of efficient planning and management strategies for conjunctive use schemes, using some examples from California (USA) and Spain.

\subsection{Economic and Hydrologic Tradeoffs of Conjunctive Use}

Some general economic advantages of conjunctive use include: greater water conservation, smaller surface water storage and distribution infrastructure, better flood control, ready integration with existing development, less danger from dam failure, and better timing of availability of water for distribution (Maknoon and Burges 1978). Conjunctive use schemes can provide other advantages, such as its adaptability to a progressive increase in water demand at a low cost, and the possibility of temporal overexploitation of aquifers to defer costly construction projects, mitigate the effects of droughts, or alleviate drainage problems (Sahuquillo 1985).

The main economic difference between ground and surface water projects is that, in general, initial investments are much lower for ground water, but operation and maintenance costs are higher. In surface water the initial investment is usually high and the operation and maintenance costs are small. An exception is that surface water treatment for urban uses usually requires higher energy and chemical costs (Sahuquillo 1989). Given the natural water distribution provided by groundwater, its integration in conjunctive use operations improves local supply availability, reducing reliance on external large-scale water transfers. To many regions, including California, this lowers operating costs and risks and increases sustainable operation. The latter also means higher investment locally (e.g. groundwater pumping and recharge infrastructure) contributing to local economic development rather than building large infrastructure elsewhere.

$\mathrm{CU}$ adds value for society, but also can induce costs to some parties as, for example, damaging senior water rights of surface water users when pumping from the aquifer reduces streamflow. Groundwater overexploitation can also produce a host of undesirable economic and environmental impacts. Adverse effects of overdraft can include: uneconomic pumping conditions, water quality degradation through induced intrusion of saline or poor quality groundwater, flow reduction in streams, wetlands and springs, land subsidence, interference with pre-existing water uses and water rights and a gradual depletion of groundwater storage (Sophocleous 2003; Zektser et al. 2005). CU is often the best solution to stop groundwater overdraft, transitioning to sustainable groundwater management with the least cost (Harou and Lund 2008). Successful CU implementation typically requires changes in 
infrastructure and operations, but also changes in institutions and institutional arrangements to offset potential third party costs and protect the ecosystems.

Although often underutilized, economic instruments are often decisive for water management to face increasing water scarcity problems. Water is often underpriced, leading to an imbalance between supply and demand and the unsustainable use of resources (NRC 1997). Water supply and demands vary over time and space, and water prices providing signals during times and locations where scarcity is higher can improve the efficiency of water use (Pulido-Velazquez et al. 2013). Some studies show that it is possible to increase welfare by using pricing to implement a conjunctive management strategy in which price signals encourage surface water use during wet years and groundwater use during dry years (e.g. Schuck and Green 2002; Riegels et al. 2013). In other cases, changes in surface water prices and costs affect the relative value of groundwater, reflecting on pumping patterns, operating costs and groundwater storage. Marques et al. (2006) investigate surface and groundwater economic uses in California, showing that lower groundwater pumping costs relative to surface water resulted in a system failure to internalize groundwater pumping externalities, as users switch to groundwater and aquifer overdraft is intensified. The overdraft raised future groundwater pumping costs, with potentially large economic impacts and risk to the feasibility of conjunctive use operations.

Flexible management of additional conjunctive use facilities and groundwater storage capacity under flexible water allocation can generate substantial economic benefits. CU adds operational flexibility to take better advantage of water market transfers, and transfers provide the allocation flexibility to take better advantage of conjunctive use (Pulido-Velazquez et al. 2004). The added flexibility afforded by conjunctive use reduces stress over the water system, especially surface water reservoirs which can be operated less conservatively when part of the storage is transferred to groundwater. This improves reliability and potential gains to all users, including environmental demands.

\subsection{Hydroeconomic Models Applied to Conjunctive Use}

The complexity of water resource systems requires methods to integrate technical, economic, environmental, legal, and social issues within a framework that develops efficient and sustainable water use strategies. Recent decades have seen widespread use of systems analysis to help on planning and management of water resources. This holistic approach requires identification, analysis and evaluation of the interactions among all components of water resource systems over space and time, considering physical and institutional constraints. Combining economic concepts and performance indicators with the modelling of the hydrologic system and infrastructure (hydroeconomic models, HEM) can provide results and insights more directly relevant for water management decisions and policies (Harou et al. 2009). Meanwhile, the common assumption of "stationary conditions" used 
in hydrologic and management modelling is nowadays under question in a context of accelerated climate change due to global warming and increasing changes in land uses (Milly et al. 2008), possessing new challenges for the modelers. In this context, hydroeconomic models are better prepared to integrate supply and demand management options to identify promising adaptive portfolios for future conditions.

\subsubsection{Model Components}

Most hydroeconomic models share basic components including hydrologic inflows, water management infrastructure, economic water demands, operating costs, and operating rules (Pulido-Velazquez et al. 2008; Harou et al. 2009). In CU models, we also need to characterize groundwater storage and heads (needed to assess pumping cost variation) and, of course, stream-aquifer interactions where significant for the management model and at the required level of accuracy (see Sect. 3.2). Figure 27.1 conceptually represents an HEM applied to conjunctive use management, illustrating the main components, modeled processes and results.

Water resource systems are often conceptualized as a flow network comprised of nodes, without (e.g. confluences or diversions) or with (reservoirs, aquifers) storage capacity, and links (natural or artificial conduits) with a limited capacity through which water moves in particular directions. A conjunctive use model should integrate surface and groundwater hydrology, as well as stream-aquifer interaction where this is relevant. While in non-economic system models, water demand is usually represented through fixed supply targets that have to be satisfied, HEMs require empirically-estimated marginal supply cost and benefit functions to establish the economic value of water supply to the different in-stream and off-stream

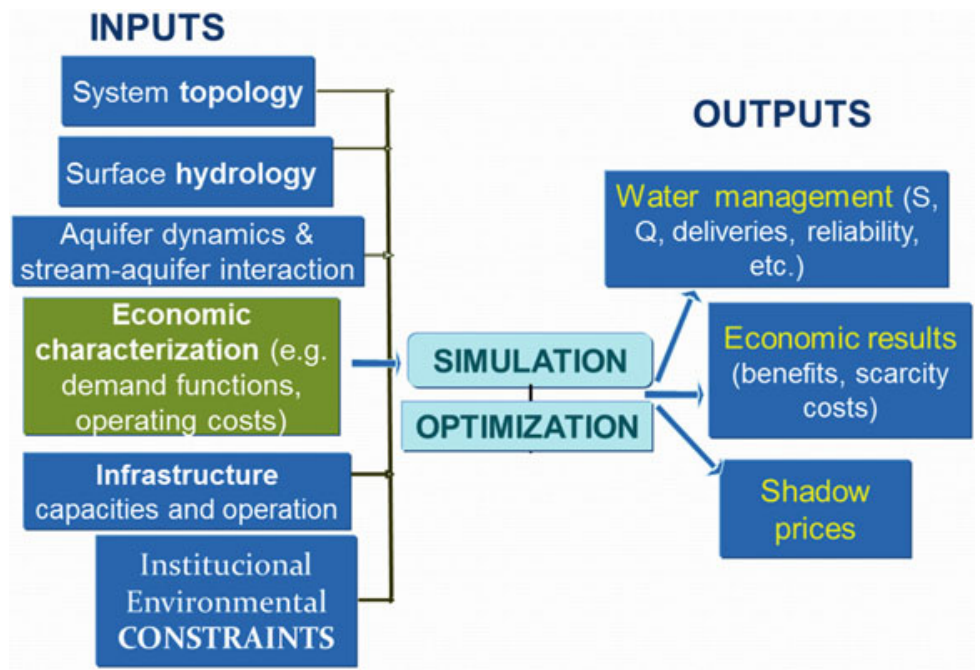

Fig. 27.1 Conceptual representation of HEM for conjunctive use management 
uses. The economic value of water can be characterized exogenously, using different valuation techniques (Young 2005) and external economic models for generating economic demand curves (representing the relation between the quantity of water delivered and its marginal value, ceteris paribus) (e.g. Jenkins et al. 2004; Pulido-Velazquez et al. 2004, 2006). The economic characterization also can be done endogenously, for example including crop production functions in the formulation of the HEM (e.g. Cai et al. 2003). Finally, the model can include different operational, environmental and institutional constraints. These constraints might be relaxed to investigate promising policy or management changes.

A variety of results are provided by HEMs, including flow and storage time series, benefits and costs, marginal economic value of water, and shadow prices for upper and lower bounds. These results can lead to useful conclusions on water allocation and operating decisions, as well as estimates of the economic values of changes in the management and/or the infrastructure capacity, opportunity costs, user's willingness to pay (see WTP coverage in Chap. 21) for water, and other economic and performance indicators (Pulido-Velazquez et al. 2008; Harou et al. 2009).

\subsubsection{Modelling Techniques}

\subsubsection{Hydraulic Management Versus Policy-Allocation Models}

$\mathrm{CU}$ management models with distributed aquifer simulation are often classified into hydraulic management models, and policy and allocation models (Gorelick 1983).

Hydraulic management models are principally concerned with managing flow, heads and mass transport in the aquifer. For example, optimal groundwater pumping constrained to subsidence control, the control of the evolution of a contaminant plume, or seawater intrusion control in a coastal aquifer. Although these models could be defined with an economic objective (such as maximizing the benefits of groundwater pumping or minimizing pumping cost), often they include other objectives such as maximizing total pumping, subject to the corresponding constraints on the aquifer response. Several examples of these types of optimization problems are provided in Ahlfeld and Mulligan (2000).

In contrast, policy evaluation and allocation models are mainly concerned with the efficient management and allocation of surface and groundwater resources (Bredehoeft 1995). Usually this approach is used in regional agriculturalmanagement problems (Bredehoeft and Young 1983; Lefkoff and Gorelick 1990; McCarl et al. 1999; Pulido-Velazquez et al. 2006) or in large multipurpose regional water supply systems, for example in California (Jenkins et al. 2004; PulidoVelazquez et al. 2004). The objective function is often defined as maximizing the total economic value of water allocation over time, so that the model will explore the optimal distribution of resources in space and time across the different competing sectors. The economic value of water use is often defined for each use using economic demand curves. 
An alternative approach is allocation models in which conjunctive use management is defined based on existing water allocation priorities, without including any explicit economic representation (eg. Fredericks et al. 1998; Pulido-Velazquez et al. 2002).

\subsubsection{Simulation Versus Optimization Models}

Simulation or descriptive models that assess system performance for predefined alternative strategies ("what if" scenarios), permit a more detailed and realistic representation of complex systems, since they are not limited by many of the simplifications needed by the optimization models. In this sense, simulation models are essential for analyzing complex processes of surface and subsurface flow and transport. In groundwater hydrology, the most common models for solving flow and transport equations are based on finite difference or finite element techniques (Anderson and Woesneer 1992). HEM applications usually compare a baseline scenario considering current facilities and operations constrained to current allocation policies with alternative policy scenarios with or without new infrastructure to assess the tradeoffs of a change in system management or design in terms of costs and benefits (Pulido-Velazquez et al. 2008).

Prescriptive optimization models are particularly useful to systematically search for promising planning/management solutions ("what's best" scenarios). A great variety of conjunctive use optimization models are available in the literature, both for hydraulic management and for policy-allocation (as defined in the previous section). Such models typically use linear, non-linear or dynamic techniques with a dynamic balance of relevant quantities (e.g. water flow, contaminant mass), appropriate constraints, and a single (usually economic) or a multiple (e.g. economic, social, target demand) objective (Lall 1995). Network flow programming has been applied for large systems assuming linear or piece-wise linearized responses (Jenkins et al. 2004). Heuristic or nonexact methods like simulated annealing and genetic algorithms have been used for tackling the difficulties of nonlinear nonconvex problems (Rao et al. 2004). Fuzzy approaches allow to deal with uncertainty or account for expert management (Safavi and Alijanian 2011). "Black-box" neural networks approaches have been also employed to simulate groundwater response functions (Karamoutz et al. 2007). There is no general algorithm for solving these problems, but rather the choice of the solver will depend on the characteristics of the system, the scope of the model, the data availability, and the specified objectives and constraints.

\subsubsection{Representing Groundwater and Stream-Aquifer Interaction in Conjunctive Use Models}

Two types of models have been used to quantify stream-aquifer interaction: lumped and distributed-parameter models. Lumped-parameter models use a few parameters to represent the average behavior of the system (e.g., the bathtub model). Most theoretical and empirical economic studies of optimal groundwater management have presented groundwater dynamics using a single-cell bathtub aquifer model, to derive optimal temporal groundwater exploitation (e.g., Burt 1967) or compare 
optimal management versus competitive myopic solutions (e.g., Gisser and Sanchez 1980; Koundouri 2004). However, other studies have shown that optimal pumping behavior predicted by single-cell bathtub models, which assume that an aquifer responds uniformly and instantly to groundwater pumping, can differ significantly from results of more realistic spatially explicit models with finite hydraulic conductivity (Brozović et al. 2006). Bredehoeft and Young (1970) and Young and Bredehoeft (1972) also showed the importance of an accurate distributed modeling of the aquifer system for conjunctive management purposes, the importance of pumping allocation and the need to manage surface and groundwater as a unit in order to achieve the maximum net benefit. In large-scale River Basin Hydroeconomic (RBHE) models, aquifers are often represented as simple reservoirs with a mass balance equation, often due to the constraints imposed by the applied optimization algorithm (as in network flow optimization models) or the lack of data or more accurate representation.

The linear reservoir model is the simplest model for stream-aquifer connections, and it has been used in simulation and optimization models to indicate promising conjunctive use alternatives at an initial planning stage (e.g., Buras 1963). To analyze a groundwater system with greater accuracy requires a distributed model that explicitly considers the spatial distribution of the aquifer and its hydrodynamic properties, the boundary conditions and the location of external stresses. Analytical solutions have been often useful for a preliminary assessment of stream-aquifer, but most available solutions are developed for ideal homogenous and isotropic aquifers of infinite or semi-infinite extent, idealistic assumptions that can have a significant effect on the accuracy of the results of streamflow depletion (Sophocleous et al. 1995; Pulido-Velazquez et al. 2005). The integration of distributed-parameter models within integrated RBHE optimization models has significant computational implications, and an efficient tool for aquifer simulation is desirable to derive optimal management alternatives or evaluate many alternatives for integrated management over long periods of time. Two major techniques for incorporating distributed groundwater flow simulation within a conjunctive use management optimization model are: the embedding and the response matrix methods (Gorelick 1983; Peralta et al. 1995). A third approach for groundwater flow modeling in basinwide management models is the Eigenvalue Method (Sahuquillo 1983; Andreu and Sahuquillo 1987), in which piezometric heads, flux vectors, and surface and groundwater interactions are obtained by explicit state equations. Unlike the 'embedding method', only the equations that define the control or state variables are loaded into the sets of constraints of the optimization model to simulate groundwater flows, offering computational advantages for the integration of linear distributed-parameter groundwater simulation models within complex conjunctive use models over a long time horizon (Andreu and Sahuquillo 1987; Pulido-Velazquez et al. 2006, 2007a). The Embedded Multireservoir Method also allows quantifying stream-aquifer interaction by simple and operational explicit state equations (Pulido-Velazquez et al. 2005).

\subsubsection{Ad-hoc Models Versus Decision Support Systems (DSS) Shells}

DSSs are interactive computer-based tools to assist in decision-making when addressing complex management problems, integrating simulation and 
optimization models (Chap. 25). DSSs often involve capabilities of computer assisted graphical design, geographically referenced data bases, and interactive and user-friendly graphical interfaces and tools for input management, results display and analysis. Some examples of DSS with conjunctive use capabilities, such as CALVIN (Jenkins et al. 2004), MODSIM (Fredericks et al. 1998), WEAP (Yates et al. 2005) or AQUATOOL (Andreu et al. 1996), although with significant differences in how water resource systems and conjunctive use are modeled and optimized.

\subsection{Selected Applications}

\subsubsection{CU Management in Southern California}

Southern California's water system imports up to $70 \%$ of its water use, with groundwater being a critical component of the region's water supply. While California's population is expected to increase significantly over the next few decades, on the supply side, traditional imports from the Colorado River and the Owens and Mono Basins are being curtailed, creating a significant water crisis (Chung et al. 2002). The economic-engineering network flow optimization model CALVIN has been used to analyze and compare the economic and reliability benefits from different conjunctive use alternatives (Pulido-Velazquez et al. 2004; Harou and Lund 2008). Results from CALVIN suggest that flexible management of additional conjunctive use facilities and groundwater storage capacity under flexible water allocation can generate substantial economic benefits to the region. Conjunctive use adds operational flexibility needed to take full advantage of water transfers, and transfers provide the allocation flexibility needed to take better advantage of conjunctive use. The value of projected conjunctive use facilities and groundwater storage along the Colorado River Aqueduct, Coachella Valley, and north of the Tehachapi mountains under economically optimized operation of the system is examined. The results reveal reduction of the demand for increased imports into Southern California, suggest changes in the system operations, and indicate significant economic benefits from expanding some conveyance and storage facilities.

\subsubsection{CU Operations and Irrigated Agriculture Decisions in California}

Simulation and optimization models often have been used to support effective conjunctive programs and operations, including approaches with physical stream/ aquifer interaction (Gorelick 1983; Peralta et al. 1995; Fredericks et al. 1998; Belaineh et al. 1999) and operating decisions to minimize surface reservoir spills (Schoups et al. 2006a, b). While these approaches help the understanding of surface 
and groundwater interaction, and how to manage it, its application to local management still lacks representation of detailed users' decisions behind water demands, including water and irrigation technology use under uncertain (stochastic) surface water supplies.

In California, federal, tribal, state and local agencies are responsible for managing surface and groundwater, including water rights regulation, groundwater quality and groundwater management plans. According to the California Department of Water Resources (DWR 2009) water users have few restrictions on groundwater use (except in adjudicated basins) as long as the water is applied to beneficial use. This may cause environmental and economic problems if there is not a proper integrated management of surface and groundwater supplies.

In this context, the hydroeconomic model presented in Marques et al. (2010) addresses farm decisions of water use and crop production. Surface and groundwater are conjunctively managed through artificial recharge to store surface water in the aquifer, and groundwater pumping to retrieve it. Artificial recharge occurs through spreading areas for infiltration, which requires some land dedicated to it. The hydroeconomic model includes surface and groundwater supply and storage, each with its costs, availability, uncertainty and use constraints, integrated with the economic product function of the user, which has water as one of the inputs. This allows the model to capture user decisions on which supply source to use, how efficiently to use it (irrigation technology), when and how much to use.

The approach is based on a two-stage stochastic programming model combining a quadratic crop profit function with permanent and temporary irrigation water use decisions to identify the potential economic gains of conjunctive use operations, and how such operations can be organized. Permanent crop decisions are modeled in the first stage, and annual (temporary) crops are modeled in the second stage, represented by a group of possible hydrologic scenarios (dry and wet years), each with a different water availability and probability of occurrence. In any hydrologic scenario, water can be withdrawn from surface supplies and pumped from the aquifer to irrigate crops, or artificially recharged for posterior use. Conjunctive use operations are represented by additional decision variables for artificial recharge area, volumes recharged and pumped. An intertemporal mass balance equation ensures aquifers recharge matches pumping in the long run to avoid aquifer overdraft. The model maximizes the net expected economic benefit of irrigated crop production in both stages, with conjunctive use operations allowing water to be transferred between different hydrologic scenarios through artificial groundwater pumping and recharge (Fig. 27.2) which is integrated with surface water use and availability.

The model application in Marques et al. (2010) indicated that groundwater availability, price, and conjunctive use operations affect crop and irrigation technology decisions. Groundwater provides a stabilizing effect, increasing permanent (more valuable) crop acreage and expanding annual crops in dry years. Crops with high consumptive demand were not supplied with costly water through low efficiency irrigation technology, and as groundwater supply was curtailed in wet years, surface water was allocated to permanent (more valuable) crops, reducing the 


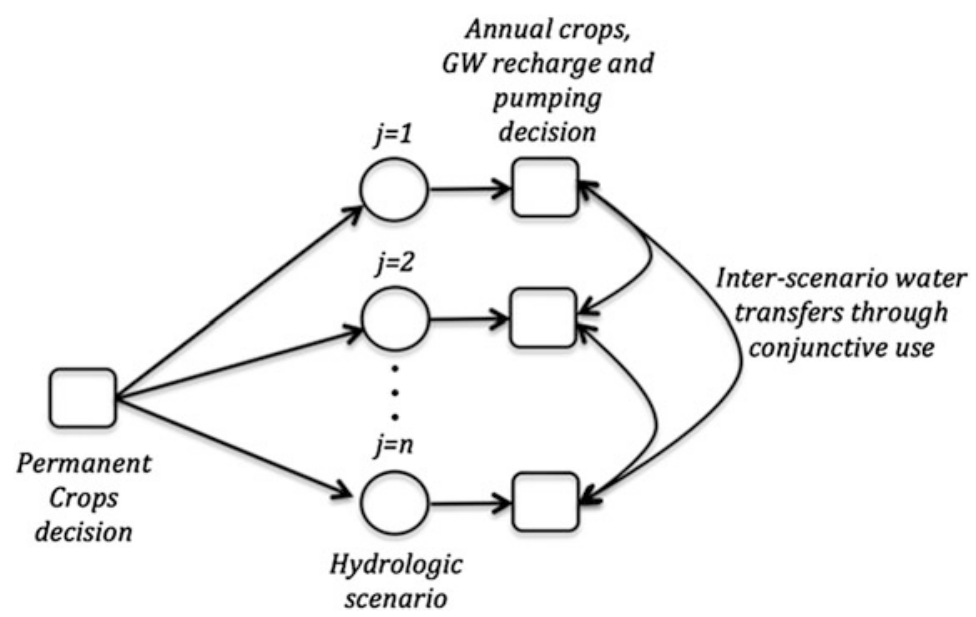

Fig. 27.2 Diagram of hydroeconomic model decision structure

acreages of annual crops. Artificial recharge was concentrated in very wet years, to take most advantage of the investment in infrastructure. With conjunctive use operations, the gains in income reliability were greater than the gains in the expected net benefit, with a trade-off between both. This information can be useful to evaluate the user's willingness-to-pay for insurance based on risk aversion. While users are likely to increase investment in groundwater pumping capacity, sacrificing some of the total net return gains to build the CU infrastructure, the model allowed the identification of a maximum groundwater pumping capacity investment beyond which no further benefits were expected in reliability or net benefit.

\subsubsection{Economically Optimal CU in the Adra-Campo de Dalias System (Spain)}

In the coastal plain of Campo de Dalias $\left(330 \mathrm{~km}^{2}\right)$ in Almeria province, southeastern Spain, the climate conditions and the application of high-tech agricultural techniques have led to high value crop production, mostly vegetables produced under greenhouses, with a spectacular increase in cultivated land and population, becoming the main factor of economic growth in the province. In this water scarce arid region, the water for the irrigation of the more than 20,000 ha. of cultivated land is obtained from groundwater pumping from the Campo de Dalias aquifer system. The intense use of groundwater for years has led to a significant decline of the water table, causing problems of water availability and quality (e.g. seawater intrusion problems). To reduce overexploitation of the Campo aquifers, water is being imported, beginning in 1987, from the Beninar Reservoir, located in the contiguous Adra River basin.

Pulido-Velazquez et al. (2002) examined different conjunctive use management alternatives for the system in a detailed simulation study. An integrated hydrologic- 
economic modeling framework for optimizing conjunctive use of surface and groundwater has also been developed for the Adra-Campo de Dalias system (Pulido-Velazquez et al. 2006, 2008). Integrated river basin modeling with distributed groundwater simulation and dynamic stream-aquifer interaction allows a more realistic representation of conjunctive use and the associated economic results. Transient distributed-groundwater flow is simulated by embedding the explicit equations derived from the eigenvalue method (Sahuquillo 1983) as constraints within the nonlinear economic-engineering optimization model. This method provides an efficient approach for aquifer modeling in conjunctive use models, using explicit state equations to characterize the selected state variables. The use of an economic objective function, maximizing the net economic value of water use, provides solutions that optimize economic efficiency in water resources management, while the model constraints guarantee the feasibility and sustainability of suggested operations.

The model results include time series of monthly flow and storage, marginal economic value of water at each location and time step, and shadow prices for upper or lower bounds in reservoirs, stream reaches, canals, and pipelines. These results lead to conclusions on water allocation and operating decisions, as well as estimates of the economic value of changes in the management and/or the capacity of the infrastructure, users' willingness-to-pay for water, and other economic and performance indicators. A systematic approach is provided to estimate time-varying resource and environmental constraint opportunity costs to users at different locations within the system, providing useful indicators for the economic analysis required by the EU Water Directive Framework (Pulido-Velazquez et al. 2006, 2008; Heinz et al. 2007).

\subsection{Challenges, Benefits and Future Directions}

Many choices face the builder of a hydroeconomic conjunctive use model, including the scale and model type for each of the three subsystems (surface water, groundwater and economic demands). Most modeling efforts showcase unique combinations of these because of unique characteristics of the modeled system and the modeler's skills and perspectives. In practice existing models, especially if calibrated and accepted by stakeholders, often influence decisions about how to build an integrated model. A major choice is whether the groundwater model will be lumped (a frequent choice for policy models) or spatially distributed (often appropriate for hydraulic management models). Other decisions, like which water use benefits to include and how to represent their economic values, are shared with all hydroeconomic models and are not particular to conjunctive use hydroeconomic models. This is the case for choosing an appropriate temporal discretization (timestep) and when optimization is used, whether the optimization model should be solved all at once (water users in the model have perfect knowledge of future hydrological flows) or time-step by time-step. 
There are several technical challenges to hydroeconomic modeling of conjunctive use of surface and groundwater. For example, in conjunctive use systems nonlinearities may arise due to the physical representation of the system (e.g. nonlinearities due to stream disconnection in stream-aquifer interaction or unconfined aquifers) or the cost structure for surface and groundwater use (e.g. nonlinearity of pumping costs, function of the product of pumping heads and pumping rates at the production well). In simulations models, this can be easily addressed. But for hydroeconomic models using optimization approaches, the potential non-linearities of stream-aquifer interactions, unconfined aquifers or pumping cost functions, introduces difficulties in solving the model and in the verification that the solution is globally optimal. Several researchers have overcome these difficulties in particular modeling efforts (Reichard 1987; Pulido-Velazquez et al. 2006, 2007b, etc.). Still it is a barrier in practice as these are specialty methods known to few practitioners. Hydroeconomic modeling conjunctive studies that use optimization algorithms to solve all governing equations including large sets of discretized spatially explicit groundwater equations may fall prey to numerical difficulties (e.g. Tung and Koltermann 1985; Harou and Lund 2008). Other studies have not reported difficulties in this task but it remains a potential challenge or barrier, particularly for large groundwater models.

Despite early and on-going successes, advanced modeling of conjunctive use in water supply planning and management industry practice is the exception rather than the rule. Often excellent surface water system modeling and groundwater modeling systems exist, but their combined use by industry is still rare globally, with more use in some areas (e.g. California, Spain, Australia, etc.). In water supply planning by utilities, where conjunctive use modeling would be particularly valuable, groundwater is often still represented as an aggregated available supply (e.g. yield). The groundwater field has repeatedly warned against 'safe yield' concepts applied to groundwater (Alley and Leake 2004), yet because adopting this approach means integrating groundwater sources into basic supply-demand models is feasible (e.g. Padula et al. 2013), it persists. Also, many decision support systems built for utility scale water supply planning start with the surface water network and its storage reservoirs; this encourages inclusion of groundwater as another storage node. WEAP (Yates et al. 2005) and AQUATOOL (Andreu et al. 1996) are notable exceptions as they allow linking discretized groundwater models to a surface water resource management model.

The papers and modeling efforts reviewed here show the potential benefits to water management studies of considering hydroeconomic aspects of conjunctive use management systems. These include, amongst others, suggesting how groundwater and surface sources can most productively be used together, how use of each resource economically affects those exploiting the other, how the two resources can efficiently interact within water markets, and how new schemes can have unexpected but significant impacts on other water supplies, either downstream or in the future. These are major benefits and, given the large capital cost of water supply investments, they are in many situations worth the investment. Below we review what future directions this field could take to achieve further scientific and practical impact. 
Future potential scientific directions of inquiry are many, starting with the continued improvement of current models and methods for integrated modeling of surface and groundwater and their link to managed systems. Linked groundwater models and surface water simulation can now be linked to single or multi-objective global search algorithms (Reed et al. 2013; Matrosov et al. 2015); this new way to seek efficient solutions opens up many possibilities, including simultaneously considering non-economic objectives. Recent efforts (Yang et al. 2009; Giuliani and Castelletti 2013; Erfani et al. 2013) to move beyond deterministic optimization to represent more realistic behavioral modeling of water users are relevant here. Many optimization modeling efforts reviewed in the paper apply to situations where water markets are relevant; where this is not the case, different computational technologies may be appropriate. Including specific policy investigations (e.g. pricing; Riegels et al. 2013) in addition to water allocation assessment will increase as the tools under discussion are used to assess particular policy investigations.

Several factors could influence growth of hydroeconomic conjunctive use modeling from pockets of excellence (e.g. Western USA, Spain and other localized contexts) to increased global use. The demand from stakeholders and water planners and the availability of easy-to-use decision support systems that model both surface and groundwater systems will likely determine how influential conjunctive use models will be in the future. If their use continues to grow, it is likely that such models with an added hydroeconomic focus will move from academia, their current most frequent institutional home, further into practice.

Open Access This chapter is distributed under the terms of the Creative Commons AttributionNoncommercial 2.5 License (http://creativecommons.org/licenses/by-nc/2.5/) which permits any noncommercial use, distribution, and reproduction in any medium, provided the original author(s) and source are credited.

The images or other third party material in this chapter are included in the work's Creative Commons license, unless indicated otherwise in the credit line; if such material is not included in the work's Creative Commons license and the respective action is not permitted by statutory regulation, users will need to obtain permission from the license holder to duplicate, adapt or reproduce the material.

\section{References}

Ahlfeld DP, Mulligan A (2000) Optimal management of flow in groundwater systems. Academic, New York

Al Khamisia SA, Prathapar SA, Ahmed M (2013) Conjunctive use of reclaimed water and groundwater in crop rotations. Agric Water Manage 116:228-234

Alley WM, Leake SA (2004) The journey from safe yield to sustainability. Ground Water 42 (1):12-16

Anderson MP, Woessner WW (1992) Applied groundwater modeling. Simulation of flow and advective transport. Academic, San Diego

Andreu J, Sahuquillo A (1987) Efficient aquifer simulation in complex system. J Water Resour Plan Manage 113(1):110-129 
Andreu J, Capilla J, Sanchis E (1996) AQUATOOL, a generalized decision support system for water-resources planning and management. J Hydrol 177:269-291

Belaineh G, Peralta RC, Hughes TC (1999) Simulation/optimization modeling for water resources management. J Water Resour Plan Manage 125(3):154-161

Blomquist WA, Schlager E, Heikkila T (2004) Common waters, diverging streams: linking institutions and water management in Arizona, California, and Colorado. RFF Press, Baltimore

Bredehoeft JD (1995) If it works, don't fix it: benefits from regional groundwater management. In: El-Kadi AI (ed) Groundwater models for resources analysis and management. Lewis Publishers, Boca Raton

Bredehoeft JD, Young RA (1970) The temporal allocation of ground water - a simulation approach. Water Resour Res 6(1):3-21

Bredehoeft JD, Young RA (1983) Conjunctive use of groundwater and surface water for irrigated agriculture: risk aversion. Water Resour Res 19(5):1111-1121

Brozović N, Sunding D, Zilberman D (2006) Optimal management of groundwater over space and time. In: Frontiers in water resource economics. Springer, New York, pp 109-135

Buras N (1963) Conjunctive operation of dams and aquifers. Proc ASCE 89(HY. 6):11-131

Burt OR (1967) Temporal allocation of groundwater. Water Resour Res 3(1):45-56

Cai X, McKinney DC, Lasdon LS (2003) Integrated hydrologic-agronomic-economic model for river basin management. J Water Resour Plan Manage 129(1):4-17

California Department of Water Resources, DWR (2009) California water plan update - resource management strategies - conjunctive management and groundwater, vol 2, chapter 8

Chung F, Kelly KK, Guivetchi K (2002) Averting a California crisis. J Water Resour Plan Manage 128(4):237-239

Coe JJ (1990) Conjunctive use - advantages, constraints, and examples. J Irrig Drain Eng 116 (3):427-443

Downing R (ed) (1998) Groundwater, our hidden asset. British Geological Survey/Earthwise Popular Science Books, Nottinghan, $59 \mathrm{p}$

Erfani T, Huskova I, Harou JJ (2013) Tracking trade transactions in water resource systems: a node-arc optimization formulation. Water Resour Res 49:3038-3043

Fox P, Narayanaswamy K, Genz A, Drewes JE (2001) Water quality transformations during soil aquifer treatment at the Mesa Northwest Water Reclamation Plant, USA. Water Sci Technol 43:343-350

Fredericks JW, Labadie JW, Altenhofen JM (1998) Decision support system for conjuctive stream-aquifer management. J Water Resour Plan Manage 124(2):69-78

Gisser M, Sanchez DA (1980) Competition versus optimal control in groundwater pumping. Water Resour Res 16(4):638-642

Giuliani M, Castelletti A (2013) Assessing the value of cooperation and information exchange in large water resources systems by agent-based optimization. Water Resour Res 49:3912-3926

Gorelick SM (1983) A review of distributed parameter groundwater management modeling methods. Water Resour Res 19(2):305-319

Hanson RT, Flint LE, Flint AL, Dettinger MD, Faunt CC, Cayan D, Schmid W (2012) A method for physically based model analysis of conjunctive use in response to potential climate changes. Water Resour Res 48:W00L08. doi:10.1029/2011WR010774

Harou JJ, Lund JR (2008) Ending groundwater overdraft in hydrologic-economic systems. Hydrogeol J 16(6):1039-1055

Harou JJ, Pulido-Velazquez M, Rosenberg DE, Medellin-Azuara J, Lund JR, Howitt RE (2009) Hydro-economic models: concepts, design, applications, and future prospects. J Hydrol 375 (3-4):627-643. doi:10.1016/j.jhydrol.2009.06.037

Heinz I, Pulido-Velazquez M, Lund JR, Andreu J (2007) Hydro-economic modeling in river basin management: implications and applications for the European water framework directive. Water Resour Manage 21(7):1103-1125

Jenkins MW, Lund JR, Howitt RE, Draper AJ, Msangi SM, Tanaka SK, Ritzema RS, Marques GF (2004) Optimization of California's water system: results \& insights. J Water Resour Plan Manage 130(4):271-280 
Karamouz M, Tabari M, Kerachian R (2007) Application of genetic algorithms and artificial neural networks in conjunctive use of surface and groundwater resources. Water Int 32(1):163-176

Kløve B, Allan A, Bertrand G et al (2011) Groundwater dependent ecosystems. Part II. Ecosystem services and management in Europe under risk of climate change and land use intensification. Environ Sci Policy 14(7):782-793

Kløve B, Ala-Aho P, Bertrand G, Gurdak JJ, Kupfersberger H, Kværner J, Muotka T, Mykrä H, Preda E, Rossi P, Uvo CB, Velasco E, Pulido-Velázquez M (2013) Climate change impacts on groundwater and dependent ecosystems. J Hydrol 518:250-266

Koundouri P (2004) Potential for groundwater management: Gisser-Sanchez effect reconsidered. Water Resour Res 40. doi:10.1029/2003WR002164

Lall U (1995) Yield model for screening surface and ground water development. J Water Resour Plan Manage 121(1):9-22

Lefkoff J, Gorelick SM (1990) Benefits of an irrigation rental market in a saline stream-aquifer system. Water Resour Res 26(7):1371-1381

Maknoon R, Burges SJ (1978) Conjunctive use of surface and groundwater. Am Water Works Assoc J 78(8):419-424

Marques GF, Lund JR, Leu MR, Jenkins M, Howitt R, Harter T, Hatchett S, Ruud N, Burke S (2006) Economically driven simulation of regional water systems: Friant-Kern, California. J Water Res Plan Manage 132(6):468-479

Marques G, Lund JR, Howitt R (2010) Modeling conjunctive use operations and farm decisions with two-stage stochastic quadratic programming. J Water Resour Plan Manage 136(3):386-394

Matrosov ES, Huskova I, Kasprzyk JR, Harou JJ, Lambert C, Reed PM (2015) Many-objective optimization and visual analytics reveal key trade-offs for London's water supply. J Hydrol. doi:10.1016/j.jhydrol.2015.11.003

McCarl BA, Dillon CR, Keplinger KO, Williams RL (1999) Limiting pumping from the Edwards Aquifer: an economic investigation of proposals, water markets, and spring flow guarantees. Water Resour Res 35(4):1257-1268

Milly PCD, Betancourt J, Falkenmark M et al (2008) Stationarity is dead: whither water management? Science 319:573-574

NRC (1997) Valuing ground water. Economics concepts and approaches. National Research Council/National Academic Press, Washington, DC

NRC (2012) Progress toward restoring the Everglades: the fourth biennial review, 2012. National Research Council/National Academies Press, Washington, DC

Padula S, Harou JJ, Papageorgiou LG, Ji L, Mohammad A, Hepworth N (2013) Least economic cost regional water supply planning - optimising infrastructure investments and demand management for South East England's 17.6 million people. Water Resour Manag 27 (15):5017-5044

Peralta RC, Cantiller RA, Terry JE (1995) Optimal large-scale conjunctive water-use planning: case study. J Water Resour Plan Manage 121(6):471-478

Perez CD, Gómez CM (2013) Designing optimum insurance schemes to reduce water overexploitation during drought events: a case study of La Campiña, Guadalquivir River Basin, Spain. J Environ Econ Policy 2(1):1-15. doi:10.1080/21606544.2012.745232

Pulido-Velazquez M, Andreu J, Sahuquillo A, Pinilla V, Sánchez A, Capilla J, Paredes J (2002) Optimization of water resources management under aquifer overexploitation conditions. In: Brebia CA, Blain WR (eds) Hydraulic information management, 488 pp. WIT Press, Southampton, UK

Pulido-Velazquez M, Jenkins MW, Lund JR (2004) Economic values for conjunctive use and water banking in southern California. Water Resour Res 40(3):W03401

Pulido-Velazquez M, Sahuquillo A, Ochoa JC, Pulido-Velazquez D (2005) Modeling of streamaquifer interaction: the embedded multireservoir model. J Hydrol 313(3-4):166-181

Pulido-Velazquez M, Sahuquillo A, Andreu J (2006) Economic optimization of conjunctive use of surface and groundwater at the basin scale. J Water Resour Plan Manage 132(6):454-467

Pulido-Velazquez D, Sahuquillo A, Andreu J, Pulido-Velazquez M (2007a) An efficient conceptual model to simulate surface water body-aquifer interaction in conjunctive use management models. Water Resour Res 43(7):W07407 
Pulido-Velazquez D, Sahuquillo A, Andreu J, Pulido-Velazquez M (2007b) A general methodology to simulate groundwater flow of unconfined aquifers with a reduced computational cost. $\mathrm{J}$ Hydrol 338(1-2):42-56

Pulido-Velazquez M, Andreu J, Sahuquillo A, Pulido-Velazquez D (2008) Hydro-economic river basin modelling: the application of a holistic surface-groundwater model to assess opportunity costs of water use in Spain. Ecol Econ 66(1):51-65

Pulido-Velazquez M, Alvarez-Mendiola E, Andreu J (2013) Design of efficient water pricing policies integrating basinwide resource opportunity costs. J Water Resour Plan Manage 139 (5):583-592

Rao SVN, Bhallamudi SM, Thandaveswara BS, Mishra GC (2004) Conjunctive use of surface and groundwater for coastal and deltaic systems. J Water Resour Plan Manage 130(3):255-267

Reed PM, Hadka D, Herman J, Kasprzyk J, Kollat J (2013) Evolutionary multiobjective optimization in water resources: the past, present, and future. Adv Water Resour 51:438-456

Reichard EG (1987) Hydrologic influences on the potential benefits of basinwide groundwater management. Water Resour Res 23(1):77-91

Riegels N, Pulido-Velazquez M, Doulgeris C, Valerie S, Jensen R, Moller F, Bauer-Gottwein P (2013) A systems analysis approach to the design of efficient water pricing policies under the EU water framework directive. J Water Res Plan Manage 139(5):574-582

Safavi H, Alijanian M (2011) Optimal crop planning and conjunctive use of surface water and groundwater resources using fuzzy dynamic programming. J Irrig Drain Eng 137(6):383-397

Sahuquillo A (1983) An eigenvalue numerical technique for solving unsteady groundwater models continuously in time. Water Resour Res 19(1):87-93

Sahuquillo A (1985) Groundwater in water resources planning: conjunctive use. Water Int 10 (2):57-63

Sahuquillo A (1989) The economic aspects of the conjunctive use of ground and surface water. In: Groundwater economics: selected papers from an UN symposium in Barcelona, Spain. Develop. in Water Science, vol. 39. Elsevier, Amsterdam

Sahuquillo A, Lluria M (2003) Conjunctive use as potential solution for stressed aquifers: social constraints. In: Llamas MR, Custodio E (eds) Intense use of groundwater. Challenges and opportunities. Balkema Publishers, Lisse

Schoups G, Addams CL, Minjares JL, Gorelick SM (2006a) Reliable conjunctive use rules for sustainable irrigated agriculture and reservoir spill control. Water Resour Res 42: W12406. doi:10.1029/206WR005007

Schoups G, Addams CL, Minjares JL, Gorelick SM (2006b) Sustainable conjunctive water management in irrigated agriculture: model formulation and application to the Yaqui Valley, Mexico. Water Resour Res 42(10): W10417. doi:10.1029/2006WR004922

Schuck EC, Green GP (2002) Supply-based water pricing in a conjunctive use system: implications for resource and energy use. Resour Energy Econ 24(3):175-192

Sophocleous M (2003) Environmental implications of intensive groundwater use with special regard to streams and wetlands. In: Llamas R, Custodio E (eds) Intensive use of groundwater. CRC Press, The Netherlands

Sophocleous M, Koussis A, Martin JL, Perkins SP (1995) Evaluation of simplified stream-aquifer depletion models for water rights administration. Ground Water 4(3):579-588

Tung YK, Koltermann CE (1985) Some computational experiences using embedding technique for ground-water management. Ground Water 23(4):455-464

Yang Y-CE, Cai X, Stipanović DM (2009) A decentralized optimization algorithm for multi-agent system based watershed management. Water Resour Res 45:W08430

Yates D, Sieber J, Purkey D, Huber-Lee A (2005) WEAP21-a demand-, priority-, and preferencedriven water planning model part 1: model characteristics. Water Int 30(4):487-500

Young RA (2005) Determining the economic value of water: concepts and methods. Resources for the Future, Washington, DC

Young RA, Bredehoeft JD (1972) Digital computer simulation for solving management problems of conjunctive groundwater and surface water systems. Water Resour Res 8(3):533-556

Zektser S, Loaiciga HA, Wolf JT (2005) Environmental impacts of groundwater overdraft: selected case studies in the southwestern United States. Environ Geol 47:396-404 


\title{
Methods for Exploring Uncertainty in Groundwater Management Predictions
}

\author{
Joseph H.A. Guillaume, Randall J. Hunt, Alessandro Comunian, \\ Rachel S. Blakers, and Baihua Fu
}

\begin{abstract}
Models of groundwater systems help to integrate knowledge about the natural and human system covering different spatial and temporal scales, often from multiple disciplines, in order to address a range of issues of concern to various stakeholders. A model is simply a tool to express what we think we know. Uncertainty, due to lack of knowledge or natural variability, means that there are always alternative models that may need to be considered. This chapter provides an overview of uncertainty in models and in the definition of a problem to model, highlights approaches to communicating and using predictions of uncertain outcomes and summarises commonly used methods to explore uncertainty in groundwater management predictions. It is intended to raise awareness of how alternative models and hence uncertainty can be explored in order to facilitate the integration of these techniques with groundwater management.
\end{abstract}

\footnotetext{
J.H.A. Guillaume $(\bowtie)$

National Centre for Groundwater Research and Training \& Integrated Catchment Assessment and Management (ICAM) Centre, Fenner School of Environment and Society, Australian National University, Building 48A, Linnaeus Way, Canberra, ACT 0200, Australia

Water \& Development Research Group (WDRG), Aalto University, Tietotie 1E, Espoo 02150,

Finland

e-mail: joseph.guillaume@aalto.fi

R.J. Hunt

United States Geological Survey, Wisconsin Water Science Center, 8505 Research Way, Middleton, WI 53562, USA

Department of Geoscience, University of Wisconsin-Madison, 1215 West Dayton Street, Madison, WI 53705, USA

e-mail: rjhunt@usgs.gov 


\subsection{Introduction} "Elementary," said he. "It is one of those instances where the reasoner can produce an effect
which seems remarkable to his neighbour, because the latter has missed the one little point
which is the basis of the deduction." - Sherlock Holmes in "The Crooked Man",
The Memoirs of Sherlock Holmes (1893)

"How often have I said to you that when you have eliminated the impossible, whatever remains, however improbable, must be the truth?" - Sherlock Holmes, The Sign of the Four, ch. 6 (1890)

"You know my methods, Watson. There was not one of them which I did not apply to the inquiry. And it ended by my discovering traces, but very different ones from those which I had expected." - Sherlock Holmes in "The Crooked Man", The Memoirs of Sherlock Holmes (1893, Doubleday p. 416)'

The issue of exploring uncertainty in model-based prediction can be described through three quotes by Sherlock Holmes. Firstly, any particular model may fail to capture a crucial characteristic of a problem. Hence, prediction needs to involve exploration of 'alternative' models in the hope that one may include the one little point which is important for obtaining a sufficiently accurate prediction. Secondly, because the scientific method cannot prove correctness, prediction of uncertain outcomes needs to focus on eliminating the impossible and incorrect. Thirdly, it is often necessary to use multiple methods - because groundwater management involves a hidden and poorly characterized subsurface, there is no definite way of determining which of many methods will provide the necessary information. Although the world of all possible methods are only within reach of experts like Sherlock Holmes, anybody who deals with prediction of uncertain outcomes will benefit from becoming aware of the approaches available and the principles underlying them. This is the purpose of this chapter.

Addressing uncertainty is an indispensable part of prediction. Groundwater management faces uncertainty on many fronts, in understanding the behaviour of the groundwater system, anticipating possible future climatic, economic or geopolitical conditions, prioritising objectives, all combining to add ambiguity in the

\footnotetext{
A. Comunian

Connected Waters Initiative Research Centre, UNSW Australia, Sydney, NSW 2052, Australia

Dipartimento di Scienze della Terra “Ardito Desio”, Università degli Studi di Milano, via

Cicognara 7, Milan 20129, Italy

e-mail: alessandro.comunian@unimi.it

R.S. Blakers

National Centre for Groundwater Research and Training \& Integrated Catchment Assessment and Management (ICAM) Centre, Fenner School of Environment and Society, Australian National University, Building 48A, Linnaeus Way, Canberra, ACT 0200, Australia

B. $\mathrm{Fu}$

National Centre for Groundwater Research and Training \& Integrated Catchment Assessment and Management (ICAM) Centre, Fenner School of Environment and Society, Australian National University, Building 48A, Linnaeus Way, Canberra, ACT 0200, Australia
} 
evaluation of management options. Focussing on the first, it is apparent that scientific research has achieved relative success in reducing this uncertainty, culminating in the ability to approximate the behaviour of a groundwater system using a 'model'. There are, however, limits to the ability of science. Far from being all-knowing, there will always be recognised and unrecognised unknowns that mean that a model will always be a simplification of reality, and the predictions it makes will always be uncertain (Hunt and Welter 2010; Guillaume et al. 2012).

A model is simply a tool to encapsulate and transparently express what we think we know and illuminate what we do not (Doherty 2011). It is only as good as the conceptualization that was put in it, and when misused can easily result in 'garbagein' producing 'garbage-out'. In interpreting results, the end-user should only weight their assessment of a model's prediction by the confidence they have in the model itself. Given the open system being modelled, an end-user and modeller likely will have sufficient confidence in a family of possible models, each of which makes a different prediction (Barnett et al. 2012). Creating an ensemble of predictions of an uncertain outcome ultimately amounts to using many models and their associated confidence to produce a probability distribution, a confidence interval, or simply a set of scenarios which are believed to have utility for the modelling purpose.

This chapter provides an overview of commonly used methods to explore uncertainty in groundwater management predictions. Their common element is that they help produce 'alternative' models in which the end-user may have sufficient confidence, even though there may be other models which appear better. The presentation is aimed at end-users of groundwater management predictions, including managers and water users, to help them become aware of the methods available to generate alternative models and hence relate to prediction uncertainty. It may therefore also be of use to modellers to help explain how a technique helps address uncertainty. It is generally accepted amongst modellers that stakeholders ultimately decide whether the accuracy of a prediction is acceptable (Refsgaard and Henriksen 2004). Evaluating prediction accuracy requires understanding how it was produced. In a modelling context, this means being able to critique the reasons why a given model(s) was selected. We encourage all end-users, particularly groundwater managers, to be aware of the different reasoning underlying these methods. We do not expect the reader of this chapter to become an expert. We focus primarily on uncertainty in groundwater models, as a fundamental tool for expressing uncertainty in groundwater management. However, many of the methods can be used with other types of models. We expect the reader may gain an understanding of how modellers can 'dance' with a model to explore alternatives. They may be better prepared to participate in judging the value of the information that was put in the modelling, and hence enhance their confidence in the predictions of uncertain outcomes produced. We hope this will consequently help dispel the magical aura and unassailable authority that model predictions often seem to carry, while giving a language for relating the uncertainty that surrounds all predictions.

In order to describe methods to explore uncertainty in a groundwater model, the chapter initially sets the scene by discussing the construction of a clear modelling 
problem definition, and options for using and communicating predictions of uncertain outcomes. The methods covered include creating alternative models with different input values and different structures (in terms of both conceptualisation and implementation). Other methods select different parameters using statistical properties of data as well as fitting observations of (multiple) predicted variables, or by aiming to test a hypothesis, or estimate the importance of variables. We finish with methods to anticipate surprise by supporting adaptation and exploring the 'known unknowns' of Hunt and Welter (2010). For each method, the general principles tend to be broadly applicable to other types of models, but are illustrated with cases specific to groundwater modelling.

\subsection{Starting from a Clear Problem Definition}

The methods described later in the chapter assume that the scope of the problem has been defined. In particular, this means that there are clear predictions to make (Barnett et al. 2012). Models are a simplification of reality, and therefore do not represent all aspects of reality, but modelling needs to adequately capture the salient behaviour of the system of interest for a given purpose (Jakeman et al. 2006). Knowing how predictions will be used should directly inform the modelling approach because it forms the basis for deciding which simplifications and simulation processes are required in the model, and which can be omitted. For example, prediction of groundwater head is a fundamentally different (and easier) problem than prediction of groundwater transport.

Once a clear set of predictions is identified, the problem is expressed in modelling terms. A model, by definition, is a simplification of a system. As shown in Fig. 28.1, it produces outputs from given inputs, such as rainfall and pumping. The response of the model to these inputs can be modified by changing the value of so-called parameters, such as properties of the modelled aquifer. We need to know what inputs are needed and what outputs are expected. An alternative view of a model is the XLRM framework (Lempert et al. 2003). An end-user may be interested in investigating the effect of different exogenous uncertainties $(\mathrm{X})$ and policy levers $(\mathrm{L})$, and will be expecting that the relationship $(\mathrm{R})$ captured by a model and its parameters will produce certain measures $(\mathrm{M})$ to evaluate them by.

Figure 28.2 shows a more detailed example of the use of a groundwater model as part of a broader integrated model aimed at assessing the impacts of changes in climate conditions and water allocation policies on surface and groundwater-

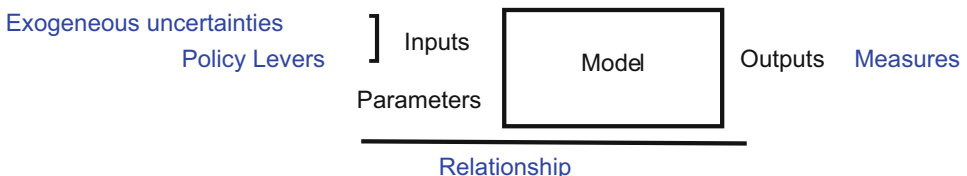

Fig. 28.1 Diagram of a model 


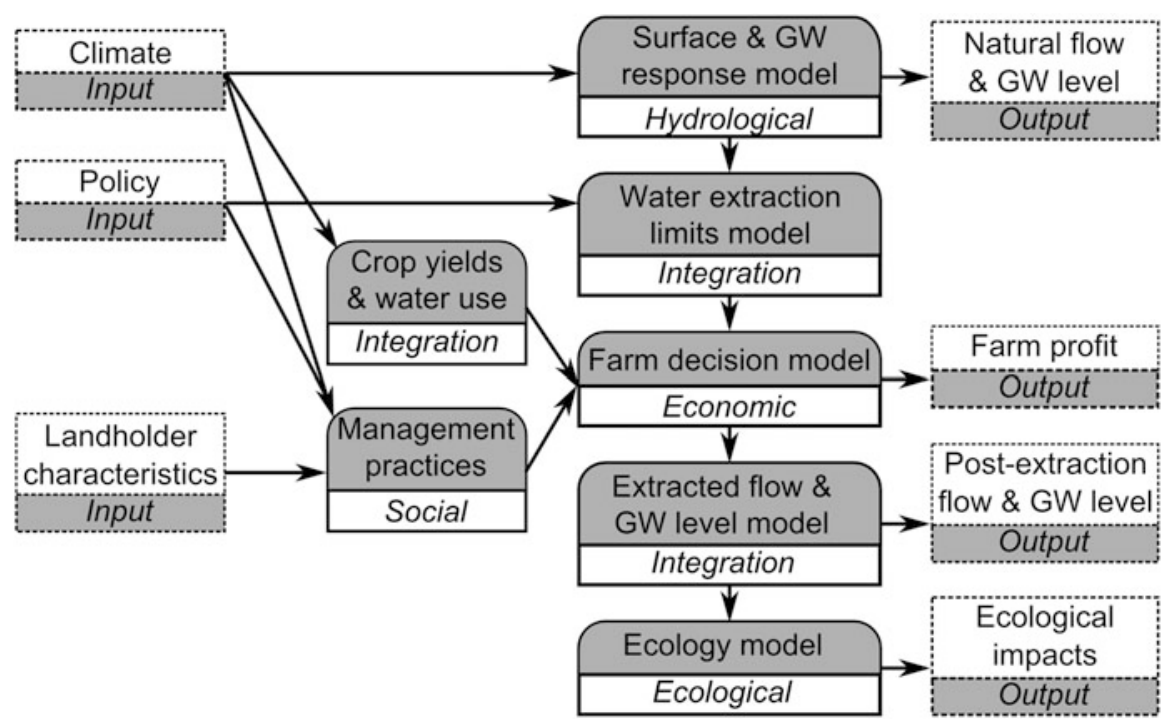

Fig. 28.2 Diagram of an integrated model (Adapted from Jakeman et al. 2014)

dependent economic and ecological systems (Jakeman et al. 2014). At the core of the integrated model is the hydrological component. The hydrological model takes historical climate data, or future climate projections, as inputs and produces estimates of natural surface-water flows and groundwater levels as outputs. A Water Extraction Limits Model uses the estimated water availability and selected water policy options to calculate the allocations available to landholders. A Farm Decision Model then calculates actual water usage and farm profit based on the pre-extraction water availability, crop characteristics and the modelled decisionmaking behaviour of landholders. The landholder behaviour is simulated by a social model, which considers levels of compliance and adoption of various land management practices. Finally, the model uses post-extraction surface water flows and groundwater levels to assess ecological impacts.

Problem definitions may however be uncertain. They may be affected by constraints on the modelling exercise, such as on cost, time, availability and quality of data and expertise, not all of which may be apparent from the start. Different users may have different conflicting objectives or contradictory understandings of the problem (Brugnach et al. 2008). There may be linguistic ambiguity, with multiple conflicting interpretations of a statement, particularly where people of different professional or disciplinary backgrounds are involved. Even if a problem statement seems qualitatively quite clear, it may be difficult to translate it into quantitative terms. For example, a groundwater well may be considered unusable or "dry" before the bore itself becomes dry (e.g. if the water level falls below the pump intake or if the remaining saturated thickness is insufficient to meet a water need). Moreover, as more is learned, the predictions required may also evolve. Preliminary 
results might show that other scenarios or policies need to be considered, or it might become apparent that an accurate prediction is simply not possible given the available knowledge, but alternative predictions might still be possible.

In each case, failure to address uncertainty may result in useless predictions. We will limit our discussion of uncertainty in problem definition to a few basic principles:

- Modellers and stakeholders need to work together to define a problem, in a manner cognisant of the uncertainty involved. All parties should avoid oversimplification of defining the problem; guidelines on this issue are available elsewhere (e.g. Johnson 2008; Voinov and Bousquet 2010)

- Modellers and stakeholders need to actively seek out different perspectives of the problem. Casting a wide net for views will help ensure that they encompass not only those views important now, but also those that may become important later. This may involve drawing on multidisciplinary teams, considering different parts of a system or seeking out contrasting world views (van Asselt and Rotmans 2002). For example, creating policy and administering may have different requirements. Modelling techniques allow for multiple objectives to be included (e.g. Reed and Minsker 2004; Mantoglou and Kourakos 2007), so it is better to avoid narrowing down prematurely.

- Be prepared to iterate - do not expect it to be correct the first time. Even as the modelling exercise progresses, remain open to the potential for the problem definition and conceptual models to change dramatically (Bredehoeft 2005). This corresponds to a Bayesian view of the world, wherein data are used to progressively update prior understanding.

In traditional management literature, decision processes are considered to have three main stages: identifying a problem, developing possible courses of action, and selecting a course of action (Janssen 1992). However, it is also possible that in highly complex and deeply uncertain problems, the definition of the problem may be dependent on one's idea for solving it (Rittel and Webber 1973). Feasible objectives of groundwater management can be limited by practical constraints and uncertainties in how a system will respond to different management interventions. For example, the objective of groundwater management can be restoring groundwater storage to a specified level, or improving groundwater storage relative to the current level. We may find the uncertainty is too high to allow us to predict the actual groundwater storage, but we can predict the direction of change (e.g. improve from current) with higher level of certainty. This finding may trigger us to reconsider what type of management objectives are likely to be achievable given uncertainties and thus what indicators/predictions we want to include in the models.

Therefore, in the context of modelling for decision making, an iterative discovery method designed for co-development of management targets (reflected by the indicators/predictions and model produces) and interventions (reflected by the drivers and scenarios used in the model) can be useful for exploring feasible 


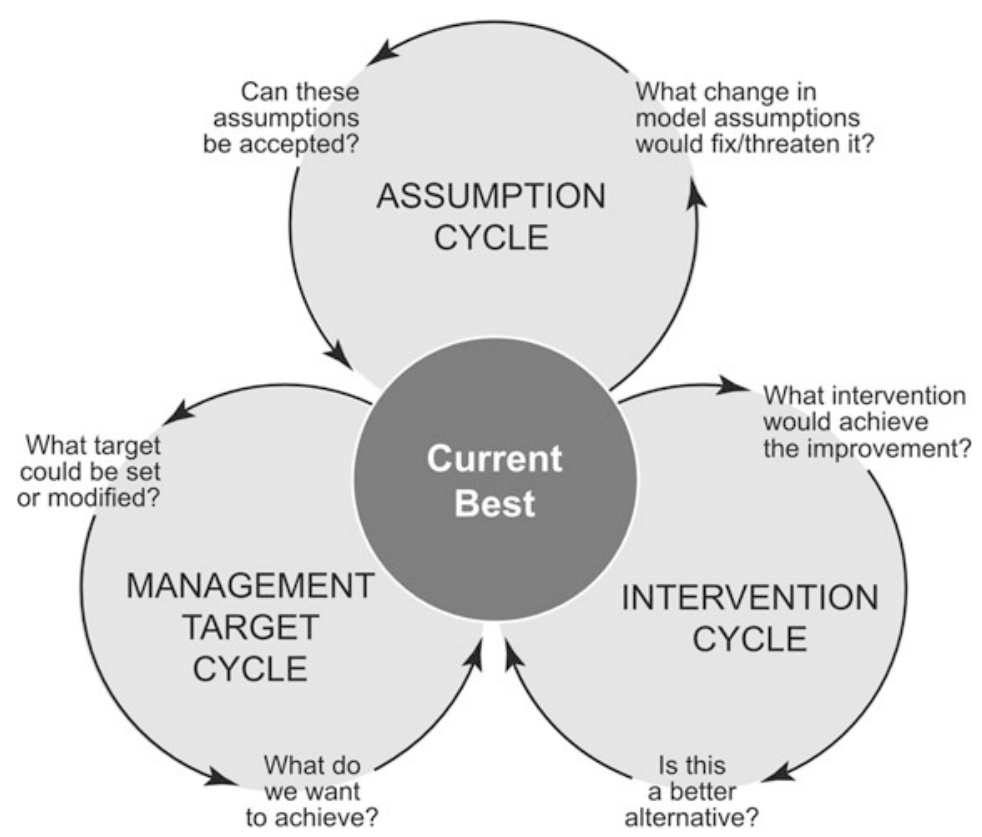

Fig. 28.3 The iterative discovery method. Starting from the current best scenario, potential desirable and undesirable outcomes are identified which prompt the three cycles (assumption, intervention and management target) in order to identify achievable and specific management targets and alternative interventions under uncertainty (From Fu et al. 2015)

management targets under deep uncertainties (Fu et al. 2015). As shown in Fig. 28.3, the method starts by evaluating a scenario describing the current best solution, for instance the current groundwater policy. Using visualizations of the solution and its impacts, the user is prompted to identify desirable or undesirable outcomes of the current best scenario. This provides the starting point for three cycles, focusing on model assumptions, alternative groundwater management interventions, and management targets such as maintaining or improving or restoring groundwater storage or the health of groundwater dependent ecosystems. The outcome of this method is a list of management targets that can and cannot be achieved, the potential interventions that correspond to these targets, and the assumptions and uncertainties associated with these interventions. These outcomes can then be used as inputs for trade-off or cost-benefit analysis of different interventions to select a suitable course of action.

This iterative discovery method highlights the importance of using models for capacity building in groundwater decision making under uncertainties. Rather than simply providing 'the' answer, the method and models are used to build a knowledge partnership between modelers and decision makers. This kind of method is therefore most useful to analysts preparing recommendations rather than decision makers receiving them. 


\subsection{Communicating and Using Predictions of Uncertain Outcomes}

The selection of methods to explore uncertainty in predictions depends not just on the problem, but also on how predictions will be used. This in turn depends on why uncertainty needs to be addressed. Notwithstanding earlier discussion, there may be times when uncertainty does not need to be addressed in detail, such as if a wrong prediction will have no impact, impacts are entirely reversible at little cost, or adverse effects of omission can be effectively handled by other aspects of decision making such as engineering safety factors. By way of contrast, we can identify six reasons that uncertainty in predictions may need to be addressed:

(a) Testing whether a conclusion may be wrong. Model predictions form the basis for expecting a result - a conclusion that might later turn out to be wrong. In groundwater management terms, this might include that a project satisfies regulatory requirements on impacts to groundwater, that an extraction limit will prevent drawdown, or that a contaminant will not reach a well. The simplest means of communicating uncertainty in this case is to present a model(s) that cannot be rejected as implausible and in which a conclusion is not guaranteed, for example, describing a potential preferential flow pathway that would be consistent with collected data.

(b) Identifying plans that are robust given uncertainty. Predictions are frequently used within a planning or decision-making framework. Decision-making frameworks based on the concept of robustness aim to identify plans that perform well in a set of models that includes potential unfavourable conditions. The "min-max" and "min-max regret" optimisation methods find a single 'robust' solution that respectively provides the best performance in the worst model scenario, or minimises regret if the future turns out to be described by a different model than expected (Kouvelis and Yu 1997). Extensions to this concept include considering multiple solutions that are close to the best one or considering more than just the worst case (Kalai et al. 2012). Optimisation under uncertainty also includes a number of methods that use sets of models with names such as 'chance constraints', 'stochastic programming', and 'probabilistic ranking' (Wagner and Gorelick 1989; Gorelick 1990; Chan 1993; Morgan et al. 1993; Bayer et al. 2008). For example, Feyen and Gorelick (2004) ensure that water-table elevations in sensitive wetland areas are not excessively lowered by the withdrawal of groundwater by verifying that constraints on hydraulic head are satisfied by all model realisations in a 'stack' of alternative models. Communication of uncertainty consists of describing the characteristics of models over which a plan has been tested.

(c) Identifying uncertain factors that have the greatest influence. The field of sensitivity analysis examines "how the variation in the output of a model ... can be apportioned ... to different sources of variation" (Saltelli et al. 2004; 
Matott et al. 2009; Saltelli and Annoni 2010). This is typically done by comparing outputs of large sets of alternative models with known differences and calculating statistics developed for the purpose (e.g. Doherty and Hunt 2009). This can help to identify dominant and insignificant drivers of system behaviour, e.g. comparing the effect of pumping in multiple wells on drawdown or comparing the effect of parameters on a prediction. Understanding uncertainty in dominant drivers will facilitate associated reductions in uncertainty in model outputs. Communication focuses on providing a ranking of factors, often with some quantitative measure of significance. Note that a ranking will likely itself be uncertain because estimates of uncertainty are themselves uncertain, in which case it may be necessary to test whether the resulting conclusion may be wrong (See item $a$ in this list).

(d) Prompting changes to models or knowledge. Model uncertainty is related to a model's limitations. Understanding the source and nature of that uncertainty can help improve modelling. This includes lack of knowledge, variability and contradiction (Refsgaard et al. 2007; Brugnach et al. 2008; Guillaume et al. 2012). Identifying a knowledge gap may prompt changes that could reduce uncertainty in predictions, such as collecting additional monitoring data. Not all uncertainties are equal - identifying important sources of uncertainty and knowledge gaps in models helps to prioritise research efforts (Fu and Guillaume 2014). Understanding the causes of variability may allow them to be explicitly modelled. Identifying the existence of contradictory views may allow the design of experiments to resolve the debate. For example: model construction itself is a means of dealing with uncertainty, as "the model-construction process organizes and formalizes potential conceptual models of a ground water system" (Hunt and Welter 2010). The field of identifiability analysis aims "to expose inadequacies in the data or suggest improvements in the model structure" (Matott et al. 2009). Data acquisition planning aims to inform what data should be collected (Beven 1993; James and Gorelick 1994; Dausman et al. 2010; Fienen et al. 2010, 2011). Each of these involves exploring and improving the state of inherently imperfect models. Communication of uncertain predictions focuses on its implications for later analyses, or on helping to justify why changes to a model have been made.

(e) Providing quantitative estimates of uncertainty to other users. The 'need' to provide an estimate of uncertainty is among the most commonly cited reason for using techniques to explore uncertainty in predictions. As the previous four points indicate, the need reflects a larger context, where uncertainty is a means to a decision-making end. In many cases, information about uncertainty can be communicated and used without necessarily expressing it in quantitative form. A more quantitative characterization of uncertainty may however be used in other processes, such as for risk management and decision theory (Freeze et al. 1990), and may be required by law in some countries as 
Fig. 28.4 Levels of detail to represent quantitative estimates of uncertainty (Modified after Walker et al. 2003; Guillaume et al. 2010)

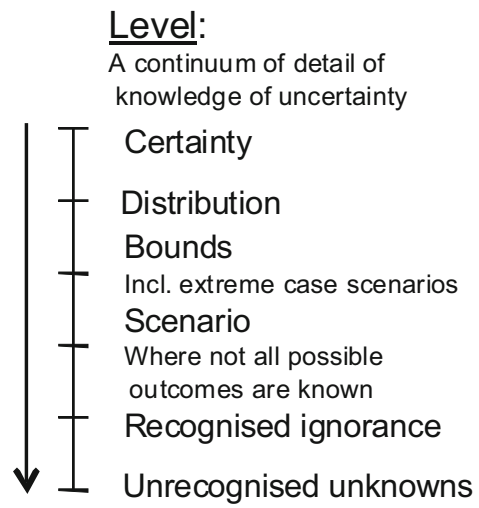

part of cost-benefit analyses or impact assessments. It may also be necessary to pass uncertainty information on to users without knowing how they will use it. In these cases, it is considered good practice to present "the modeller's estimate of the representative uncertainty given what is known about the system, the type of prediction(s), and the modeller's experience with the model and model calibration" (Hunt 2012).

Estimates of uncertainty can be represented at various levels of detail, as illustrated in Fig. 28.4 (Walker et al. 2003; Guillaume et al. 2010). For a given source of uncertainty, there may only be enough information to represent it as bounds or scenarios, rather than probabilities. For example, it might be more appropriate to use best-case and worst-case scenarios (Renard 2007; Paté-Cornell 1996). Where there are many sources of uncertainty, they may need to be represented at multiple different levels, for example variability of rainfall as a distribution, future prices of irrigated crops as bounds, and possible groundwater policies or irrigator pumping patterns as scenarios (Guillaume et al. 2012). Uncertainties that are known at a high level of detail can also be represented at lower levels of detail. For example, probabilities can be represented not just as probability distributions or cumulative distribution functions, but also using means and standard-deviations, confidence intervals and an ensemble of samples from a distribution.

In all cases, the consumers of the uncertainty estimate become the primary focus of how best to relate estimates to others. A groundwater scientist cannot expect that those needing to use the estimates will understand the academic terms and metrics (Hunt 2012). Therefore, translation of estimates into formats of direct use to the decision-making process should be used when possible (e.g. Hunt et al. 2001). Care needs to be taken when communicating estimates of uncertainty, particularly in the case of probabilities. Interpretation of 
probabilities tends to be biased, such that it is better to communicate them as frequencies, even if the probability refers to the likelihood of a one-off event (Anderson 1998). Rather than providing tables of probabilities, they may be better visualised (Barnett et al. 2012) by using maps or graphs. Where possible, expressing probability with its consequence allows it to be interpreted in terms of risk, reliability or probabilities of exceedance (Paté-Cornell 1996), and therefore provides a closer tie to its implications. Crucially, because of the potential for unrecognised unknowns, presentation of uncertain predictions should avoid stating uncertainty estimates in isolation. It is preferable to instead list the specific aspects of uncertainty that have been considered in producing an estimate, with the understanding that some may have been overlooked (Hunt and Welter 2010; Roy 2010; Guillaume et al. 2012). There is an extensive literature on the presentation and interpretation of uncertainty estimates (Wardekker et al. 2008; Kloprogge et al. 2007), even in the case of scenarios (Alcamo 2008).

(f) Passing on qualitative information about uncertainty. In a strict theoretical sense, the presence of unknowable model structure error means that true uncertainty cannot be characterized (e.g. Beven 2009), and true quantitative estimates are unattainable. Moreover, where a prediction is used only as a scenario to prompt discussion, a qualitative approach may be sufficient. The emphasis in this case may be on how the prediction was produced, and the limitations involved in doing so. For example, modelling of limits to growth was deliberately aimed to open a debate (Meadows et al. 1972), and uncertainty primarily needs to be addressed to convince the audience to take the arguments made by the model seriously. One way of approaching this is through quality assurance of the modelling process and its constituent assumptions (Refsgaard et al. 2005; Guillaume 2011). Another is to include qualitative judgements about the information and how it is produced (Funtowicz and Ravetz 1990; Kloprogge et al. 2011; Van Der Sluijs et al. 2005).

\subsection{Methods for Generating Alternative Models}

The preceding section described multiple ways of using uncertainty information. Alternative models often form an important construct within them for expressing uncertainty, where the uncertainty is represented by using a combination, or ensemble, of model realisations. Each model realisation can consist of different parameter values, inputs and/or model structures, as described in Fig. 28.1. The remainder of this chapter briefly presents a variety of methods for generating alternative models. Each section describes how the method produces models and 
key underlying assumptions with reference to examples. The methods are summarised in Box 28.1.

\section{Box 28.1 Types of Methods for Generating Alternative Models}

28.4.1 Models with different input values

28.4.2 Models with different 'structures'

- Models with different conceptualisations

- Models with different mathematical and computational implementations

28.4.3 Models with different parameter values

- Geostatistics: models satisfying statistical properties of data

- Parameter estimation: sampling models that fit data

- Multi-objective parameter estimation: sampling models that fit contrasting data

- Hypothesis testing: searching for models that fit data and satisfy a hypothesis

- Sensitivity analysis: selecting models to understand influence of drivers

\subsubsection{Models to anticipate surprise}

- Models to support adaptation

- Models that explore the unknown

\subsubsection{Models with Different Input Values}

Model results depend on the inputs of sources, sinks and system properties and initial and boundary conditions. Hydraulic heads are given as initial and boundary conditions at the start of the modelled period and at boundaries of the modelled aquifer, such as water levels in lakes, rivers or the ocean. Flows are given as conditions to capture inflows or outflows, whether above ground (e.g. pumping, streamflow or rainfall), or under-ground to and from outside the model area (e.g. regional groundwater flow).

Inputs and boundary conditions are approximate, can be expected to contain errors, and can be expected to change over time. Alternative models can therefore be created by changing the values of these inputs. We give some examples, but any model input could be altered. Values can be set based on expectations in the future (e.g. sea level rise, development of irrigation). Values can be randomly sampled 
from a feasible range of distribution in what is referred to as a Monte Carlo procedure. To capture historical variability, observations can be sampled from existing time series (e.g. Guillaume et al. 2012). Time series can be generated by using a statistical model, for example a weather generator. Outputs can be used from other studies, for example climate scenarios. Groundwater models can also be coupled or integrated with other models, such as ones that models surface water flows and levels (e.g. Graham and Butts 2005; Kollet and Maxwell 2006; Brunner and Simmons 2012), water flows and temperature (Hunt et al. 2013), or irrigator decision making and pumping (Hanson et al. 2010; Guillaume et al. 2012). Corrections to time series can also be made by using parameters that can be estimated along with other parts of the model (Vrugt et al. 2008).

These methods assume that it is sufficiently easy to modify the data used in the modelling software, and that input scenarios chosen are meaningful. It is not costeffective or useful to produce many scenarios unless there is a clear way of summarising and understanding them, whether as a statistical distribution of a phenomenon, or as standalone scenarios.

\subsubsection{Models with Different 'Structures'}

As discussed with reference to Fig. 28.1, modellers distinguish the model proper from its parameters and inputs. The model proper is referred to as its 'structure', and can differ both in how it is conceptualised, which processes are included or excluded, and how it is implemented in mathematical and computational terms (Gupta et al. 2012).

\subsubsection{Models with Different Conceptualisations}

A model's conceptualisation includes both its physical structure, such as the layout of an aquifer or catchment, and process structure, including recharge, aquifer flow and discharge mechanisms (Gupta et al. 2012). In groundwater flow modelling, physical structure tends to be a greater issue because the subsurface environment is observed by sampling, which is necessarily incomplete. Surprises in conceptualisation of the physical structure have included (Bredehoeft 2005) flow of brine within salt, faster flow through unknown factures, lack of evidence of whether a fault is or is not permeable, and lack of understanding of the connection of surface and groundwater, at surface seeps or in river bed. Although groundwater processes are generally well understood, there may still be unanticipated recharge events, unexpected effects of land subsidence, and overlooked chemical reactions.

There are several ways to provide diverse model conceptualisations, each with their own assumptions. A simple approach is to use a set of models pre-determined by hydrogeologists and modellers. However, it cannot be assumed that it is possible to identify all possibilities (Bredehoeft 2005).

An alternative is to approach modelling iteratively, building on previous effort (Haitjema 1995, p. 245; Bredehoeft 2005). This involves starting from an initial simple model, then using a stepwise process to identify limitations and refining 
models to include additional processes or physical structures. For example, there might be changes in system properties such as subsidence due to potential changes in human operations, such that indirect factors that influence pumping (e.g. economic considerations) should be included as part of a model rather than as a separate input (e.g. Hanson et al. 2010).

Using all possible models can however be overwhelming. Professional judgement or statistical criteria (e.g. Singh et al. 2010) can be used to rank the models or filter some out to know where to focus. However, this risks eliminating models that might turn out to better represent the unknowable future, so it is worth treating such a decision as provisional, and keeping an open mind about returning to the models excluded.

Fortunately for decision-making, it is often not necessary for the model to describe precisely what is occurring in the groundwater system. Instead, conservative estimates can be used that can inform decisions regarding margins of safety (e.g. in Bredehoeft 1983; Tiedeman and Gorelick 1993). In practice, the best one can hope for is to identify models that bracket the true value (Doherty 2011), from which safety factors can be derived from model results even if deliberately overand under-estimated (Guillaume et al. 2012). This approach however assumes that there is a known bad thing to avoid (Freeze et al. 1990) and costs of being overly conservative are formally recognized.

\subsubsection{Models with Different Computational Implementations}

Modelling requires that conceptualisations be made explicit in mathematical and computational form. Achieving this level of precision typically requires additional assumptions, regarding spatial variability, equations and their computational solution (Gupta et al. 2012).

Most numerical groundwater models discretize space into piecewise-constant quantities with a nodal grid or mesh. This discretization process raises the question of appropriate scale, and how the trade-off of computational burden and model resolution is decided. It is also possible to vary the resolution, and to use a combination of fine and coarse resolutions (Mehl et al. 2006). No grid or set of elements will fully capture a conceptual model, so the trade-off is subjective in that a modeller and end-user have discretion to select a variety of alternative scales based on practical considerations, such as computational cost. The objective of the model is of primary importance; models used to determine regional trends in groundwater level will require a different resolution than those used to evaluate the local flow of a contaminant.

\subsubsection{Models with Different Parameter Values}

Parameters play a key role in easily generating alternative models. In the context of groundwater modelling, Bredehoeft (2005) observed that "in many cases hydrogeologists were not sufficiently informed to imagine what is the entire set of possible conceptual models." In most cases, detailed properties of specific 
groundwater systems would be even more difficult to specify a priori. Instead, the modeller uses a general structure and defines parameters that when varied will encompass a variety of specific system properties. Multiple sets of parameter values can then be specified, or can be estimated or constrained by observations from the field. A strength of these methods is that hydrogeologists' knowledge of the broad scale system, and its effect on local scale properties that result, can be tested and evaluated; and vice-versa, hydrogeologists' knowledge can be used to evaluate the quality of data.

\subsubsection{Geostatistics: Models Satisfying Statistical Properties of Data}

Geostatistics provides a systematic means of using statistical properties of observed spatial data to generate alternative conceptualisations of physical properties. It interpolates given data points while satisfying observed heterogeneity and connectivity, which is particularly important for flow of contaminants (Renard 2007).

Data are used to generate a statistical model of heterogeneity (Marsily et al. 2005). The statistical model is in most cases a 'variogram', which captures the probabilistic degree of dependence between any two points in space (Delhomme 1979). More advanced techniques, like multiple-point statistics, adopt a richer model of heterogeneity where the relationship between complex patterns of points is enclosed in a so called training image (e.g. Mariethoz and Caers 2014), complementing data with additional geological 'soft' knowledge (Strebelle 2002; Hu and Chugunova 2008; Meerschman et al. 2013). Both these geostatistical methods are stochastic, in the sense that once a model of heterogeneity is selected (variogram or training image), an infinite number of equally probable realisations of geological heterogeneity can be generated, allowing the exploration of the corresponding uncertainties.

Four realisations of a multiple-point statistics conditional simulation are illustrated in Fig. 28.5, together with observed data points. Noting that a sand channel is observed at points 2, 4 and 3, one might ask: what is the probability that the points are connected by the same sand channel? In three of the four realisations presented here the three points belong to the same sand channel (realisations \#1, \#2, and \#4) while in the other (realisation \#3) the point 2 belongs to a different sand channel. The statistical techniques by which these realisations are generated allow probabilities to be calculated, given a sufficiently large number of realisations, if necessary assumptions are satisfied.

Geostatistical methods require dedicated tools and training to be used. They can require significant computer time, and depending on complexity of the problem, not all physical relationships in structure can yet be captured by theory. In addition, the choice of the model of heterogeneity in itself represents a source of uncertainty, closely related to the conceptualization of the geological model (see Sect. 28.4.2.1). Notwithstanding these drawbacks, geostatistical techniques are expanding from the mining and oil industries into the groundwater sector as they represent an important tool to explore uncertainty-related problems. 

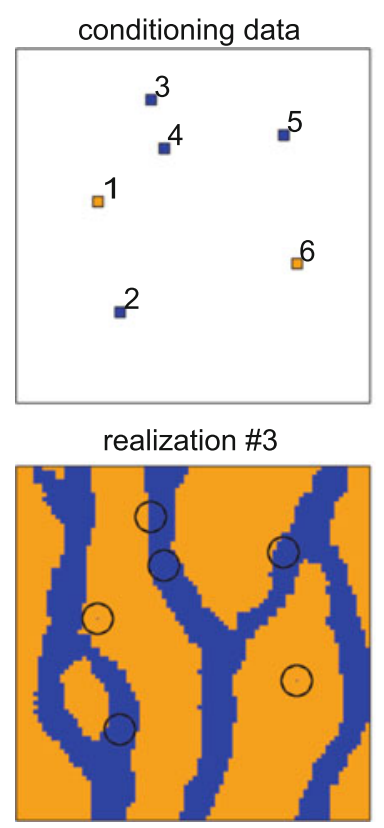

Fig. 28.5 Conditioning data and four realizations of a multiple-point statistics simulation of a sand channel system (The training image used for the simulation is taken from Strebelle 2002)

\subsubsection{Parameter Estimation: Sampling Models That Fit Data}

Parameters within a model can be easily manipulated, yielding a family of model realisations that can be explored, each with the same site geometry or structure (Barnett et al. 2012). So, for example, many models with different hydraulic conductivity and storativity in parts of an aquifer might fit the data relatively well, even if the overall structure of the aquifer is kept constant.

However, groundwater models typically carry sufficient resolution to represent hydraulic conductivity and storativity at a fine spatial and temporal scale, and it is often not possible to directly estimate parameters at that level of detail (Barnett et al. 2012), due to computational difficulties or expense of data collection. Instead, parameters are estimated for 'zones' or 'pilot points' from which all the more detailed parameters are calculated. The use of zones, also known as parameter lumping, involves subdividing the model based on geological boundaries or other reasons into regions that will be given the same hydraulic properties. Although this approach is conceptually simple, disadvantages include that it can be difficult to define such zones ahead of time, it may become apparent that geological properties do vary within a zone, and the abrupt changes in hydraulic properties at the edges of zones may not seem natural. Moreover, such a traditional zonation approach can reduce the effectiveness of the model to extract information from the field data in ways that cannot be quantified (Hunt et al. 2007; Doherty and Hunt 2010a). The pilot points approach involves setting parameter values at a fixed set of points and 
then interpolating across the model, using some of the geostatistical techniques described above (de Marsily 1978; Doherty 2003; Doherty et al. 2010a). This results in a more automated process generating a smooth variation of hydraulic properties.

Values of parameters can be estimated with a number of different approaches. A first aim is to identify a single model that best fits the observed data and the softknowledge of the system, to form a single construct for decision-making purposes. This initially involves a process of trial and error, trying different parameter values to progressively minimise the difference between the model outputs and data. This history matching is then typically automated using formal nonlinear regression methods, which automate the trial and error testing of parameters to minimise an 'objective function' that provides a measure of difference between model outputs and data. A variety of approaches are available for the design of the optimisation algorithm (Duan et al. 1992; Vrugt et al. 2003) parameterization approach (Doherty and Hunt 2010b), and selection of objective functions (Renard 2007; Schoups and Vrugt 2010; Bennett et al. 2013). Problems can prevent automated parameter estimation from consistently identifying a unique set of parameters (Sorooshian and Gupta 1983; Doherty and Hunt 2010b; Barnett et al. 2012). Most notably, all models simplify the world and leverage additional soft-knowledge to ensure the complexity of the model does not exceed the information available in the data (Jakeman and Hornberger 1993; Moore and Doherty 2005; Hunt et al. 2007; Barnett et al. 2012). This allows a single set of parameters to be identified, in a process known as regularisation (Moore and Doherty 2006), whether done ad hoc as in trial and error history matching, or with advanced algorithms (Hunt et al. 2007).

The second type of method does not seek to identify a single best parameter set but instead identifies realisations, or a set of models, that fit the data well enough by either statistical or less formal 'acceptable performance' criteria. Statistical criteria make assumptions about the distribution of errors (Schoups and Vrugt 2010), which, if correct, allow estimation of probability distributions of parameters. All models are in principle retained, but for a given output (e.g. hydraulic head at a point in time and space), models that yield extreme output values can be ignored. For example, by accepting that one in every 100 identical predictions could be wrong, a $99 \%$ confidence interval can be calculated for the model output. Depending on the mathematical form of the model, 'linear methods' can be used to provide quick estimates (e.g. Doherty et al. 2010b). Even computationally more demanding techniques (e.g. when few parameters are used, Markov Chain Monte Carlo, Keating et al. 2010; Laloy and Vrugt 2012) are still approximate in that all estimates of uncertainty will be lacking in some regard (Barnett et al. 2012).

Approaches that use less formal 'acceptable performance' criteria can be quite diverse. Set membership methods identify parameters when the error in data is assumed to be bounded (Walter and Piet-Lahanier 1990). Generalised Likelihood Uncertainty Estimation (GLUE) extends this idea by defining limits of acceptability (Beven 2006, 2009) against which randomly sampled models are tested. Similarly Null Space Monte Carlo (Tonkin and Doherty 2009) uses theory about parameter 
estimation to randomly sample other parameters that satisfy a minimum performance requirement.

Many of these techniques that rely on random sampling may require a long time or many computers to run. This is particularly the case if the model is slow (takes longer than a few minutes), or if the method requires a large number of model runs (i.e. highly parameterized models). In these cases, it may be advantageous to use a 'surrogate model' (e.g. Keating et al. 2010; Doherty and Christensen 2011; Asher et al. 2015). A surrogate model uses a smaller number of model runs to then mathematically approximate a complex model using a simpler function. They therefore run faster and allow the more complex techniques to still be used.

\subsubsection{Multi-objective Parameter Estimation: Sampling Models That Fit Contrasting Data}

The methods discussed in the preceding section can be extended to evaluate models against multiple types of data. As models are necessarily a simplification of reality, even if a model fits one type of data well, such as a local pumping test, it may not make accurate predictions of other outputs, such as regional flows. It is known that information about hydraulic head alone does not allow both recharge and transmissivity to be simultaneously estimated in some conditions (Haitjema 1995, 2006). It is therefore desirable to use a variety of data sources to determine in which alternative models we might have sufficient confidence (Kim et al. 1999; Schoups et al. 2005; Hunt et al. 2006; Renard 2007). Groundwater models in particular can potentially predict a number of different outputs, for which data can often be obtained. Flow data can be compared to predicted spring flows and leakage to and from a river. Temperature data can be compared to temperature resulting from mixing, e.g. of surface water and groundwater. Salinity or concentrations of some contaminants measured in the field can be compared to predicted concentrations of these substances. Use of tracer substances, either introduced or naturally occurring in the aquifer, can be compared to predicted flow paths, travel time and groundwater age (time since water entered the aquifer). Recent ecohydrological tracers such as viruses (e.g. Hunt et al. 2014) allow characterization of very short time of travel $(<3$ years $)-$ ages not well characterized by traditional tracers.

It can also commonly occur that a model with a single parameter set is not able to simulate every prediction equally well. Instead, there is a trade-off between fitting different datasets that may or may not inform parameters important for prediction, and the prediction of interest. Therefore, it is recognized that multiple alternative models may be required to provide better predictions for when there is more than one prediction of interest (Moore and Doherty 2005).

Where the uncertainty in predictions is too great, models can be used to optimize data collection to cost-effectively reduce the uncertainty associated with a given prediction. For example, existing models can be used to estimate the effect of establishing a new monitoring borehole at particular locations (Dausman et al. 2010), though results may be affected by the existing assumptions in the models used (Fienen et al. 2011). New data collection often consists of extensions of existing head and flux monitoring networks, but can also encompass estimates of 
model parameters obtained from dedicated tests, such as from soil properties of geological drilling logs, lab tests and from measuring the response in groundwater level during aquifer tests (Illman et al. 2008).

\subsubsection{Hypothesis Testing: Searching for Models That Fit Data and Satisfy a Hypothesis}

Alternative models can be explicitly identified that seek to test a hypothesis, rather than just focussing on fitting data, as is the case with all the previous methods to obtain models with different parameters. The idea is that communicating uncertainty will involve assessing the probability that something bad might happen (Freeze et al. 1990; Doherty 2011), for example, a contaminant reaches the drinking water well, or an ecosystem dies from lack of water. Knowing this ahead of time, we can explicitly search for a plausible model that might return such a prediction.

One approach is to define criteria by which to test whether alternative models are acceptable and to find the model that is closest to meeting the hypothesis, for example the model where the contaminant comes closest to the well, or the ecosystem has the least volume of water possible. This can be achieved by making conservative (yet defensible) simplifying assumptions, or by expressing the relevant criteria mathematically and using 'constrained optimisation' tools.

Yet, a priori determinations of what is plausible can artificially limit the range of alternative models evaluated. Moore et al. (2010) remove this limitation by expressing the problem as a trade-off of predicted value against fit to the observed data, which in turn allows the user to determine the level of acceptable uncertainty (Fig. 28.6). Rather than explicitly defining acceptable performance criteria, "Pareto front" graphs are drawn showing the intrinsic trade-off of the prediction reaching a

Fig. 28.6 Pareto front defining trade-off between objective function (lower numbers indicate better fit) and predicted particle travel time (From Moore et al. 2010)

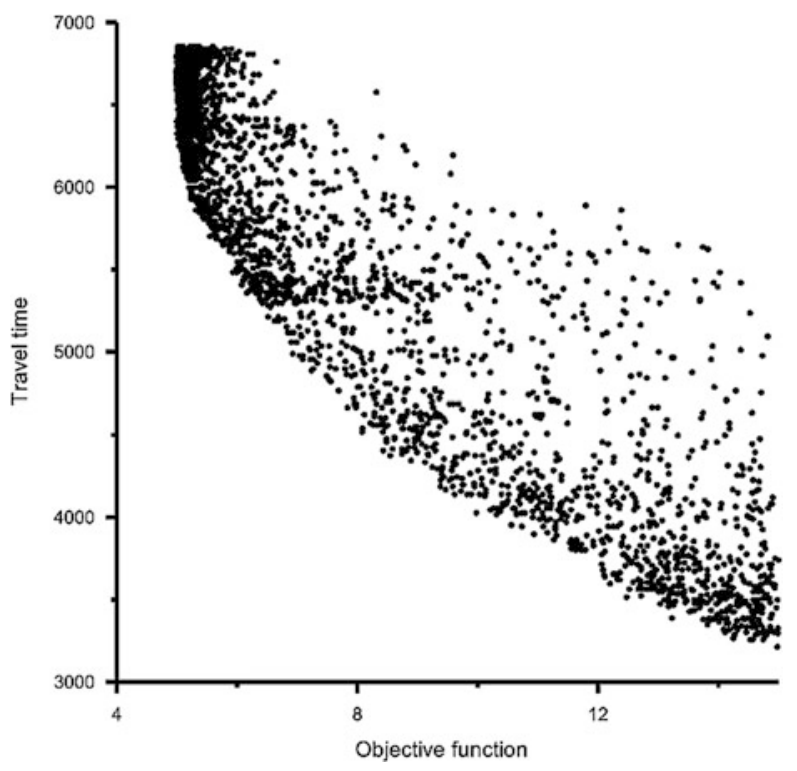


societally relevant threshold against the fit given by existing data for the system simulated. This makes it easy to relate uncertainty in terms of the prediction of interest, and can be constructed for multiple possible hypotheses and levels of acceptable criteria.

\subsubsection{Sensitivity Analysis: Selecting Models to Understand Influence of Drivers}

Purpose-designed methods are also available where the aim is to efficiently identify uncertain drivers - those that have the greatest influence. These techniques are commonly referred to as 'sensitivity analysis' (Saltelli et al. 2004). These techniques may be based on local perturbations, where they only provide information about the specific model and set of parameters that is perturbed. Local sensitivity information may not reflect the sensitivity over the full range of plausible parameters. Therefore, sensitivity methods can also be global, which provides information about a broader sample of values the different sources of variation can take. Sensitivity analysis can either provide information about the effect of a factor keeping all others constant (Saltelli and Annoni 2010), or total effect of a factor with interactions with other factors (e.g. global sensitivity statistics such as Morris, Sobol, FAST).

\subsubsection{Models to Anticipate Surprise}

It is inevitable in all environmental modelling that there might be 'unknown unknowns' and therefore surprises (Bredehoeft 2005; Hunt and Welter 2010). Model structures are unlikely to serendipitously include processes or structures that modellers do not know exist. Models that are calibrated by using existing data are tuned to reflect processes that can be identified from that data. Predictions of flow of contaminants could be completely underestimated if fractures exist that were not explicitly incorporated into the model. We discuss two approaches to creating models that help deal with this surprise: models to support adaptation, and models to explore the unknown.

\subsubsection{Models to Support Adaptation}

In principle, surprise can be dealt with by adaptive management. Rather than expecting modelling to anticipate all uncertainty, management plans remain open to change and plans for an iterative modelling and management process (Bredehoeft 2005). In the context of groundwater, models are still crucial to this process. Due to slow response times, when a change is detected, it may already be too late to do anything about it (Bredehoeft and Durbin 2009). Even if action is taken immediately, impacts may still worsen before they improve. It is therefore essential to try to anticipate the delays that might occur within a system. Model scenarios can also help to predict "sell-by" dates at which current plans might be expected to fail, to help plan adaptive pathways (Haasnoot et al. 2013). As discussed earlier, models can be used to help plan the monitoring needed to detect 
unexpected changes with an understanding of the time until impact. In parallel, model scenarios can be created to evaluate how future options might be curtailed as a consequence of short-term choices (Wong and Rosenhead 2000). Methods exist to allow model parameters to be efficiently updated given new data, and to detect when the data does not fit the current model (e.g. Cheng et al. 2011). This is particularly relevant where models are used operationally, such as in mine dewatering and water supply.

\subsubsection{Models to Explore the Unknown}

Potential surprises can also be anticipated by placing fewer restrictions on what is considered possible, and using the model prediction as a discussion point. Considering a larger set of models helps inform adaptation by discussing "what we do if this situation did occur?" This is even possible if no data are available.

This can be thought of as vulnerability analysis, identifying model properties in which negative outcomes occur. For example, Nazemi et al. (2013) identify changes in climate that would result in water scarcity problems, deferring the judgement as to whether those climate changes could occur. Scenario discovery (Bryant and Lempert 2010) randomly samples a large number of parameters and then identifies the values of parameters for which the negative outcome might occur. Break-even analysis identifies models at tipping points, for example, the infiltration rate or hydraulic conductivity at which managed aquifer recharge using basin infiltration is uneconomical (Frey and Patil 2002). Similar techniques have been applied to identify the circumstances in which two management options are equivalent, i.e. the point at which a different option becomes superior (Ravalico et al. 2009).

\subsection{Conclusions}

This chapter discussed a variety of methods for generating alternative models in order to explore uncertainty in predictions that can be applied to integrated groundwater management. The methods used depend on how the problem is defined, resources available, and how it is intended that the predictions of uncertain outcomes are used. Although many of these methods require hydrogeological, mathematical and computational expertise, together they provide a broad toolbox for identifying a more encompassing view of what might happen. Stakeholders are more likely to be forewarned with a range of plausible alternatives that they may have to face, which, in turn, can facilitate better decision making.

Open Access This chapter is distributed under the terms of the Creative Commons AttributionNoncommercial 2.5 License (http://creativecommons.org/licenses/by-nc/2.5/) which permits any noncommercial use, distribution, and reproduction in any medium, provided the original author(s) and source are credited.

The images or other third party material in this chapter are included in the work's Creative Commons license, unless indicated otherwise in the credit line; if such material is not included in the work's Creative Commons license and the respective action is not permitted by statutory regulation, users will need to obtain permission from the license holder to duplicate, adapt or reproduce the material. 


\section{References}

Alcamo J (ed) (2008) Environmental futures: the practice of environmental scenario analysis. Elsevier, Amsterdam

Anderson JL (1998) Embracing uncertainty: the interface of Bayesian statistics and cognitive psychology. Conserv Ecol 2(1):2

Asher MJ, Croke BFW, Jakeman AJ, Peeters LJM (2015) A review of surrogate models and their application to groundwater modeling. Water Resour Res 51(8). doi:10.1002/2015WR016967

Barnett B, Townley R, Post V, Evans R, Hunt RJ, Peeters L, Richardson S, Werner AD, Knapton A, Boronkay A (2012) Australian groundwater modelling guidelines. Report no 82. National Water Commission, Canberra

Bayer P, Bürger CM, Finkel M (2008) Computationally efficient stochastic optimization using multiple realizations. Adv Water Resour 31(2):399-417. doi:10.1016/j.advwatres.2007.09.004

Bennett ND, Croke BFW, Guariso G, Guillaume JHA, Hamilton SH, Jakeman AJ, MarsiliLibelli S, Newham LTH, Norton JP, Perrin C, Pierce SA, Robson B, Seppelt R, Voinov AA, Fath BD, Andreassian V (2013) Characterising performance of environmental models. Environ Model Software 40:1-20. doi:10.1016/j.envsoft.2012.09.011

Beven K (1993) Prophecy, reality and uncertainty in distributed hydrological modeling. Adv Water Resour 16:41-51. doi:10.1016/0309-1708(93)90028-E

Beven K (2006) A manifesto for the equifinality thesis. J Hydrol 320(1-2):18-36. doi:10.1016/j. jhydrol.2005.07.007

Beven KJ (2009) Environmental modelling: an uncertain future? Routledge, New York

Bredehoeft JD (1983) Ground water: a review. Rev Geophys 21(3):760-765. doi:10.1029/ RG021i003p00760

Bredehoeft J (2005) The conceptualization model problem - surprise. Hydrogeol J 13(1):37-46. doi:10.1007/s10040-004-0430-5

Bredehoeft J, Durbin T (2009) Ground water development - the time to full capture problem. Ground Water 47(4):506-514. doi:10.1111/j.1745-6584.2008.00538.x

Brugnach M, Dewulf A, Pahl-Wostl C, Taillieu T (2008) Toward a relational concept of uncertainty: about knowing too little, knowing too differently, and accepting not to know. Ecol Soc 13(2):30

Brunner P, Simmons CT (2012) HydroGeoSphere: a fully integrated, physically based hydrological model. Ground Water 50(2):170-176. doi:10.1111/j.1745-6584.2011.00882.x

Bryant BP, Lempert RJ (2010) Thinking inside the box: a participatory, computer-assisted approach to scenario discovery. Technol Forecast Soc Chang 77:34-49. doi:10.1016/j. techfore.2009.08.002

Chan N (1993) Robustness of the multiple realization method for stochastic hydraulic aquifer management. Water Resour Res 29(9):3159-3167. doi:10.1029/93wr01410

Cheng W-C, Putti M, Kendall DR, Yeh WWG (2011) A real-time groundwater management model using data assimilation. Water Resour Res 47(6). doi:10.1029/2010wr009770

Dausman AM, Doherty J, Langevin CD, Sukop MC (2010) Quantifying data worth toward reducing predictive uncertainty. Ground Water 48(5):729-740. doi:10.1111/j.1745-6584. 2010.00679.x

de Marsily G (1978) De l'identification des systèmes hydro-géologiques. Centre d'Informatique Géologique, Ecole des Mines de Paris, Paris

Delhomme JP (1979) Spatial variability and uncertainty in groundwater flow parameters: a geostatistical approach. Water Resour Res 15(2):269-280. doi:10.1029/WR015i002p00269

Doherty J (2003) Ground water model calibration using pilot points and regularization. Ground Water 41(2):170-177. doi:10.1111/j.1745-6584.2003.tb02580.x

Doherty J (2011) Modeling: picture perfect or abstract art? Ground Water 49(4):455-455. doi:10. $1111 /$ j.1745-6584.2011.00812.x 
Doherty J, Christensen S (2011) Use of paired simple and complex models to reduce predictive bias and quantify uncertainty. Water Resour Res 47(12), W12534. doi:10.1029/ 2011WR010763

Doherty J, Hunt RJ (2009) Two statistics for evaluating parameter identifiability and error reduction. J Hydrol 366(1-4):119-127. doi:10.1016/j.jhydrol.2008.12.018

Doherty J, Hunt RJ (2010a) Response to comment on: Two statistics for evaluating parameter identifiability and error reduction. J Hydrol. doi:10.1016/j.jhydrol.2009.10.012

Doherty JE, Hunt RJ (2010b) Approaches to highly parameterized inversion: A guide to using PEST for groundwater-model calibration. U.S. Geological Survey Scientific Investigations Report 2010-5169, 60 p. http://pubs.usgs.gov/sir/2010/5169/

Doherty JE, Fienen MF, Hunt RJ (2010a) Approaches to highly parameterized inversion: Pilotpoint theory, guidelines, and research directions. U.S. Geological Survey Scientific Investigations Report 2010-5168, 36 p. http://pubs.usgs.gov/sir/2010/5168/

Doherty JE, Hunt RJ, Tonkin MJ (2010b) Approaches to highly parameterized inversion: A guide to using PEST for model-parameter and predictive-uncertainty analysis. U.S. Geological Survey Scientific Investigations Report 2010-5211, 71 p. http://pubs.usgs.gov/sir/2010/5211/

Duan Q, Sorooshian S, Gupta V (1992) Effective and efficient global optimization for conceptual rainfall-runoff models. Water Resour Res 28(4):1015-1031. doi:10.1029/91wr02985

Feyen L, Gorelick SM (2004) Reliable groundwater management in hydroecologically sensitive areas. Water Resour Res 40(7), W07408. doi:10.1029/2003wr003003

Fienen MN, Doherty JE, Hunt RJ, Reeves HW (2010) Using prediction uncertainty analysis to design hydrologic monitoring networks - Example applications from the Great Lakes Water Availability Pilot Project. U.S. Geological Survey Scientific Investigations Report 2010-5159, 44 p. http://pubs.usgs.gov/sir/2010/5159/

Fienen MN, Hunt RJ, Doherty JE, Reeves HW (2011) Using models for the optimization of hydrologic monitoring. U.S. Geological Survey Fact Sheet 2011-3014, 6 p. http://pubs.usgs. gov/fs/2011/3014/

Freeze RA, Massmann J, Smith L, Sperling T, James B (1990) Hydrogeological decision analysis: 1. A framework. Ground Water 28(5):738-766. doi:10.1111/j.1745-6584.1990.tb01989.x

Frey CH, Patil SR (2002) Identification and review of sensitivity analysis methods. Risk Anal 22:553-578. doi:10.1111/0272-4332.00039

Fu B, Guillaume JHA (2014) Assessing certainty and uncertainty in riparian habitat suitability models by identifying parameters with extreme outputs. Environ Model Software 60:277-289

Fu B, Guillaume JHA, Jakeman AJ (2015) An iterative method for discovering feasible management interventions and targets conjointly using uncertainty visualizations. Environ Modell Softw 71:159-73. doi:10.1016/j.envsoft.2015.05.017

Funtowicz SO, Ravetz JR (1990) Uncertainty and quality in science for policy. Springer, Dordrecht

Gorelick S (1990) Large scale nonlinear deterministic and stochastic optimization: formulations involving simulation of subsurface contamination. Math Program 48(1-3):19-39. doi:10.1007/ bf01582250

Graham DN, Butts MB (2005) Flexible, integrated watershed modelling with MIKE SHE. In: Singh VP, Frevert DK (eds) Watershed models. CRC Press, Boca Raton, pp 245-272. ISBN:0849336090

Guillaume JHA (2011) A risk-based tool for documenting and auditing the modelling process. In: Chan F, Marinova D, Anderssen RS (eds) MODSIM2011, 19th international congress on modelling and simulation. Modelling and Simulation Society of Australia and New Zealand, December 2011, pp 1652-1658. ISBN: 978-0-9872143-1-7. www.mssanz.org.au/ modsim2011/I9/guillaume.pdf. Accessed 14 Jan 2014

Guillaume JHA, Pierce SA, Jakeman AJ (2010) Managing uncertainty in determining sustainable aquifer yield. Paper presented at the National Groundwater Conference 2010, Canberra. http:// www.groundwater2010.com/documents/GuillaumeJoseph_000.pdf. Accessed 14 Jan 2014

Guillaume JHA, Qureshi ME, Jakeman AJ (2012) A structured analysis of uncertainty surrounding modeled impacts of groundwater extraction rules. Hydrogeol J 205(5):915-932. doi:10.1007/ s10040-012-0864-0 
Gupta HV, Clark MP, Vrugt JA, Abramowitz G, Ye M (2012) Towards a comprehensive assessment of model structural adequacy. Water Resour Res 48(8), W08301. doi:10.1029/ 2011 wr011044

Haasnoot M, Kwakkel JH, Walker WE, ter Maat J (2013) Dynamic adaptive policy pathways: a method for crafting robust decisions for a deeply uncertain world. Glob Environ Chang 23 (2):485-498. doi:10.1016/j.gloenvcha.2012.12.006

Haitjema HM (1995) Analytic element modeling of groundwater flow. Academic Press, San Diego, p 394

Haitjema $\mathrm{H}$ (2006) The role of hand calculations in ground water flow modeling. Ground Water 44 (6):786-791. doi:10.1111/j.1745-6584.2006.00189.x

Hanson RT, Schmid W, Faunt CC, Lockwood B (2010) Simulation and analysis of conjunctive use with MODFLOW's farm process. Ground Water 48(5):674-689. doi:10.1111/j.1745-6584. 2010.00730.x

Hu LY, Chugunova T (2008) Multiple-point geostatistics for modeling subsurface heterogeneity: a comprehensive review. Water Resour Res 44(11), W11413. doi:10.1029/2008wr006993

Hunt RJ (2012) Uncertainty. In: Australian groundwater modelling guidelines. Waterlines report series No 82, National Water Commission, Canberra, pp 92-105. ISBN: 978-1-921853-91-3

Hunt RJ, Welter DE (2010) Taking account of "Unknown Unknowns". Ground Water 48(4):477. doi:10.1111/j.1745-6584.2010.00681.x

Hunt RJ, Steuer JJ, Mansor MTC, Bullen TD (2001) Delineating a recharge area for a spring using numerical modeling, Monte Carlo techniques, and geochemical investigation. Ground Water 39(5):702-712. doi:10.1111/j.1745-6584.2001.tb02360.x

Hunt RJ, Feinstein DT, Pint CD, Anderson MP (2006) The importance of diverse data types to calibrate a watershed model of the Trout Lake Basin, Northern Wisconsin, USA. J Hydrol 321 (1-4):286-296. doi:10.1016/j.jhydrol.2005.08.005

Hunt RJ, Doherty J, Tonkin MJ (2007) Are models too simple? Arguments for increased parameterization. Ground Water 45(3):254-261. doi:10.1111/j.1745-6584.2007.00316.x

Hunt RJ, Walker JF, Selbig WR, Westenbroek SM, Regan RS (2013) Simulation of climatechange effects on streamflow, lake water budgets, and stream temperature using GSFLOW and SNTEMP, Trout Lake Watershed, Wisconsin. U.S. Geological Survey Scientific Investigations Report 2013-5159, 118 p. http://pubs.usgs.gov/sir/2013/5159/

Hunt RJ, Borchardt MA, Bradbury KR (2014) Viruses as groundwater tracers: using ecohydrology to characterize short travel times in aquifers. Ground Water 52(2):187-193. doi:10.1111/gwat. 12158

Illman WA, Craig AJ, Liu X (2008) Practical issues in imaging hydraulic conductivity through hydraulic tomography. Ground Water 46(1):120-132. doi:10.1111/j.1745-6584.2007.00374.x

Jakeman AJ, Hornberger GM (1993) How much complexity is warranted in a rainfall-runoff model? Water Resour Res 29(8):2637-2649. doi:10.1029/93wr00877

Jakeman AJ, Letcher RA, Norton JP (2006) Ten iterative steps in development and evaluation of environmental models. Environ Model Software 21(5):602-614. doi:10.1016/j.envsoft.2006. 01.004

Jakeman A, Kelly R, Ticehurst J, Blakers R, Croke B, Curtis A, Fu B, Sawah S, Gardner A, Guillaume J, Hartley M, Holley C, Hutchings P, Pannell D, Ross A, Sharp E, Sinclair D, Wilson A (2014) Modelling for managing the complex issue of catchment-scale surface and groundwater allocation. In: Obaidat MS, Filipe J, Kacprzyk J, Pina N (eds) Simulation and modeling methodologies, technologies and applications, vol 256. Springer, pp 25-41. doi:10. 1007/978-3-319-03581-9_2

James BR, Gorelick SM (1994) When enough is enough: the worth of monitoring data in aquifer remediation design. Water Resour Res 30(12):3499-3513. doi:10.1029/94wr01972

Janssen R (1992) Multiobjective decision support for environmental management. Kluwer, Dordrecht, $232 \mathrm{p}$

Johnson MS (2008) Public participation and perceptions of watershed modeling. Soc Nat Res 22 (1):79-87. doi:10.1080/08941920802220347 
Kalai R, Lamboray C, Vanderpooten D (2012) Lexicographic $\alpha$-robustness: an alternative to min-max criteria. Eur J Oper Res 220(3):722-728. doi:10.1016/j.ejor.2012.01.056

Keating EH, Doherty J, Vrugt JA, Kang Q (2010) Optimization and uncertainty assessment of strongly nonlinear groundwater models with high parameter dimensionality. Water Resour Res 46(10), W10517. doi:10.1029/2009wr008584

Kim K, Anderson MP, Bowser CJ (1999) Model calibration with multiple targets: a case study. Ground Water 37(3):345-351. doi:10.1111/j.1745-6584.1999.tb01110.x

Kloprogge P, Sluijs JP, Wardekker JA (2007) Uncertainty communication: issues and good practice. Copernicus Institute for Sustainable Development and Innovation, Utrecht University, Utrecht

Kloprogge P, Van Der Sluijs JP, Petersen AC (2011) A method for the analysis of assumptions in model-based environmental assessments. Environ Model Software 26(3):289-301. doi:10. 1016/j.envsoft.2009.06.009

Kollet SJ, Maxwell RM (2006) Integrated surface-groundwater flow modeling: a free-surface overland flow boundary condition in a parallel groundwater flow model. Adv Water Resour 29 (7):945-958. doi:10.1016/j.advwatres.2005.08.006

Kouvelis P, Yu G (1997) Robust discrete optimization and its applications. Kluwer, New York

Laloy E, Vrugt JA (2012) High-dimensional posterior exploration of hydrologic models using multiple-try DREAM(ZS) and high-performance computing. Water Resour Res 48(1), W01526. doi:10.1029/2011wr010608

Lempert RJ, Popper SW, Bankes SC (2003) Shaping the next one hundred years: new methods for quantitative, long-term policy analysis. Rand Corporation, Santa Monica

Mantoglou A, Kourakos G (2007) Optimal groundwater remediation under uncertainty using multi-objective optimization. Water Res Manag 21(5):835-847. doi:10.1007/s11269-0069109-0

Mariethoz G, Caers J (2014) Multiple-point geostatistics: stochastic modelling with training images. Wiley-Blackwell, Chichester, $400 \mathrm{p}$, (in press)

Marsily G, Delay F, Gonçalvès J, Renard P, Teles V, Violette S (2005) Dealing with spatial heterogeneity. Hydrogeol J 13(1):161-183. doi:10.1007/s10040-004-0432-3

Matott LS, Babendreier JE, Purucker ST (2009) Evaluating uncertainty in integrated environmental models: a review of concepts and tools. Water Resour Res 45(6):W06421. doi:10.1029/ 2008wr007301

Meadows DH, Meadows DL, Randers J, Behrens WW III (1972) The limits to growth: a report for the Club of Rome's project on the predicament of mankind. Potomac Associates, New York

Meerschman E, Pirot G, Mariethoz G, Straubhaar J, Van Meirvenne M, Renard P (2013) A practical guide to performing multiple-point statistical simulations with the Direct Sampling algorithm. Comput Geosci 52:307-324. doi:10.1016/j.cageo.2012.09.019

Mehl S, Hill MC, Leake SA (2006) Comparison of local grid refinement methods for MODFLOW. Ground Water 44(6):792-796. doi:10.1111/j.1745-6584.2006.00192.x

Moore C, Doherty J (2005) Role of the calibration process in reducing model predictive error. Water Resour Res 41(5):W05020. doi:10.1029/2004wr003501

Moore C, Doherty J (2006) The cost of uniqueness in groundwater model calibration. Adv Water Resour 29(4):605-623. doi:10.1016/j.advwatres.2005.07.003

Moore C, Wöhling T, Doherty J (2010) Efficient regularization and uncertainty analysis using a global optimization methodology. Water Resour Res 46(8):W08527. doi:10.1029/ 2009wr008627

Morgan DR, Eheart JW, Valocchi AJ (1993) Aquifer remediation design under uncertainty using a new chance constrained programming technique. Water Resour Res 29(3):551-561. doi:10. $1029 / 92 \mathrm{wr} 02130$

Nazemi A, Wheater HS, Chun KP, Elshorbagy A (2013) A stochastic reconstruction framework for analysis of water resource system vulnerability to climate-induced changes in river flow regime. Water Resour Res 49(1):291-305. doi:10.1029/2012wr012755 
Paté-Cornell ME (1996) Uncertainties in risk analysis: six levels of treatment. Reliab Eng Syst Saf 54(2-3):95-111. doi:10.1016/S0951-8320(96)00067-1

Ravalico JK, Maier HR, Dandy GC (2009) Sensitivity analysis for decision-making using the MORE method - a Pareto approach. Reliab Eng Syst Saf 94(7):1229-1237. doi:10.1016/j.ress. 2009.01.009

Reed PM, Minsker BS (2004) Striking the balance: long-term groundwater monitoring design for conflicting objectives. J Water Resour Plan Manag 130(2):140-149. doi:10.1061/(ASCE) 0733-9496(2004)130:2(140)

Refsgaard JC, Henriksen HJ (2004) Modelling guidelines - terminology and guiding principles. Adv Water Resour 27(1):71-82. doi:10.1016/j.advwatres.2003.08.006

Refsgaard JC, Henriksen HJ, Harrar WG, Scholten H, Kassahun A (2005) Quality assurance in model based water management - review of existing practice and outline of new approaches. Environ Model Software 20(10):1201-1215. doi:10.1016/j.envsoft.2004.07.006

Refsgaard JC, van der Sluijs JP, Højberg AL, Vanrolleghem PA (2007) Uncertainty in the environmental modelling process - a framework and guidance. Environ Model Software 22 (11):1543-1556. doi:10.1016/j.envsoft.2007.02.004

Renard P (2007) Stochastic hydrogeology: what professionals really need? Ground Water 45 (5):531-541. doi:10.1111/j.1745-6584.2007.00340.x

Rittel HJ, Webber M (1973) Dilemmas in a general theory of planning. Pol Sci 4:155-169

Roy B (2010) To better respond to the robustness concern in decision aiding: four proposals based on a twofold observation. In: Zopounidis C, Pardalos PM (eds) Handbook of multicriteria analysis, vol 103. Springer, Berlin/Heidelberg, pp 3-24. doi:10.1007/978-3-540-92828-7_1

Saltelli A, Annoni P (2010) How to avoid a perfunctory sensitivity analysis. Environ Model Software 25(12):1508-1517. doi:10.1016/j.envsoft.2010.04.012

Saltelli A, Chan K, Scott E (2004) Sensitivity analysis. Wiley, New York

Schoups G, Vrugt JA (2010) A formal likelihood function for parameter and predictive inference of hydrologic models with correlated, heteroscedastic, and non-Gaussian errors. Water Resour Res 46(10):1-17. doi:10.1029/2009wr008933

Schoups G, Lee Addams C, Gorelick SM (2005) Multi-objective calibration of a surface watergroundwater flow model in an irrigated agricultural region: Yaqui Valley, Sonora, Mexico. Hydrol Earth Syst Sci 9(5):549-568. doi:10.5194/hess-9-549-2005

Singh A, Mishra S, Ruskauff G (2010) Model averaging techniques for quantifying conceptual model uncertainty. Ground Water 48(5):701-715. doi:10.1111/j.1745-6584.2009.00642.x

Sorooshian S, Gupta VK (1983) Automatic calibration of conceptual rainfall-runoff models: the question of parameter observability and uniqueness. Water Resour Res 19(1):260-268. doi:10. 1029/WR019i001p00260

Strebelle S (2002) Conditional simulation of complex geological structures using multiple-point statistics. Math Geol 34(1):1-21. doi:10.1023/a:1014009426274

Tiedeman C, Gorelick SM (1993) Analysis of uncertainty in optimal groundwater contaminant capture design. Water Resour Res 29(7):2139-2153. doi:10.1029/93wr00546

Tonkin M, Doherty J (2009) Calibration-constrained Monte Carlo analysis of highly parameterized models using subspace techniques. Water Resour Res 45(12). doi:10.1029/ 2007 wr006678

van Asselt MBA, Rotmans J (2002) Uncertainty in integrated assessment modelling. Clim Change 54(1):75-105. doi:10.1023/A:1015783803445

van der Sluijs JP, Craye M, Funtowicz S, Kloprogge P, Ravetz J, Risbey J (2005) Combining quantitative and qualitative measures of uncertainty in model-based environmental assessment: the NUSAP system. Risk Anal 25(2):481-492. doi:10.1111/j.1539-6924.2005.00604.x

Voinov A, Bousquet F (2010) Modelling with stakeholders. Environ Model Software 25 (11):1268-1281. doi:10.1016/j.envsoft.2010.03.007

Vrugt JA, Gupta HV, Bastidas LA, Bouten W, Sorooshian S (2003) Effective and efficient algorithm for multiobjective optimization of hydrologic models. Water Resour Res 39(8). doi:10.1029/2002wr001746 
Vrugt JA, ter Braak CJF, Clark MP, Hyman JM, Robinson BA (2008) Treatment of input uncertainty in hydrologic modeling: doing hydrology backward with Markov chain Monte Carlo simulation. Water Resour Res 44(12):W00B09. doi:10.1029/2007wr006720

Wagner BJ, Gorelick SM (1989) Reliable aquifer remediation in the presence of spatially variable hydraulic conductivity: from data to design. Water Resour Res 25(10):2211-2225. doi:10. 1029/WR025i010p02211

Walker WE, Harremoës P, Rotmans J, van der Sluijs JP, van Asselt MBA, Janssen P, von Krauss MPK (2003) Defining uncertainty: a conceptual basis for uncertainty management in modelbased decision support. Integr Assess 4(1):5-17. doi:10.1076/iaij.4.1.5.16466

Walter E, Piet-Lahanier H (1990) Estimation of parameter bounds from bounded-error data: a survey. Math Comp Simul 32(5-6):449-468. doi:10.1016/0378-4754(90)90002-Z

Wardekker JA, van der Sluijs JP, Janssen PHM, Kloprogge P, Petersen AC (2008) Uncertainty communication in environmental assessments: views from the Dutch science-policy interface. Environ Sci Pol 11(7):627-641. doi:10.1016/j.envsci.2008.05.005

Wong HY, Rosenhead J (2000) A rigorous definition of robustness analysis. J Oper Res Soc 51 (2):176-182. doi: $10.2307 / 254258$ 


\title{
Erratum to: Integrated Groundwater Management
}

\author{
Anthony J. Jakeman, Olivier Barreteau, Randall J. Hunt, \\ Jean-Daniel Rinaudo, and Andrew Ross
}

(C) The Author(s) 2016

A.J. Jakeman et al. (eds.), Integrated Groundwater Management, DOI 10.1007/978-3-319-23576-9

In the book titled "Integrated Groundwater Management" the affiliation of the author Prof. "Olivier Barreteau" in the copyright page of FM is incorrect and should read as follows:

Olivier Barreteau

IRSTEA, UMR G-EAU

Montpellier, France

The updated original online version for this book can be found at

DOI 10.1007/978-3-319-23576-9 


\section{IGM Author Biographies}

Fatah Ameur is a $\mathrm{PhD}$ student at IAV Hassan II, Rabat (Morocco). He is an agricultural engineer, specializing in water management. He earned a master's degree in irrigation and water control. Currently he undertakes research on the inequalities in access to groundwater in a context of overexploitation in the Saiss (Morocco).

Juliette Anglade is a PhD student at the University Pierre and Marie Curie (UPMC, Paris, France). She completed an MSc in Hydrology-Hydrogeology at the UPMC. Her research focuses on assessing the agronomic and environmental performances of low-inputs systems, and their effects on surface and groundwater resources, with emphasis on nitrate contaminations.

Muhammad Arshad is a civil engineer and $\mathrm{PhD}$ research scholar in Managed Aquifer Recharge at the Australian National University and the National Centre for Groundwater Research and Training. He has worked for more than 15 years with United Nations and consulting engineers on water resource management and delivery of water infrastructure projects. Arshad specializes in delivering large scale water sanitation and hygiene (WASH) programs including WASH emergency response and coordination.

Fabienne Barataud is a Research Engineer at the National Research Agricultural Institute (INRA) and she currently holds the assistant direction of the ASTER unit (Mirecourt, France). Her research focuses on analyzing cooperative agreements for water protection, studying the interactions between stakeholders and the place of knowledge, and building original tools to accompany collective actions.

Olivier Barreteau is senior water scientist at IRSTEA, Director of the UMR G-EAU in Montpellier. He has 20 years of experience of interdisciplinary research at the interface between hydrology, modelling, and management sciences in projects on local water governance, using social simulation with Agent based modelling and role playing games. He is founder member of the Companion Modeling network. He is in charge of coordination of the joint Land and Water program for the French Ministry of Environment.

Okke Batelaan is Strategic Professor in Hydrogeology, Flinders University, Adelaide, Australia. He has an extensive teaching, research and publication record in hydro(geo)logy and project experience from four continents. He is editor-in-chief of Journal of Hydrology: Regional Studies and MDPI-Hydrology.

Marc Benoît is a Research Agronomist within the National Research Agricultural Institute (Inra). He currently holds a position of Senior Scientist in the Research for Action and Development Department, at the Aster Research Unit (Mirecourt, France). His research focuses on 
landscape agronomy, and investigating water resources protection through agrarian systems transitions.

Henning Bjornlund holds two academic positions; he is a Canada Research Chair in Water Policy and Management at University of Lethbridge and a Professor at the University of South Australia. He has researched water policy and management issues in Australia since 1993 and in Canada since 2005 . Henning has written widely about water policy and management issues with around 300 publications and presentations.

Rachel S. Blakers is a PhD Scholar at the Australian National University with support from the National Centre for Groundwater Research and Training. Her PhD research is on hydrological model development and uncertainty analysis in the context of integrated assessment projects.

Nate Booth is the Chief, Office of Water Information at the U.S. Geological Survey (USGS). Nate is a hydrologist with significant interest and experience within the areas of geo and hydro informatics. He is responsible for the collection, storage and delivery of water information for the USGS.

Mark A. Borchardt, Ph.D is a Research Microbiologist at the Agricultural Research Service, United States Department of Agriculture, and Program Leader for the Laboratory for Infectious Disease and the Environment, United States Geological Survey, Wisconsin Water Science Center located in Marshfield, Wisconsin. His research focus is on waterborne infectious disease as related to contamination from human and livestock foecal sources.

Boyan Brodaric is a research scientist at the Geological Survey of Canada working primarily on data interoperability, including applications in hydrology, natural hazards, and geology. He sits on the board of several journals and conferences, is involved in the development of international geospatial data standards, and leads the Canadian Groundwater Information Network, a national cyber-infrastructure for groundwater information.

Nicholas Brozović is Director of Policy at the Robert B. Daugherty Water for Food Institute at the University of Nebraska. He is an economist with extensive experience in water policy and management worldwide. His research focuses on using economic analysis to evaluate and design management policies for spatial, dynamic natural resource systems. He is currently working to establish functioning resource markets, such as groundwater markets, that can be used as research and teaching platforms and as models of sustainability for industry.

Yvan Caballero is a senior hydrologist and hydrogeologist at BRGM, France, where he coordinates the scientific program on Groundwater Resources Potential Characterization. His main topics are on global change impact on surface and groundwater resources, including karstic groundwater resources, integrated water management, and exploring recharge estimation methods.

Joël Casanova BRGM - French geological survey, has 28 years of experience as an Expert Geochemist and Project Leader in charge of R \& D projects concerning environmental geochemistry based on the use of multi-element and multi-isotope techniques. He is also involved in various fields related to surface and ground water resource management which include: tracing of groundwater circulation, managed aquifer recharge and defining exploration methods.

Alessandro Comunian is Assistant Professor with the Department of Earth Sciences "Ardito Desio", at University of Milan. His research focuses on the characterization of the geological heterogeneity using geostatistical methods, with a focus of multiple-point statistics. 
Daniel Connell works in the Crawford School of Public Policy at the Australian National University where he teaches courses on environmental and water policy. His research focuses on the governance arrangements applying to rivers in multilayered political systems such as Australia, South Africa, the United States, Mexico, the European Union (Spain), India, China and Brazil. He is also a co-editor of Federal Rivers published by Edward Elgar in 2014.

Julian Conrad is a consulting geohydrologist and director of the groundwater consultancy GEOSS, based in Stellenbosch, South Africa. He joined the CSIR (Council for Scientific and Industrial Research), based in Stellenbosch, in 1990. After 11 years at the CSIR, Julian then started the groundwater consultancy, GEOSS.

Richard Cresswell is a Senior Associate with Jacobs Engineering Group, providing hydrogeological advice to the mining, coal seam gas and large infrastructure industries, specialising in hydrogeochemical and isotopic investigations. He was previously a Principal Research Scientist at CSIRO's Division of Land and Water, leading sustainable yields projects and the salinity dynamics end at the CRC for Landscapes, Environment and Mineral Exploration. Prior to that Richard was a project leader for the Salinity Monitoring and Management Support Program at the Federal Bureau of Rural Sciences.

Allan Curtis is a strategic research professor at Charles Sturt University and is a Principal Investigator with the National Centre for Groundwater Research and Training. His research focuses on the contribution of human and social capital to sustainable development. He has specific expertise in the role of local organisations, understanding rural landholder adoption of sustainable practices and program evaluation.

Nicolas Devau is Biogeochemist at BRGM - French geological survey, specializing in hydrogeochemistry and soil sciences, with specific skills on mineral-aqueous interactions and biogeochemical processes. He developed and used new numerical approaches and modelling tools in order to better understand how geochemical and microbiological processes affect inorganic pollutants mobility/stability in the vadose zone-aquifer continuum of several systems, notably in the theme of active management of water resources.

Peter Dillon is Honorary Fellow, CSIRO working in a team on managed aquifer recharge for 20 years, particularly associated with aquifer storage and recovery with stormwater and recycled water. He is a founding co-chair of the IAH Commission on Managing Aquifer Recharge, and aims to foster improved scientific knowledge and its uptake in improved governance of MAR through new water resources management policies and health and environmental protection guidelines.

Guillermo Donoso is Professor of Water Economics at the Pontificia Universidad Católica de Chile. He has researched water governance and water allocation mechanisms with an emphasis on water markets the past 20 years. He has consulted for the United Nations Development Programme (UNDP), the Inter-American Development Bank (IADB), the GTZ and the World Bank in projects for Latin America.

Derek Eamus is Professor of Environmental Sciences at the University of Technology Sydney. He has researched the ecophysiology of groundwater dependent woodlands for the past 20 years in temperate and tropical Australia. For the past 5 years he was a Chief Investigator in the National Centre for Groundwater Research and Training and was lead author for the textbook "Ecohydrology: vegetation function, water and resource management" published by CSIRO Press.

David J. Eaton is a Professor in Natural Resource Policy Studies with the Lyndon B. Johnson School of Public Affairs at The University of Texas at Austin, Texas, USA. Dr. Eaton's research 
focuses on sustainable development in international river basins, evaluation of energy-water conservation programs, and prevention of pollution.

Sondoss Elsawah is a Research Fellow at University of New South Wales and adjunct fellow at the Australian National University specialising in development of integrated models and Decision Support Systems. Her work focuses on using systems thinking approaches to support social learning and policy making in social-ecological systems. She has worked on a number of projects including climate change assessment, water allocation planning, and mining impact assessment. She has received the prestigious Australian Water Association award for water research.

Nicolas Faysse is a social scientist at the joint research unit on Water Resource Management, Actors and Uses and at CIRAD (France). He is currently posted at ENA Meknes, Morocco. He works on water management institutions, development policies and projects, and approaches for farmer capacity-building.

Guilherme Fernandes Marques is a Civil Engineer and associate professor at Instituto de Pesquisas Hidraulicas (IPH), Universidade Federal do Rio Grande do Sul, Brazil. His field of research involves application of optimization methods to water and environmental problems, including hydro-economics, conjunctive use of surface and groundwater, reservoir operation and hydropower optimization.

Michael Fienen is a Research Hydrologist specializing in groundwater modeling, parameter estimation, statistical and probabilistic modeling, and uncertainty analysis at the U.S. Geological Survey (USGS) Wisconsin Water Science Center. He is also an adjunct assistant professor in the Department of Geoscience at the University of Wisconsin - Madison.

Peter Fitch is a research scientist with CSIRO Land and Water flagship. His research projects are in the areas of environmental informatics with particular interest in web delivery and use of hydrological information using a broad range of technologies including standards based. He has significant industry experience designing and developing hydrological measurement systems, and has more recently focussed on scientific transparency.

Baihua Fu is a Research Fellow at the Australian National University and the National Centre for Groundwater Research. She has extensive experience in hydro-ecological modelling, environmental knowledge engineering and uncertainty assessment of environmental models. Her recent research focuses on assessing impacts of climate change and water management on water quality and freshwater ecology.

Patrice Garin is senior agronomist and geographer at IRSTEA, at the joint research unit "Water Management, Stakeholders and Uses" (UMR G-EAU) in Montpellier. He is the manager of the Master Eau - special field "Water and Society" in Montpellier II university. His research focuses on the analysis of irrigation practices and participatory processes in water management, mainly in irrigated areas.

Francesca Greco is a $\mathrm{PhD}$ candidate at King's College London, Department of Geography. She has analysed water policy issues in the Middle East and in Sub-Saharan Africa. Her main research interests are: groundwater use and sustainability, food supply-chain and trade, hydro-hegemony power-analysis, and virtual water "flows" dynamics. She is currently working at the United Nations World Water Assessment Programme (UNESCO) on regional water monitoring and gender-sensitive water indicators for the post-2015 agenda. 
Timothy R. Green is a research hydrologist with the USDA Agricultural Research Service in Fort Collins, Colorado, USA. His career includes research with the USGS Water Resources Division and CSIRO Australia Land and Water. Tim has served on the UNESCO-GRAPHIC project, and was Guest Professor at ETH Zurich, Switzerland. Tim is a fellow of the American Society of Agronomy and the Soil Science Society of America.

Richard Greene is a Senior Lecturer in Soil and Land Management in the Fenner School of Environment and Society at the Australian National University, Canberra, Australia. He was previously a Senior Research Scientist at CSIRO's Division of Wildlife and Ecology, researching the management of semi-arid rangelands soils. Prior to that he was a Soils Research Officer with the Victorian Department of Agriculture, based at the Irrigation Research Institute, Tatura, where he worked on the physico-chemical properties of soils under irrigated agriculture.

Joseph H. A. Guillaume is a Postdoctoral Researcher with the Water and Development Research Group at Aalto University, Finland. He completed his $\mathrm{PhD}$ at the Australian National University with the National Centre for Groundwater Research and Training (NCGRT). His research focuses on taking a critical systems approach to improving the management of uncertainty in modelling.

Meriem Farah Hamamouche is a PhD student at IAV Hassan II (Morocco). She studies the integration of groundwater resources in a surface irrigation system in the Algerian Sahara. She obtained her MSc in irrigation and water control at IAV Hassan II in 2012 and graduated as an agricultural engineer at ENSA, El Harrach (Algeria) in 2011.

Serena Hamilton is a Postdoctoral Research Fellow at the Australian National University and Edith Cowan University. Her research interests include integrated assessment and modelling, Bayesian networks and decision support tools for natural resources management. Her recent research has focused on modelling freshwater ecological systems under limited data and knowledge.

Ali Hammani is a Professor and head of the "Sustainable Water Management" research unit at IAV Hassan II (Morocco). He is a senior scientist in irrigation and water management with more than 20 years of experience in Morocco and the Mediterranean. He coordinated several research projects on water management.

Julien J. Harou is Professor of Water Management and Water Engineering Chair at The University of Manchester and Honorary Professor at UCL. Recently he has worked with DEFRA, the European Commission, UK water regulators, water utilities, the World Bank, IUCN, and WWF on assessment of water policies and investments.

Tarik Hartani is a senior agricultural water management scientist at ENSA (Algeria). He has more than 15 years of professional experience in the Mediterranean region and Africa. He supervises several PhD's in irrigation and agricultural water quality management, and coordinated $10 \mathrm{R} \& \mathrm{D}$ national and international projects.

Masaki Hayashi is a Professor in the Department of Geoscience, University of Calgary, where he holds a Canada Research Chair in Physical Hydrology. His research interests are in the connection between groundwater and surface water, and how it is affected by land use change and climatic variability.

Cécile Hérivaux has 10 years' experience in applied research at BRGM in the field of groundwater resources management. She has been involved in assessing the economic benefits of 
groundwater protection, adaptation strategies to climate change, water scarcity and sea level rise issues.

Cameron Holley is Senior Lecturer/Senior Research Fellow (DECRA), UNSW Law, University of New South Wales Australia. He is a member of the Connected Waters Initiative Research Centre (UNSW) and Research Affiliate at the National Centre for Groundwater Research and Training. His areas of expertise include collaborative governance, water planning, water law, environmental law and water regulation.

Randall J. Hunt is a Research Hydrologist with the United States Geological Survey. He completed his MSc and $\mathrm{PhD}$ at the University of Wisconsin-Madison, where he currently holds a position of Adjunct Professor within the Department of Geoscience. His research focuses on investigating groundwater flow and its effects on natural resources including wetland, stream, lake, and ecological systems.

Karen Hussey is Associate Professor at the Fenner School of Environment and Society, and a Public Policy Fellow with the Australian National Institute of Public Policy (ANIPP), at the Australian National University. Her research interests include policy, institutional and economic dimensions of sustainable development, particularly with respect to water, energy and climate security. Prior to taking up her position at the Fenner School, Karen was based in Brussels for 4 years as the ANU Vice Chancellor's Representative in Europe.

Anthony John (Tony) Jakeman is Professor, Fenner School of Environment and Society, and Director of the Integrated Catchment Assessment and Management Centre, The Australian National University. Interests include system identification, integrated assessment methods and decision support systems for water and associated land resource problems. He is Professor, Univerity of Queensland and recently leader of the National Centre for Groundwater Research and Training Program on Integrating Socioeconomics, Policy and Decision Support. He has held visiting positions at Stanford, Cambridge and Lancaster Universities, CSIRO, Cemagref/IRSTEA in France and the US Geological Survey.

Marcel Kuper is a senior irrigation scientist at CIRAD (Montpellier, France), and Visiting Professor at IAV Hassan II (Rabat, Morocco). He has more than 25 years of professional experience in Asia, Africa, and the Mediterranean. He supervises several PhDs in irrigation management, and is project leader of international research projects. He works currently on issues of groundwater governance, and innovation systems related to irrigation.

Jie Liu a PhD in hydrogeology from the University of Alabama. She was a postdoctoral fellow at Peking University from 2007 to 2009. Since 2009, she has been an associate professor in the Center for Water Research, Peking University. She has been chairing the Water Ethics working group of UNESCO since 2008. Liu's major research interests include groundwater flow and transport modelling, basin-scale groundwater management, and surface water-groundwater interactions.

Elena Lopez-Gunn runs ICATALIST, a company specializing in social innovation and knowledge transfer with clients like Repsol, an energy company and FAO. She is an Associate Professor at IE Business School. She was an Alcoa Research Fellow at the London School of Economics. Her areas of expertise include collective action, water resources governance, climate change adaptation, public policy evaluation and social innovation.

Jay R. Lund is Director of the Center for Watershed Sciences and a Professor of Civil and Environmental Engineering at the University of California - Davis. He has long engaged on many 
aspects of theory and practice for water management and policy, usually trying to integrate economics and operations research with traditional engineering.

Serge Marlet is a senior water management and agronomy scientist at CIRAD (France). He has been hosted by INRGREF in Tunisia since 2006 . He has 30 years of professional international experience in sustainable soil and water management in irrigation systems and is currently working with Water Users Associations.

Emily Mendham is a Research Fellow at Charles Sturt University. Her research focuses on the social dimensions of natural resource management on private land. Her expertise includes understanding the drivers and implications of changing ownership and management of rural land and landholder adoption of practices.

Michael Mitchell is a Research Fellow with the School of Land and Food at the University of Tasmania. His fellowship is provided through the Landscape and Policy Hub, funded through the Australian Government's National Environmental Research Program. His research interests relate to the social dimensions of natural resource management, and he is currently investigating strategies to apply resilience thinking techniques into regional and landscape-scale planning processes.

Marielle Montginoul is research director in Economics in the National Research Institute of Science and Technology for Environment and Agriculture (IRSTEA) at the Joint Research Unit G-Eau. Her work focuses on understanding and modeling farmers and households' water consumption behaviors. She more specifically studies instruments that can be used to reveal these behaviors when information is incomplete. Her research also focuses on economic tools to manage water withdrawals, with a focus on water pricing. She mobilizes a wide range of methodologies including surveys, experimental economics, and scenarios workshops.

Clemence Moreau focuses on issues of social justice related to water allocation, participatory methods for water management and social learning. She has been involved in projects in France and Tunisia. She is currently working for Agricultural Research for Development (CIRAD).

Marian J. Neal (Patrick) has an interdisciplinary research background in wetland/landscape ecology, water governance, transboundary water management and social and environmental justice. Her interests include water allocation decision making, understanding the multi-scale, multi-level governance of complex socialecological systems and social justice. Marian is currently Programme Manager for Transboundary Water at the Stockholm International Water Institute (SIWI), Sweden.

Rebecca Nelson is the Law Council of Australia's Australian Young Environmental Lawyer of the Year 2013-2014. She consults on water law and policy in the US and Australia for government agencies and NGOs. She holds Bachelor degrees in law and environmental engineering (University of Melbourne); and a Master of the Science of Law and Doctor of the Science of Law (Stanford University). Her dissertation focused on groundwater law.

Marie Pettenati is at BRGM - French geological survey, and has 7 years of experience as a Specialist in reactive transport models conceptualization for organic and inorganic pollutants in the vadose zone-aquifer continuum, particularly in the theme of active management of water resources. Her hydrogeology and hydrogeochemistry skills are applied to study equilibrium in natural aquifers, transfer of inorganic pollutants in soils, aquifers and mining sites, hydrogeochemical and thermo-kinetic modelling to study water-rock-gas interactions and consideration of biogeochemical processes in the hydrogeochemical modelling. 
Suzanne A. Pierce is the Texas Advanced Computing Center and with the Environmental Sciences Institute of the Jackson School of Geosciences at The University of Texas at Austin, Texas, USA. A hydrogeologist, She studies decision support systems and participatory processes for application to groundwater management and energy-water problems.

Jamie Pittock is Senior Lecturer in the Fenner School of Environment and Society at The Australian National University. He worked for non-government environmental organisations in Australia and internationally from 1989 to 2007, including as Director of WWF's Global Freshwater Programme from 2001 to 2007. His research focuses on better governance of the interlinked issues of water management, energy and food supply, responding to climate change and conserving biological diversity.

Manuel Pulido-Velazquez is an Associate Professor at the Technical University of Valencia (UPV), Spain, and senior researcher and Vice Director of the Research Institute of Water and Environmental Engineering (IIAMA). His main research focus is on the development of computer models for integrated management of water resource systems, using hydrology, engineering, economics and system analysis techniques. He has published extensively on conjunctive use of surface and groundwater from different perspectives.

Philippe Quevauviller is a Research Programming and Policy Officer at the European Commission in Brussels in the area of water and security policies. He has been a researcher in chemical oceanography. Besides his work at the European Commission, he is Associate Professor at the Hydrology Department of the Vrije Universiteit Brussel (VUB).

Pichu Rengasamy is a Senior Research Fellow in the School of Agriculture, Food and Wine of the University of Adelaide, Australia. He has devoted most of his research on the chemical and physical properties of salt-affected soils, particularly sodic soils. He has collaborated with Plant Scientists on soil-plant interactions in various categories of salt-affected soils with the aim of developing plants to adapt to different abiotic stress found in these soils. His recent research includes waste water irrigation affecting soil structural stability and $\mathrm{Al}$ toxicity in highly alkaline soils.

Jean-Daniel Rinaudo is senior economist at BRGM (French Geological Survey) where he coordinates the scientific program on Environmental and Risk economics. Trained as an agricultural and resource economist, he started his career at the International Water Management Institute, studying corruption in large irrigation systems in Pakistan. He then joined BRGM where his work focuses on the economics of groundwater management. In his research, he frequently combines the use of quantitative approaches (mathematical programming, econometrics, forecasting models, hydro-economic modeling) with more qualitative participatory methodologies.

Andrew Ross is a visiting fellow at the Australian National University, and until recently contracted to the Groundwater Section of UNESCO's Division of Water Sciences in Paris. His major current work is on transboundary aquifer management, groundwater governance and conjunctive water use. He is also interested in policy integration and implementation, and the research-policy interface.

Edella Schlager is a Professor at the Institute of the Environment and School of Government and Public Policy, The University of Arizona. She has a PhD from the University of Indiana. Her areas of expertise include comparative institutional analyses of water laws, policies, property rights, and compacts, polycentric systems of water governance and their adaption to changing environmental, legal, and social circumstances. 
Karina Schoengold is an assistant professor of natural resources and environmental economics with a joint appointment in the Department of Agricultural Economics and the School of Natural Resources in the University of Nebraska-Lincoln. Her main interests are environmental and natural resources economics, water resource economics, natural resource pricing, technology adoption, irrigation technology options and agricultural economics.

John M. Sharp, Jr is a Professor in the Jackson School of Geosciences at The University of Texas at Austin, Texas, USA. His hydrogeological research covers flow in fractured and carbonate rocks, thermohaline free convection, sedimentary basin hydrogeology, subsidence and coastal land loss, groundwater management, and the effects of urbanization.

Darren Sinclair is a Research Fellow at The Australian National University. His position is funded under an ARC Linkage Grant, in partnership with the NSW Office of Water. Darren was also a Research Fellow at the National Centre for Groundwater Research and Training, Fenner School of Environment and Society, The Australian National University. His areas of expertise include water regulation, enforcement and governance, and environmental, health and safety regulation more broadly.

Abraham E. Springer is Professor of Hydrogeology and Past Director of the School of Earth Sciences and Environmental Sustainability at Northern Arizona and was the Fulbright Visiting Chair of Water and Environment at the University of Lethbridge, Alberta, Canada studying the ecohydrology of springs of Western Canada.

Matt Stenson is a technology specialist with Australia's Commonwealth Scientific and Industrial Research Organisation's (CSIRO) Land and Water Flagship. His areas of research include environmental informatics, information management and transparency. He has considerable experience in the development of modelling and information systems, especially in the areas of hydrology and hydrogeology.

Lawrence E. Stevens is an evolutionary ecologist and the Director of the Springs Stewardship Institute at the Museum of Northern Arizona in Flagstaff. He has published on a wide array of topics, including biogeography, riparian and springs ecosystem ecology, regulated stream ecology, and rare species biology.

Andrew Stone has 35 years' experience in Africa and the US as a university professor, consultant, groundwater advocate and educator. As Executive Director of the non-profit American Ground Water Trust he develops programs to promote effective groundwater management, communicate the environmental and economic value of groundwater, showcase science and technology solutions, increase citizen, community and decision-maker awareness and facilitate stakeholder participation in water resource decisions.

Wendy Timms is a Senior Lecturer at the UNSW School of Mining Engineering, and is affiliated with the UNSW Connected Waters Research Centre, and the Australian Centre for Sustainable Mining Practices and was a Chief Investigator with the National Centre for Groundwater Research and Training. She has 20 years of experience as a hydrogeologist, across Australia and Canada, on water and waste issues in mining and agriculture. Her experience spans consulting engineering, government and research focused on sustainable management of groundwater and water quality, particularly with regard to interaction of saline water and low permeability clayey sediments and rock.

Kelly Warner is a Supervisory Hydrologist with the United States Geological Survey and is in charge of national and state water-quality and groundwater investigations. She has led the USGS 
National Water-Quality Assessment study of the glacial aquifer system for 15 years. Her research focuses on groundwater-quality relations to environmental and human -induced change.

Sarah Ann Wheeler is Associate Professor and Australian Research Council Future fellow at the University of Adelaide. Her research interests are irrigated farming, organic farming, water markets, crime and gambling. Sarah is currently an Associate Editor of the Australian Journal of Agricultural and Resource Economics, a guest editor for a special edition for Agricultural Water Management, and on the editorial board of Agricultural Science.

Chunmiao Zheng holds the positions of Chair Professor and Director of the Center for Water Research at Peking University, and the George Lindahl III Endowed Professor at the University of Alabama. The primary areas of his academic research are hydrologic modelling, water management, and eco-hydrological processes. 


\section{Index}

A

Aboriginal, 271

Active DSS, 651

Active management areas (AMAs), 242, 245, 248, 249

Adaptability, 150, 659, 696

Adaptation, 13, 15, 51, 76, 89, 91, 98, 124-127, $147,150,152,161-163,224,236,245$, $426,429,513,575,640,694,714,722$, $730-731$

Adaptive, 6, 13, 67, 125, 126, 161, 162, 230, $437,605,620,626,658,698,730$

management, 124, 161, 162, 198, 232, 308, $485,658,730$

Adoption, 6, 10, 126, 156, 189, 204, 360-362, 484, 486, 576, 640, 644, 659-660, 677, 683,715

Aeolian dust, 381

Agricultural contaminant, 36, 358, 364, 657

Agriculture, 59, 62-65, 68, 79, 87, 88, 103, $104,108,111,113,115,116,123,146$, $149,151,173,181,192,200,202,210$, $218,220,238,243,258,260,263,266$, 267, 269, 273-291, 362, 385, 387, 393, 394, 396, 398, 400, 414, 418, 426, 437, $473,494,506,507,559,561-563,575$

irrigated /irrigation, 63, 79, 151, 202, 220, 243, 258, 260, 267, 393, 396, 398, 426, 494, 586, 587, 592-595, 600, 602-604, 610, 702-704

Algeria, 31, 584-594, 596, 599, 604, 607, 608 Allocation, 77, 78, 126, 147-149, 151, 152, 155-159, 161-166, 168, 175-179, 181, 182, 187, 188, 191, 223, 231, 234, 235, 241-243, 248, 254-256, 258, 263, 267, 269, 273-291, 409, 441, 445, 482, 494, 496, 499, 502-504, 510-513, 552, 553, 556, 559-562, 569-572, 577, 593, 621, 641, 644,
652-654, 658, 660, 661, 695, 697, 699-702, 705, 707, 714

Almeria, 237, 238, 246, 248, 704

Alternative, 19, 39, 42, 50, 77, 78, 102, 126, $162,202,205,207,230,240,249,257$, $262,274,277,281,291,384,387,389$, 418, 419, 426, 438, 439, 481, 498, 522, $530,555,556,564,624,631,647,648$, $650,651,653,656,658-660,686$, 700-702, 704, 712-714, 716-719, $721-731$

model, 19, 713, 714, 718, 719, 721, 722, $724,728,729,731$

Ammonia $\left(\mathrm{NH}_{3}\right), 83$

Analytical, 12, 17, 168, 206, 207, 214, 369, $623,642,644,647,701$

analyses, 647

support, 200, 205-207

Anarchy, 584-611

Andalusia, 238

Anthropogenic threats to groundwater, 334-336

Aquifer

performance, 641, 642, 644, 648, 649

recharge, 51, 60, 61, 77, 79, 80, 85, 181, $234,238,255,352$

salinization in coastal areas, 386-387

salinization in inland areas, 385

Aquifer storage and recovery (ASR), 230, 352, $416,436,445$

Aquifer thermal energy systems (ATES), 83

Aquifer yield, 629, 641, 645, 657

Arboriculture, 603

Arizona, 180, 238, 241-243, 245-249, 329, 500, 506-508

Arsenic, 23, 37, 59, 349, 421

Atrazine, 349, 359, 363, 364

Attribute, 338, 642, 645-647

Augmentation plans, 231, 243, 244, 246, 248 
Australia, 15, 17, 18, 28, 31, 32, 36, 37, 39, 51, $59,62,77,78,80,82,84-86,88,89,91$, $109,147,150-153,156-157,159,161$, $163,165-166,168,173-186,188-192$, 198, 218-221, 223-225, 231-249, 258-261, 273, 274, 278, 282, 306-307, $315,318,323,327,337,338,349,350$, 383, 388, 389, 391, 393, 398, 402, 407, $408,421,436-449,470,478,480,482$, 483, 486, 493-514, 552, 654, 656, 668, $672,673,677,679,685,706$

law, 505

Automatic knowledge capture, 651

Availability, 17, 26, 29, 40, 41, 68, 77, 113, $114,121,126,184,236,248,301,348$, $352,369,406,414,417,418,425,442$, 496, 499, 500, 571, 593, 599, 644, 660, 673, 677, 679, 686-688, 696, 700, 703, $704,707,715$

\section{B}

Base flow, 23, 27, 77, 104, 105, 107, 111, 115, $117,185,231,304,306,314,315,318$, 321

Basin, 28, 31, 34, 51, 61, 65, 69, 77, 82, 89, $106,112,117,121,122,124,125,127$, $150-155,157,160,161,163-165,167$, 168, 174, 177-183, 186-188, 190, 192, 193, 198-206, 209, 212, 213, 218-221, 231, 237, 239-241, 243-246, 248, 263, 290, 291, 307, 315, 323, 327, 340, 354, $388,389,391,393,398,404,408,416$, 423, 426, 439, 442, 445-449, 460, 462, 463, 467, 471, 499, 502-504, 509, 511, 513, 524-526, 529, 563, 568, 574, 577, 590, 593, 594, 605, 609, 647, 653, 654, $656,701,704,705,731$

infiltration, 422, 428, 445-449, 731

Bayesian Networks (BNs), 13, 14, 480, 658, 659

Behaviour change, 478

Bengal - West, 89

Best management practice (BMP), 201, 405, 406

Biodiversity, 76-92, 107, 186, 225, 269, 304, 494

Biofuel

ethanol, 39, 78, 79

jatropha, 79

palm oil, 78

Biomass, 79, 85

Biotic assemblages, 323-324

Borehole, 80, 81, 83, 84, 110, 120, 121, 125, $157,266,354,446,552,555,561,676$
Brazil, 78, 499

Break-even analysis, 731

C

California, 27, 36, 38, 82, 88, 126, 127, 177-179, 182, 184, 185, 192, 218, 277, 355, 437, 479, 500, 506-509, 513, 514, 695-697, 699, 702-704, 706

Candidate solutions, 642, 648, 658, 659

Carbon carbon capture and storage (CCS), 84 sequestration, $15,76,78,84-86$ soil, 76

Carbon dioxide $\left(\mathrm{CO}_{2}\right), 84$

Catalonia, 237, 238, 246, 248, 249

Cation ratio of soil structural stability (CROSS), 384, 385

Chemical, 37, 50, 55, 57, 58, 63, 83, 105, 115, $116,119,123,154,180,181,189,191$, 209-211, 238, 299, 318, 348, 350, 355, $356,358,378,381-392,407,416,418$, $419,422,425,428,429,520,523,642$, 696, 723

tracing, 642

China, 5, 17, 26-28, 30, 34, 37-39, 86, 88, 110, $326,335,352,437,456-473,494,499$, $525,527,552,658$

Chinese groundwater governance, 461

Clay micro-aggregates, 383

Clean development mechanism (CDM), 85

Climate change

adaptation, 76, 86-90

direct impacts, 15, 76, 77

indirect impact, 117

mitigation, 15, 76-86, 91, 126

Climate proofing, 125

Climate variability, 98, 102, 107-109, 113-116, 119, 174, 230, 340, 499

Coal bed methane (CBM), 39, 80, 183, 184, 388, 407

Collaborative approaches, 17, 482-483

Collaborative planning, 168, 232, 233, 247

Collective action, 7, 16, 147, 230-249, 483, 487,598

Collective tube-wells, 596, 598

Colorado, 158, 162, 163, 184, 185, 188, 239, 241-249, 323, 332, 339, 505, 568, 702

Communicating uncertainty, 718, 729

Communication, 6, 8, 12, 14, 32, 41, 64, 160, $162,207,481,630,631,647,648,651$, $695,718,719$

Community engagement, 165, 629, 632

Complexity, 12, 15, 18, 25, 50-69, 91, 100, 102, 108, 123, 149, 184, 188, 199, 205, 
206, 236, 241, 256, 278, 290, 308, 361, 369, 420, 423, 466, 470, 477-478, 486, 498, 499, 532, 590, 621, 630, 631, 633, 634, 640, 644, 645, 647, 658-660, 668, $696,697,725,727$

Complex system, 50, 587, 589, 700

Compliance, 148, 160, 177, 189-191, 201, 208, 211, 354, 404, 407, 408, 420, 483, 554, $555,632,653,715$

Conceptual model uncertainty, 716, 719

Concerns, 50, 66, 69, 81-84, 88, 115, 126, 154, $174,175,178,183,190,192,193,198$, 201, 202, 207, 209, 213, 254, 257, 258, $263,304,308,351,352,356,357,365$, $366,370,388,389,400,419-421,425$, 426, 442, 462, 466, 467, 482, 513, 527, $528,536,537,545,564,565,568,569$, $575,586,594,632,634,641,642,644$, $647,649,657,673,677,684,689,694$

Conflict, 7, 9, 22, 23, 604, 605, 625, 629, 632, $635,644,660$

Conjunctive management, 695-697, 701

Conjunctive use, 655, 658, 694-698, 700-707

Consensus, 590, 620, 641, 648, 651, 695 yield, 648

Consultation, 629, 647

Contaminant, 81, 116, 117, 189, 190, 299, 348, $352-369,424$

transport, 116, 117, 352, 365

Contamination, 34-38, 58, 59, 63, 79-81, 108, $117,124,175,192,215,304,318,335$, $336,355,358,362-368,387,416$, 421-423, 429, 456, 460-462, 467, 470, $487,522-524,528,530$

Cooperation, 23, 40, 41, 127, 159, 188, 207, 208, 219, 340, 466, 556, 648

Coordinate, 127, 159, 178, 189, 203, 208, 219, 241, 244, 246, 339, 361, 467

Correlative groundwater rights, 177

Courts, 91, 154, 158, 160, 177, 184, 188, 257, $512,513,559,561$

Crisis, 16, 232, 242, 245, 247-249, 513, 590, $604,606,610,702$

Criterion, 284, 351, 417, 423, 424, 429, 627, 646,648

Cross-boundary groundwater management, 187

\section{D}

Daily fluctuations in groundwater depth, 320

Data management life cycles, 668-674

Data model, 676-677

Data network, 18, 33, 674, 678, 679, 681, 684, 687-689
Dataset, 122, 216, 338, 641, 645, 689, 728

Decision analytic techniques, 657

Decision makers, 4, 9, 14, 19, 92, 126, 182, $183,186,193,199,238,249,301,308$, $624,625,641,644,645,647,648,652$, 660,717

Decision-making, 4, 6-8, 12, 66, 90, 127, 147, $163,167,183,188,205,208,213,217$, $230,235,238,245,247,249,255,257$, 258, 269, 275, 287, 291, 298, 300, 301, $308,348,358,368,426,479,480,482$, 484, 495, 498, 629, 650, 660, 701, 715, 718-720, 724, 727

Decision objectives, 648

Decision problem, 640, 642, 644, 646-648, $651,655,657$

Decision support systems (DSS), 18, 640-661, 701-702, 706, 707

type, 650,651

Decline, 5, 28, 30, 52, 77, 104, 111-113, 115, $116,158,254,305,322,326,334,335$, 337, 339, 387, 437, 460, 462, 466, 534, $553,557,600,605,610,704$

Definitions of groundwater, 175

Deliberation, 647, 649-651, 657

Demand, 61, 64, 65, 76, 77, 79, 82, 87-89, 104, $111,112,115,116,123,125-127,162$, $185,223,225,274,314,333,414,419$, 426, 428, 436-439, 494, 495, 499, 503, 504, 507, 511, 514, 557, 562, 564, 574, 578, 587, 588, 593, 594, 599, 606, 610, $646,652,660,696-700,702,703$, 706,707

management, 15, 17, 76, 78, 125, 162, 436, $437,593,594,610,696,698$

Depletion, 22-33, 41, 59, 76, 79, 82, 87, 111, $112,121,146,155,156,158,173,175$, $188,263,289,333,335,378,406,437$, 438, 456, 466, 494, 511, 533, 564, 565, $568,569,572,577,634,643,694$, 696, 701

Deployment, 78, 83, 91, 609, 660, 680, 684,687

Deserts, 39, 82, 119, 259, 263, 276, 277, 302,326

Deuterium, 321

2,4-D (2,4-dichlorophenoxy acetic acid), 363

Discharge, 56, 77, 104, 107, 108, 111-112, $115,117,121,124,180,190-192,215$, 264, 298, 299, 305, 307, 314, 316, 318-321, 323, 327, 328, 330, 331, $334-337,339,340,379,380,382,386$, 388, 389, 419, 420, 422, 463, 469, 495, $587,590,597,643,646,654,723$ 
Dispute, 81, 155, 208, 213, 234, 257, 263, 634, $640,641,647,660$

Drinking water, 52, 86, 98, 124, 146, 151-153, $156,165,190,202,205,255,302,303$, 349, 353-357, 362, 364-368, 389, 390, 399, 404, 415, 418, 420, 421, 423, 426-429, 437, 439, 459, 464, 493, 501, 520-522, 524, 528, 530, 536, 537, 563, 591,729

Drip irrigation, 51, 60, 576, 588, 594, 599, 601, $606,607,609$

Dry cooling, 82, 91

E

Earthquakes, 59, 81

Ecohydrology, 16, 298-309, 329

E. coli, 366, 368

Ecology, 11, 16, 116, 120, 264, 299-303, 308, $314,321,327,337,340,487,622$

Economic, 11, 41, 80, 180, 260, 449, 513,521

cost, 82, 348, 356, 367, 368

Ecosystem functions, 223

Electricity, 63, 79, 80, 82, 83, 88, 89, 91, 500, $554,557,587,599,654,673$

Emergent decision problems, 657

Emission, 77, 79, 83-85, 99-101, 110, 117, $123,125,154,191,201,202$

Endangered species, 10, 105, 156, 158, 164, $244,505,511,512,564,565,568$

Energy

coal/coal-fired, 80,84

fossil, 77, 80, 83

renewable, $15,63,78,83$

Engagement, 127, 150, 151, 481, 485, 629, 644,648

Environmental

flows, 40, 89, 219, 235, 260, 389, 443, 468, 497, 507, 509

justice, 16, 254-269

management, 6, 224, 260, 431, 478, 645

water(ing), 89, 148, 156, 158, 179, 219, 230, 232, 248, 266, 442-444

Equity, 16, 255, 263, 276, 513, 555, 594

Eucalyptus, 307, 323

Europe, 5, 15, 28, 32, 37, 82, 83, 105, 115, 127, $151,152,154,157,161-163,173,239$, 348-370, 415, 428, 430, 520, 527, 553, $555,557,678$

Law, 154

European Union (EU), 15, 78, 124, 146-168, $174,176-179,181,183,184,187-192$, 198, 200, 202, 209-211, 218, 303, 304, $349,353,360,414,470,558$
European Water Framework Directive (WFD), $152,154,161,163,166,168,176,188$, 199, 204, 238

Evaporative basins, 81

Evapotranspiration, 24, 25, 52, 62, 77, 86, $103-105,109,110,114,116,122,299$, $300,302,307,325,328,331,340,378$, $380,381,418,643$

eVI, 326, 327, 329

Exchangeable sodium percentage (ESP), 383

Externalities, 51, 66, 78, 91, 466, 494, 496, $498,513,514,567,695,697$

Extraction rate, 40, 501, 646

Extractive resource industries, 387-389

\section{F}

Facilitators, 651

Fairness, 149, 157, 158, 267, 275, 482, 561

Farmer, 16, 51, 59, 63, 65, 66, 89, 124, 126, $149,163,164,179,230,233,235,236$, 238, 239, 266, 269, 273-275, 277-291, $358,361,362,388,394,398,442,447$, 480, 482, 500, 514, 520, 524, 540, 554, $555,557,559,561-564,576,589,596$, $598,605,608$

Farming systems, 285, 587, 598, 599, 607, 610

Feasibility space, 648, 649

Feedback, 6, 13-15, 23, 53, 66, 69, 100, 105, $106,114,115,125,128,150,280,299$, $308,409,426,479$

Fen, 299, 324, 325

Flood, 51, 59, 60, 77, 86, 105, 110, 117, 150, 159, 200, 206, 340, 387, 394, 436, 439, 441-449, 468-470

Floodwater, 442, 446, 447

Flow-net construction, 642

Food

production, 30, 76, 79, 86-89, 219, 585

security, 29, 473, 484, 494, 610

Forest, 6, 61, 77, 85, 90, 107, 127, 315, 335, 418,554

Framing, 76, 640, 642, 649

Freshening processes, 401-402, 404, 408

G

Gaining reaches, 89

Gas

coal bed/seam, 81, 183, 225, 388, 442, 486

produce water, 80

shale, 81

unconventional, 39, 78, 80-82, 91

Geomorphology, 323, 339

Geophysical methods, 642 
Geostatistics, 722, 725

Geothermal, 63, 64, 78-80 hot rock, 80

Global change, 15, 63, 76-92, 98, 99, 118-122, 125,127

Global water data, 107

The Gnangarra Mound, 338

Goal, 4, 7, 23, 54, 79, 148, 154, 155, 166, 168 , $178,180,181,183,187,189-191,202$, $205,257,260,267-269,306,308,357$, 406, 436, 467, 473, 566, 620, 646, 648,695

Governance, 7-9, 15-16, 50, 51, 64, 67-69, 76, 78, 79, 84, 90-92, 124, 146-156, 163-168, 176, 183, 184, 223, 231, 235, 242, 254-256, 258-266, 268-269, 456, $470,472,478-480,482-484,488,620$, $621,630,642,644,645,647-650$, 659,669

Governing laws, 212

Government, 63, 67, 76, 78, 80, 84-86, 88-90, $124,127,147-150,152,153,155$, $158-161,163,164,167,174,176-178$, 186, 190, 191, 200, 213, 215, 219, 221, 222, 224, 231-236, 241, 242, 244, 247-249, 260, 261, 268, 279, 290, 368, 369, 406, 439, 441, 449, 461, 467, 469, 470, 472, 478-483, 485, 486, 495, 496, 501, 505, 507, 514, 551, 559, 561-563, $568,601,605,606,628,630,647,673$, 685,686

Greenhouse, 99, 238, 596, 598

Greenhouse gas (GHG), 77, 79, 84, 99-101, 117

emissions, 38, 78, 80, 83, 440

Groundwater

access, 149, 158, 214, 484, 499, 501, 585, 607,610

attributes, 314-318

availability, 16, 17, 24, 29, 82, 147, 156, $160,307,314,315,318,320,332,340$, $578,601,644-646,703$

bodies, 154, 155, 183, 190, 191, 206, 209, 210, 212, 304, 414, 428, 529, 695

database, 32

dependent ecosystem, 16, 147, 153, 165, 166, 186, 225, 231, 248, 259, 261, 274, 304, 314-340, 406, 437, 460, 501, 520, $522,540,645,717$

economy, 584, 585, 587-589, 591, 592, 596, 599-601, 604-611

governance, $7,9,15-17,79,90,146-168$, 184, 254-269, 456, 470, 472, 478-488, $585,641,642,644,648,655$ infrastructure, 59-60

licences and permits, 182

management, 50, 53, 57, 60, 63, 64, 66-69, 76-92, 98, 114, 124, 128, 147-150, 152, $159,160,164,165,167,174,179,184$, $187,193,198,199,202,208,212,224$, 225, 234, 238, 244, 254, 258, 269,

299-302, 304-309, 316, 348, 350-353, $355,357,358,360,362,364,367,399$, 406, 414, 428, 456, 463, 465, 466, 468-472, 478-480, 483, 486, 494, 497, 504, 505, 507, 512, 513, 528, 531, 540, 552, 554, 555, 558, 562, 564-568, 570, 575-578, 620, 622, 631-634, 640, 644, 649, 656-661, 668, 696, 700, 703, 712, $713,716-718$

management districts, 306, 569, 659

managers, 126, 644, 713

modelling, 646, 714, 724

monitoring, 28, 30, 33, 160, 161, 174, 209, $369,402,406,464,465,467,473,576$, $645,655,679,684$

overdraft, 441, 460, 465-467, 605, 606, 696 plan, 153, 234

planning, 159, 163, 168, 179, 209, 234, 629,632

quality, 5, 6, 10, 11, 16, 17, 23, 26, 27, 31, $36,50,52,58,59,62,63,65,83,84$, $108,115-118,147-149,153,156,159$, 166, 174, 184, 189-191, 211, 223, 224, $266,318,333,334,336,340,352,357$, $360,369,389,399,404,406,408,414$, 419, 429, 449, 456, 460-461, 463, 464, 466, 467, 470, 495, 520, 521, 523, 528, 529, 531, 539-541, 645, 696, 703

recharge, 7, 27, 35, 36, 38, 60-62, 68, 76, $77,85,86,99,104,106,108-111,114$, $117,122,127,128,264,266,318,334$, $388,414,428,445,458,463,468,506$, $556,557,576,593$

resource, 5, 7, 9, 10, 16, 18, 22, 23, 29, 31, $32,36,40,41,50,52,54-57,61-64,76$, 78-80, 83, 86-92, 98, 104, 108, 109, $111,113-116,122,124-127,129$, 146-148, 150, 153, 156-159, 166, 167, $183,190,209,222,223,225,232,233$, 239, 254, 266, 267, 298, 303, 305, 314, 329, 358, 359, 361, 362, 399, 404, 414, 449, 456-464, 466, 469, 470, 472, 473, 483, 504, 506, 511, 520-523, 527-530, 532, 538-540, 572, 578, 584, 586, 587, 591-594, 596, 598, 599, 604, 606, 609, $620,631,633,640,646,647,659$, 694, 699 
Groundwater (cont.)

salinity, 120, 153, 330, 385, 387, 388, $398-407,441,728$

storage, 32, 33, 61, 69, 77, 107, 112, 113, 120-122, 126, 298, 437, 442, 466, 508, $648,694,697,698,702,716,717$

studies, 19, 303, 671, 674, 676, 679, 684, 689 surface water connectivity, 52, 153

use, 7, 15, 25-27, 29, 31, 51, 59-63, 68, 76, $125,146,147,149,151,153,156,157$, $160,162,167,183,184,188,193,219$, $225,237,239,273,274,279,282,321$, $327,330,348,350,409,459,468,482$, 483, 494-498, 501, 502, 505, 506, 508, 510-512, 514, 520, 529-531, 552-554, 556-558, 562, 564-567, 571, 572, 578, 584-611, 635, 660, 694, 697, 703, 706 user, $8,9,146,147,150,155,167,187$, 243, 279, 482, 494, 505, 509, 511, 512, 527, 554, 555, 557, 559, 565, 568, 578, $585,590,593$

withdrawal limits, 178-181

Groundwater dependent ecosystems (GDEs), 16, 41, 147, 153, 165, 166, 168, 179, 183, 186-187, 223, 225, 231, 248, 255, 259, 261, 274, 299, 304, 306, 314-340, 406, 437, 460, 501, 520, 522, 540, 564, $645,694,717$

Groundwater management district (GMD), $306,569,659$

Groundwater-surface water interaction, 58, 114, 187, 221, 236

Group facilitation, 651

\section{H}

Heterogeneity, 162, 275, 445, 564, 679, 725

Horticulture, 52, 115, 586, 596, 598, 600, 602, 604,605

Human, 9-10, 17, 34, 50, 52, 59-61, 66, 77, 87, $88,90,98,99,104,111-113,115,117$, $118,123,125,127,153,155,166,174$, 182, 184, 191, 193, 200, 206, 209, 254, $255,257,268,275,301,314,318,333$, 335-337, 348, 350-352, 354-369, 380, $382,417,463,466,471,478,479,481$, 484-486, 488, 529, 554, 559, 576, 661

behavior, 640

capital, 17, 478, 485

contaminant, 364

right to water, $174,184-185,193$

Hydrogen, 83, 383

Hydrogeochemicalchanges, 390-392
Hydrogeologic, 17, 18, 40, 112, 116, 300, 423, $442,462,641-643,646-647,654$, 661,676

attributes, 642

Hydrogeology, 11, 58, 163, 300, 443, 445, $462,487,496,642,645,646,648$, 674,678

Hydrological connectivity (connections), 232

Hydrological cycle, 61, 99, 108, 122, 230, 254, 418, 668

Hydrological modelling, 235, 236, 320, 430

Hydrology, 58, 76, 102-118, 122-123, 163, 299-303, 308, 327, 339, 426, 496, 553, $646,676,678,684,698,700$

Hygrophyte plant, 303

Hypothesis testing, 308, 722

I

Identifying GDEs, 319-329

India, 5, 26-29, 33, 34, 36-40, 42, 59, 86, 88, $89,124,335,436,437,483,494,499$, $500,585,608$

Indicator, 7, 13, 99, 121, 148, 211, 213-215, $288,302,303,320,323,327,328,338$, $355,366,368,383,385,510,522,538$, $540,646,697,699,705,716$

Indigenous, 225, 259-261, 480

Individual tube-well, 596, 598

Indus Valley, Pakistan, 379, 385

Inequalities, 276, 281, 283-287, 291, 479, 585, 608-610

Informatics, 658, 674

Information, 56, 58, 76, 81, 90, 101, 102, 107, $118,124,125,128,157,159-163,167$, 183, 198, 200, 204-208, 213, 214, 222, 233-236, 243, 247, 256, 274, 290, 320, $322,324,329,353,354,364,367,390$, 442, 449, 457, 460, 463, 464, 467, 470-473, 481, 495, 498, 508, 522, 527-529, 532, 536, 538, 540, 545, $552-558,561,563,575-578,588,590$, $592,627,629,630,633,634,640,642$, 644-646, 648, 651, 661, 673, 677, 678, 680-682, 684-686, 689, 704, 712, 713, 719-721, 726-728, 730

management, 329

Informative, 642, 647, 648

Input, 24, 33, 61, 117, 154, 201, 210, 212, 216, $230,255,264,301,319,320,330$, $357-363,379,388,395,398,557,587$, 589, 603, 640, 646, 647, 651, 669, 687, $703,714,715,717,721-723$ 
Institutional

arrangements, 127, 247, 486, 499

framework, 200, 238, 273, 472, 496, 520, $558-560,570-572$

reforms, 17, 472, 593

settings, 168, 230, 249, 470, 552, 558

variables, 248

Institutions, 32, 68, 90, 91, 127, 147, 149, 152-157, 163, 166, 167, 185, 198, 199, $219,236,241,254,263,268,472,478$, 497, 504, 512-514, 558, 559, 568, 578

Integrated assessment (IA), 6, 7, 10-14, 67, $480,520-541,651,655$

Integrated assessment and modelling (IAM), $646,651,657$

Integrated data, 22, 640, 671

management, 32

Integrated groundwater data, 668-689

Integrated groundwater management (IGM), 4-19, 25, 30, 50, 90, 98, 124-128, 199, 298-309, 348-370, 456-473, 486, 640-642, 646, 731

Integrated management, 15, 23, 41, 91, 154, 168, 174, 198, 200, 206, 223, 231, $232,236,237,245,246,248,249,309$, 404, 405, 427, 469, 472, 509, 568, 701,703

Integrated model, 7, 12-14, 645, 646, 651, 658, $671,675,676,685,689$

Integrated water planning, 198-225, 230, 469

Integrated water resources management (IWRM), 90-92, 125, 266, 357, 436, 472, 473, 593, 641, 696

Integration, 7, 10-12, 14, 32, 41, 50, 59-61, 91, $122,123,154,163,166,198,230,301$, 322 , 350, 407-409, 442, 456, 464-472, $520,608,640,646,658,660,668$, 675-678, 688, 689, 695, 696, 701

Intensive Groundwater Use Control Areas (IGUCAs), 179, 180, 306

Interactive deliberation, 650

Interdependency, 269, 644, 660

Internationally shared aquifers, 207

Interstate water allocation agreements, 243

Interstate water sharing agreement, 244

Invisible, 9, 466, 483, 520, 589, 608, 631

Irrigated agriculture, 31, 88, 104, 108, 111, 113, 586, 587, 591-595, 600, $602-604,610$

Irrigation, $35,51,52,54,57,60,62,65,66,78$, $79,87,88,91,98,111,113,124-126$, $146,151,157,164,179,218,219,225$.
230, 234, 239, 241, 243, 259, 260, 263, 264, 266, 273, 277, 280, 284, 286-288, $305,306,334,335,378-382,385,386$, 388-391, 393-402, 404-409, 414, 426, 436-449, 460, 468, 469, 480, 481, 493-495, 500, 502, 503, 510, 526, 553-557, 559-561, 563, 565, 567, 570, 576, 584-596, 598-601, 604-610, 652, $653,694,695,703,704,722$

frontiers, 584-611

\section{J}

Jucar, 237, 239, 240, 246, 248, 249

Justice, 154, 208, 254-269, 275-282, 284-291, $479,482,487$

$\mathbf{K}$

Knowledge management, 645, 649

Knowledge processes, 641

L

La Mancha, 237

Land management, 11, 395, 400, 402, 715

Land use, $15,50,52,58,61-69,85,105$, $108-111,115,123,126-128,157,160$, 191, 200, 203, 224, 289, 333, 336, 352, $394,409,449,484,485,587,645,654$, $660,694,698$

Law, 68, 99, 154, 155, 158, 162, 173-193, 207. $208,213,245,248,263,283,353,359$, $360,368,420,463,465,468-472,505$, 506, 509, 510, 558-561, 563, 569-571, $576,577,589,633,719$

Legal, 61, 68, 91, 148, 149, 161, 174, 175, 183, $185,187,199,201,208-210,218,234$, $238,247,248,254,255,306,368,466$, 468-470, 472, 473, 482, 497, 499, 505, $507,509,512,513,520,552,558-560$, $562,564,570-572,576,644,653,661$, 695,697

Legislation, 16, 17, 24, 153, 155, 159, 175, 181, $182,184,191,192,201,210,211,213$, $217,218,223,268,471,472,479,512$, $513,589,685$

Levelised cost, 440, 441, 448, 449

Level of uncertainty, 39

Liberation, 387, 584-611

Licence-exempt wells, 174

Limits of acceptability, 727 
M

Managed aquifer recharge (MAR), 8, 17, 67, 77, 87, 174-176, 190, 223, 225, 237, 414-431, 436-449, 468, 731

Managed groundwater storage, 32, 61, 69, 436, 693-707

Management, 6-12, 14, 30, 50, 53-54, 61, 64-66, 69, 76-78, 81, 86-91, 102, 113, $123-128,147,148,150,152-157$, 159-168, 174, 176, 179-183, 186-188, 190, 192, 198-210, 212, 218, 219, 221-225, 230-249, 255, 258, 260, 263, 266, 268, 274, 280, 282, 287, 300-309, $314,315,329,339,348,350-369,378$, $381,385,387,388,392-400,402$, 404-409, 414, 415, 425, 427, 429, 431, 436-449, 456, 461-473, 478-480, 483-488, 493, 494, 497, 498, 501, 504-506, 508, 509, 511, 513, 528-530, $532,535,536,539,552,553,559,562$, $565,566,568,569,572,575-578,585$, 587, 590, 591, 593, 594, 598, 606, 608, $620,622,624,630,632-634,640,641$, 644, 645, 647-661, 668-689, 694-706, $712-731$

Management of salt-affected soils, 379, 385

Market incentives, 61, 91

Maximum Contaminant Level (MCL), 348, 353,356

Mediation, 651

Mediators, 651

Mediterranean, 127, 237, 238, 337, 415, 418, $439,593,605,655$

Meinzer, O.E, 25, 303, 316

Methane, 39, 80, 81

Metric, 22, 26, 30, 53, 84, 106, 298, 299, 308

Mexico, 5, 26, 36, 40, 86, 188, 242, 322, 323, $354,437,499,552$

Micro-irrigation, 593, 609

Middle East, 28, 40, 59, 98, 303, 593

Mine water, 389

Misconceptions, 24, 631, 640, 644

Mixing diagram, 391, 392

Model, 56, 90, 99-102, 106, 114, 122, 123, $187,202,206,214,236,240,256,257$, 274, 283, 290, 291, 322, 327, 328, 340, $391,420,498,531,536,538,541,542$, $545,553,557,624,626,630,631,643$, 646, 649, 651-655, 657-659, 669-671, 674-678, 680, 686, 687, 698-707, $712-716,718-731$

calibration, 720

construction, 719

mediated negotiation, 659

structure uncertainty, 721
Modelling, 7, 12-14, 18-19, 67, 102, 115, 211, 232, 236, 240, 249, 320, 325, 329, 388, $391,405,406,425,429,430,446,480$, $482,590,625,630,631,640,644,658$, $685,686,697,699-702,713-716,719$, $721,723,724,730$

Models as discussion points, 731

Moderate-resolution Imaging Spectroradiometer (MODIS), 121, 326,327

Mohammed ibn al-Hasan al-Hasib al-Karaji, 302 Monitoring, 55, 57, 58, 110, 118, 120-122, $127,128,149,152-154,159-162,165$, 166, 174, 187, 190, 191, 201, 205, 206, 209-211, 221, 222, 224, 225, 230, 232, $235,236,238,266,308,316,329,339$, $340,353,354,365,366,369,379,385$, $388,399,400,402,404-406,408,415$, $425,428,446,464,465,467,469,473$, 496-498, 503, 505, 506, 510, 520, 553, $554,565,566,568,571,575-577,592$, $648,655,668,681-684,687,689,719$, 728,730

Feedback, 648

Monte Carlo, 100, 656, 723, 727

Morocco, 31, 584-594, 600, 604, 605, 607-609

Multi-criteria analysis, 658

Multi-disciplinary, 76, 205, 300, 303, 327, 426, $487,640,644,659,660$

Multi-objective parameter estimation, 722

Multiple-point statistics, 725, 726

Murray-Darling Basin (MDB), 31, 77, 89, 151, $153,161,178,181,218-221,232,237$, $307,391,398,404,408,442,499$, 502-504, 514

$\mathbf{N}$

Namoi catchment, Australia, 399

National data network, 19

National Water Initiative (NWI), 91, 152, 153, $178,180,221-223,232,233,260$, 261,501

Natural attributes, 642, 643, 646

Natural capital, 521

Natural contaminants, 23, 80, 356

Natural resource management (NRM), 17, 86, $223,258,260,478,479,483,485$, 486,628

Nature of uncertainty, 719

Nebraska, 28, 111, 178, 188, 244, 355, $505,506,509-511,513,565,566$, $568-569$

Negotiation, 69, 126, 204, 208, 219, 235 , $239,240,242,263,274,275,278,279$, 
284, 287, 291, 358, 361, 589, 628, 649-651, 657

Net present values (NPV), 393, 397, 408

Nevada, 82, 323, 325, 355, 508

New South Wales (NSW), 31, 151, 163, 180, 186-187, 191, 218-220, 233, 234, 237, 248, 249, 379, 385, 399, 402, 404, 406, 407, 441-446, 501-504

Nitrate $\left(\mathrm{NO}_{3}\right), 37,58,116,153,189,192,210$, $211,335,336,350,356,359,362,363$, $428,429,461,523$

Non-point pollution, 360

Non-point source pollution, 66, 191, 192, 417, 420,520

Non-renewable, 5, 87, 124, 261, 263, 267. 590-592, 604

Normalised Difference Vegetation Index (NDVI), 326-329, 331, 332

Normative, 208, 289, 642, 648

North Africa, 18, 23, 28, 31, 584-611

North China Plain (NCP), 28, 30, 352, 459-467

Numerical analyses, 647

Numerical modeling, 41, 642

\section{O}

Oasis, 326, 596, 598

Oman, 30, 499, 500

Ontology, 642, 646

Operational constraints, 659

Operational management, 200-205, 414,656

Optimization, 53, 640, 642, 650, 654-656, 658, $660,699-702,705-707$

Output, 7, 12, 14, 24, 101, 121, 154, 214, 255, $256,626,640,645,646,669,714,715$, $719,723,727,728$

Overexploitation, 5, 11, 29, 63, 88, 89, 124, 180, 254, 290, 414, 530, 531, 535, 557-559, 578, 585, 586, 590, 594, 599, 603-606, 610, 696, 704

Ownership, 15, 61, 68, 156, 174-176, 218, 231, 496, 498, 506, 567, 570

\section{$\mathbf{P}$}

Pakistan, 5, 17, 26, 27, 34, 40, 88, 393-398, 407,500

Parameter, 123, 287, 333, 370, 399, 425, 590, $642,643,645,646,656,660,685,700$, $714,719,723-731$

estimation, 722,727

uncertainty, 646
Participants, 207, 231, 280, 283, 480, 485, 627, 632-634, 648, 655, 658

Participation, 154, 159, 167, 182, 245, 247-249, 262, 290, 426, 429, 473, 480, $486,629,633,634,683$

Participatory, 13, 199, 203, 207, 480, 483, 593, $628,634,644,647,648,654,657$

processes, 18, 480, 644, 657

Passive DSS, 651

Performance metrics, 647, 648

Perth, 51, 59, 65, 86, 87, 437-439, 501

Pesticide, 36, 65, 117, 189, 211, 336, 356-358, 362-364, 382, 428, 495, 523, 587

Petroleum spills, 657

Phreatophyte, 303, 307, 338

Physical capital, 694

Phytosociologists, 303

Piper diagram, 390, 391

Planning, 61, 62, 98, 102, 125, 127, 153, 159, $161,163-165,168,175,178-183,190$, 191, 198-200, 202-206, 208, 209, 218, 219, 221-224, 231, 235, 237, 239, 244, 246, 260-262, 362, 467, 469, 479, 480, 493, 504, 592, 629-632, 634, 643, 650, 656, 660, 696, 697, 700, 701, 706, 718,719

Point source pollution, 63, 156, 174, 191

Policy, 29, 50, 52, 54, 60, 61, 63-68, 76, 78, 79, $86,88,90-92,125,127,128,147,150$, $154,159,162-164,166,168,177,178$, 180, 181, 184, 190, 198, 200-209, 216, 217, 221-222, 224, 230, 231, 234, 241, 245, 247-249, 261, 268, 269, 274, 276-278, 284, 287, 289-291, 305, 306, $352,360,379,393,398,404,406-409$, 427, 456, 468, 470, 473, 480, 481, 485-487, 495-499, 513, 514, 522, 539-541, 552-555, 558, 559, 561-564, 569, 570, 576, 577, 585, 593-594, $620-635,640,641,653,658-660$, 699-700, 705, 707, 714-717

instruments, 8, 485, 593

measures, 585, 593-594

Political voice, 238, 247, 249

Pollution control, 154, 155, 201, 465, 555

Polymerase chain reaction (PCR), 367

Precipitation, 24, 77, 79, 85, 86, 99-106, $108-111,113,116,122,200,266,299$, $369,370,381,388,424,425,507,604$

Preference, 13, 158, 162, 168, 200, 257, 275, 276, 285, 291, 419, 429, 431, 528, 529, $531,536,541,564,640,644,647$, 648,660

sets, 648 
Preventative Action Limit (PAL), 348

Prior appropriation, 152, 155, 156, 158, 162, 164-166, 177, 180, 183, 239, 243, 244, $276,277,281,283,291,506,509$

Priorities, 18, 40, 68, 90, 149, 153, 155, 162, $166,168,200,203,361,487,520,620$, $641,653,700$

Private tube-wells, 584, 589, 592, 596, 608

Proactive DSS, 651

Problem definition, 12, 18, 487, 629, 631, 713, 715,716

Problem formulation, 647-649

Problem framing, 649

Process interaction, 123

Property rights, 61, 148, 152, 176, 177, 277, 282, 483, 485, 496-498, 503, 505, 507, $509,556,558,560,576,578$

Public participation, 127, 154, 160, 182, 200, 203, 208-209, 267, 470-471

Public tube-wells, 592, 608, 609

Pump, 38, 59, 63, 156-158, 183, 242, 263, 467, 499, 510, 511, 554, 560, 567, 569, 587, 588, 591, 592, 594, 595, 598, 600-603, $607,642,645,656,715$

testing, 642

Pumping, 51, 56-59, 77, 88, 111, 112, $115-118,125,126,146,153,155,157$, 158, 179-187, 189, 214, 230, 238, 240, 242-246, 262, 273, 281, 283, 288, 299, 306, 334-336, 338, 351-356, 362, 386, 400-402, 414, 415, 417, 445, 465, 467, $469,494,499,500,503,506-511,513$, $552,553,556,557,559,560,563-565$, 567-569, 575, 577, 589, 590, 599, 601, $606,609,632,643,645,648,653-656$, 695-699, 701, 703, 704, 706, 714, 719, $720,722-724,728$

Q

Qanats, 303

Quality, 50-52, 54, 57-59, 61-63, 65, 66, 80, $83,84,89,99,102,106,108,115-118$, $124,126,127,147-150,152-154,156$, $157,159-161,165,166,168,174,181$, 184, 189-193, 199-201, 203, 204, 206, 208-211, 213, 214, 223-225, 230, 241, 255, 266, 269, 302, 314-318, 333-336, 339, 340, 348-370, 378, 381, 382, 387-390, 399, 404, 406, 408, 414-420, $422,427-429,431,443,446,449,456$, 460-467, 469-473, 479, 481, 484, 487, 495, 506, 520-526, 528, 529, 531, 536, $537,539-543,575,597,598,605,620$, $645,648,650,652,653,657,658,669$,
671-674, 683, 684, 694-696, 703, 704, $715,721,725$

Quantitative PCR (qPCR), 367, 368

Quantity, 11, 16, 24, 40, 50, 61, 65, 99, 102, $106,115,116,118,127,150,152,155$, $157,160,166,168,174,177,178,180$, 181, 183, 189, 190, 193, 199, 203, 204, 206, 213, 214, 216, 217, 219, 255, 314, 369, 382, 406, 414, 428, 465-467, 469, 471, 472, 498, 512, 520, 528, 571, 620, $646,658,684,699$

Quasi-crystals, 383

$\mathbf{R}$

Radioactive materials, 657

Rainwater harvesting, 88

Rates of groundwater use, 322, 329-333

Real time sensing, 658

Recharge, 51, 52, 54-56, 58-62, 65, 67, 68, 76, 77, 79, 80, 82, 85-87, 89, 99, 102, $104-111,113-117,119,122,127,128$, $154,156,157,174-176,180,181,190$, $201,210,223-225,238,242,243,245$, $255,261,264,266,302,305,318,327$, $333,334,337,338,340,352,355,358$, $378,380,382,386,388,389,402,404$, 408, 414-431, 436-449, 458, 463, 468, 494, 495, 498, 502, 504, 506, 507, 530, $553,556,557,575,576,587,593,604$, 606, 643, 646, 653, 694, 696, 703, 704, 723,728

Refugia, 89

Regulation, 15, 18, 40, 66, 69, 78, 84, 85, 87, $116,125,148,150,152,153,157,164$, $165,174,177,178,185,188,189,191$, 198-225, 237, 243, 245, 264, 268, 274, $279,289,333,362,368,369,407,420$, $425,462,463,467,468,470-472$, 496-499, 505-510, 512, 552, 555, 558, 562-564, 567, 568, 570, 575, 578, 585, 593, 703

Remote sensing (RS), 22, 41, 118, 120-122, 324-329, 331-332, 340, 563

of vegetation structure, 324-325

water fluxes, 328-329

Response curves, 216, 308

Riparian, 124, 219, 304-307, 315, 321, 326, 331,340

Risk assessment, 209, 369, 404, 423, 657

Riverbank filtration, 417, 437

River basin agency, 600

River basin management (RBM), 154, 155, $157,164,198-205$

Robustness, 718 
Rock

fracture, 167, 237, 264, 365, 399

hydraulic fracturing, $80-81$

strata, 81

Root zone salinity, 17

Rural landholders, 484-486

S

Safe-yield, 22-25, 178, 180, 181, 305, 306, 331,494

Sahara, 591, 594, 595, 599

Salinity

primary, 153, 351, 381, 391

secondary, 381

Salinization, 17, 26, 34-36, 42, 60, 62, $378-409,414,437,460$

Salt accumulation, 380-385, 394-396, 407

Salt balance, 395, 396

Saltcedar, 307

Scenario discovery, 731

Schimper, A.F.W., 303

Science-based decision making, 642, 649

Science dialogue, 647

Science visualization, 658

Segura, 237, 240, 656

Seismicity, 81

Sensitivity analysis, 718, 722, 730

Sentinel metrics, 308

Sharecroppers, 598

Shared vision, 648

Sharing, 16, 41, 87, 159, 160, 164, 187-189, 236, 237, 244, 254, 255, 279, 289, 290, 470-473, 503, 562, 578, 630, 632, 644, 684,685

Simulation, 33, 100, 101, 106, 115, 122-123, $533,623,642,645,646,653-656,658$, $660,699-702,704,707,714,725,726$

Social

capital, 17, 479, 483, 485, 486

differentiation, 585

ecological systems, 69,478

impact assessment, 17, 481-482, 487

justice, 16, 263, 268, 273-291

research, 478, 479, 486, 487

research practices, 479

research principle, 479

science, $17,478-488,514$

theory, 478

Sodium adsorption ratio (SAR), 383-385

Soil, 10, 15, 52, 62, 63, 85, 106, 110, 128, 225, $254,281,284,303,318,323,328,332$, $333,335,378-409,437,449,588,604$ water, 103, 105-107, 121, 123, 321, 322, $332,383,385,405$
Solar thermal, 78, 82-84

South Africa, 59, 85, 264-266, 278, 325, 437, 499

South-to-North Water Transfer Project, 468

Spain, 16, 27, 36, 64, 82, 157, 164, 178, 231-249, 273, 274, 335, 437, 499, 527, 552-554, 563, 652-656, 696, 704-707

Spatial variability, 104, 118, 119, 724

Spring, 40, 55, 77, 107, 231, 260, 274, 303, $315,316,318,323-325,329,332,334$, $335,339-340,536,654,728$

restoration, 323, 339

Stable isotopes and tracers, 321

Stakeholder, 9, 81, 127, 150, 154, 159, 160, $174,209,216,233,234,288,359,360$, 478-480, 485, 487, 488, 495, 621, 624, $625,628-634,640,642,644,647-649$, $655,658,660$

engagement, 9, 17, 160, 479-480, 487, 624, 629,644

State, $8,36,56,69,83,85,88,89,91,100,102$, $107,120,126,147,152,153,155,156$, 158-164, 176-181, 184, 188-192, 208, 212-219, 223-224, 231, 232, 236, 241-248, 257, 263, 266, 276, 287, 300, $305,353,356,368,369,404,406-408$, 420, 427, 439, 441, 456-461, 463, 467, $469,471,497,505-511,523,524,552$, $559,563-565,568-570,576-578$, 584-589, 595-602, 605-610, 632, 640, $643,651,654-656,658,661,673,683$, $701,703,705,719$

Statistics, 101, 114, 121, 220, 308, 588, 589, $591,592,595,719,730$

Stomata, 329

Storage, 56, 61, 69, 76, 77, 80, 82-84, 87, 104, $105,107,108,112-115,120-122,125$, $126,128,167,192,221,223,231,234$, 239, 242, 243, 246, 282, 298, 301, 352, 383, 389, 416, 417, 419, 423, 436, 437, 439, 441, 442, 445-449, 456, 461, 466, 487, 494, 499, 508, 643, 646, 648, 652-654, 668, 669, 671, 673, 674, 676, 687, 689, 694-699, 702, 703, 705, 706, 716,717

Stormwater, 336, 415, 418, 428, 436, 437, 439-441, 449

Stygofauna, 314, 315, 318, 336

Subject matter expertise, 640

Surface evaporation, 332

Surface water, 50-52, 54, 56-61, 65-69, 77, $80,85,86,89-91,98,103,105,112$, $114,121,128,150,152-154,156,158$, $160,161,163,167,174-176,178-181$, 185-188, 190, 193, 199, 200, 204, 212, 
214, 218, 221-224, 230-234, 236-241, 243-249, 255, 283, 291, 298-300, 305, $307,315,318,319,322,333,334,357$, $358,362,378,386-389,405,406,415$, 417-419, 421, 427, 428, 436, 441, 443, 445, 449, 456, 465, 467-469, 473, 494, 497-499, 501, 502, 504, 506-511, 513, 514, 530, 531, 539, 558, 564, 565, 567, $568,575,577,578,585,588,590,592$, 596, 598, 604, 605, 609, 645, 654, 656, 676, 681, 684, 685, 694-697, 703, $705-707,715,723,728$

trade, 504, 508

Surprise, 176, 602, 714, 722, 730-731

Sustainability, 65, 91, 103, 112, 113, 115, 116, $125,177,184,213,215,223,258$, 267-269, 301, 308, 398, 409, 430, 485, $488,495,503,557,564,575,576,593$, $608,622,628,661,705$

Sustainable, 25, 50, 54, 60, 63-65, 76, 78, 80, $82,86,88,90-92,124,127,147-149$, 152-154, 165, 178, 180, 181, 201, 208, $219,220,222-225,233,235,266,268$, $269,274,277,279,290,306,314,329$, $358,385,406,447,473,483,485,486$, 496, 498, 501-505, 553, 575, 578, 606, $622,629,632,653,656,658,696,697$

\section{T}

Target, 8, 61, 64, 80, 81, 148, 154, 201, 203 , $205,300,360,388,389,446,485,486$, $555,562,569,648,698,716,717$

Technology, 10, 15, 18, 23, 39, 59, 68, 76, 78, $82,83,91,118,120,125,126,277,340$, $367,369,414,415,429,430,463,576$, $587,594,606,640,659,668,674,684$, $689,695,703,707$

Terrestrial processes, 100

Texas, 28, 39, 81, 88, 90, 111, 176, 177, 179, $182,188,500,505,507,511-513,565$, $566,569,653,661$

Theory of Planned Behaviour, 486

Threats to GDEs, 314, 333-340

Threshold, 4, 35, 69, 77, 85, 100, 154, 185, 186, 189-191, 210, 211, 214, 300, 308, 315, $326,338,340,348,383,385,444,445$, $556,645,730$

Tipping point, 69, 300, 308, 604, 731

Total coliform, 366

Trade-off, 7, 9, 12-14, 18, 59, 68, 86, 185, 231, $235,246,290,298,300,308,481,503$, $704,717,728,729$
Transboundary water conflict, 22, 39-41

Transient salinity, 379, 380, 382, 407

Tree planting, 76, 84-86

Trust, $8,9,186,231,291,478,483,486,487$, $497,561,620,634,660,686$

Tube-well, 461, 500, 585-592, 595-599, 601-603, 607-609

association, 598, 608

Tunisia, 31, 584-589, 591-593, 604, 605, 608, 652

Typology of uncertainty, 285

\section{$\mathbf{U}$}

Uncertainty, 12, 55, 66, 67, 77, 100, 101, 126, $128,147,160,184,185,217,220,308$, $357,427,496,621,630,634,640$, 645-647, 650, 652, 653, 658, 660, 700, $703,712-731$

in model inputs, 722

quantification, 128

United States of America, 268

Law, 231-246, 505-512

Unknown unknowns, 730

Upper Guadalquivir, 239, 246

V

Vadose zone, 103-107, 116, 119

Value, 82, 84, 92, 122, 156, 167, 176, 181, 211, $225,237,239,255,258,274,278,281$, $285,286,299,301,306,333,383,394$, 404, 437, 439, 441, 447-449, 478, 496, 497, 506, 513, 520-522, 526, 527, 530, 536-539, 560, 561, 571, 574, 591, 592, 607, 625, 627, 630, 645-647, 656, 672, 673, 696-699, 702, 704, 705, 713, 714, 724,729

Values-beliefs-norms(personal) (VBN) theory, 486

Variability, 55, 56, 76, 89, 98, 100-102, 104, 106-109, 111-116, 118, 119, 125, 127, $148,174,189,198,200,218,221,324$, $327,340,360,381,399,443,445,499$, $556,645,694,719,720,723$

Variable, 27, 28, 31, 87, 101, 103-105, 108, $109,114,118,119,122,128,152,160$, $165,166,168,225,230,234,235,248$, $325,402,445,536,538,623,644,646$, $656,660,701,703,705,714$

Variogram, 725

Vegetation, 52, 55-58, 62, 65, 77, 84, 85, 102, $109,110,121-123,128,264,301$, 
303-305, 307, 315, 316, 318-322, 324-333, 337-340, 380, 385, 394, 401, $407,409,460,656$

indices, 325-329

Viruses, 58, 63, 302, 364-369, 421, 728

Vitruvius, 302

Vulnerability, 110, 117, 209, 223, 224, 338, 364-367, 731

analysis, 731

\section{W}

Water

accounting, 153, 221, 222, 388

Act 2007 (Australia), 153, 175, 178, 180

allocation, 13, 16, 149, 152, 155-159, 162, $166,168,178,179,191,223,224,232$, 254, 258, 267, 269, 274, 275, 278, 279, 281, 285, 287-291, 409, 441, 445, 482, 503, 504, 510, 559, 561, 562, 569, 593, $641,658,695,697,699,702,705,707$, 714

availability, 17, 30, 31, 66, 69, 77, 125, 160, $161,179,222,238,298,318,325,337$, 338, 340, 399, 418, 430, 441, 494, 508, 593, 703, 704, 715

budgeting, 642

consumption, 5, 8, 21, 76, 78, 84, 87, 219, 423,557

courts, 160, 242, 243, 245

demand management, 593, 594, 610

Framework and Groundwater Directives, 304

framework directive, 157, 163, 178, 181, 183, 184, 187, 189, 198, 209, 210, 427, $520,527,529$

infrastructure, 58, 185, 231, 446, 695

law, 243, 263, 283, 420, 463, 465, 468-470, $472,505,559,560$

managers, 18, 19, 92, 163, 205, 275, 354, $356,361,483,552,553,661$

markets, $8,78,85,86,91,152,153,156$, 157, 168, 222, 247, 495-499, 501, 506, 507, 509, 512-514, 558, 567, 572, 574, 578, 585, 608, 706, 707

quality, 16, 51, 58, 62, 63, 65, 66, 83, 89, $110,113,116-118,120,148,153-155$, $157,160,162,174,180,182,191,192$, 201, 210, 224, 225, 238, 248, 334, 348, 350-353, 357, 361, 362, 364, 367-369, $378,388,407,420,421,425,428,430$, 437, 446, 469, 472, 486, 499, 513, 526, 536,540 resources, 6, 36, 58, 110, 113, 124, 125, $161,164,175,198,237,261,269,281$, 287, 333, 358, 414, 431, 436-449, 470, $561,630,640,641,644,658,676$, 685-688, 697, 698, 706

rights, 155, 179, 183, 240, 242, 243, 245, 246, 306

saving, 30, 563, 576, 578, 594, 606

sharing plans(WSPs), 186, 233-237, 248, 406, 443

storage, 33, 61, 86, 87, 104, 107, 115, 121, 122, 221, 241, 243, 298, 383, 441, 445, 447, 695, 696

supply, 51, 52, 57, 59, 60, 62, 64, 65, 76, 79, $86,115,116,124,126,127,162,176$, 179, 190, 200, 230, 237, 238, 241, 281, $303,305,318,329,331,335,353,381$, $388,414,426,428,439,440,459,469$, 499, 504, 506, 522, 524, 527, 528, 530, $533,535,538,557,559$

transaction, 589

use efficiency, 125, 437, 552, 558, 563

users, 53, 67, 126, 146, 148-150, 152, 157, 159-161, 163-165, 202, 208, 209, 218, 222, 230-233, 235-237, 241-249, 258, 275, 281, 288, 444, 483, 512-514, 524, $553,560,567,574,576,577$

Water-bank, 242, 511

Water-energy nexus, 22, 23, 38-39

Web services, 671, 674, 680-682, 684, 685, 687-689

Wellhead protection, 190, 224, 416, 420

Wells, 53, 57, 59, 61, 63, 65-67, 69, 78, 80-82, 84-87, 98, 99, 101, 102, 104, 106, 107, $111-114,118,119,121,123,124,126$, $146,148-150,157,158,167,174-176$, $178,182,185,187,198,202,209,212$, 214, 221, 225, 230-232, 238, 240, 242-246, 248, 249, 257, 259, 264, 275, $282,285,298-300,302-304,308,323$, $329,331,334,336,350,352,354-357$, $365-367,383,385,386,388,389,400$, 404, 406-408, 415, 417, 420, 429, 430, 437, 440, 445-448, 460, 461, 463, 464, 466, 468, 472, 479, 481, 495-498, 502, 503, 505, 508-510, 513, 522, 528, 532, 536-538, 540, 542, 545, 553, 554, 559, 560, 565-567, 569-571, 577, 584, 586-592, 596-603, 607, 609, 610, 680, $681,683,684,719$

Western Australia (WA), 51, 59, 109, 191, 220, 282, 315, 323, 337, 338, 438, 439, 501, 502,505 
Wetland, 57, 59, 89, 264, 299, 304, 305, 308, $\quad \mathbf{X}$ $316,319,321,323,324,332,439$, 526,696

Xerophyte plant, 303

Wicked problem, 9, 478, 479, 620, 626

Willows, 302, 307 Y

Withdrawal, 15, 24, 25, 59, 80, 104, 110, 115, Yield, 148, 178, 180, 181, 220, 223, 235, 274, $146,151,178,181,185,192,212-214, \quad 277,279,290,299,305,306,321,331$, 216-218, 259, 299, 305, 308, 399, 406, $\quad 367,396,406,483,485,486,496,503$, $414,493,503,552,553,572,575,576, \quad 571,586,599,643,646-648,653,654$, $578,591,592$ 661, 694, 706, 727 